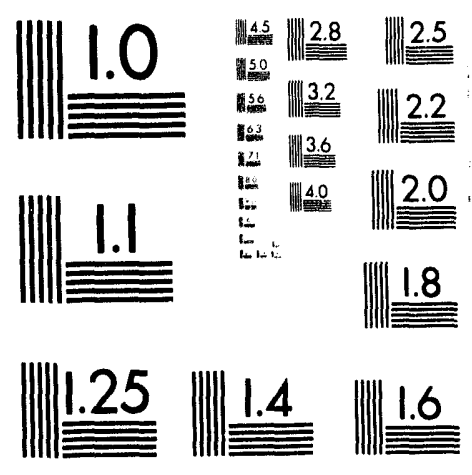



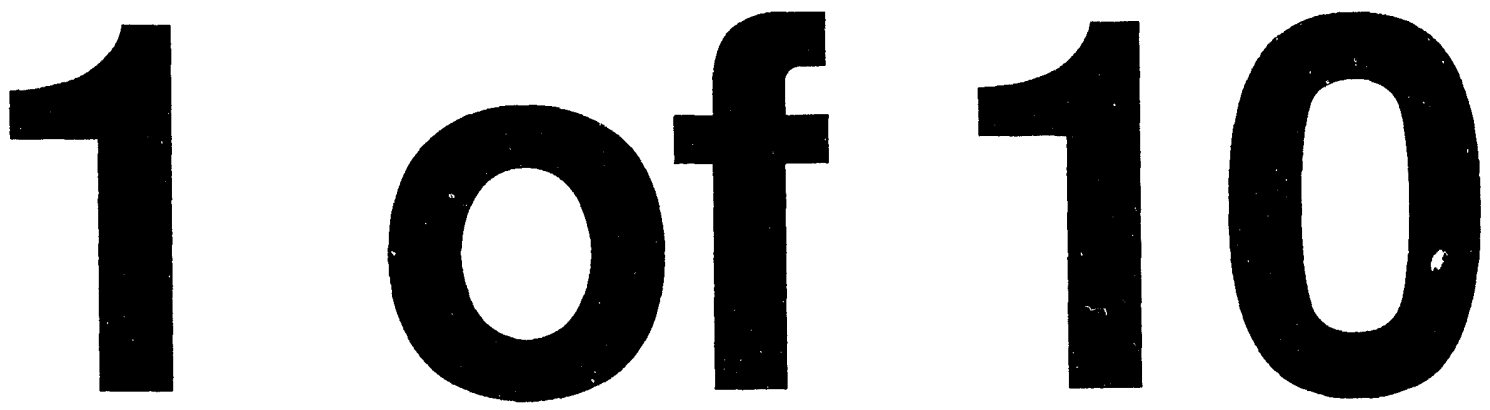
DOE/RL-89-28

Revision 1

\section{6-B-3 Expansion Ponds Closure Plan}

Date Published

December 1993
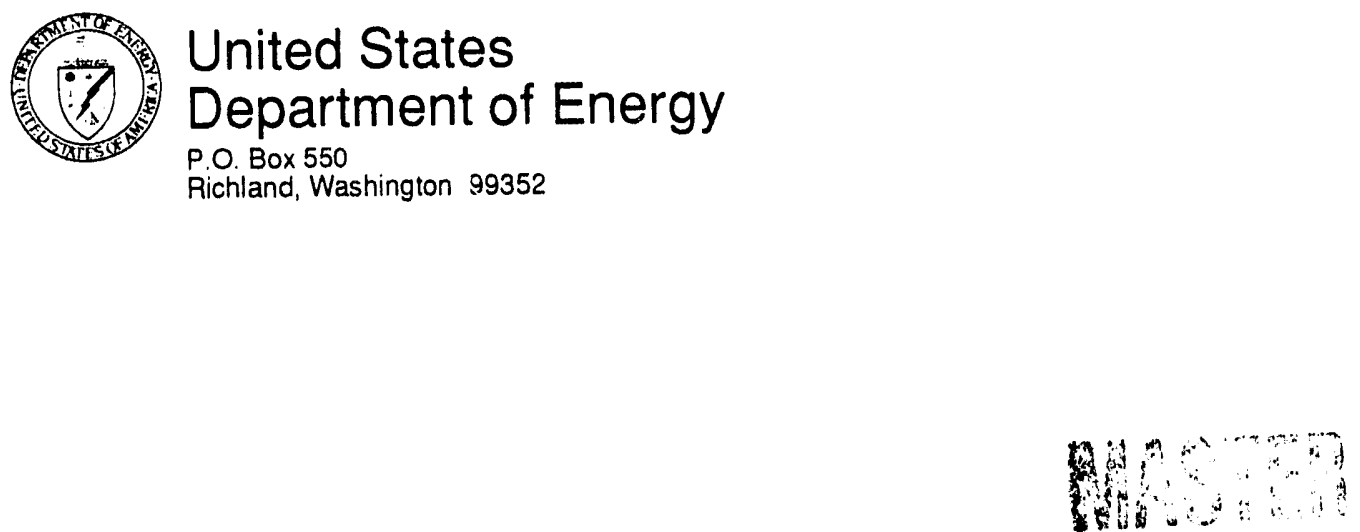


\section{STATE ENVIRONMENTAL POLICY ACT (SEPA) \\ ENVIRONMENTAL CHECKLIST FORM}

FOR THE CLOSURE OF THE 216-B-3 EXPANSION PONDS

\section{REVISION 1}

OCTOBER 1993

WASHINGTON ADMINISTRATIVE CODE

ENVIRONMENTAL CHECKLIST FORMS

[WAC 197-11-960] 
SEPA Checklist 216-B-3 Pond System Closure

Page 1 of 19

STATE ENVIRONMENTAL POLICY ACT ENVIRONMENTAL CHECKLIST

\section{A. BACKGROUND}

1. Name of proposed project, if applicable:

Closure of the 216-B-3 Expansion Ponds. This State Environmental Policy Act (SEPA) Checklist is being submitted concurrently with the Resource Conservation and Recovery Act of 1976 (RCRA) Closure/Postclosure Plan for the 216-B-3 Expansion Ponds, which consist of the 216-B-3A, 216-B-3B, and 216-B-3C Ponds. The entire 216-B-3 Pond System consists of these expansion ponds and the 216-B-3-3 feeder ditch and 216-B-3 Pond.

The designation "216-8-3 Pond" in this Checklist refers to the original pond that was placed into service in 1945. Information contained in this checklist pertains only to the 216-8-3 Pond System. In the context of the document, "site" refers to only the physical area covered by the pond system, whereas "Site" refers to the Hanford Site.

2. Names of applicants:

U.S. Department of Energy-Richland Operations (DOE-RL); and Westinghouse Hanford Company (Westinghouse Hanford)

3. Address and phone number of applicants and contact persons:

U.S. Department of Energy

Richland Operations Office

P.O. Box 550

Richland, Washington 99352

Contact persons:

J. D. Bauer, Program Manager

Office of Environmental Assurance, Permits and Policy

(509) 376-5441

4. Date checklist prepared:

October, 1993

5. Agency requesting checklist:

State of Washington

Department of Ecology (Ecology)

Mail Stop PV-11

01ympia, Washington 98504-8711
Westinghouse Hanford Company P. O. Box 1970 Richland, Washington 99352

R. E. Lerch, Deputy Director Restoration and Remediation Westinghouse Hanford Company 
SEPA Checklist

216-B-3 Pond System Closure

Page 2 of 19

6. Proposed timing or schedule (including phasing, if applicable):

A phased soil and sediment sampling and analysis program was completed to assess the presence and extent of contamination within the 216-B-3 Pond System. Based on the results of the sampling and analysis program, a decision has been made to clean close the expansion ponds, 216-B-3A, $216-B-3 B$, and $216-B-3 C$ while integrating closure of the remainder of the 216-B-3 Pond System with RCRA Corrective Measures for the 200-BP-11 Operable Unit

Clean closure of the expansion ponds is being initiated to meet the Hanford Federal Facility Agreement and Consent Order (Tri-Party Agreement), Milestone M-17-10 for June 1995 which requires that liquid discharges to hazardous 1 and disposal units cease unless such units have been clean closed in accordance with RCRA. Following clean closure, the expansion ponds will continue to receive nondangerous waste water from the 200 East Area facilities.

Pending approval by Ecology and EPA, the 216-B-3 Pond and the 216-B-3-3 Ditch will be decommissioned and wastes stabilized in place to minimize risks to human health and the environment. Final closure of the 216-B-3-3 Ditch and the 216-B-3 Pond will be coordinated with the 200-BP-11 operable unit. The work plan for this unit is planned for completion in Fiscal Year 1995.

7. Do you have any plans for future additions, expansions, or further activity related to or connected with this proposal? If yes, explain.

Following clean closure, the expansion ponds will continue to receive nondangerous waste water from the 200 East Area facilities.

Future activities related to this proposal include a RCRA facility Investigation/Corrective Measures Study (RFI/CMS) of the 200-BP-11 operable unit, of which the 216-B-3 Pond System is a part. Final disposition of the 216-B-3-3 Ditch and the 216-B-3 Pond will be coordinated with the final closure of the 200-BP-11 operable unit.

8. List any environmental information you know about that has been prepared, or will be prepared, directly related to this proposal.

- This SEPA Checklist is being submitted to Ecology concurrently with the RCRA 216-B-3 Expansion Ponds Closure P1an, D0E/RL 89-28

Revision 1 .

- In 1987, the U.S. Department of Energy submitted the 216-B-3 Pond Preliminary Closure/Postclosure Plan to Ecology. An updated Closure /Post Closure Plan, DOE/RL 89-28, was submitted in 1990.

- A RCRA Part A Permit Application for the 216-B-3 Pond System was submitted to Ecology on August 1, 1986. Revisions to the Part A 
SEPA Checklist

Permit Application were submitted to Ecology in August and November of 1987, and a third revision was submitted concurrently with the 216-B-3 Pond System Closure/Postclosure Plan in 1990. Currently, the unit specific Part $A$ permit application is being modified to separate the three expansion ponds (3A, 3B, and $3 C$ ) from the remainder of the 216-B-3 Pond System.

- An RFI/CMS will be conducted for the 200-BP-11 operable unit.

- NEPA documentation for the interim stabilization of the 216-B-3 Pond, the 216-B-3-3 Ditch, and the 216-B-3A Pond has been completed and the work has been categorically excluded by the DOE from further NEPA review.

Additional environmental information regarding the 200 Area plateau and the Hanford Site in general can be found in Hanford Site National Environmental Policy Act (NEPA) Characterization, PNL-6415 Rev. 5, Pacific Northwest Laboratory, 1992, Richland, Washington.

9. Do you know whether applications are pending for government approvals of other proposals directly affecting property covered by your proposal?

No such applications are known to be pending.

10. List any government approvals or permits that will be needed for your proposal, if known.

Ecology is the lead agency authorized to approve the 216-B-3 Expansion Ponds Closure Plan under requirements authorized by RCRA and Chapter 173303 of the Washington Administrative Code (WAC). Following clean closure of the expansion ponds, a State Waste Discharge Permit under WAC 173-216 will be required from Ecology for discharge of nondangerous waste water to the 216-B-3B and $3 C$ Ponds.

No other permits are known to be required at this time.

11. Give a brief, complete description of your proposal, including the proposed uses and the size of the project and site. There are several questions later in this checklist that ask you to describe certain aspects of your proposal. You do not need to repeat those answers on this page.

The closure plan for the 216-B-3 Expansion Ponds is summarized as follows.

- Soil and sediment sampling and analys is (This program has been completed). Vadose zone soil and sediment sampling and analys is was conducted at the 216-B-3 Pond System. Analytical results were evaluated to define any constituents of concern, defined as constituents derived from dangerous waste disposal in the expansion 
SEPA Checklist

216-B-3 Pond System Closure

Page 4 of 19

ponds that statistically are above background levels. Action levels were established for constituents of concern based on background levels and health based limits and are defined as concentration thresholds that soil composition should not exceed for clean closure. Analytical results from the samples taken from the expansion ponds and the 216-B-3 Pond System showed that dangerous waste constituents of concern were below action levels. Details of the sampling and analysis and the results are contained in Chapter 7 of the closure plan submitted with this checklist.

- Clean close the expansion ponds $(216-B-3 A,-3 B,-3 C)$. "Clean close," as used in this context, means that no waste or wastecontaminated soil, structures, or equipment that could pose a threat to human health or the environment will remain onsite following completion of closure activities. When certification of clean closure has been accepted by Ecology, the expansion ponds will not be su'ject to regulation under RCRA or WAC 173-303. Following clean closure, the expansion ponds will continue to receive nondangerous waste water from the 200 East Area facilities.

- Decommission the 216-B-3-3 Ditch and the 216-B-3 Pond. The pond and ditch will be removed from service and interim actions (e.g., placement of soil fill over waste) will be taken to stabilize the waste in place. Final closure of these two units will be coordinated with the 200-BP-11 operable unit due to the proximity of other nearby inactive waste management units (i.e., the $216-8-3-1$ Ditch and the 216-B-3-2 Ditch).

- Decontaminate and remove structures and associated equipment. If clean closure is approved for the $3 A$ and $3 B$ ponds, the dikes around the ponds will be retained in the current configuration and the existing piezometer network will continue to monitor seepage through the dike. The piezometers associated with the 216-B-3 Pond and a groundwater monitoring well will be plugged and abandoned in accordance with Chapter 173-160 of the WAC.

There are four flow control and spillway structures that monitor and control the flow of water from the 216-B-3 Pond to the 3A Pond and from the $3 A$ to the $3 B$ and $3 C$ Ponds. When 216-B-3 Pond is removed from service, these four structures will be demolished and removed in conjunction with the interim stabilization of 216-B-3 and 216-B-3A. Details of the demolition and disposal of the wastes are in Chapter 7 of the closure plan submitted with this checklist.

- Interim stabilize the 216-B-3A pond. This pond will not be used for future water disposal because of the proximity of the 216-B-3 Pond. The $3 A$ Pond may not be contaminated with hazardous or radioactive constituents above proposed action levels. If this is determined, it may not be necessary to interim stabilize this pond. If contamination is present, it will be removed and consolidated, if 
SEPA Checkl ist

216-B-3 Pond System Closure

Page 5 of 19

possible, in the 216-B-3 Pond. The pond may then have a clean soil layer or other suitable cover placed over it and be revegetated. If the pond must be interim stabilized, it will be done following stabilization of the 216-B-3 Pond and 216-B-3-3 Ditch. Details of the interim stabilization are in Chapter 7 of the closure plan submitted with this checklist.

The 216-B-3 pond covers approximately 35 acres. The 216-B-3A and 216-B-3B Ponds each cover approximately 11 acres, while the 216-B-3C Pond covers approximately 41 acres. The 216-B-3-3 Ditch is approximately 3,700 feet long, 30 feet wide at ground level, 6 feet wide at the bottom, and 4 to 8 feet deep.

12. Location of the proposal. Give sufficient information for a person to understand the precise location of your proposed project, including a street address, if any, and section, township, and range, if known. If a proposal would occur over a range of area, provide the range or boundaries of the site(s). Provide a legal description, site plan, vicinity map, and topographic map, if reasonably available. While you should submit any plans required by the agency, you are not required to duplicate maps or detailed plans submitted with any permit applications related to this checklist.

The 216-B-3 Pond is located approximately 3,700 feet east of the Hanford Site 200 East Area perimeter fence, on the 200 Area Plateau. The 200 East Area is linked to $B$ Pond by the 216-B-3-3 Ditch and the 216-A-29 Ditch. The 216-B-3A, 3B, and $3 C$ Ponds are adjacent to the 216-B-3 Pond on the east. Maps and plans of the area are contained in the RCRA closure/postclosure plan submitted with this Checklist. The facility is located in the NE 1/4 of Section 1, T12N, R26E, and the NW 1/4 of Section 6, T12N, R27E of the Willamette Base and Meridian.

B. ENVIRONMENTAL ELEMENTS

1. Earth

a. General description of the site: Flat, rolling, hilly, steep slopes, mountainous, other.

Flat.

b. What is the steepest slope on the site (approximate percent slope)? The approximate slope of the land at the facility is less than two percent. 
SEPA Checklist

c. What general types of soil are found on the site (for example, clay, sand, gravel, peat, muck)? If you know the classification of agricultural soils, specify them and note any prime farmland.

The soil found at the 216-B-3 Pond System consists mostly of a sand and pebble conglomerate, and pebble conglomerate. No farming is permitted on the site.

d. Are there surface indications or history of unstable soils in the immediate vicinity? If so, describe.

No.

e. Describe the purpose, type, and approximate quantities of any filling or grading proposed. Indicate the source of the fill.

Earthen fill material will be placed in the 216-B-3 Pond to stabilize and contain contamination known to exist in that pond. If removal of contaminated soil is required for clean closure of the 216-B-3A Pond, the contaminated soil will be consolidated and placed in the 216-B-3 Pond. Any such deposit will be covered with soil and sediment fill material for stabilization. Earthen fill material also will be placed in the 216-B-3-3 Ditch.

Some fill material will be obtained from stockpiles along the north and south shores of the 216-B-3 Pond. Sources for additional fill material, if required, have not been identified at this time.

f. Could erosion occur as a result of clerring, construction, or use? If so, describe.

Significant erosion is not expected because of the flat topography, dry climate, and soil type present at the site.

g. About what percentage of the site will be covered with impervious surfaces after project construction (for example, asphalt or buildings)?

None at this time.

h. Proposed measures to reduce or control erosion, or other impacts to the earth, if any:

The potential for wind erosion will be mitigated by wetting any soil excavation surfaces and reestablishing vegetation over backfilled surfaces of the 216-B-3 Pond and the 216-B-3-3 Ditch. 
2. Air

a. What types of emissions to the air would result from the proposal (i.e., dust, automobile, odors, industrial wood smoke) during construction and when the project is completed? If any, generally describe and give approximate quantities if known.

Minor amounts of exhaust will be generated by vehicles used to gain access to the site and for groundwater monitoring. Heavy equipment and trucks used to remove contaminated soil and to backfill the 216-B-3 Pond, the 216-B-3-3 Ditch, and the 216-B-3A pond (if necessary) will generate dust and minor amounts of exhaust.

b. Are there any offsite sources of emissions or odors that may affect your proposal? If so, generally describe.

No.

c. Proposed measures to reduce or control emissions or other impacts to the air, if any:

To reduce the potential for dust generation during closure activities, water trucks will be available onsite periodically to spray effected areas if required and sprinklers will be used if any areas become dry.

3. Water

a. Surface

1) Is there any surface water body in or in the immediate vicinity of the site (including year-round and seasonal streams, saltwater, lakes, ponds, wetlands)? If yes, describe type and provide names. If appropriate, state what stream or river it flows into.

No natural surface water bodies or wetlands exist on or in the vicinity of the site. However, the 216-B-3 Pond System contains fluctuating levels of standing process water.

2) Will the project require any work over, in, or adjacent to (within 200 feet of) the described waters? If yes, please describe and attach available plans.

Earthen fill material will be placed in the 216-B-3 Pond, 216-B-3-3 Ditch, and the 216-B-3A Pond during interim stabilization. Detailed information is included in the closure plan submitted with this checklist. 
SEPA Checklist

216-B-3 Pond System Closure

Page 8 of 19

3) Estimate the amount of fill and dredge material that would be placed in or removed from surface water or wetlands and indicate the area that would be affected. Indicate the source of the fill.

No fill material will be placed in or removed from natural surface waters or wetlands.

4) Will the proposal require surface water withdrawals or diversions? Give general description, purpose, and approximate quantities if known.

No.

5) Does the proposal lie within a 100-year floodplain? If so, note location on the site plan.

No.

6) Does the proposal involve any discharges of waste material to surface waters? If so, describe the type of waste and anticipated volume of discharge.

No.

b. Ground

1) Wi11 groundwater be withdrawn, or will water be discharged to groundwater? Give general description, purpose, and approximate quantities if known.

Nondangerous process and cooling water is discharged to the 216-B-3 Pond System from various Hanford Site 200 East Area facilities. The ponds are not lined; therefore, this waste water eventually migrates into the groundwater beneath the facility. The volume of water discharged to the system is currentiy monitored in the supply ditch (216-B-3-3 Ditch) approximately 2,500 feet out from the 200 East Area perimeter fence (approximately 1,500 feet from the inlet to the main lobe). Discharged volumes in the past have varied from 7 milition to 22 million gallons per day, depending on the operating status of plants discharging to the system. Natural precipitation, averaging approximately 6 inches per year, also accumulates in the unlined ponds and migrates into the subsurface. Following the clean closure of the expansion ponds and removal of the 216-B-3 Pond and 216-B-3-3 Ditch from service, this nondangerous waste water will discharge directly to the $3 B$ and $3 C$ ponds. This discharge rate is expected to average about 3.6 million gallons per day. 
SEPA Checklist 216-B-3 Pond System Closure

Page 9 of 19

Small quantities of groundwater are withdrawn from monitoring wells. During the first year after completion of groundwater monitoring wells, groundwater is withdrawn from the wells on a quarterly basis and submitted for laboratory analysis. During subsequent years, groundwater is withdrawn on a semiannual basis, unless otherwise specified by Ecology. Before sample collection from a well, at least three borehole volumes of water must be purged from the well to ensure a representative groundwater sample is collected.

2) Describe waste materials that will be discharged into the ground from septic waste tanks or other sources, if any (for example: Domestic sewage; industrial, containing the following chemicals...; agricultural; etc.). Describe the general size of the system, the number of such systems, the number of houses to be served (if applicable), or the number of animals or humans the system(s) are expected to serve.

No waste material will be intentionally discharged to the ground as a result of closure activities.

The 216-B-3 Pond is located approximately 3,700 feet east of the 200 East Area perimeter fence. From the 200 East Area, waste water flows via the 216-B-3-3 Ditch and via the 216-A-29 Ditch, which intersects the 216-B-3-3 Ditch, to the 216-B-3 Pond. The 216-B-3 Pond System is comprised of the 216-B-3-3 Ditch, the 216-B-3 Pond, and three expansion lobes (216-B-3A, $3 B$, and $-3 C)$. The $216-B-3$ Pond System receives nondangerous waste water from the 200 East Area facilities. Following the clean closure of the expansion ponds and removal of the 216-B-3 Pond and 216-B-3-3 Ditch from service, this nondangerous waste water will discharge directly to the $3 B$ and $3 C$ ponds.

Detailed information on the constituents contained in the waste water is contained in Chapters 3.0 and 4.0 of the RCRA closure/postclosure plan submitted with this Checklist.

c. Water Run-off (including storm water):

1) Describe the source of run-off (including storm water) and methods of collection and disposal, if any (include quantities, if known). Where will this water flow? Will this water flow into other waters? If so, describe.

The only source of run-off that will be associated with the 216-B-3 Pond System closure activities will be precipitation. Al1 precipitation will be allowed to infiltrate the surrounding porous soil or mingle with standing water in expansion ponds that are clean closed and that will continue to be used for waste water disposal. 
SEPA Checkl ist

216-B-3 Pond System Closure

Page 10 of 19

2) Could waste materials enter ground or surface waters? If so, generally describe.

Discharges to ground and surface waters are discussed in the answers to Checklist questions B.3.a.6, and B.3.b.1 and 2.

d. Proposed measures to reduce or control surface, ground, and run-off water impacts, if any:

The flow of water between the ponds is controlled by spillways equipped with overflow control barriers. Manually operated slide gates on the overflow control structures regulate the amount of water discharged to the culverts that carry water between the ponds. The slide gates normally are set to allow overflow water from one pond to pass into the next pond. Excess capacity is designed into the facility to prevent the escape of overflow water from the Ponds.

4. Plants

a. Check the types of vegetation found on the site:

$X$ deciduous trees: alder, maple, aspen, other evergreen trees: fir, cedar, pine, other

$\frac{X}{X}$ shrubs

pasture

crop or grain

$\bar{X}$ wet soil plants: cattail, buttercup, bulrush, skunk cabbage, other

water plants: water lily, eelgrass, milfoil, other

other types of vegetation

Standing water in the 216-8-3 Pond System lobes, and the 216-B-3-3 Ditch supports a variety of vegetation typical of a riparian habitat. Poplar, willow, and Russian olive trees grow along the edges of the lobes, along with cattail, bulrush, various small shrubs, and grass.

b. What kind and amount of vegetation will be removed or altered?

Small vegetated areas adjacent to the site may be affected by closure activities. Areas denuded of vegetation as a result of this project will be revegetated as appropriate.

c. List threatened or endangered species known to be on or near the site.

No threatened or endangered species are known to exist on or near the site. A biological survey has been completed for the 216-B-3 Pond System. Additional information concerning endangered and 
SEPA Checklist

216-8-3 Pond System Closure

Page 11 of 19

threatened plants on the Hanford Site can be found in the documents referred to in the answer to Checklist question A.8.

d. Proposed landscaping, use of native plants, or other measures to preserve or enhance vegetation on the site, if any.

To minimize erosion, stabilized portions of the 216-B-3-3 Ditch and the 216-B-3 Pond System will be revegetated appropriately with species well-suited to the local climate.

\section{Animals}

a. Circle any birds and animals which have been observed on or near the site or are known to be on or near the site:

birds: hawk, heron, eagle, songbirds, other mammals: deer, bear, elk, beaver, other

fish: bass, salmon, trout, herring, shellfish, other

Process discharges to the 216-B-3 Pond System provide a source of water to nesting, wintering, and migratory waterfowl, as well as to many locally common mammal species. Birds commonly sighted in the area include heron, ducks, songbirds, and pigeons. Other animals seen in the area include deer, coyote, lagomorphs, and various small rodents. Goldfish and unidentified small minnows have also been seen in B Pond. Additional information on birds and animals on the Hanford Site can be found in the documents referred to in the answer to Checklist question A.8.

b. List any threatened or endangered species known to be on or near the site.

The facility is not known to be used by any threatened or endangered species. A biological survey has been completed for the 216-B-3 Pond System. Additional information concerning endangered and threatened species on the Hanford Site can be found in the documents referred to in the answer to Checklist question A.8.

c. Is the site part of a migration route? If so, explain.

The adjacent Columbia River is part of the broad Pacific Flyway for waterfowl migration and other birds also migrate along the river. Process discharges to the 216-B-3 Pond System provide a source of water to nesting, wintering, and migratory waterfowl.

d. Proposed measures to preserve or enhance wildlife, if any:

None at this time. 
SEPA Checklist

6. Energy and Natural Resources

a. What kinds of energy (electric, natural gas, 011 , wood stove, solar) will be used to meet the completed project's energy needs? Describe whether it will be used for heating, manufacturing, etc.

Gasoline, diesel fuel, and/or motor oil may be used to power equipment necessary for groundwater monitoring and the closure activities described in this checklist.

b. Would your project affect the potential use of solar energy by adjacent properties? If so, generally describe.

No.

c. What kinds of energy conservation features are included in the plans of this proposal? List other proposed measures to reduce or control energy impacts, if any:

None.

7. Environmental Health

a. Are there any environmental health hazards, including exposure to toxic chemicals, risk of fire and explosion, spill, or hazardous waste, that could occur as a result of this proposal? If so, describe.

There may be some potential for exposure to hazardous chemicals and radioactive waste during groundwater monitoring and other sampling activities, and the closure activities described in this checklist. Procedures to prevent and manage hazards are presented in the RCRA Closure/Postclosure plan.

1) Describe special emergency services that might be required.

Fire, ambulance, and patrol assistance might be required in the event of an unexpected emergency. These services are available on the Hanford Site.

2) Proposed measures to reduce or control environmental health hazards, if any:

Closure activities will be performed in a manner that minimizes impacts to human health and the environment. Personnel will receive radioactive and hazardous waste worker training and will be cognizant of applicable health and safety measures. All personnel conducting soil sampling, soil removal, and stabilization activities will wear appropriate protective 
clothing. Such personnel will be monitored for contamination upon leaving the facility.

The RCRA closure/postclosure $p 1$ an and plans specific to closure activities (e.g., the health and safety plan for soil sampling) address specific training requirements and measures to reduce or control environmental health hazards. Identified training requirements include Occupational Safety and Health Administration (OSHA) training. Decontamination solutions, cleanup debris, protective clothing, and groundwater monitoring well purgewater will be collected and appropriately disposed of.

b. Noise

1) What type of noise exists in the area which may affect your project (for example: traffic, equipment, operation, other)?

None.

2) What types and levels of noise would be created by or associated with the project on a short-term or a long-term basis (for example: traffic, construction, operation, other)? Indicate what hours noise would come from the site.

Soil and groundwater sampling activities, groundwater monitoring, and waste stabilization/soil removal activities temporarily will increase noise levels during normal day shift hours.

3) Proposed measures to reduce or control noise impacts, if any:

None at this time.

8. Land and Shoreline Use

a. What is the current use of the site and adjacent properties?

The 216-B-3 Pond System is currently being used for disposal of nondangerous waste water from various 200 East Area facilities. Waste water is transferred to the system via the 216-B-3-3 Ditch. The B Pond is a part of the U.S. Government-owned Hanford Site, which is used for the production of special nuclear materials and the management of wastes associated with the production of those materials.

b. Has the site been used for agriculture? If so, describe.

No portion of the Hanford Site, including the 216-B-3 Pond System site, has been used for agricultural purposes since 1943. 
SEPA Checklist

216-B-3 Pond System Closure

Page 14 of 19

c. Describe any structures on the site.

A detailed description of the 216-B-3 Pond and 216-B-3-3 Ditch structures is provided in the closure/postclosure plan with which this Checklist is being submitted. The following general description is provided for informational purposes.

Process water flows from the Hanford Site 200 East Area to the 216-B-3 Pond via the 216-B-3-3 Ditch. At the head end of the 216-B-3-3 Ditch are feeder pipelines and a headwall structure. The PUREX Plant process discharge is discharged to the 216-A-29 Ditch, which intersects the 216-B-3-3 Ditch upstream from the 216-B-3 Pond. Along the 216-B-3-3 Ditch, approximately 1,500 feet from the inlet to the main lobe, is a small flume and flowmeter, used to measure the flow of process discharge water to the system. Discharge water flows unimpeded to the 216-B-3 Pond.

Two gated overflow outlets allow water to drain through culverts from the 216-3-3 Pond to the 216-B-3A Pond. One of these is a nonoperational culvert that at one time discharged to a cement-1ined ditch leading to the 216-B-3A Pond. The other overflow outlet directs water directly to the 216-B-3A Pond through two buried pipes. From the 216-B-3A Pond, one gated overflow outlet leads to each of the remaining two lobes. All overflow from the 216-B-3A Pond is currently routed to the 216-B-3C Pond; the 216-B-3B Pond is dry.

Earthen dikes separate the 216-B-3 Pond from the 216-B-3A Pond, and the 216-B-3A Pond from the 216-B-3B Pond. Piezometers have been placed in both of these dikes to track water table elevations beneath the lobes.

d. Will any structures be demolished? If so, what?

A11 structures immediately associated with the 216-B-3-3 Ditch and the 216-B-3 Pond will be removed from operation as part of the interim stabilization of the ditch and pond. Such structures include the headwall and piping at the head end of the 216-B-3-3 Ditch, the flume and flowmeter along the 216-B-3-3 Ditch, and the two outlets from the 216-B-3 Pond to the 216-B-3A Pond. The concrete 216-B-3-3 Ditch headwalls will be demolished and buried in place. The associated piping will be plugged and backfilled with concrete. Cement structures and rock-containing wire baskets associated with the flume will be demolished and buried in place. The flowmeter and all three pipes from the 216-B-3 Pond to the 216-B-3A Pond will be removed and properly disposed of, depending on the type of residual contamination. The cement lining of the nonoperational ditch leading to the 216-B-3A Pond and the cement headwall of the overflow control structures will be demolished and buried in the 216-B-3 Pond. The piezometers and/or groundwater 
monitoring wells on the dike separating the 216-B-3 Pond and the 216-B-3A Pond will be sealed and abandoned. The two flow control and spillway structures from the 216-B-3A Pond to the $3 B$ and $3 C$ Ponds will be demolished and disposed of. Details of this proposed work are in the RCRA Closure/Postclosure Plan submitted with this checklist.

e. What is the current zoning classification of the site?

The Hanford Site is zoned by Benton County as an Unclassified Use (U) district.

f. What is the current comprehensive plan designation of the site?

The 1985 Benton County Comprehensive Land Use Plan designates the Hanford Site as the "Hanford Reservation." Under this designation, 1 and on the Hanford Site may be used for "activities nuclear in nature." Nonnuclear activities are authorized "if and when DOE approval for such activities is obtained."

g. If applicable, what is the current master shoreline program designation of the site?

Does not apply.

h. Has any part of the site been classified as an "environmentally sensitive" area? If so, specify.

No.

i. Approximately how many people would reside or work in the completed project?

None.

j. Approximately how many people would the completed project displace? None.

k. Proposed measures to avoid or reduce displacement impacts, if any: None; Does not apply.

1. Proposed measures to ensure the proposal is compatible with existing and projected 1 and uses and plans, if any:

None; Does not apply. (See answer to Checklist question B.8.f.) 
9. Housing

a. Approximately how many units would be provided, if any? Indicate whether high, middle, or low-income housing.

None.

b. Approximately how many units, if any, would be eliminated?

Indicate whether high, middle, or low-income housing.

None.

c. Proposed measures to reduce or control housing impacts, if any:

Does not apply.

10. Aesthetics

a. What is the tallest height of any proposed structure(s), not including antennas; what is the principal exterior building material (s) proposed?

Does not apply.

b. What views in the immediate vicinity would be altered or obstructed? None.

c. Proposed measures to reduce or control aesthetic impacts, if any: Does not apply.

11. Light and Glare

a. What type of light or glare will the proposal produce? What time of the day would it mainly occur?

None.

b. Could light or glare from the finished project be a safety hazard or interfere with views?

No.

c. What existing offsite sources of light and glare may affect your proposal?

None. 
d. Proposed measures to reduce or control light and glare impacts, if ?ny:

Does not apply.

\section{Recreation}

a. What designated and informal recreational opportunities are in the immediate vicinity?

None.

b. Would the proposed project displace any existing recreational uses? If so, describe.

Does not apply.

c. Proposed measures to reduce or control impacts on recreation, including recreation opportunities to be provided by the project or applicant, if any:

Does not apply.

13. Historic and Cultural Preservation

a. Are there any places or objects listed on, or proposed for, national, state, or local preservation registers known to be on or next to the site? If so, generally describe.

No places or objects listed on, or proposed for, national, state, or local preservation registers are known to be on or next to the site. A cultural resource review has been conducted for the site. Additional information on the Hanford Site environment can be found in the documents referred to in the answer to Checklist question A.8.

b. Generally describe any landmarks or evidence of historic, archaeological, scientific, or cultural importance known to be on or next to the site.

There are no known archaeological, historical, or native American religious sites at or next to the facility. A cultural resource review has been conducted for the site. Additional information on the Hanford Site environment can be found in the documents referred to in the answer to Checklist question A.8.

c. Proposed measures to reduce or control impacts, if any:

A cultural resource review will provide the vehicle for necessary approvals required under the National Historic Preservation Act. 
SEPA Checklist

216-B-3 Pond System Closure

Page 18 of 19

14. Transportation

a. Identify public streets and highways serving the site, and describe proposed access to the existing street system. Show on site plans, if any.

The site lies within the controlled access area of the Hanford Site and is not publicly accessible.

b. Is the site currently served by public transit? If not, what is the approximate distance to the nearest stop?

Does not apply. (See answer to Checklist question B.14.a.)

c. How many parking spaces would the completed project have? How many would the project eliminate?

None.

d. Will the proposal require any new roads or streets, or improvements to existing roads or streets, not including driveways? If so, generally describe (indicate whether public or private).

No.

e. Wili the project use (or occur in the immediate vicinity of) water, rail, or air transportation? If so, generally describe.

No.

f. How many vehicular trips per day would be generated by the completed project? If known, indicate when peak volumes would occur.

None.

g. Proposed measures to reduce or control transportation impacts, if any:

Does not apply.

\section{Public Services}

a. Would the project result in an increased need for public services (for example: fire protection, police protection, health care, schools, other)? If so, generally describe.

No. 
b. Proposed measures to reduce or control direct impacts on public services, if any:

Does not apply.

\section{Utilities}

a. List utilities currently available at the site: electricity, natural gas, water, refuse service, telephone, sanitary sewer, septic system, other.

\section{None.}

b. Describe the utilities that are proposed for the project, the utility providing the service, and the general construction activities on the site or in the immediate vicinity which might be needed.

None.

\section{SIGNATURES}

The above answers are true and complete to the best of my knowledge. I understand that the lead agency is relying on them to make its decision.

J.D. Bauer, Program Manager
office of Environmental Assurance, Permits and Policy

U.S. Department of Energy

Richland Operations office

R. E. Lerch,LDeputy Director Restoration and Remediation Westinghouse Hanford Company
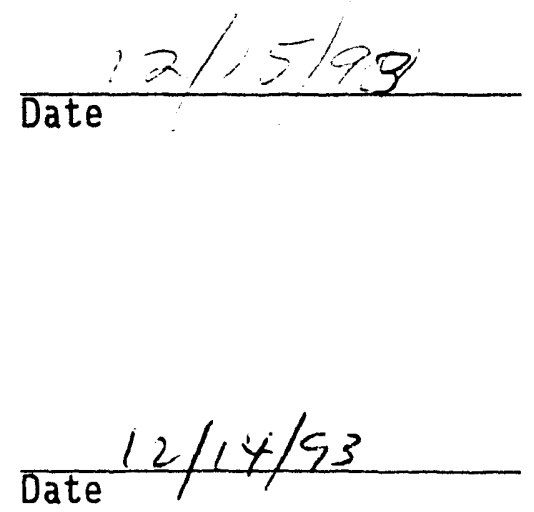
DOE/RL-89-28, Rev. 1

$12 / 15 / 93$

\title{
216-B-3 EXPANSION PONDS CLOSURE PLAN
}

\author{
FOREWORD
}

The Hanford Site is owned and operated by the U.S. Department of Energy, Richland Operations Office. The Hanford Site manages and produces radioactive, dangerous, and mixed waste (containing both radioactive and dangerous components). The radioactive waste and radioactive component of mixed waste is interpreted by the U.S. Department of Energy to be regulated under the Atomic Energy Act of 1954; dangerous waste and the nonradioactive dangerous waste components of mixed waste are interpreted to be regulated under the Resource Conservation and Recovery Act of 1976 and the Washington State Department of Ecology Dangerous Waste Regulations, Washington Administrative Code 173-303.

For the purposes of the Resource Conservation and Recovery Act, the Hanford Site is considered to be a single facility. A single dangerous waste permit identification number issued to the Hanford Site by the U.S. Environmental Protection Agency and Washington State is Environmental Protection Agency/State Identification Number WA890008967. This identification number encompasses a number of waste management units within the Hanford Facility. Waste management units that are no longer operating will be closed under interim status (using final status standards in Washington Administrative Code 173-303-610).

Since 1987, Westinghouse Hanford Company has been a major contractor to the U.S. Department of Energy, Richland Operations Office and has served as co-operator of the 216-B-3 Pond System, the waste management unit addressed in this closure plan. For the purposes of the Resource Conservation and Recovery Act, Westinghouse Hanford Company is identified as "co-operator" and signs in that capacity. Any identification of Westinghouse Hanford Company as an operator elsewhere in this closure plan is not meant to conflict with Westinghouse Hanford Company's designation as co-operator but is rather based on Westinghouse Hanford Company's contractual status (i.e., as a management and operations contractor) for the U.S. Department of Energy, Richland Operations Office.

The 216-B-3 Expansion Ponds Closure Plan (Revision 1) consists of a Part A Dangerous Waste Permit Application and a Resource Conservation and Recovery Act Closure Plan. An explanation of the Part A submitted with this document is provided at the beginning of the Part A Section. The closure plan consists of nine chapters and five appendices. 
DOE/RL-89-28, Rev. 1

$12 / 15 / 93$

This page intentionally left blank. 


\section{CONTENTS}

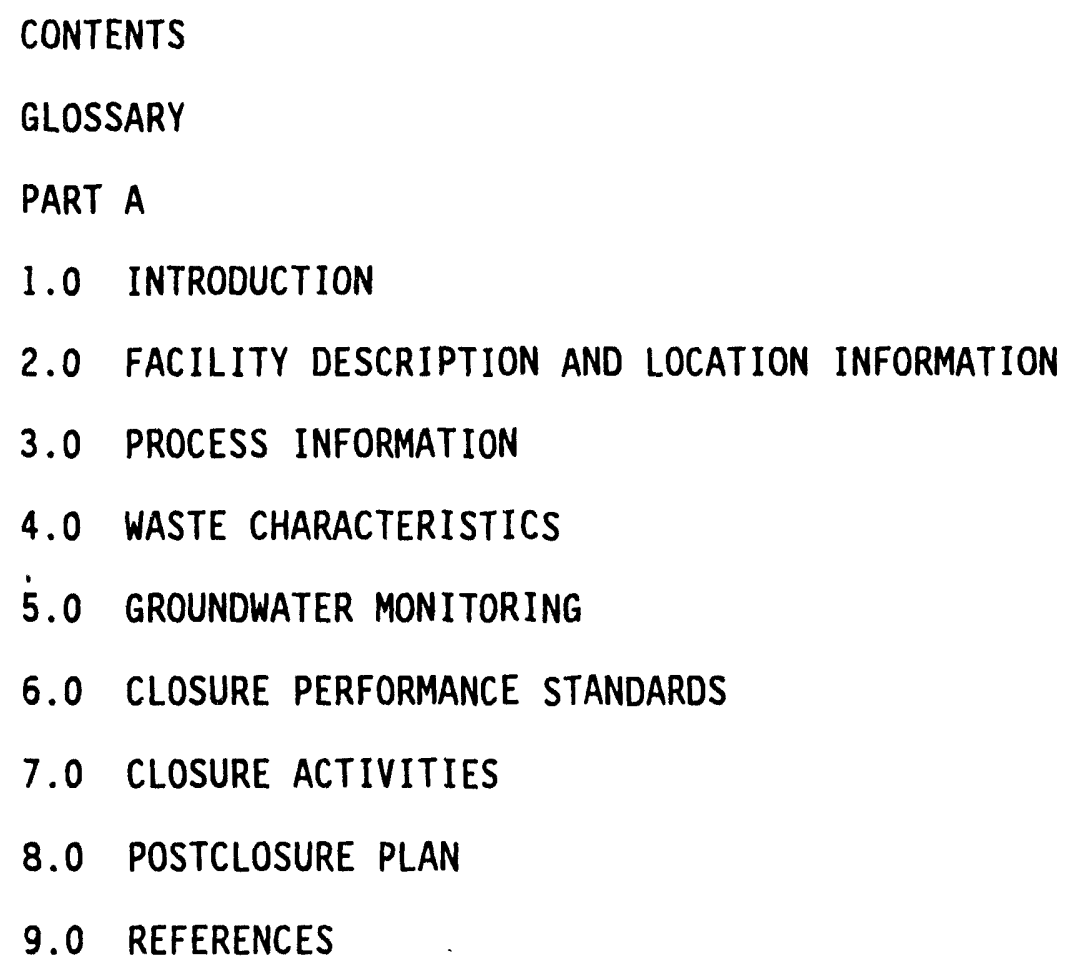




$$
\text { 1 } \quad \mathrm{DOE} / \mathrm{RL}-89-28 \text {, Rev. } 1
$$

This page intentionally left blank. 


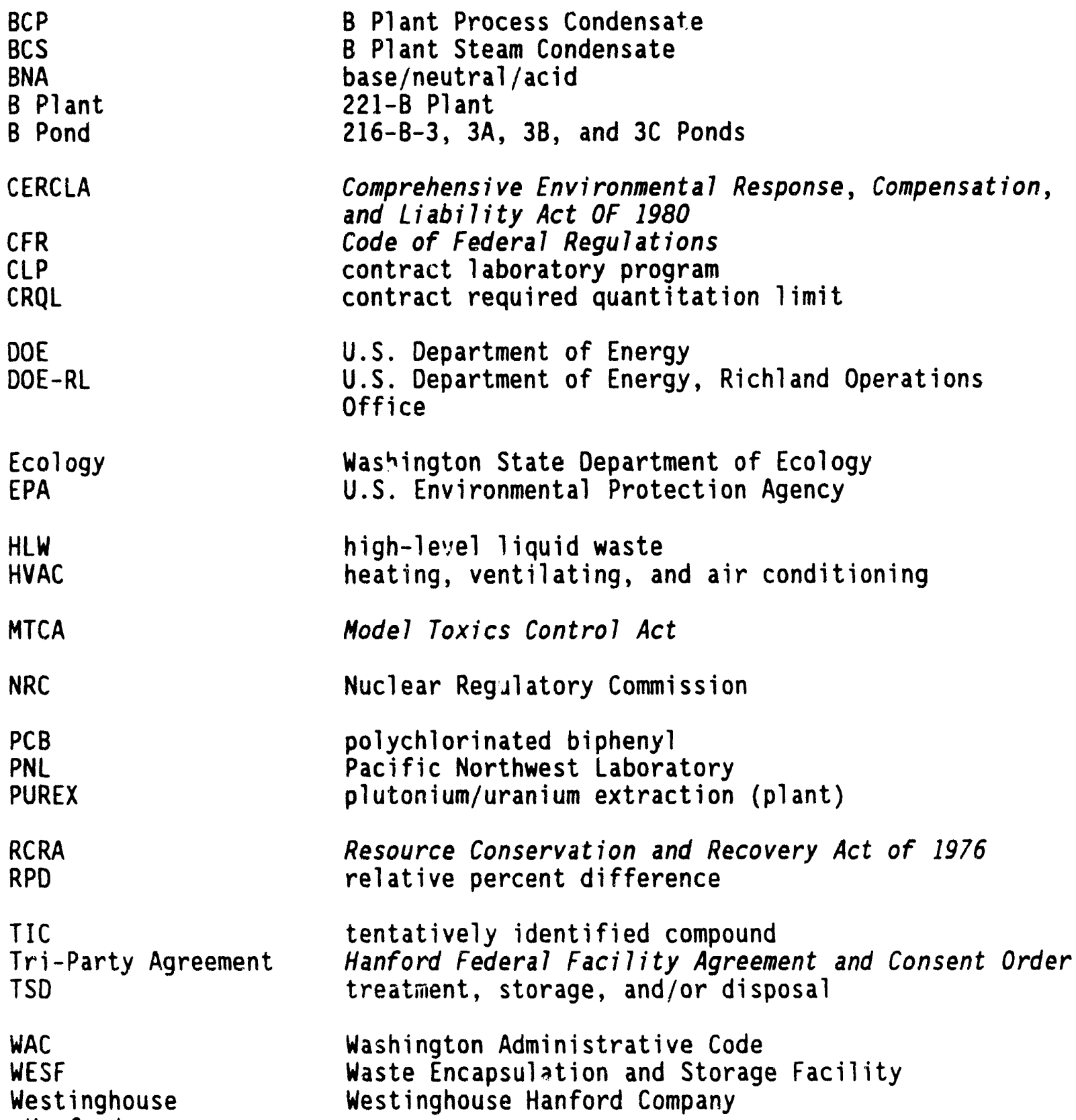


DOE/RL-89-28, Rev . 1

$12 / 15 / 93$

This page intentionally left blank.

viii 


\section{METRIC CONVERSION CHART}

The following conversion chart is provided to the reader to aid in conversion.

Into metric units

Out of metric units

\begin{tabular}{|c|c|c|c|c|c|}
\hline If you know & $\begin{array}{c}\text { Multiply } \\
\text { by }\end{array}$ & To get & If you know & $\begin{array}{c}\text { Multiply } \\
\text { by }\end{array}$ & To get \\
\hline \multicolumn{3}{|c|}{ Length } & \multicolumn{3}{|c|}{ Length } \\
\hline inches & 25.40 & millimeters & millimeters & 0.0393 & inches \\
\hline inches & 2.54 & centimeters & centimeters & 0.393 & inches \\
\hline feet & 0.3048 & meters & meters & 3.2808 & feet \\
\hline yards & 0.914 & meters & meters & 1.09 & yards \\
\hline miles & 1.609 & kilometers & kilometers & 0.62 & miles \\
\hline \multicolumn{3}{|c|}{ Area } & \multicolumn{3}{|c|}{ Area } \\
\hline $\begin{array}{l}\text { square } \\
\text { inches }\end{array}$ & 6.4516 & $\begin{array}{l}\text { square } \\
\text { centimeters }\end{array}$ & $\begin{array}{l}\text { square } \\
\text { centimeters }\end{array}$ & 0.155 & $\begin{array}{l}\text { square } \\
\text { inches }\end{array}$ \\
\hline square feet & 0.092 & $\begin{array}{l}\text { square } \\
\text { meters }\end{array}$ & $\begin{array}{l}\text { square } \\
\text { meters }\end{array}$ & 10.7639 & $\begin{array}{l}\text { square } \\
\text { feet }\end{array}$ \\
\hline $\begin{array}{l}\text { square } \\
\text { yards }\end{array}$ & 0.836 & $\begin{array}{l}\text { square } \\
\text { meters }\end{array}$ & $\begin{array}{l}\text { square } \\
\text { meters }\end{array}$ & 1.20 & $\begin{array}{l}\text { square } \\
\text { yards }\end{array}$ \\
\hline $\begin{array}{l}\text { square } \\
\text { miles }\end{array}$ & 2.59 & $\begin{array}{l}\text { square } \\
\text { kilometers }\end{array}$ & $\begin{array}{l}\text { square } \\
\text { kilometers }\end{array}$ & 0.39 & $\begin{array}{l}\text { square } \\
\text { miles }\end{array}$ \\
\hline acres & 0.404 & hectares & hectares & 2.471 & acres \\
\hline \multicolumn{3}{|c|}{ Mass (weight) } & \multicolumn{3}{|c|}{ Mass (weight) } \\
\hline ounces & 28.35 & grams & grams & 0.0352 & ounces \\
\hline pounds & 0.453 & kilograms & kilograms & 2.2046 & pounds \\
\hline short ton & 0.907 & metric ton & metric ton & 1.10 & short ton \\
\hline \multicolumn{3}{|c|}{ Volume } & \multicolumn{3}{|c|}{ Volume } \\
\hline $\begin{array}{l}\text { fluid } \\
\text { ounces }\end{array}$ & 29.57 & milliliters & milliliters & 0.03 & $\begin{array}{l}\text { fluid } \\
\text { ounces }\end{array}$ \\
\hline quarts & 0.95 & Titers & liters & 1.057 & quarts \\
\hline gallons & 3.79 & Titers & Titers & 0.26 & gallons \\
\hline cubic feet & 0.03 & $\begin{array}{l}\text { cubic } \\
\text { meters }\end{array}$ & $\begin{array}{l}\text { cubic } \\
\text { meters }\end{array}$ & 35.3147 & cubic feet \\
\hline cubic yards & 0.76 & $\begin{array}{l}\text { cubic } \\
\text { meters }\end{array}$ & $\begin{array}{l}\text { cubic } \\
\text { meters }\end{array}$ & 1.308 & $\begin{array}{l}\text { cubic } \\
\text { yards }\end{array}$ \\
\hline \multicolumn{3}{|c|}{ Temperature } & \multicolumn{3}{|c|}{ Temperature } \\
\hline Fahrenheit & $\begin{array}{l}\text { subtract } \\
32 \text { then } \\
\text { multiply } \\
\text { by } 5 / 9 \text { ths }\end{array}$ & Celsius & Celsius & $\begin{array}{l}\text { multiply } \\
\text { by } \\
9 / 5 \text { ths, } \\
\text { then add } \\
32\end{array}$ & Fahrenheit \\
\hline
\end{tabular}

Source: Engineering Unit Conversions, M. R. Lindeburg, PE., Second Ed., 1990, Professional Publications, Inc., Belmont, California. 
DOE/RL-89-28, Rev. 1

$12 / 15 / 93$

This page intentionally left blank. 
DOE/RL-89-28, Rev. 1

$12 / 15 / 93$

PART A

Part A-i 
DOE/RL-89-28, Rev. 1

$12 / 15 / 93$

This page intentionally left blank. 
DOE/RL-89-28, Rev. 1

$12 / 15 / 93$

\section{PART A}

2

3

4

Part A-i 
$\mathrm{DOE} / \mathrm{RL}-89-28$, Rev. 1

$12 / 15 / 93$

1
2
3
4
5

This page intentionally left blank. 


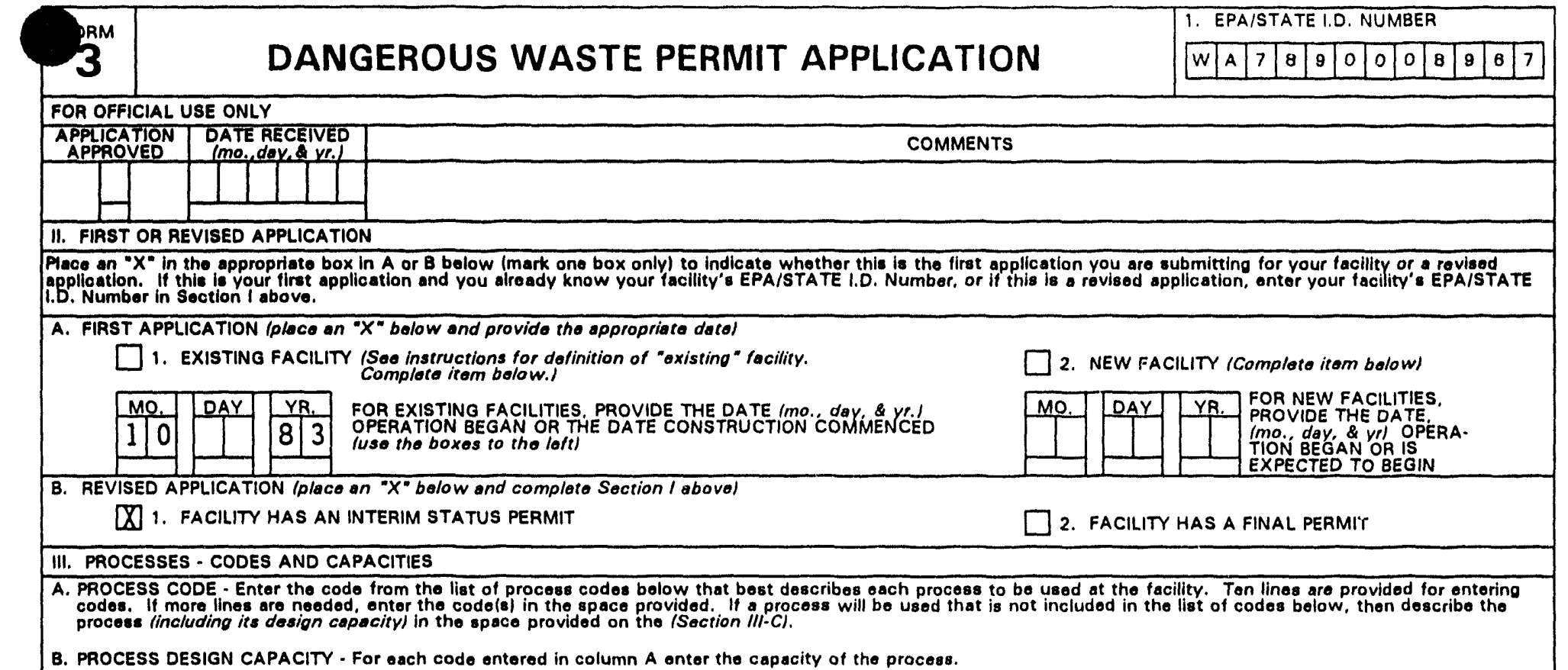

B. PROCESS DESIGN CAPACITY - For each code entered in column A onter the capacity of the process.

\section{AMOUNT - Enter the amount.}

2. UNIT OF MEASURE - For each amount entered in column B(1), enter the code from the list of unit measure codes below that describes the unit of measure used. Only the units of measure that are listed below should be used.

\begin{tabular}{ccc} 
PRO- & APPROPRIATE UNITS OF \\
PROCESS & CESS & MEASURE FOR PROCESS \\
CODE & DESION CAPACITY \\
\hline
\end{tabular}

Storage:

CONTAINER (barrol, drum, etc) WASTE PILE

SURFACE IMPOUNDMENT

Disposal:

LANDFILL

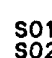

SO2

SO4

GALLONS OR LITERS

GALLONS OR LITERS

CUBIC YARDS

D8O GALLONS OR LITERS would cover one acre to a

depth of one foot

D82 ACRES OR HECTARES

DB3 GALLONS PER DAY OR

SURFACE IMPOUNDMENT

084

GALLONS OR LITERS
INJECTION WELL

GALLONS OR LITERS

D81 ACRE-FEET the volume that

LAND APPLICATION

\section{UNIT OF}

UNIT OF MEASURE MEASURE

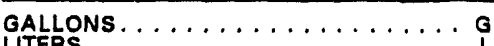

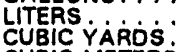

CUBIC METERS GALLONS PER DAY $\ldots \ldots \ldots \ldots \ldots \ldots \ldots \ldots$ C

$\ldots \ldots$ i

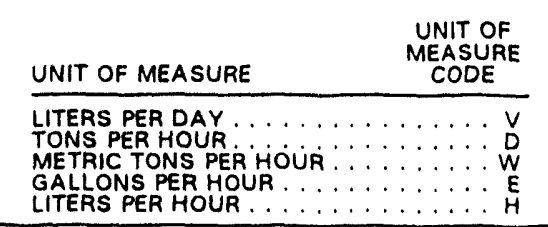

APPROPRIATE UNITS OF
MEASURE FOR PROCESS DESIGN CAPACITY

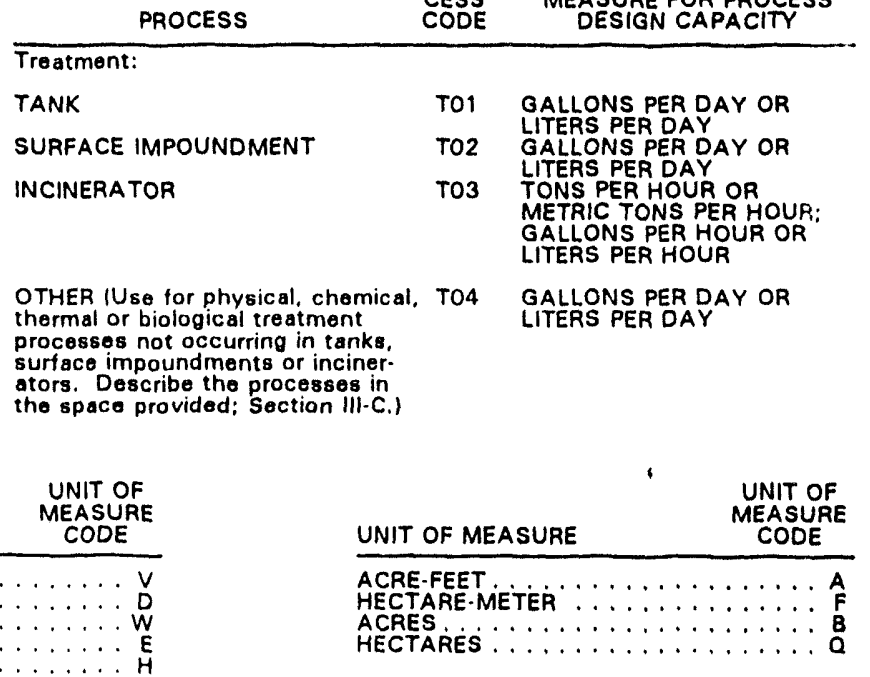

EXAMPLE FOR COMPLETING SECTION III shown in line numbers $X-1$ and $X \cdot 2$ belowl: A facility has two storago tanks, ono tonk can

hold 200 gallons and the othor can hold 400 gallons. The facility also has an incinerator that can burn up to 28 gallons per hour.

\begin{tabular}{|c|c|c|c|c|c|}
\hline \multirow{3}{*}{ 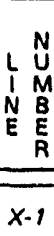 } & \multirow{2}{*}{\multicolumn{3}{|c|}{$\begin{array}{l}\text { A. PRO- } \\
\text { CESS } \\
\text { CODE } \\
\text { (from list } \\
\text { obovol }\end{array}$}} & \multicolumn{2}{|c|}{ B. PROCESS DESIGN CAPACITY } \\
\hline & & & & 1. $\underset{\text { (spocify) }}{\text { AMOUNT }}$ & \\
\hline & $s$ & 0 & 2 & 600 & \\
\hline$x-2$ & $r \mid$ & 0 & 3 & 20 & \\
\hline & $T$ & 0 & 2 & $27,960,000$ & \\
\hline 2 & D) & 8 & 4 & $27,960,000$ & \\
\hline 3 & & & & & \\
\hline 4 & & & & & \\
\hline
\end{tabular}

ECL30-300- ECY 030-31 Form 3 Rov. $2 / 84$ gallons. The facility also has an incinerator that can burn up to 20 gallons per hour.
B. PROCESS DESIGN CAPACITY

\begin{tabular}{|c|c|}
$\begin{array}{c}2 . \text { UNIT } \\
\text { OF MEA. } \\
\text { SURE } \\
\text { lenter } \\
\text { codel }\end{array}$ & $\begin{array}{c}\text { FOR } \\
\text { OFFICIAL } \\
\text { USE } \\
\text { ONLY }\end{array}$ \\
\hline
\end{tabular}

1. AMOUNT

\begin{tabular}{|c|c|c|c|c|c|c|}
\hline & & & & B. PROCESS DESI & & \\
\hline $\begin{array}{l}\text { UNIT } \\
\text { F MEA } \\
\text { SURE } \\
\text { lenter } \\
\text { codel }\end{array}$ & $\begin{array}{c}\text { FOR } \\
\text { OFFICIAL } \\
\text { USE } \\
\text { ONLY }\end{array}$ & $\begin{array}{cc}L & U \\
i & M \\
N & M \\
E & E \\
& R\end{array}$ & $\begin{array}{l}\text { CESS } \\
\text { CODE } \\
\text { (from list } \\
\text { abovel }\end{array}$ & 1. $\underset{\text { (specify) }}{\text { AMOUNT }}$ & $\begin{array}{l}\text { 2. UNIT } \\
\text { OF MEA. } \\
\text { SURE } \\
\text { lentor } \\
\text { codel }\end{array}$ & $\begin{array}{c}\text { FOR } \\
\text { OFFICIAL } \\
\text { USE } \\
\text { ONLY }\end{array}$ \\
\hline- & & 5 & & & & \\
\hline$E$ & & 6 & & & & \\
\hline$U$ & & 7 & & & & \\
\hline G & & 8 & & & & \\
\hline & & 9 & & & & \\
\hline & & 10 & & & & \\
\hline
\end{tabular}

FOR USE ONLY 
Continued from the front.

PROCESSES (continued)

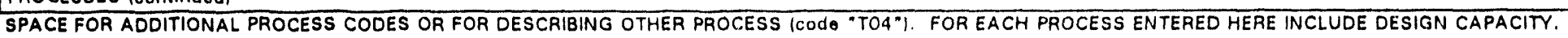
TO2. DB4

The 216-8-3 Expansion Ponds (Expansion Ponds) consist of three interconnected ponds called the 216-B-3A ( $3 \mathrm{~A}$ ) Pond, the $216-8-3 B$
$216-8-3$ Pond system, which includes the $316-8-3$ Main Pond (Main pond) a separate dangerous waste treatment and disposal unit as a result of the restart of the Plutonium Uranium Extraction (PUREX) Plant in 1983 and the decomissioning of the Gable Mountain Pond in 1987. The $3 A$ Pond was placed into service in october 1983 and remains in service today. ine $3 A$ Pond receives effluent from the Main Pond through spillway in the dike separating the two ponds. $A$ similar spill way allowed the 38 Pond. Which was operational from June 1984 to May 1985 to receive effluent from the $3 \mathrm{~A}$ Pond. The $3 \mathrm{~A}$ and $3 \mathrm{~B}$ Ponds each cover an area of approximately 11 acres $(4,4$ hectares). the 3C Pond began operation in 1985 and is still in service today. The $3 C$ Pond was constructed by excavating 6 feet (1.8 meters) of soil over a $44-a c r e$ (16-hectare) sur
similar to the ones used for the $3 A$ and $3 B$ Ponds conveys effluent from the $3 \mathrm{~A}$ Pond to the $3 \mathrm{C}$ Pond.

Waste water (primarily process and cooling water) from the PUREX Plant, the B Plant Complex, the $242-A$ Evaporator, and other 200 East Area units is received by the expansion ponds through the Main Pond. ihe Expansion Ponds received corrosive waste as a result of the regeneration of the PUREX Plant demineralizer colums (D84). Treatment of the waste occurred by the reaching the Expansion ponds. Residual corrosivity was neutralized by the calcareous nature of the Expansion Ponds

The process design capacities given for the waste process codes 102 [27,960,000 gallons (105,840,000 (iters) per day] and D84 $[27,960,000$ gallons (105,840,000 liters)] represent the Expansion Ponds proportional share (based on percolation capacity) of the process design capacity of the ent ire B Pond System. At the peak of operations approximately 22 , 000,000 gallons

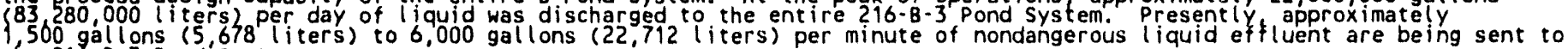
the $216-8-3$ Pond System.

Construction was begun on a new pipeline in 1990 that will allow waste water to bypass the $216-8-3$ Main Pond and discharge directly to the Expansion Ponds.

IV. DESCRIPTION OF DANGEROUS WASTES

A. DANGEROUS WASTE NUMBER. Entor the four digit number from Chapter 173.303 WAC for oach listed dangerous waste you will handlo. If you handlo dangerous wastes which ore not listed in Chapter 773.303 WAC. onter the four digit number(s) that describes the characteristics and/or the toxic con. damperous wastes which aro not listed in

B. ESTIMATED ANNUAL QUANTITY. For oach listed waste ontered in column A ostimate tho quantity of that waste that will be handlod on an annual basis. For each characteristic or toxic contaminant ontered in column A estimate the total annual quantity of all the non-listed waste(s) that will be handled which possoss that characteristic or contaminant.

C. UNIT OF MEASURE - For each quantity entered in column B enter the unit of measure code. Units of measure which must be used and the oppropriate codes are:

$\frac{\text { ENGLISH UNIT OF MEASURE }}{\text { POUNDS } \ldots \ldots \ldots \ldots \ldots \ldots \ldots \ldots \text { P }}$

$\frac{\text { METRIC UNIT OF MEASURE }}{\text { MILOGRAMS } \ldots \ldots \ldots \ldots \ldots \ldots \ldots \ldots \text { KETRIC TONS } \ldots \ldots \ldots \ldots \ldots}$

If facility records use any other unit of measure for quantity, the units of measure must be convertec into one of the required units of measure taking into accournt llo appropriate density or specific gravity of the waste.

D. PROCESSES

1. PROCESS CODES:

For listed dangerous waste: For each listed dangerous waste entered in column A select the code(s) from the list of process codes contained in Section III to indicate how the waste will be stored, treated, and/or disposed of at the facility.

For non-listed dangerous wastes: For each characteristic or toxic contaminarit entered in Column A, select the code(s) from the list of process codes contained in Section III to indicate all the processes that will be used to store, treat, and/or dispose of all the non-listed dangerous wastes that possess that characteristic or toxic contaminant.

Note: Four spaces are provided for entering process codes. If more are needed: (1) Enter the first three as described above: (2) Enter "O00" in the extreme right box of Item IV.D(1): and (3) Enter in the space provided on page 4. the line number and the additional code(s).

2. PROCESS DESCRIPTION: It a code is not listed for a process that will be used, describe the process in the space provided on the form.

NOTE: DANGEROUS WASTES DESC RIBED BY MORE THAN ONE DANGEROUS WASTE NUMBER . Dangerous wastes that can be described by more than one Waste Number shall be described on the form as follows:

1. Select one of the Dangerous : Waste Numbers and enter it in column $A$. On the same line complete columns 8 , C. and D by estimating the total annual quantity of the waste and describing all the processes to be used to treat, store, and/or dispose of the waste.

2. In column $A$ of the next line enter the other Dangerous Waste Number that can be used to describe the waste. In column D(2) on that line enter "included with above" and make no other entries on that line.

3. Repeat step 2 for each other Dangerous Waste Number that can be used to describe the dangerous waste.

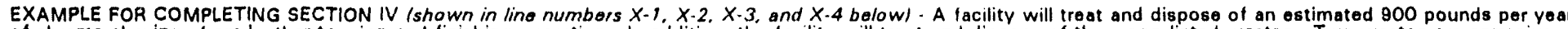
of chrome shavings from leather tanning and finishing operation. In addition, the facility will treat and dispose of three non-listed wastes. Two wastes are corrosive of

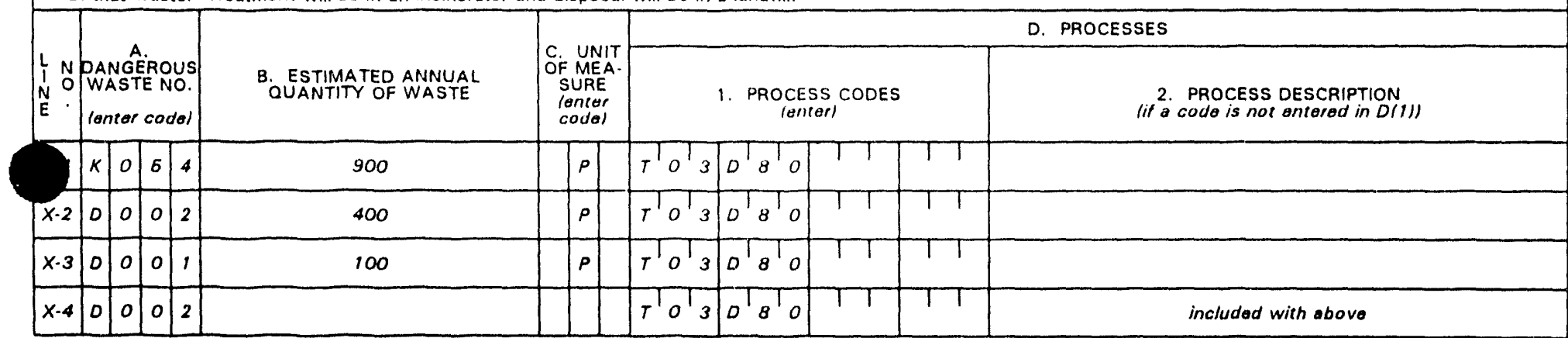

ECL30. 271 - ECY 030.31 Form 3 
Continued from pago 2

NOTE: Photocopy this oage buforo completing if you have mote that af ivdstes to list

1.D. NUMBER lantored trom page ")

\begin{tabular}{|l|l|l|l|l|l|l|l|l|l|l|l|}
\hline W & $A$ & 7 & 8 & 9 & 0 & 0 & 0 & 8 & 9 & 6 & 7 \\
\hline
\end{tabular}

OESCRIPTION OF DANGEROUS WASTES (continUed)

\begin{tabular}{|c|c|c|c|c|c|c|c|c|}
\hline \multirow{2}{*}{\multicolumn{2}{|c|}{ 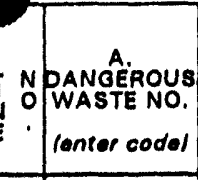 }} & \multirow[b]{2}{*}{$\begin{array}{l}\text { B. ESTIMATED ANNUAL } \\
\text { OUANTIIY OF WASTE }\end{array}$} & \multirow[b]{2}{*}{ 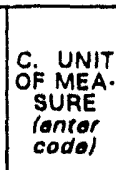 } & \multicolumn{5}{|r|}{ D. PROCESSES } \\
\hline & & & & \multicolumn{4}{|c|}{$\begin{array}{l}\text { 1. PROCESS, CODES } \\
\text { |antorf }\end{array}$} & $\begin{array}{l}\text { 2. PROOESS DESCRIPTION } \\
\text { lif a code is not onterod in DII }\end{array}$ \\
\hline & 0.012 & $117.200,000$ & $p$ & To2 & 084 & $T T$ & $T T$ & Neutralization/Percolation \\
\hline & NT:OL & $2,573,000$ & 4 & 1 & 1 & & & included with above \\
\hline 3 & 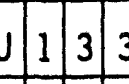 & $1,478,000$ & $\mathrm{P}$ & T02 & D84 & $T$ & & Neutralization/Percolation \\
\hline $4 \sqrt{1}$ & 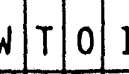 & 484,000 & $\mathrm{P}$ & To2 & D84 & 11 & & Neutralization/Percolation \\
\hline 5 & 0.006 & 149,000 & 4 & $y$ & 1 & 11 & & included with above \\
\hline
\end{tabular}

6

7

8

10

11

13

14

16

16

17

18

19

20

21

22

23

24

2 
Contimusad trom thio trumt.

DESCRIPTION OF DANGEROUS WASTES ICOMHUUUUU

USE THIS SPACE TO LIST ADDITIONAL PROCESS CODES FROM SECTION DIII OH PAGE 3

The 216-8-3 Expansion Ponds (Expansion Ponds) received dangerous waste from two main sources: (1) corrosive and toxic dangerous waste resulting from the regeneration of demineralizer columns at the PUREX Plant, and (2) spills of dangerous or mixed waste at the PUREX Plant. Backwash from the regeneration of the demineralizer columns was frequently corrosive (D002) and sometimes contained toxic concentrations of chemicals used in the regeneration process, including nitric acid, sulfuric acid, sodium hydroxide, and potassium hydroxide (WTO2). Spills at the PUREX Plant included hydrazine (U133), cadmium nitrate (WT01/D006), and ammonium fluoride/ammonium nitrate (WT01). Since 1984, administrative and engineering barriers have been put in place at the PUREX Plant to prevent dangerous waste from being discharged into the Expansion Ponds.

The quantity of waste listed for D002/WTO2 is an estimated annual quantity based on the Expansion Ponds proportional share (based on percolation capacity) of the amount of corrosive and toxic dangerous waste received by the entire 216-B-3 Pond System (which includes the 216-B-3 Main Pond, a separate dangerous waste treatment and disposal unit). The quantities of waste listed for U133 and WT01/0006 represent the Expansion Ponds' proportional share (based on percolation capacity) of the total recorded amount of hydrazine, cadmium, and ammonium fluoride/ammonium nitrate received by the entire $B$ Pond System from the time the PUREX Plant resumed operations in 1983 until the last known chemical discharge occurred in 1987.

The quantities of waste listed for U133 and WT01/0006 include the water in which the chemicals were discharged. Water makes up most of the weight of these discharges.

\section{FACILITY DRAWING}

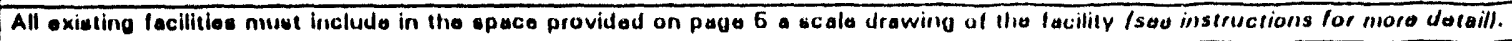

VI. PHOTOGRAPHS

All oxisting facilitios must include photographe laorial or pround-lovoll that clearly dalineate all oxisting structures: oxisting storago, treatment and disposal aroas: and

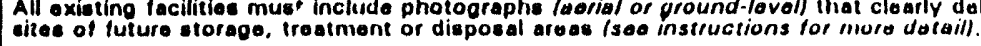

VII. FACILITY GEOGRAPHIC LOCATION This information is provided on the attached drawings and photos.

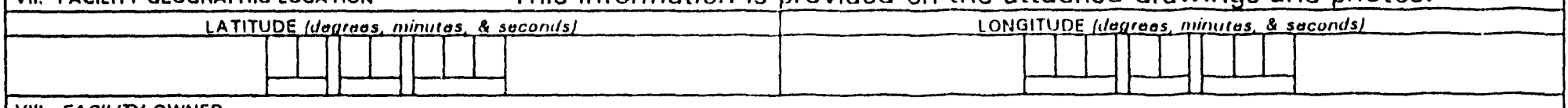

VIII. FACILITY OWNER

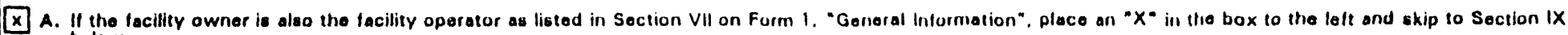
bolow.

B. If the fecility owner is not the facility operator as listed in Section VII on Furm 1. camplete the following itums

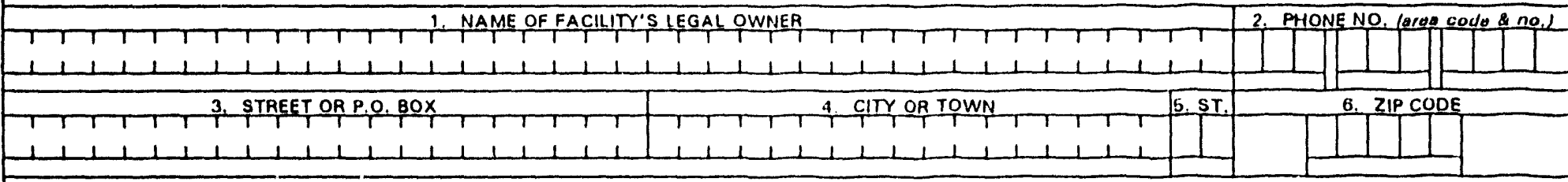

IX. OWNER CEATIFICATION

I ceatify undor ponally of low that l have porsonally oxamined ond ant farmiliar with tha information submitred in this and all atcachad documbents. and that basad on

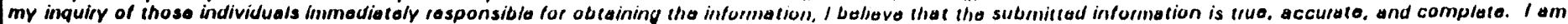

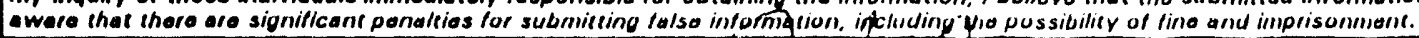

\begin{tabular}{|l|l|l|l|l|l|l|l}
\hline NAME (print or (ypo) & DATE SIGNED
\end{tabular}

John D. Hagoner, Manager

U.S. Department of Energy

Richland Operations of fice

X. OPERATOR CERTIFICATION

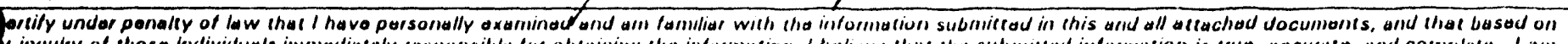

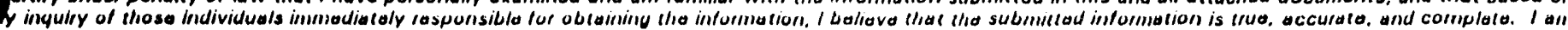

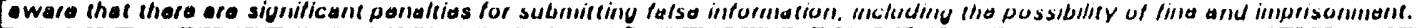

NAME (print of trpo)

SIGNATURE

DATE SIGNED

SEE ATTACHMENT

ECL3O-271 - ECY 030.31 Form 3

PAGE 4 OF 6

CONTINUE ON PAGE 6 
216-B-3 Expansion Ponds

Rev. $0,12 / 16 / 93$, Page 5 of 7

X. OPERATOR CERTIFICATION

I certify under penalty of law that I have personally examined and am familiar with the information submitted in this and all attached documents, and that based on my inquiry of those individuals immediately responsible for obtaining the information, I believe that the submitted information is true, accurate, and complete. I am aware that there are significant penalties for submitting false information, including the possibility of fine and imprisonment.
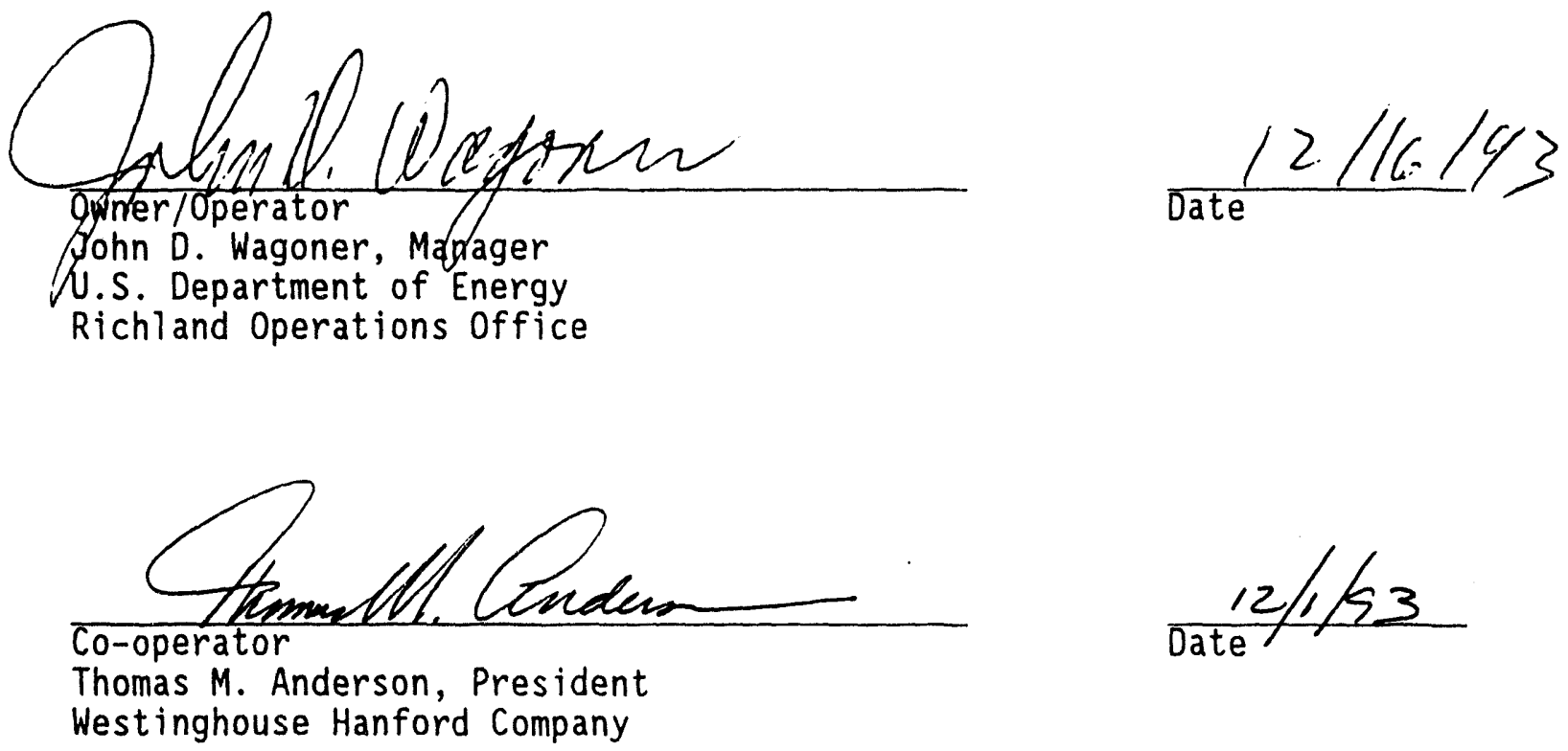


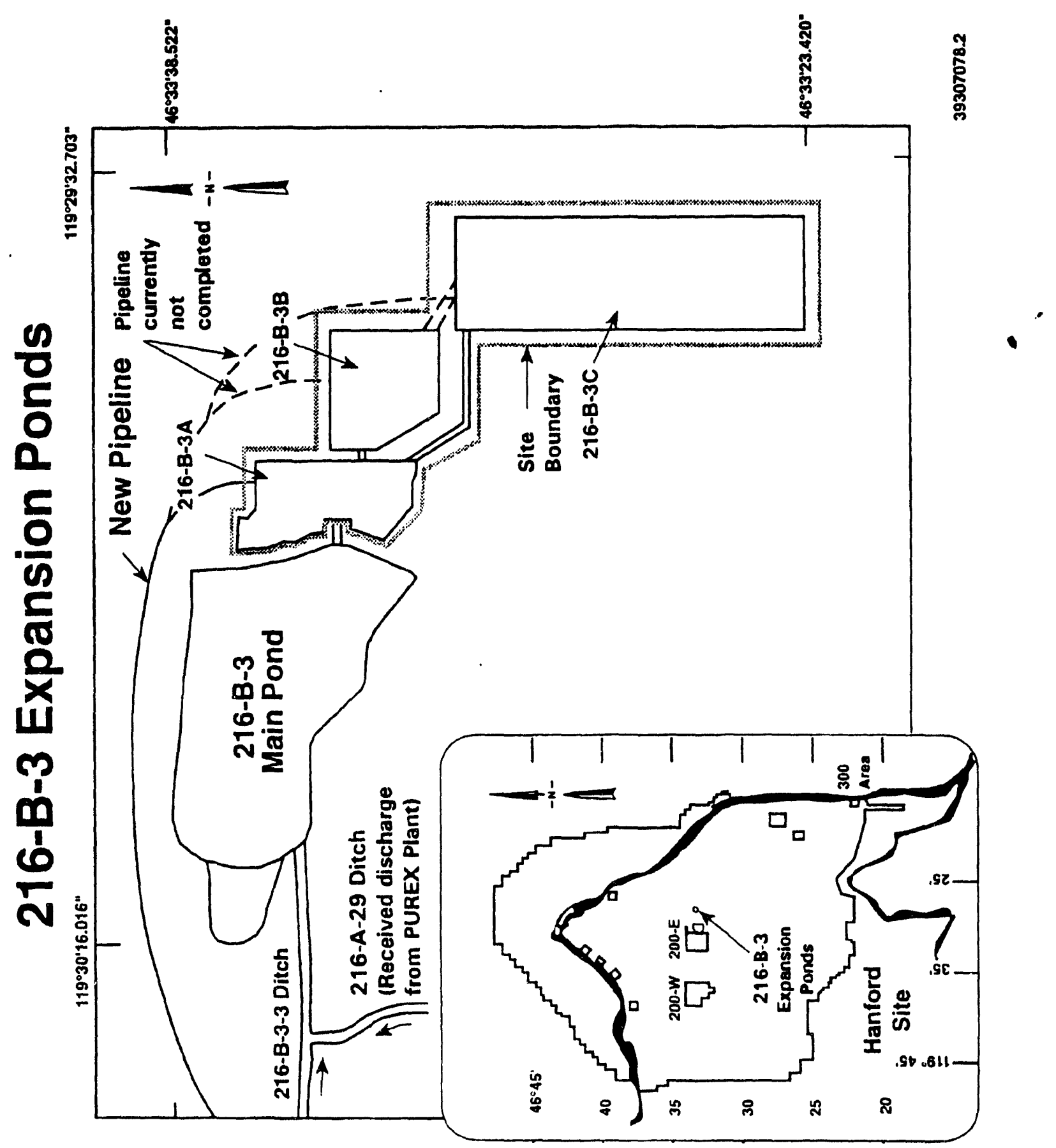




\section{6-B-3 Expansion Ponds}

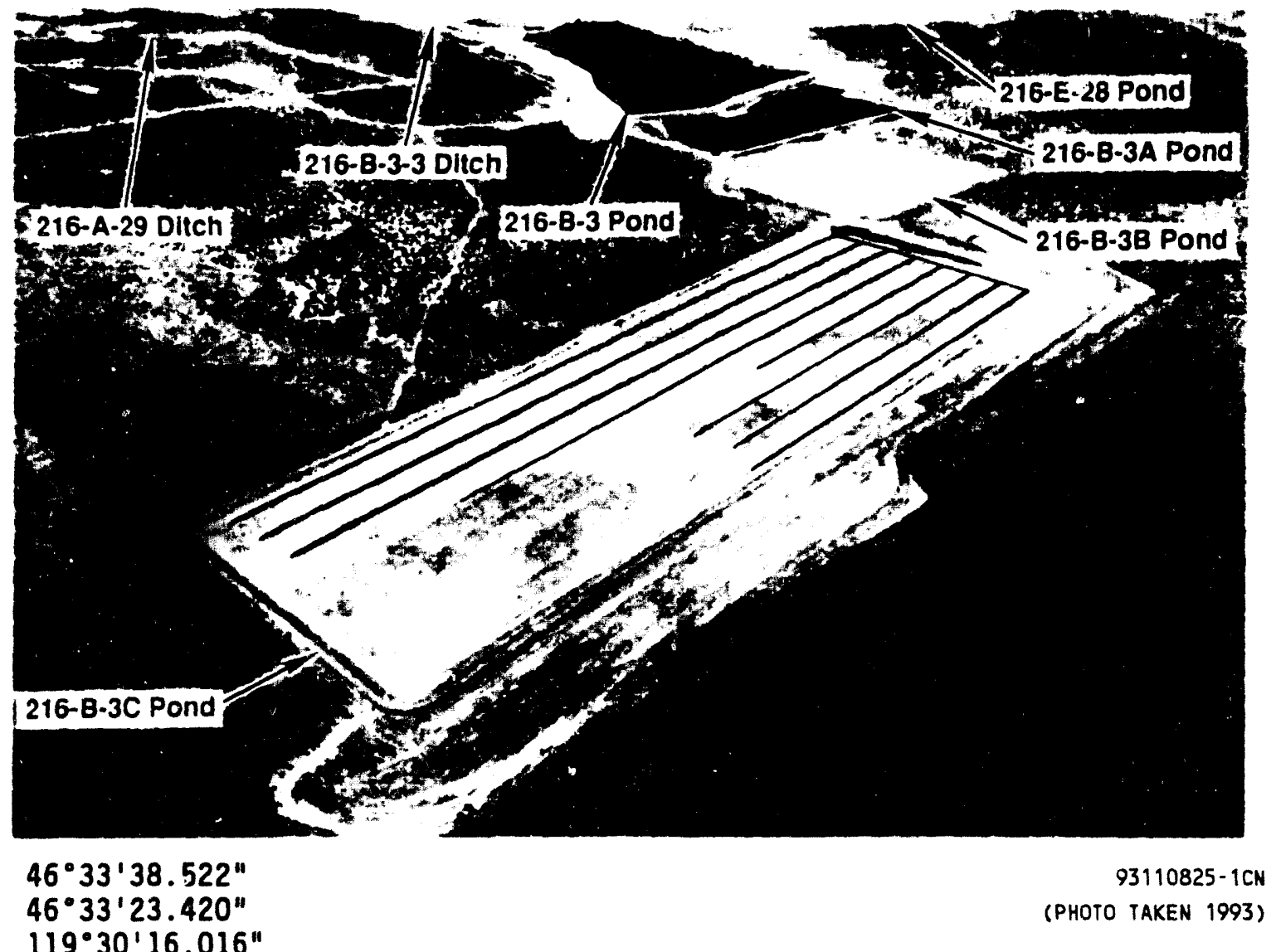

$119^{\circ} 29^{\prime} 32.703^{\prime \prime}$ 
DOE /RL-89-28, Rev. 1
$12 / 15 / 93$

CONTENTS

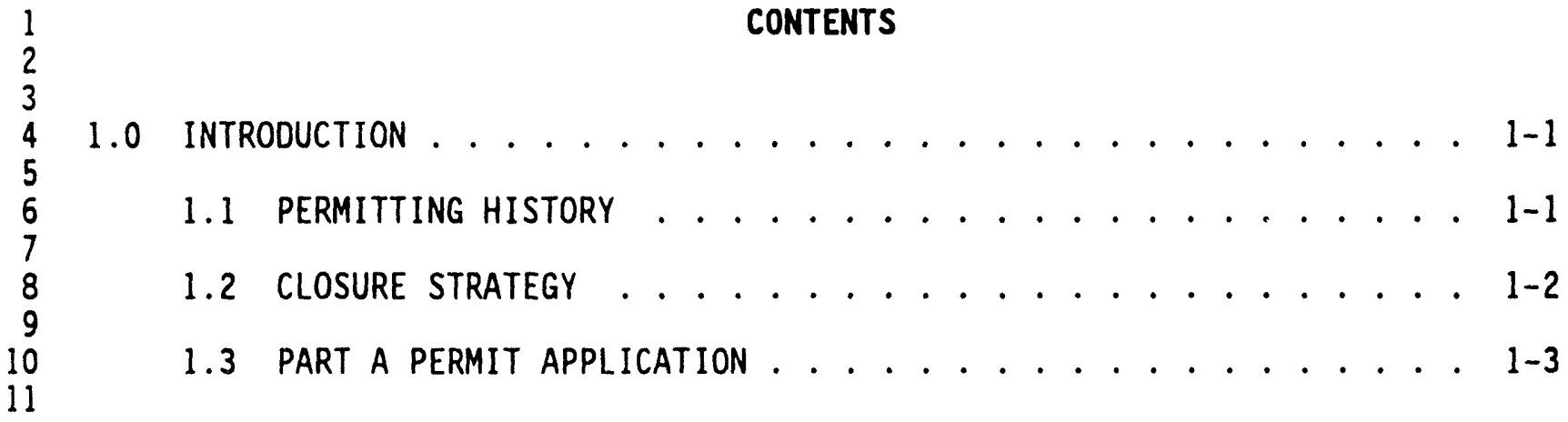

931119.0811

$1-i$ 
DOE/RL-89-28, Rev. 1

$12 / 15 / 93$

1
2
3
4
5

This page intentionally left blank. 
DOE/RL-89-28, Rev. 1

$12 / 15 / 93$

\subsection{INTRODUCTION}

This document describes the activities for clean closure of the expansion ponds associated with 216-B-3 Pond System. The 216-B-3 Pond System is operated by the U.S. Department of Energy, Richland Operations Office (DOE-RL) and co-operated by Westinghouse Hanford Company (Westinghouse Hanford).

Although the U.S. Government holds legal title to this facility, the DOE-RL, for purposes of defining Resource Conservation and Recovery Act of 1976 (RCRA) facilities, is considered the legal owner of the facility under existing U.S. Environmental Protection Agency (EPA) interpretive regulations (51 FR 7722).

The 216-B-3 Pond System consists of a series of four earthen, unlined, interconnected ponds and the 216-B-3-3 Ditch that receive waste water from various 200 East Area operating facilities. These four ponds, collectively referred to in this document as 'B Pond', are designated the 216-B-3, $216-B-3 A(3 A), 216-B-3 B(3 B)$, and the 216-B-3C (3C) Ponds. These ponds were placed in service in 1945, 1983, 1984, and 1985, respectively. The $3 A, 3 B$, and $3 C$ ponds are referred to as expansion ponds. Location information and a detailed description of the 216-B-3 Pond System are provided in Chapter 2.0.

Waste water (primarily cooling water, steam condensate, and sanitary water) from various 200 East Area facilities is discharged to the 216-B-3-3 Ditch. Water discharged to the 216-B-3-3 Ditch flows directly into the 216-B-3 Pond. Water overflows from the 216-B-3 Pond into the $3 A$ Pond and from the $3 A$ Pond into the $3 C$ Pond. The $3 B$ Pond has not received waste water since May 1985; however, when in operation, the $3 B$ Pond received overflow from the $3 A$ Pond. Two other ditches, 216-B-3-1 and 216-B-3-2, previously transmitted waste water to the 216-B-3 Pond. These ditches were decommissioned and the waste stabilized in place (i.e., backfilled) before 1980 .

In the past, waste water discharges to B Pond and the 216-B-3-3 Ditch contained mixed waste (radioactive waste and dangerous waste). The radioactive portion of mixed waste has been interpreted by the U.S. Department of Energy (DOE) to be regulated under the Atomic Energy Act of 1954; the nonradioactive dangerous portion of mixed waste is regulated under RCRA. Mixed waste also may be considered a hazardous substance under the Comprehensive Environmental Response, Compensation, and Liability Act of 1980 (CERCLA) when considering remediation of waste sites.

\subsection{PERMITTING HISTORY}

As a result of dangerous waste discharges to $B$ Pond, a RCRA Part A permit application (Rev. 0) was submitted to the Washington State Department of Ecology (Ecology) in 1986. Revision 1 of the Part A permit application was submitted in August 1987 and Revision 2 was submitted in November 1987. The permit application was submitted under the single Dangerous Waste Permit Identification Number, WA7890008967, issued to the Hanford Site by the EPA and Ecology. The permit application designates the 216-B-3 Pond System a surface 
impoundment, subject to RCRA regulations for treatment, storage, and/or disposal (TSD) units. Revision 3 of the Part A permit application is included in Section 1.3 .

Currently, the unit-specific Part $A$ permit application is being modified to separate the three expansion ponds ( $3 A, 3 B$, and $3 C$ Ponds) from the remainder of the unit (216-B-3 Pond and 216-B-3-3 Ditch). This modification is made to allow clean closure of the expansion ponds while integrating closure activities for the 216-B-3 Pond and 216-B-3-3 Ditch with RCRA corrective action for the 200-BP-11 Operable Unit. Clean closure of the expansion ponds is being initiated to meet the Hanford Federal Facility Agreement and Consent Order (Tri-Party Agreement), Milestone M-17-10, "Cease all liquid discharges to hazardous 1 and disposal units unless such units have been clean closed in accordance with RCRA (Ecology et al. 1992). The date associated with this milestone is June 1995.

A closure/postclosure plan was submitted in 1990 (DOE-RL 1990). Based on the 1990 closure plan strategy and sampling and analysis results, a decision was made to clean close the expansion ponds while integrating closure of the remainder of the 216-B-3 Pond System with the activities for the operable unit. The current closure plan is based on this decision and is being submitted to provide current site characterization information and closure strategy for the $3 A, 3 B$, and $3 C$ Ponds.

\subsection{CLOSURE STRATEGY}

The Hanford Site has been divided into operable units to facilitate cleanup under CERCLA, the State of Washington Hazardous Waste Management Act of 1976, and RCRA corrective action provisions. An operable unit is a grouping of individual waste management units based primarily on geographic area, common waste sources, and similar geohydrologic properties. The Hanford Site waste management units have been categorized into past practice units and TSD units. A past practice unit is a waste management unit where waste has been disposed of (intentionally or unintentionaliy) but is not subject to regulation as a TSD unit. All waste management units, including TSD units, within an operable unit generally will undergo investigation and remediation (closure) at the same time.

The 216-B-3 Pond System is located within the 200-BP-11 Operable Unit. Two other major waste management units located within this operable unit are the inactive 216-B-3-1 and 216-B-3-2 Ditches. These two ditches cover an extensive area that extends from immediately west of the 216-B-3 Pond to the 200 East Area perimeter fence. 
The following summarizes the closure strategy proposed in this plan for the 216-B-3 Pond System.

- Clean close the $3 \mathrm{~A}, 3 \mathrm{~B}$, and $3 \mathrm{C}$ Ponds (expansion ponds). Clean close as used in this context means that no dangerous waste or dangerous waste contaminated soil, structures, or equipment will remain onsite that pose a threat to human health or the environment. The ponds will continue to receive nondangerous waste water.

- Remove the 216-B-3 Pond and 216-B-3-3 Ditch from service.

\subsection{PART A PERMIT APPLICATION}

Currently, the unit-specific Part $A$ permit application is being modified to separate the three expansion ponds ( $3 A, 3 B$, and $3 C$ Ponds) from the remainder of the unit (the 216-B-3 Pond and 216-B-3-3 Ditch). This modification is being made to allow clean closure of the expansion ponds while integrating closure activities for the 216-B-3 Pond and 216-B-3-3 Ditch with RCRA corrective action for the 200-BP-11 Operable Unit.

Revision 3 of the Part A, Form 3, for the 216-B-3 Pond System was submitted in 1990 with the 216-B-3 Pond System Closure/Postclosure Plan. The original Part A (Rev. 0) was submitted to Ecology in 1986. Revision 1 was submitted in August 1987 and Revision 2 was submitted in November 1987. The reasons for Revision 3 were twofold. First, new information was obtained that allowed for the development of a detailed chemical discharge history for the years 1983 to 1987 . The last known reportable chemical discharge occurred in April 1987. Second, the chemical discharges were evaluated at the point of discharge into the environment. The chemical discharge history, which this Part $A$ is based on, is from the Plutonium/Uranium Extraction (PUREX) Plant. Other facilities that discharged to B Pond either did not have the potential to discharge dangerous waste or a record search did not reveal documentation of dangerous waste discharges. A summary of the PUREX Plant chemical discharges is located in Chapter 4.0, Table 4-3.

The PUREX Plant chemical discharge history was developed by first comparing previous chemical discharge histories to construct one complete discharge history. The discharges then were matched with various Hanford Site records (e.g., off-normal/event reports, unusual occurrence reports, CERCLA/Ecology hazardous substance release reports, or event fact sheets) to substantiate the discharge. If records documenting the discharge could not be located or if the information in the records was inadequate to allow an evaluation, and processing knowledge could not be substituted, the discharge was not incorporated into Revision 3 of the Part A permit application.

To evaluate the discharges at the point of introduction into the environment, the following information was required to determine the 
concentration in the PUREX Plant chemical sewer (chemical discharges from the PUREX Plant would have originated from the PUREX Plant chemical sewer, Chapter 4.0, Section 4.1.1):

- Plant processing conditions or, more accurately, the chemical sewer flow rate at the time of the discharge

- Duration of the discharge

- Mass (weight) of the chemical discharged.

For a number of discharges, the actual flow rate through the chemical sewer at the time of the occurrence was documented on Hanford Site records. In the event that daily records could not be located, an average flow rate was calculated from either a published cumulative weekly or a monthly volume.

For several discharges, chemical sewer flow rates could not be located or calculated. Best estimates were determined based on PUREX Plant operating conditions.

The duration of the discharge for a majority of the discharges was obtained directly from CERCLA/Ecology hazardous substance release reports. However, this type of record was not in existence for earlier discharges; in these cases, best estimates based on processing knowledge were used.

The mass (weight) of the chemicals discharged was obtained from Hanford site records. However, for several of these discharges, the mass (weight) could not be determined because of plant configuration. These discharges were not incorporated in Revision 3 of the Part A because of the substantial lack of information.

When the information on flow rate, duration, and weight was obtained, the concentration in the chemical sewer was calculated, and the discharge was evaluated to determine if the discharges were designated as a dangerous or extremely hazardous waste in accordance with the state and federal Dangerous Waste Regulations. A majority of the discharges were either acidic or basic in nature. The $\mathrm{pH}$ of these discharges was determined, and the limits for corrosivity were applied to determine if the discharge should be designated as a dangerous waste in accordance with Washington State Department of Ecology "Dangerous Waste Regulations," Washington Administrative Code (WAC) 173-303-090(6). The second largest category of discharges were chemical makeups (mixtures) that did not meet plant specifications and could not be used in the process. The mixtures were evaluated by calculating the equivalent concentration and comparing the concentration with the toxic dangerous waste mixtures graph to determine if the discharge should be designated as a dangerous waste or as an extremely hazardous waste per WAC 173-303-084. The next category was discharged mixtures containing hydrazine. These discharges automatically were designated because hydrazine is a listed constituent per WAC 173-303-081. The final category was discharged mixtures containing cadmium. These discharges were designated for the characteristic of extraction procedure (EP) toxicity per WAC 173-303-090(8). 
The discharges designated as dangerous waste or extremely hazardous waste were assigned the appropriate waste designation code. The designation code and the quantity of waste in pounds corresponding with the code were placed in the Part A, Section IV, "Description of Dangerous Wastes." [Note: water makes up most of the weight (pounds) of the discharge.] Table 4-3 in Chapter 4.0 provides a summary of chemical discharges that includes actual pounds of pure chemical and the waste designation codes. The following paragraphs describe how the discharges were designated, how the designation codes were selected, and how the pounds of chemicals discharged were determined.

The annual quantity of corrosive waste designated 0002 per WAC 173-303-090(6) was determined by combining the quantity of corrosive waste discharged from demineralizer regeneration for the calendar year with the most generations $(115,109,823$ pounds taken from the 1987 records) with the annual average of corrosive waste discharged during unusual events that occurred periodically between 1983 and 1987 (22,086,642 pounds/4 years = $5,521,660$ pounds). These two quantities $(115,109,923$ pounds and $5,521,660$ pounds) totalled an annual discharge of $120,700,000$ pounds. Some of the corrosive waste (D002) discharged during the unusual events indicated previously also was designated as WT02 dangerous waste per WAC 173-303-084. The annual average of WTO2 dangerous waste was determined by averaging the discharges that were designated both 0002 and WTO2 during operations from 1983 to $1987(10,549,226$ pounds $/ 4$ years $=2,637,306$ pounds per year $)$.

From 1983 to 1987, there were five discharges that contained hydrazine. Because hydrazine is a 1 isted constituent per WAC 173-303-081, it was decided to report the total amount discharged to $B$ Pond rather than report an annual discharge. The quantity of hydrazine (U133) discharged was determined by totaling the five discharges that occurred from 1983 to 1987.

Several of the discharges were designated as WTO1 extremely hazardous waste per WAC 173-303. Specifically, there were several cadmium spills and one ammonium fluoride/ammonium nitrate spill that fell into this category. The quantity of extremely hazardous waste was determined by totalling the cadmium discharges $(318,000$ pounds) with the ammonium fluoride/ammonium nitrate discharge ( 185,000 pounds). Cadmium also is designated as a D006 dangerous waste per WAC 173-303-084(8). The cadmium discharges were listed in the Part A under both the D006 and WTOl designations. 


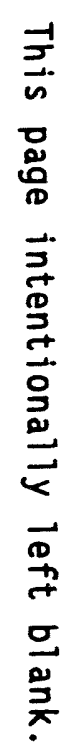

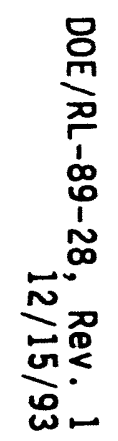


CONTENTS

2.0 FACILITY DESCRIPTION AND LOCATION INFORMATION . . . . . . . . 2-1

2.1 THE HANFORD SITE .................... 2-1

2.2 THE 216-B-3 POND SYSTEM . . . . . . . . . . . . . 2-1

2.2.1 Operational History of the 216-B-3 Pond and Discharge Ditches ............. . 2-2

2.2.2 Operational History of the $216-B-3 A$ and 2I6-B-3B Ponds............... 2-3

2.2.3 Operational History of the 216-B-3C Pond...... 2-5

2.2.4 Dike Piezometers............... 2-6

2.2.5 Future Use................. 2-7

2.3 SECURITY INFORMATION ................ 2-7

\section{FIGURES}

2-1. Hanford Site and Regional Map ................... F2-1

2-2. The 216-B-3 Pond System Location Map... . . . . . . . . . . . . F2-2

2-4. Sketch of the 216-B-351 Spillway . . . . . . . . . . . . . . . F2-4

2-5. Photograph of the 216-B-351 Overflow Control Structure (August 1989) .................... . . . . . .

2-6. Photograph of the 216-B-351 Spillway (August 1989) . . . . . . . F2-6

2-7. Photograph of the 216-B-351 Spillway Outfall (August 1989) . . . . F2-7

2-8. Sketch of the 216-B-353 Spillway . . . . . . . . . . . . . . F2-8

2-9. Photograph of the 216-B-353 Overfiow Control Structure (August 1989) ...................... . . . . .

2-10. Photograph of the 216-B-353 Stililing Basin (August 1989). . . F2-10

2-11. Sketch of the 216-B-352 Spillway. . . . . . . . . . . . . . F2-11

2-12. Photograph of the 216-B-352 Overflow Control Structure

(August 1989). . . . . . . . . . . . . . . . . F2-12

2-13. Photograph of the 216-B-352 Overflow Control Structure (August 1989) .................. F2-13

2-14. Generalized Cross Section of the 216-B-352, 215-B-353, and 216-B-354 Overflow Control Structure ..... F2-14

2-15. Plan View Sketch of the 216-B-3C Pond . . . . . . . . . . . F2-15

2-16. Sketch of the 216-B-354 Spillway . . . . . . . . . . . . . . . F2-16

2-17. Photograph of the 216-B-354 Overflow Control Structure (August 1989) . . . . . . . . . . . F2-17

2-18. Photograph of the 216-B-354 Spillway Outfall (August 1989) ..................... . F2-18

2-19. Piezometer Location Map . . . . . . . . . . . . . . . . . F2-19

2-20. Typical Multiple Piezometer Installation. . . . . . . . . F2-20 
DOE/RL-89-28, Rev. 1

$12 / 15 / 93$

TABLE

4 2-1. Piezometer Coordinates, Dimensions, and Water Levels . . . . . . T2-1 
DOE/RL-89-28, Rev. 1

$12 / 15 / 93$

51 52

\subsection{FACILITY DESCRIPTION AND LOCATION INFORMATION}

This chapter briefly describes the Hanford Site, the B Pond and discharge ditches, and the current security program.

\subsection{THE HANFORD SITE}

The Hanford Site covers approximately 560 square miles of semiarid land that is owned by the U.S. Government and managed by the DOE-RL. The Hanford Site is located northwest of the city of Richland, Washington, in the Columbia Basin (Figure 2-1). The city of Richland adjoins the southernmost portion of the Hanford Site boundary and is the nearest population center. In early 1943, the U.S. Army Corps of Engineers selected the Hanford Site as the location for reactor, chemical separation, and related facilities, and activities for the production and purification of plutonium.

Activities at the Hanford Site are centralized in numerically designated areas. The reactor facilities are located along the Columbia River in what are known as the 100 Areas. The reactor fuel processing and waste management facilities are in the 200 Areas, which are on a plateau approximately 7 miles from the Columbia River.

The 300 Area, located adjacent to Richland, contains the reactor fuel manufacturing facilities and the research and development laboratories. The 400 Area, 5 miles northwest of the 300 Area, contains the Fast Flux Test Facility used in the testing of liquid metal reactor systems. The 600 Area covers all locations not specifically given an area designation. Adjacent to north Richland, the 1100 Area contains facilities associated with administration, maintenance, transportation, and materials procurement and distribution. The 3000 Area, between the 1100 and 300 Areas, contains engineering and administrative offices. Administrative buildings also are located in the 700 Area, which is in downtown Richland.

\subsection{THE 216-B-3 POND SYSTEM}

The locations of the $3 A, 3 B$, and $3 C$ Ponds, the 216-B-3 Pond, and the 216-B-3-3 Ditch are shown in Figure 2-2. Also shown in this figure are nearby waste management units: the 216-E-28 Contingency Pond and the 216-B-3-1, 216-B-3-2, and 216-A-29 Ditches. An aerial photograph of the subject area is shown in Figure 2-3. All of the previously mentioned ponds and ditches are part of the 200-BP-11 operable unit, with the exception of the 216-A-29 Ditch. The 216-A-29 Ditch is a separate TSD unit that is currently part of the 200-P0-05 operable unit. The closure/postclosure plan for the 216-A-29 Ditch currently is scheduled to be submitted to Ecology and EPA in May 1996 in accordance with the Tri-Party Agreement (Ecology et al. 1992). The 216-B-3 Pond and the 216-B-3-3 Ditch are scheduled to be closed as part of an integrated effort with RCRA past practice activities at the 200-BP-11 Operable Unit. The work plan for this integrated effort currently is planned to be completed in fiscal year 1995. 
DOE/RL-89-28, Rev. 1

$12 / 15 / 93$

\subsubsection{Operational History of the 216-B-3 Pond and Discharge Ditches}

This closure plan only addresses closure of the expansion ponds and the structures that interconnect them. The 216-B-3 main pond, 216-B-3-3 ditch and associated concrete structures for flow measurement and control into and out of the main pond to the $3 A, 3 B$, and $3 C$ ponds will be addressed in the integrated effort for closure of the 216-B-3 Pond and RCRA past practice activities of the 200-BP-11 Operable Unit. This section on the operation history of the 216-B-3 Pond and discharge ditches is provided for information only.

The 216-B-3 Pond, in service since 1945, is located in a natural topographic depression. From 1945 through 1964, waste water was discharged to the 216-B-3 Pond via the unlined, earthen 216-B-3-1 Ditch. The ditch widened towards the inlet to the pond, and as a result, the ditch covered a fairly large, swampy surface area that terminated in a small, shallow pond (216-B-3 Pond).

In 1955, the 216-A-29 Ditch was placed in service to receive PUREX Plant chemical sewer waste water. The 216-A-29 Ditch discharged directly into the 216-8-3-1 Ditch. The 216-B-3-1 Ditch was decommissioned and backfilled with soil in 1964 after an accidental release of mixed fission products from the PUREX Plant. This release was discharged to the 216-B-3-1 Ditch via the PUREX Plant cooling water line rather than the 216-A-29 Ditch.

The unlined, earthen 216-B-3-2 Ditch was excavated in 1964 to replace the 216-B-3-1 Ditch. The 216-A-29 Ditch discharged into the 216-B-3-2 Ditch approximately 1,000 feet west of the 216-B-3 Pond. The 216-B-3-2 Ditch was decommissioned and backfilled with soil in 1970 after an accidental release of strontium-90 from $B$ Plant. As a result of this release, the contaminated 216-B-3 Pond bank soil was consolidated into the pond, and the north, south, and west shorelines were diked with 3 feet of sand and gravel.

The unl ined, earthen 216-B-3-3 Ditch was excavated in 1970 to replace the 216-B-3-2 Ditch, and the 216-A-29 Ditch was routed to discharge into the 216-B-3-3 Ditch approximately 1,500 feet west of the inlet to the 216-B-3 Pond. The 216-B-3-3 Ditch is approximately 3,700 feet long, 30 feet wide at ground level, 6 feet wide at the bottom, and 4 to 8 feet deep. A fiberglass-reinforced polyester flume and flowmeter were installed downstream from the 216-A-29 Ditch and 216-B-3-3 Ditch confluence. The 216-A-29 Ditch was removed from service in 1991. As it was removed from service, the 216-A-29 Ditch was interim stabilized to maintain the ditch in a stable configuration until closure actions are initiated. Interim stabilization consists of placing soil over the radioactively contaminated ditch bottom. This soil covering satisfies shielding requirements and forms a physical barrier against wind dispersion.

In December 1970, the dike along the eastern shore of the 216-B-3 Pond failed, and in 1971, major construction work was initiated to extend and raise the earthen dike. Construction materials were obtained from a borrow pit located near the pond, and were laid in 8-inch-(or less) thick layers. The 
1 dike now is approximately 1,380 feet long and 42 feet wide near the top, with 2 basalt riprap added for erosion protection.

An area of approximately 4.1 acres immediately west of the 216-8-3 Pond was diked during the 1970's to provide an overflow area for the 216-B-3 Pond. This overflow area was decommissioned and backfilled in 1985.

The 216-B-3 Pond currently covers a surface area of approximately 35 acres, and is between 2 and 18 feet deep. Historical records indicate that the surface area of the pond has varied from 19 to 46 acres.

Most of the 200 East Area waste water was discharged to both $B$ Pond and Gable Mountain Pond (216-A-25 Pond) until 1987, when decommissioning of Gable Mountain Pond was completed. Most of the 200 East Area waste water, exclusive of the PUREX Plant chemical sewer and a few other facilities, was routed to the cooling water line that runs parallel to the 200 East Area perimeter fence. From the cooling water line, the waste water could have been diverted to either the 216-B-3 Pond or Gable Mountain Pond. Since the decommissioning of Gable Mountain Pond, all waste water is discharged to the 216-B-3 Pond.

\subsubsection{Operational History of the 216-B-3A and 216-B-3B Ponds}

The 216-B-3A ( $3 A$ Pond) and 216-B-3B (3B Pond) Ponds were constructed to receive increased discharges that would result from restart of the PUREX Plant. The ponds were constructed using a cut-and-fill construction method over a 22-acre surface area (11 acres each). Eight-millimeter polyethylene plastic was placed along the slope of the pond banks and covered with approximately 3 inches of pit run gravel. The plastic was extended approximately 3 feet out onto the pond bottom and 2 feet back from the top of the dike.

Spillway 216-B-351, which included a 24-inch-diameter culvert, a headwall with a manually operated slide gate, and a ditch with a flume and flowmeter, was constructed in the dike between the 216-B-3 Pond and the $3 A$ Pond. The spillway was designed so that water would flow through the culvert, down a 2-foot-wide ditch lined with concrete and erosion-control fabric, through a fiberglass-reinforced polyester 12-inch flume and into the $3 \mathrm{~A}$ Pond.

A spillway consisting of an open ditch lined with erosion-control fabric was constructed in the dike between the $3 A$ and $3 B$ Ponds. Erosion-control fabric is constructed of two layers of heavy-duty industrial nylon filled with fine aggregate concrete. The spillway was designed so that the $3 \mathrm{~A}$ Pond overflowed into the $3 B$ Pond when the $3 A$ Pond reached its maximum operating capacity of approximately 3.5 feet.

The 216-B-351 spillway, in the dike between the 216-B-3 Pond and $3 A$ Pond, was modified in 1983 to accommodate anticipated flow rates (Figures 2-4, 2-5, $2-6$, and 2-7). The 24-inch-diameter culvert was replaced by a 36-inch-diameter, 12-gauge, spiral-corrugated, galvanized steel pipe. 
1 The fiberglass flume liner was removed, the concrete support walls were recast

2 to widen the water flow area, and the flowmeter was removed.

3 A steel-reinforced concrete overflow control structure was constructed at

4 the inlet to the pipe. The following structures were installed on the

5 overflow control structure:

- Manually operated 42 - by 36-inch downward opening slide gate

- Trash guard constructed of 2-inch-woven, diamond-mesh, galvanized wire

- Staff gauge for measuring water surface elevation

- Metal grating over the surface to allow personnel access.

This spillway operated in the same manner as the original--water flowed from the 216-B-3 Pond through the 36-inch pipe, down the ditch, and into the $3 A$ Pond.

The 3A Pond was placed into service in October 1983. The pond was operated until January 1984, when the dike between the $3 A$ and $3 B$ Ponds failed at the connecting spillway. All discharge from the dike failure was contained in the $3 B$ Pond, which had remained unused until this time. The dike failure is suspected to be the result of water seeping through the dike under the erosion-control fabric lining the spillway.

In response to this incident, flow to the 216-B-3 Pond was reduced and the $3 A$ and $3 B$ Ponds were isolated. A trench, oriented north-south and approximately 600 feet long, 30 feet wide, and 5 feet deep, was excavated into a permeable sand and gravel layer beneath the $3 \mathrm{~A}$ Pond bottom to provide an area of increased infiltration. Discharge to the $3 A$ Pond was resumed, but at a reduced rate, to contain flow and infiltration to the newly constructed trench.

A new spillway (216-B-353) was designed and constructed to replace the open ditch between the $3 A$ and $3 B$ Ponds (Figures 2-8, 2-9, and 2-10). Shortly afterwards, a second spilliway (216-B-352) was constructed in the dive between the 216-B-3 Pond and $3 A$ Pond (Figures 2-11, 2-12, and 2-13). This spillway was constructed to handle the increased water flow resulting from the decommissioning of Gable Mountain Pond.

Both new spillways were constructed to the same design: two 30-inch-diameter corrugated metal pipes through the existing dikes, a steel-reinforced concrete overflow control structure, and a stilling basin. The following structures were installed on the overflow control structure:

- Control weir and manually operated, downward-opening slide gate for each 30-inch-diameter pipe

- Trash guard constructed of 2-inch diamond-mesh, 9-gauge, galvanized wire supported by a 2-inch-diameter pipe

- Staff gauge for measuring water surface elevation 
DOE/RL-89-28, Rev. 1 $12 / 15 / 93$

- Continuous 6-inch rubber dumbbe11-type water stop

- Metal grating over the surface to allow personnel access.

A generalized cross section of the overflow control structure is shown in Figure 2-14. The overflow control structure was designed to provide automatic overflow, regardless of slide gate setting, before the upstream pond reached maximum liquid levels.

Stilling basins were constructed at the spillway outfall in the bottom of the ponds to control erosion. The basins were lined with erosion-control fabric and filled with riprap. The riprap extended beyond the basins and was placed over the pipes on the lower dike slopes.

The debris from the dike failure was removed from the $3 B$ Pond and a series of trenches were excavated in the 38 Pond bottom to increase the infiltration rate. The excavated material was placed along the shores of the 216-B-3 Pond as diking.

The $3 A$ and $3 B$ Ponds were fully operational by June 1984 . The $3 B$ Pond was taken out of service in May 1985, and up to 7 feet of material was excavated from the pond bottom, to a depth below the bottom of the trenches. The excavated material was placed as diking on the north shore of the

216-B-3 Pond. The 3B Pond has not been used since it was taken out of service in May 1985.

\subsubsection{Operational History of the 216-B-3C Pond}

The 216-B-3C Pond ( $3 C$ Pond) was constructed to accommodate increased flow resulting from the decommissioning of Gable Mountain Pond. A plan view sketch of the $3 C$ Pond is shown in Figure 2-15.

The 3C Pond was constructed by excavating 6 feet of soil over a 41-acre surface area. Eight parallel north-south trenches, approximately 8 to 14 feet wide and 4 feet deep, were constructed in the pond bottom to increase infiltration. An east-west trench in the $3 \mathrm{C}$ Pond bottom connects the 216-B-354 outfall with the eight north-south trenches. The excavated material was placed in a spoil mound along the east and part of the north and south sides of the pond. The slopes of the pond were stabilized with 3 inches of 1-to 6-inch-size grave1. A gravel maintenance road was constructed along the edge of the pond.

A spillway (216-B-354) similar in design to the spillways that control flow into the $3 A$ and $3 B$ Ponds, as discussed previously, was constructed to convey water from the $3 A$ Pond to the $3 C$ Pond (Figures 2-16, 2-17, and 2-18). The spillway consists of two 30-inch-diameter corrugated-metal pipes, a steel-reinforced concrete overflow control structure, and a stilling basin, and was designed for a maximum flow capacity of 20,000 gallons a minute or $5028,800,000$ gallons a day. The two 30-inch-diameter pipes were installed by 
excavating a ditch approximately 950 feet in length from the $3 \mathrm{~A}$ Pond to the 3C Pond. A 4-inch-thick cushion of sand was placed under the pipe and backfill was placed over the pipe to the existing grade.

The areas disturbed by the construction of the pond and spillway, except for the pond bottom, spoil mound, and gravel-stabilized areas, were revegetated by mulching and crimping with straw, then applying seed.

\subsubsection{Dike Piezometers}

In 1984, 22 piezometers were installed in a total of 10 boreholes in the earthen dikes impounding the 216-B-3 Pond and $3 A$ Pond (Figure 2-19). These piezometers were installed in response to the dike failure that occurred between the $3 A$ and $3 B$ Ponds. By design, the 10- to 20-foot-thick earthen dikes permit a certain amount of saturated flow through and beneath the fill material from which they are constructed. The function of the piezometers is to monitor this saturated flow. Water level measurements are made at least once a month with an electric water level tape.

The piezometers were installed in 6-inch-diameter boreholes that ranged from 8 to 75 feet in depth. Single or multiple piezometers were constructed in each borehole (Figure 2-20). Single piezometer completions are noted as $P$, dual completions as $Q$, and triple completions as $R$ (Table 2-1). The piezometer tube consists of a polyethylene screen (12 inches in length) attached to an l-inch inside diameter polyvinyl chloride tubing that extends to the surface. The annular space around the screen is packed with sand to provide good transmissivity, while bentonite clay above and below each screened section prevents vertical water movement along the outside of the piezometer tube.

The following scheme was used to situate the screened intervals within each borehole. The deepest piezometer was placed within the uppermost

saturated zone, if present less than 75 feet from the surface, to monitor flow through the dike. A second piezometer was placed within the dike if the water table was well below the dike fill material. A third, intermediate piezometer was installed in several wells to provide better vertical resolution.

Although most of the wells originally intersected zones of saturation in or beneath the dikes, water levels dropped soon after installation, leaving most piezometers dry. A decline in the infiltration rate of the first expansion pond (3A) may have caused this phenomenon. Based on current water level observations, little or no saturated flow is occurring through the dikes. However, bentonite clay, used to seal the piezoneter tubes, is present at the bottom of several piezometers and may be plugging the screens, thereby causing inaccurate readings. Integrity testing of the piezometers conducted in 1986 indicated restricted flow in some of the deeper piezometers. But the shallower piezometers, those monitoring the dike material, appeared to be functioning properly. 
DOE/RL-89-28, Rev. 1

$12 / 15 / 93$

\subsubsection{Future Use}

2

The 216-E-28 Contingency Pond was constructed in 1987 north of B Pond (see Figure 2-3) to provide emergency overflow capability for B Pond. The Contingency Pond is not a part of the subject TSD unit, nor is it a separate TSD unit because it has not received influent. A 48-inch-diametercorrugated-metal pipeline was constructed from the PUREX Plant cooling water line (discharging to the 216-8-3-3 Ditch) to the Contingency Pond.

To support the 216-B-3 Pond closure process, a prior project, $W-019$, ' $B$ Pond Influent Control Upgrades', installed a pipeline bypass around the 216-B-3 Pond to discharge the waste water directly into the $3 A$ Pond. A 36-inch-diameter, high-density polyethylene pipeline was constructed in early 1990 from the Contingency Pond pipeline to the $3 A$ Pond. The purpose of this pipeline was to convey al1 $B$ Pond waste water discharges from the cooling water line directly to the $3 A$ Pond, thus bypassing the 216-B-3 Pond, 216-B-3-3 Ditch, and 216-A-29 Ditch. An outfall structure (stilling basin), similar in design to the existing stilling basins, was constructed outside the north edge of the $3 A$ Pond.

Current closure planning requires the $3 \mathrm{~A}$ Pond to be clean closed along with the clean closure of the $3 B$ and $3 C$ Ponds. However, because of the proximity of the $3 A$ Pond to the $216-B-3$ Pond, it has been agreed to take the $3 A$ Pond out of service along with the 216-B-3 Pond. To accomplish this, a bypass is required to divert the waste water around the $3 \mathrm{~A}$ Pond and into the $3 B$ and/or the $3 C$ Pond. Project $X-009$, currently in construction, will provide the capability to bypass the $3 A$ Pond and reroute the waste water to either the $3 B$ Pond, the $3 C$ Pond, or both simultaneously. A pipeline equipped with control gates will also be installed from the $3 B$ Pond to the $3 C$ Pond to provide capability to drain waste water from $3 B$ Pond into the $3 C$ Pond.

\subsection{SECURITY INFORMATION}

An effective security program is maintained at the Hanford Site because of the presence of several facilities that handle dangerous and radioactive materials and the continuing activities associated with these materials. Staffed barricades are maintained around the clock at checkpoints on vehicular access roads leading to the 216-B-3 Pond System. All personnel accessing these and other Hanford Site areas must have a DOE-issued security identification badge indicating the appropriate authorization. Personnel also might be subject to a random search of items carried into or out of the Hanford Site.

Site personnel receive training on Hanford Site security regulations in the form of required security education and on-the-job training. Procedures for ensuring personnel compliance with security requirements and provisions for security training are maintained at the Hanford Site. Periodic security-compliance audits and inspections ensure that these procedures are followed. 
DOE/RL-89-28, Rev. 1

$12 / 15 / 93$

1 The 216-B-3 Pond System boundaries are currentiy enclosed by a

2 single-strand chain and post fence that has appropriate radiological warning 3 signs. 

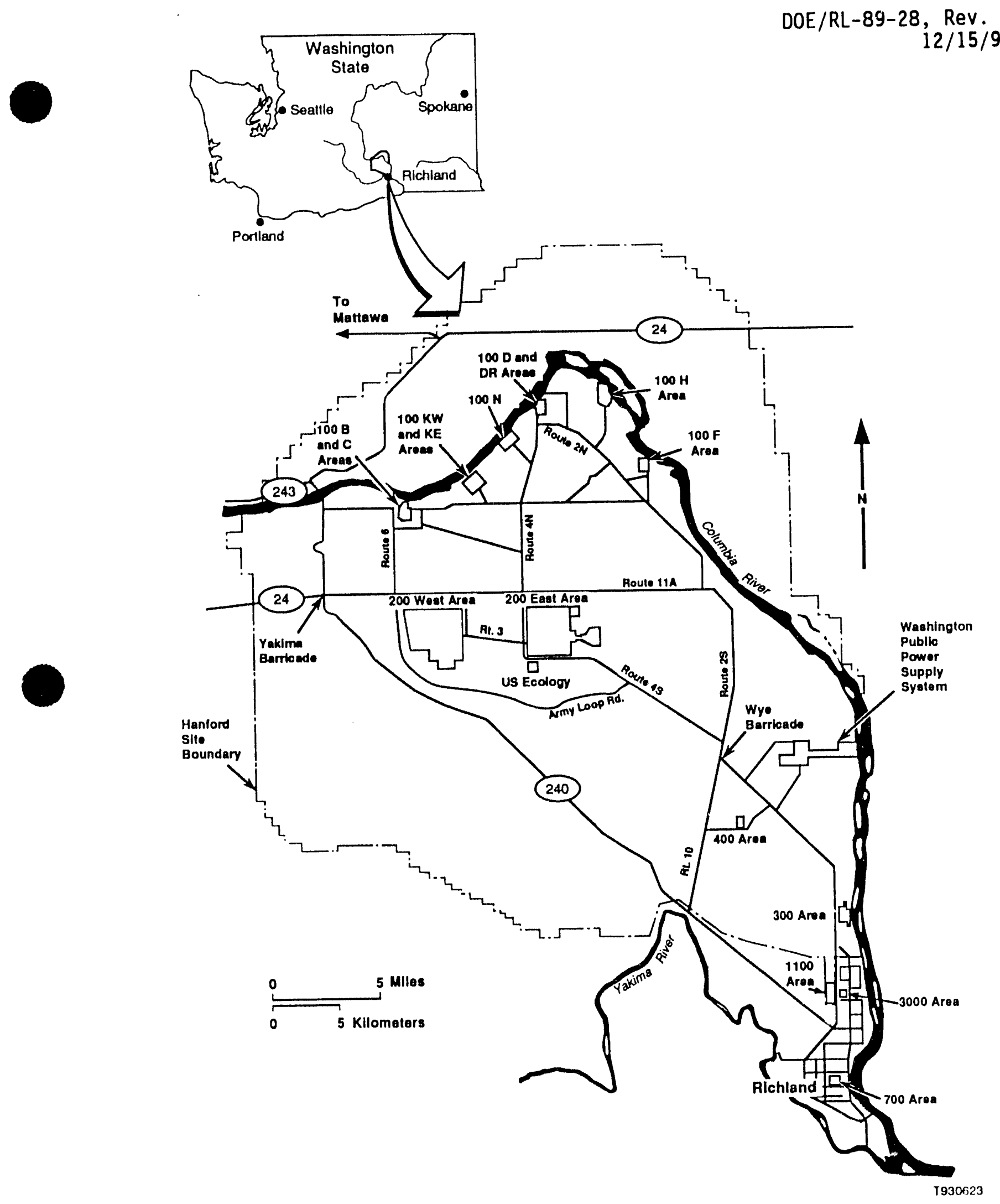

Figure 2-1. Hanford Site and Regional Map. 


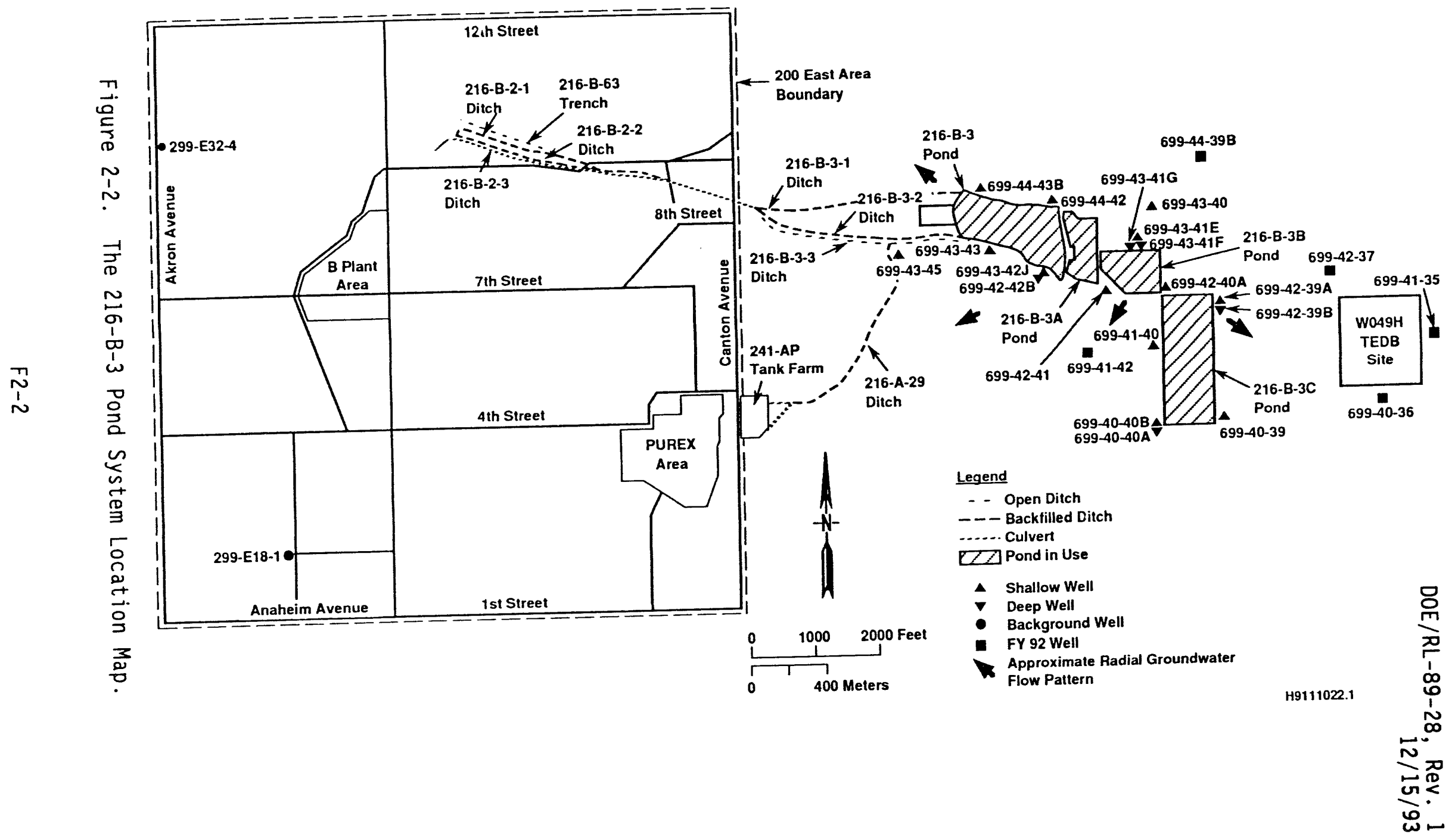


$\mathrm{DOE} / \mathrm{RL}-89-28, \operatorname{Rev} \cdot 1$

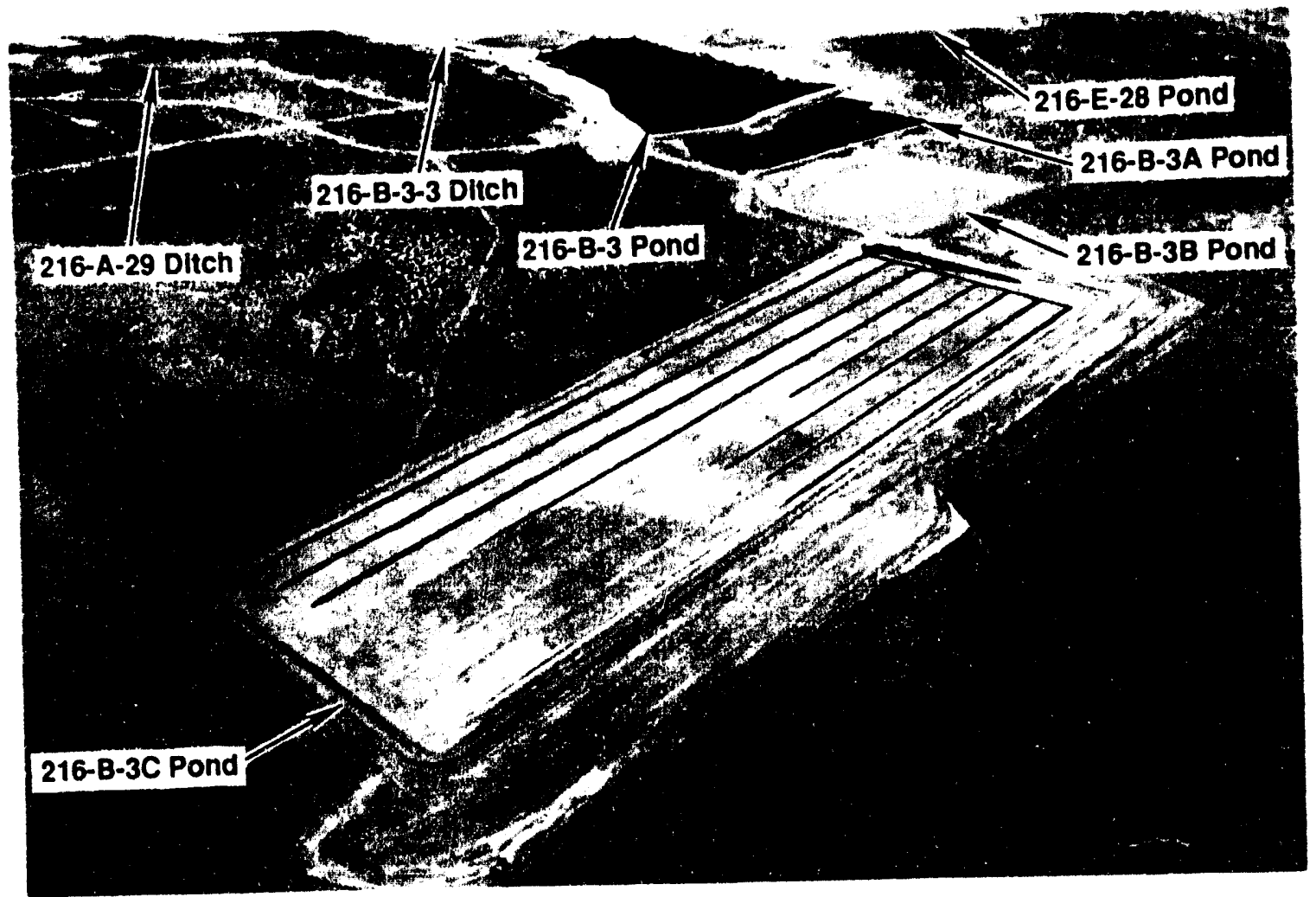

Figure 2-3. Aerial Photograph of the B Pond Area (1988). 
216-B-351

Overflow Control Structure

36-in. Corrugated Metal Pipe

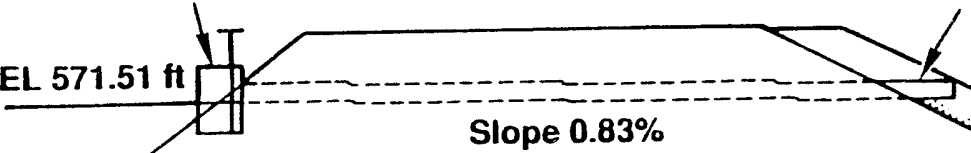

Slope $0.83 \%$

Erosion Control Fabric

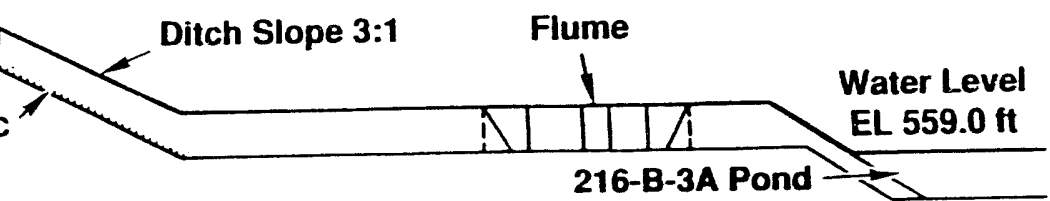

Slide Gate

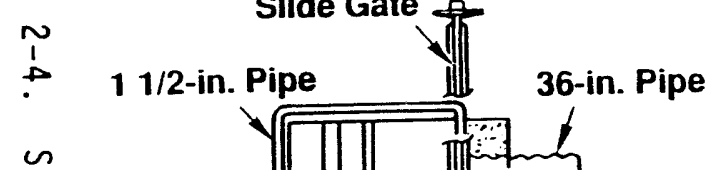

1

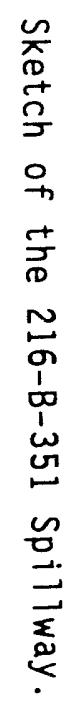

Zhain Link

=abric

$\checkmark$

î

\section{Overflow Control Structure}

Scale: None

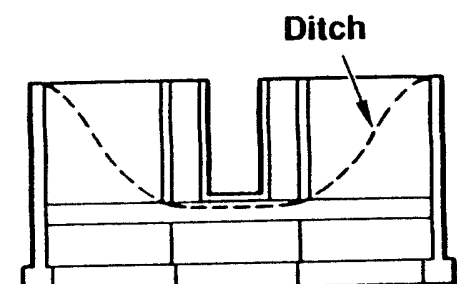

Section A-A

Scale: None

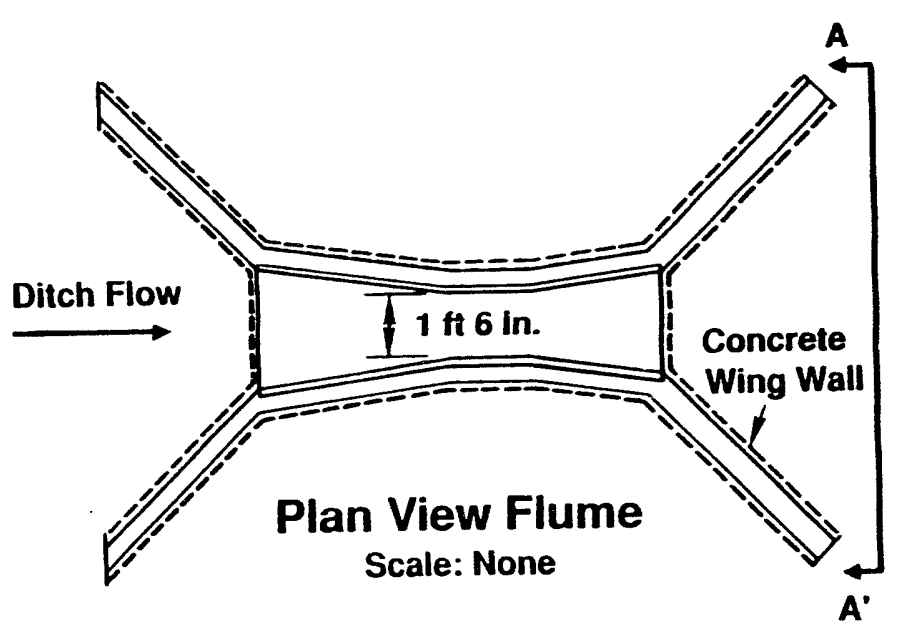

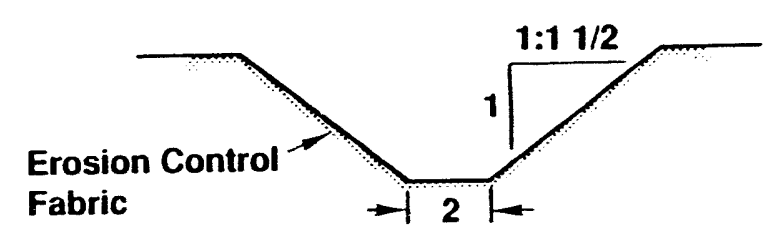

Typical Ditch

Scale: None 
DOE/RL-89-28, Rev. 1

$12 / 15 / 93$

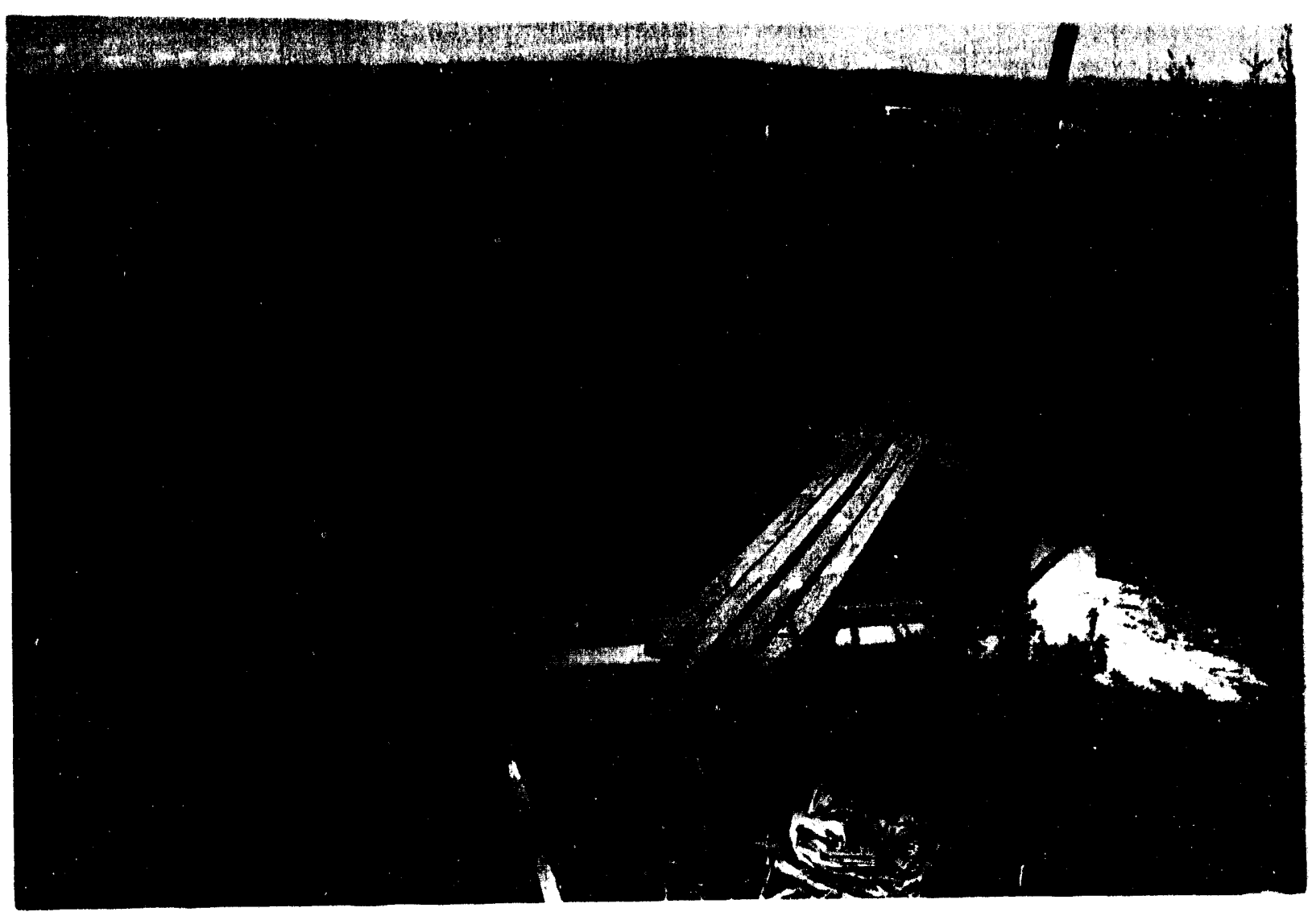

(PHOTOGRAPH TAKEN 1989)

Figure 2-5. Photograph of the 216-B-351 Overflow Control Structure.

F2-5 


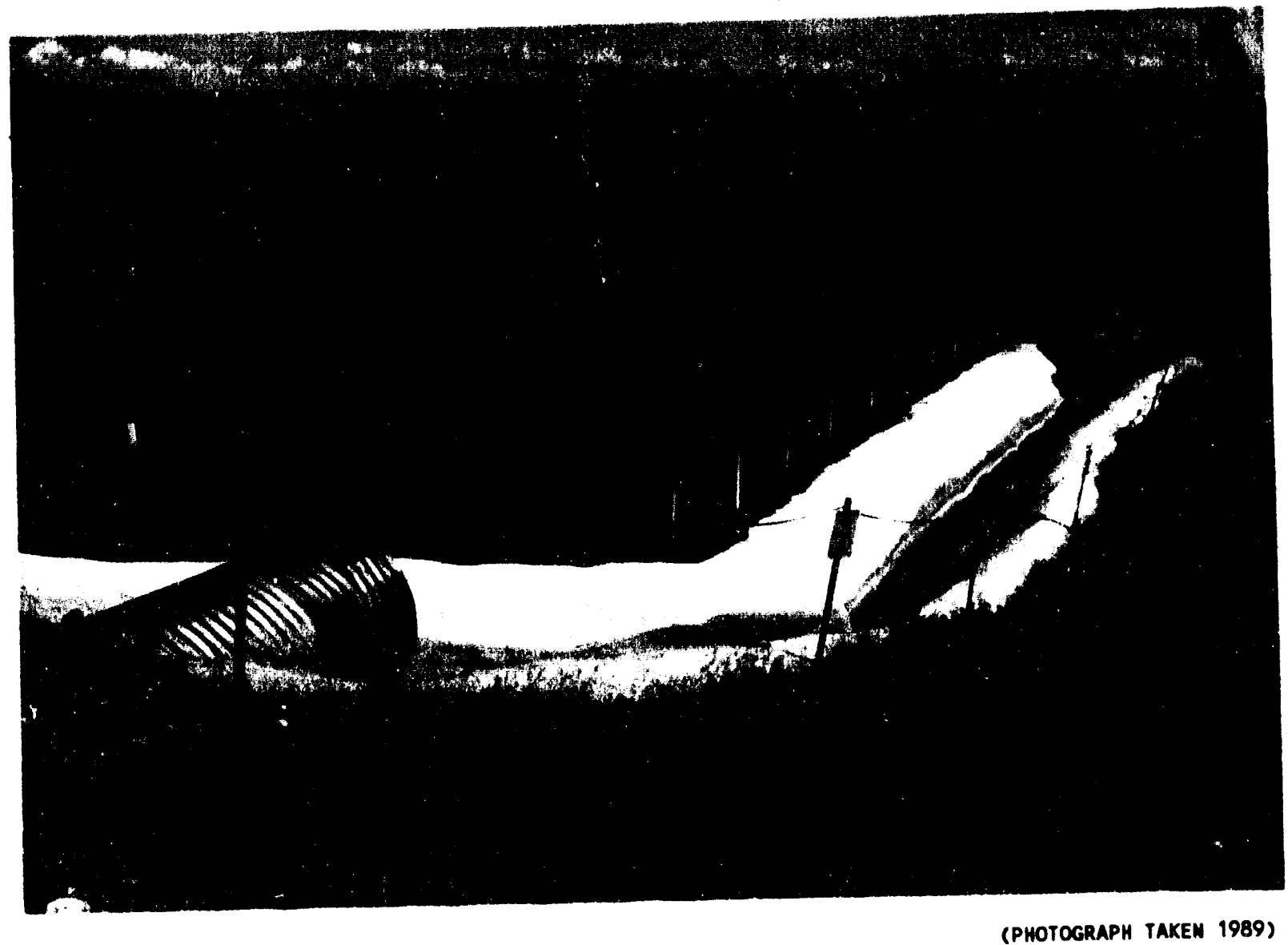

Figure 2-6. Photograph of the 216-B-351 Spillway. 


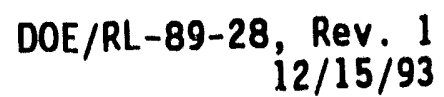

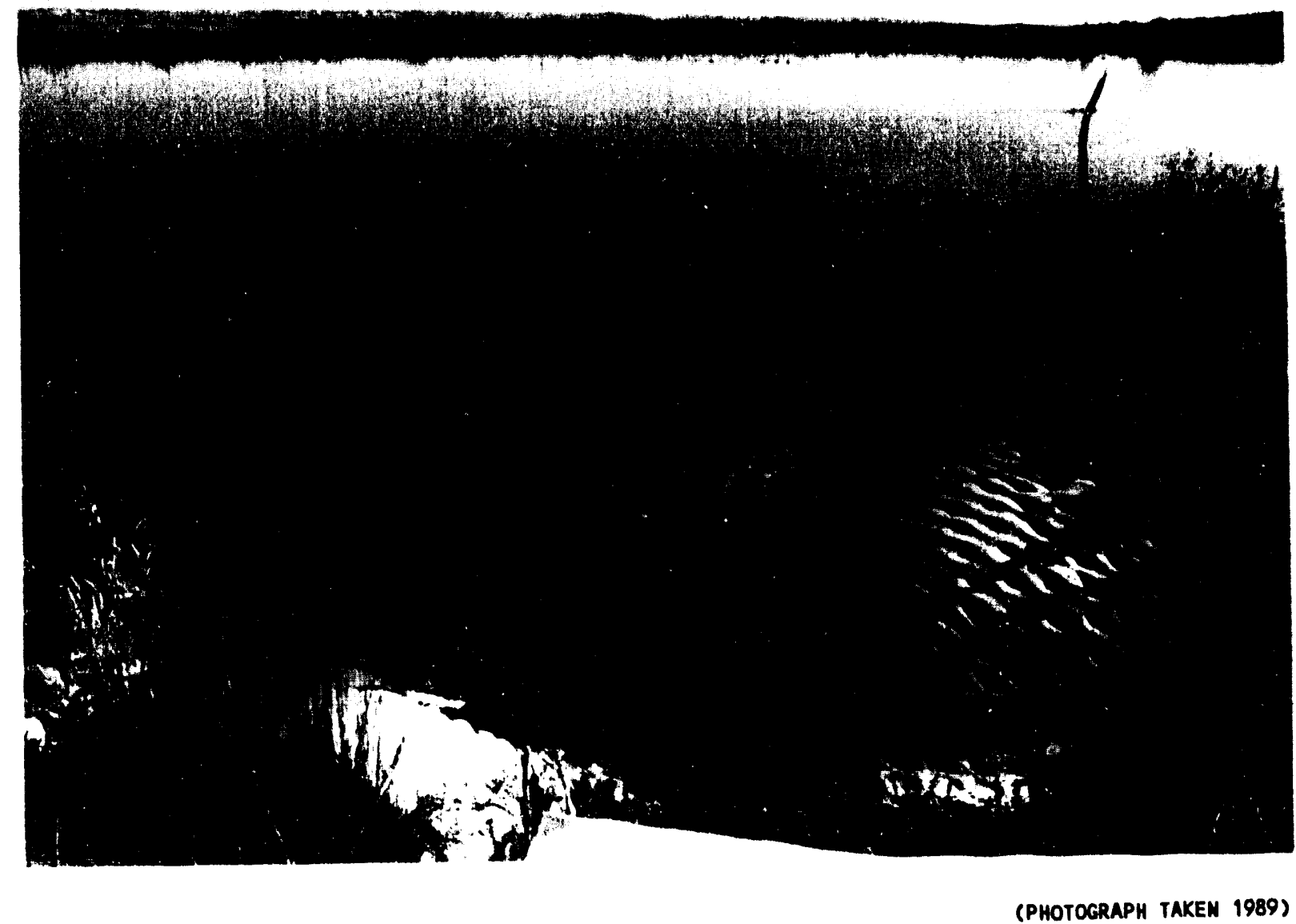

Figure 2-7. Photograph of the 216-B-351 Spillway Outfall. 


S99LL68L

$H_{0 Z}=\cdot u \mid$

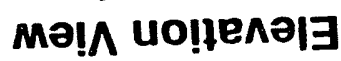

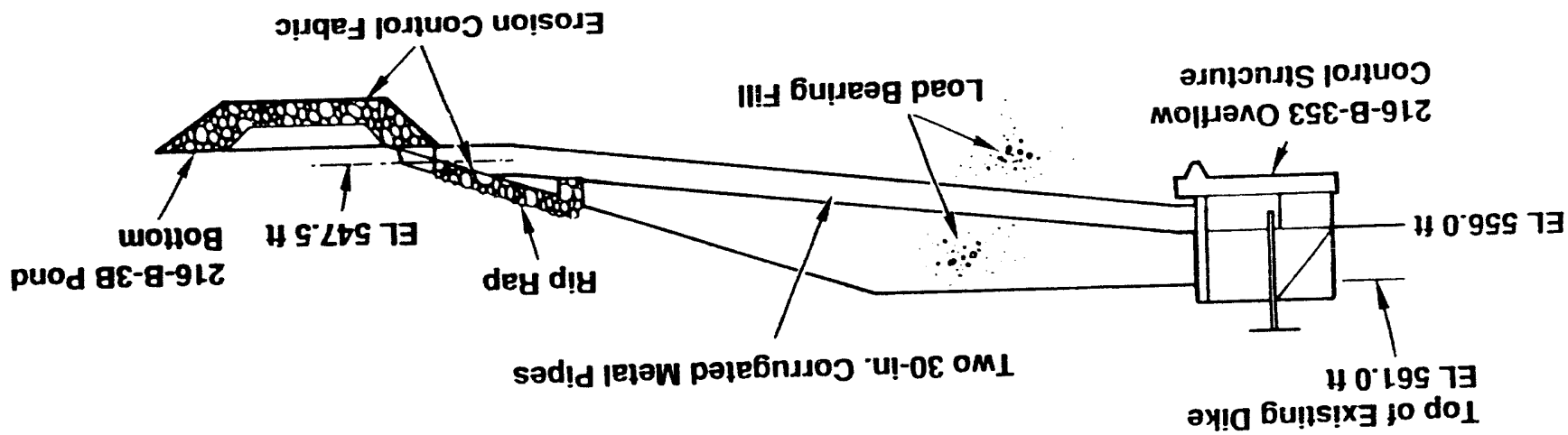

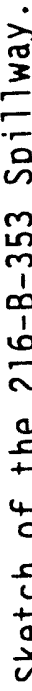

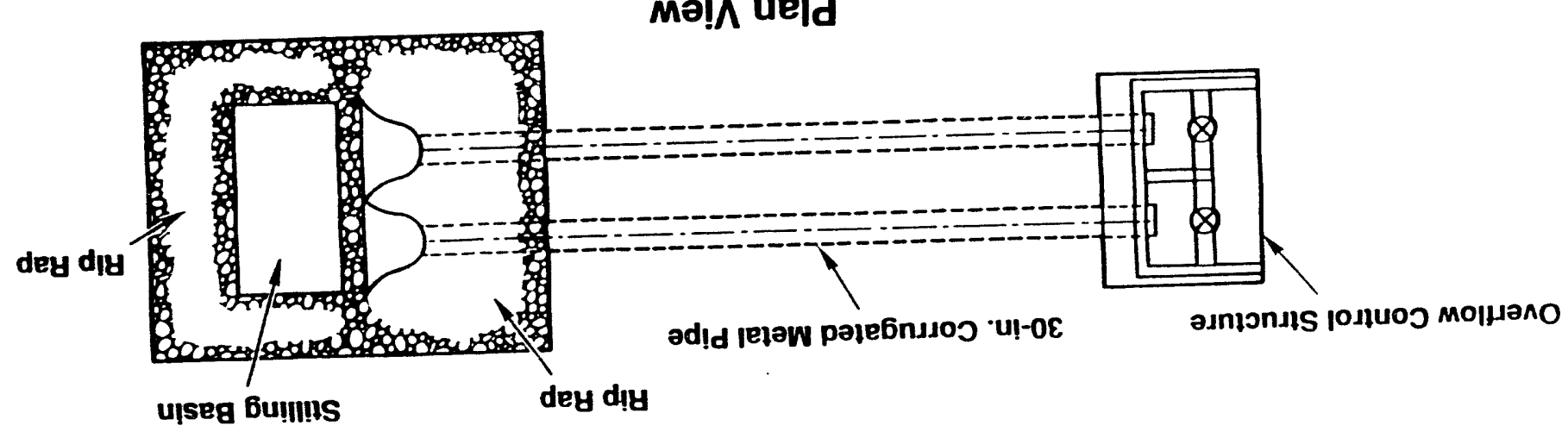




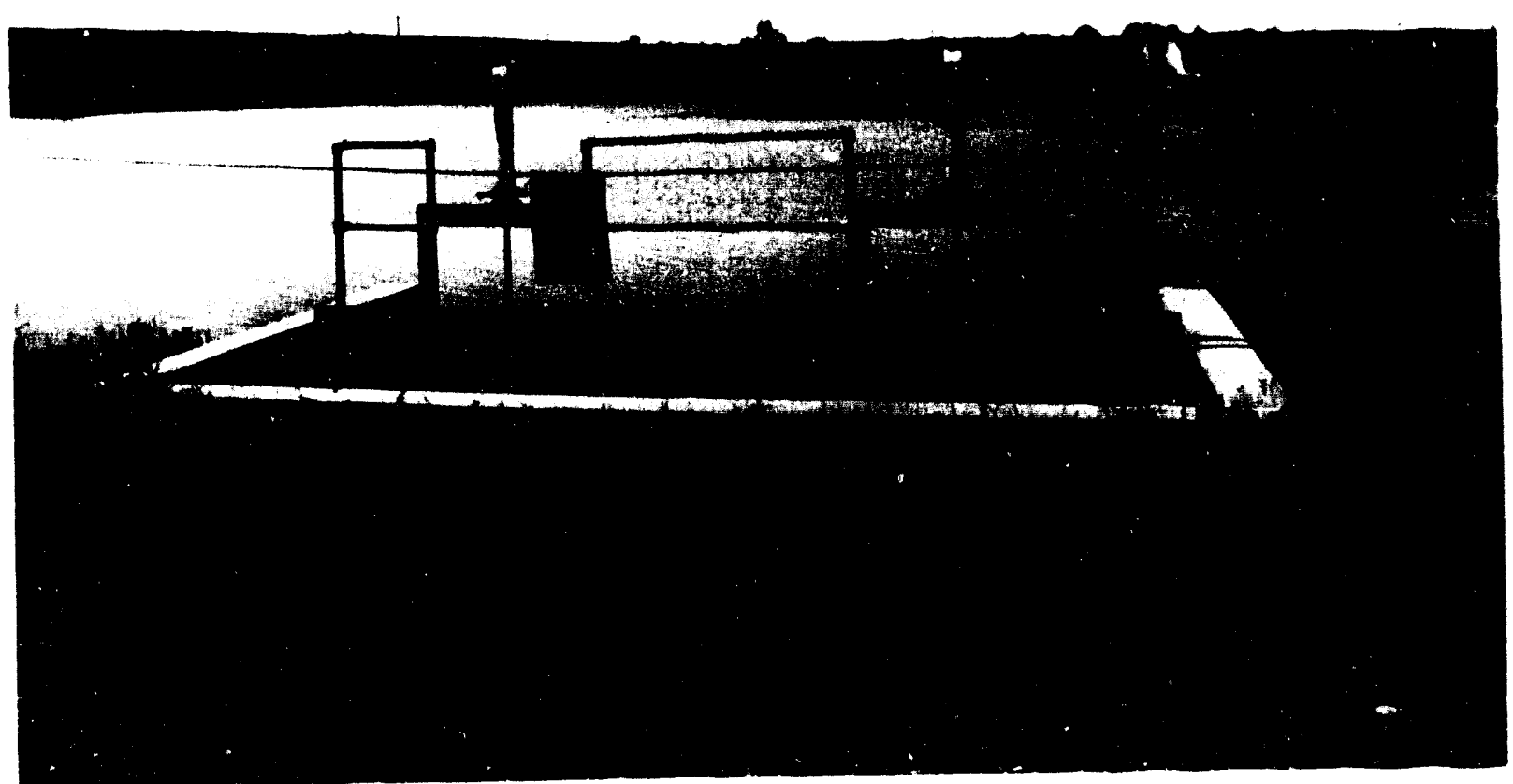

(PHOTOGRAPH TAKEN 1989)

Figure 2-9. Photograph of the 216-B-353 Overflow Control Structure. 
DOE/RL-89-28, Rev. 1

$12 / 15 / 93$

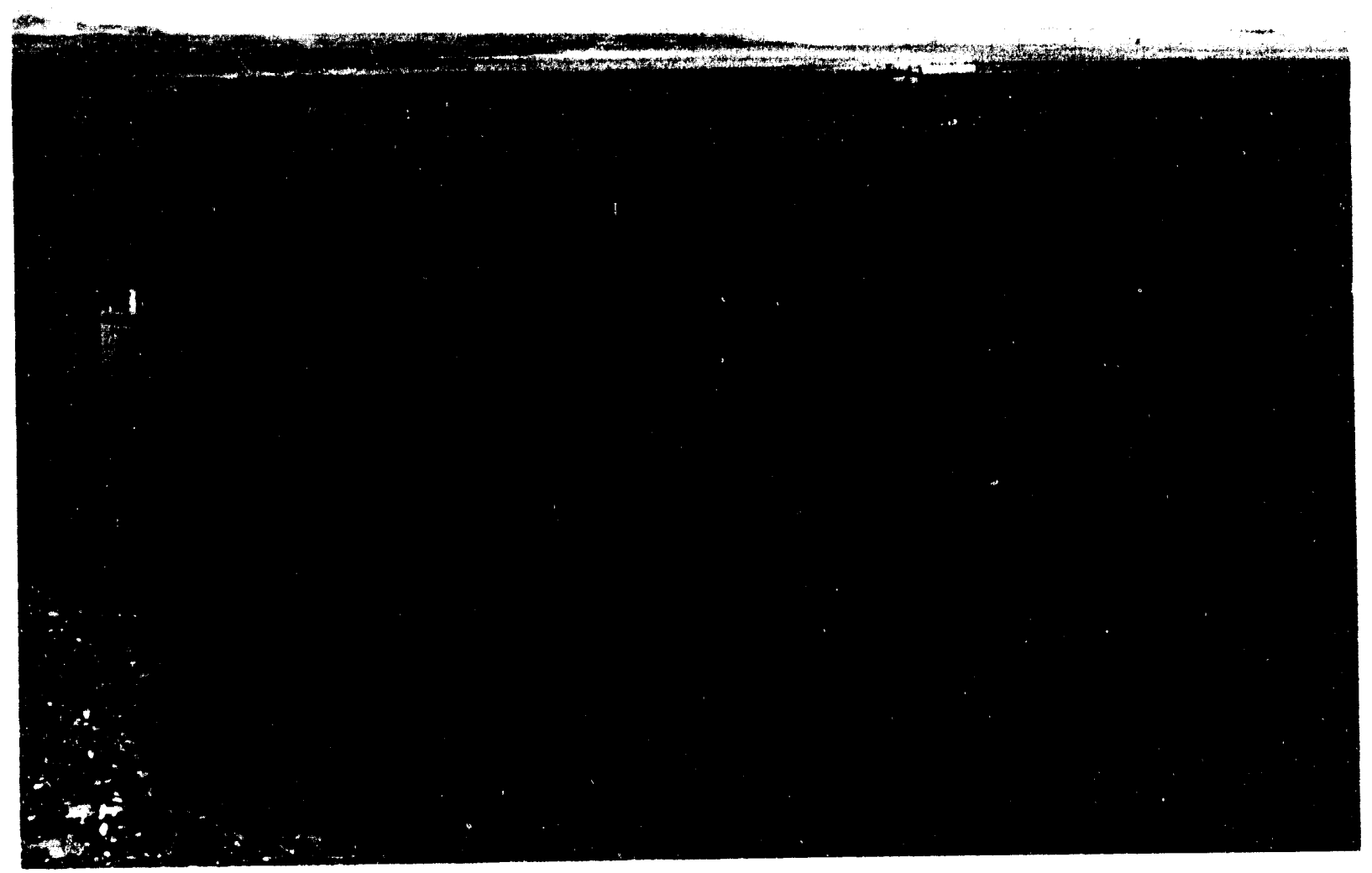

(PHOTOGRAPH TAKEN 1989)

Figure 2-10. Photograph of the 216-B-353 Stilling Basin. 


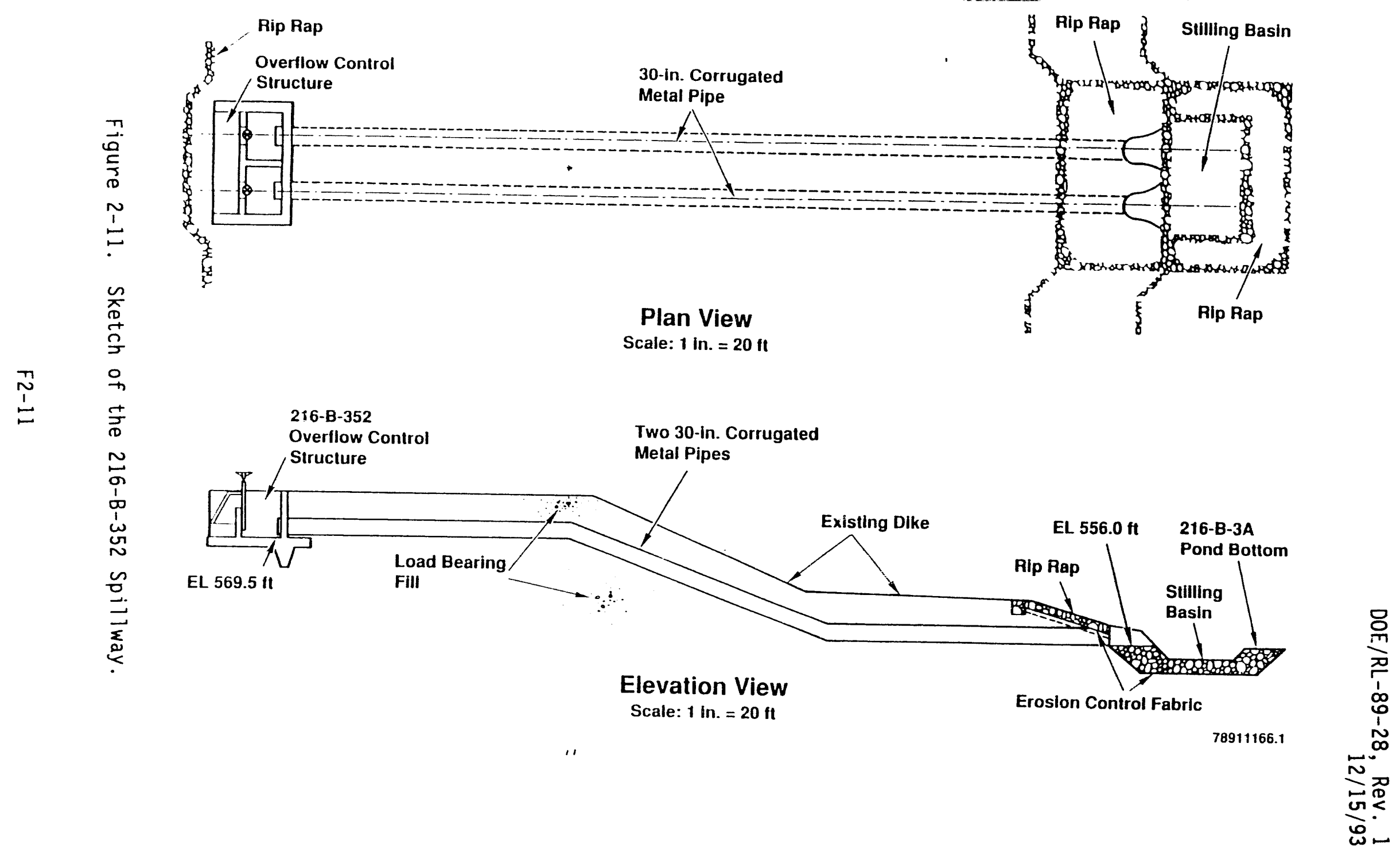


DOE/RL-89-28, Rev. 1

$12 / 15 / 93$

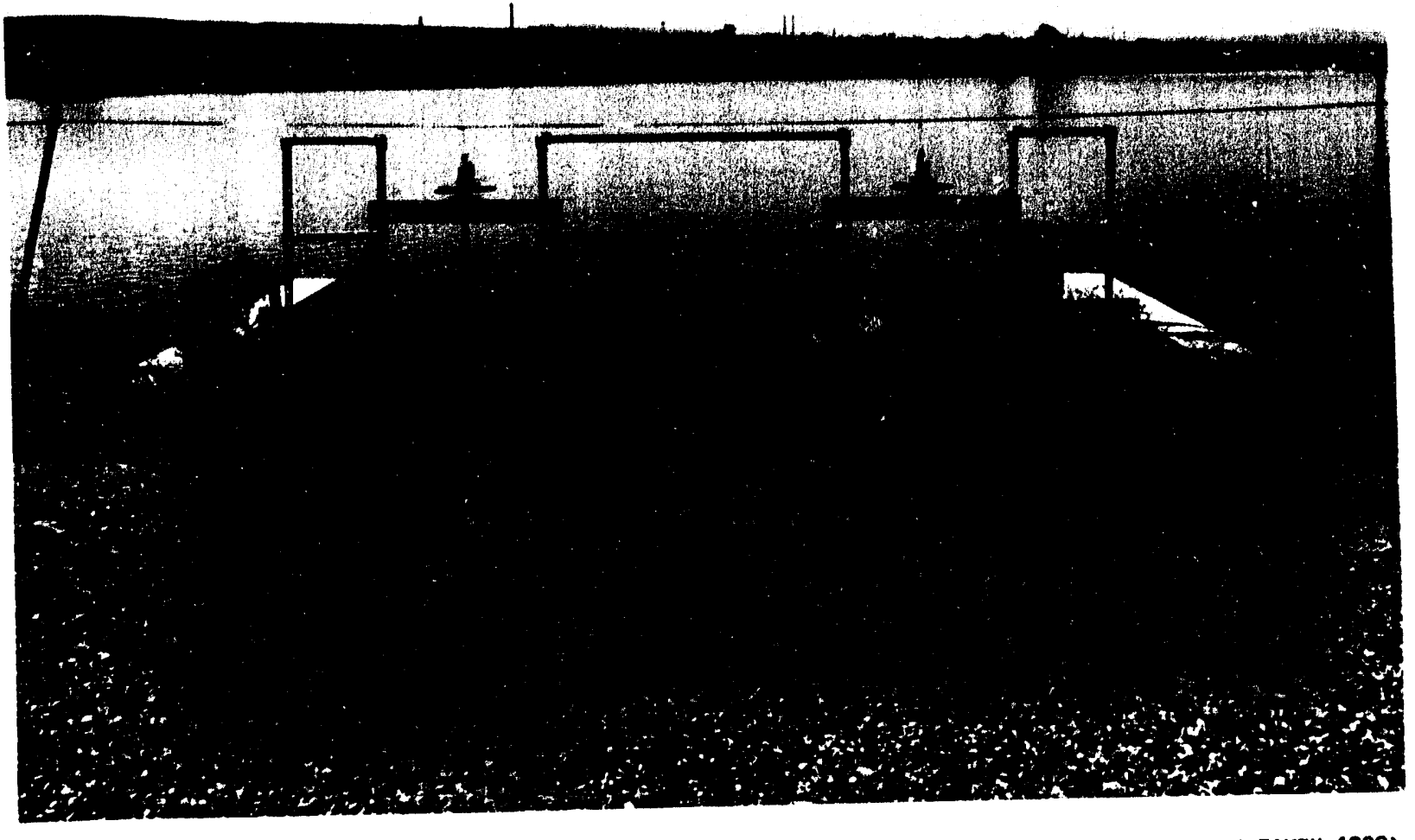

(PHOTOGRAPH TAKEN 1989)

Figure 2-12. Photograph of the 216-B-352 Overflow Control Structure. 
DOE/RL-89-28, Rev. 1

$12 / 15 / 93$

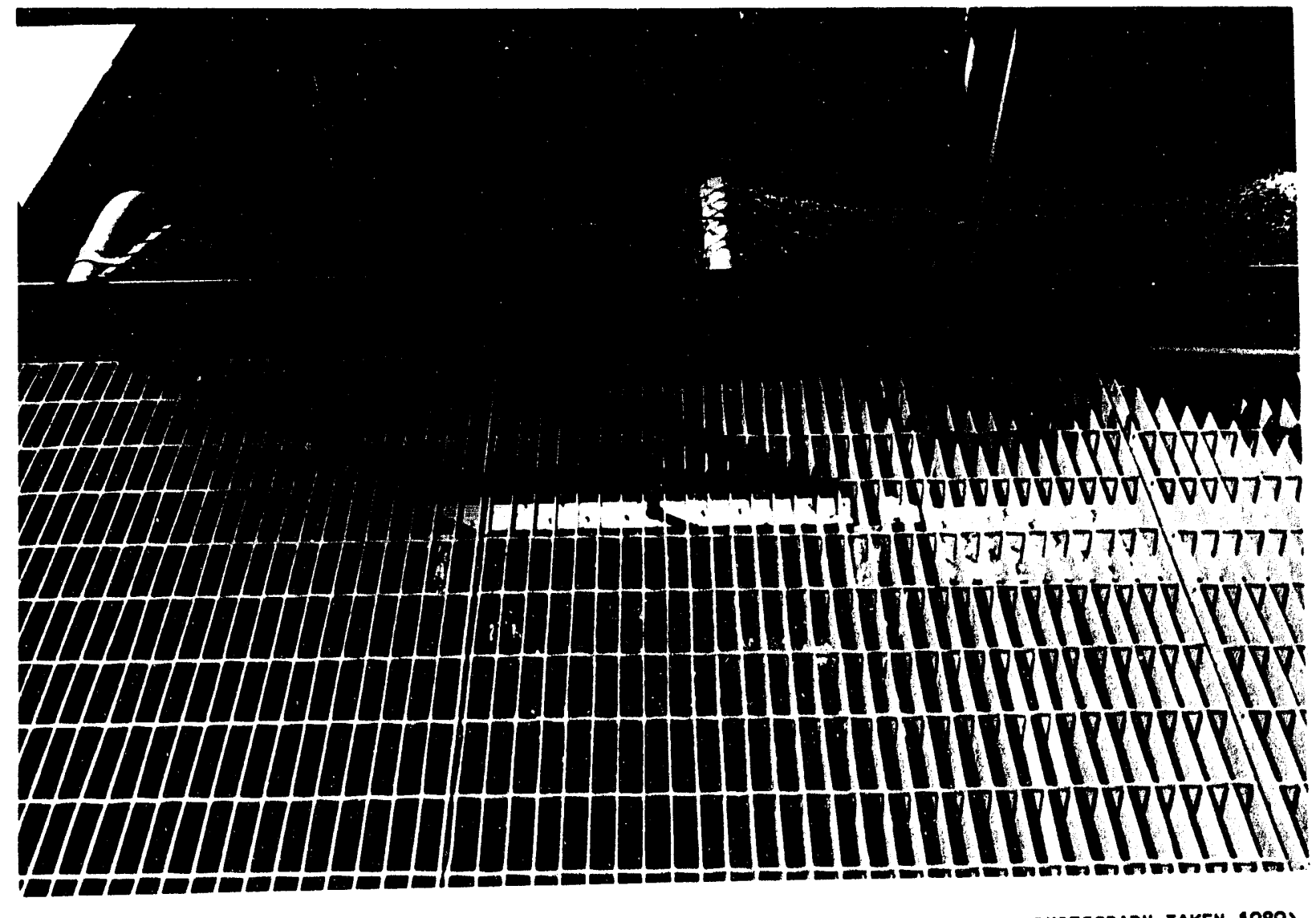

(PHOTOGRAPH TAKEN 1989)

Figure 2-13. Photograph of the 216-B-352 Overflow Control Structure. 
DOE/RL-89-28, Rev. 1

$12 / 15 / 93$

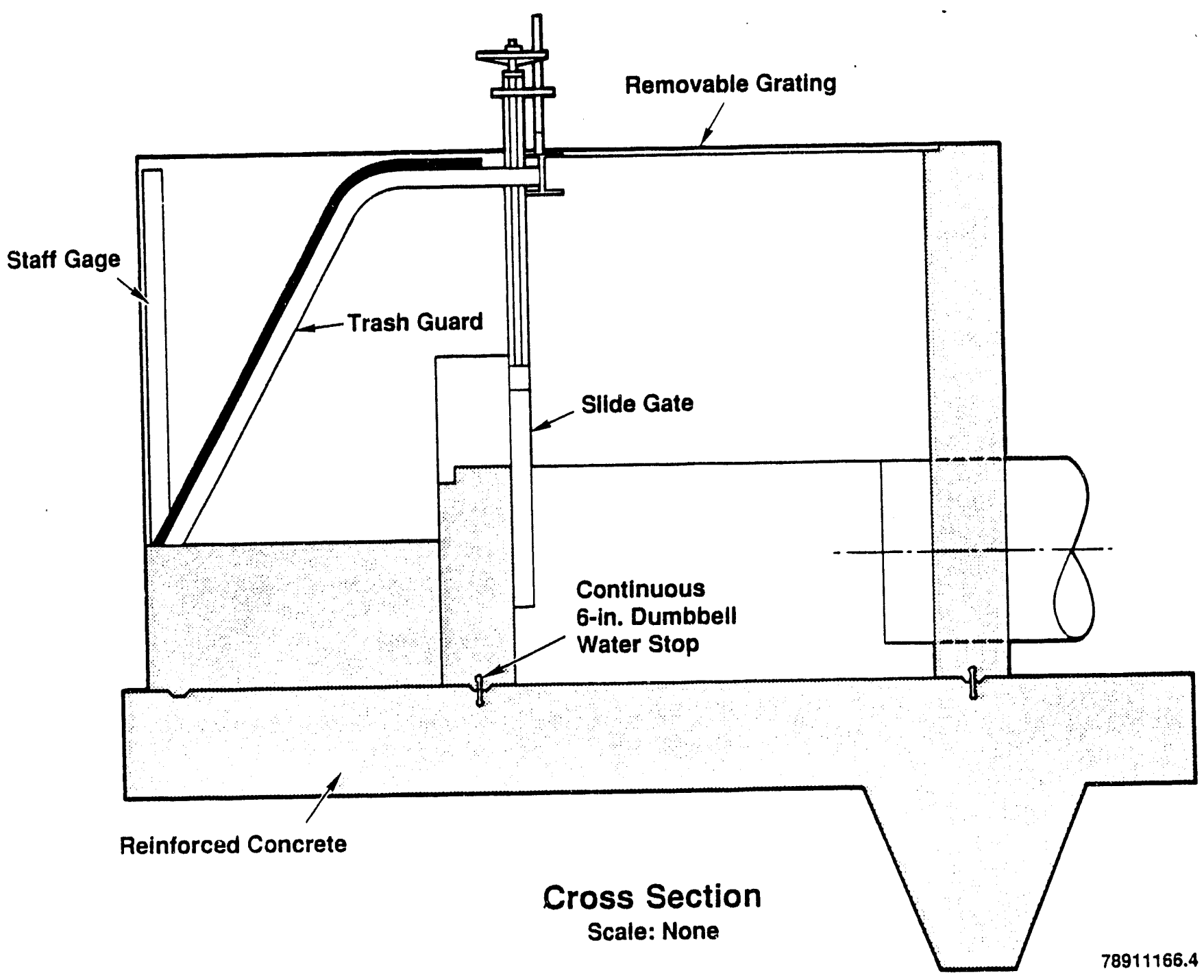

Figure 2-14. Generalized Cross Section of the 216-B-352, 215-B-353, and 216-B-354 Overflow Control Structure. 


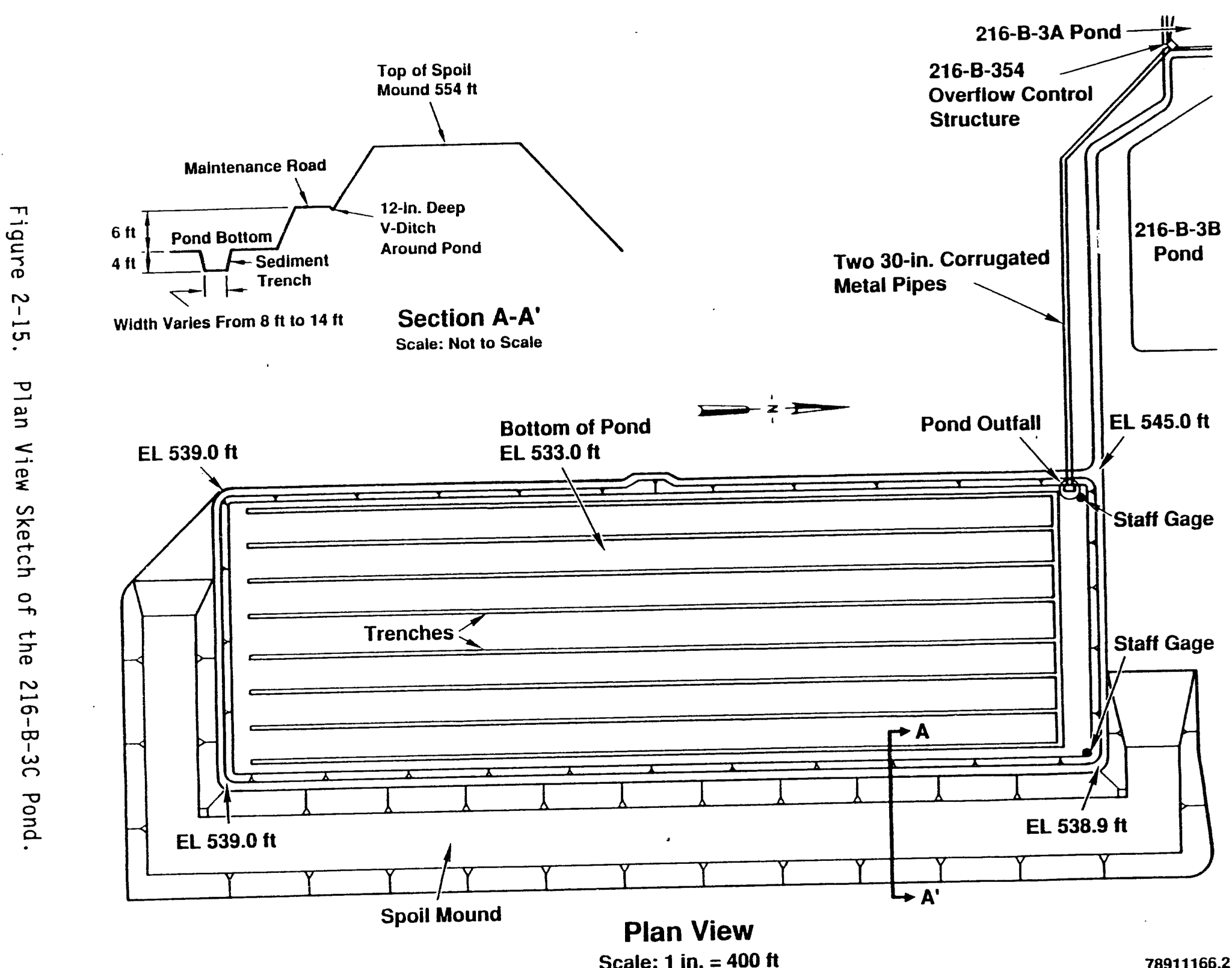




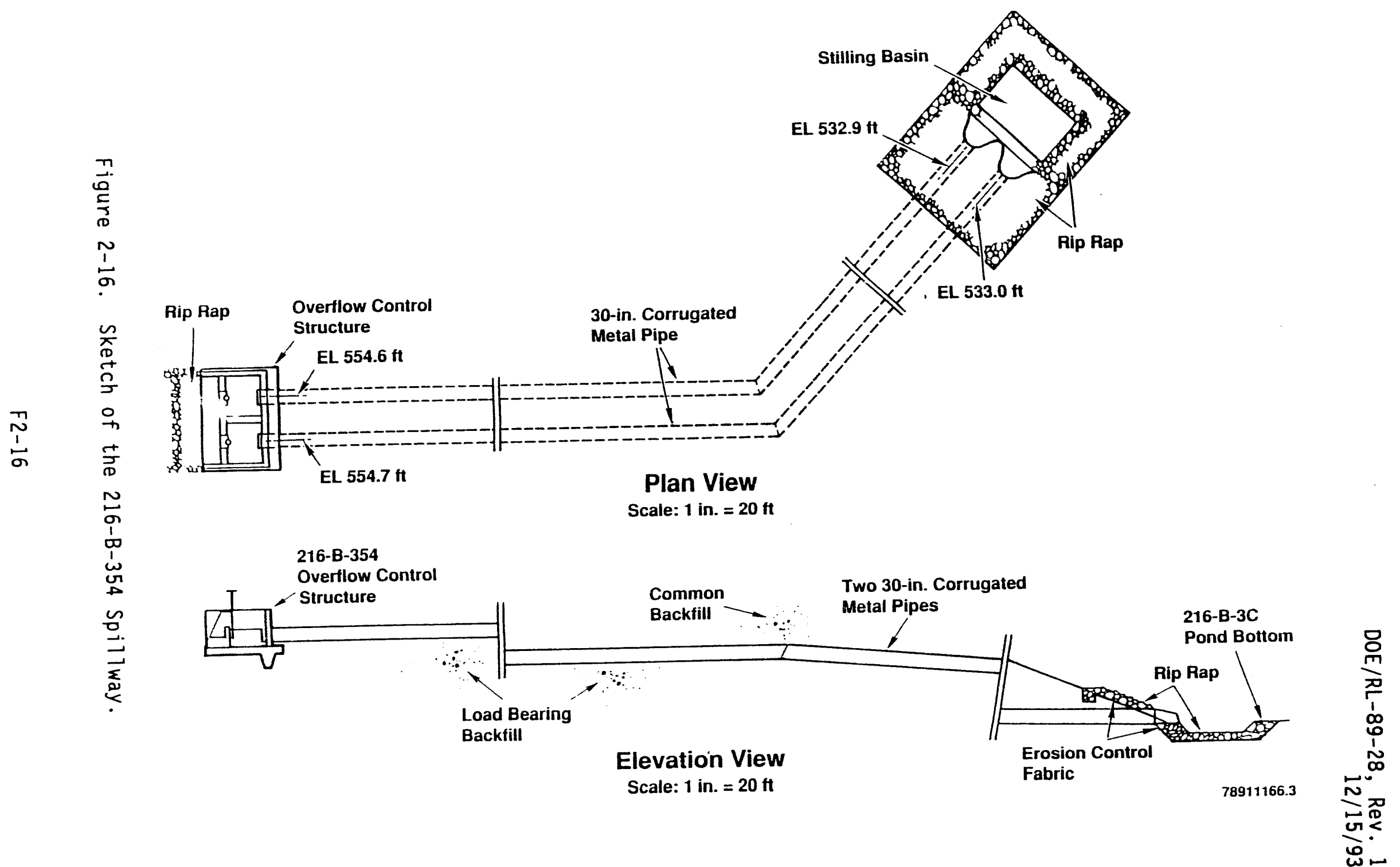


$\mathrm{DOE} / \mathrm{RL}-89-28, \operatorname{Rev}, 1$

$12 / 15 / 93$

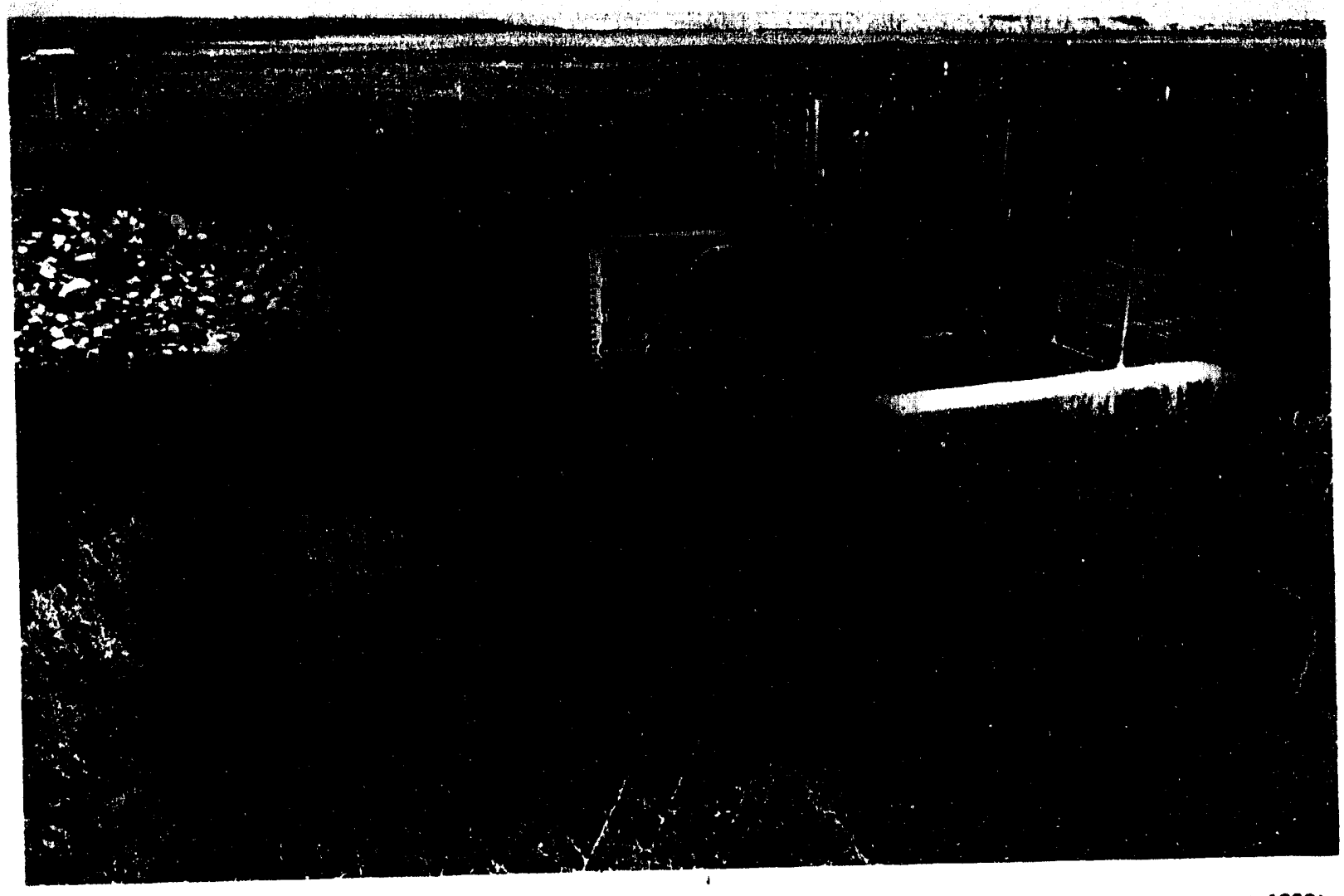

(PHOTOGRAPH TAKEN 1989)

Figure 2-17. Photograph of the 216-B-354 Overflow Control Structure. 
DOE/RL-89-28, Rev. 1

$12 / 15 / 93$

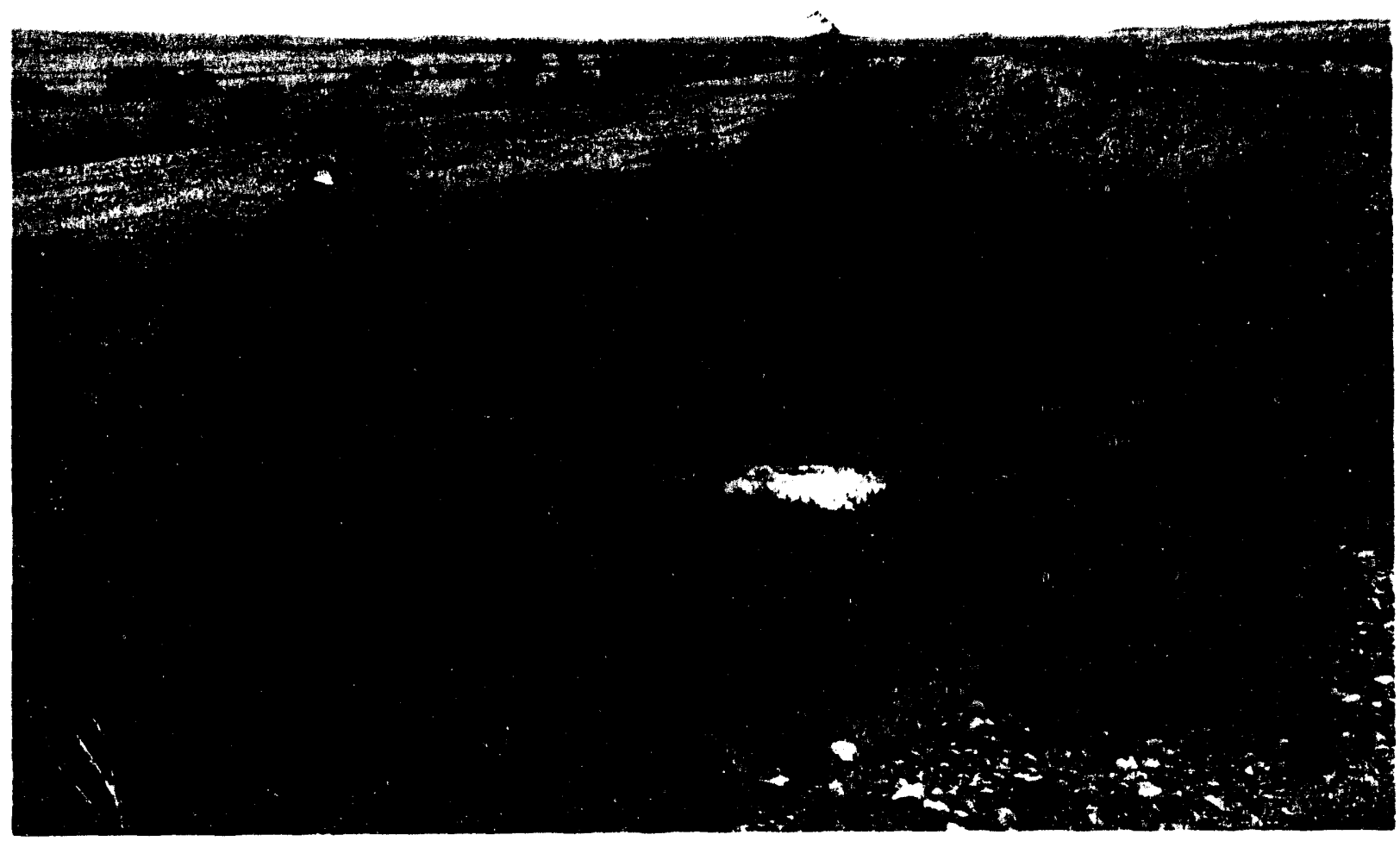

(PHOTOGRAPH TAKEN 1989)

Figure 2-18. Photograph of the 216-B-354 Spillway Outfall. 


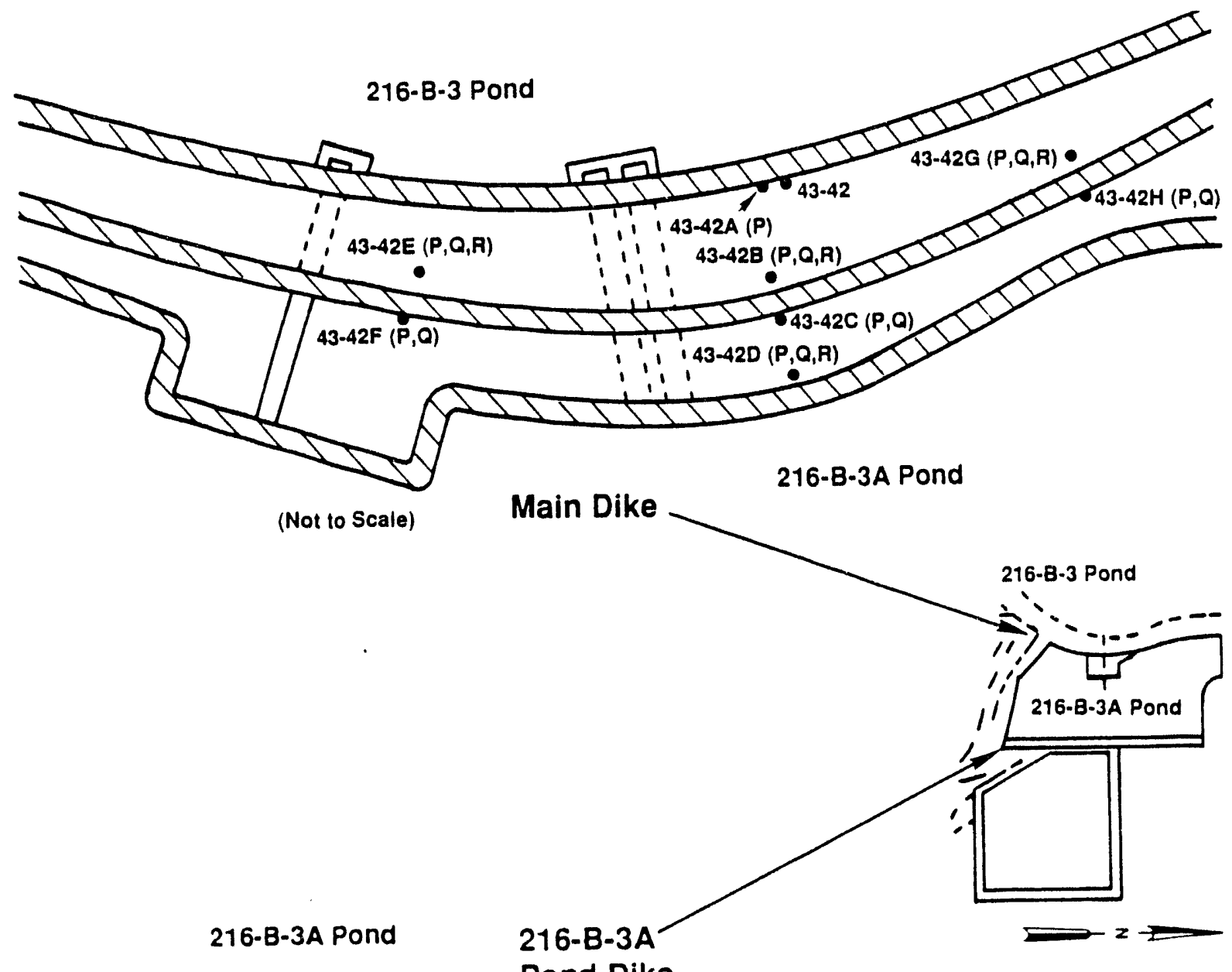

\section{Pond Dike}

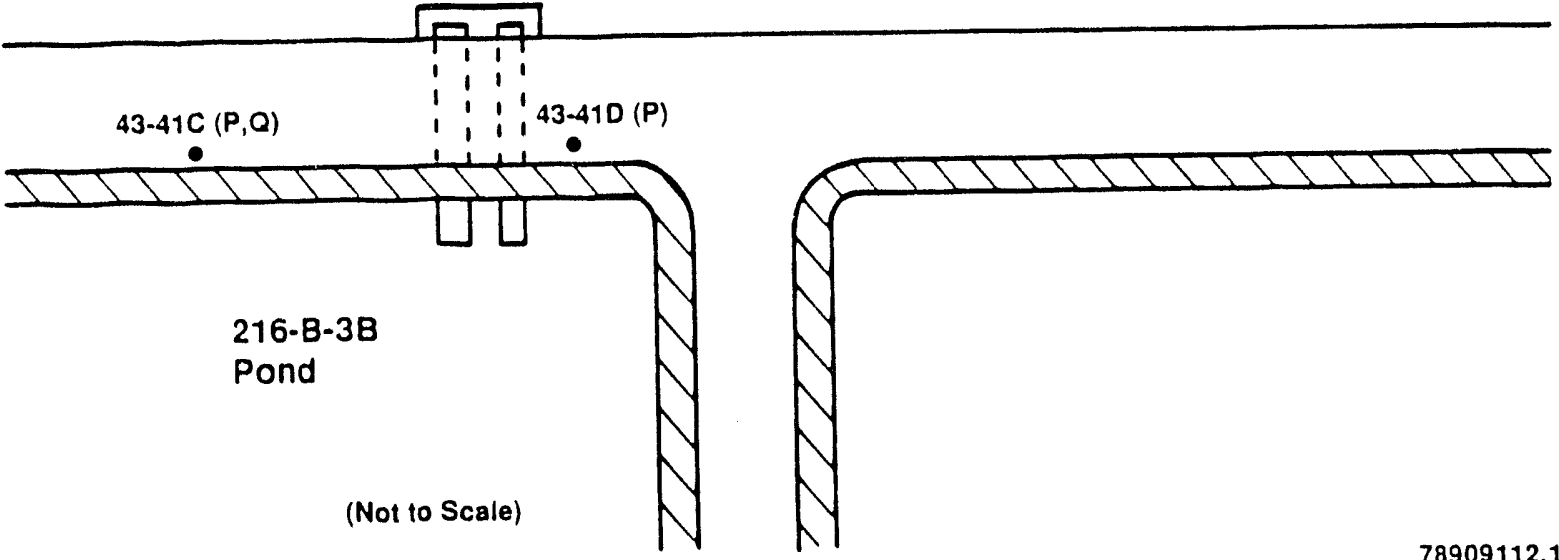

78909112.1

Figure 2-19. Piezometer Location Map. 
DOE/RL-89-28, Rev. 1

$12 / 15 / 93$

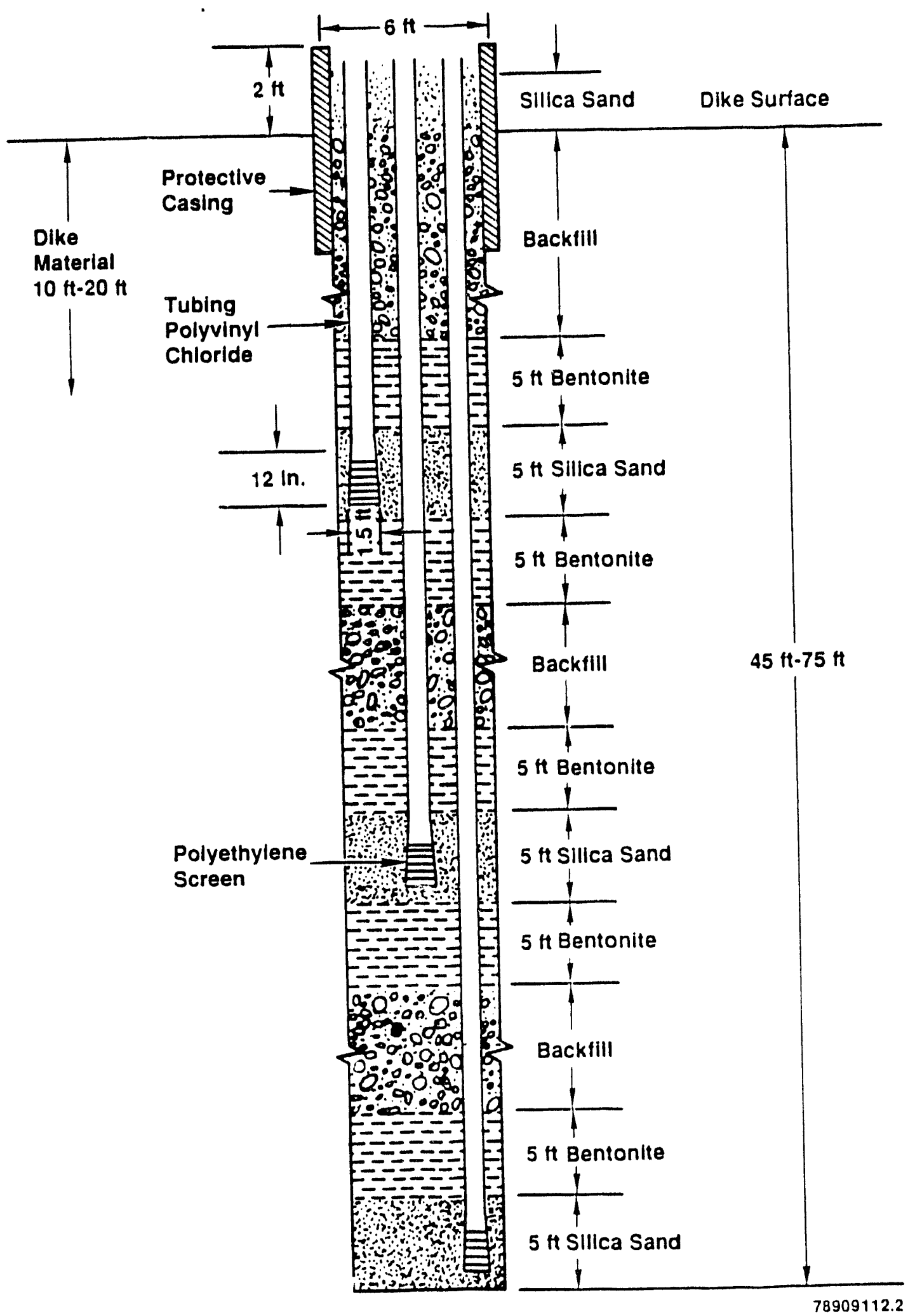

Figure 2-20. Typical Multiple Piezometer Installation. 
Table 2-1. Piezometer Coordinates, Dimensions, and Water Levels.

\begin{tabular}{|c|c|c|c|c|c|c|c|}
\hline \multirow{3}{*}{$\begin{array}{l}\text { Piezometer } \\
\text { number }\end{array}$} & \multirow{3}{*}{$\begin{array}{l}\text { Piezo- } \\
\text { meter }\end{array}$} & \multirow{2}{*}{\multicolumn{2}{|c|}{$P$ lant coordinates }} & \multicolumn{2}{|c|}{$\begin{array}{c}\text { Elevation } \\
\text { (feet above mean sea level) }\end{array}$} & \multirow{3}{*}{$\begin{array}{c}\text { Depth from } \\
\text { top to } \\
\text { bottom } \\
\text { (feet) }\end{array}$} & \multirow{3}{*}{$\begin{array}{l}\text { Depth to } \\
\text { water } \\
\text { (feet) }\end{array}$} \\
\hline & & & & \multirow{2}{*}{ Top of pipe } & \multirow{2}{*}{$\begin{array}{l}\text { Piezometer } \\
\text { bottom }\end{array}$} & & \\
\hline & & North & West & & & & \\
\hline $699-43-42 A$ & $P$ & $N 43110.33$ & $W 41812.50$ & 578.8 & 568.4 & 10.4 & 9.7 \\
\hline \multirow[t]{3}{*}{$699-43-42 B$} & P & $N 43117.46$ & 141772.55 & 577.6 & 529.3 & 50.6 & 48.1 \\
\hline & 0 & & & 577.7 & 527.1 & 21.2 & Dry \\
\hline & $\mathbf{R}$ & & & 577.7 & 556.5 & 11.3 & Dry \\
\hline \multirow[t]{2}{*}{$699-43-42 C$} & $P$ & $N 43125.08$ & $W 41747.37$ & 566.5 & 515.2 & 51.3 & Dry \\
\hline & 0 & & & 566.5 & 531.4 & 35.1 & Dry \\
\hline \multirow[t]{3}{*}{$699-43-420$} & $P$ & $N 43131.33$ & $W 41726.12$ & 564.8 & 517.6 & 47.3 & ory \\
\hline & 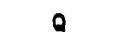 & & & 564.8 & 532.2 & 32.65 & Dry \\
\hline & $\mathbf{R}$ & & & 564.8 & 549.6 & 15.3 & Dry \\
\hline \multirow[t]{3}{*}{$699-43-42 E$} & $\mathbf{P}$ & N42892.14 & $W 41705.14$ & 578.6 & 501.3 & 77.4 & Dry \\
\hline & Q & & & 578.6 & 525.9 & 52.8 & Dry \\
\hline & R & & & 578.6 & 563.6 & 15.1 & Dry \\
\hline \multirow[t]{2}{*}{$699-43-42 F$} & $P$ & N42893.96 & $W 41666.49$ & 565.9 & 494.4 & 71.5 & ory \\
\hline & 0 & & & 565.9 & 528.4 & 37.5 & Dry \\
\hline \multirow[t]{3}{*}{$699-43-426$} & $\mathbf{P}$ & N43362.37 & $W 41828.35$ & 578.8 & 513.3 & 65.5 & Dry \\
\hline & 0 & & & 578.8 & 532.0 & 46.8 & ory \\
\hline & $R$ & & & 578.8 & 564.5 & 14.3 & ory \\
\hline \multirow[t]{2}{*}{$699-43-42 \mathrm{H}$} & $\mathbf{P}$ & $N 43368.19$ & $W 41789.84$ & 565.1 & 513.3 & 51.8 & Dry \\
\hline & 0 & & & 565.1 & 542.7 & 22.4 & Dry \\
\hline \multirow[t]{2}{*}{$699-43-41 c$} & $P$ & N42676.73 & $W 41171.57$ & 563.5 & 546.7 & 16.8 & Dry \\
\hline & 0 & & & 563.5 & 554.4 & 9.1 & Dry \\
\hline $699-43-410$ & $P$ & N42834.80 & $W 41172.21$ & 563.4 & 552.6 & 10.8 & ory \\
\hline
\end{tabular}




\section{CONTENTS}

3.0 PROCESS INFORMATION . . . . . . . . . . . . . . . . . . 3-1

3.1 THE PUREX PLANT FEED STREAMS . . . . . . . . . . . . . . 3-1

3.1.1 Chemical Sewer ... . . . . . . . . . . . 3-3

3.1.1.1 Heating and Ventilation Condensate . . . . 3-4

3.1.1.2 Carrier Water . . . . . . . . . . . . . 3-4

3.1.1.3 Vacuum Pump Seal Water ... . . . . . . . 3-4

3.1.1.4 Pipe and Operating Gallery . . . . . . . . 3-5

3.1.1.5 Miscellaneous Floor Drains . . . . . . . . 3-6

3.1.1.6 Recovered Nitric Acid System . . . . . . . 3-6

3.1.1.7 Aqueous Makeup Area . . . . . . . . . . . . . 3-7

3.1.1.8 The 203-A Uranium Storage Area . . . . . . . 3-8

3.1.1.9 The 211-A Chemical Storage Area . . . . . . . 3-8

3.1.1.10 Flash Tank Tk-618-1 .. . . . . . . . . . . . 3-9

3.1.1.11 Distilled Water Systems .......... 3-9

3.1.1.12 The Tank Tk-2901A Overflow . . . . . . . . 3-9

3.1.1.13 Sanitary Pipe Trench Condensate . . . . . 3-10

3.1.2 Cooling Water Line ............ . . . 3-10

3.1.2.1 Uranium Concentrator $(E-K 4)$. . . . . . . 3-10

3.1.2.2 Concentrator Condensers .. . . . . . . . 3-11

3.1.2.3 Dissolver Down Draft Towers . . . . . . . . . . 3-11

3.1.2.4 The PUREX Plant Tunnels' Water-Fillable Doors . 3-11

3.1.2.5 Process Tanks............... 3-11

3.1.3 Steam Condensate Discharge . . . . . . . . . . . 3-11

3.1.3.1 Concentrator Coils . . . . . . . . . 3-12

3.1.3.2 Dissolver Coils............ . 3-12

3.1.3.3 Quench Water ............. 3-12

3.2 TANK FARM WASTE MANAGEMENT OPERATIONS . . . . . . . . . . 3-12

3.2.1 The 242-A Evaporator . . . . . . . . . . . . . . . .3-13

3.2.2 The 244-AR Vault ............... . . 3-15

3.2.3 The 244-BXR Vault ............ . . 3-17

3.2.4 The 241-BY Tank Farm . . . . . . . . . . . . . . . 3-17

3.2.5 The 242-B Evaporator . . . . . . . . . . . . . . 3-17

3.2.6 The 244-CR Vault . . . . . . . . . . . . . . . . . 3-17

3.2.7 The 241-A Aging Waste Ventilation System Complex. . . 3-18

3.3 THE 283-E WATER TREATMENT FACILITY . . . . . . . . . . . . 3-18

3.3.1 Reservoir Overflow ................ 3-19

3.3.2 Settling Basin Flushing ............. . . 3-19

3.3.3 Filter Backflush Water . . . . . . . . . . . . . 3-19

3.4 THE 284-E POWERHOUSE ................. . . 3-19

3.4.1 Boiler Blowdown .. . . . . . . . . . . . . . 3-20

3.4.2 Cooling Water .. . . . . . . . . . . . . 3-20

3.4.3 Floor Drains..... . . . . . . . . . . 3-20

3.4.4 Water Softener Regeneration Solution ........ 3-21 


\section{CONTENTS (cont)}

3.5 THE B PLANT FEED STREAMS ................ . . 3-21

3.5.1 The B Plant Cooling Water .. . . . . . . . . . . 3-22

3.5.2 The B Plant Process Condensate Stream . . . . . . . . 3-23

3.5.3 The B Plant Steam Condensate . . . . . . . . . . 3-24

3.5.4 Chemical Sewer ................. 3-25

3.5.4.1 The 221-B Drain System . . . . . . . . 3-25

3.5.4.2 The 271-B Drain System .......... . 3-26

3.5.4.3 The 211-B Tank Storage Area . . . . . . . . . . 3-27

3.5.4.4 The 217-B Demineralized Water Unit Building

Drains . . . 3-27

3.5.4.5 The 276-B Organic Makeup Building Drains . . 3-27

3.5.4.6 The 225-B Encapsulation Facility . . . . . 3-27

3.5.4.7 The 212-B Cask Station ........ . . . 3-27

3.5.4.8 The 2902-B High Tank Overfiow Orains . . . . 3-27

3.5.4.9 The 222-B Laboratory .... . . . . . . . 3-27

3.5.4.10 The 224-B Facility. . . . . . . . . . . 3-28

3.5.4.11 292-B Facility. . . . . . . . . . . . . 3-28

3.5.4.12 TK-900... . . . . . . . . . . . . 3-28

3.5.4.13 Five Street and Yard Drains . . . . . . 3-28

3-1. Flow Routes to B Pond ..................... . F3-1

FIGURE

\section{TABLES}

3-1. Summary of Discharge Sources for the 216-B-3 Pond . . . . . . . . . T3-1

3-2. PUREX Plant Flow Rates . . . . . . . . . . . . . . . . T3-2

3-3. Average Flow Rates Discharged to the 216-B-3 Pond System . . . . T3-3 


\subsection{PROCESS INFORMATION}

This chapter describes the processes that generate the waste streams discharged to the 216-B-3 Pond System. The 216-B-3 Pond System receives cooling water from the 221-B Building (B Plant), 242-A Evaporator, 241-A Aging Waste Ventilation System Complex, and 244-AR Vault. In addition, the 216-B-3 Pond System receives discharges from the $B$ Plant chemical sewer, PUREX Plant chemical sewer, 283-E Water Treatment Facility, and 284-E Powerhouse. In the past, the 216-B-3 Pond received waste water from PUREX cooling water, 244-CR Vault, 242-B Evaporator, 244-BXR Vault and 241-BY Tank Farm. The 216-B-3 Pond System has also received waste water from several miscellaneous sources, such as construction activities. Other waste streams may be discharged to the 216-B-3 Pond System in the future. Table 3-1 provides a summary of the waste streams discharged to the 216-B-3 Pond System and the associated discharge dates.

Since 1970, the waste streams have been discharged to the 216-B-3 Pond via the 216-B-3-3 Ditch. The flow was divided between 216-B-3 Pond and 216-A-25 (Gable Mountain) Pond via a diversion valve near the head end of the 216-B-3-3 Ditch. This practice was discontinued when the 216-A-25 Pond was decommissioned in 1987. Figure 3-1 depicts the various flow routes to the 216-B-3 Pond System.

Effluents entering the 216-B-3 Pond atmospheric condensate, cooling water, sar.

onsist primarily of steam condensate. Cooling water and steam cuivensate discharged to the 216-B-3 Pond System have the potential to become radioactive if there is a breach in the tubes separating the cooling water or steam from the process solutions. Cooling and heating operations, unless otherwise specified, are open-10op systems. That is, the cooling water or steam is not reused after accomplishing the cooling or heating operation. All streams that have the potential to receive radionuclides are monitored for radiation in order to automatically divert the stream to a basin when a predetermined radiation level is reached, alert personnel that alternate cooling routes need to be valved in, or shut down the process.

\subsection{THE PUREX PLANT FEED STREAMS}

The PUREX Plant was used to process irradiated nuclear fuel. The supply of nuclear fuel was obtained from the 100 Area Fuel Basins where it was stored after it was discharged from the $\mathrm{N}$ Reactor. Plutonium and uranium were the primary product materials recovered from the irradiated fuel.

The PUREX Plant began operation in January 1956 and operated until June 1972, when the facility was placed on standby. After upgrading the fiant, the facility was restarted in November 1983 and operated until 1991 . It was transitioned from operational to standby mode in 1992 and is now being 
transitioned to shutdown mode. During shutdown, the facility will not be staffed and will produce no 1 iquid effluent streams. The facility will remain in a deactivated state for several years until final decontamination and decommissioning.

Discharge from the PUREX P1ant to the 216-B-3 Pond Sysiem comes from the chemical sewer. The cooling water and steam condensate streams were shut down and diverted to the chemical sewer during the 1992 transition to standby. In the past, the steam condensate stream could be sent to the 216-B-3 Pond System after being diverted to the 216-A-42 Diversion Basin. The steam condensate stream normally was discharged to the 216-A-30 Crib and the 216-A-37-2 Crib. The steam condensate flow was split in a diversion box on the 216-A-30 Crib so that two-thirds of the flow went to the 216-A-30 Crib and the remaining effluent went to the nearby 216-A-37-2 Crib.

Diversion of the chemical sewer to the 216-A-42 Diversion Basin occurs automatically when a high radionuclide content is detected or when an electrical failure occurs. The chemical sewer discharge must be diverted manually to the 216-A-42 Diversion Basin whenever the $\mathrm{pH}$ is greater than or equal to 12.5 or less than or equal to 2.0. An audible alarm is received in the PUREX Plant central control room and dispatch office that alerts the process operators to an abnormal condition that may require a diversion of the chemical sewer discharge to the 216-A-42 Diversion Basin.

After a stream has been diverted to the 216-A-42 Diversion Basin, the basin is sampled to determine the $\mathrm{pH}$ and radionuclide content of the liquid. The $\mathrm{pH}$ of the basin contents is measured because the most likely dangerous waste constituent would be a corrosive material. If sample analyses indicate the solution in the basin is out of range (with respect to dangerous waste characteristics and/or radioactivity), the following options exist.

- Send the material back to the PUREX Plant for reprocessing.

- Route the material to the Tank Farms via the PUREX Plant.

Liquid in the basin is pumped to the 216-B-3 Pond via the 216-B-3-3 Ditch when the sample analysis indicates the material is within the proper specifications for disposal to the environment.

Composite samples of the stream are taken weekly. A composite sample consists of numerous small samples that are obtained automatically during one week by the flow-proportional sampler and stored in a small tank. This sample is a representative average of the stream discharge over a one-week interval. An operator obtains the composite sample weekly for analysis. The cooling water and steam condensate are analyzed for $\mathrm{pH}$, total alpha, and total beta; the chemical sewer is analyzed for $\mathrm{pH}$, total alpha, total beta, and nitrate.

Approximate flow rates for the chemical sewer, cooling water, and steam condensate discharge for the PUREX Plant are provided in Table 3-2. 


\subsubsection{Chemical Sewer}

The chemical sewer stream was the most likely source for discharge of a dangerous material, in liquid form, to the 216-B-3 Pond System. Since 1984, numerous administrative and engineering barriers have been implemented to prevent dangerous waste from being disposed of to the chemical sewer.

Administrative controls consist of the following:

- Maintaining operating procedures to ensure that chemicals are not improperly disposed of

- Regenerating simultaneousiy (i.e., co-regeneration) the anion and cation beds for the demineralized water system (now shut down)

- Requiring an operator at each tank (when making transfers between tanks not within the vicinity of each other) to prevent overfilling

- Verifying (double) of valving to minimize inadvertent transfers or draining of tanks.

Physical barriers include the following:

- $\mathrm{pH}$ monitors and alarms

- Containment dikes

- Liquid-level instrumentation with interlocking inlet isolation valves to prevent overfilling tanks

- Catch tanks established within the aqueous makeup area to contain spills

- B-669 elementary neutralization system (now shut down)

- Pancake blanks installed on chemical headers in the processing and operating gallery. Pancake blanks are circular metal plates with a projecting tab. The blanks are designed to be inserted at flange joints in chemical headers to prevent the flow of liquids and gases. The projecting tab serves as physical evidence that a line has been blanked off.

To assist in detecting dangerous materials being released to the environment, a pH meter was installed in November 1985 in the chemical sewer line monitoring system. The $\mathrm{pH}$ meter monitors the chemical sewer line monitoring system for radiation and corrosion.

The chemical sewer can receive liquid from the following sources:

- Heating and ventilation condensate

- Carrier water

- Vacuum pump seal water 
DOE/RL-89-28, Rev. 1 $12 / 15 / 93$

- Pipe and operating gallery

- Miscellaneous floor drains

- Recovered nitric acid system (no longer a source)

- Aqueous makeup area

- 203-A (former) uranium storage area

- 211-A chemical storage area

- Flash tank Tk-618-1

- Distilled water systems

- Tank Tk-2901A overflow

- Sanitary pipe trench condensate.

3.1.1.1 Heating and Ventilation Condensate. In addition to establishing necessary pressure gradients to prevent the spread of radionuclides throughout the PUREX Plant, the heating and ventilation system is used to condition air (e.g., to remove dust, humidify, and adjust to final desired temperature) for personnel comfort. Air enters the building through an inlet damper and is preheated with low-pressure steam (nominaliy 10 pounds per square inch) to minimize moisture accumulation in the filter. Following the heating operation, the air passes through a filter used to eliminate coarse dirt and dust particles. After filtering, the air goes into a chamber where it is humidified and washed simultaneously. Water flowing through the air washes away fine dirt and dust particles. Washing air with water accomplishes the simultaneous humidification. The clean and humidified air then is reheated to a desired temperature using low-pressure steam.

Condensate from steam heating and water used for air washing and humidification are routed to the chemical sewer line. Because these operations are performed on ambient outside air, the resulting 1 iquid streams should not adversely affect the composition in the chemical sewer discharge.

To provide for local temperature control, steam heaters are installed in ductwork leading to control rooms, offices, laboratory, and locker rooms. The steam condensate generated from these units also is routed to the chemical sewer line.

3.1.1.2 Carrier Water. The purpose of arrier water is to ensure that adequate flow is available to prevent the accumulation of material in the chemical sewer line during low flow periods. Carrier water is supplied continuously to the chemical sewer line via the raw water line at approximately 30 gallons per minute. This ensures that continuous monitoring is available for immediate detection of abnormal conditions. Raw water is unfiltered and untreated water obtained from the river. Therefore, any constituents found in the raw water supply would have existed before extraction from the river.

3.1.1.3 Vacuum Pump Seal Water. A vacuum system provides a vacuum source for the continuous air samplers located throughout the facility. Continuous air samplers are used to detect potential radioactive contamination in ambient (building) air that is exhausted via the facility stacks. A continuous air sampler is a standpipe with a paper filter holder. Air is pulled through the filter at a uniform rate and the filter is removed at fixed intervals and counted for radioactive contamination. Consistent, abnormally high radiation 
1

2

counts on a filter indicate a possible radiation leak in the vicinity of the sampler. The vacuum is provided by one of two vacuum pumps ( $P-C V-94-1$ and $\mathrm{P}-\mathrm{CV}-94-2$ ) that discharge the air to the atmosphere. Water is provided to the seals of these vacuum pumps to carry away excess heat from the seals and to serve as a lubricant. The uncontaminated water then is discharged to the chemical sewer.

3.1.1.4 Pipe and Operating Gallery. The pipe and operating gallery provides space for the electrical switchgear, instrument racks, nonradioactive chemical piping (or headers), several batch chemical addition tanks, and associated gang valves that serve the in-cell equipment. Because most of the valves are controlled from control panels, only a few operations are required in the gallery.

The pipe and operating gallery floor drains in the PUREX Plant were potential pathways for chemicals into the chemical sewer. Several upgrades have been installed to preclude chemicals from entering the chemical sewer line.

In 1986 , a11 possible routes from the pipe and operating gallery tanks and the nonradioactive chemical headers to the floor drains were identified. Engineering barriers, such as pancake blanks and blind flanges, were installed to prevent chemicals from reaching the floor.

Administratively, the pipe and operating gallery floor drains normally are diverted to tanks in the canyon. "When the pipe and operating gallery floor is cleaned, the floor drains initially are flushed to the canyon to ensure that any chemicals that are present have been flushed to the canyon. After initial flushing, the drains are diverted to the chemical sewer. Diversion of the pipe and operating gallery drains from the canyon to the chemical sewer requires supervisory authorization.

To prevent overfilling the pipe and operating gallery tanks, liquid-level capacitance probes were installed inside the tanks with three alarm functions:

- Low-level (20 percent of tank capacity) High-level ( 85 percent of tank capacity) righ-high level ( 90 percent of tank capacity).

The 'low-level' alarm was installed to alert personnel that a tank is losing liquid; indicating a drain valve is open, leaking through, or that a transfer had taken or is taking place. A 'high-level' alarm was installed to alert operations personnel that a tank is filling up and is almost full. If an anticipated transfer is not taking place, this serves as a warning that

'The use of 'canyon' in Hanford Site facilities refers to that portion of 46 47 a nuclear fuel processing building where remotely controlled radioactive processing of materials takes place. 
something is leaking into the tank (i.e., there is a leaking inlet valve or an inadvertent transfer). On a 'high-high level' al arm, motor-operated valves installed on all the inlet lines to a tank will close to prevent further liquid additions as the overflow point is approached.

3.1.1.5 Miscellaneous Floor Drains. Floor drains located in the PUREX Plant that are not in radiation areas and are not in the vicinity of the drains for dangerous waste are routed directly to the chemical sewer line. The floor drains receive water from draining condensate from the steam lines, safety showers, showers, and water coolers throughout the facility. The floor drain locations are as follows:

- Battery room

- Compressor room

- Laboratory change rooms

- Laboratory ventilation room

- Locker and shower rooms

- Instrument and maintenance shops

- Building supply ventilation rooms.

3.1.1.6 Recovered Nitric Acid System. Nitric acid was used at the PUREX Plant to dissolve uranium and to enhance solvent extraction performance and operations. The use of nitric acid was preferred for economic reasons. Nitric acid was recovered easily without generating large volumes of contaminated liquid waste. This resulted in minimizing the amount of fresh nitric acid required for the PUREX PIant process. The recovery was performed by breaking down nitric acid into oxides of nitrogen (gas composed of various nitrous oxides) and recovering the gas by absorption into water. The acidic water was recovered and concentrated to 50 weight percent nitric acid using a fractionator (a distillation column).

The acid fractionator (T-U6) was comprised of four main streams: feed, distillate, recycle, and bottoms. The feed was the dilute acidic water obtained in the recovery of nitrous oxide, the bottoms were the 50 weight percent (approximately 10 to 12 molar) nitric acid (product), and the distillate was the acidic water vapor (approximately 0.005 molar nitric acid) driven off from concentrating the feed.

The distillate (vapor form) was cooled (condensed) via a heat erchanger (condenser) using raw water as a coolant. This resulted in the vapor changing phases from a gas to a liquid. A condenser consists of tubes which cooling water flows through and this is surrounded by a shell that directs vapor fiow around the tubes. The two streams are physically separated by the wall thickness of the tubes. For mixing to occur, a tube in the condenser would have had to develop a hole. Because of the pressure difference between the cooling water header and the vacuum conditions that existed in the condenser shell, water would have flowed into the condenser shell instead of the slightly radioactive acidic solution flowing into the cooling water. 
The condensed liquid was routed to a condensate collection tank (TK-U8) where the distillate was routed to the following:

- Tank Tk-F10 for use in the condensate recycle system

- The backup facility for the recovery of nitrous oxides

- The recycle stream to the acid fractionator.

A significant portion of the flow to the chemical sewer was attributed to the cooling water used to condense the distillate. Thus, cooling water flow to the condenser resulted in a large flow increase to the chemical sewer while the PUREX Plant was operating.

The reboiler section of a distillation column is the point where heat is supplied to vaporize the volatile portion of the feed. A reboiler is a heat exchanger that is used for heating solutions. Steam that is used to provide the heat is routed through the shell of the heat exchanger and condensed on the outside of the tubes. The feed stream to be heated is routed through the iriside of the tubes. Physical contact between the two streams does not occur. Steam condensate is routed to the chemical sewer line and the recovered nitric acid is reused in the process.

Before 1986, effluents from the acid fractionator went through a diversion box that was designed to divert flow to the chemical sewer or the 216-A-9 Crib. The crib was undersized for the fractionator flow; thus, flow to the crib was blanked off and the valve to the chemical sewer was left open. Fractionator overflow to the chemical sewer was eliminated in September 1986. If tank TK-U8 should overflow, the solution is routed to tank Tk-U3 and tank Tk-U4 where it is neutralized and routed to Tank Farms.

\subsubsection{Aqueous Makeup Area. Before modifications in the PUREX Plant to} eliminate dangerous waste discharges, the 216-B-3 Pond System received occasional batches of spilled materials and out-of-specification chemicals. Recent facility upgrades have been incorporated to allow the rerouting of chemical makeups (that are not within the proper tolerances for use) el sewhere and to minimize unintentional releases to the chemical sewer line. To accomplish these goals, aqueous makeup-area catch tanks and liquid-level instrumentation systems have been installed that cut off flow to makeup tanks when the liquid levels approach overflow.

To prevent overfilling makeup tanks, liquid-level capacitance probes were installed inside the tanks with three alarm functions:

- Low-level (20 percent of tank capacity)

- High-level (85 percent of tank capacity)

- High-high level (90 percent of tank capacity).

The 'low-level' alarm was installed to alert personnel that a tank is losing liquid; indicating a drain valve is open, leaking through, or that a transfer had taken or is taking place. A 'high-level' alarm was installed to alert operations personnel that a tank is filling up and is almost full. If 
an anticipated transfer is not taking place, this serves as a warning that something is leaking into the tank (i.e., there is a leaking inlet valve or an inadvertent transfer). On a 'high-high level' alarm, motor-operated valves installed on all the inlet lines to a tank will close to prevent further liquid additions as the overflow point is approached.

In organizing the catch tank system for the aqueous makeup area, compatibility of various chemicals was considered. This resulted in establishing catch tanks for acidic, basic, and reductant type solutions. Floor drains are routed to the appropriate catch tank for the area of the aqueous makeup that is serviced by them. Catch tanks in the aqueous makeup area are monitored every 8 hours and have high-level instrumentation associated with them. When the level in a catch tank reaches about 10 percent of tank capacity, a 'high-level' alarm sounds. The solution then is sampled to determine where in the process the tank contents could be used. If a use for the solution cannot be determined, the tank contents are pumped to a drum and properly shipped under the appropriate waste regulations. A 'high-high level' alarm serves as a backup to the 'high-level' alarm. The 'high-high level' alarm sounds when the catch tank reaches approximately 50 percent of the tank capacity.

The catch tanks (Tk-103A, -104, -107A, -108, -110, -111, -112, and -113) serve as a backup to the makeup tanks and offer protection against leaks and overflows. Furthermore, catch tanks are used for rerouting chemical makeups that are out of tolerance for reuse. This results in minimizing the amount of waste generated at the PUREX Plant. Surveillance of all aqueous makeup tanks, in addition to catch tanks, is performed every 8 hours to detect abnormal problems that could result in a catch tank overflowing a potential dangerous waste solution.

3.1.1.8 The 203-A Uranium Storage Area. Sump waste from the 203-A uranium storage area is collected in a sump collection tank, Tk-Pl. When the appropriate level is reached, the tank is sampled for radionuclide content. The contents of this tank are routed to the double-shell tank farm system where eventual evaporation and long-term storage of the radionuclides occurs. A route exists to transfer solution to the chemical sewer line if the radionuclide content is low enough. However, this route has been isolated and is no longer used.

3.1.1.9 The 211-A Chemical Storage Area. The 211-A chemical storage area is used to store and transfer bulk liquid chemicals. In addition, it houses the demineralizers for production of demineralized water used in chemical makeups and processes.

Even though all tanks in the 211-A chemical storage area have high-level alarms, additional steps were taken to minimize overflowing a tank to the chemical sewer line. In 1986, dikes were installed around the storage tanks at the 211-A chemical storage area to contain spilled liquids. When a dike fills with liquid, the contents are sampled to make a determination concerning disposal/use of the material. If the material is nondangerous

(e.g., rainwater) and requires disposal, the solution is transferred to the chemical sewer line using a portable pump. If the material is dangerous, the 
1 solution is transferred into drums for proper disposal or used in the plant 2 processes. Before 1986, drains around the tanks and tank overflow lines went 3 to the chemical sewer line. Floor drains now have been covered with concrete and the overflow lines are rerouted to the dike area that surrounds the tank.

Demineralizers are ion-exchange resin beds that remove dissolved minerals from the sanitary (i.e., potable) water supply. A demineralizer consists of two ion-exchange resin beds. One bed is for the removal of cations (positively charged) and the other bed removes anions (negatively charged). When the beds become exhausted (i.e., breakthrough occurs), regeneration is accomplished using sulfuric acid for the cation bed and sodium hydroxide for the anion bed. During regeneration, sulfuric acid and sodium hydroxide are routed to a catch tank for elementary neutralization. The catch tank contents are sampled to ensure the solution $\mathrm{pH}$ is between 2 and 12.5. If necessary, the $\mathrm{pH}$ can be adjusted chemically to within proper tolerances before disposal into the chemical sewer.

Before the installation of the neutralization system in September 1989, regeneration of the two beds was done simultaneously (co-regeneration), starting in February 1986. Co-regeneration resulted in self-neutralization of the two regeneration streams, thus minimizing the potential for adding corrosive substances to the chemical sewer line. Simultaneous regeneration successfully decreased the amount of corrosive material discharged to the 216-B-3 Pond System. Before February 1986, the demineralizers were regenerated separately, which resulted in discharging corrosive waste to the 216-B-3 Pond System.

3.1.1.10 Flash Tank Tk-618-1. This tank is used to receive steam condensate and spray water from heating coils located in the pipe and operating gallery. The steam condensate is generated from heating the outside air supply and the spray water is used to wash and humidify the incoming air. The nondangerous effluent from Tank Tk-618-1 is routed to the chemical sewer.

3.1.1.11 Distilled Water Systems. There were two primary distilled water systems at the PUREX Plant that have now been shut down. One of the systems was used for chemical makeups associated with the final plutonium cycle. Specifications required for the final plutonium product were too restrictive to permit the use of demineralized water. The other system was for use in the PUREX Plant laboratory. Distilled water was used in the laboratory to perform sample analyses without introducing contaminants found in demineralized water.

Distilled water was produced by boiling demineralized water and collecting the condensate overhead. The condensate was routed to a distilled water holding tank until needed. Demineralized water with remaining minerals was discarded. Steam condensate generated from the production of distilled water, the residual demineralized water, and tank overflow associated with the storage of distilled water for both systems, was discharged to the chemical sewer. There was no dangerous waste associated with the production of distilled water from demineralized water.

3.1.1.12 The Tank Tk-2901A Overflow. The Tank Tk-2901A is a 50,000-gallon water tower that provides an emergency supply of sanitary (i.e., potable) water in the event of a failure at the 283-E Water Treatment Facility or a 
DOE/RL-89-28, Rev. 1

1

rupture in the 200 East Area distribution system. This tank continually overflows to the chemical sewer line. In the summer months, overflow is necessary to ensure that the tank remains full due to evaporation losses. In the winter months, overflo' is maintained to prevent the tank from freezing.

3.1.1.13 Sanitary Pipe Trench Condensate. To prevent pipes from freezing, many of the sanitary lines outside of the PUREX Plant are heated. The source of heating for these lines is steam. A steam line, usually composed of copper tubing, is attached and insulated next to the sanitary line. Condensate from these steam lines is routed to the chemical sewer line.

\subsubsection{Cooling Water Line}

The cooling water line primarily received cooling water discharges from most equipment used in the PUREX Plant process. The cooling water stream was shut down in June 1992. The cooling water or steam passed through a coil inside a piece of equipment. Unless there was a breach in the coil, the cooling water or steam never physically contacted radioactive or dangerous material; therefore, the cooling water stream usually was nonradioactive and did not contain dangerous waste.

The cooling water line received liquid from the following sources:

- Uranium concentrator (E-K4)

- Concentrator condensers

- Dissolver down-draft towers

- PUREX P1ant tunnel's water-fillable doors

- Miscellaneous process tanks.

3.1.2.1 Uranium Concentrator (E-K4). In the PUREX Plant process, solutions were concentrated to obtain the proper product concentration or to be reused as a feed stream. The concentration of these solutions was accomplished by using vessels called concentrators. A concentrator was essentially a large tank containing a steam heating coil with a tower on top. The tower was used for the following purposes:

- Strip organic material from the feed material via steam vapors to prevent a potential explosion in the concentrator

- Absorb fission products contained in the rising vapor.

Steam condensate and cooling water from the final uranium-cycle concentrator coil were routed to the cooling water line. Even though steam was commoniy used for concentration, water could be routed to the coil to check the integrity of the coil and to cool material in the concentrator for emptying by using a jet pump. 
3.1.2.2 Concentrator Condensers. In a concentrator, after the vapor stream (commoniy referred to as overheads) rises through the tower, the vapor stream passes through a condenser to be cooled. Raw water is used as the cooling medium for the condenser and is sent to the cooling water line after cooling the vapor stream. The overheads (condensate) were recycled and the excess was routed to the $216-A-45 \mathrm{Crib}$.

3.1.2.3 Dissolver Down Draft Towers. Dissolvers were used in the cladding removal (declad) and fuel dissolution, rocesses. In the declad process, Zircaloy (a metal jacket surrounding fuel) is dissolved using an ammonium fluoride/ammonium nitrate solution that resulted in the liberation and production of ammonia gas. The fuel dissolution process involved dissolving the solid fuel (uranium and plutonium). The fuel was dissolved using nitric acid, which resulted in the liberation of oxides of nitrogen. Offgases from both the declad and dissolution processes were routed through the dissolver down draft towers. Cooling water was used as the cooling medium to condense the water vapor that, in turn, absorbed the rising ammonia (during declad) or nitrous oxide (during dissolution) vapors. The cooling water was routed to the cooling water line, the ammonia condensate was routed to a receiver tank for further processing, and the dilute nitric acid was routed back to the dissolver for further participation in the dissolution process.

3.1.2.4 The PUREX Plant Tunnels' Water-Fillable Doors. Large failed equipment from the PUREX Plant was stored in the PUREX Plant tunnels. currently, there are two tunnels. The doors on the tunnels could be filled with water. The water-fillable doors served as shieliding from the dose rates of the failed equipment. Currently, neither tunnel door contains water nor are they expected to be filled in the future. However, should the water-fillable doors ever be filled, this water would be discharged into the cooling water line.

3.1.2.5 Process Tanks. Temperature control of processing tanks was important to ensure that the process was operating safely and efficiently. Cooling water, steam, or both, were used in maintaining proper tank temperatures. Unless there was a breach in a coil, the cooling water or steam did not come into physical contact with the processing solutions. Should a breach occur, the coil was pressurized so that steam or cooling water would leak into the tank. The only time that contamination could enter the coil was when the coil momentarily was depressurized when switching from cooling to heating or heating to cooling.

\subsubsection{Steam Condensate Discharge}

The steam condensate discharge primarily received cooling water and steam condensate discharges from most of the equipment that required heating during normal use in the PUREX Plant process. The steam condensate stream was shut down in June 1992. The cooling water or steam passed through a coil inside a

'Zircaloy is a trademark for alloys of zirconium with low percentages of antimony, iron, chromium, and nickel (Sax and Lewis 1987).

931119.0800 
piece of equipment. Unless there was a breach in the coil, the cooling water or steam never came into physical contact with radioactive or dangerous material; therefore, the steam condensate discharge usually was nonradioactive and did not contain dangerous waste.

Unless the steam condensate discharge stream was diverted to the 216-A-42 Diversion Basin because of high radiation or an electrical failure, the steam condensate discharge normally was discharged to the 216-A-30 Crib and the 216-A-37-2 Crib.

The steam condensate discharge consisted of steam condensate and water from the following sources:

- Concentrator coils

- Dissolver coils

- Quench water.

3.1.3.1 Concentrator Coils. All concentrators, with the exception of the final uranium-cycle concentrator, had the coil outlet routed to the steam condensate discharge. These concentrators were used for the concentration of product materials, preparation for waste treatment, recycling of materials, and feed preparation by breaking down polymer material.

3.1.3.2 Dissolver Coils. As mentioned previously, the dissolvers were used for performing the 'declad' and 'dissolution' steps. Steam coils in these tanks for supplied the necessary heat to initiate the declad and dissolution reactions.

3.1.3.3 Quench Water. In the event that a hole formed in a tube bundle, radioactive material could have entered the steam condensate discharge stream. To prevent the potential spread of radioactive material to the ground surface via manholes and the pump pit by the rising steam vapors, quench water was added immediately outside the facility to cool the stream contents. The quench water was supplied from the main raw water line to the facility.

\subsection{TANK FARM WASTE MANAGEMENT OPERATIONS}

The waste management program at the Hanford Site provides for the segregation, concentration, and solidification of liquid radioactive waste. The processing of irradiated fuel rods to recover useful materials is accompanied by the production of radioactive waste. Because some of this waste remains radioactive for decades, it must be handled, contained, and disposed of in a manner that provides optimum protection for personnel and the environment.

The Tank Farm waste management operations have several facilities that currently supply or previously have supplied effluent to the 216-B-3 Pond system. These facilities are listed below:

- 242-A Evaporator

- 244-AR vautt 
- 244-BXR Vault

- 241-BY Tank Farm

- 242-B Evaporator

- 244-CR Vault

- 241-A Aging Waste Ventilation System Complex.

Continuous effluent streams from the 242-A Evaporator, 244-AR Vault, and 241-A Aging Waste Ventilation System Complex are sampled using composite samplers. A composite sample consists of numerous small samples that are obtained automatically by the sampler during a specified time frame and stored in a small tank. This sample is a representative average of the stream discharge over a predetermined sample-interval period. At the end of a sampling-interval period, an operator obtains the composite sample for analysis. The samples are analyzed for total alpha and beta radionuclides and solution pH. Samples are not obtained from the 241-BY Tank Farm and the 244-CR Vault since these facilities are no longer operating.

The average flow rates discharged to the 216-B-3 Pond System from the various tank farm facilities, along with the composite sampling period, are provided in Table 3-3.

\subsubsection{The 242-A Evaporator}

The 242-A Evaporator is used for the concentration of low-level radioactive solutions at the Hanford Site. Feed is supplied to the evaporator from the 241-102-AW tank, the evaporator feed tank. Radioactive liquid waste that has been identified for concentration is transferred to Tank 241-102-AW. Feed is supplied from the 241-102-AW tank in the range of 90 to 140 gallons per minute.

Concentration of the feed stream results in the production of two liquid process streams. The outlet streams consist of a process condensate stream, which is condensed water vapor evaporated from the feed, and a slurry stream containing concentrated feed. Additionally, the process condensate stream contains steam condensate from the vacuum jets used to maintain the evaporator under vacuum.

Process condensate was sent through an ion-exchange column to reduce the final cesium and strontium levels. The condensate was then routed to a retention basin where it was sampled to determine if the composition was suitable for transfer to the 216-A-37-1 Crib. If the condensate was not within proper specifications, it was routed back to the 241-102-AW tank for reprocessing. Discharge to the 216-A-37-1 Crib was halted in 1989 during evaporator shutdown activities. Future process condensate discharge will be routed to the Liquid Effluent Retention Facility for temporary storage.

Steam is used to heat the feed solution contained in the reboiler $(E-A-1)$. Because the reboiler is essentially a large heat exchanger, steam never is in contact with the process material. The steam is condensed, routed to a flow-measurement tank, and monitored for radiation levels while flowing to a retention basin. If a high radiation level is detected, the stream 
automatically is diverted from the retention basin to the 241-102-AW tank. The steam condensate in the retention basin is sampled to determine total radiation levels (alpha and beta) before being sent to the 216-B-3 Pond system.

The cooling water used to condense the process condensate is routed through a radiation monitor on its way to the 216-B-3 Pond system. Because of the low potential of radionuclide contamination, there is no automatic diversion capability on this stream. Should a small leak occur in the tube bundle that separates the cooling water from the process condensate, the large pressure differential between the two streams will prevent the process condensate from contaminating the cooling water. This is because the cooling water is maintained under 30 pounds of positive pressure, while the process condensate is maintained under a vacuum. The presence of contaminated cooling water would indicate a massive failure of the condenser, and the evaporator would be shut down.

The concentrated stream (slurry) is routed to a predesignated, 1,000,000-gallon, underground, double-shell storage tank. In the underground storage tank, the slurry separates into liquid and solid phases by the settling of solids. The liquid layer eventually is transferred back to tank 102-AW for further concentration.

Additional sources of nondangerous liquid effluent to B Pond from the 242-A Evaporator are attributed to steam condensate from the standby steam turbine exhaust fan, building heating and ventilation steam condensate, building air wash water, air compressor system cooling water, and steam condensate from compressed air dryers.

The standby steam turbine exhaust fan serves as a back up to the electric exhaust fans for the potentially radioactive atmosphere portions ('hot areas') of the 242-A Evaporator. In order to prevent the spread of radionuclides from the 'hot area' of the facility to the 'cold area' (nonradioactive contaminated atmosphere), the 'hot area' of the facility is maintained at a lower pressure (vacuum conditions) than normal atmospheric conditions. Should the electric exhaust fans shut down because of failure or loss of electrical power, the standby steam turbine exhaust fan will be operated to prevent the spread of radionuclides to other portions of the facility.

In addition to establishing necessary pressure gradients to prevent the spread of radionuclides throughout the 242-A Evaporator, the heating and ventilation system is used to condition air (e.g., to remove dust, humidify, and adjust to final desired temnarature) for personnel comfort. Air initially enters the building through an inlet damper and is preheated with low-pressure steam (nominally 10 pounds per square inch) to minimize moisture accumulation in the filter. Following the heating operation, the air passes through a filter used to eliminate coarse dirt and dust particles. After filtering, the air goes into a chamber where it is humidified and washed simultaneously. Water flowing through the air washes fine dirt and dust particles from the 


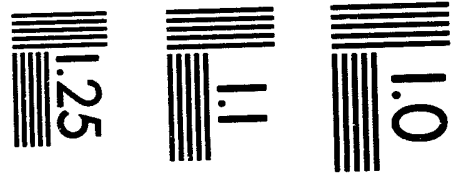

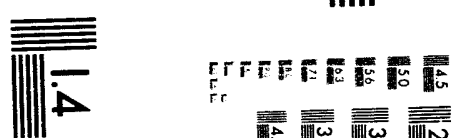

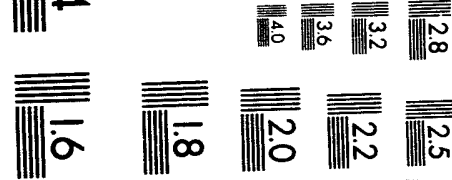



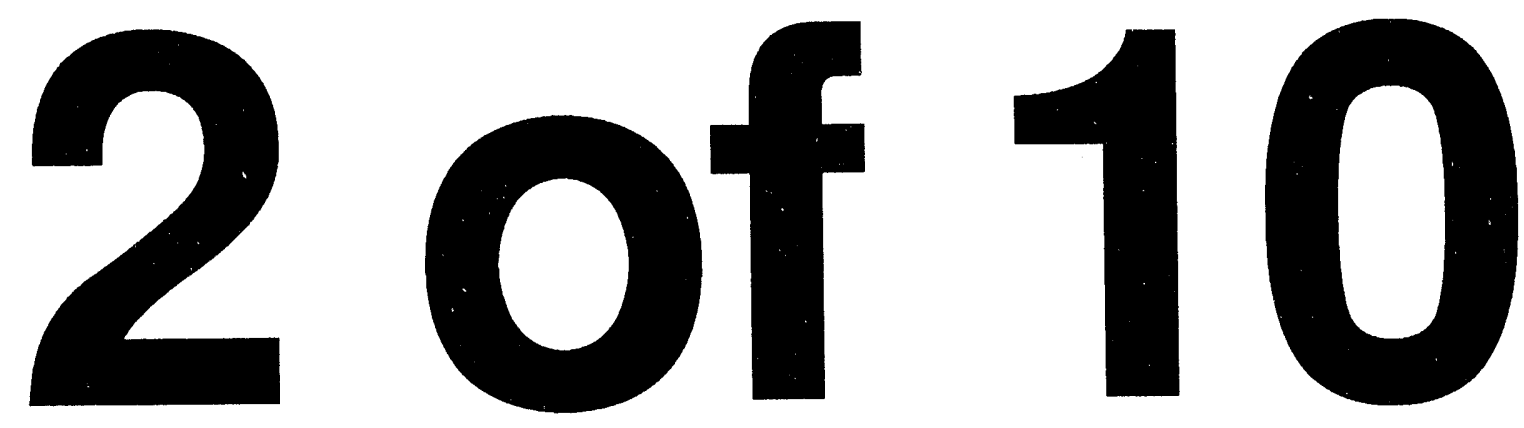
DOE/RL-89-28, Rev. 1

$12 / 15 / 93$

supplied air. Washing air with water accomplishes the simultaneous humidification. The clean and humidified air then is reheated to a desired temperature using low-pressure steam.

Condensate from steam heating and water used for air washing and humidification are routed to $B$ Pond. Because these operations are performed on ambient outside air, the resulting liquid streams should not adversely affect the composition of the liquid effluent to B Pond.

The compressed air system uses cooling water to cool the air compressors and to act as a coolant for the after-cooler. There are two air compressors in the 242-A Evaporator that operate in paralle1, each delivering 1,000 standard cubic feet per minute of air at 100 pounds per square inch-gage. The after-cooler is a heat exchanger used to remove heat from compressed air following discharge from the compressor.

After compressing and cooling the air, the air is routed through an air dryer that contains a desiccant (moisture-absorbing material). The desiccant absorbs most of the water that is contained in the compressed air. This process is similar to the process by which an ion-exchange column absorbs ions. The efficiency of moisture removal from the compressed air depends on how much moisture already has been absorbed by desiccant material. As the desiccant absorbs water, less material is available to absorb moisture.

To increase the efficiency of water removal from the air, two air dryers are installed in parallel. While one dryer is online removing water from the air supply, the other air dryer is regenerating. Regeneration involves heating the desiccant material to evaporate the water contained within the desiccant material. Steam is used as a heating source to regenerate the desiccant material through a heat exchanger.

\subsubsection{The 244-AR Vauit}

The 244-AR Vault began operation in 1969 and continued to operate through 1978. The 244-AR Vault facility was originally used to prepare radioactive waste for transfer to B Plant for removal of cesium and strontium. The radioactive waste was generated by other Hanford Site activities and was temporarily stored in underground itorage tanks before being transferred to the 244-AR Vault tanks. Currently, the 244-AR Vault is in standby with no radioactive waste operations in progress. However, to maintain the facility for future use, some operational requirements are being met. Cooling water is used to cool the compressors that supply instrument air to the facility. Additionally, cooling water and heating steam are also supplied to the ventilation system to control the temperature of the inlet air to the facility. Discharges from these systems comprise the facility's current (standby mode) waste stream. At present, no record sampling or radiation monitoring instruments are associated with this waste stream. This is because of the inactive nature of the facility, and the fact that the waste stream is discharged from a closed system that has minimal potential for contamination. 
Modifications have been undertaken in order for the 244-AR Vault to become an interim storage and transfer facility for neutralized current acid waste (NCAW). The 244-AR Vault Cooling Water Stream-Specific Report (WHC 1990a) indicates that all necessary modifications to support this usage are tentatively scheduled for completion in 1994. One important completed modification has been the installation of the closed-loop cooling system for the vault tanks. During facility operation, the waste stream will be continuously monitored and sampled at the 2904-AR Building after combining all waste streams at Manhole No. 1. A small portion of the effluent stream will be split, with part flowing to the proportional sampler and part flowing through the continuous radiation monitor. During normal operation, if radioactivity is detected, the flow is automatically diverted to a retention basin by a three-way valve and the uncontaminated water would flow to 216-B-3 Pond.

Since fiscal year 1985, upgrades have been made to 244-AR Vault systems to reduce potential radioactive discharges for facility operation. These changes are described as follows.

Cooling and heating coils have been pressurized with process air during facility standby/shutdown conditions at a pressure higher than the tank pressure to force any coil leakage toward the liquid waste and prevent contamination of the inside of the coil. A loss of process air will cause an alarm to annunciate in the control room and at the Computerized Automated Surveillance System panel to alert operators of a potential coil leak.

Floor drains in the vicinity of the Jet Gang Valves have been blanked. In the unlikely event that the jet gang valves leak or siphon, the effluents that drip to the floor would not flow to the 216-B-3 Pond. Collection and disposal of these leakages will be under administrative control (i.e., collected and disposed of according to written procedure rather than being sent to the cooling water waste stream).

The condensate from the $\mathrm{K}-1$ (operating areas) and $\mathrm{K}-2$ (canyon/process areas) inlet air systems is surveyed regularly in accordance with established procedures to ensure that the steam condensate and the cooling water are not contaminated.

The liquid effluent sampler has been upgraded to include a detector failure alarm.

Preventive maintenance and $\mathrm{plant}$ operating procedures have been implemented to ensure the integrity of the barriers that prevent contamination of the liquid effluents.

A closed-loop cooling system has been installed to replace the oncethrough vessel cooling system. To date, this closed-loop system has not been used because the facility is inactive. The once-through cooling has been retained as an emergency backup to the closed-loop cooling system. 
D0E/RL-89-28, Rev. 1

$12 / 15 / 93$

11

\subsubsection{The 244-BXR Vault}

The 244-BXR Vault is a deactivated facility that will eventually be decommissioned. This facility was used to store liquids and sludges sluiced from the single-shell tanks located at 241-B, 241-BX, and 241-BY Tank Farms before the material was transferred to 221-U Plant for uranium recovery. Cooling water used for cooling the holding tanks was routed to $B$ Pond.

\subsubsection{The 241-BY Tank Farm}

The 241-BY Tank Farm contains in-tank solidification Units 1 and 2. The units were used to concentrate liquid contained inside tanks 241-102-BY and 241-112-BY. In-tank solidification Unit 1 began operation in January 1965 and in-tank solidification Unit 2 began operation in February 1968 . The in-tank solidification units' operations ceased in July 1973.

In-tank solidification Unit 1 concentrated the contents of tank 241-102-BY using hot air. Heated air was routed inside the tank to boil off the liquid fraction. In-tank solidification Unit 2 had electric cal-rods (electric resistance heating elements) inserted in the tank. When the cal-rods were energized, the contents of tank 241-112-BY would boil. Vapor generated from the in-tank solidification units was filtered and condensed. Process condensate from in-tank solidification Unit 1 went to the 216-B-50 Crib and the process condensate from in-tank solidification Unit 2 went to the 216-B-57 Crib. Cooling water used for c00ling the process condensate stream was sent to the 216-B-3-3 Ditch and the 216-B-3 Pond.

\subsubsection{The 242-B Evaporator}

The 242-B Evaporator is a deactivated facility that eventually will be decommissioned. This facility was used to concentrate solutions primarily contained in single-shell tanks located at 241-B, 241-BX, and 241-BY Tank Farms. Cooling water used for cooling the condenser was routed to $B$ Pond.

\subsubsection{The 244-CR Vault}

The 244-CR Vault is a deactivated facility that eventually will be decommissioned. This facility was used for uranium and strontium recovery from radioactive waste in the 241-C Tank Farm. Uranium recovery required transferring the recovered solution to $U \mathrm{Pl}$ ant and strontium recovery required routing the solution to $B$ Plant.

Water used to cool the facility air compressor was discharged to the 216-B-3 Pond System. This source was terminated in 1986. 
DOE/RL-89-28, Rev. 1

$12 / 15 / 93$

\subsubsection{The 241-A Aging Waste Ventilation System Complex}

The 241-A Aging Waste Ventilation System Complex is used to perform the following activities.

- Maintain vacuums on the high-level radioactive waste storage tanks (241-AY and -AZ Tank Farms).

- Condense radioactive vapors generated from these tanks.

- Filter the tank exhaust before discharging to the environment.

As mentioned previously, high-level radioactive waste storage tanks are self-boiling. This results in the generation of large quantities of condensible, radioactive vapors.

Vapors generated from the boiling tanks are liquified in condensers E-413, -414, and -415 , using raw water as a cooling medium. Condensate is routed to a condensate holdup tank $(241-A-417)$ and sent back to a self-boiling tank in the 241-AY or -AZ Tank Farm to maintain the liquid level. The cooling water then is routed to $B$ Pond after passing through a proportional sampler and monitor.

An emergency cooling system (closed loop) exists to provide the necessary cooling water to the surface condensers in the event that the raw water supply from 241-C Farm fails or the radiation level in the exit cooling water stream exceeds a preset level on the radiation monitor. The emergency cooling system consists of a warm water sump, cooling tower, cold water sump, and a deep well pump.

The warm water sump receives cooling water after it has cooled the surface condensers. The warm water is routed to the cooling tower that cools water by using the cooling effects associated with partial evaporation of warm water (1atent heat of evaporation). The remaining cooled water is sent to the cold water sump to be reused as the cooling water supply stream for the surface condensers. The deep well pump provides makeup water to the cold water sump in order to maintain the sump volume because part of the water is lost due to evaporation occurring in the cooling tower.

Should the cold water sump overflow, liquid would be routed to the warm water sump. If the warm water sump overflows, this liquid would be routed to the proportional sampler and would be monitored with the normal cooling water supply before being sent to $B$ Pond.

\subsection{THE 283-E WATER TREATMENT FACILITY}

The 283-E Water Treatment Facility purifies and treats raw water and produces sanitary (i.e., potable) water for the 200 East Area. As mentioned previously, raw water is pumped unfiltered from the Columbia River. Raw water initially enters a reservoir near the 284-E Powerhouse where it is stored before treatment. Treating this water involves adding a coagulant (aluminum 
sulfate hydrate) that allows particulate settling to occur in the basin.

After settling, the water is routed through a filter for final purification. The filter layers consist of porcelain beads, gravel, sand, and anthracite coal.

Average effluent flow rates from this facility are not available because a flowmeter has not been installed. The 283-E Water Treatment Facility is a nonradioactive facility; thus, radiation monitoring equipment is not used on the discharge of this stream. Waste water sources to the 216-B-3 Pond System from the 283-E Water Treatment Facility include the following:

- Reservoir overflow

- Settling basin flushing

- Filter backflush water.

\subsubsection{Reservoir Overflow}

Water is pumped from the Columbia River to a reservoir located at the 283-E Water Treatment Facility. Flow into the reservoir is controlled by manually adjusting an inlet valve. Should the reservoir overfill, the water goes to the 216-B-3 Pond System via the powerhouse ditch and pipeline.

\subsubsection{Settling Basin Flushing}

There are four settling basins used to purify raw water. The basins periodically are flushed to remove the solids that accumulate in the bottom during the settling period following coagulation. The flushwater containing the solids is sent to the 216-B-3 Pond System for final disposal.

\subsubsection{Filter Backflush Water}

Water passes through a filter that removes the coarse particles first and the finer particles last. This is done to minimize plugging of the filter. The first stage of the filter is the porcelain beads, followed by gravel, sand, and anthracite coal. Anthracite coal is used for removing noxious odors present in the water.

When the filter starts to plug, water is run through the filter in the reverse direction. This dislodges the fine and coarse particulates from the filter. The backflush water containing the particulates is sent to the 216-B-3 Pond System.

\subsection{THE 284-E POWERHOUSE}

The 284-E Powerhouse is a coal-fired plant used to generate steam. Electricity normally is not generated at this facility; however, there is a standby steam-driven electrical generator at the powerhouse that provides standby power to the powerhouse and certain other facilities during power 
outages. There are five coal-fired boilers and a backup oil-fired boiler. The maximum production of steam is approximately 350,000 pounds per hour at 225 pounds per square inch.

Steam generated at this facility is used at other process facilities (i.e., B Plant, the PUREX P1 ant, and the 242-A Evaporator) for heating and process operations.

One liquid effluent stream, which goes to the 216-B-3 Pond System, is generated at the 284-E Powerhouse. Currently, a flowmeter has not been installed to monitor this flow. The 284-E Powerhouse is a nonradioactive facility; thus, radiation monitoring equipment is not used on the discharge of this stream. Sources that produce this effluent stream are as follows:

- Boiler blowdown

- Cooling water

- Floor drains

- Water softener regeneration solution.

\subsubsection{Boiler Blowdown}

During the production of steam, minerals not removed in the water softener collect in the boiler. The boiler blowdown is used to bleed off this material. The boiler blowdown also contains antiscaling and water oxygen scavenger compounds (Deartrol 4812 and Dearborn 66, respectively') that are added to the water. Antiscaling chemicals are added to minimize scale formation on the boiler tubes and to maintain efficient boiler operation. oxygen scavenger compounds are added for corrosion protection against free oxygen. The antiscaling and oxygen scavenger chemicals present in the boiler blowdown are nondangerous wastes.

\subsubsection{Cooling Water}

Cooling water is used to cool pump bearings and the faces of the boilers during boiler operation. The cooling water does not come into contact with any dangerous materials.

\subsubsection{Floor Drains}

Floor drains are located throughout the facility. Sources of liquid to the drains include safety showers, sanitary water, and steam condensate.

${ }^{1}$ Deartrol 4812 and Dearborn 66 are trademarks of W.R. Grace \& Co. 


\subsubsection{Water Softener Regeneration Solution}

Sanitary water passes through a water softener to remove calcium and magnesium contained in the water before use in the boiler. This minimizes scaling on the tube bundles. A water softener unit consists of an ion-exchange column containing an organic resin and a sodium chloride (salt) crystal holding tank. This equipment is similar to that which is found in homes, but it is constructed on a larger scale. The salt tank is used to regenerate the column. Resin in an ion-exchange column initially is loaded with sodium ions. When sanitary water passes through the resin, calcium and magnesium are preferentially extracted and the sodium ions are released. When the resin becomes saturated with calcium and magnesium ions, extraction no longer occurs. To rejuvenate the resin, a concentrated sodium chloride solution is passed through the column. Sodium ions are able to displace the calcium and magnesium ions from the resin because the equilibrium coefficient for the resin prefers sodium extraction at high sodium concentrations.

\subsection{THE B PLANT FEED STREAMS}

The B Plant has had a number of missions since its construction in 1943. Its first mission was the recovery of plutonium using a bismuth phosphate chemical separation process. The process was carried out from April 1945 to October 1952. The B Plant was shut down after REDOX and the PUREX Plant came online. The B Plant was modified to begin its second mission in 1968--the recovery, purification, and encapsulation of cesium and strontium.

Encapsulated cesium and strontium capsules currently are stored at the facility.

Discharge to the 216-B-3 Pond System from B Plant originated from three sources: $B$ Plant cooling water [including the Waste Encapsulation and Storage Facility (WESF) ${ }^{1}$, B Plant steam condensate, and B Plant chemical sewer.

The $B$ Plant cooling water is the source of some radionuclides and potential chemical contaminants in the 216-B-3 Pond System. As discussed in Chapter 4.0, Section 4.2.1, B Plant cooling water is essentially free of radioactive contamination. The $B$ Plant cooling water also includes cooling water discharged from heat exchangers at the WESF. The cooling water discharged from the WESF does noi come into direct contact with the stored cesium and strontium capsules, but is circulated through heat exchangers, cooling the pool cell water.

Pool cell water, which is used to cool the cesium and strontium capsules, normally is disposed of by an alternate method. Currently, B Plant cooling water and the B Plant chemical sewer are discharged to the 216-B-3 Pond system. The average flow rate of $B$ Plant cooling water is about 1,500 to 1,800 gallons per minute.

'Waste Encapsulation Storage Facility cooling water mixes with B Plant cooling water (from 1974 to present). 
The B Plant steam condensate was discharged to the 216-B-3 Pond between 1945 and 1967. The steam condensate was sent to the 216-B-55 Crib from 1967 to 1990. The steam condensate stream consisted of cooling water from the 200 East Area line, steam condensate from the E-23-3 concentrator, and discharge from cooling coils in process tanks (tanks Tk 28-4, Tk 31-1, and Tk 31-6).

Starting in 1945, the B Plant chemical sewer was discharged to the 216-B-3 Pond. The chemical sewer was diverted to the 216-B-63 Trench on May 7,1970 , after a radionuclide release that occurred because of an equipment failure (Chapter 4.0, Section 4.2.2.). In February 1992, the chemical sewer was combined with the $B$ Plant cooling water and discharged to the 216-B-3 Pond.

The major contributors to the chemical sewer are the 2902-B High Tank [which contains potable (i.e., sanitary) water], cooling water from B Plant and WESF air compressor after-coolers, and some 221-B steam condensate. The chemical sewer also receives minor contributions from air conditioning units and space heaters (radiators). The chemical sewer has an average flow rate of approximately 150 gallons per minute.

According to B Plant emergency procedures, if B Plant cooling water becomes radioactively contaminated, it would be diverted away from the 216-B-3 Pond System to the 216-B-59 Retention Basin. If contamination reaches the 207-B diversion facility, the cooling water could be diverted to the 216-B-63 Trench. In addition, the chemical sewer would be diverted to the 216-B-63 Trench.

\subsubsection{The B Plant Cooling Water}

The B Plant cooling water comes from the 200 East Area raw water 1 ine and is passed through cooling coils in the plant process tanks and vessels. The cooling water is discharged from the plant as two separate streams. Each stream is monitored continuously for compliance with radiological standards.

The first stream is collected in a 24 -inch header and receives discharge from those processing vessels that are considered to have a low potential for possible contact with radioactive solutions. Should one of these vessels leak, the effect on the environment would be minimal. Feed for this stream includes several processing condensers, B Plant steam condensate condenser, effluent from the 212-B cask station, and all cooling water from the 225-B encapsulation facility pool cell heat exchangers.

The first stream is monitored continuously for radioactivity using separate beta and gamma monitors. Signals from the monitor transmitter are received in the dispatcher's office by the Facility Process Monitoring Control System. The system sounds an alarm if high radiation is detected. In the event that high radiation levels are detected, the first stream can be diverted manually to the 216-B-63 Ditch. 
DOE/RL-89-28, Rev. 1 $12 / 15 / 93$

The second stream receives feed primarily from cooling coils on process tanks in $\mathrm{B} P$ Plant.

The second stream is continuously monitored for radiation (beta, gamma) activity. The stream is diverted automatically to the 216-B-59 Retention Basin if found to exceed radiological control limits. As with the first stream, signals from the monitor transmitter are received in the dispatcher's office. If the second stream meets requirements for discharge to the environment, it is combined with the first stream.

The combined stream is sampled continuously on a flow proportional basis before entering one of two 565,000-gallon basins (207-B facility), and the aliquot is deposited into a five-gallon holding tank. The contents of the holding tank are agitated weekly and a sufficient volume of sample is withdrawn to provide weekly analytical determinations for process control (pH, total beta, total alpha, and individual isotopes, if necessary). A separate volume of sample also is withdrawn weekly and samples collected are combined for a monthly composite. Analyses are performed by the 222-S Laboratory. Reported results become the 'record' data for the combined stream.

From the 207-B facility, the water flows to the 216-B-3-3 Ditch leading to the 216-B-3 Pond System. Water exceeding requirements could be diverted to the 216-B-63 Trench or otherwise returned to B Plant.

\subsubsection{The B Plant Process Condensate Stream}

The $B$ Plant Process Condensate (BCP) liquid effluent stream is generated only during operation of the $B P$ Plant low-level waste concentrator. The $B C P$ consists of condensed water evaporated from low-level radioactive liquid waste by the $\mathrm{B} P \mathrm{Plant}$ concentrator. The major operating systems contributing to the $B C P$ liquid effluent stream from the B Plant Facility are the systems for ventilating process vessels, and the building heating, ventilating, and air conditioning (HVAC) unit.

The $B C P$ is currently inactive, as is the $B$ Plant low-level waste concentrator. In the future, the $B C P$ is to be connected to the Combined Cooling Water Header and ultimately discharged to B Pond if a 216 Permit is obtained.

The low-level waste concentrator $(E-23-3)$ is a single-pass shell and tube heat exchanger with liquid waste on the tube side and saturated steam, flowing counter-currently, on the shell side. The heat, supplied by steam, raises the liquid waste feed from its initial temperature to the boiling temperature and vaporizes the solvent (water). As a result of the concentration process in the low-level waste concentrator, three waste streams are generated and routed outside of B Plant. They are the high-level liquid waste (HLW), BCP, and the $B$ Plant Steam Condensate (BCS). The HLW is disposed of to underground storage in the 200 Area Tank Farms. Routing of the BCS is discussed in Section 3.5.3. 
The process condensate from the low-level waste concentrator (the BCP) passes through the D-23-2 de-entrainment vessel and the demineralized watercooled E-23-4 condenser. The $B C P$ is drained to one of two holding tanks in the 221-BF via the BCP tank in the 221-BB Building. The BCP is produced at a rate of about 35 gallons per minute, or about 100,800 gallons per month. The flow rate of the $B C P$ averages about 2.33 gallons per month for a typical month's operation.

The BCP liquid effluent stream has the potential for becoming radiologically contaminated. To protect against release of radiologically contaminated condensate to the BCP liquid effluent stream, the process condensate is collected in one of the two 13,000-gallon holding tanks in 221-BF, sampled, and retained until sample analysis has been completed. If not contaminated, the $B C P$ is routed to the 24-inch-diameter $B$ Plant Cooling Water Header and on to the 216-B-3 Pond. If radiologically contaminated, the $B C P$ is routed to tank TK-24-1 in the 221-B Building for re-processing through the low-level radioactive liquid waste system or routed to the 200 East Tank Farms.

\subsubsection{The B Plant Steam Condensate}

Steam is supplied as a heat source to B Plant by the 284-E Powerhouse. The steam is routed through heating coils (primarily heat exchangers and evaporators) and collected in a header in the 221-B Building. The B Plant steam condensate was discharged to the 216-B-3 Pond between 1945 and 1967. The steam condensate is currently inactive.

Monitoring practices for the steam condensate system are discussed below. Though the system was designed to prevent the steam from contacting radioactively contaminated surfaces, it did have a potential for radiological contamination because of the possible failure of sealing gaskets or heat exchanger tubes.

To prevent radiologically contaminated discharges, the steam condensate was monitored constantly for gamma and beta activity. The flow was collected in a header in the 221-B building. If the steam condensate stream did not meet requirements, the flow was diverted automatically to the 216-B-64 Retention Basin or manually diverted to a 225-gallon tank that triggered an alarm in the B Plant dispatcher's office. Discharges of B Plant steam condensate not meeting requirements were recycled to $B$ Plant and treated before being sent to double-shell storage tanks.

The steam condensate stream was sampled continuously by a proportional sampler or at an approved frequency if the sampler was inoperative. The sample was analyzed daily for $\mathrm{pH}$, alpha, and beta concentrations.

The steam condensate will be collected in the 216-B-64 Retention Basin when the waste concentrator becomes operational. The stream will be sampled at the basin and batch discharged to the cooling water stream. If it does not meet discharge criteria, it will be routed back to B Plant for disposal to the 200 Area Tank Farms. 
DOE/RL-89-23, Rev. 1

$12 / 15 / 93$

\subsubsection{Chemical Sewer}

From 1945 to 1970 , contributors to B Plant chemical sewer generally included used steam and water from space heaters, tank heaters and air conditioning units, overflow from chemical tanks, and nonradioactive solutions used in housekeeping procedures. Overflow from aqueous makeup and scale chemical tanks was prevented by using tank-level monitors at the time the chemical sewer was discharged to the 216-B-3 Pond. The tank-level monitors for the aqueous makeup tanks also sounded an alarm to alert operators to high in-tank levels ( 80 percent capacity). Similarly, loss of chemical through aqueous makeup tank/coil leakage was prevented by a low-tank-level al arm that alerted operators when the tank dropped below 30 percent capacity. At this time, the chemical sewer was discharged to the 216-B-3 Pond and the stream was monitored for radiation using a sodium iodide counter. Sampling occurred in the 2904-EA sample facility, which was about 500 feet north of the 221-B Building.

A time-proportional sampler was used to gather samples for laboratory analysis. The sampler took a sample every six minutes and deposited the sample in a holding tank. Each week, five samples were removed from the holding tank and analyzed for chemical composition, $\mathrm{pH}$, and total beta. Two samples were analyzed weekly for radiological characteristics. A separate sample was taken weekly and surveyed with a sodium iodide counter. The samples were gathered manually if the proportional sampler was inoperative.

In February 1992, the chemical sewer was joined to the cooling water stream. The combined stream is discharged to the 216-B-3 Pond. The chemical sewer is monitored in the 211-BA neutralization facility for pH, total beta, and total gamma. Sampling is performed using the B Plant cooling water sampling system. The 211-BA neutralization facility began operation in February 1992. The facility can neutralize up to 200 gallons per minute to a range between a $\mathrm{pH}$ of 5 and 9 . The facility was built to eliminate $\mathrm{pH}$ discharges greater than 12.5 or less than 2 from reaching the environment.

The B Plant chemical sewer consists of the following:

- 221-B Drain System

- 271-B Drain System

- 211-B Tank Storage Area

- 217-B Demineralized Water Unit Building Drains

- 276-B Organic Makeup Building Drains

- 225-B Encapsulation Facility

- 212-B Cask Station

- 2902-B High Tank Overflow Drains

- 222-B Laboratory

- 224-B Facility

- 292-B Facility

- TK-900

- Five street and yard drains.

3.5.4.1 The 221-B Drain System. Drains from the 221-B building are discharged into a 6 -inch stainless-steel header in the $B$ Plant electrical 
1 gallery. Flow is controlled by a three-way valve that normally diverts the effluent into a chemical sewer collection tank (Tk-900). Contents of Tk-900 are held until laboratory analysis of sample results confirm that the contents can be released as a batch to the chemical sewer. If the contents of tank Tk-900 do not meet requirements, the contents are diverted to tank Tk-10-1.

The chemical sewer stream is monitored continuously for radiation by a gamma monitor located upstream from the diversion valve on the 6 -inch stainless-steel header. If the monitor detects high activity, the stream automatically is diverted to tank Tk-10-1 in B Plant.

Contributors to the 221-B drain system include floor drains and overflow from aqueous makeup tanks located in the operating gallery. The floor drains located throughout the operating and pipe galleries collect water from safety showers and other nonradioactive liquids used in housekeeping operations. These floor drains are connected to a 3 -inch drain pipe that discharges into the 6-inch header in the electrical gallery.

Tanks in the aqueous makeup area contain various chemicals and are equipped with an overflow drainage system. Currently, acid-base overflow from the aqueous makeup tanks in the operating gallery is neutralized before being discharged into the chemical sewer. After neutralization, the overflow is discharged via a 3-inch pipe and collected in the same 6-inch header as the floor drains. In addition, neutralization is also carried out in the 211-BA Neutralization Facility.

The electrical gallery has a sump for each of its 18 sections. Each sump collects water and other nonradioactive liquids used in housekeeping operations. Each sump has a liquid detector that sounds in the dispatcher's office. If the possibility that high radioactive liquids are present in these sumps, their contents are remotely diverted in the 6 -inch stainless steel header to tank Tk-10-1.

3.5.4.2 The 271-B Drain System. The effluent from 271-B that flows to the chemical sewer includes all cooling water from ventilation systems in the 271-B Building, waste water from all sink and floor drains, and waste water from heating and cooling coils in the aqueous makeup tanks. The system consists of a sump located in the southwest corner of the millwright's shop in 271-B and a 3-horsepower pump that directs the drain effluent to the chemical sewer via a 6 -inch clay pipe. The 271-B area currently is used as a welding, instrument, and machine shop.

This sump also collects effluent from the HVAC unit. This unit discharges water from the air washer unit during summer operations and steam condensate via a condensate tank during winter operations. The condensate tank also receives condensate from the 271-B heating system (radiators) and from the hot-water (sanitary water) tank heating coil. Heating and cooling coils from the aqueous makeup tanks, TK-101 and TK-102, discharge water and steam condensate via the floor drain. The largest contributor to the chemical sewer is cooling water from air compressors located in the 271-B basement. 
3.5.4.3 The 211-B Tank Storage Area. The only contributor to the chemical sewer from the 211-B Tank Storage Area is steam condensate from heating coils for the demineralized water tanks.

\begin{abstract}
3.5.4.4 The 217-B Demineralized Water Unit Building Drains. This inactive facility used ion-exchange resin beds to remove minerals from potable (i.e., sanitary) water before June 1993. The demineralized water unit building drain system consisted of three sumps that collected effluent from tank drains and overflow lines. These drains, along with a steam condensate line, went to the chemical sewer via an 8-inch steel pipe.
\end{abstract}

Approximately two to four times a year, the ion-exchange resin beds were regenerated by flushing the beds with dilute sulfuric acid and sodium hydroxide. During the pre-1970 period when the chemical sewer was discharged to the 216-B-3 Pond System, these effluents were not neutralized before being discharged to the chemical sewer. This resulted in a discharge of up to 6 percent sulfuric acid and 4 percent sodium hydroxide into the chemical sewer. Currently, these effluents are buffered to a pH between 2 and 12 , using sodium bicarbonate and monosodium phosphate solutions.
3.5.4.5 The 276-B Organic Makeup Building Drains. The organic makeup building drain system consists of several floor drains that collected and delivered overflow from three tanks in the facility. During the pre-1970 period when the chemical sewer was discharged to the 216-B-3 Pond, these three tanks contained normal paraffin hydrocarbons, tributylphosphate, and Di(2-ethylhexy1)phosphoric acid. These tanks have been out of service since 1990 but are still in operable condition. The 276-B space heater still discharges steam condensate to the chemical sewer.

\title{
3.5.4.6 The 225-B Encapsulation Facility. The encapsulation facility drain
} system consists of the 225-B Chemical Drain System, the truck port drains, and the aqueous makeup floor drains. The chemical and truck port drains currently are capped off to prevent release via these drains. The aqueous makeup drains provide a route for chemical makeup tank overflow, tank cooling water, and tank heater condensate to reach the chemical sewer.
3.5.4.7 The 212-B Cask Station. The 212-B Cask Station is a staging area used to receive liquids in casks with various radionuclide concentrations. The cask station drain system consists of a 2-inch floor drain pipe that exits the building and traverses the electrical gallery of 221-B discharging to the chemical sewer. Currently, two tanks are serviced by this drainage system. In most cases, these tanks contained water used to flush casks, and on rare occasions, these tanks may have contained weak acid or weak base solutions.

3.5.4.8 The 2902-B High Tank Overflow Drains. The 2902-B Water Tank contains potable water overflow. The water tank contributes approximately 15 gallons per minute of water to the chemical sewer flow.

3.5.4.9 The 222-B Laboratory. The laboratory facilities in this building were dismantled and converted into offices. The laboratory discontinued operation in the 1950's and it is not known what discharges may have occurred 
from this facility. All floor drains currently are plugged and discharge to the chemical sewer is limited to water from an air conditioning unit and radiators.

3.5.4.10 The 224-B Facility. The processing facilities in the 224-B building were dismantled and converted into offices. All floor drains currently are plugged, and discharge to the chemical sewer is limited to water from an air conditioning unit and radiators. A survey of historical data indicates that the 224-B Facility was involved in the recovery of nonradioactive by-products during the plutonium recovery mission (1945 to 1952). Documentation of any chemical releases from this facility could not be located.

3.5.4.11 292-B Facility. Floor drains from the 292-B air sampler building are routed to the chemical sewer.

3.5.4.12 TK-900. Tank TK-900 is a collection tank for effluent from the 6 -inch stainless steel header in the 221-B Electric Gallery. Once the tank is filled, the tank effluent is sampled. If the sample results are within established $\mathrm{pH}$, total alpha, and total beta limits, the tank effluent is discharged to the chemical sewer. If these limits are exceeded, the tank effluent is sent to tank farms for disposal.

3.5.4.13 Five Street and Yard Drains. The five yard and street drains collect storm water runoff from around $B$ Plant and route to the chemical sewer. 


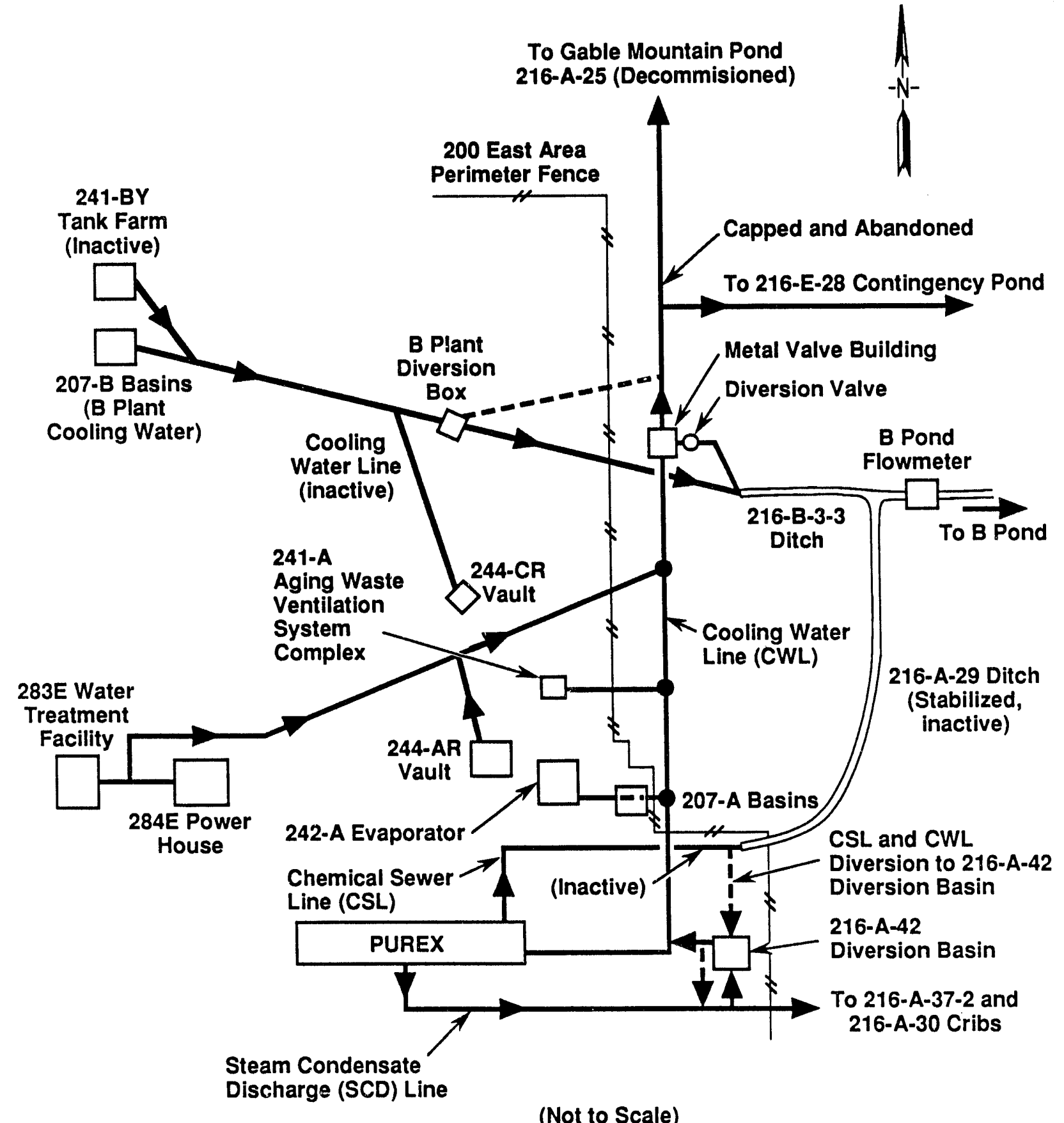

H9311021.1

Figure 3-1. Flow Routes to B Pond. 
2$$
3
$$$$
4
$$$$
5
$$

$$
6
$$$$
8
$$$$
9
$$$$
10
$$$$
11
$$$$
12
$$$$
13
$$$$
14
$$$$
15
$$$$
16
$$$$
17
$$$$
18
$$$$
19
$$$$
20
$$$$
21
$$$$
22
$$

Table 3-1. Summary of Discharge Sources for the 216-B-3 Pond. (sheet 1 of 2)

\begin{tabular}{|c|c|c|c|}
\hline Waste water source & $\begin{array}{c}\text { Transport routes } \\
A\end{array}$ & $\begin{array}{l}\text { Dates source } \\
\text { reported active } \\
\text { (month/year) }\end{array}$ & $\begin{array}{l}\text { Currently } \\
\text { active }\end{array}$ \\
\hline
\end{tabular}

\section{B Plant:}

Process cooling water

Steam conciensate

Chemical sewer

$\begin{array}{lll}x & x & x \\ x & x & \\ x & x & x\end{array}$

$4 / 45$ to present

$x$

$4 / 45$ to $9 / 67$

$4 / 45$ to $5 / 70$,

$2 / 92$ to present

$x$

1974 to 1978

WESF

284-E Powerhouse:

Liquid effluent ${ }^{c}$

$x \quad x \quad x$

$4 / 45$ to present

$x$

283-E Water Treatment Facility:

Filter backwash

$x \quad x$

4/45 to present

$x$

242-B Evaporator:

Cooling Water

$x$

$12 / 51$ to $10 / 54$

244-CR Vau7t:

Cooling water

$x \quad x$

$3 / 52$ to late 1983

PUREX PIant:

Chemical sewer

Acid fractionator condensate

Process cooling water

$x \quad x \quad x$

$\times \quad X \quad 11 / 55$ to present

$x \quad 2 / 58$ to $9 / 86$

244-BXR Vault:

Cooling Water

$x$

$7 / 52$ to $7 / 57$ 
3

4

5
Table 3-1. Summary of Discharge Sources for 216-B-3 Pond. (sheet 2 of 2)

\begin{tabular}{|c|c|c|c|c|}
\hline Waste water source & $\begin{array}{c}\text { Transport } \\
\text { A }\end{array}$ & ${ }_{C}^{\text {routes }}{ }^{a}$ & $\begin{array}{l}\text { Dates source } \\
\text { reported active } \\
\text { (month/year) }\end{array}$ & $\begin{array}{l}\text { Currently } \\
\text { active }\end{array}$ \\
\hline \multicolumn{5}{|l|}{ 241-BY Tank Farm: } \\
\hline $\begin{array}{l}\text { ITS Unit } 1 \text { cooling water } \\
\text { ITS Unit } 2 \text { cooling water }\end{array}$ & $\begin{array}{l}x \\
x\end{array}$ & $\begin{array}{l}x \\
x\end{array}$ & $\begin{array}{l}1 / 65 \text { to } 7 / 73 \\
2 / 68 \text { to } 7 / 73\end{array}$ & \\
\hline \multicolumn{5}{|l|}{ 244-P,R Vault: } \\
\hline Liquid effluent ${ }^{c}$ & $x$ & $x$ & $1 / 69$ to present & $x$ \\
\hline \multicolumn{5}{|c|}{$\begin{array}{l}\text { 241-A Aging Waste Ventilation } \\
\text { System Complex: }\end{array}$} \\
\hline Cooling water & & $x$ & $1 / 71$ to present & $x$ \\
\hline \multicolumn{5}{|l|}{ 242-A Evaporator } \\
\hline $\begin{array}{l}\text { Cooling water } \\
\text { Steam condensate }\end{array}$ & & $\begin{array}{l}x \\
x\end{array}$ & $\begin{array}{l}3 / 77 \text { to present } \\
3 / 77 \text { to present }\end{array}$ & $\begin{array}{l}x \\
x\end{array}$ \\
\hline
\end{tabular}

${ }^{a}$ Transport routes from diversion box:

$A=216-B-3-1$ Ditch (active $4 / 45$ to $7 / 64$ )

$B=216-B-3-2$ Ditch (active $7 / 64$ to $9 / 70$ )

$C=216-B-3-3$ Ditch (active $9 / 70$ to present)

$D=216-A-29$ Ditch (active $11 / 55$ to $7 / 91$ ).

Waste Encapsulation Storage Facility.

consists primarily of cooling water.

"Part of the chemical sewer discharge.

eIn-tank solidification. 
Table 3-2. PUREX Plant Flow Rates.

\begin{tabular}{|c|c|c|c|}
\hline & $\begin{array}{c}\text { Operating } \\
\text { (gallons per minute) }\end{array}$ & $\begin{array}{l}\text { Shu } \\
\text { (gallons }\end{array}$ & $\begin{array}{l}\text { down } \\
\text { jer minute) }\end{array}$ \\
\hline Chemical sewer & 1,100 & 300 & $\begin{array}{l}\text { typical; } \\
\text { (600 TPA limit } \\
\text { for max/min } \\
\text { average) }\end{array}$ \\
\hline $\begin{array}{l}\text { Cooling water } \\
\text { Steam condensate }\end{array}$ & $\begin{array}{r}9,100 \\
600 \\
\end{array}$ & $\begin{array}{l}0 \\
0 \\
\end{array}$ & \\
\hline Total & 10,800 & 300 & \\
\hline
\end{tabular}




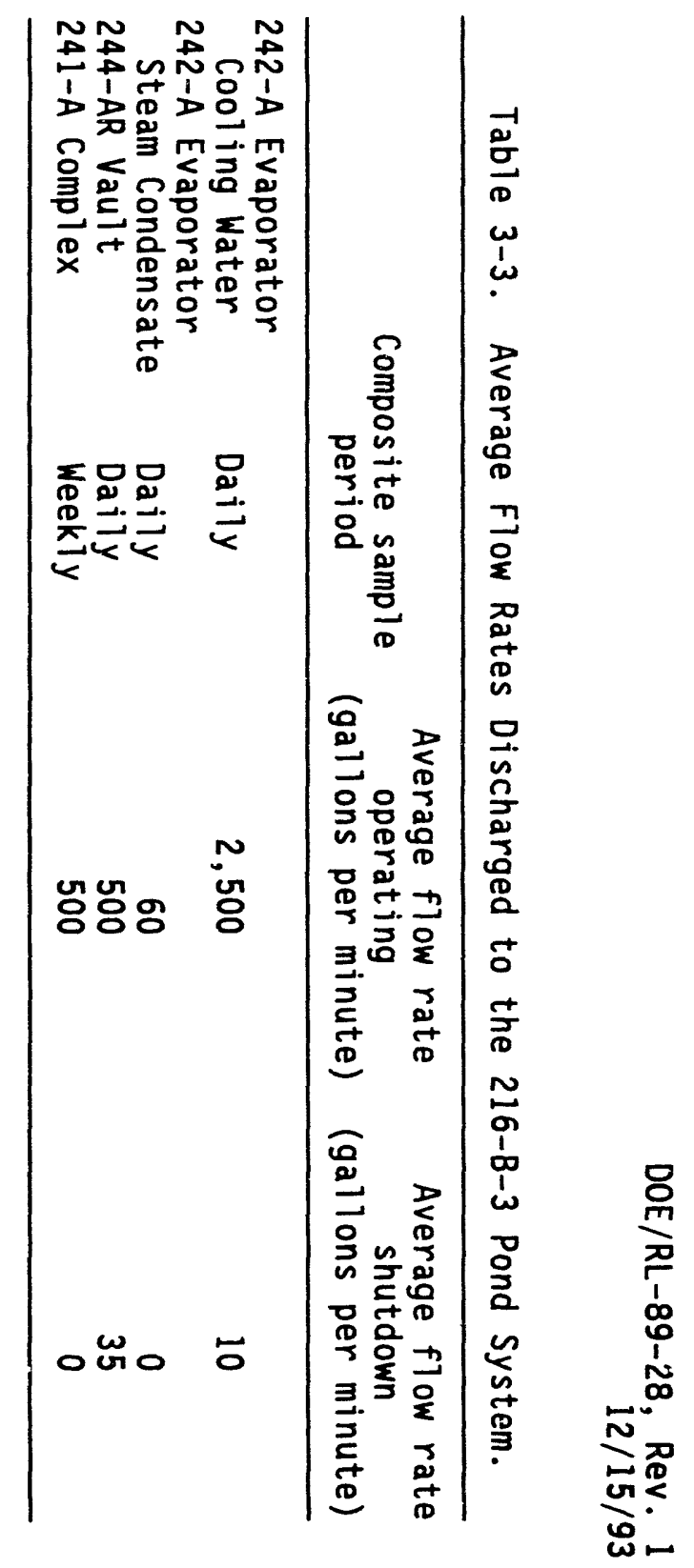


DOE/RL-89-28, Rev. 1

$12 / 15 / 93$

1

2

3

4

5

6

\section{CONTENTS}

4.0 WASTE CHARACTERISTICS ................... 4-1

4.1 THE PUREX PLANT . . . . . . . . . . . . . . 4-3

4.1.1 The PUREX Plant Chemical Sewer .......... 4-4

4.1.2 The PUREX Plant Steam Condensate.......... 4-5

4.1 .3 The PUREX Plant Cooling Water ......... 4-6

4.2 THE B PLANT . . . . . . . . . . . . . . . . 4-6

4.2.1 Process cooling water .......... 4-6

4.2.2 The B Plant Chemical Sewer ........... 4-7

4.2.3 The B Plant Steam Condensate.......... 4-8

4.3 TANK FARM WASTE MANAGEMENT OPERATIONS . . . . . . . . . . 4-8

4.4 THE 283-E WATER TREATMENT FACILITY AND 284-E POWERHOUSE . . . . 4-8 


\section{TABLES}

4-1. The 216-B-3 Pond Cumulative, Decayed Radionuclide Inventory . . . . 4T-1

4-2. Chemicals Used at the PUREX Plant ... . . . . . . . . . . . . . 4T-2

4-3. Releases into The PUREX Plant Chemical Sewer Line..... . . . . . 4T-3

4-4. Activity Percentage of Radionuclides from the PUREX Plant F-15 Tank Leak . . . . . . . . . . . . . . . . . . . . . . . 4T-4

4-5. Potential Contaminants in the B Plant Chemical Sewer . . . . . 4T-5

4-6. Chemicals Used in Treatment/Decontamination Following the 1970 Release .. . . . . . . . . . . . . . . . . 4T-6

4-7. Estimated Radionuclides Released to the 216-B-3 Pond March 22, 1970 . . . . . . . . . . . . . . . . . . . . . . . . 4T-7

4-8. Chemicals Used at the B Plant and the Waste Encapsulation Storage Facility .. . . . . . . . . . . . . . . . 4T-8 
DOE/RL-89-28, Rev. 1

$12 / 15 / 93$

\subsection{WASTE CHARACTERISTICS}

This chapter describes the characteristics of waste water discharged to the 216-B-3 Pond System. The 216-B-3 Pond System has received liquid mixed waste from various facilities operating in the 200 East Area. Administrative and physical controls have been implemented since 1984 to eliminate any potential to discharge dangerous waste to the 216-B-3 Pond System.

The 216-B-3 Pond System currently receives the majority of its waste water from the PUREX Plant and the 221-B Plant (B Plant). Specifically, the largest contributing streams are B Plant cooling water, B Plant chemical sewer, and PUREX PIant chemical sewer. Additional routine sources of effluent to the 216-B-3 Pond System are from the 242-A Evaporator, 244-AR Vault, 241-A Aging Waste Ventilation System Complex, 283-E Water Treatment Facility, and 284-E Powerhouse. Other waste streams may be discharged to the 216-B-3 Pond System in the future.

Historically, B Plant steam condensate discharge, 242-B Evaporator, 244-BXR Vault, 241-BY Tank Farm, and 244-CR Vault waste water discharges were routed to the 216-B-3 Pond. Additionally, the 216-B-3 Pond System has received waste water from several miscellaneous sources e.g., purge water from groundwater well development, miscellaneous construction activities, and operational discharges from temporary sources such as new tank farm and grout vault hydrotests.

Effluents entering the 216-B-3 Pond System consist primarily of atmospheric condensate, cooling water, sanitary (potable) water, and steam condensate. Cooling water is unfiltered Columbia River water that is supplied to the 200 East Area raw water distribution lines. Pumps at the 283-E Water Treatment Facility boost water pressures to adequate levels for facility operations and needs. Sanitary (i.e., potable) water consists of treated and filtered Columbia River water that is suitable for human consumption. The 284-E Powerhouse generates steam that enters the 200 East Area distribution system. Water used to produce steam consists of sanitary water that has been processed through a water softener and chemically treated to control corrosion rates and scale buildup.

The cooling water stream consists primarily of raw water used in cooling process equipment; however, it al so receives some steam condensate from selected pieces of equipment. The steam condensate stream consists primarily of condensate from steam supplied to heat process equipment; however, it also receives some raw water used in cooling selected pieces of equipment.

Cooling water and steam condensate discharged to the 216-B-3 Pond System have the potential to become radioactive if there is a breach in the tubes separating the cooling water or steam from the process solutions. The waste streams that could potentially become radioactively contaminated have always been monitored for radionuclide content. These streams are monitored for radiation to automatically divert the stream to a basin when a predetermined radiation level is reached, to alert personnel that alternate cooling routes 
need to be valved in, or to shutdown the process. This includes all the facility waste streams listed previously with the exception of the 283-E Water Treatment Facility and 284-E Powerhouse. These two waste streams do not have the potential to become radioactively contaminated as they do not process radioactive materials.

A number of documents exist on both radiological and nonradiological constituents in the waste streams that discharge to the 216-B-3 Pond System. These include annual reports of radioactive liquid wastes discharged to the ground (Aldrich 1987; Cooney et al. 1988; and Thomas and Cooney 1989), a report evaluating dangerous characteristics of liquid discharges to the ground (Jungflesch 1988), and a recent report (Waste Stream Characterization Report, WHC-EP-0287, WHC 1989) that consolidates the information provided in these other documents.

The annual reports of radioactive liquid wastes discharged to the ground provide an estimate of the annual and cumulative radionuclide inventory discharged to the soil column. Table 4-1 provide an estimate of the cumulative decayed inventory of radionuclides discharged to the 216-8-3 Pond through 1987 (Cooney and Thomas 1989, pg D-4, WHC-EP-0414-1). The later reports, such as WHC-EP-0141-1, al so provide estimates of the radionuclide contribution of each individual waste stream, and provides information on the quantities of airborne and liquid waste discharges of dangerous and radioactive materials.

The individual liquid-waste stream estimates are derived from samples of liquid effluents collected over a month's time, which are composited, and then analyzed for gross alpha and gross beta radioactivity, as well as for specific radioactive parameters. These monthly estimates then are used to derive the annual estimate of radionuclide contribution from that waste stream. In many cases, monthly liquid sample results are below the lower limit of detection. However, the values at the lower limit of detection are included in the calculation for annual average and annual activity values to avoid underestimating the actual concentration and annual activity. The monthly radioactive sample information for 1976 through 1988 has been consolidated in WHC-EP-0287 (WHC 1989). The radioactive waste discharge history before 1976 also is provided in WHC-EP-0287, Volume 3, pp. All-39 (WHC 1989).

The Waste Stream Characterization Report, WHC-EP-0287 (WHC 1989), provides information on chemical characteristics of 33 waste streams that are discharged to the soil column at the Hanford Site. The report was compiled as part of a study that was undertaken by the DOE, at the request of Ecology and EPA, to document the history and characteristics of liquid discharges at the Hanford Site. This study is described in WHC-EP-0367, Rev. 0, Liquid Effluent Study Final Project Report (WHC 1990).

This study, undertaken to characterize the 33 waste streams discharged to the soil column at the Hanford Site, provided the data necessary to determine if any of the 33 liquid effluent streams were a dangerous waste according to WAC 173-303-070(4). An application for certification of this proposed designation was submitted to Ecology in accordance with WAC 173-303-075. 
Of all the waste streams that have discharged to the 216-B-3 Pond System, $B$ Plant and PUREX Plant chemical sewers were the most likely to contain dangerous wastes. Administrative and physical controls have been instituted to eliminate dangerous waste discharges from these two waste streams. In addition, the WHC-EP-0367 report proposed that all streams discharging to the $B$ Pond, including B Plant and PUREX sewers, be classified as nondangerous.

The following sections discuss the chemical and some of the radionuclide releases to the 216-B-3 Pond. Very little data are available concerning chemical releases before the late 1980 's because this type of information routinely was not maintained or reported before the determination was made that RCRA regulations applied to nuclear facilities (subject to the Atomic Energy Act of 1954, as amended). However, a fairly complete chemical discharge history has been compiled for the PUREX Plant chemical sewer since restart in 1983. The contribution of radionuclides to the 216-B-3 Pond from the plant waste streams is included in Table 4-1. The text also discusses some of the larger well-documented radionuclide releases to 216-B-3 Pond System that resulted from equipment failure.

\subsection{THE PUREX PLANT}

The PUREX Plant began processing irradiated nuclear fuel in 1956 . Since that time, a variety of fuels have been processed. To meet the diversity of the fuel processing campaigns, a variety of chemicals have been used. Table 4-2 lists the chemicals that have been used at the PUREX Plant since 1955. The PUREX Plant laboratory chemicals have been excluded because there is no disposal pathway from the laboratory to the 216-B-3 Pond System. Because there is very little documentation during the years 1981 to 1983 , and virtually no documentation before 1981, it is impossible to ascertain which chemicals on Table 4-2 could have been discharged to the 216-B-3 Pond System. Most of Table 4-2 is derived from the Inventory of Chemicals used at Hanford Site Production Plants and Support Operations (1944-1980) (Klem 1988a, pg. 15 and 17).

Currently, the 216-B-3 Pond System receives the PUREX Plant waste water discharges from the PUREX Plant chemical sewer. The probability of a chemical spill reaching the PUREX chemical sewer has been greatly reduced by PUREX shutdown activities such as the removal of most bulk chemicals.

Since approximately 1984, administrative and physical controls have been successfully implemented to eliminate dangerous waste discharges to the 216-B-3 Pond System from the PUREX Plant chemical sewer, with the last known reportable chemical discharge occurring in April 1987. 
DOE/RL-89-28, Rev. 1

$12 / 15 / 93$

\subsubsection{The PUREX Plant Chemical Sewer}

This section deals with the known chemical and radioactive discharges from the PUREX PIant to the 216-B-3 Pond System. Historically, for chemicals to reach the 216-B-3 Pond System via the chemical sewer, there were several mechanisms:

- Overflow of condensate from the acid fractionator

- Effluent discharges from regenerating the demineralizers

- Disposal of out-of-tolerance chemical makeups

- Accidental spills.

Before 1986, the acid fractionator condensate occasionally would overflow from tank 48 to the PUREX Plant chemical sewer. Based on process knowledge, the condensate would have been slightly acidic $(0.005 \mathrm{molar})$. The calculated $\mathrm{pH}(\mathrm{pH}=2.30)$ would not have caused the overflow to be designated as a dangerous waste during normal operation. If condensate overflowed because of a U8 pump failure, theoretically it is conceivable that the condensate would drop the $\mathrm{pH}$ of the chemical sewer below a pH of 2. However, continued plant operations under these conditions is unlikely. First, the loss of routine water additions from tank 48 would have impacted backup facility operation, and second, the loss of the acid fractionator recycle stream could have increased the radionuclide content of the condensate overflowing to the PUREX Plant chemical sewer. If the radionuclide content surpassed the radiation monitor threshold, the chemical sewer would have been diverted to the 216-A-42 Diversion Basin. Plant records reveal that the PUREX Plant chemical sewer has been diverted in the past to the 216-A-42 Diversion Basin. Administratively, diversions to the basin are addressed immediately so as not to limit the available space in 216-A-42 Diversion Basin. There is no documentation to substantiate that the overflow was corrosive during process upsets or during equipment failures. In 1986, tank 48 overflow lines were blanked and rerouted to tanks U3 and U4. Through the careful management of water additions to the process, overflow is no longer a problem.

The most frequent dangerous waste discharge to the 216-B-3 Pond System occurred during the regeneration of the PUREX PIant demineralizers. During regeneration with sulfuric acid and sodium hydroxide, the $\mathrm{pH}$ of the effluents routinely dropped below 2 and exceeded 12.5. These corrosive discharges continued frequently until co-regeneration practices were instituted in February 1986. Co-regeneration practices successfully reduced but did not eliminate the potential of discharging corrosive effluents to the chemical sewer. In September 1989, a catch tank was placed in service to hold the regeneration effluents. This catch tank allows the regeneration effluents to be neutralized as necessary before release to the PUREX Plant chemical sewer. Before co-regeneration practices, some neutralization would have occurred prior to and upon reaching the pond as a result of the successive discharge of acidic and caustic waste. Residual acidic waste would have been neutralized by the calcareous nature of the soil. The PUREX deionizers have been permanently shut down. 


\subsubsection{The PUREX Plant Steam Condensate}

The PUREX Plant steam condensate did not contain dangerous wastes. A record search did not reveal any documentation to substantiate any dangerous waste discharges in the past. As stated previously, the steam condensate could have become radioactively contaminated if there was a breach in the tubes that separated the steam from the process solution.

The PUREX Plant steam condensate discharge was routed to the 216-B-3 Pond System only after the effluent had been diverted to the 216-A-42 Diversion Basin. The steam condensate discharge normally was routed to the 216-A-30 Crib. In the event that an incident occurred that resulted in the release of radionuclides above a preset level, the stean condensate discharge was diverted to the 216-A-42 Diversion Basin. After determining the radionuclide content, the diverted effluent was routed to one of three places, the 216-A-30 Crib, 216-B-3 Pond System, or back to PUREX Plant. 
DOE/RL-89-28, Rev. 1

$12 / 15 / 93$

\subsubsection{The PUREX Plant Cooling Water}

The PUREX Plant cooling water did not contain dangerous wastes. A record search did not reveal any documentation to substantiate any dangerous waste discharges in the past. As stated previously, cooling water could have become radioactively contaminated if there was a breach in the tubes that separated cooling water from the process solution.

The PUREX Plant cooling water supplied radionuclides to the 216-B-3 Pond as a result of a breach in a cooling coil on June 12, 1964. The breach released approximately 10,000 curies of mixed fissions products. An estimate of the relative percentages of radionuclides is presented in Table 4-4. Approximately 25 percent $(2,500$ curies $)$ of the release went directly to the 216-B-3 Pond and the remainder to 216-A-25 Gable Mountain Pond. The volume associated with this release is unknown. Measured activity of the 216-B-3 Pond water declined rapidly with time, from a high of about 1,500 picocuries per cubic centimeter immediately following the release. As a result of this accidental discharge, the original 216-B-3-1 Ditch was closed and covered and replaced in July 1964 by the 216-B-3-2 Ditch. The shoreline sediments of the 216-B-3 Pond were bulldozed into the pond and the shoreline was built up with earth fill to elevate the pond water surface and cover contaminated soil.

\subsection{THE B PLANT}

Waste water streams discharged to the 216-B-3 Pond System included B Plant chemical sewer, B Plant steam condensate, and B Plant cooling water. Currently, cooling water and the chemical sewer are discharged to the 215-B-3 Pond System from B Plant. The following sections discuss the known (i.e., documented) and potential releases of dangerous and radioactive constituents from $B$ Plant waste streams to the 216-B-3 Pond System.

\subsubsection{Process Cooling Water}

Process cooling water has been discharged to the 216-B-3 Pond System from B Plant since April 1945. Chemical discharges to B Plant process cooling water were estimated for calendar year 1969. This estimate, which is assumed to be typical of that time period, indicates that B Plant cooling water was essentially free of chemical contamination.

In November 1981, it became necessary to clean out the calcium carbonate scale that coated the 24-inch cooling water discharge line. On November 3 and 4,1981 , the scale was removed from the line using 4,100 gallons of a 28 percent hydrochloric acid solution and high pressure water. The acid solution was neutralized using 1,850 gallons of 50 percent sodium hydroxide. The majority of the calcium carbonate scale was removed manually through the inspection hole for the 24-inch 1 ine. In addition, 25 gallons of a scale inhibitor containing 45 percent potassium hydroxide was used to coat the 24 -inch line. 
The average concentration of alpha and beta in the cooling water for 1988 is 3.53 picocuries per liter (alpha) and 21.9 picocuries per 1 iter (beta) (Coony and Thomas 1989, pg. C-21). At a flow rate of $3.1 \times 10^{8}$ (1iters per month), the annual estimated radiation entering the 216-B-3 Pond system from B Plant is about 1,300 microcuries per year (alpha) and 8,100 microcuries per year (beta).

\subsubsection{The B Plant Chemical Sewer}

The B Plant chemical sewer was discharged to the 216-B-3 Pond System from April 1945 to May 1970. Chemical discharges to the chemical sewer were estimated for calendar year 1969. This estimate, which is the basis for Table 4-5, is assumed to be typical for the chemical sewer at the time. The chemical sewer was reconnected to the 216-8-3 Pond in February 1992 with comprehensive source controls that will prevent future chemical discharges.

On November 7, 1963, a coil leak developed in B Plant tank Tk-6-1. This leak resulted in the release of 1.3 million gallons of water containing approximately 30 curies of cesium-137 and 0.05 curies of strontium- 90 . Documentation of the incident indicates that no complexing agents were used for decontamination. Therefore, no dangerous waste contamination occurred as a result of this incident.

On March 22, 1970, approximately 1,000 curies of strontium-90 were released to the chemical sewer when a portable manometer system failed. gallery and/or ventilation systems were treated/decontaminated with the chemicals 1 isted in Table 4-6 following the radioactive release. These chemicals were released to the chemical sewer; quantities were not documented.

In an effort to precipitate the strontium released to the 216-B-3 Pond System in 1970, an additional 70,000 pounds of trisodium phosphate and 31,000 pounds of calcium chloride were sprayed on the 216-B-3 Pond in two separate aerial applications.

The March 22, 1970 radionuclide release was much larger than the 1963 release. Though about 1,000 curies of strontium-90 were released, the majority of the contamination was contained in the 216-B-2-2 Ditch, which was dammed 1,000 feet downstream from the spi11. The 216-B-2-2 Ditch discharged into the 216-B-3-2 Ditch. As a result of this release, the 216-B-3-2 Ditch (which discharged to the 216-B-3 Pond) was closed and covered and replaced by the 216-B-3-3 Ditch. The estimated release to the 216-B-3 Pond is presented in Table 4-7.

Prior to January 1992, the B Plant chemical sewer included run-off from the pump pits in the 211-B storage tank area and sumps from inside the tank storage basins. The specific physical and administrative controls to limit dangerous waste discharged to the chemical sewer from 1945 to 1970 are not known. Therefore, during an emergency or upset condition (e.g., rupture of a storage tank), chemicals stored at the facility had a potential to be discharged to the chemical sewer. Though no record of such a discharge is 
documented, the chemicals stored at B Plant during the time the chemical sewer was discharged to the 216-B-3 Pond are listed in Table 4-8.

The majority of information in Table 4-8 was derived from the Inventory of Chemicals Used at the Hanford Site Production Plants and Support Operations (1944-1980) (Klem 1988a pg. 18-20). This document lists chemicals used in fuel separation (1945-1952) and chemicals used in the encapsulation process (1974-1976).

Although the chemical sewer was diverted from the 216-B-3 Pond System in 1970, the stream had a remote chance of discharging to the 216-B-3 Pond System during a cooling water emergency (Chapter 3.0, Section 3.5). Therefore, the chemicals used in processing after 1970 also are included in Table 4-8.

\subsubsection{The B Plant Steam Condensate}

The B Plant steam condensate, which is generated from a batch operated evaporator, was discharged to the 216-B-3 Pond System from April 1945 until September 1967. The steam condensate was diverted to the 216-B-55 Crib in 1967. Generally, the steam condensate stream is not radiologically or chemically contaminated. Although a heating coil failure could conceivably result in contamination of this stream, documentation of such an occurrence could not be located.

\subsection{TANK FARM WASTE MANAGEMENT OPERATIONS}

Liquid discharges from the 242-A Evaporator, 244-AR Vault, 242-B Evaporator, 244 BXR Vault, 241-BY Tank Farm, 244-CR Vault, and 241-A Aging Waste Ventilation System Complex consisted primarily of cooling water and steam condensate. The 242-A Evaporator, 244-AR Vault, and 241-A Aging Waste Ventilation System complex still discharge primarily cooling water and steam condensate to the 216-B-3 Pond System. Cooling water and steam condensate do not contain dangerous waste. Cooling water and steam condensate have the potential to become radioactively contaminated if there is a breach in the tubes separating the cooling water or steam from the process solutions. Additionally, a record search did not reveal any documentation to substantiate any dangerous waste discharges from these facilities to the 216B-3 Pond in the past.

\subsection{THE 283-E WATER TREATMENT FACILITY AND 284-E POWERHOUSE}

The 283-E Water Treatment and the 284-E Powerhouse effluent streams have not and do not contain dangerous waste; additionally, these streams do not have the potential of becoming radioactively contaminated. The water for 
these facilities is obtained from the Columbia River. The constituents present in the discharge streams (above the normal concentrations present in the Columbia River) are from treatment for various uses; these constituents are:

- Aluminum from the production of drinking water using aluminum sulfate as the flocculating agent

- Fines from backwashing filters used to filter treated Columbia River water to produce drinking water

- Chemical species contained in the boiler anti-scaling and dissolved-oxygen scavenger chemicals (i.e., Deartrol* 4812 and Dearborn 66, respectively.) Deartrol* 4812 contains sodium hydroxide and ethylenediam itetraacetic acid (EDTA) and Dearborn* 66 contains sodium sulfite.

Although the boiler blowdown and cooling water do not come into contact with dangerous materials, there is a possibility of metals leaching from the system piping. A variety of heavy metals have been identified in both the cooling water and boiler blowdown from the 284-E Plant. The detected analytes are listed in specific report, Addendum 24 (WHC-EP-0342). The heavy metals include iron ( $\mathrm{Fe})$, chromium $(\mathrm{Cr})$, copper $(\mathrm{Cu})$, zinc $(\mathrm{Zn})$, and lead $(\mathrm{Pb})$. The values for $\mathrm{Fe}, \mathrm{Cu}$, and $\mathrm{Zn}$ are less than the values required under WAC 173-200. The values for $\mathrm{Cr}$ and $\mathrm{Pb}$ are less than the laboratory detection limits. Consequently, the actual values may be in a range between zero and the detection limit. The reported $\mathrm{Cr}$ values are for total $\mathrm{Cr}$, which includes both hexavalent and trivalent chromium. Differentiation of the levels for the two types of chromium are not a requirement of the specific report, Addendum 24 (WHC-EP-0342).

Metals are analyzed by the ICP method in groundwater at the 216-B-3 Pond System Resource Conservation and Recovery Act (RCRA) monitoring wells. Total chromium was detected above the WAC 173-200 standard from unfiltered samples (from the July 1991 sampling effort). Chromium values ranged from 29 to $150 \mathrm{ppb}$ for unfiltered samples and 32-40 ppb for filtered samples. Values for iron also exceeded the WAC 173-200 standard and ranged from 190 to $1100 \mathrm{ppb}$ for unfiltered samples and from 34 to $640 \mathrm{ppb}$ for filtered samples from the July 1991 sampling effort. Values for lead, copper, and zinc were below the WAC 173-200 standard. Ecology references groundwater contamination standards under the Ground Water Quality Criteria in Table 1 of WAC 173-200-040. RCRA facility closure activities are not regulated under these criteria, which may be applied as Comprehensive Environmental Response, Compensation and Liability Act (CERCLA) operable unit cleanup standards. Groundwater contamination is addressed under applicable CERCLA regulations. Therefore, the above reference table and associated disposition are provided as a courtesy to Ecology to assist in illustrating the uncontaminated nature of the boiler blowdown and cooling water. Any evidence of chemical constituents in the groundwater above Ground Water Quality Criteria standards will be addressed when the facility is remediated under CERCLA operable unit status. 


$$
\text { DOE/RL-89-28, Rev. } 1
$$

$12 / 15 / 93$

This page intentionally left blank. 
Table 4-1. The 216-B-3 Pond Cumulative, Decayed Radionuclide Inventory.

$\begin{array}{llrl}\text { Radionuclides } & \begin{array}{l}\text { Inventory } \\ \text { (curies) }\end{array} & \text { Radionuclides } & \begin{array}{r}\text { Inventory } \\ \text { (curies) }\end{array}\end{array}$

Cumulative volume of water discharged: $2.26 \times 10^{11}$ liters

9 Total alpha $<1.60 \times 10^{1} \quad$ Total beta $<3.93 \times 10^{2}$

10 Tritium $\left({ }^{3} \mathrm{H}\right) \quad 8.29 \times 10^{2} \quad$ Strontium-90 $\left({ }^{90} \mathrm{Sr}\right) \quad<1.03 \times 10^{2}$

11 Ruthenium-106 ( $\left.{ }^{106} \mathrm{Ru}\right)<1.34 \times 10^{-4}$ Cesium-137 $\left({ }^{137} \mathrm{Cs}\right) \quad<9.49 \times 10^{1}$

12 Promethium-147 $\left({ }^{147} \mathrm{Pm}\right)<1.03 \quad$ Uranium (gross) (U) $<2.07$

13 Plutonium-239 ( $\left.{ }^{239} \mathrm{Pu}\right) \quad<5.52 \times 10^{-1} \quad$ Americium-241 $\left({ }^{241} \mathrm{Am}\right) \quad<3.52$

14 < = values below detectable range. 
Table 4-2. Chemicals Used at the PUREX Plant.

\begin{tabular}{ll} 
& \multicolumn{2}{c}{ Compound name } \\
\hline Acetic acid & Periodic acid \\
Aluminum nitrate nonahydrate & Phosphoric acid \\
Aluminum nitrate (mono basic) & Potassium fluoride \\
Ammonium fluoride & Potassium hydroxide \\
Ammonium nitrate & Potassium permanganate \\
Cadmium nitrate & Shell E-2342*b \\
Dibutyl butyl phosphonate & Silver nitrate \\
DOW Anti-Foam B*a & Sodium carbonate \\
Ferric nitrate & Sodium ferrocyanide \\
Ferrous sulfamate & Sodium fluoride \\
Formaldehyde & Sodium hydroxide \\
Hydrazine & Sodium nitrate \\
Hydrogen peroxide & Sodium nitrite \\
Hydroxyacetic acid & Sodium sulfate \\
Hydroxylamine nitrate & Sodium thiosulfate \\
Lanthanum nitrate & Soltrol-170*c \\
Lead nitrate & Sugar \\
Mercuric nitrate & Sulfamic acid \\
Nickel nitrate & Sulfuric acid \\
Nitric acid & Tartaric acid \\
Normal paraffin hydrocarbon & Tri-n-dodecylamine \\
Oxalic dcid & Tributyl phosphate \\
& Trichloroethane \\
\hline
\end{tabular}

${ }^{a}$ Silicon emulsion. DOW Anti-Foam B is a trademark of Dow Corning Corporation.

bapthalene and paraffins. She11 E-2342 is a trademark of She 11 oil Company.

${ }^{c} \mathrm{C}_{10} \mathrm{H}_{22}$ to $\mathrm{C}_{16} \mathrm{H}_{34}$ paraffins. Soltrol-170 is a trademark of Phifilps Chemical Company. 
Table 4-3. Releases into The PUREX Plant Chemical Sewer Line.

(sheet 1 of 2)

\begin{tabular}{|c|c|c|c|}
\hline Date & Chemical & Pounds & Designation $^{a}$ \\
\hline $05 / 20 / 83$ & $\begin{array}{l}\text { Aluminum nitrate } \\
\text { nonahydrate }\end{array}$ & 17,725 & NONE \\
\hline $10 / 17 / 83$ & $\begin{array}{l}\text { Potassium permanganate } \\
\text { Sodium carbonate }\end{array}$ & $\begin{array}{r}10,700 \\
1,412\end{array}$ & NONE \\
\hline $02 / 09 / 84$ & Potassium hydroxide & 83,000 & D002 \\
\hline $02 / 26 / 84$ & Sodium hydroxide & 3,700 & D002, WT02 \\
\hline $05 / 16 / 84$ & Cadmium nitrate & $25-50$ & D006, WT01 \\
\hline $06 / 06 / 84$ & $\begin{array}{l}\text { Hydrazine } \\
\text { Hydroxylamine nitrate }\end{array}$ & $\begin{array}{r}332 \\
90\end{array}$ & U133 \\
\hline $08 / 22 / 84$ & Nitric acid & 9,000 & D002 \\
\hline $10 / 02 / 84$ & $\begin{array}{l}\text { Hydrazine } \\
\text { Hydroxylamine nitrate }\end{array}$ & $\begin{array}{l}280 \\
407\end{array}$ & U133, WTO2 \\
\hline $11 / 01 / 84$ & Sulfuric acid & 3,482 & NONE \\
\hline $11 / 27 / 84$ & $\begin{array}{l}\text { Nitric acid } \\
\text { Ferrous sulfamate } \\
\text { Sulfamic acid }\end{array}$ & $\begin{array}{r}349 \\
43 \\
68\end{array}$ & NONE \\
\hline $12 / 02 / 84$ & Potassium hydroxide & 150 & 0002 \\
\hline $12 / 02 / 84$ & Potassium hydroxide & 62,683 & D002, WTO2 \\
\hline $01 / 10 / 85$ & $\begin{array}{l}\text { Hydroxylamine nitrate } \\
\text { Hydrazine } \\
\text { Nitric acid }\end{array}$ & $\begin{array}{r}100 \\
21 \\
66\end{array}$ & U133 \\
\hline $01 / 18 / 85$ & Nitric acid & 6,236 & D002, WTO2 \\
\hline $02 / 08 / 85$ & Sodium nitrate & 160 & NONE \\
\hline $04 / 04 / 85$ & $\begin{array}{l}\text { Ferrous sulfamate } \\
\text { Nitric acid } \\
\text { Sulfamic acid }\end{array}$ & $\begin{array}{r}52 \\
269 \\
132\end{array}$ & NONE \\
\hline $05 / 14 / 85$ & $\begin{array}{l}\text { Nitric acid } \\
\text { Hydroxylamine nitrate } \\
\text { Hydrazine }\end{array}$ & $\begin{array}{c}190 \\
98 \\
0.4\end{array}$ & U133 \\
\hline $05 / 27 / 85$ & Nitric acid & $\begin{array}{r}223 \\
T 4-3.1\end{array}$ & NONE \\
\hline
\end{tabular}




\begin{tabular}{lccl}
\multicolumn{4}{c}{ Table 4-3. Releases into The PUREX Plant Chemical Sewer Line. } \\
(sheet 2 of 2)
\end{tabular}

\footnotetext{
${ }^{a}$ Ecology waste designation (WAC 173-303).
} 
1 Table 4-4. Activity Percentage of Radionuclides from the 2 PUREX Plant F-15 Tank Leak (June 1964).

\begin{tabular}{|c|c|c|c|}
\hline Radionuclide & $\begin{array}{l}\text { Percent total } \\
\text { activity }\end{array}$ & $\begin{array}{l}\text { Percent tota } \\
\text { Radionuclide }\end{array}$ & 1 activity \\
\hline Strontium-89 ( $\left.{ }^{89} \mathrm{Sr}\right)$ & 9.5 & ${ }^{\mathrm{b}} \mathrm{Tell}$ urium-129 ( $\left.{ }^{129} \mathrm{Te}\right)$ & 0.21 \\
\hline Strontium-90 ( $\left.{ }^{90} \mathrm{Sr}\right)$ & 0.4 & Cesium-137 ( $\left.{ }^{137} \mathrm{Cs}\right)$ & 0.33 \\
\hline Yttrium-90 $\left({ }^{90} \mathrm{Y}\right)$ & 0.4 & Barium-137 ( $\left.{ }^{137} \mathrm{Ba}\right)$ & 0.33 \\
\hline Yttrium-91 $\left({ }^{91} Y\right)$ & 11.5 & Barium-140 ( $\left.{ }^{140} \mathrm{Ba}\right)$ & 0.28 \\
\hline Zirconium-95 $\left({ }^{95} \mathrm{Zr}\right)$ & 14.8 & Lanthanum-140 ( $\left.{ }^{140} \mathrm{La}\right)$ & 0.33 \\
\hline${ }^{b}$ Niobium-95 $\left({ }^{95} \mathrm{Nb}\right)$ & 0.3 & Cerium-141 $\left({ }^{141} \mathrm{Ce}\right)$ & 4.7 \\
\hline${ }^{c}$ Niobium-95 $\left({ }^{95} \mathrm{Nb}\right)$ & 23.2 & Praseodymium-143 ( $\left.{ }^{143} \mathrm{Pr}\right)$ & 0.4 \\
\hline Ruthenium-103 ( $\left.{ }^{103} \mathrm{Ru}\right)$ & 5.6 & Cesium-144 ( $\left.{ }^{144} \mathrm{Cs}\right)$ & 9.3 \\
\hline Rhodium-103 ( $\left.{ }^{103} \mathrm{Rh}\right)$ & 5.6 & Praseodymium-144 ( $\left.{ }^{144} \mathrm{Pr}\right)$ & 9.3 \\
\hline Ruthen ium-106 ( $\left.{ }^{106} \mathrm{Ru}\right)$ & 0.75 & Promethium-147 ( $\left.{ }^{147} \mathrm{Pm}\right)$ & 1.35 \\
\hline Rhodium-106 ( $\left.{ }^{106} \mathrm{Rh}\right)$ & 0.75 & & \\
\hline
\end{tabular}

18

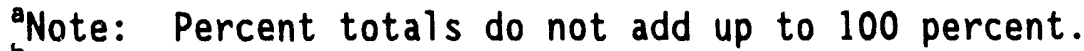
ground stable. 
Table 4-5. Potential Contaminants in the B Plant Chemical Sewera

Average concentration
Chemical
(parts per million) (grams per year)
parts per million)

(grams per year)

\section{Ammonia}

8 Di(2-ethylhexyl)phosphoric acid

9 Citric acid

10 Hydroxyacetic acid

11 Carbon dioxide

12 Hydroxyethyl

13 ethylenediaminetetraacetic acid

14 Trisodium nitrilo triacetate

15 Normal paraffin hydrocarbons

16 (kerosene)

17 Nitric acid

18 Oxalic acid

19 Sodium hydroxide

20 Sulfuric acid

21 Phosphotungstic acid

22 Sodium bisulfate

23 Sodium carbonate

24 Tartaric Acid

25

26

27

28

29

30

31

32

Tributylphosphate
6 Aluminum nitrate nonahydrate
$4.73 \times 10^{-5}$
63.5

\section{2}
$1.74 \times 10^{6}$
0.57
$7.52 \times 10^{4}$
11.2
$1.48 \times 10^{6}$
13.6
$1.80 \times 10^{6}$
10.3
$1.36 \times 10^{6}$
12.0
$1.59 \times 10^{6}$
0.13
$1.72 \times 10^{4}$

0.53

$2.02 \times 10^{5}$

26.0

$3.41 \times 10^{6}$

0.086

$1.14 \times 10^{4}$

47.3

$6.24 \times 10^{6}$

0.62

$8.22 \times 10^{4}$

0.89

$1.17 \times 10^{5}$

1.79

$2.36 \times 10^{5}$

3.75

$4.95 \times 10^{5}$

2.30

$3.04 \times 10^{5}$

0.33

$4.35 \times 10^{4}$

${ }^{a}$ Chemical loss based on a flow rate of $1.32 \times 10^{8}$ liters per year $\left(3.48 \times 10^{7}\right.$ gallons per year) and a density of 1.0 gram per milliliter. 
Table 4-6. Chemicals Used in Treatment/Decontamination Following the 1970 Release.

\begin{tabular}{ll}
\hline \multicolumn{1}{c}{ Chemical } & \multicolumn{1}{c}{ Comments } \\
\hline Mantek "one stroke"* & Paint remover \\
Phosphoric acid & \\
Caustic tartrate & contains 3\% chromate \\
Turco 4502* & $90 \%$ oxalic acid \\
Turco 4518* & $50 \%$ sulfamic acid \\
Turco 4306* & $45 \%$ sodium bisulfate \\
& $50 \%$ phosphoric acid \\
Turco 4512A* & Sulfuric acid/sodium dichromate \\
$\mathrm{H}_{2} \mathrm{SO}_{4} / \mathrm{Na}_{2} \mathrm{Cr}_{2} \mathrm{O}_{4}$ &
\end{tabular}

*Mantek "one stroke" is a trademark of Manville Building Materials Corporation.

Turco 4502*, Turco 4518*, Turco 4506*, Turco 4512A* are trademarks of Turco Products Incorporated. 
Table 4-7. Estimated Radionuclides Released to the 216-B-3 Pond March 22, 1970.

\begin{tabular}{lc}
\hline \multicolumn{1}{c}{ Radionuclide } & Curies \\
\hline Total beta & 154 \\
Cesium-137 $\left({ }^{137} \mathrm{Cs}\right)$ & 13 \\
Strontium-90 $\left({ }^{90} \mathrm{Sr}\right)$ & 50 \\
Cerium praseodymium-144 $\left({ }^{144} \mathrm{Ce}-\mathrm{Pr}\right)$ & 54 \\
\hline
\end{tabular}

11 
Table 4-8. Chemicals Used at the B Plant and the Waste Encapsulation Storage Facility.

\begin{tabular}{ll} 
& Chemical \\
\hline Acetone & Nickel ferrocyanide \\
Aluminum & Nitric acid \\
Ammonia (anhydrous) & Normal paraffin hydrocarbons \\
Ammonium Carbonate & Oxalic acid \\
Ammonium nitrate & Phosphoric acid \\
Ammonium sulfite & Phosphotungstic acid \\
Ammonium silicofluoride & Potassium permanganate \\
Ammonium sulfate & Potassium hydroxide \\
Boric acid & Silver nitrate \\
Calcium chloride & Sodium phosphate \\
Carbon dioxide & Sodium nitrite \\
Ceric nitrate & Sodium nitrate \\
Cesium chloride & Sodium dichromate \\
Citric acid & Sodium hydroxide \\
Di(2-ethylhexyl) phosphoric acid & Sodium fluoride \\
Ferrous sulfate & Sodium sulfate \\
Hydrochloric acid & Sodium persulfate \\
Hydrogen fluoride & Sodium gluconate \\
Hydrogen peroxide & Sodium carbonate \\
Hydroxyacetic acid & Sodium acetate \\
aHyflo-super-cel (contains silica) & Sodium bismuthate \\
Lanthanum nitrate & Strontium fluoride \\
Lanthanum-neodymium nitrate & Sugar \\
Lead nitrate & \\
Sulfuric acid & Trisodium hydroxyethylethylene- \\
Tartaric acid & diaminetriacetic acid (HEDTA) \\
Tetrasodium ethylenediamine- & Trichloroethane \\
tetraacetic acid (EDTA) & Zirconyl nitrate \\
Tributyl phosphate & \\
\hline
\end{tabular}

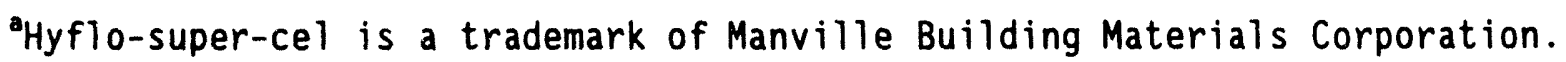




\section{CONTENTS}

5.0 GROUNDWATER MONITORING . . . . . . . . . . . . . . 5-1

5.1 INTERIM-STATUS PERIOD GROUNDWATER MONITORING . . . . . . . . . 5-1

5.1.1 Wel1 Locations and Construction . . . . . . . . . . . 5-2

5.1.1.1 Well Locations . . . . . . . . . . . . . . 5-2

5.1.1.2 Details of Well Design and Construction . . . 5-3

5.1.2 Sampling and Analysis Plan ............. 5-4

5.1.2.1 Geologic Sampling ............ . 5-4

5.1.2.2 Sample Analyses . . . . . . . . . . . . . 5-4

5.1.2.3 Borehole Logging . . . . . . . . . . . . . 5-5

5.1.2.4 Borehole Development and Aquifer Testing . . . 5-5

5.1.2.5 Determination of Groundwater Flow Paths . . . . 5-5

5.1.2.6 Groundwater Quality .. . . . . . . . . . 5-6

5.1.2.7 Statistical Evaluation . . . . . . . . . . 5-6

5.1.3 Results of the B Pond Groundwater Monitoring . . . . . . 5-6

5.1.3.1 Potentiometric Levels . . . . . . . . . 5-6

5.1.3.2 Groundwater Quality . . . . . . . . . . . . . 5-7

5.1.3.3 Quality Assurance and Quality Control .. . . . 5-9

5.1.4 Groundwater Quality Assessment . . . . . . . . . . 5-10

5.2 AQUIFER IDENTIFICATION . . . . . . . . . . . . 5-10

5.2.1 Climate .................. . 5-10

5.2.2 Physiography .. . . . . . . . . . . . . . . . 5-11

5.2.3 Regional Geology ............... . 5-12

5.2.3.1 Tectonic Framework . . . . . . . . . . . 5-12

5.2.3.2 Structural Geology .. . . . . . . . . . 5-12

5.2.3.3 Stratigraphy .. . . . . . . . . . . 5-13

5.2.4 Regional Hydrology .............. . . 5-17

5.2.4.1 Surface Water . . . . . . . . . . . . 5-17

5.2.4.2 Groundwater .............. . . . 5-18

5.2.5 Hydrogeology of the B Pond Area ............ . 5-21

5.2.5.1 Geology of the B Pond Site. . . . . . . . 5-21

5.2.5.2 Hydrology of the B Pond Site . . . . . . . . . 5-22

5.2.5.3 Direction and Rate of Groundwater Movement . . 5-25 
DOE/RL-89-28, Rev. 1

$12 / 15 / 93$

\section{FIGURES}

5-1. Locations of the Hanford Site and the Separations Area . . . . . F5-1

5-2. Monitoring Well Locations, 216-B-3 Pond . . . . . . . . . . . F5-2

5-3. Separations Area Water Table Map, December 1987 . . . . . . . . . F5-3

5-4. Tritium Plumes Within the Separations Area--1987 Data . . . . . F5-4

5-5. Wind Rose Patterns for the Hanford Site . . . . . . . . . . . . F5-5

5-6. Geomorphic Units Within the Central Highlands and Columbia

Basin Subprovinces That Contain the Columbia River Basalt Group . F5-6

5-7. Structural Subprovinces of the Columbia Plateau . . . . . . . . F5-7

5-8. Tectonic Structures Adjacent to the 200 Areas, Top of

Basalt . . . . . . . . . . . . . . . . . . . . F5-8

5-9. Stratigraphic Nomenclature of Units Penetrated Within the

Pasco Basin . . . . . . . . . . . . . . . . . F5-9

5-10. Late Quaternary Landforms Within and Adjacent to the

Pasco Basin .. . . . . . . . . . . . . . . . . F5-10

5-11. Locations of Surface Water Bodies on the Hanford Site . . . F5-11

5-12. Locations of Principle Dams Within the Columbia Plateau (after DOE 1988b) . . . . . . . . . . . . . . . F5-12

5-13. Water Table Map of the Hanford Site . . . . . . . . . . . F5-13

5-14. Cross-Section A-A'.................. . F5-14

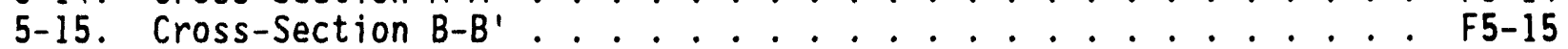

5-16. Comparison of Potentiometric Surface of the Rattlesnake Ridge Confined Aquifer with the Water Table of the Unconfined Aquifer................. F5-16

\section{TABLES}

5-1. Construction Summary--B Pond Groundwater Monitoring Network . . . . T5-1

5-2. Groundwater Constituents, Parameters ${ }^{a}$, and Drinking Water Standards . . . . . . . . . . . . . . . . . . . T5-2

5-3. Results of Indicator Parameter Analyses . . . . . . . . . . . T5-3

5-4. Estimated Background Levels for Selected Constituents in Hanford Ground Water 
DOE/RL-89-28, Rev. 1

$12 / 15 / 93$

\subsection{GROUNDWATER MONITORING}

This chapter describes the groundwater monitoring program at the B Pond site, including well installation and design, hydrogeologic characterization, and data collection. Current knowledge of regional and site hydrogeology is summarized.

The B Pond System is located east of the Separations Area (Figure 5-1). The Separations Area includes the 200 East and 200 West Areas and all of the associated liquid waste disposal facilities.

\subsection{INTERIM-STATUS PERIOD GROUNDWATER MONITORING}

Installation of groundwater monitoring wells is required for compliance with interim status regulations ( 40 CFR 265 , Subpart $F$ ). This section describes the interim status groundwater monitoring network at the B Pond site, hydrogeologic characterization methods, and results of groundwater monitoring to date.

The objectives of interim-status groundwater monitoring at $B$ Pond (Luttrell et a1. 1989, pp. 49) are as follows.

- Characterize the stratigraphy and the horizontal and vertical groundwater flow directions and rates beneath $B$ Pond, with focus on the uppermost aquifer.

- Determine if any statistically significant amounts of dangerous waste constituents that originate from B Pond are detectable in the groundwater.

A network of groundwater monitoring wells has been established around $B$ Pond to measure water levels, obtain groundwater samples, and evaluate aquifer properties. Analyses of data from downgradient wells will be compared to data from wells outside of the influence of $B$ Pond ('background' wells) to determine whether contaminants from B Pond are present in the groundwater.

The RCRA groundwater monitoring at B Pond was initiated in 1988 as an contamination indicator evaluation program for an interim-status facility. The applicable monitoring requirements are described in 40 Code of Federal Regulations (CFR) 265.92 and 265.93 and WAC 173 303-645. Section 6.3.1 of the Tri-Party Agreement (Ecology et a1. 1992) specifies, "Any demonstration for clean closure of a disposal unit, or selected treatment or storage units as determined by the lead regulatory agency, must include documentation that groundwater and soils have not been adversely impacted by that TSD group/unit, as described in WAC 173-303-645." The WAC 173-303-645 governs final-status facilities, with subsection (4)(a) requiring analys is of appropriate 40 CFR 264 Appendix IX constituents, and subsection (5)(a), Table 1, listing maximum concentration limits for certain constituents. To meet the intent of the Tri-Party Agreement, the B Pond monitoring wells will be sampled once for the 40 CFR 264 Appendix IX constituents to verify that none of these dangerous 
waste constituents has migrated into the groundwater from B Pond. Any detected Appendix IX constituents will be added to the list of parameters to be monitored semiannually. In addition, the list of regular monitoring parameters includes those in Table 1 of WAC 173-303-645. Groundwater sampling is discussed in more detail in Section 5.1.2.

The groundwater monitoring program and the hydrologic system in the $B$ Pond vicinity are described in the following documents:

- 216-B-3 Pond Preliminary Closure/Postclosure Plan (DOE-RL 1989)

- 40 CFR 265 Interim-Status Ground-Water Monitoring Plan for the 216-B-3 Pond (Luttrell et al. 1989)

- RCRA Groundwater Monitoring Progress Reports

- RCRA Groundwater Monitoring Compliance Projects for Hanford Site Facilities: Progress Report for the Period October 1 to December 31, 1988 (Fruland et al. 1989)

- RCRA Groundwater Monitoring Projects for Hanford Facilities: Progress Report for the Period January 1 to March 31, 1989 (Smith et al. 1989a).

- RCRA Groundwater Monitor Projects for Hanford Facilities: Progress Report for the Period April 1 to June 30, 1989 (Smith et al. 1989b).

Additional progress reports will be published quarterly.

Chemical and hydrogeologic data for the Separations Area and vicinity (including $B$ Pond) are available in annual environmental reports (e.g., Wilbur et a1. 1983; Graham et al. 1984; Serkowski et al. 1988). A hydrogeologic characterization report that will assimilate collected data for $B$ Pond is being prepared.

\subsubsection{Well Locations and Construction}

The groundwater monitoring network for B Pond includes 13 wells (Figure 5-2). Well locations and construction are discussed in the following sections.

5.1.1.1 Well Locations. Two wells are monitored for background water quality. These wells (299-E18-1 and 299-E32-4) were constructed for other RCRA monitoring projects. Another well in the vicinity of B Pond (699-42-40A) existed at the site before RCRA monitoring and is used as a downgradient well. Four other downgradient wells were installed for RCRA monitoring in 1988 and six more were installed in 1989. Well construction information is summarized in Table 5-1 and Appendix A. Geographic well coordinates are provided in Appendix A.

Artificial recharge to the groundwater system from $B$ Pond has created a groundwater mound beneath the site (Section 5.1.3). Consequently, every location surrounding the facility is hydrologically downgradient. 
In the absence of upgradient locations, wells believed to be unaffected by $B$ Pond are used to determine the background water chemistry.

Well 299-E18-1 is located approximately 2.25 miles west-southwest of B Pond, and well 299-E32-4 is located approximately 2.75 miles west of B Pond

( $:$ e Figure 5-2). These wells are located downgradient of the 200 West Area and along flow paths that presumably would move through the northern and southern parts of the 200 East Area if the groundwater mound beneath B Pond was not present. The wells are located as near to B Pond as possible yet outside the influence of the groundwater mound, as indicated by regional contaminant plume maps (Law et al. 1987, pp. 75-86, DOE 1992, Ford 1993, Johnson 1993) and the Separations Area water table map (Figure 5-3). The background wells are completed in the uppermost aquifer and are constructed to meet RCRA design requirements.

Five of the downgradient monitoring wells are located around the 216-B-3 Pond because it has a greater likelihood for contamination than do the expansion ponds. The well locations are 100 to 200 feet from the edge of the pond. This distance was chosen to keep drilling activities outside of zoned decommissioned radiation areas adjacent to the pond and because potential contaminants could have spread laterally in the vadose zone before reaching the water table. One well (699-43-45) is located west of B Pond. This well will provide information on the overflow area and the lower segment of the 216-B-3-3 Ditch, both of which are known to have received dangerous waste.

Most of the monitoring wells are completed at the top of the aquifer. Two wells were completed at the base of the aquifer to monitor groundwater quality and groundwater potential in the lower part of the aquifer. One of these deep wells $(699-42-42 B)$ was installed on the southeast side of $B$ Pond, near shallow well 699-43-42J. Another deep well (499-43-41F) was installed north of the pond near shallow well 699-43-41E. Wells 699-42-42B and 699-43-41F will provide initial deep groundwater monitoring points in the central area of $B$ Pond System, where vertical gradients are expected to be greatest.

As more data are collected, the adequacy of the monitoring network will be assessed. If necessary, additional wells will be installed to monitor the upper portion of the 216-B-3-3 Ditch or other potential 'gaps' in the network.

5.1.1.2 Details of Well Design and Construction. All of the wells in the $B$ Pond monitoring network were drilled with the cable tool method. All but one of the wells (699-42-40A) are constructed of 4-inch-diameter stainless steel casing and screen. The screens are surrounded by quartz sand filter packs. The wells are sealed from above the filter pack with bentonite (to near land surface) and cement grout (to land surface). A concrete surface seal and well pad were emplaced around each well. Construction details are summarized in Table 5-1. Construction diagrams and lithologic diagrams for each well in the monitoring network are contained in Appendix A. Additional information on drilling, well installation, construction, well development, geophysical logging, and surveying is contained in Luttrell et al. (1989, pp. 49-68) and Fruland et al. (1989, pp. 12.1-12.6). 
Well 699-42-40A was installed in 1981. It is constructed of carbon steel casing with a packer and stainless steel screen and has a surface seal of 18 feet of cement grout. The water table has risen since this we 11 was constructed, and the screen is now 15 feet below the water table. This well was evaluated recently to assess whether it satisfies the requirements of WAC 173-303 for use as a resource protection well. The well does not fully satisfy those requirements. It will be remediated, if possible, or will be replaced with a new well.

\subsubsection{Sampling and Analysis Plan}

Hydrogeologic characterization studies are being conducted to define the geologic and hydrogeologic conditions and properties that control contaminant flow paths. Data collection and interpretation focus on geology, geochemistry, hydrogeology, hydrochemistry, and groundwater monitoring. Characterization work is summarized in the following sections and described more fully in Luttrell et al. (1989, pp. 62-72). The groundwater sampling and analysis plan for B Pond (Luttrell et al. 1989, Appendix D) describes sample collection, field chemical measurements, analytical methods, preservation techniques, chain-of-custody control, and quality control. Laboratory analytical methods are adapted from EPA (1986b). The procedures for groundwater sample collection, water-level measurements, and field chemical measurements are contained in Pacific Northwest Laboratory (PNL) (1989). Applicable procedures are 1 isted in the following sections.

5.1.2.1 Geologic Sampling. Geologic samples are collected at 5-foot intervals or at changes in lithology during drilling. The samples are described in the field and archived for additional analyses. Additional samples may be collected for special analyses (e.g., hydraulic conductivity tests). Applicable procedures from PNL (1989) are as follows:

- DO-1 Collection and Documentation of Borehole Samples and Well Construction Data

- D0-2 Split-Barrel Auger Sediment Sampling.

5.1.2.2 Sample Analyses. Laboratory analyses, followed by procedures used on sediment samples, include the following:

- Sieve analysis (Gee and Bauder 1986, PNL 1989 (SA-2)

- Moisture content (ASTM 1988, Klute 1986)

- Calcium carbonate content (Allison and Moodie 1965, Nelson 1982)

- Petrography

- Hydrometer analyses of zones that contain much silt or clay (Gee and Bauder 1986)

- Saturated hydraulic conductivity (Klute and Dirksen 1986)

- Chemical analyses of contamination indicator parameters.

Moisture content data are available for several wells and are included in Fruland et a1. (1989, pp. 12.4-12.6). Results of other laboratory analyses will be included in a hydrogeologic characterization report. 
5.1.2.3 Borehole Logging. Gamma, neutron, and density logs were run in boreholes 699-43-42J, 699-43-43, and 699-42-42B. A gamma log was run in boreholes 699-44-42, 699-43-45, 699-44-43B, 699-43-41E, 699-40-39, 699-41-40, and 699-43-41F. Copies of logs from wells installed in 1988 are included in Fruland et al. (1989, Appendix C). Geophysical logging of the wells drilled in 1989 will be described in future quarterly reports. The PNL (1989) geophysical logging procedures include the following:

- GL-5 Neutron Probe Procedure

- GL-6 Bulk Density Probe Procedure

- GL-7 Gamma Ray Procedure.

5.1.2.4 Borehole Development and Aquifer Testing. Well development generally was conducted in two stages: initial development that sometimes included aquifer testing and final well development after the final well materials were installed. The purpose of borehole development is to remove drilling fluids from the well and fine-grained materials from around the well screens. Initial development also can provide information for determining the optimum pumping rates for subsequent aquifer tests. Boreholes 699-43-43 and 699-44-42 were developed before and after well completion activities. The other downgradient RCRA wells were developed after well completion.

The purpose of hydrologic testing is to determine estimates of transmissivity, hydraulic conductivity, and, if possible, storativity of the uppermost aquifer beneath B Pond. Estimates of transmissivity and hydraulic conductivity have been determined from data collected from constant-discharge tests, recovery tests, and slug injection and/or withdrawal tests. The intent was to determine storativity, if possible, from data collected from constantdischarge or recovery in multiple-well tests.

Hydrologic (aquifer pumping) tests were conducted in wells 699-42-42B, 699-43-43, and 699-44-42. Single-well constant-discharge aquifer tests and subsequent recovery tests were performed in wells 699-43-43 and 699-44-42. A constant-discharge test as well as a recovery test with one observation well (699-43-42J) were conducted in well 699-42-42B. Slug injection and/or withdrawal tests were performed in wells 699-44-43B, 699-40-39, and 699-43-41F. Results of these tests are summarized in Section 5.2.5. Aquifer testing is controlled by the following procedures from PNL (1989):

- AT-4 Well Development

- AT-5 Constant Discharge Test

- AT-6 Aquifer Slug Injection and Withdrawal Test.

5.1.2.5 Determination of Groundwater Flow Paths. Water levels are measured monthly in the monitoring wells and in several other nearby well 2 to determine hydraulic head distribution. Water-level data are discussed in Section 5.1.3. Water levels are monitored according to the following procedures (PNL 1989):

- WL-1 Water-Level Measurement Procedure

- WL-2 Procedure for Standardizing Steel Tapes. 
5.1.2.6 Groundwater Quality. Water samples were collected and analyzed quarterly from downgradient wells 699-42-40A, 699-42-42B, 699-43-42J, and 699-43-43 and background wells 299-E18-1 and 299-E32-4 for the first year of monitoring. Quarterly sampling of these wells began the fourth quarter of calendar year 1988, and these wells are now sampled semiannually. The wells installed in 1989 (i.e., 699-43-45, 699-44-43B, 699-43-41E, 699-40-39, 699-41-40, and 699-43-41F) were sampled quarterly for the first year and semiannually thereafter.

Groundwater samples are analyzed for parameters required by 40 CFR 265.92, and for volatile organic constituents, hydrazine, ammonia, and tritium ('regular' list of constituents). In addition, samples will be analyzed once for constituents 1isted in 40 CFR 264, Appendix IX and WAC 173-303-9905. If any Appendix IX or WAC 173-303-9905 constituents are detected and confirmed in groundwater samples from $B$ Pond wells, these constituents will be added to the regular list.

Results of chemical analyses of groundwater samples are discussed in Section 5.1.3. The collection of groundwater samples are controlled by the following procedures (PNL 1989):

- GC-1 Groundwater Sample Collection Procedure

- GC-2 In-Line Sample Filtration Procedure

- FA-1 Temperature Measurement Procedure

- FA-2 Calibration of Conductivity Meter and Measurement of Field Conductivity

- FA-3 Calibration of pH Meter and Measurement of Field pH

- Laboratory Analyses Based on SW-846 (EPA 1986b)

- AD-2 Groundwater Sample Chain-of-Custody Procedure.

5.1.2.7 Statistical Evaluation. RCRA Groundwater monitoring at B Pond began in November 1988. Four quarters of background data have been collected, and statistical analyses are being performed to determine average concentrations of indicator parameters, as required by 40 CFR 265.93(b). Indicator parameters are $\mathrm{pH}$, specific conductance, total organic carbon, and total organic halogen. Indicator parameters of the downgradient weils are compared semiannually to background wells. These data are analyzed periodically to evaluate whether groundwater quality is affected by discharges to B Pond.

Statistical methods to determine mean background groundwater quality, variance, and coefficient of variation will be based on the RCRA Ground-Water Monitoring Technical Enforcement Guidance Document (EPA 1986a, Appendix B).

\subsubsection{Results of the B Pond Groundwater Monitoring}

This section presents the results of groundwater monitoring to date, including potentiometric levels and groundwater quality.

5.1.3.1 Potentiometric Levels. The water table in the immediate vicinity of $B$ Pond is approximately 125 to 150 feet below ground surface, near the contact between the Hanford and Ringold Formations. The thickness of the unconfined 
aquifer ranges from approximately 30 feet to over 70 feet. Groundwater levels in the unconfined aquifer beneath B Pond have risen approximately 35 to 40 feet since waste disposal operations began. This groundwater mound is a major feature controlling the direction of groundwater fiow near the 200 East Area. Figure 5-3 illustrates the water table in the vicinity of the Separations Area.

Variations in the volume of liquid disposed to B Pond cause a fluctuation in the artificial recharge and consequently, in the water table. However, the general 'topography' of the water table surface is relatively consistent, and groundwater flows radially from the mound beneath $B$ Pond. Horizontal gradients near the pond range from approximately 0.002 to 0.007 .

The $B$ Pond groundwater mound also has altered vertical flow. A downward gradient of approximately 0.1 is observed between wells $699-43-42 \mathrm{~J}$ and 699-42-42B. In most areas of the Hanford Site, groundwater potential in the Rattlesnake Ridge aquifer is higher than in the suprabasalt aquifer; therefore, groundwater tends to flow upward. Because the groundwater mound beneath B Pond has created an area where hydraulic head is greater in the suprabasalt aquifer, there is a potential for groundwater to flow from the suprabasalt sediments into deeper aquifers.

5.1.3.2 Groundwater Quality. Groundwater samples are analyzed for the constituents and parameters 1 isted in Table 5-2, as required by 40 CFR 265.92 and WAC 173-303-645, and for hydrazine, ammonia, and tritium. 0ther radioactive constituents are analyzed on an ad hoc basis. Groundwater samples from all wells also have been or will be analyzed for the constituents 1 isted in WAC 173-303-9905 and 40 CFR 264, Appendix IX. Results of chemical analyses are contained in quarterly progress reports (e.g., Fruland et al. 1989, pp. 12.7-12.17; Smith et al. 1989b pp 12.6-12.12) and in Appendix B. The following is a summary of water quality data from November 1988 through August 1989.

Groundwater Protection Constituents (40 CFR 264.97 and WAC 173-303-645)-Al1 groundwater protection constituents were below the maximum concentration limits in filtered groundwater samples. Elevated levels of chromium were observed in unfiltered samples from several wells in the $B$ Pond monitoring network. The highest value was 206 parts per billion in we11 699-43-42J in August 1989. The drinking water standard for chromium is 50 parts per billion (40 CFR 141). Elevated chromium concentrations have been observed in various wells across the Hanford Site and appear to be residual from well drilling or construction (Fruland et a1. 1989, pp. 1.5-1.6). Filtered samples contained no detectable chromium.

Indicator parameters--Results of indicator parameter analyses through April 1993 are presented in Table 5-3. An explanation of symbols used in this table is presented at the front of Appendix $B$. Specific conductance of the background wells, 299-E18-1 and 299-E32-4, was slightly higher than in the downgradient wells. Values ranged from 137 micromhos per centimeter in well 699-42-40A to 568 micromhos per centimeter in well 299-E18-1. The pH ranged from 7.0 to 8.2 and was comparable for background and downgradient wells. Total organic carbon was below the laboratory CRQL in all wells. 
Total organic halogen was generally below the CRQL (10 parts per billion), but was slightly above that level in several samples. One set of samples from well 699-42-42B showed total organic halogens between 60 and 70 parts per billion.

Manganese and Iron--Samples collected from well 699-42-40B in November 1988 exhibited iron and manganese concentrations one or two orders of magnitude greater than the other wells. This is a carbon-steel-casing well located next to well 699-42-40A and monitors essentially the same horizon. Well 699-42-40A did not show high manganese and iron concentrations. Samples from well 699-42-40B had high turbidity, and it appears the samples were not representative of true groundwater quality; this well is no longer included in the $B$ Pond groundwater monitoring network.

Tritium--The highest tritium concentration observed in $B$ Pond wells between November 1988 and August 1989 was 79,500 picocuries per liter in wel1 699-42-42B. The primary drinking water standard for tritium is 20,000 picocuries per liter (40 CFR 141). The adjacent shallow well (699-43-42J) had tritium concentrations over an order of magnitude smaller than well 699-42-42B. Tritium concentrations in the other wells in the B Pond network ranged over 4 orders of magnitude.

Section 6.3 of the Tri-Party Agreement (Ecology et al. 1992) states that a land disposal unit being closed in conjunction with an operable unit may be 'clean closed' under RCRA if it is shown not to contain hazardous waste or hazardous constituents, and "Any remaining CERCLA-only materials would be addressed as part of the past-practice process as designated for that operable unit." To minimize overlap between RCRA and CERCLA investigations for the operable unit that includes $B$ Pond, tritium will be addressed with the 200-BP-11 operable unit.

Tritium is incorporated into water molecules, and is extremely mobile in groundwater. A recent tritium plume map is presented in Figure 5-4 (Connelly et a1. 1992). This map does not include the most recent data from the $B$ Pond monitoring wells. Recent groundwater data indicate the plume may extend further to the southwest than indicated in Figure 5-4. Tritium concentrations in groundwater in the 200 East Area and in the vicinity of $B$ Pond were much higher in the 1960's and 1970's than they are currently. In 1964, concentrations greater than 3,000,000 picocuries per liter were observed in the southeastern corner of the 200 East Area, and concentrations beneath $B$ Pond were probably between 300,000 and 3,000,000 picocuries per 1iter (Wilbur et al. 1983, Plate 4). At that time, there were no groundwater monitoring wells associated with $B$ Pond, so historical data are limited. Tritium concentrations were about the same in 1968 and 1972, but the plume had migrated to the east and southeast.

The primary source of the tritium plume is associated with the PUREX Plant in the southeast corner of the 200 East Area; however, the shape of the plume through time indicates that the 216-B-3 Pond also contributed. By 1980 , tritium concentrations beneath the $B$ Pond area had decreased by about one order of magnitude [i.e., to between 30,000 and 300,000 picocuries per liter (Graham and Brown 1981, pp. 27-28)]. The map of the tritium plume for 
1987 shows concentrations at about this same level $(20,000$ to 200,000 picocuries per liter) in the immediate vicinity of B Pond. The plume emanating from the 200 East Area is now distinct from the one emanating from $B$ Pond, with lower concentrations in between (Figure 5-4).

The wells around $B$ Pond that are completed in the finer grained sediments seem to contain higher concentrations of tritium than wells completed in the coarser grained sediments. These high levels of tritium are probably remnants of the higher levels of tritium seen in the aquifer in the past. Because the transmissivity of these sediments is low, the older, high-tritium water is not flushed out as quickly as it was from the coarser-grained sediments.

5.1.3.3 Quality Assurance and Quality Control. This section discusses the results of the quality control measures for groundwater samples collected for B Pond in November 1988 through August 1989. Quality assurance procedures for the collection and analysis of groundwater and geologic samples were presented in Section 5.1.2.

Duplicate, split, blank, and matrix spike samples are submitted regularly with groundwater samples to determine whether laboratory and field practices are yielding representative data. Quality control data are analyzed monthly and possible causes of any significant anomalies are assessed. Results of these assessments are summarized in quarterly progress reports. A summary of the quality control findings for B Pond is presented in the following paragraphs.

Duplicate--Duplicate samples were analyzed in the same laboratory to test precision. Results indicate that the data are within acceptable limits. Analytical results for duplicate samples are included in the chemical data in Appendix B.

Split--Some samples were split and analyzed by two different laboratories (United States Testing Company, Incorporated, and PNL) up until May 1990 to test accuracy. The results generally were consistent (i.e., within 2.8 standard deviations) but there were exceptions.

- There was a difference in potassium from well 699-42-40A in November 1988. Alkali metals such as potassium are not as accurately reflected by the inductively coupled plasma method as are other metals. Therefore, the differences between laboratories are seen as being of little significance.

- Results of radiological analyses (gross alpha and gross beta) were rather inconsistent in November 1988 and February 1989, presumably because the analytical methods of the two laboratories were different. Analytical methods of the laboratories have been reconciled.

- Slight differences in iron concentrations were noted between laboratories in samples from well 699-43-43 for March 1989. The U.S. Testing Company reported 31 and less than 30 parts per billion iron on duplicate samples; PNL reported 76 parts per billion iron. This difference may have been due to sample contamination. 
Blank--Blank samples taken between November 1988 and August 1989 were found to contain low concentrations of acetone (15 to 13 parts per billion, respectively). The presence of acetone was attributed to laboratory contamination. Some volatile organic constituents were found in the February 1989 blanks. These constituents were traced to a contaminated source of the water in the laboratory. This problem was corrected and did not affect the integrity of the groundwater samples. Blanks analyzed for metals in November 1988 showed small quantities of zinc, calcium, and iron; these may al so represent laboratory contamination.

\subsubsection{Groundwater Quality Assessment}

If the indicator evaluation monitoring program demonstrates a significant change in one or more of the indicator parameters, groundwater quality assessment monitoring will be initiated 40 CFR 265.93(d). The purpose of assessment monitoring is to determine the concentration and distribution of any dangerous waste constituents migrating from the facility, and to estimate the rate and extent of contaminant migration. The program may involve additional well monitoring, new well installation, additional field and laboratory testing, or mathematical modeling. The groundwater quality assessment program is described in more detail in Luttrell et al. (1989, pp. 73-79).

\subsection{AQUIFER IDENTIFICATION}

This section describes the regional setting of the Hanford Site, including its physiography, climate, geology (i.e., stratigraphy, tectonic framework, seismicity), and hydrology. Hydrogeology of the B Pond site also is described.

\subsubsection{Climate}

Since 1945, climatological data have been collected at the Hanford Meteorological Station, located between the 200 East and West Areas. Temperature and precipitation data also are available from nearby locations for the period 1912 to 1943. A summary of these data through 1980 has been published by Stone et al. (1983). Data from the Hanford Meteorological Station are representative of the general climatic conditions for the region and describe the specific climate of the 200 Area Plateau.

The Cascade Range greatly influences the climate of the Hanford Site by causing a rain-shadow effect and by serving as a source of cold air drainage, both of which have a considerable effect on the wind conditions.

Prevailing wind directions on the 200 Area Plateau are from the northwest in all months of the year (Figure 5-5). Secondary maxima occur for southwesterly winds. Monthly average wind speeds are lowest during the winter months, averaging 6 to 7 miles an hour, and highest during the summer, averaging 9 to 10 miles an hour. 
The DOE (1988b, p. 5.1-10-5.1-11) lists averages and extremes of temperatures measured at the Hanford Meteorology Station over a period from 1912 to 1980 . The average daily maximum temperature ranges from $36.9{ }^{\circ} \mathrm{F}$ in January to $91.9^{\circ} \mathrm{F}$ in July. Average daily minimum range from $22.1^{\circ} \mathrm{F}$ in January to $61.1{ }^{\circ} \mathrm{F}$ in July. The record high temperature is $114^{\circ} \mathrm{F}$ (July 27, 1939) and the record low is $-27{ }^{\circ} \mathrm{F}$ (December 12, 1919).

The annual average relative humidity at the Hanford Meteorological Station is 54 percent. It is highest during the winter months, averaging about 75 percent, and lowest during the summer months, averaging about 35 percent.

Precipitation measurements have been made at the Hanford Meteorological Station since 1945. Average annual precipitation is 6.3 inches at the Hanford Meteorological Station. Most of the precipitation occurs during the winter, with nearly half of the annual amount occurring from November through February. Days with greater than 0.5 inch precipitation occur less than 1 percent of the year. Rainfall intensities of 0.5 inch per hour persisting for 1 hour are expected once every 10 years. Rainfall intensities of 1 inch per hour for 1 hour are expected only once every 500 years. The winter monthly average ranges from 0.3 inch in March to 5.3 inches in January. The record snowfall of 24.4 inches occurred in February 1916. Snowfall accounts for about 38 percent of all precipitation from December through February.

\subsubsection{Physiography}

The Hanford Site lies within the Central Plains and Yakima Folds physiographic regions within the Columbia Basin subprovince of the Columbia Intermontane Province (Figure 5-6). The Columbia Plateau is the portion of the Columbia Intermontane Province that is covered by the Columbia River Basalt Group (Thornbury 1965, pp. 442-470).

The physiography of the Hanford Site is dominated by the low-relief piains of the Central Plains region and basaltic ridges of the Yakima Folds region (Gable Mountain-Umtanum Ridge, Yakima Ridge, Saddle Mountains, and Rattlesnake Mountains-Rattlesnake Hills).

The surface topography of the Hanford Site is dominantly the work of two principal geomorphic processes:

- Pleistocene cataclysmic flooding

- Holocene eolian activity.

Cataclysmic flood deposits formed when ice dams in western Montana and northern Idaho were breached, allowing large volumes of water to spill across eastern and central Washington, forming the channeled scabland. The last major flood occurred about 13,000 years before present during the late Pleistocene Epoch. Landforms in the Pasco Basin, left behind as a result of late Pleistocene flooding, include anastomosing flood channels, giant current ripples, bergmounds, and giant flood bars. One of these flood bars forms a 
prominent terrace, referred to as the Cold Creek bar (Bretz et al. 1956, pp. 1010-1014). The Hanford Site 200 Areas are located along this flood bar.

Since the end of the Pleistocene, winds locally have reworked the flood sediments, depositing mostly dune sand in the Central Plains, and loess (windblown silt) around the margins of the Pasco Basin. Much of the dune sand has been stabilized by anchoring vegetation. However, stabilized dunes are reactivated easily in areas where vegetation has been disturbed by fire or man.

\subsubsection{Regional Geology}

This section describes the tectonic framework, structural geology, and stratigraphy of the Hanford Site.

5.2.3.1 Tectonic Framework. The Columbia Plateau is a part of the North American continental plate and lies in a back-arc setting east of the Cascade Range. It is bounded on the north by the Okanogan Highlands, on the east by the Northern Rocky Mountains and Idaho Batholith, and on the south by the High Lava Plains and the Snake River Plain.

5.2.3.2 Structural Geology. The Columbia Plateau can be divided into three informal structural subprovinces (Figure 5-7): Blue Mountains, Palouse, and Yakima Fold Belt. These structural subprovinces are delineated on the basis of their structural fabric, unlike the physiographic provinces that are defined on the basis of landforms. The Hanford Site is located near the junction of the Yakima Fold Belt and the Palouse subprovinces.

Yakima Fold Belt Subprovince--The principal characteristics of the Yakima Fold Belt are a series of segmented, narrow, asymmetric anticlines that have wavelengths between 3 and 19 miles and amplitudes commonly less than 0.6 mile. These anticlinal ridges are separated by broad synclines or basins that, in many cases, contain thick accumulations of Neogene- to Quaternary-age sediments. The Pasco Basin is one of the larger structural basins in the Columbia Plateau.

Thrust or high-angle reverse faults with fault planes that strike parallel or subparallel to the axial trends are found principally along the limbs of the anticlines (DOE 1988b, pp. 1.3-32-1.3-33). The amount of vertical stratigraphic offset associated with these faults varies but commoniy exceeds hundreds of meters.

The deformation of the Yakima Folds occurred under north-south compression and was probably contemporaneous with the eruption of the basalt flows (DOE 1988b, pp. 1.3-32-1.3-33). The fold belt was growing during the eruption of the Columbia River Basalt Group and continued to grow through the Pliocene, into the Pleistocene and, perhaps, to the present.

Cold Creek Syncline--The DOE-RL waste management areas are located within the Cold Creek syncline. The Cold Creek syncline (Figure 5-8) lies between the Umtanum Ridge-Gable Mountain unlift and the Yakima Ridge uplift and is the 
principal structural unit that contains the 200 Areas. The Cold Creek syncline is an asymmetric and relatively flat-bottomed structure. The 200 Areas lie on the northern flank, and the bedrock dips gently to the south (approximately 5 degrees).

Groundwater hydraulic heads in the cold Creek syncline have been found to be affected by a geologic feature marked by the Yakima Barricade geophysical anomaly (Figure 5-8), which occurs on the west side of the Cold Creek syncline. This feature is marked by a west-to-east drop in hydraulic gradient in the confined aquifer. The data suggest that this feature is either a steeply dipping fold or a high-angle fault that formed during the late Miocene to early Pliocene. The absence of deformed Middle Ringold sediments indicates that movement ended by late Pliocene.

Umtanum Ridge-Gable Mountain Structural Trend--The Umtanum Ridge-Gable Mountain structural trend is a segmented anticlinal ridge extending for a length of 85 miles in an east-west direction and passing north of the 200 Areas (see Figure 5-8). This structure consists of five segments. From the west, Umtanum Ridge plunges eastward and joins the Gable Mountain-Gable Butte segment just east of the western boundary of the Hanford Site. The easternmost segment, the southeast anticline, "rends southeast off the eastern boundary of the Gable Mountain-Gable Butte segment.

The Umtanum Ridge is an asymmetrical, north-vergent-to-locally-overturned anticline with a major thrust to high-angle reverse fault on the north side (Goff 1981, Pp. 41-46; PSP\&L 1982, Pp. 2N-12-2N-14) that dies out eastward toward Gable Mountain. Gable Mouritain and Gable Butte are two topographically isolated, anticlinal ridges that are composed of a series of northwest trending, doubly plunging, en echelon anticlines, synclines, and associated faults. Capable faulting has been identified on Gable Mountain (NRC 1982, pp. 2-27-2-29; PSP\&L 1982, PP. 20-5).

Yakima Ridge--The Yakima Ridge uplift extends from west of Yakima, Washington, to the center of the Pasco Basin, where it forms the southern boundary of the Cold Creek syncline (see Figure 5-8). The easternmost surface expression of the Yakima Ridge uplift is represented by an anticline that plunges eastward into the Pasco Basin (Myers et al. 1979, Plate III). The eastern extension of Yakima Ridge is buried mostly beneath late Cenozoic sediments but is assumed to be similar to the exposed parts.

5.2.3.3 Stratigraphy. Geologic materials underlying the Hanford Site consist of numerous formally and informally recognized stratigraphic units

(Figure 5-9). These units are discussed in three groups:

- Columbia River Basalt Group

- Ellensburg Formation

- Suprabasalt sediments.

Columbia River Basalt Group--The Columbia River Basalt Group (Figure 5-9) comprises an assemblage of tholeitic, continental flood basalts of Miocene age. These flows cover an area of more than 63,000 square miles in Washington, Oregon, and Idaho, and have an estimated volume of about 
170,000 cubic kilometers (DOE 1988b, pp. 1.2-3). Isotopic age determinations suggest flows of the Columbia River Basalt Group were erupted during a period from approximately 17 to 6 million years before present, with more than 98 percent by volume being erupted in a 2.5 million-year period (17 to 14.5 million years before present).

Columbia River basalt flows were erupted from north-northwest-trending fissures or linear vent systems in north-central and northeastern oregon, eastern Washington, and western Idaho (Swanson et al. 1975, pp. 877-905). The Columbia River Basalt Group formally is divided into five formations, from oldest to youngest: Imnaha Basalt, Picture Gorge Basalt, Grande Ronde Basalt, Wanapum Basalt, and Saddle Mountains Basalt. Of these, only the Grande Ronde, Wanapum, and Saddle Mountains Basalts are known to be present in the Pasco Basin. The Saddle Mountains Basalt forms the uppermost basalt unit in the Pasco Basin except along some of the bounding ridges where Wanapum and Grande Ronde Basalts are exposed.

Ellensburg Formation--The Ellensburg Formation (see Figure 5-9) includes epiclastic and volcaniclastic sedimentary rocks that are interbedded with the Columbia River Basalt Group in the central and western part of the Columbia Plateau (Schmicke 1964, pp. 375-376; Swanson et al. 1979, p. G25). The age of the Ellensburg Formation is principally Miocene, although locally it may be equivalent to early Pliocene. The thickest accumulations of the Ellensburg Formation lie along the western margin of the Columbia Plateau where Cascade Range volcanic and volcaniclastic materials interfinger with the Columbia River Basalt Group. Within the Pasco Basin, individual interbeds have been named (i.e., Mabton, Selah, and Cold Creek) and these deposits are found primarily in the Wanapum and Saddle Mountains Basalts. The lateral extent and thickness of interbedded sediments generally increase upward in the section (Reidel and Fecht 1981, pp. 3-30). Two major facies, volcaniclastic and fluvial, are present as distinct or mixed deposits.

Suprabasalt Sediments--The suprabasalt sediments within and adjacent to the Hanford Site (see Figure 5-9) were derived from a variety of sedimentary environments, although the fluvial-lacustrine Ringold Formation and the glaciofluvial Hanford formation dominate the preserved stratigraphic record (DOE 1988b, Pp. 1.2-63-1.2-72). The following discussion on the suprabasalt sediments is divided into three sections:

- Late Neogene deposits

- Plio-Pleistocene hiatus

- Quaternary deposits.

Late Neogene Deposits--Late Neogene (i.e., late Miocene to Pliocene) deposits, younger than the Columbia River Basalt Group, are represented by the Ringold Formation within the Pasco and Quincy basins of the central Columbia Plateau (Grolier and Bingham 1978, pp. 38-50; Newcomb et al. 1972, pp. 10-16; Rigby and Othberg 1979, pp. 15-17). The fluvial-lacustrine Ringold Formation was deposited in generally east-west-trending valleys by the ancestral Columbia River and its tributaries in response to the development of the Yakima Fold Belt. While exposures of the Ringold Formation are limited to the

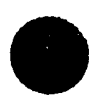


White Bluffs within the central Pasco Basin, and to the Smyrna and Taunton Benches north of the Pasco Basin, extensive data on the Ringold Formation are available from boreholes.

The Ringold Formation is classified into three facies associations that represent variations in the paleogeography during Ringold time. Section Type I, composed of gravel and associated sand and silt, represents a migrating channel deposit of the major, throughgoing, ancestral Columbia and/or Snake River systems confined to the central portion of the Pasco Basin. Section Type II is composed mostly of overbank sand, silt, and clay deposited along the margins of the basin, beyond the influence of the main channel. Section Type III, a fanglomerate, occurs locally around the extreme margins of the basin and mostly is composed of angular basaltic debris derived from side-stream alluvium shed off bedrock ridges.

Two approaches have been used to subdivide Section Type I Ringold Formation deposits in the central Pasco Basin. One is based on 1 ithofacies and the other on upward-fining cycles. Newcomb (1958, pp. 328-337) divided the Ringold into three lithofacies: a coarse-grained middle unit bounded above and below by fine-grained units. Tallman et al. (1979, pp. 18-19) describes a fourth lithofacies unit, the coarse-grained basal Ringold unit which underlies the fine-grained lower Ringold unit in the west-central Pasco Basin. The basal Ringold unit is further subdivided into coarse- and fine-grained subunits within the central Cold Creek syncline. A second approach is used by Puget Sound Power and Light Company (PSP\&L 1981, pp. $2 R-15-2 R-19)$ south and east of Gable Mountain where they divided the subsurface Ringold Formation into four fluvial cycles (Units I through IV).

Plio-Pleistocene Hiatus--The late Pliocene to early Pleistocene generally is characterized as a period of regional incision on the Columbia Plateau. Within the Pasco Basin, this is reflected by the abrupt termination and eroded nature of the top of the Ringold Formation (Brown 1960, pp. 4-6;

Bjornstad 1985, pp. 524; Newcomb et al. 1972, pp. 15-16). Following incision, a well-developed soil formed atop the eroded surface.

The exact timing and duration of incision is unknown; however, it probably occurred from 1 to 2 million years before present. Incision is bracketed between 0.9 million years before present and equal to, or younger than, 3.4 million years before present (Figure 5-9), the respective ages of the basalt from Haystack Butte (Bela 1982) and the youngest age reported from the Ringold Formation (DOE 1988b). Haystack Butte lava lies near river level within the Columbia River Gorge, approximately 90 miles southwest of the Pasco Basin, indicating that incision (as much as 492 feet in the Pasco Basin) had ceased by 0.9 million years before present.

Plio-Pleistocene Unit--A locally derived unit, consisting of either a sidestream alluvium or pedogenetic calcrete, occurs at the unconformity between the Ringold Formation and the Hanford formation (Bjornstad 1984, DOE 1988b). The sidestream alluvial facies are derived from Cold Creek and its tributaries and are characterized by relatively thick zones of unweathered 
1 basalt clasts, along with pedogenetically altered loess or colluvium. The pedogenic calcrete facies consists of one or more layers of carbonate-cemented Plio-Pleistocene detritus.

Early 'Palouse' Soil--overlying the Plio-Pleistocene unit in the Cold Creek syncline area is a fine-grained sand-to-silt believed to be mainly of eolian origin, derived from an older reworked Plio-Pleistocene unit or the upper Ringold (DOE 1988b, Bjornstad 1990). The early Palouse soil is differentiated from the overlying slackwater flood deposits by a greater calcium carbonate content, a massive structure in core samples, and a high natural gamma response in geophysical logs.

Quaternary Deposits--Aggradation of sediments resumed during the Quaternary, following the period of late Pliocene to early Pleistocene incision. Quaternary deposits are associated with a variety of depositional processes, including those associated with volcanism, glaciation, lakes, rivers, wind, and mass wasting. In the central Columbia Plateau, the Quaternary record is dominated by proglacial cataclysmic flood deposits, with lesser amounts of fluvial and eolian deposits that lie below, between, and above flood deposits. Nonflooded areas on the Columbia Plateau often are mantled by alluvium, colluvium, or loess (i.e., wind-blown silt).

Cataclysmic Flood Deposits--Proglacial flood deposits blanket low-lying areas over most of the central Columbia Plateau. Most cataclysmic flood deposits that are preserved are late Pleistocene. The last major flood sequence is dated at about 13,000 years before present by the presence of Mount St. Helens 'S' tephra (Mullineaux et al. 1978, pp. 178) with these sediments. The largest and most frequent floods came from glacial Lake Missoula in northwestern Montana; however, smaller floods may have escaped down valley from glacial lakes Clark and Columbia along the northern margin of the Columbia Plateau (Waitt 1980, pp. 668-671). Another source of Pleistocene floodwaters came down the Snake River from glacial Lake Bonneville (Malde 1968). Lake Bonneville flood deposits have not been positively identified within the Pasco Basin. This may be because of erosion and/or burial by younger flood deposits from Lake Missoula. The last Lake Bonneville flood occurred about 14,000 to 15,000 years before present (Scott et a1. 1982, pp. 582-586, 0'Connor 1993).

Normally, two types of flood deposits are observed: a coarse-grained, main-channel facies and a finer-grained, slack-water facies. Within the Pasco Basin, these are referred to as the Pasco gravels and the Touchet beds, members of the Hanford formation (Myers et a1. 1979, pp. III-66-III-68).

Deciphering the history of cataclysmic flooding in the Pasco Basin is complicated not only by floods from multiple sources, but also because paths of Lake Missoula floodwaters migrated and changed course with the advance and retreat of the Cordilleran ice sheet (Baker and Bunker 1985, pp. 32-34). Cataclysmic floods inundated the central Columbia Plateau several times during the Pleistocene. At least three major flooding episodes (early, middle, and late Pleistocene) are recognized in the Pasco Basin, although many more minor flood events probably occurred during each of these major episodes. The 
evidence for the different ages of flooding include changes in magnetic polarity, truncated clastic dikes, and soil development atop flood sequences (Baker et al. 1987, pp. 413 to 437 , Baker et al. 1991).

Clastic dikes commonly are associated with, but not restricted to, cataclysmic flood deposits on the Columbia Plateau. While there is general agreement that clastic dikes formed during cataclysmic flooding, a primary mechanism to satisfactorily explain the formation of all dikes has not been identified (Black 1979, WPPSS 1981, pp. 2.5-58-2.5-64). Among the more probable explanations are fracturing initiated by hydrostatic loading and hydraulic injection associated with receding floodwaters. Seismicity also may have a role in their formation, although there is no available evidence at the present to establish a connection.

Other Quaternary Deposits--Alluvium is present not only as a surficial deposit along major river and stream courses (Figure 5-10), but also in the subsurface, where it is found underlying and interbedded with proglacial flood deposits. Two types of alluvium are recognized in the Pasco Basin: quartzitic-mainstream and basalt-rich-sidestream alluvium. Colluvium (talus and slopewash) is a common Holocene deposit in moderate-to-high relief areas and, like dune sand that is found locally in the arid central plateau, commonly is not preserved in the stratigraphic record.

Varying thicknesses of loess or sand mantle much of the Columbia Plateau. Active and stabilized sand dunes are widespread over the Pasco Basin (Figure 5-10).

Landslide deposits in the Pasco Basin are of variable age and genes is. Most are associated with north limbs of the Yakima folds, such as on the north side of Rattlesnake Mountain, or along steep river embankments such as the White Bluffs in the Pasco Basin (see Figure 5-10).

\subsubsection{Regional Hydrology}

This section presents a description of surface and groundwater hydrology of the Pasco Basin and the Hanford Site.

5.2.4.1 Surface Water. The Hanford Site occupies approximately one-third of the land area within the Pasco Basin. Primary surface water features associated with the Hanford Site are the Columbia and Yakima Rivers and their major tributaries, the Snake and Walla Walla Rivers. With the exception of the Columbia River, there are no perennial streams within the Hanford Site. Ephemeral streams and major surface ponds are depicted in Figure 5-11. Waste water cribs and ditches also are present on the Site, associated with nuclear fuel processing and waste disposal activities. A network of dams and multipurpose water resource projects are located along the course of the Columbia River (Figure 5-12).

The Columbia River is considered to be free flowing along approximately two-thirds of the Hanford Site. This area of the river, referred to as the Hanford reach, extends from Priest Rapids Dam to the headwaters of Lake 
Wallula (the reservoir behind McNary Dam). Flow inventories are discussed in DOE (1988b, pp. 3.1-9-3.1-15). Flow along this reach is controlled by the Priest Rapids Dam. Several drains and intakes also are present along this reach, including irrigation outfalls from the Columbia Basin Irrigation Project and intakes for Hanford Site water use.

Cold Creek and its tributary, Dry Creek, are ephemeral streams within the Yakima River drainage system. Both streams drain areas along the western part of the Hanford Site and cross the southwestern part toward the Yakima River. Surface flow, which may occur during spring run-off or after heavier-thannormal precipitation, infiltrates into the surface sediments. Rattlesnake Springs, located on the western part of the Hanford Site, forms a small surface stream that flows for approximately 1.8 miles before disappearing into the ground. West Lake, an expression of the water table, is a small, shallow lake in a natural topographic low.

Approximately one-third of the Hanford Site is drained by the Yakima River system. The average annual discharge of the Yakima River to the Columbia River (over a recorded 57-year period) is approximately 3,600 cubic feet per second (DOE 1988b, pp. 3.1-14). Extremes include a maximum discharge of 67,000 cubic feet per second on December 23, 1933 and a minimum discharge of 105 cubic feet per second on September 11, 1906 (USGS 1985, pp. 322).

Flow in the Columbia River at the Priest Rapids Dam (i.e., above the Hanford Site) averages 120,000 cubic feet per second. Maximum flow for the 66-year period of record was 690,000 cubic feet per second on June 12, 1948; minimum flow was 4,120 cubic feet per second on February 10, 1932 (DOE 1988b, pp. 3.1-13). Normal river elevations range from 394 feet above mean sea level where the Columbia River enters the Hanford Site to 341 feet where the river leaves the Hanford Site.

Large Columbia River floods have occurred in the past, but the likelihood of large-scale flooding has been reduced by the construction of several dams upstream of the Hanford Site. The probable maximum flood calculated for the Columbia River below Priest Rapids Dam is 1,440,000 cubic feet per second (Gephart et al. 1979, pp. III-49). The probable maximum flood would inundate portions of the 100 Areas, but would not reach the Separations Area or B Pond (Gephart et a1. 1979, pp. III-51).

Routine water-quality monitoring of the Columbia River is conducted by the DOE-RL for both radiological and nonradiological parameters. Reports on the monitoring have been published annually since 1983 by PNL (e.g., Jaquish and Mitchell 1988). Ecology has issued a Class A (excellent) quality designation for the Columbia River water along the reach from Grand Coulee Dam, through the Pasco Basin, to McNary Dam. This designation requires that all industrial uses of this water be compatible with other uses, including drinking, wildlife habitat, and recreation. In general, Columbia River water is characterized by a very low suspended load, a low nutrient content, and an absence of microbial contaminants (DOE 1988b, pp. 3.4-13).

5.2.4.2 Groundwater. The Hanford Site is underlain by an unconfined aquifer system, consisting of glaciofluvial, fluvial, and lacustrine sediments, and a 
DOE/RL-89-28, Rev. 1

$12 / 15 / 93$

system of deeper confined to semiconfined aquifers in the basalt flow tops, flow bottoms, and sedimentary interbeds. The multiaquifer system has been conceptualized as consisting of four primary geohydrologic units:

- Suprabasalt Hanford and Ringold Formation sediments

- Saddle Mountains Basalt

- Wanapum Basalt

- Grande Ronde Basalt.

The regional limits of the unconfined aquifer system are the boundaries of the Pasco Basin. The aquifer is made up of the glaciofluvial sands and gravels of the Hanford formation and the fluvial-lacustrine sediments of the Ringold Formation. The aquifer is relatively continuous throughout the Pasco Basin. It ranges in thickness from zero, along the flanks of the bordering structures and at basalt highs within the basin, to greater than 230 feet in some central basin areas. The base of the unconfined aquifer is generally the basalt surface, but semiconfining silts and clays are present above the basalt in some areas.

Recharge to the unconfined aquifer system is derived from natural and artificial sources. Sources of natural recharge are precipitation from the higher bordering elevations and water infiltration from ephemeral streams and influent reaches of the Columbia and Yakima Rivers. As indicated in Section 5.2.1, the average annual precipitation in the vicinity of the 200 Areas is approximately 6.3 inches. The amount of precipitation falling at the higher elevation of Rattlesnake Mountain is approximately 15.0 inches per year. Mean annual run-off, however, is less than 0.5 inch (Leonhart 1979, pp. II-55). The actual amount of recharge to the unconfined sediments from precipitation is minimal because of the very high evapotranspiration rates in the basin [five to nine times that of precipitation (Leonhart 1979, pp. II-55)]. Gee (1987, pp. 5.3-5.4) indicates that minimum recharge (greater 0.04 inch per year) occurs where soils are fine and vegetation consists of deep-rooted plants, and a possible maximum recharge ( 3.9 inches per year) may occur where soils are coarse in texture and there is no vegetation. Surface recharge to the sediments in the 200 Areas is suspected to range from near zero to 2.4 inches per year (Last et a1. 1989, pp. 6.2).

Artificial recharge to the unconfined sediments in the Pasco Basin occurs through agricultural irrigation and waste water disposal practices. Most of the agricultural irrigation originates on the eastern and northern sides of the Columbia River (in Franklin County) and in Cold Creek Valley to the west of the Hanford Site (in Benton County). The average estimated water use for these areas before 1979 was $7.4 \times 10^{10}$ gallons per year for Benton County and $1.9 \times 10^{11}$ gallons per year for Frankl in County (Leonhart 1979, PP. II $-59-$ II -60$)$.

Waste water disposal to ponds, trenches, and other facilities in the 200 Areas has resulted in the formation of large groundwater mounds beneath the major disposal areas at the 216-U-10 Pond (U Pond), the Gable Mountain Pond, and B Pond (see Figure 5-11). Since the start of disposal practices, the water table under $U$ Pond rose over 85 feet. The mound under $B$ Pond rose by approximately 35 feet. The smaller mound beneath $B$ Pond reflects the 
higher transmissivity of the aquifer in that area. Waste water disposal to $U$ Pond was discontinued in 1984, but the associated groundwater mound persists due to the lower transmissivity of the saturated sediments and local effluent discharge to trenches and cribs in the area.

Principal groundwater flow direction within the unconfined aquifer system is west to east across the Pasco Basin to the Columbia River. Local variations in this general direction reflect the presence of groundwater mounds associated with liquid-waste disposal facilities or where bedrock ridges (e.g., Gable Mountain) protrude above the water table (Figure 5-3). The most pronounced mounds are located beneath the 200 Areas. Groundwater in the unconfined aquifer flux flows northward between Gable Mountain and Gable Butte, and the hydraulic gradient beneath the 200 East Area has been reduced to near zero due to the influence of the westward-flowing component of groundwater flow from B Pond mound. Figure 5-13 illustrates the water table beneath the Hanford Site.

Because of the heterogeneous nature of the sediments, the hydraulic properties of the unconfined aquifer system within the Pasco Basin are variable. Hydraulic conductivities for the Hanford formation $(2,000$ to 10,000 feet per day) are much greater than those of the middle member of the Ringold Formation ( 9 to 230 feet per day) (Graham et al. 1981, pp. 3-12). The main body of the suprabasalt aquifer occurs within the middle member of the Ringold Formation.

Water from the unconfined aquifer in the Pasco Basin generally has low specific conductance (125 to 1,250 micromhos per centimeter). The water is principally a calcium-bicarbonate type, with local variations (Graham et al. 1981, pp. 2-4). The estimated background concentrations of chemical constituents within the groundwater of the unconfined aquifer at the Hanford Site is given in Table 5-4.

Confined aquifers are present in the sedimentary interbeds and/or interflow zones between dense basalt flows of the Columbia River basalts. The main water-bearing portions of the interflow zones are networks of interconnecting vesicles and fractures of the flow tops and flow bottoms. Hydraulic conductivity of flow tops in the Saddle Mountains Basalt has a geometric mean between 10 feet per day and 100 feet per day (DOE 1988b, pp. 3.9-93). Sedimentary interbeds in the Saddle Mountains Basalt have hydraulic conductivities between 1 foot per day and 10 feet per day (DOE 1988b, pp. 3.9-99). Hydraulic conductivity of basalt flow interiors is approximately five orders of magnitude lower than flow tops.

Recharge to the Saddle Mountains Basalt apparently occurs along the southwestern and western boundaries of the Pasco Basin. Some recharge also may occur in the eastern Saddle Mountains along the northern boundary of the Pasco Basin (DOE 1988b, pp. 3.7-14). Groundwater al so flows from the suprabasalt aquifer into the Rattlesnake Ridge interbed in the western half of the Hanford Site (DOE 1988b, pp. 3.9-116).

The configuration of the potentiometric surface and hydrochemistry indicate that the Saddle Mountains Basalt aquifers discharge into the 
1 Columbia River (DOE 1988b, pp. 3.7-14 and 3.7-15). These discharges occur 2 between the Columbia River's confluence with the Yakima and Snake Rivers and 3 the eastern portion of the Hanford Site. The Saddle Mountains Basalt aquifers 4 also may discharge into the lower Snake and Walla Walla Rivers in the Pasco 5 Basin. In the eastern half of the Hanford Site, the Rattlesnake Ridge aquifer

has a higher potential than the suprabasalt sediments (DOE 1988b, pp. 3.9-116), and here groundwater has the potential to flow upward through the confining units into the Ringold Formation.

Erosional 'windows' through the dense basalt flow interiors provide the potential for direct interconnections between the unconfined and uppermost confined aquifers. Graham et al. (1984, pp. 70-87) indicate that some contamination was present in the uppermost confined aquifer (Rattlesnake Ridge), south and east of the Gable Mountain Pond. Graham et al. (1984, pp. 67-68) evaluated the hydrologic relationships between the Rattlesnake Ridge aquifer and the unconfined aquifer in this area and delineated a potential area of intercommunication beneath the northeastern portion of the 200 East Area.

\subsubsection{Hydrogeology of the B Pond Area}

This section summarizes results of hydrogeologic characterization at the $B$ pond site to date and describes site geology and hydrology.

5.2.5.1 Geology of the B Pond Site. The generalized geology of the area is shown in two cross sections (Figures 5-14 and 5-15). The locations of the boreholes used in creating the fence diagram are shown in Figure 5-2.

The depth to the top of the basalt is approximately 200 feet based on boreholes 699-42-42, 699-43-42, and 699-42-40C. The uppermost confined aquifers in the basalt and interflow aquifer system are the Elephant Mountain interflow zone and the Rattlesnake Ridge interbed. The sediment thickness above the basalt varies by no more than 30 feet between the three boreholes. Above the basalt, the Ringold Formation, the Hanford formation, and eolian sediments are present.

The Ringold Formation directly overlies the basalt and is approximately 100 feet thick in the three boreholes that penetrate the entire suprabasalt section. The water table occurs near the Hanford-Ringold contact, and the Ringold Formation makes up the bulk of the uprermost aquifer (Figures 5-14 and 5-15). The top of the Ringold Formation in the central part of the $B$ Pond area is marked by a calcic paleosol composed of yellow sandy-silty material. This feature occurs as a lenticular body about 100 feet below the land surface, pinching out to the west and south of the $B$ Pond area.

The Ringold Formation throughout the $B$ Pond area is primarily a sand and pebble conglomerate, and a pebble conglomerate (Lindsey et al. 1992). Several beds of clay-muds and silts are intercalated with these conglomerates in the southern part of the B Pond area. These beds pinch out to the north and west and form a series of local, low-permeability beds. 
The Hanford formation mainly comprises sand and pebble conglomerates and pebble conglomerates. Boreholes 699-43-42, 699-41-40, and 699-43-43, however, encountered cobbles and boulders immediately above the Ringold Formation.

Throughout the central and northern parts of the area, Holocene eolian sands overlie the Hanford formation.

5.2.5.2 Hydrology of the B Pond site. This section describes properties of the principal hydrologic units in the subsurface beneath B Pond. These units are the unsaturated zone, the Hanford formation, coarse- and fine-grained facies of the Ringold Formation, and the uppermost aquifers within the basalt and interbeds. Hydrogeologic investigations to date indicate that the 'uppermost aquifer' in the vicinity of $B$ Pond may be defined as the suprabasalt aquifer system.

The unsaturated zone beneath $B$ Pond ranges in thickness from 124 feet at wells $699-42-40 A$ and $699-42-40 B$ to between 150 and 160 feet at wells 699-42-42B, 699-43-42J, 699-43-43, 699-44-42, and 699-45-42. The zone is composed primarily of Hanford formation sediments (Figures 5-14 and 5-15), mostly sands and gravels, with minor amounts of silt and clay. The unsaturated zone includes the top few feet of the fine-grained Ringold Lower Mud unit near wells 699-40-39 and 699-41-40, where the water table is below the Hanford-Ringold contact.

Moisture content analyses were performed on sediment samples taken while drilling the RCRA wells. Samples were not collected at regular intervals in all wells; water was added occasionally during drilling, which precluded sampling for natural moisture content. Most values ranged from 3 to 7 percent. Zones of significantly higher moisture content were observed in wells 699-44-42 (at 80-90 feet of depth), 699-43-43 (35-40 and 85 feet), 699-42-42B (35, 50-60, 70-80, and 90 feet), 699-43-45 (14, 43-55 feet), and 699-41-40 (126-149 feet, which is below the potentiometric surface). These zones of relatively high moisture content appear to be associated with sand lenses, but because sampling was discontinuous, it is not possible to trace the extent of the high moisture zones.

A thin layer of perched water was encountered while drilling well 699-43-45 in muddy sand at approximately 44 feet below 1 and surface. This perched water zone does not appear to be extensive; no perched water was noted in the other wells except in well 699-40-36 which was drilled for the W-049H TEDF Facility. No perched water was observed beneath $3 \mathrm{C}$ Pond, al though the fine-grained layer at the top of the saturated zone is thickest in this region, and percolation rates from $3 C$ Pond are higher than from the other ponds.

The uppermost aquifer in the vicinity of $B$ Pond comprises sediments of the Hanford and Ringold formations. It ranges in thickness from approximately 50 feet in the northwestern part of the site to approximately 100 feet in the southeast. This aquifer characteristically has been referred to as unconfined. However, hydrogeologic data from recently installed monitoring wells indicate that part of the aquifer within the suprabasalt sediments is confined or semiconfined. The aquifer is unconfined to the west and north of 
216-B-3 Pond and is progressively more confined in the southeast part of the site, beneath $3 C$ Pond. There is no marked difference in hydraulic head measured in the confined and unconfined portions of the aquifer.

The uppermost aquifer system beneath B Pond includes a portion of the Hanford formation and the Ringold Formation. As discussed in Section 5.2.5.1, the Ringold Formation includes a coarse-grained facies (sand and gravel) and a discontinuous fine-grained facies (silt and clay). The fine-grained layer locally acts as a confining unit. Aquifer tests and laboratory tests have been conducted for each of these units to estimate hydraulic properties. Results of some of these tests are discussed in the following paragraphs. Slug injection/withdrawal tests were conducted during the summer of 1989 . Analysis and review of the results have not been completed at the time of this writing, but will be included in a site characterization report.

Hanford formation--Constant-discharge tests in two of the wells (699-43-43 and 699-44-42) were conducted over an interval including portions of both the Hanford and Ringold Formations in the upper part of the unconfined aquifer. Hydraulic properties determined from these tests are probably more representative of the Hanford formation than the Ringold Formation because the Hanford formation generally is more permeable than the Ringold Formation, therefore yielding more water per unit thickness (i.e., higher transmissivity). In addition, the portion of the screen length extending over the Hanford formation was greater than that over the Ringold Formation for each of the tests.

Estimates of hydraulic conductivity of the Hanford formation were determined from results of tests conducted in these two wells. Hydraulic conductivity values were determined to be 2,100 feet per day and 4,200 feet per day from wells 699-43-43 and 699-44-42, respectively. Calculation of these values assumes that water was derived only from the screened interval.

Graham et al. (1981, pp. 3-12) estimated storativity of the Hanford formation in the Separations Area as 0.07 .

Coarse-grained Ringold Unit--A multiple-well constant-discharge test was conducted at well 699-42-42B, and well 699-43-42J was used as an observation well. The tested interval in the pumping well represented the Ringold Formation in the lower part of the uppermost aquifer. The aquifer at this well is considered to be semiconfined or confined. The results of the test yielded a value of hydraulic conductivity of 6 feet per day. Storativity and the ratio of horizontal to vertical hydraulic conductivity could not be determined from this test because of the lack of response in the observation well.

Another multiple-well constant-discharge aquifer test was conducted at well 699-42-40C in 1982 (Graham et al. 1984, pp. C.10 and C.11). The observation wells used during the test were 699-42-40A and 699-42-40B. This test was conducted in the lowermost sediments of the Ringold Formation. 
Transmissivities determined from results of this test yielded values of 310 square feet per day (well 699-42-40A) and 360 square feet per day (wel1 699-42-40B). Estimates of storativity are $1.7 \times 10^{-2}$ (observation well 699-42-40A) and $9.3 \times 10^{-3}$ (observation well 699-42-40B).

Fine-grained Ringold Unit--Falling-head and constant-head permeameter tests were conducted on sediment samples collected from well 699-42-42B to determine vertical hydraulic conductivity. These sediment samples represent fine-grained materials of the Ringold Formation in the upper portion of the aquifer, each representing a different interval from the sediment profile. Results of the falling-head test yielded a vertical saturated hydraulic conductivity of approximately 0.07 foot per day. Results of the constant-head test yielded a vertical saturated hydraulic conductivity of approximately 0.002 foot per day.

Basalt and Interflow Aquifer System--The two uppermost confined aquifers in the basalt beneath $B$ Pond are the interbed-interflow zone between Elephant Mountain flows and the Rattlesnake Ridge aquifer. The Elephant Mountain aquifer consists of interconnected vesicles, basalt rubble, and in some places sands and clays. The Rattlesnake Ridge aquifer consists of the flow bottom of the Elephant Mountain Member, the flow top of the Pomona basalt, and the Rattlesnake Ridge Interbed (Graham et al. 1984, pp. 10). The Rattlesnake Ridge Interbed is composed of (in descending order) tuffite, volcanic ash, overbank flood deposits, and a clay matrix-supported basaltic conglomerate. The interbed is 50 to 65 feet thick in the vicinity of $B$ Pond.

The confining unit between the Rattlesnake Ridge aquifer and the unconfined aquifer is composed of the dense interiors of the Elephant Mountain Member. At well 699-42-40C, the thickness of the Elephant Mountain Member is about 100 feet (Graham et al. 1984, p. 49). The thickness of the Elephant Mountain Member to the southeast of $B$ Pond is unknown because of a lack of wells penetrating the basalts.

Results of aquifer tests in the basalt aquifer system conducted near $B$ Pond are summarized in the following paragraphs.

Elephant Mountain Member--A constant-discharge test at well 699-42-40C in 1982 (Graham et al. 1984, pp. C.12) was conducted over an interval open to the Elephant Mountain Interfiow Zone. Results of the test yielded a transmissivity of approximately 8 square feet per day.

Rattlesnake Ridge Aquifer--The two constant-discharge tests, two recovery tests, and two slug tests performed in wel1 699-42-40C in 1982 (Graham et al. 1984, Pp. C.13-C.16 and D.7-D.8) were conducted in the sediments of the Rattlesnake Ridge confined aquifer. Results of the constant-discharge tests yielded transmissivity values of 300 square feet per day and 310 square feet per day, and the recovery tests yielded transmissivity values of 170 square feet per day and 260 square feet per day. 
The slug test included both injection and withdrawal tests or "phases." The slug injection test results yielded a transmissivity value of 910 square feet per day, and the slug withdrawal test results yielded a transmissivity value of 130 square feet per day.

Hydraulic conductivities of the Columbia River basalts flow interiors are extremely low, ranging from $3 \times 10^{-6}$ to $3 \times 10^{-8}$ feet per day (DOE 1988b, pp. 3.9-101).

5.2.5.3 Direction and Rate of Groundwater Movement. Water table maps of the Separations Area indicate that groundwater flows radially outward from a groundwater high beneath $B$ Pond. Flow is interrupted by basalt that extends above the water table to the north and northeast (see Figure 5-13). Groundwater flow in the 200 East Area is not well defined. The groundwater gradient in this area is very sma11; differences in water levels between wells are often within the margin of measurement uncertainty. Groundwater converges in the 200 East Area from the west and east, then diverges with a component flowing northward between Gable Mountain and Gable Butte, and another component flowing southeast toward the Columbia River.

Direction of groundwater flow over time also can be inferred by examining the patterns of groundwater chemistry. A tritium plume associated with the Separations Area is illustrated in Figure 5-4. Concentration gradients around B Pond show a pattern similar to the groundwater gradient.

There is also a downward vertical hydraulic gradient within the uppermost aquifer system beneath B Pond. This is evident from a comparison of potentiometric levels between wells $699-42-42 B$ and 699-43-42J.

We11 699-43-42J is completed in the upper portion of the uppermost aquifer (open interval of 156.9 to 177.4 feet below land surface), and well 699-42-42B is completed in the lower portion of the uppermost aquifer (open interval of 192.9 to 203.2 feet below land surface). The potentiometric levels measured in these wells on May 24, 1989, were 419.64 and 417.58 feet above mean sea level respectively. This downward gradient of approximately 0.1 is caused by the mounding and recharge resulting from discharges to $B$ Pond.

The $B$ Pond also has created a downward gradient from the suprabasalt aquifer to the underlying Rattlesnake Ridge interbed in the immediate vicinity of the mound (Figure 5-16; Kasza and Schatz 1989, pp. 4). This is a reversal of the natural gradient between these hydrologic units.

Groundwater chemistry on the Rattlesnake Ridge aquifer has been studied to assess whether there is interconnection with unconfined groundwaters (Graham et al. 1984). Tritium is present in the Rattlesnake Ridge aquifer, with the highest concentrations associated with the 200 East Area. Well 699-42-40C, adjacent to B Pond, showed low levels of tritium in the Rattlesnake Ridge aquifer; these levels may have been induced during construction of the well. Tritium concentrations decreased from 39 to 12.2 picocuries per liter during an aquifer test of this well, indicating that the contamination was very local. Other Rattlesnake Ridge wells contained tritium less than or equal to 1.4 picocuries per liter. Apparently, groundwater flow is minimal from the unconfined to the confined aquifer beneath $B$ Pond. Any 


\section{contamination in the Rattlesnake Ridge aquifer eventually will discharge back} to the unconfined aquifer (Graham et a1. 1984. pp. 89).

The movement of the tritium plume provides a means of tracing groundwater flow through time and for estimating its velocity over a larger area from $B$ Pond to the southeast (Wilbur et a1. 1983, Plates 3 through 6 ). The configuration of the plume in 1964 indicates that groundwater flowed at an average rate of 1.5 kilometers per year ( 14 feet per day) since the PUREX Plant began operations. Data from 1972 indicate a tritium migration of 18.3 kilometers in 16 years, or an average of 1.1 kilometers per year (10 feet per day). These estimates could represent groundwater flow in the more permeable, upper portion of the unconfined aquifer. Few wells are completed in the less permeable strata, so no estimates of fiow rate have been made for these layers.

As discussed previously, the vertical hydraulic gradient is estimated to be two orders of magnitude greater than the horizontal gradient, so the downward flow of groundwater beneath $B$ Pond is significant. This water may enter underlying aquifers in the basalt and interflow aquifer system (Chapter 6.0, Section 6.3.3). There are insufficient data to estimate vertical groundwater velocity in the suprabasalt aquifer.

An estimate of the average linear groundwater velocity can be calculated based on Darcy's Law. The calculations assume horizontal flow and a homogeneous aquifer. Estimates for the Hanford formation range from 50 to 240 feet per day. The approximate velocity in the Ringold Formation ranges from 0.03 to 0.1 foot per day. These estimates apply to the area of the groundwater mound beneath $B$ Pond. 


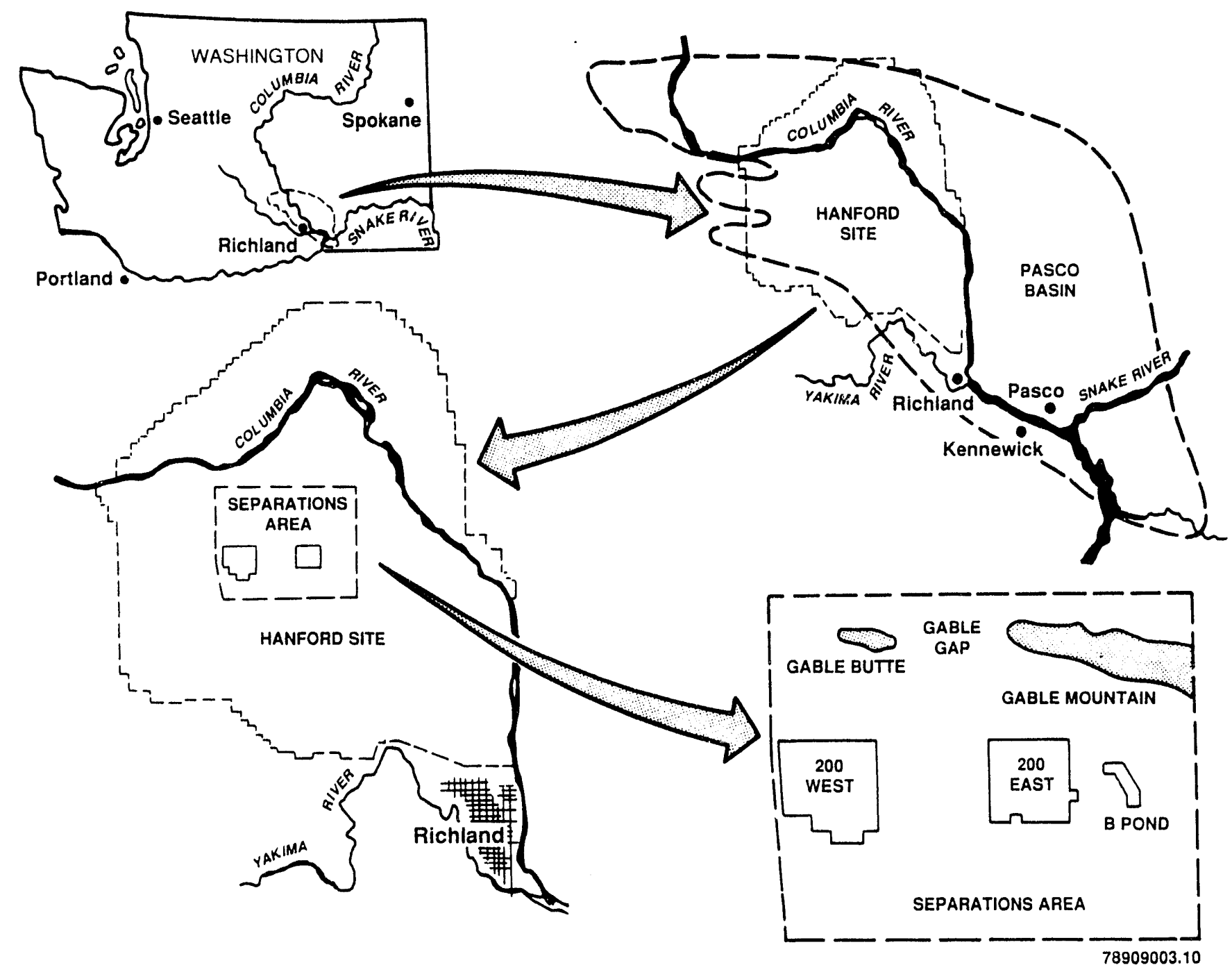

Figure 5-1. Locations of the Hanford Site and the Separations Area. 


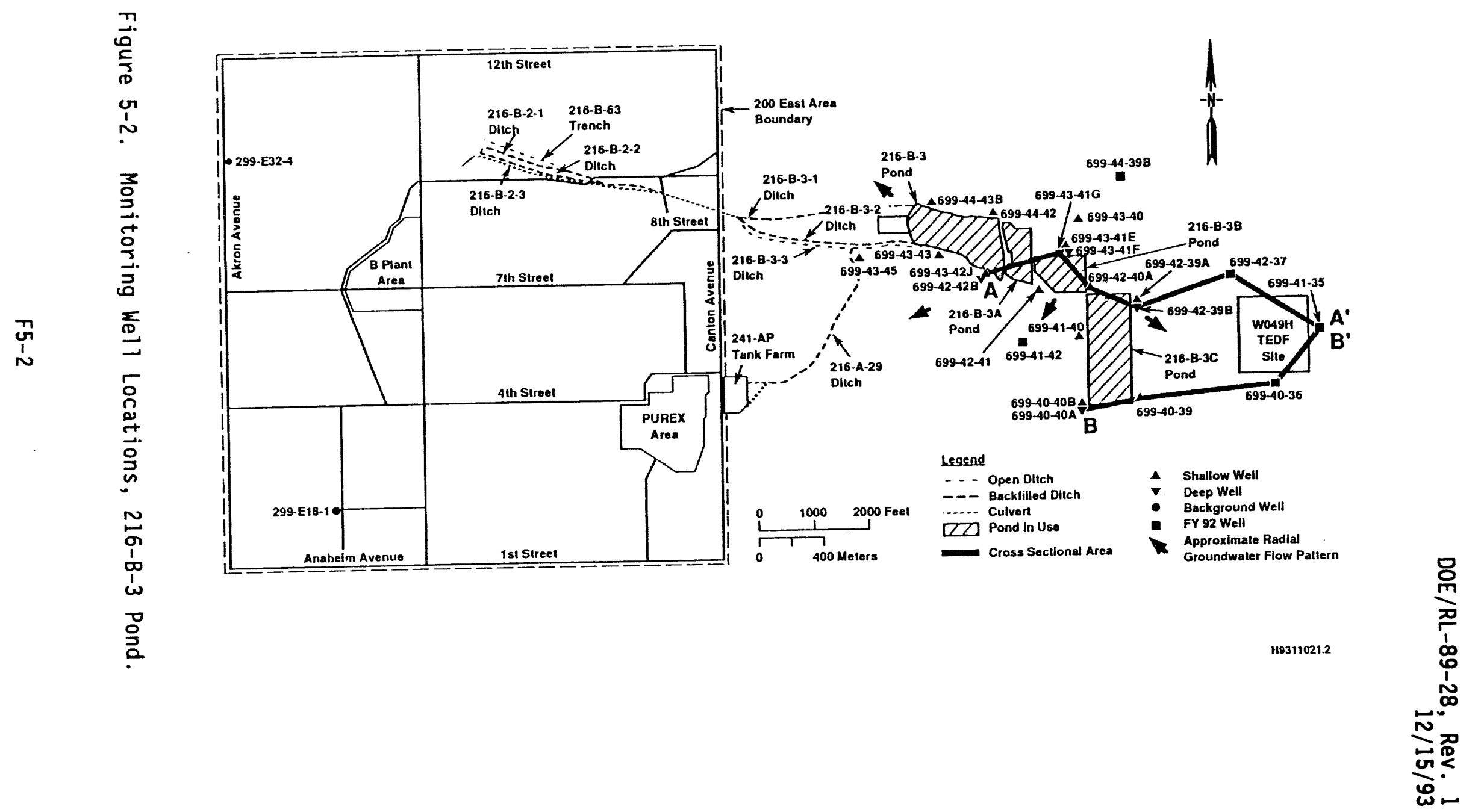




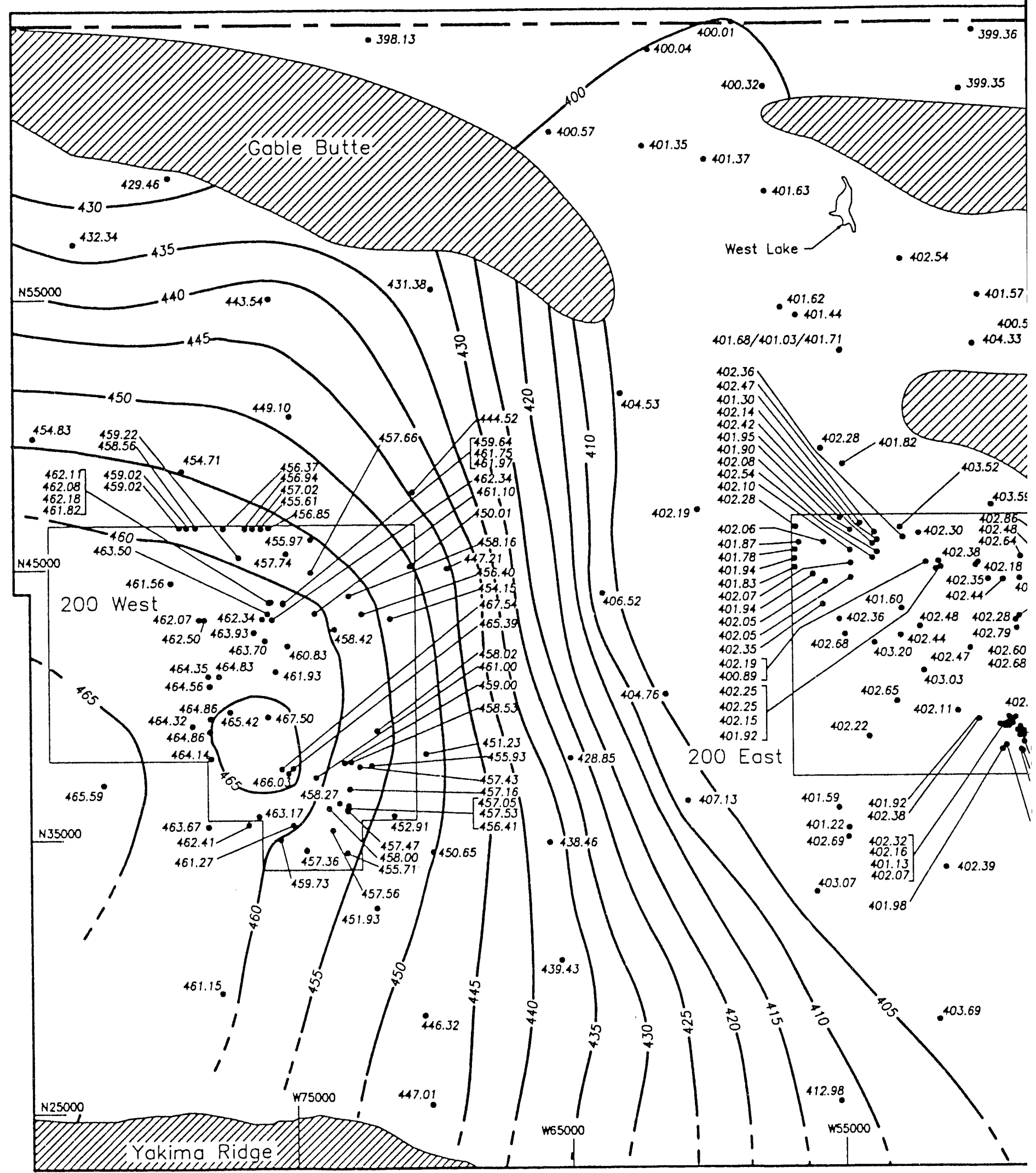




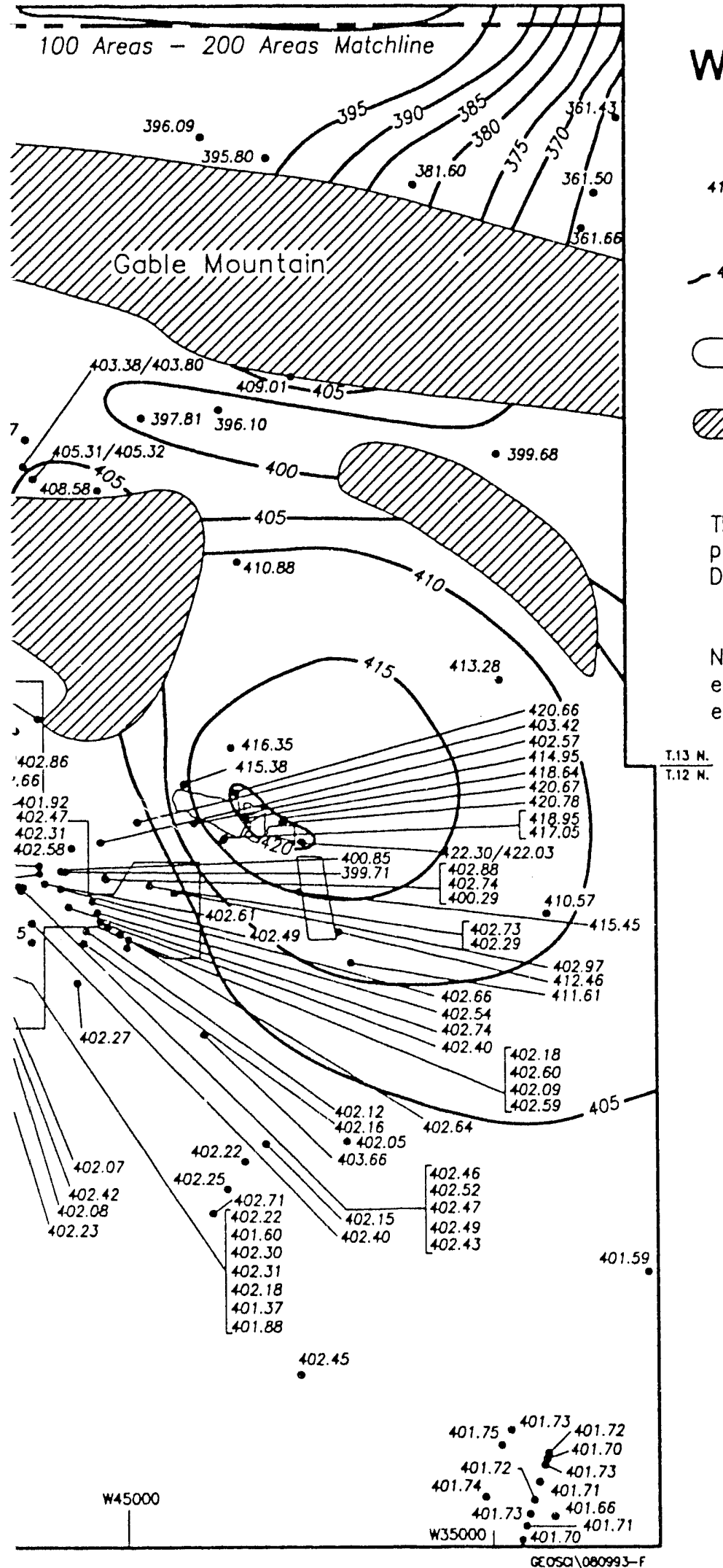

\title{
200 Areas \\ Water Table Elevation December 1992
}

\author{
W11.49 Water table elevation (feet
above mean sea level) \\ Groundwater table elevation \\ $400-$ contour interval $=5 \mathrm{ft}$ \\ Ponds \\ Areas where the basalt surface is \\ above the woter table \\ (Connelly, et al. 1992A and 1992B)
}

The 200 Areos water table elevation map has been prepared by the Geosciences Function, Environmental Division, of Westinghouse Hanford Company.

Note: To convert to metric, multiply elevation ( $\mathrm{ft}$ ) by 0.3048 to obtain elevation (m).
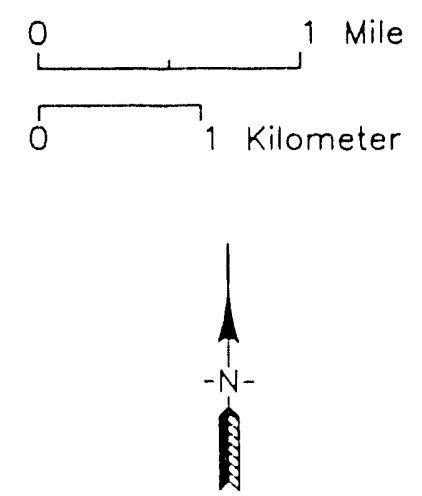

Figure 5-3. Separations Area Water Table Map. 


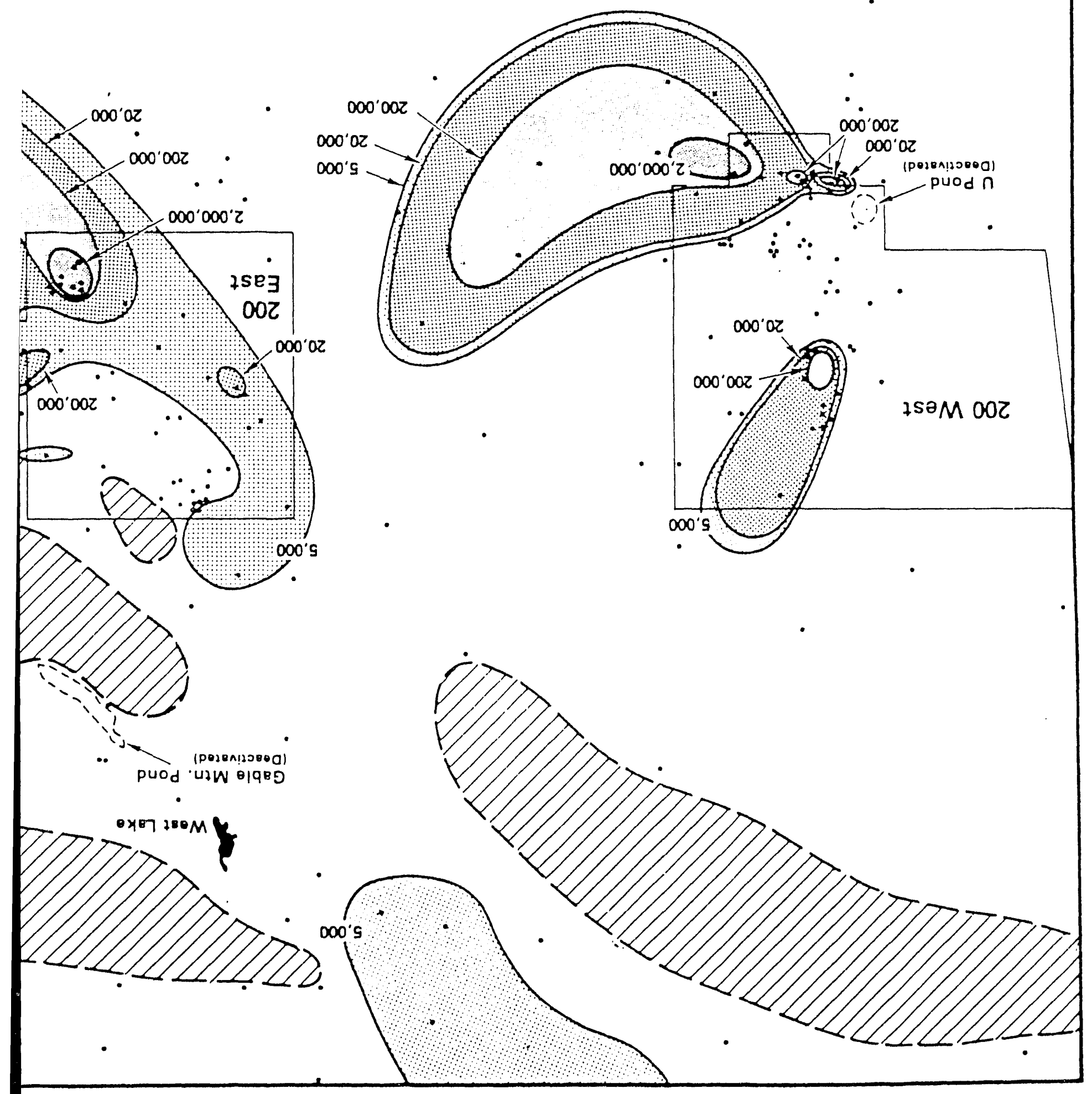




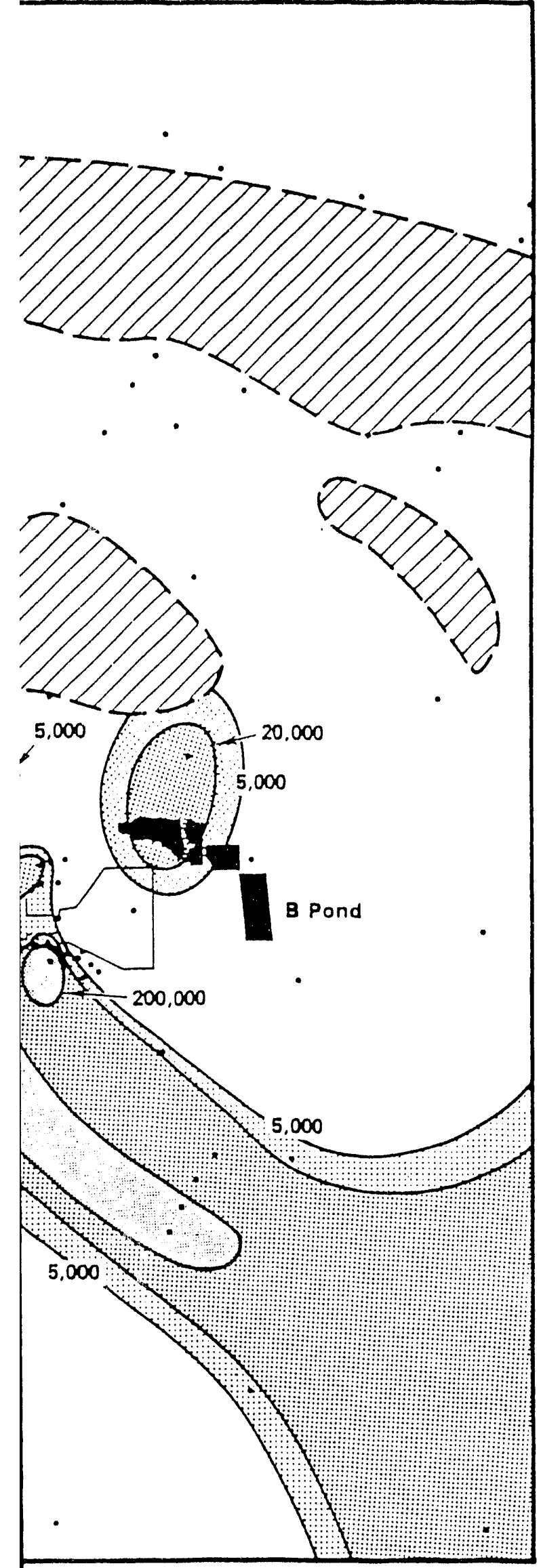

DOE/RL-89-28, Rev. 1

$12 / 15 / 93$

\section{Tritium Plumes Within the Separations Area 1987 Data}

(Serkowski et al., 1988)

Tritium $\mathrm{pCi} / \mathrm{L}$

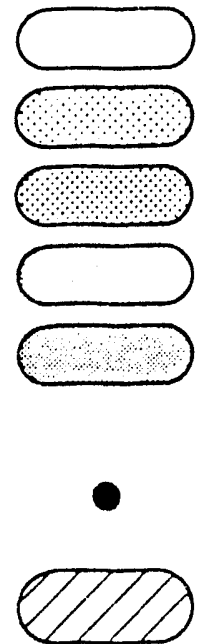

$<5,000$

$5,000-19,000$

20,000-199,000

$200,000-1,999,000$

$\geq 2,000,000$

Locations of Wells Sampled

for Tritium in 1987

Estimated Basalt

Above Water Table

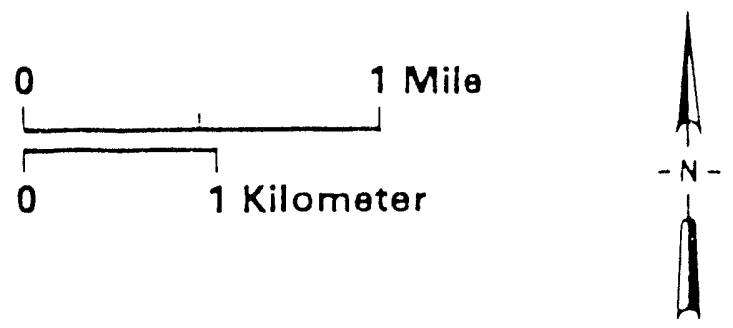

Figure 5-4. Tritium Plumes Within the Separations Area--1987 Data (Serkowski et al. 1988, pp. 6-5/6). 


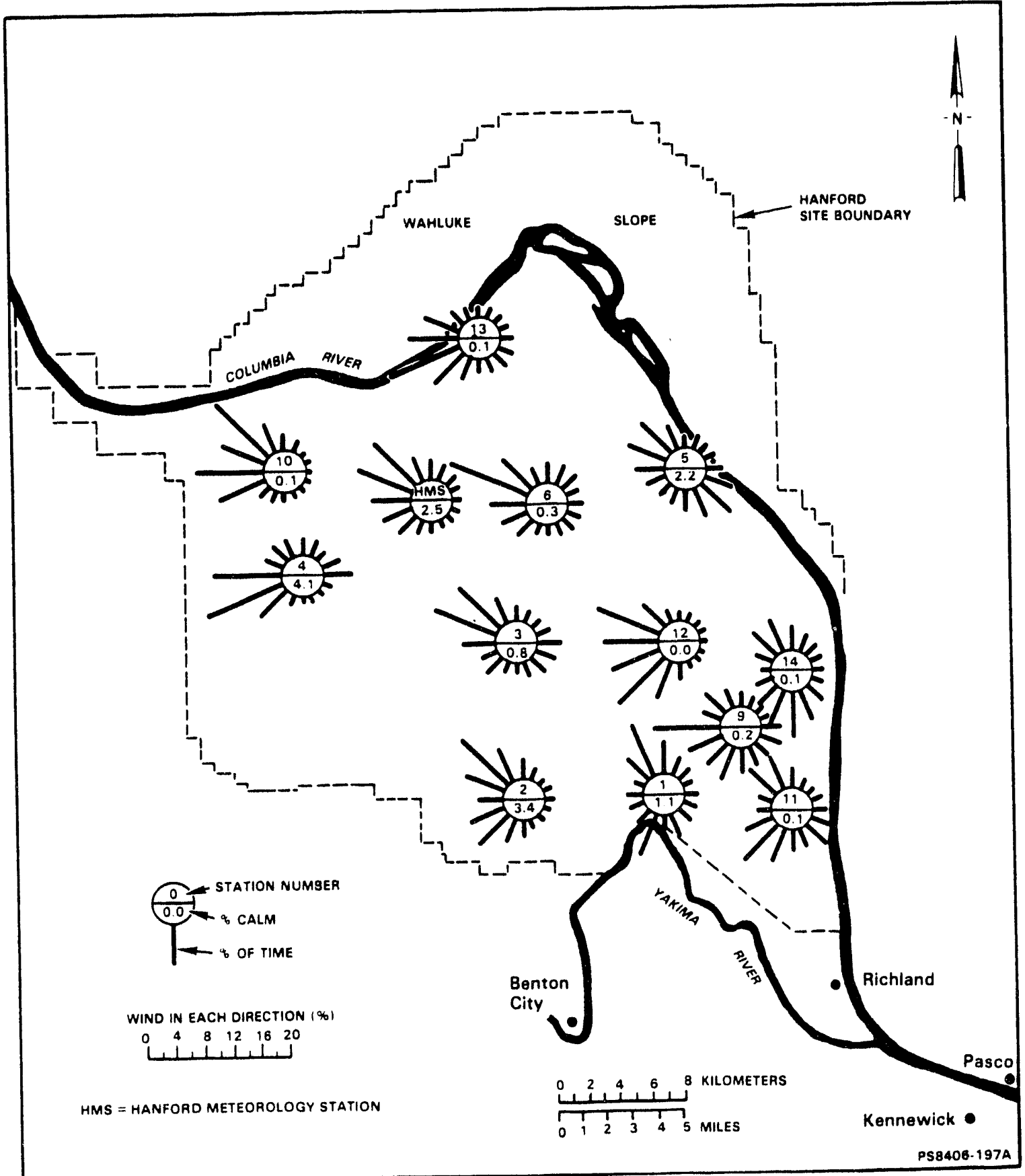

Figure 5-5. Wind Rose Patterns for the Hanford Site (after DOE 1988b). 


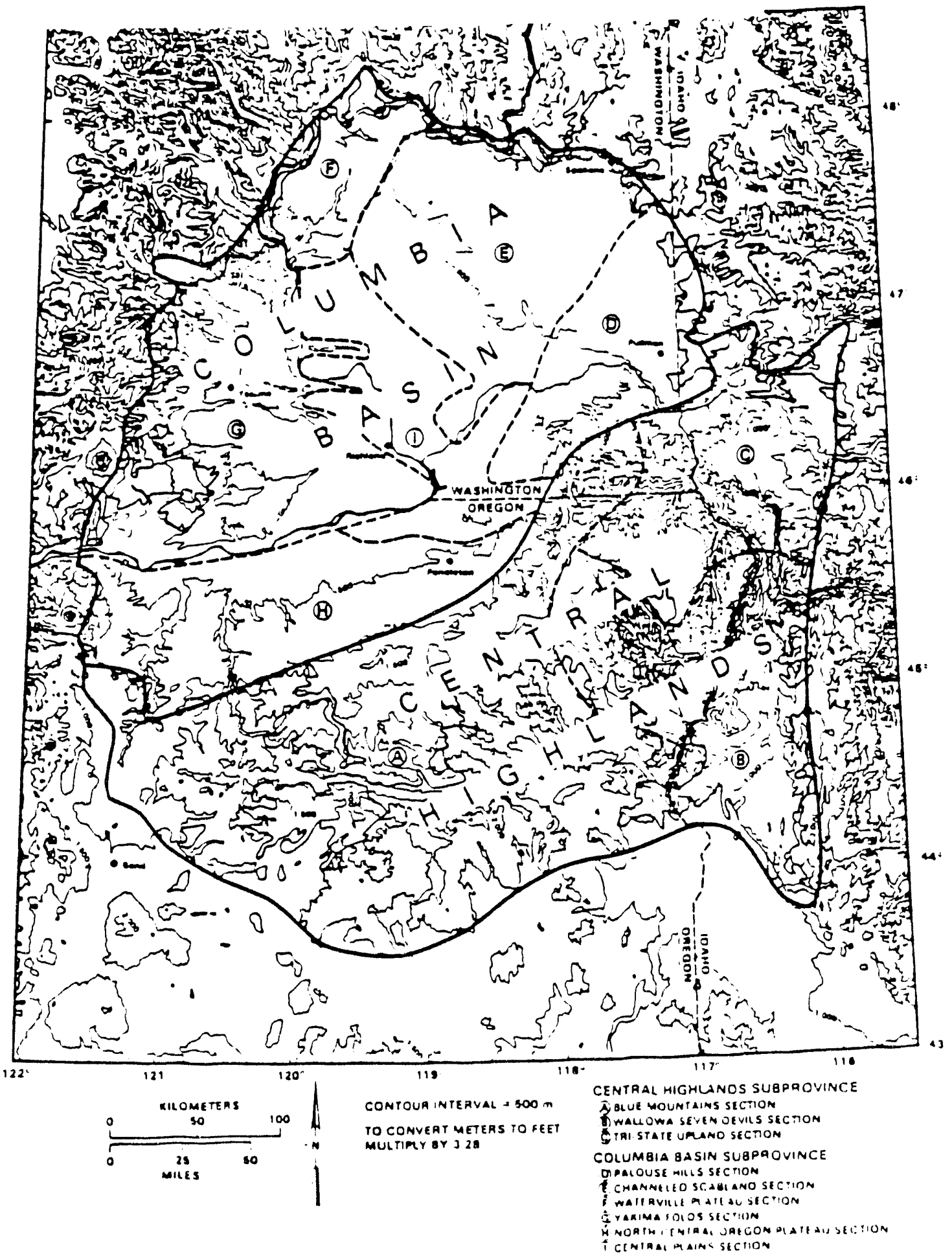

Figure 5-6. Geomorphic Units Within the Central Highlands and Columbia Basin Subprovinces That Contain the Columbia River Basalt Group (after Thornbury 1965, p. 445). 


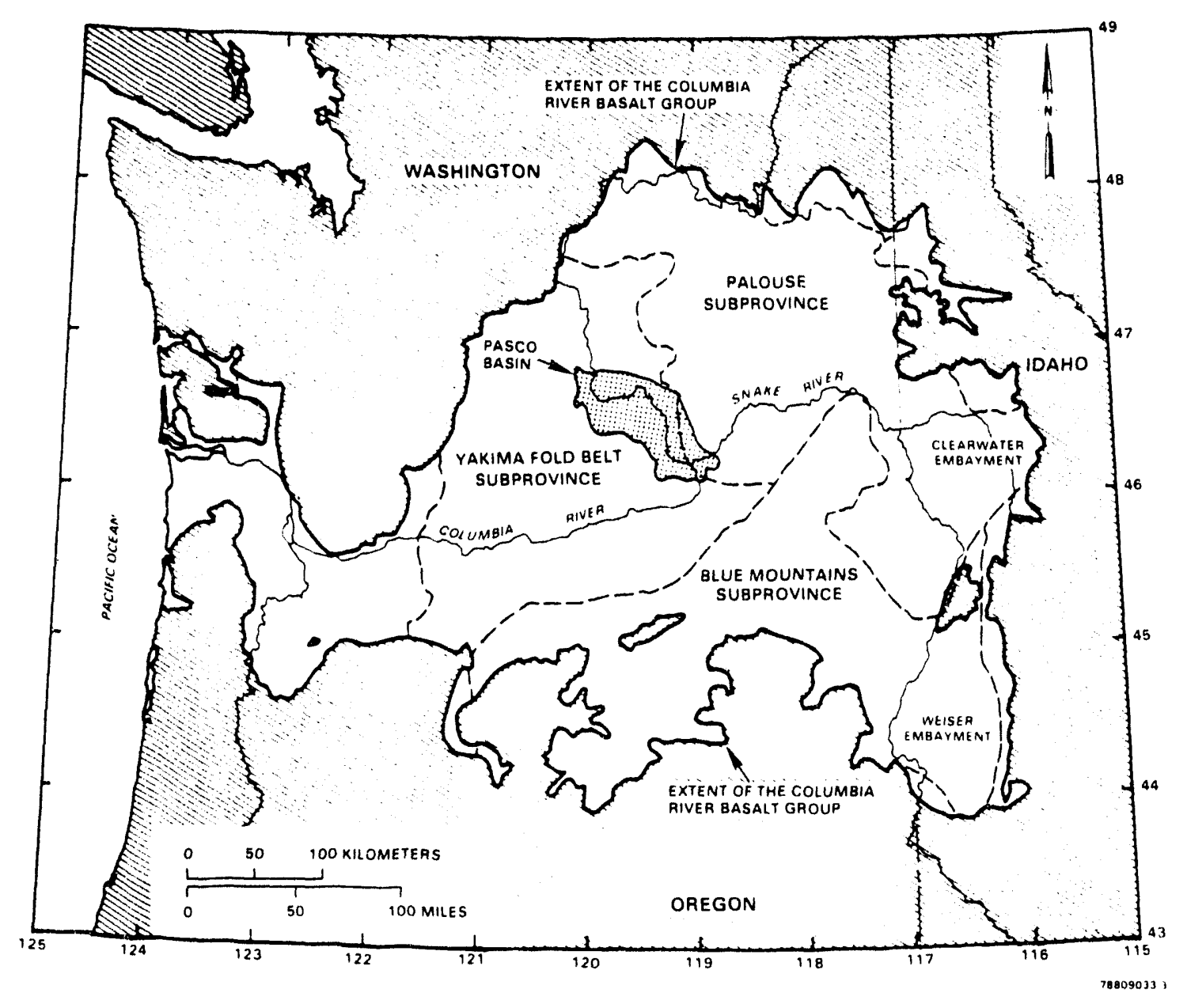

Figure 5-7. Structural Subprovinces of the Columbia Plateau (DOE 1988b, pp. 1.3-15). 


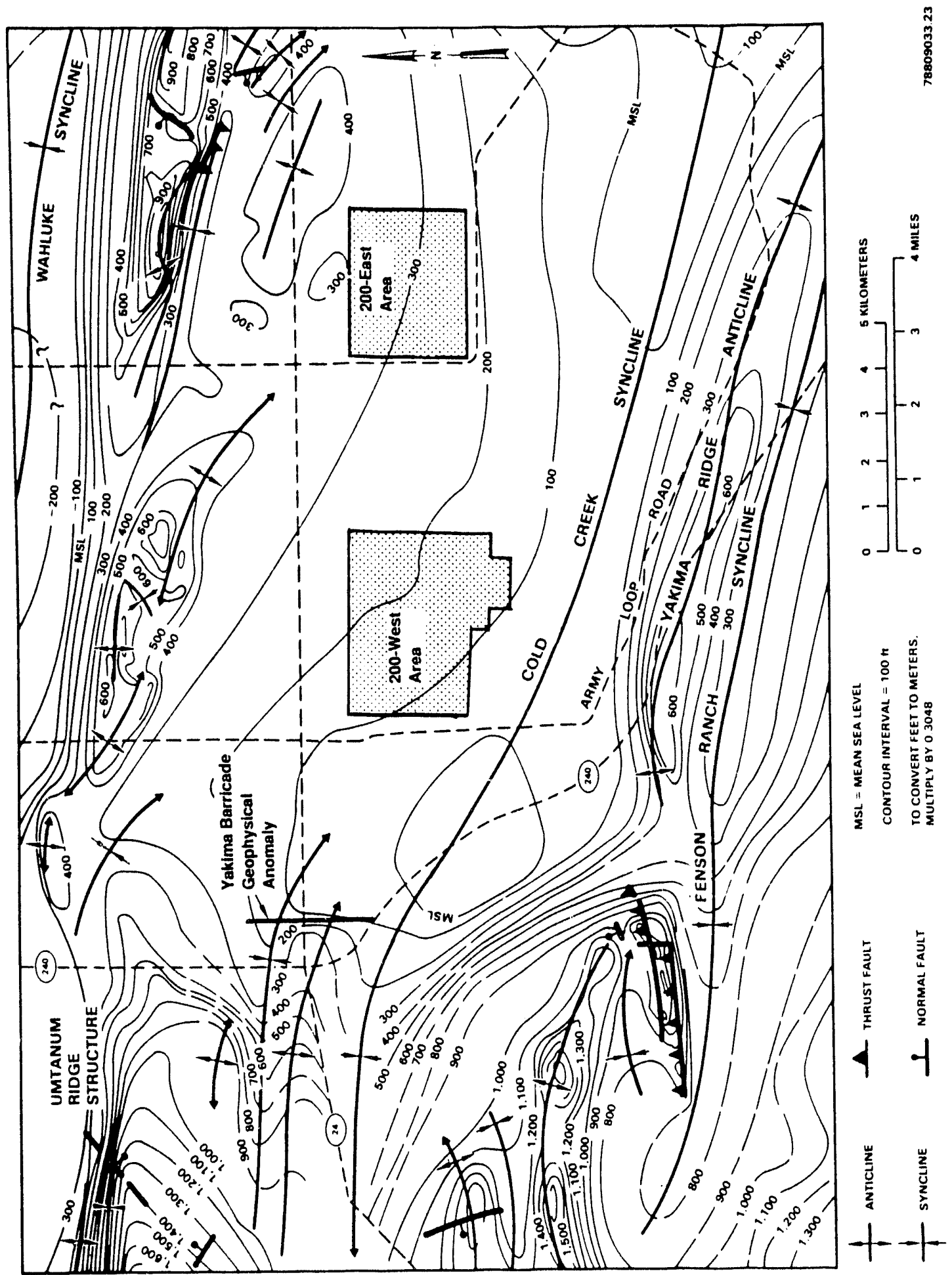

Figure 5-8. Tectonic Structures Adjacent to the 200 Areas, Top of Basalt (after DOE 1988b). 


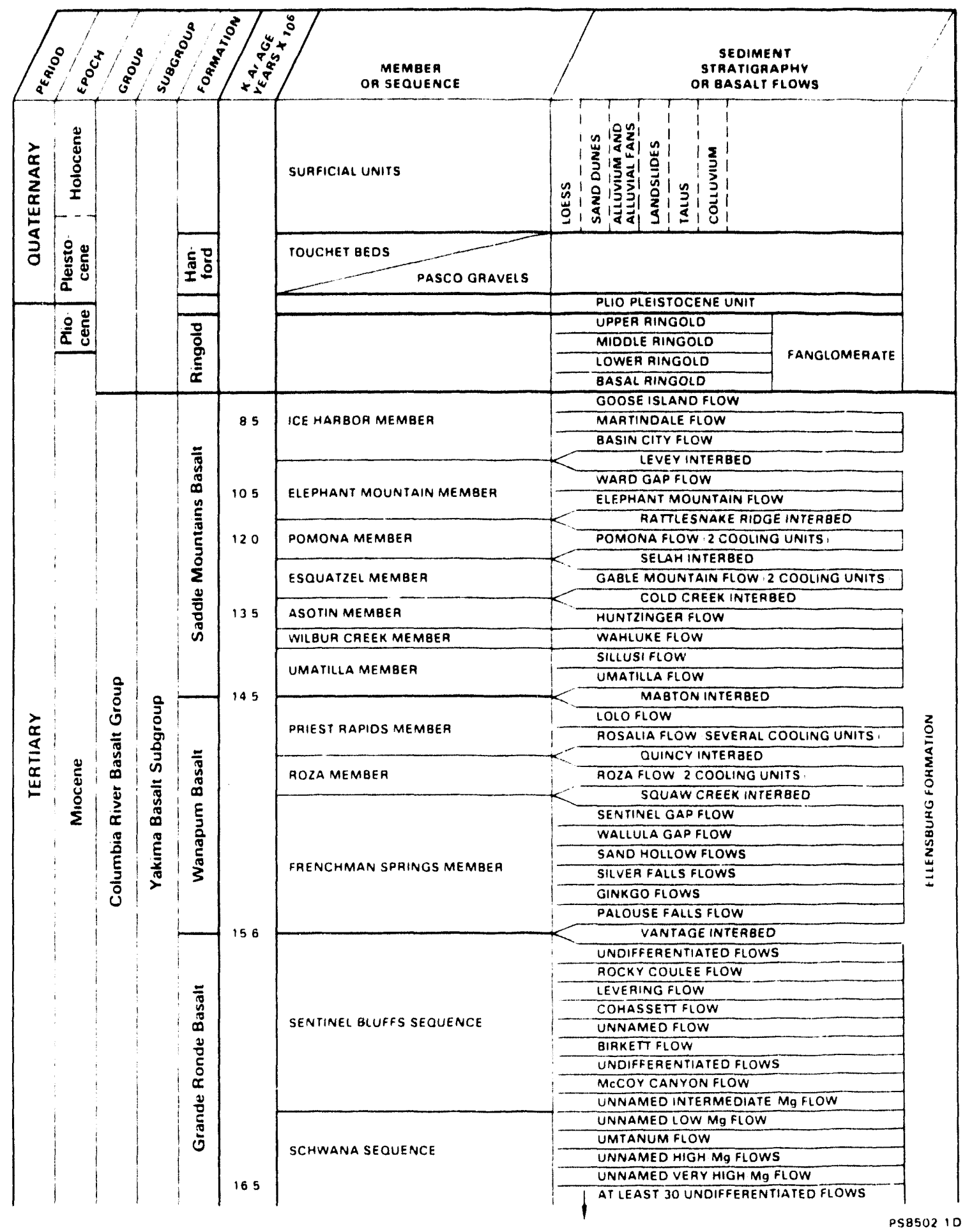

Figure 5-9. Stratigraphic Nomenclature of Units Penetrated Within the Pasco Basin. 

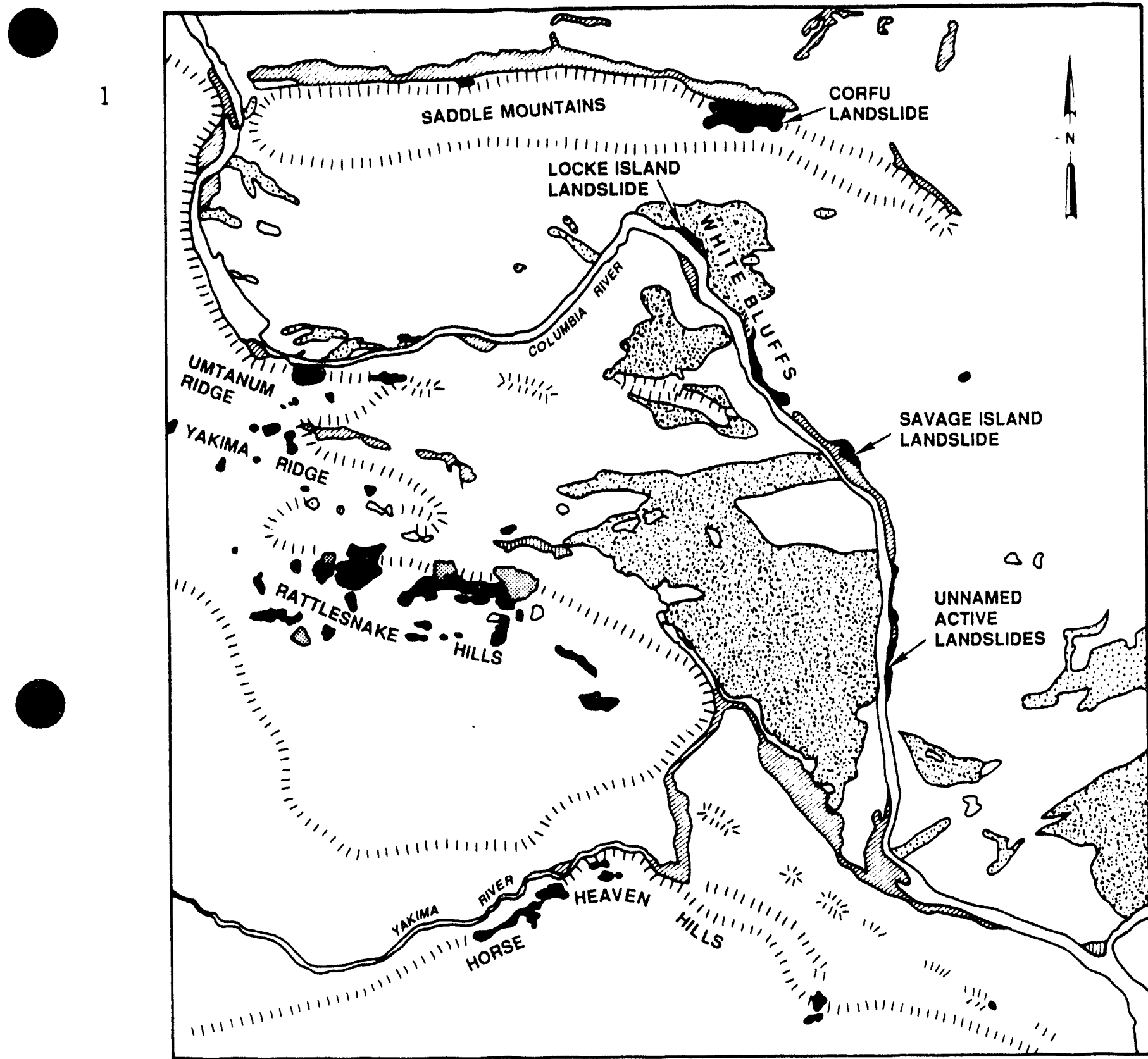

\begin{tabular}{|c|c|c|c|c|}
\hline 13 & ACTIVE & & & ALLLUVIAL PLAIN \\
\hline & STABILIZED & DUNES & & LANDSLIDES \\
\hline & ALLUVIAL FA & & $91111^{5}$ & ANTICLINAL \\
\hline
\end{tabular}

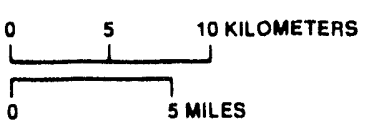

78909003.9

Figure 5-10. Late Quaternary Landforms Within and Adjacent to the Pasco Basin (after DOE 1988b). 


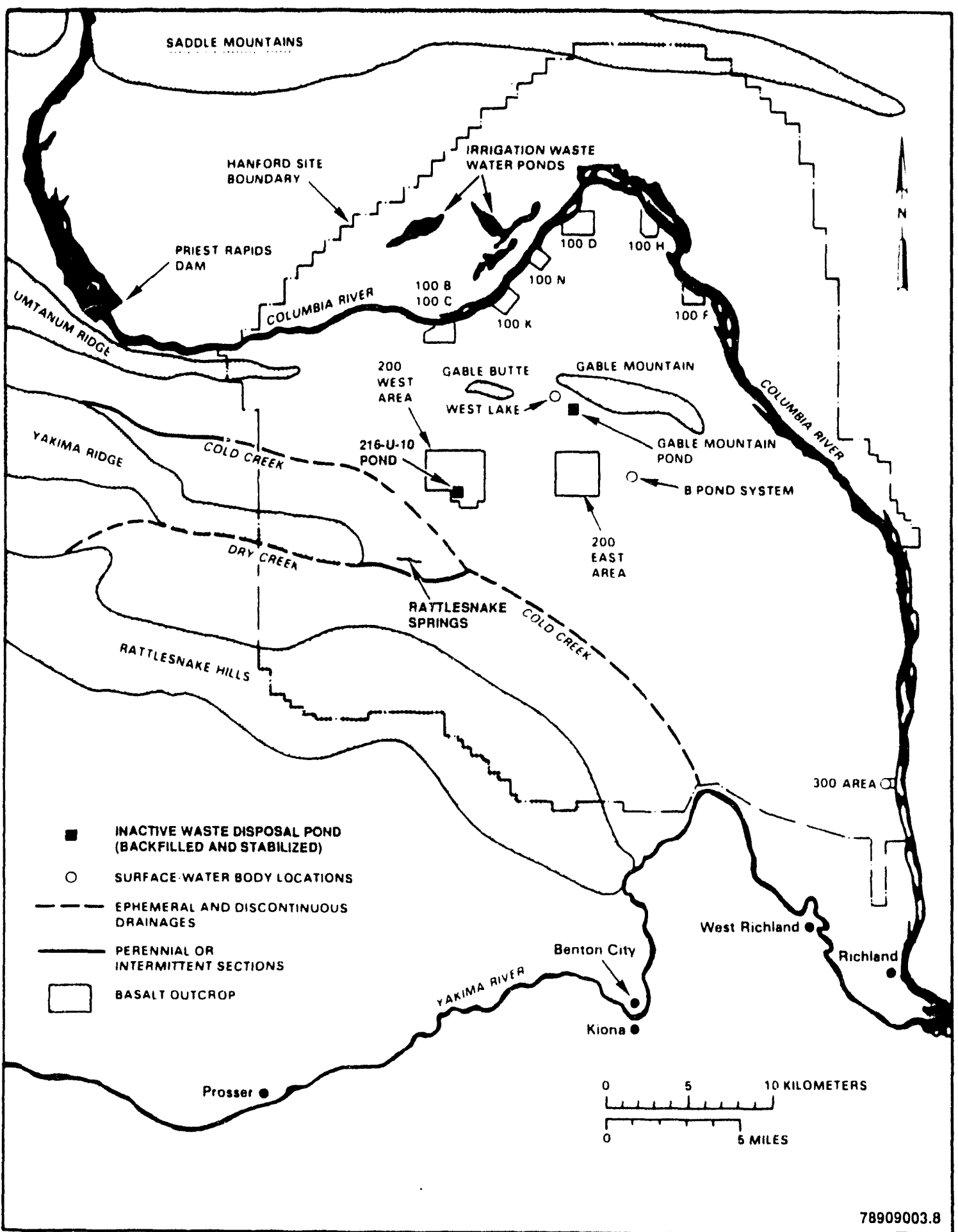

Figure 5-11. Locations of Surface Water Bodies on the Hanford Site (after DOE 1988b). 


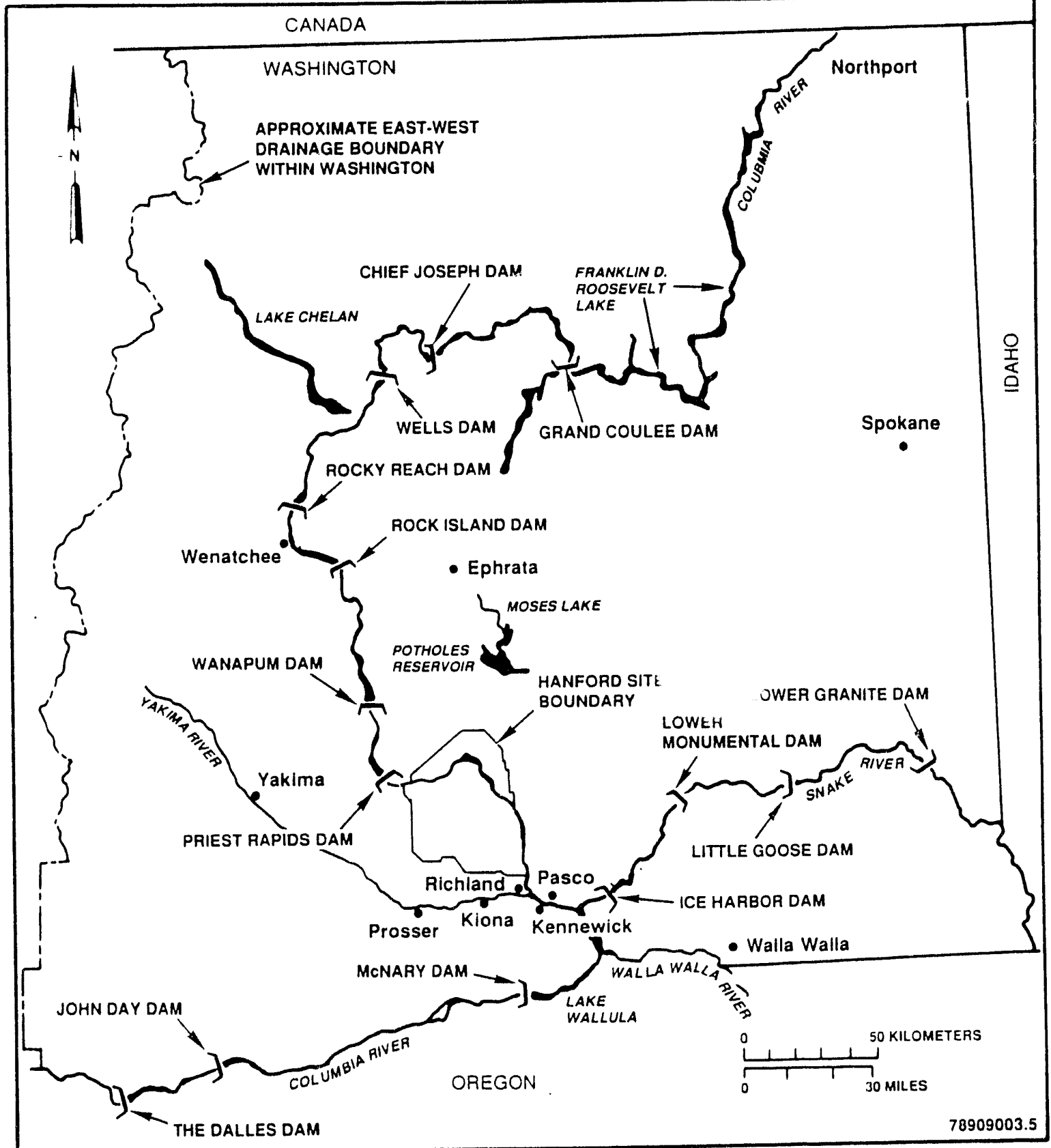

Fiaure 5-12. Locations of Principle Dams Within the Columbia Plateau (after DOE 1988b). 


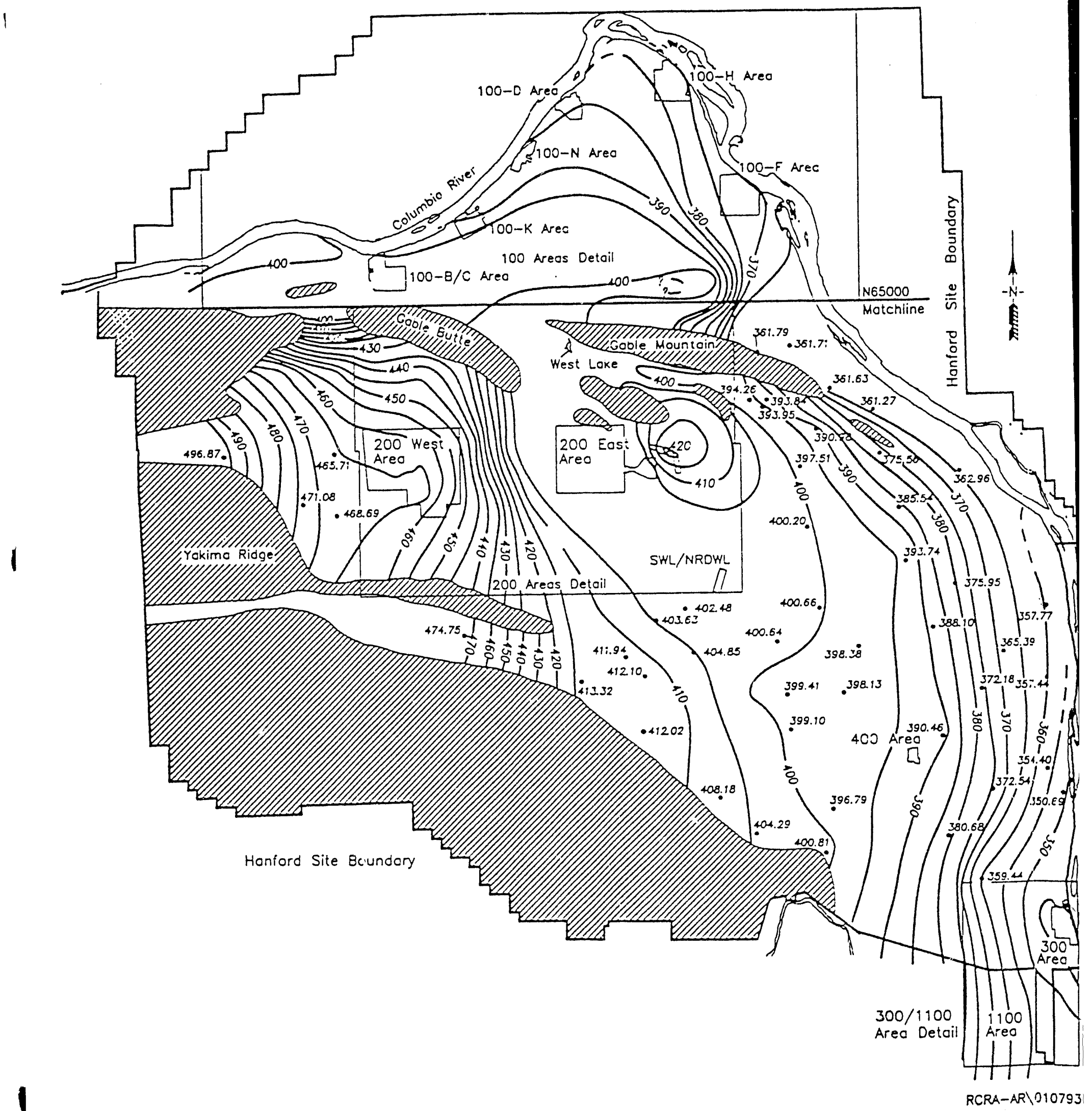




\section{Hanford Site Water Table Map June 1992}

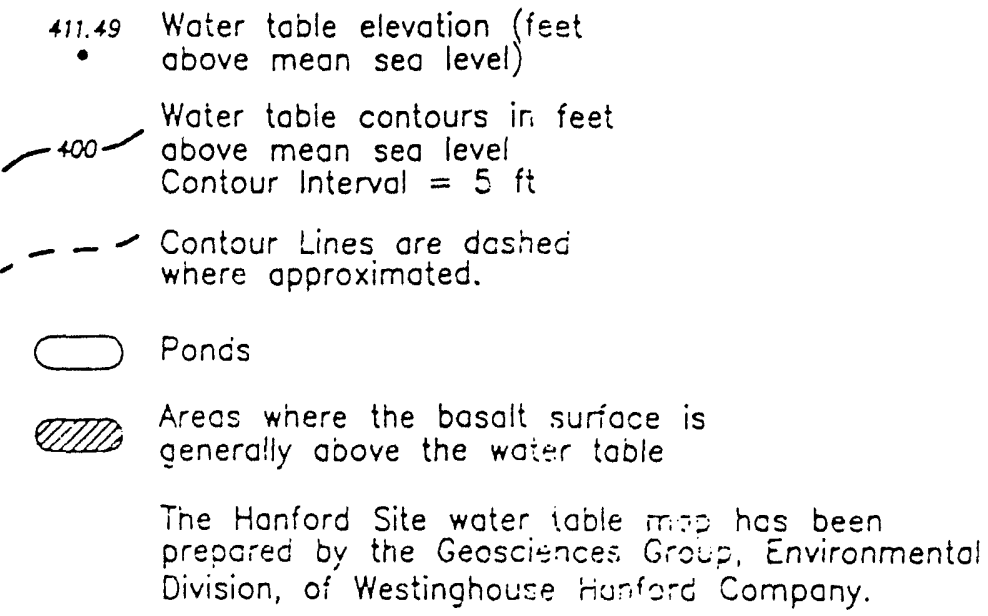

From: Kosza, et ol., 1992

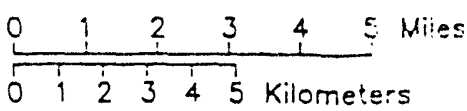


A

\section{Northwest}

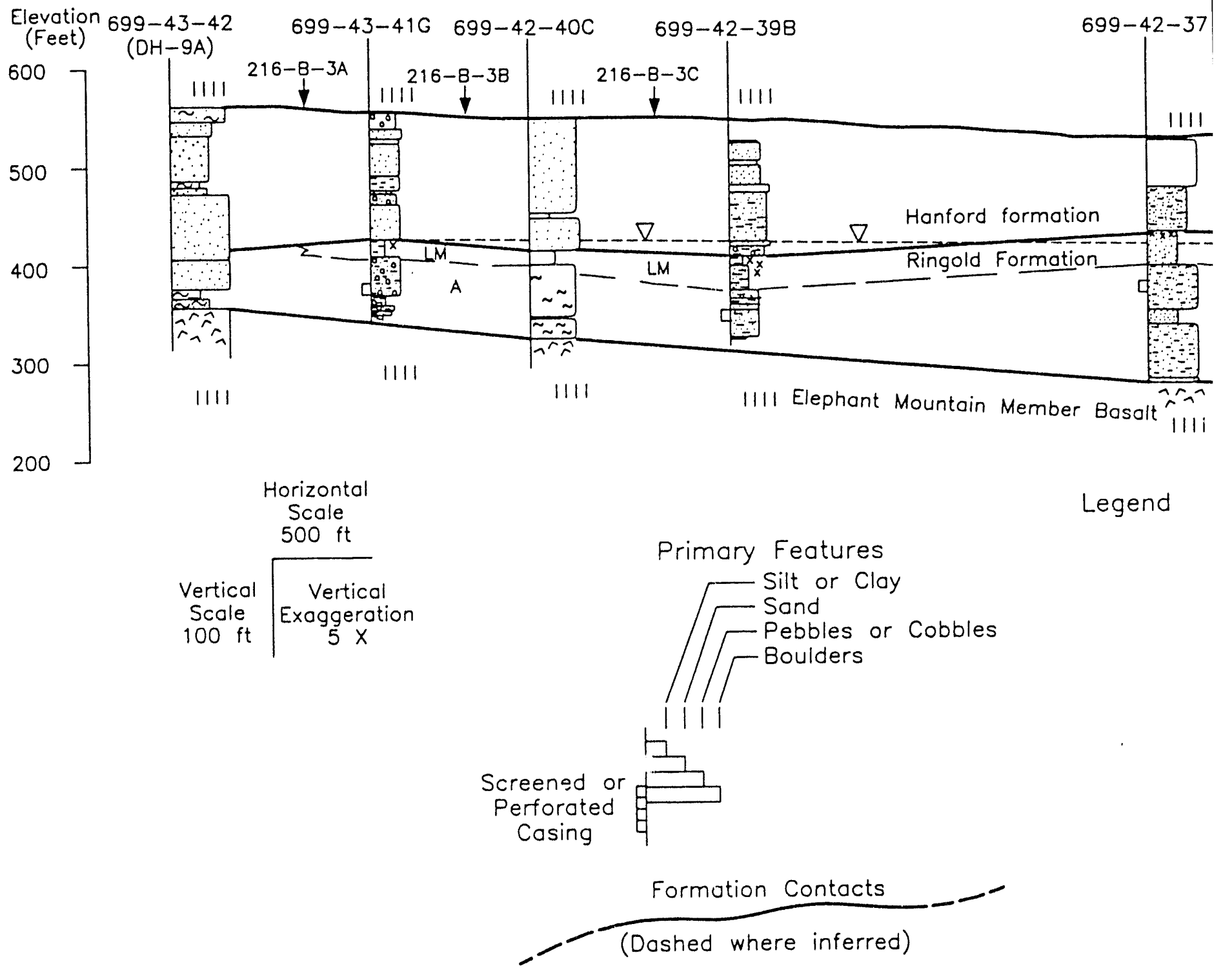




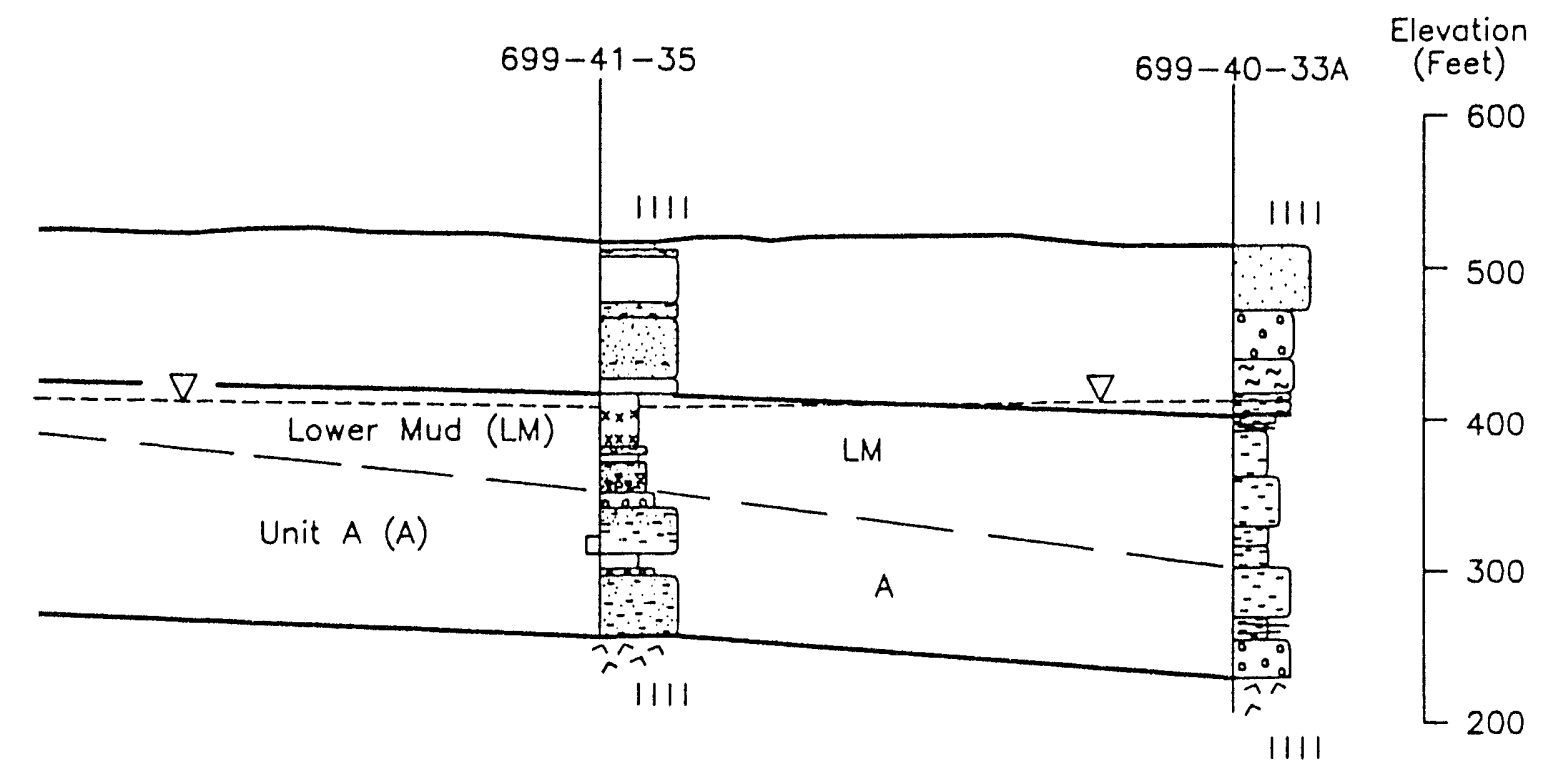

Secondary Features

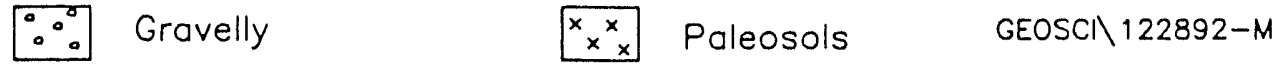

$\because$ Sandy $\quad v v^{2}$ Basalt

$\because$ Silty or Clayey $\equiv \begin{aligned} & \text { Thin, coarser-grained } \\ & \text { Interbeds }\end{aligned}$

$\left[\begin{array}{l}1 \\ 1 \\ 1\end{array}\right]$ Pedogenic Carbonat.

Southeast

$A^{\prime}$ 


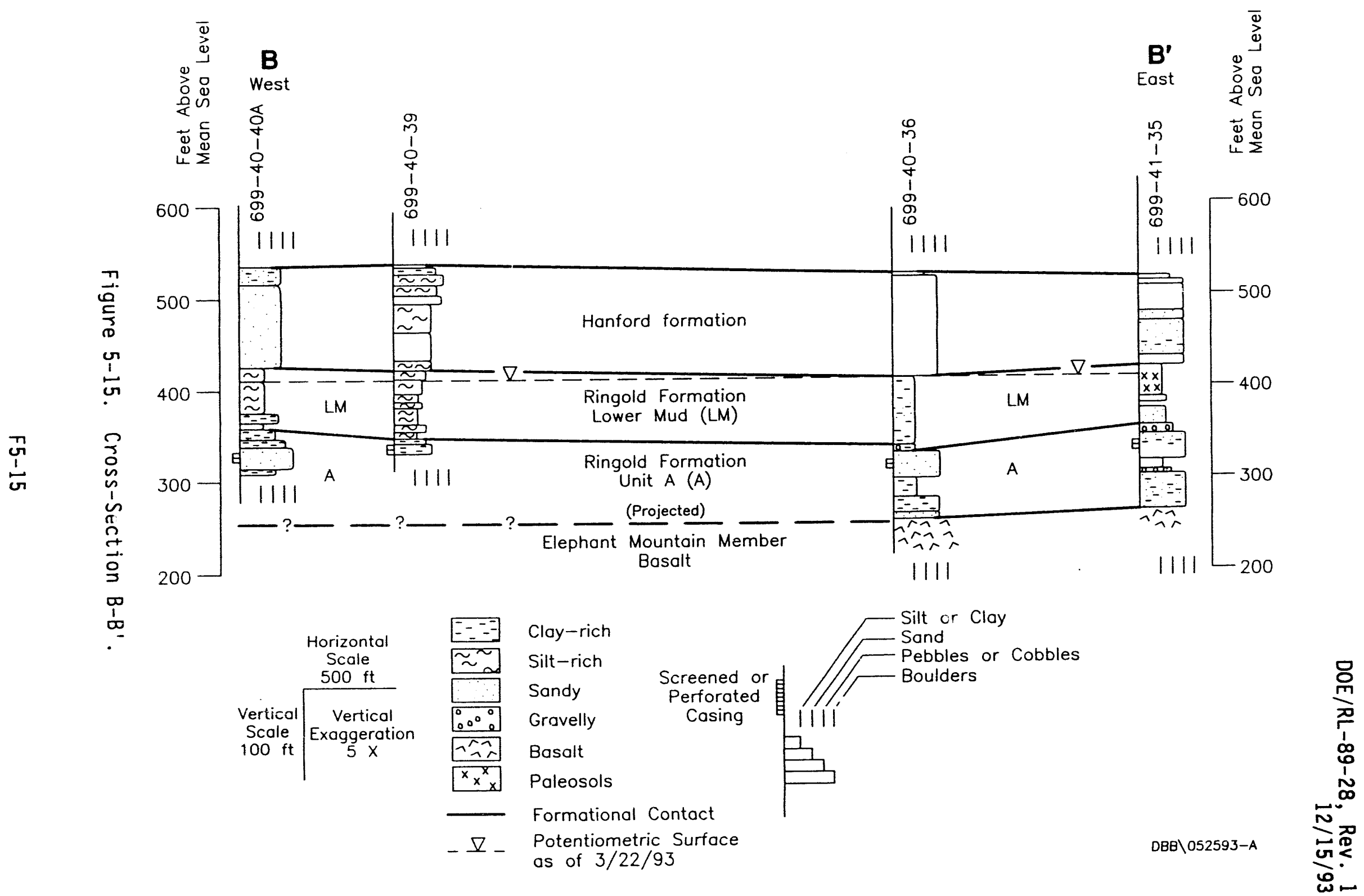


DOE/RL-89-28, Rev. 1

$12 / 15 / 93$

]

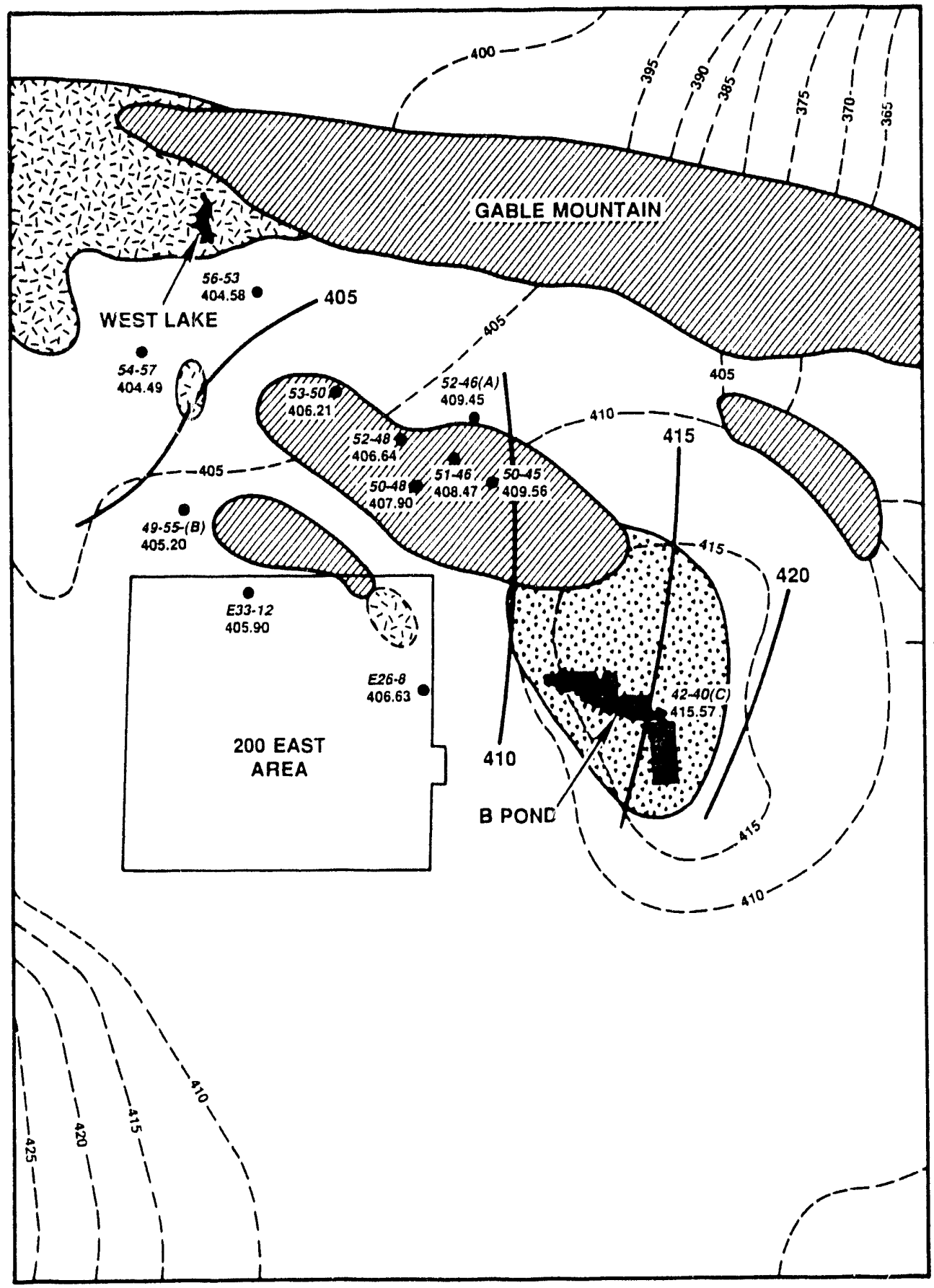

COMPARISON OF POTENTIOMETRIC SURFACE OF THE RATTLESNAKE RIDGE CONFINED AQUIFER WITH THE WATER TABLE OF THE UNCONFINED AQUIFER

\section{JANUARY 1989}

POTENTIOMETRIC SURFACE OF THE RATTLESNAKE RIDGE IN FEET ABOVE MEAN SEA LEVEL. (H MSL)

WATER-TABLE CONTOURS IN FEET ABOVE MEAN SEA LEVEL (I MSL)

T.7. AREAS OF COMPLETE EAOSION OF THE ELEPHANT MOUNTAIN BASAL (GRAHAM, et al, 1984)

AFEAS OF DOWNWARD HYDRAULIC GRADIENT

5146 WELLS IN CONFINED AOUIFER 408.47 USED IN PREPARATION OF MAP

T. POND

DIII Basalt above water table, as INFERRED 6/1984

$\frac{T .13 \mathrm{~N} .}{\text { T. } 12 \mathrm{~N} .}$

T. $12 \mathrm{~N}$.

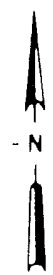

78909003.4

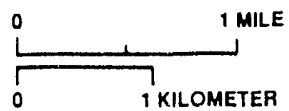

Figure 5-16. Comparison of Potentiometric Surface of the Rattlesnake Ridge Confined Aquifer with the Water Table of the Unconfined Aquifer. 
1 Table 5-1. Construction Summary--B Pond Groundwater Monitoring Network.

\begin{tabular}{|c|c|c|c|c|c|c|}
\hline Well number & $\begin{array}{c}\text { Date } \\
\text { completed }\end{array}$ & $\begin{array}{l}\text { Total depth } \\
\left.\text { drilled }^{\text {(feet }}{ }^{a}\right)\end{array}$ & $\begin{array}{c}\text { Screened } \\
\text { depth } \\
\left(\text { feet }^{a}\right)\end{array}$ & Aquifer & $\begin{array}{l}\text { Dep } \\
\text { Wa } \\
\text { (fe } \\
\text { and } \\
\text { mea }\end{array}$ & $\begin{array}{l}\text { h to } \\
\text { ier } \\
t^{\mathrm{a}} \text { ) } \\
\text { date } \\
\text { ured }\end{array}$ \\
\hline $299-E 18-1^{c}$ & $8 / 88$ & 332 & $309-327$ & Top of unconfined & 318 & $6 / 93$ \\
\hline $299-E 32-4^{c}$ & $9 / 87$ & 310 & $278-298$ & Top of unconfined & 284 & $6 / 93$ \\
\hline $699-40-36$ & $12 / 92$ & 280 & $209-219$ & Top of semiconfined & 118 & $6 / 93$ \\
\hline $699-40-39$ & $7 / 89$ & 212 & $201-211$ & Top of semiconfined & 129 & $6 / 93$ \\
\hline $699-40-40 \mathrm{~A}$ & $10 / 91$ & 227 & $215-225$ & Lower semiconfined & 130 & $6 / 93$ \\
\hline $699-40-408$ & $10 / 91$ & 202 & $188-199$ & Top of semiconfined & 131 & $6 / 93$ \\
\hline $699-41-35$ & $11 / 92$ & 260 & $198-200$ & Top of semiconfined & 108 & $4 / 93$ \\
\hline $699-41-40$ & $6 / 89$ & 176 & $164-174$ & Top of semiconfined & 131 & $6 / 93$ \\
\hline $699-41-42$ & $8 / 92$ & 343 & $270-281$ & Top of unconfined & 233 & $4 / 93$ \\
\hline $699-0,2-37$ & $11 / 92$ & 268 & $144-154$ & Top of semiconfined & 105 & $6 / 93$ \\
\hline $699-42-39 A$ & $6 / 91$ & 181 & $169-180$ & Top of semiconfined & 139 & $6 / 93$ \\
\hline $699-42-39 B$ & $10 / 91$ & 216 & 203-214 & Lower semiconfined & 140 & $6 / 93$ \\
\hline $699-42-40 \mathrm{~A}$ & $7 / 81$ & 176 & $139-171$ & Top of unconfined & 124 & $6 / 93$ \\
\hline $699-42-41$ & $8 / 91$ & 157 & $134-155$ & Top of unconfined & 147 & $6 / 93$ \\
\hline $699-42-42 B$ & $10 / 88$ & 250 & $183-203$ & Top of semiconfined & 166 & $6 / 93$ \\
\hline $699-43-40$ & $10 / 91$ & 137 & $114-135$ & Top of unconfined & 122 & $6 / 93$ \\
\hline $699-43-41 E$ & $5 / 89$ & 149 & $135-146$ & Top of semiconfined & 130 & $6 / 93$ \\
\hline $699-43-41 \mathrm{~F}$ & $6 / 89$ & 176 & $165-176$ & Lower semiconfined & 130 & $6 / 93$ \\
\hline $699-43-41 G$ & $10 / 91$ & 201 & $188-199$ & $\begin{array}{l}\text { Top of lower } \\
\text { semiconfined } \\
\end{array}$ & 135 & $6 / 93$ \\
\hline $699-43-42 \mathrm{~J}$ & $9 / 88$ & 180 & $157-177$ & Lower unconfined & 163 & $6 / 93$ \\
\hline $699-43-43$ & $9 / 88$ & 180 & $158-178$ & Top of unconfined & 164 & $6 / 93$ \\
\hline $699-43-45$ & $6 / 89$ & 204 & $183-203$ & Top of unconfined & 195 & $6 / 93$ \\
\hline $699-44-39 B$ & 9/92 & 182 & $99-119$ & Top of unconfined & 94 & $6 / 93$ \\
\hline $699-44-42$ & $9 / 88$ & 173 & $152-172$ & Top of unconfined & 159 & $6 / 93$ \\
\hline $699-44-43 B$ & $5 / 89$ & 176 & $156-176$ & Top of unconfined & 165 & $6 / 93$ \\
\hline
\end{tabular}

28

29

30

31

32

33

34

NOTE: All wells are constructed with 4-inch diameter stainless steel casing and screen except for the following wells: 699-42-40A (8-inch carbon steel casing with 8-inch telescoping stainless steel screen), Depths are approximate.

SS--Stainless steel; CS--carbon stee1; casing diameter in parentheses. 'Background well. 
Table 5-2. Groundwater Constituents, Parameters ${ }^{a}$, and Drinking Water Standards. (sheet 1 of 2)

\begin{tabular}{|c|c|}
\hline Constituent & Drinking water standard ${ }^{b}$ \\
\hline Arsenic & 0.05 milligrams per liter \\
\hline Barium & 1.0 \\
\hline Cadmium & 0.01 \\
\hline Chromium & 0.10 \\
\hline Fluoride & 1.4 to 2.4 \\
\hline Lead & 0.05 \\
\hline Mercury & 0.002 \\
\hline Nitrate (as $\left.\mathrm{NO}_{3}^{-}\right)$ & 45.0 \\
\hline Selenium & 0.01 \\
\hline Silver & 0.05 \\
\hline Endrin & 0.0002 \\
\hline Lindane & 0.004 \\
\hline Methoxychlor & 0.1 \\
\hline Toxaphene & 0.005 \\
\hline $2,4-D$ & 0.1 \\
\hline $2,4,5-T P$ silvex & 0.01 \\
\hline Radium & 5 picocuries per liter \\
\hline Gross alpha & 15 picocuries per liter \\
\hline Gross beta & 4 millirems per year \\
\hline Turbidity (surface water only) & 1 turbidity unit \\
\hline Coliform bacteria & $1 / 100$ milliliter \\
\hline \multicolumn{2}{|c|}{ Groundwater quality parameters } \\
\hline Chloride & $250(s)$ \\
\hline Iron & $0.3(s)$ \\
\hline Manganese & $0.05(s)$ \\
\hline Phenols & none \\
\hline Sodium & none \\
\hline Sulfate & $250(s)$ \\
\hline
\end{tabular}


Table 5-2. Groundwater Constituents, Parameters ${ }^{a}$, and Drinking Water Standards. (sheet 2 of 2)

\begin{tabular}{|c|c|}
\hline Constituent & Drinking water standard ${ }^{b}$ \\
\hline \multicolumn{2}{|c|}{ Groundwater contamination indicator parameters } \\
\hline $\mathrm{pH}$ & $6.5-8.5$ \\
\hline Specific conductance & none \\
\hline Total organic carbon & none \\
\hline Total organic halogen & none \\
\hline \multicolumn{2}{|c|}{ Site-specific parameters } \\
\hline Hydrazine & none \\
\hline Ammonium & none \\
\hline Tritium & 20,000 picocuries/liter \\
\hline \multicolumn{2}{|c|}{ Assessment monitoring parameters } \\
\hline \multicolumn{2}{|c|}{ Herbicides } \\
\hline \multicolumn{2}{|c|}{ Pesticides } \\
\hline \multicolumn{2}{|c|}{ Polychlorinated biphenyls (PCBs) } \\
\hline \multicolumn{2}{|c|}{ Enhanced volatiles } \\
\hline \multicolumn{2}{|c|}{ Semivolatiles } \\
\hline
\end{tabular}

${ }^{a}$ Regulatory requirements for sampling parameters are subject to change because of federal regulations.

Unless otherwise noted, standards are based on maximum contaminant levels given in 40 CFR 141. Other standards are denoted as follows: $(s)=$ secondary maximum contaminant levels given in 40 CFR 143.

CUnless noted, concentrations are in milligrams per liter.

Enhanced volatiles include enhanced 1 ist identified in Appendix IX of 40 CFR Part 261. 
Table 5-3. Results of Indicator Parameter Analyses.

\begin{tabular}{|c|c|c|c|c|c|c|c|c|c|}
\hline $\begin{array}{l}\text { Well } \\
\text { Name }\end{array}$ & $\begin{array}{c}\text { Collection } \\
\text { Date }\end{array}$ & $\begin{array}{l}\text { Sample } \\
\text { Number }\end{array}$ & $\begin{array}{c}\text { COND FIELD } \\
\text { Who } \\
1 / .\end{array}$ & $\begin{array}{c}\text { COND LAB } \\
\text { who } \\
1 / .\end{array}$ & & $1 / 6.5-8.5 \mathrm{~s}$ & $.01 / 6.5-8.5 \mathrm{~s}$ & $\begin{array}{c}\text { TOC } \\
\text { ppb } \\
1000 \%\end{array}$ & $\begin{array}{c}\text { TOX } \\
\text { ppb } \\
10 \%\end{array}$ \\
\hline \multirow[t]{43}{*}{ 299-E18-1 } & $8 / 16 / 88$ & H00072T7 & 812 & 534 & 1 & 7.80 & 7.90 & $532 \mathrm{U}$ & $1.3 \mathrm{U}$ \\
\hline & & H00072T8 & 809 & 521 & 1 & 7.80 & 7.90 & $397 \mathrm{U}$ & $-4.8 U$ \\
\hline & & H0007ZT9 & 891 & 529 & i & 7.90 & 7.90 & $382 U$ & $11.4 \mathrm{U}$ \\
\hline & & H0007zVO & 812 & 531 & i & 7.80 & 7.90 & $890 \mathrm{U}$ & $11.5 \mathrm{U}$ \\
\hline & $11 / 10 / 88$ & H00072V2 & 595 & 571 & 1 & 8.60 & 7.90 & $400 u$ & $4.0 \mathrm{U}$ \\
\hline & & H00072v3 & 594 & 583 & i & 8.50 & 7.90 & $300 \mathrm{U}$ & $3.0 \mathrm{U}$ \\
\hline & & H00072V4 & 593 & 588 & i & 8.50 & 8.00 & $300 \mathrm{U}$ & $3.0 \mathrm{U}$ \\
\hline & & H00072V5 & 594 & 586 & 1 & 8.60 & 7.90 & $300 \mathrm{U}$ & $.0 U$ \\
\hline & $11 / 23 / 88$ & H0007zV6 & 633 & & i & 8.50 & & 1 & \\
\hline & $2 / 15 / 89$ & H00072V8 & 537 & 514 & i & 7.00 & 7.90 & $200 \mathrm{U}$ & $5.0 \mathrm{U}$ \\
\hline & & H00072V9 & 531 & 517 & 1 & 6.90 & 7.80 & $200 \mathrm{U}$ & $5.0 \mathrm{U}$ \\
\hline & & HOOOTZWO & 532 & 510 & 1 & 6.90 & 7.70 & $200 \mathrm{U}$ & $.0 \mathrm{U}$ \\
\hline & & H00072W1 & 534 & 512 & 1 & 7.00 & 7.80 & $200 \mathrm{U}$ & $5.0 \mathrm{U}$ \\
\hline & $5 / 26 / 89$ & H0007ZW2 & 550 & 503 & i & 7.89 & 8.00 & $500 \mathrm{U}$ & $4.0 \mathrm{U}$ \\
\hline & & H00072W3 & 549 & 498 & I & 7.89 & $8.0 r$ & $600 \mathrm{U}$ & $3.0 \mathrm{U}$ \\
\hline & & H00072W4 & 549 & 484 & i & 7.89 & 8.60 & $300 \mathrm{U}$ & $3.0 \mathrm{U}$ \\
\hline & & H00072W5 & 549 & 474 & 1 & 7.89 & 8.00 & $500 \mathrm{U}$ & $3.0 \mathrm{U}$ \\
\hline & $8 / 08 / 89$ & H0007ZH6 & 564 & 533 & 1 & 7.89 & 8.00 & $300 \mathrm{U}$ & $3.0 \mathrm{U}$ \\
\hline & & H00072H7 & 567 & 535 & 1 & 7.88 & 8.00 & $300 \mathrm{U}$ & $2.0 \mathrm{U}$ \\
\hline & & H0007ZW8 & 568 & 534 & i & 7.88 & 8.00 & $300 \mathrm{U}$ & $4.0 \mathrm{U}$ \\
\hline & & H00072W9 & 567 & 532 & i & 7.89 & 8.00 & $400 \mathrm{U}$ & $4.0 \mathrm{U}$ \\
\hline & $10 / 31 / 89$ & $H 00072 \times 0$ & 552 & & i & 7.95 & & $500 \mathrm{U}$ & $1.0 \mathrm{U}$ \\
\hline & $11 / 29 / 89$ & $H 00072 \times 1$ & 563 & 542 & 1 & 8.09 & 7.30 & $200 \mathrm{U}$ & $3.0 u$ \\
\hline & & H00072X2 & 560 & 552 & 1 & 8.10 & 7.80 & $300 \mathrm{U}$ & $8.0 \mathrm{U}$ \\
\hline & & $H 00072 \times 3$ & 561 & 550 & 1 & 8.09 & 7.80 & $300 \mathrm{U}$ & $4.0 \mathrm{U}$ \\
\hline & & $H 00072 \times 4$ & 562 & 543 & i & 8.08 & 7.80 & $300 \mathrm{U}$ & $5.0 \mathrm{U}$ \\
\hline & $5 / 30 / 90$ & H00072X5 & 529 & 545 & i & 7.98 & 7.90 & $200 \mathrm{U}$ & $1.0 \mathrm{U}$ \\
\hline & & H0007ZX6 & 530 & 557 & i & 7.97 & 7.90 & $200 \mathrm{U}$ & \\
\hline & & $H 00072 \times 7$ & 530 & 556 & 1 & 7.98 & 7.90 & $500 \mathrm{U}$ & \\
\hline & & $H 0007 Z \times 8$ & 529 & 558 & $i$ & 7.99 & 7.90 & $200 \mathrm{U}$ & \\
\hline & $7 / 09 / 91$ & $H 00071 \times 9$ & 521 & 540 & 1 & 8.07 & 8.25 & u & $u$ \\
\hline & $9 / 06 / 91$ & B00LB6 & 515 & & 1 & 8.02 & & 1 & \\
\hline & & B0OLB7 & 516 & & $i$ & 8.02 & & i & \\
\hline & & BOOLB8 & 515 & & i & 8.03 & & i & \\
\hline & & BOOLB9 & 515 & & $i$ & 8.04 & & 1 & \\
\hline & $1 / 24 / 92$ & 801059 & 527 & & $i$ & 8.08 & & $1000 \mathrm{U}$ & $10.0 \mathrm{UA}$ \\
\hline & $6 / 03 / 92$ & В06PH8 & 558 & & i & 7.99 & & $1000 \mathrm{U}$ & $10.0 \mathrm{UA}$ \\
\hline & & B06PH9 & 556 & & i & 7.98 & & $1000 \mathrm{U}$ & $10.0 \mathrm{~A}$ \\
\hline & & B06PJO & 560 & & 1 & 7.98 & & $1000 \mathrm{U}$ & $10.0 \mathrm{UA}$ \\
\hline & & B06PJ1 & 560 & & 1 & 7.97 & & $1000 \mathrm{U}$ & $10.0 \mathrm{~A}$ \\
\hline & $11 / 03 / 92$ & BO7LH9 & 553 & & i & 8.22 & & i & $10.0 \mathrm{UA}$ \\
\hline & & B07LH2 & 554 & & 1 & 8.22 & & i & 10.0 UA \\
\hline & & B07LH3 & 556 & & 1 & 8.21 & & 1 & 10.0 UA \\
\hline
\end{tabular}


Table 5-3. Results of Indicator Parameter Analyses.

2

(sheet 2 of 17 )

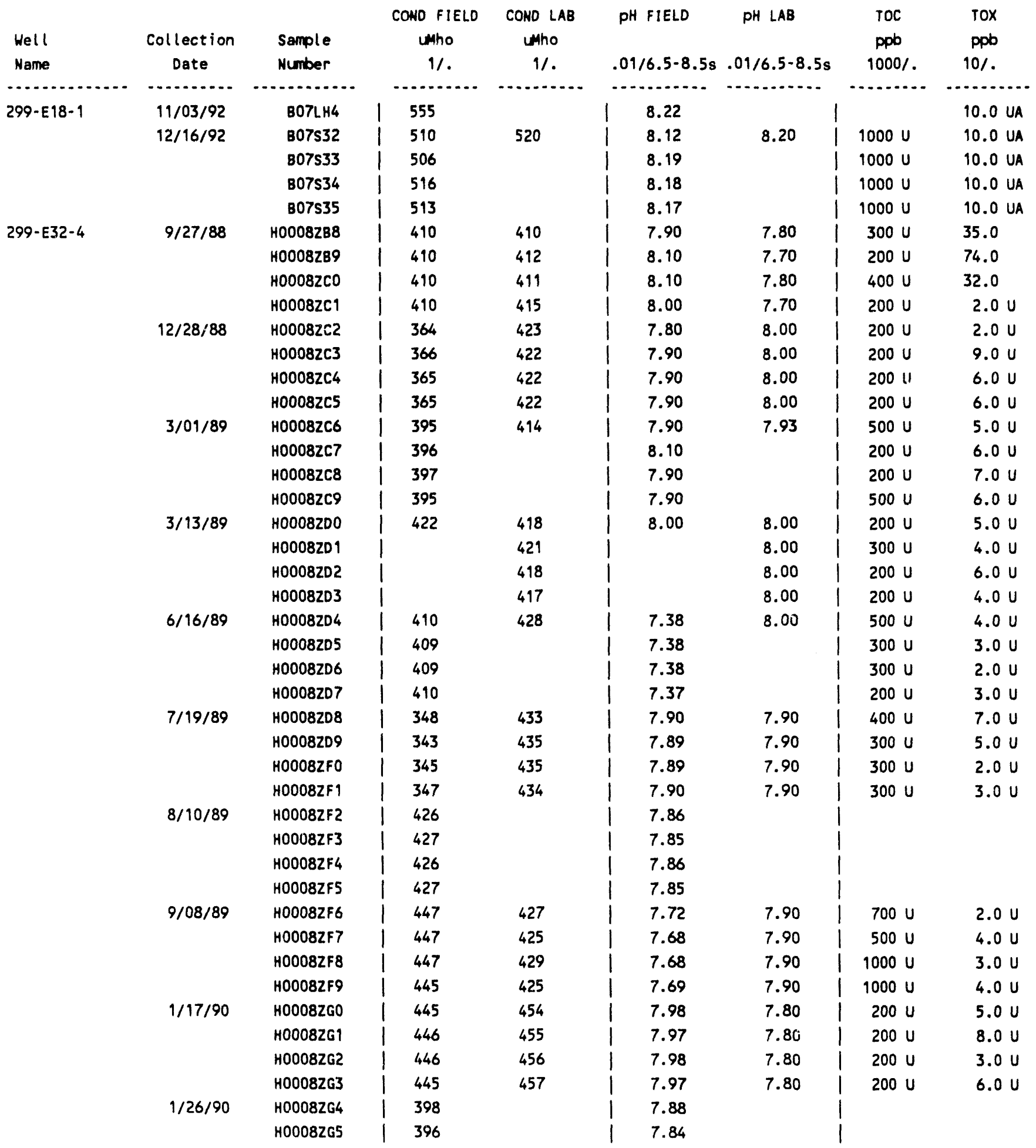


Table 5-3. Results of Indicator Parameter Analyses.

2 (sheet 3 of 17)

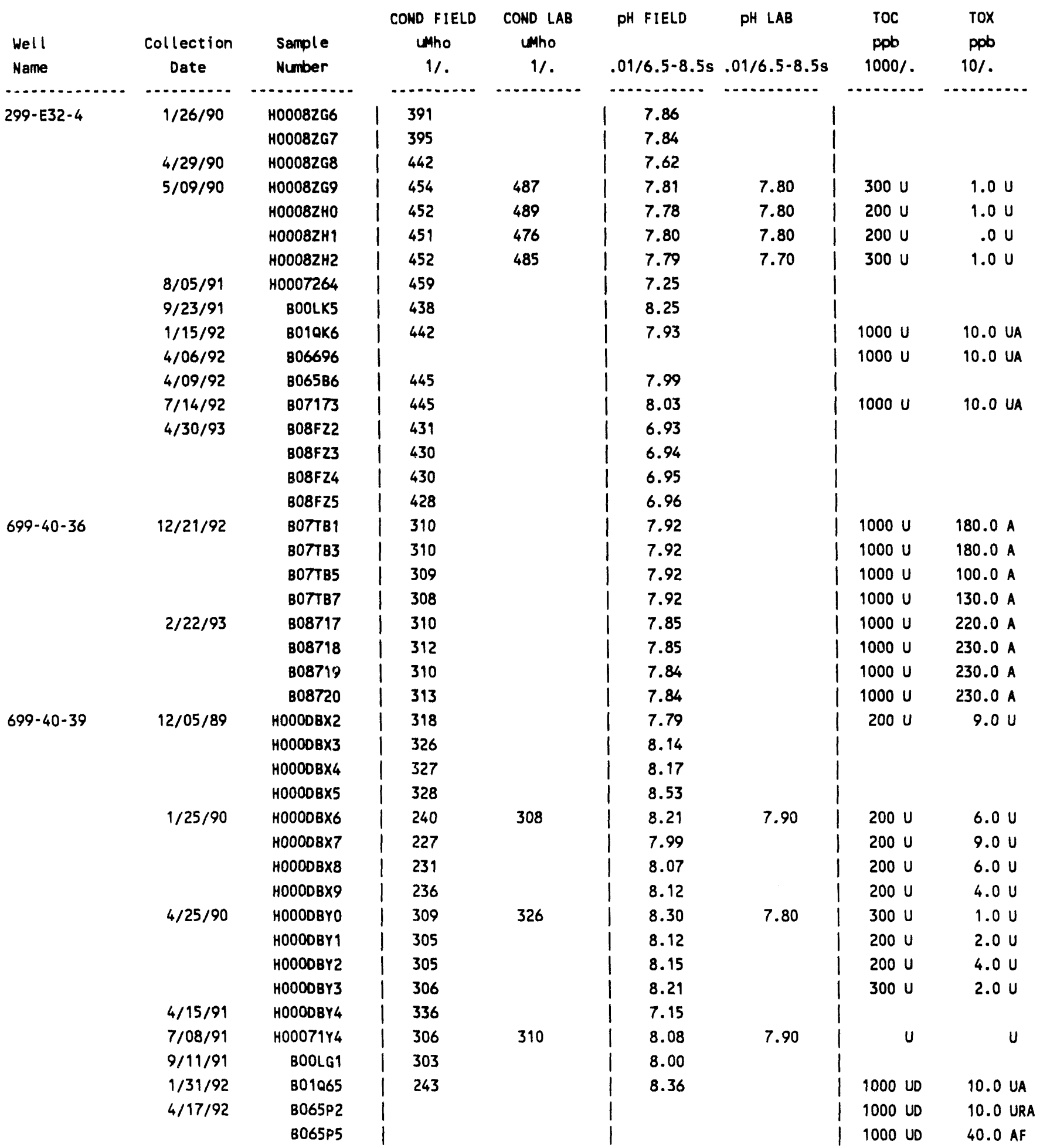


Table 5-3. Results of Indicator Parameter Analyses.

(sheet 4 of 17)

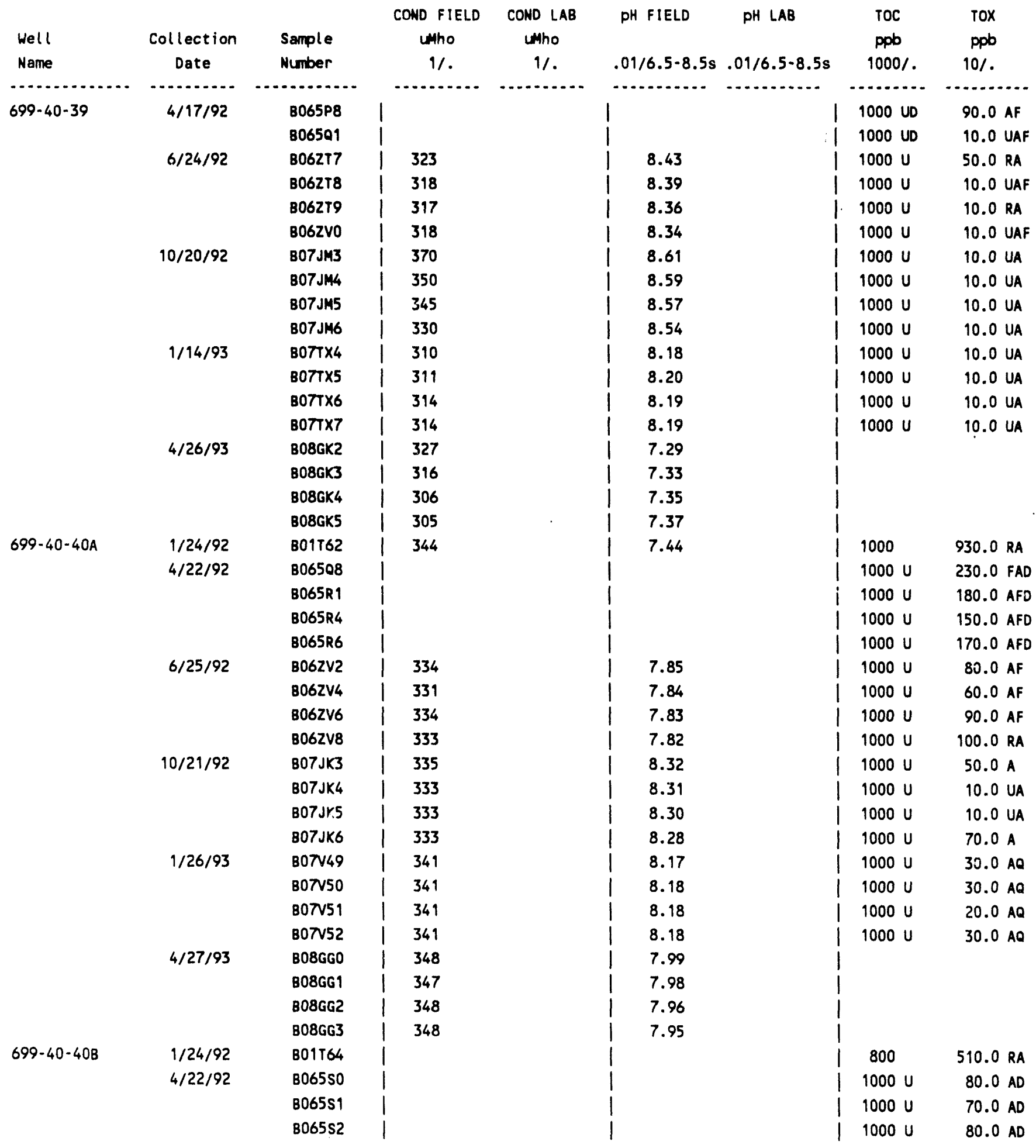




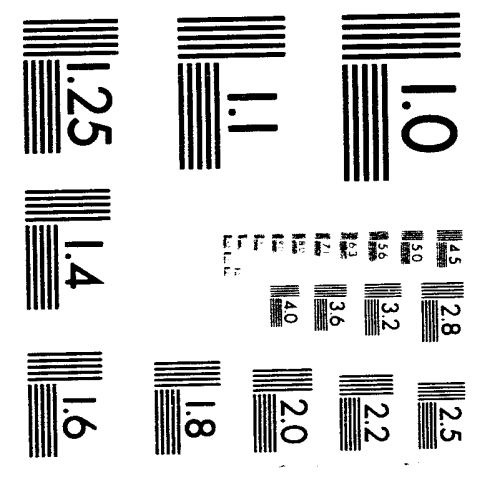



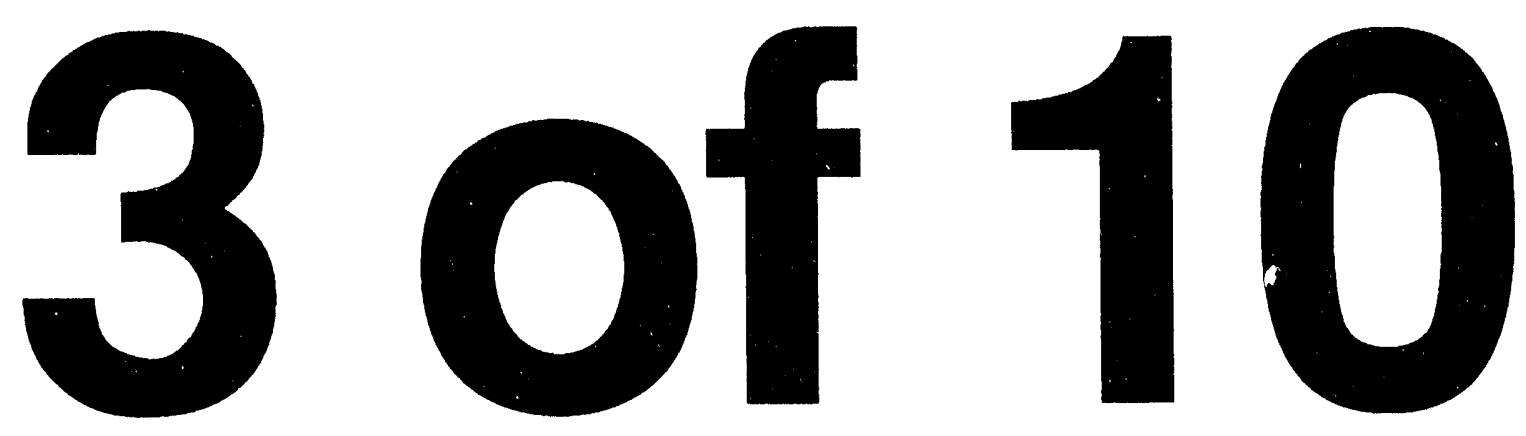
Table 5-3. Results of Indicator Parameter Analyses.

(sheet 5 of 17)

\begin{tabular}{|c|c|c|c|c|c|c|c|c|}
\hline $\begin{array}{l}\text { Well } \\
\text { Name }\end{array}$ & $\begin{array}{l}\text { Collection } \\
\text { Date }\end{array}$ & $\begin{array}{l}\text { Sample } \\
\text { Number }\end{array}$ & $\begin{array}{c}\text { COND FIELD } \\
\text { Uho } \\
1 / .\end{array}$ & $\begin{array}{c}\text { COND LAB } \\
\text { umho } \\
1 \%\end{array}$ & $.01 / 6.5-8.5 \mathrm{~s}$ & $.01 / 6.5-8.5 \mathrm{~s}$ & $\begin{array}{c}\text { TOC } \\
\text { Ppb } \\
1000 \% .\end{array}$ & $\begin{array}{c}\text { TOX } \\
\text { ppb } \\
10 \%\end{array}$ \\
\hline \multirow{17}{*}{$699-40-40 B$} & 4/22./92 & $8065 \mathrm{s3}$ & 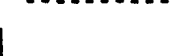 & - & - & - & , & 70.0 AD \\
\hline & $6 / 29 / 92$ & 806242 & 325 & & 7.94 & & $1000 \mathrm{U}$ & $170.0 \mathrm{AF}$ \\
\hline & & $\mathrm{B} 062 \mathrm{W3}$ & 324 & & 7.92 & 1 & $1000 \mathrm{U}$ & $60.0 \mathrm{AF}$ \\
\hline & & B062W4 & 322 & & 7.91 & 1 & $1000 \mathrm{U}$ & $70.0 \mathrm{RA}$ \\
\hline & & B062W5 & 323 & & 7.90 & & $1000 \mathrm{U}$ & $60.0 \mathrm{RA}$ \\
\hline & $10 / 21 / 92$ & B07JK8 & 281 & & 7.49 & & $1000 \mathrm{U}$ & $30.0 \mathrm{~A}$ \\
\hline & & B07JK9 & 283 & & 7.49 & & $1000 \mathrm{U}$ & $30.0 \mathrm{~A}$ \\
\hline & & B07JLO & 282 & & 7.49 & 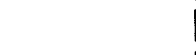 & $1000 \mathrm{U}$ & $30.0 \mathrm{~A}$ \\
\hline & & B07JL1 & 281 & & 7.48 & & $1000 \mathrm{U}$ & $30.0 \mathrm{~A}$ \\
\hline & $1 / 26 / 93$ & B07N54 & 284 & & 7.60 & & $1000 \mathrm{U}$ & $10.0 \mathrm{AQ}$ \\
\hline & & BOTV55 & 283 & & 7.60 & T & $1000 \mathrm{U}$ & $10.0 A Q$ \\
\hline & & Bo7N56 & 282 & & 7.61 & & $1000 \mathrm{U}$ & $20.0 \mathrm{AQ}$ \\
\hline & & B07v57 & 290 & & 7.81 & & $1000 \mathrm{U}$ & $20.0 \mathrm{AQ}$ \\
\hline & 4/22/93 & B08GF5 & 319 & & 7.56 & 7.90 & | & \\
\hline & & B08GF6 & 319 & & 7.55 & & I & \\
\hline & & B08GF7 & 317 & & 7.54 & & | & \\
\hline & & B08GF8 & 317 & & 7.53 & & i & \\
\hline \multirow[t]{8}{*}{$699-41-35$} & $12 / 21 / 92$ & В07т89 & 325 & & 7.95 & & $1000 \mathrm{U}$ & $150.0 \mathrm{~A}$ \\
\hline & & BO7TCO & 323 & & 7.94 & & $1000 \mathrm{U}$ & $110.0 \mathrm{~A}$ \\
\hline & & B07TC1 & 323 & & 7.94 & & $11000 \mathrm{U}$ & $110.0 \mathrm{~A}$ \\
\hline & & B07TC2 & 322 & & 7.94 & & $1000 \mathrm{U}$ & $100.0 \mathrm{~A}$ \\
\hline & $2 / 22 / 93$ & 808707 & 324 & & 7.44 & & $1000 \mathrm{U}$ & $600.0 \mathrm{~A}$ \\
\hline & & B08708 & 323 & & 7.44 & & $1000 \mathrm{U}$ & $480.0 \mathrm{~A}$ \\
\hline & & 808709 & 322 & & 7.45 & & $1000 \mathrm{U}$ & $350.0 \mathrm{~A}$ \\
\hline & & B08710 & 321 & & 7.46 & & $1000 \mathrm{U}$ & $400.0 \mathrm{~A}$ \\
\hline \multirow[t]{18}{*}{$699-41-40$} & $12 / 05 / 89$ & H000DD44 & 383 & & 8.08 & & $400 \mathrm{U}$ & 10.0 \\
\hline & & 40000045 & 371 & & 7.85 & & | & \\
\hline & & H0000046 & 367 & & 7.82 & & | & \\
\hline & & H0000047 & 371 & & 7.75 & & | & \\
\hline & $1 / 25 / 90$ & H0000048 & 300 & 377 & 8.07 & 8.00 & $400 \mathrm{U}$ & $7.0 \mathrm{U}$ \\
\hline & & HOOODD 49 & 322 & & 8.06 & & $400 \mathrm{U}$ & $9.0 \mathrm{U}$ \\
\hline & & 40000050 & 314 & & 8.06 & & $400 \mathrm{U}$ & $3.0 \mathrm{U}$ \\
\hline & & H0000051 & 309 & & 8.07 & & $400 \mathrm{U}$ & $4.0 \mathrm{U}$ \\
\hline & $4 / 19 / 90$ & H0000052 & 376 & 403 & 8.21 & 7.90 & $600 \mathrm{U}$ & $1.0 \mathrm{U}$ \\
\hline & & HO00DD53 & 368 & & 8.22 & & $600 \mathrm{U}$ & $3.0 \mathrm{U}$ \\
\hline & & H0000054 & 369 & & 8.23 & & $600 \mathrm{U}$ & $1.0 \mathrm{U}$ \\
\hline & & H00000.55 & 275 & & 8.24 & & 1400 & $2.0 \mathrm{U}$ \\
\hline & 4/15/91 & H000005E & 378 & & 8.38 & & I & \\
\hline & $7 / 10 / 91$ & H00071Y1 & 383 & 380 & 8.33 & 8.20 & $u$ & U \\
\hline & 9/11/91 & BOOLG2 & 375 & & 8.31 & & | & \\
\hline & $1 / 31 / 92$ & B010C8 & 384 & & 8.25 & & 1000 UD & $20.0 \mathrm{AF}$ \\
\hline & $4 / 28 / 92$ & B065s5 & 1 & & I & & 1000 UD & 20.0 QAD \\
\hline & & B065S6 & & & & & 1000 UD & 10.0 UA \\
\hline
\end{tabular}


1

2

Table 5-3. Results of Indicator Parameter Analyses.

(sheet 6 of 17)

\begin{tabular}{|c|c|c|c|c|c|c|c|c|}
\hline $\begin{array}{l}\text { Well } \\
\text { Name }\end{array}$ & $\begin{array}{l}\text { Collection } \\
\text { Date }\end{array}$ & $\begin{array}{l}\text { Sample } \\
\text { Number }\end{array}$ & $\begin{array}{c}\text { COND FIELD } \\
\text { Uho } \\
1 / .\end{array}$ & $\begin{array}{c}\text { COND LAB } \\
\text { Uho } \\
1 / .\end{array}$ & $.01 / 6.5-8.5 \mathrm{~s}$ & $.01 / 6.5-8.5 \mathrm{~s}$ & $\begin{array}{l}\text { TOC } \\
\text { ppob } \\
1000 \%\end{array}$ & $\begin{array}{c}\text { TOX } \\
\text { ppb } \\
10 \% .\end{array}$ \\
\hline \multirow{14}{*}{$699-41-40$} & 100100 & 806557 & . & & 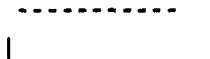 & & 1000 UD & 10.0 AD \\
\hline & 4/28/92 & $\begin{array}{l}806557 \\
806558\end{array}$ & 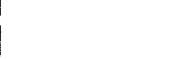 & & 1 & & 1000 UD & 20.0 AD \\
\hline & $6 / 24 / 92$ & B062X2 & 381 & & 8.34 & 1 & $1000 \mathrm{U}$ & $10.0 \mathrm{UA}$ \\
\hline & & $B 062 \times 3$ & 381 & & 8.31 & 1 & $1000 \mathrm{U}$ & $10.0 \mathrm{UA}$ \\
\hline & & $8062 \times 4$ & 382 & & $8.3 \mathrm{C}$ & 1 & $1000 \mathrm{U}$ & $10.0 \mathrm{UA}$ \\
\hline & & $8062 \times 5$ & 379 & & 8.24 & & $1000 \mathrm{U}$ & $10.0 \mathrm{UA}$ \\
\hline & $10 / 20 / 92$ & B07JM7 & 392 & & 8.74 & 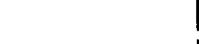 & $1000 \mathrm{U}$ & $10.0 \mathrm{UA}$ \\
\hline & & B07JM8 & 390 & & $8 . \pi$ & & $1000 \mathrm{U}$ & $10.0 \mathrm{UA}$ \\
\hline & & B07JM9 & 388 & & 8.75 & & $1000 \mathrm{U}$ & $10.0 \mathrm{UA}$ \\
\hline & & B07JNO & 388 & & 8.75 & & $1000 \mathrm{U}$ & $10.0 \mathrm{UA}$ \\
\hline & $1 / 14 / 93$ & BO7TX9 & 358 & & 8.36 & & $1000 \mathrm{U}$ & $10.0 \mathrm{UA}$ \\
\hline & & BOTTYO & 359 & & 8.36 & & $1000 \mathrm{U}$ & $10.0 \mathrm{UA}$ \\
\hline & & B07TY1 & 360 & & 8.37 & & $1000 \mathrm{U}$ & $10.0 \mathrm{UA}$ \\
\hline & & BOTTY2 & 360 & & 8.38 & & $1000 \mathrm{U}$ & $10.0 \mathrm{UA}$ \\
\hline \multirow[t]{8}{*}{$699-41-42$} & $1 / 08 / 93$ & B07v59 & 257 & & 8.31 & & $1000 \mathrm{U}$ & $10.0 \mathrm{UA}$ \\
\hline & & B07v60 & 259 & & 8.29 & & $1000 \mathrm{U}$ & $10.0 \mathrm{UA}$ \\
\hline & & B07v61 & 259 & & 8.29 & & $1000 \mathrm{U}$ & $10.0 \mathrm{UA}$ \\
\hline & & BOTV62 & 262 & & 8.29 & & $1000 \mathrm{U}$ & $20.0 \mathrm{BA}$ \\
\hline & $4 / 22 / 93$ & B08GG5 & 268 & & 8.35 & 8.50 & & \\
\hline & & B08GG6 & 267 & & 8.34 & & & \\
\hline & & B08GG7 & 267 & & 8.34 & t & & \\
\hline & & B08GG8 & 268 & & 8.34 & 1 & & \\
\hline \multirow[t]{8}{*}{$699-42-37$} & $12 / 22 / 92$ & B07TC4 & 361 & & 8.11 & & $1000 \mathrm{U}$ & $10.0 \mathrm{UA}$ \\
\hline & & B07TC5 & 360 & & 8.10 & & $1000 \mathrm{U}$ & $40.0 \mathrm{~A}$ \\
\hline & & B07TC6 & 359 & & 8.08 & & $1000 \mathrm{U}$ & $20.0 \mathrm{~A}$ \\
\hline & & $807 T C 7$ & 356 & & 8.09 & & $1000 \mathrm{U}$ & $20.0 \mathrm{BA}$ \\
\hline & $2 / 23 / 93$ & B08712 & 381 & & 8.10 & & $1000 \mathrm{U}$ & $10.0 \mathrm{UA}$ \\
\hline & & B08713 & 382 & & 8.10 & & $1000 \mathrm{U}$ & $10.0 \mathrm{~A}$ \\
\hline & & B08714 & 382 & & 8.10 & & $1000 \mathrm{U}$ & $20.0 A$ \\
\hline & & 808715 & 382 & & 8.10 & & $1000 \mathrm{U}$ & $10.0 \mathrm{UA}$ \\
\hline \multirow[t]{13}{*}{$699-42-39 A$} & $1 / 23 / 92$ & B01T66 & $328 \mathrm{P}$ & & $7.37 \mathrm{P}$ & & 1000 UP & 10.0 UAP \\
\hline & 4/17/92 & B065T1 & I & & 1 & & 1000 UP & 10.0 UFP \\
\hline & & B065T2 & | & & 1 & & 1000 UP & $60.0 \mathrm{PF}$ \\
\hline & & B065T3 & | & & 1 & & 1000 UP & 10.0 UPF \\
\hline & & $8065 T 4$ & | & & 1 & & 1000 UP & 10.0 UFPA \\
\hline & $6 / 25 / 92$ & B062X7 & $353 \mathrm{P}$ & & $7.27 \mathrm{P}$ & & 1000 UP & 10.0 UAP \\
\hline & & B062X8 & $354 \mathrm{P}$ & & $7.33 P$ & & 1000 UP & 10.0 UPA \\
\hline & & B062X9 & $356 \mathrm{P}$ & & $7.34 P$ & & 1000 UP & 10.0 UAP \\
\hline & & $8062 Y 0$ & $354 \mathrm{P}$ & & $7.34 \mathrm{P}$ & & 1000 UP & 10.0 UPA \\
\hline & $10 / 21 / 92$ & B07JL3 & 312 & & 7.77 & & 1000 UP & $10.0 \mathrm{UA}$ \\
\hline & & B07JL4 & 312 & & 7.76 & & 1000 UP & 10.0 UA \\
\hline & & B07JL5 & 312 & & 7.70 & & 1000 UP & 10.0 UA \\
\hline & & B07JL6 & 312 & & 7.71 & & 1000 UP & $10.0 \mathrm{UA}$ \\
\hline
\end{tabular}


Table 5-3. Results of Indicator Parameter Analyses.

2 (sheet 7 of 17)

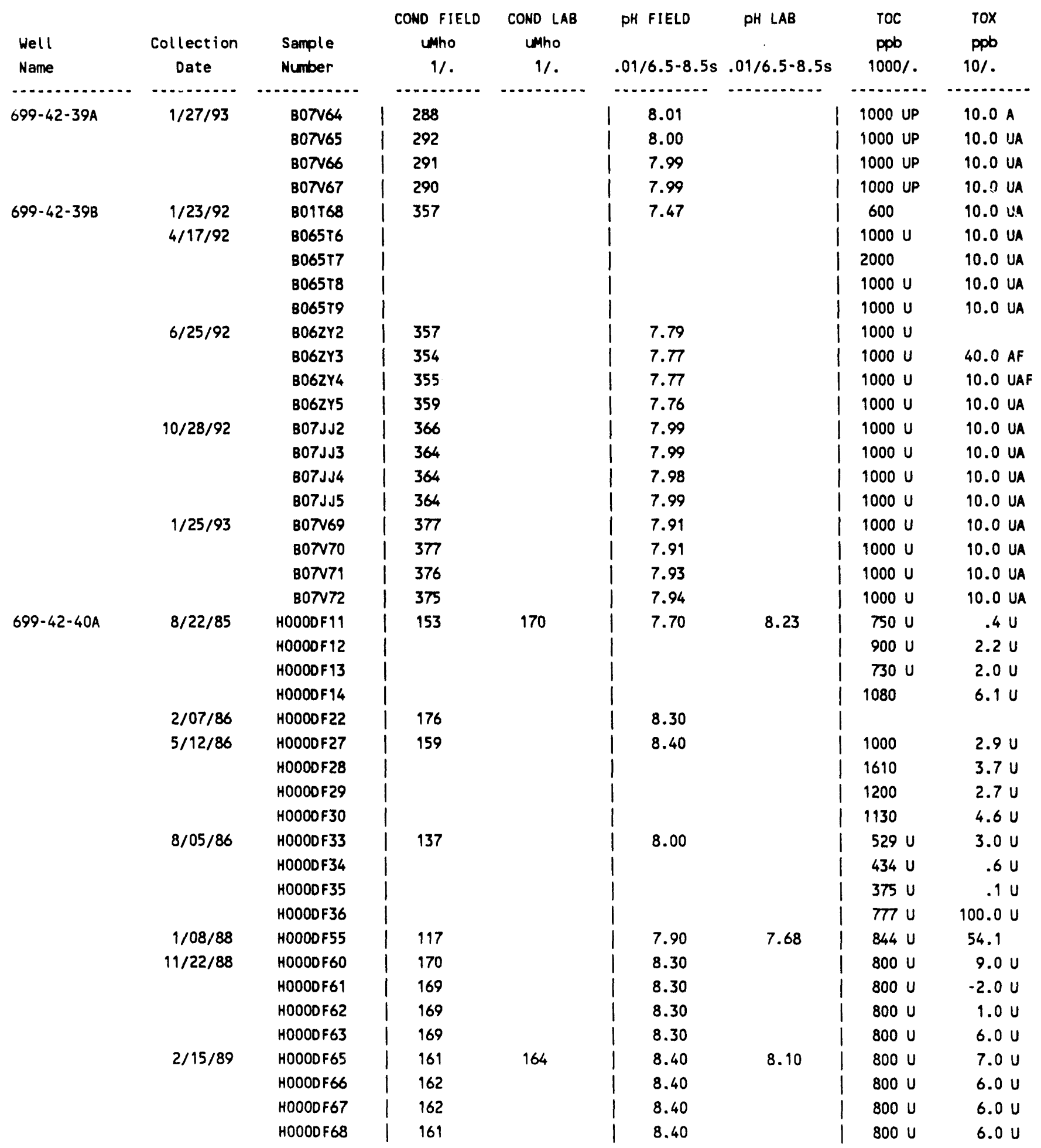


Table 5-3. Results of Indicator Parameter Analyses.

2 (sheet 8 of 17 )

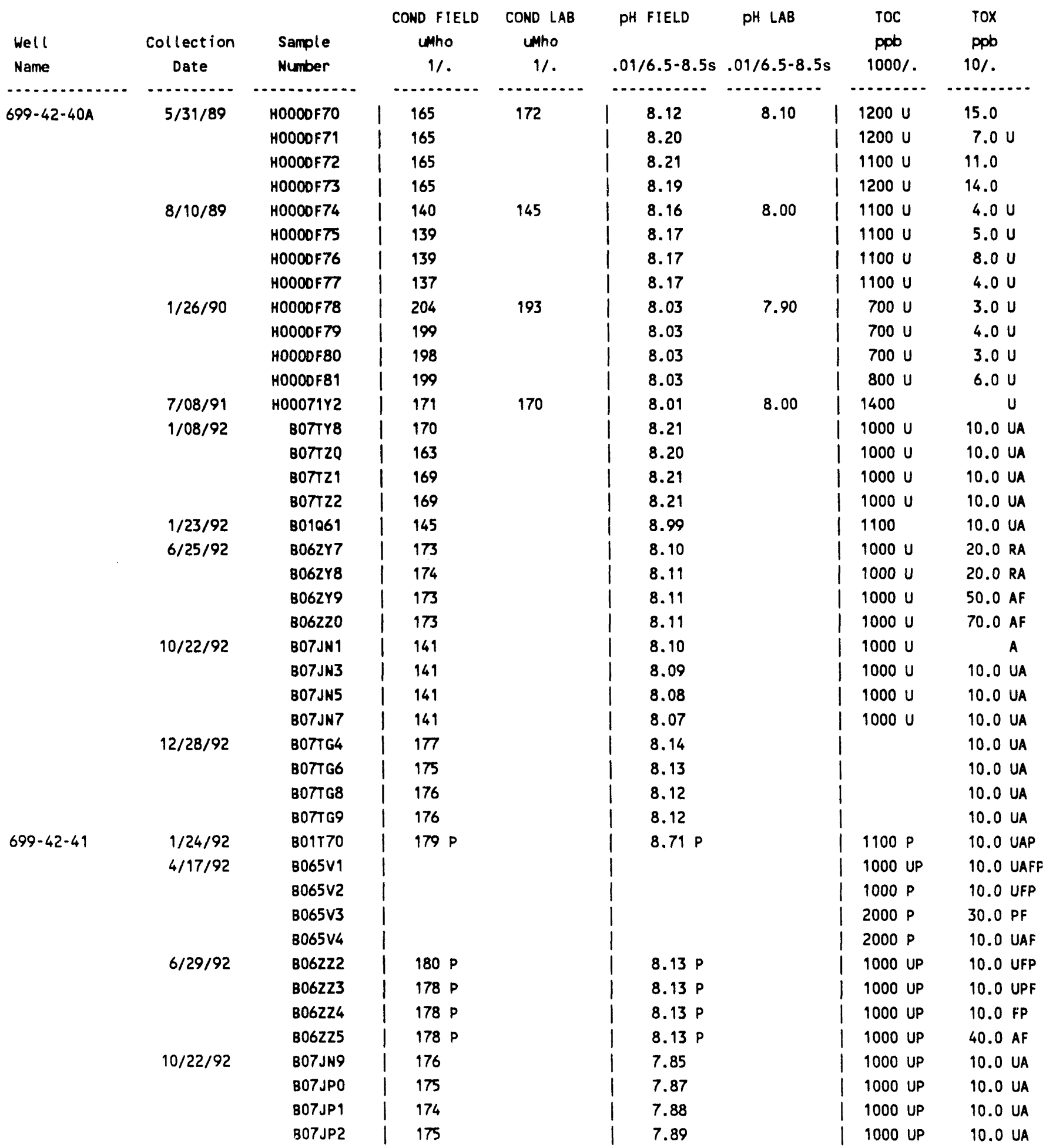


Table 5-3. Results of Indicator Parameter Analyses. (sheet 9 of 17 )

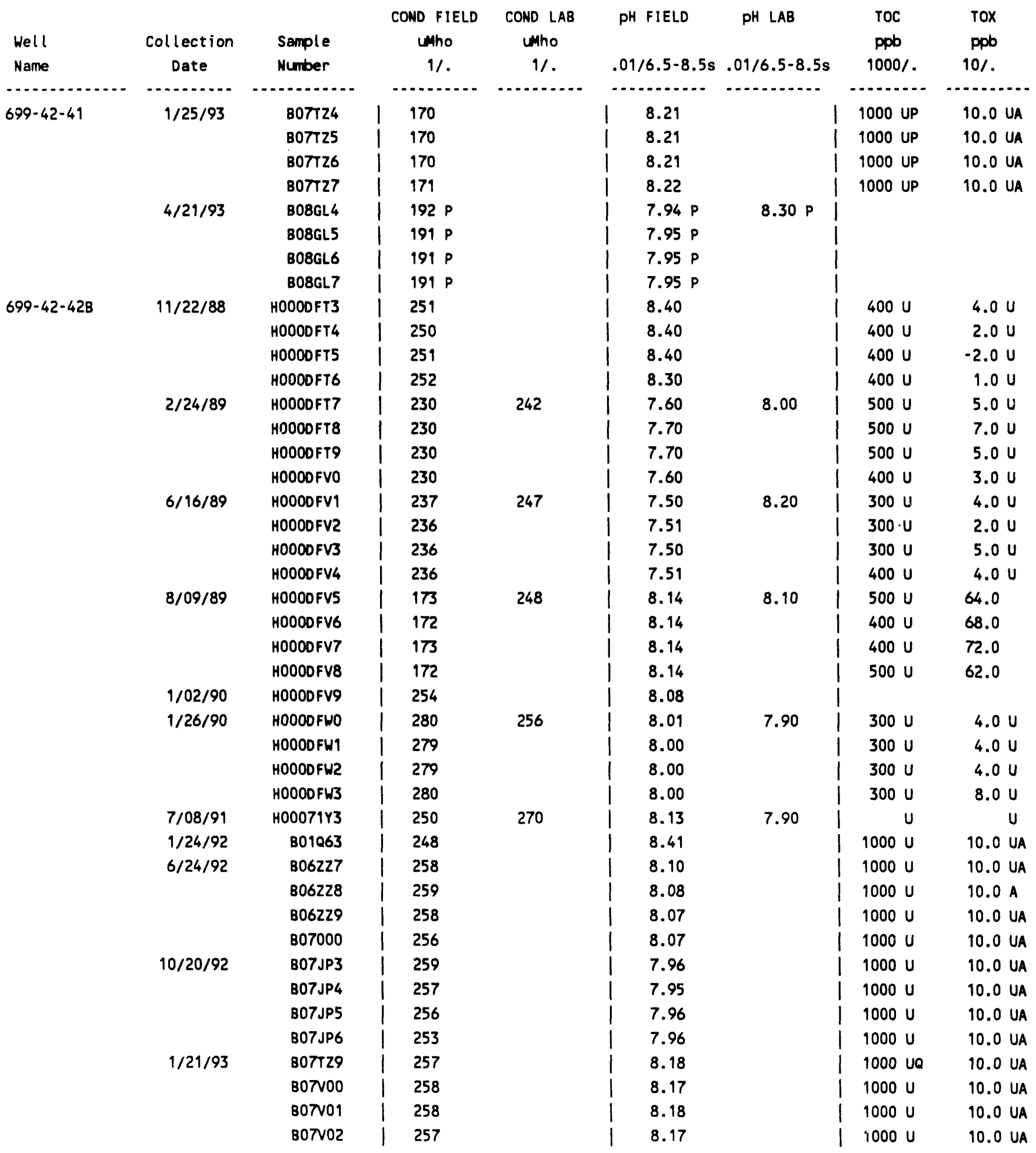


Table 5-3. Results of Indicator Parameter Analyses.

2

(sheet 10 of 17)

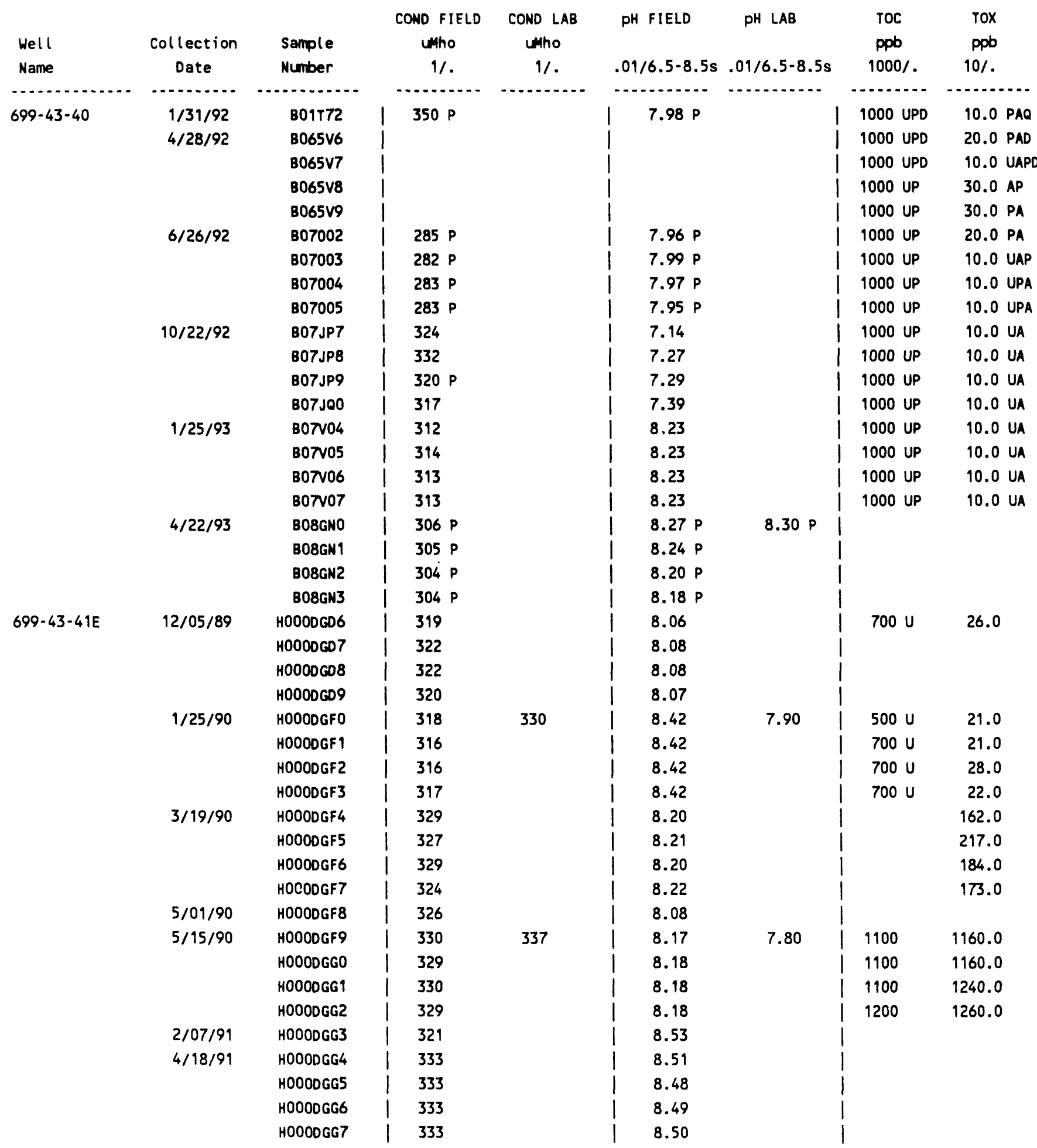


Table 5-3. Results of Indicator Parameter Analyses.

2 (sheet 11 of 17 )

\begin{tabular}{|c|c|c|c|c|c|c|c|c|}
\hline $\begin{array}{l}\text { Well } \\
\text { Name }\end{array}$ & $\begin{array}{c}\text { Collection } \\
\text { Date }\end{array}$ & $\begin{array}{l}\text { Sample } \\
\text { Number }\end{array}$ & $\begin{array}{c}\text { COND FIELD } \\
\text { Uho } \\
1 / .\end{array}$ & $\begin{array}{c}\text { COND LAB } \\
\text { uWho } \\
1 / .\end{array}$ & $.01 / 6.5-8.5 \mathrm{~s}$ & $.01 / 6.5-8.5 \mathrm{~s}$ & $\begin{array}{c}\text { TOC } \\
\text { pppb } \\
1000 \% .\end{array}$ & $\begin{array}{c}\text { TOX } \\
\text { ppb } \\
10 \% .\end{array}$ \\
\hline \multirow[t]{24}{*}{$699-43-41 E$} & $6 / 28 / 91$ & H0007203 & 333 & 330 & 8.16 & 8.20 & $u$ & 130.0 \\
\hline & & H0007204 & 1 & 330 & 1 & 8.30 & $u$ & 130.0 \\
\hline & $9 / 11 / 91$ & BOOLG3 & 331 & & 8.15 & & I & \\
\hline & $1 / 23 / 92$ & B010C3 & 321 & & 8.67 & & $1000 \mathrm{U}$ & $50.0 \mathrm{RA}$ \\
\hline & 4/17/92 & $8065 P 4$ & 1 & & 1 & & $11000 \mathrm{U}$ & $60.0 A$ \\
\hline & & B065P7 & 1 & & 1 & & $11000 \mathrm{U}$ & $50.0 \AA$ \\
\hline & & $B 06500$ & 1 & & 1 & & $11000 \mathrm{U}$ & $50.0 \mathrm{~A}$ \\
\hline & & 806503 & i & & I & & $1000 \mathrm{U}$ & $50.0 \mathrm{~A}$ \\
\hline & $6 / 24 / 92$ & B062V3 & 323 & & 8.31 & & $1000 \mathrm{U}$ & $50.0 \mathrm{RA}$ \\
\hline & & B062V5 & 322 & & 8.32 & & $1000 \mathrm{U}$ & 40.0 RA \\
\hline & & B062V7 & 323 & & 8.32 & & $1000 \mathrm{U}$ & 80.0 AF \\
\hline & & B062V9 & 322 & & 8.32 & & I $1000 \mathrm{U}$ & $40.0 \mathrm{AF}$ \\
\hline & $10 / 20 / 92$ & B07J01 & 318 & & 8.74 & & $11000 \mathrm{U}$ & $10.0 \mathrm{~A}$ \\
\hline & & 807J02 & 317 & & 8.74 & & $1000 \mathrm{U}$ & $20.0 \mathrm{~A}$ \\
\hline & & B07J03 & 318 & & 8.74 & & $11000 \mathrm{U}$ & $20.0 \AA$ \\
\hline & & B07JQ4 & 316 & & 8.75 & & $1000 \mathrm{U}$ & $30.0 \AA$ \\
\hline & $1 / 25 / 93$ & BO7v09 & 323 & & 8.81 & & I $1000 \mathrm{U}$ & $20.0 \mathrm{~A}$ \\
\hline & & Bo7v10 & 326 & & 8.78 & & $1000 \mathrm{U}$ & $20.0 \mathrm{~A}$ \\
\hline & & Borv11 & 319 & & 8.76 & & $1000 \mathrm{U}$ & $20.0 \mathrm{~A}$ \\
\hline & & BO7v12 & 324 & & 8.76 & & $11000 \mathrm{U}$ & $10.0 \mathrm{~A}$ \\
\hline & $4 / 22 / 93$ & B08GN4 & 320 & & 8.52 & 8.70 & 1 & \\
\hline & & B08GN5 & 321 & & 8.50 & & 1 & \\
\hline & & B08GN6 & 321 & & 8.50 & & 1 & \\
\hline & & B08GN7 & 320 & & 8.48 & & | & \\
\hline \multirow[t]{19}{*}{$699-43-41 F$} & $12 / 05 / 89$ & HOOODGG8 & 318 & & 8.09 & & $400 \mathrm{U}$ & 19.0 \\
\hline & & HODODGG9 & 324 & & 8.10 & & | & \\
\hline & & HOOODGHO & 332 & & 8.10 & & | & \\
\hline & & HOOODGH1 & 321 & & 8.09 & & 1 & \\
\hline & $1 / 25 / 90$ & HOOODGH2 & 292 & 298 & 8.27 & 7.70 & $300 \mathrm{U}$ & $1.0 \mathrm{U}$ \\
\hline & & HOOODGH3 & 292 & & 8.30 & & $300 \mathrm{U}$ & $8.0 \mathrm{U}$ \\
\hline & & HOOODGH4 & 291 & & 8.28 & & $400 \mathrm{U}$ & 11.0 \\
\hline & & HOOODGH5 & 292 & & 8.30 & & $300 \mathrm{U}$ & $7.0 \mathrm{U}$ \\
\hline & $4 / 18 / 90$ & HOOODGH6 & 282 & 324 & 8.05 & 7.50 & 1100 & 1270.0 \\
\hline & & HOOODGH7 & 282 & & 8.01 & & 1200 & 1170.0 \\
\hline & & HOOODGH8 & 285 & & 8.02 & & 1200 & 1310.0 \\
\hline & & HOOODGH9 & 279 & & 8.06 & & 1000 & 998.0 \\
\hline & $5 / 01 / 90$ & HOOODGJO & 305 & & 7.91 & & 1 & \\
\hline & $2 / 07 / 91$ & HOOODGJ1 & 320 & & 8.22 & & 1 & \\
\hline & $4 / 18 / 91$ & H000DGJ2 & 316 & & 7.99 & & I & \\
\hline & & HOOODGJ3 & 318 & & 7.98 & & 1 & \\
\hline & & HOOODGJ4 & 317 & & 7.99 & & 1 & \\
\hline & & HOOODGJ5 & 317 & & 8.00 & & | & \\
\hline & $7 / 02 / 91$ & H00071Y5 & 314 & 320 & 8.21 & 8.00 & U & 23.0 \\
\hline
\end{tabular}


Table 5-3. Results of Indicator Parameter Analyses. (sheet 12 of 17 )

\begin{tabular}{|c|c|c|c|c|c|c|c|c|c|c|}
\hline $\begin{array}{l}\text { Well } \\
\text { Name }\end{array}$ & $\begin{array}{l}\text { Collection } \\
\text { Date }\end{array}$ & $\begin{array}{l}\text { Sample } \\
\text { Number }\end{array}$ & & $\begin{array}{c}\text { COND FIELD } \\
\text { Who } \\
1 / .\end{array}$ & $\begin{array}{c}\text { COND LAB } \\
\text { Who } \\
1 / .\end{array}$ & .01 & $/ 6.5-8.5 \mathrm{~s}$ & $.01 / 6.5-8.5 \mathrm{~s}$ & $\begin{array}{c}\text { TOC } \\
\text { ppb } \\
1000 \% .\end{array}$ & $\begin{array}{c}\text { ToX } \\
\text { ppb } \\
10 \% .\end{array}$ \\
\hline …... & . & . & & n. & . & & ........... & & ............. & \\
\hline \multirow[t]{17}{*}{$699-43-41 F$} & 9/11/91 & BO0LG4 & 1 & 312 & & 1 & 7.79 & 1 & & \\
\hline & $5 / 05 / 92$ & B065RO & 1 & 307 & & 1 & 8.10 & 1 & $1000 \mathrm{U}$ & $10.0 \mathrm{UA}$ \\
\hline & & B065R3 & 1 & 306 & & 1 & 8.08 & 1 & $1000 \mathrm{U}$ & $20.0 \mathrm{~A}$ \\
\hline & & B065R5 & i & 305 & & 1 & 8.08 & 1 & $1000 \mathrm{U}$ & $20.0 \mathrm{~A}$ \\
\hline & & B065R7 & I & 307 & & 1 & 8.07 & 1 & $1000 \mathrm{U}$ & $10.0 \AA$ \\
\hline & $6 / 25 / 92$ & B062W7 & 1 & 334 & & 1 & 8.25 & 1 & $1000 \mathrm{U}$ & $50.0 \mathrm{RA}$ \\
\hline & & B062W8 & 1 & 334 & & i & 8.22 & 1 & $1000 \mathrm{U}$ & 10.0 URA \\
\hline & & B062109 & i & 335 & & i & 8.19 & & $1000 \mathrm{U}$ & 10.0 URA \\
\hline & & $B 062 \times 0$ & 1 & 335 & & 1 & 8.17 & & $1000 \mathrm{U}$ & 10.0 URA \\
\hline & $10 / 21 / 92$ & B07J05 & 1 & 304 & & 1 & 8.05 & & $1000 \mathrm{U}$ & $10.0 \mathrm{~A}$ \\
\hline & & B07J06 & 1 & 301 & & I & 8.03 & & $1000 \mathrm{U}$ & 10.0 UA \\
\hline & & B07J07 & 1 & 302 & & 1 & 8.04 & & $1000 \mathrm{U}$ & $10.0 \mathrm{~A}$ \\
\hline & & B07J08 & 1 & 302 & & i & 8.03 & & $1000 \mathrm{U}$ & $10.0 \cup A$ \\
\hline & $1 / 22 / 93$ & B07v14 & 1 & 305 & & 1 & 8.38 & & $1000 \mathrm{U}$ & $10.0 \mathrm{UA}$ \\
\hline & & BOTN15 & 1 & 305 & & 1 & 8.36 & & $1000 \mathrm{U}$ & $10.0 \mathrm{UA}$ \\
\hline & & B07v16 & 1 & 304 & & 1 & 8.36 & & $1000 \mathrm{U}$ & $10.0 \mathrm{UA}$ \\
\hline & & Borv17 & 1 & 303 & & 1 & 8.34 & & $1000 \mathrm{U}$ & $10.0 \mathrm{UA}$ \\
\hline \multirow[t]{21}{*}{$699-43-416$} & $1 / 23 / 92$ & $801 T 74$ & 1 & 304 & & 1 & 8.49 & & 600 & $360.0 \mathrm{RA}$ \\
\hline & $4 / 17 / 92$ & 8065W1 & 1 & & & 1 & & & $1000 \mathrm{U}$ & $10.0 \mathrm{~A}$ \\
\hline & & 8065W2 & 1 & & & 1 & & & $1000 \mathrm{U}$ & $10.0 \mathrm{~A}$ \\
\hline & & 8065 W3 & 1 & & & 1 & & & $1000 \mathrm{U}$ & $10.0 \mathrm{~A}$ \\
\hline & & 8065144 & 1 & & & 1 & & & $1000 \mathrm{U}$ & $10.0 \mathrm{~A}$ \\
\hline & $6 / 26 / 92$ & B07007 & 1 & 297 & & 1 & 8.59 & & $1000 U$ & 10.0 UA \\
\hline & & B07008 & 1 & 300 & & 1 & 8.58 & & $1000 \mathrm{U}$ & $20.0 A$ \\
\hline & & 807009 & 1 & 298 & & 1 & 8.59 & & $1000 \mathrm{U}$ & $20.0 \mathrm{~A}$ \\
\hline & & B07010 & 1 & 298 & & 1 & 8.58 & & $1000 \mathrm{U}$ & $10.0 \mathrm{~A}$ \\
\hline & $10 / 28 / 92$ & B07JL8 & 1 & 295 & & 1 & 8.71 & & $1000 \mathrm{U}$ & $20.0 A$ \\
\hline & & B07JL9 & 1 & 292 & & 1 & 8.71 & & $1000 \mathrm{U}$ & $A D$ \\
\hline & & B07JMO & 1 & 292 & & 1 & 8.69 & & $1000 \mathrm{U}$ & $A D$ \\
\hline & & B07JM1 & 1 & 291 & & 1 & 8.70 & & $1000 \mathrm{U}$ & $20.0 \mathrm{~A}$ \\
\hline & $1 / 25 / 93$ & B07v74 & 1 & 304 & & 1 & 8.79 & & $1000 \mathrm{U}$ & 10.0 UA \\
\hline & & BOTVTS & 1 & 303 & & 1 & 8.76 & & $1000 \mathrm{U}$ & $10.0 \mathrm{UA}$ \\
\hline & & BO7v76 & 1 & 303 & & 1 & 8.75 & & $1000 \mathrm{U}$ & 10.0 UA \\
\hline & & BOTVT & 1 & 302 & & 1 & 8.74 & & $1000 \mathrm{U}$ & $10.0 \mathrm{UA}$ \\
\hline & $4 / 27 / 93$ & BO8GJO & 1 & 299 & & 1 & 7.97 & & 1 & \\
\hline & & B08GJ1 & 1 & 299 & & 1 & 7.98 & & 1 & \\
\hline & & B08GJ2 & 1 & 298 & & 1 & 7.99 & & | & \\
\hline & & B08GJ3 & 1 & 299 & & 1 & 7.99 & & | & \\
\hline \multirow[t]{5}{*}{$699-43-42 J$} & $11 / 22 / 88$ & HOOODGP2 & 1 & 187 & & 1 & 8.00 & & $600 \mathrm{U}$ & $2.0 \mathrm{U}$ \\
\hline & & HOOODGP3 & 1 & 187 & & 1 & 8.30 & & $700 \mathrm{U}$ & $5.0 \mathrm{U}$ \\
\hline & & HOOODGP 4 & 1 & 187 & & 1 & 8.00 & & $800 \mathrm{U}$ & $4.0 \mathrm{U}$ \\
\hline & & HOOOOGP5 & 1 & 187 & & 1 & 8.20 & & $600 \mathrm{U}$ & $6.0 \mathrm{U}$ \\
\hline & $2 / 24 / 89$ & HOOODGP6 & 1 & 239 & 222 & 1 & 8.10 & 8.00 & $500 \mathrm{U}$ & $5.0 \mathrm{U}$ \\
\hline
\end{tabular}


Table 5-3. Results of Indicator Parameter Analyses.

(sheet 13 of 17 )

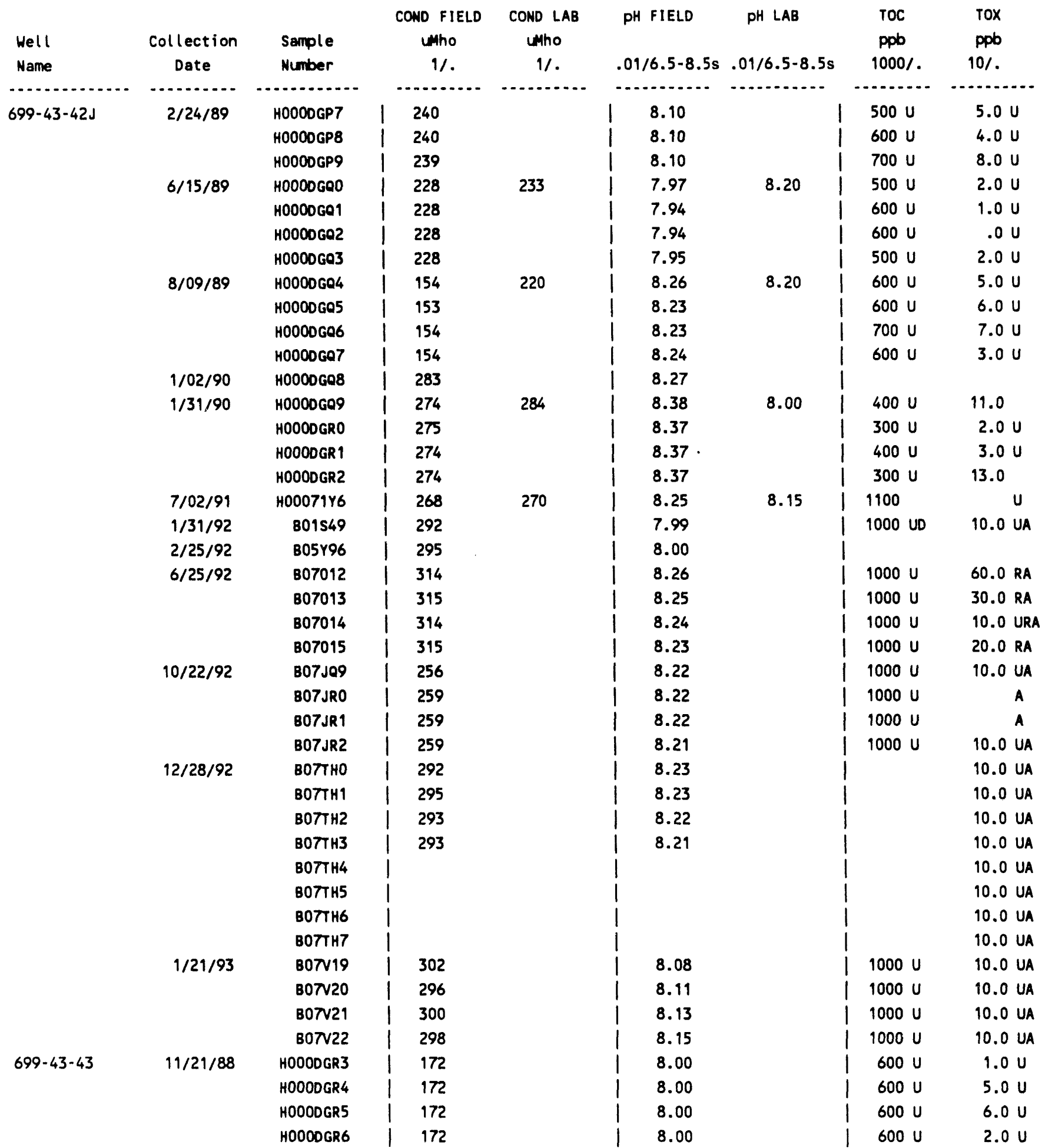


1

2

Table 5-3. Results of Indicator Parameter Analyses. (sheet 14 of 17)

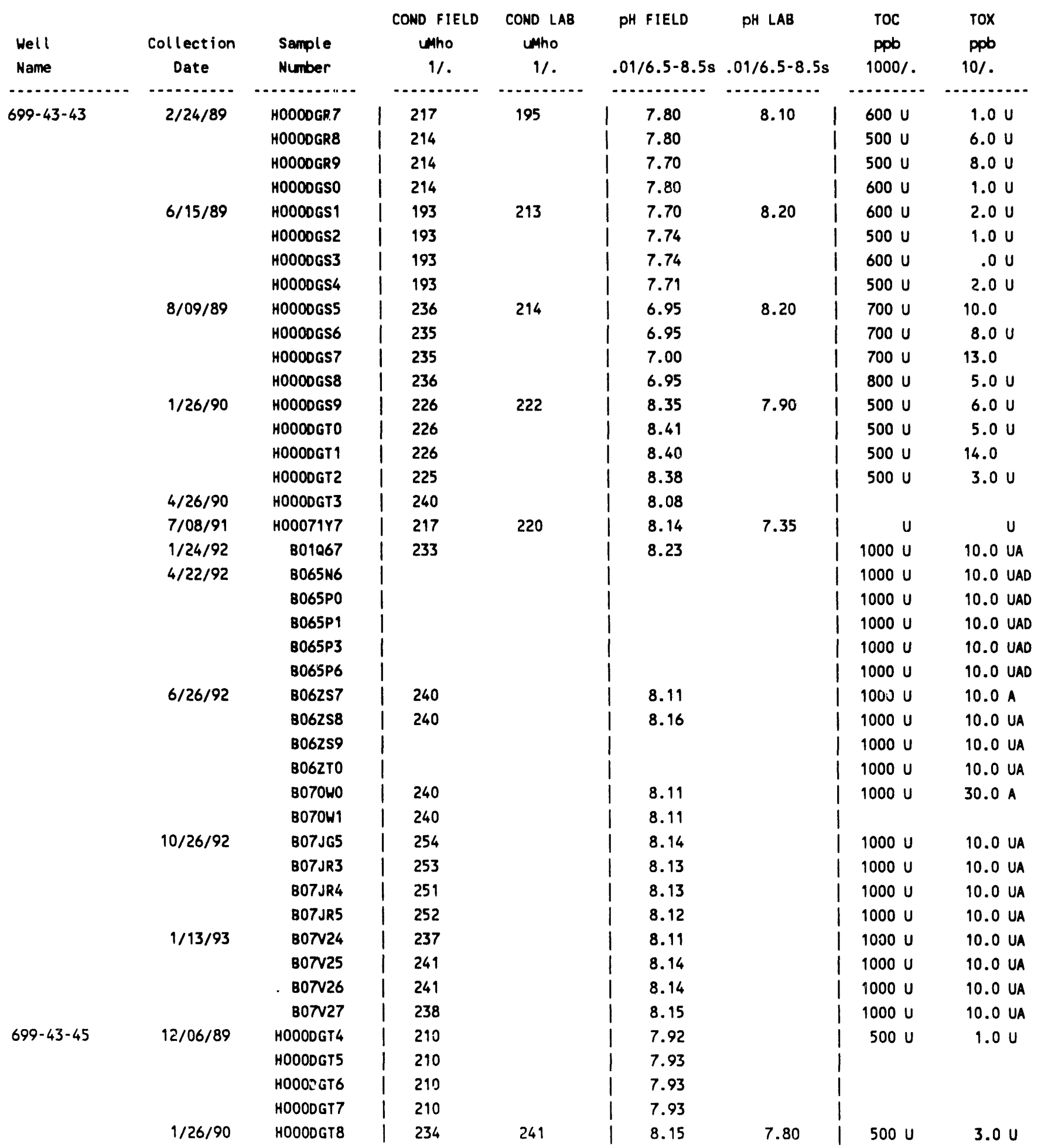


Table 5-3. Results of Indicator Parameter Analyses.

2 (sheet 15 of 17)

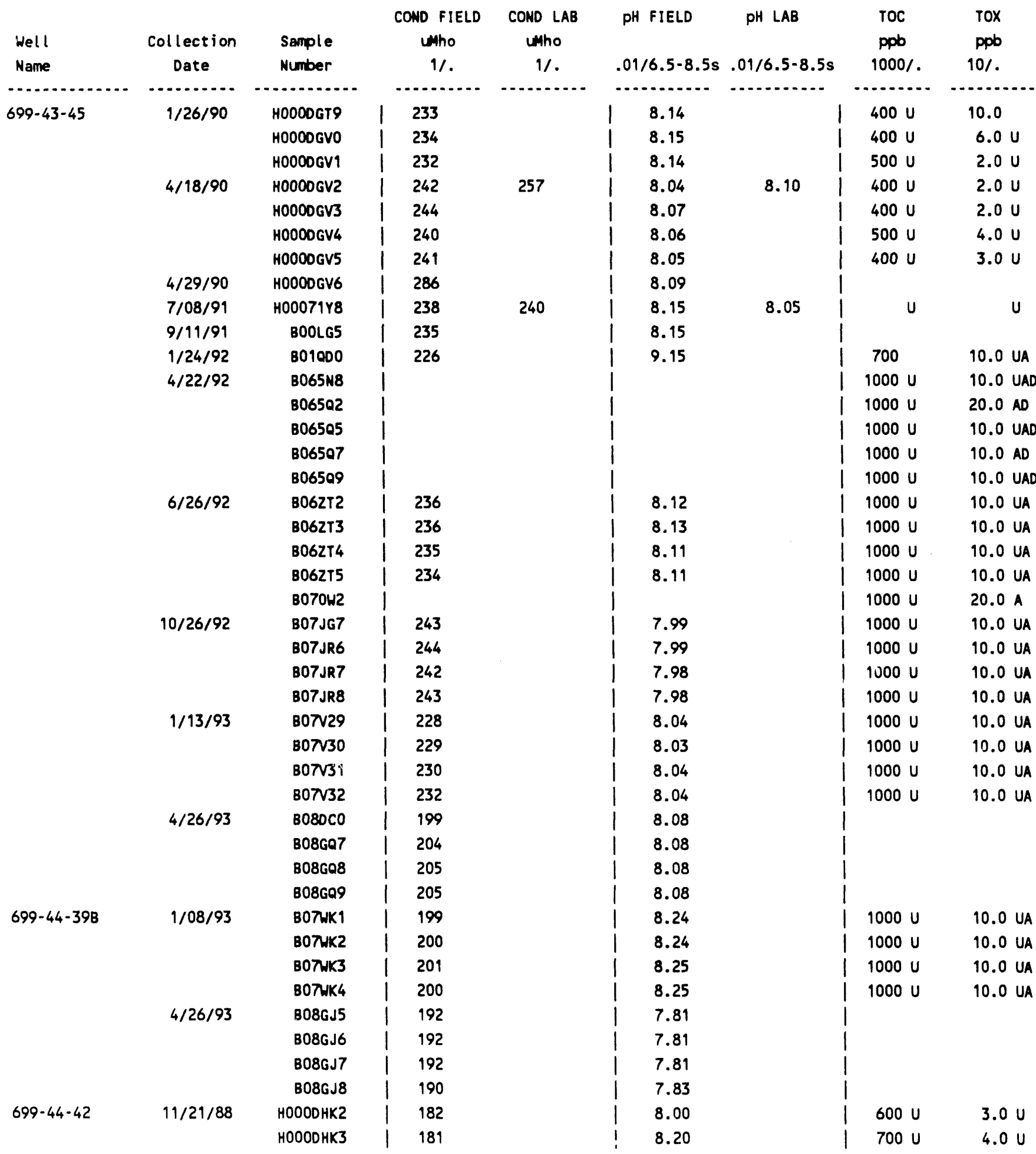


Table 5-3. Results of Indicator Parameter Analyses.

(sheet 16 of 17 )

\begin{tabular}{|c|c|c|c|c|c|c|c|c|c|}
\hline $\begin{array}{l}\text { Well } \\
\text { Name }\end{array}$ & $\begin{array}{c}\text { Collection } \\
\text { Date }\end{array}$ & $\begin{array}{l}\text { Sample } \\
\text { Number }\end{array}$ & $\begin{array}{c}\text { COND FIELD } \\
\text { who } \\
1 / .\end{array}$ & $\begin{array}{c}\text { COND LAB } \\
\text { who } \\
1 / .\end{array}$ & & $16.5-8.5 \mathrm{~s}$ & $.01 / 6.5-8.5 \mathrm{~s}$ & $\begin{array}{l}\text { TOC } \\
\text { ppb } \\
1000 \%\end{array}$ & $\begin{array}{c}\text { TOX } \\
\text { ppb } \\
10 \% .\end{array}$ \\
\hline - & . & n........... & . & 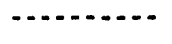 & & ........... & 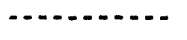 & . & - \\
\hline \multirow[t]{42}{*}{$699-46-42$} & $11 / 21 / 88$ & HOOOOHK4 & 182 & & 1 & 8.20 & & $600 \mathrm{U}$ & $2.0 \mathrm{U}$ \\
\hline & & H000DHK5 & 182 & & 1 & 8.20 & & $600 \mathrm{U}$ & $2.0 \mathrm{U}$ \\
\hline & $2 / 17 / 89$ & H0000HKG & 240 & 222 & i & 7.60 & 8.10 & I $1800 \mathrm{U}$ & $5.0 \mathrm{U}$ \\
\hline & & HOOODHK7 & 239 & & i & 7.60 & & i $1700 u$ & $2.0 \mathrm{U}$ \\
\hline & & HnOODHKB & 240 & & i & 7.60 & & I $1800 \mathrm{U}$ & $5.0 \mathrm{U}$ \\
\hline & & HOOOOHK9 & 239 & & i & 7.60 & & $1900 \mathrm{U}$ & $6.0 \mathrm{U}$ \\
\hline & $6 / 15 / 89$ & HOOODHLO & 188 & 217 & i & 7.82 & 8.20 & $600 \mathrm{U}$ & $2.0 \mathrm{U}$ \\
\hline & & HOOODHL1 & 188 & & 1 & 7.64 & & $600 \mathrm{U}$ & 23.0 \\
\hline & & HOOODHL2 & 188 & & 1 & 7.69 & & $600 \mathrm{U}$ & $2.0 \mathrm{U}$ \\
\hline & & HOOOOHL3 & 189 & & 1 & 7.73 & & $600 \mathrm{U}$ & $4.0 \mathrm{U}$ \\
\hline & 8/08/89 & HOOOOHL4 & 226 & 231 & | & 8.12 & 7.40 & $800 \mathrm{U}$ & $2.0 \mathrm{U}$ \\
\hline & & HOOOOHLS & 222 & & 1 & 8.11 & & $700 \mathrm{U}$ & $3.0 \mathrm{U}$ \\
\hline & & HOOODHL6 & 223 & & 1 & 8.11 & & $800 \mathrm{U}$ & $2.0 \mathrm{U}$ \\
\hline & & HOOOOHL7 & 224 & & | & 8.11 & & $800 \mathrm{U}$ & $4.0 \mathrm{U}$ \\
\hline & $1 / 31 / 90$ & HООООНL8 & 227 & 238 & 1 & 8.35 & 7.90 & $500 u$ & $2.0 \mathrm{U}$ \\
\hline & & HOOODHL9 & 228 & & 1 & 8.39 & & $500 \mathrm{U}$ & $2.0 \mathrm{U}$ \\
\hline & & НООООНМО & 228 & & 1 & 8.40 & & $500 \mathrm{U}$ & $7.0 \mathrm{U}$ \\
\hline & & HOOOOHM1 & 228 & & 1 & 8.38 & & $500 \mathrm{U}$ & $4.0 \mathrm{U}$ \\
\hline & $4 / 26 / 90$ & HOOOOHM2 & 244 & & 1 & 8.12 & & 1 & \\
\hline & $7 / 10 / 91$ & H00071Y9 & 233 & 240 & 1 & 8.20 & 8.10 & $u$ & u \\
\hline & $1 / 31 / 92$ & B01552 & 323 & & 1 & 8.13 & & 1000 UD & $20.0 \mathrm{RA}$ \\
\hline & $2 / 25 / 92$ & B05Y97 & 240 & & I & 7.87 & & 1 & \\
\hline & $6 / 25 / 92$ & B07017 & 244 & & 1 & 8.08 & & $1000 \mathrm{U}$ & $20.0 \mathrm{~A}$ \\
\hline & & B07018 & 243 & & 1 & 8.08 & & $1000 \mathrm{U}$ & $20.0 \mathrm{~A}$ \\
\hline & & B07019 & 243 & & 1 & 8.08 & & $1000 \mathrm{U}$ & $30.0 \mathrm{~A}$ \\
\hline & & B07020 & 249 & & 1 & 8.07 & & $1000 \mathrm{U}$ & $20.0 A$ \\
\hline & $10 / 22 / 92$ & B07JR9 & 227 & & 1 & 8.25 & & $1000 \mathrm{U}$ & 10.0 UA \\
\hline & & B07JSO & 228 & & I & 8.25 & & $1000 \mathrm{U}$ & $20.0 \mathrm{~A}$ \\
\hline & & B07JS1 & 227 & & 1 & 8.29 & & $1000 \mathrm{U}$ & $10.0 \mathrm{UA}$ \\
\hline & & B07JS2 & 228 & & 1 & 8.28 & & $1000 \mathrm{U}$ & $10.0 \mathrm{~A}$ \\
\hline & $1 / 13 / 93$ & B07734 & 256 & & I & 8.32 & & $1000 \mathrm{U}$ & $10.0 \mathrm{UA}$ \\
\hline & & $807 \sqrt{35}$ & 253 & & 1 & 8.30 & & $1000 \mathrm{U}$ & $10.0 \mathrm{UA}$ \\
\hline & & $807 \sqrt{36} 6$ & 250 & & 1 & 8.28 & & $1000 \mathrm{U}$ & $10.0 \mathrm{~A}$ \\
\hline & & $807 \sqrt{37}$ & 250 & & 1 & 8.27 & & $1000 \mathrm{U}$ & $10.0 \mathrm{~A}$ \\
\hline & & Bo7v38 & 1 & & 1 & & & $1000 \mathrm{U}$ & $10.0 \mathrm{UA}$ \\
\hline & & Bo7v39 & 1 & & 1 & & & $1000 \mathrm{U}$ & 10.0 UA \\
\hline & & B07N40 & 1 & & 1 & & & $1000 \mathrm{U}$ & 10.0 UA \\
\hline & & B07N41 & 1 & & 1 & & & $1000 \mathrm{U}$ & $10.0 \mathrm{UA}$ \\
\hline & $4 / 26 / 93$ & B08GPG & 239 & & 1 & 7.96 & & 1 & \\
\hline & & B08GP7 & 240 & & 1 & 7.97 & & 1 & \\
\hline & & B08GP8 & 240 & & 1 & 7.97 & & 1 & \\
\hline & & B08GP9 & 240 & & 1 & 7.97 & & I & \\
\hline $699-44-43 B$ & $12 / 20 / 89$ & НООООНMЗ & 298 & & 1 & 8.19 & & $400 \mathrm{U}$ & $3.0 \mathrm{U}$ \\
\hline
\end{tabular}


Table 5-3. Results of Indicator Parameter Analyses. (sheet 17 of 17)

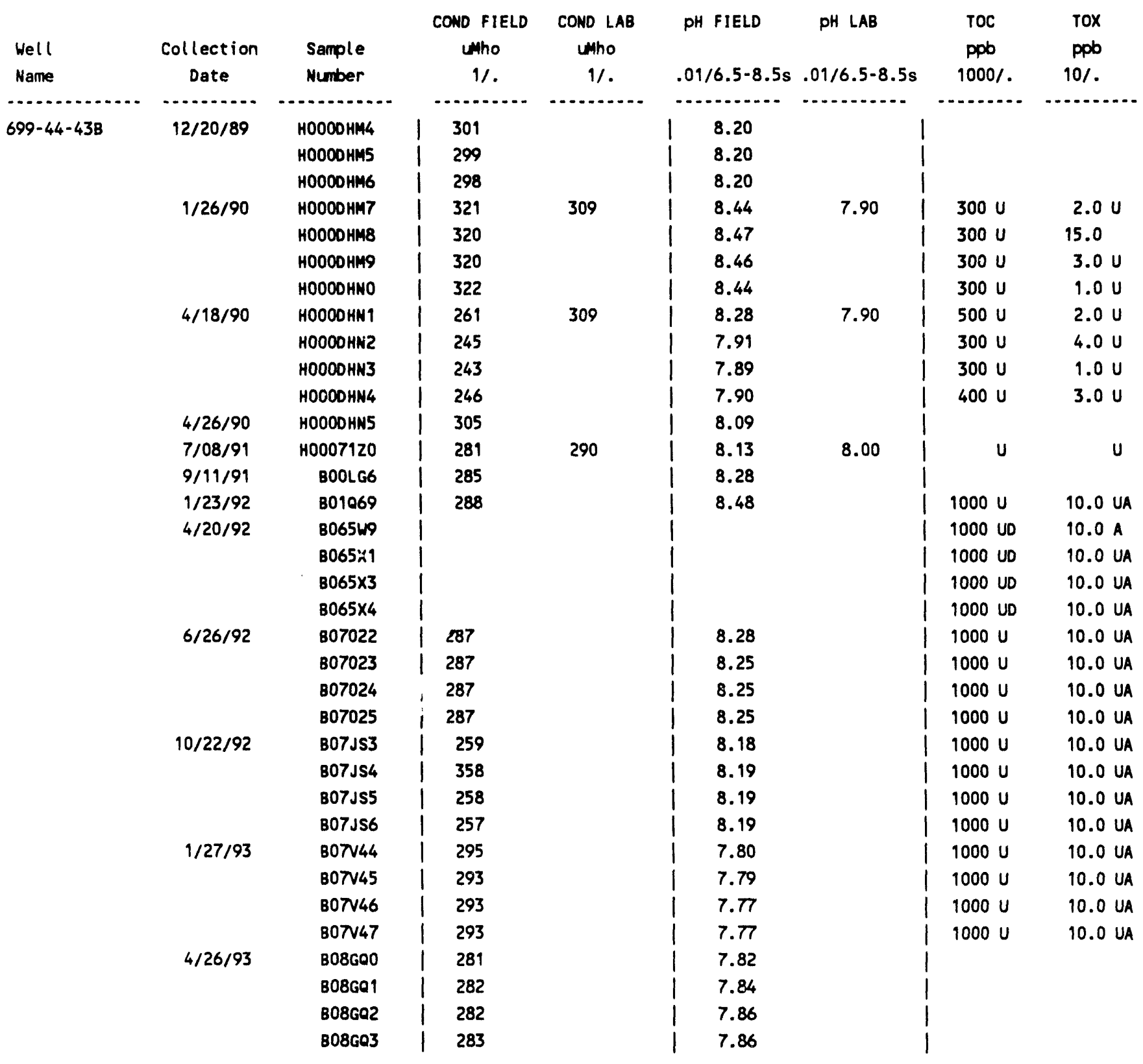


Table 5-4. Estimated Background Levels for Selected Constituents in Hanford Ground Water (Evans et a1. 1989). (sheet 1 of 2)

\begin{tabular}{|c|c|c|}
\hline Constituent & Detection limit & $\begin{array}{c}\text { Background } \\
\text { concentration }\end{array}$ \\
\hline Aluminum & $2^{b}$ & $<2^{b}$ \\
\hline Ammonia & 50 & $<50$ \\
\hline Arsenic & $0.2^{b}$ & $3.9 \pm 2.4^{b}$ \\
\hline Barium & 6 & $42 \pm 20$ \\
\hline Beryllium & $0.3^{b}$ & $0.3^{b}$ \\
\hline Bismuth & $0.02^{b}$ & $0.02^{b}$ \\
\hline Boron & $50^{b}$ & $<50^{b}$ \\
\hline Cadmium & $0.2^{b}$ & $0.02^{b}$ \\
\hline Calcium & 50 & $40,400 \pm 10,300$ \\
\hline Chloride & 500 & $10,300 \pm 6,500$ \\
\hline Chromium & $2^{b}$ & $4.0 \pm 2.0^{b}$ \\
\hline Copper & $1^{b}$ & $<1^{b}$ \\
\hline Cyanide & 10 & $<10$ \\
\hline Fluoride & 500 & $370 \pm 100$ \\
\hline Lead & $0.5^{b}$ & $<0.5^{b}$ \\
\hline Magnesium & 10 & $11,800 \pm 3,400$ \\
\hline Manganese & 5 & $7 \pm 5$ \\
\hline Mercury & 0.1 & $<0.1$ \\
\hline Nickel & $4^{b}$ & $<4^{b}$ \\
\hline Phosphate & 1,000 & $<1,000$ \\
\hline Potassium & 100 & $4,950 \pm 1,240$ \\
\hline Selenium & $2^{b}$ & $<2^{b}$ \\
\hline Silver & 10 & $<10$ \\
\hline Sodium & 10 & $18,260 \pm 10,150$ \\
\hline Strontium & 20 & $236 \pm 102$ \\
\hline Sulfate & 500 & $34,300 \pm 16,900$ \\
\hline Uranium & $0.5^{c}$ & $1.7 \pm 0.8^{c}$ \\
\hline Vanadium & 5 & $17 \pm 9$ \\
\hline Zinc & 5 & $6 \pm 2$ \\
\hline
\end{tabular}


Table 5-4. Estimated Background Levels for Selected Constituents in Hanford Ground Water (Evans et al. 1989). (sheet 2 of 2)

3

4

5

6

7

8

9

10

11

12

13

14

15

\begin{tabular}{|l|c|c|}
\hline \multicolumn{1}{|c|}{ Constituent } & Detection 1 imit $^{\mathrm{a}}$ & $\begin{array}{c}\text { Background } \\
\text { concentration }\end{array}$ \\
\hline Alkalinity & -- & $123,000 \pm 21,000$ \\
\hline $\mathrm{pH}$ & -- & $7.64 \pm 0.16$ \\
\hline $\begin{array}{l}\text { Total organic } \\
\text { carbon }\end{array}$ & 200 & $586 \pm 347$ \\
\hline Conductivity & $1^{\mathrm{d}}$ & $380 \pm 82^{\mathrm{d}}$ \\
\hline \multicolumn{3}{|c|}{} \\
\hline Gross alpha & $0.5^{\mathrm{c}}$ & $2.5 \pm 1.4^{\mathrm{c}}$ \\
\hline Gross beta & $4^{\mathrm{c}}$ & $19 \pm 12^{\mathrm{c}}$ \\
\hline Radium & $0.2^{\mathrm{c}}$ & $0.2^{\mathrm{c}}$ \\
\hline
\end{tabular}

${ }^{a}$ Units in ppb unless otherwise noted. Uncertainties are \pm one standard deviation.

Based on ICP/MS data.

Units in $\mathrm{pC} \mathrm{i} / \mathrm{L}$.

dunits in $\mu \mathrm{mho} / \mathrm{cm}$. 
6.0 ClOSURE PERFORMANCE : 5 TANDARDS . . . . . . . . . . . . . . . . . 6-1

6.1 ClOSURE STRATEGY . . . . . . . . . . . . . . . . . . . 6-1 6.1.1 Closure Strategy for the Expansion Ponds . . . . . 6-1

6.2 MINIMIZE NEED FOR FURTHER MAINTENANCE . . . . . . . . . . 6-2

6.3 PROTECT HUMAN HEALTH AND THE ENVIRONMENT . . . . . . . . . . 6-3

6.4 RETURN LAND TO THE APPEARANCE AND USE OF SURROUNDING LAND AREAS... . . . . . . . . . . . . . . . . . . 6-4

6-1. RCRA Closure Logic Flow Diagram . . . . . . . . . . . . . F6-1

\section{FIGURE} 20 
DOE/RL-89-28, Rev. 1

$12 / 15 / 93$

1

2

3

4

5

This page intentionally left blank. 


\subsection{CLOSURE PERFORMANCE STANDARDS}

This chapter describes how closure of the 216-B-3A, 216-B-3B, and the 216-B-3C Ponds will meet the closure requirements of WAC 173-303-610.

\subsection{CLOSURE STRATEGY}

The strategy is to clean close the three expansion ponds. After 'Clean closure', as used in this context, no dangerous waste or dangerous waste contaminated soil, structures, or equipment that pose a threat to human health or the environment will remain onsite.

\subsubsection{Closure Strategy for the Expansion Ponds}

The proposed strategy for closure of the expansion ponds is clean closure. Clean closure of the $3 A, 3 B$, and $3 C$ Ponds is contingent upon verification that constituents remaining in the vadose zone and originating from disposal of dangerous waste in the ponds are not present in concentrations that represent a threat to human health or the environment. The possibility of detecting dangerous waste contamination in the ponds was low because (1) the ponds have been in use for a relatively short period of time and (2) administrative and physical controls have been implemented to eliminate the potential for inadvertent disposal of dangerous waste.

Figure 6-1 presents the logic used to assess the closure options for the three expansion ponds. This diagram is based on information obtained from vadose zone soil and sediment sampling. Soil sampling and analys is were conducted as described in Chapter 7.0. Analytical results were evaluated to identify any potential constituents of concern. Constituents of concern are those constituents derived from dangerous waste disposal activities that statistically exceed background levels.

Action levels were based on background and health-based limits. The term 'action levels', as used here, refers to concentration thresholds that should not be exceeded in soil for clean closure. A discussion on the determination of action levels is presented in Chapter 7.0, Section 7.1.1. Concentrations of constituents of concern were compared with background levels and health-based levels. As no constituents detected above background levels were present in levels greater than the health-based action levels, no remedial actions are proposed.

Because the analytical results from the sampling efforts at the expansion ponds and the B-Pond System showed that dangerous waste constituents of concern were below action levels, no additional analyses at the structures are planned. The structures will be removed and disposed of in a manner based on the results of radiation surveys.

A groundwater monitoring network has been installed around B Pond to assess the impact of waste-disposal practices on the uppermost aquifer 
underlying $B$ Pond. Based on the results of groundwater monitoring, it appears that there are no dangerous waste constituents present at levels of concern.

\subsection{MINIMIZE NEED FOR FURTHER MAINTENANCE}

The closure performance standard in WAC 173-303-610(2)(a)(i) requires the owner or operator of a TSD facility to close the facility in a manner that minimizes the need for further maintenance.

As discussed in Section 6.1, the primary strategy for closure of the 216-B-3A, $-3 B$, and $-3 C$ Ponds is clean closure. Because the three expansion ponds are being clean closed, RCRA requirements to monitor sediments and subsoils for dangerous waste contaminants within these portions of the TSD unit will be eliminated. Waste water streams routed to the $B$ Pond expansion ponds will continue to be sampled upstream of the percolation ponds. A separate plan for characterizing liquid effluents at the Hanford Site and evaluating the potential for migration of contaminants within disposal-site soils (including $B$ Pond) has been prepared for the DOE by Westinghouse Hanford (Sommer et a1. 1989).

Because $B$ Pond is located within the 200-BP-11 operable unit, facility maintenance, radiation monitoring, and groundwater monitoring activities a 11 must be continued at least until the operable unit remediation/closure has been completed.

If there are concerns over any radioactive contamination at the expansion ponds, interim stabilization will be performed. This is expected to be a possibility for the 216-B-3A Pond only. Interim stabilization actions are designed to (1) isolate and immobilize radiological contaminants within subject portions of the facility pending final closure and, (2) minimize maintenance requirements while strategies are developed for final closure/ remediation of the 200-BP-11 operable unit. Personnel at the Hanford Site have had extensive experience with the technique of stabilizing sites by installing an interim cover of clean, coarse soil over contaminated surface soils. Some level of maintenance is associated with any stabilization method. With the proposed technique, (Chapter 7.0, Section 7.?) maintenance requirements are envisioned to consist of surveillance with possible minor repairs. Surveillance would ensure that the objectives of isolation and immobilization of waste are not compromised by processes such as erosion, animal intrusion, uptake of contaminants by vegetation, and upward migration of contaminants by capillary movement of soil moisture. Minimal maintenance requirements (other than surveillance) are expected.

Groundwater monitoring wells within the 200-BP-11 operable unit must be maintained, at least through the CERCLA operable unit activities, to ensure the continuity of groundwater monitoring. The types of activities that may be required to maintain the wells include inspection and repair of the sample pumps and flushing of screens to ensure an adequate flow of water into the wells. 
DOE/RL-89-28, Rev. 1

$12 / 15 / 93$

\subsection{PROTECT HUMAN HEALTH AND THE ENVIRONMENT}

The performance standard in WAC 173-303-610(2)(a)(ii) requires the owner or operator of a TSD facility to close the facility in a manner that controls, minimizes, or eliminates, to the extent necessary to protect human health and the environment, postclosur! escape of dangerous waste, dangerous constituents, leachate, contaminated run-off, or dangerous waste decomposition products to the ground, surface water, groundwater, or the atmosphere. In addition, WAC 173-303-650(6)(a) requires the owner or operator to:

- Remove or decontaminate all dangerous waste and dangerous waste residues, contaminated containment system components (e.g., liners), contaminated subsoils, and structures and equipment contaminated with dangerous waste and leachate and managed as dangerous waste

- Close as a landfill by eliminating free liquids, stabilizing remaining waste, and covering the surface impoundment with a final cover; and comply with postclosure requirements.

The following describes how the requirements of WAC 173-303-650(6)(a) and WAC 173-303-610(2)(a)(ii) will be accomplished.

The $3 A, 3 B$, and $3 C$ Ponds are to be clean closed. Consistent with this intent and strategy, it was determined that the following actions would be performed before certification of clean closure.

- Sample bottom sediments, subsoils, and associated structures to determine the specific nature and extent of residual dangerous waste contaminants.

- Remove soil from the expansion ponds, as necessary, to reduce contaminant concentrations to within proposed action levels for all dangerous waste contaminants that are present.

- Remove and dispose of associated structures.

Based on the results of the three sampling efforts associated with characterization of the $3 \mathrm{~A}, 3 \mathrm{~B}$, and $3 \mathrm{C}$ Ponds, these ponds are to be clean closed. These sampling efforts are described in Chapter 7.0, Section 7.1. The results of these sampling efforts indicate that no contaminants of concern are present in concentrations above action levels.

Closure of the 216-B-3 Pond and the 216-B-3-3 Ditch is being addressed within the scope of the 200-BP-11 operable unit integrated WP/CP. 


\subsection{RETURN LAND TO THE APPEARANCE AND USE} OF SURROUNDING LAND AREAS

In accordance with WAC $173-303-610(2)(a)(i i i)$, the owner or operator of a TSD facility is required to close the facility in a manner that returns the 1 and to the appearance and use of surrounding 1 and areas to the degree possible given the nature of the previous dangerous waste activity.

Clean closure is the proposed closure strategy for the three expansion ponds $(3 A, 3 B$, and $3 C)$. After Ecology accepts certification of clean closure, the DOE-RL intends to continue to use the expansion ponds to dispose of nondangerous waste water from facilities in the 200 East Area. Therefore, no site reclamation actions are planned. 
DOE/RL-89-28, Rev. 1

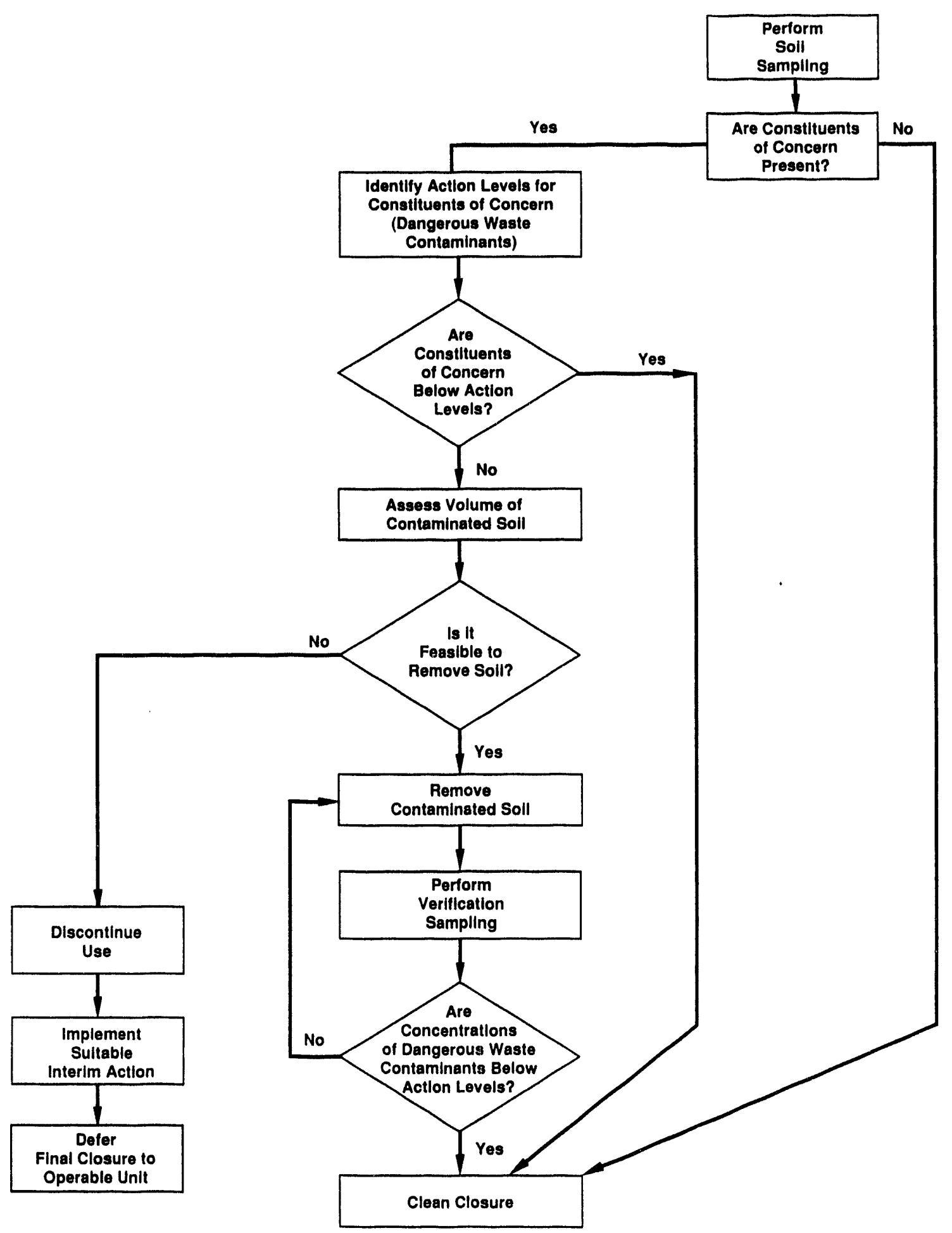

78911166.8

Figure 6-1. RCRA Closure Logic Flow Diagram. 


\section{CONTENTS}

7.0 ClOSURE ACTIVITIES . . . . . . . . . . . . . . 7-1

7.1 SOIL AND SEDIMENT SAMPLING . . . . . . . . . . . . . . 7-1

7.1.1 Soil Sampling and Analysis Plan .......... . 7-2

7.1.2 Phase 1 Sampling . . . . . . . . . . . . . . . 7-2

7.1.2.1 Phase 1 Sampling Objectives . . . . . . . 7-2

7.1.2.2 Analytical Parameters . . . . . . . . . . 7-2

7.1.2.3 Sampling Methodology . . . . . . . . . . . 7-3

7.1.2.4 Analytical Methods and Analytical Quality

Assurance and Quality Control ...... . 7-5

7.1.2.5 Summary of Phase 1 Analytical Results . . . . 7-5

7.1.3 Phase 2 Sampling . . . . . . . . . . . . . . . 7-5

7.1.3.1 Phase 2 Sampling Objectives . . . . . . . . 7-6

7.1.3.2 Analytical Parameters . . . . . . . . . . . 7-6

7.1.3.3 Sampling Methodology . . . . . . . . . . . 7-6

7.1.3.4 Analytical Methods and Analytical Quality

Assurance and Quality Control ...... . 7-7

7.1.3.5 Summary of Phase 2 Analytical Results . . . . 7-10

7.1.4 Phase 3 Sampling . . . . . . . . . . . . . . . 7-11

7.1.4.1 Phase 3 Sampling Objectives . . . . . . . . . 7-11

7.1.4.2 Analytical Parameters . . . . . . . . . . 7-12

7.1.4.3 Sampling Methodology . . . . . . . . . 7-12

7.1.4.4 Analytical Methods and Analytical Quality

Assurance and Quality Control ..... . 7-15

7.1.4.5 Summary of Phase 3 Analytical Results . . . . . 7-16

7.1.5 Summary of Sampling and Analyses Results for 216-B-3A,
$216-B-3 B$, and 216-B-3C Ponds . . . . . . . . . . . . 17

7.2 INTERIM STABILIZATION OF THE 216-B-3A POND . . . . . . . . 7-17

7.2.1 Phase 1: Drawdown and Interim Stabilization of Pond

Sediments . . . . . . . . . . . . . . . . 7-17

7.2.2 Phase 2: Backfilling of the Percolation Trench . . . 7-18

7.2.3 Phase 3: Topsoil Placement, Revegetation, and Marker

Post Placement . . . . . . . . . . . . . . 7-18

7.2.4 Post-Stabilization Surveillance . . . . . . . . . . 7-19

7.2.5 Project Documentation . . . . . . . . . . . 7-19

7.3 DECONTAMINATION/REMOVAL OF STRUCTURES AND ASSOCIATED

FIXED EQUIPMENT . . . . . . . . . . . . . . . . . . 7-19

7.3.1 The 216-B-3A Pond Dikes . . . . . . . . . . . . 7-20

7.3.1.1 Proposed Disposition for the 216-B-3A Pond Dike and Associated Piezometers . . . . . . . 7-20

7.3.1.2 Abandonment of Piezometers . . . . . . . . 7-20

7.3.2 The 216-B-353 Flow Control and Spillway Structure . . . 7-20

7.3.2.1 Proposed Disposition . . . . . . . . . 7-20

7.3.2.2 Removal Plan . . . . . . . . . . . . 7-20

7.3.3 The 216-B-354 Flow Control and Spiliway Structure . . 7-21

7.3.3.1 Proposed Disposition ........... . 7-21

7.3.3.2 Removal Plan ............... 7-21 
7-1. Random Sample Locations for 216-B-3A and -3B Ponds (Phase 1) . . . F7-1

7-2. Random Sample Locations for 216-B-3C Pond (Phase 1) . . . . . . . F7-2

7-3. Background Sample Locations (Phase 1) . . . . . . . . . . . . F7-3

7-4. Typical Closure Certification Document . . . . . . . . . . . . . F7-4

\section{TABLES}

7-1. Analytical Parameters for Individual Samples . . . . . . . . . T7-1

7-2. Analytical Parameters for Composite Samples . . . . . . . . . . T7-2

7-3. Water Sample Parameters . . . . . . . . . . . . . . . . . T7-3

7-4. Analytical Parameters for Ali Subsurface Samples Additional Analytical Parameters for Selected Subsurface Samples. . T7-5 40 
DOE/RL 89-28, Rev. 1

\subsection{CLOSURE ACTIVITIES}

This chapter discusses the activities that have been or will be conducted during closure of the 216-B-3 Pond System. The following summarizes the closure activities for the $3 \mathrm{~A}, 3 \mathrm{~B}$, and $3 \mathrm{C}$ expansion ponds.

- Sample and analyze the pond soil and sediment to assess the presence and possible extent of contamination. If the pond soil is not contaminated with dangerous waste constituents, no further action will be required to achieve clean closure. Soil sampling and analysis are discussed in Section 7.1.1.

- The engineered structures associated with the ponds will be removed. If the structures are left in place the gate valves will be welded in the closed position. Disposition of structures is discussed in Section 7.2.

- Interim stabilize the $3 A$ Pond, if necessary, to isolate and immobilize radioactive contaminants. Interim stabilization is discussed in Section 7.3.

- Certify closure upon completion of closure activities. Certification of closure is discussed in Section 7.7 .

Based on the results of the sampling and analysis activities described in Section 7.1, clean closure was selected for the 216-B-3A, 216-B-3B, and 216-B-3C Ponds.

Groundwater monitoring activities will be conducted to assess the impact of disposal practices on the uppermost aquifer. Groundwater monitoring activities are discussed in Chapter 5.0.

\subsection{SOIL AND SEDIMENT SAMPLING}

A phased approach was used in the analyses of the soil and sediment of the expansion ponds. This approach allows information from earlier phases to be considered in the design of subsequent samples efforts. Sampling consisted of three phases. Phase l sampling, completed in 1989, consisted of initial surface soil and sediment sampling in the expansion ponds, the 216-B-3 Pond and in the 216-B-3-3 Ditch. Phase 2 sampling, completed in 1992, was an additional surface soil and sediment sampling effort. Phase 2 sampling was limited to the expansion ponds and was used to confirm the results of the Phase 1 sampling effort and verification for clean closure. Phase 3 sampling, completed in 1991 prior to Phase 2 sampling, consisted of subsurface (vadose zone) soil and sediment sampling beneath the three expansion ponds. The data generated were used to provide a technical assessment of whether dangerous waste discharges at the expansion ponds have contaminated the surrounding soil and sediment. Based on the results of this phased sampling effort clean closure was chosen for the 216-B-3A, 216-B-3B, and 216-B-3C Ponds. 
DOE/RL 89-28, Rev. 1

$12 / 15 / 93$

\subsubsection{Soil Sampling and Analysis Plan}

\subsubsection{Phase 1 Sampling}

Phase 1 sampling was conducted between August and September of 1989. Sampling objectives, analytical parameters, the sampling methodology, and numbers, types, and locations of samples collected during Phase 1 are described in the following sections.

7.1.2.1 Phase 1 Sampling Objectives. The purpose of Phase 1 (Appendix C) characterization was to gather initial information on the constituents of concern in the surface soils and sediments of the entire 216-B-3 Pond system (216-B-3 Pond, 216-B-3A Pond, 216-B-3B Pond, 216-B-3C Pond, and the 216-B-3-3 Ditch). It was envisioned that information from Phase 1 sampling would be used to plan and carry out subsequent phases of sampling. As this was an initial scoping investigation, it was envisioned that additional requirements for surface sampling and analysis for the constituents of concern might be identified based on the results obtained from this initial phase.

The following were specific objectives of Phase 1.

- Assess surface soil and sediment contamination within the 216-B-3 Pond, the 216-B-3-3 Ditch, and the expansion ponds.

- Identify constituents of concern.

- Establish local background values.

- Calculate rough estimates of variability for these constituents.

7.1.2.2 Analytical Parameters. The available information concerning past waste disposal practices relative to the 216-B-3 Pond System indicates that inorganic constituents, including metals, certain ions, and radioisotopes, are the most potentially significant contaminants of concern. Therefore, individual soil samples were analyzed mainly for inorganic constituents, including metals and radionuclides (Table 7-1), but screening also was carried out for organic constituents, including pesticides and PCBs.

Composite samples were analyzed for the parameters listed in Table 7-2. Tables 7-1 and 7-2 together include the constituents on the 40 CFR 264 Appendix IX list of dangerous constituents. This list has been formulated by the EPA to represent the dangerous waste constituent 1 ist of compounds for which standardized testing procedures are available. The Appendix IX 1ist accounts for the alteration and/or degradation of dangerous waste constituents following the ir release to the environment, and primarily includes organics. Many of these analytes were not expected to be present, as organics were not the primary chemical constituents used by the operating facilities that discharged to the 216-B-3 Pond System. However, many of the 200 East Area facilities have discharged waste water to the B Pond System since the 1940's and 1950's, and detailed records concerning the types and quantities of chemicals discharged were not maintained. Therefore, the analytical parameter 
1 list included Appendix IX constituents to verify that they are not present in the pond soils in concentrations that would represent threats to human health or the environment.

All samples collected during Phase 1 were field screened onsite with hand-held instruments for radiological constituents and organic vapors. Background samples were analyzed for the inorganic parameters listed in Tables 7-1 and 7-2. Quality assurance split and duplicate samples were subjected to the same analyses as the original samples. Equipment blanks were analyzed for all parameters listed in Tabies 7-1 and 7-2.

\subsubsection{Sampling Methodology. Random sample locations were assigned by} projecting a sampling grid over each area to be sampled. The grid spacing for the 216-B-3A and $-3 B$ Ponds was 50 feet; a 100-foot linear spacing was used for the 216-B-3C Pond. Sample locations were selected using a random number process. Random sample locations for the three expansion ponds are shown in Figures 7-1 and 7-2. The random locations were supplemented with biased sample locations to ensure that adequate numbers of samples would be taken in areas of greatest suspected contamination.

7.1.2.3.1 Numbers, Types, and Locations of Samples from 216-B-3A Pond. The $3 A$ Pond, currently filled with overflow water from the 216-B-3 Pond, was sampled as two blocks: (1) the trench within the pond and (2) the pond outside the trench. The trench was sampled in three locations and the pond outside the trench was sampled in four locations (Figure 7-1). Random sample location pairs are $(7,15),(10,17),(4,18)$, and $(9,16)$ for the pond and $(4,7)$, $(6,13)$, and $(6,17)$ for the trench. One composite sample was collected from each of the saripling blocks. Twelve samples were collected as follows:

- Seven random samples selected within the blocks

- Two composite samples--one from the trench and one from the sediments outside the trench. (A compositf: sample is a combination of splits from individual samples.)

- One split sample

- One duplicate sample

- One equipment blank.

7.1.2.3.2 Numbers, Types, and Locations of Samples from 216-B-3B Pond. The 3B Pond had a series of percolation trenches excavated in the bottom and it was filled with water as recently as 1985 . Since that time, the bottom has been excavated and several feet of soil have been removed. The pond has not been used since the excavation; however, small quantities of water have been discharged to the $3 B$ Pond as a result of seepage through the overflow control structure between the $3 A$ and $3 B$ Ponds. Other small discharges to $3 B$ Pond have occurred as a risult of wave action over-topping the central structure between $3 A$ and $3 B$ Ponds during high-wind conditions. Because disturbance of the pond bottom has obscured original depositional patterns, a simple random sampling 
approach was used. Five random samples were taken in the $3 B$ Pond

(Figure 7-1). Random sample location pairs are $(9,12),(3,12),(9,11),(9,1)$, and $(11,1)$. Nine samples were collected as follows:

- Five random samples

- One composite sample made up of splits from individual samples

- One split sample

- One duplicate sample

- One equipment blank.

7.1.2.3.3 Numbers, Types, and Locations of Samples from 216-B-3C Pond. The 216-B-3C Pond covers approximately 41 acres. Percolation trenches were excavated in the bottom. Only the percolation trenches have received water and only a portion of the trenches routinely are wetted. As shown in Figure 7-2, each of the eight approximately 2,200-foot trenches was randomly sampled once--at 1,300, 900, 300,1,200,1,800, 2,100, 400, and 500 feet, respectively--counting from the northwest corner. Two composite samples were taken: one from splits of samples taken in the wetted portions of the trenches and one from splits of samples taken in the dry portions of the trenches. Thirteen samples were collected as follows:

- One sample from a random location in each of the trenches ( 8 samples total)

- Two composite samples made up of splits from individual samples

- One split sample

- One duplicate sample

- One equipment blank.

7.1.2.3.4 Local Background Samples. Background soil samples were collected as a part of Phase 1 sampling to establish local background threshold values for comparison with the 216-B-3 Pond System soil constituent concentrations. No additional background sampling was performed in conjunction with Phases 2 or 3.

Background soil samples were taken from the surface sediments in the 216-E-28 Contingency Pond because it has not received influent and is located near the 216-B-3 Pond System in the same geologic formation at a similar depth. Additional background samples were collected from other undisturbed locations, as shown in Figure 7-3. Background samples collected from multiple locations provide an estimate of the variability of background levels in the area. Sample locations and numbers of samples were selected on best professional judgment. Twelve samples were collected as follows:

- Five random samples from the contingency pond

- Five samples selected to form a rough perimeter of B Pond

- One split sample 
DOE/RL 89-28, Rev. 1

$12 / 15 / 93$

- One duplicate sample

- Zero equipment blanks--Equipment blanks usually are taken one per sampling day and were included in previous totals.

\subsubsection{Analytical Methods and Analytical Quality Assurance and Quality} Control. Phase 1 samples were analyzed in accordance with SW-846 methods (EPA 1986b) when available. Contract analytical services for dangerous waste constituents in environmental media were performed as stipulated in the contractor's laboratory procedures and quality assurance and quality control manuals. The contractor was directed to conform to EPA-approved methods when available. Quality assurance and quality control procedures were reviewed and precision and accuracy (bias) values were provided to be met by the contractor laboratory.

7.1.2.5 Summary of Phase 1 Analytical Results. The following information is excerpted from Phase I Characterization of the 216-B-3 Pond System (Kramer 1991), which is incorporated into this closure plan as Appendix C. Local Background samples were taken from the 216-E-28 Contingency Pond and from another group of sites in native sagebrush habitat peripheral to 216-B-3 Pond. The two background sample populations were found to be statistically dissimilar. For example, calcium values for the Contingency Pond samples ranged from 6,830 to $9,923 \mathrm{ug} / \mathrm{g}$ (mean 8,700 coefficient of variation $17.2 \%$ ), whereas calcium in samples from the $B$ Pond vicinity ranged from 3,172 to $3,872 \mathrm{ug} / \mathrm{g}$ (mean 3,555 coefficient of variation $8.02 \%$ ). Values from the sagebrush sites were used as the primary comparative bas is for defining local background threshold. Values from Contingency Pond samples are reported as alternative background limits.

Determinations of most background analytes were accepted as normally distributed. Ammonium values were best characterized as having a log-normal distribution. The distributions of zinc and zirconium values were neither normal or log-normal.

Phase 1 samples from the $3 A, 3 B$, and $3 C$ Ponds did not contain any organic constituents of interest (including volatiles, semivolatiles, herbicides, pesticides, and/or PCBs) in meaningful quantities, al though a number of common laboratory contaminants were reported. None of the samples from the three expansion ponds exhibited elevated levels of metals or ions relative to local (primary or alternative) background values.

\subsubsection{Phase 2 Sampling}

Phase 2 was designed to provide supplemental sampling, as necessary, to develop a more complete assessment of surface soil and sediment contamination within the $3 \mathrm{~A}, 3 \mathrm{~B}$, and $3 \mathrm{C}$ expansion ponds. Phase 2 sampling and analysis was performed following Phase 1 and Phase 3 . Phase 2 sampling was conducted between August and September of 1992. Sampling objectives, analytical parameters, the sampling methodology, and numbers, types, and locations of samples collected during Phase 2 are described in the following sections. The 
DOE/RL 89-28, Rev. 1

$12 / 15 / 93$

discussion of Phase 2 sampling and analysis is excerpted from Phase 2

Characterization of the 216-B-3A,-3B, and -3C Expansion Ponds (Blumenkranz 1993), which is included as Appendix $D$ of this closure plan.

7.1.3.1 Phase 2 Sampling Objectives. Phase 2 sampling was carried out, in part, to substantiate the conclusions of Phase 1. Ecology had expressed concerns over the quality control and data validation associated with the Phase 1 analytical data. Documentation from the contractor laboratory was insufficient to perform the level of data validation requested by Ecology.

7.1.3.2 Analytical Parameters. As in Phase 1, individual soil samples were analyzed primarily for inorganic constituents, including metals and radionuclides (Table 7-3), but samples also were screened for organic constituents, including pesticides and PCBs. Trip blanks were analyzed for volatile organic unly. The samples were analyzed by Roy $F$. Weston Laboratory in Lionville, Pennsylvania. TMA/NORCAL in Richmond, California, analyzed split samples.

7.1.3.3 Sampling Methodology. Because of the different nature of the $3 A, 3 B$, and $3 C$ Ponds, each pond was sampled as a separate entity. However, a common sampling strategy was applied to all of the ponds. Three sample locations were identified for each pond, as follows:

- One sample was collected at the influent point of each pond. This location would be expected to be contaminated with any heavy solids that might be present.

- A second sample was collected from the deepest point in the pond. Should any contamination be present, light materials and fines would be expected to accumulate at this point.

- A third sample was collected at a point expected to contain high levels of the analytes of concern (relative to other locations), as determined by an evaluation of Phase 1 sample results (WHC 1991) and by field observation.

In the $3 A$ and $3 C$ Ponds, which are currently receiving waste water, the location of the second (deepest) sample point was determined by measuring the water depth visually and then confirming the relative depth with a probe. The probe consisted of conduit pipe with marks at 1-foot increments.

Additionally, while this sampling event focused on soil and sediments at the 216-B-3 Pond System, at the request of Ecology, water samples were taken from the two active (wet) ponds.

Samples were collected in the same manner as in Phase 1 . The sampling equipment utilized included a long pole and a 3.25-inch by 12-inch soil recovery auger. Multiple borings were necessary to obtain sufficient quantities of material for all of the indicated analyses. These were commingled in a stainless steel bowl prior to allocation to individual sample containers. Stainless steel shovels were used to collect samples in the northern portion of $3 C$ Pond, near the infuent point. Stainless steel 
scoopulas, spoons, bowls, shovels, and augers were prepared for use in accordance with Environmental Investigation Instruction 5.5, "Decontamination of Equipment for RCRA/CERCLA Sampling" (WHC-CM-4-10). Sample media were monitored for radiation. Flat-bottomed aluminum boats were used as a floating sample platform to collect samples from the $3 \mathrm{~A}$ Pond.

\subsection{Numbers, Types, and Locations of Samples from 216-B-3A Pond.} Sample locations are shown in Figure 3 of Appendix $D$. In the $3 A$ Pond, the first soil sample taken at the influent point where water from 216-3-B Pond enters the $3 A$ Pond. Water samples also were taken at this location. A second soil/ sediment sample was taken from the deepest portion of the pond. This point is located at the north end of the trench excavated into the bottom of the pond. A water sample was also taken in this vicinity. A third soil/sediment sample was taken at the east side of the pond, near the transfer structure to $3 \mathrm{~B}$ Pond. The thickest accumulation of sediment was identified at this location.

\subsection{Numbers, Types, and Locations of Samples from 216-B-3B Pond.} Because this pond is currently not in service, the bottom soils/sediments are exposed and directly accessible for sampling. Due to previous excavation activities, the "deepest point" of the $3 B$ Pond could not be determined. One sample of soil/sediment was taken near the inlet structure to the pond, approximately 10 feet to the east of the designated surface contamination area. A second sample point was located approximately 100 feet east and 15 feet south of the inlet. The slope of the pond bottom suggested that settleable contaminates likely would have been deposited in this vicinity when the pond was in use. Discrete samples of the surface soil and the underlying soils were taken at this point.

\subsection{Numbers, Types, and Locations of Samples from 216-B-3C Pond.} Three samples were collected from $3 C$ Pond. The high inflow rate to $3 C$ Pond made sampling in the immediate vicinity of the inlet structure impractical. The first point sampled was located 70 feet downstream and 15 feet north of the inlet structure. This area was characterized by heavy sedimentation. A water sample also was taken at this location. A second set of soil/sediment samples was taken at the intersection of the third north/south trench and the main east/west feed trench. Based on visual inspection, this location was determined to be the deepest point in the pond. A third sample, consisting of dry sediments, was collected from the fourth trench at a point approximately 100 feet south of the feed trench.

\subsubsection{Analytical Methods and Analytical Quality Assurance and Quality} Control. A water sample duplicate and split were taken at the $3 \mathrm{~A}$ Pond. A soil/sediment sample duplicate and split were taken at the $3 B$ Pond for chemical and radiological analyses. Two equipment blanks were prepared, one for water matrix and one for soil matrix. Water matrix trip blanks were included in all sample shipping containers. Trip blanks of clean silica sand were included in all shipments of soil/sediment samples. Trip blanks were analyzed for volatile organics only.

As indicated in Table 7-3, Phase 2 samples were analyzed by SW-846 methods (EPA 1986b) when available. Metals were analyzed either by the 
inductively coupled plasma (ICP) method or the graphite furnace atomic absorption method. Determinations for gross radioactivity and for strontium-90 followed laboratory-specific procedures; there are no SW-846 methods for radiological analyses.

The analytical results were subjected to data validation in accordance with the RCRA procedure (level B) in the Sample Management and Administration Manual (WHC 1990). Data validation included a review of the following quality control elements reported by the contractor laboratories in data deliverables:

- Holding times

- Blank analyses

- Surrogates

- Matrix spikes

- Duplicates.

All data received from the Weston laboratory were determined to be acceptable with the exception of the initial semi-volatile organic analysis of one sample, which was qualified as unusable due to low surrogate recovery. This sample was re-extracted and reanalyzed.

All holding time criteria were met for both water and soil samples analyzed by Weston with the exception of semi-volatile and pesticide/PCB extraction criteria (exceeded by one day) for one sample.

Weston prepared and analyzed laboratory blanks for both soil and water sample matrices. Analyses of the blanks identified the following potential laboratory contaminants:

- Volatile organics

- Acetone (soil blanks only)

- Methylene chloride

- Semivolatile organics

- Di-n-butylphthalate

- Bis-(2-ethylhexyl)-phthalate

- Metals

- Copper, lead, and zinc.

Compounds detected in the organics blanks were below the contract-required quantitation limit and are estimated values. Analytes detected in the metals blanks were at levels less than the contract-required detection limit. When evidence of blank contamination was present, blank validation criteria were applied to determine appropriate qualification for associated sample results.

Weston prepared and analyzed matrix spike samples and reported the results as percent recovery as an indication of accuracy. Spiked sample results were generally within control limits for percent recovery. Matrix spike recovery for thallium, lead, and silver were low in one or more of the Weston delivery groups. Weston also analyzed surrogate compounds for organics analyses and reported results in terms of percent recovery as another 
indication of accuracy. Reported surrogate recoveries were outside control

limits for several volatile, semivolatile, and pesticide/PCB samples in one or more of the Weston delivery groups. Results that fell outside of the applicable control limits were qualified according to the validation procedure. No indication of significant matrix effects were observed in the sample results.

Duplicate samples were prepared and analyzed, and data were reported as relative percent difference (RPD) by Weston as an indication of laboratory precision. For analyses of organics, RPD calculations were made between matrix spike/matrix spike duplicate samples. For inorganic analyses, RPD calculations were made between initial and duplicate sample results. Reported RPDs for duplicate samples were high for aluminum, magnesium, and zinc in one or more of the Weston delivery groups. Results that fell outside of the applicable control limits were qualified according to the validation procedure.

Weston utilized contract laboratory program (CLP 3/90) protocols to perform sample analyses instead of the requested SW- 846 methods. The use of CLP protocols is expected to have minimal impact on the data. The detection levels achieved using CLP were adequate to support decisions regarding closure of the 216-B-3 Pond System expansion pond. It is concluded that the data are acceptable with the qualifiers listed. These qualifiers were taken into account in further evaluations of the data set by project personnel.

TMA analyzed samples using SW-846 protocols. All data received from the TMA laboratory were determined to be acceptable with exception of the antimony result for one sample. The antimony result for that sample was qualified as unusable due to a very low matrix spike recovery. Holding time criteria were met for the analyses of soil and water :amples with the exception of cyanide results for two samples. The TMA resu?ts have been qualified accordingly.

TMA prepared and analyzed laboratory blanks for both soil and water sample matrices. Analyses of the blanks identified the following compounds as potential laboratory contaminants:

- Volatile organics

- Acetone

- Benzene

- Semivolatile organics

- Butylbenzylphthalate

- Metals

- Aluminum, calcium, copper, iron, magnesium, mercury, silver, sodium, vanadium, and zinc.

Target compounds and tentatively identified compounds detected in the organics blanks were below the contract-required quantitation limit and are estimated values. Analytes detected in metals blanks were at levels less than the 
contract-required detection limit. When evidence of blank contamination was present, blank validation criteria were applied to determine appropriate qualification for associated sample results.

TMA prepared and analyzed matrix spike samples and reported the results as percent recovery as an indication of accuracy. Spiked sample results were generally within control limits for percent recovery. Aluminum, cadmium, iron, thallium, antimony, and zinc matrix spike recoveries were outside control limits in one or more quality control samples. TMA also analyzed surrogate compounds for organics analyses and reported results in terms of percent recovery as another indication of accuracy. Results that fe $i 1$ outside the applicable control limits were qualified according to the validation procedure. No indication of significant matrix effects was observed in the sample results.

Duplicate samples were prepared and analyzed, and data were reported as relative percent difference (RPD) by TMA as an indication of laboratory precision. For organics analyses, RPD calculations were made between matrix spike/matrix spike duplicate samples. For inorganics analyses, RPD

calculations were made between initial and duplicate sample results. Reported RPDs for duplicate samples were high for aluminum, barium, iron, arsenic lead, and sodium in one or more of the TMA quality control samples. Results that fell outside the applicable control limits were qualified according io the validation procedure.

7.1.3.5 Summary of Phase 2 Analytical Results. Phase 2 analytical results were compared to background levels and to health-based limits. Analytical results were compared to Hanford Site background threshold values (DOE 1993) and to the local background values determined during Phase l sampling. Health-based limits were calculated as stipulated in WAC 173-340, Model Toxics Control Act (MTCA) Cleanup Regulation. The calculations are described in Appendix D.

Hanford Site Background is a sitewide approach to determining background levels that was developed as an alternative to local unit-based background determinations at the Hanford Site. The Hanford Site Background approach is based on the premise that most or all Hanford waste management units are associated with vadose zone sediments of similar geologic origin, therefore, the chemical composition of these sediments should be similar. The range of natural soil compositions is then used to establish a single set of soil background data. Hanford Site Background data set accurately represents the range of natural variability in soil composition across the Site, and provides a consistent, credible, and efficient basis for evaluating soil contamination.

No volatile organic compounds were detected in any of the water samples. of the compounds found in the soil samples, all the compounds found in the trip blank were disregarded with respect to determining contamination. The remaining analytes detected, toluene, methylene chloride, anc acetone, are considered to be common laboratory contaminants, and with the exception of two toluene hits, were found only in very low concentrations. The two toluene values of possible concern, greater than $100 \mu \mathrm{g} / \mathrm{kg}$, were found in very dry 
surface soil samples from 3B Pond. These values can be compared to the MTCA cleanup levels in WAC $173-340-740(3)$; all reported values are significantly below the cleanup levels.

No semi-volatile organic compounds were detected in any of the soil samples. All semi-volatile organic compounds found in the water samples were at very low levels. The methoxyethoxyethanol was found in two routine samples at concentrations less than or equal to that found in the trip blanks. Therefore, this compound was attributed to contamination after sampling. Methylcyclopentanol was found in one duplicate sample, but was not reported in the original analysis. No pesticides or PCBs were detected in any samples.

Metal analyte values exceeding laboratory instrument detection limits were compared to Hanford Site Background values (DOE-RL 1993). In calculating background threshold values from the reference data, certain soil classes such as topsoil and volcanic ash were excluded. The Phase 2 results include individual values for copper, lead, zinc, antimony, and cadmium that exceed Hanford Site background threshold values. These analytes were then compared to the local area background values determined during Phase 1 sampling, to common concentrations found in soils, and to MTCA Method B cleanup levels, with the exception of lead, which was compared to the more stringent MTCA Method A cleanup level. Method A levels for lead were used for comparison because data for the Method B cleanup level calculation were not available. From these comparisons, it is concluded that no metal analytes are present at concentrations that would be indicative of contamination. The data suggest that the soils and sediments at the sampled locations would not be classified as dangerous waste under the WAC 173-303 Dangerous Waste Regulations.

\subsubsection{Phase 3 Sampling}

The scope of Phase 3 sampling and analysis was to collect data for use in evaluating potential dangerous waste contamination of the vadose zone beneath the three expansion ponds of the 216-B-3 Pond System. One borehole was drilled through the vadose zone in each of the expansion ponds. Soil samples were collected and submitted for chemical analyses similar to those performed in Phase 1. Some nonchemical data also were collected in conjunction with the drilling. After drilling and sampling were completed, gross gamma logging was done in each borehole. The discussion of Phase 3 sampling and analys is is excerpted from Vadose Zone Investigation of 216-B-3A, 216-B-3B, and 216-B-3C Ponds (Kramer 1992), which is included as Appendix $E$ of this closure plan.

7.1.4.1 Phase 3 Sampling Objectives. Objectives of Phase 3 sampling and analysis were as follows:

- Determine whether dangerous waste constituents are present in the vadose zone beneath the lobes

- Determine which constituents (if any) are present in concentrations of concern 
- Assess the distribution of contaminants (if any) with depth in the vadose zone.

7.1.4.2 Analytical Parameters. Samples were analyzed for the inorganic constituents identified in Table 3-1 of Appendix $E$. The indicated methods are a combination of EPA SW-846 methods for metals and wet-chemistry methods for ions. Split samples were analyzed for the analytes listed in Table 3-1, with the following exceptions: ammonia, boron, chloride, fluoride, molybdenum, nitrate, silicon, sulfate, and sulfide.

Organic analyses inciuded pesticides/PCBs, herbicides, organophosphorus pesticides, dioxins/furans, volatile organics, and base/neutral/acid (BNA) compounds. Split samples generally were analyzed for the following:

- Target Compound List Volatiles (CLP SOW 2/88--Rev. 5/89)

- Target Compound List Semivolatiles (CLP SOW 2/88--Rev. 5/89)

- Pesticide and PCB Target Compounds (CLP SOW).

One split sample was analyzed for semivolatiles by EPA 8270 .

\subsubsection{Sampling Methodology.}

7.1.4.3.1 Drilling and Sampling at 216-8-3A Pond. Phase 3 sampling was initiated at $3 A$ Pond. Several months prior to drilling, a pad was constructed by placing and extending clean fill outward from the shoreline into the pond. This pad was located near the north shore of the pond, approximately 25 yards from the east corner.

Borehole BH-3A-1 (699-43-411) was drilled through the fill into the original pond bottom sediments. Samples were planned at 2-feet intervals for the first 10 feet below the former pond bottom and at a decreasing frequency thereafter until ground water was intercepted. All depths were referenced to ground surface elevation (i.e., grade surface on the drill pad). The pond bottom was encountered at approximately 6.5 feet.

Drilling was done with a cable tool rig. Samples were collected using a 5-inch outside diameter stainless steel split tube with stainless steel liners. A 10 -inch outside diameter, Schedule 40 casing was first used, followed by 8 - and then 6 -inch casings. The 10 -inch casing string was set at 20.4-feet. The 8-inch casing was set at 77.7 feet. Samples were collected per procedures of the Environmental Investigations and site Characterization Manual, WHC-CM-7-7. Samples for chemical analys is were placed in supplier-cleaned glass bottles.

Samples were screened for radioactivity with hand held instruments. A field photoionization detector was used to monitor for organic vapors. No evidence of contamination was detected by either of the two screening instruments. Aliquots submitted to an onsite laboratory revealed no evidence of radiological contamination. All aliquots were found to be below the applicable administrative limits for release from Hanford Site radiological controls. 
Difficult drilling was experienced at approximately 100 feet due to large cobbles and boulders. After two samples were collected from the interval 101.0 to 102.2 feet, hardtooling was employed. This required adding some raw water (untreated Columbia River water) to the hole. Drilling improved below 105 feet, and hardtooling was discontinued. A small amount (approximately $\frac{1}{2}$ gallon) of additional raw water was used at a depth of 112 feet to facilitate sample capture (recovery) in the core barrel. The next sample interval was 120.7 to 123.2 feet.

The final sample from the $3 A$ Pond borehole was collected from a depth of 142.75 to 143.85 feet. Recovery in the split spoon was estimated at only 50 percent. Observations in the field log note the sample as "very wet." The water level was measured at 142.75 feet.

A gross gamma log was run in the cased hole during February and March of 1991. Later, the casing was removed, and the borehole was backfilled, abandoned and marked in accordance with EII 6.5 (WHC-CM-7-7).

The following samples were collected from $3 A$ Pond and submitted for analysis:

- Twenty-two regular samples

- Two field duplicates

- Two split samples

- Two blanks, consisting of pure silica sand.

7.1.4.3.2 Drilling and Sampling at 216-B-3B Pond. Borehole BH 3B-1 (699-42-41B) was located in the center of the dry 3B Pond. Samples were collected with a split tube sampler. All sampling equipment (split tube samplers, bowls, spoons, etc.) was cleaned and decontaminated prior to use per EII 5.5, 1706 KE Laboratory Decontamination of RCRA/CERCLA Sampling Equipment, (WHC-CM-7-7). Recoveries from the first several sample intervals were estimated at 50 percent due to the coarse soil texture (i.e., sand and gravel). Finer-textured soils were encountered below a depth of 7 feet.

The drilling method and sampling frequency were similar to the other Phase 3 boreholes. Samples were planned at 2 -foot intervals for the first 10 feet and at a decreasing frequency thereafter until ground water was intercepted. Samples were collected as previously described for the $3 \mathrm{~A}$ Pond, except that no drilling pad or fill material was placed over the area to be investigated. All depths were referenced to ground surface elevation. The 10 -inch casing string was set at 21.1 feet. The 8 -inch casing was set at 78.2 feet. Samples were screened with field instruments for radioactivity and hazardous organic vapors. No evidence of radioactivity or organic vapors was detected.

The borehole was advanced by drive barrel to approximately 74 feet before there was any need to add water to the hole. One gallon of raw water was added to facilitate drilling at this depth, which was about 6 feet above the next sample interval, 79.8 to 81.5 feet. 
Hard tool drilling was required at 95 to 103 feet and at 109 to 113 feet. A total of 30 gallons of raw water was added to the hole in these intervals. Three soil samples collected from these intervals potentially were affected by the addition of raw water. In each case, the samples were collected several feet below the depth where the last of the water had been added. The final sample, consisting of wet silt, was collected at a depth of 123.5 feet. Final depth of the borehole was 124.7 feet.

A gross gamma log was run in the cased hole during March 1991. Later, the casing was removed, and the borehole was backfilled, abandoned, and marked in accordance with EII procedures.

The following samples were collected from 3B Pond and submitted for analysis:

- Twenty-two regular samples

- Two field duplicates

- Two split samples

- Two blanks, consisting of pure silica sand.

7.1.4.3.3 Drilling and Sampling at 216-B-3C Pond. The $3 C$ Pond (which functionally is a series of percolation trenches) was in active use at the time of this investigation. Borehole $\mathrm{BH} 3 \mathrm{C}-1$ (699-41-4) was located on dry ground between trenches in the northwest quadrant of the pond area. The water surface in the adjacent trench was several feet below the borehole collar elevation.

Drilling and sampling methods were identical to those previously described. As with the other two boreholes, samples were collected more frequently from the upper portion of the borehole. Five samples were collected from the first 10 feet. The 10 -inch casing string was set at 32.1 feet. An 8-inch casing was used for the remainder of the borehole. In-field monitoring of samples showed no radioactivity or hazardous organic vapors.

Moisture was a factor in sample recovery. Samples collected from the upper part of the borehole were damp, but moisture appeared to increase at about 18 feet. There was no standing water in the hole at 19 feet, however, some difficulty was experienced retaining soil in the sample barrel. Poor recovery also limited planned sampling in the 20 to 25 feet range. There was standing water in the borehole at a depth of 27.8 feet. Drilling and sampling conditions improved below that depth, but for the remainder of the borehole moisture was present in all samples. Intermittent saturated zones were encountered between 74 and 80 feet. Drilling was terminated at a depth of 80.9 feet.

A gross gamma log was run in the cased hole during March 1991. Afterward, the casing was removed, and the borehole was backfilled and abandoned in accordance with EII procedures. The borehole location is marked with a brass survey monument. 
The following samples were collected from $3 C$ Pond and submitted for analysis:

- Eighteen regular samples

- Two field duplicates

- Two split samples

- Two blanks, consisting of pure silica sand.

\subsubsection{Analytical Methods and Analytical Quality Assurance and Quality}

Control. During Phase 3, 22 regular soil samples were collected from BH-3A-1; 22 regular soil samples were collected from BH-3B-1; and 18 regular soil samples were collected from $\mathrm{BH}-3 \mathrm{C}-1$ (62 regular samples). Two splits, two field duplicates, and two soil blanks were submitted for analysis from each borehole ( 80 Phase 3 samples total).

Phase 3 analyses were performed by four different offsite contractor laboratories. The primary laboratory was Martin Marietta's K-25 laboratory in Oak Ridge, Tennessee. Phosphorous pesticide and dioxin analyses were subcontracted to IT Analytical Services in Knoxville, Tennessee. Split samples were analyzed by Roy $F$. Weston laboratories in Lionville, Pennsylvania. Radiochemical analysis of split samples was subcontracted by Weston to Teledyne in Westwood, New Jersey.

Samples were analyzed for inorganic constituents by the methods 1 isted in Table 3-1 of Appendix E. Split samples were analyzed and reported according to CLP protocol (CLP SOW, March 1990) for the analytes listed in Table 7-6 minus ammonia, boron, chloride, fluoride, molybdenum, nitrate, silicon, sulfate, and sulfide.

Summary statistics for inorganic analyses are provided in Table 4-8 of Appendix E. Statistical evaluation of results reported for split samples, which were analyzed by the primary laboratory and the split laboratory independently, indicated that the split laboratory tended to report lower analyte concentrations than the primary contractor.

Organic analyses included pesticides/PCBs, herbicides, organophosphorus pesticides, dioxins/furans, volatile organics, and BNA compounds. All organic analyses were performed by EPA SW-846 methods or contractor

laboratory-specific methods based on CLP protocols. Most split samples were analyzed for the following:

- Target Compound List Volatiles (CLP SOW 2/88--Rev. 5/89)

- Target Compound List Semivolatiles (CLP SOW 2/88--Rev. 5/89)

- Pesticide and PCB Target Compounds (CLP SOW).

One split sample was analyzed for semivolatiles by EPA 8270 . Organic analyses were performed on fifty percent of the regular samples (specifically, 11 samples from $3 A$, 11 from $3 B$, and 9 from $3 C$ ), together with 1 split, 1 field duplicate, and 1 blank from each borehole. Ali 40 samples were analyzed for pesticides/PCBs, herbicides, organophosphorus pesticides, volatile organic compounds, and BNA compounds. Thirty samples (including all 9 QC samples) 
DOE/RL 89-28, Rev. 1

$12 / 15 / 93$

1 were analyzed for total tetra through octa dioxin and furan homologs. The samples analyzed for dioxin/furan compounds were all from shallow vadose zone depths.

Most Phase 3 sample results were qualified as estimated. The most prevalent reason for qualification was the application of the pre-extraction holding time limit for water samples as a data validation criterion, even though the matrix for all Phase 3 samples was soil. All samples, including silica sand and field duplicates, were extracted outside the 7-day criterion. All extracts were analyzed within the allotted 40 days after extraction. Additionally, any tentatively identified compounds (TICS) reported were routinely qualified by the laboratory as estimated.

7.1.4.5 Summary of Phase 3 Analytical Results. As indicated above, the split laboratory tended to report lower inorganic analyte concentrations than the primary contractor, suggesting a potential bias in concentration data reported by the primary laboratory. In particular, chromium concentrations in Phase 3 samples frequently exceeded Phase 1 threshold values. However, chromium values were still one to two orders of magnitude below EPA's protective trigger level for further investigation or Ecology's MTCA "Method A" cleanup level for industrial soil.

Beryllium was detected in all regular Phase 3 soil samples. Beryllium was not found in any Phase 1 samples (regular or background soil). However, the difference appears to be attributable to a lower contract required quantitation limit (CRQL) specification for Phase 3 analyses. Beryllium was reported to be present in Phase 3 samples at levels below the Phase 1 contract detection limit. The reported levels are within the range of natural background for the Hanford Site (DOE 1993). Antimony was detected in four samples, at levels comparable with natural background. Mercury, selenium, thallium, and cyanide were reported, but at levels less than CRQLS.

All pesticides/PCBs, herbicides, organophosphorus pesticides, and dioxin/furan homologs were reported as nondetected, or were qual ified as nondetected upon validation. Analyses of QC samples were all within acceptable limits for these groups of compounds.

No volatile organic compounds of significance were found. Traces of three common solvents, methylene chloride, acetone, and 4-methyl-2-pentanone (a.k.a. methyl isobutyl ketone or hexone), were reported in several samples. Methylene chloride was detected in two samples at concentrations less than the CRQL. Acetone was identified in six samples, all at levels less than the SW-846 practical quantitation limit. Four-methy1-2-pentanone was detected in three samples at concentrations less than the CRQL. The three compounds are common laboratory contaminants.

No semivolatile target compounds were identified above their respective CRQLs. Two target compounds, benzoic acid and diethylphthalate, were reported at levels below CRQLs. However, both of these compounds also were identified in at least one blank. The primary laboratory reported an average of 
approximately 13 TICs per Phase 3 sample, whereas the split laboratory reported slightly more than 3 per sample. Identical compounds occurred at similar concentrations in associated laboratory blanks.

In summary, the results of Phase 3 sampling and analysis indicate that there is no apparent basis for regulating vadose zone soils beneath the three 216-B-3 Pond System expansion ponds based on ignitability, corrosivity, reactivity, or toxicity characteristics as identified in WAC 173-303-090, or carcinogenic, persistent, or toxic criteria as identified in WAC 173-303-100. There is no indication that any listed dangerous waste constituents (organic or inorganic) are present in vadose zone soils at the site at levels of regulatory concern.

\subsubsection{Summary of Sampling and Analyses Results for 216-B-3A, 216-B-3B, and 216-B-3C Ponds}

Based on the results of the sampling and analysis efforts described in this section, clean closure was selected for the 216-B-3A, 216-B-3B, and 216-B-3C ponds.

\subsection{INTERIM STABILIZATION OF THE 216-B-3A POND}

The $3 A$ Pond will not be used in the future due to its proximity to the 216-B-3 Pond. Sampling has demonstrated that the 3A Pond is not contaminated with hazardous constituents above proposed action levels. If it is determined that the $3 \mathrm{~A}$ Pond is radiologically contaminated it may be necessary to interim stabilize this pond. If radiological contamination is present, the contaminated soil will be removed and consolidated, if possible, into the 216-B-3 Pond. After surveying and/or soil removal, the surface contamination posting signs will be removed. In either case, the pond may then have a clean soil layer or other suitable rooting medium placed over it and be revegetated.

If the $3 A$ Pond must be interim stabilized, then stabilization will occur in three phases as depicted in Figure 7-8. Isolation and dismantling of structures associated with this pond will be an integral part of the interim stabilization. Interim stabilization of the $3 A$ Pond will occur after until interim stabilization of the 216-B-3 Pond and 216-B-3-3 Ditch has been completed.

\subsubsection{Phase 1: Drawdown and Interim Stabilization of Pond Sediments}

The shoreline area and surrounding surface contamination zone will be interim stabilized with a minimum of two feet of clean backfill. Clean soil will be worked out over the contaminated areas, progressing towards the water's edge. When the entire shoreline and adjacent surface contamination zone have been interim stabilized, the quantity of waste water discharged to the $3 A$ Pond will be reduced, with the excess being diverted from the $3 A$ Pond to the $3 B$ and/or $3 C$ Ponds. Waste water transfers via the 216-B-354 flow control structure will be terminated.

931119.0815 
As the pond level is lowered, the clean soil layer will be extended out over the exposed sediments following the pond bottom topography. Flow into the pond will be controlled such that the water level continues to drop, allowing interim stabilization of the exposed sediments. Work will progress from the highest elevation points to the low point, which is a north-south oriented trench dug to increase the percolation capacity of the pond. The water level will be reduced to the top of the trench. Sediments will be allowed to dry sufficiently to allow successful interim stabilization but not to the point as to allow airborne contamination. Water will be applied if pond sediments are in danger of drying enough to allow airborne contamination. A flow channel leading from the diversion pipeline to the reduced pool in the $3 \mathrm{~A}$ Pond will be maintained. Clean soil will be placed up to the edge of this channel so that no unwetted sediments will be exposed.

\subsubsection{Phase 2: Backfilling of the Percolation Trench}

This phase entails the placement of clean soil into the percolation trench. The trench will be brought up to the surrounding grade with clean soil. The water level in the trench will be maintained at a constant elevation that is roughly equal to the projected final grade, i.e., the level with the surrounding pond bottom. The trench will be filled with clean soil to cover all potentially contaminated sediments. Waste water will then be diverted to the $3 \mathrm{~B}$ and/or $3 \mathrm{C}$ Ponds or other suitable location, and the trench allowed to empty. Sediments will be allowed to dry sufficiently to allow interim stabilization, but not to the point as to allow air borne contamination. Clean fill will then be pushed into the trench. At the end of Phase 2, the trench will have been backfilled to the surrounding grade. As the water level is reduced and eventually eliminated, exposed sediments in the flow channel between the diversion pipeline and the $3 \mathrm{~A}$ Pond will be interim stabilized.

\subsubsection{Phase 3: Topsoil Placement, Revegetation, and Marker Post Placement}

Topsoil will be placed over the coarse soil fill. The topsoil will provide a suitable rooting medium. The topsoil layer will be approximately 12 inches thick, and will be excavated from a nearby borrow area. Perennial grasses will be planted to minimize soil erosion. A high nitrogen fertilizer will be spread over the site and a mixture of Siberian and Thickspike perennial wheatgrass or other suitable grasses will be planted to minimize soil erosion. Straw mulch will then be broadcast over the area and crimped into the soil. The perennial mix requires autumn planting to establish a viable stand. If interim stabilization is completed too late in the fall for a planting, an annual grass such as rye can be planted in the early spring, followed in autumn by the perennial.

Once the stabilization has been completed, the areas that were decontaminated will be surveyed to confirm that there are no radioactive 
materials present on the surface. After interim stabilization, radioactively 2 contaminated areas will be posted as "underground radioactive material" in 3 accordance with WHC-CM-4-10.

\subsubsection{Post-Stabilization Surveillance}

In the period between interim stabilization and final remediation, routine surveillance and maintenance of the 216-B-3 Pond System will be performed. The Westinghouse Hanford Environmental Assurance organization will establish a schedule for periodic surveillance of the site. Initially, the frequency is expected to be semi-annualiy or every six months. The surveillance will include monitoring the site for the following: surface radioactive material, potential uptake of radioactivity by vegetation, intrusion into subsurface radioactive materials by animals or insects, proper posting, and general appearance and condition.

Any items found to be out of compliance will be identified for corrective action. Items which cannot be fixed immediately will be documented and tracked until they are corrected. The landlord organization will periodically inspect the site to ensure the posting and barriers are in good condition. Annually, the site will be cleaned of unwanted vegetation and sprayed with a selective herbicide or sterilant. Besides surveillance, the 216-B-3 Pond system will be placed on the schedule for herbicide application. The selective herbicide is used to control deep-rooted vegetation without harming the desirable grasses. The sterilant is used where no vegetation is wanted. The herbicide will be applied under the direction of the Westinghouse Hanford Site Commercial Pesticide Applicator.

\subsubsection{Project Documentation}

A final report will be prepared and issued documenting the $3 A$ Pond interim stabilization project. The report will include a description of the activities performed at the site and note any significant variation from the original plan. Topographic surveys from before and after stabilization will be included in the report along with key photographs. If any noteworthy problems are encountered during the stabilization, their resolution will be documented in a "Lessons Learned" section. The interim stabilization final report will be entered into the administrative record for the site.

\subsection{DECONTAMINATION/REMOVAL OF STRUCTURES AND ASSOCIATED FIXED EQUIPMENT}

This section describes the decontamination and removal activities of the structures associated with the 216-B-3 Pond expansion ponds. 
DOE/RL 89-28, Rev. 1

$12 / 15 / 93$

\subsubsection{The 216-B-3A Pond Dikes}

The proposed disposition for the earthen dikes and the associated piezometers and boreholes are discussed in the following sections.

\subsubsection{Proposed Disposition for the 216-B-3A Pond Dike and Associated} Piezometers. Clean closure is proposed for the $3 A$ Pond and the $3 B$ Pond. If clean closure of the $3 A$ Pond and the $3 B$ Pond will be feasible and practical without the need to remove contaminated soil from either pond, then the diking around the ponds will be retained in the current configuration. This earthen dike also contains a network of piezometers (see Chapter 2.0, Figure 2-20). If the $3 A$ and the $3 B$ Ponds are clean closed as proposed, then no action is proposed with regard to these piezometers; they will be maintained for continued use to monitor seepage through the dike.

7.3.1.2 Abandonment of Piezometers. The piezometers associated with the 216-B-3 Pond will be plugged and abandoned after the 216-B-3 Pond has been removed from service. Piezometers are defined as 'resource protection wells' in WAC 173-160 and requirements for abandonment are stipulated in WAC 173-160-560. Plugging and abandonment of piezometers on the Hanford Site will follow WHC-CM-7-7, EII 6.5, "Plugging and Abandoning of Characterization Boreholes," which conforms to WAC. In addition, a groundwater monitoring borehole (699-43-42) will be abandoned in the same manner as the piezometers. This well has cracked casing and will be taken out of service to prevent communication between $B$ Pond and the underlying aquifer.

The proposed method of abandonment is to plug the piezometer tubes ( 1 to 3 per borehole) with a high-solids bentonite. Ecology will be notified at least 72 hours before initiating abandonment activities. Documentation of abandonment activities will be performed as specified in WHC-CM-7-7, EII 6.5, "Plugging and Abandoning of Characterization Boreholes."

\subsubsection{The 216-B-353 Flow Control and Spillway Structure}

The proposed disposition and contingency plans for sampling, decontamination, and removal are discussed in the following sections.

7.3.2.1 Proposed Disposition. The 216-B-353 flow control and spillway structure monitors and controls waste water transfer from the $3 A$ Pond to the 3B Pond (see Chapter 2.0, Figures 2-8, 2-9, 2-10, and 2-14). The structure has not been used since May 1985. Clean closure is proposed for the $3 A$ and 3B Ponds. No future use is planned for the $3 \mathrm{~A}$ Pond, therefore, the structure will be demolished and removed.

7.3.2.2 Removal Plan. Removal of the 216-B-353 flow control and spillway structure is to follow the same general approach indicated for the 216-8-351 (see Section 7.2.2.2) and 216-B-352 control structures (see Section 7.2.3.2). The 216-B-353 flow control and spillway structure has a formed, reinforced concrete overflow structure at the inlet, with two control weirs and steel slide gates, a metal trash guard constructed of galvanized-wire fabric supported by a 2 -inch-diameter pipe, and an expanded metal grating. Waste 
1

2

water is transferred via two 30-inch-diameter, corrugated-steel pipes to a stilling basin lined with riprap. The pipe consists of 20-foot sections, with $0-r i n g ~ s e a l s$ and band couplers at the joints. Pipe runs in the 216-B-353 structure each have two $8^{\circ}$ elbows at changes in profile. Each pipe is about 60 feet long. The pipes are buried under 5 to 10 feet of cover.

The concrete inlet structure will be demolished. The concrete will be broken with a pneumatic or hydraulic concrete breaker, which may be either a hand-operated type (e.g., a jackhammer) or a larger, machine-mounted unit. As it is exposed, embedded reinforcing bar and/or wire will be severed with an acetylene torch, enabling the debris to be physically separated and loaded out. Concrete demolition waste may be consolidated into the 216-B-3 Pond during interim stabilization of the pond. No sampling of concrete associated with the 216-B-353 structure is proposed.

Before removal, exposed surfaces of metal components (slide gate assembly, trash guard and supports, and expanded metal grating) will be surveyed for radiological contamination with hand-held detectors to determine appropriate dispositions for all materials. Metal scrap that can be unconditionally released from radiological controls (in accordance with WHC-CM-4-10, Section 9) will be disposed of as uncontaminated scrap. If radiological contaminants are present, the scrap metal will be handled and disposed of as indicated in Section 7.2.8.

Limited surveying of the corrugated pipes will be performed before removal. A backhoe or hydraulic excavator will be used to remove the overlying cover soil. The pipe will be disassembled at the joints, hoisted out in sections, and then cut into manageable lengths for disposal. If the pipe is unconditionally released from radiological controls (in accordance with WHC-CM-4-10, Section 9) it will be disposed of as uncontaminated scrap metal. If radiological contaminants are present, the scrap will be handled and disposed of as indicated in Section 7.2.10. The sections will be crushed flat (if practical) or cut apart lengthwise to facilitate disposal.

\subsubsection{The 216-B-354 Flow Control and Spillway Structure}

The proposed disposition and contingency plans for sampling, decontamination and removal are discussed in the following sections.

\subsubsection{Proposed Disposition. The 216-B-354 flow control and spillway} structure monitors and controls the transfer of waste water from the $3 A$ Pond to the $3 C$ Pond (see Chapter 2.0, Figures 2-14, 2-16, 2-17, and 2-18). Clean closure is proposed in this closure plan for both the $3 A$ Pond and the $3 C$ Pond. However, there is no future use planned for the $3 A$ Pond, therefore, there is no need to preserve the 216-B-354 flow control structure for future use and the structure will be demolished and removed.

\subsubsection{Removal Plan. Removal of the 216-B-354 flow control and spillway} structure is to follow the same general approach indicated for the 216-B-351, 216-B-352, and 216-B-353 control structures (see Sections 7.2.3.2, 7.2.4.2, and 7.2 .5 .3$)$. The 216-B-354 control structure has a formed 
1

reinforced-concrete overflow structure at the inlet, with two control weirs and steel slide gates, a metal trash guard constructed of galvanized-wire fabric supported by a 2 -inch-diameter pipe, and an expanded metal grating. Waste water is transferred via two 30-inch-diameter, corrugated-steel pipes to a stilling basin lined with riprap. The pipe consists of 20-foot sections, with 0-ring seals and band couplers at the joints. Each pipe has one 45 degree elbow along the length of the pipe. Each pipe is about 1,000 feet long. The pipes are buried under 5 to 10 feet of cover.

The concrete inlet structure will be demolished. The concrete will be broken with a pneumatic or hydraulic concrete breaker, which may be either a hand-operated type (e.g., a jackhammer) or a larger, machine-mounted unit. As it is exposed, embedded reinforcing bar and/or wire will be severed with an acetylene torch, enabling the debris to be physically separated and loaded out. Concrete demolition waste will be disposed of in an appropriate disposal site if radiologically contaminated or other disposal site if not radiologically contaminated. No sampling for hazardous constituents of concrete associated with the 216-B-354 structure is proposed.

Before removal, exposed surfaces of metal components (slide gate assembly, trash guard and supports, and expanded metal grating) will be surveyed for radiological contamination with hand-held detectors to determine appropriate dispositions for all materials. Metal components will be cut away with an acetylene torch. After removal, the components will be cut into smaller pieces to the extent necessary to facilitate loading them into waste containers. Metal scrap that is substantially free that can be unconditionally released from radiological controls (in accordance with WHC-CM-4-10, Section 9) will be disposed of as uncontaminated scrap. If the metal slide gate assembly is unconditionally released from radiological controls, it may be salvaged for reuse. If radiological contaminants are present, the scrap metal will be handled and disposed of as indicated in Section 7.2.8.

\subsubsection{Procedures for Handling and Disposal of Waste}

Requirements and procedures for packaging, container labeling, manifesting, inspection, loading, placarding, transportation (onsite and offsite), and disposal of dangerous, radioactive, and mixed waste for points of origin and/or destination on the Hanford Site are discussed in detail in the following documents:

- WHC-CM-2-14, Hazardous Materials Packaging and Shipping

- WHC-CM-5-16, Nonradioactive Dangerous Waste Packaging and Disposal Requirements

- WHC-EP-0063-1, Hanford Site Radioactive Solid Waste Acceptance Criteria (Stickney 1989). 
Information from these documents is summarized in the following sections. Each of these functions will be managed and performed in conjunction with removal of any contaminated structural materials/debris from the 216-B-3 Pond System to onsite or offsite disposal units.

7.3.4.1 Packaging. Containers that are suitable for the specific types of contaminants present and that comply with applicable U.S. Department of Transportation, DOE, Nuclear Regulatory Commission, EPA, and Washington State Department of Transportation regulatory requirements, will be provided for packaging of waste at the site. Containers are available for shipping various types and classes of hazardous waste at the Hanford Site. A safety analysis report for packaging is required for any container that will be used to transport materials containing radioactive waste. Considerations in the selecting of an appropriate container include the following:

- Quantity, type, form, and classification of radionuclides (if any) to be packaged

- Need for shielding and/or heat transfer (e.g., cooling)

- Size, shape, and weight of material to be shipped

- Destination, mode of transport, and consignee's ability to handle receipt of the shipment

- Dose rate and contamination considerations

- Availability of shipping containers.

7.3.4.2 Container Labeling. Any waste package containing dangerous waste regulated as dangerous waste or extremely hazardous waste will have a properly completed EPA hazardous waste sticker with the following information:

- Uniform Hazardous Waste Manifest unique identification number, page number, and waste item line identification letter

- Proper shipping name and identification number

- Generator's name and address:

U.S. Department of Energy

P. 0. Box 550, 2401 Stevens Drive

Richland, WA 99352

- EPA/Ecology ID No. for the Hanford Site: WA7890008967

- EPA/Ecology Waste No. (dangerous waste codes)

- Accumulation start date.

Waste packages with PCB contaminants (if any) will bear a properly completed EPA 'Waste for Disposal' sticker and a "Caution: Contains PCB's" 
sticker in accordance with 40 CFR 761. Additional labeling will be provided in accordance with 49 CFR 172. Waste packages originating on the Hanford Site will have various additional markings on the top and sides (e.g., 'This End Up, ' inventory number, unit number, package weight, and hazard class information).

The following marks and labels are to be attached to waste packages containing radioactive materials:

- Responsible generator

- Date sealed and shipped

- Radiation survey data

- Estimated activity and identity of radioactive materials present

- Gross weight if greater than 55 pounds

- Radioactive labels (20-year equivalent labels for mixed waste)

- Other hazard class labels (U.S. Department of Transportation-approved labels) as appropriate.

7.3.4.3 Manifesting. A Uniform Hazardous Waste Manifest will be completed for each offsite shipment of dangerous or mixed waste. For monitoring and control of radioactive solid waste shipments from the Hanford Site, the 'Storage/Disposal Approval Record' and the 'Solid Waste Disposal Analysis Record' are used. No offsite shipments are planned for these closure activities.

7.3.4.4 Inspection. If any waste that requires a Uniform Hazardous Waste Manifest is shipped from a point of origin on the Hanford Site, the DOE requires the shipment be inspected and approved for transport. The inspection is performed after the waste has been packaged and manifested to ensure compi iance with the loading, placarding, transportation, and disposal requirements discussed in the following sections.

7.3.4.5 Loading. All shipments will be inspected before loading to ensure compliance with packaging and manifesting instructions. Loaded shipments will be inspected to ensure compliance with applicable U.S. Department of Transportation requirements. For radioactive solid waste shipments, there are specific tiedown requirements for each approved shipping container.

The tiedown requirements are documented in the safety analys is report for packaging prepared for each container.

7.3.4.6 Placarding. Placarding of shipments of contaminated materials/debris will conform to all applicable regulations imposed by 49 CFR 172.504 and the 49 state of Washington. Appropriate placards will be provided to the carrier 
after the load and the vehicle have been inspected. If the vehicle is equipped with permanent placards, the inspector will ensure that placards for the appropriate hazards are displayed.

7.3.4.7 Transportation. All waste shipments, whether to onsite or offsite destinations, are scheduled in advance. Schedules will comply with the 90-day shipping deadline imposed on dangerous waste, if applicable (and the 30-day deadiine that applies to PCBs, if PCBs should be present in the waste). Radiation release surveys also must be scheduled. Unconditional radiological release stickers/documentation are valid only for a 24-hour period following their issuance. A separate release sticker is required for each container. The Hanford Site procedures require that all onsite shipments of radioactive waste be escorted by radiation protection technologists and Hanford Patrol personnel.

7.3.4.8 Disposal. Radioactive waste generated as a result of decontamination and removal activities on the Hanford Site is disposed of at the Hanford Site low-level burial grounds (currently under RCRA interim status; permit number WA7890008967). Radioactive mixed waste is sent to the Central Waste Complex (currently under RCRA; interim status; permit number WA7890008967) for interim storage and future treatment or disposal. The Hanford Site requirements for radioactive solid waste packaging, storage, and disposal. (WHC-CM-2-14) will be followed when preparing waste for storage and/or disposal.

Solid waste that is nonradioactive and nondangerous will be handled and disposed of as nonregulated solid waste.

\subsection{SCHEDULE FOR CLOSURE}

This section addresses schedule information regarding performance of various closure activities.

Sampling activities have been completed and are described in Section 7.1, Soil and Sediment Sampling.

Monitoring of site groundwater is an active program that will continue following closure in support of the 200-BP-11 operable unit investigation (unless directed otherwise by Ecology). office:

Official copies of the closure plan will be located at the following

U.S. Department of Energy,

Richland Operations office

Federal Building

825 Jadwin Avenue

P.0. Box 550

Richland, Washington 99352. 
The DOE-RL office will be responsible for amending this closure plan, as deemed necessary, according to the amendment procedures in WAC 173-303-610. The closure plan will be kept at the DOE-RL office until closure is complete and certified.

\subsection{AMENDMENT OF PLAN}

In addition, as required by WAC 173-303-610(3)(b), the closure plan will be amended if, when conducting final closure activities, unexpected events require a modification of the approved closure plan. If an amendment to the approved closure plan is required, the DOE-RL will submit a written request to Ecology to authorize a change to the approved plan. The written request will include a copy of the closure plan amendment for approval.

\subsection{CERTIFICATION OF CLOSURE}

Within 60 days of closure of the TSD Unit, the DOE-RL will submit to the Benton County Auditor and the lead regulatory agency a certification of closure and a duly certified survey plat. The certification of closure will be signed by both the DOE-RL and a registered independent professional engineer, stating that the unit has been closed in accordance with the approved closure plan. The certification will be submitted by registered mail or an equivalent delivery service. Documentation supporting the independent registered professional engineer's certification will be supplied

The DOE-RL and the independent professional engineer will certify with a document similar to Figure 7-4. 


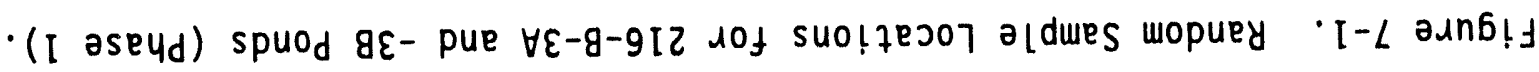

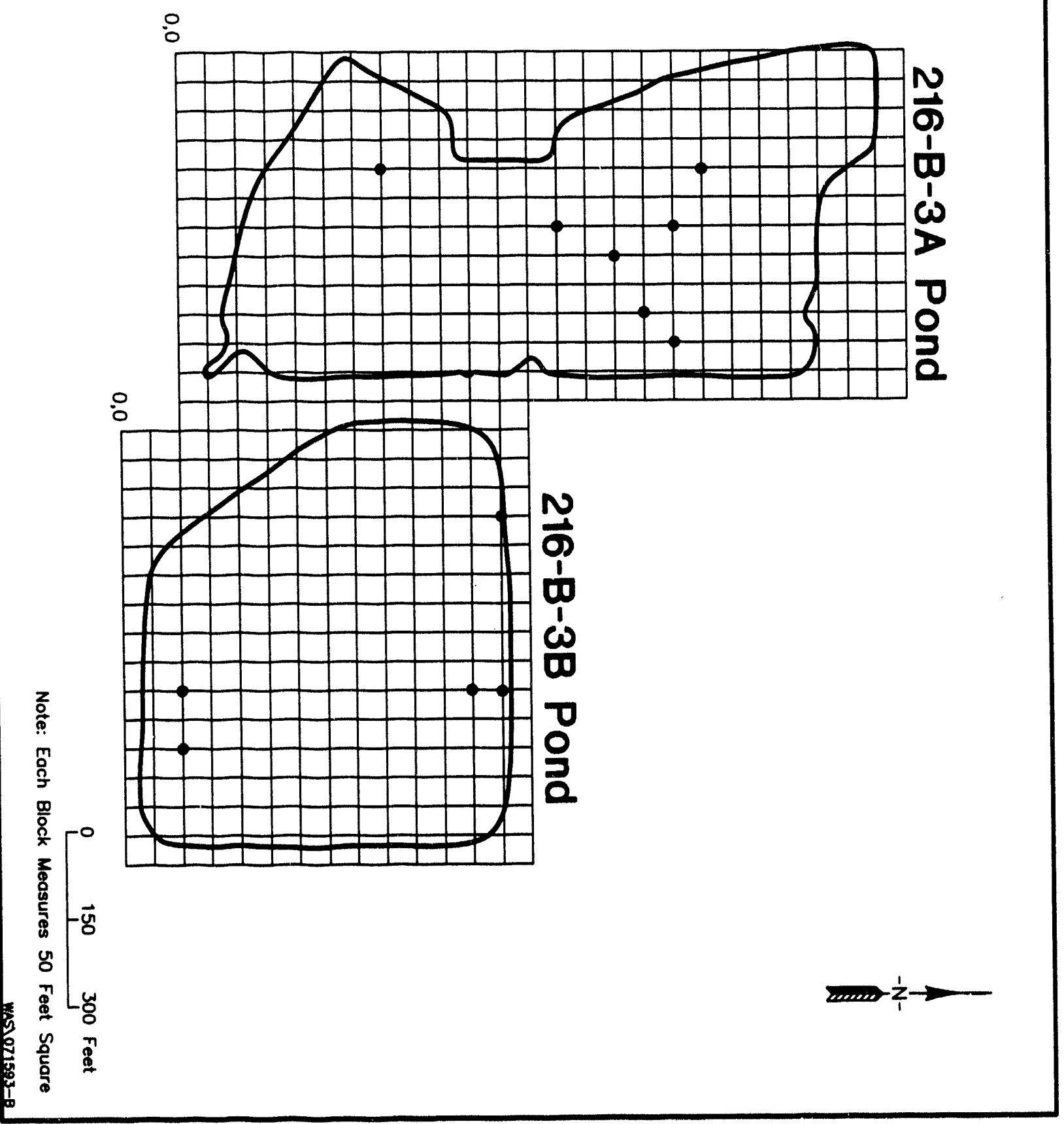




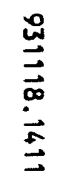

\section{○}

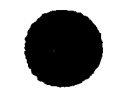

$\overrightarrow{0}$
$\stackrel{0}{c}$
Dे
L

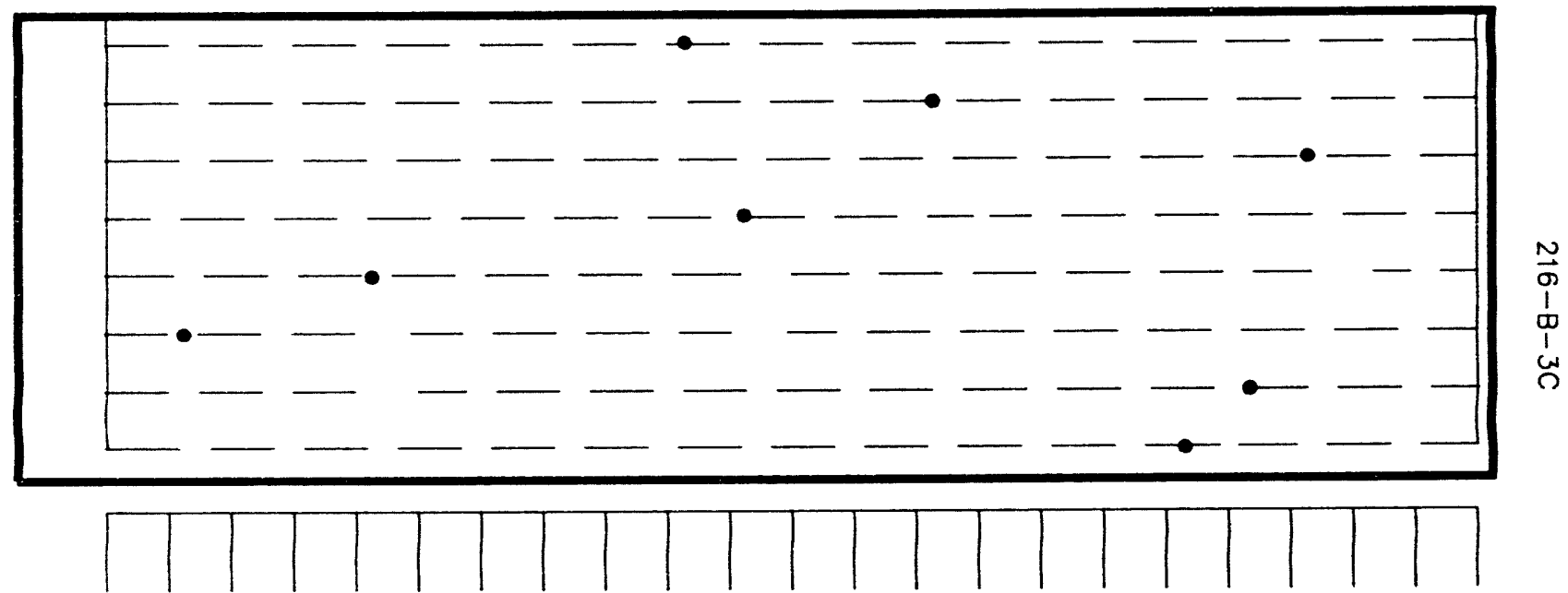

$\underset{1}{\tilde{1}}$

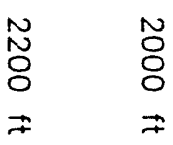

D
0
0
0
0
0
0
0
1
$m$

$20000-z_{1}^{1} \rightarrow$ 


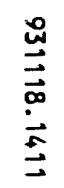

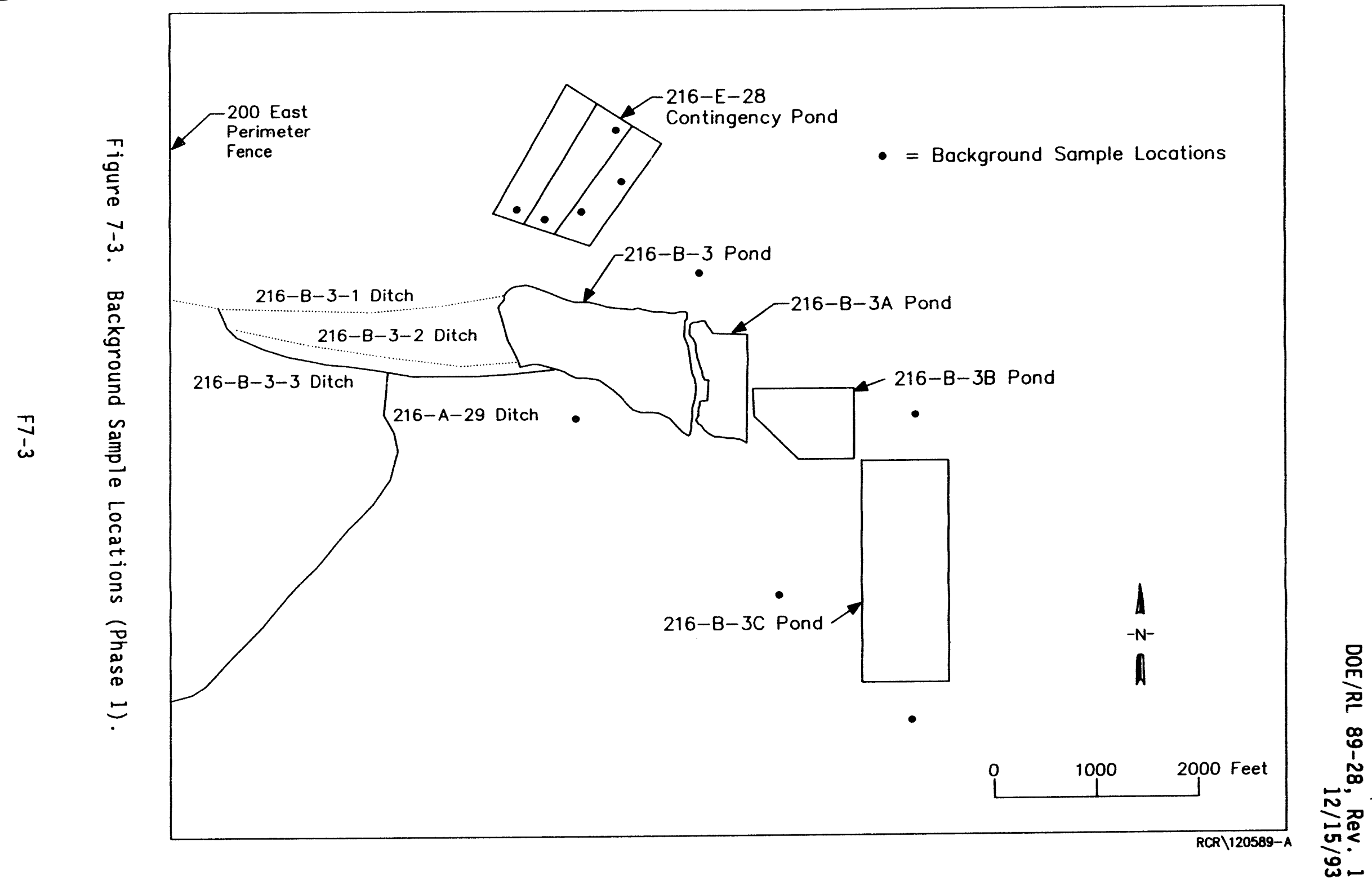


DOE/RL 89-28, Rev. 1

$12 / 15 / 93$

2

3

4

5

6

7

8

9

10

11

12

13

14

15

16

17

18

19

20

21

22

23

24

25

26

27

28

29

30

31

\section{CLOSURE CERTIFICATION}

FOR

Hanford Site

U.S. Department of Energy, Richland Operations Office

Owner/Operator Signature DOE-RL Representative

(Typed Name)

P.E.\#

State

Signature Independent Registered Professional Engineer

Date

Date

(Typed Name, Professional Engineer license number, state of issuance, and date of signature)

Figure 7-4. Typical Closure Certification Document. 
Table 7-1. Analytical Parameters for Individual Samples.

\begin{tabular}{|c|c|c|}
\hline Parameter or group & Analysis method & Sample size (grams) \\
\hline \multicolumn{3}{|c|}{ Metals } \\
\hline $\begin{array}{l}\text { Extraction procedure } \\
\text { toxic metals, enhanced }\end{array}$ & EPA $6010^{\circ}$ & 100 \\
\hline Arsenic & EPA $7060 / 7061^{b}$ & 5 \\
\hline Lead & EPA $7425^{\circ}$ & 5 \\
\hline Mercury & EPA $7470^{\circ}$ & 5 \\
\hline Selenium & EPA $7740 / 7741^{b}$ & 5 \\
\hline Thallium & EPA $7841^{\circ}$ & 5 \\
\hline \multicolumn{3}{|c|}{ Ions } \\
\hline Anions ${ }^{c}$ & EPA $300^{\circ}$ & 90 \\
\hline Sulfide & EPA $9030^{b}$ & 45 \\
\hline Cyanide & EPA $9010^{b}$ & 90 \\
\hline Ammonium & ASTM D $1426-C / D^{d}$ & 70 \\
\hline \multicolumn{3}{|c|}{ Radiologic } \\
\hline Gross alpha & EPA $9310^{\circ}$ & 5 \\
\hline Gross beta & EPA $9310^{b}$ & 5 \\
\hline \multicolumn{3}{|c|}{ Organic } \\
\hline $\begin{array}{l}\text { Volatile organic } \\
\text { compounds }\end{array}$ & EPA $8240^{\circ}$ & $\begin{array}{c}40 \text { milliliters } \\
\text { duplicate samples }\end{array}$ \\
\hline
\end{tabular}

${ }^{a}$ Extraction procedure toxic metals, enhanced, include: aluminum, antimony, arsenic, barium, beryllium, boron, cadmium, calcium, chromium, cobalt, copper, iron, lead, lithium, magnesium, manganese, mercury, molybdenum, nickel, potassium, selenium, silicon, silver, sodium, strontium, tin, titanium, vanadium, zinc, zirconium.

BEPA 1986c.

'Includes: bromide, chloride, fluoride, nitrate, nitrite, phosphate, sulfate.

ASTM 1988. 
Table 7-2. Analytical Parameters for Composite Samples.

2

3

4

\begin{tabular}{|l|c|c|}
\hline \multicolumn{1}{|c|}{ Parameter or group } & Analysis method & Sample size (grams) \\
\hline \multicolumn{3}{|c|}{ Radionuclides } \\
\hline Strontium-90 & U.S. Testing Co. ${ }^{\mathrm{a}}$ method & 5 \\
\hline Cesium-137 & U.S. Testing Co. ${ }^{\mathrm{a}}$ method & 100 \\
\hline \multicolumn{2}{|c|}{ Organics } \\
\hline $\begin{array}{l}\text { Semivolatile organic } \\
\text { compounds }\end{array}$ & EPA $8270^{\mathrm{b}}$ & 45 \\
\hline $\begin{array}{l}\text { Pesticides and } \\
\text { polychlorinated } \\
\text { biphenyls }\end{array}$ & EPA $8080^{\mathrm{b}}$ & 50 \\
\hline Chlorinated herbicides & EPA $8150^{\mathrm{b}}$ & 135 \\
\hline Phosphorous pesticides & EPA $8140^{\mathrm{b}}$ & 50 \\
\hline
\end{tabular}

U.S. Testing Company, Incorporated, Richland, Washington.

BEPA 1986C.

'Includes: Aldrin, chlordane, chiorobenzilate, 4, 4'-dichlorodiphenyldichloroethane, 4, 4'-dichlorodiphenyldichloroethylene, 4,4'-dichlorodiphenyltrichloroethane, dieldrin, endosulfan I and II, endosulfan sulfate, endrin, heptachlor, heptachlor epoxide, kepone, lindane, (and jsomers), methoxychlor, polychorinated biphenyls, toxaphene.

Includes: 2,4-D, 2,4,5-TP silvex, 2,4,5-T.

Includes: dimehoate, disulfoton, methyl parathion, phorate, tetraethylpyrophosphate. 
Table 7-3. Soil Sample Parameters.

2

3

4

5

6

7

8

9

10

11

12

13

14

15

16
Arsenic

Fluoride

Gross beta

Ion chromatography

Mercury

Total radium

Thallium

Total organic carbon

Total organic halogens Reactivity

Ignitability

Extraction procedure toxic metals

Fluorometric titration for uranium

Volatile organic compounds [8240 (EPA 1986C)]

Semivolatile organic compounds [8270 (EPA 1986c)] 
Table 7-4. Analytical Parameters for All Subsurface Samples.

\begin{tabular}{|c|c|c|}
\hline Parameter or group & Analysis method & Sample size (grams) \\
\hline \multicolumn{3}{|c|}{ Metals } \\
\hline $\begin{array}{l}\text { EP toxic metals, } \\
\text { enhanced }\end{array}$ & EPA $6010^{b}$ & 100 \\
\hline \multicolumn{3}{|c|}{ Ions } \\
\hline Anions ${ }^{c}$ & EPA $300^{\circ}$ & 90 \\
\hline Ammonium & ASTM D $1426-C / D^{d}$ & 70 \\
\hline \multicolumn{3}{|c|}{ Radiological } \\
\hline Gross alpha & EPA $9310^{\circ}$ & 5 \\
\hline Gross beta & EPA $9310^{\circ}$ & 5 \\
\hline
\end{tabular}

12 EP toxic metals, enhanced, include: aluminum, antimony, arsenic, 13 barium, beryllium, boron, cadmium, calcium, chromium, cobalt, copper, iron, 14 lead, lithium, magnesium, manganese, mercury, molybdenum, nickel, potassium, 15 selenium, silicon, silver, sodium, strontium, tin, titanium, vanadium, zinc, 16 zirconium.

17 EEPA 1986C.

18 sulfate.

'Includes: bromide, chloride, fluoride, nitrate, nitrite, phosphate, 20 ASTM (1988). 
3

4

5

6

7

8

9

10

11

12

13

14

15

16

17

18

19

20

21

22

23

24

25

26

27

28

29

Table 7-5. Additional Analytical Parameters for Selected Subsurface Samples.

\begin{tabular}{|l|c|c|}
\hline \multicolumn{1}{|c|}{ Parameter or group } & Analysis method & Sample size (grams) \\
\hline \multicolumn{3}{|c|}{ Ions } \\
\hline Sulfide & EPA $9030^{\mathrm{a}}$ & 45 \\
\hline Cyanide & EPA $9010^{\mathrm{a}}$ & 90 \\
\hline & Radionuclides \\
\hline${ }^{90} \mathrm{Sr}$ & U.S. Testing Method & 5 \\
\hline${ }^{137} \mathrm{Cs}$ & U.S. Testing Method & 100 \\
\hline \multicolumn{3}{|c|}{ Organics } \\
\hline $\begin{array}{l}\text { Volatile organic } \\
\text { Compounds }\end{array}$ & EPA $8240^{\mathrm{a}}$ & $\begin{array}{c}40 \text { milliliters } \\
\text { duplicate sample }\end{array}$ \\
\hline $\begin{array}{l}\text { Semivolatile organic } \\
\text { Compounds }\end{array}$ & EPA $8270^{\mathrm{a}}$ & 45 \\
\hline $\begin{array}{l}\text { Pesticides and } \\
\text { polychlorinated } \\
\text { biphenyls }\end{array}$ & EPA $8080^{\mathrm{a}}$ & 50 \\
\hline Chlorinated herbicides & EPA $8150^{\mathrm{a}}$ & 135 \\
\hline \begin{tabular}{l} 
Phosphorous pesticides \\
\hline
\end{tabular} & EPA $8140^{\mathrm{a}}$ & 45 \\
\hline
\end{tabular}

${ }^{a}$ EPA $(1986 \mathrm{c})$.

Includes: Aldrin, chlordane, chlorobenzilate, $4,4^{\prime}$-dichlorodiphenyldichloroethylene, 4,4'-dichlorodipheny-dichloroethane, 4,4'-dichlorodiphenyldichlorotrichloroethane, dieldrin, endosulfan sulfate, endosulfan I and II, endrin, heptachlor, heptachlor epoxide, kepone, lindane (and isomers), methoxychlor, polychorinated biphenyls, toxaphene.

Includes: $2,4-D, 2,4,5-T P$ silvex, 2,4,5-T.

'Includes: dimehoate, disulfoton, methyl parathion, phorate, tetraethylpyrophosphate. 
$\stackrel{\infty}{\circ}$

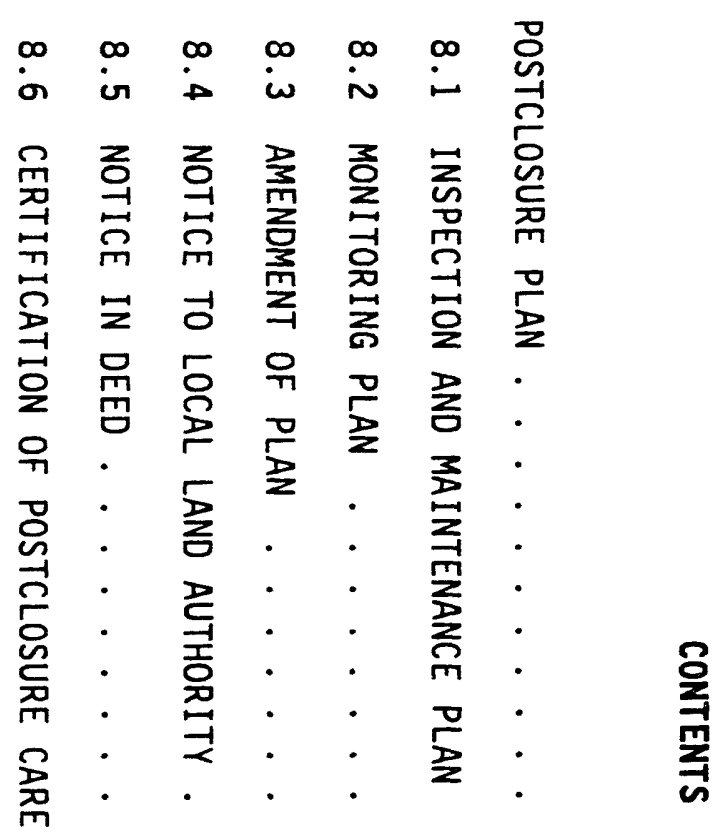


DOE/RL-89-28, Rev . 1

$12 / 15 / 93$

This page intentionally left blank. 


\subsection{POSTCLOSURE PLAN}

This closure/postclosure plan proposes clean closure of the three expansion ponds. Postclosure care will not be required if clean closure is achieved. Final closure/postclosure of other portions of the 216-B-3 Pond system (including the overflow area) and the 216-B-3-3 Ditch will be coordinated with the 200-BP-11 operable unit activities. A final cover design, specific postclosure care requirements, and the postclosure permit application, for those portions of the TSD unit that cannot be clean closed, will be developed following the operable unit RCRA Facility

Investigation/Corrective Measures Study.

\subsection{INSPECTION AND MAINTENANCE PLAN}

The facility will be visually inspected throughout the postclosure care period. Inspections will be conducted in accordance with an established schedule, and observations will be recorded in a logbook that will be maintained throughout the postclosure care period. The information obtained during the inspections will be used to assess when maintenance activities are necessary. Inspection and maintenance activities will be assigned to personnel that are properly trained to conduct these activities.

The following will be checked during the scheduled inspections as appropriate:

- Condition of the security control devices

- Condition of vegetative cover

- Animal activity such as burrows

- Condition of groundwater monitoring wells including locks, guardposts, and pumps.

Following inspections, maintenance activities will be initiated to correct any problems noted during the inspection.

\subsection{MONITORING PLAN}

The current groundwater monitoring program for B Pond is described in Chapter 5.0. Monitoring will continue in accordance with this program through closure of the TSD unit. If it is determined that postclosure care is required for the TSD unit, the program will be modified, as necessary, to meet a11 the requirements of WAC 173-303-645. 


\subsection{AMENDMENT OF PLAN}

The postclosure plan may be amended any time during the active life of the facility or during the postclosure care period. The DOE-RL must submit a written request to authorize a change in the approved postclosure plan whenever (1) changes in operating plans or facility design affect the approved postclosure plan or (2) events that occur during the active life of the facility, including partial and final closure, affect the approved postclosure plan.

The approved postclosure plan will be amended by submitting a written request to Ecology and the EPA to authorize a change to the approved postclosure plan. The written request will include a copy of the amended postclosure plan for approval. The request will be submitted at least 60 days before the proposed change in facility design or operation or no later than 60 days after an unexpected event has occurred that has affected the postclosure plan.

\subsection{NOTICE TO LOCAL LAND AUTHORITY}

No later than the submission of the certification of closure, the DOE-RL will submit to the Benton County Land Planning Department, Ecology, and the EPA a survey plat indicating the location and dimensions of the 216-8-3 Pond System with respect to permanently surveyed benchmarks. The survey plat submitted will (1) be prepared and certified by a professional 1 and surveyor and (2) contain a note, prominently displayed, that states the DOE-RLs obligation to restrict disturbance of the dangerous waste disposal unit in accordance with the requirements of WAC 173-303-610(a).

In addition, no later than 60 days after certification of closure, the DOE-RL will submit to the Benton County Land Planning Department a record of the type, location, and quantity of dangerous waste disposed within the facility.

\subsection{NOTICE IN DEED}

Within 60 days of the certification of closure, the DOE-RL wi11, in accordance with state regulations, sign, notarize, and file for recording, the following notice. The notice will be sent to the Auditor of Benton County, P.0. Box 470, Prosser, Washington, with instructions to record this notice in the General Index. This document normally is reviewed in property title searches.

\section{TO WHOM IT MAY CONCERN}

The United States Department of Energy-Richland Operations Office, an operations office of the United States Department of Energy, which is a department of the United States government, the undersigned, whose local address is the Federal Building, 825 Jadwin Avenue, Richland, Washington, 
1 hereby gives the following notice as required by 40 CFR 264.119(b) and WAC 173-303-610(10) (whichever is applicable):

(a) The United States of America is, and since April 1943, has been in possession in fee simple of the following described lands: (1egal description of the 216-B-3 Pond System).

(b) The United States Department of Energy-Richland Operations Office, by operation of the 216-B-3 Pond System, has disposed of hazardous and/or dangerous waste under the terms of regulations promulgated by the United States Environmental Protection Agency and the Washington State Department of Ecology (whichever is applicable) at the above described land.

(c) The future use of the above described land is restricted under terms of 40 CFR 264.117(c) and WAC 173-303-610(7)(d) (whichever is applicable).

(d) Any and all future purchasers of this land should inform themselves of the requirements of the regulations and ascertain the amount and nature of waste disposed on the above described property.

(e) The United States Department of Energy-Richland Operations Office has filed a survey plat with the Benton County Planning Department and with the United States Environmental Protection Agency, Region $X$ and the Washington State Department of Ecology (whichever are applicable) showing the location and dimensions of site, and a record of the type, location, and quantity of waste disposed of within the unit.

\subsection{CERTIFICATION OF POSTCLOSURE CARE}

No later than 60 days after completion of the established postclosure care period, the DOE-RL will submit to Ecology a certification of postclosure care. This certification will be signed by both the DOE-RL and an independent professional engineer registered in the state of Washington, stating that postclosure care for the facility was performed in accordance with the approved postclosure plan. The certification will be submitted by registered mai1. Documentation supporting the postclosure certification will be retained and furnished to Ecology upon request.

Owner/Operator Postclosure Certification--The DOE-RL will self-certify with the following document or a document similar to it:

The undersigned, the owner and the operator of the 216-B-3 Pond System, hereby certify that I have reviewed the approved 216-B-3 Pond System Postclosure Plan and made visual inspection of the facility, and to the best of my information and belief, all postclosure activities were performed in accordance with the specifications identified in the approved postclosure plan. (Signature and date) 
Professional Engineer Postclosure Certification--The DOE-RL will engage an independent professional engineer, registered in the state of Washington, to certify that postclosure care for the facility has been conducted in accordance with the approved postclosure $\mathrm{plan}$. The DOE-RL will require the professional engineer to sign the following document or a document similar to it:

The undersigned, an independent registered professional engineer, hereby certify that I have reviewed the approved 216-B-3 Pond System Postclosure Plan and made visual inspection of the facility and to the best of my information and belief, all postclosure activities were performed in accordance with the specifications identified in the approved postclosure plan. (Signature, date, registered professional engineer 1 icense number, business address, and phone number) 
DOE/RL-89-28, Rev. 1 $12 / 15 / 93$

\section{CONTENTS}

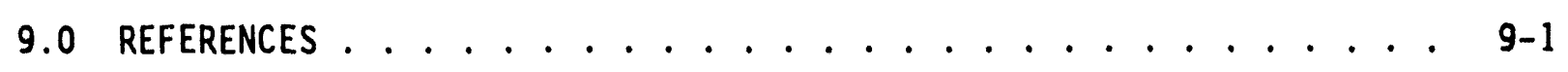

9.1 DOCUMENTS . . . . . . . . . . . . . . . . . 9-1

9.2 CODE OF FEDERAL REgULATIONS AND FEDERAL REgISTER . . . . . . 9-8

9.3 FEDERAL AND STATE ACTS . . . . . . . . . . . . . . 9-8

9.4 REVISED CODE OF WASHINGTON AND WASHINGTON ADMINISTRATIVE CODE 9-9

9.5 U.S. DEPARTMENT OF ENERGY ORDER . . . . . . . . . . . . . . . 9-9 
DOE/RL-89-28, Rev. 1

$12 / 15 / 93$

This page intentionally left blank. 


\subsection{REFERENCES}

\subsection{DOCUMENTS}

Aldrich, R. C., 1987, Radioactive Liquid Wastes Discharged to Ground in the 200 Areas During 1986, RHO-HS-SR-86-3 4Q LIQ P, March 4, 1987, Rockwe 11 Hanford Operations, Richland, Washington.

Allison, L. E., and C. D. Moodie, 1965, "Carbonate," in Methods of Soil Analysis, Part 2, Edited by C. A. Black, American Society of Agronomy, Madison, Wisconsin, pp. 1379-1396.

ASTM, 1988, Annual Book of ASTM Standards, American Standard Testing Materials, Philadelphia, Pennsylvania.

Baker, V. R., B. N. Bjornstad, A. J. Busacca, K. R. Fecht, E. P. Kiver, U. L. Moody, J. G. Rigby, D. F. Stradline, and A. M. Tallman, 1991, Quaternary Geology of the Columbia Plateau in Morrison, R. B., ed., Quaternary Nonglacial Geology, Conterminous U.S.: Boulder, Colorado, Geological Society of America, The Geology of North America, v, K-2.

Baker, V. R., and R. C. Bunker, 1985, "Cataclysmic Late Pleistocene Flooding From Glacial Lake Missoula: A Review," Quaternary Science Reviews, Vol. 4, pp. 1-41.

Baker, V. R., R. Greely, P. D. Komar, D. A. Swanson, and R. B. Waitt, Jr., 1987, "Columbia and Snake River Plains," Geomorphic Systems of North America, Edited by W. L. Graf, Geological Society of America Centennial Special, Volume 2, Boulder, Colorado, pp. 403-468.

Bela, J. L., 1982, Geologic and Neotectonic Evaluation of North-Central Oregon: The Dalles $1^{\circ} \times 2^{\circ}$ Quadrangle, GMS-27, Oregon Department of Geology and Mineral Industries, Portland, Oregon.

Bjornstad, B. N., 1984, Suprabasalt Stratigraphy Within and Adjacent to the Reference Repository Location, RHO-BWI-DP-039, Rockwel1 Hanford Operations, Richland, Washington.

Bjornstad, B. N., 1985, "Late Cenozoic Stratigraphy and Tectonic Evolution Within a Subsiding Basin, South-Central Washington," Abstracts with Program, Geological Society of America, Vol. 17 (7), p. 524.

Black, R. F., 1979, Clastic Dikes of the Pasco Basin, Southeastern Washington, RHO-BWI-C-64, Rockwell Hanford Operations, Richland, Washington.

Bretz, J. H., T. U. Smith, and G. E. Neff, 1956, "Channeled Scabland of Washington; New Data and Interpretations," Geological Society of America Bulletin, Vol. 67(8), pp. 957-1049. 
DOE/RL-89-28, Rev. 1

$12 / 15 / 93$

Brown, D. J, 1960, An Eolian Deposit Beneath 200 West Area, HW-67549, General Electric Co., Richland, Washington.

Connelly, M. P., Borghese, J. V., Delaney, C. D., Ford, B. H., Lindberg, J. W., Trent, S. J., 1992, Hydrogeologic Model for the 200 East Groundwater Aggregate Area, WHC-SD-EN-TI-019.

Connor, J. E., 1993, Hydrology, Hydraulics, and Geomorphology of the Bonneville Flood, U.S.G.S. Special Paper \#274, Geological Society of America, Boulder, Colorado.

Coony, F. M., D. B. Howe, and L. J. Voigt, 1988, Westinghouse Hanford Company Effluent Releases and Solid Waste Management Report for 1987: 200/600/1100 Areas, May 1988, WHC-EP-0141, Westinghouse Hanford Company, Richland, Washington.

Coony, S. M. and S. P. Thomas, 1989, Westinghouse Hanford Company Effluent Discharges and Solid Waste Management Report for Calendar Year 1988: 200/600 Areas, June 1989, WHC-EP-0141-1, Westinghouse Hanford Company, Richland, Washington.

DOE, 1988, Consultation Draft Site Characterization Plan, Reference Repository Location, Hanford Site, Washington, DOE/RW-0164, U.S. Department of Energy, Washington, D.C.

DOE-RL, 1990, 216-B-3 Pond System Closure/Postclosure P7an, DOE/RL 89-28, Rev. O, U.S. Department of Energy-Richland Operations Office, Richland, Washington.

DOE-RL, 1992, 200 East Groundwater Aggregate Area Management Study Report, DOE/RL 92-19, U.S. Department of Energy-Richland Operations Office, Richland, Washington.

Ecology, EPA, and DOE, 1992, Hanford Federal Facility Agreement and Consent Order, 2 vols., as amended, Washingten State Department of Ecology, U.S. Environmental Protection Agency, and U.S. Department of Energy, Olympia, Washington.

EPA, 1985, Guide for Decontaminating Buildings, Structures, and Equipment at Superfund Sites, EPA/600/2-85/028, U.S. Environmental Protection Agency, Cincinnati, Ohio.

EPA, 1986a, RCRA Groundwater Monitoring iechnical Enforcement Guidance Document OSWER-9950.1, U.S. Environmental Protection Agency, Washington, D.C.

EPA, 1986b, Test Methods for Evaluating Solid Waste: Physical/Chemical Methods, SW-846, 3rd Edition, as revised, U.S. Environmental Protection Agency, Washington, D.C. 
EPA, 1987, Data Quality Objectives for Remedial Response Activities Development Process, EPA/540/G-87/003, OSWER Directive 9335.3-01, Office of Emergency and Remedial Response and Office of Waste Programs Enforcement, U.S. Environmental Protection Agency, Washington, D.C.

EPA, 1988a, CERCLA Compliance with Other Laws Manual, OSWER Directive 9234.1-01, August 8, 1988, U.S. Environmental Protection Agency, Office of Remedial Response, Washington, D.C.

EPA, 1988b, Guidance for the Statistical Analysis of Groundwater Monitoring DATA at RCRA Facilities, EPA 530-SW-89-026, U.S. Environmental Protection Agency, Washington, D.C.

Evans, J. C., R. W. Bryce, and D. R. Sherwood, 1989, Hanford Site Groundwater Monitoring for January through June 1988, PNL-6886-1, Pacific Northwest Laboratory, Richland, Washington.

Ford, B. H., 1993, Groundwater Field Characterization Report for the 200 Aggregate Area Management Study, WHC-SD-EN-TI-020, Westinghouse Hanford Company, Richland, Washington.

Frul and, R. M., D. J. Bates, and R. E. Lundgren, 1989, RCRA Ground-Water Monitoring Projects for Hanford Facilities: Progress Report for the Period October 1 to December 31, 1988, PNL-6844, Pacific Northwest Laboratory, Richland, Washington.

Gee, G. W., 1987, Recharge at the Hanford Site: Status Report, PNL-6403, Pacific Northwest Laboratory, Richland, Washington.

Gee, G. W. and J. W. Bauder, 1986, "Particle-Size Analysis," Methods of Soil Analysis, Part 1, Edited by A. Klute, pp. 383-409, American Society of Agronomy, Madison, Wisconsin.

Gee, G. W. and M. E. Dodson, 1981, "Soil Water Content by Microwave Drying: A Routine Procedure," Soil Science Society of America Journal 45(6): 234-1237.

Gephart, R. E., R. C. Arnett, R. G. Baca, L. S. Leonhart, and F. A. Spane, Jr., 1979, Hydrologic Studies Within the Columbia Plateau, Washington: An Integration of Current knowledge, RHO-BWI-ST-5, Rockwe11 Hanford Operations, Richland, Washington.

Goff, F. E., 1981, Preliminary Geology of Eastern Umtanum Ridge, South-Central Washington, RHO-BWI-C-21, Rockwe11 Hanford Operations, Richland, Washington.

Graham, M. J. and W. R. Brown, 1981, Results of the Separations Area Ground-Water Monitoring Network for 1980, RHO-LD-165, Rockwell Hanford Operations, Richland, Washington. 
Graham, M. J., G. V. Last, and K. R. Fecht, 1984, An Assessment of Aquifer Intercommunication in the $B$ Pond Gable Mountain Pond Area of the Hanford Site, RHO-RE-ST-12 P, Rockwell Hanford Operations, Richland, Washington.

Graham, M. J., M. D. Hall, S. R. Strait, and W. R. Brown, 1981, Hydrology of the Separations Area, RHO-ST-42, Rockwe 11 Hanford Operations, Richland, Washington.

Grolier, M. J., and Bingham, J. W., 1978, Geology of Parts of Grant, Adams, and Franklin Counties, East-Central Washington, Bullet in 71, Washington State Department of Natural Resources, Olympia, Washington.

Jaquish, R. E., and P. J. Mitche11, eds., 1988, Environmental Monitoring at Hanford for 1987, PNL 6464, Pacific Northwest Laboratory, Richland, Washington.

Johnson, V. G., 1993, Westinghouse Hanford Company Operational Groundwater Status Report, 1990-1992, WHC-EP-0595, Westinghouse Hanford Company, Richland, Washington.

Jungfleisch, F. L., 1988, Preliminary Evaluation of Hanford Liquid Discharges to Ground, WHC-EP-0052, Westinghouse Hanford Company, Ri.chland, Washington.

Kasza, G. L. and A. L. Schatz, 1989, Groundwater Maps of the Hanford Site Separations Area, January 1989, WHC-EP-0142-2, Westinghouse Hanford Company, Richland, Washington.

Klem, M. J., 1989, Inventory of Chemicals Used at the Hanford Production Plants and Support Operations (1944-1980), WHC-EP-0172, Westinghouse Hanford Company, Richland, Washington.

Klute, A., 1986, "Water Retention: Laboratory Methods," in Methods of Soils Analysis, part 1, Edited by A. Klute, American Society of Agronomy, Madison, Wisconsin, pp. 635-660.

Klute, A., and C. Dirksen, 1986, "Hydraul ic Conductivity and Diffusivity: Laboratory Methods," Methods of Soil Analysis, Part 1, Edited by

A. Klute, American Society of Agronomy, Madison, Wisconsin, pp. 687-732.

Last, G. V., B. N. Bjornstad, M. P. Bergeron, D. W. Wallace, D. R. Newcomer, J. A. Schramke, and M. A. Chamness, 1989 Hydrogeology for the 200 Areas Low-Level Burial Grounds - An Interim Report, 2 vols., PNL6820, Pacific Northwest Laboratory, Richland, Washington.

Law, A. G., J. A. Serkowski, and A. L. Schatz, 1987, Results of the Separations Area Ground-Water Monitoring Network for 1986, RHO-RE-SR-87-24 P, Rockwell Hanford Operations, Richland, Washington. 
Leonhart, L. S., 1979, Surface Hydrologic Investigations of the Columbia Plateau Region, Washington, RHO-BWI-ST-6, Rockwe11 Hanford Operations, Richland, Washington.

Lindsey, K. A., B. N. Bjornstad, J. W. Lindberg, and K. M. Hoffman, 1992, Geologic Setting of the 200 East Area: An Update, WHC-SD-EN-TI-012, Westinghouse Hanford Company, Richland, Washington .

Luttrel1, S. P., M. A. Chamness, and S. Dudziak, 1989, Interim-Status Groundwater Monitoring Plan for the 216-B-3 Pond, WHC-SD-EN-AP-013, Rev. 0, Westinghouse Hanford Company, Richland, Washington.

Malde, H.E., 1968, The Catastrophic Late Pleistocene Bonneville Flood in the Snake River Plain, Idaho, Professional Paper 596, U.S. Geological Survey, Washington, D.C.

McGhan, V. L., 1989, Hanford Wells, PNL-6907, Pacific Northwest Laboratory, Richland, Washington.

Mullineaux, D. R., R. E. Wilcox, W. F. Ebaugh, R. Fryxe11, and M. Rubin, 1978, "Age of the Last Major Scabland Flood of the Columbia Plateau in Eastern Washington," Quaternary Research, Vol. 10, pp. 171-180.

Myers, C. W., S. M. Price, and J. A. Caggiano, M. P. Cochran, W. J. Czimer, N. J. Davidson, R. C. Edwards, K. R. Fecht, G. E. Holmes, M. G. Jones, J. R. Kunk, R. D. Landon, R. K. Ledgerwood, J. T. Lillie, P. E. Long, T. H. Mitchell, E. H. Price, S. P. Reidel, and A. M. Tallman, 1979, Geologic Studies of the Columbia Plateau, A Status Report, RHO-BWI-ST-4, Rockwell Hanford Operations, Richland, Washington.

Nelson, R. E., 1982, "Carbonate and Gypsum," Methods of Soil Analysis, Part 2, Edited by A. L. Page, R. H. Miller, and D. R. Keeney, American Society of Agronomy, Madison, Wisconsin, pp. 181-197.

Newcomb, R. C., 1958, "Ringold Formation of the Pleistocene age in the Type Locality, The White Bluffs, Washington", American Journal of Science, Vol. 256, pp. 328-340.

Newcomb, R. C., J. R, Strand, and F. J. Frank, 1972, Geology and Ground-Water Characteristics of the Hanford Reservation of the U.S. Atomic Energy Commission, Washington, Professional Paper 717, U.S. Geological Survey, Washington, D.C.

NRC, 1982, Safety Evaluation ieport Related to the Operation of WPPSS Nuclear Project No. 2, NUREG-0892 Supplement No. 1, U.S. Nuclear Regulatory Commission, Washington, D.C.

PNL, 1987, Environmental Monitoring at Hanford for 1986, PNL-6120, Pacific Northwest Laboratory, Richland, Washington. 
PNL, 1989, Procedures for Ground-Water Investigations, PNL-6894, Pacific Northwest Laboratory, Richland, Washington.

PSP\&L, 1981, Skagit/Hanford Nuclear Project, Application for Site Certification/Environmental Report, Vol. 2, Puget Sound Power and Light Co., Bellevue, Washington.

PSP\&L, 1982, Skagit/Hanford Nuclear Project, Preliminary Safety Analysis Report, Vo1. 4, Appendix 20, Amendment 23, Puget Sound Power and Light Co., Bellevue, Washington.

Reidel, S. P., 1984, The Saddle Mountains; The Evolution of an Anticline in the Yakima Fold Belt: American Journal of Science, Vol. 284(8), pp. $942-978$.

Reidel, S. P. and K. R. Fecht, 1981, "Wanapum and Saddle Mountains Basalts of the Cold Creek Syncline Area," Subsurface Geology of the Cold Creek Syncline, RHO-BWI-ST-14, C. W. Meyers and S. M. Price, eds., Rockwell Hanford Operations, Richland, Washington.

Rigby, J. G., and K. Othberg, N. P. Campbel1, L. Hanson, E. P. Kiver, D. F. Stradling, G. D. Webster, 1979, Reconnaissance Surficial Geologic Mapping of the Late Cenozoic Sediments of the Columbia Basin, Washington, Report 79-3, Washington State Department of Natural Resources, Division of Geology and Earth Resources, $01 y m p i a$, Washington.

Roos, R. C. and K. A. Woodworth, 1989, 216-B-3 Pond Characterization of the Hazardous Waste Inventory in the Near Surface Soil and Sediments, WHC-SD-EN-AP-016, Rev. 1, Westinghouse Hanford Company, Richland Washington.

Sax, N. I., 1984, Dangerous Properties of Industrial Materials, 6th ed., Van Nostrand Reinhold Company, Inc., New York, New York.

Sax, N. I. and R. J. Lewis, Sr., 1987, Hawley's Condensed Chemical Dictionary, llth ed., Von Nostrand Reinhold Company, Inc., New York, New York.

Schmincke, H. U., 1964, Petrology, Paleocurrents, and Stratigraphy of the Ellensburg Formation and Interbedded Yakima Basalt Flows, South-Central Washington, Ph.D. Dissertation, Johns Hopkins University, Baltimore, Maryland.

Scott, W. E., K. L. Pierce, J. P. Bradbury, and R. M. Forester, 1982, "Revised Quaternary Stratigraphy and Chronology in the American Falls Area, Southeastern Idaho," B. Bonnichen and R. M. Brechenridge, eds., in Cenozoic Geology of Idaho, Bullet in 26, Idaho Bureau of Mines and Geology, Moscow, Idaho.

Serkowski, J. A., A. G. Law, J. J. Ammerman, and A. L. Schatz, 1988, Results of Ground-Water Monitoring for Radionuclides in the Separations 
Area--1987, WHC-EP-0152, Westinghouse Hanford Company, Richland, Washington.

Smith, R. M., D. J. Bates, and R. E. Lundgren, 1989b, Resource Conservation and Recovery Act Ground-Water Monitoring Projects for Hanford

Facilities: Progress Report for the Period April 1 to June 30, 1989, PNL-7134, Pacific Northwest Laboratory, Richland, Washington.

Smith, R. M., D. J. Bates, and R. E. Lundgren, 1989a, Resource Conservation and Recovery Act Ground-Water Monitoring Projects for Hanford

Facilities: Progress Report for the Period January 1 to March 31, 1989, PNL-6957, Pacific Northwest Laboratory, Richland Washington.

Snedecor, G. W. and W. G. Cochran, 1980, Statistical Methods, 7th ed., The Iowa State University Press, Ames, Iowa.

Sommer, D. J., D. L. Flyckt, V. G. Johnson, A. G. Law, J. C. Sonnichsen, 1989, Liquid Effluent Study Project Plan, WHC-EP-0275, Rev. 2, Westinghouse Hanford Company Defense Waste and Environmental Divisions, Richland, Washington.

Stickney, R. G., 1989, Hanford Radioactive Solid Waste Acceptance Criteria, WHC-EP-0063-1, Westinghouse Hanford Company, Richland, Washington.

Stone, W. A., J. M. Thorp, 0. P. Gifford, and D. S. Hoitink, 1983, Climatological Summary for the Hanford Area, PNL-4622, Pacific Northwest Laboratory, Richland, Washington.

Swanson, D. A., T. L. Wright, P. R. Hooper, and R. D. Bentley, 1979, Revisions in Stratigraphic Nomenclature of the Columbia River Basalt Group, Bulletin 1457-G, U.S. Geological Survey, Washington, D.C.

Tallman, A. M., K. R. Fecht, M. C. Marratt, and G. V. Last, 1979, Geology of the Separations area, Hanford Site, South-Central Washington, RHO-ST-23, Rockwe1l Hanford Operations, Richland, Washington.

Thornbury, W. D., 1965, Regional Geomorphology of the United States, John Wiley and Sons, Inc., New York, New York.

USGS, 1985, Water Resources Data for Washington, Water Year 1983, Water-Data Report WA-83-1, U.S. Geological Survey, Tacoma, Washington, p. 322.

Waitt, R. B., Jr., 1980, "About Forty Last-Glacial Lake Missoula Jokulhlaups Through Southern Washington," Journal of Geology, Vo1. 88, pp.653-679.

WHC-CM-4-10, ALARA Program Manual, Westinghouse Hanford Company Radiological Engineering, Richland, Washington.

WHC-CM-7-7, Environmental Investigations and Site Characterizations Manual, Westinghouse Hanford Company, Richland, Washington. 
WHC-CM-2-14, Hazardous Material Packaging and Shipping, Westinghouse Hanford Company Procurement and Materials Management, Richland, Washington.

WHC-CM-5-16, Nonradioactive Dangerous Waste Packaging and Disposal Requirements, Westinghouse Hanford Defense Waste Engineering, Richland, Washington.

WHC, 1989, Waste Stream Characterization Report, Volume 1-4, August 1989, WHC-EP-0287, Westinghouse Hanford Company, Richland, Washington.

Wilbur, J. S., M. J. Graham, and A. H. Lu, 1983, Results of the Separations Area Ground-Water Monitoring Network for 1982, RHO-RE-SR-83-24 P, Rockwell Hanford Operations, Richland, Washington.

WPPSS, 1981, Final Safety Analysis Report, WPPSS Nuclear Project No. 2, Amendment 18, Washington Public Power Supply System, Richland, Washington.

\subsection{CODE OF FEDERAL REGULATIONS AND FEDERAL REGISTER}

10 CFR 61.55, Waste Classification, Licensing Requirements for Land Disposal of Radioactive Waste

40 CFR 141, National Primary Drinking Water Regulations

40 CFR 143, National Secondary Drinking Water Regulations

40 CFR 264, Standards for Owners and Operators of Hazardous Waste Treatment, Storage, and Disposal Facilities

40 CFR 265, Interim Status Standards for Owners and Operators of Hazardous Waste Treatment, Storage, and Disposal Facilities

40 CFR 761, Polychlorinated Biphenyls (PCBs) Manufacturing, Processing, Distribution in Commerce, and Use Prohibitions

49 CFR 172, Hazardous Materials Tables and Hazardous Materials Communications Requirements and Emergency Response Information Requirements

51 FR 7722, Hazardous Waste Management System; Supplement to Preamble to Final Codification Rule

52 FR 8704, Interim Status Standards for Owners and Operators of Hazardous Waste Treatment, Storage, and Disposal Facilities; Final Rule

\subsection{FEDERAL AND STATE ACTS}

Atomic Energy Act of 1954, 42 USC 2011 et seq. 
Comprehensive Environmental Response, Compensation, and Liability Act of 1980, 42 USC 9601 et seq.

Hazardous and Solid Waste Amendments of 1984, 42 USC 6912(a), 6921, 6922, $6924,6925,6926,6930,6935,6937,6939,6991$, and 6993.

Resource Conservation and Recovery Act of 1976, 42 USC 6901 et seq.

Solid Waste Disposal Act, 42 USC 3251 et seq.

State of Washington Hazardous Waste Management Act of 1976, Revised Code of Washington, Chapter 70.105 et seq., 01ympia, Washington.

Toxic Substances Control Act, 1976, 15 USC 2601 et seq.

\subsection{REVISED CODE OF WASHINGTON AND WASHINGTON ADMINISTRATIVE CODE}

WAC 173-160, Minimum Standards for Construction and Maintenance of Wells

WAC 173-303, Dangerous Waste Regulations

WAC 248-54, Public Water Supplies

\subsection{U.S. DEPARTMENT OF ENERGY ORDER}

5820.2A Radioactive Waste Management 
-

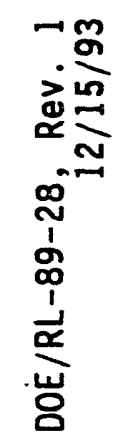

음 


\author{
APPENDICES \\ A GEOLOGIC AND WELL CONSTRUCTION DIAGRAMS \\ B THE B POND GROUNDWATER CHEMISTRY \\ C 216-B-3 POND SYSTEM PHASE 1 SOIL AND SEDIMENT SAMPLING \\ D 216-B-3 POND SYSTEM PHASE 2 SOIL AND SEDIMENT SAMPLING \\ OF $A, B$, AND $C$ LOBES \\ E 216-B-3 POND SYSTEM PHASE 3 VADOSE ZONE SAMPLING
}


DOE/RL 89-28, Rev. 1

$12 / 15 / 93$

1
2
3
4
5

This page intentionally left blank. 
DOE/RL 89-28, Rev. 1

$12 / 15 / 93$

\section{APPENDIX A}

GEOLOGIC AND WELL CONSTRUCTION DIAGRAMS

APP $A-i$ 
DOE/RL 89-28, Rev. 1

This page intentionally left blank. 
2

29

30

31

32

33

34

35

36

37

38

39

40

41

42

43

44

45

46

47

48

49

50

51

\section{APPENDIX A}

\section{GEOLOGIC AND WELL CONSTRUCTION DIAGRAMS}

This appendix comprises geologic and well construction diagrams for wells in the 216-B-3 Pond monitoring network. The lithologic and well construction information was obtained from driller logs and geologist logs. Listed below are well coordinates and elevations.

\begin{tabular}{|c|c|c|c|}
\hline Well number & $\begin{array}{l}\text { Completion } \\
\text { date }\end{array}$ & $\begin{array}{c}\text { Hanford } \\
\text { coordinates }\end{array}$ & $\begin{array}{c}\text { Casing elevation } \\
\text { (ft msl) }\end{array}$ \\
\hline 299-E18-1 & $8 / 88$ & $\begin{array}{l}\text { N38458 } \\
\text { W54458 }\end{array}$ & 720.24 \\
\hline $299-E 32-4$ & $9 / 87$ & $\begin{array}{l}\text { N44985 } \\
\text { W55713 }\end{array}$ & 685.88 \\
\hline $699-40-36$ & $12 / 92$ & $\begin{array}{l}\text { N39830 } \\
\text { W36432 }\end{array}$ & 528.92 \\
\hline $699-40-39$ & $7 / 89$ & $\begin{array}{l}\text { N39878 } \\
\text { W39224 }\end{array}$ & 541.84 \\
\hline $699-40-40 A$ & $10 / 91$ & $\begin{array}{r}710 \\
j 072\end{array}$ & 541.21 \\
\hline $699-40-40 B$ & $10 / 91$ & $\begin{array}{l}\text { N39761 } \\
\text { W40080 }\end{array}$ & 542.18 \\
\hline $699-41-35$ & $11 / 92$ & $\begin{array}{l}\text { N40856 } \\
\text { W35476 }\end{array}$ & 520.38 \\
\hline $699-41-40$ & $6 / 89$ & $\begin{array}{l}\text { W41030 } \\
\text { W40285 }\end{array}$ & 545.94 \\
\hline $699-42-37$ & $11 / 92$ & $\begin{array}{l}\text { N41846 } \\
\text { W37451 }\end{array}$ & 519.40 \\
\hline $699-42-39 A$ & $9 / 91$ & $\begin{array}{l}\text { N41867 } \\
\text { W39485 }\end{array}$ & 558.14 \\
\hline $699-42-39 B$ & $10 / 91$ & $\begin{array}{l}\text { N41816 } \\
\text { W39478 }\end{array}$ & 558.32 \\
\hline $699-42-40 A$ & $7 / 81$ & $\begin{array}{l}\text { N42420 } \\
\text { W40205 }\end{array}$ & 545.53 \\
\hline
\end{tabular}


DOE/RL 89-28, Rev. 1

\begin{tabular}{|c|c|c|c|}
\hline Well number & $\begin{array}{c}\text { Completion } \\
\text { date }\end{array}$ & $\begin{array}{l}\text { Hanford } \\
\text { coordinates }\end{array}$ & $\begin{array}{c}\text { Casing elevation } \\
(\text { ft } \mathrm{ms} 1)\end{array}$ \\
\hline $699-42-41$ & $8 / 91$ & $\begin{array}{l}\text { N42246 } \\
\text { W41196 }\end{array}$ & 567.30 \\
\hline $699-42-42 B$ & $10 / 88$ & $\begin{array}{l}\text { N42473 } \\
\text { W42301 }\end{array}$ & 583.23 \\
\hline $699-43-40$ & $10 / 91$ & $\begin{array}{l}N 43357 \\
\text { W40379 }\end{array}$ & 542.20 \\
\hline $699-43-41 E$ & $5 / 89$ & $\begin{array}{l}\text { N42995 } \\
\text { W40723 }\end{array}$ & 547.89 \\
\hline $699-43-41 F$ & $6 / 89$ & $\begin{array}{l}N 42945 \\
\text { W40721 }\end{array}$ & 551.01 \\
\hline $699-43-41 G$ & $10 / 91$ & $\begin{array}{l}\text { N42969 } \\
\text { W40763 }\end{array}$ & 551.34 \\
\hline $699-43-42 \mathrm{~J}$ & $9 / 88$ & $\begin{array}{l}\text { N42532 } \\
\text { W42274 }\end{array}$ & 581.68 \\
\hline $699-43-43$ & $9 / 88$ & $\begin{array}{l}\text { N42942 } \\
\text { W43184 }\end{array}$ & 579.37 \\
\hline $699-43-45$ & $6 / 89$ & $\begin{array}{l}\text { N42977 } \\
\text { W44644 }\end{array}$ & 597.68 \\
\hline $699-44-39 B$ & $9 / 92$ & $\begin{array}{l}\text { N43426 } \\
\text { W39140 }\end{array}$ & 513.40 \\
\hline $699-44-42$ & $9 / 88$ & $\begin{array}{l}\text { N43783 } \\
\text { W41965 }\end{array}$ & 579.22 \\
\hline $699-44-43 B$ & $5 / 89$ & $\begin{array}{l}\text { N43997 } \\
\text { W43363 }\end{array}$ & 580.12 \\
\hline
\end{tabular}




\section{9-E18-1}

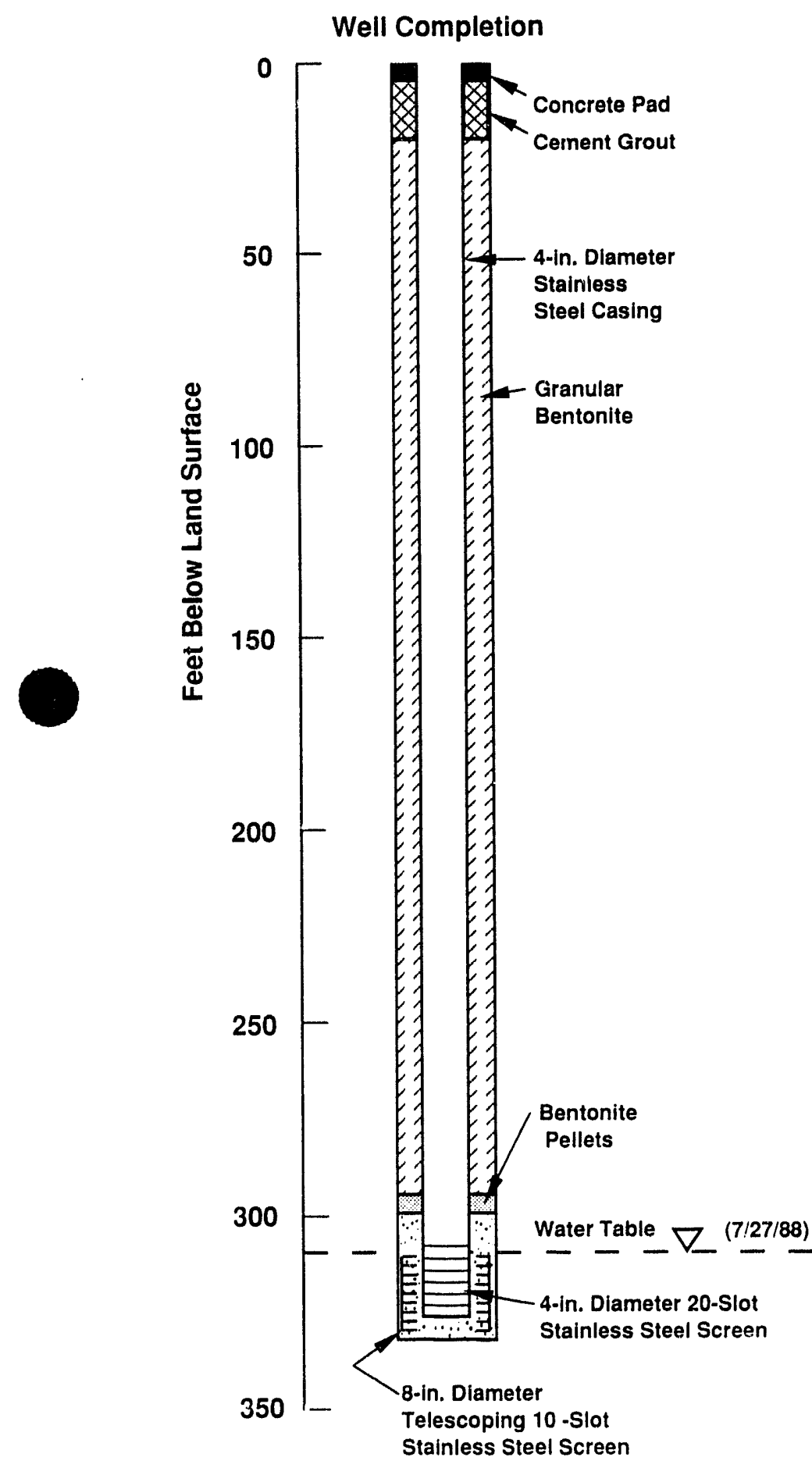

Lithology

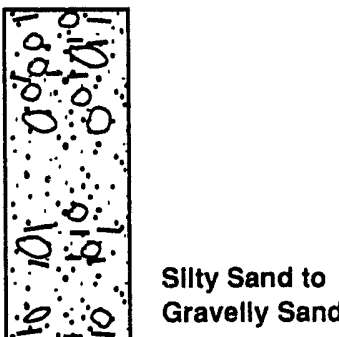

Drilling Comments

Not to Scale

Casing Elevations: $597.68 \mathrm{ft}$

Depth to Water: $187.10 \mathrm{ft}(5 / 89)$

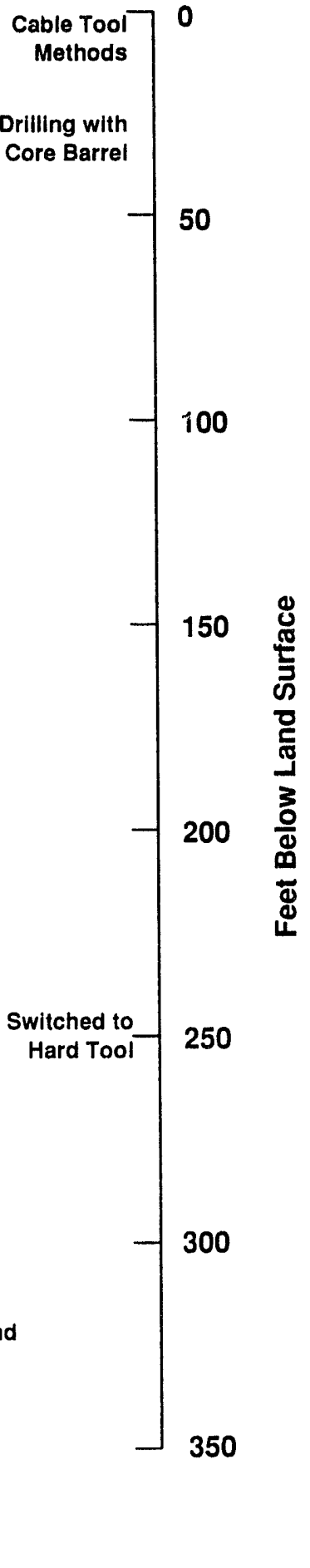


299-E32-4
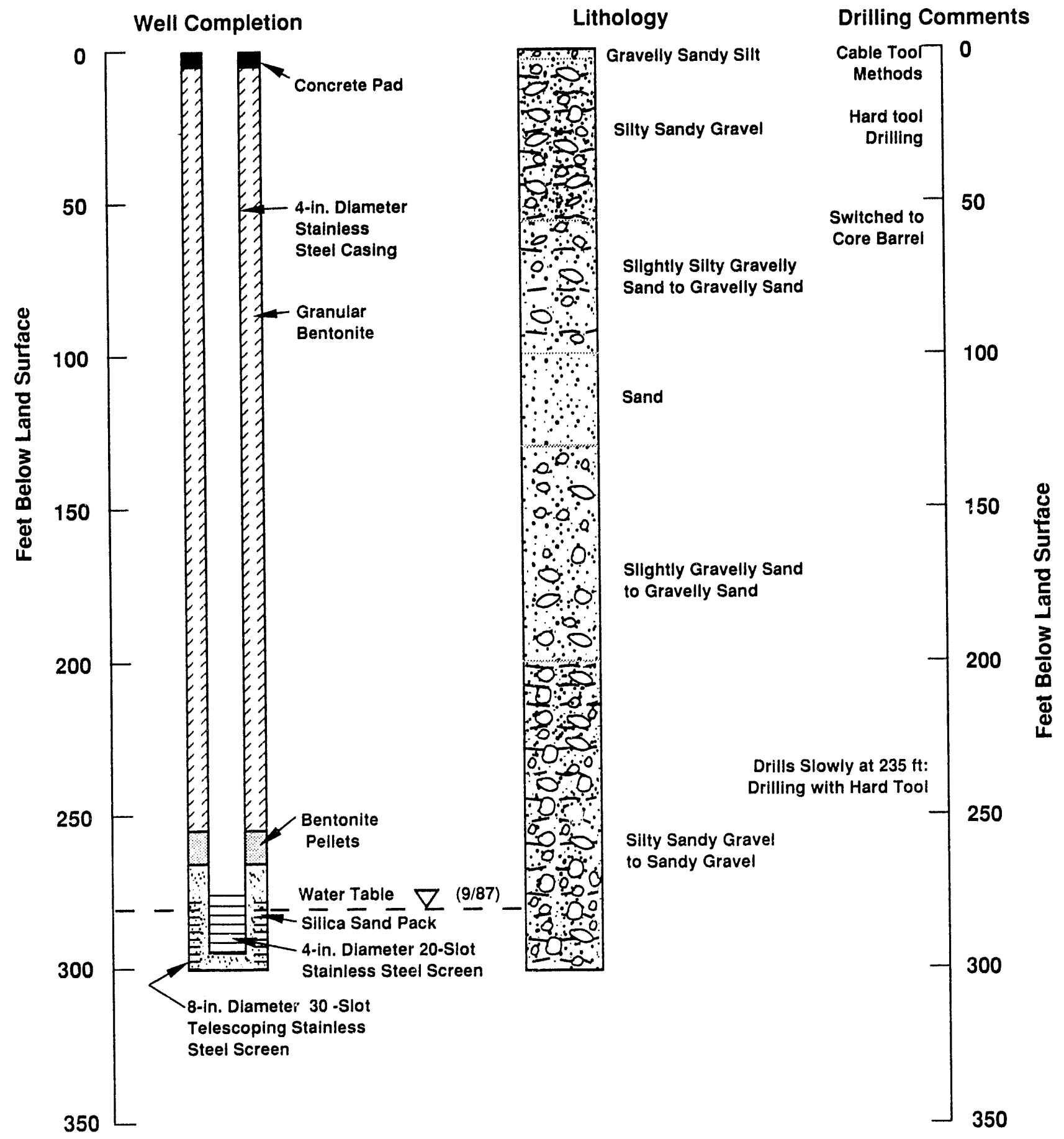

Well Completed 9/87

Casing Elevations: $685.88 \mathrm{ft}$

Not to Scale

Depth to Water: $280.34 \mathrm{ft}(9 / 87)$ 


\section{9-40-39 (BP-5)}
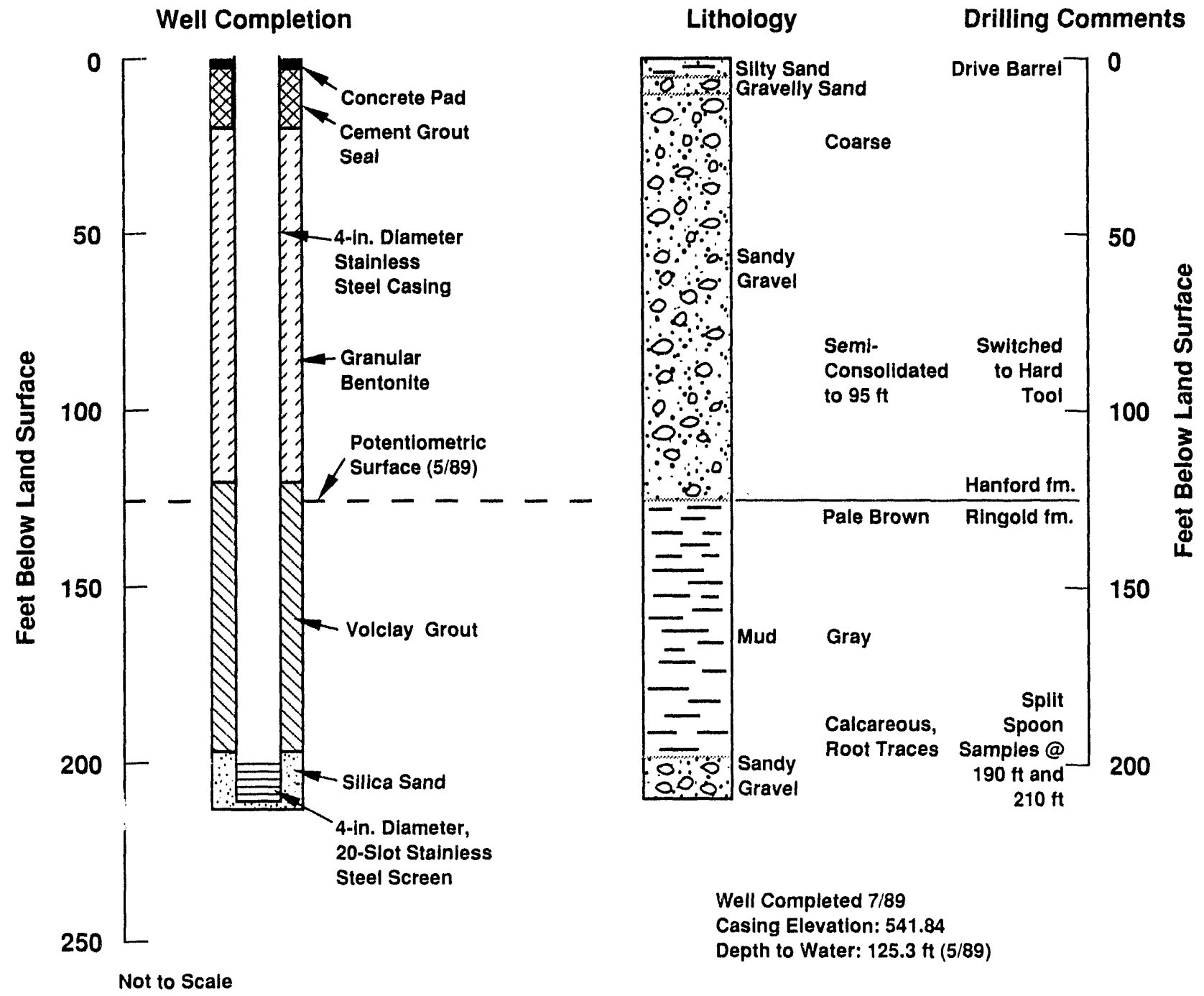

S8908052.7 
699-41-40 (BP-6)

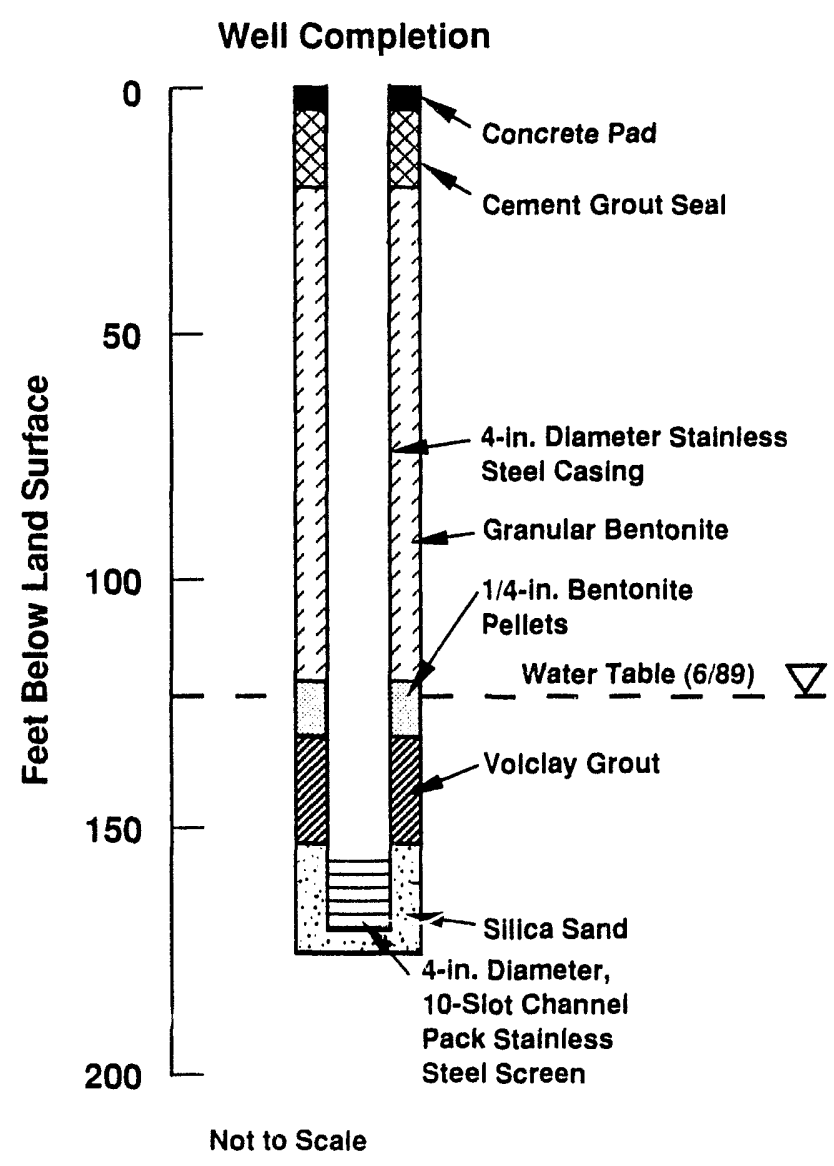

Lithology

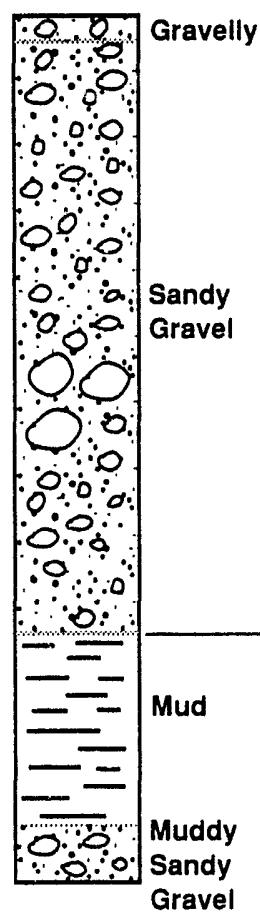

Well Completed 6/89

Casing Elevation: $545.94 \mathrm{ft}$

Depth to Water: $127 \mathrm{ft}(6 / 89)$

Brown

\section{Drilling Comments}

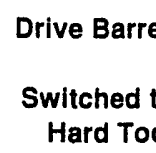

0

Hard Tool

Boulders

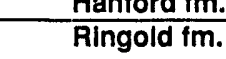

Yellowish Brown

Olive Gray

Calcareous

to Split

Spoon

50

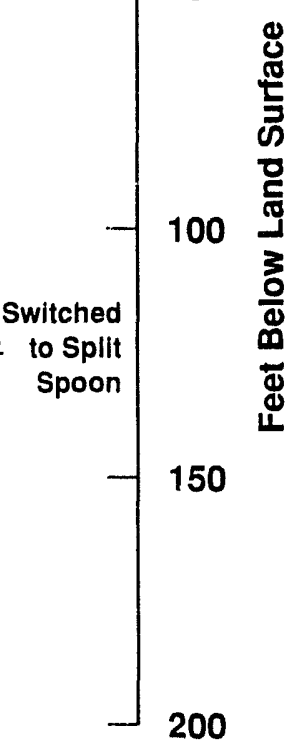

200 


\section{9-42-40A}

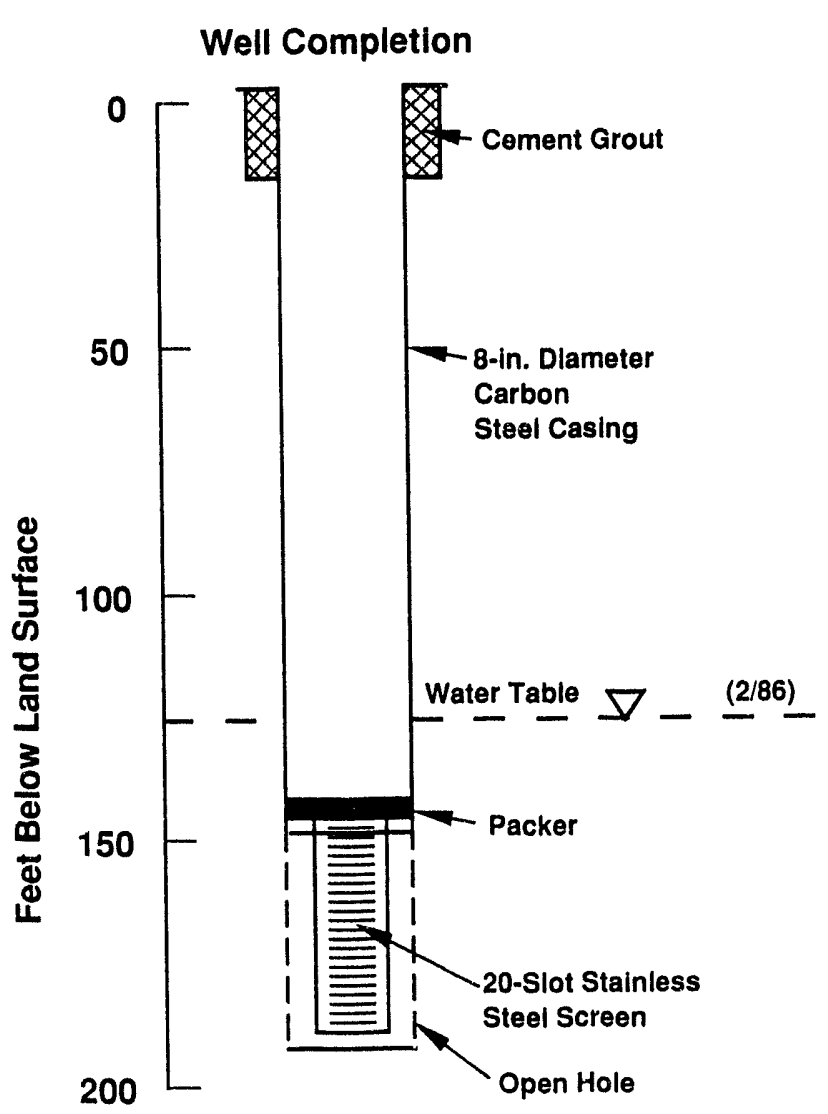

Lithology

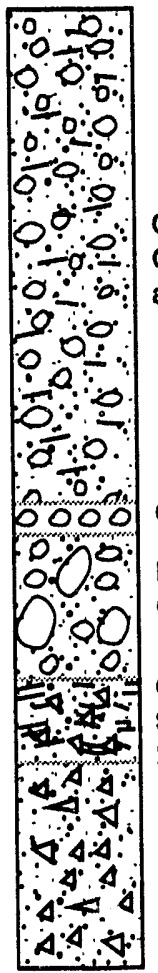

Sandy

Gravel

and Silt
Drilling Comments

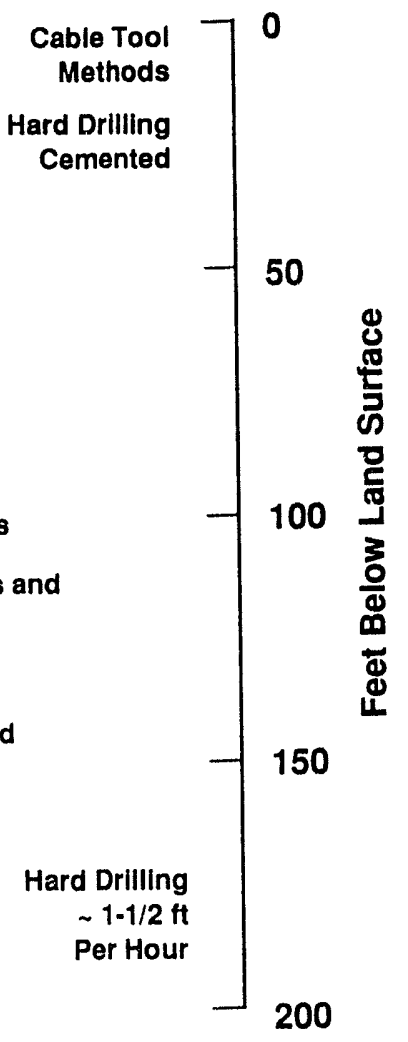

Gravel, Sand
Gravelly Sandy
Silty Clay; Tan
Brown in Color

Gravelly Sandy
Silty Clay; Tan and
Brown in Color

Gravelly Sandy
Silty Clay; Tan
Brown in Color

Cemented

Boulders, Cobbles and

Gravel w/Sand

200

Well Completed 7/81

Casing Elevation: $545.53 \mathrm{ft}$

Depth to Water: $124.50 \mathrm{ft}(12 / 86)$ 
699-42-42B (BP-10)

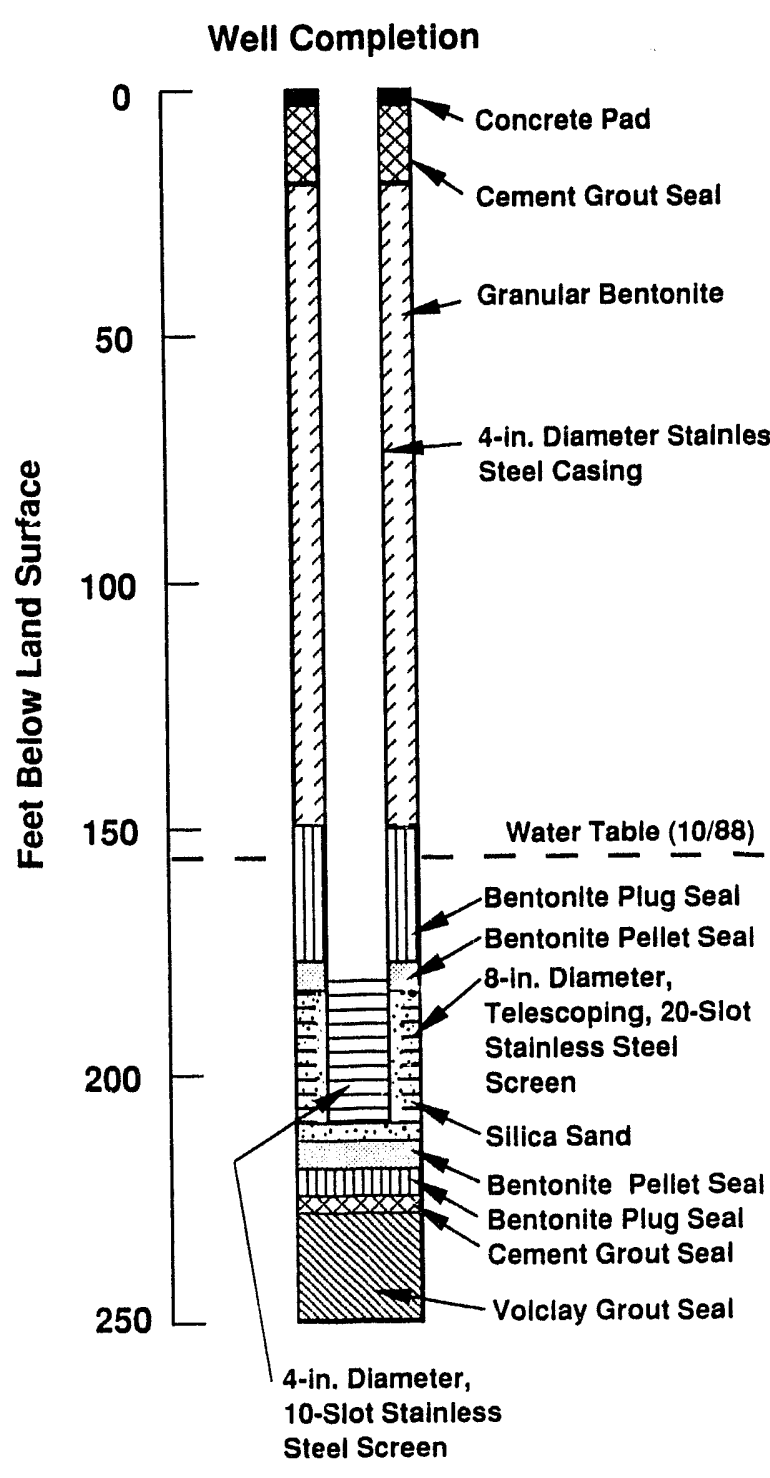

Not to Scale

$\nabla$

Lithology

Drilling Comments

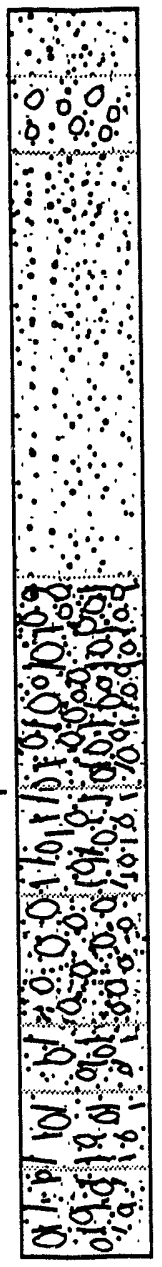

Sand

Slightly Gravelly

Sand

Cable Tool
Methods
Core Barrel:
$0-109 \mathrm{ft}$
Hard Tool:
$109-160 \mathrm{ft}$
$180-250 \mathrm{ft}$

0

Split Spoon

Sand

Samples:

160-180 ft

SIlty Sandy Gravel

Gravelly Silty Clayey

Sand to Gravelly Sandy

Silty Clay

Gravelly Sand to Silty

Sandy Gravel

Slightly Graveily Silty

Clayey Sand

Gravelly Sandy Silty

Clay to Silty Clay

Silty Clayey Sandy Grave! to Slightly Gravelly Silty

Clayey Sand

50

100

\&

200

250

Well Completed 10/5/88

Casing Elevation: $583.23 \mathrm{ft}$

Depth to Water: $160.85 \mathrm{Ht}(10 / 7 / 88)$

79001203.2 
699-43-41E (BP-4)

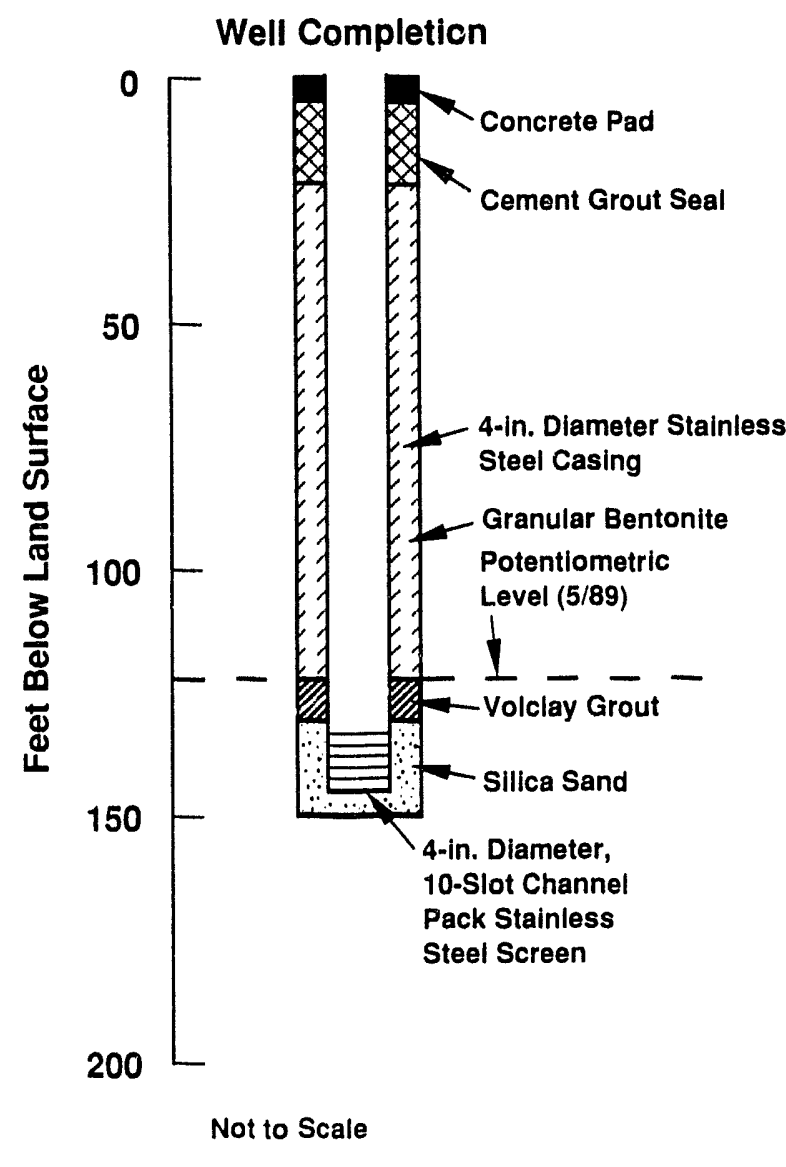

Lithology

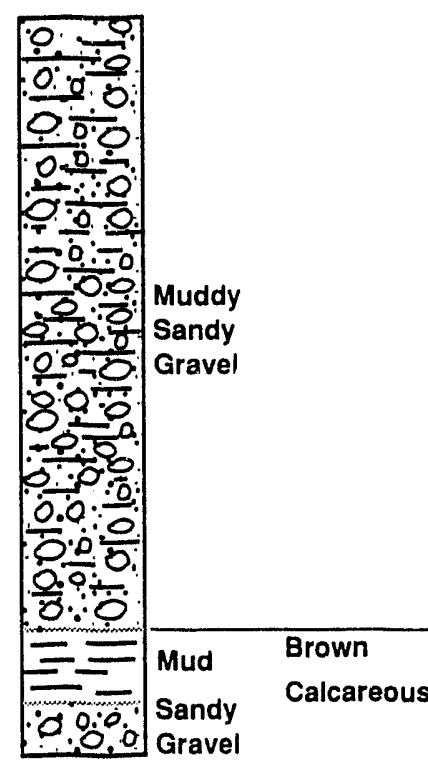

Drilling Comments

Hard Tool 7

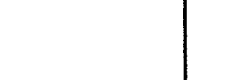

Hanford fm. Ringold fm.

50

100

高

3

응



巡

150

200

Well Completed 5/89

Casing Elevation: $550.86 \mathrm{ft}$

Depth to Water: $125.95 \mathrm{ft}(5 / 89)$ 


\section{9-43-41F (BP-9)}

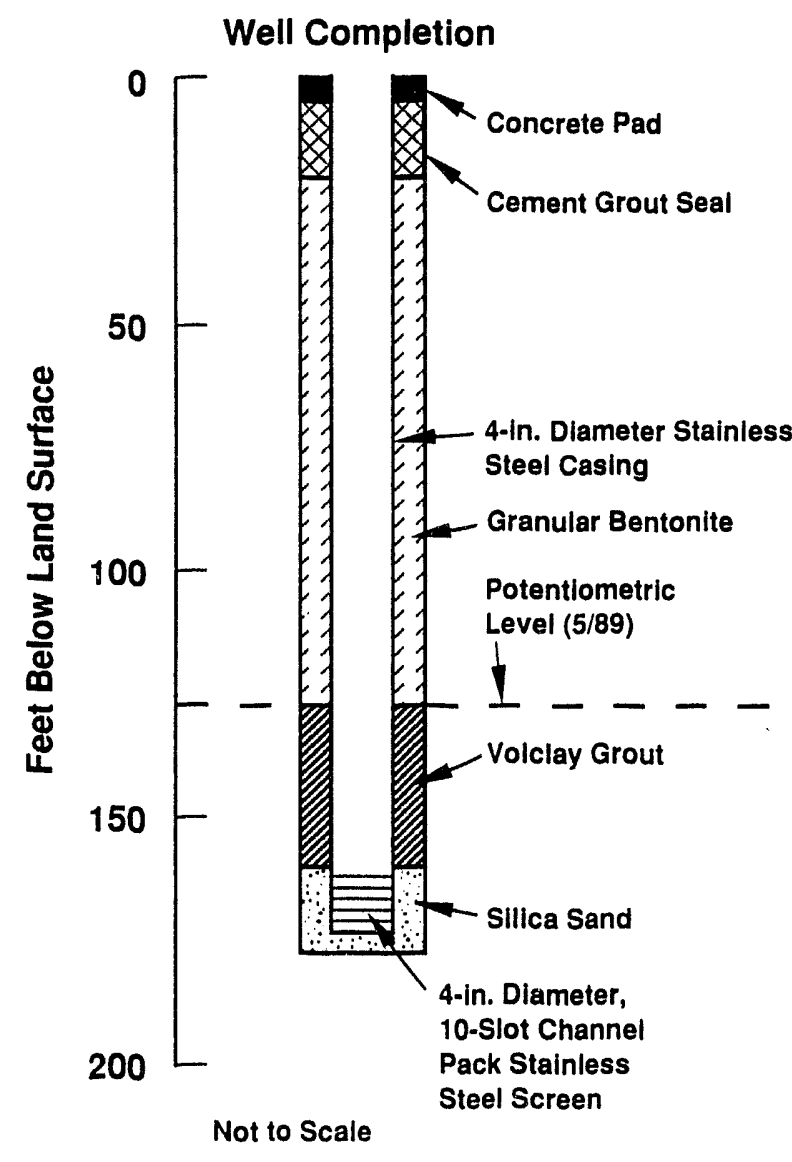

Lithology

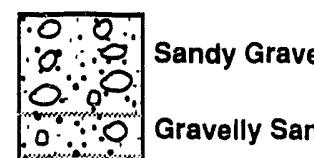

$\begin{array}{cc}0.0 \\ 0 \\ 0 & 0 \\ 0 & 0 \\ 0 & 0\end{array}$

o

0

$\because \div$

$0 \because$ Sandy

$\because 0$ Gravel

$0: \div$

$\therefore$

$\therefore 0$

- 00

0.0

$\because 0.0$ Mud Brown

$\therefore \%$

:0:

$0: 0: 0$

Mud Gray

Split Spoon

Well Completed 6/89

Casing Elevation: $551.01 \mathrm{ft}$

Depth to Water: $126.36 \mathrm{ft}$ (5/89)
Drilling Comments

Drive Barrel

Switch to

Hard Tool

50

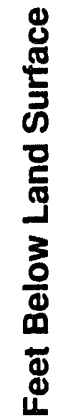

150

200 ous lit Spoon @ $135 \mathrm{ft}$

0

部




\section{9-43-42J (BP-7)}

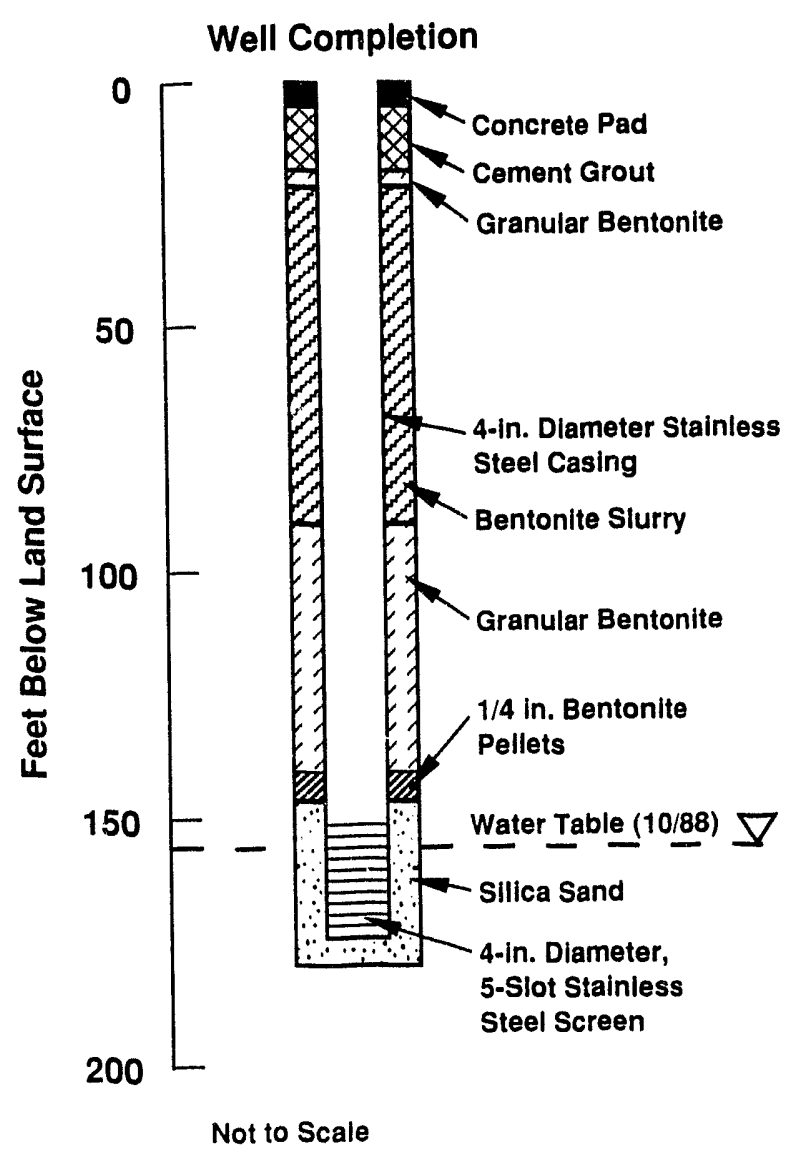

Lithology

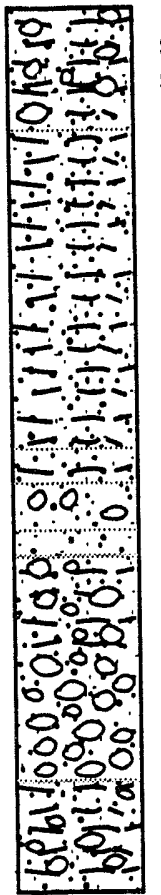

Slightly Gravelly Sandy

Silt to Sandy Gravel

SIlty Sand to Slightly

Sllty Sand

Slightly Gravelly Sand Sand

Sandy Gravel to Silty Sandy Gravel

Gravelly Sandy Silty Clay to Gravelly Silty Clayey Sand
Well Completed 9/2/88

Casing Elevation: $581.68 \mathrm{ft}$

Depth to Water: $157.1 \mathrm{ft}(10 / 7 / 88)$
Drilling Comments

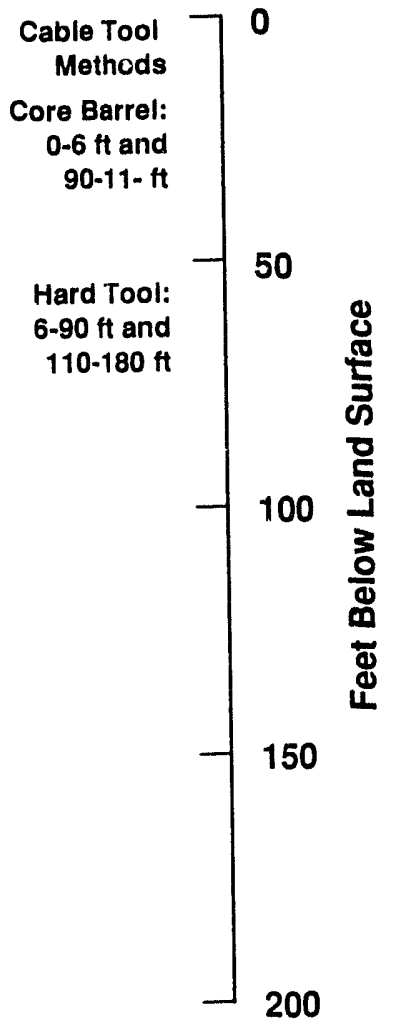




\section{9-43-43 (BP-8)}

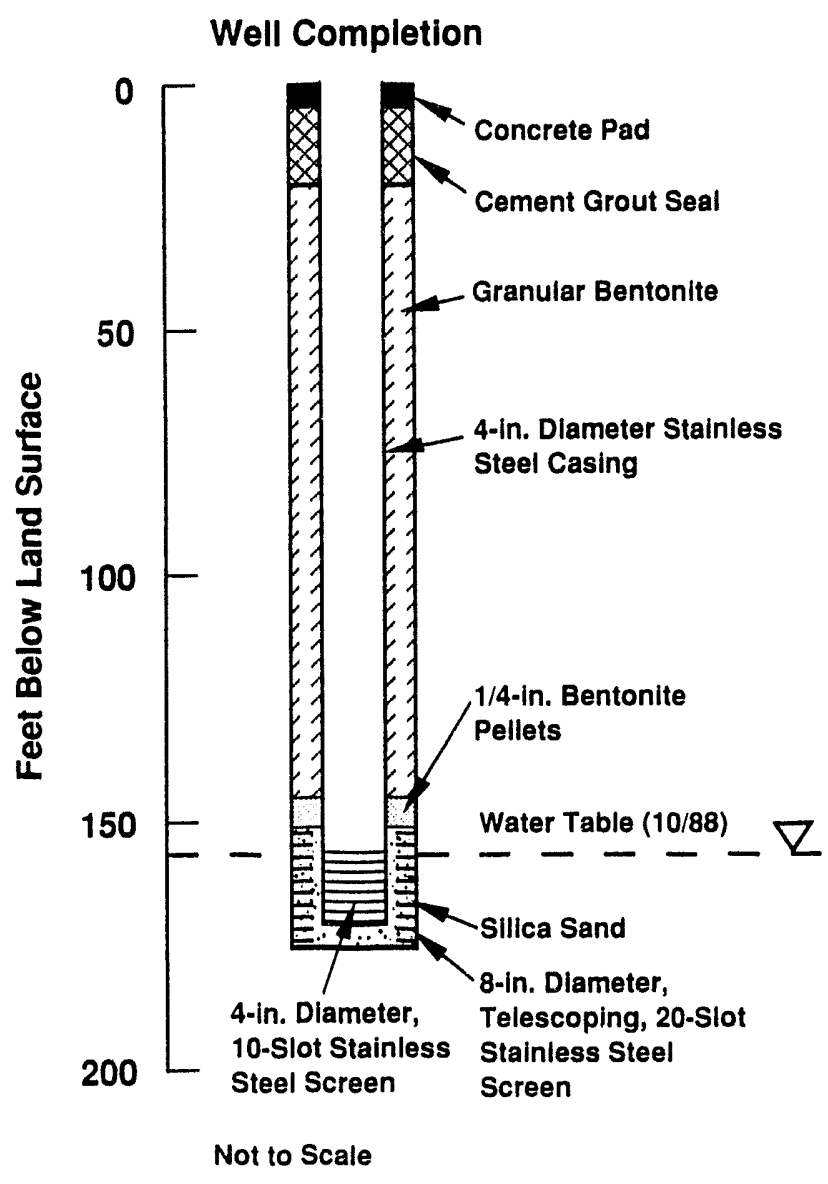

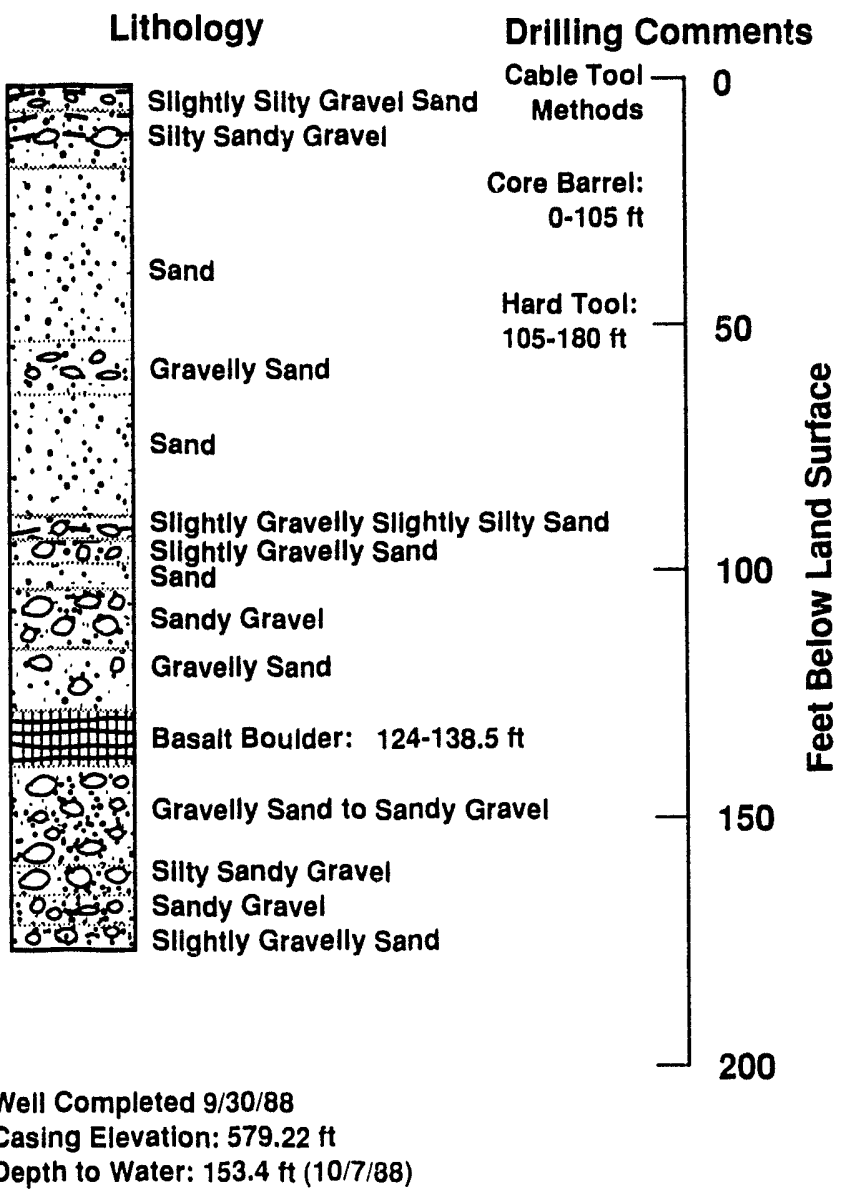


699-43-45 (BP-1)

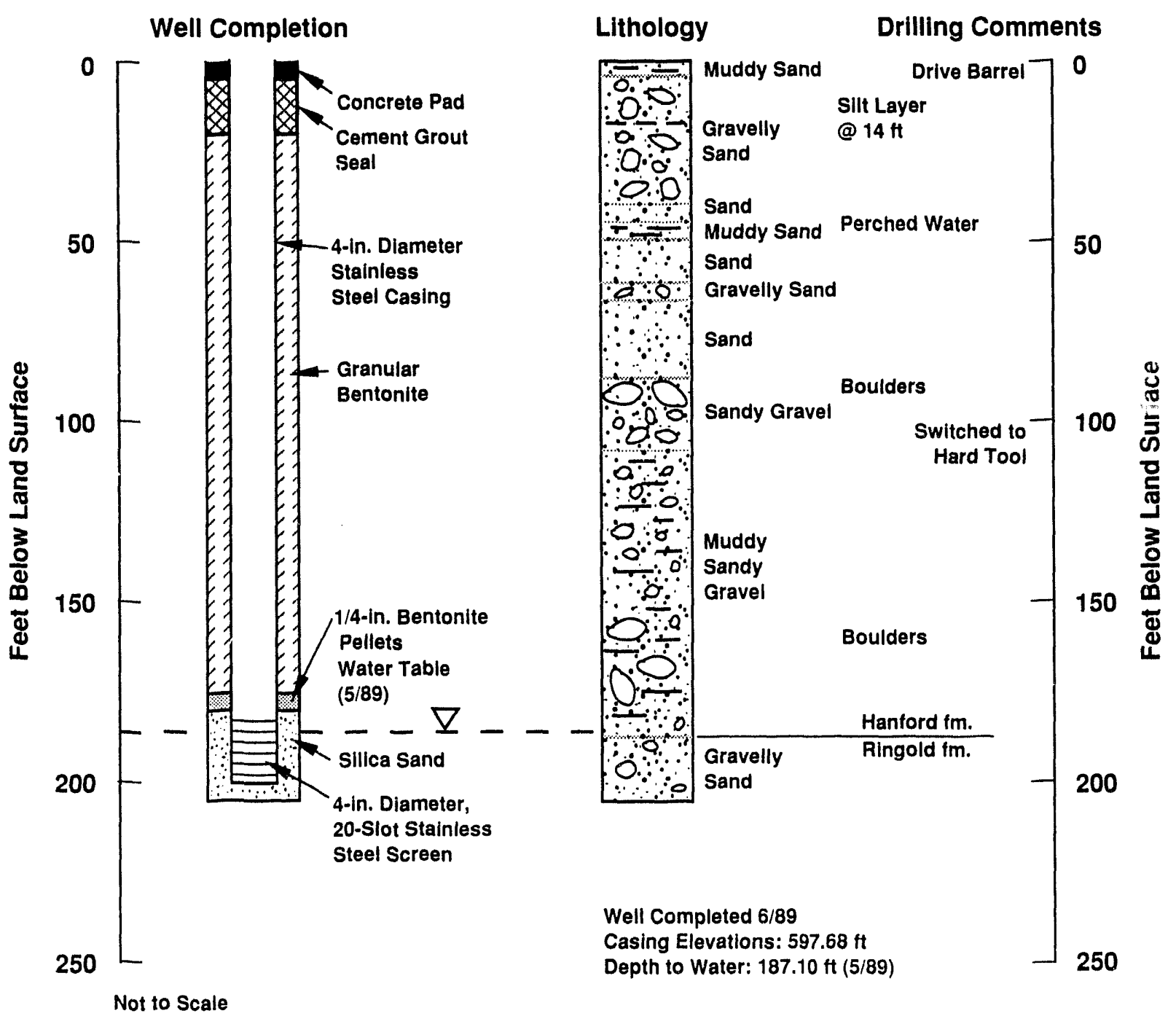


699-44-42 (BP-3)

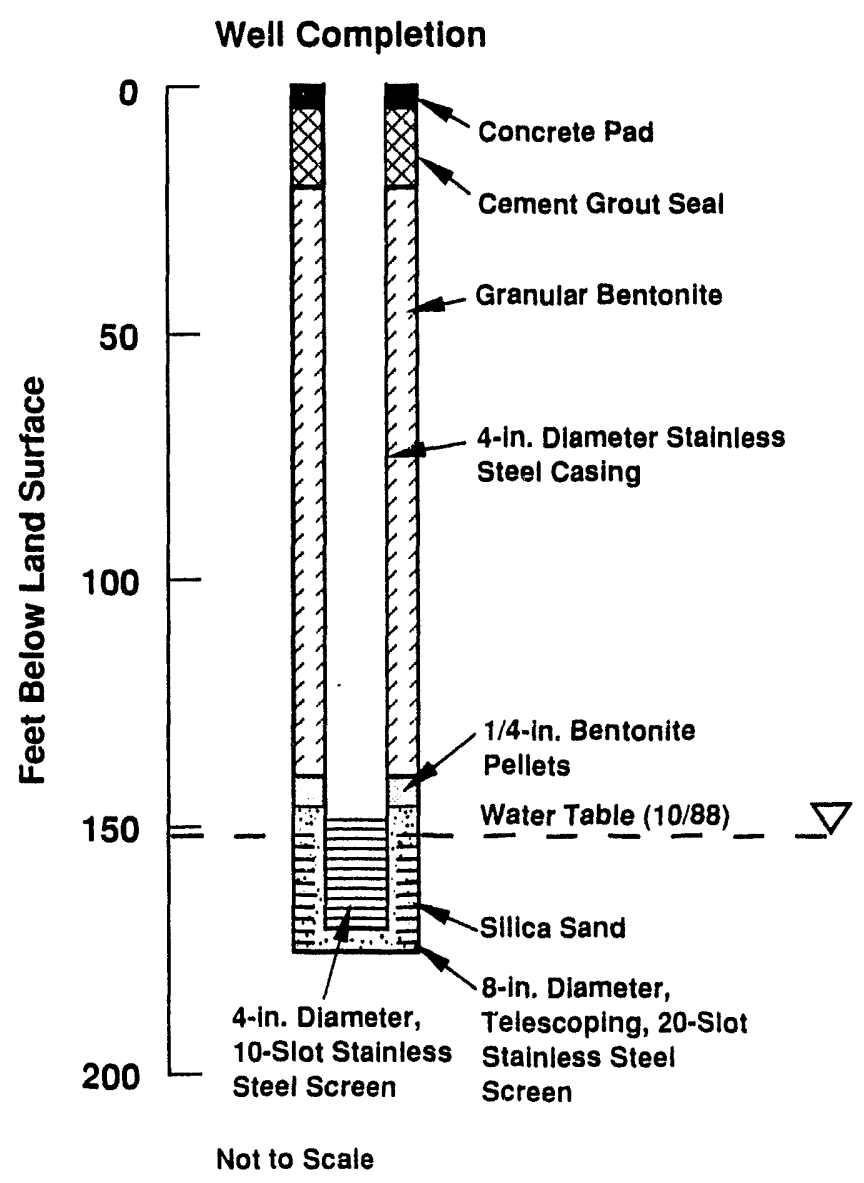

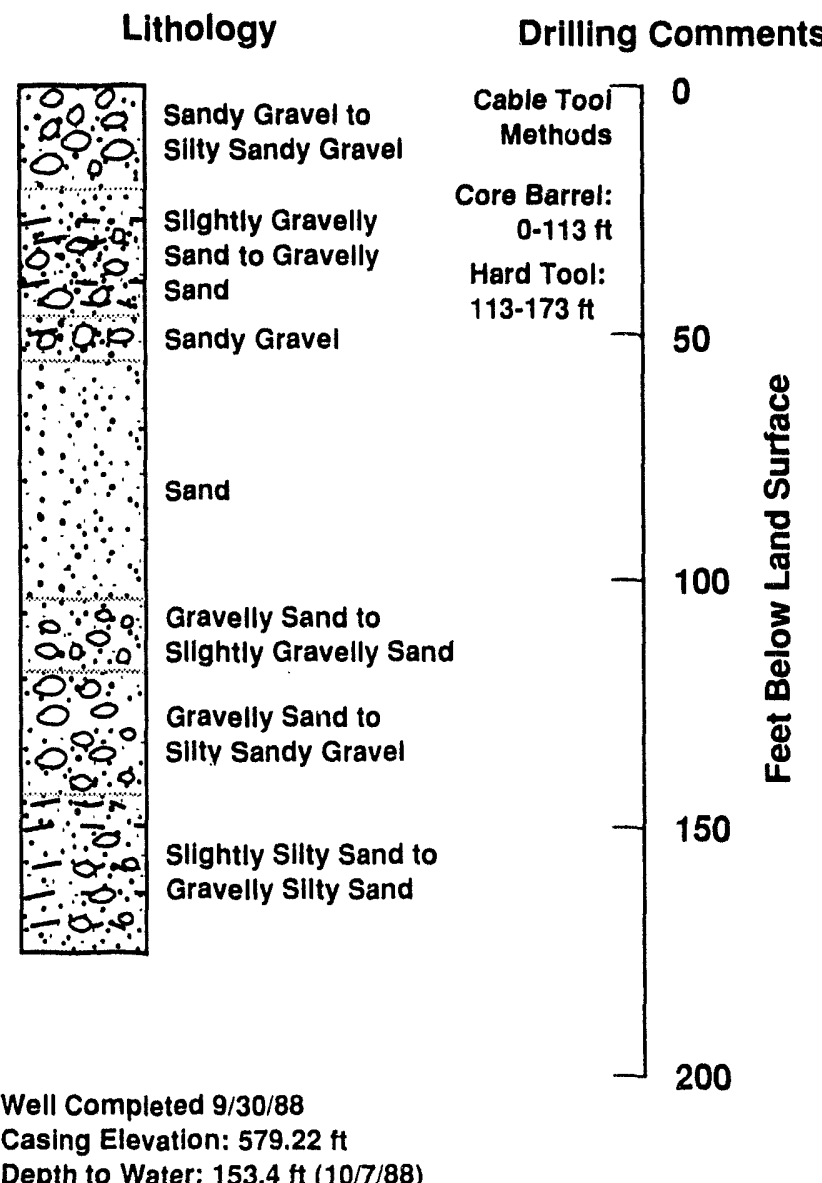




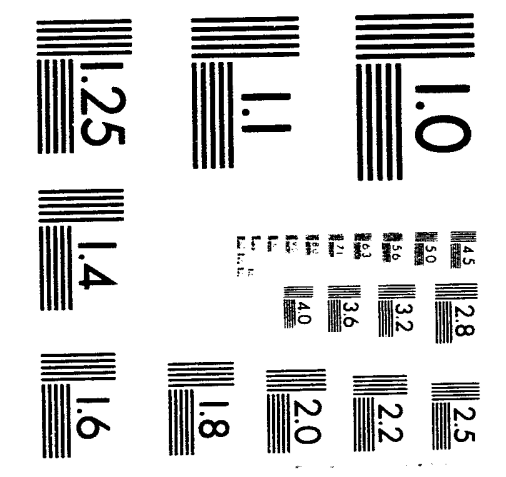



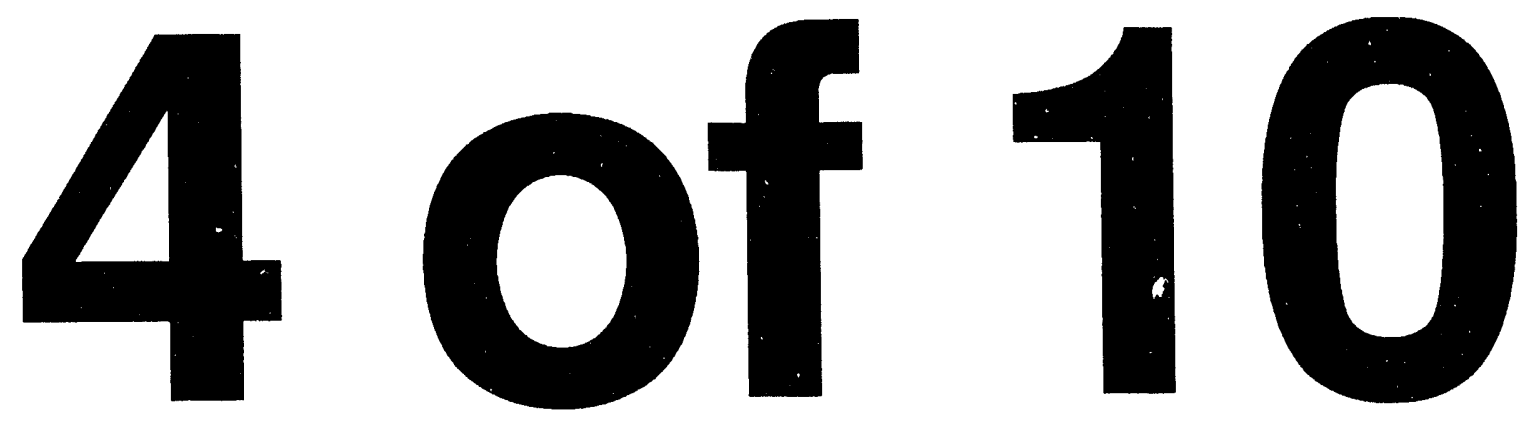


\section{9-44-43B (BP-2)}

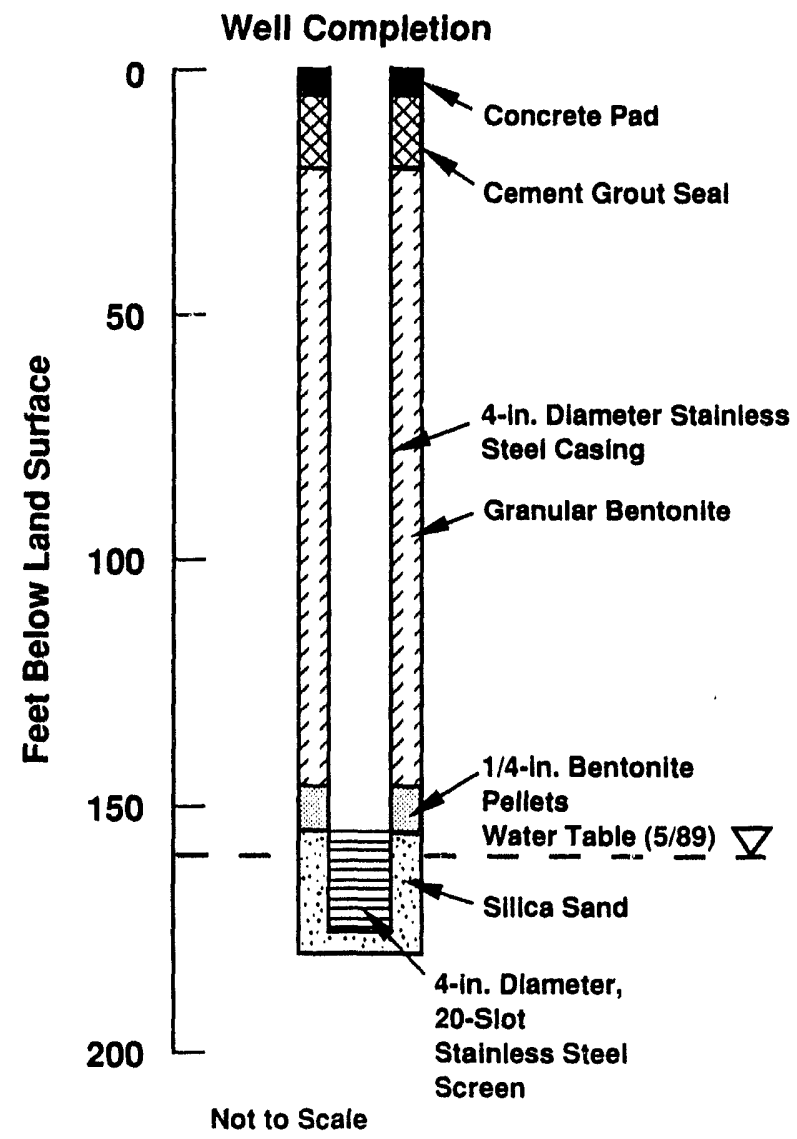

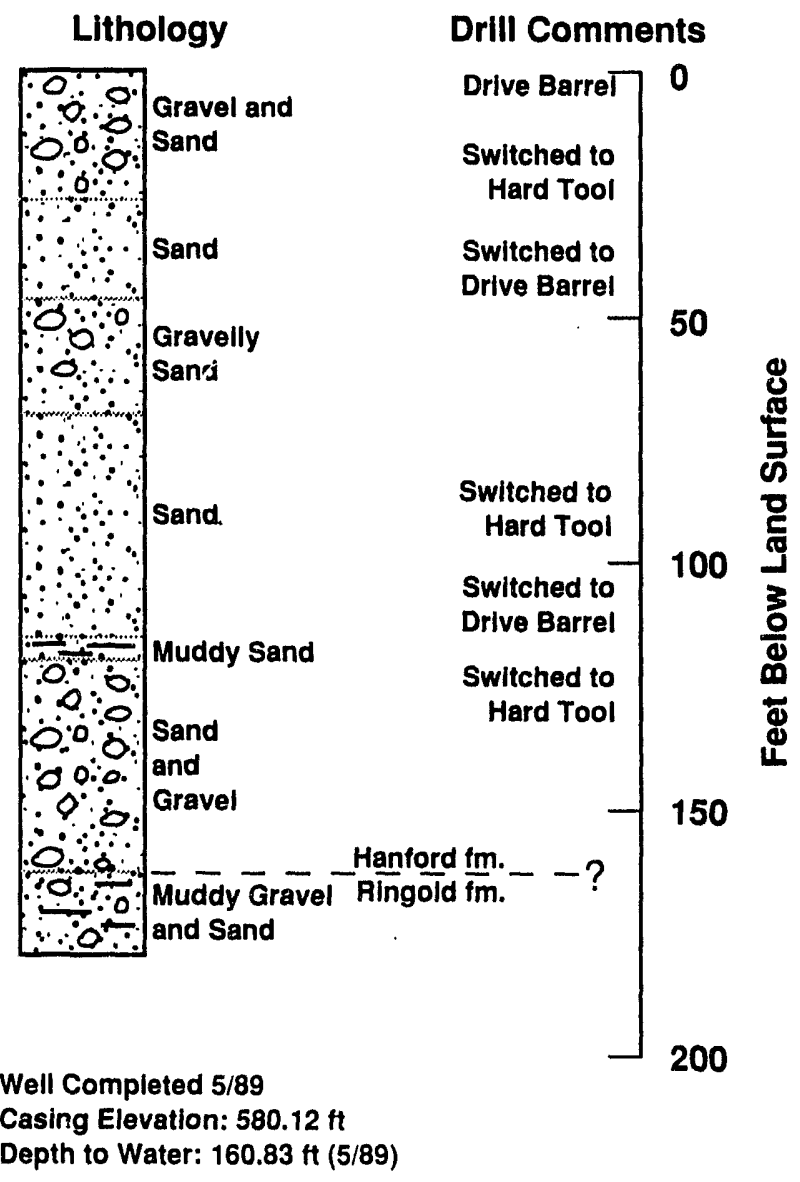


$699-40-40 A$

Well Completion

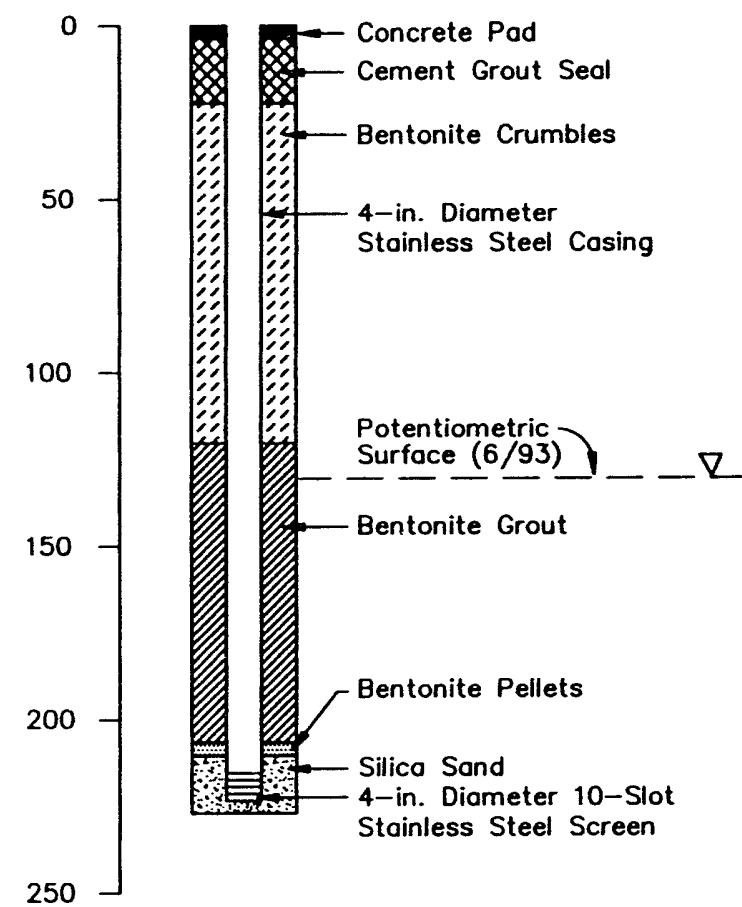

Lithology/Stratigraphy

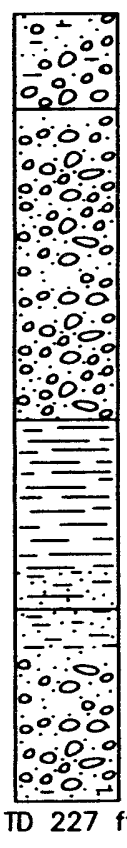

$0-15 \mathrm{ft}$ Silty Sandy Gravel

15 - $75 \mathrm{ft}$ Sondy Gravel

75 - 105 ft Slightly Sandy Gravel

105 - 116 ft Silty Sandy Gravel

Hanford $\mathrm{fm}$.

116 - $130 \mathrm{ft}$ Silty Clay

$130-160$ ft Slightly Silty Clay

160 - 171 ft Slightly Silty Sand

171 - $175 \mathrm{ft}$ Sandy Silt

175 - $185 \mathrm{ft}$ Silty Sond

185 - $190 \mathrm{ft}$ Grovelly Sand

190 - $225 \mathrm{ft}$ Sandy Gravel

225 - 227 ft Silty Sand

Well Completed 10/91

Cosing Elevation $541.21 \mathrm{ft}$

Depth to Woter $130 \mathrm{ft}(6 / 93)$
Drilling Comments

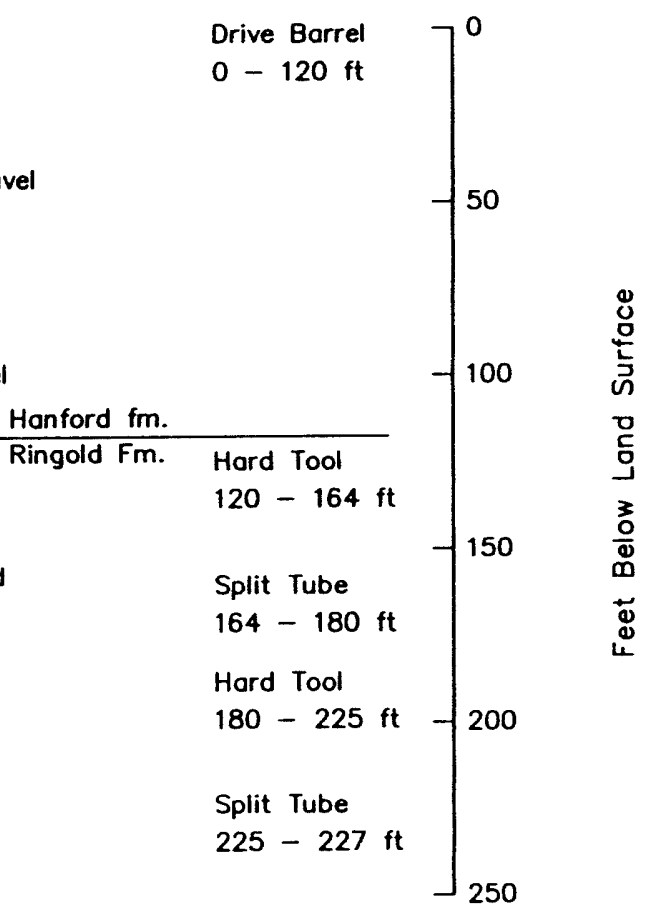

GEN\40-40A 
$699-40-40 B$

Well Completion

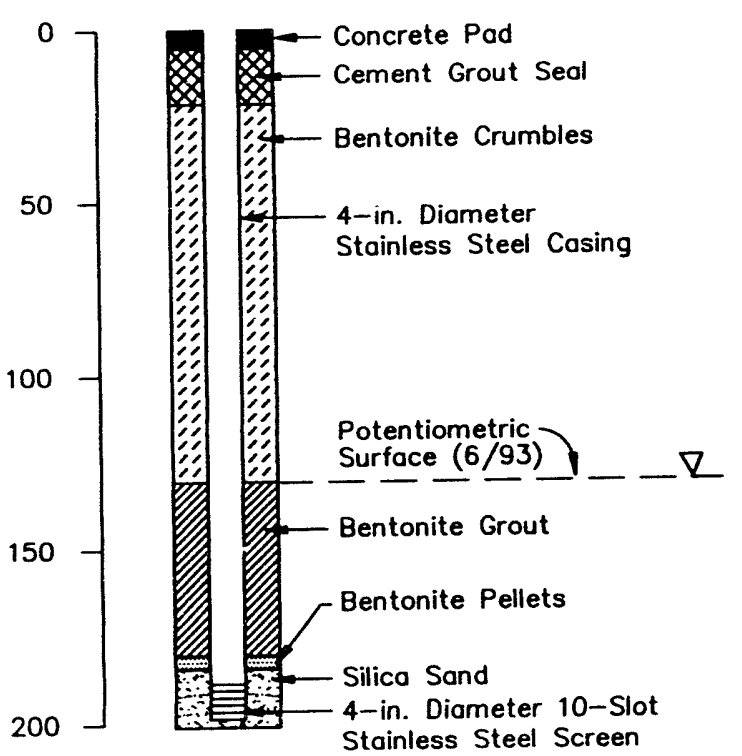

Lithology/Strotigraphy

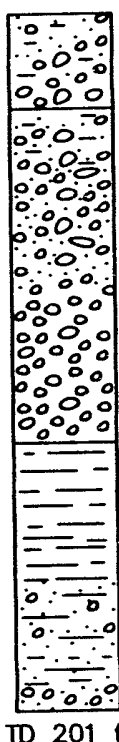

Sandy Gravel

Sandy Gravel

Gravel

Silt/Clay

Silty Sand

Sondy Gravel
Gravelly Silty Sand

Silty Gravelly Sand

Hanford $\mathrm{fm}$

Gravelly Sondy Cloy

Well Compieted 10/91

Casing Elevation $542.18 \mathrm{ft}$

Depth to Water $131 \mathrm{ft}(6 / 93)$
Drilling Comments

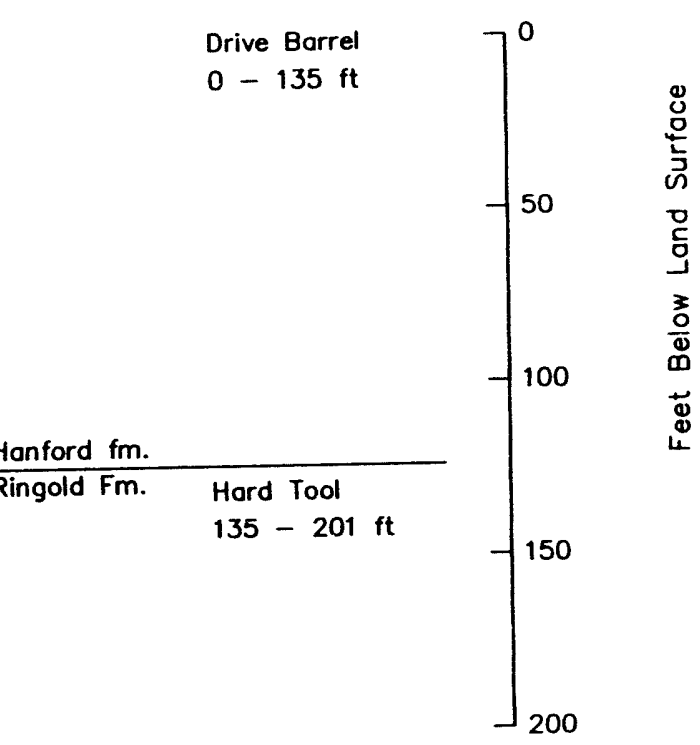

GEN $\backslash 40408$ 
$699-40-36$

Well Completion

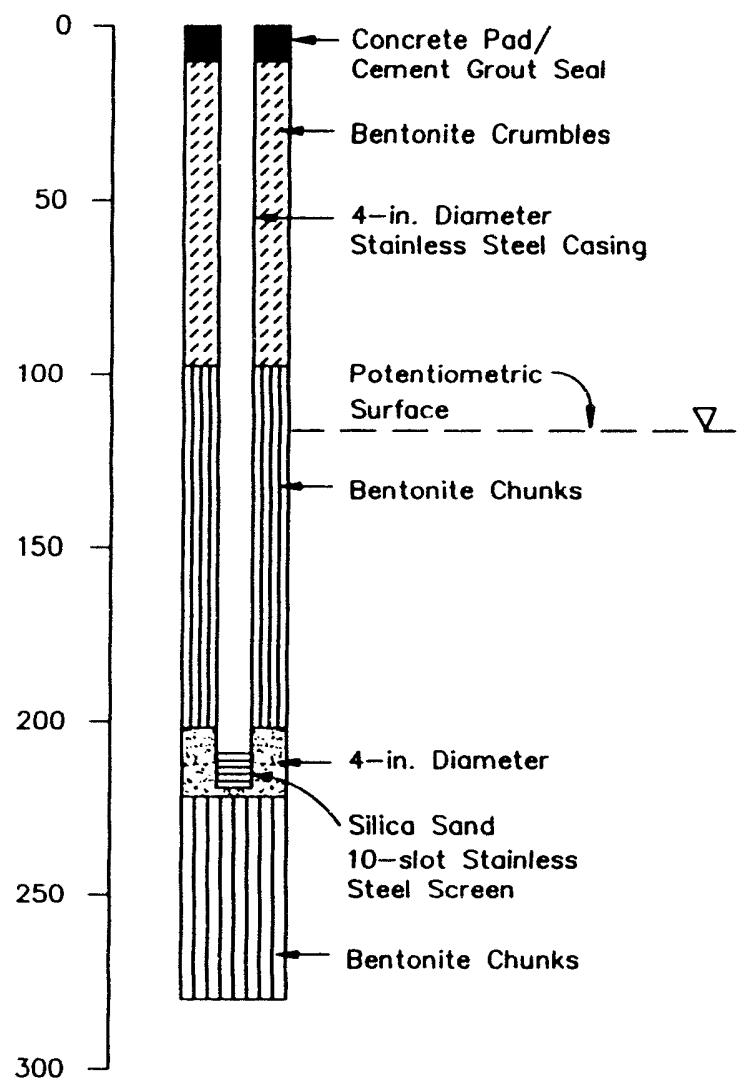

Lithology/Stratigrapliy

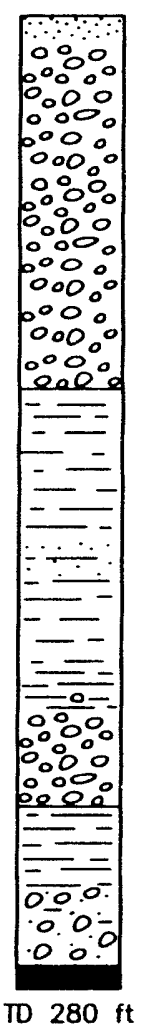

$$
\text { 西 }
$$$$
\begin{aligned}
& 0-4 \mathrm{ft} \text { Eolian Sand } \\
& 4-7 \mathrm{ft} \text { Sandy Silty }
\end{aligned}
$$$$
4 \text { - } 7 \mathrm{ft} \text { Sandy Silty Gravel }
$$$$
7 \text { - } 113 \mathrm{ft} \text { Gravel }
$$$$
49 \text { - } 73.5 \mathrm{ft} \text { Sondy grovel }
$$$$
73.5 \text { - } 80 \mathrm{ft} \text { Silty sandy gravel }
$$$$
113-193 \mathrm{ft} \text { Clay/Silt }
$$

Occasional Sand

Interbeds $(152-155 \mathrm{ft})$

Interbeds $(152-155 \mathrm{ft})$
Slightly Sandy $155-160 \mathrm{ft}$

193 - 198 ft Slightly Grovelly

Silty Clay

198 - $227 \mathrm{ft}$ Sandy Gravel

227 - $250 \mathrm{ft} \mathrm{Clay/Silt}$

250 - 265 ft Silty Sondy Grovel

265 - 272 ft Sandy Gravel

272 - $280 \mathrm{ft}$ Bosolt - Elephant

Drilling Comments

tn. Member

Drive Barrel
$0-160 \mathrm{ft}$

50

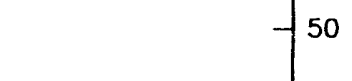

Ringold Fm.

$-100$

巳ั

\section{Well Completed 12/92}

Cosing Elevotion $528.92 \mathrm{ft}$

Depth to Water $118 \mathrm{ft}(6 / 93)$ 
$699-41-35$

Well Completion

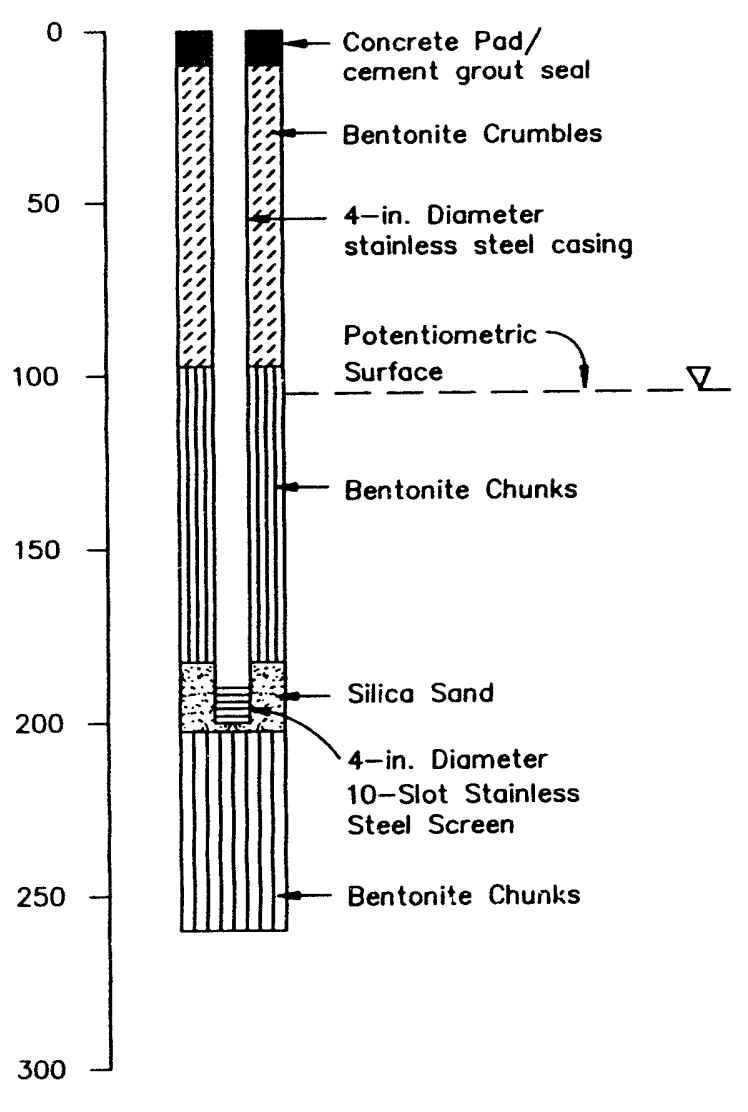

Lithology/Stratigraphy

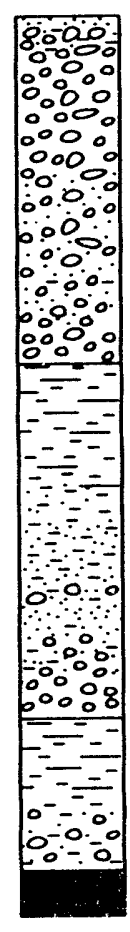

TD $260 \mathrm{ft}$
$0-3 \mathrm{ft}$ Sand

3 - 7 ft Silty Sandy Gravel

7 - $38.5 \mathrm{ft}$ Grovel

38.5 - 49 ft Silty Sandy Grovel

49 - $73.5 \mathrm{ft}$ Sondy Grovel

73.5 - $80 \mathrm{ft}$ Silty Sondy Grovel

80 - $89 \mathrm{ft}$ Sandy Gravel

89 - $101 \mathrm{ft}$ Gravel

$101-138 \mathrm{ft}$ Silt

138 - $143 \mathrm{ft}$ Clayey/Silty Sand

143 - $145.6 \mathrm{ft} \mathrm{Clay/Silt}$

$145.6146 .1 \mathrm{ft}$ Sandy Clay

$146.1147 .6 \mathrm{ft}$ Clayey Sand

147.6 - $155 \mathrm{ft}$ Sandy Clay

155 - $157 \mathrm{ft}$ Slightly Clayey Sand

165 - $170 \mathrm{ft}$ Slightly Clayey Sand

$170-174 \mathrm{ft}$ Sand

174 - $180 \mathrm{ft}$ Gravelly Silty Sand

180 - $188 \mathrm{ft}$ Silty Sondy Grovel

188-203 ft Grovel

203 - $223 \mathrm{ft}$ Clay

$223-230 \mathrm{ft}$ Gravel

$230247 \mathrm{ft}$ Silty Sandy Gravel

Drilling Comments

Well Completed 11/92

Casing Elevation 520.38

Depth to Water $108 \mathrm{ft}(4 / 93)$

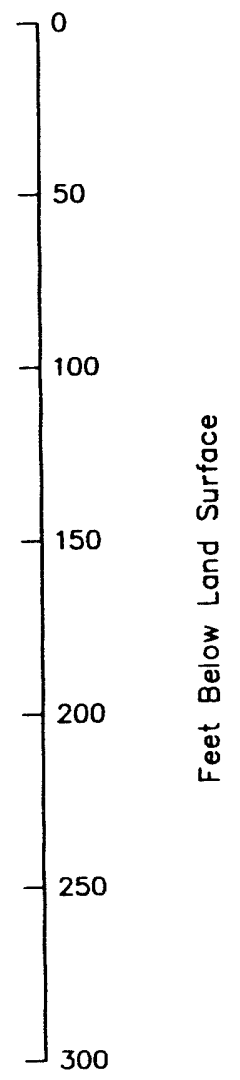

cอN14i-35 
$699-41-42$

Well Completion

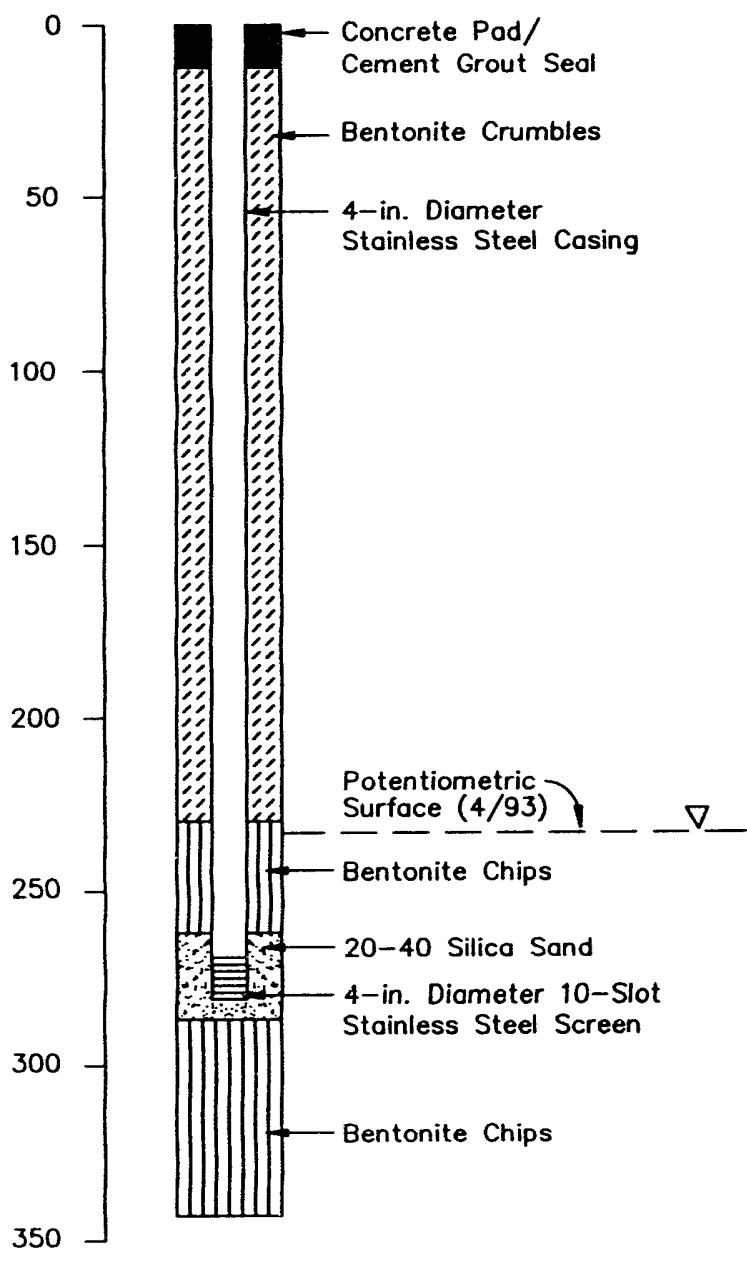

Lithology/Stratigraphy

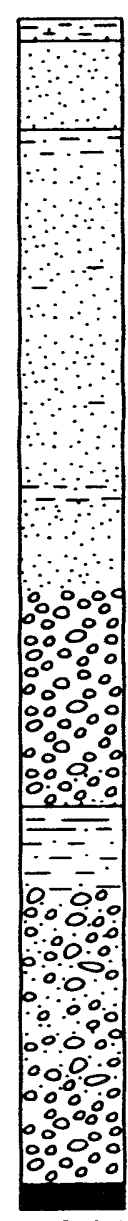

TD $342.92 \mathrm{ft}$

Sandy Gravel
$0-6 \mathrm{ft}$ Sandy Silt

6 - $33 \mathrm{ft}$ Sand

33 - $41 \mathrm{ft}$ Silty Sond

$41-65 \mathrm{ft}$ Sand

65 - $80 \mathrm{ft}$ Increosing Fines

80 - $101 \mathrm{ft}$ Sand

101 - $164 \mathrm{ft}$ Sand Alternative

Granular to Silty Sand

164 - 212 Pebble-Cobble Gravel

216 - 226 Pebble-Cobble Grovel

$228-238$ Silt/Clay

238 - 254 Silty Sand

254 - 335 Grovel to
Drilling Comments

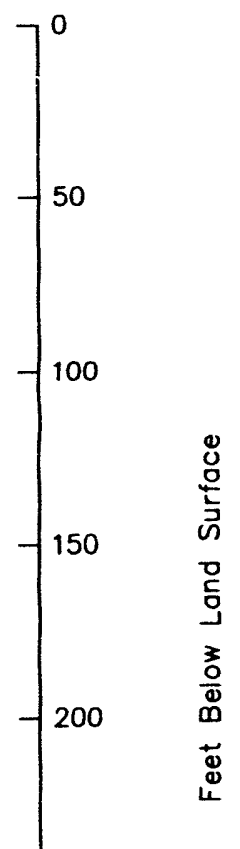

Well Completed $8 / 92$

Casing Elevation $643.91 \mathrm{ft}$

GEN \41-42 
$699-42-37$

Well Completion

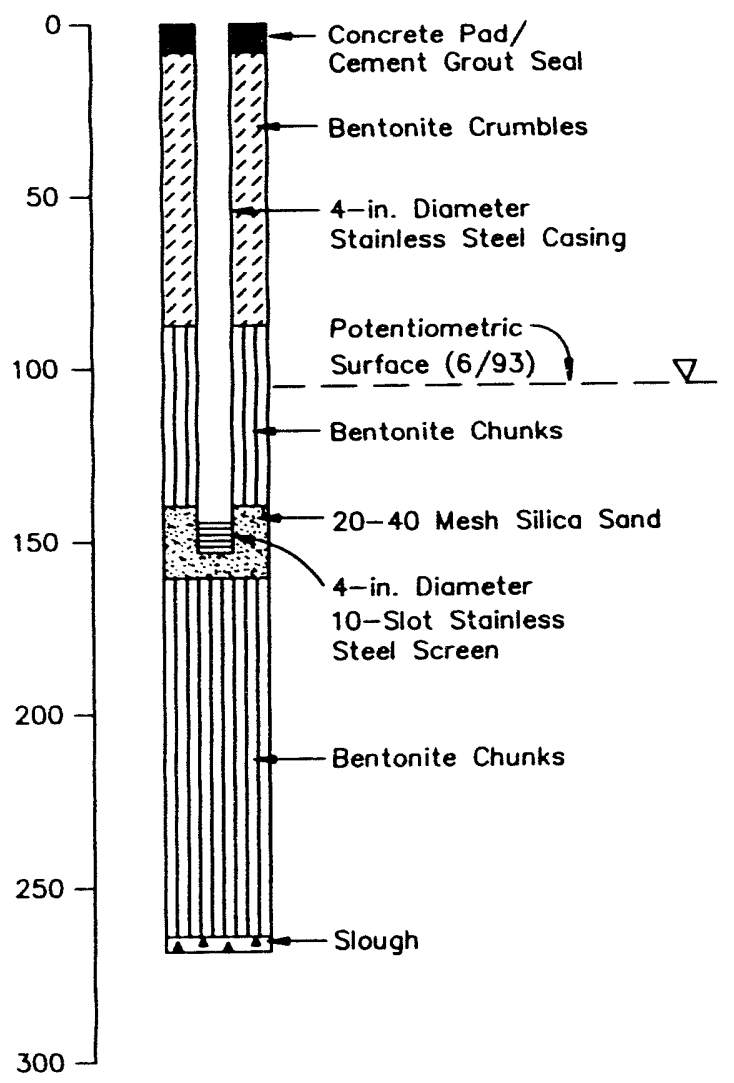

Lithology/Stratigraphy

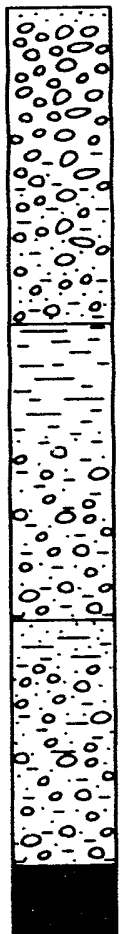

TD $268 \mathrm{ft}$
0 - $2 \mathrm{ft}$ Sand

2 - 48.5 ft Gravel

48.5 - 92 ft Silty Sandy Gravel

Ringold Fm.

Hard Tool

92 - 121 ft Clay/Silt

121 - 129 ft Sondy Silty Cloy

129 - $176 \mathrm{ft}$ Silty Sandy Gravel

176 - $191 \mathrm{ft}$ Silty Cloy, Sand ot $180 \mathrm{ft}$

191 - $245 \mathrm{ft}$ Silty Sondy Gravel

$<1 \mathrm{ft}$ Silty Sondy Clay ot $214 \mathrm{ft}$

6 in. Silty Sandy Cloy at $219 \mathrm{ft}$

$248.5-268 \mathrm{ft}$

Basalt

$100-128 \mathrm{ft}$

Drive Barrel

$128-137 \mathrm{ft}$

Hard Tool

$137-268 \mathrm{ft}$

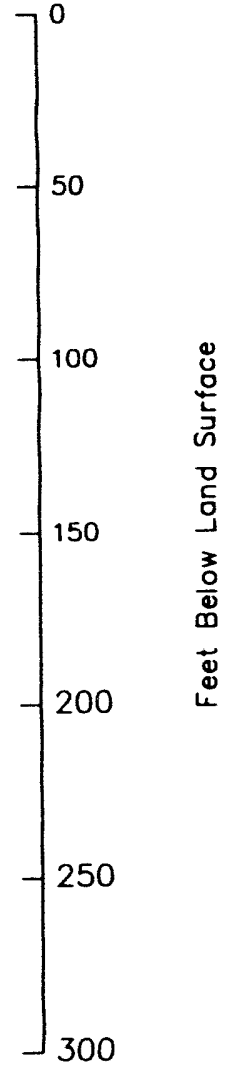

Well Completed $11 / 92$

Casing Elevation 519.40

Depth to Woter $105 \mathrm{ft}(6 / 93)$ 
$699-42-39 A$

Well Completion

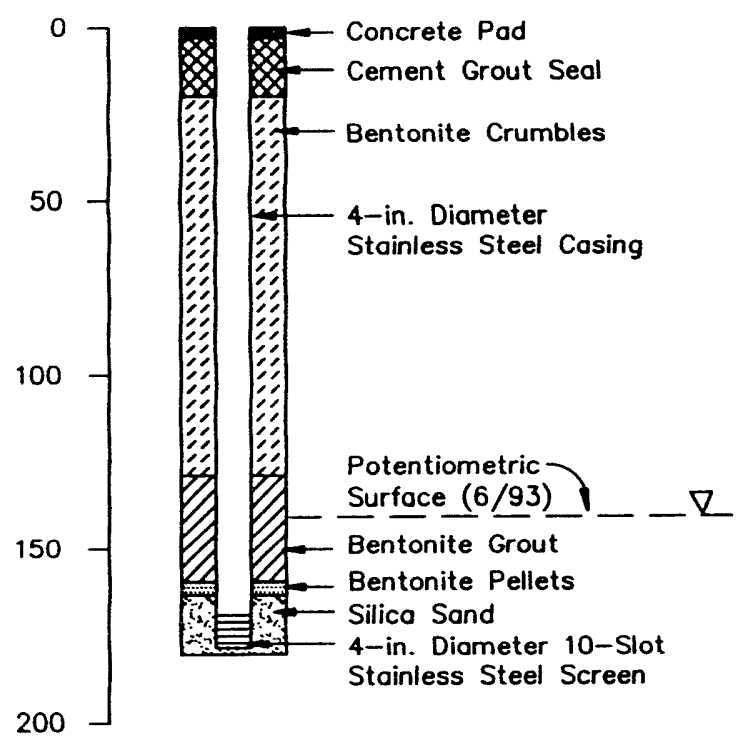

Lithology/Stratigraphy

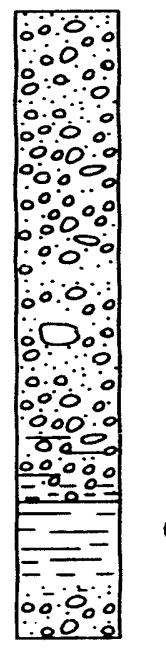

TD $180.65 \mathrm{ft}$

Sandy Grovel

Clayey Silt to Gravelly Sand

Boulder at $90 \mathrm{ft}$

Sandy Clayey Grovel

Silty Sand Hanford $\mathrm{fm}$. Ringold Fm.

Drive Barrel

$0-145 \mathrm{ft}$

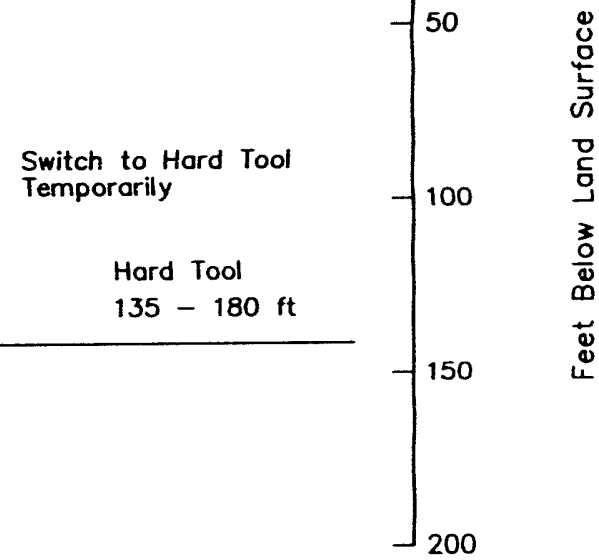

Well Completed 9/91

Casing Elevation $558.14 \mathrm{ft}$

Depth to Water $139 \mathrm{ft}(6 / 93)$ 
$699-42-39 B$

Well Completion

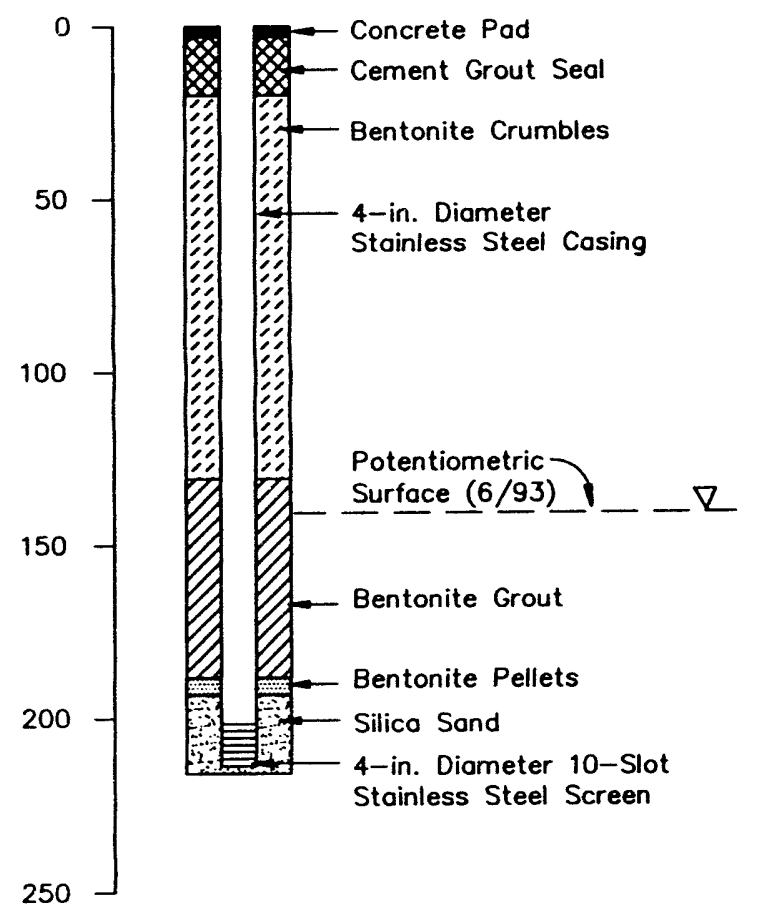

Lithology/Stratigraphy

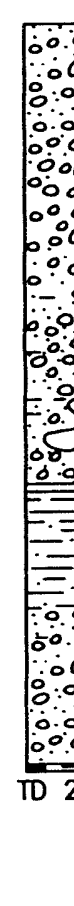

\section{Sandy Gravel with} lesser Grovelly Sand and Silty Gravel

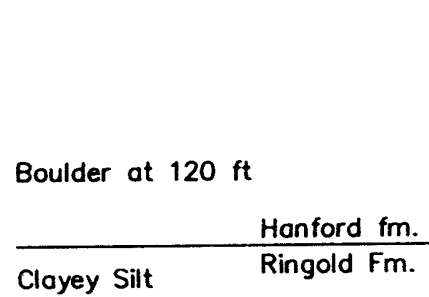

Sondy Clayey Silt

Sandy Silty Gravel

Silt/Clay at Bottom of Hole

Well Completed 10/91

Cosing Elevation $558.32 \mathrm{ft}$

Depth to Water $140 \mathrm{ft}(6 / 93)$

\section{Drilling Comments}

Drive Barrel $0-145 \mathrm{ft}$

Switch to Hard Tool Temporarily

$\underbrace{}_{\substack{\text { Hord Tool } \\ 145-216 \mathrm{ft}}} \underbrace{150}_{250}$


$699-42-41$

Well Completion

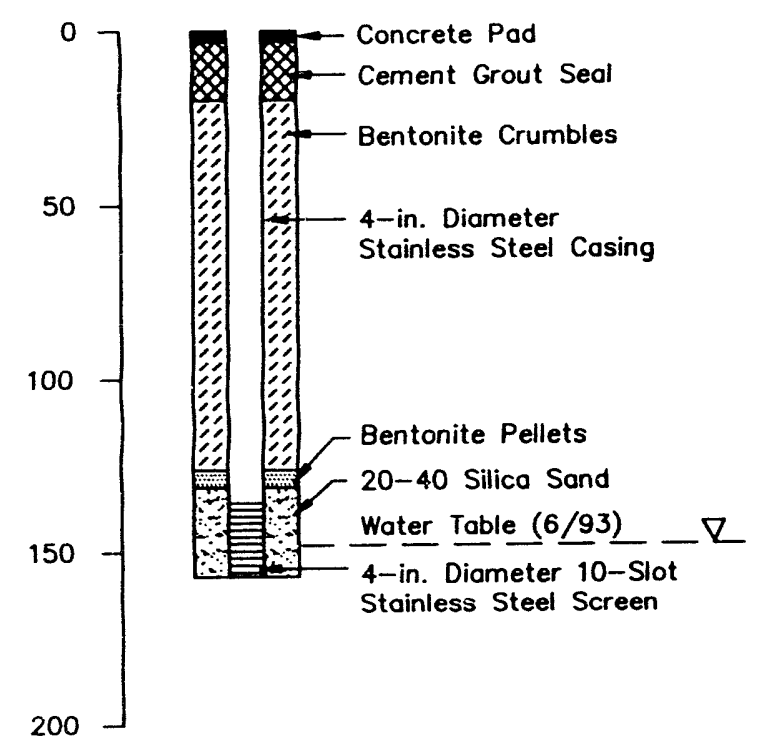

Lithology/Stratigraphy

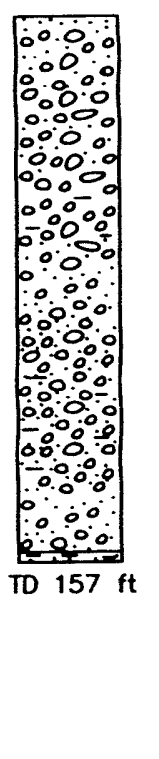

Sondy Gravel

Gravelly Sand

Silty Sand
Drilling Comments

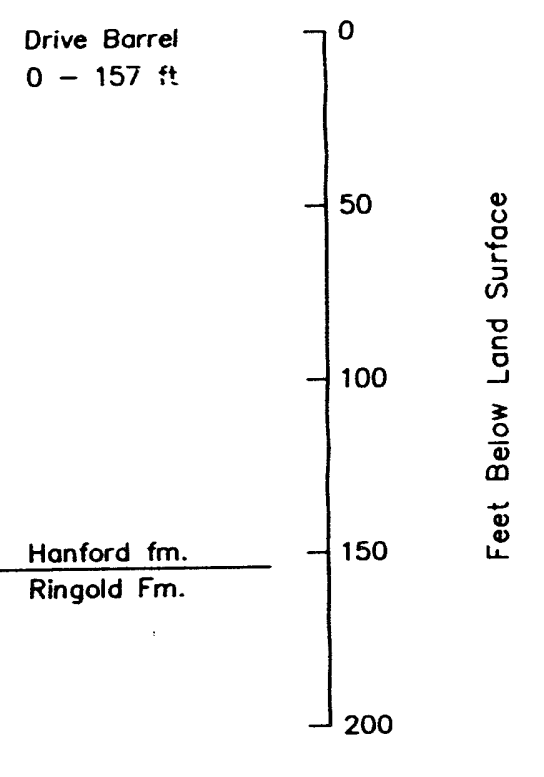

Well Completed 8/91

Cosing Elevation $567.30 \mathrm{ft}$

Depth to Water $147 \mathrm{ft}(6 / 93)$

Silty Sandy Gravel

GEN \42-41 
$699-43-40$

Well Completion

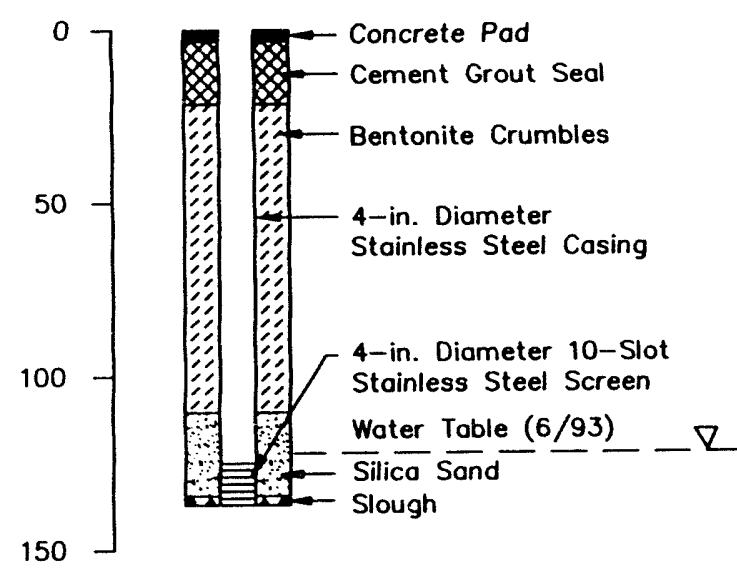

Lithology/Stratigraphy

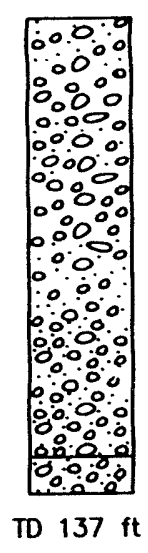

Sondy Grovel

Gravel

Sandy Gravel

Gravel

Sandy Grovel

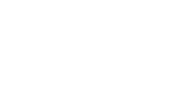

Interbedded Sand

and Grovel

Well Completed 10/91

Cosing Elevation $542.20 \mathrm{ft}$

Depth to Woter $122 \mathrm{ft}(6 / 93)$
Drilling Comments

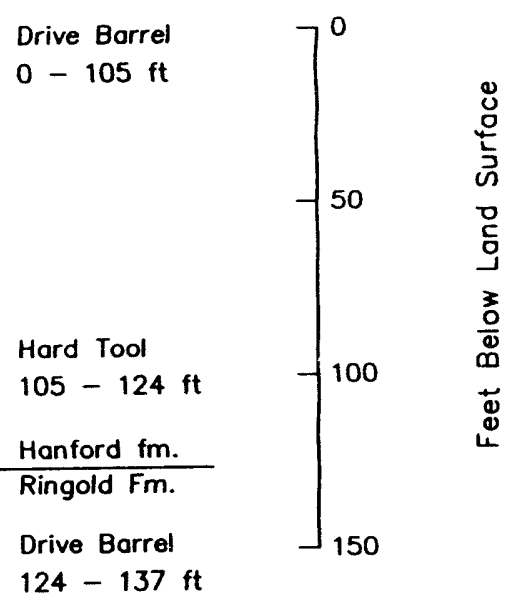


$699-43-41 G$

Well Completion

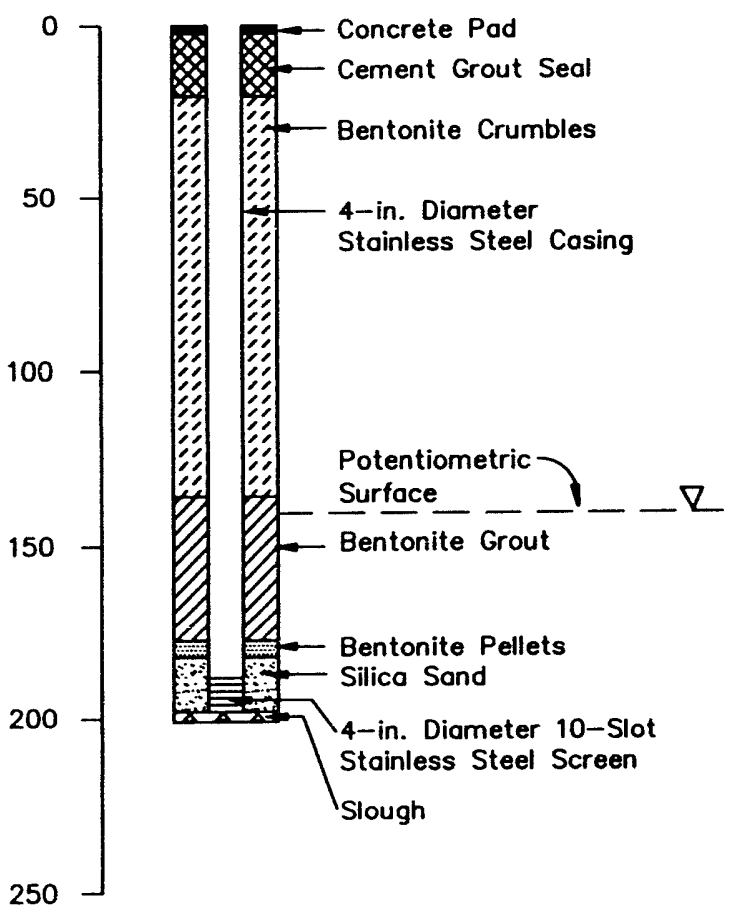

Lithology/Stratigraphy

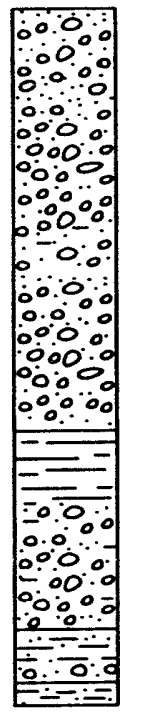

TD $201 \mathrm{ft}$

Gravelly Sand

Sandy Gravel
Drilling Comments

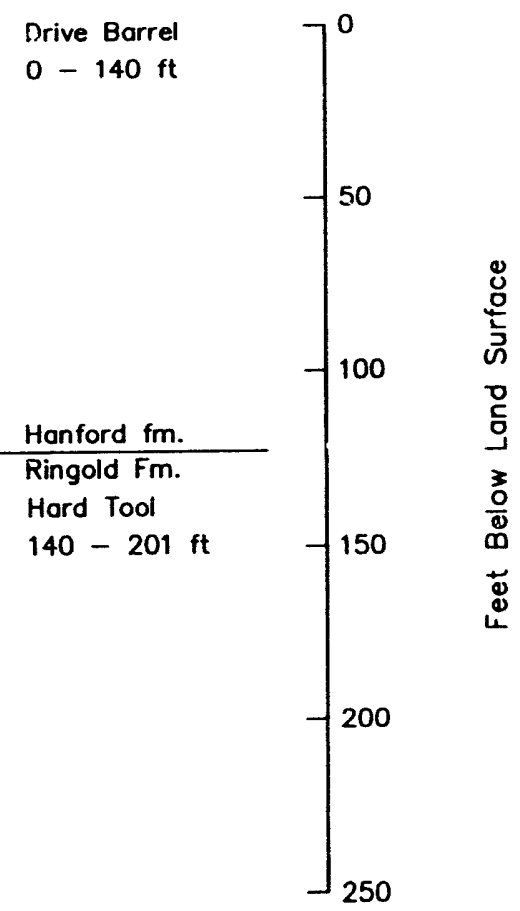

GEN\43416

Clayey Sandy Gravel

Silty Sand to Sandy Silt

Well Completed 10/91

Cosing Elevotion 551.34

Depth to woter $135 \mathrm{ft}(6 / 93)$ 
$699-44-393$

Well Completion

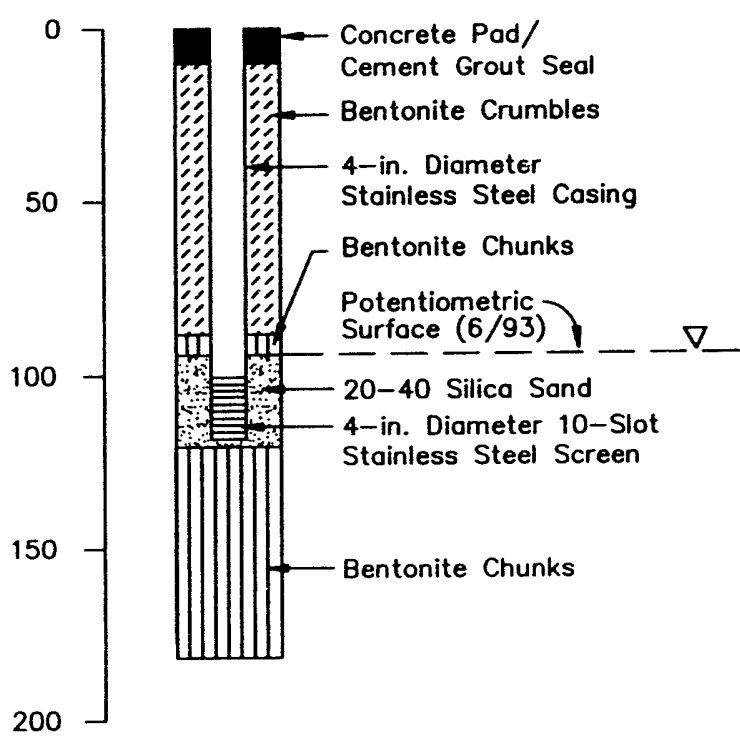

Lithology

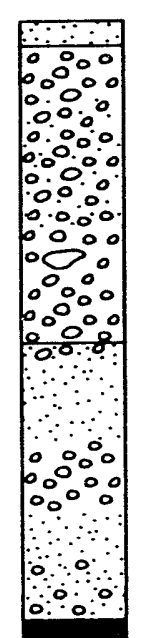

0 - $5 \mathrm{ft}$ Sand

5 - $20 \mathrm{ft}$ Gravel

20 - $60 \mathrm{ft}$ Slightly Sondy Gravel

63 - $69 \mathrm{ft}$ Grovel

Boulder ot $68 \mathrm{ft}$

69 - $92 \mathrm{ft}$ Grovel

92 - $95 \mathrm{ft}$ Gravelly Silty Sand

$95-120 \mathrm{ft}$ Sand

120 - $135 \mathrm{ft}$ Gravel

135 - $140 \mathrm{ft}$ Grovelly Sand

140 - $155 \mathrm{ft}$ Sand

155 - $172 \mathrm{ft}$ Gravelly Sand

172. - 182 Basalt

TD $181.90 \mathrm{ft}$

\section{Drilling Comments}

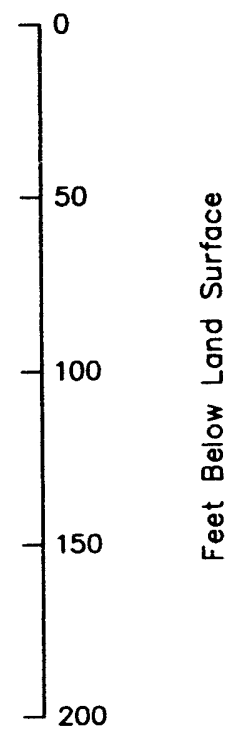

Well Completed $9 / 92$

Cosing Elevation $513.40 \mathrm{ft}$

Depth to Woter $94 \mathrm{ft}(6 / 93)$ 
DOE/RL 89-28, Rev. 1

$12 / 15 / 93$

\section{APPENDIX B}

THE B POND GROUNDWATER CHEMISTRY 
DOE/RL 89-28, Rev. 1

$12 / 15 / 93$

1
2
3
4
5

This page intentionally left blank. 


\section{APPENDIX B \\ THE B POND GROUNDWATER CHEMISTRY}

This appendix contains results of analyses of groundwater samples from the wells in the B Pond monitoring network from November 1988 through August 1989. The column headers consist of the following:

Well Name: Abbreviated number of monitoring well (e.g., 2-E18-1 = 299-E18$1 ; 6-42-42 B=699-4 ?-42 B$, etc. $)$.

Constituent Name: Chemical constituent.

Units: Analytical units of detection limit, drinking water standard, and analysis value. Unit abbreviations are:

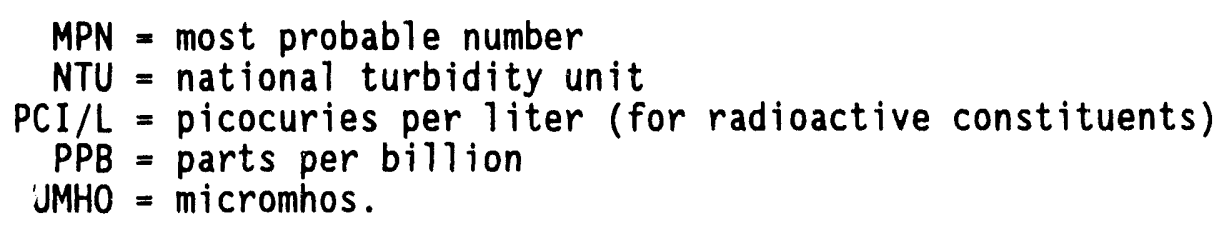

Detection Limit: The laboratory contractual detection limit.

Drinking Water Standard: Drinking water standards from a variety of regulations. These are provided here only for reference. The uppermost aquifer at the $B$ Pond site is not used as a source of drinking water.

Sample Date: Month, day, and year that sample was collected.

Analysis Value: Reported results of laboratory analysis. The symbol ' $<$ ' indicates that result is less than detection limit. 
DOE/RL 89-28, Rev. 1

$12 / 15 / 93$

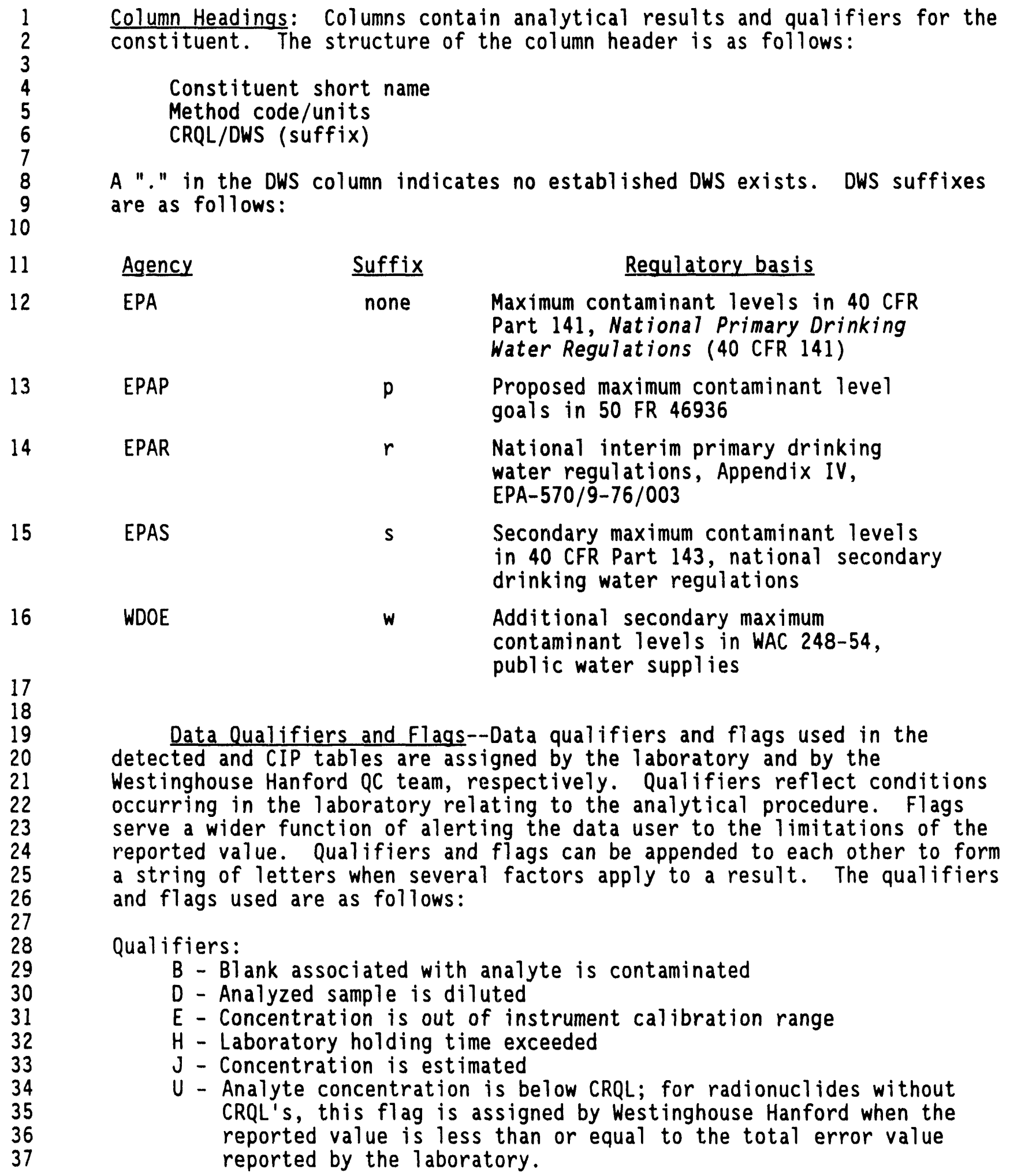

Column Headings: Columns contain analytical results and qualifiers for the

Constituent short name

Method code/units

CRQL/DWS (suffix)

A "." in the DWS column indicates no established DWS exists. DWS suffixes are as follows:

Agency Suffix Regulatory basis

Part 141, National Primary Drinking

Water Regulations (40 CFR 141)

goals in 50 FR 46936

National interim primary drinking water regulations, Appendix IV, EPA-570/9-76/003

in 40 CFR Part 143 , national secondar in 40 CFR Part 143, national secondary

Additional secondary maximum contaminant levels in WAC 248-54, public water supplies

Data Qualifiers and Flags--Data qualifiers and flags used in the detected and CIP tables are assigned by the laboratory and by the Westinghouse Hanford QC team, respectively. Qualifiers reflect conditions occurring in the laboratory relating to the analytical procedure. Flags serve a wider function of alerting the data user to the limitations of the reported value. Qualifiers and flags can be appended to each other to form a string of letters when several factors apply to a result. The qualifiers and flags used are as follows:

B - Blank associated with analyte is contaminated

D - Analyzed sample is diluted

- Concentration is out of instrument

$J$ - Concentration is estimated

$U$ - Analyte concentration is below CRQL; for radionuclides without CRQL's, this flag is assigned by Westinghouse Hanford when the reported by the laboratory. 
DOE/RL 89-28, Rev. 1

$12 / 15 / 93$

Flags:

A - Result associated with audit finding described in Section 1.2

P - Potential problem; see text associated with table

$Q$ - Result associated with suspect $Q C$ data

$R$ - Suspect data currently under review

+ - Suspect water-level data currently under review

* - CRQL is greater than DWS, so exceedance of DWS is undetermined. 
Gค $⿴$ N

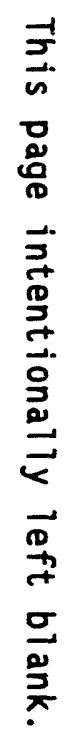

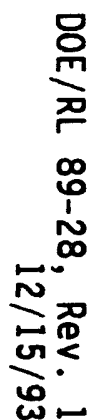


CONTAMINATION INDICATOR PARAMETERS

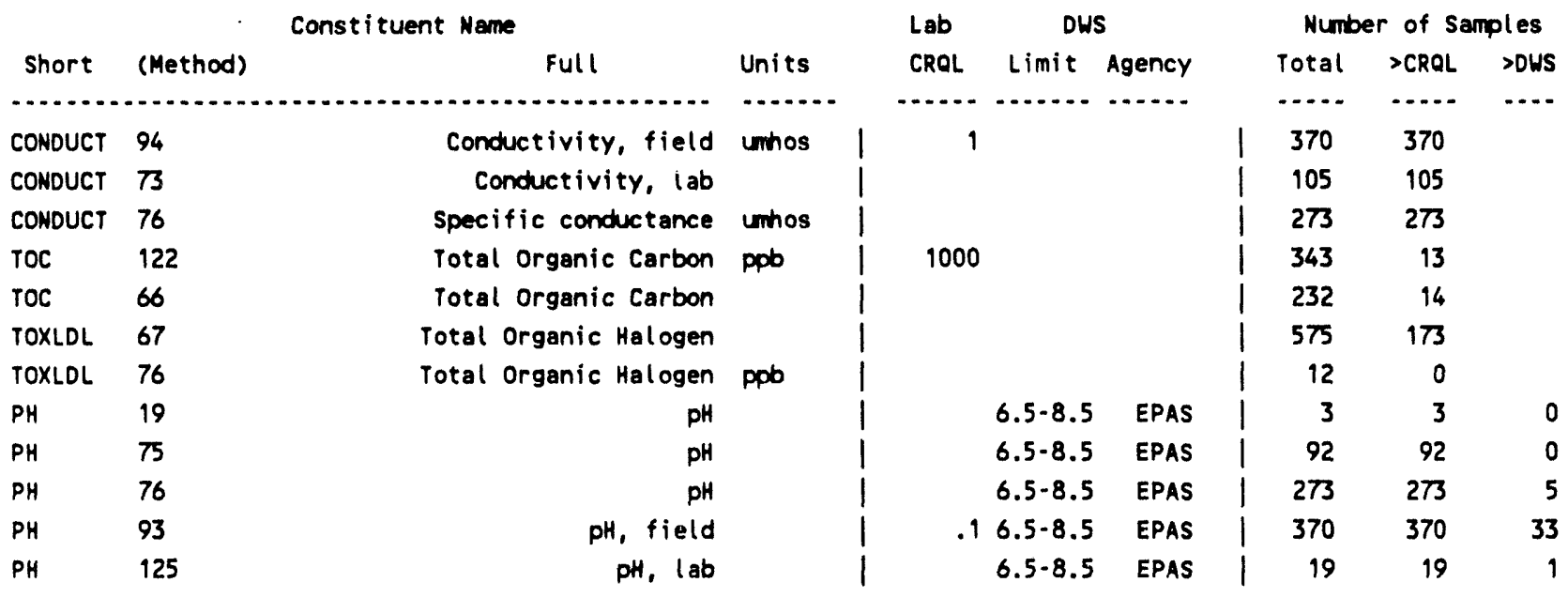

DRINKING WATER PARAMETERS

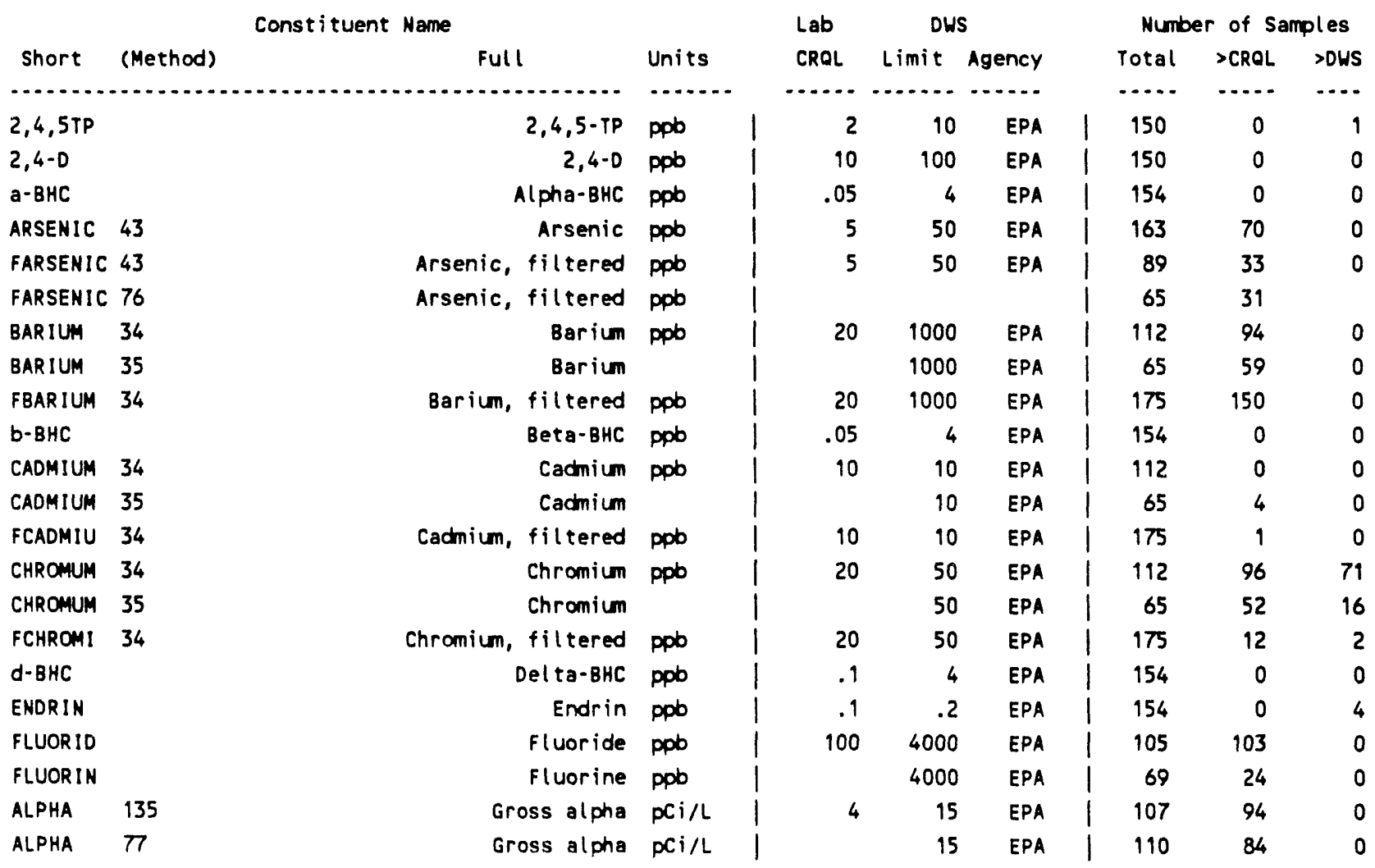


(sheet 2 of 15)

\begin{tabular}{|c|c|c|c|c|c|c|c|c|c|}
\hline \multirow[b]{2}{*}{ Short } & \multirow[b]{2}{*}{ (Method) } & \multirow[t]{2}{*}{ Constituent Name } & \multirow[b]{2}{*}{ Units } & \multirow{2}{*}{$\begin{array}{l}\text { Lab } \\
\text { CRQL }\end{array}$} & \multicolumn{2}{|c|}{ DWS } & \multicolumn{3}{|c|}{ Number of Samples } \\
\hline & & & & & Limit & Agency & Total & $>$ CRQL & >OWS \\
\hline$\cdots \ldots$ & $\cdots$ & 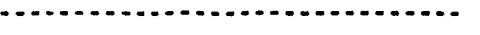 & $\cdots$ & $\cdots$ & $\cdots$ & $\cdots$ & $\cdots$ & $\cdots$ & $\cdots$ \\
\hline BETA & 136 & Gross beta & $\mathrm{pCi} / \mathrm{L}$ & 8 & 50 & EPA & 107 & 103 & 0 \\
\hline BETA & 77 & Gross beta & $\mathrm{PCi} / \mathrm{L}$ & & 50 & EPA & 134 & 130 & 2 \\
\hline LEAD & 34 & Lead & & & & & 1 & 0 & \\
\hline LEAD & 40 & Lead & ppb & 5 & 50 & EPA & 90 & 8 & 0 \\
\hline LEAD & 76 & Lead & ppb & & & & 67 & 5 & \\
\hline FLEAD & 40 & Lead, filtered & ppb & 5 & 50 & EPA & 154 & 1 & 0 \\
\hline MERCURY & 41 & Mercury & ppb & .2 & 2 & EPA & 82 & 0 & 0 \\
\hline MERCURY & 76 & Mercury & ppb & & & & 64 & 0 & \\
\hline FMERCUR & 41 & Mercury, filtered & ppob & .2 & 2 & EPA & 143 & 0 & 0 \\
\hline METHLOR & & Methoxychlor & ppb & 2 & 100 & EPA & 154 & 0 & 0 \\
\hline RADIUM & 137 & Radium & $\mathrm{pCi} / \mathrm{L}$ & 1 & 5 & EPA & 101 & 34 & 0 \\
\hline RADIUM & 77 & Radiun & $\mathrm{PC} i / \mathrm{L}$ & & 5 & EPA & 66 & 33 & 0 \\
\hline SELENUM & 48 & Selenium & ppb & 10 & 10 & EPA & 89 & 0 & 0 \\
\hline SELENUM & 76 & Selenium & ppob & & & & 68 & 9 & \\
\hline FSELENI & 48 & Selenium, filtered & ppob & 10 & 10 & EPA & 154 & 9 & 1 \\
\hline SILVER & 34 & silver & ppob & 20 & 50 & EPA & 112 & 0 & 0 \\
\hline SILVER & 35 & silver & & & 50 & EPA & 65 & 0 & 0 \\
\hline FSILVER & 34 & silver, filtered & ppb & 20 & 50 & EPA & 175 & 0 & 0 \\
\hline TOXAENE & 17 & Toxaphene & ppb & 2 & 5 & EPA & 90 & 0 & 0 \\
\hline TOXAENE & 37 & Toxaphene & & & 5 & EPA & 64 & 0 & 0 \\
\hline TURBID & 126 & Turbidity & NTU & .1 & 1 & EPA & 92 & 92 & 50 \\
\hline TURBID & 76 & Turbidity & NTU & & & & 54 & 54 & \\
\hline g-BHC & & gamma-BHC (L indane) & ppb & .05 & 4 & EPA & 154 & 0 & 0 \\
\hline
\end{tabular}

GROUNOWATER QUALITY PARAMETERS

\begin{tabular}{|c|c|c|c|c|c|c|c|c|c|}
\hline \multirow[b]{2}{*}{ Short } & \multirow[b]{2}{*}{ (Method) } & \multirow[t]{2}{*}{ Constituent Name } & \multirow[b]{2}{*}{ Units } & \multirow{2}{*}{$\begin{array}{l}\text { Lab } \\
\text { CROL }\end{array}$} & \multicolumn{2}{|c|}{ DWS } & \multicolumn{3}{|c|}{ Number of Samples } \\
\hline & & & & & Limit & Agency & Total & $>C R Q L$ & >DWS \\
\hline$\cdots \cdots$ & $\ldots \ldots$ & - & $\ldots \ldots$ & - & $\cdots \ldots$ & $\ldots \ldots$ & $\ldots$. & $\ldots$. & $\ldots$ \\
\hline CHLORID & 124 & Chloride & ppb $\quad 1$ & 200 & 250000 & EPAS & 105 & 105 & 0 \\
\hline CHLORID & 46 & Chloride & 1 & & 250000 & EPAS & 69 & 69 & 0 \\
\hline IRON & 34 & Iron & $p p b$ & 20 & 300 & EPAS & 112 & 111 & 79 \\
\hline IPON & 35 & Iron & i & & 300 & EPAS & 65 & 65 & 32 \\
\hline FIRON & 34 & Iron, filtered & ppob & 20 & 300 & EPAS & 175 & 104 & 8 \\
\hline MANGESE & 34 & Manganese & ppb & 10 & 50 & EPAS & 112 & 77 & 44 \\
\hline MANGESE & 35 & Manganese & i & & 50 & EPAS & 65 & 51 & 9 \\
\hline FMANGAN & 34 & Manganese, filtered & ppob & 10 & 50 & EPAS & 175 & 73 & 47 \\
\hline LPHENOL & 19 & Phenol & ppb & 10 & & & 24 & 0 & \\
\hline LPHENOL & 30 & Phenol & ppob & 1 & & & 134 & 3 & \\
\hline LPHENOL & 32 & Phenol & 1 & & & & 18 & 0 & \\
\hline SODIUM & 34 & Sodium & ppb & 300 & & & 112 & 112 & \\
\hline SOOIUM & 35 & Sodium & & & & & 65 & 65 & \\
\hline FSOO IUM & 34 & Sodium, filtered & pob & 300 & & & 175 & 175 & \\
\hline
\end{tabular}


(sheet 3 of 15)

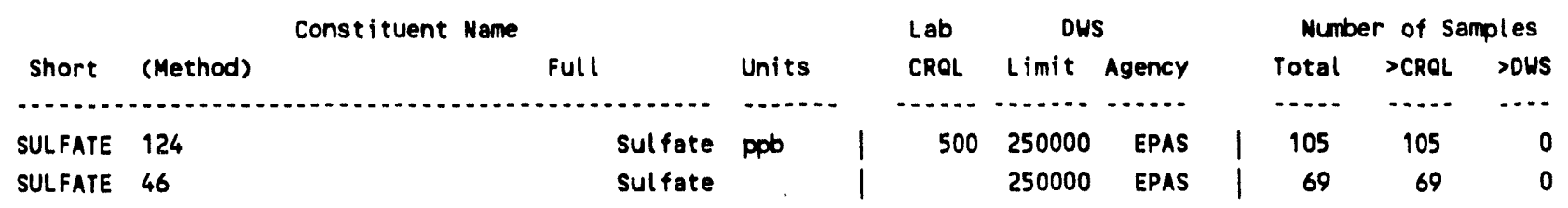

SITE SPECIFIC AND OTHER CONSTITUENTS

\begin{tabular}{|c|c|c|c|c|c|c|c|c|c|}
\hline \multirow[b]{2}{*}{ Short } & \multirow[b]{2}{*}{ (Method) } & \multirow[t]{2}{*}{ Constituent Name } & \multirow[b]{2}{*}{ Units } & \multirow{2}{*}{$\begin{array}{l}\text { Lab } \\
\text { CROL }\end{array}$} & \multicolumn{2}{|l|}{ DWS } & \multicolumn{3}{|c|}{ Number of Samples } \\
\hline & & & & & Limit & Agency & Total & $>C R Q L$ & >DWS \\
\hline n........ & & (n) & $\cdots \cdots$ & $\cdots \cdots$ & …..... & $\cdots \cdots$ & $\cdots$ & $\cdots \cdots$ & $\cdots$ \\
\hline & & & & & & & 3 & 1 & \\
\hline $1112-t c$ & & $1,1,1,2$-Tetrachlor oethane & ppb & 5 & & & 38 & 0 & \\
\hline $1,1,1-T$ & 16 & 1,1,1-Trichloroethane & ppb & 5 & 200 & EPA & 90 & 0 & 0 \\
\hline 1, 1,1-T & 25 & 1,1,1-Trichloroethane & ppob & .5 & 200 & EPA & 3 & 0 & 0 \\
\hline $1122-t c$ & & 1,1,2,2-Tetrachloroethane & ppb & 5 & & & 38 & 0 & \\
\hline $1,1,2-T$ & 16 & 1,1,2-Trichloroethane & ppb & 5 & & & 90 & 0 & \\
\hline $1,1,2-T$ & 25 & 1,1,2-Trichloroethane & ppb & .5 & & & 3 & 0 & \\
\hline $1,1-01 C$ & 16 & 1,1-Dichloroethane & ppb & 5 & & & 22 & 0 & \\
\hline $1,1-D I C$ & 25 & 1,1-Dichloroethane & ppb & 1 & & & 3 & 0 & \\
\hline $1,1-01 C$ & 45 & 1,1-Dichloroethane & & & & & 60 & 0 & \\
\hline DICETHY & & 1,1-Dichloroethene & ppob & 5 & 7 & EPA & 39 & 0 & 25 \\
\hline $1,1-D I M$ & & 1,1-Dimethylhydrazine & & & & & 18 & 0 & \\
\hline 1234TE & & 1,2,3,4-tetrachlorobenzene & ppob & & & & 18 & 0 & \\
\hline 1235TE & & $1,2,3,5$-tetrachlorobenzene & & & & & 18 & 0 & \\
\hline $123-\operatorname{trp}$ & 16 & 1,2,3-Trichloropropane & ppob & 5 & & & 38 & 0 & · \\
\hline $123-\operatorname{trp}$ & 76 & 1,2,3-Trichloropropene & ppb & & & & 8 & 0 & \\
\hline 123TRI & & 1,2,3-trichlorobenzene & ppb & & & & 18 & 0 & \\
\hline TETRCHB & 19 & $1,2,4,5-$ Tetrachlorobenzene & ppb & 10 & & & 18 & 0 & \\
\hline TETRCHB & 21 & 1,2,4,5-Tetrachlorobenzene & ppb & & & & 18 & 0 & \\
\hline TRICHLB & 19 & 1,2,4-Trichlorobenzene & ppob & 10 & & & 18 & 0 & \\
\hline TRICHLB & 21 & 1,2,4-Trichlorobenzene & ppb & & & & 18 & 0 & \\
\hline DIBRCHL & & 1,2-0 ibromo-3-chloropropane & ppob & 5 & & & 38 & 0 & \\
\hline DIBRETH & & 1,2-Dibromoethane & ppb & 5 & & & 38 & 0 & \\
\hline 12-oben & 19 & 1,2-Dichlorobenzene & ppb & 10 & & & 18 & 0 & \\
\hline 12-dben & 21 & 1,2-Dichlorobenzene & ppb & & & & 18 & 0 & \\
\hline $1,2-D I C$ & 16 & 1,2-Dichloroethane & ppb & 5 & 5 & EPA & 82 & 0 & 8 \\
\hline $1,2-010$ & 25 & 1,2-Dichloroethane & ppb & .5 & 5 & EPA & 3 & 0 & 0 \\
\hline 12-DCE & & 1,2-Dichloroethene & ppb & 5 & & & 1 & 0 & \\
\hline DICPANE & & 1,2-Dichloropropane & ppb & 5 & & & 38 & 0 & \\
\hline $1,2-0 \mathrm{IM}$ & & 1,2-Dimethylhydrazine & & & & & 18 & 0 & \\
\hline DIPHHYO & & 1,2-D iphenylhydrazine & ppb & & & & 15 & 0 & \\
\hline 135TRI & & 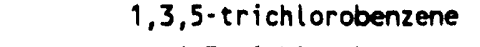 & ppb & & & & 18 & 0 & \\
\hline 13-aben & 19 & 1,3-Dichlorobenzene & ppb & 10 & & & 18 & 0 & \\
\hline 13-dben & 20 & 1,3-Dichlorobenzene & & & & & 18 & 0 & \\
\hline DICPENE & & 1,3-Dichloropropene & & & & & 25 & 0 & \\
\hline
\end{tabular}


(sheet 4 of 15)

\begin{tabular}{|c|c|c|c|c|c|c|c|c|c|}
\hline \multirow[b]{2}{*}{ Short } & \multirow[b]{2}{*}{ (Method) } & \multirow{2}{*}{$\begin{array}{l}\text { Constituent Name } \\
\text { Full }\end{array}$} & \multirow[b]{2}{*}{ Units } & \multirow{2}{*}{$\begin{array}{l}\text { Lab } \\
\text { CRQL }\end{array}$} & \multicolumn{2}{|c|}{ DWS } & \multicolumn{3}{|c|}{ Number of Samples } \\
\hline & & & & & Limit & Agency & Total & $>C R Q L$ & >OWS \\
\hline$\ldots \ldots$ & & - & ......... & $\cdots \ldots$ & $\cdots$ & $\cdots \ldots$ & $\cdots .$. & $\cdots \cdot$ & $\cdots$ \\
\hline DIBUTEN & & 1,4-Dichloro-2-butene & ppob & 5 & & & 13 & 0 & \\
\hline 14 - dben & 16 & 1,4-Dichlorobenzene & ppob & 5 & $7=9$ & EPA & 29 & 0 & 0 \\
\hline 14-aben & 19 & 1,4-0 ichlorobenzene & ppob & 5 & $\pi: 0$ & EPA & 1 & 0 & 0 \\
\hline 14 -dben & 21 & 1,4-0ichlorobenzene & ppob & & $\pi 50$ & EPA & 18 & 0 & 0 \\
\hline 14-dben & 24 & 1,4-Dichlorobenzene & | & & 750 & EPA & 52 & 0 & 0 \\
\hline 14 - dben & 25 & 1,4-Dichlorobenzene & ppb & 2 & 750 & EPA & 3 & 0 & 0 \\
\hline DIOXANE & & 1,4-0ioxane & ppob & 200 & & & 39 & 0 & \\
\hline NAPHQUI & 19 & 1,4-Naphtoquinone & ppob & 10 & & & 18 & 0 & \\
\hline NAPHQUI & 21 & 1,4-Naphtoquinone & ppb & & & & 15 & 0 & \\
\hline CHLOREA & & 1-(0-Chl orophenyl) thiourea & 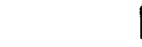 & & & & 13 & 0 & \\
\hline ACETREA & & $1-$ Acetyl-2-thiourea & t & & & & 13 & 0 & \\
\hline 1BUTYN & 16 & $1-$ Butanol & ppm & 1 & & & 9 & 0 & \\
\hline IBUTYN & 28 & 1-Butanol & tha & & & & 12 & 0 & \\
\hline CHLEPOX & & 1-Chloro-2,3-epoxypropene & ppb & & & & 15 & 0 & \\
\hline NAPHREA & & 1-Maphthyl-2-thiourea & 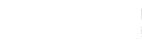 & & & & 13 & 0 & \\
\hline 1-napha & 19 & 1-Naphthyl amine & ppb & 10 & & & 18 & 0 & \\
\hline 1-napha & 21 & 1-Naphthylamine & ppb & & & & 15 & 0 & \\
\hline IPROPAN & & 1-Propanol & & & & & 11 & 0 & \\
\hline TETRCHP & 19 & $2,3,4,6$ - Tetrachlorophenol & ppob & 10 & & & 18 & 0 & \\
\hline TETRCHP & 21 & $2,3,4,6$ - Tetrachlorophenol & ppob & & & & 15 & 0 & \\
\hline $2378 T C D$ & 51 & $2,3,7,8-T C D D$ & ppb & .005 & & & 12 & 0 & \\
\hline $2378 \mathrm{TCD}$ & 76 & $2,3,7,8-T C D D$ & ppob & & & & 2 & 0 & \\
\hline $2,4,5-T$ & & $2,4,5-T$ & ppob & 2 & & & 140 & 0 & \\
\hline $245-\operatorname{trp}$ & 19 & 2,4,5-Trichlorophenol & ppb & 10 & & & 18 & 0 & \\
\hline $245-\operatorname{trp}$ & 21 & $2,4,5-$ Trichlorophenol & ppb & & & & 15 & 0 & \\
\hline $246-\operatorname{trp}$ & 19 & 2,4,6-Trichlorophenol & ppb & 10 & & & 18 & 0 & \\
\hline $246-\operatorname{trp}$ & 21 & 2,4,6-Trichlorophenol & ppb & & & & 15 & 0 & \\
\hline $246-\operatorname{trp}$ & 30 & $2,4,6-T r i c h l o r o p h e n o l$ & ppob & 5 & & & 86 & 0 & \\
\hline 24 -dchp & 19 & 2,4-D ichlorophenol & ppb & 10 & & & 18 & 0 & \\
\hline $24-d c h p$ & 21 & 2,4-Dichlorophenol & ppob & & & & 15 & 0 & \\
\hline 24 -dchp & 30 & 2,4-Dichlorophenol & ppb & 5 & & & 86 & 0 & \\
\hline DIMPHEN & 19 & 2,4-D imethylphenol & ppb & 10 & & & 22 & 0 & \\
\hline DIMPHEN & 30 & 2,4-D imethylphenol & ppob & 5 & & & 86 & 1 & \\
\hline DINPHEN & 19 & 2,4-D initrophenol & ppb & 50 & & & 18 & 0 & \\
\hline DINPHEN & 30 & 2,4-Dinitrophenol & ppb & 150 & & & 86 & 2 & \\
\hline DINPHEN & 72 & 2,4-0 initrophenol & & & & & 15 & 0 & \\
\hline 24 -dint & 19 & 2,4-0 initrotoluene & ppb & 10 & & & 18 & 0 & \\
\hline 24-dint & 21 & $2,4-D$ initrotoluene & ppob & & & & 15 & 0 & \\
\hline 26-dchp & 19 & 2,6-0 ichlorophenol & ppb & 10 & & & 18 & 0 & \\
\hline 26-dchp & 21 & 2,6-Dichlorophenol & $\mathrm{ppb}$ & & & & 15 & 0 & \\
\hline 26-dchp & 30 & 2,6-0 ichlorophenol & ppb & 5 & & & 86 & 0 & \\
\hline 26-dint & 19 & 2,6-D initrotoluene & ppb & 10 & & & 18 & 0 & \\
\hline 26-dint & 21 & 2,6-Dinitrotoluene & ppob & & & & 15 & 0 & \\
\hline ACEFENE & 19 & 2-Acetylaminofluorene & ppb & 10 & & & 18 & 0 & \\
\hline
\end{tabular}


(sheet 5 of 15)

Constituent Name

\begin{tabular}{|c|c|c|c|}
\hline \multicolumn{4}{|c|}{ Constituent Name } \\
\hline Short & (Method) & Full & Units \\
\hline & 29 & 2-Acetylaninoftuorene & \\
\hline $\begin{array}{l}\text { ACETENE } \\
\text { CHLTHER }\end{array}$ & 21 & 2-Chlorsethyl vinyl ether & $p p 0$ \\
\hline CHLNAPH & 19 & 2-Chloronaph thal ene & ppb \\
\hline CHLNAPH & 21 & 2-Chloronaphthalene & ppb \\
\hline CHLPHEN & 19 & 2-Chlorophenol & ppb \\
\hline CHLPHEN & 21 & 2-Chlorophenol & ppb \\
\hline CHLPHEN & 30 & 2-Chlorophenol & ppb \\
\hline CYCHDIN & & 2-Cyclohexyl-4,6-dini trophenol & ppb \\
\hline 2HEXANO & & 2-Hexanone & ppb \\
\hline METAZIR & & 2-Methylaziridine & ppb \\
\hline METACTO & & 2-Methyllactonitrile & ppb \\
\hline 2MENAPH & 19 & 2-Methyl naphthal ene & ppb \\
\hline 2MENAPH & 21 & 2-Methyl naphthal ene & ppb \\
\hline 2METHPH & & 2-Methylphenol & ppb \\
\hline 2-napha & 19 & 2-Nephthylemine & ppb \\
\hline 2-napha & 21 & 2-Nephthylamine & ppb \\
\hline ONITANI & & 2-Nitroaniline & ppb \\
\hline 2NITPH & 19 & 2-Nitrophenol & ppb \\
\hline 2NITPH & 30 & 2-Nitrophenol & ppb \\
\hline PICOLIN & 16 & 2-Picoline & ppb \\
\hline PICOLIN & 21 & 2-picoline & ppb \\
\hline 2PROPAN & & 2-Propanol & ppb \\
\hline PROPYNO & & 2-Propyn-1-ol & \\
\hline METPROP & & 2-methyl-2-(methyl thio) propions & ppob \\
\hline BUTDINP & 21 & 2-sec-Butyl-4,6-dinitrophenol (DN & ppb \\
\hline BUTDINP & 30 & 2-sec-Butyl-4,6-dinitrophenol (DN & $p p b$ \\
\hline BUTDINP & 49 & 2-sec-Butyl-4,6-dini trophenol (DN & ppob \\
\hline DICHBEN & 19 & $3,3^{\prime}-\mathrm{Dichl}$ orobenz idine & ppob \\
\hline DICHBEN & 21 & 3,3'-Dichlorobenzidine & ppb \\
\hline DIMETHB & & 3,3'-D ime thoxybenz idine & ppb \\
\hline DIMEYLB & & 3,3'-D imethylbenzidine & ppb \\
\hline CHLPROP & & 3-Chloropropionitrile & \\
\hline METCHAN & 19 & 3-Methylchol anthrene & ppb \\
\hline METCHAN & 21 & 3-Methylchol anthrene & ppb \\
\hline MNITANI & 19 & 3-Nitroaniline & ppb \\
\hline MNITANI & 21 & 3-Nitroaniline & ppob \\
\hline DDD & & $4,4^{\prime}-000$ & ppb \\
\hline DDE & & $4,4^{\prime}-$ DDE & ppb \\
\hline DDT & & $4,4^{\prime}-$ DOT & ppb \\
\hline METBISC & & $4,4^{\prime}$-Methylenebis (2-chloroanil in & ppb \\
\hline 460N2MP & 19 & 4,6-0 ini tro-2-methylphenol & ppb \\
\hline 460N2MP & 30 & 4,6-D initro-2-methylphenol & ppb \\
\hline 460N2MP & 72 & 4,6-0 initro-2-methylphenol & \\
\hline AMINOYL & 19 & 4-Aminobiphenyl & ppob \\
\hline
\end{tabular}

Lab DWS

CRQL Limit Agency

....................

10

10

5

50

10

10

10

5

5

5

1

20

10

10

50

.1

.05

.1

50

200

10
Number of Samples Total >CRQL >OWS ..... ..... .... 15

o$$
0
$$$$
0
$$$$
0
$$$$
0
$$$$
0
$$$$
0
$$$$
0
$$$$
0
$$$$
0
$$$$
0
$$$$
0
$$$$
0
$$$$
0
$$$$
0
$$$$
0
$$$$
0
$$$$
0
$$$$
\begin{aligned}
& 18 \\
& 18 .
\end{aligned}
$$$$
\begin{aligned}
& 18 \% 0 \\
& 86
\end{aligned}
$$$$
\begin{array}{ll}
86 & 2 \\
13 & 0
\end{array}
$$$$
\begin{array}{ll}
13 & 0 \\
15 & 0
\end{array}
$$$$
10
$$$$
140
$$$$
150
$$$$
150
$$$$
860
$$$$
\begin{array}{ll}
86 & 0
\end{array}
$$$$
\begin{array}{ll}
84 & 0 \\
18 & 0
\end{array}
$$$$
\begin{array}{ll}
15 & 0
\end{array}
$$$$
150
$$$$
1330
$$$$
140
$$$$
18 \quad 0
$$$$
15 \quad 0
$$$$
18 \quad 0
$$$$
110
$$$$
104 \quad 0
$$$$
\text { | } 104 \quad 0
$$$$
104 \quad 0
$$$$
15 \quad 0
$$$$
\begin{array}{ll}
18 & 0
\end{array}
$$$$
\begin{array}{ll}
18 & 0 \\
86 & 0
\end{array}
$$ 
(sheet 6 of 15)

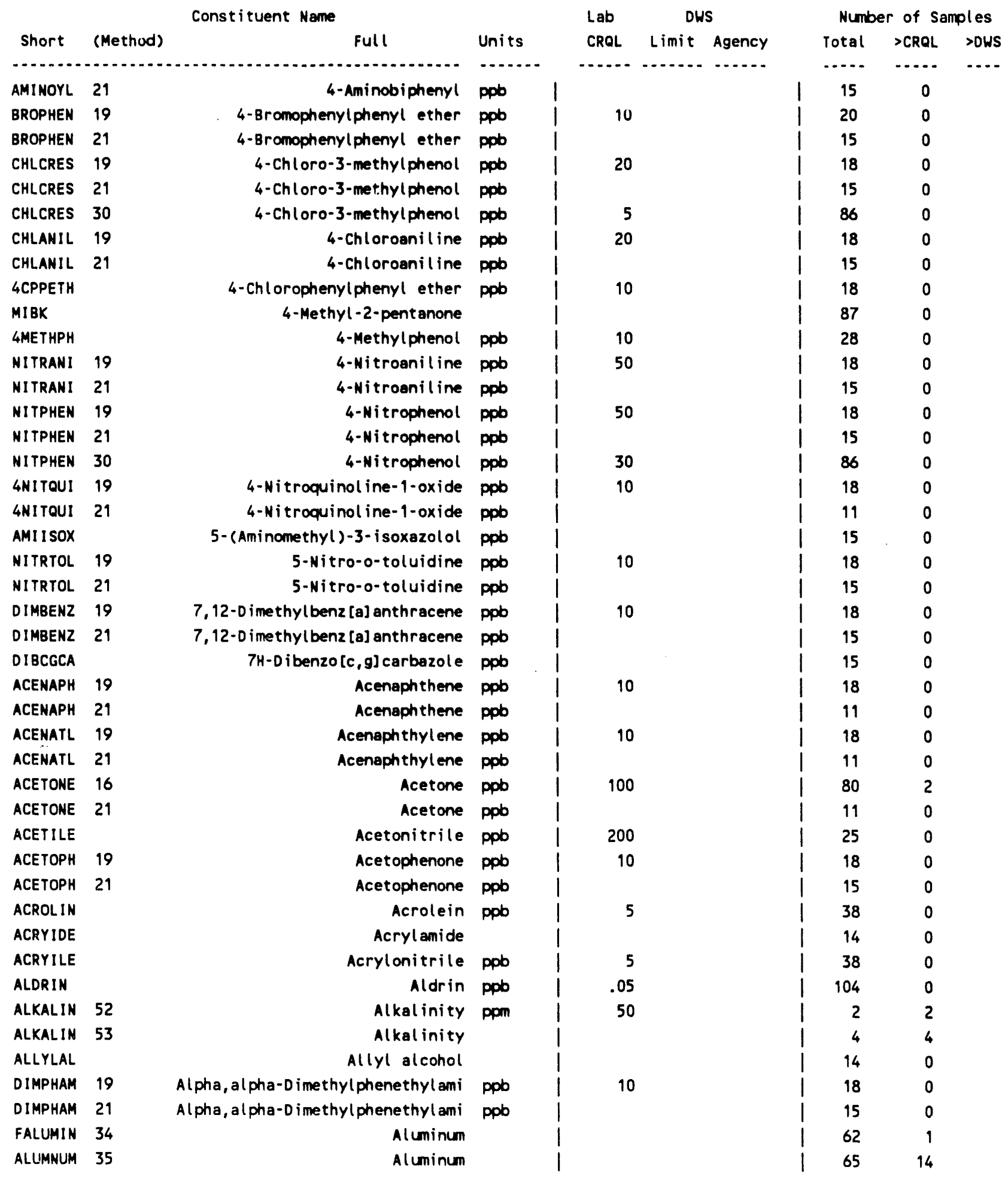


(sheet 7 of 15)

\begin{tabular}{|c|c|c|c|c|c|c|c|c|c|}
\hline \multirow[b]{2}{*}{ Short } & \multicolumn{2}{|r|}{ Constituent Name } & \multirow[b]{2}{*}{ Units } & \multirow{2}{*}{$\begin{array}{l}\text { Lab } \\
\text { CRQL }\end{array}$} & \multicolumn{2}{|l|}{ DWS } & \multicolumn{3}{|c|}{ Number of Samples } \\
\hline & (Method) & Full & & & Limit & Agency & Total & $>C R Q L$ & $>$ OWS \\
\hline$\ldots \ldots \ldots$ & . & , n & $\cdots+\cdots$ & $\ldots$ & $\ldots \ldots$ & $\ldots \ldots$ & $\cdots$ & $\cdots \cdots$ & $\cdots$ \\
\hline AM-241 & 147 & Americium-241 & $\mathrm{pCi} / \mathrm{L}$ & .1 & & & 5 & 1 & \\
\hline AM-241 & 77 & Americium-241 & $\mathrm{PCi} / \mathrm{L}$ & i & & & 8 & 1 & \\
\hline AMITROL & & Amitrole & ppb & | & & & 15 & 0 & \\
\hline AMmONIU & & Ammonium ion & & | & & & 137 & 15 & \\
\hline ANILINE & 19 & Aniline & ppb & 10 & & & 18 & 0 & \\
\hline ANILINE & 21 & Aniline & ppb & | & & & 15 & 0 & \\
\hline ANTHRA & 19 & Anthracene & ppb & 10 & & & 18 & 0 & \\
\hline ANTHRA & 21 & Anthrucene & ppb & | & & & 11 & 0 & \\
\hline ANTIONY & 34 & Antimony & ppb & 200 & & & 112 & 0 & \\
\hline ANTIONY & 35 & Antimony & & 1 & & & 63 & 0 & \\
\hline FANTIMO & 34 & Antimony, filtered & ppb & 200 & & & 174 & 0 & \\
\hline $58-125$ & & Ant imony - 125 & $\mathrm{pCi} / \mathrm{L}$ & | & & & 8 & 0 & \\
\hline ARAMITE & 19 & Aramite & ppb & 10 & & & 18 & $a$ & \\
\hline ARAMITE & 21 & Aramite & ppb & 1 & & & 15 & 0 & \\
\hline AR1016 & 17 & Aroclor-1016 & ppob & i & & & 22 & 0 & \\
\hline AR1016 & 33 & Aroclor-1016 & & 1 & & & 21 & 0 & \\
\hline AR1221 & 17 & Aroclor-1221 & ppb & 1 & & & 22 & 0 & \\
\hline AR1221 & 33 & Aroclor-1221 & & 1 & & & 21 & 0 & \\
\hline AR1232 & 17 & Aroclor-1232 & ppb & 1 & & & 22 & 0 & \\
\hline AR1232 & 33 & Aroclor-1232 & & | & & & 21 & 0 & \\
\hline AR1242 & 17 & Aroclor-1242 & ppb & 1 & & & 22 & 0 & \\
\hline AR1242 & 33 & Aroclor- 1242 & & 1 & & & 21 & 0 & \\
\hline AR 1248 & 17 & Aroclor -1248 & ppb & 1 & & & 22 & 0 & \\
\hline AR 1248 & 33 & Aroclor -1248 & & i & & & 21 & 0 & \\
\hline Ah 1254 & 17 & Aroclor-1254 & ppob & | & & & 22 & 0 & \\
\hline AR1254 & 33 & Aroclor-1254 & & 1 & & & 21 & 0 & \\
\hline AR1260 & 17 & Aroclor- 1260 & ppob & | & & & 22 & 0 & \\
\hline AR 1260 & 33 & Aroclor -1260 & & 1 & & & 21 & 0 & \\
\hline AURAMIN & & Auramine & ppob & 1 & & & 15 & 0 & \\
\hline BENZCAC & & Benz $[c]$ acridine & ppb & 1 & & & 15 & 0 & \\
\hline BENZENE & 16 & Benzene & ppb & 1 & 5 & EPA & 83 & 0 & 2 \\
\hline BENZENE & 25 & Benzene & ppb & 1 & 5 & EPA & 3 & 0 & 0 \\
\hline BENOICM & & Benzene, dichloromethyl- & ppb & | & & & 15 & 0 & \\
\hline BENTHOL & & Benzenethiol & ppb & | & & & 15 & 0 & \\
\hline BENDINE & & Benzidine & ppb & | & & & 15 & 0 & \\
\hline BENZMAN & 19 & Benzo(a)anthracene & ppb & 10 & & & 18 & 0 & \\
\hline BENZAAN & 21 & Benzo(a) anthracene & ppb & 1 & & & 15 & 0 & \\
\hline BENZOPY & 19 & Btizo(a)pyrene & ppob & 10 & & & 18 & 0 & \\
\hline BENZNPY & 21 & Benzo( $a$ )pyrene & ppb & 1 & & & 15 & 0 & \\
\hline BENZBFL & 19 & Benzo(b)fluoranthene & ppb & 10 & & & 18 & 0 & \\
\hline BENZBFL & 21 & Benzo(b) fluoranthene & ppob & 1 & & & 15 & 0 & \\
\hline BGHIPER & 19 & Benzo(ghi)perylene & ppo & 10 & & & 18 & 0 & \\
\hline BGHIPER & 21 & Benzo(ghi) perylene & $p p b$ & 1 & & & 11 & 0 & \\
\hline BENZJFL & & Benzo(j)fluoranthene & ppob & i & & & 15 & 0 & \\
\hline
\end{tabular}


(sheet 8 of 15)

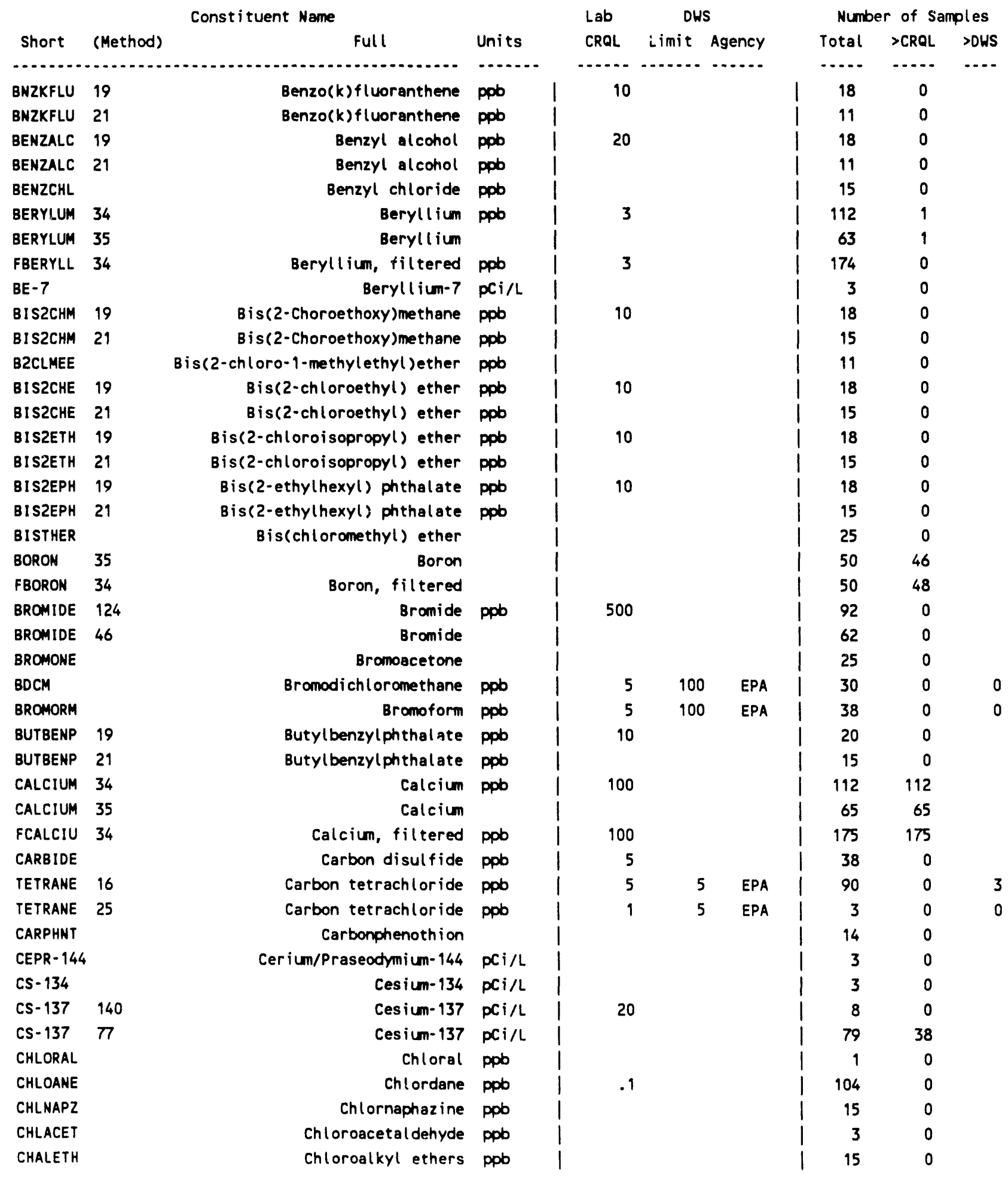


(sheet 9 of 15)

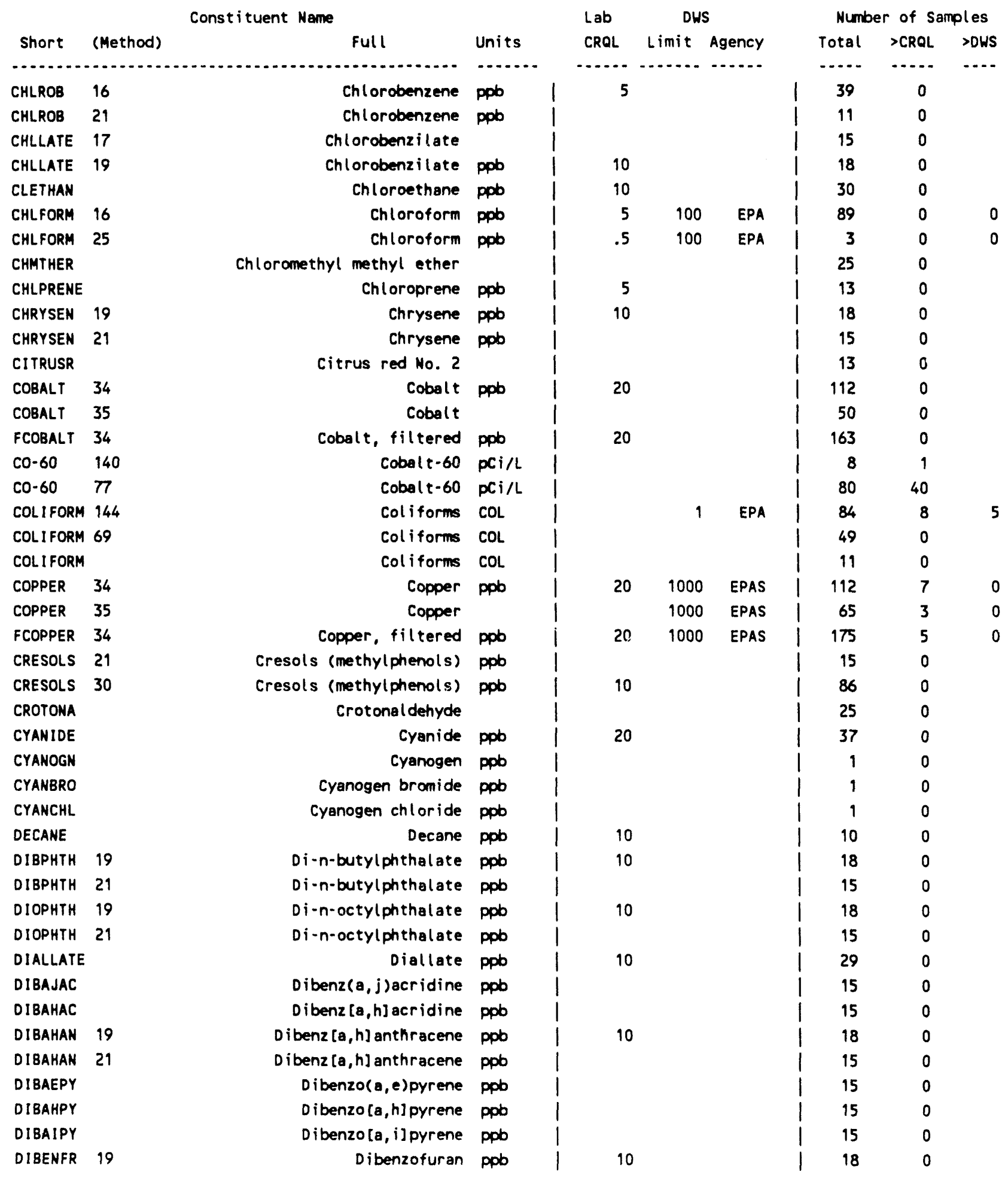


(sheet 10 of 15)

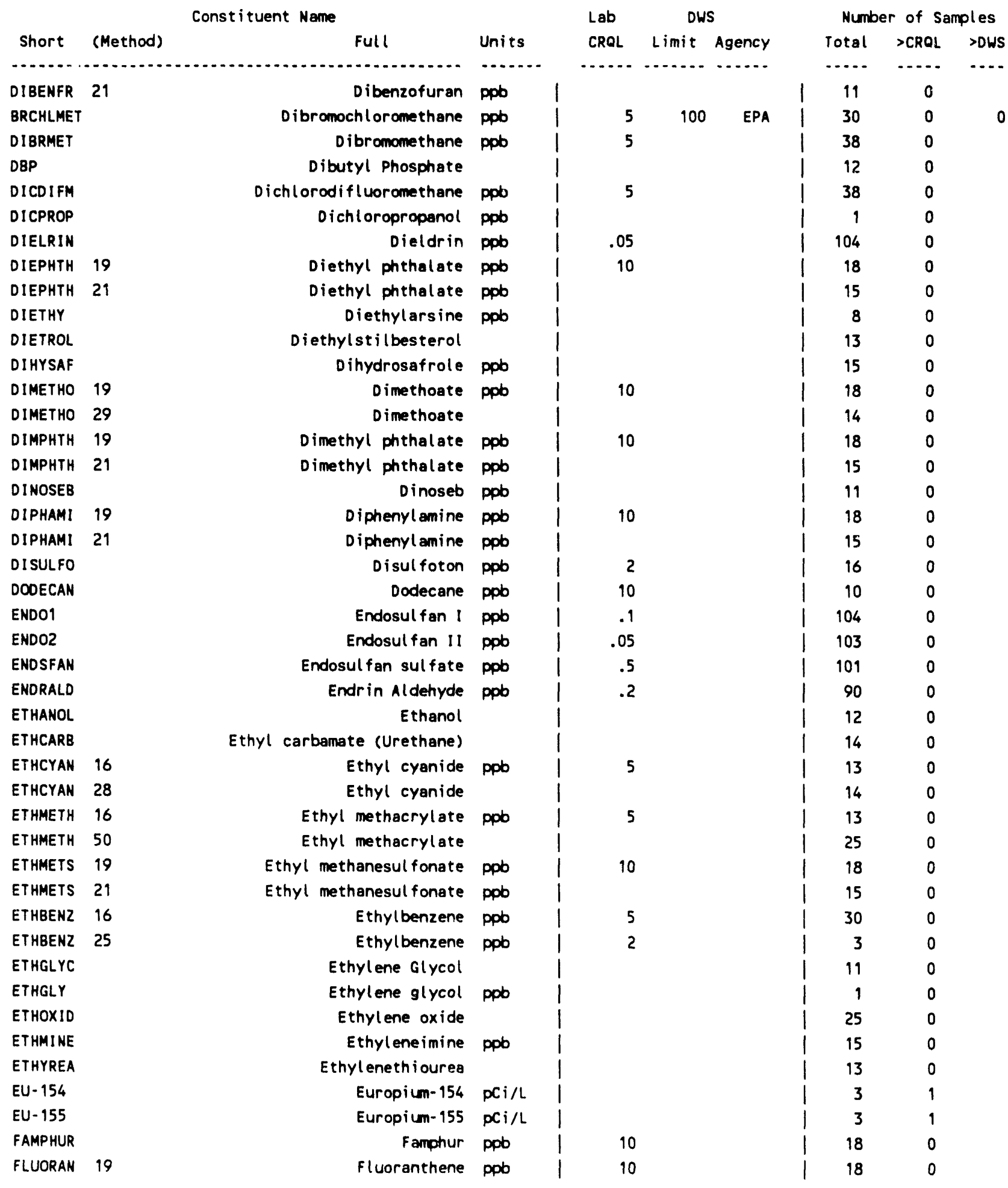


(sheet 11 of 15)

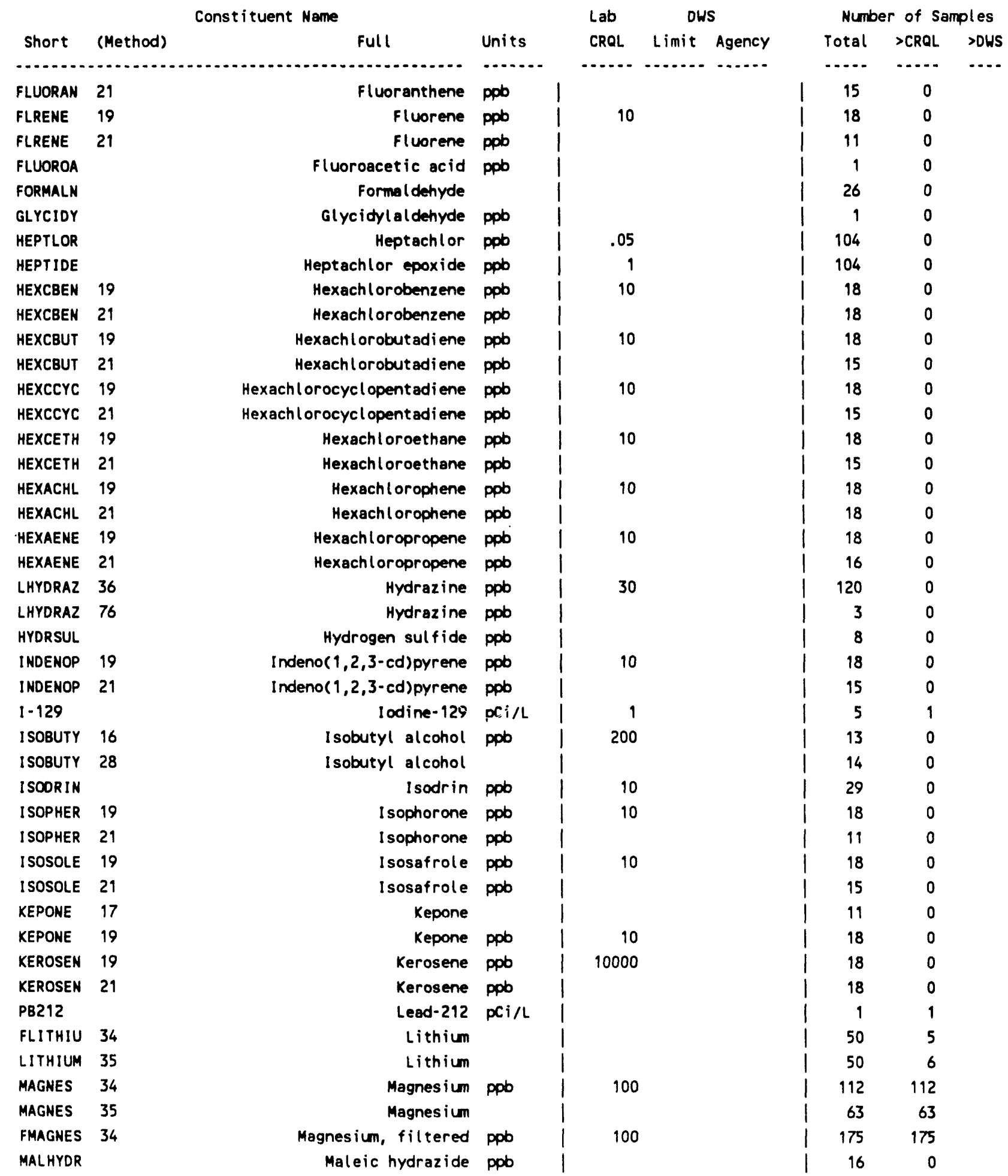


(sheet 12 of 15)

\begin{tabular}{|c|c|c|c|c|c|c|c|c|c|}
\hline \multirow[b]{2}{*}{ Short } & \multirow[b]{2}{*}{ (Method) } & \multirow[t]{2}{*}{ Constituent Name } & \multirow[b]{2}{*}{ Units } & \multirow{2}{*}{$\begin{array}{l}\text { Lab } \\
\text { CRQL }\end{array}$} & \multicolumn{2}{|c|}{ DWS } & \multicolumn{3}{|c|}{ Number of Samples } \\
\hline & & & & & Limit & Agency & Total & $>$ CRQL & $>$ OWS \\
\hline$\cdots$ & & . & ......... & -...... & $\cdots$ & ....... & $\cdots$ & -... & $\cdots$ \\
\hline MALOILE & & Malononitrile & ppb & & & & 15 & 0 & \\
\hline MELPHAL & & Melphal an & ppob & & & & 15 & 0 & \\
\hline METHACR & & Methacrylonitrile & ppob & 5 & & & 38 & 0 & \\
\hline METHTHI & & Methanethiol & & & & & 25 & 0 & \\
\hline METHAPY & & Methapyrilene & ppb & 10 & & & 33 & 0 & \\
\hline METHNYL & & Metholonyl & ppb & & & & 15 & 0 & \\
\hline IOOOMET & & Methyl Iodide & ppb & 5 & & & 38 & 0 & \\
\hline METHBRO & & Methyl bromide & ppb & 10 & & & 38 & 0 & \\
\hline METHCHL & & Methyl chloride & ppb & 10 & & & 38 & 0 & \\
\hline METHONE & & Methyl ethyl ketone & ppb & 100 & & & 90 & 0 & \\
\hline METACRY & 16 & Methyl methacrylate & ppb & 5 & & & 13 & 0 & \\
\hline METACRY & 21 & Methyl methacrylate & ppb & & & & 19 & 0 & \\
\hline METMSUL & 19 & Methyl methanesulfonate & ppb & 10 & & & 18 & 0 & \\
\hline METMSUL & 21 & Methyl methanesul fonate & ppb & & & & 15 & 0 & \\
\hline METHPAR & & Methyl parathion & ppob & .5 & & & 16 & 0 & \\
\hline METHYCH & 16 & Methytene chloride & ppob & 5 & & & 89 & 1 & \\
\hline METHYCH & 25 & Methylene chloride & ppb & 5 & & & 3 & 0 & \\
\hline METHHYD & & Methylhydrazine & ppob & & & & 1 & 0 & \\
\hline METHIOU & & Methyl thiouracil & ppob & & & & 15 & 0 & \\
\hline FMOL YBD & 34 & Molybdernum & & & & & 50 & 0 & \\
\hline$? ?$ & 35 & Molybdenum & & & & & 50 & 0 & \\
\hline MBP & & Monobutyl Phosphate & & & & & 12 & 0 & \\
\hline NNDIEHY & & N,N-Diethylhydrazine & & & & & 25 & 0 & \\
\hline NHIURET & & $\mathrm{N}-\mathrm{Ni}$ troso-N-methylurethane & ppb & & & & 15 & 0 & \\
\hline DIPRNIT & 19 & N-Nitroso-di-n-dipropylamine & ppb & 10 & & & 18 & 0 & \\
\hline DIPRNIT & 21 & N-Nitroso-di-n-dipropylamine & ppb & & & & 15 & 0 & \\
\hline NAIBUTY & 19 & N-Nitrosodi-n-butylamine & ppb & 10 & & & 18 & 0 & \\
\hline NNIBUTY & 21 & $N-N i$ trosodi-n-butylamine & ppb & & & & 15 & 0 & \\
\hline NNIDIEA & & $\mathrm{N}-\mathrm{Ni}$ trosodiethanol amine & & & & & 15 & 0 & \\
\hline NNIDIEY & 19 & N-Nitrosodiethylamine & ppb & 10 & & & 18 & 0 & \\
\hline NHIDIEY & 21 & $\mathrm{~N}$-Nitrosodiethylamine & ppb & & & & 15 & 0 & \\
\hline NHIDIME & 19 & N-Nitrosodimethylamine & ppb & 10 & & & 18 & 0 & \\
\hline NNIDIME & 21 & $N-N$ itrosodimethylamine & ppb & & & & 15 & 0 & \\
\hline NND IPHA & 19 & $N-N$ itrosodiphenyl amine & ppo & 10 & & & 18 & 0 & \\
\hline NNDIPHA & 21 & N-Nitrosodiphenylamine & ppob & & & & 11 & 0 & \\
\hline NNIMETH & 19 & $N-N i$ trosome thyle thylamine & ppb & 10 & & & 18 & 0 & \\
\hline NNIMETH & 21 & $\mathrm{~N}-\mathrm{Ni}$ trosomethyle thylamine & ppb & & & & 15 & 0 & \\
\hline NNIVINY & & N-Nitrosomethylvinylamine & ppb & & & & 15 & 0 & \\
\hline NNIMORP & $19^{\circ}$ & N-Nitrosomorphol ine & ppb & 10 & & & 18 & 0 & \\
\hline NNIMORP & 21 & $\mathrm{~N}-\mathrm{Ni}$ trosomorphol ine & ppb & & & & 15 & 0 & \\
\hline NNINICO & & N-Nitrosonornicotine & ppb & & & & 15 & 0 & \\
\hline NNIPIPE & 19 & N-Nitrosopiperidine & ppb & 10 & & & 18 & 0 & \\
\hline NNIPIPE & 21 & $\mathrm{~N}-\mathrm{Nitrosopiperidine}$ & ppb & & & & 15 & 0 & \\
\hline PHENREA & & N-Phenyl th iourea & & & & & 13 & 0 & \\
\hline
\end{tabular}


(sheet 13 of 15)

\begin{tabular}{|c|c|c|c|c|c|c|c|c|c|}
\hline \multirow[b]{2}{*}{ Short } & \multicolumn{3}{|c|}{ Constituent Name } & \multirow{2}{*}{$\begin{array}{l}\text { Lab } \\
\text { CRQL }\end{array}$} & \multicolumn{2}{|c|}{ DWS } & \multicolumn{3}{|c|}{ Number of Samples } \\
\hline & (Method) & Full & Units & & Limit & Agency & Total & $>C R Q L$ & $>$ OWS \\
\hline …....... & $\cdots \cdot$ & . & $\cdots \cdots$ & $\cdots \cdots$ & $\cdots+\cdots$ & $\cdots \cdots$ & $\cdots$ & $\cdots \cdot$ & $\cdots$ \\
\hline PROPYLA & & N-Propylamine & & & & & 14 & 0 & \\
\hline NAPHTHA & 19 & Naphthal ene & ppob & 10 & & & 28 & 0 & \\
\hline NAPHTHA & 21 & Naphthal ene & ppb & & & & 18 & 0 & \\
\hline NICKEL & 34 & Nickel & ppob & 30 & & & 112 & 63 & \\
\hline NICKEL & 35 & Nickel & & & & & 65 & 44 & \\
\hline FNICKEL & 34 & Nickel, filtered & ppob & 30 & & & 175 & 8 & \\
\hline NICOTIN & & Nicotinic acid & ppob & & & & 16 & 0 & \\
\hline NITRATE & 124 & Nitrate & ppb & 200 & 45000 & EPA & 92 & 88 & 1 \\
\hline NITRATE & 130 & Nitrate & ppb & 200 & 45000 & EPA & 21 & 21 & 0 \\
\hline NITRATE & 46 & Nitrate & & & 45000 & EPA & 80 & 68 & 0 \\
\hline NITRATE & 76 & Nitrate & Ppm & & & & 15 & 15 & \\
\hline NITRITE & 124 & Nitrite & ppb & 200 & & & 92 & 0 & \\
\hline NITRITE & 55 & Nitrite & & & & & 62 & 0 & \\
\hline NITBENZ & 19 & Nitrobenzene & ppb & 10 & & & 18 & 0 & \\
\hline NITBENZ & 21 & Nitrobenzene & ppb & & & & 15 & 0 & \\
\hline NITRPYR & 19 & Nitrosopyrrol idine & ppb & 10 & & & 18 & 0 & \\
\hline NITRPYR & 21 & Nitrosopyrrolidine & ppb & & & & 15 & 0 & \\
\hline TR!PHOS & 19 & 0,0,0-Triethyl phosphorothioste & ppb & 10 & & & 18 & 0 & \\
\hline TRIPHOS & 21 & 0,0,0-Triethyl phosphorothioate & ppb & & & & 15 & 0 & \\
\hline DIPHOS & & 0,0-diethyl0-2-pyraz inylphosphor & ppb & 10 & & & 29 & 0 & \\
\hline OSMIUM & & Osmium & ppb & & & & 3 & 0 & \\
\hline PCDDS & & PCDDs & & & & & 10 & 0 & \\
\hline PCDFS & & PCDFs & & & & & 10 & 0 & \\
\hline PARALDE & & Paraldehyde & & & & & 14 & 0 & \\
\hline PARATHI & 19 & Parathion & ppb & 10 & & & 18 & 0 & \\
\hline PARATHI & 29 & Parathion & & & & & 14 & 0 & \\
\hline PENTCHB & 19 & Pentach lorobenzene & ppb & 10 & & & 18 & 0 & \\
\hline PENTCHB & 21 & Pentachlorobenzene & ppb & & & & 18 & 0 & \\
\hline PENTACH & & Pentachloroethane & ppb & 5 & & & 38 & 0 & \\
\hline PENTCHN & 19 & Pentachloronitrobenzene (PCNB) & ppb & 10 & & & 18 & 0 & \\
\hline PENTCHN & 21 & Pentachloronitrobenzene (PCNB) & ppb & & & & 15 & 0 & \\
\hline PENTCHP & 19 & Pentachlorophenol & ppb & 50 & & & 28 & 0 & \\
\hline PENTCHP & 21 & Pentachlorophenol & ppb & & & & 15 & 0 & \\
\hline PENTCHP & 30 & Pentachlorophenol & pob & 100 & & & 86 & 0 & \\
\hline PERCHLO & & Perchlorate & & & & & 9 & 0 & \\
\hline PHENT IN & 19 & Phenacet in & ppb & 10 & & & 18 & 0 & \\
\hline PHENTIN & 21 & Phenacetin & ppb & & & & 15 & 0 & \\
\hline PHENANT & 19 & Phenanthrene & ppb & 10 & & & 18 & 0 & \\
\hline PHENAKT & 21 & Phenanthrene & ppb & & & & 11 & 0 & \\
\hline PHENINE & & Phenylenediamine & ppb & & & & 15 & 0 & \\
\hline PHORATE & & Phorate & ppob & 2 & & & 13 & 2 & \\
\hline PHOSPHA & 124 & Phosphate & ppb & 400 & & & 95 & 9 & \\
\hline PHOSPHA & 46 & Phosphate & & & & & 69 & 4 & \\
\hline PHTHEST & & Phthalic acid esters & ppb & & & & 15 & 0 & \\
\hline
\end{tabular}


(sheet 14 of 15)

\begin{tabular}{|c|c|c|c|c|c|c|c|c|c|}
\hline \multirow[b]{2}{*}{ Short } & \multirow[b]{2}{*}{ (Method) } & \multirow[t]{2}{*}{ Constituent Name } & \multirow[b]{2}{*}{ Units } & \multirow{2}{*}{$\begin{array}{l}\text { Lab } \\
\text { CROL }\end{array}$} & \multicolumn{2}{|l|}{ DWS } & \multicolumn{3}{|c|}{ Number of Samples } \\
\hline & & & & & Limit & Agency & Total & $>\mathrm{CRQL}$ & $>$ OWS \\
\hline 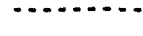 & (..... & - & (......... & n.... & (n) & (n) & $\cdots \cdot$ & $\cdots$ & $\cdots$ \\
\hline PU-238 & 146 & Plutonium-238 & $\mathrm{PCi} / \mathrm{L}$ & .1 & & & 8 & 0 & \\
\hline$P U-238$ & 77 & Plutonium-238 & $\mathrm{PC} i / L$ & & & & 20 & 0 & \\
\hline PU39-40 & 146 & Plutonium-239/40 & $\mathrm{PCi} / \mathrm{L}$ & .1 & & & 8 & 0 & \\
\hline PU39-40 & 77 & Plutonium-239/40 & $\mathrm{PC} i / L$ & & & & 20 & 1 & \\
\hline POTASUM & 34 & Potassium & ppb & 300 & & & 112 & 112 & \\
\hline POTASUM & 35 & Potassium & & & & & 65 & 65 & \\
\hline FPOTASS & 34 & Potassium, filtered & ppb & 300 & & & 175 & 175 & \\
\hline PRONIDE & 19 & Pronemide & ppb & 10 & & & 18 & 0 & \\
\hline PRONIDE & 21 & Pronamide & ppo & & & & 15 & 0 & \\
\hline PROPCN & & Propionitrile & & & & & 17 & 0 & \\
\hline PYRENE & 19 & Pyrene & ppb & 10 & & & 18 & 0 & \\
\hline PYRENE & 21 & Pyrene & ppb & & & & 11 & 0 & \\
\hline PYRIDIN & & Pyridine & ppb & 5 & & & 39 & 0 & \\
\hline RESERP I & & Reserpine & ppb & & & & 15 & 0 & \\
\hline RESORC 1 & & Resorcinol & ppb & & & & 15 & 0 & \\
\hline$R U-106$ & 140 & Ruthenium- 106 & pCi/L & & & & 8 & 0 & \\
\hline$R U-106$ & 77 & Ruthenium- 106 & $\mathrm{pCi} / \mathrm{L}$ & & & & 79 & 35 & \\
\hline SAFROL & 19 & Safrol & ppb & 10 & & & 18 & 0 & \\
\hline SAFROL & 21 & Safrol & ppb & & & & 15 & 0 & \\
\hline FSILICO & 34 & silicon & & & & & 50 & 50 & \\
\hline SILICON & 35 & silicon & & & & & 50 & 50 & \\
\hline STRONUM & 35 & Stront $i$ ism & & & & & 63 & 60 & \\
\hline FSTRONUM & 34 & Strontium, filtered & & & & & 61 & 61 & \\
\hline SR-90 & 141 & Stront ium-9) & $\mathrm{pCi} / \mathrm{L}$ & 5 & 8 & EPA & 5 & 0 & 0 \\
\hline SR-90 & 77 & Strontium-90 & $\mathrm{pCi} / \mathrm{L}$ & & 8 & EPA & 71 & 32 & 2 \\
\hline STRYCHN & & strychnine & ppb & & & & 16 & 0 & \\
\hline STYRENE & & Styrene & ppb & 5 & & & 30 & 0 & \\
\hline SULFIDE & & Sulfide & ppb & 10000 & & & 16 & 0 & \\
\hline TC-99 & 143 & Technetium-99 & & & & & 8 & 6 & \\
\hline TC-99 & 77 & Technet ium-99 & $p C i / L$ & & & & 1 & 1 & \\
\hline TMP_C & & Temperature, field & DegC & & & & 264 & 264 & \\
\hline PERCENE & 16 & Tetrachloroethene & ppob & 5 & & & 90 & 0 & \\
\hline PERCENE & 25 & Tetrachloroethene & ppb & .5 & & & 3 & 0 & \\
\hline TETPHNL & & Tetrachlorophenols & ppb & 10 & & & 86 & 1 & \\
\hline TETRADE & & Tetradecane & ppob & 10 & & & 10 & 0 & \\
\hline PYROPHOS & & Tetraethyldi thiopyrophosphate & ppob & 10 & & & 18 & 0 & \\
\hline TETEPYR & & Tetraethylpyrophosphate & & & & & 14 & 0 & \\
\hline TAF & & Tetrahydrofuran & & & & & 79 & 0 & \\
\hline THALLIUM & 42 & Thallium & ppb & 5 & & & 2 & 0 & \\
\hline THALLIUM & 76 & Thallium & ppb & 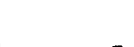 & & & 12 & 0 & \\
\hline FTHALIUM & 42 & Thallium, filtered & ppb & 5 & & & 13 & 0 & \\
\hline THIONOX & & Thiofanox & ppb & & & & 15 & 0 & \\
\hline THIOURA & & Thiourea & & & & & 13 & 0 & \\
\hline THIURAM & & Thiuram & ppb & & & & 15 & 0 & \\
\hline
\end{tabular}


(sheet 15 of 15)

\begin{tabular}{|c|c|c|c|c|c|c|c|c|c|c|}
\hline \multicolumn{5}{|c|}{ Const ituent Name } & \multicolumn{3}{|l|}{ Lab } & \multicolumn{3}{|c|}{ Number of Samples } \\
\hline Short & (Method) & Full & Units & & CROL & Limit $A$ & Agency & Total & $>\mathrm{CRQL}$ & >DWS \\
\hline$\cdots+\ldots . .$. & (n. & , & $\cdots \ldots$ & & $\cdots+\cdots$ & $\cdots+\ldots$ & $\cdots$ & $\cdots$ & $\cdots \cdot$ & $\cdots$ \\
\hline $\operatorname{TIN}$ & 34 & Tin, filtered & & 1 & & & & 112 & 0 & \\
\hline FTIN & 34 & Tin, filtered & & i & & & & 163 & 0 & \\
\hline TIN & 35 & Tin, filtered & & 1 & & & & 50 & 0 & \\
\hline FTITAN & 34 & Titanium & & 1 & & & & 50 & 0 & \\
\hline TITAN & 35 & Titanium & & l & & & & 50 & 2 & \\
\hline TOLUENE & 16 & Toluene & ppob & i & 5 & & & 83 & 0 & \\
\hline TOLUENE & 25 & Toluene & ppob & i & 2 & & & 3 & 0 & \\
\hline TOLUDIA & & Tolvenediamine & ppb & 1 & & & & 15 & 0 & \\
\hline TC & & Total Carbon & ppob & i & 2000 & & & 59 & 59 & \\
\hline TOS & & Total Dissolved Solids & & 1 & & & & 9 & 9 & \\
\hline TRIBUTPH & & Tributyl Phosphate & ppob & i & & & & 28 & 0 & \\
\hline TRIBUPH & & Tributylphosphoric Acid & pob & i & & & & 14 & 0 & \\
\hline TRICENE & 16 & Trichloroethene & popb & 1 & 5 & 5 & EPA & 90 & 0 & 3 \\
\hline TRICENE & 25 & Trichloroethene & ppob & i & 1 & 5 & EPA & 3 & 0 & 0 \\
\hline TRCMEOL & & Trichloromethanethiol & & 1 & & & & 25 & 0 & \\
\hline TRCMFLM & & Trichloromonofluorome thane & ppob & i & 5 & & & 38 & 0 & \\
\hline TRIPHNL & & Trichlorophenols & ppob & i & 5 & & & 86 & 0 & \\
\hline TRISPHO & & Tris(2,3-dibromopropyl) phosphat & ppob & 1 & & & & 15 & 0 & \\
\hline TRITIUM & 142 & Tritium & $\mathrm{PCi} / \mathrm{L}$ & i & 500 & 20000 & EPA & 116 & 92 & 54 \\
\hline TRITIUM & 77 & Tritiun & $\mathrm{pCi} / \mathrm{L}$ & i & & 20000 & EPA & 125 & 85 & 30 \\
\hline UNKNOWN & & Unknown & ppb & i & & & & 1 & 1 & \\
\hline UNKALI & & Unknown aliphatic hydrocarbon & ppb & 1 & & & & 1 & 1 & \\
\hline URANIUM & 145 & Uranium & ppb & i & .5 & & & 9 & 9 & \\
\hline URANIUM & 77 & Uranium & $\mathrm{pCi} / \mathrm{L}$ & 1 & & & & 47 & 46 & \\
\hline$U-234$ & & Uranium-234 & $\mathrm{PCi} / \mathrm{L}$ & i & & & & 6 & 6 & \\
\hline$U-235$ & & Uranium-235 & $\mathrm{PCi} / \mathrm{L}$ & 1 & & & & 6 & 2 & \\
\hline$U-238$ & & Uranium-238 & $\mathrm{PC} i / \mathrm{L}$ & 1 & & & & 6 & 6 & \\
\hline VANADUM & 34 & Vanadium & ppob & i & 30 & & & 112 & 35 & \\
\hline VAMADUM & 35 & Vanadium & & i & & & & 65 & 54 & \\
\hline FVANADI & 34 & Vanadium, filtered & ppob & i & 30 & & & 175 & 83 & \\
\hline VINYLAC & & Vinyl acetate & ppb & 1 & 5 & & & 30 & 0 & \\
\hline VINYIDE & 16 & Vinyl chloride & $p p b$ & 1 & 10 & 2 & EPA & 82 & 0 & $82^{\star}$ \\
\hline VINYIDE & 25 & Vinyl chloride & ppob & i & 2 & 2 & EPA & 3 & 0 & 0 \\
\hline WARFRIN & & Marfarin & $p p b$ & 1 & & & & 15 & 0 & \\
\hline M-XYLE & & $x y$ lene(m) & ppb & i & 5 & & & 13 & 0 & \\
\hline XYLENEO & & $x y(e n e(0)$ & ppob & i & 5 & & & 13 & 0 & \\
\hline XYLENEP & & $x y l e n e(p)$ & ppob & i & 5 & & & 13 & 0 & \\
\hline OPXYLE & & xylenes & & 1 & & & & 68 & 0 & \\
\hline XYLENE & 16 & Xylenes (total) & ppb & 1 & 5 & & & $\pi$ & 0 & \\
\hline XYLENE & 25 & $x y l$ enes (total) & ppb & i & 5 & & & 3 & 0 & \\
\hline ZINC & 34 & zinc & ppb & 1 & 10 & & & 112 & 60 & \\
\hline ZINC & 35 & zinc & & i & & & & 65 & 46 & \\
\hline FZINC & 34 & zinc, filtered & ppob & i & 10 & & & 175 & 59 & \\
\hline $2 N-65$ & & Zinc -65 & $\mathrm{PCi} / \mathrm{L}$ & 1 & & & & 3 & 0 & \\
\hline
\end{tabular}


(sheet 16 of 15)

\begin{tabular}{|c|c|c|c|c|c|c|c|c|c|}
\hline \multirow[b]{2}{*}{ Short } & \multirow[b]{2}{*}{ (Method) } & \multirow[t]{2}{*}{ Constituent Name } & \multirow[b]{2}{*}{ Units } & \multirow{2}{*}{$\begin{array}{l}\text { Lab } \\
\text { CRQL }\end{array}$} & \multicolumn{2}{|c|}{ DWS } & \multicolumn{3}{|c|}{ Number of Samples } \\
\hline & & & & & Limit & Agency & Total & $>C R Q L$ & $>$ DWS \\
\hline$\ldots \ldots$ & $\ldots . . .$. & . & $\ldots \ldots$ & $\cdots \cdots$ & $\cdots \ldots$ & $\ldots \ldots$ & $\ldots$. & $\cdots$ & $\cdots$ \\
\hline FZIRCON & 34 & Zirconium & & & & & 50 & 0 & \\
\hline$? ?$ & 35 & Zirconium & & & & & 50 & 0 & \\
\hline ZRNB-95 & & Zirconium/Niobium-95 & $\mathrm{pCi} / \mathrm{L}$ & & & & 3 & 0 & \\
\hline ALLYLCL & & allylchloride & ppb & 100 & & & 30 & 0 & \\
\hline CIS12DE & & cis-1,2-Dichloroethylene & ppb & 1 & & & 3 & 0 & \\
\hline TDICPENE & & cis-1,3-0 ichloropropene & ppob & 5 & & & 13 & 0 & \\
\hline MCRESOL & & m-Cresol & ppob & 10 & & & 28 & 0 & \\
\hline DINBENZ & & m-dinitrobenzene & ppob & 10 & & & 33 & 0 & \\
\hline 2NITPH & & o-Nitroaniline & ppob & & & & 11 & 0 & \\
\hline ONITANI & & $0-N i$ troaniline & ppob & & & & 11 & 0 & \\
\hline OTOLHYD & & 0-Toluidine & ppob & 10 & & & 18 & 0 & \\
\hline TOLDHYD & & O-Toluidine hydrochloride & ppb & & & & 15 & 0 & \\
\hline PBENZQU & & p-Benzoquinone & ppob & & & & 15 & 0 & \\
\hline DIMEAMB & 19 & P-D ime thyl aminoazobenzene & ppob & 10 & & & 18 & 0 & \\
\hline DIMEAMB & 21 & P-Dimethyl aminoazobenzene & ppb & & & & 15 & 0 & \\
\hline PHEND IA & & p-Phenyl enediamine & ppb & 10 & & & 18 & 0 & \\
\hline SYMTRIN & 19 & sym.-Trini trobenzene & ppob & 10 & & & 18 & 0 & \\
\hline SYMTRIN & 21 & sym-Trinitrobenzene & ppb & & & & 15 & 0 & \\
\hline TRANDCE & 16 & trans-1,2-Dichloroethylene & ppob & 5 & & & 82 & 0 & \\
\hline TRANDCE & 25 & trans-1,2-Dichloroethylene & & & & & 3 & 0 & \\
\hline DICPENE & & trans-1,3-Dichloropropene & ppb & 5 & & & 13 & 0 & \\
\hline TDIBUTEN & & trans-1,4-dichloro-2-butene & ppob & 5 & & & 25 & 0 & \\
\hline
\end{tabular}

For explanation of this table, see section 1.4 of report. 
(sheet 1 of *t)

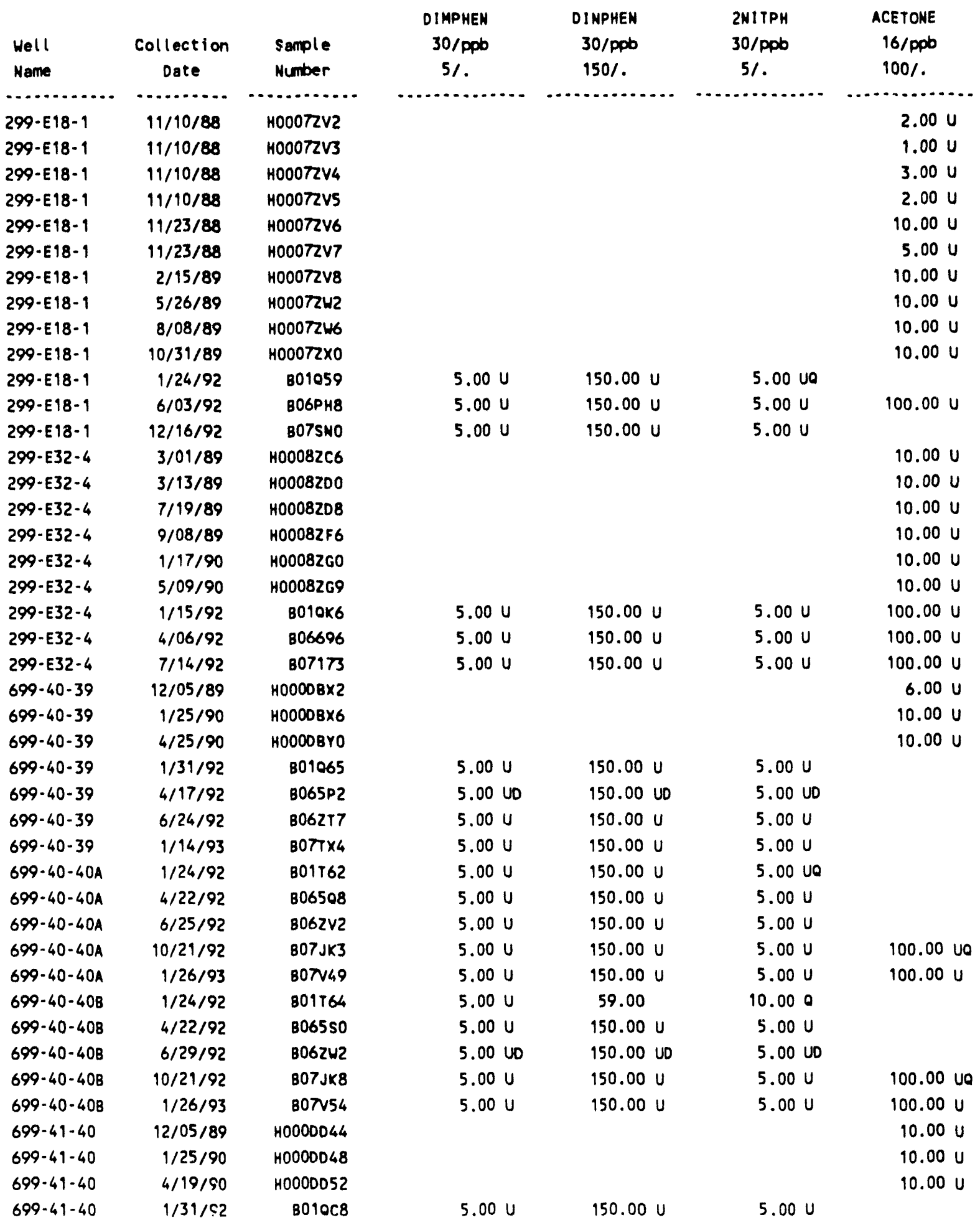


(sheet 2 of $*$ )

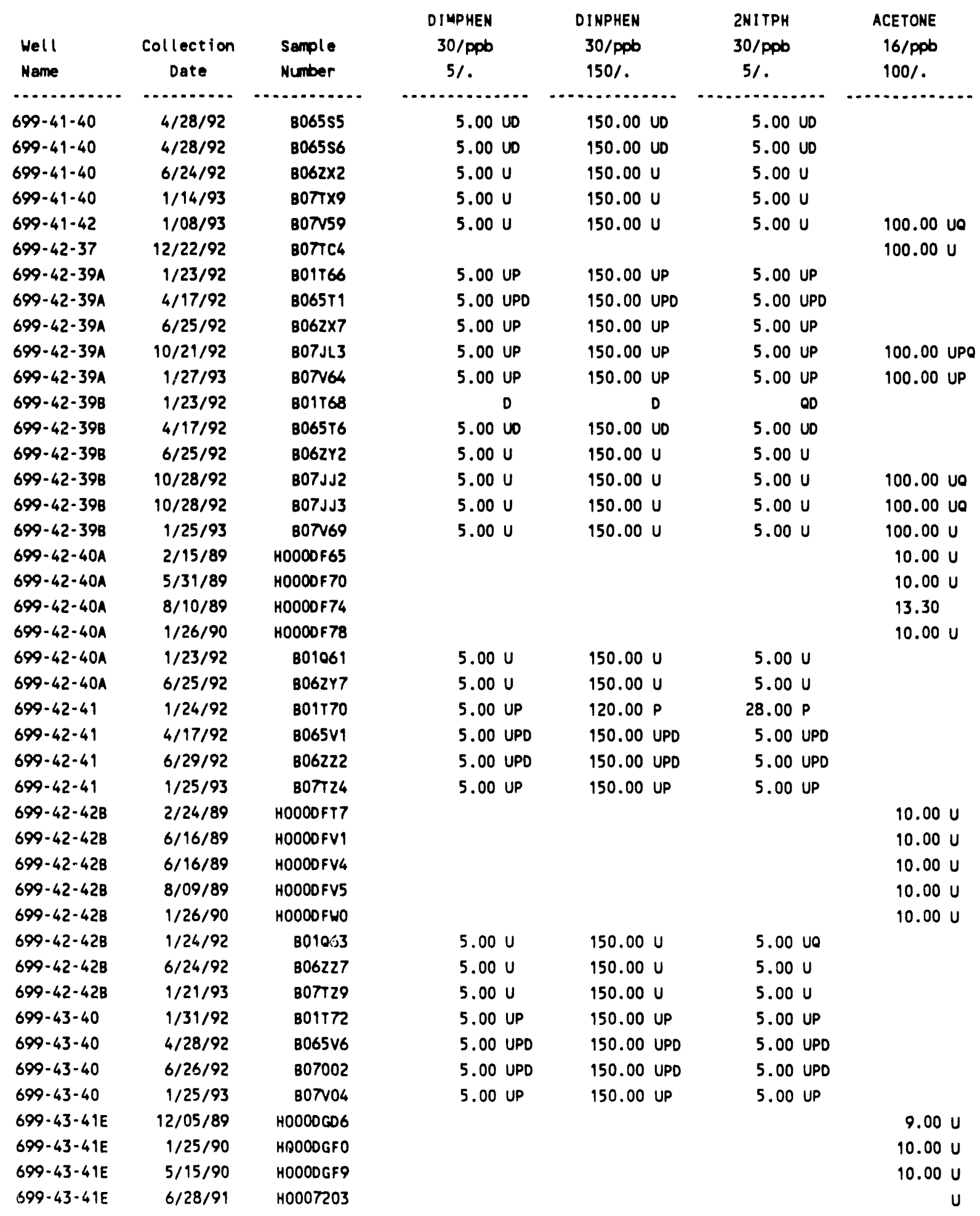


(sheet 3 of **)

\begin{tabular}{|c|c|c|c|c|c|c|}
\hline $\begin{array}{l}\text { Hell } \\
\text { Name }\end{array}$ & $\begin{array}{c}\text { Collection } \\
\text { Date }\end{array}$ & $\begin{array}{l}\text { Sample } \\
\text { Number }\end{array}$ & $\begin{array}{c}\text { DIMPHEN } \\
30 / \text { pPb } \\
5 / .\end{array}$ & $\begin{array}{c}\text { DINPHEN } \\
30 / \text { ppb } \\
150 /\end{array}$ & $\begin{array}{c}2 N I T P H \\
30 / p p b \\
5 / .\end{array}$ & $\begin{array}{c}\text { ACETONE } \\
16 / \mathrm{ppb} \\
100 /\end{array}$ \\
\hline י & 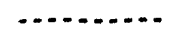 & . & . & - & . & $\cdots$ \\
\hline $699-43-41 E$ & $6 / 28 / 91$ & H0OO7204 & & & & U \\
\hline $699-43-41 E$ & $1 / 23 / 92$ & 801003 & $5.00 \mathrm{U}$ & $150.00 \mathrm{U}$ & 5.00 UQ & \\
\hline $699-43-41 E$ & $4 / 17 / 92$ & $8065 P 4$ & 5.00 UD & 150.00 UD & 5.00 UD & $100.00 \mathrm{U}$ \\
\hline $699-43-41 E$ & $6 / 24 / 92$ & $8062 \sqrt{3}$ & $5.00 \mathrm{U}$ & $150.00 \mathrm{U}$ & $5.00 \mathrm{U}$ & $100.00 \mathrm{U}$ \\
\hline $699-43-41 E$ & $1 / 25 / 93$ & B07v09 & $5.00 \mathrm{U}$ & $150.00 \mathrm{U}$ & $5.00 \mathrm{U}$ & \\
\hline $699-43-41 F$ & $12 / 05 / 89$ & H0OODGG8 & & & & $8.00 \mathrm{U}$ \\
\hline $699-43-41 F$ & $1 / 25 / 90$ & HOOOOGH2 & & & & $10.00 \mathrm{U}$ \\
\hline $699-43-41 F$ & $4 / 18 / 90$ & HOOOOGH6 & & & & $10.00 \mathrm{U}$ \\
\hline $699-43-41 F$ & $7 / 02 / 91$ & H00071Y5 & & & & $u$ \\
\hline $699-43-41 F$ & $5 / 05 / 92$ & B065RO & 5.00 UD & 150.00 UD & 5.00 UD & $100.00 \mathrm{U}$ \\
\hline $699-43-41 F$ & $6 / 25 / 92$ & $B 062 W 7$ & $5.00 \mathrm{U}$ & $150.00 \mathrm{U}$ & $5.00 \mathrm{U}$ & $100.00 \mathrm{U}$ \\
\hline $699-43-41 F$ & $1 / 22 / 93$ & Bo7v14 & $5.00 \mathrm{U}$ & $150.00 \mathrm{U}$ & $5.00 \mathrm{U}$ & \\
\hline $699-43-416$ & $1 / 23 / 92$ & B01T74 & $5.00 \mathrm{U}$ & $150.00 \mathrm{U}$ & 5.00 Ua & \\
\hline $699-43-41 G$ & $4 / 17 / 92$ & B065W1 & 5.00 UD & 150.00 UD & 5.00 UD & \\
\hline $699-43-416$ & $6 / 26 / 92$ & B07007 & 5.00 UD & 150.00 UD & 5.00 UD & \\
\hline $699-43-416$ & $10 / 28 / 92$ & B07JL8 & $5.00 \mathrm{U}$ & $150.00 \mathrm{U}$ & $5.00 \mathrm{U}$ & 100.00 va \\
\hline $699-43-416$ & $1 / 25 / 93$ & B07N74 & $5.00 \mathrm{U}$ & $150.00 \mathrm{U}$ & $5.00 \mathrm{U}$ & $100.00 \mathrm{U}$ \\
\hline $699-43-42 \mathrm{~J}$ & $2 / 24 / 89$ & HOOODGP6 & & & & $10.00 \mathrm{U}$ \\
\hline $699-43-42 J$ & $6 / 15 / 89$ & $H 000 D G 00$ & & & & $10.00 \mathrm{U}$ \\
\hline $699-43-42 J$ & $8 / 09 / 89$ & H0OODGO4 & & & & $6.00 \mathrm{U}$ \\
\hline $699-43-42 \mathrm{~J}$ & $8 / 09 / 89$ & H0000G07 & & & & 12.00 \\
\hline $699-43-42 \mathrm{~J}$ & $1 / 31 / 90$ & HOOODGO9 & & & & $10.00 \mathrm{U}$ \\
\hline $699-43-42 \mathrm{~J}$ & $1 / 31 / 92$ & 801549 & $5.00 \mathrm{U}$ & $150.00 \mathrm{U}$ & $5.00 \mathrm{U}$ & \\
\hline $699-43-42 \mathrm{~J}$ & $1 / 31 / 92$ & B01550 & 8.00 & $150.00 \mathrm{U}$ & $5.00 \mathrm{U}$ & \\
\hline $699-43-42 J$ & $6 / 25 / 92$ & B07012 & $5.00 \mathrm{U}$ & $150.00 \mathrm{U}$ & $5.00 \mathrm{U}$ & \\
\hline $699-43-42 \mathrm{~J}$ & $1 / 21 / 93$ & Bo7v19 & $5.00 \mathrm{U}$ & $150.00 \mathrm{U}$ & $5.00 \mathrm{U}$ & \\
\hline $699-43-43$ & $2 / 24 / 89$ & HOOOOGR7 & & & & $10.00 \mathrm{U}$ \\
\hline $699-43-43$ & $2 / 24 / 89$ & HOOOOGSO & & & & $10.00 \mathrm{U}$ \\
\hline $699-43-43$ & $6 / 15 / 89$ & H0OODGS1 & & & & $10.00 \mathrm{U}$ \\
\hline $699-43-43$ & $8 / 09 / 89$ & HOOODGS5 & & & & $10.00 \mathrm{U}$ \\
\hline $699-43-43$ & $1 / 26 / 90$ & HOOOOGS9 & & & & $10.00 \mathrm{U}$ \\
\hline $699-43-43$ & $1 / 24 / 92$ & B01067 & $5.00 \mathrm{U}$ & $150.00 \mathrm{U}$ & 5.00 Uo & \\
\hline $699-43-43$ & $4 / 22 / 92$ & B065N6 & $5.00 \mathrm{U}$ & $150.00 \mathrm{U}$ & $5.00 \mathrm{U}$ & \\
\hline $699-43-43$ & $6 / 26 / 92$ & BO70WO & 5.00 UD & 150.00 UD & 5.00 UD & \\
\hline $699-43-43$ & $10 / 26 / 92$ & B07JGS & $5.00 \mathrm{U}$ & $150.00 \mathrm{U}$ & $5.00 \mathrm{U}$ & \\
\hline $699-43-43$ & $1 / 13 / 93$ & Bo7N24 & $5.00 \mathrm{U}$ & $150.00 \mathrm{U}$ & $5.00 \mathrm{U}$ & \\
\hline $699-43-45$ & $12 / 06 / 89$ & HOOODGT4 & & & & $10.00 \mathrm{U}$ \\
\hline $699-43-45$ & $1 / 26 / 90$ & HOOOOGT8 & & & & $10.00 \mathrm{U}$ \\
\hline $699-43-45$ & $4 / 18 / 90$ & H0OODGV2 & & & & $10.00 \mathrm{U}$ \\
\hline $699-43-45$ & $1 / 24 / 92$ & $B 01000$ & $5.00 \mathrm{U}$ & $150.00 \mathrm{U}$ & 5.00 Ua & \\
\hline $699-43-45$ & $4 / 22 / 92$ & B065N8 & $5.00 \mathrm{U}$ & $150.00 \mathrm{U}$ & $5.00 \mathrm{U}$ & \\
\hline $699-43-45$ & $6 / 26 / 92$ & B070W2 & 5.00 UD & 150.00 UD & 5.00 UD & \\
\hline $699-43-45$ & $10 / 26 / 92$ & B07JG7 & $5.00 \mathrm{U}$ & $150.00 \mathrm{U}$ & $5.00 \mathrm{U}$ & \\
\hline
\end{tabular}


(sheet 4 of $* *$ )

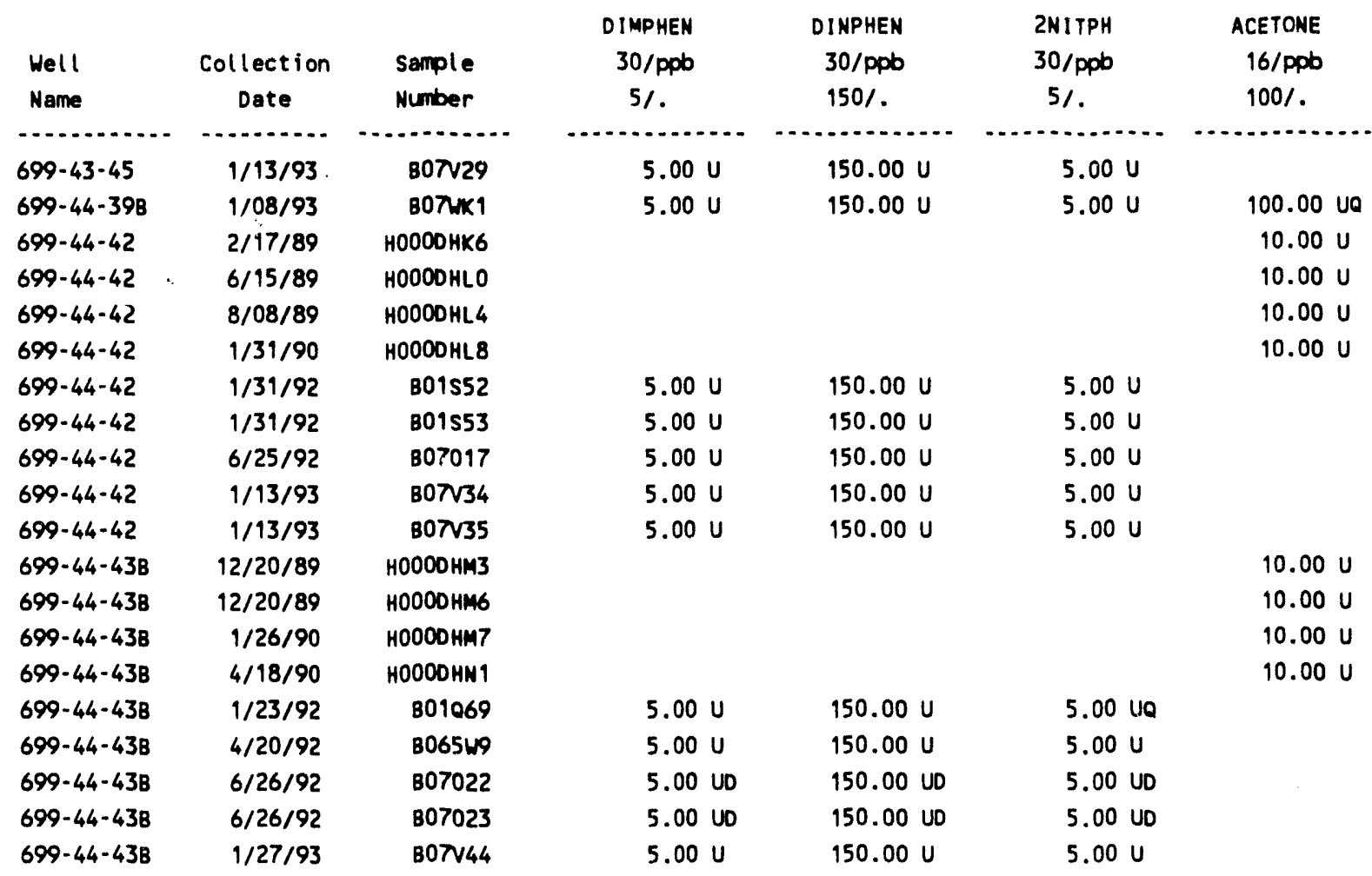

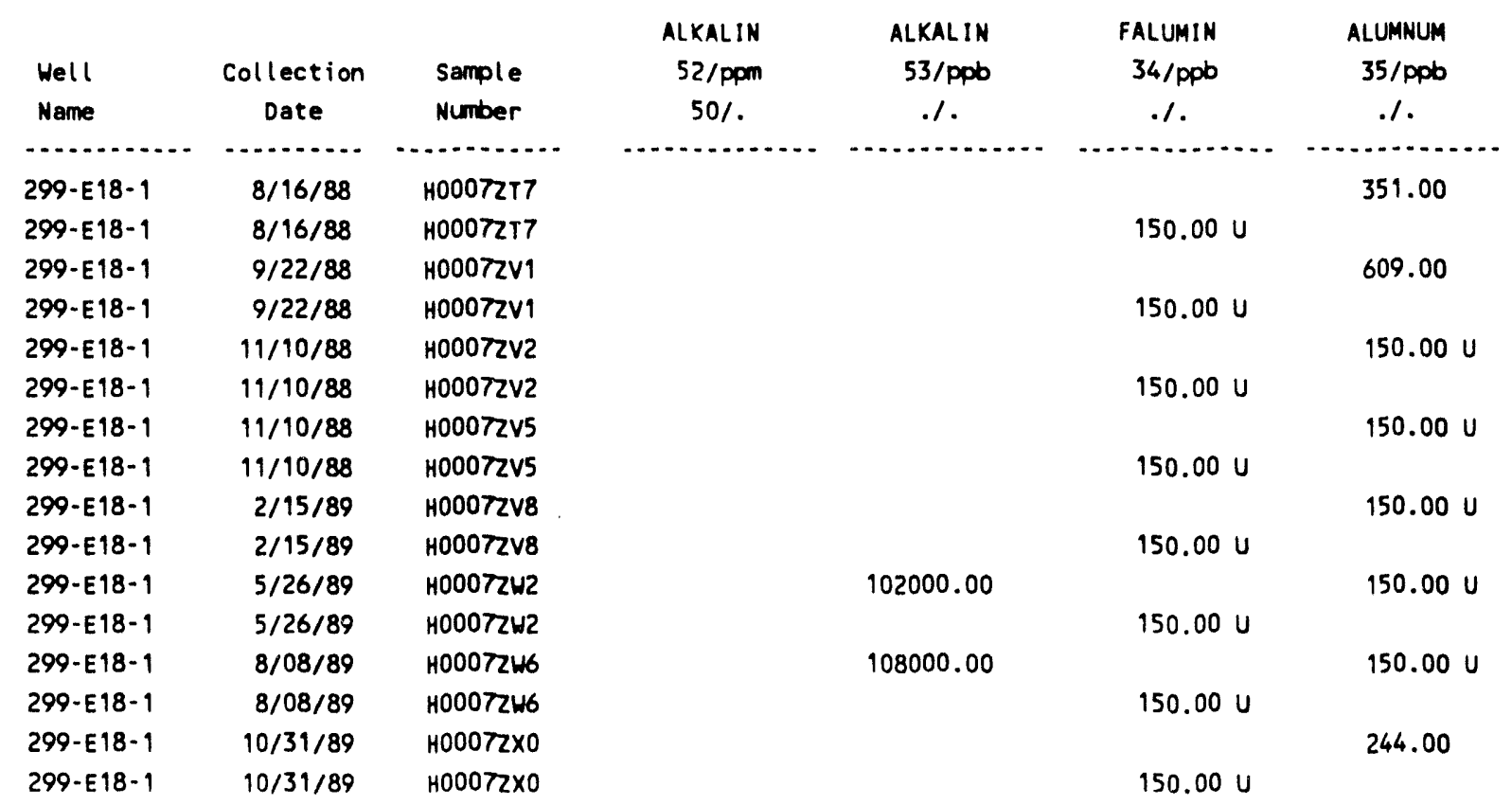


(sheet 5 of $\star \star$ )

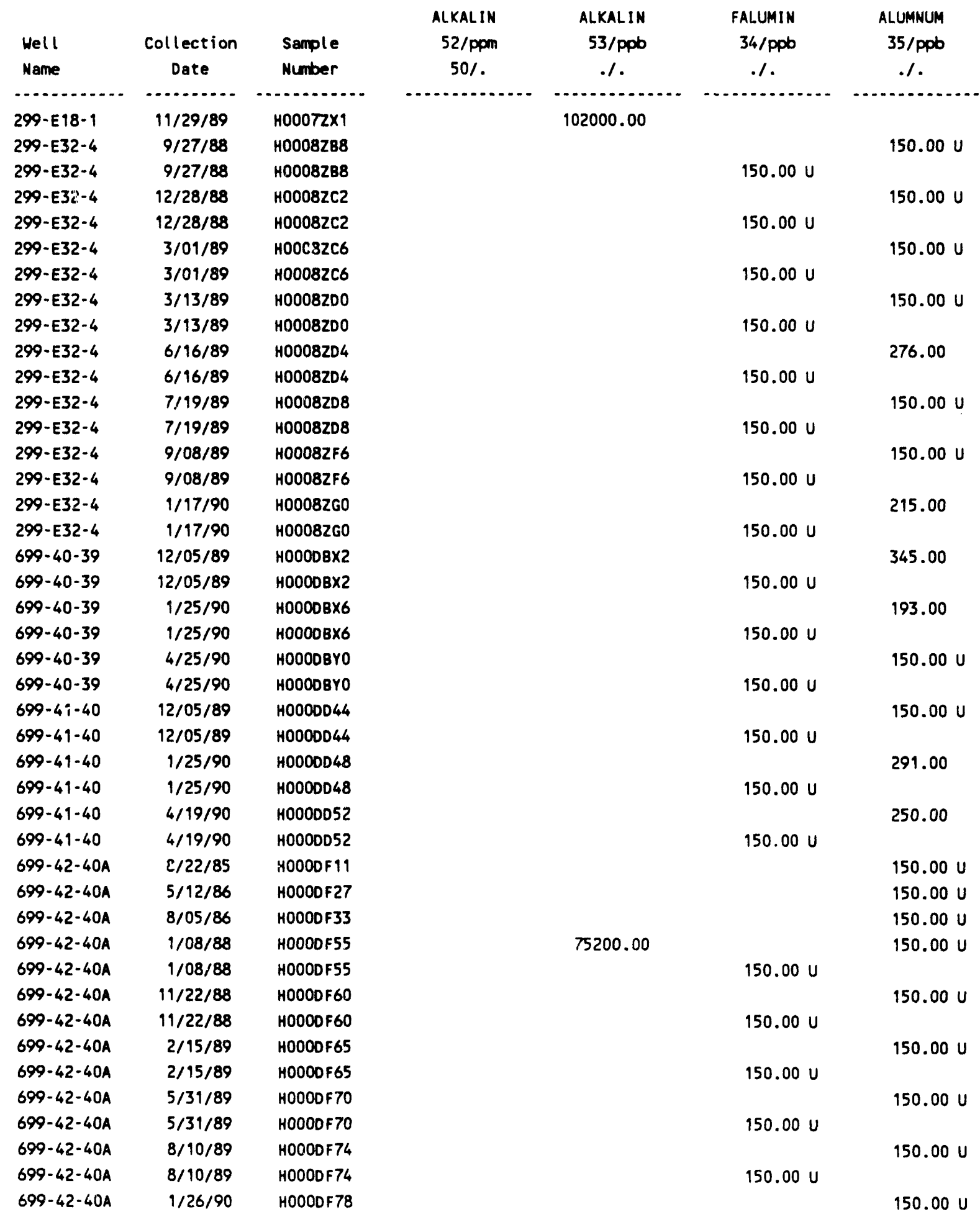


(sheet 6 of **)

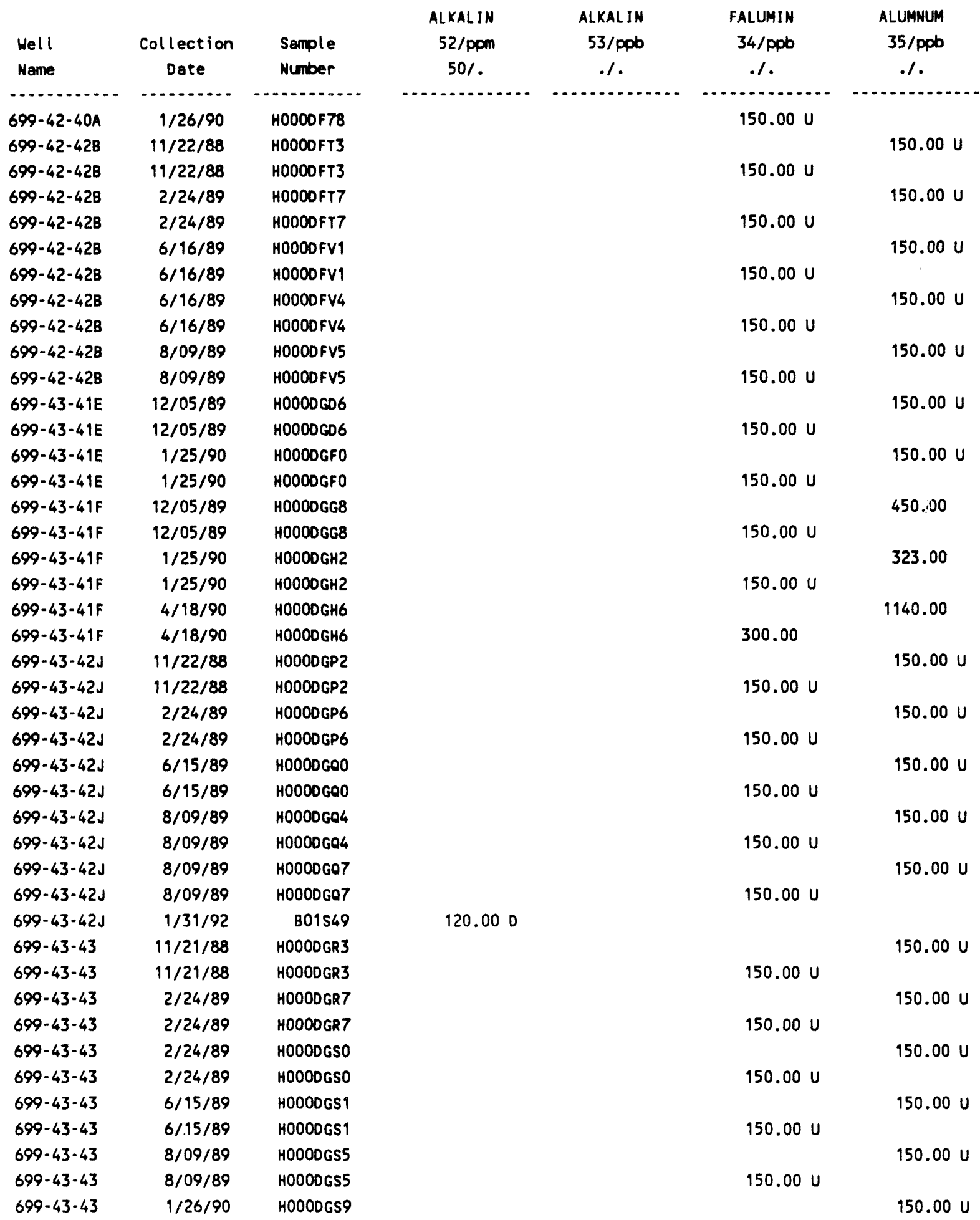


(sheet 7 of $\star *$ )

\begin{tabular}{|c|c|c|c|c|c|c|}
\hline $\begin{array}{l}\text { Well } \\
\text { Name }\end{array}$ & $\begin{array}{c}\text { Collection } \\
\text { Date }\end{array}$ & $\begin{array}{l}\text { Sample } \\
\text { Number }\end{array}$ & $\begin{array}{c}\text { ALKALIN } \\
52 / \mathrm{ppm} \\
50 /\end{array}$ & $\begin{array}{c}\text { ALKAL IN } \\
53 / \mathrm{ppb} \\
.1\end{array}$ & $\begin{array}{c}\text { FALUMIN } \\
34 / \mathrm{ppb} \\
.1\end{array}$ & $\begin{array}{c}\text { ALUMNUM } \\
35 / \mathrm{ppb} \\
.1\end{array}$ \\
\hline - & n............. & 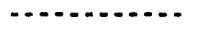 & . & - nan & . & \\
\hline $699-43-43$ & $1 / 26 / 90$ & HOOODGS9 & & & $150.00 \mathrm{U}$ & \\
\hline $699-43-45$ & $12 / 06 / 89$ & H0OODGT4 & & & & $150.00 \mathrm{U}$ \\
\hline $699-43-45$ & $12 / 06 / 89$ & HOOODGT4 & & & $150.00 \mathrm{U}$ & \\
\hline $699-43-45$ & $1 / 26 / 90$ & H0000GT8 & & & & $150.00 \mathrm{U}$ \\
\hline $699-43-45$ & $1 / 26 / 90$ & HOOOOGT8 & & & $150.00 \mathrm{U}$ & \\
\hline $699-43-45$ & $4 / 18 / 90$ & H0OODGV2 & & & & $150.00 \mathrm{U}$ \\
\hline $699-43-45$ & $4 / 18 / 90$ & H0000GV2 & & & $150.00 \mathrm{U}$ & \\
\hline $699-44-42$ & $11 / 21 / 88$ & HOOODHK2 & & & & $150.00 \mathrm{U}$ \\
\hline $699-44-42$ & $11 / 21 / 88$ & HOOODHK2 & & & $150.00 \mathrm{U}$ & \\
\hline $699-44-42$ & $2 / 17 / 89$ & HOOODHKG & & & & $150.00 \mathrm{U}$ \\
\hline $699-44-42$ & $2 / 17 / 89$ & HOOODHKG & & & $150.00 \mathrm{U}$ & \\
\hline $699-44-42$ & $6 / 15 / 89$ & HOOOOHLO & & & & $150.00 \mathrm{U}$ \\
\hline $699-44-42$ & $6 / 15 / 89$ & HOOODHLO & & & $150.00 \mathrm{U}$ & \\
\hline $699-44-42$ & $8 / 08 / 89$ & HOOOOHL 4 & & & & $150.00 \mathrm{U}$ \\
\hline $699-44-42$ & $8 / 08 / 89$ & HOOOOHL 4 & & & $150.00 \mathrm{U}$ & \\
\hline $699-44-42$ & $1 / 31 / 90$ & HOOOOHL 8 & & & & $150.00 \mathrm{U}$ \\
\hline $699-44-42$ & $1 / 31 / 90$ & HOOODHL8 & & & $150.00 \mathrm{U}$ & \\
\hline $699-44-42$ & $1 / 31 / 92$ & B01S52 & $100.00 \mathrm{D}$ & & & \\
\hline $699-44-43 B$ & $12 / 20 / 89$ & HOOOOHM3 & & & & $150.00 \mathrm{U}$ \\
\hline $699-44-43 B$ & $12 / 20 / 89$ & HОOОDHM3 & & & $150.00 \mathrm{U}$ & \\
\hline $699-44-43 B$ & $12 / 20 / 89$ & HOOODHMG & & & & 168.00 \\
\hline $699-44-43 B$ & $12 / 20 / 89$ & HOOOOHMG & & & $150.00 \mathrm{U}$ & \\
\hline $699-44-43 B$ & $1 / 26 / 90$ & HOOOOHM7 & & & & $150.00 \mathrm{U}$ \\
\hline $699-44-43 B$ & $1 / 26 / 90$ & ноОООонM7 & & & $150.00 \mathrm{U}$ & \\
\hline $699-44-43 B$ & $1 / 26 / 90$ & HOOOOHNO & & & & $150.00 \mathrm{U}$ \\
\hline $699-44-43 B$ & $1 / 26 / 90$ & HOOODHNO & & & $150.00 \mathrm{U}$ & \\
\hline $699-44-43 B$ & $4 / 18 / 90$ & HOOOOHN1 & & & & 405.00 \\
\hline $699-44-43 B$ & $4 / 18 / 90$ & HOOOOHN1 & & & $150.00 \mathrm{U}$ & \\
\hline
\end{tabular}

\begin{tabular}{|c|c|c|c|c|c|c|}
\hline & & & $A M-241$ & $A M-241$ & AMMONIU & ARSENIC \\
\hline Hell & Collection & Sample & $147 / D C i / L$ & $\pi / p C i / L$ & $54 / p p b$ & 43/ppb \\
\hline Name & Date & Number & .1 &.$/$ & $100 \%$ & $5 / 50$ \\
\hline n & n. & . & 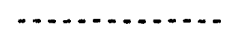 & , & . & , n \\
\hline 299-E18-1 & $8 / 16 / 88$ & H00072T7 & & & & $5.00 u$ \\
\hline 299-E18-1 & $9 / 22 / 88$ & H0007ZV1 & & & & $5.00 \mathrm{U}$ \\
\hline 299-E18-1 & $11 / 10 / 88$ & HoOOTZV2 & . & & $50.00 \mathrm{U}$ & $5.00 \mathrm{U}$ \\
\hline 299-E18-1 & $11 / 10 / 88$ & H0007Zv5 & & & $50.00 \mathrm{U}$ & $5.00 \mathrm{U}$ \\
\hline 299-E18-1 & $2 / 15 / 89$ & H0007ZV8 & & & $50.00 \mathrm{U}$ & $5.00 \mathrm{U}$ \\
\hline $299-E 18-1$ & $5 / 26 / 89$ & H0007ZWZ & & & & $5.00 \mathrm{U}$ \\
\hline 299-E18-1 & $8 / 08 / 89$ & H00072W6 & & & $50.00 \mathrm{U}$ & $5.00 \mathrm{U}$ \\
\hline $299-E 18-1$ & $10 / 31 / 89$ & $400072 \times 0$ & & .03 & $50.00 \mathrm{U}$ & $5.00 \mathrm{U}$ \\
\hline
\end{tabular}


(sheet 8 of $\star \star$ )

\begin{tabular}{|c|c|c|c|c|c|c|}
\hline $\begin{array}{l}\text { Well } \\
\text { Name }\end{array}$ & $\begin{array}{c}\text { Collection } \\
\text { Date }\end{array}$ & $\begin{array}{l}\text { Sample } \\
\text { Number }\end{array}$ & $\begin{array}{c}A M-241 \\
147 / \mathrm{PCi} / \mathrm{L} \\
. /\end{array}$ & $\begin{array}{c}A M-241 \\
77 / P C i / L \\
. / .\end{array}$ & $\begin{array}{l}\text { AMMON IU } \\
54 / \mathrm{ppD} \\
100 /\end{array}$ & $\begin{array}{c}\text { ARSENIC } \\
43 / p p b \\
5 / 50\end{array}$ \\
\hline 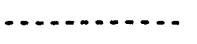 & .............. & $\cdots$ & , n & , & . & 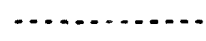 \\
\hline 299-E18-1 & $1 / 24 / 92$ & 801059 & & & $100.00 \mathrm{U}$ & \\
\hline 299-E18-1 & $6 / 03 / 92$ & В06РH8 & & & $100.00 \mathrm{U}$ & $5.00 \mathrm{U}$ \\
\hline 299-E18-1 & $12 / 16 / 92$ & B07532 & & & & $5.00 \mathrm{U}$ \\
\hline 299-E18-1 & $12 / 16 / 92$ & BOTSNO & & & $100.00 \mathrm{U}$ & \\
\hline $299-E 32-4$ & $9 / 27 / 88$ & H0008ZB8 & & & $50.00 \mathrm{U}$ & $5.00 \mathrm{U}$ \\
\hline $299-E 32-4$ & $12 / 28 / 88$ & H0008ZC2 & & & $50.00 \mathrm{U}$ & $5.00 \mathrm{U}$ \\
\hline $299-E 32-4$ & $3 / 01 / 89$ & $\mathrm{H} 0008 \mathrm{ZC} 6$ & & & $50.00 \mathrm{U}$ & $5.00 \mathrm{U}$ \\
\hline $299-E 32-4$ & $3 / 13 / 89$ & H0008ZDO & & & $50.00 \mathrm{U}$ & $5.00 \mathrm{U}$ \\
\hline $299-E 32-4$ & $6 / 16 / 89$ & $H 0008 Z D 4$ & & & $50.00 \mathrm{U}$ & $5.00 \mathrm{U}$ \\
\hline $299-E 32-4$ & $7 / 19 / 89$ & H0008ZD8 & & & $50.00 \mathrm{U}$ & $5.00 \mathrm{U}$ \\
\hline $299-E 32-4$ & $9 / 08 / 89$ & H00082F6 & & & $50.00 \mathrm{U}$ & $5.00 \mathrm{U}$ \\
\hline $299-E 32-4$ & $1 / 17 / 90$ & H0008ZGO & & & $50.00 \mathrm{U}$ & $5.00 \mathrm{U}$ \\
\hline $299-E 32-4$ & $5 / 09 / 90$ & H0008ZG9 & & & $50.00 \mathrm{U}$ & $5.00 \mathrm{U}$ \\
\hline 299-E32-4 & $9 / 23 / 91$ & B00LK5 & .05 & & & \\
\hline 299-E32-4 & $1 / 15 / 92$ & B010K6 & $.00 \mathrm{U}$ & & 20.00 & $5.00 \mathrm{U}$ \\
\hline $299-E 32-4$ & $4 / 06 / 92$ & 806696 & $-.00 \mathrm{U}$ & & $100.00 \mathrm{U}$ & $5.00 \mathrm{U}$ \\
\hline $299-E 32-4$ & $4 / 09 / 92$ & B065B6 & $\cdot .00 \mathrm{U}$ & & & \\
\hline $299-E 32-4$ & $7 / 14 / 92$ & 807173 &. $.00 \mathrm{U}$ & & 200.00 & $5.00 \mathrm{U}$ \\
\hline $699-40-36$ & $12 / 21 / 92$ & В07TB1 & & & $100.00 \mathrm{U}$ & $5.00 \mathrm{U}$ \\
\hline $699-40-36$ & $2 / 22 / 93$ & 808717 & & & $100.00 \mathrm{U}$ & $5.00 \mathrm{U}$ \\
\hline $699-40-39$ & $12 / 05 / 89$ & $H 00008 \times 2$ & & $.01 \mathrm{U}$ & $50.00 \mathrm{U}$ & $5.00 \mathrm{U}$ \\
\hline $699-40-39$ & $1 / 25 / 90$ & H0000BX6 & & & $50.00 \mathrm{U}$ & $5.00 \mathrm{U}$ \\
\hline $699-40-39$ & $4 / 25 / 90$ & HOOODBYO & & & $50.00 \mathrm{U}$ & $5.00 \mathrm{U}$ \\
\hline $699-40-39$ & $7 / 08 / 91$ & H00071Y4 & & & & $u$ \\
\hline $699-40-39$ & $1 / 31 / 92$ & 801065 & & & 20.00 & $5.00 \mathrm{U}$ \\
\hline $699-40-39$ & $4 / 17 / 92$ & B065P2 & & & 100.00 UD & $5.00 \mathrm{U}$ \\
\hline $699-40-39$ & $6 / 24 / 92$ & B06217 & & & & $5.00 \mathrm{U}$ \\
\hline $699-40-39$ & $1 / 14 / 93$ & $8077 \times 4$ & & & $100.00 \mathrm{U}$ & $5.00 \mathrm{U}$ \\
\hline $699-40-40 \mathrm{~A}$ & $1 / 24 / 92$ & B01T62 & & & 60.00 & $5.00 \mathrm{U}$ \\
\hline $699-40-40 \mathrm{~A}$ & $4 / 22 / 92$ & B06508 & & & $100.00 \mathrm{U}$ & $5.00 \mathrm{U}$ \\
\hline $699-40-40 \mathrm{~A}$ & $6 / 25 / 92$ & B062V2 & & & & $5.00 \mathrm{U}$ \\
\hline $699-40-40 \mathrm{~A}$ & $10 / 21 / 92$ & B07JK3 & & & 100.00 UQ & $5.00 \mathrm{U}$ \\
\hline $699-40-40 \mathrm{~A}$ & $1 / 26 / 93$ & B07N49 & & & $100.00 \mathrm{U}$ & $5.00 \mathrm{U}$ \\
\hline $699-40-40 B$ & $1 / 24 / 92$ & $801 T 64$ & & & $100.00 \mathrm{U}$ & $5.00 \mathrm{U}$ \\
\hline $699-40-40 B$ & $4 / 22 / 92$ & B06550 & & & $100.00 \mathrm{U}$ & $5.00 \mathrm{U}$ \\
\hline $699-40-40 B$ & $6 / 29 / 92$ & B062W2 & & & & $5.00 \mathrm{U}$ \\
\hline $699-40-40 B$ & $10 / 21 / 92$ & B07JK8 & & & 100.00 Uo & $5.00 \mathrm{U}$ \\
\hline $699-40-40 B$ & $1 / 26 / 93$ & B07V54 & & & $100.00 \mathrm{U}$ & $5.00 \mathrm{U}$ \\
\hline $699-41-35$ & $12 / 21 / 92$ & в07789 & & & $100.00 \mathrm{U}$ & $5.00 \mathrm{U}$ \\
\hline $699-41-35$ & $2 / 22 / 93$ & 808707 & & & $100.00 u$ & $5.00 \mathrm{U}$ \\
\hline $699-41-40$ & $12 / 05 / 89$ & H0OODD44 & & $.01 \mathrm{U}$ & 140.00 & $5.00 \mathrm{U}$ \\
\hline $699-41-40$ & $1 / 25 / 90$ & $H 0000048$ & & & $50.00 \mathrm{U}$ & $5.00 \mathrm{U}$ \\
\hline $699-41-40$ & $4 / 19 / 90$ & H0000D52 & & & $50.00 \mathrm{U}$ & $5.00 \mathrm{U}$ \\
\hline
\end{tabular}


(sheet 9 of $*$ )




(sheet 10 of ${ }^{\star *}$ )

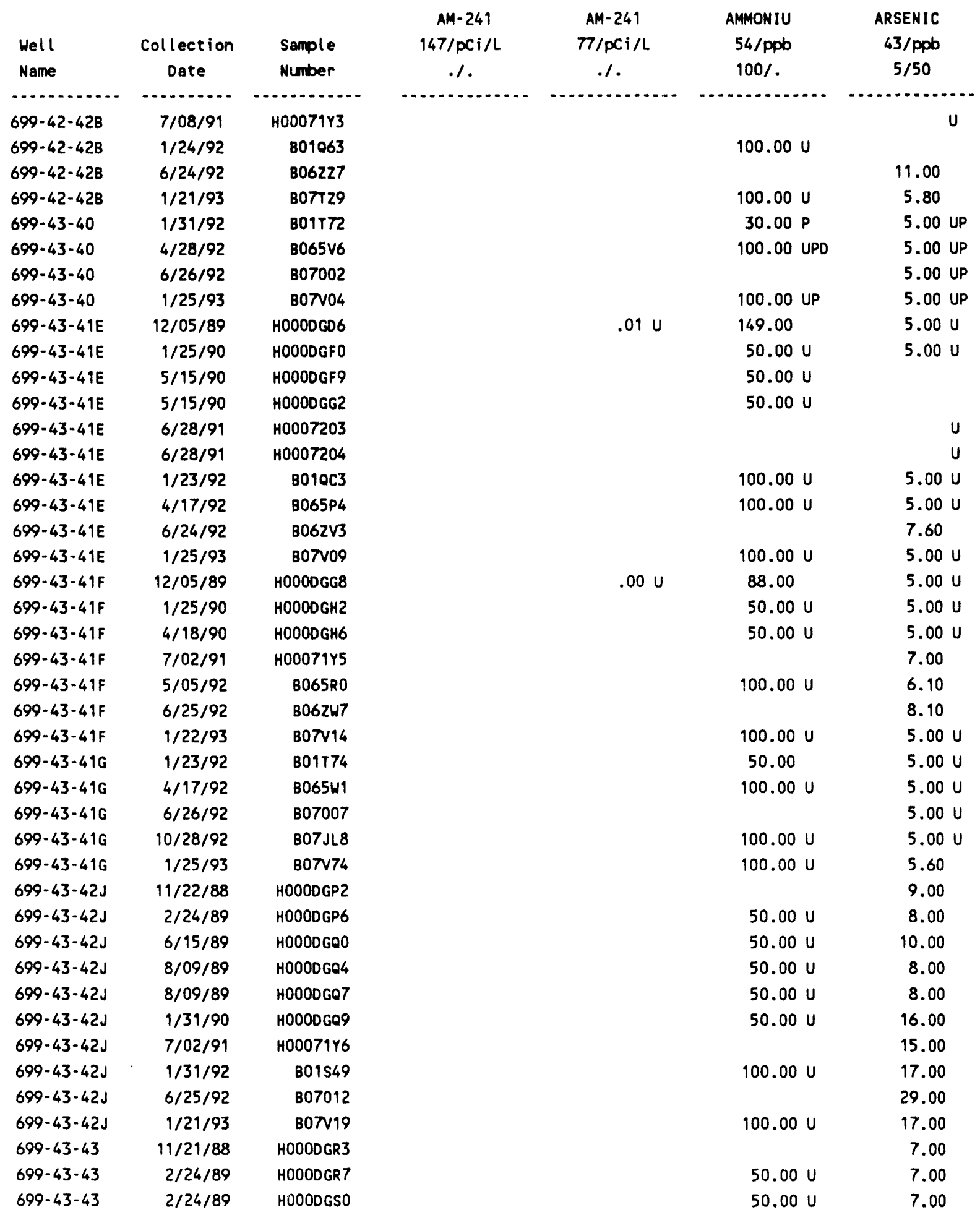


(sheet 11 of $\star \star$ )

\begin{tabular}{|c|c|c|c|c|c|c|}
\hline Well & Collection & Sample & $\begin{array}{c}A M-241 \\
147 / P C i / L\end{array}$ & $\begin{array}{c}A M-241 \\
\pi / D C i / L\end{array}$ & $\begin{array}{l}\text { AMMONIU } \\
54 / \mathrm{ppb}\end{array}$ & $\begin{array}{l}\text { ARSENIC } \\
43 / p p b\end{array}$ \\
\hline Name & Date & Number & .1 & .1 & $100 \%$ & $5 / 50$ \\
\hline . & 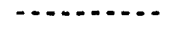 & n & $\cdots \cdot$ & $\cdots$ & ; & \\
\hline $699-43-43$ & $6 / 15 / 89$ & H000DGS1 & & & $50.00 \mathrm{U}$ & 8.00 \\
\hline $699-43-43$ & $8 / 09 / 89$ & H0000GS5 & & & $50.00 \mathrm{U}$ & 7.00 \\
\hline $699-43-43$ & $1 / 26 / 90$ & HOOODGS9 & & & $50.00 \mathrm{U}$ & 8.00 \\
\hline $699-43-43$ & $7 / 08 / 91$ & H00071Y7 & & & & 8.00 \\
\hline $699-43-43$ & $1 / 24 / 92$ & 801067 & & & $100.00 \mathrm{U}$ & \\
\hline $699-43-43$ & $1 / 24 / 92$ & B01T83 & & & & 7.10 \\
\hline $699-43-43$ & $4 / 22 / 92$ & B065N6 & & & $100.00 \mathrm{U}$ & 7.90 \\
\hline $699-43-43$ & $6 / 26 / 92$ & BO70w0 & & & $100.00 \mathrm{U}$ & 7.10 \\
\hline $699-43-43$ & $10 / 26 / 92$ & B07JG5 & & & $100.00 \mathrm{U}$ & 9.20 \\
\hline $699-43-43$ & $1 / 13 / 93$ & B07N24 & & & 100.00 & 6.80 \\
\hline $699-43-45$ & $12 / 06 / 89$ & HOOOOGT4 & & $.01 \mathrm{U}$ & $50.00 \mathrm{U}$ & 10.00 \\
\hline $699-43-45$ & $1 / 26 / 90$ & HOOODGT8 & & & $50.00 \mathrm{U}$ & 12.00 \\
\hline $699-43-45$ & $4 / 18 / 90$ & H0000GV2 & & & $50.00 \mathrm{U}$ & 11.00 \\
\hline $699-43-45$ & $7 / 08 / 91$ & H00071Y8 & & & & 10.00 \\
\hline $699-43-45$ & $1 / 24 / 92$ & B01000 & & & $100.00 \mathrm{U}$ & 8.60 \\
\hline $699-43-45$ & $4 / 22 / 92$ & B065N8 & & & $100.00 \mathrm{U}$ & 8.30 \\
\hline $699-43-45$ & $6 / 26 / 92$ & B070W2 & & & 100.00 & 8.30 \\
\hline $699-43-45$ & $10 / 26 / 92$ & B07JG7 & & & $100.00 \mathrm{U}$ & 11.00 \\
\hline $699-43-45$ & $1 / 13 / 93$ & BOTV29 & & & $100.00 \mathrm{U}$ & 10.00 \\
\hline $699-44-398$ & $1 / 08 / 93$ & BOTNK1 & & & $100.00 \mathrm{U}$ & $5.00 \mathrm{U}$ \\
\hline $699-44-42$ & $11 / 21 / 88$ & HOOOOHK2 & & & & 11.00 \\
\hline $699-44-42$ & $2 / 17 / 89$ & H0OODHK & & & $50.00 \mathrm{U}$ & 13.00 \\
\hline $699-44-42$ & $6 / 15 / 89$ & HOOODHLO & & & $50.00 \mathrm{U}$ & 14.00 \\
\hline $699-44-42$ & $8 / 08 / 89$ & HOOOOHL 4 & & & $50.00 \mathrm{U}$ & 11.00 \\
\hline $699-44-42$ & $1 / 31 / 90$ & HOOOOHL8 & & & $50.00 \mathrm{U}$ & 16.00 \\
\hline $699-44-42$ & $7 / 10 / 91$ & HOOOT1Y9 & & & & 14.00 \\
\hline $699-44-42$ & $1 / 31 / 92$ & B01S52 & & & $100.00 \mathrm{U}$ & 12.00 \\
\hline $699-44-42$ & $6 / 25 / 92$ & 807017 & & & & 18.00 \\
\hline $699-44-42$ & $1 / 13 / 93$ & B07V34 & & & $100.00 \mathrm{U}$ & 10.00 \\
\hline $699-44-42$ & $1 / 13 / 93$ & B07V35 & & & $100.00 \mathrm{U}$ & 10.00 \\
\hline $699-44-43 B$ & $12 / 20 / 89$ & HOOODHM3 & & $.00 \mathrm{U}$ & $50.00 \mathrm{U}$ & 7.00 \\
\hline $699-44-43 B$ & $12 / 20 / 89$ & HOOODHMG & & $.01 \mathrm{U}$ & $50.00 \mathrm{U}$ & 7.00 \\
\hline $699-44-43 B$ & $1 / 26 / 90$ & HOOODHM7 & & & $50.00 \mathrm{U}$ & 9.00 \\
\hline $699-44-43 B$ & $1 / 26 / 90$ & HOOODHNO & & & $50.00 \mathrm{U}$ & 7.00 \\
\hline $699-44-438$ & $4 / 18 / 90$ & HOOOOHN 1 & & & $50.00 \mathrm{U}$ & 7.00 \\
\hline $699-44-43 B$ & $7 / 08 / 91$ & H000712O & & & & 7.00 \\
\hline $699-44-43 B$ & $1 / 23 / 92$ & B01069 & & & $100.00 \mathrm{U}$ & 6.10 \\
\hline $699-44-438$ & $4 / 20 / 92$ & 8065W9 & & & $100.00 \mathrm{U}$ & 7.10 \\
\hline $699-44-43 B$ & $6 / 26 / 92$ & B07022 & & & & 6.30 \\
\hline $699-44-438$ & $6 / 26 / 92$ & 807023 & & & & $5.00 \mathrm{U}$ \\
\hline $699-44-43 B$ & $1 / 27 / 93$ & BOTV44 & & & $100.00 \mathrm{U}$ & 6.80 \\
\hline
\end{tabular}


(sheet 12 of $* \star$ )

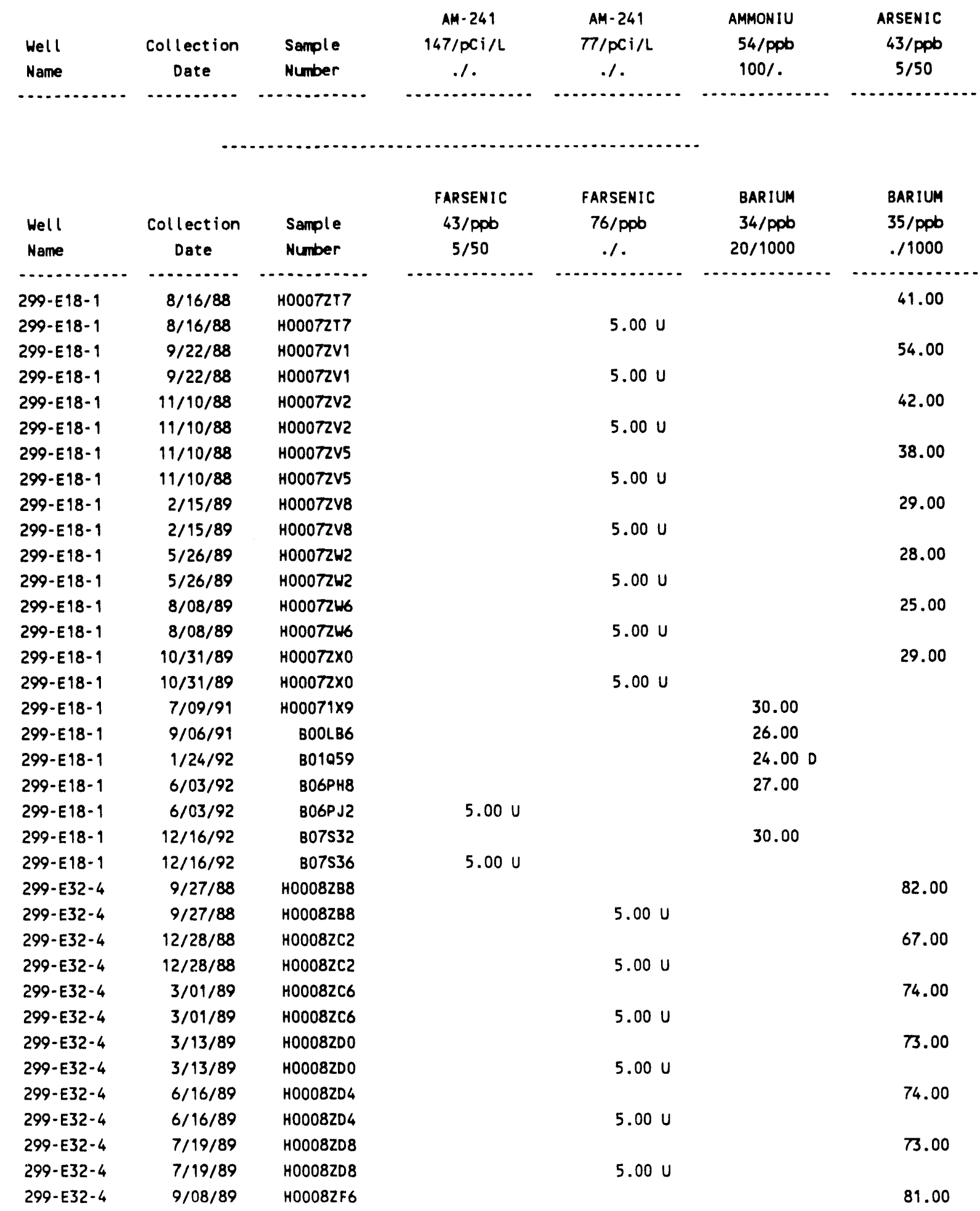


(sheet 13 of $*$ )

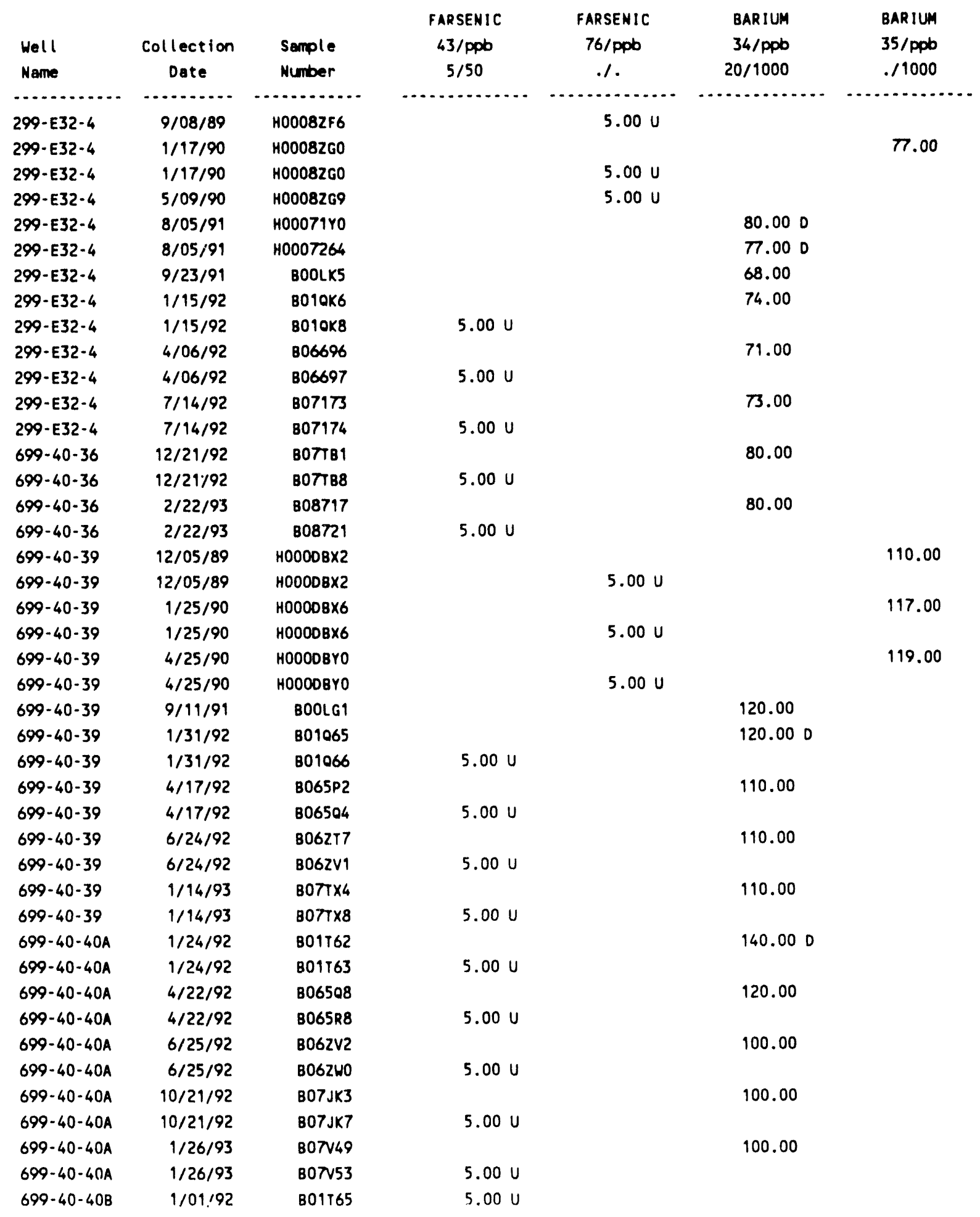


(sheet 14 of $\star$ )

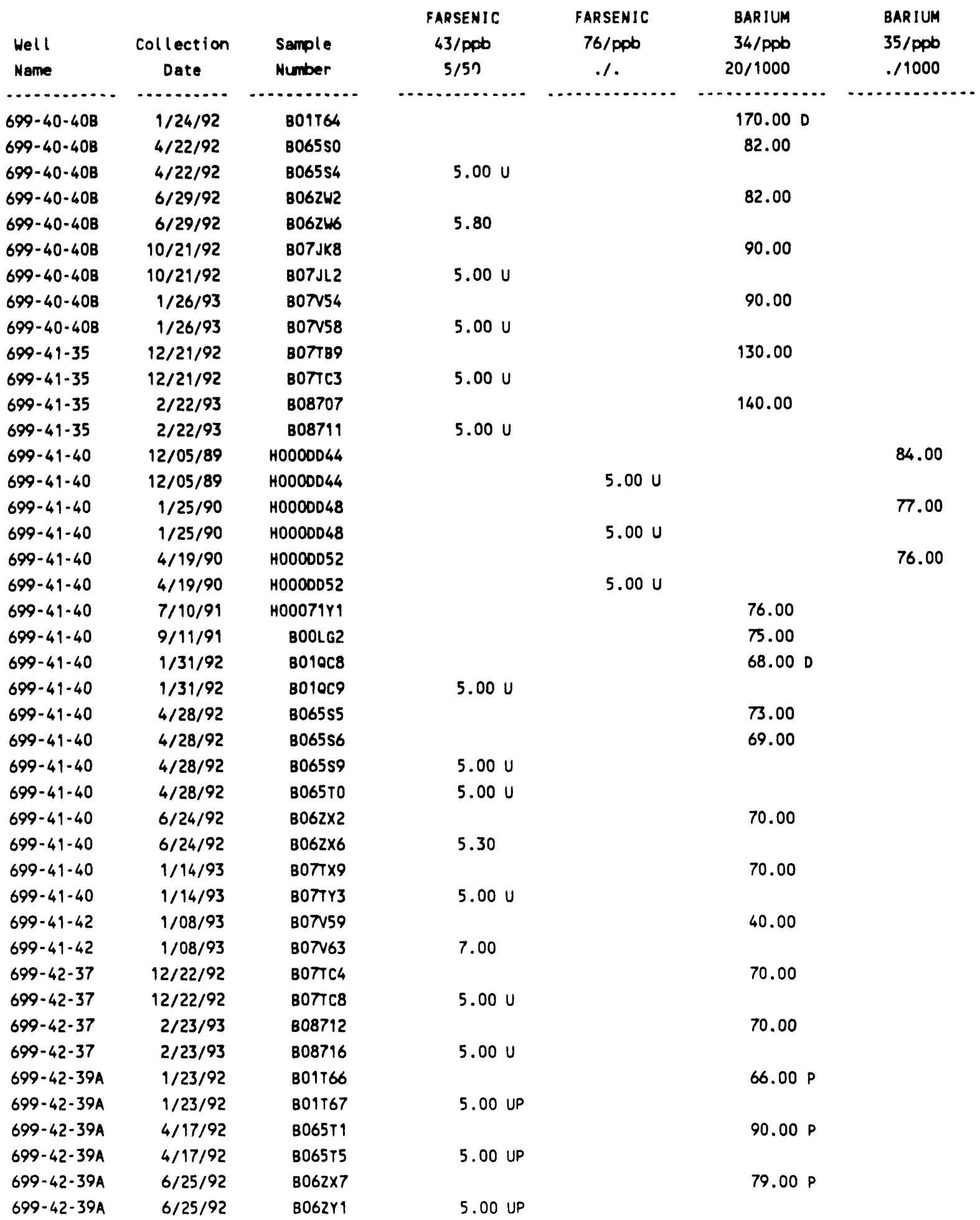


(sheet 15 of *)

\begin{tabular}{|c|c|c|c|c|c|c|}
\hline $\begin{array}{l}\text { Hell } \\
\text { Neme }\end{array}$ & $\begin{array}{c}\text { Collection } \\
\text { Date }\end{array}$ & $\begin{array}{l}\text { Semple } \\
\text { Number }\end{array}$ & $\begin{array}{c}\text { FARSENIC } \\
43 / \mathrm{ppb} \\
5 / 50\end{array}$ & $\begin{array}{c}\text { FARSENIC } \\
\text { 76/PpD } \\
.1\end{array}$ & $\begin{array}{l}\text { BARIUM } \\
34 / p p b \\
20 / 1000\end{array}$ & $\begin{array}{l}\text { BARIUM } \\
35 / p p b \\
. / 1000\end{array}$ \\
\hline . & $\cdots$ & 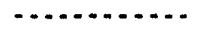 & 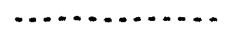 & . & . & $\cdots \cdots$ \\
\hline $699-42-39 A$ & $10 / 21 / 92$ & $807 \mathrm{JL} 3$ & & & $80.00 \mathrm{P}$ & \\
\hline $699-42-391$ & $10 / 21 / 92$ & B07JL7 & 5.00 UP & & & \\
\hline $699-42-391$ & $1 / 27 / 93$ & $807 v 64$ & & & $60.00 \mathrm{P}$ & \\
\hline $699-42-391$ & $1 / 27 / 93$ & BOTV68 & 5.00 UP & & & \\
\hline $699-42-398$ & $1 / 23 / 92$ & B01T68 & & & 87.00 & \\
\hline $699-42-398$ & $1 / 23 / 92$ & $801 T 69$ & $5.00 \mathrm{U}$ & & & \\
\hline $699-42-398$ & $4 / 17 / 92$ & $8065 T 6$ & & & 89.00 & \\
\hline $699-42-398$ & $4 / 17 / 92$ & B065VO & $5.00 \mathrm{U}$ & & & \\
\hline $699-42 \cdot 398$ & $6 / 25 / 92$ & B06ZYZ & & & 89.00 & \\
\hline $699-42-398$ & $6 / 25 / 92$ & $8062 Y 6$ & $5.00 \mathrm{U}$ & & & \\
\hline $699-42-398$ & $10 / 28 / 92$ & B07JJ2 & & & 80.00 & \\
\hline $699-42-398$ & $10 / 28 / 92$ & $807 \mathrm{JJ} 3$ & & & 80.00 & \\
\hline $699-42-398$ & $10 / 28 / 92$ & $807 J J 6$ & $5.00 \mathrm{U}$ & & & \\
\hline $699-42-398$ & $10 / 28 / 92$ & $807 \mathrm{JJ} 7$ & $5.00 \mathrm{U}$ & & & \\
\hline $699-42-398$ & $1 / 25 / 93$ & BOTV69 & & & 80.00 & \\
\hline $699-42-398$ & $1 / 25 / 93$ & BOTV73 & $5.00 \mathrm{U}$ & & & \\
\hline $699-42-40 A$ & $8 / 22 / 85$ & HOOODF11 & & & & $6.00 \mathrm{U}$ \\
\hline $699-42-40 A$ & $5 / 12 / 86$ & H0OODF 27 & & & & 6.00 \\
\hline $699-42-40 A$ & $8 / 05 / 86$ & H0000F33 & & & & $6.00 \mathrm{U}$ \\
\hline $699-42-40 A$ & $1 / 08 / 88$ & H0000F55 & & & & $6.00 \mathrm{U}$ \\
\hline $699-42-40 A$ & $1 / 08 / 88$ & H000OF55 & & $5.00 \mathrm{U}$ & & \\
\hline $699-42-40 A$ & $11 / 22 / 88$ & H0O0DF60 & & & & 6.00 \\
\hline $699-42-40 A$ & $11 / 22 / 88$ & $H 0000 F 60$ & & $5.00 \mathrm{U}$ & & \\
\hline $699-42-40 A$ & $2 / 15 / 89$ & H0000F65 & & & & $6.00 \mathrm{U}$ \\
\hline $699-42-40 A$ & $2 / 15 / 89$ & H0000F 65 & & $5.00 \mathrm{U}$ & & \\
\hline $699-42-40 A$ & $5 / 31 / 89$ & HOOODF 70 & & & & $6.00 \mathrm{U}$ \\
\hline $699-42-40 A$ & $5 / 31 / 89$ & H000OF 70 & & $5.00 \mathrm{U}$ & & \\
\hline $699-42-40 A$ & $8 / 10 / 89$ & H0OOOF74 & & & & $6.00 \mathrm{U}$ \\
\hline $699-42-40 A$ & $8 / 10 / 89$ & HOOOOF 74 & & $5.00 \mathrm{U}$ & & \\
\hline $699-42-40 \mathrm{~A}$ & $1 / 26 / 90$ & HOOODF 78 & & & & 7.00 \\
\hline $699-42-40 \mathrm{~A}$ & $1 / 26 / 90$ & HOOOOF78 & & $5.00 \mathrm{U}$ & & \\
\hline $699-42-40 \mathrm{~A}$ & $7 / 08 / 91$ & H00071Y2 & & & $20.00 \mathrm{U}$ & \\
\hline $699-42-40 \mathrm{~A}$ & $1 / 08 / 92$ & $807 T Y 8$ & & & $20.00 \mathrm{U}$ & \\
\hline $699-42-40 \mathrm{~A}$ & $1 / 08 / 92$ & B07T23 & $5.00 \mathrm{U}$ & & & \\
\hline $699-42-40 \mathrm{~A}$ & $1 / 23 / 92$ & B01061 & & & 73.00 & \\
\hline $699-42-40 \mathrm{~A}$ & $6 / 25 / 92$ & B06ZY7 & & & 30.00 & \\
\hline $699-42-40 \mathrm{~A}$ & $6 / 25 / 92$ & B06221 & $5.00 \mathrm{U}$ & & & \\
\hline $699-42-41$ & $1 / 24 / 92$ & B01т70 & & & 20.00 UPD & \\
\hline $699 \cdot 42-41$ & $1 / 24 / 92$ & B01T71 & 5.00 UP & & & \\
\hline $699-42-41$ & $4 / 17 / 92$ & $8065 \mathrm{~V} 1$ & & & 20.00 UP & \\
\hline $699-42-41$ & $4 / 17 / 92$ & B065V5 & 5.00 UP & & & \\
\hline $699-42-41$ & $6 / 29 / 92$ & 806222 & & & 20.00 UP & \\
\hline $699-42-41$ & $6 / 29 / 92$ & 806226 & $5.80 \mathrm{P}$ & & & \\
\hline
\end{tabular}


(sheet 16 of $*$ )

\begin{tabular}{|c|c|c|c|c|c|c|}
\hline $\begin{array}{l}\text { Well } \\
\text { Name }\end{array}$ & $\begin{array}{c}\text { Collection } \\
\text { Date }\end{array}$ & $\begin{array}{l}\text { Sample } \\
\text { Number }\end{array}$ & $\begin{array}{c}\text { FARSENIC } \\
43 / \mathrm{ppb} \\
5 / 50\end{array}$ & $\begin{array}{c}\text { FARSENIC } \\
\text { 76/ppb } \\
.1\end{array}$ & $\begin{array}{l}\text { BARIUM } \\
34 / p p b \\
20 / 1000\end{array}$ & $\begin{array}{l}\text { BARIUM } \\
35 / \mathrm{ppb} \\
. / 1000\end{array}$ \\
\hline . & $\cdots$ & , & 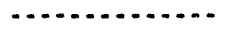 & . & . & . \\
\hline $699-42-41$ & $1 / 25 / 93$ & B0TT24 & & & 20.00 UP & \\
\hline $699-42-41$ & $1 / 25 / 93$ & B07Tz8 & 5.00 UP & & & \\
\hline $699-42-42 B$ & $11 / 22 / 88$ & HOOOOFT3 & & & & 30.00 \\
\hline $699-42-42 B$ & $11 / 22 / 88$ & H0OODFT3 & & 6.00 & & \\
\hline $699-42-42 B$ & $2 / 24 / 89$ & HOOODFT7 & & & & 28.00 \\
\hline $699-42-42 B$ & $2 / 24 / 89$ & HOOOOFT7 & & 6.00 & & \\
\hline $699-42-428$ & $6 / 16 / 89$ & H0000FV1 & & & & 27.00 \\
\hline $699-42-42 B$ & $6 / 16 / 89$ & H0OODFV1 & & 7.00 & & \\
\hline $699-42-42 B$ & $6 / 16 / 89$ & HOOOOFV4 & & & & 26.00 \\
\hline $699-42-42 B$ & $6 / 16 / 89$ & HOOODFV4 & & 7.00 & & \\
\hline $699-42-42 B$ & $8 / 09 / 89$ & HOOODFVS & & & & 21.00 \\
\hline $699-42-42 B$ & $8 / 09 / 89$ & H000OFV5 & & 6.00 & & \\
\hline $699-42-42 B$ & $1 / 26 / 90$ & HOOODFWO & & 7.00 & & \\
\hline $699-42-42 B$ & $7 / 08 / 91$ & H00079Y3 & & & 24.00 & \\
\hline $699-42-42 B$ & $1 / 24 / 92$ & $B 01063$ & & & 22.000 & \\
\hline $699-42-42 B$ & $6 / 24 / 92$ & B06227 & & & 23.00 & \\
\hline $699-42-42 B$ & $6 / 24 / 92$ & 807001 & 11.00 & & & \\
\hline $699-42-42 B$ & $1 / 21 / 93$ & в077z9 & & & 20.00 & \\
\hline $699-42-428$ & $1 / 21 / 93$ & BOTV03 & 7.20 & & & \\
\hline $699-43-40$ & $1 / 31 / 92$ & B01T72 & & & $\pi 5.00 \mathrm{PD}$ & \\
\hline $699-43-40$ & $1 / 31 / 92$ & B01T73 & 5.00 UP & & & \\
\hline $699-43-40$ & $4 / 28 / 92$ & B065V6 & & & $54.00 P$ & \\
\hline $699-43-40$ & $4 / 28 / 92$ & B065WO & 5.00 UP & & & \\
\hline $699-43-40$ & $6 / 26 / 92$ & 807002 & & & $67.00 P$ & \\
\hline $699-43-40$ & $6 / 26 / 92$ & B07006 & 5.00 UP & & & \\
\hline $699-43-40$ & $1 / 25 / 93$ & $807 v 04$ & & & $60.00 \mathrm{P}$ & \\
\hline $699-43-40$ & $1 / 25 / 93$ & B07N08 & 5.00 UP & & & \\
\hline $699-43-41 E$ & $12 / 05 / 89$ & H0000GD6 & & & & 61.00 \\
\hline $699-43-41 E$ & $12 / 05 / 89$ & H0000GD6 & & $5.00 \mathrm{U}$ & & \\
\hline $699-43-41 E$ & $1 / 25 / 90$ & HOOODGFO & & & & 56.00 \\
\hline $699-43-41 E$ & $1 / 25 / 90$ & HOOOOGFO & & $5.00 \mathrm{U}$ & & \\
\hline $699-43-41 E$ & $6 / 28 / 91$ & $\mathrm{H} 0007203$ & & & 41.000 & \\
\hline $699-43-41 E$ & $6 / 28 / 91$ & $\mathrm{H} 0007204$ & & & $42.00 \mathrm{D}$ & \\
\hline $699-43-41 E$ & $1 / 23 / 92$ & B010C3 & & & 44.00 & \\
\hline $699-43-41 E$ & $1 / 23 / 92$ & B010C4 & $5.00 \mathrm{U}$ & & & \\
\hline $699-43-41 E$ & $4 / 17 / 92$ & $8065 P 4$ & & & 36.00 & \\
\hline $699-43-41 E$ & $4 / 17 / 92$ & 806506 & $5.00 \mathrm{U}$ & & & \\
\hline $699-43-41 E$ & $6 / 24 / 92$ & $\mathrm{~B} 062 \mathrm{~V} 3$ & & & 39.00 & \\
\hline $699-43-41 E$ & $6 / 24 / 92$ & $8062 W 1$ & 6.60 & & & \\
\hline $699-43-41 E$ & $1 / 25 / 93$ & BOTV09 & & & 40.00 & \\
\hline $699-43-41 E$ & $1 / 25 / 93$ & $807 v 13$ & $5.00 \mathrm{U}$ & & & \\
\hline $699-43-41 F$ & $12 / 05 / 89$ & H0000GG8 & & & & 52.00 \\
\hline $699-43-41 F$ & $12 / 05 / 89$ & H000DGG8 & & $5.00 \mathrm{U}$ & & \\
\hline
\end{tabular}


(sheet 17 of $\star$ )

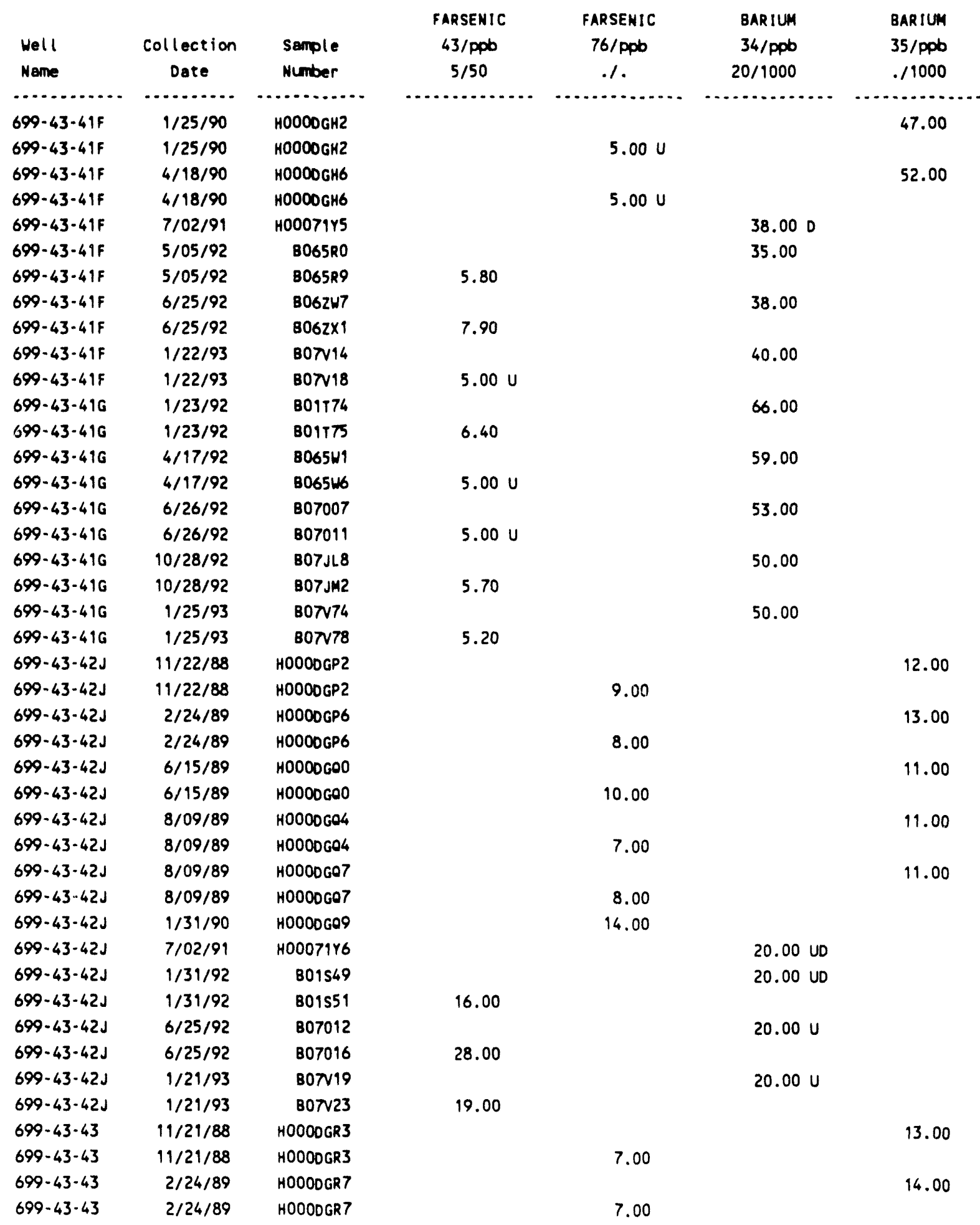


(sheet 18 of $\star *$ )

\begin{tabular}{|c|c|c|c|c|c|c|}
\hline $\begin{array}{l}\text { Hell } \\
\text { Name }\end{array}$ & $\begin{array}{c}\text { Collection } \\
\text { Date }\end{array}$ & $\begin{array}{l}\text { Semple } \\
\text { Number }\end{array}$ & $\begin{array}{c}\text { FARSENIC } \\
43 / \mathrm{ppb} \\
5 / 50\end{array}$ & $\begin{array}{l}\text { FARSENIC } \\
\text { 76/ppb } \\
. /\end{array}$ & $\begin{array}{l}\text { BARIUM } \\
34 / p p b \\
20 / 1000\end{array}$ & $\begin{array}{l}\text { BARIUM } \\
35 / \mathrm{ppb} \\
. / 1000\end{array}$ \\
\hline . & 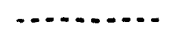 & n & $\cdots$ & 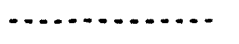 & 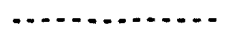 & and \\
\hline $699-43-43$ & $2 / 24 / 89$ & HOOODGSO & & & & 12.00 \\
\hline $699-43-43$ & $2 / 24 / 89$ & HOOOOGSO & & 7.00 & & \\
\hline $699-43-43$ & $6 / 15 / 89$ & HOOOOGS1 & & & & 9.00 \\
\hline $699-43-43$ & $6 / 15 / 89$ & HOOODGS1 & & 8.00 & & \\
\hline $699-43-43$ & $8 / 09 / 89$ & HOOODGS5 & & & & 12.00 \\
\hline $699-43-43$ & $8 / 09 / 89$ & H00ODGS5 & & 9.00 & & \\
\hline $699-43-43$ & $1 / 26 / 90$ & H0000GS9 & & & & 14.00 \\
\hline $699-43-43$ & $1 / 26 / 90$ & HOOODGS9 & & 8.00 & & \\
\hline $699-43-43$ & $7 / 08 / 91$ & H00079Y7 & & & $20.00 \mathrm{U}$ & \\
\hline $699-43-43$ & $1 / 24 / 92$ & B01067 & & & 20.00 UD & \\
\hline $699-43-43$ & $1 / 24 / 92$ & B01T84 & 9.50 & & & \\
\hline $699-43-43$ & $4 / 22 / 92$ & B065N6 & & & $20.00 \mathrm{U}$ & \\
\hline $699-43-43$ & $4 / 22 / 92$ & $8065 N 7$ & 7.60 & & & \\
\hline $699-43-43$ & $6 / 26 / 92$ & 8070w0 & & & 20.00 UD & \\
\hline $699-43-43$ & $6 / 26 / 92$ & Bo70w1 & 7.00 & & & \\
\hline $699-43-43$ & $10 / 26 / 92$ & B07JG5 & & & $20.00 \mathrm{U}$ & \\
\hline $699-43-43$ & $10 / 26 / 92$ & B07JG6 & 9.40 & & & \\
\hline $699-43-43$ & $1 / 13 / 93$ & BOTV24 & & & $20.00 \mathrm{U}$ & \\
\hline $699-43-43$ & $1 / 13 / 93$ & B07V28 & 7.70 & & & \\
\hline $699-43-45$ & $12 / 06 / 89$ & HODODGT4 & & & & 40.00 \\
\hline $699-43-45$ & $12 / 06 / 89$ & HOOODGT4 & & 9.00 & & \\
\hline $699-43-45$ & $1 / 26 / 90$ & H0000GT8 & & & & 41.00 \\
\hline $699-43-45$ & $1 / 26 / 90$ & H0000GT8 & & 12.00 & & \\
\hline $699-43-45$ & $4 / 18 / 90$ & H0OODGV2 & & & & 39.00 \\
\hline $699-43-45$ & $4 / 18 / 90$ & H0OODGV2 & & 11.00 & & \\
\hline $699-43-45$ & $7 / 08 / 91$ & H00071Y8 & & & 41.00 & \\
\hline $699-43-45$ & $9 / 11 / 91$ & 800LG5 & & & 37.00 & \\
\hline $699-43-45$ & $1 / 24 / 92$ & 801000 & & & $32.00 \mathrm{D}$ & \\
\hline $699-43-45$ & $1 / 24 / 92$ & 801001 & 11.00 & & & \\
\hline $699-43-45$ & $4 / 22 / 92$ & B065N8 & & & 36.00 & \\
\hline $699-43-45$ & $4 / 22 / 92$ & B065N9 & 9.30 & & & \\
\hline $699-43-45$ & $6 / 26 / 92$ & B070W2 & & & 35.000 & \\
\hline $699-43-45$ & $6 / 26 / 92$ & B070W3 & 8.50 & & & \\
\hline $699-43-45$ & $10 / 26 / 92$ & B07JG7 & & & 40.00 & \\
\hline $699-43-45$ & $10 / 26 / 92$ & B07JG8 & 11.00 & & & \\
\hline $699-43-45$ & $1 / 13 / 93$ & B07N29 & & & 30.00 & \\
\hline $699-43-45$ & $1 / 13 / 93$ & B07V33 & 9.60 & & & \\
\hline $699-44-398$ & $1 / 08 / 93$ & B07UK1 & & & $20.00 \mathrm{U}$ & \\
\hline $699-44-398$ & $1 / 08 / 93$ & B07UK5 & $5.00 \mathrm{U}$ & & & \\
\hline $699-44-42$ & $11 / 21 / 88$ & HOOODHK2 & & & & 12.00 \\
\hline $699-44-42$ & $11 / 21 / 88$ & HOOOD:IK2 & & 12.00 & & \\
\hline $699-44-42$ & $2 / 17 / 89$ & HOOODHKG & & & & 14.00 \\
\hline $699-44-42$ & $2 / 17 / 89$ & HOOODHKG & & 12.00 & & \\
\hline
\end{tabular}


(sheet 19 of $\star *$ )

\begin{tabular}{|c|c|c|c|c|c|c|}
\hline & & & $\begin{array}{l}\text { FARSENIC } \\
43 / \mathrm{pob}\end{array}$ & $\begin{array}{l}\text { FARSENIC } \\
76 / 0006\end{array}$ & $\begin{array}{l}\text { BARIUM } \\
34 / \text { Dob }\end{array}$ & $\begin{array}{l}\text { BARIUM } \\
35 / \mathrm{pob}\end{array}$ \\
\hline Name & $\begin{array}{l}\text { Collection } \\
\text { Date }\end{array}$ & $\begin{array}{l}\text { Sample } \\
\text { Humber }\end{array}$ & $\begin{array}{c}45 / p p b \\
5 / 50\end{array}$ & $\begin{array}{c}\text { 10/ppo } \\
. /\end{array}$ & $\begin{array}{l}34 / 10 p 0 \\
20 / 1000\end{array}$ &.$/ 1000$ \\
\hline - & - & n & (n) & . & $\ldots$ & 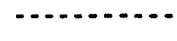 \\
\hline $699-44-42$ & $6 / 95 / 89$ & HOOOOHLO & & & & 13.00 \\
\hline $699-44-42$ & $6 / 15 / 89$ & HООООНLО & & 13.00 & & \\
\hline $699-44-42$ & $8 / 08 / 89$ & HOOOOHL 4 & & & & 12.00 \\
\hline $699-44-42$ & $8 / 08 / 89$ & HOOOOHL 4 & & 8.00 & & \\
\hline $699-44-42$ & $1 / 31 / 90$ & HOOODHL8 & & & & 14.00 \\
\hline $699-44-42$ & $1 / 31 / 90$ & H0OOOHL8 & & 15.00 & & \\
\hline $699-44-42$ & $7 / 10 / 91$ & H00071Y9 & & & $20.00 \mathrm{U}$ & \\
\hline $699-44-42$ & $1 / 31 / 92$ & B01552 & & & $27.00 \mathrm{D}$ & \\
\hline $699-44-42$ & $1 / 31 / 92$ & 801554 & 12.00 & & & \\
\hline $699-44-42$ & $6 / 25 / 92$ & B07017 & & & 39.00 & \\
\hline $699-44-42$ & $6 / 25 / 92$ & B07021 & 18.00 & & & \\
\hline $699-44-42$ & $1 / 13 / 93$ & B07v34 & & & 30.00 & \\
\hline $699-44-42$ & $1 / 13 / 93$ & B07N35 & & & 30.00 & \\
\hline $699-44-42$ & $1 / 13 / 93$ & BOTV42 & 12.00 & & & \\
\hline $699-44-42$ & $1 / 13 / 93$ & $807 N 43$ & 10.00 & & & \\
\hline $699-44-43 B$ & $12 / 20 / 89$ & HOOOOHM3 & & & & 47.00 \\
\hline $699-44-43 B$ & $12 / 20 / 89$ & HOOOOHM3 & & 6.00 & & \\
\hline $699-44-43 B$ & $12 / 20 / 89$ & HОOОDHМб & & & & 47.00 \\
\hline $699-44-43 B$ & $12 / 20 / 89$ & HOOODHMG & & 6.00 & & \\
\hline $699-44-43 B$ & $1 / 26 / 90$ & HOOODHM7 & & & & 52.00 \\
\hline $699-44-43 B$ & $1 / 26 / 90$ & МОООDHM7 & & 8.00 & & \\
\hline $699-44-43 B$ & $1 / 26 / 90$ & HOOOOHNO & & & & 52.00 \\
\hline $699-44-43 B$ & $1 / 26 / 90$ & НООООНNО & & 7.00 & & \\
\hline $699-44-43 B$ & $4 / 18 / 90$ & HOOODHN1 & & & & 51.00 \\
\hline $699-44-43 B$ & $4 / 18 / 90$ & HОOООНN1 & & 7.00 & & \\
\hline $699-44-438$ & $7 / 08 / 91$ & H00071ZO & & & 49.00 & \\
\hline $699-44-43 B$ & $9 / 11 / 91$ & BOOLG6 & & & 46.00 & \\
\hline $699-44-43 B$ & $1 / 23 / 92$ & 801069 & & & 42.00 & \\
\hline $699-44-43 B$ & $1 / 23 / 92$ & B01070 & $5.00 \mathrm{U}$ & & & \\
\hline $699-44-43 B$ & $4 / 20 / 92$ & 806519 & & & 48.00 & \\
\hline $699-4,4-43 B$ & $4 / 20 / 92$ & $B 065 \times 5$ & 7.30 & & & \\
\hline $699-44-438$ & $6 / 26 / 92$ & B01MT4 & 6.10 & & & \\
\hline $699-44-43 B$ & $6 / 26 / 92$ & B07022 & & & 48.00 & \\
\hline $699-44-43 B$ & $6 / 26 / 92$ & B07023 & & & 47.00 & \\
\hline $699-44-438$ & $6 / 26 / 92$ & B07026 & 6.00 & & & \\
\hline $699-44-43 B$ & $1 / 27 / 93$ & BOTV44 & & & 50.00 & \\
\hline $699-44-438$ & $1 / 27 / 93$ & B07V48 & 6.10 & & & \\
\hline
\end{tabular}


(sheet 20 of $\star *$ )

\begin{tabular}{|c|c|c|c|c|c|c|}
\hline Well & Collection & Sample & $\begin{array}{l}\text { FBARIUM } \\
34 / p p b\end{array}$ & $\begin{array}{r}\text { BERYLUM } \\
34 / \mathrm{ppb}\end{array}$ & $\begin{array}{l}\text { BERYLUM } \\
35 / \mathrm{ppb}\end{array}$ & $\begin{array}{r}\text { FBERYLL } \\
34 / \mathrm{ppb}\end{array}$ \\
\hline Name & Date & Number & $20 / 1000$ & $3 /$ & .1 & $3 /$ \\
\hline - & $\cdots$ & 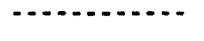 & 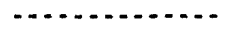 & $\cdots$ & $\cdots$ & \\
\hline 299-E18-1 & $8 / 16 / 88$ & H0007ZT7 & & & $5.00 \mathrm{U}$ & \\
\hline 299-E18-1 & $8 / 16 / 88$ & HOOOT2T7 & 41.00 & & & $5.00 \mathrm{U}$ \\
\hline 299-E18-1 & $9 / 22 / 88$ & H00072V1 & 48.00 & & & \\
\hline 299-E18-1 & $11 / 10 / 88$ & H0007ZV2 & & & $5.00 \mathrm{U}$ & \\
\hline 299-E18-1 & $11 / 10 / 88$ & H00072V2 & 43.00 & & & $5.00 \mathrm{U}$ \\
\hline 299-E18-1 & $11 / 10 / 88$ & H0007ZV5 & & & $5.00 \mathrm{U}$ & \\
\hline 299-E18-1 & $11 / 10 / 88$ & H00072V5 & 38.00 & & & $5.00 \mathrm{U}$ \\
\hline 299-E18-1 & $2 / 15 / 89$ & H0007ZV8 & & & $5.00 \mathrm{U}$ & \\
\hline 299-E18-1 & $2 / 15 / 89$ & H00072V8 & 31.00 & & & $5.00 \mathrm{U}$ \\
\hline $299-E 18-1$ & $5 / 26 / 89$ & H00072W2 & & & $5.00 \mathrm{U}$ & \\
\hline $299-E 18-1$ & $5 / 26 / 89$ & H0007ZW2 & 25.00 & & & $5.00 \mathrm{U}$ \\
\hline 299-E18-1 & $8 / 08 / 89$ & H00072W6 & & & $5.00 \mathrm{U}$ & \\
\hline 299-E18-1 & $8 / 08 / 89$ & H0007ZW6 & 34.00 & & & $5.00 \mathrm{U}$ \\
\hline 299-E 18-1 & $10 / 31 / 89$ & H0007ZXO & & & $5.00 \mathrm{U}$ & \\
\hline 299-E18-1 & $10 / 31 / 89$ & H00072X0 & 28.00 & & & $5.00 \mathrm{U}$ \\
\hline $299-E 18-1$ & $7 / 09 / 91$ & H00071X9 & & 3.80 & & \\
\hline 299-E18-1 & $7 / 09 / 91$ & H00071X9F & 25.00 & & & $3.00 \mathrm{U}$ \\
\hline 299-E18-1 & $9 / 06 / 91$ & BOOLB6 & & $3.00 \mathrm{U}$ & & \\
\hline 299-E18-1 & $9 / 06 / 91$ & BOOLBGF & 24.00 & & & $3.00 \mathrm{U}$ \\
\hline 299-E18-1 & $1 / 24 / 92$ & B01059 & & 3.00 UD & & \\
\hline $299-E 18-1$ & $1 / 24 / 92$ & 801060 & $23.00 \mathrm{D}$ & & & 3.00 UD \\
\hline 299-E18-1 & $6 / 03 / 92$ & BOGPH8 & & $3.00 \mathrm{U}$ & & \\
\hline 299-E18-1 & $6 / 03 / 92$ & B06PJ2 & 27.00 & & & $3.00 \mathrm{U}$ \\
\hline 299-E18-1 & $12 / 16 / 92$ & B07\$32 & & $3.00 \mathrm{U}$ & & \\
\hline 299-E18-1 & $12 / 16 / 92$ & อา7536 & 30.00 & & & $3.00 \mathrm{U}$ \\
\hline $299-E 32-4$ & $9 / 27 / 88$ & H0008288 & & & $5.00 \mathrm{U}$ & \\
\hline 299-E32-4 & $9 / 27 / 88$ & H0008ZB8 & 73.00 & & & $5.00 \mathrm{U}$ \\
\hline 299-E32-4 & $12 / 28 / 88$ & H0008ZC2 & & & $5.00 \mathrm{U}$ & \\
\hline $299-E 32-4$ & $12 / 28 / 88$ & H0OOBZC2 & 70.00 & & & $5.00 \mathrm{U}$ \\
\hline $299-E 32-4$ & $3 / 01 / 89$ & H00082C6 & & & $5.00 \mathrm{U}$ & \\
\hline $299-E 32-4$ & $3 / 01 / 89$ & H0008ZC6 & 73.00 & & & $5.00 \mathrm{U}$ \\
\hline $299-E 32-4$ & $3 / 13 / 89$ & H0008ZDO & & & $5.00 \mathrm{U}$ & \\
\hline $299-E 32-4$ & $3 / 13 / 89$ & H0008ZDO & 72.00 & & & $5.00 \mathrm{U}$ \\
\hline 299-E32-4 & $6 / 16 / 89$ & H0O08Z204 & & & $5.00 \mathrm{U}$ & \\
\hline $299-E 32-4$ & $6 / 16 / 89$ & H0008ZD4 & 70.00 & & & $5.00 \mathrm{U}$ \\
\hline $299-E 32-4$ & $7 / 19 / 89$ & H0008208 & & & $5.00 \mathrm{U}$ & \\
\hline $299-E 32-4$ & $7 / 19 / 89$ & H0008ZD8 & 69.00 & & & $5.00 \mathrm{U}$ \\
\hline $299-E 32-4$ & $9 / 08 / 89$ & H00082F6 & & & 10.00 & \\
\hline $299-E 32-4$ & $9 / 08 / 89$ & H0008ZF6 & 71.00 & & & $5.00 \mathrm{U}$ \\
\hline $299-E 32-4$ & $1 / 17 / 90$ & H00082GO & & & $5.00 \mathrm{U}$ & \\
\hline $299-E 32-4$ & $1 / 17 / 90$ & H0008ZGO & 76.00 & & & $5.00 \mathrm{U}$ \\
\hline $299-E 32-4$ & $8 / 05 / 91$ & HOOOTIYO & & 3.00 UD & & \\
\hline $299-E 32-4$ & $8 / 05 / 91$ & HOOOTIYOF & 74.00 & & & $3.00 \mathrm{U}$ \\
\hline
\end{tabular}


(sheet 21 of $*$ )

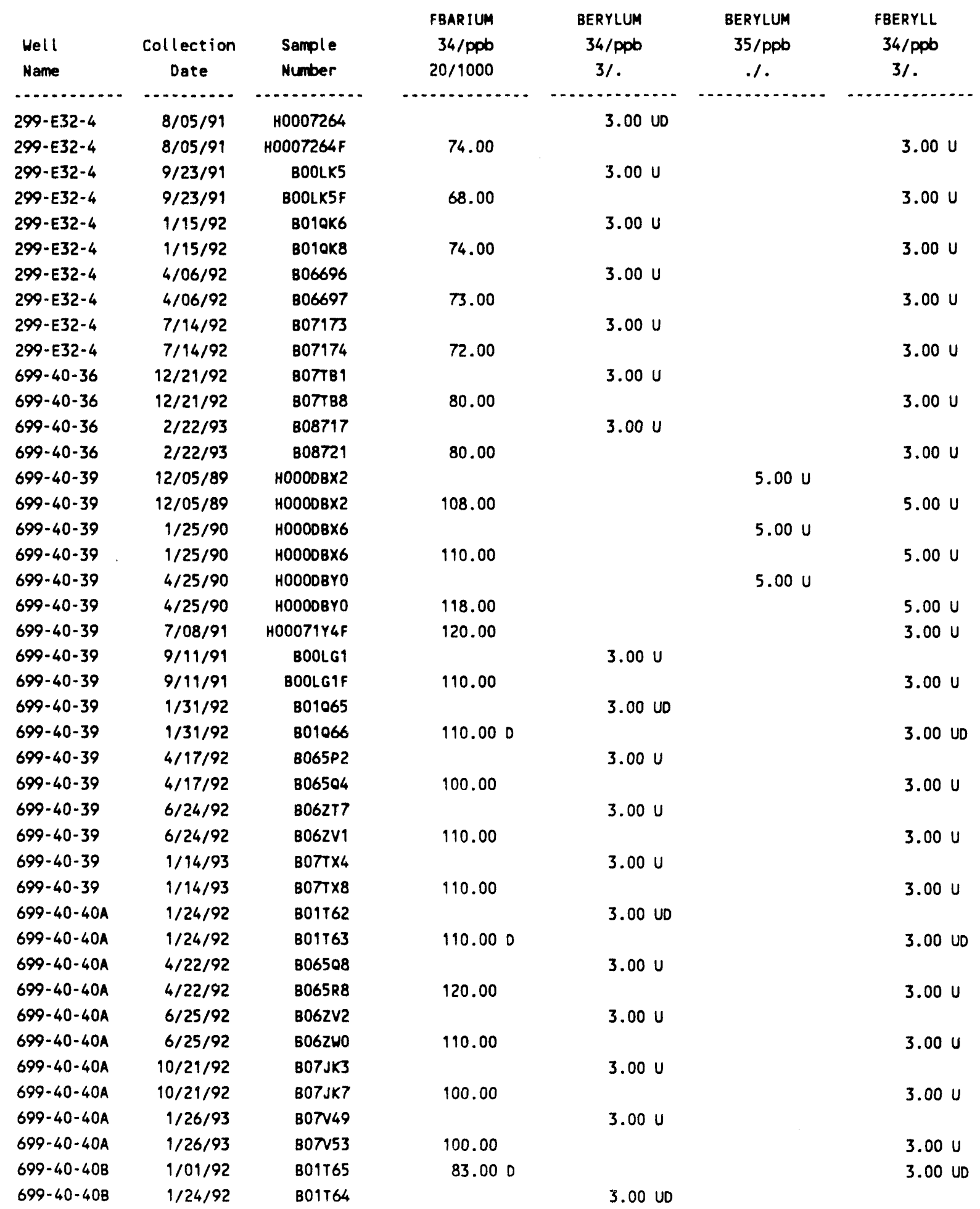


(sheet 22 of $\star *)$

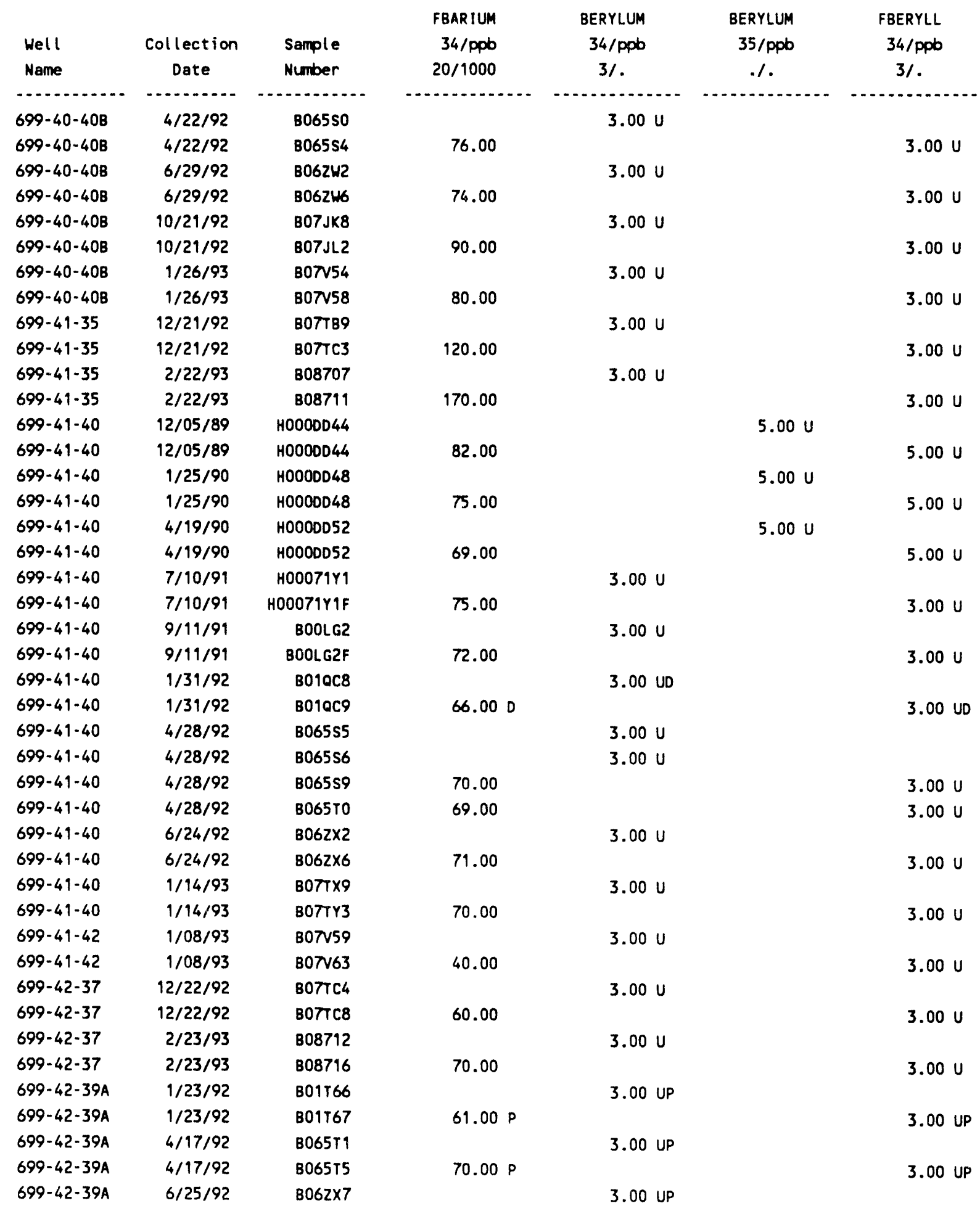


(sheet 23 of $\star \star$ )

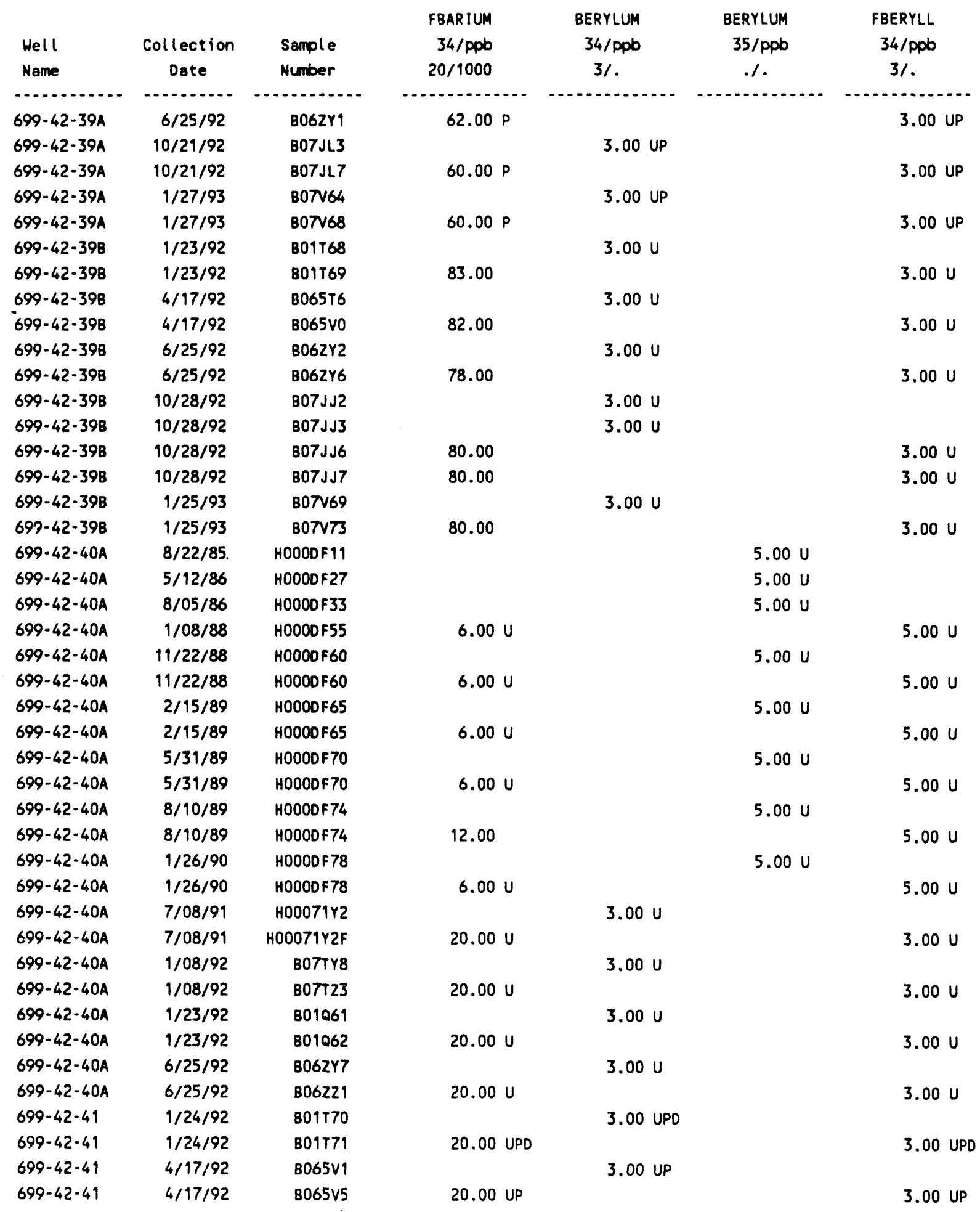


(sheet 24 of $*$ )

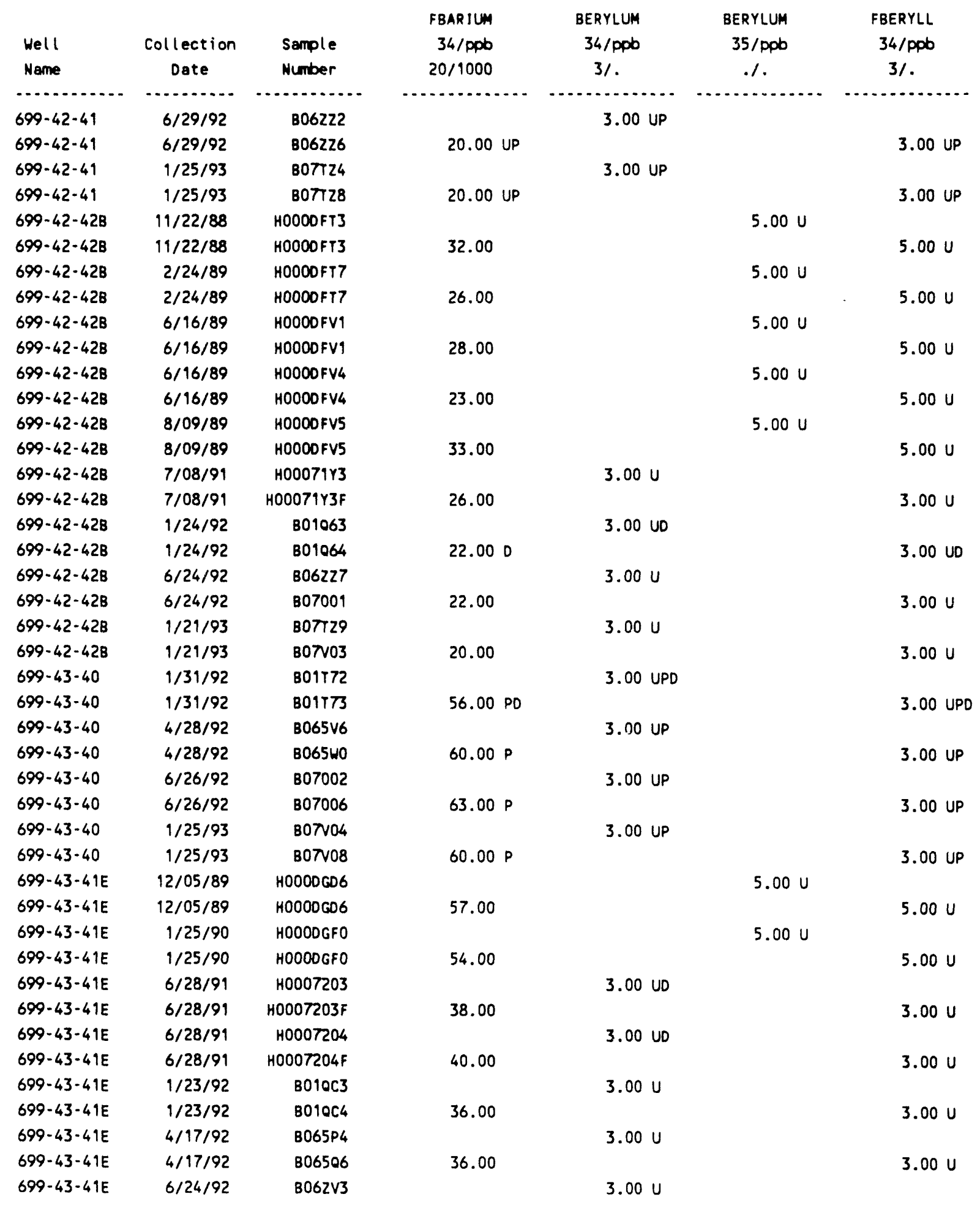


(sheet 25 of $\star \star$ )

\begin{tabular}{|c|c|c|c|c|c|c|}
\hline Well & Collection & Sample & $\begin{array}{l}\text { FBARIUM } \\
34 / p p b\end{array}$ & $\begin{array}{l}\text { BERYLUM } \\
34 / \mathrm{ppb}\end{array}$ & $\begin{array}{r}\text { BERYLUM } \\
35 / \mathrm{ppb}\end{array}$ & $\begin{array}{l}\text { FBERYLL } \\
34 / \mathrm{ppb}\end{array}$ \\
\hline Name & Dete & Number & $20 / 1000$ & $3 /$ & .1. & $3 /$. \\
\hline , & 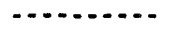 & - & , n & , & $\cdots$ & $\cdots$ \\
\hline $699-43-41 E$ & $6 / 24 / 92$ & B062W1 & 38.00 & & & $3.00 \mathrm{U}$ \\
\hline $699-43-41 E$ & $1 / 25 / 93$ & BOTV09 & & $3.00 \mathrm{U}$ & & \\
\hline $699-43-41 E$ & $1 / 25 / 93$ & B07v13 & 40.00 & & & $3.00 \mathrm{U}$ \\
\hline $699-43-41 F$ & $12 / 05 / 89$ & HOOODGG8 & & & $5.00 \mathrm{U}$ & \\
\hline $699-43-41 F$ & $12 / 05 / 89$ & HOOODGG8 & 50.00 & & & $5.00 \mathrm{U}$ \\
\hline $699-43-41 F$ & $1 / 25 / 90$ & HOOODGH2 & & & $5.00 \mathrm{U}$ & \\
\hline $699-43-41 F$ & $1 / 25 / 90$ & HOOODGH2 & 42.00 & & & $5.00 \mathrm{U}$ \\
\hline $699-43-41 F$ & $4 / 18 / 90$ & H0OODGH6 & & & $5.00 \mathrm{U}$ & \\
\hline $699-43-41 F$ & $4 / 18 / 90$ & HOOODGH6 & 44.00 & & & $5.00 \mathrm{U}$ \\
\hline $699-43-41 F$ & $7 / 02 / 91$ & H00071Y5 & & 3.00 UD & & \\
\hline $699-43-41 F$ & $7 / 02 / 91$ & H00071Y5F & 37.00 & & & $3.00 \mathrm{U}$ \\
\hline $699-43-41 F$ & $5 / 05 / 92$ & B065RO & & $3.00 \mathrm{U}$ & & \\
\hline $699-43-41 F$ & $5 / 05 / 92$ & B065R9 & 36.00 & & & $3.00 \mathrm{U}$ \\
\hline $699-43-41 F$ & $6 / 25 / 92$ & B06ZW7 & & $3.00 \mathrm{U}$ & & \\
\hline $699-43-41 F$ & $6 / 25 / 92$ & $8062 \times 9$ & 34.00 & & & $3.00 \mathrm{U}$ \\
\hline $699-43-41 F$ & $1 / 22 / 93$ & Bo7N14 & & $3.00 \mathrm{U}$ & & \\
\hline $699-43-41 F$ & $1 / 22 / 93$ & $807 v 18$ & 40.00 & & & $3.00 \mathrm{U}$ \\
\hline $699-43-416$ & $1 / 23 / 92$ & B01T74 & & $3.00 \mathrm{U}$ & & \\
\hline $699-43-416$ & $1 / 23 / 92$ & B01T75 & 53.00 & & & $3.00 \mathrm{U}$ \\
\hline $699-43-41 G$ & $4 / 17 / 92$ & B065W1 & & $3.00 \mathrm{U}$ & & \\
\hline $699-43-410$ & 4/17/92 & B065U6 & 56.00 & & & $3.00 \mathrm{U}$ \\
\hline $699-43-416$ & $6 / 26 / 92$ & B07007 & & $3.00 \mathrm{U}$ & & \\
\hline $699-43-416$ & $6 / 26 / 92$ & B07011 & 53.00 & & & $3.00 \mathrm{U}$ \\
\hline $699-43-41 G$ & $10 / 28 / 92$ & B07JL8 & & $3.00 \mathrm{U}$ & & \\
\hline $699-43-41 G$ & $10 / 28 / 92$ & B07JM2 & 50.00 & & & $3.00 \mathrm{U}$ \\
\hline $699-43-416$ & $1 / 25 / 93$ & BO7v74 & & $3.00 \mathrm{U}$ & & \\
\hline $699-43-41 G$ & $1 / 25 / 93$ & B07V78 & 50.00 & & & $3.00 \mathrm{U}$ \\
\hline $699-43-42 J$ & $11 / 22 / 88$ & HOOODGP2 & & & $5.00 \mathrm{U}$ & \\
\hline $699-43-42 J$ & $11 / 22 / 88$ & H0OODGP2 & 13.00 & & & $5.00 \mathrm{U}$ \\
\hline $699-43-42 J$ & $2 / 24 / 89$ & HOOODGP6 & & & $5.00 \mathrm{U}$ & \\
\hline $699-43-42 J$ & $2 / 24 / 89$ & HOOODGP6 & 12.00 & & & $5.00 \mathrm{U}$ \\
\hline $699-43-42 \mathrm{~J}$ & $6 / 15 / 89$ & HOOODGQO & & & $5.00 \mathrm{U}$ & \\
\hline $699-43 \cdot 42 \mathrm{~J}$ & $6 / 15 / 89$ & HOOODGQO & 13.00 & & & $5.00 \mathrm{U}$ \\
\hline $699-43-42 \mathrm{~J}$ & $8 / 09 / 89$ & HOOODGQ4 & & & $5.00 \mathrm{U}$ & \\
\hline $699-43-42 J$ & $8 / 09 / 89$ & HOOOOGO4 & 17.00 & & & $5.00 \mathrm{U}$ \\
\hline $699-43-42 J$ & $8 / 09 / 89$ & H0OOOGQ7 & & & $5.00 \mathrm{U}$ & \\
\hline $699-43-42 J$ & $8 / 09 / 89$ & H0OOOGGO7 & 14.00 & & & $5.00 \mathrm{U}$ \\
\hline $699-43 \cdot 42 \mathrm{~J}$ & $7 / 02 / 91$ & H00071Y6 & & 3.00 UD & & \\
\hline $699-43-42 \mathrm{~J}$ & $7 / 02 / 91$ & H00071YGF & $20.00 \mathrm{U}$ & & & $3.00 \mathrm{U}$ \\
\hline $699-43-42 \mathrm{~J}$ & $1 / 31 / 92$ & 801549 & & 3.00 UD & & \\
\hline $699-43-42 \mathrm{~J}$ & $1 / 31 / 92$ & B01S51 & 20.00 UD & & & 3.00 UD \\
\hline $699-43-42 \mathrm{~J}$ & $6 / 25 / 92$ & B07012 & & $3.00 \mathrm{U}$ & & \\
\hline $699-43-42 J$ & $6 / 25 / 92$ & B07016 & $20.00 \mathrm{U}$ & & & $3.00 \mathrm{U}$ \\
\hline
\end{tabular}


(sheet 26 of $\star *$ )

\begin{tabular}{|c|c|c|c|c|c|c|}
\hline $\begin{array}{l}\text { Well } \\
\text { Name }\end{array}$ & $\begin{array}{c}\text { Collection } \\
\text { Date }\end{array}$ & $\begin{array}{l}\text { Sample } \\
\text { Number }\end{array}$ & $\begin{array}{l}\text { FBARIUM } \\
34 / \text { ppb } \\
20 / 1000\end{array}$ & $\begin{array}{c}\text { BERYLUM } \\
34 / \mathrm{ppb} \\
3 /\end{array}$ & $\begin{array}{c}\text { BERYLUM } \\
35 / \mathrm{ppb} \\
.1\end{array}$ & $\begin{array}{c}\text { FBERYLL } \\
34 / \mathrm{ppb} \\
3 /\end{array}$ \\
\hline $699-43-42 \mathrm{~J}$ & $1 / 21 / 93$ & BOTV19 & - & $3.00 \mathrm{U}$ & , n & \\
\hline $699-43-42 \mathrm{~J}$ & $1 / 21 / 93$ & Borv23 & $20.00 \mathrm{U}$ & & & $3.00 \mathrm{U}$ \\
\hline $699-43-43$ & $11 / 21 / 88$ & HOOOOGR3 & & & $5.00 \mathrm{U}$ & \\
\hline $699-43-43$ & $11 / 21 / 88$ & H0OOOGR3 & 12.00 & & & $5.00 \mathrm{U}$ \\
\hline $699-43-43$ & $2 / 24 / 89$ & HOOOOGR7 & & & $5.00 \mathrm{U}$ & \\
\hline $699-43-43$ & $2 / 24 / 89$ & HOOOOGRT & 13.00 & & & $5.00 \mathrm{U}$ \\
\hline $699-43-43$ & $2 / 24 / 89$ & HOOODGSO & & & $5.00 \mathrm{U}$ & \\
\hline $699-43-43$ & $2 / 24 / 89$ & HOOODGSO & 13.00 & & & $5.00 \mathrm{U}$ \\
\hline $699-43-43$ & $6 / 15 / 89$ & HOOODGS1 & & & $5.00 \mathrm{U}$ & \\
\hline $699-43-43$ & $6 / 15 / 89$ & HOOODGS1 & 13.00 & & & $5.00 \mathrm{U}$ \\
\hline $699-43-43$ & $8 / 09 / 89$ & HOOODGS5 & & & $5.00 \mathrm{U}$ & \\
\hline $699-43-43$ & $8 / 09 / 89$ & H0OODGS5 & 18.00 & & & $5.00 \mathrm{U}$ \\
\hline $699-43-43$ & $1 / 26 / 90$ & HOOODGS9 & & & $5.00 \mathrm{U}$ & \\
\hline $699-43-43$ & $1 / 26 / 90$ & HOOODGS9 & 15.00 & & & $5.00 \mathrm{U}$ \\
\hline $699-43-43$ & $7 / 08 / 91$ & H00071Y7 & & $3.00 \mathrm{U}$ & & \\
\hline $699-43-43$ & $7 / 08 / 91$ & H00071Y7F & $20.00 \mathrm{U}$ & & & $3.00 \mathrm{U}$ \\
\hline $699-43-43$ & $1 / 24 / 92$ & 801067 & & 3.00 UD & & \\
\hline $699-43-43$ & $1 / 24 / 92$ & 801068 & 20.00 UD & & & 3.00 UD \\
\hline $699-43-43$ & $4 / 22 / 92$ & $8065 N 6$ & & $3.00 \mathrm{U}$ & & \\
\hline $699-43-43$ & $4 / 22 / 92$ & B065N7 & $20.00 \mathrm{U}$ & & & $3.00 \mathrm{U}$ \\
\hline $699-43-43$ & $6 / 26 / 92$ & BO70wO & & 3.00 UD & & \\
\hline $699-43-43$ & $6 / 26 / 92$ & B070W1 & $20.00 \mathrm{U}$ & & & $3.00 \mathrm{U}$ \\
\hline $699-43-43$ & $10 / 26 / 92$ & B07JG5 & & $3.00 \mathrm{U}$ & & \\
\hline $699-43-43$ & $10 / 26 / 92$ & B07JG6 & $20.00 \mathrm{U}$ & & & $3.00 \mathrm{U}$ \\
\hline $699-43-43$ & $1 / 13 / 93$ & $807 v 24$ & & $3.00 \mathrm{U}$ & & \\
\hline $699-43-43$ & $1 / 13 / 93$ & 807v28 & $20.00 U$ & & & $3.00 \mathrm{U}$ \\
\hline $699-43-45$ & $12 / 06 / 89$ & HOOODGT 4 & & & $5.00 \mathrm{U}$ & \\
\hline $699-43-45$ & $12 / 06 / 89$ & H0OODGT4 & 38.00 & & & $5.00 \mathrm{U}$ \\
\hline $699-43-45$ & $1 / 26 / 90$ & HOOODGT8 & & & $5.00 \mathrm{U}$ & \\
\hline $699-43-45$ & $1 / 26 / 90$ & HOOODGT 8 & 38.00 & & & $5.00 \mathrm{U}$ \\
\hline $699-43-45$ & $4 / 18 / 90$ & H000DGV2 & & & $5.00 \mathrm{U}$ & \\
\hline $699-43-45$ & $4 / 18 / 90$ & H0OOOGV2 & 39.00 & & & $5.00 \mathrm{U}$ \\
\hline $699-43-45$ & $7 / 08 / 91$ & H00071Y8 & & $3.00 \mathrm{U}$ & & \\
\hline $699-43-45$ & $7 / 08 / 91$ & H00079Y8F & 37.00 & & & $3.00 \mathrm{U}$ \\
\hline $699-43-45$ & $9 / 11 / 91$ & BOOLGS & & $3.00 \mathrm{U}$ & & \\
\hline $699-43-45$ & $9 / 11 / 91$ & BOOLG5F & 36.00 & & & $3.00 \mathrm{U}$ \\
\hline $699-43-45$ & $1 / 24 / 92$ & $B 01000$ & & 3.00 UD & & \\
\hline $699-43-45$ & $1 / 24 / 92$ & B010D1 & $33.00 \mathrm{D}$ & & & 3.00 UD \\
\hline $699-43-45$ & $4 / 22 / 92$ & B065N8 & & $3.00 \mathrm{U}$ & & \\
\hline $699-43-45$ & $4 / 22 / 92$ & B065N9 & 36.00 & & & $3.00 \mathrm{U}$ \\
\hline $699-43-45$ & $6 / 26 / 92$ & 8070W2 & & 3.00 UD & & \\
\hline $699-43-45$ & $6 / 26 / 92$ & B070W3 & 36.00 & & & $3.00 \mathrm{U}$ \\
\hline $699-43-45$ & $10 / 26 / 92$ & B07JG7 & & $3.00 \mathrm{U}$ & & \\
\hline
\end{tabular}


(sheet 27 of *)

\begin{tabular}{|c|c|c|c|c|c|c|}
\hline $\begin{array}{l}\text { Well } \\
\text { Name }\end{array}$ & $\begin{array}{l}\text { Collection } \\
\text { Date }\end{array}$ & $\begin{array}{l}\text { Sample } \\
\text { Number }\end{array}$ & $\begin{array}{l}\text { FBARIUM } \\
34 / \text { ppb } \\
20 / 1000\end{array}$ & $\begin{array}{c}\text { BERYLUM } \\
34 / \text { ppb } \\
3 \%\end{array}$ & $\begin{array}{c}\text { BERYLUM } \\
35 / \mathrm{ppb} \\
. /\end{array}$ & $\begin{array}{c}\text { FBERYLL } \\
34 / \mathrm{ppb} \\
3 / .\end{array}$ \\
\hline $699-43-45$ & $10 / 26 / 92$ & B07JG8 & 30.00 & & & $3.00 \mathrm{U}$ \\
\hline $699-43-45$ & $1 / 13 / 93$ & B07v29 & & $3.00 \mathrm{U}$ & & \\
\hline $699-43-45$ & $1 / 13 / 93$ & B07v33 & 30.00 & & & $3.00 \mathrm{U}$ \\
\hline $699-44-398$ & $1 / 08 / 93$ & B07UK1 & & $3.00 \mathrm{U}$ & & \\
\hline $699-44-398$ & $1 / 08 / 93$ & BO7UK5 & $20.00 \mathrm{U}$ & & & $3.00 \mathrm{U}$ \\
\hline $699-44-42$ & $11 / 21 / 88$ & H0000HK2 & & & $5.00 \mathrm{U}$ & \\
\hline $699-44-42$ & $11 / 21 / 88$ & HOOOOHK2 & 12.00 & & & $5.00 \mathrm{U}$ \\
\hline $699-44-42$ & $2 / 17 / 89$ & HOOODHKG & & & $5.00 \mathrm{U}$ & \\
\hline $699-44-42$ & $2 / 17 / 89$ & HOOODHK6 & 15.00 & & & $5.00 \mathrm{U}$ \\
\hline $699-44-42$ & $6 / 15 / 89$ & HOOOOHLO & & & $5.00 \mathrm{U}$ & \\
\hline $699-44-42$ & $6 / 15 / 89$ & HOOODHLO & 12.00 & & & $5.00 \mathrm{U}$ \\
\hline $699-44-42$ & $8 / 08 / 89$ & HOOODHL 4 & & & $5.00 \mathrm{U}$ & \\
\hline $699-44-42$ & $8 / 08 / 89$ & HOOODHL 4 & 17.00 & & & $5.00 \mathrm{U}$ \\
\hline $699-44-42$ & $1 / 31 / 90$ & H000OHL8 & & & $5.00 \mathrm{U}$ & \\
\hline $699-44-42$ & $1 / 31 / 90$ & HOOOOHL8 & 13.00 & & & $5.00 \mathrm{U}$ \\
\hline $699-44-42$ & $7 / 10 / 91$ & H00071Y9 & & $3.00 \mathrm{U}$ & & \\
\hline $699-44-42$ & $7 / 10 / 91$ & HO0071Y9F & $20.00 \mathrm{U}$ & & & $3.00 \mathrm{U}$ \\
\hline $699-44-42$ & $1 / 31 / 92$ & B01552 & & 3.00 UD & & \\
\hline $699-44-42$ & $1 / 31 / 92$ & 801554 & $27.00 \mathrm{D}$ & & & 3.00 UD \\
\hline $699-44-42$ & $6 / 25 / 92$ & B07017 & & $3.00 \mathrm{U}$ & & \\
\hline $699-44-42$ & $6 / 25 / 92$ & B07021 & 39.00 & & & $3.00 \mathrm{U}$ \\
\hline $699-44-42$ & $1 / 13 / 93$ & B07v34 & & $3.00 \mathrm{U}$ & & \\
\hline $699-44-42$ & $1 / 13 / 93$ & B07v35 & & $3.00 \mathrm{U}$ & & \\
\hline $699-44-42$ & $1 / 13 / 93$ & B07N42 & 30.00 & & & $3.00 \mathrm{U}$ \\
\hline $699-44-42$ & $1 / 13 / 93$ & B07N43 & 30.00 & & & $3.00 \mathrm{U}$ \\
\hline $699-44-438$ & $12 / 20 / 89$ & HOOODHM3 & & & $5.00 \mathrm{U}$ & \\
\hline $699-44-43 B$ & $12 / 20 / 89$ & HOOODHM3 & 50.00 & & & $5.00 \mathrm{U}$ \\
\hline $699-44-43 B$ & $12 / 20 / 89$ & HOOODHMG & & & $5.00 \mathrm{U}$ & \\
\hline $699-44-43 B$ & $12 / 20 / 89$ & HOOODHMG & 52.00 & & & $5.00 \mathrm{U}$ \\
\hline $699-44-438$ & $1 / 26 / 90$ & HOOODHM7 & & & $5.00 \mathrm{U}$ & \\
\hline $699-44-438$ & $1 / 26 / 90$ & HOOODHM7 & 49.00 & & & $5.00 \mathrm{U}$ \\
\hline $699-44-43 B$ & $1 / 26 / 90$ & HOOODHNO & & & $5.00 \mathrm{U}$ & \\
\hline $699-44-438$ & $1 / 26 / 90$ & HOOODHNO & 49.00 & & & $5.00 \mathrm{U}$ \\
\hline $699-44-43 B$ & $4 / 18 / 90$ & HOOODHN 1 & & & $5.00 \mathrm{U}$ & \\
\hline $699-44-43 B$ & $4 / 18 / 90$ & HOOODHMI & 47.00 & & & $5.00 \mathrm{U}$ \\
\hline $699-44-43 B$ & 7/08/91 & H0007120 & & $3.00 \mathrm{U}$ & & \\
\hline $699-44-43 B$ & $7 / 08 / 91$ & H0007120F & 50.00 & & & $3.00 \mathrm{U}$ \\
\hline $699-44-43 B$ & $9 / 11 / 91$ & BOOLG6 & & $3.00 \mathrm{U}$ & & \\
\hline $699-44-43 B$ & 9/11/91 & BOOLG6F & 43.00 & & & $3.00 \mathrm{U}$ \\
\hline $699-44-43 B$ & $1 / 23 / 92$ & B01069 & & $3.00 \mathrm{U}$ & & \\
\hline $699-44-43 B$ & $1 / 23 / 92$ & B01070 & 46.00 & & & $3.00 \mathrm{U}$ \\
\hline $699-44-43 B$ & $4 / 20 / 92$ & B065 W9 & & $3.00 \mathrm{U}$ & & \\
\hline $699-44-438$ & $4 / 20 / 92$ & B065×5 & 46.00 & & & $3.00 \mathrm{U}$ \\
\hline
\end{tabular}


(sheet 28 of $* \star$ )

\begin{tabular}{|c|c|c|c|c|c|c|}
\hline Wall & collertion & Samole & FBARIUM & $\begin{array}{l}\text { BERYLUM } \\
34 / 00 b\end{array}$ & $\begin{array}{l}\text { BERYLUM } \\
35 / 00 b\end{array}$ & $\begin{array}{r}\text { FBERYLL } \\
34 / 006\end{array}$ \\
\hline Name & Date & Number & $20 / 1000$ & 31 & .1 & $3 /$ \\
\hline 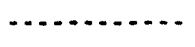 & 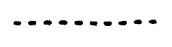 & 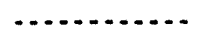 & (n) & . & (n) & \\
\hline $699-44-43 B$ & $6 / 26 / 92$ & BO1MT4 & 46.00 & & & $3.00 \mathrm{U}$ \\
\hline $699-44-43 B$ & $6 / 26 / 92$ & 807022 & & $3.00 \mathrm{U}$ & & \\
\hline $699-44-43 B$ & $6 / 26 / 92$ & B07023 & & $3.00 \mathrm{U}$ & & \\
\hline $699-44-43 B$ & $6 / 26 / 92$ & B07026 & 45.00 & & & $3.00 \mathrm{U}$ \\
\hline $699-44-43 B$ & $1 / 27 / 93$ & B07N44 & & $3.00 \mathrm{U}$ & & \\
\hline $699-44-43 B$ & $1 / 27 / 93$ & B07N48 & 50.00 & & & $3.00 \mathrm{U}$ \\
\hline
\end{tabular}

\begin{tabular}{|c|c|c|c|c|c|c|}
\hline & & & BORON & FBORON & CADMIUM & CADMIUM \\
\hline Well & Collection & Sample & 35/ppb & $34 / p p b$ & 34/ppb & 35/ppb \\
\hline Name & Date & Number & .1 & .1 & $10 / 10$ &.$/ 10$ \\
\hline$\ldots$ & $\ldots$ & $\cdots$ & 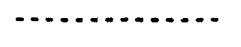 & (n) & (n) & . \\
\hline 299-E18-1 & $8 / 16 / 88$ & H0007ZT7 & & & & $2.00 \mathrm{U}$ \\
\hline 299-E18-1 & $9 / 22 / 88$ & H00072V1 & & & & $2.00 \mathrm{U}$ \\
\hline $299-E 18-1$ & $11 / 10 / 88$ & H0007ZV2 & & & & $2.00 \mathrm{U}$ \\
\hline 299-E18-1 & $11 / 10 / 88$ & H0007ZV5 & & $\cdot$ & & $2.00 \mathrm{U}$ \\
\hline 299-E18-1 & $2 / 15 / 89$ & H0007ZV8 & 33.00 & & & $2.00 \mathrm{U}$ \\
\hline 299-E18-1 & $2 / 15 / 89$ & H0007ZV8 & & 38.00 & & \\
\hline $299-E 18-1$ & $5 / 26 / 89$ & H0007ZW2 & 37.00 & & & $2.00 \mathrm{U}$ \\
\hline $299-E 18-1$ & $5 / 26 / 89$ & H0007ZW2 & & 34.00 & & \\
\hline 299-E18-1 & $8 / 08 / 89$ & H0007ZW6 & 38.00 & & & $2.00 \mathrm{U}$ \\
\hline 299-E18-1 & $8 / 08 / 89$ & H0007ZW6 & & 42.00 & & \\
\hline $299-E 18-1$ & $10 / 31 / 89$ & H00072XO & 31.00 & & & $2.00 \mathrm{U}$ \\
\hline $299-E 18-1$ & $10 / 31 / 89$ & $100072 \times 0$ & & 30.00 & & \\
\hline $299-E 18-1$ & $7 / 09 / 91$ & $H 00071 \times 9$ & & & $10.00 \mathrm{U}$ & \\
\hline $299-E 18-1$ & $9 / 06 / 91$ & BOOLB6 & & & $10.00 \mathrm{U}$ & \\
\hline $299-E 18-1$ & $1 / 24 / 92$ & 801059 & & & 10.00 UD & \\
\hline 299-E18-1 & $6 / 03 / 92$ & B06PH8 & & & $10.00 \mathrm{U}$ & \\
\hline $299-E 18-1$ & $12 / 16 / 92$ & B07s32 & & & $10.00 \mathrm{U}$ & \\
\hline $299-E 32-4$ & $9 / 27 / 88$ & H0008ZB8 & & & & $2.00 \mathrm{U}$ \\
\hline $299-E 32-4$ & $12 / 28 / 88$ & $\mathrm{H} 00082 \mathrm{CZ}$ & & & & $2.00 \mathrm{U}$ \\
\hline $299-E 32-4$ & $3 / 01 / 89$ & H0008ZC6 & 31.00 & & & $2.00 \mathrm{U}$ \\
\hline $299-E 32-4$ & $3 / 01 / 89$ & $\mathrm{H} 00082 \mathrm{C} 6$ & & 33.00 & & \\
\hline $299-E 32-4$ & $3 / 13 / 89$ & H0008ZDO & 38.00 & & & $2.00 \mathrm{U}$ \\
\hline 299-E32-4 & $3 / 13 / 89$ & H0OOBZDO & & 41.00 & & \\
\hline $299-E 32-4$ & $6 / 16 / 89$ & $\mathrm{H} 00082 \mathrm{D} 4$ & 59.00 & & & $2.00 \mathrm{U}$ \\
\hline $299-E 32-4$ & $6 / 16 / 89$ & H0008ZD4 & & 45.00 & & \\
\hline $299-E 32-4$ & $7 / 19 / 89$ & H0008ZD8 & 61.00 & & & $2.00 \mathrm{U}$ \\
\hline $299-E 32-4$ & $7 / 19 / 89$ & H0008ZD8 & & 62.00 & & \\
\hline $299-E 32-4$ & $9 / 08 / 89$ & H0008ZF6 & 23.00 & & & $2.00 \mathrm{U}$ \\
\hline $299-E 32-4$ & $9 / 08 / 89$ & H0008ZFG & & 24.00 & & \\
\hline $299-E 32-4$ & $1 / 17 / 90$ & H0OOBZGO & 42.00 & & & $2.00 \mathrm{U}$ \\
\hline
\end{tabular}


(sheet 29 of $\star *$ )

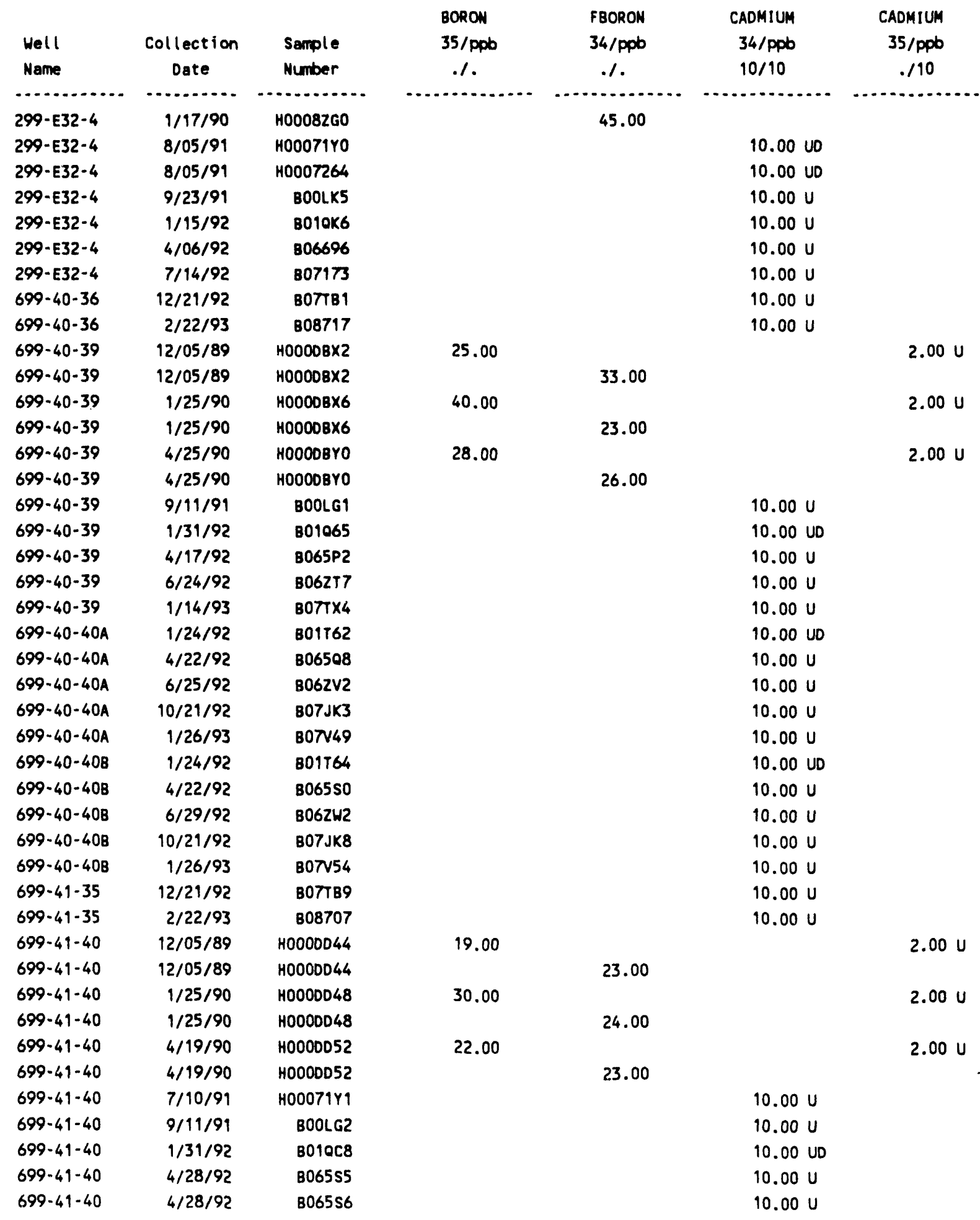


(sheet 30 of $\star$ )

\begin{tabular}{|c|c|c|c|c|c|c|}
\hline $\begin{array}{l}\text { Hell } \\
\text { Name }\end{array}$ & $\begin{array}{c}\text { Collection } \\
\text { Date }\end{array}$ & $\begin{array}{l}\text { Sample } \\
\text { Number }\end{array}$ & $\begin{array}{c}\text { BORON } \\
35 / p p b \\
.1\end{array}$ & $\begin{array}{c}\text { FBORON } \\
34 / \mathrm{ppb} \\
.1\end{array}$ & $\begin{array}{l}\text { CADMIUM } \\
34 / \text { ppb } \\
10 / 10\end{array}$ & $\begin{array}{c}\text { CADMIUM } \\
35 / p p b \\
. / 10\end{array}$ \\
\hline$\cdots+\ldots$ & $\ldots$ & $\ldots$ & 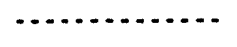 & - & (n) & $\ldots \ldots \ldots$ \\
\hline $699-49-40$ & $6 / 24 / 92$ & $8062 \times 2$ & & & $10.00 \mathrm{U}$ & \\
\hline $699-41-40$ & $1 / 14 / 93$ & $8077 \times 9$ & & & $10.00 \mathrm{U}$ & \\
\hline $699-41-42$ & $1 / 08 / 93$ & B07v59 & & & $10.00 \mathrm{U}$ & \\
\hline $699-42-37$ & $12 / 22 / 92$ & BO7TC4 & & & $10.00 \mathrm{U}$ & \\
\hline $699-42-37$ & $2 / 23 / 93$ & B08712 & & & $10.00 \mathrm{U}$ & \\
\hline $699-42-39 A$ & $1 / 23 / 92$ & $801 T 66$ & & & 10.00 UP & \\
\hline $699-42-39 A$ & $4 / 17 / 92$ & B065T1 & & & 10.00 UP & \\
\hline $699-42-39 A$ & $6 / 25 / 92$ & $8062 \times 7$ & & & 10.00 UP & \\
\hline $699-42-39 A$ & $10 / 21 / 92$ & B07JL3 & & & 10.00 UP & \\
\hline $699-42-39 A$ & $1 / 27 / 93$ & B07v64 & & & 10.00 UP & \\
\hline $699-42-39 B$ & $1 / 23 / 92$ & B01T68 & & & $10.00 \mathrm{U}$ & \\
\hline $699-42-398$ & $4 / 17 / 92$ & $8065 T 6$ & & & $10.00 \mathrm{U}$ & \\
\hline $699-42-398$ & $6 / 25 / 92$ & B06ZY2 & & & $10.00 \mathrm{U}$ & \\
\hline $699-42-39 B$ & $10 / 28 / 92$ & B07JJ2 & & & $10.00 \mathrm{U}$ & \\
\hline $699-42-398$ & $10 / 28 / 92$ & $807 \mathrm{JJ} 3$ & & & $10.00 \mathrm{U}$ & \\
\hline $699-42 \cdot 398$ & $1 / 25 / 93$ & B07N69 & & & $10.00 \mathrm{U}$ & \\
\hline $699-42 \cdot 40 \mathrm{~A}$ & $8 / 22 / 85$ & HOOODF11 & & & & $2.00 \mathrm{U}$ \\
\hline $699-42 \cdot 401$ & $5 / 12 / 86$ & H0000F27 & & & & $2.00 \mathrm{U}$ \\
\hline $699-42-40 A$ & $8 / 05 / 86$ & H0OODF33 & & & & $2.00 \mathrm{U}$ \\
\hline $699-42-40 A$ & $1 / 08 / 88$ & HOOOOF55 & & & & $2.00 \mathrm{U}$ \\
\hline $699-42-40 A$ & $11 / 22 / 88$ & $H 0000 F 60$ & & & & $2.00 \mathrm{U}$ \\
\hline $699-42-40 A$ & $2 / 15 / 89$ & H0OODF65 & $10.00 \mathrm{U}$ & & & $2.00 \mathrm{U}$ \\
\hline $699-42-40 \mathrm{~A}$ & $2 / 15 / 89$ & HOOODF65 & & $10.00 \mathrm{U}$ & & \\
\hline $699-42-40 A$ & $5 / 31 / 89$ & HOOODF 70 & 26.00 & & & $2.00 \mathrm{U}$ \\
\hline $699-42-40 A$ & $5 / 31 / 89$ & HOOODF 70 & & 10.00 & & \\
\hline $699-42-40 A$ & $8 / 10 / 89$ & HOOODF 74 & 10.00 & & & 3.00 \\
\hline $699-42-40 A$ & $8 / 10 / 89$ & H0OOOF 74 & & 19.00 & & \\
\hline $699-42-40 A$ & $1 / 26 / 90$ & HOOODF 78 & 12.00 & & & $2.00 \mathrm{U}$ \\
\hline $699-42-40 A$ & $1 / 26 / 90$ & HOOODF 78 & & 12.00 & & \\
\hline $699 \cdot 42 \cdot 40 \mathrm{~A}$ & $7 / 08 / 91$ & H00071Y2 & & & $10.00 \mathrm{U}$ & \\
\hline $699-42-40 A$ & $1 / 08 / 92$ & B07TY8 & & & $10.00 \mathrm{U}$ & \\
\hline $699-42-40 A$ & $1 / 23 / 92$ & B01061 & & & $10.00 \mathrm{U}$ & \\
\hline $699-42-40 A$ & $6 / 25 / 92$ & $8062 Y 7$ & & & $10.00 \mathrm{U}$ & \\
\hline $699-42-41$ & $1 / 24 / 92$ & В01T70 & & & 10.00 UPD & \\
\hline $699-42 \cdot 41$ & $4 / 17 / 92$ & B065VI & & & 10.00 UP & \\
\hline $699-42 \cdot 41$ & $6 / 29 / 92$ & 806222 & & & 10.00 UP & \\
\hline $699 \cdot 42 \cdot 41$ & $1 / 25 / 93$ & 807724 & & & 10.00 UP & \\
\hline $699-42-42 B$ & $11 / 22 / 88$ & HOOODFT3 & & & & $2.00 \mathrm{U}$ \\
\hline $699-42-428$ & $2 / 24 / 89$ & HOOODFT7 & 14.00 & & & 2.00 \\
\hline $699-42-42 B$ & $2 / 24 / 89$ & HOOODFT7 & & 17.00 & & \\
\hline $699-42-428$ & $6 / 16 / 89$ & HOOODFV1 & 17.00 & & & $2.00 \mathrm{U}$ \\
\hline $699-42-42 B$ & $6 / 16 / 89$ & HOOODFV1 & & 18.00 & & \\
\hline $699-42-42 B$ & $6 / 16 / 89$ & HOOODFV4 & 28.00 & & & $2.00 \mathrm{U}$ \\
\hline
\end{tabular}


(sheet 31 of $*$ )

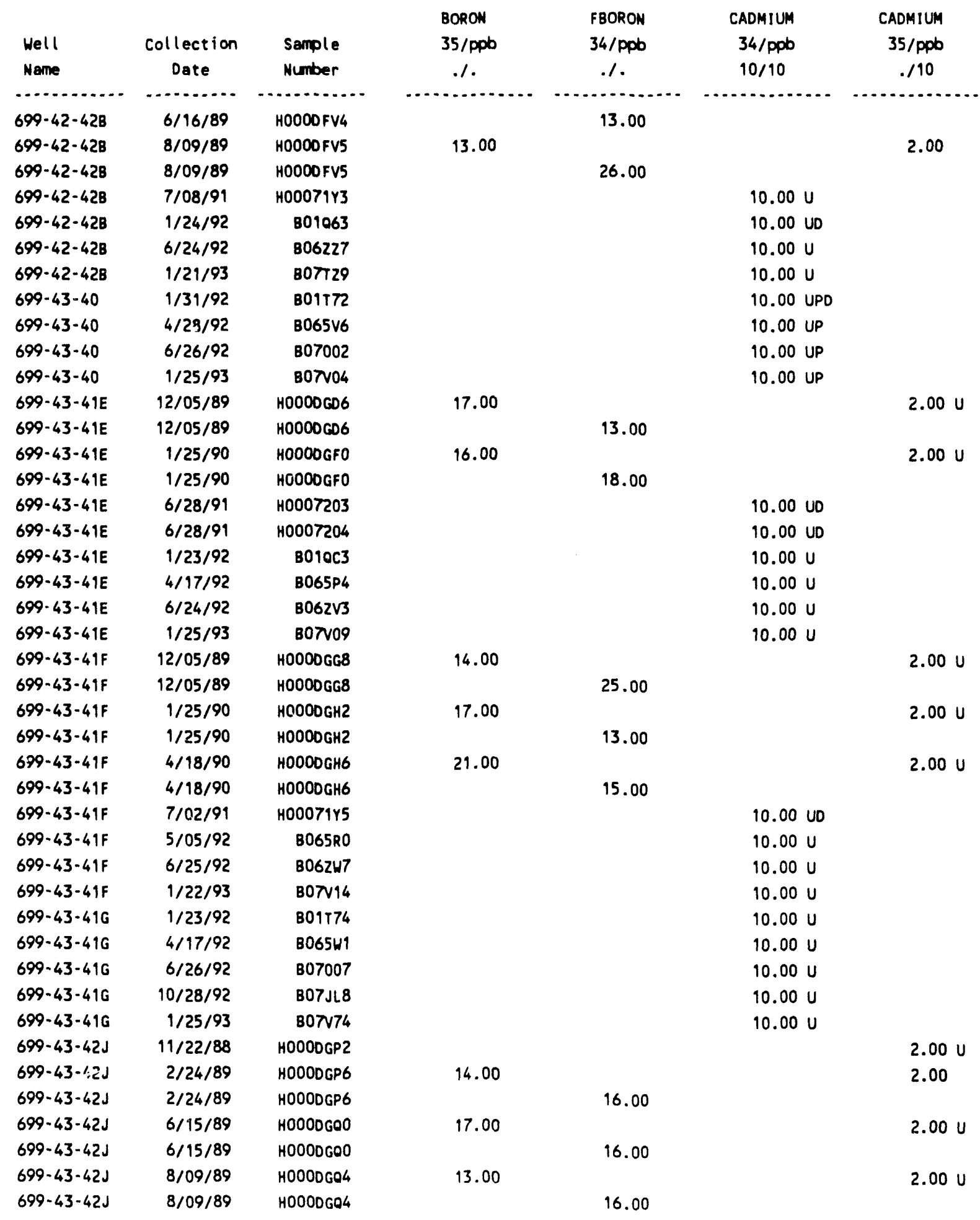


(sheet 32 of $* *$ )

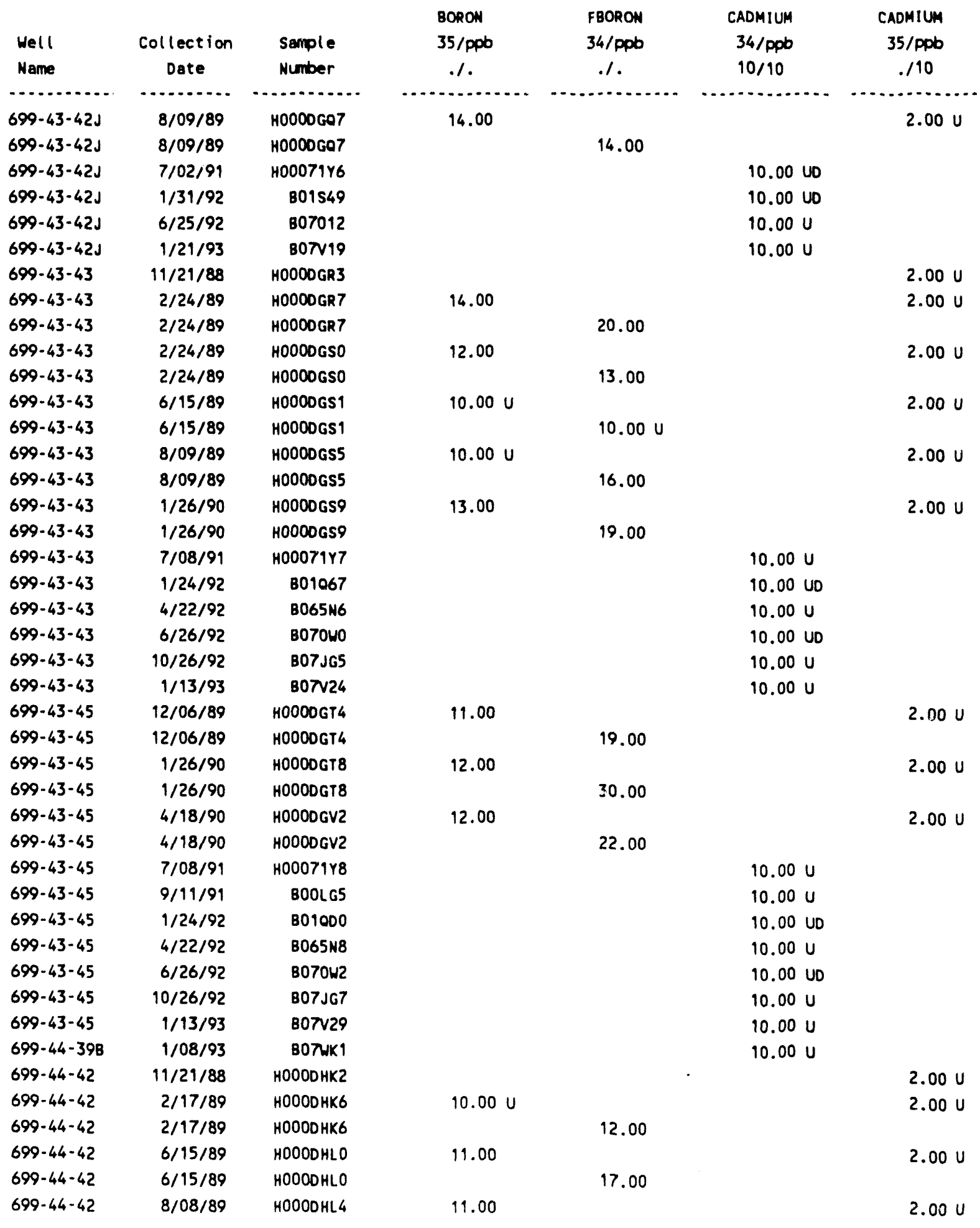


(sheet 33 of $\star \star$ )

\begin{tabular}{|c|c|c|c|c|c|c|}
\hline & & & BORON & FBORON & CADMIUM & CADMIUM \\
\hline Well & Collection & Sample & 35/ppb & 34/ppb & $34 / \mathrm{ppb}$ & 35/ppb \\
\hline Name & Date & Number & .1 &.$/$ & $10 / 10$ &.$/ 10$ \\
\hline - & . & (n) & . & - & - & - \\
\hline $599-44-42$ & $8 / 08 / 89$ & HOOOOHL 4 & & 16.00 & & \\
\hline $699-44-42$ & $1 / 31 / 90$ & HOOOOHL8 & 54.00 & & & $2.00 \mathrm{U}$ \\
\hline $699-44-42$ & $1 / 31 / 90$ & HOOODHL8 & & 20.00 & & \\
\hline $699-44-42$ & $7 / 10 / 91$ & HOOOT1Y9 & & & $10.00 \mathrm{U}$ & \\
\hline $699-44-42$ & $1 / 31 / 92$ & B01S52 & & & 10.00 UD & \\
\hline $699-44-42$ & $6 / 25 / 92$ & B07017 & & & $10.00 \mathrm{U}$ & \\
\hline $699-44-42$ & $1 / 13 / 93$ & $807 \sqrt{34}$ & & & $10.00 \mathrm{U}$ & \\
\hline $699-4:-42$ & $1 / 13 / 93$ & B07V35 & & & $10.00 \mathrm{U}$ & \\
\hline $699-44-43 B$ & $12 / 20 / 89$ & HOOOOHM3 & 13.00 & & & $2.00 \mathrm{U}$ \\
\hline $699-44-438$ & $12 / 20 / 89$ & HOOODHM3 & & 16.00 & & \\
\hline $699-44-43 B$ & $12 / 20 / 89$ & HOOODHMG & 14.00 & & & $2.00 \mathrm{U}$ \\
\hline $699-44-43 B$ & $12 / 20 / 89$ & HOOODHM6 & & 15.00 & & \\
\hline $699-44-43 B$ & $1 / 26 / 90$ & HOOODHM7 & 37.00 & & & $2.00 \mathrm{U}$ \\
\hline $699-44-43 B$ & $1 / 26 / 90$ & HOOODHM7 & & 23.00 & & \\
\hline $699-44-43 B$ & $1 / 26 / 90$ & HOOODHNO & 29.00 & $\cdot$ & & $2.00 \mathrm{U}$ \\
\hline $699-44-43 B$ & $1 / 26 / 90$ & HOCODHNO & & 23.00 & & \\
\hline $699-44-43 B$ & $4 / 18 / 90$ & H0OOOHN1 & 16.00 & & & $2.00 \mathrm{U}$ \\
\hline $699-44-43 B$ & $4 / 18 / 90$ & HOOODHNI & & 17.00 & & \\
\hline $699-44-43 B$ & $7 / 08 / 91$ & $H 0007120$ & & & $10.00 \mathrm{U}$ & \\
\hline $699-44-43 B$ & $9 / 11 / 91$ & B00LG6 & & & $10.00 \mathrm{U}$ & \\
\hline $699-44-43 B$ & $1 / 23 / 92$ & B01069 & & & $10.00 \mathrm{U}$ & \\
\hline $699-44-43 B$ & $4 / 20 / 92$ & B065W9 & & & $10.00 \mathrm{U}$ & \\
\hline $699-44-43 B$ & $6 / 26 / 92$ & B07022 & & & $10.00 \mathrm{U}$ & \\
\hline $699-44-43 B$ & $6 / 26 / 92$ & B07023 & & & $10.00 \mathrm{U}$ & \\
\hline \multirow[t]{2}{*}{$699-44-43 B$} & $1 / 27 / 93$ & B07N44 & & & $10.00 \mathrm{U}$ & \\
\hline & & & FCADMIU & CALCIUM & CALCIUM & FCALCIU \\
\hline Well & Collection & Sample & $34 / p p b$ & $34 / p p b$ & 35/ppb & 34/ppb \\
\hline Name & Date & Number & $10 / 10$ & $100 \%$ & .1 & $100 /$ \\
\hline$\cdots$ & $\cdots$ & $\cdots$ & n. & - & n. & 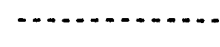 \\
\hline 299-E18-1 & $8 / 16 / 88$ & H00072T7 & & & 57300.00 & \\
\hline 299-E18-1 & $8 / 16 / 88$ & H00072T7 & $2.00 \mathrm{U}$ & & & 70800.00 \\
\hline 299-E18-1 & $9 / 22 / 88$ & H0007ZV1 & & & 72800.00 & \\
\hline 299-E18-1 & $9 / 22 / 88$ & H0007ZV1 & $2.00 \mathrm{U}$ & & & 73700.00 \\
\hline 299-E18-1 & $11 / 10 / 88$ & H0007ZV2 & & & 67400.00 & \\
\hline 299-E18-1 & $11 / 10 / 88$ & H0007ZV2 & $2.00 \mathrm{U}$ & & & 63200.00 \\
\hline $299-E 18-1$ & $11 / 10 / 88$ & H0007ZV5 & & & 57700.00 & \\
\hline 299-E18-1 & $11 / 10 / 88$ & H0007ZV5 & $2.00 \mathrm{U}$ & & & 58400.00 \\
\hline 299-E18-1 & $2 / 15 / 89$ & H0007ZV8 & & & 55700.00 & \\
\hline 299-E18-1 & $2 / 15 / 89$ & H0007ZV8 & $2.00 \mathrm{U}$ & & & 57600.00 \\
\hline 299-E18-1 & $5 / 26 / 89$ & H0007ZW2 & & & 58000.00 & \\
\hline
\end{tabular}


(sheet 34 of $* *$ )

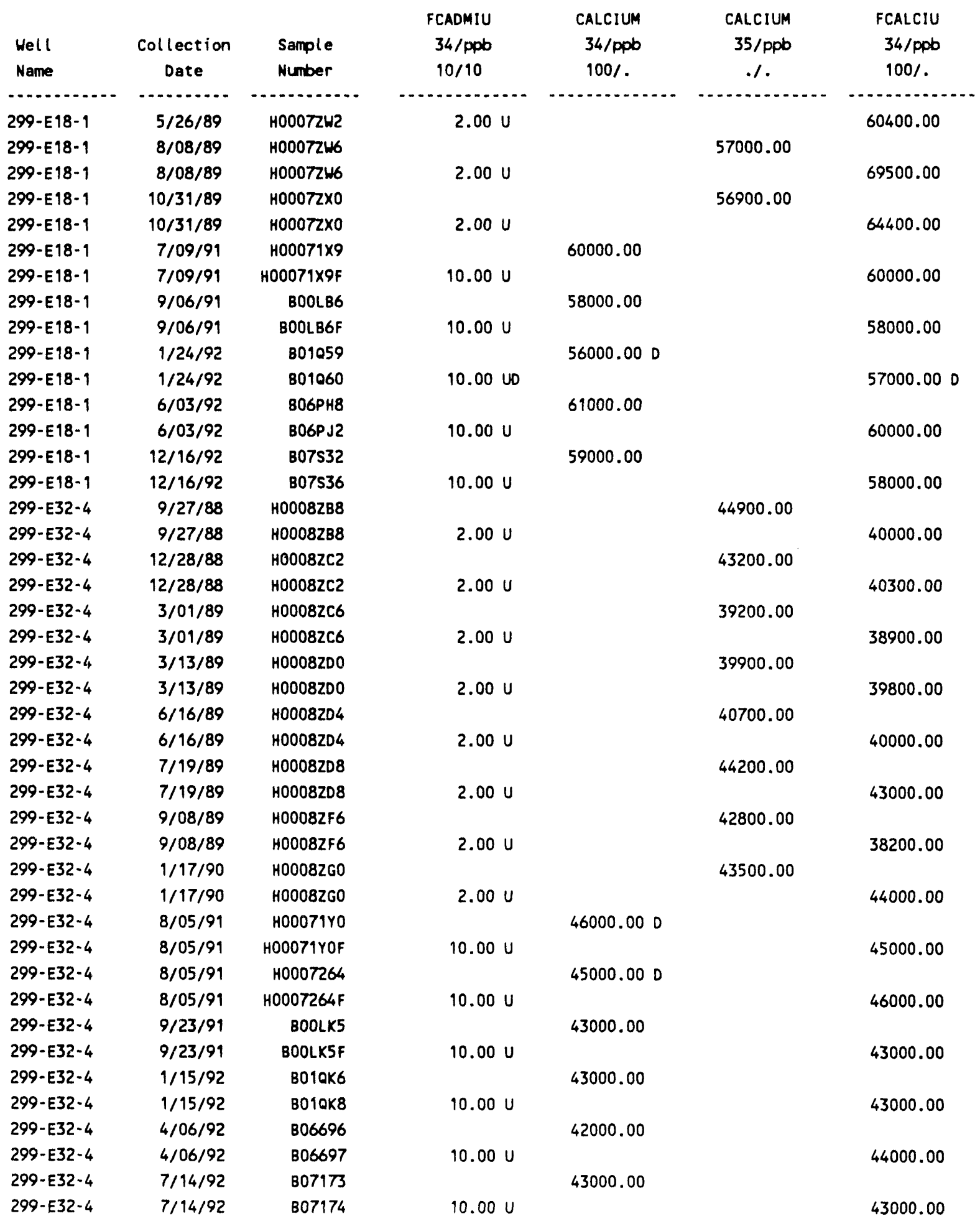


(sheet 35 of $\star *$ )

\begin{tabular}{|c|c|c|c|c|c|c|}
\hline $\begin{array}{l}\text { Hell } \\
\text { Name }\end{array}$ & $\begin{array}{c}\text { Collection } \\
\text { Date }\end{array}$ & $\begin{array}{l}\text { Sample } \\
\text { Number }\end{array}$ & $\begin{array}{l}\text { FCADMIU } \\
34 / \text { ppb } \\
10 / 10\end{array}$ & $\begin{array}{l}\text { CALCIUM } \\
34 / \mathrm{ppb} \\
100 /\end{array}$ & $\begin{array}{c}\text { CALCIUM } \\
35 / p p b \\
.1\end{array}$ & $\begin{array}{c}\text { FCALCIU } \\
34 / \mathrm{ppb} \\
100 /\end{array}$ \\
\hline מ & . & n & . & . & . & $\cdots$ \\
\hline $699-40-36$ & $12 / 21 / 92$ & B07TB1 & & 15000.00 & & \\
\hline $699-40-36$ & $12 / 21 / 92$ & B07TB8 & $10.00 \mathrm{U}$ & & & 15000.00 \\
\hline $699-40-36$ & $2 / 22 / 93$ & B08717 & & 15000.00 & & \\
\hline $699-40-36$ & $2 / 22 / 93$ & B08721 & $10.00 \mathrm{U}$ & & & 17000.00 \\
\hline $699-40-39$ & $12 / 05 / 89$ & HОOОOBX2 & & & 19500.00 & \\
\hline $699-40-39$ & $12 / 05 / 89$ & HOOODBX2 & $2.00 \mathrm{U}$ & & & 19500.00 \\
\hline $699-40-39$ & $1 / 25 / 90$ & HOOODBX6 & & & 20100.00 & \\
\hline $699-40-39$ & $1 / 25 / 90$ & HOOODBX6 & $2.00 \mathrm{U}$ & & & 19100.00 \\
\hline $699-40-39$ & $4 / 25 / 90$ & HOOODBYO & & & 19500.00 & \\
\hline $699-40-39$ & $4 / 25 / 90$ & HOOODBYO & $2.00 \mathrm{U}$ & & & 20500.00 \\
\hline $699-40-39$ & $7 / 08 / 91$ & H00071Y4F & $10.00 \mathrm{U}$ & & & 22000.00 \\
\hline $699-40-39$ & $9 / 11 / 91$ & B00LGI & & 21000.00 & & \\
\hline $699-40-39$ & $9 / 11 / 91$ & BOOLG1F & $10.00 \mathrm{U}$ & & & 20000.00 \\
\hline $699-40-39$ & $1 / 31 / 92$ & 801065 & & $21000.00 \mathrm{D}$ & & \\
\hline $699-40-39$ & $1 / 31 / 92$ & 801066 & $10.00 \mathrm{UD}$ & & & $20000.00 \mathrm{D}$ \\
\hline $699-40-39$ & $4 / 17 / 92$ & B065P2 & & 20000.000 & & \\
\hline $699-40-39$ & $4 / 17 / 92$ & B06504 & $10.00 \mathrm{U}$ & & & 19000.000 \\
\hline $699-40-39$ & $6 / 24 / 92$ & B062T7 & & 22000.00 & & \\
\hline $699-40-39$ & $6 / 24 / 92$ & $8062 \mathrm{~V} 1$ & $10.00 \mathrm{U}$ & & & 22000.00 \\
\hline $699-40-39$ & $1 / 14 / 93$ & $8077 \times 4$ & & 21000.00 & & \\
\hline $699-40-39$ & $1 / 14 / 93$ & $8077 \times 8$ & $10.00 \mathrm{U}$ & & & 21000.00 \\
\hline $699-40-40 \mathrm{~A}$ & $1 / 24 / 92$ & B01T62 & & $23000.00 \mathrm{D}$ & & \\
\hline $699-40-40 \mathrm{~A}$ & $1 / 24 / 92$ & В01т63 & 10.00 UD & & & $21000.00 \mathrm{D}$ \\
\hline $699-40-40 \mathrm{~A}$ & $4 / 22 / 92$ & 806508 & & 20000.00 & & \\
\hline $699-40-40 A$ & $4 / 22 / 92$ & B065R8 & $10.00 \mathrm{U}$ & & & 21000.00 \\
\hline $699-40-40 \mathrm{~A}$ & $6 / 25 / 92$ & B062V2 & & 20000.00 & & \\
\hline $699-40-40 \mathrm{~A}$ & $6 / 25 / 92$ & B062W0 & $10.00 \mathrm{U}$ & & & 19000.00 \\
\hline $699-40-40 \mathrm{~A}$ & $10 / 21 / 92$ & B07JK3 & & 20000.00 & & \\
\hline $699-40-40 A$ & $10 / 21 / 92$ & B07JK7 & $10.00 \mathrm{U}$ & & & 20000.00 \\
\hline $699-40-40 \mathrm{~A}$ & $1 / 26 / 93$ & BOTV49 & & 20000.00 & & \\
\hline $699-40-40 \mathrm{~A}$ & $1 / 26 / 93$ & Borv53 & $10.00 \mathrm{U}$ & & & 20000.00 \\
\hline $699-40-40 B$ & $1 / 01 / 92$ & $B 01 T 65$ & 10.00 UD & & & $23000.00 \mathrm{D}$ \\
\hline $699-40-40 B$ & $1 / 24 / 92$ & B01T64 & & $29000.00 \mathrm{D}$ & & \\
\hline $699-40-40 \mathrm{~B}$ & $4 / 22 / 92$ & 806550 & & 24000.00 & & \\
\hline $699-40-40 B$ & $4 / 22 / 92$ & B065S4 & $10.00 \mathrm{U}$ & & & 22000.00 \\
\hline $699-40-40 B$ & $6 / 29 / 92$ & B062W2 & & 23000.00 & & \\
\hline $699-40-40 \mathrm{~B}$ & $6 / 29 / 92$ & B062146 & $10.00 \mathrm{U}$ & & & 21000.00 \\
\hline $699-40-40 B$ & $10 / 21 / 92$ & 807JK8 & & 24000.00 & & \\
\hline $699-40-40 B$ & $10 / 21 / 92$ & B07JL2 & $10.00 \mathrm{U}$ & & & 24000.00 \\
\hline $699-40-40 B$ & $1 / 26 / 93$ & B07v54 & & 24000.00 & & \\
\hline $699-40-40 B$ & $1 / 26 / 93$ & B07v58 & $10.00 \mathrm{U}$ & & & 24000.00 \\
\hline $699-41-35$ & $12 / 21 / 92$ & В07TB9 & & 18000.00 & & \\
\hline $699-41-35$ & $12 / 21 / 92$ & 807TC3 & $10.00 \mathrm{U}$ & & & 18000.00 \\
\hline
\end{tabular}


(sheet 36 of $\star$ )

\begin{tabular}{|c|c|c|c|c|c|c|}
\hline Well & Collection & Sample & $\begin{array}{r}\text { FCADMIU } \\
34 / p p b\end{array}$ & $\begin{array}{l}\text { CALCIUM } \\
34 / p p b\end{array}$ & $\begin{array}{l}\text { CALCIUM } \\
35 / \text { pob }\end{array}$ & $\begin{array}{l}\text { FCALCIU } \\
34 / \mathrm{ppb}\end{array}$ \\
\hline Name & Date & Number & $10 / 10$ & $100 /$ & .1 & $100 \%$ \\
\hline - & (n) & , n & nan & - & - & 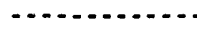 \\
\hline $699-41-35$ & $2 / 22 / 93$ & B08707 & & 18000.00 & & \\
\hline $699-41-35$ & $2 / 22 / 93$ & 808711 & $10.00 \mathrm{U}$ & & & 23000.00 \\
\hline $699-41-40$ & $12 / 05 / 89$ & $H 0000044$ & & & 28900.00 & \\
\hline $699-41-40$ & $12 / 05 / 89$ & $H 0000044$ & $2.00 \mathrm{U}$ & & & 28900.00 \\
\hline $699-41-40$ & $1 / 25 / 90$ & $H 0000 D 48$ & & & 28300.00 & \\
\hline $699-41-40$ & $1 / 25 / 90$ & $H 0000048$ & $2.00 \mathrm{U}$ & & & 29600.00 \\
\hline $699-41-40$ & $4 / 19 / 90$ & H0000052 & & & 29000.00 & \\
\hline $699-41-40$ & $4 / 19 / 90$ & H0000052 & $2.00 \mathrm{U}$ & & & 27300.00 \\
\hline $699-41-40$ & $7 / 10 / 91$ & H00071Y1 & & 30000.00 & & \\
\hline $699-41-40$ & $7 / 10 / 91$ & H00071Y1F & $10.00 \mathrm{U}$ & & & 30000.00 \\
\hline $699-41-40$ & $9 / 11 / 91$ & BOOLG2 & & 29000.00 & & \\
\hline $699-41-40$ & $9 / 11 / 91$ & BOOLGZF & $10.00 \mathrm{U}$ & & & 30000.00 \\
\hline $699-41-40$ & $1 / 31 / 92$ & B010C8 & & 28000.000 & & \\
\hline $699-41-40$ & $1 / 31 / 92$ & B010C9 & 10.00 UD & & & $28000.00 \mathrm{D}$ \\
\hline $699-41-40$ & $4 / 28 / 92$ & B06555 . & & 29000.000 & & \\
\hline $699-41-40$ & $4 / 28 / 92$ & 806556 & & $28000.00 Q$ & & \\
\hline $699-41-40$ & $4 / 28 / 92$ & B06559 & $10.00 \mathrm{U}$ & & & $29000.00 Q$ \\
\hline $699-41-40$ & $4 / 28 / 92$ & В065TO & $10.00 \mathrm{U}$ & & & 28000.000 \\
\hline $699-41-40$ & $6 / 24 / 92$ & $8062 \times 2$ & & 31000.00 & & \\
\hline $699-41-40$ & $6 / 24 / 92$ & $8062 \times 6$ & $10.00 \mathrm{U}$ & & & 31000.00 \\
\hline $699-41-40$ & $1 / 14 / 93$ & B07TX9 & & 29000.00 & & \\
\hline $699-41-40$ & $1 / 14 / 93$ & $807 T Y 3$ & $10.00 \mathrm{U}$ & & & 29000.00 \\
\hline $699-41-42$ & $1 / 08 / 93$ & B07N59 & & 19000.00 & & \\
\hline $699-41-42$ & $1 / 08 / 93$ & B07N63 & $10.00 \mathrm{U}$ & & & 19000.00 \\
\hline $699-42-37$ & $12 / 22 / 92$ & B07TC4 & & 23000.00 & & \\
\hline $699-42-37$ & $12 / 22 / 92$ & BOTTC8 & $10.00 \mathrm{U}$ & & & 23000.00 \\
\hline $699-42-37$ & $2 / 23 / 93$ & B08712 & & 24000.00 & & \\
\hline $699-42-37$ & $2 / 23 / 93$ & B08716 & $10.00 \mathrm{U}$ & & & 25000.00 \\
\hline $699-42-39 A$ & $1 / 23 / 92$ & B01T66 & & $30000.00 \mathrm{P}$ & & \\
\hline $699-42-39 A$ & $1 / 23 / 92$ & B01T67 & 10.00 UP & & & $29000.00 \mathrm{P}$ \\
\hline $699-42-39 A$ & $4 / 17 / 92$ & B065T1 & & $31000.00 \mathrm{P}$ & & \\
\hline $699-42-39 A$ & $4 / 17 / 92$ & B065T5 & 10.00 UP & & & $28000.00 P$ \\
\hline $699-42-39 A$ & $6 / 25 / 92$ & $8062 \times 7$ & & $30000.00 \mathrm{P}$ & & \\
\hline $699-42-39 A$ & $6 / 25 / 92$ & $806 Z Y 1$ & 10.00 UP & & & $28000.00 P$ \\
\hline $699-42-39 A$ & $10 / 21 / 92$ & B07JL3 & & $31000.00 \mathrm{P}$ & & \\
\hline $699-42-39 A$ & $10 / 21 / 92$ & B07JL7 & 10.00 UP & & & $30000.00 \mathrm{P}$ \\
\hline $699-42-39 A$ & $1 / 27 / 93$ & B07N64 & & $30000.00 \mathrm{P}$ & & \\
\hline $699-42-39 A$ & $1 / 27 / 93$ & B07N68 & 10.00 UP & & & $29000.00 \mathrm{P}$ \\
\hline $699-42-39 B$ & $1 / 23 / 92$ & B01T68 & & 27000.00 & & \\
\hline $699-42-398$ & $1 / 23 / 92$ & B01T69 & $10.00 \mathrm{U}$ & & & 27000.00 \\
\hline $699-42-39 B$ & $4 / 17 / 92$ & $8065 T 6$ & & 27000.00 & & \\
\hline $699-42-39 B$ & $4 / 17 / 92$ & B065V0 & $10.00 \mathrm{U}$ & & & 27000.00 \\
\hline $699-42-398$ & $6 / 25 / 92$ & B06ZYZ & & 27000.00 & & \\
\hline
\end{tabular}


(sheet 37 of $\star$ )

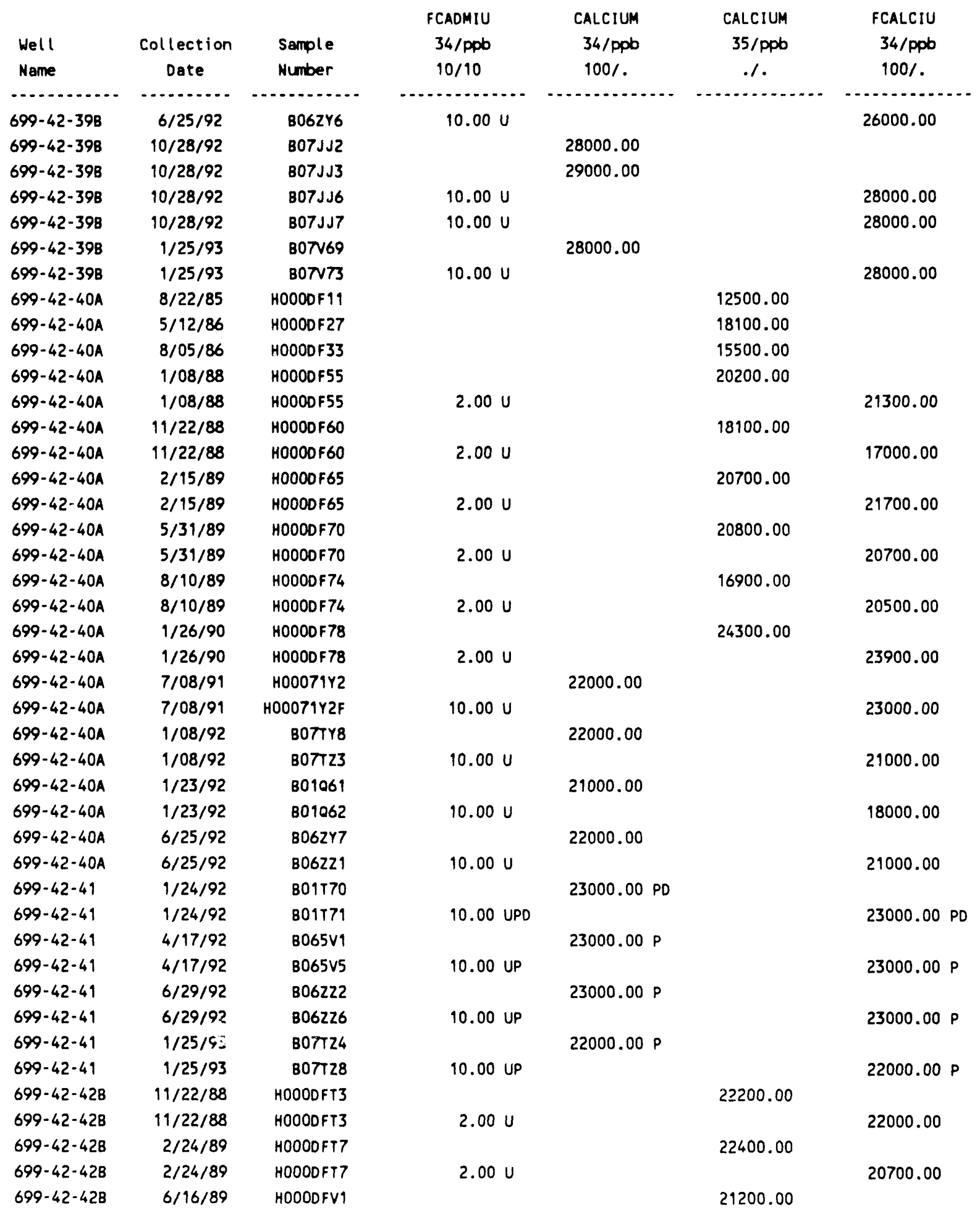


(sheet 38 of $\star$ )

\begin{tabular}{|c|c|c|c|c|c|c|}
\hline $\begin{array}{l}\text { Well } \\
\text { Name }\end{array}$ & $\begin{array}{c}\text { Collection } \\
\text { Date }\end{array}$ & $\begin{array}{l}\text { Sample } \\
\text { Number }\end{array}$ & $\begin{array}{l}\text { FCADMIU } \\
34 / \text { ppb } \\
10 / 10\end{array}$ & $\begin{array}{l}\text { CALCIUM } \\
34 / \text { ppb } \\
100 /\end{array}$ & $\begin{array}{c}\text { CALCIUM } \\
35 / p p b \\
.1\end{array}$ & $\begin{array}{l}\text { FCALCIU } \\
34 / \text { ppb } \\
100 /\end{array}$ \\
\hline , & $\ldots+\ldots$ & . & (n. & . & ( & (............ \\
\hline $699-42-42 B$ & $6 / 16 / 89$ & HOOODFVI & $2.00 \mathrm{U}$ & & & 21800.00 \\
\hline $699-42-42 B$ & $6 / 16 / 89$ & HOOODFV4 & & & 20200.00 & \\
\hline $699-42-42 B$ & $6 / 16 / 89$ & HOOODFV4 & $2.00 \mathrm{U}$ & & & 19600.00 \\
\hline $699-42-42 B$ & $8 / 09 / 89$ & H0000FVS & & & 19500.00 & \\
\hline $699-42-42 B$ & $8 / 09 / 89$ & H000DFV5 & $2.00 \mathrm{U}$ & & & 22800.00 \\
\hline $699-42-42 B$ & $7 / 08 / 91$ & H00071Y3 & & 22000.00 & & \\
\hline $699-42-42 B$ & $7 / 08 / 91$ & H00071Y3F & $10.00 \mathrm{U}$ & & & 25000.00 \\
\hline $699-42-42 B$ & $1 / 24 / 92$ & $B 01063$ & & $23000.00 \mathrm{D}$ & & \\
\hline $699-42-42 B$ & $1 / 24 / 92$ & B01064 & 10.00 UD & & & $22000.00 \mathrm{D}$ \\
\hline $699-42-428$ & $6 / 24 / 92$ & $B 06227$ & & 23000.00 & & \\
\hline $699-42-42 B$ & $6 / 24 / 92$ & 807001 & $10.00 \mathrm{U}$ & & & 22000.00 \\
\hline $699-42-42 B$ & $1 / 21 / 93$ & BOTTZ9 & & 24000.00 & & \\
\hline $699-42-42 B$ & $1 / 21 / 93$ & B07v03 & $10.00 \mathrm{U}$ & & & 22000.00 \\
\hline $699-43-40$ & $1 / 31 / 92$ & В01T72 & & $21000.00 \mathrm{PD}$ & & \\
\hline $699-43-40$ & $1 / 31 / 92$ & В01т73 & 10.00 UPD & & & $23000.00 \mathrm{PD}$ \\
\hline $699-43-40$ & $4 / 28 / 92$ & B065V6 & & $23000.00 \mathrm{P}$ & & \\
\hline $699-43-40$ & $4 / 28 / 92$ & B065WO & 10.00 UP & & & $23000.00 \mathrm{P}$ \\
\hline $699-43-40$ & $6 / 26 / 92$ & B07002 & & $24000.00 P$ & & \\
\hline $699-43-40$ & $6 / 26 / 92$ & B07006 & 10.00 UP & & & $24000.00 \mathrm{P}$ \\
\hline $699-43-40$ & $1 / 25 / 93$ & B07v04 & & $26000.00 \mathrm{P}$ & & \\
\hline $699-43-40$ & $1 / 25 / 93$ & B07N08 & 10.00 UP & & & $26000.00 \mathrm{P}$ \\
\hline $699-43-41 E$ & $12 / 05 / 89$ & HOOODGD 6 & & & 24300.00 & \\
\hline $699-43-41 E$ & $12 / 05 / 89$ & H0OODGD 6 & $2.00 \mathrm{U}$ & & & 23400.00 \\
\hline $699-43-41 E$ & $1 / 25 / 90$ & HOOODGFO & & & 25000.00 & \\
\hline $699-43-41 E$ & $1 / 25 / 90$ & HOOODGFO & $2.00 \mathrm{U}$ & & & 24500.00 \\
\hline $699-43-41 E$ & $6 / 28 / 91$ & H0007203 & & $26000.00 \mathrm{D}$ & & \\
\hline $699-43-41 E$ & $6 / 28 / 91$ & H0007203F & $10.00 \mathrm{U}$ & & & 26000.00 \\
\hline $699-43-41 E$ & $6 / 28 / 91$ & H0007204 & & 27000.000 & & \\
\hline $699-43-41 E$ & $6 / 28 / 91$ & H0007204F & $10.00 \mathrm{U}$ & & & 26000.00 \\
\hline $699-43-41 E$ & $1 / 23 / 92$ & $8010 \mathrm{C} 3$ & & 25000.00 & & \\
\hline $699-43-41 E$ & $1 / 23 / 92$ & $8010 \mathrm{C} 4$ & $10.00 \mathrm{U}$ & & & 26000.00 \\
\hline $699-43-41 E$ & $4 / 17 / 92$ & B065P4 & & 25000.00 & & \\
\hline $699-43-41 E$ & $4 / 17 / 92$ & B06506 & $10.00 \mathrm{U}$ & & & 25000.00 \\
\hline $699-43-41 E$ & $6 / 24 / 92$ & $B 062 \sqrt{3}$ & & 27000.00 & & \\
\hline $699-43-41 E$ & $6 / 24 / 92$ & 8062W1 & $10.00 \mathrm{U}$ & & & 27000.00 \\
\hline $699-43-41 E$ & $1 / 25 / 93$ & 807v09 & & 27000.00 & & \\
\hline $699-43-41 E$ & $1 / 25 / 93$ & B07V13 & $10.00 \mathrm{U}$ & & & 26000.00 \\
\hline $699-43-41 F$ & $12 / 05 / 89$ & HOOODGG8 & & & 26000.00 & \\
\hline $699-43-41 \mathrm{~F}$ & $12 / 05 / 89$ & HOOODGG8 & $2.00 \mathrm{U}$ & & & 26500.00 \\
\hline $699-43-41 F$ & $1 / 25 / 90$ & HOOODGH2 & & & 26600.00 & \\
\hline $699-43-41 F$ & $1 / 25 / 90$ & HOOOOGH2 & $2.00 \mathrm{U}$ & & & 25100.00 \\
\hline $699-43-41 F$ & $4 / 18 / 90$ & HOOODGH6 & & & 25100.00 & \\
\hline $699-43-41 F$ & $4 / 18 / 90$ & HOOODGH6 & $2.00 \mathrm{U}$ & & & 24800.00 \\
\hline
\end{tabular}


(sheet 39 of $\star *$ )

\begin{tabular}{|c|c|c|c|c|c|c|}
\hline $\begin{array}{l}\text { Well } \\
\text { Name }\end{array}$ & $\begin{array}{c}\text { Collection } \\
\text { Date }\end{array}$ & $\begin{array}{l}\text { Sample } \\
\text { Number }\end{array}$ & $\begin{array}{l}\text { FCADMIU } \\
34 / \mathrm{ppb} \\
10 / 10\end{array}$ & $\begin{array}{l}\text { CALCIUM } \\
34 / \mathrm{ppb} \\
100 /\end{array}$ & $\begin{array}{c}\text { CALCIUM } \\
35 / p p b \\
. /\end{array}$ & $\begin{array}{l}\text { FCALCIU } \\
\text { 34/ppb } \\
100 / .\end{array}$ \\
\hline - & . & - & 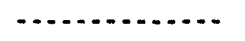 & 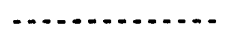 & - & $\ldots$ \\
\hline $699-43-41 F$ & $7 / 02 / 91$ & H00071Y5 & & 27000.000 & & \\
\hline $699-43-41 F$ & $7 / 02 / 91$ & H00071Y5F & $10.00 \mathrm{U}$ & & & 27000.00 \\
\hline $699-43-41 F$ & $5 / 05 / 92$ & B065RO & & 26000.00 & & \\
\hline $699-43-41 F$ & $5 / 05 / 92$ & B065R9 & $10.00 \mathrm{U}$ & & & 27000.00 \\
\hline $699-43-41 F$ & $6 / 25 / 92$ & B062U7 & & 25000.00 & & \\
\hline $699-43-41 F$ & $6 / 25 / 92$ & $B 062 \times 1$ & $10.00 \mathrm{U}$ & & & 25000.00 \\
\hline $699-43-41 F$ & $1 / 22 / 93$ & Bo7v14 & & 27000.00 & & \\
\hline $699-43-41 F$ & $1 / 22 / 93$ & B07v18 & $10.00 \mathrm{U}$ & & & 27000.00 \\
\hline $699-43-416$ & $1 / 23 / 92$ & B01T74 & & 23000.00 & & \\
\hline $699-43-416$ & $1 / 23 / 92$ & В01т75 & $10.00 \mathrm{U}$ & & & 23000.00 \\
\hline $699-43-416$ & $4 / 17 / 92$ & B065W1 & & 23000.00 & & \\
\hline $699-43-41 G$ & $4 / 17 / 92$ & B065W6 & $10.00 \mathrm{U}$ & & & 23000.00 \\
\hline $699-43-416$ & $6 / 26 / 92$ & B07007 & & 23000.00 & & \\
\hline $699-43-416$ & $6 / 26 / 92$ & 807011 & $10.00 \mathrm{U}$ & & & 23000.00 \\
\hline $699-43-416$ & $10 / 28 / 92$ & B07JL8 & & 24000.00 & & \\
\hline $699-43-416$ & $10 / 28 / 92$ & B07JM2 & $10.00 \mathrm{U}$ & & & 24000.00 \\
\hline $699-43-41 G$ & $1 / 25 / 93$ & Bo7v74 & & 22000.00 & & \\
\hline $699-43-41 G$ & $1 / 25 / 93$ & B07V78 & $10.00 \mathrm{U}$ & & & 24000.00 \\
\hline $699-43-42 J$ & $11 / 22 / 88$ & HOOODGP2 & & & 22400.00 & \\
\hline $699-43-42 J$ & $11 / 22 / 88$ & HOOODGP2 & $2.00 \mathrm{U}$ & & & 23400.00 \\
\hline $699-43-42 J$ & $2 / 24 / 89$ & HOOOOGPG & & & 25000.00 & \\
\hline $699-43-42 \mathrm{~J}$ & $2 / 24 / 89$ & HOOODGP6 & 3.00 & & & 24800.00 \\
\hline $699-43-42 J$ & $6 / 15 / 89$ & HOOODGOO & & & 25300.00 & \\
\hline $699-43-42 J$ & $6 / 15 / 89$ & HOOODGOO & $2.00 \mathrm{U}$ & & & 26100.00 \\
\hline $699-43-42 J$ & $8 / 09 / 89$ & HOOCOGO4 & & & 23000.00 & \\
\hline $699-43-42 J$ & $8 / 09 / 89$ & HOOODGO4 & $2.00 \mathrm{U}$ & & & 25000.00 \\
\hline $699-43-42 J$ & $8 / 09 / 89$ & H0OODGQ7 & & & 22000.00 & \\
\hline $699-43-42 \mathrm{~J}$ & $8 / 09 / 89$ & HOOODGQ7 & $2.00 \mathrm{U}$ & & & 25600.00 \\
\hline $699-43-42 \mathrm{~J}$ & $7 / 02 / 91$ & H00071Y6 & & $21000.00 \mathrm{D}$ & & \\
\hline $699-43-42 \mathrm{~J}$ & $7 / 02 / 91$ & H00071YGF & $10.00 \mathrm{U}$ & & & 21000.00 \\
\hline $699-43-42 J$ & $1 / 31 / 92$ & 801549 & & $20000.00 \mathrm{D}$ & & \\
\hline $699-43-42 J$ & $1 / 31 / 92$ & 801551 & 10.00 UD & & & $20000.00 \mathrm{D}$ \\
\hline $699-43-42 J$ & $6 / 25 / 92$ & 807012 & & 19000.00 & & \\
\hline $699-43-42 \mathrm{~J}$ & $6 / 25 / 92$ & 807016 & $10.00 \mathrm{U}$ & & & 15000.00 \\
\hline $699-43-42 J$ & $1 / 21 / 93$ & BOTV19 & & 20000.00 & & \\
\hline $699-43-42 J$ & $1 / 21 / 93$ & Borv23 & $10.00 \mathrm{U}$ & & & 19000.00 \\
\hline $699-43-43$ & $11 / 21 / 88$ & HOOOOGR3 & & & 25200.00 & \\
\hline $699-43-43$ & $11 / 21 / 88$ & HOOODGR3 & $2.00 \mathrm{U}$ & & & 23500.00 \\
\hline $699-43-43$ & $2 / 24 / 89$ & HOOODGR7 & & & 24600.00 & \\
\hline $699-43-43$ & $2 / 24 / 89$ & HOOODGR7 & $2.00 \mathrm{U}$ & & & 22600.00 \\
\hline $699-43-43$ & $2 / 24 / 89$ & HOOODGSO & & & 25400.00 & \\
\hline $699-43-43$ & $2 / 24 / 89$ & HOOODGSO & $2.00 \mathrm{U}$ & & & 22600.00 \\
\hline $699-43-43$ & $6 / 15 / 89$ & HOOODGS1 & & & 25600.00 & \\
\hline
\end{tabular}


(sheet 40 of $\star *$ )

\begin{tabular}{|c|c|c|c|c|c|c|}
\hline Well & Collection & Sample & $\begin{array}{l}\text { FCADMIU } \\
34 / \mathrm{ppb}\end{array}$ & $\begin{array}{l}\text { CALCIUM } \\
34 / \mathrm{ppb}\end{array}$ & $\begin{array}{l}\text { CALCIUM } \\
35 / \mathrm{ppb}\end{array}$ & $\begin{array}{l}\text { FCALCIU } \\
34 / \mathrm{ppb}\end{array}$ \\
\hline Name & Date & Number & $10 / 10$ & $100 \%$ & .1 & $100 /$ \\
\hline$\cdots$ & $\cdots$ & $\cdots$ & 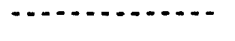 & (n) & $\cdots$ & $\ldots$ \\
\hline $699-43-43$ & $6 / 15 / 89$ & HOOODGS1 & $2.00 \mathrm{U}$ & & & 24900.00 \\
\hline $699-43-43$ & $8 / 09 / 89$ & H0OODGS5 & & & 24600.00 & \\
\hline $699-43-43$ & $8 / 09 / 89$ & H000DGS5 & $2.00 \mathrm{U}$ & & & 26400.00 \\
\hline $699-43-43$ & $1 / 26 / 90$ & HOOOOGSO & & & 25600.00 & \\
\hline $699-43-43$ & $1 / 26 / 90$ & HOOODGS9 & $2.00 \mathrm{U}$ & & & 25900.00 \\
\hline $699-43-43$ & $7 / 08 / 91$ & H00071Y7 & & 28000.00 & & \\
\hline $699-43-43$ & $7 / 08 / 91$ & H00079Y7F & $10.00 \mathrm{U}$ & & & 27000.00 \\
\hline $699-43-43$ & $1 / 24 / 92$ & B01067 & & $28000.00 \mathrm{D}$ & & \\
\hline $699-43-43$ & $1 / 24 / 92$ & 801068 & 10.00 UD & & & $28000.00 \mathrm{D}$ \\
\hline $699-43-43$ & $4 / 22 / 92$ & B065N6 & & 30000.00 & & \\
\hline $699-43-43$ & $4 / 22 / 92$ & B065N7 & $10.00 \mathrm{U}$ & & & 29000.00 \\
\hline $699-43-43$ & $6 / 26 / 92$ & Bo70wo & & $29000.00 \mathrm{D}$ & & \\
\hline $699-43-43$ & $6 / 26 / 92$ & B070W1 & $10.00 \mathrm{U}$ & & & 28000.00 \\
\hline $699-43-43$ & $10 / 26 / 92$ & B07JG5 & & 29000.00 & & \\
\hline $699-43-43$ & $10 / 26 / 92$ & $807 J G 6$ & $10.00 \mathrm{U}$ & & & 29000.00 \\
\hline $699-43-43$ & $1 / 13 / 93$ & BOTV24 & & 29000.00 & & \\
\hline $699-43-43$ & $1 / 13 / 93$ & B07v28 & $10.00 \mathrm{U}$ & & & 28000.00 \\
\hline $699-43-45$ & $12 / 06 / 89$ & HOOODGT4 & & & 26300.00 & \\
\hline $699-43-45$ & $12 / 06 / 89$ & H0OOOGT4 & $2.00 \mathrm{U}$ & & & 26200.00 \\
\hline $699-43-45$ & $1 / 26 / 90$ & HOOODGT8 & & & 26500.00 & \\
\hline $699-43-45$ & $1 / 26 / 90$ & HOOODGT8 & $2.00 \mathrm{U}$ & & & 25900.00 \\
\hline $699-43-45$ & $4 / 18 / 90$ & HOOODGV2 & & & 25400.00 & \\
\hline $699-43-45$ & $4 / 18 / 90$ & H0000GV2 & $2.00 \mathrm{U}$ & & & 26300.00 \\
\hline $699-43-45$ & $7 / 08 / 91$ & H00071Y8 & & 29000.00 & & \\
\hline $699-43-45$ & $7 / 08 / 91$ & H00071Y8F & $10.00 \mathrm{U}$ & & & 29000.00 \\
\hline $699-43-45$ & $9 / 11 / 91$ & BOOLG5 & & 27000.00 & & \\
\hline $699-43-45$ & $9 / 11 / 91$ & BOOLG5F & $10.00 \mathrm{U}$ & & & 28000.00 \\
\hline $699-43-45$ & $1 / 24 / 92$ & $B 01000$ & & $27000.00 \mathrm{D}$ & & \\
\hline $699-43-45$ & $1 / 24 / 92$ & B01001 & 10.00 UD & & & $27000.00 \mathrm{D}$ \\
\hline $699-43-45$ & $4 / 22 / 92$ & B065N8 & & 30000.00 & & \\
\hline $699-43-45$ & $4 / 22 / 92$ & B065N9 & $10.00 \mathrm{U}$ & & & 30000.00 \\
\hline $699-43-45$ & $6 / 26 / 92$ & BO70H2 & & $28000.00 \mathrm{D}$ & & \\
\hline $699-43-45$ & $6 / 26 / 92$ & B070W3 & $10.00 \mathrm{U}$ & & & 28000.00 \\
\hline $699-43-45$ & $10 / 26 / 92$ & B07JG7 & & 28000.00 & & \\
\hline $699-43-45$ & $10 / 26 / 92$ & B07JG8 & $10.00 \mathrm{U}$ & & & 28000.00 \\
\hline $699-43-45$ & $1 / 13 / 93$ & Borv29 & & 27000.00 & & \\
\hline $699-43-45$ & $1 / 13 / 93$ & B07v33 & $10.00 \mathrm{U}$ & & & 26000.00 \\
\hline $699-44-398$ & $1 / 08 / 93$ & B07NK1 & & 20000.00 & & \\
\hline $699-44-398$ & $1 / 08 / 93$ & BOTWK5 & $10.00 \mathrm{U}$ & & & 21000.00 \\
\hline $699-44-42$ & $11 / 21 / 88$ & HOOODHK2 & & & 24100.00 & \\
\hline $699-44-42$ & $11 / 21 / 88$ & HOOODHK2 & $2.00 \mathrm{U}$ & & & 24100.00 \\
\hline $699-44-42$ & $2 / 17 / 89$ & HOOODHKG & & & 21700.00 & \\
\hline $699-44-42$ & $2 / 17 / 89$ & H0OODHKG & $2.00 \mathrm{U}$ & & & 22300.00 \\
\hline
\end{tabular}


(sheet 41 of $\star *$ )

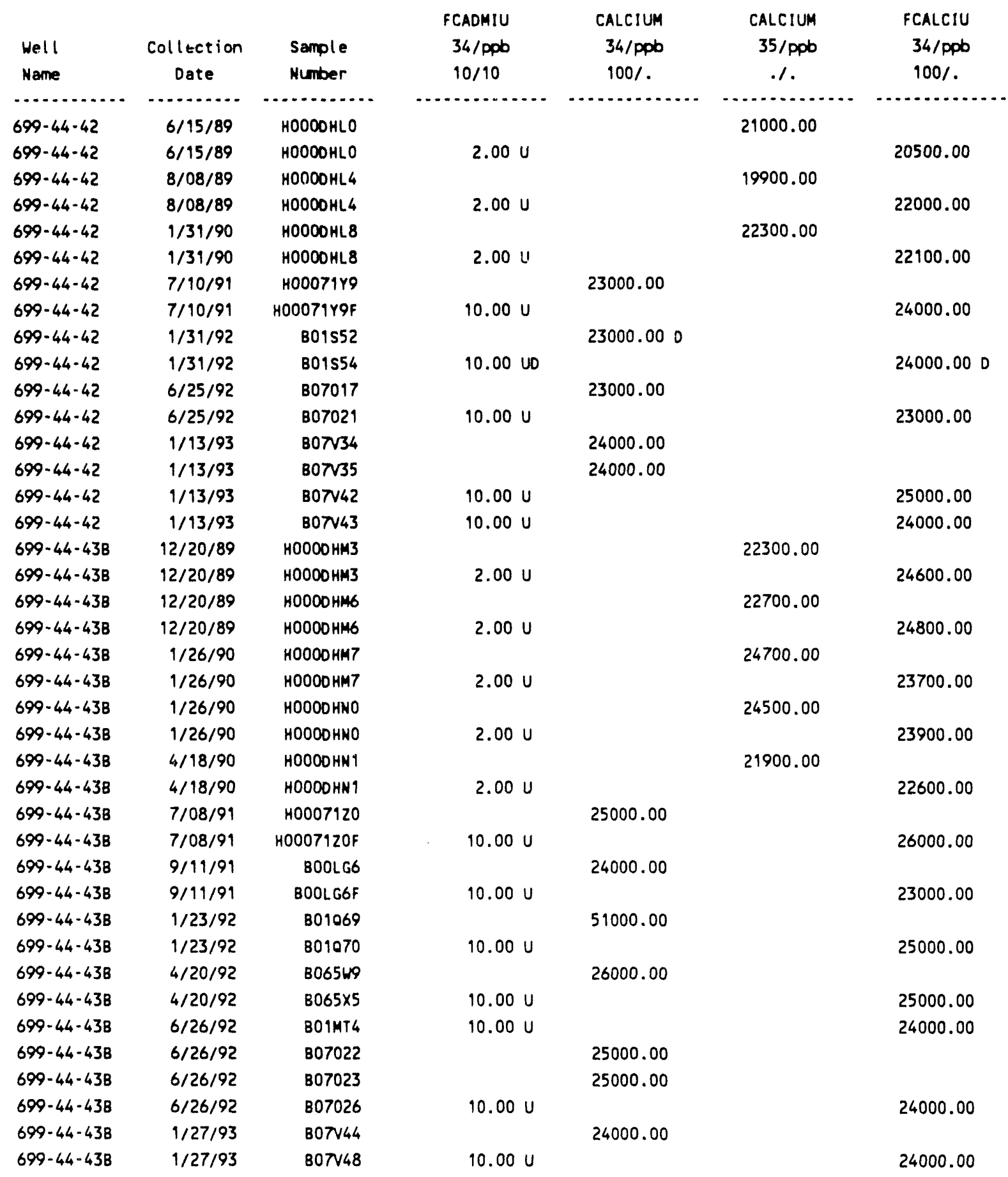


(sheet 42 of ${ }^{\star *}$ )

\begin{tabular}{|c|c|c|c|c|c|c|}
\hline & & & CS-137 & CHLORID & CHLORID & CHROMUM \\
\hline Hell & Collection & Sample & $\pi / p c i / L$ & 124/ppb & 46/ppb & 34/ppb \\
\hline Name & Date & Number & .1 & $200 / 250000 \mathrm{~s}$ &.$/ 250000 \mathrm{~s}$ & $20 / 50$ \\
\hline . & 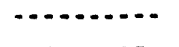 & - & - & . & (n) & \\
\hline $299-E 18-1$ & $8 / 16 / 88$ & H0007ZT7 & & & 6550.00 & \\
\hline 299-E18-1 & $11 / 10 / 88$ & H0007ZV2 & & & 6800.00 & \\
\hline 299-E18-1 & $11 / 10 / 88$ & H0007ZV5 & & & 6200.00 & \\
\hline 299-E18-1 & $2 / 15 / 89$ & H0007ZV8 & & & 6900.00 & \\
\hline 299-E18-1 & $5 / 26 / 89$ & H0007ZW2 & & & 7100.00 & \\
\hline 299-E18-1 & $8 / 08 / 89$ & H0007ZW6 & & & 6000.00 & \\
\hline 299-E18-1 & $10 / 31 / 89$ & $H 00072 \times 0$ & $1.18 \mathrm{U}$ & & 8000.00 & \\
\hline 299-E18-1 & $5 / 30 / 90$ & $H 00072 \times 5$ & & & 6900.00 & \\
\hline 299-E18-1 & $7 / 09 / 91$ & H00071X9 & & 7600.00 & & 150.00 \\
\hline 299-E18-1 & $9 / 06 / 91$ & B00LB6 & & & & 96.00 \\
\hline 299-E18-1 & $1 / 24 / 92$ & B01059 & & 7600.00 & & $71.00 \mathrm{D}$ \\
\hline $299-E 18-1$ & $6 / 03 / 92$ & В06РH8 & & 7800.00 & & 60.00 \\
\hline 299-E18-1 & $12 / 16 / 92$ & B07s32 & & 7800.00 & & 140.00 \\
\hline $299-E 32-4$ & $9 / 27 / 88$ & H0O082B8 & 6.59 & & 8470.00 & \\
\hline $299-E 32-4$ & $12 / 28 / 88$ & $\mathrm{H} 00082 \mathrm{C2}$ & & & 8700.00 & \\
\hline $299-E 32-4$ & $3 / 01 / 89$ & H0008ZC6 & & & 8400.00 & \\
\hline $299-E 32-4$ & $3 / 13 / 89$ & H0008ZDO & $1.44 \mathrm{U}$ & & 9300.00 & \\
\hline $299-E 32-4$ & $6 / 16 / 89$ & HOOOO8ZD & & & 9100.00 & \\
\hline $299-E 32-4$ & $7 / 19 / 89$ & H0008ZD8 & $1.77 \mathrm{U}$ & & 9220.00 & \\
\hline 299-E32-4 & $9 / 08 / 89$ & H0008ZF6 & $1.89 \mathrm{U}$ & & 9000.00 & \\
\hline $299-E 32-4$ & $1 / 17 / 90$ & H0008ZGO & $4.52 \mathrm{U}$ & & 9800.00 & \\
\hline $299-E 32-4$ & $5 / 09 / 90$ & H0008ZG9 & $-.30 \mathrm{U}$ & & 9200.00 & \\
\hline $299-E 32-4$ & $8 / 05 / 91$ & H00071YO & & & & $180.00 \mathrm{D}$ \\
\hline 299-E32-4 & $8 / 05 / 91$ & $H 0007264$ & & & & $160.00 \mathrm{D}$ \\
\hline $299-E 32-4$ & $9 / 23 / 91$ & 800LK5 & & & & 35.00 \\
\hline $299-E 32-4$ & $1 / 15 / 92$ & B010K6 & & 10000.00 & & 110.00 \\
\hline 299-E32-4 & $4 / 06 / 92$ & 806696 & & 9000.00 & & 30.00 \\
\hline 299-E32-4 & $4 / 09 / 92$ & $8065 B 6$ & & 9100.00 & & \\
\hline $299-E 32-4$ & $7 / 14 / 92$ & B07173 & & 9700.00 & & 62.00 \\
\hline $699-40-36$ & $12 / 21 / 92$ & B07TB1 & & 3100.00 & & 30.00 \\
\hline $699-40-36$ & $2 / 22 / 93$ & B08717 & & 3400.00 & & 30.00 \\
\hline $699-40-39$ & $12 / 05 / 89$ & HOOODBX2 & $.71 \mathrm{U}$ & & 3100.00 & \\
\hline $699-40-39$ & $1 / 25 / 90$ & HOOODBX6 & & & 3400.00 & \\
\hline $699-40-39$ & $4 / 25 / 90$ & HOOODBYO & & & 3200.00 & \\
\hline $699-40-39$ & $7 / 08 / 91$ & H00071Y4 & & 3200.00 & & \\
\hline $699-40-39$ & $9 / 11 / 91$ & B00LG1 & & & & 65.00 \\
\hline $699-40-39$ & $1 / 31 / 92$ & B01065 & & 3100.00 & & $570.00 \mathrm{D}$ \\
\hline $699-40-39$ & $4 / 17 / 92$ & $B 065 P 2$ & & $3700.00 \mathrm{D}$ & & $20.00 \mathrm{U}$ \\
\hline $699-40-39$ & $6 / 24 / 92$ & B06217 & & 3100.00 & & 20.00 \\
\hline $699-40-39$ & $1 / 14 / 93$ & $8077 \times 4$ & & 2800.00 & & 630.00 \\
\hline $699-40-40 A$ & $1 / 24 / 92$ & B01T62 & & 5600.00 & & $120.00 \mathrm{D}$ \\
\hline $699-40-40 \mathrm{~A}$ & $4 / 22 / 92$ & 806508 & & 6600.00 & & 72.00 \\
\hline $699-40-40 A$ & $6 / 25 / 92$ & 806ZV2 & & 5700.00 & & 130.00 \\
\hline
\end{tabular}


(sheet 43 of $\star \star$ )

\begin{tabular}{|c|c|c|c|c|c|c|}
\hline & & & CS-137 & CHLOR ID & CHLOR ID & CHROMUM \\
\hline Well & Collection & Sample & $77 / p C i / L$ & 124/ppb & 46/ppb & 34/ppb \\
\hline Name & Date & Number & .1 & $200 / 250000 \mathrm{~s}$ &.$/ 250000 \mathrm{~s}$ & $20 / 50$ \\
\hline - & , nen & 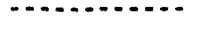 & , & - & , & (n) \\
\hline $699-40-40 A$ & $10 / 21 / 92$ & B07JKK3 & & 6400.00 & & 60.00 \\
\hline $699-40-40 \mathrm{~A}$ & $1 / 26 / 93$ & B07V49 & & 5600.00 & & 70.00 \\
\hline $699-40-40 B$ & $1 / 24 / 92$ & $801 T 64$ & & 4400.00 & & $770.00 \mathrm{D}$ \\
\hline $699-40-40 B$ & $4 / 22 / 92$ & 806550 & & 6100.00 & & 300.00 \\
\hline $699-40-40 B$ & $6 / 29 / 92$ & B062W2 & & $4600.00 \mathrm{D}$ & & 340.00 \\
\hline $699-40-40 B$ & $10 / 21 / 92$ & $807 J K 8$ & & 4800.00 & & 550.00 \\
\hline $699-40-40 B$ & $1 / 26 / 93$ & B07V54 & & 5000.00 & & 270.00 \\
\hline $699-41-35$ & $12 / 21 / 92$ & В07789 & & 3400.00 & & $20.00 \mathrm{U}$ \\
\hline $699-41-35$ & $2 / 22 / 93$ & 808707 & & 3600.00 & & $20.00 \mathrm{U}$ \\
\hline $699-41-40$ & $12 / 05 / 89$ & HOOODD 44 & $.63 \mathrm{U}$ & & 6400.00 & \\
\hline $699-41-40$ & $1 / 25 / 90$ & $H 0000048$ & & & 7400.00 & \\
\hline $699-41-40$ & $4 / 19 / 90$ & 40000052 & & & 6500.00 & \\
\hline $699-41 \cdot 40$ & $7 / 10 / 91$ & H00071Y1 & & 7700.00 & & 73.00 \\
\hline $699-41-40$ & $9 / 11 / 91$ & B00LG2 & & & & 52.00 \\
\hline $699-41-40$ & $1 / 31 / 92$ & B010C8 & & 7600.00 & & 630.000 \\
\hline $699-49-40$ & $4 / 28 / 92$ & $B 06555$ & & $7300.00 \mathrm{D}$ & & 52.00 \\
\hline $699-41-40$ & $4 / 28 / 92$ & B065S6 & & 7200.000 & & 51.00 \\
\hline $699-41-40$ & $6 / 24 / 92$ & $8062 \times 2$ & & 7200.00 & & 53.00 \\
\hline $699-41-40$ & $1 / 14 / 93$ & $807 \pi \times 9$ & & 7200.00 & & 260.00 \\
\hline $699-41-42$ & $1 / 08 / 93$ & $807 V 59$ & & 4200.00 & & 20.00 \\
\hline $699-42-37$ & $12 / 22 / 92$ & B07TC4 & & 7800.00 & & 30.00 \\
\hline $699-42-37$ & $2 / 23 / 93$ & B08712 & & 7900.00 & & 50.00 \\
\hline $699-42-39 A$ & $1 / 23 / 92$ & $801 T 66$ & & $8700.00 \mathrm{P}$ & & $88.00 \mathrm{P}$ \\
\hline $699-42-39 A$ & $4 / 17 / 92$ & B065T1 & & $9500.00 P$ & & $120.00 \mathrm{P}$ \\
\hline $699-42-39 A$ & $6 / 25 / 92$ & $8062 \times 7$ & & $8400.00 \mathrm{P}$ & & $310.00 \mathrm{P}$ \\
\hline $699-42 \cdot 39 A$ & $10 / 21 / 92$ & $807 \mathrm{JL} 3$ & & $8300.00 \mathrm{P}$ & & $240.00 \mathrm{P}$ \\
\hline $699-42-39 A$ & $1 / 27 / 93$ & B07N64 & & $8300.00 \mathrm{P}$ & & $360.00 \mathrm{P}$ \\
\hline $699-42-398$ & $1 / 23 / 92$ & B01T68 & & 8400.00 & & 190.00 \\
\hline $699-42-39 B$ & 4/17/92 & B065T6 & & 8700.00 & & 230.00 \\
\hline $699-42 \cdot 39 B$ & $6 / 25 / 92$ & B06ZY2 & & 8700.00 & & 160.00 \\
\hline $699-42-39 B$ & $10 / 28 / 92$ & 807JJ2 & & 9000.00 & & 100.00 \\
\hline $699-42-39 B$ & $10 / 28 / 92$ & B07JJ3 & & 9700.00 & & 90.00 \\
\hline $699-42 \cdot 39 B$ & $1 / 25 / 93$ & B07V69 & & 8300.00 & & 230.00 \\
\hline $699-42-40 A$ & $2 / 03 / 83$ & $H 00000 \times 8$ & -2.85 & & & \\
\hline $699-42-40 A$ & $2 / 28 / 83$ & H0OODDX9 & -1.45 & & & \\
\hline $699-42-40 A$ & $3 / 28 / 83$ & HOOODDYO & -1.94 & & & \\
\hline $699-42-40 A$ & $4 / 14 / 83$ & HOOODDY2 & .40 & & & \\
\hline $699-42-40 A$ & $5 / 12 / 83$ & H0OODDY3 & -3.04 & & & \\
\hline $699-42-40 A$ & $6 / 16 / 83$ & HOOODOY 4 & -5.39 & & & \\
\hline $699-42-40 A$ & $7 / 14 / 83$ & HOOODDY5 & -2.16 & & & \\
\hline $699-42-40 A$ & $8 / 19 / 83$ & HOOODDY 6 & 2.54 & & & \\
\hline $699-42-40 A$ & $9 / 27 / 83$ & HOOODDY7 & -5.35 & & & \\
\hline $699-42-40 A$ & $10 / 12 / 83$ & HOOODOY 8 & -14.40 & & & \\
\hline
\end{tabular}


(sheet 44 of $* *$ )

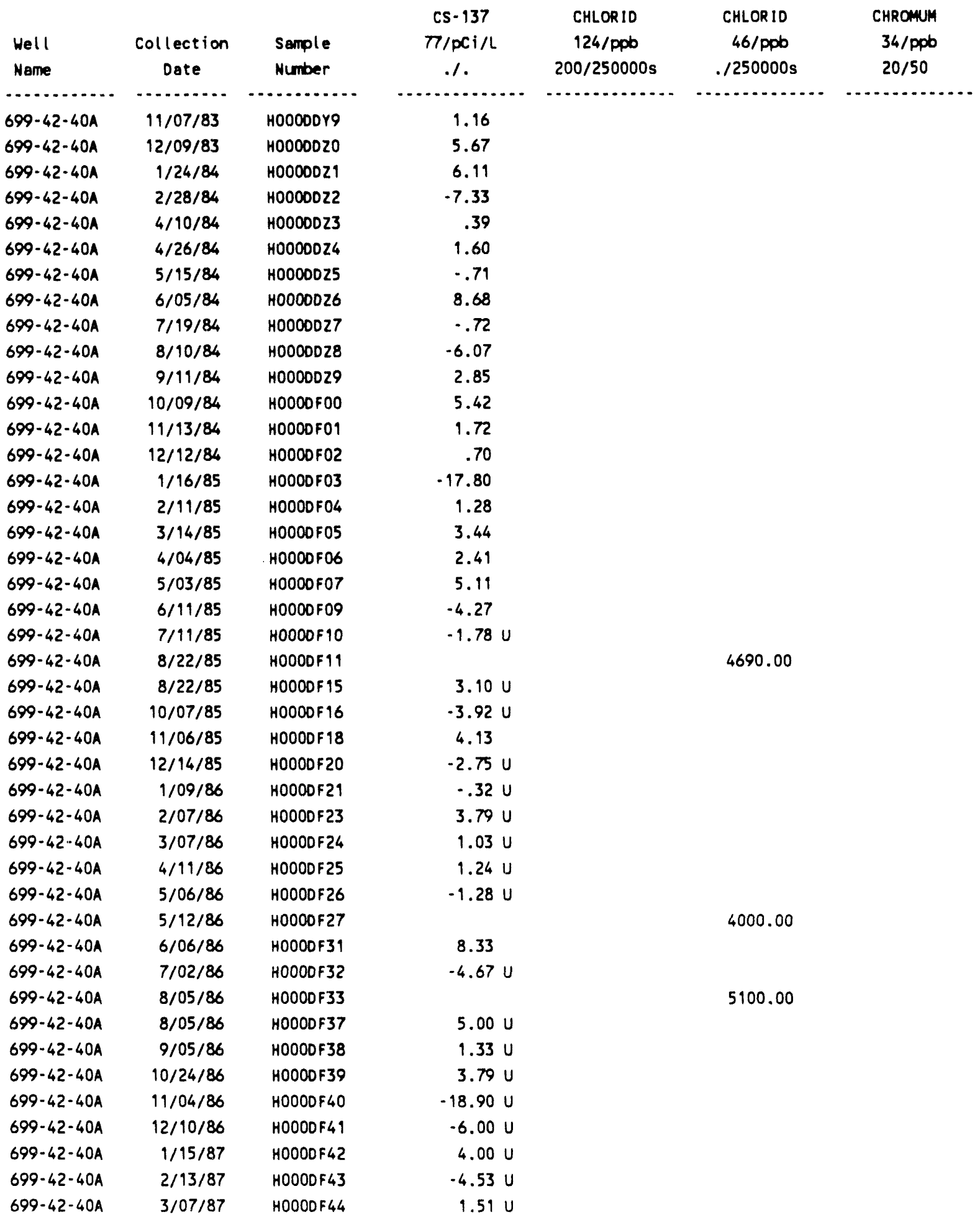


(sheet 45 of $\star$ )

\begin{tabular}{|c|c|c|c|c|c|c|}
\hline & & & CS- 137 & CHLOR ID & CHLORID & CHROMUM \\
\hline Hell & Collection & Sample & $\pi / p c i / L$ & 124/ppb & 46/ppb & $34 / p p b$ \\
\hline Name & Date & Number & .1 & $200 / 250000 \mathrm{~s}$ &.$/ 250000 \mathrm{~s}$ & $20 / 50$ \\
\hline 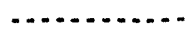 & n............... & 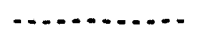 & (n) & $\ldots$ & (n) & n. \\
\hline $699-42 \cdot 40 A$ & $4 / 06 / 87$ & $H 0000 F 46$ & 4.13 & & & \\
\hline $699-42-40 A$ & $5 / 08 / 87$ & H0OOOF 47 & $-1.38 U$ & & & \\
\hline $699-42-40 \mathrm{~A}$ & $6 / 04 / 87$ & $H 0000 F 48$ & 6.33 & & & \\
\hline $699-42-40 A$ & $7 / 09 / 87$ & $10000 F 49$ & $2.41 \mathrm{U}$ & & & \\
\hline $699-42-40 A$ & $8 / 11 / 87$ & $H 0000 F 50$ & 4.48 & & & \\
\hline $699-42-40 A$ & $9 / 09 / 87$ & HOOODF51 & $3.79 \mathrm{U}$ & & & \\
\hline $699-42-40 A$ & $10 / 06 / 87$ & H0O0OF52 & $.96 U$ & & & \\
\hline $699-42-40 A$ & $11 / 04 / 87$ & H0OODF53 & $1.37 \mathrm{U}$ & & & \\
\hline $699-42-40 A$ & $12 / 01 / 87$ & H0OODF54 & 7.14 & & & \\
\hline $699-42-40 A$ & $1 / 08 / 88$ & H0000F55 & & & 2340.00 & \\
\hline $699-42-40 A$ & $1 / 08 / 88$ & H0000F56 & $4.30 \mathrm{U}$ & & & \\
\hline $699-42-40 A$ & $5 / 23 / 88$ & H0OODF57 & $-2.26 \mathrm{U}$ & & & \\
\hline $699-42-40 A$ & $7 / 19 / 88$ & $H 0000 F 58$ & $-4.51 U$ & & & \\
\hline $699-42-40 A$ & $11 / 15 / 88$ & H000DF59 & $-.63 \mathrm{U}$ & & & \\
\hline $699-42-40 A$ & $11 / 22 / 88$ & $H 0000 F 60$ & & & 2500.00 & \\
\hline $699-42-40 \mathrm{~A}$ & $2 / 06 / 89$ & HOOOOF 64 & $0.00 u$ & & & \\
\hline $699-42-40 A$ & $2 / 15 / 89$ & $H 0000 F 65$ & & & 3100.00 & \\
\hline $699-42-40 A$ & $4 / 07 / 89$ & $40000 F 69$ & 3.78 & & & \\
\hline $699-42-40 A$ & $5 / 31 / 89$ & $H 0000 F 70$ & & & 3100.00 & \\
\hline $699-42-40 \mathrm{~A}$ & $8 / 10 / 89$ & H0OOOF 74 & & & 4000.00 & \\
\hline $699-42-40 A$ & $1 / 26 / 90$ & H0OOOF 78 & & & 4100.00 & \\
\hline $699-42 \cdot 40 A$ & $7 / 08 / 91$ & H0O071Y2 & & 2300.00 & & $20.00 \mathrm{U}$ \\
\hline $699-42-40 \mathrm{~A}$ & $1 / 08 / 92$ & B07TY8 & & & & $20.00 \mathrm{U}$ \\
\hline $699-42-40 A$ & $1 / 23 / 92$ & B01061 & & 3600.00 & & $20.00 \mathrm{U}$ \\
\hline $699-42-40 A$ & $6 / 25 / 92$ & $8062 Y 7$ & & 3100.00 & & $20.00 \mathrm{U}$ \\
\hline $699-42-41$ & $1 / 24 / 92$ & B01T70 & & $3700.00 \mathrm{P}$ & & $75.00 \mathrm{PD}$ \\
\hline $699-42-41$ & $4 / 17 / 92$ & B065V1 & & $3600.00 \mathrm{P}$ & & $79.00 \mathrm{P}$ \\
\hline $699-42-41$ & $6 / 29 / 92$ & 806222 & & $2500.00 \mathrm{PD}$ & & $69.00 \mathrm{P}$ \\
\hline $699-42-41$ & $1 / 25 / 93$ & B07TZ4 & & $1500.00 \mathrm{P}$ & & $30.00 \mathrm{P}$ \\
\hline $699-42-42 B$ & $11 / 22 / 88$ & H0OODFT3 & & & 3700.00 & \\
\hline $699-42 \cdot 428$ & $2 / 24 / 89$ & HOOODFT7 & & & 3600.00 & \\
\hline $699-42-42 B$ & $6 / 16 / 89$ & HOOODFV & & & 3900.00 & \\
\hline $699-42-42 B$ & $6 / 16 / 89$ & HOOODFV4 & & & 3900.00 & \\
\hline $699-42-428$ & $8 / 09 / 89$ & H0000FV5 & & & 3800.00 & \\
\hline $699-42-42 B$ & $7 / 08 / 91$ & H00071Y3 & & 4500.00 & & 79.00 \\
\hline $699-42-42 B$ & $1 / 24 / 92$ & B01063 & & 4100.00 & & $38.00 \mathrm{D}$ \\
\hline $699-42-42 B$ & $6 / 24 / 92$ & 806227 & & 3900.00 & & $20.00 \mathrm{U}$ \\
\hline $699-42-42 B$ & $1 / 21 / 93$ & B07TZ9 & & 3800.00 & & 60.00 \\
\hline $699-43-40$ & $1 / 31 / 92$ & В01т72 & & $5200.00 \mathrm{P}$ & & $260.00 \mathrm{PD}$ \\
\hline $699-43-40$ & $4 / 28 / 92$ & B065V6 & & $5400.00 \mathrm{PD}$ & & $46.00 P$ \\
\hline $699-43-40$ & $6 / 26 / 92$ & 807002 & & $5000.00 P$ & & 20.00 UP \\
\hline $699-43-40$ & $1 / 25 / 93$ & B07N04 & & $6100.00 \mathrm{P}$ & & $90.00 \mathrm{P}$ \\
\hline $699-43-41 E$ & $12 / 05 / 89$ & HOOODGDG & $-.71 \mathrm{U}$ & & 6600.00 & \\
\hline
\end{tabular}


(sheet 46 of $\star$ )

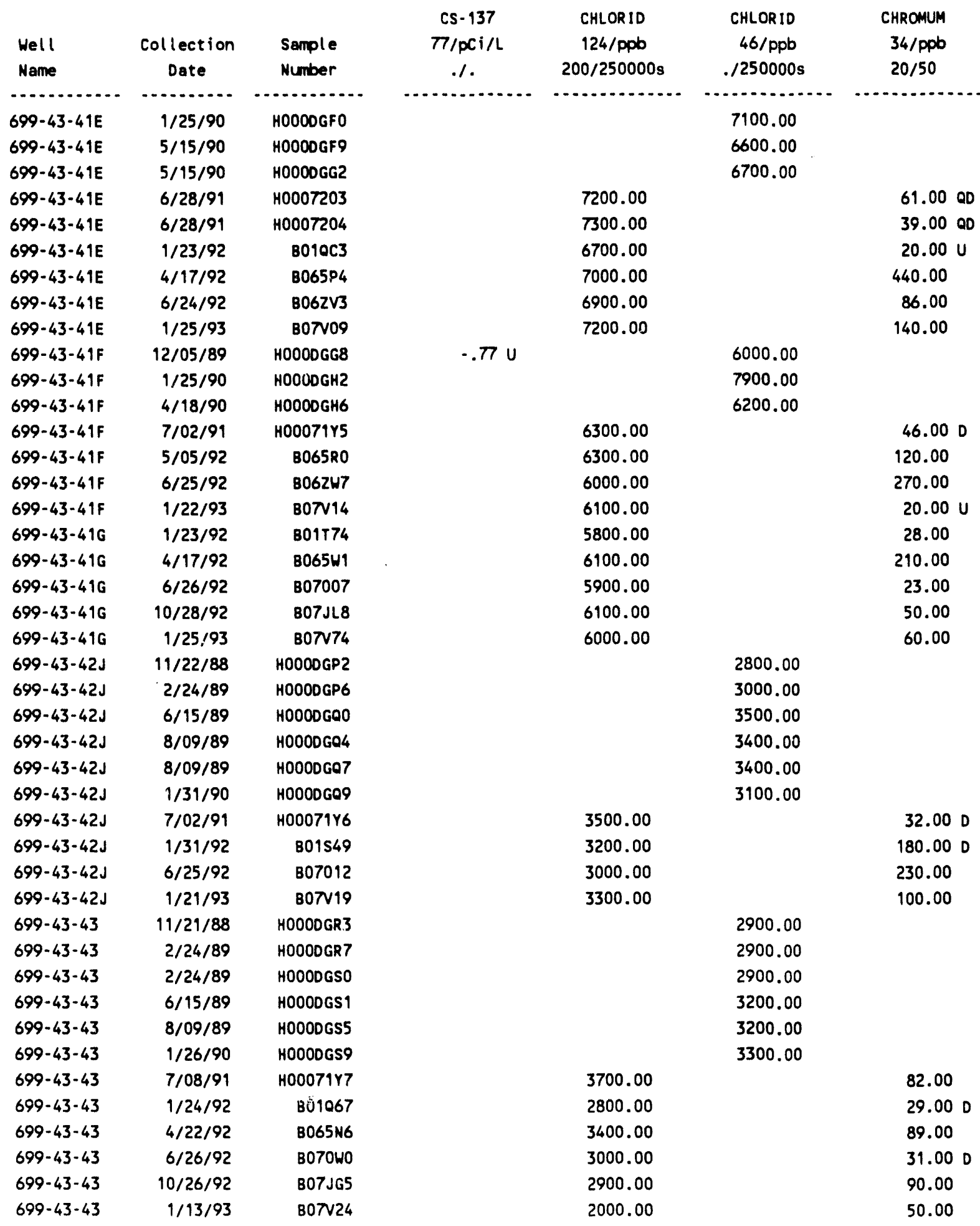


(sheet 47 of $\star \star$ )

\begin{tabular}{|c|c|c|c|c|c|c|}
\hline & & & CS- 137 & CHLORID & CHLORID & CHROMUM \\
\hline Well & Collection & Sample & $77 / p C i / L$ & 124/ppb & 46/ppb & 34/ppb \\
\hline Name & Date & Number & .1 & $200 / 250000 \mathrm{~s}$ &.$/ 250000 \mathrm{~s}$ & $20 / 50$ \\
\hline . & ................. & . & n. & (n) & - & \\
\hline $699-43-45$ & $12 / 06 / 89$ & HOOODGT4 & $-.22 U$ & & 2500.00 & \\
\hline $699-43-45$ & $1 / 26 / 90$ & HOOOOGT8 & & & 2900.00 & \\
\hline $699-43-45$ & $4 / 18 / 90$ & H0OOOGV2 & & & 2700.00 & \\
\hline $699-43-45$ & $7 / 08 / 91$ & H00071Y8 & & 3000.00 & & 100.00 \\
\hline $699-43-45$ & $9 / 11 / 91$ & BOOLG5 & & & & 38.00 \\
\hline $699-43-45$ & $1 / 24 / 92$ & 801000 & & 2900.00 & & 150.000 \\
\hline $699-43-45$ & $4 / 22 / 92$ & $8065 N 8$ & & 3500.00 & & 94.00 \\
\hline $699-43-45$ & $6 / 26 / 92$ & B070W2 & & 2800.00 & & 20.00 UD \\
\hline $699-43-45$ & $10 / 26 / 92$ & B07JG7 & & 2900.00 & & 110.00 \\
\hline $699-43-45$ & $1 / 13 / 93$ & BOTN29 & & 2300.00 & & 90.00 \\
\hline $699-44-398$ & $1 / 08 / 93$ & 807Nk1 & & 2900.00 & & $20.00 \mathrm{U}$ \\
\hline $699-44-42$ & $11 / 21 / 88$ & HOOODHK2 & & & 3100.00 & \\
\hline $699-44-42$ & $2 / 17 / 89$ & HOOOOHKG & & & 3300.00 & \\
\hline $699-44-42$ & $6 / 15 / 89$ & HOOOOHLO & & & 3300.00 & \\
\hline $699-44-42$ & $8 / 08 / 89$ & HOOOOHL 4 & & & 3100.00 & \\
\hline $699-44-42$ & $1 / 31 / 90$ & HOOODHL8 & & & 3200.00 & \\
\hline $699-44-42$ & $7 / 10 / 91$ & H00071Y9 & & 3500.00 & & 29.00 \\
\hline $699-44-42$ & $1 / 31 / 92$ & B01S52 & & 2900.00 & & $66.00 \mathrm{D}$ \\
\hline $699-44-42$ & $6 / 25 / 92$ & B07017 & & 3000.00 & & 130.00 \\
\hline $699-44-42$ & $1 / 13 / 93$ & B07v34 & & 2100.00 & & 30.000 \\
\hline $699-44-42$ & $1 / 13 / 93$ & $807 \sqrt{35}$ & & 2100.00 & & 20.00 va \\
\hline $699-44-43 B$ & $12 / 20 / 89$ & H0OOOHM3 & $-4.42 U$ & & 4300.00 & \\
\hline $699-44-43 B$ & $12 / 20 / 89$ & HOOODHMG & $-9.51 \mathrm{U}$ & & 4300.00 & \\
\hline $699-44-43 B$ & $1 / 26 / 90$ & HOOOOHM7 & & & 4600.00 & \\
\hline $699-44-43 B$ & $1 / 26 / 90$ & HOOODHNO & & & 4600.00 & \\
\hline $699-44-438$ & $4 / 18 / 90$ & HOOODHN 1 & & & 4400.00 & \\
\hline $699-44-438$ & $7 / 08 / 91$ & HOOOZ1ZO & & 4100.00 & & 76.00 \\
\hline $699-44-438$ & $9 / 11 / 91$ & BOOLG6 & & & & 32.00 \\
\hline $699-44-43 B$ & $1 / 23 / 92$ & B01069 & & 3700.00 & & $20.00 \mathrm{U}$ \\
\hline $699-44-43 B$ & $4 / 20 / 92$ & 8065W9 & & 3900.00 & & 86.00 \\
\hline $699-44-43 B$ & $6 / 26 / 92$ & B07022 & & 3600.00 & & $20.00 \mathrm{U}$ \\
\hline $699-44-43 B$ & $6 / 26 / 92$ & B07023 & & 3600.00 & & 23.00 \\
\hline $699-44-43 B$ & $1 / 27 / 93$ & BOTN44 & & 3700.00 & & 80.00 \\
\hline
\end{tabular}

\begin{tabular}{|c|c|c|c|c|c|c|}
\hline & & & CHROMUM & FCHROMI & $c 0-60$ & $c 0-60$ \\
\hline Hell & Collection & Sample & 35/ppb & $34 / p p b$ & $140 / \mathrm{PCi} / \mathrm{L}$ & $\pi / p C j / L$ \\
\hline Name & Date & Number & .150 & $20 / 50$ & .1 & .1 \\
\hline - & 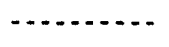 & $\ldots \ldots$ & ( & 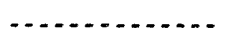 & . & $\ldots$ \\
\hline $299-E 18-1$ & $8 / 16 / 88$ & H0007ZT7 & 30.00 & & & \\
\hline 299-E18-1 & $8 / 16 / 88$ & H0007ZT7 & & $10.00 \mathrm{U}$ & & \\
\hline $299-E 18-1$ & $9 / 22 / 88$ & H0007zV1 & 104.00 & & & \\
\hline
\end{tabular}


(sheet 48 of $* *$ )

\begin{tabular}{|c|c|c|c|c|c|c|}
\hline Well & Collection & Sample & $\begin{array}{l}\text { CHROMUM } \\
35 / \mathrm{ppb}\end{array}$ & $\begin{array}{l}\text { FCHROMI } \\
34 / \mathrm{ppb}\end{array}$ & $\begin{array}{c}\text { Co-60 } \\
140 / \mathrm{pCi} / \mathrm{L}\end{array}$ & $\begin{array}{c}c 0-60 \\
77 / p C i / L\end{array}$ \\
\hline Name & Date & Number & .150 & $20 / 50$ & .1 & .1 \\
\hline . & - n & (n) & (n) & - nen & $\cdots$ & \\
\hline 299-E18-1 & $9 / 22 / 88$ & H0007ZV1 & & $10.00 \mathrm{U}$ & & \\
\hline 299-E18-1 & $11 / 16 / 88$ & H0007ZV2 & 30.00 & & & \\
\hline 299-E18-1 & $11 / 10 / 88$ & H0007ZV2 & & $10.00 \mathrm{U}$ & & \\
\hline 299-E18-1 & $11 / 10 / 88$ & H0007ZV5 & 20.00 & & & \\
\hline 299-E18-1 & $11 / 10 / 88$ & H0007ZV5 & & $10.00 \mathrm{U}$ & & \\
\hline 299-E18-1 & $2 / 15 / 89$ & H0007ZV8 & 22.00 & & & \\
\hline 299-E18-1 & $2 / 15 / 89$ & H0007zv8 & & $10.00 \mathrm{U}$ & & \\
\hline 299-E18-1 & $5 / 26 / 89$ & H00OTZW2 & 20.00 & & & \\
\hline 299-E18-1 & $5 / 26 / 89$ & H0007ZW2 & & $10.00 \mathrm{U}$ & & \\
\hline 299-E18-1 & $8 / 08 / 89$ & H00072W6 & 100.00 & & & \\
\hline 299-E18-1 & $8 / 08 / 89$ & H00072W6 & & $10.00 \mathrm{U}$ & & \\
\hline 299-E18-1 & $10 / 31 / 89$ & $400072 \times 0$ & 39.00 & & & $.76 \mathrm{U}$ \\
\hline 299-E18-1 & $10 / 31 / 89$ & H0007ZXO & & $10.00 \mathrm{U}$ & & \\
\hline $299-E 18-1$ & $7 / 09 / 91$ & H00071X9F & & $20.00 \mathrm{U}$ & & \\
\hline $299-E 18-1$ & $9 / 06 / 91$ & B0OLB6 & & & $-3.59 \mathrm{U}$ & \\
\hline $299-E 18-1$ & $9 / 06 / 91$ & BOOLB6F & & $20.00 \mathrm{U}$ & & \\
\hline 299-E18-1 & $1 / 24 / 92$ & B01060 & & 20.00 UD & & \\
\hline $299-E 18-1$ & $6 / 03 / 92$ & B06PH8 & & & $-3.79 \mathrm{U}$ & \\
\hline $299-E 18-1$ & $6 / 03 / 92$ & B06PJ2 & & $20.00 \mathrm{U}$ & & \\
\hline $299-E 18-1$ & $12 / 16 / 92$ & B07\$36 & & $20.00 \mathrm{U}$ & & \\
\hline $299-E 32-4$ & $9 / 27 / 88$ & H0008ZB8 & 25.00 & & & $-7.93 U$ \\
\hline $299-E 32-4$ & $9 / 27 / 88$ & H0008ZB8 & & $10.00 \mathrm{U}$ & & \\
\hline $299-E 32-4$ & $12 / 28 / 88$ & H0008ZC2 & 38.00 & & & \\
\hline $299-E 32-4$ & $12 / 28 / 88$ & H0008ZC2 & & $10.00 \mathrm{U}$ & & \\
\hline 299-E32-4 & $3 / 01 / 89$ & $\mathrm{H} 00082 \mathrm{CG}$ & 30.00 & & & \\
\hline $299-E 32-4$ & $3 / 01 / 89$ & H0008ZC6 & & $10.00 \mathrm{U}$ & & \\
\hline $299-E 32-4$ & $3 / 13 / 89$ & HOOOBZDO & 43.00 & & & $-.20 \mathrm{U}$ \\
\hline $299-E 32-4$ & $3 / 13 / 89$ & $H 0008 Z D O$ & & $10.00 \mathrm{U}$ & & \\
\hline $299-E 32-4$ & $6 / 16 / 89$ & H0008ZD4 & 58.00 & & & \\
\hline $299-E 32-4$ & $6 / 16 / 89$ & H0008ZD 4 & & $10.00 \mathrm{U}$ & & \\
\hline $299-E 32-4$ & $7 / 19 / 89$ & H0008ZD8 & 46.00 & & & $.38 \mathrm{U}$ \\
\hline $299-E 32-4$ & $7 / 19 / 89$ & H0008ZD8 & & $10.00 \mathrm{U}$ & & \\
\hline $299-\mathrm{E} 32-L$ & $9 / 08 / 89$ & H0008ZF6 & 43.00 & & & $4.36 \mathrm{U}$ \\
\hline $299-E 32-4$ & $9 / 08 / 89$ & H0008ZFG & & $10.00 \mathrm{U}$ & & \\
\hline 299-E32- 4 & $1 / 17 / 90$ & H0O08ZGO & 82.00 & & & $1.07 \mathrm{U}$ \\
\hline 299-E32-4 & $1 / 17 / 90$ & H0008ZGO & & $10.00 \mathrm{U}$ & & \\
\hline $299-E 32-4$ & $5 / 09 / 90$ & H0008ZG9 & & & & $2.63 \mathrm{U}$ \\
\hline $299-E 32-4$ & $8 / 05 / 91$ & HOOOTIYOF & & $20.00 \mathrm{U}$ & & \\
\hline $299-E 32-4$ & $8 / 05 / 91$ & H0007264 & & & $3.94 \mathrm{U}$ & \\
\hline $299-E 32-4$ & $8 / 05 / 91$ & H0007264F & & $20.00 \mathrm{U}$ & & \\
\hline $299-E 32-4$ & $9 / 23 / 91$ & B0OLK5 & & & $-.71 \mathrm{U}$ & \\
\hline $297-E 32-4$ & $9 / 23 / 91$ & B0OLK5F & & $20.00 \mathrm{U}$ & & \\
\hline $299-E 32-4$ & $1 / 15 / 92$ & B010K6 & & & 4.36 & \\
\hline
\end{tabular}


(sheet 49 of $\star *$ )

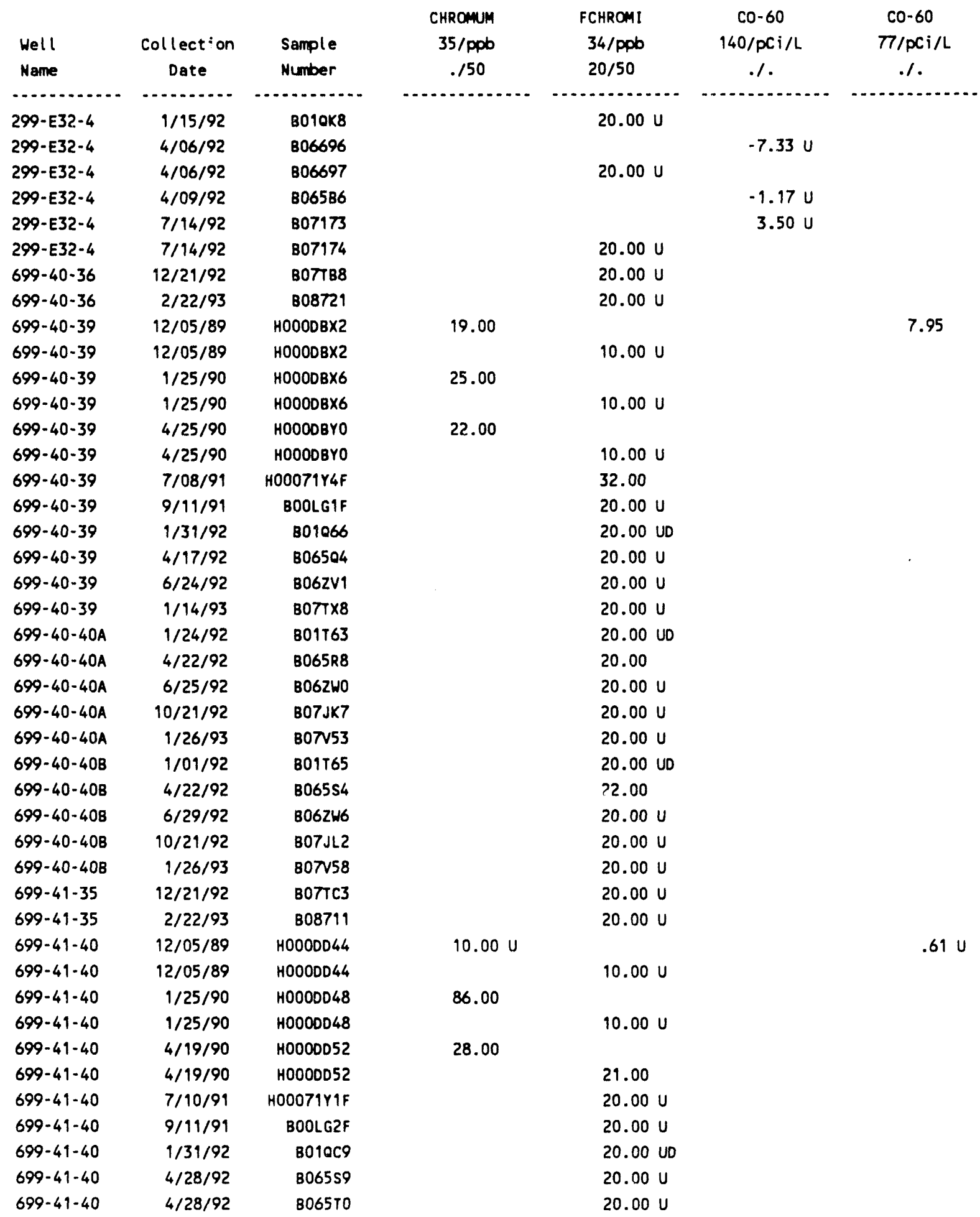


(sheet 50 of $* *$ )

\begin{tabular}{|c|c|c|c|c|c|c|}
\hline Well & Collection & Sample & $\begin{array}{l}\text { CHROMUM } \\
35 / \mathrm{ppb}\end{array}$ & $\begin{array}{l}\text { FCHROMI } \\
34 / \mathrm{ppb}\end{array}$ & $\begin{array}{c}\mathrm{Co-60} \\
140 / \mathrm{pCi} / \mathrm{L}\end{array}$ & $\begin{array}{l}\mathrm{Co-60} \\
77 / \mathrm{pCi} / \mathrm{L}\end{array}$ \\
\hline Nane & Date & Number &.$/ 50$ & $20 / 50$ &.$/$ &.$/$ \\
\hline ( & $\cdots$ & (n) & - n. & . & $\cdots$ & \\
\hline $699-41-40$ & $6 / 24 / 92$ & $8062 \times 6$ & & $20.00 \mathrm{U}$ & & \\
\hline $699-41-40$ & $1 / 14 / 93$ & $807 T Y 3$ & & $20.00 \mathrm{U}$ & & \\
\hline $699-41-42$ & $1 / 08 / 93$ & BOTV63 & & $20.00 \mathrm{U}$ & & \\
\hline $699-42-37$ & $12 / 22 / 92$ & BOTTC8 & & $20.00 \mathrm{U}$ & & \\
\hline $699-42-37$ & $2 / 23 / 93$ & B08716 & & $20.00 \mathrm{U}$ & & \\
\hline $699-42-39 A$ & $1 / 23 / 92$ & B01T67 & & 20.00 UP & & \\
\hline $699-42-39 A$ & $4 / 17 / 92$ & B065T5 & & 20.00 UP & & \\
\hline $699-42-39 A$ & $6 / 25 / 92$ & B062Y1 & & 20.00 UP & & \\
\hline $699-42-39 A$ & $10 / 21 / 92$ & B07JL7 & & 20.00 UP & & \\
\hline $699-42 \cdot 39 A$ & $1 / 27 / 93$ & BOTV68 & & 20.00 UP & & \\
\hline $699-42-398$ & $1 / 23 / 92$ & B01T69 & & 29.00 & & \\
\hline $699-42-398$ & $4 / 17 / 92$ & B065VO & & $20.00 \mathrm{U}$ & & \\
\hline $699-42-398$ & $6 / 25 / 92$ & $B 062 Y 6$ & & $20.00 \mathrm{U}$ & & \\
\hline $699-42-398$ & $10 / 28 / 92$ & B07JJ6 & & 20.00 Ue & & \\
\hline $699-42-398$ & $10 / 28 / 92$ & B07JJ7 & & 50.000 & & \\
\hline $699-42-398$ & $1 / 25 / 93$ & $807 v 73$ & & $20.00 \mathrm{U}$ & & \\
\hline $699-42-40 A$ & $2 / 03 / 83$ & $100000 \times 8$ & & & & -.37 \\
\hline $699-42-40 A$ & $2 / 28 / 83$ & $100000 \times 9$ & & & & -7.77 \\
\hline $699-42-40 A$ & $3 / 28 / 83$ & HOOOOOYO & & & & 3.84 \\
\hline $699-42-40 A$ & $4 / 14 / 83$ & HOOODOYZ & & & & -2.99 \\
\hline $699-42-40 A$ & $5 / 12 / 83$ & H0OOODY3 & & & & .21 \\
\hline $699-42 \cdot 40 \mathrm{~A}$ & $6 / 16 / 83$ & HOOODDY 4 & & & & -1.69 \\
\hline $699-42-40 A$ & $7 / 14 / 83$ & HOOODOY 5 & & & & 2.57 \\
\hline $699-42-40 A$ & $8 / 19 / 83$ & HOOODDYG & & & & -2.99 \\
\hline $699-42-40 A$ & $9 / 27 / 83$ & HOOODDY7 & & & & -3.26 \\
\hline $699-42-40 A$ & $10 / 12 / 83$ & HOOODDY 8 & & & & $\cdot .62$ \\
\hline $699-42-40 A$ & $11 / 07 / 83$ & HOOOODY9 & & & & -16.70 \\
\hline $699-42-40 A$ & $12 / 09 / 83$ & HOOODDZO & & & & 2.45 \\
\hline $699-42-40 A$ & $1 / 24 / 84$ & H00000Z1 & & & & -14.10 \\
\hline $699-42-40 \mathrm{~A}$ & $2 / 28 / 84$ & H00000Z2 & & & & 1.11 \\
\hline $699-42-40 A$ & $4 / 10 / 84$ & H00000Z3 & & & & 2.23 \\
\hline $699-42-40 A$ & $4 / 26 / 84$ & H0000DZ4 & & & & -4.07 \\
\hline $699-42-40 A$ & $5 / 15 / 84$ & H0OODDZ25 & & & & -3.70 \\
\hline $699-42-40 A$ & $6 / 05 / 84$ & H0000DZ6 & & & & -4.74 \\
\hline $699-42-40 A$ & $7 / 19 / 84$ & H0OODDZ7 & & & & .52 \\
\hline $699-42-40 \mathrm{~A}$ & $8 / 10 / 84$ & H0OODOZZ & & & & 1.01 \\
\hline $699-42-40 A$ & $9 / 11 / 84$ & H0OODDZ9 & & & & 5.90 \\
\hline $699-42-40 A$ & $10 / 09 / 84$ & HOOODFOO & & & & 7.33 \\
\hline $699-42-40 A$ & $11 / 13 / 84$ & HOOODFO1 & & & & -2.82 \\
\hline $699-42-40 A$ & $12 / 12 / 84$ & HOOODFOZ & & & & 1.21 \\
\hline $699-42-40 A$ & $1 / 16 / 85$ & H0OODFO3 & & & & -7.85 \\
\hline $699-42-40 A$ & $2 / 11 / 85$ & $\mathrm{HOOODFO4}$ & & & & 5.07 \\
\hline $699-42-40 A$ & $3 / 14 / 85$ & H000DF05 & & & & 4.53 \\
\hline
\end{tabular}


(sheet 51 of $\star$ )

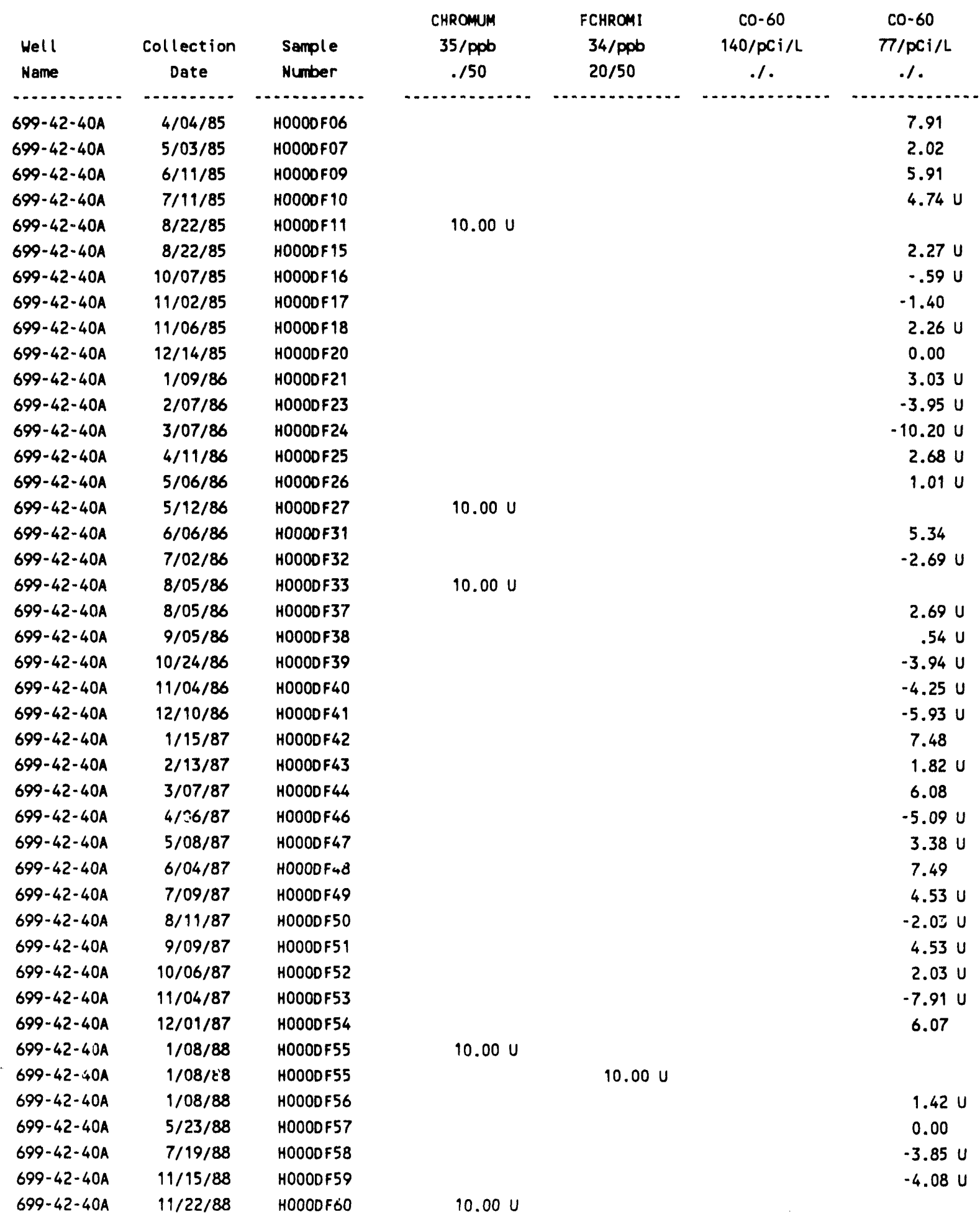


(sheet 52 of ${ }^{\star}$ )

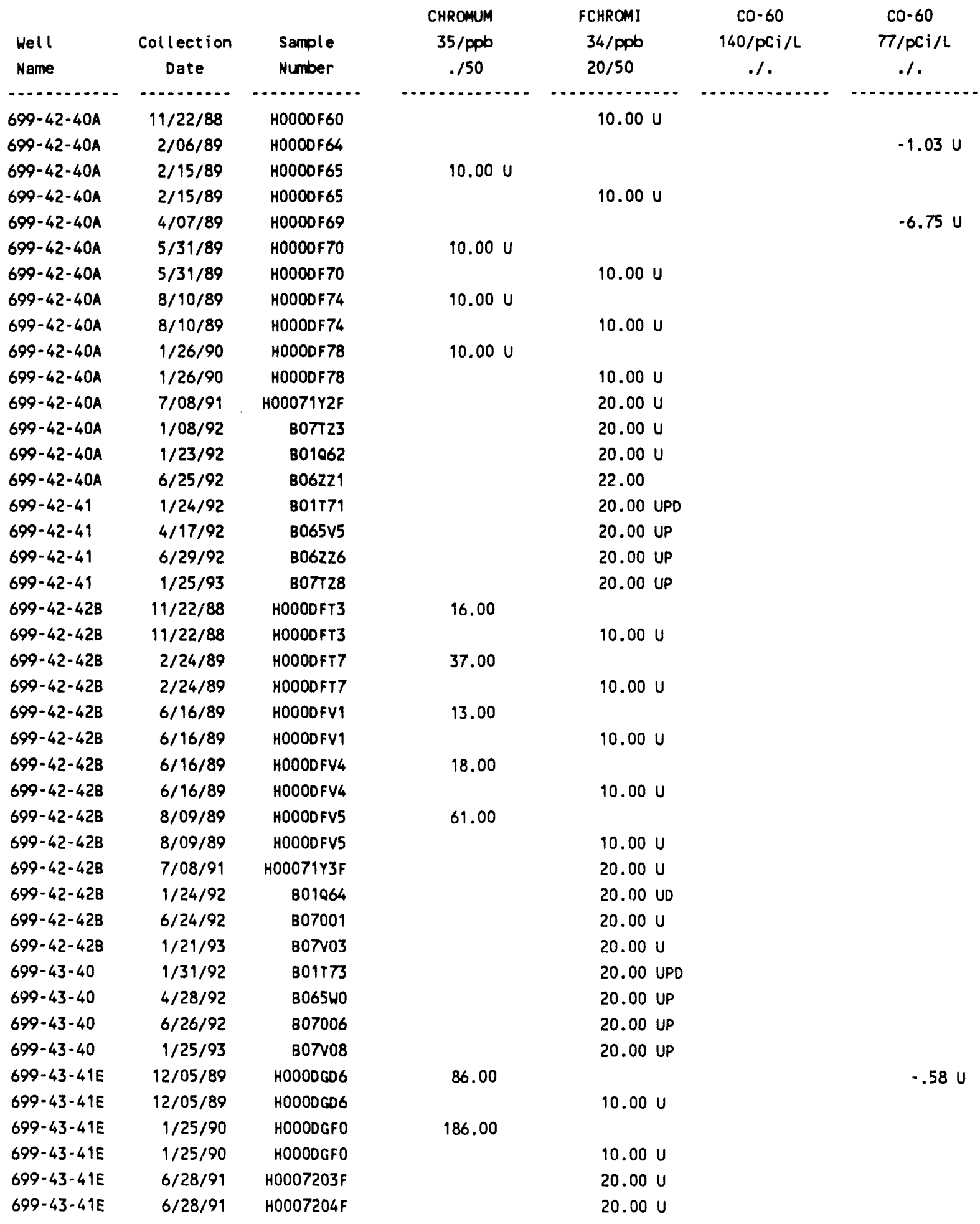


(sheet 53 of $\star \star$ )

\begin{tabular}{|c|c|c|c|c|c|c|}
\hline $\begin{array}{l}\text { Well } \\
\text { Name }\end{array}$ & $\begin{array}{c}\text { Collection } \\
\text { Date }\end{array}$ & $\begin{array}{l}\text { Sample } \\
\text { Number }\end{array}$ & $\begin{array}{c}\text { CHROMUM } \\
35 / \mathrm{ppb} \\
. / 50\end{array}$ & $\begin{array}{l}\text { FCHROMI } \\
34 / \text { ppb } \\
20 / 50\end{array}$ & $\begin{array}{c}\mathrm{CO}-60 \\
140 / \mathrm{pCi} / \mathrm{L} \\
. /\end{array}$ & $\begin{array}{c}\mathrm{CO}-60 \\
77 / \mathrm{pCi} / \mathrm{L} \\
. /\end{array}$ \\
\hline - & . & $\ldots$ & - & - & , n & . \\
\hline $699-43-41 E$ & $1 / 23 / 92$ & $8010 C_{4}$ & & $560.00 \mathrm{~F}$ & & \\
\hline $699-43-41 E$ & $4 / 17 / 92$ & 806506 & & $20.00 \mathrm{U}$ & & \\
\hline $699-43-41 E$ & $6 / 24 / 92$ & $8062 W 1$ & & $20.00 \mathrm{U}$ & & \\
\hline $699-43-41 E$ & $1 / 25 / 93$ & B07v13 & & $20.00 \mathrm{U}$ & & \\
\hline $699-43-41 F$ & $12 / 05 / 89$ & H0OODGG8 & 69.00 & & & $-2.49 \mathrm{U}$ \\
\hline $699-43-41 F$ & $12 / 05 / 89$ & H0OODGG8 & & $10.00 \mathrm{U}$ & & \\
\hline $699-43-41 F$ & $1 / 25 / 90$ & HOOOOGH2 & 25.00 & & & \\
\hline $699-43-41 F$ & $1 / 25 / 90$ & H0000GH2 & & $10.00 \mathrm{U}$ & & \\
\hline $699-43-41 F$ & $4 / 18 / 90$ & HOOODGH6 & 23.00 & & & \\
\hline $699-43-41 F$ & $4 / 18 / 90$ & HOOODGH6 & & $10.00 \mathrm{U}$ & & \\
\hline $699-43-41 F$ & $7 / 02 / 91$ & H00071Y5F & & $20.00 \mathrm{U}$ & & \\
\hline $699-43-41 F$ & $5 / 05 / 92$ & B065R9 & & $20.00 \mathrm{U}$ & & \\
\hline $699-43-41 F$ & $6 / 25 / 92$ & $8062 \times 1$ & & $20.00 \mathrm{U}$ & & \\
\hline $699-43-41 F$ & $1 / 22 / 93$ & B07V18 & & $20.00 \mathrm{U}$ & & \\
\hline $699-43-41 G$ & $1 / 23 / 92$ & B01T75 & & $20.00 \mathrm{U}$ & & \\
\hline $699-43-416$ & $4 / 17 / 92$ & B065H6 & & $20.00 \mathrm{U}$ & & \\
\hline $699-43-416$. & $6 / 26 / 92$ & B07011 & & $20.00 \mathrm{U}$ & & \\
\hline $699-43-416$ & $10 / 28 / 92$ & B07JM2 & & $20.00 \mathrm{U}$ & & \\
\hline $699-43-41 G$ & $1 / 25 / 93$ & B07N78 & & $20.00 \mathrm{U}$ & & \\
\hline $699-43-42 \mathrm{~J}$ & $11 / 22 / 88$ & HOOODGP2 & 33.00 & & & \\
\hline $699-43-42 \mathrm{~J}$ & $11 / 22 / 88$ & HOOODGP2 & & $10.00 \mathrm{U}$ & & \\
\hline $699-43-42 J$ & $2 / 24 / 89$ & HOOODGP6 & 41.00 & & & \\
\hline $699-43-42 \mathrm{~J}$ & $2 / 24 / 89$ & HOOODGPG & & $10.00 \mathrm{U}$ & & \\
\hline $699-43-42 J$ & $6 / 15 / 89$ & HOOOOGOO & 51.00 & & & \\
\hline $699-43-42 \mathrm{~J}$ & $6 / 15 / 89$ & HOOODGOO & & $10.00 \mathrm{U}$ & & \\
\hline $699-43-42 J$ & $8 / 09 / 89$ & HOOOOGQ4 & 206.00 & & & \\
\hline $699-43-42 J$ & $8 / 09 / 89$ & HOOODGO4 & & $10.00 \mathrm{U}$ & & \\
\hline $699-43-42 J$ & $8 / 09 / 89$ & H0000G07 & 118.00 & & & \\
\hline $699-43-42 \mathrm{~J}$ & $8 / 09 / 89$ & H0000G07 & & $10.00 \mathrm{U}$ & & \\
\hline $699-43-42 \mathrm{~J}$ & $7 / 02 / 91$ & H00071Y6F & & $20.00 \mathrm{U}$ & & \\
\hline $699-43-42 \mathrm{~J}$ & $1 / 31 / 92$ & B01551 & & 20.00 UD & & \\
\hline $699-43-42 \mathrm{~J}$ & $6 / 25 / 92$ & B07016 & & $20.00 \mathrm{U}$ & & \\
\hline $699-43-42 \mathrm{~J}$ & $1 / 21 / 93$ & B0TV23 & & $20.00 \mathrm{U}$ & & \\
\hline $699-43-43$ & $11 / 21 / 88$ & HOOOOGR3 & 57.00 & & & \\
\hline $699-43-43$ & $11 / 21 / 88$ & HOOODGR3 & & $10.00 \mathrm{U}$ & & \\
\hline $699-43-43$ & $2 / 24 / 89$ & HOOODGR7 & 34.00 & & & \\
\hline $699-43-43$ & $2 / 24 / 89$ & HOODDGR7 & & $10.00 \mathrm{U}$ & & \\
\hline $699-43-43$ & $2 / 24 / 89$ & HOOODGSO & 23.00 & & & \\
\hline $699-43-43$ & $2 / 24 / 89$ & HOOODGSO & & 10.00 & & \\
\hline $699-43-43$ & $6 / 15 / 89$ & HOOODGS1 & 10.vì is & & & \\
\hline $699-43-43$ & $6 / 15 / 89$ & HOOODGS 1 & & $10.00 \mathrm{U}$ & & \\
\hline $699-43-43$ & $8 / 09 / 89$ & HOOODGS5 & 22.00 & & & \\
\hline $699-43-43$ & $8 / 09 / 89$ & H000DGS5 & & $10.00 \mathrm{U}$ & & \\
\hline
\end{tabular}


(sheet 54 of $\star$ )

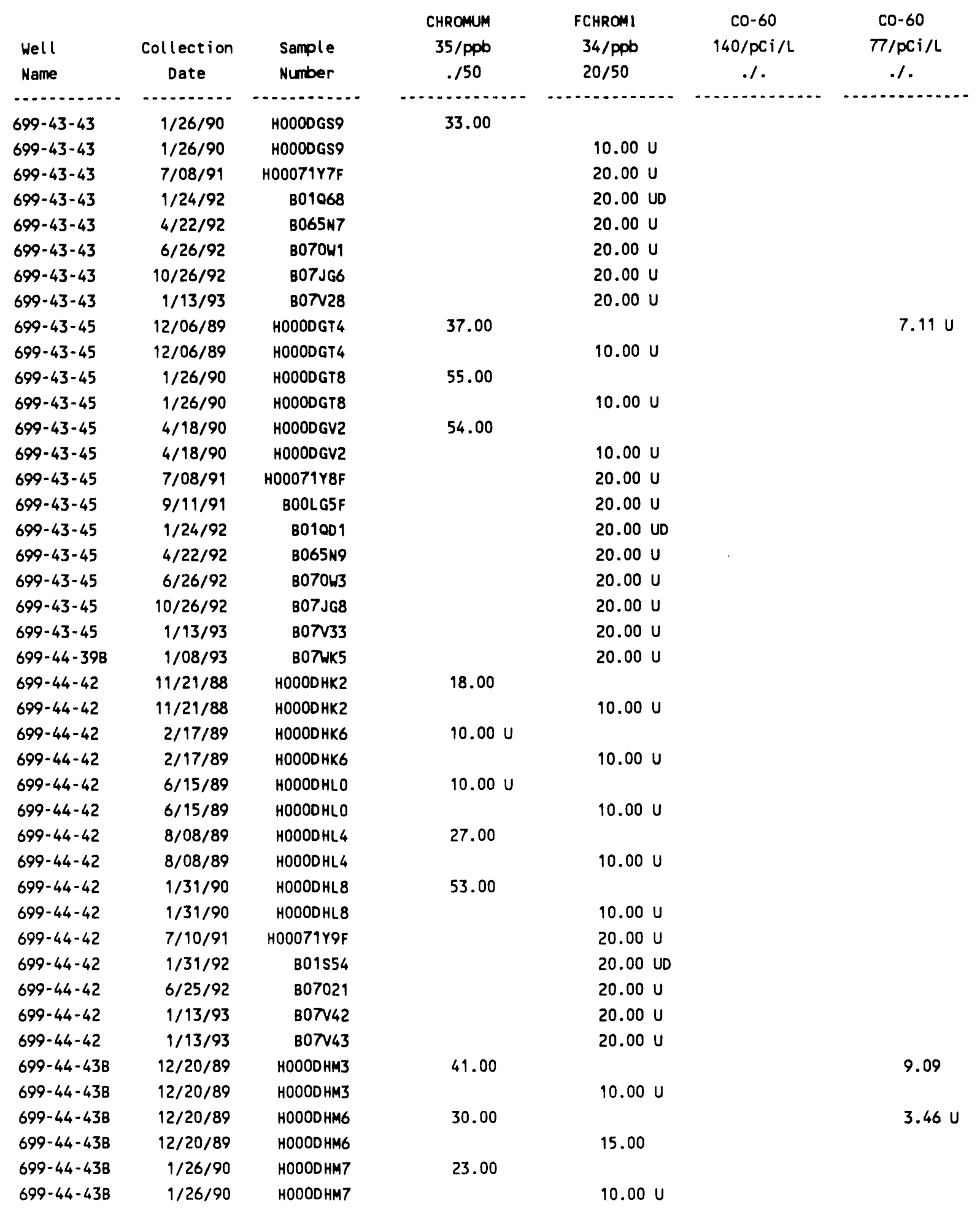


(sheet 55 of $\star *$ )

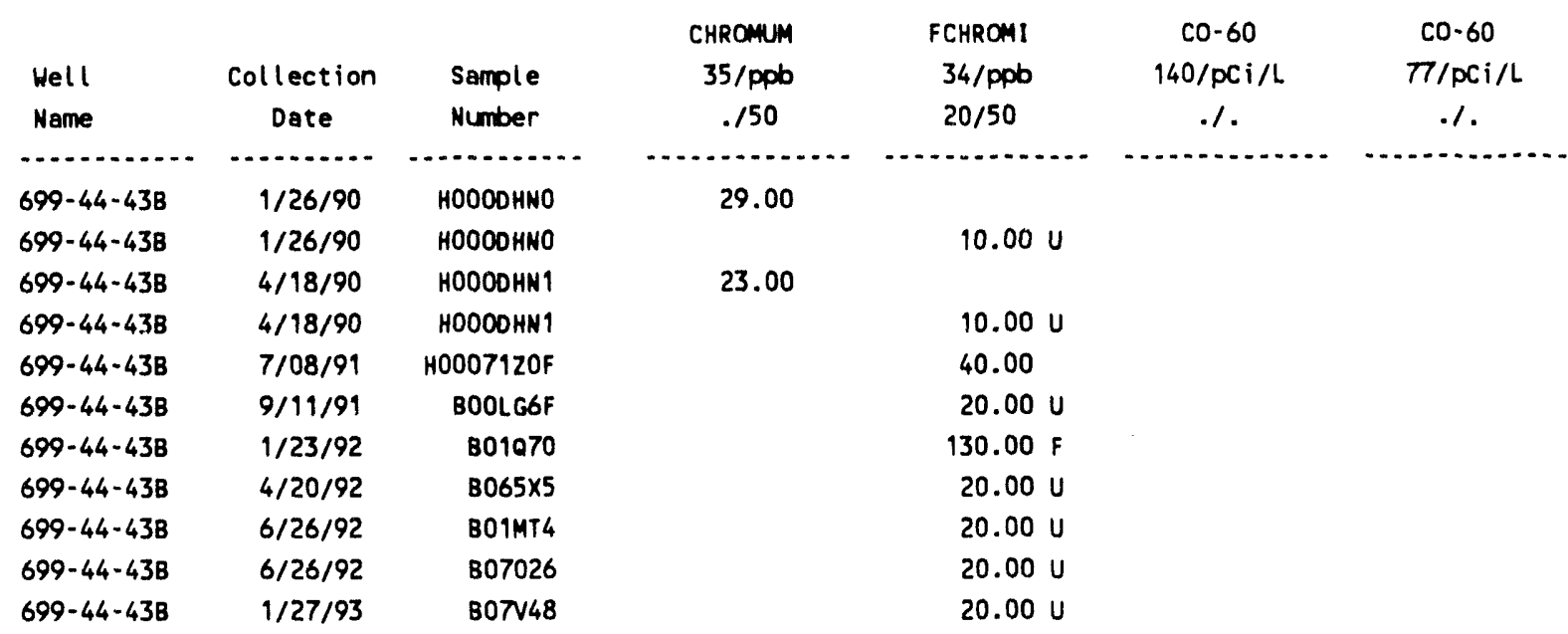

\begin{tabular}{|c|c|c|c|c|c|c|}
\hline & & & COL I FORM & COPPER & COPPER & FCOPPER \\
\hline Well & Collection & Sample & $144 / \mathrm{COL}$ & $34 / p p b$ & $35 / \mathrm{ppb}$ & $34 / p p b$ \\
\hline Name & Date & Number & $1 / 1$ & $20 / 1000 \mathrm{~s}$ &.$/ 1000 \mathrm{~s}$ & $20 / 1000 \mathrm{~s}$ \\
\hline n & $\ldots \ldots$ & $\ldots$ & n. & n. & (n. & n \\
\hline $299-E 18-1$ & $8 / 16 / 88$ & H00072T7 & & & $10.00 \mathrm{U}$ & \\
\hline 299-E18-1 & $8 / 16 / 88$ & HOOOTZT7 & & & & $10.00 \mathrm{U}$ \\
\hline $299-E 18-1$ & $9 / 22 / 88$ & H0007ZV1 & & & $10.00 \mathrm{U}$ & \\
\hline $299-E 18-1$ & $9 / 22 / 88$ & H0007ZV1 & & & & $10.00 \mathrm{U}$ \\
\hline $299-E 18-1$ & $11 / 10 / 88$ & H00072V2 & & & $10.00 \mathrm{U}$ & \\
\hline 299-E18-1 & $11 / 10 / 88$ & H00072V2 & & & & $10.00 \mathrm{U}$ \\
\hline 299-E18-1 & $11 / 10 / 88$ & H0007ZVS & & & 12.00 & \\
\hline $299-E 18-1$ & $11 / 10 / 88$ & H00072V5 & & & & $10.00 \mathrm{U}$ \\
\hline 299-E18-1 & $2 / 15 / 89$ & H0007ZV8 & & & $10.00 \mathrm{U}$ & \\
\hline 299-E18-1 & $2 / 15 / 89$ & H00072V8 & & & & $10.00 \mathrm{U}$ \\
\hline $299-E 18-1$ & $5 / 26 / 89$ & H0OOTZW2 & & & $10.00 \mathrm{U}$ & \\
\hline 299-E18-1 & $5 / 26 / 89$ & HOOOTZW2 & & & & $10.00 \mathrm{U}$ \\
\hline $299-E 18-1$ & $8 / 08 / 89$ & H0OOTZW6 & & & $10.00 \mathrm{U}$ & \\
\hline 299-E18-1 & $8 / 08 / 89$ & H0007ZW6 & & & & $10.00 \mathrm{U}$ \\
\hline 299-E18-1 & $10 / 31 / 89$ & $H 00072 \times 0$ & & & $10.00 \mathrm{U}$ & \\
\hline $299-E 18-1$ & $10 / 31 / 89$ & $H 00072 \times 0$ & & & & $10.00 \mathrm{U}$ \\
\hline $299-E 18-1$ & $7 / 09 / 91$ & H00071X9 & & $20.00 \mathrm{U}$ & & \\
\hline $299-E 18-1$ & $7 / 09 / 91$ & $H 0007^{\circ} \times 9 F$ & & & & $20.00 \mathrm{U}$ \\
\hline 299-E18-1 & $9 / 06 / 91$ & BOOLB6 & & $20.00 \mathrm{U}$ & & \\
\hline 299-E18-1 & $9 / 06 / 91$ & B00LB6F & & & & $20.00 \mathrm{U}$ \\
\hline $299-E 18-1$ & $1 / 24 / 92$ & B01059 & & 20.00 UD & & \\
\hline 299-E18-1 & $1 / 24 / 92$ & B01060 & & & & 20.00 UD \\
\hline $299-E 18-1$ & $6 / 03 / 92$ & B06PH8 & $1.00 \mathrm{U}$ & $20.00 \mathrm{U}$ & & \\
\hline 299-E18-1 & $6 / 03 / 92$ & B06PJ2 & & & & $20.00 \mathrm{U}$ \\
\hline $299-E 18-1$ & $12 / 16 / 92$ & 807532 & $1.00 \mathrm{U}$ & $20.00 \mathrm{U}$ & & \\
\hline
\end{tabular}


(sheet 56 of $\star *$ )

\begin{tabular}{|c|c|c|c|c|c|c|}
\hline & & & COLIFORM & COPPER & COPPER & FCOPPER \\
\hline Hell & Collection & Sample & $144 / \mathrm{COL}$ & $34 / p p b$ & $35 / p p b$ & 34/ppb \\
\hline Name & Date & Number & $1 / 1$ & $20 / 1000 \mathrm{~s}$ &.$/ 1000 \mathrm{~s}$ & $20 / 1000 \mathrm{~s}$ \\
\hline - & - & 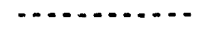 & . & - & , n & (n) \\
\hline 299-E18-1 & $12 / 16 / 92$ & B07s36 & & & & $20.00 \mathrm{U}$ \\
\hline $299-E 32-4$ & $9 / 27 / 88$ & H00082B8 & & & $10.00 \mathrm{U}$ & \\
\hline $299-E 32-4$ & $9 / 27 / 88$ & H00082B8 & & & & $10.00 \mathrm{U}$ \\
\hline $299-E 32-4$ & $12 / 28 / 88$ & HOOOBZC2 & & & $10.00 \mathrm{U}$ & \\
\hline 299-E32-4 & $12 / 28 / 88$ & $\mathrm{H} 00082 \mathrm{CZ}$ & & & & $10.00 \mathrm{U}$ \\
\hline $299-E 32-4$ & $3 / 01 / 89$ & H00082C6 & & & 13.00 & \\
\hline $299-E 32-4$ & $3 / 01 / 89$ & $\mathrm{H} 00082 \mathrm{CG}$ & & & & $10.00 \mathrm{U}$ \\
\hline $299-E 32-4$ & $3 / 13 / 89$ & H000820O & & & $10.00 \mathrm{U}$ & \\
\hline $299-E 32-4$ & $3 / 13 / 89$ & H0008ZDO & & & & $10.00 \mathrm{U}$ \\
\hline 299-E32-4 & $6 / 16 / 89$ & $H 00082 D 4$ & & & $10.00 \mathrm{U}$ & \\
\hline $299-E 32-4$ & $6 / 16 / 89$ & H0008204 & & & & $10.00 \mathrm{U}$ \\
\hline $299-E 32-4$ & $7 / 19 / 89$ & H0008208 & & & $10.00 \mathrm{U}$ & \\
\hline $299-E 32-4$ & $7 / 19 / 89$ & H0008208 & & & & $10.00 \mathrm{U}$ \\
\hline $299-E 32 \cdot 4$ & $9 / 08 / 89$ & H00082F6 & & & $10.00 \mathrm{U}$ & \\
\hline $299-E 32-4$ & $9 / 08 / 89$ & $H 00082 F 6$ & & & & $10.00 \mathrm{U}$ \\
\hline $299-E 32-4$ & $1 / 17 / 90$ & HOOOBZGO & & & $10.00 \mathrm{U}$ & \\
\hline $299-E 32-4$ & $1 / 17 / 90$ & $\mathrm{H} 00082 \mathrm{GO}$ & & & & $10.00 \mathrm{U}$ \\
\hline $299-E 32-4$ & $8 / 05 / 91$ & HOOOTIYO & & 20.00 UD & & \\
\hline $299-E 32-4$ & $8 / 05 / 91$ & H0007IYOF & & & & $20.00 \mathrm{U}$ \\
\hline $299-E 32-4$ & $8 / 05 / 91$ & H0007264 & & 20.00 UQC & & \\
\hline $299-E 32-4$ & $8 / 05 / 91$ & H0007264F & & & & 33.000 \\
\hline $299-E 32-4$ & $9 / 23 / 91$ & B00LK5 & & 25.00 & & \\
\hline $299-E 32-4$ & $9 / 23 / 91$ & B00LK5F & & & & $20.00 \mathrm{U}$ \\
\hline 299-E32-4 & $1 / 15 / 92$ & B010K6 & $32.00 \mathrm{~F}$ & $20.00 \mathrm{U}$ & & \\
\hline 299-E32-4 & $1 / 15 / 92$ & B010K8 & & & & $20.00 \mathrm{U}$ \\
\hline $299-E 32-4$ & $4 / 06 / 92$ & 806696 & $1.00 \mathrm{U}$ & $20.00 \mathrm{U}$ & & \\
\hline 299-E32-4 & $4 / 06 / 92$ & 806697 & & & & $20.00 \mathrm{U}$ \\
\hline 299-E32-4 & $7 / 14 / 92$ & 807173 & $1.00 \mathrm{U}$ & $20.00 \mathrm{U}$ & & \\
\hline $299-E 32-4$ & $7 / 14 / 92$ & B07174 & & & & $20.00 \mathrm{U}$ \\
\hline $699-40-36$ & $12 / 21 / 92$ & BOTTB1 & & $20.00 \mathrm{U}$ & & \\
\hline $699-40-36$ & $12 / 21 / 92$ & B07TB8 & & & & $20.00 \mathrm{U}$ \\
\hline $699-40-36$ & $2 / 22 / 93$ & 808717 & $1.00 \mathrm{U}$ & $20.00 \mathrm{U}$ & & \\
\hline $699-40-36$ & $2 / 22 / 93$ & B08721 & & & & $20.00 \mathrm{U}$ \\
\hline $699-40-39$ & $12 / 05 / 89$ & H0OODBX2 & & & $10.00 \mathrm{U}$ & \\
\hline $699-40-39$ & $12 / 05 / 89$ & H0OODBX2 & & & & $10.00 \mathrm{U}$ \\
\hline $699-40-39$ & $1 / 25 / 90$ & HOOODBX6 & & & $10.00 \mathrm{U}$ & \\
\hline $699-40-39$ & $1 / 25 / 90$ & HOOODBX6 & & & & $10.00 \mathrm{U}$ \\
\hline$\epsilon^{\prime} \quad 40-39$ & $4 / 25 / 90$ & HOOODBYO & & & $10.00 \mathrm{U}$ & \\
\hline $69 \cdot 7 \cdot 40-39$ & $4 / 25 / 90$ & HOOODBYO & & & & $10.00 \mathrm{U}$ \\
\hline $699-40-39$ & $7 / 08 / 91$ & H00079Y५F & & & & $20.00 \mathrm{U}$ \\
\hline $699-40-39$ & $9 / 11 / 91$ & BOOLG1 & & $20.00 \mathrm{U}$ & & \\
\hline $699-40-39$ & $9 / 11 / 91$ & B00LG1F & & & & 29.00 \\
\hline $699-40-39$ & $1 / 31 / 92$ & 801065 & $1.00 \mathrm{U}$ & 20.00 UD & & \\
\hline
\end{tabular}


(sheet 57 of $\star *$ )

\begin{tabular}{|c|c|c|c|c|c|c|}
\hline Well & Collection & Sarrle & COLIFORM & COPPER & $\begin{array}{l}\text { COPPER } \\
35 / 00 b\end{array}$ & $\begin{array}{r}\text { FCOPPER } \\
34 / p 0 b\end{array}$ \\
\hline Name & Date & Number & $1 / 1$ & $20 / 1000 \mathrm{~s}$ &.$/ 1000 \mathrm{~s}$ & $20 / 1000 \mathrm{~s}$ \\
\hline | & ............... & . & , n & - & - & • \\
\hline $699-40-39$ & $1 / 31 / 92$ & 801066 & & & & 20.00 UD \\
\hline $699-40-39$ & $4 / 17 / 92$ & B065P2 & $1.00 \cup 0$ & $20.00 \mathrm{U}$ & & \\
\hline $699-40-39$ & $4 / 17 / 92$ & B065Q4 & & & & $20.00 \mathrm{U}$ \\
\hline $699-40-39$ & $6 / 24 / 92$ & B062T7 & $1.00 \mathrm{U}$ & $20.00 \mathrm{U}$ & & \\
\hline $699-40-39$ & $6 / 24 / 92$ & B062V1 & & & & $20.00 \mathrm{U}$ \\
\hline $699-40-39$ & $1 / 14 / 93$ & B07T $\times 4$ & $1.00 \mathrm{U}$ & $20.00 \mathrm{U}$ & & \\
\hline $699-40-39$ & $1 / 14 / 93$ & $8077 \times 8$ & & & & $20.00 \mathrm{U}$ \\
\hline $699-40-40 \mathrm{~A}$ & $1 / 24 / 92$ & B01T62 & $1.00 \mathrm{U}$ & 20.00 UD & & \\
\hline $699-40-40 A$ & $1 / 24 / 92$ & B01T63 & & & & 20.00 UD \\
\hline $699-40-40 \mathrm{~A}$ & $4 / 22 / 92$ & 806508 & $1.00 \mathrm{U}$ & $20.00 \mathrm{U}$ & & \\
\hline $699-40-40 \mathrm{~A}$ & $4 / 22 / 92$ & 8065R8 & & & & $20.00 \mathrm{U}$ \\
\hline $699-40-40 \mathrm{~A}$ & $6 / 25 / 92$ & B062V2 & $1.00 \mathrm{U}$ & $20.00 \mathrm{U}$ & & \\
\hline $699-40-40 \mathrm{~A}$ & $6 / 25 / 92$ & B06ZWO & & & & $20.00 \mathrm{U}$ \\
\hline $699-40-40 \mathrm{~A}$ & $10 / 21 / 92$ & B07JK3 & $1.00 \mathrm{U}$ & $20.00 \mathrm{U}$ & & \\
\hline $699-40-40 A$ & $10 / 21 / 92$ & B07JK7 & & & & $20.00 \mathrm{U}$ \\
\hline $699-40-40 \mathrm{~A}$ & $1 / 26 / 93$ & B07v49 & $27.00 \mathrm{~F}$ & $20.00 \mathrm{U}$ & & \\
\hline $699-40-40 \mathrm{~A}$ & $1 / 26 / 93$ & B07v53 & & & & $20.00 \mathrm{U}$ \\
\hline $699-40-40 B$ & $1 / 01 / 92$ & B01T65 & & & & 20.00 UD \\
\hline $699-40-40 B$ & $1 / 24 / 92$ & B01T64 & $1.00 \mathrm{U}$ & 37.000 & & \\
\hline $699-40-40 B$ & $4 / 22 / 92$ & B065SO & $1.00 \mathrm{U}$ & $20.00 \mathrm{U}$ & & \\
\hline $699-40-40 B$ & $4 / 22 / 92$ & B065S4 & & & & $20.00 \mathrm{U}$ \\
\hline $699-40-40 B$ & $6 / 29 / 92$ & B062W2 & $1.00 \mathrm{U}$ & $20.00 \mathrm{U}$ & & \\
\hline $699-40-40 B$ & $6 / 29 / 92$ & B062W6 & & & & $20.00 \mathrm{U}$ \\
\hline $699-40-40 \mathrm{~B}$ & $10 / 21 / 92$ & B07JK8 & $200.00 \mathrm{~F}$ & 20.00 & & \\
\hline $699-40-40 B$ & $10 / 21 / 92$ & B07JL2 & & & & $20.00 \mathrm{U}$ \\
\hline $699-40-408$ & $1 / 26 / 93$ & $807 \times 54$ & $200.00 \mathrm{~F}$ & $20.00 \mathrm{U}$ & & \\
\hline $699-40-408$ & $1 / 26 / 93$ & B07V58 & & & & $20.00 \mathrm{U}$ \\
\hline $699-41-35$ & $12 / 21 / 92$ & 807789 & & $20.00 \mathrm{U}$ & & \\
\hline $699-41-35$ & $12 / 21 / 92$ & B07tC3 & & & & $20.00 \mathrm{U}$ \\
\hline $699-41-35$ & $2 / 22 / 93$ & B08707 & $1.00 \mathrm{U}$ & $20.00 \mathrm{U}$ & & \\
\hline $699-41-35$ & $2 / 22 / 93$ & B08711 & & & & $20.00 \mathrm{U}$ \\
\hline $699-41-40$ & $12 / 05 / 89$ & $\mathrm{H} 0000044$ & & & $10.00 \mathrm{U}$ & \\
\hline $699-41-40$ & $12 / 05 / 89$ & HOOODDO44 & & & & $10.00 \mathrm{U}$ \\
\hline $699-41-40$ & $1 / 25 / 90$ & $H 0000048$ & & & $10.00 \mathrm{U}$ & \\
\hline $699-41-40$ & $1 / 25 / 90$ & H0OODD 48 & & & & 16.00 \\
\hline $699-41-40$ & $4 / 19 / 90$ & H0OODD52 & & & $10.00 \mathrm{U}$ & \\
\hline $699-41-40$ & $4 / 19 / 90$ & H0000052 & & & & $10.00 \mathrm{U}$ \\
\hline $699-41-40$ & $7 / 10 / 91$ & HOOOT1Y1 & & $20.00 \mathrm{U}$ & & \\
\hline $699-41-40$ & $7 / 10 / 91$ & H00071Y1F & & & & $20.00 \mathrm{U}$ \\
\hline $699-41-40$ & $9 / 11 / 91$ & BOOLG2 & & $20.00 \mathrm{U}$ & & \\
\hline $699-41-40$ & $9 / 11 / 91$ & $B 00 L G 2 F$ & & & & 26.00 \\
\hline $699-41-40$ & $1 / 31 / 92$ & B010C8 & $1.00 \mathrm{U}$ & 22.000 & & \\
\hline $699-41-40$ & $1 / 31 / 92$ & B010C9 & & & & 20.00 UD \\
\hline
\end{tabular}


(sheet 58 of $* *$ )

\begin{tabular}{|c|c|c|c|c|c|c|}
\hline & & & COLIFORM & COPPER & COPPER & FCOPPER \\
\hline $\begin{array}{l}\text { Well } \\
\text { Name }\end{array}$ & $\begin{array}{l}\text { Collection } \\
\text { Date }\end{array}$ & $\begin{array}{l}\text { Sample } \\
\text { Number }\end{array}$ & $\begin{array}{c}144 / \mathrm{COL} \\
1 / 1\end{array}$ & $\begin{array}{c}\text { 34/ppb } \\
20 / 1000 \text { s }\end{array}$ & $\begin{array}{l}35 / \mathrm{ppb} \\
. / 1000 \mathrm{~s}\end{array}$ & $\begin{array}{c}\text { 34/ppb } \\
20 / 1000 \text { s }\end{array}$ \\
\hline 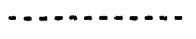 & a.n. & $\ldots$ & n.t. & n. & n........ & $\cdots$ \\
\hline $699-41-40$ & $4 / 28 / 92$ & 806555 & $1.00 \mathrm{U}$ & $20.00 \mathrm{U}$ & & \\
\hline $699-49-40$ & $4 / 28 / 92$ & 806556 & $1.00 \mathrm{U}$ & $20.00 \mathrm{U}$ & & \\
\hline $699-41-40$ & $4 / 28 / 92$ & B065S9 & & & & $20.00 \mathrm{U}$ \\
\hline $699-41-40$ & $4 / 28 / 92$ & B065TO & & & & $20.00 \mathrm{U}$ \\
\hline $699-41-40$ & $6 / 24 / 92$ & $8062 \times 2$ & $1.00 \mathrm{U}$ & $20.00 \mathrm{U}$ & & \\
\hline $699-41-40$ & $6 / 24 / 92$ & $8062 \times 6$ & & & & $20.00 \mathrm{U}$ \\
\hline $699-41-40$ & $1 / 14 / 93$ & $807 \pi \times 9$ & $1.00 \mathrm{U}$ & $20.00 \mathrm{U}$ & & \\
\hline $699-49-40$ & $1 / 14 / 93$ & $807 T Y 3$ & & & & $20.00 \mathrm{U}$ \\
\hline $699-41-42$ & $1 / 08 / 93$ & B07N59 & $1.00 \mathrm{U}$ & $20.00 \mathrm{U}$ & & \\
\hline $699-41-42$ & $1 / 08 / 93$ & B07V63 & & & & $20.00 \mathrm{U}$ \\
\hline $699-42-37$ & $12 / 22 / 92$ & BO7TC4 & & $20.00 \mathrm{U}$ & & \\
\hline $699-42-37$ & $12 / 22 / 92$ & BOTTC8 & & & & $20.00 \mathrm{U}$ \\
\hline $699-42-37$ & $2 / 23 / 93$ & B08712 & $1.00 \mathrm{U}$ & $20.00 \mathrm{U}$ & & \\
\hline $699-42-37$ & $2 / 23 / 93$ & B08716 & & & & $20.00 \mathrm{U}$ \\
\hline $699-42-39 A$ & $1 / 23 / 92$ & B01T66 & 1.00 UP & 20.00 UP & & - \\
\hline $699-42-39 A$ & $1 / 23 / 92$ & B01T67 & & & & 20.00 UP \\
\hline $699-42-39 A$ & $4 / 17 / 92$ & 806511 & 1.00 UPO & 20.00 UP & & \\
\hline $699-42-39 A$ & $4 / 17 / 92$ & B065T5 & & & & 20.00 UP \\
\hline $699-42-39 A$ & $6 / 25 / 92$ & $B 062 \times 7$ & 1.00 UP & 20.00 UP & & \\
\hline $699-42-39 A$ & $6 / 25 / 92$ & B062Y1 & & & & 20.00 UP \\
\hline $699-42-39 A$ & $10 / 21 / 92$ & 807JL3 & 1.00 UP & 20.00 UP & & \\
\hline $699-42-39 A$ & $10 / 21 / 92$ & B07JL7 & & & & 20.00 UP \\
\hline $699-42-39 A$ & $1 / 27 / 93$ & B07N64 & 1.00 UP & 20.00 UP & & \\
\hline $699-42-39 A$ & $1 / 27 / 93$ & B07N68 & & & & 20.00 UP \\
\hline $699-42-398$ & $1 / 23 / 92$ & $801 T 68$ & $1.00 \mathrm{U}$ & $20.00 \mathrm{U}$ & & \\
\hline $699-42-398$ & $1 / 23 / 92$ & $801 T 69$ & & & & $20.00 \mathrm{U}$ \\
\hline $699-42-398$ & $4 / 17 / 92$ & B065T6 & 1.00 Ua & $20.00 \mathrm{U}$ & & \\
\hline $699-42-398$ & $4 / 17 / 92$ & B065VO & & & & $20.00 \mathrm{U}$ \\
\hline $699-42-398$ & $6 / 25 / 92$ & B062Y2 & $1.00 \mathrm{U}$ & $20.00 \mathrm{U}$ & & \\
\hline $699-42-39 B$ & $6 / 25 / 92$ & B06ZYG & & & & $20.00 \mathrm{U}$ \\
\hline $699-42-39 B$ & $10 / 28 / 92$ & B07JJ2 & $1.00 \mathrm{U}$ & $20.00 \mathrm{U}$ & & \\
\hline $699-42-398$ & $10 / 28 / 92$ & B07JJ3 & $1.00 \mathrm{U}$ & $20.00 \mathrm{U}$ & & \\
\hline $699-42-398$ & $10 / 28 / 92$ & $807 \mathrm{JJ} 6$ & & & & $20.00 \mathrm{U}$ \\
\hline $699-42-398$ & $10 / 28 / 92$ & $807 \mathrm{JJ} 7$ & & & & $20.00 \mathrm{U}$ \\
\hline $699-42-39 B$ & $1 / 25 / 93$ & B07N69 & $1.00 \mathrm{U}$ & $20.00 \mathrm{U}$ & & \\
\hline $699-42-398$ & $1 / 25 / 93$ & BON73 & & & & $20.00 \mathrm{U}$ \\
\hline $699-42-40 A$ & $8 / 22 / 85$ & HOOODF 11 & & & $10.00 \mathrm{U}$ & \\
\hline $699-42-40 A$ & $5 / 12 / 86$ & H0OODF27 & & & $10.00 \mathrm{U}$ & \\
\hline $699-42-40 \mathrm{~A}$ & $8 / 05 / 86$ & $H 0000 F 33$ & & & $10.00 \mathrm{U}$ & \\
\hline $699-42-40 A$ & $1 / 08 / 88$ & HOOODF55 & & & $10.00 \mathrm{U}$ & \\
\hline $699-42-40 A$ & $1 / 08 / 88$ & HOOODF55 & & & & $10.00 \mathrm{U}$ \\
\hline $699-42-40 \mathrm{~A}$ & $11 / 22 / 88$ & HOOODF 60 & & & $10.00 \mathrm{U}$ & \\
\hline $699-42-40 \mathrm{~A}$ & $11 / 22 / 88$ & $H 0000 F 60$ & & & & $10.00 \mathrm{U}$ \\
\hline
\end{tabular}


(sheet 59 of $\star *$ )

\begin{tabular}{|c|c|c|c|c|c|c|}
\hline & & & COLIFORM & COPPER & COPPER & FCOPPER \\
\hline Well & Collection & Sample & $144 / \mathrm{COL}$ & $34 / p p b$ & 35/ppb & 34/ppb \\
\hline Name & Date & Number & $1 / 1$ & $20 / 1000 \mathrm{~s}$ &.$/ 1000 \mathrm{~s}$ & $20 / 1000 \mathrm{~s}$ \\
\hline ( & . & n & 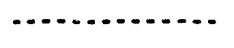 & (n) & 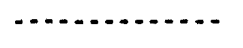 & . \\
\hline $699-42-40 A$ & $2 / 15 / 89$ & $H 0000 F 65$ & & & $10.00 \mathrm{U}$ & \\
\hline $699-42-40 \mathrm{~A}$ & $2 / 15 / 89$ & $H 0000 F 65$ & & & & $10.00 \mathrm{U}$ \\
\hline $699-42-40 A$ & $5 / 31 / 89$ & HOOODF 70 & & & $10.00 \mathrm{U}$ & \\
\hline $699-42-40 A$ & $5 / 31 / 89$ & $H 0000 F 70$ & & & & $10.00 \mathrm{U}$ \\
\hline $699-42-40 A$ & $8 / 10 / 89$ & H0000F74 & & & $10.00 \mathrm{U}$ & \\
\hline $699-42-40 A$ & $8 / 10 / 89$ & H0O0DF74 & & & & $10.00 \mathrm{U}$ \\
\hline $699-42-40 A$ & $1 / 26 / 90$ & H0000F78 & & & $10.00 \mathrm{U}$ & \\
\hline $699-42-40 A$ & $1 / 26 / 90$ & HOOODF78 & & & & $10.00 \mathrm{U}$ \\
\hline $699-42-40 A$ & $7 / 08 / 91$ & H00071Y2 & & $20.00 \mathrm{U}$ & & \\
\hline $699-42-40 \mathrm{~A}$ & $7 / 08 / 91$ & H00071Y2F & & & & $20.00 \mathrm{U}$ \\
\hline $699-42-40 \mathrm{~A}$ & $1 / 08 / 92$ & B07TY8 & & $20.00 \mathrm{U}$ & & \\
\hline $699-42-40 \mathrm{~A}$ & $1 / 08 / 92$ & 807723 & & & & $20.00 \mathrm{U}$ \\
\hline $699-42-40 A$ & $1 / 23 / 92$ & 801061 & & $20.00 \mathrm{U}$ & & \\
\hline $699-42-40 \mathrm{~A}$ & $1 / 23 / 92$ & 801062 & & & & $20.00 \mathrm{U}$ \\
\hline $699-42-40 A$ & $6 / 25 / 92$ & B06ZY7 & $1.00 \mathrm{U}$ & $20.00 \mathrm{U}$ & & \\
\hline $699-42-40 A$ & $6 / 25 / 92$ & B06221 & & & & $20.00 \mathrm{U}$ \\
\hline $699-42-41$ & $1 / 24 / 92$ & B01T70 & 1.00 UP & 20.00 UPD & & \\
\hline $699-42-41$ & $1 / 24 / 92$ & B01T71 & & & & 20.00 UPD \\
\hline $699-42-41$ & $4 / 17 / 92$ & $8065 \mathrm{VI}$ & 1.00 UP & 20.00 UP & & \\
\hline $699-42-41$ & $4 / 17 / 92$ & $8065 \mathrm{~V} 5$ & & & & 20.00 UP \\
\hline $699-42-41$ & $6 / 29 / 92$ & 806222 & 1.00 UP & 20.00 UP & & \\
\hline $699-42-41$ & $6 / 29 / 92$ & 806226 & & & & 20.00 UP \\
\hline $699-42-41$ & $1 / 25 / 93$ & B07T24 & 1.00 UP & 20.00 UP & & \\
\hline $699-42-41$ & $1 / 25 / 93$ & B07т28 & & & & 20.00 UP \\
\hline $699-42-42 B$ & $11 / 22 / 88$ & H0OOOFT3 & & & $10.00 \mathrm{U}$ & \\
\hline $699-42-428$ & $11 / 22 / 88$ & HOOODFT3 & & & & $10.00 \mathrm{U}$ \\
\hline $699-42-42 B$ & $2 / 24 / 89$ & HOOOOFT7 & & & $10.00 \mathrm{U}$ & \\
\hline $699-42-428$ & $2 / 24 / 89$ & HOOODFT7 & & & & $10.00 \mathrm{U}$ \\
\hline $699-42-428$ & $6 / 16 / 89$ & HOOODFV1 & & & $10.00 \mathrm{U}$ & \\
\hline $699-42-428$ & $6 / 16 / 89$ & HOOODFV1 & & & & $10.00 \mathrm{U}$ \\
\hline $699-42-42 B$ & $6 / 16 / 89$ & HOOODFV4 & & & $10.00 \mathrm{U}$ & \\
\hline $699-42-42 B$ & $6 / 16 / 89$ & HOOODFV 4 & & & & $10.00 \mathrm{U}$ \\
\hline $699-42-428$ & $8 / 09 / 89$ & HOOODFVS & & & $10.00 \mathrm{U}$ & \\
\hline $699-42-42 B$ & $8 / 09 / 89$ & HOOODFVS & & & & $10.00 \mathrm{U}$ \\
\hline $699-42-42 B$ & $7 / 08 / 91$ & H00071Y3 & & $20.00 \mathrm{U}$ & & \\
\hline $699-42-42 B$ & $7 / 08 / 91$ & H00071Y3F & & & & $20.00 \mathrm{U}$ \\
\hline $699-42-42 B$ & $1 / 24 / 92$ & B01063 & & 20.00 UD & & \\
\hline $699-42-42 B$ & $1 / 24 / 92$ & 801064 & & & & 20.00 UD \\
\hline $699-42-42 B$ & $6 / 24 / 92$ & 806227 & $1.00 \mathrm{U}$ & $20.00 \mathrm{U}$ & & \\
\hline $699-42-42 B$ & $6 / 24 / 92$ & 807001 & & & & $20.00 \mathrm{U}$ \\
\hline $699-42-42 B$ & $1 / 21 / 93$ & 807729 & & $20.00 u$ & & \\
\hline $699-42-428$ & $1 / 21 / 93$ & B07V03 & & & & $20.00 \mathrm{U}$ \\
\hline $699-43-40$ & $1 / 31 / 92$ & B01ז72 & $15.00 \mathrm{P}$ & 20.00 UPD & & \\
\hline
\end{tabular}


(sheet 60 of **)

\begin{tabular}{|c|c|c|c|c|c|c|}
\hline & & & COLIFORM & COPPER & COPPER & FCOPPER \\
\hline Well & Collection & Sample & $144 / \mathrm{COL}$ & $34 / \mathrm{ppb}$ & 35/ppb & 34/ppb \\
\hline Name & Date & Number & $1 / 1$ & $20 / 1000 \mathrm{~s}$ &.$/ 1000 \mathrm{~s}$ & $20 / 1000$ s \\
\hline . & (n) & , n & , & . & (n) & (n) \\
\hline $699-43-40$ & $1 / 31 / 92$ & B01T73 & & & & 20.00 UPD \\
\hline $699-43-40$ & $4 / 28 / 92$ & B065V6 & 1.00 UP & 20.00 UP & & \\
\hline $699-43-40$ & $4 / 28 / 92$ & B065W0 & & & & 20.00 UP \\
\hline $699-43-40$ & $6 / 26 / 92$ & B07002 & 1.00 UP & 20.00 UP & & \\
\hline $699-43-40$ & $6 / 26 / 92$ & 807006 & & & & 20.00 UP \\
\hline $699-43-40$ & $1 / 25 / 93$ & BOTV04 & 1.00 UP & 20.00 UP & & \\
\hline $699-43-40$ & $1 / 25 / 93$ & BOTV08 & & & & 20.00 UP \\
\hline $699-43-41 E$ & $12 / 05 / 89$ & HOOODGD6 & & & $10.00 \mathrm{U}$ & \\
\hline $699-43-41 E$ & $12 / 05 / 89$ & HOOODGD6 & & & & $10.00 \mathrm{U}$ \\
\hline $699-43-41 E$ & $1 / 25 / 90$ & HOOODGFO & & & 15.00 & \\
\hline $699-43-41 E$ & $1 / 25 / 90$ & HOOODGFO & & & & $10.00 \mathrm{U}$ \\
\hline $699-43-41 E$ & $6 / 28 / 91$ & H0007203 & & 20.00 UD & & \\
\hline $699-43-41 E$ & $6 / 28 / 91$ & H0007203F & & & & $20.00 \mathrm{U}$ \\
\hline $699-43-41 E$ & $6 / 28 / 91$ & H0007204 & & 20.00 UD & & \\
\hline $699-43-41 E$ & $6 / 28 / 91$ & H0007204F & & & & $20.00 \mathrm{U}$ \\
\hline $699-43-41 E$ & $1 / 23 / 92$ & B010c3 & $1.00 \mathrm{U}$ & $20.00 \mathrm{U}$ & & \\
\hline $699-43-41 E$ & $1 / 23 / 92$ & $8010 C_{4}$ & & & & 26.00 \\
\hline $699-43-41 E$ & $4 / 17 / 92$ & B065P4 & 1.00 vo & $20.00 \mathrm{U}$ & & \\
\hline $699-43-41 E$ & $4 / 17 / 92$ & 806506 & & & & $20.00 \mathrm{U}$ \\
\hline $699-43-41 E$ & $6 / 24 / 92$ & B062V3 & $1.00 \mathrm{U}$ & $20.00 \mathrm{U}$ & & \\
\hline $699-43-41 E$ & $6 / 24 / 92$ & B062W1 & & & & $20.00 \mathrm{U}$ \\
\hline $699-43-41 E$ & $1 / 25 / 93$ & B07V09 & $1.00 \mathrm{U}$ & $20.00 \mathrm{U}$ & & \\
\hline $699-43-41 E$ & $1 / 25 / 93$ & B07V13 & & & & $20.00 \mathrm{U}$ \\
\hline $699-43-41 F$ & $12 / 05 / 89$ & H0OOOGG8 & & & $10.00 \mathrm{U}$ & \\
\hline $699-43-41 F$ & $12 / 05 / 89$ & HOOODGG8 & & & & $10.00 \mathrm{U}$ \\
\hline $699-43-41 F$ & $1 / 25 / 90$ & HOOODGH2 & & & $10.00 \mathrm{U}$ & \\
\hline $699-43-41 F$ & $1 / 25 / 90$ & H0OOOGH2 & & & & $10.00 \mathrm{U}$ \\
\hline $699-43-41 F$ & $4 / 18 / 90$ & H0ODDGH6 & & & $10.00 \mathrm{U}$ & \\
\hline $699-43-41 F$ & $4 / 18 / 90$ & HOOODGH6 & & & & $10.00 \mathrm{U}$ \\
\hline $699-43-41 F$ & $7 / 02 / 91$ & H00079Y5 & & 20.00 UD & & \\
\hline $699-43-41 F$ & $7 / 02 / 91$ & H00071Y5F & & & & $20.00 \mathrm{U}$ \\
\hline $699-43-41 F$ & $5 / 05 / 92$ & $3065 R 0$ & $1.00 \mathrm{U}$ & $20.00 \mathrm{U}$ & & \\
\hline $699-43-41 F$ & $5 / 05 / 92$ & B065R9 & & & & $20.00 \mathrm{U}$ \\
\hline $699-43-41 F$ & $6 / 25 / 92$ & B062W7 & $1.00 \mathrm{U}$ & $20.00 \mathrm{U}$ & & \\
\hline $699-43-41 F$ & $6 / 25 / 92$ & $8062 \times 1$ & & & & $20.00 \mathrm{U}$ \\
\hline $699-43-41 F$ & $1 / 22 / 93$ & BOTN14 & $1.00 \mathrm{v}$ & $20.00 \mathrm{U}$ & & \\
\hline $699-43-41 F$ & $1 / 22 / 93$ & B07N18 & & & & $20.00 \mathrm{U}$ \\
\hline $699-43-41 G$ & $1 / 23 / 92$ & B01T74 & $1.00 \mathrm{U}$ & $20.00 \mathrm{U}$ & & \\
\hline $699-43-41 G$ & $1 / 23 / 92$ & B01T75 & & & & $20.00 \mathrm{U}$ \\
\hline $699-43-41 G$ & $4 / 17 / 92$ & B065W1 & 1.00 va & $20.00 \mathrm{U}$ & & \\
\hline $699-43-416$ & $4 / 17 / 92$ & B065W6 & & & & $20.00 \mathrm{U}$ \\
\hline $699-43-41 G$ & $6 / 26 / 92$ & B07007 & $1.00 \mathrm{U}$ & $20.00 \mathrm{U}$ & & \\
\hline $699-43-41 G$ & $6 / 26 / 92$ & B07011 & & & & $20.00 \mathrm{U}$ \\
\hline
\end{tabular}




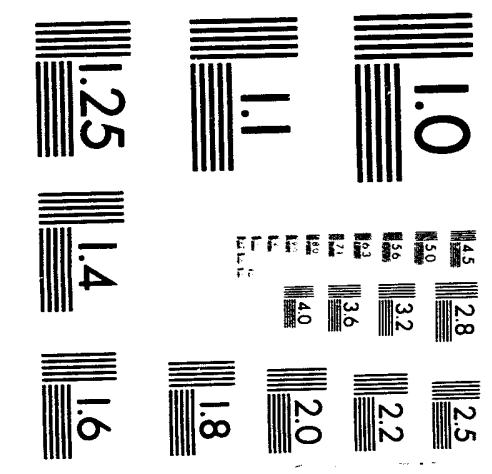



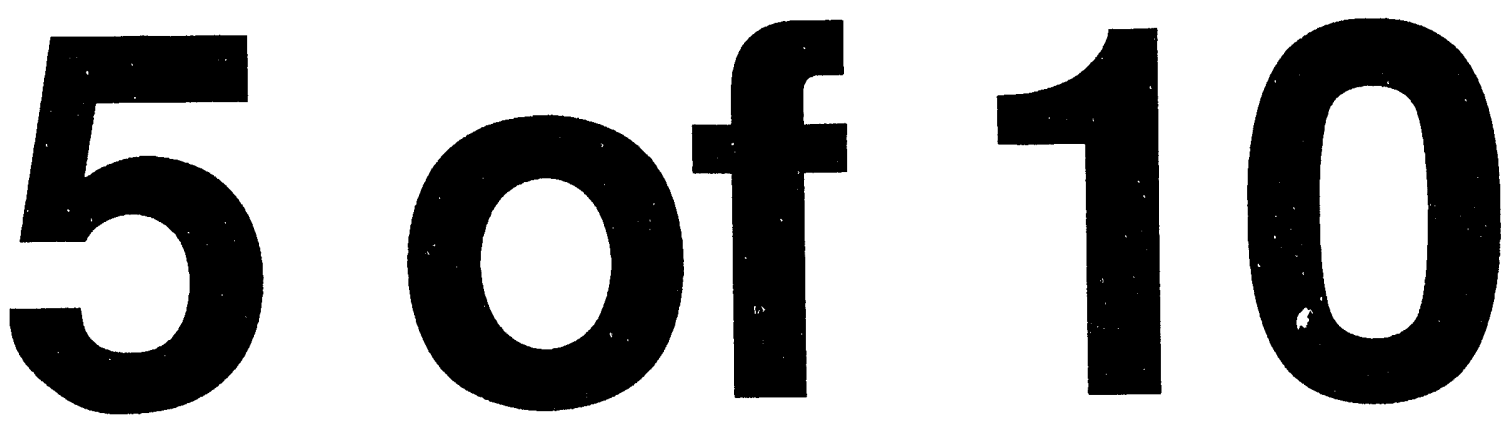
(sheet 61 of $\star *$ )

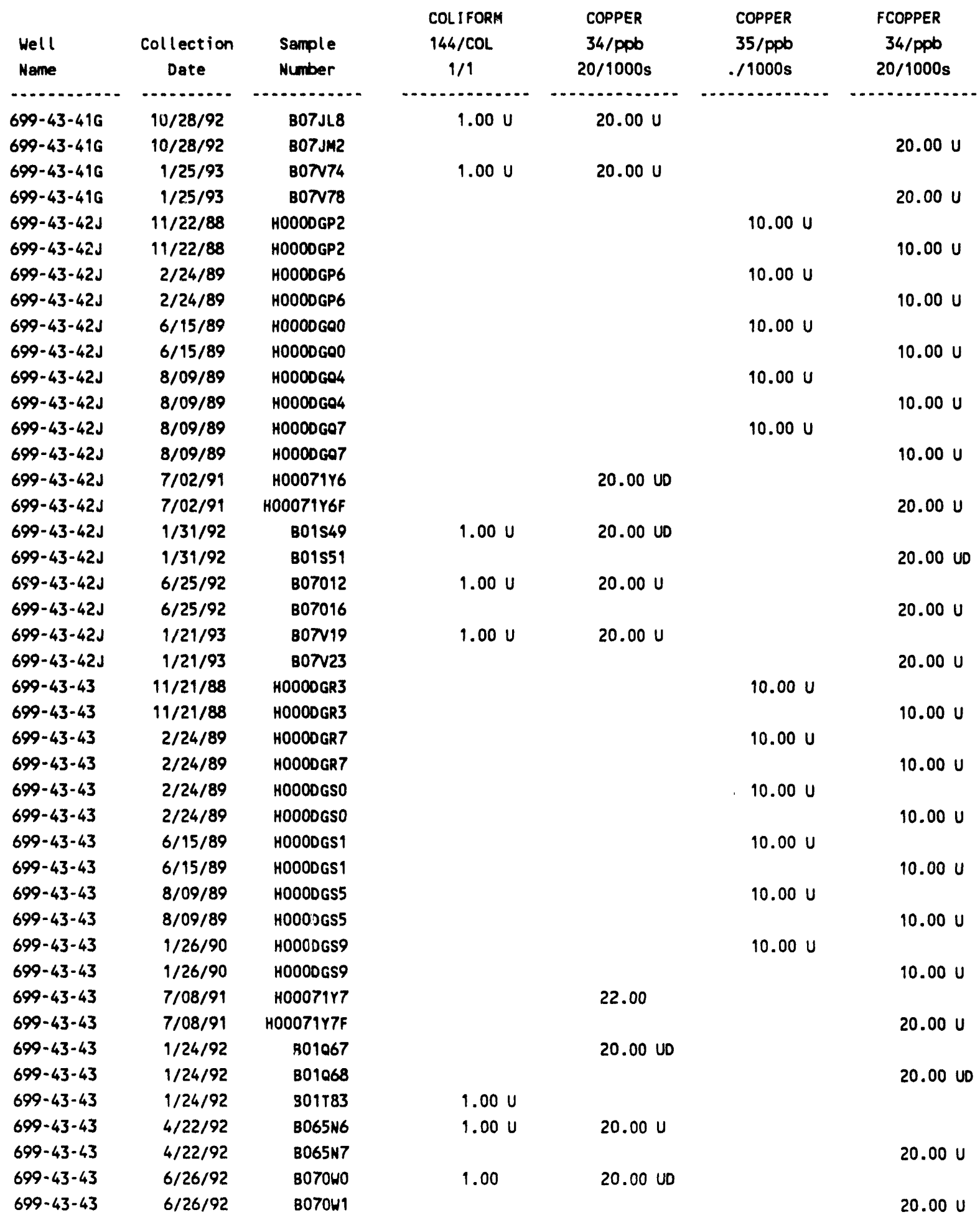


(sheet 62 of $\star *$ )

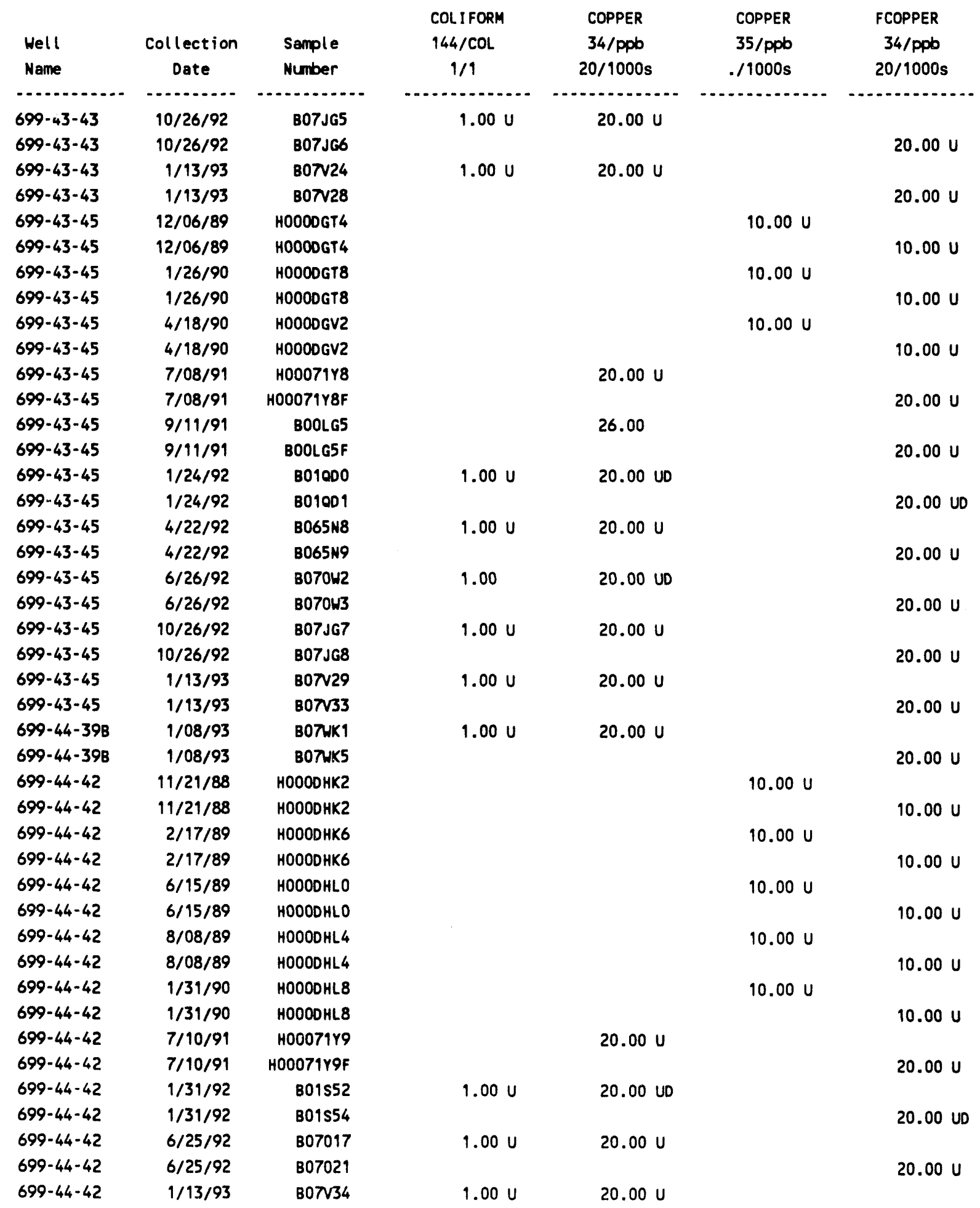


(sheet 63 of $*$ )

\begin{tabular}{|c|c|c|c|c|c|c|}
\hline & & & COLIFORM & $\begin{array}{l}\text { COPPER } \\
34 / 00 b\end{array}$ & $\begin{array}{l}\text { COPPER } \\
35 / 0 n h\end{array}$ & $\begin{array}{r}\text { FCOPPER } \\
\end{array}$ \\
\hline $\begin{array}{l}\text { Well } \\
\text { Neme }\end{array}$ & $\begin{array}{c}\text { Collection } \\
\text { Date }\end{array}$ & $\begin{array}{l}\text { Sample } \\
\text { Number }\end{array}$ & $\begin{array}{c}144 / \mathrm{COL} \\
1 / 9\end{array}$ & $\begin{array}{c}\text { 34/ppb } \\
20 / 1000 \text { s }\end{array}$ & $\begin{array}{l}35 / p p b \\
. / 1000 s\end{array}$ & $\begin{array}{c}34 / \mathrm{ppb} \\
20 / 1000 \mathrm{~s}\end{array}$ \\
\hline - & . & 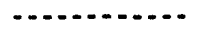 & - & n. & 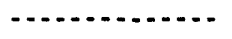 & \\
\hline $699-44-42$ & $1 / 13 / 93$ & B07N35 & $1.00 \mathrm{U}$ & $20.00 \mathrm{U}$ & & \\
\hline $699-44-42$ & $1 / 13 / 93$ & Bo7v42 & & & & $20.00 \mathrm{U}$ \\
\hline $699-44-42$ & $1 / 93 / 93$ & $807 v 43$ & & & & $20.00 \mathrm{U}$ \\
\hline $699-44-43 B$ & $12 / 20 / 89$ & H0OODHM3 & & & $10.00 \mathrm{U}$ & \\
\hline $699-44-43 B$ & $12 / 20 / 89$ & HOOOOHM3 & & & & $10.00 \mathrm{U}$ \\
\hline $699-44-43 B$ & $12 / 20 / 89$ & HOOOOHMG & & & $10.00 \mathrm{U}$ & \\
\hline $699-44-43 B$ & $12 / 20 / 89$ & HOOOOHMG & & & & $10.00 \mathrm{U}$ \\
\hline $699-44-43 B$ & $1 / 26 / 90$ & HOOODHM7 & & & $10.00 \mathrm{U}$ & \\
\hline $699-44-43 B$ & $1 / 26 / 90$ & HOOOOHM7 & & & & $10.00 \mathrm{U}$ \\
\hline $699-44-43 B$ & $1 / 26 / 90$ & HOOODHNO & & & $10.00 \mathrm{U}$ & \\
\hline $699-44-43 B$ & $1 / 26 / 90$ & HOOODHNO & & & & $10.00 \mathrm{U}$ \\
\hline $699-44-438$ & $4 / 18 / 90$ & H0OOOHN1 & & & $10.00 \mathrm{U}$ & \\
\hline $699-44-43 B$ & $4 / 18 / 90$ & HOOODHN1 & & & & $10.00 \mathrm{U}$ \\
\hline $699-44-43 B$ & $7 / 08 / 91$ & H0007120 & & $20.00 \mathrm{U}$ & & \\
\hline $699-44-43 B$ & $7 / 08 / 91$ & H0007120F & & & & $20.00 \mathrm{U}$ \\
\hline $699-44-43 B$ & $9 / 11 / 91$ & BOOLG6 & & $20.00 \mathrm{U}$ & & \\
\hline $699-44-43 B$ & $9 / 11 / 91$ & BOOLG6F & & & & $20.00 \mathrm{U}$ \\
\hline $699-44-43 B$ & $1 / 23 / 92$ & B01069 & $1.00 \mathrm{U}$ & $20.00 \mathrm{U}$ & & \\
\hline $699-44-43 B$ & 1/23/92 & B01070 & & & & $20.00 \mathrm{U}$ \\
\hline $699-44-43 B$ & $4 / 20 / 92$ & B065W9 & $1.00 \mathrm{U}$ & 22.00 & & \\
\hline $699-44-43 B$ & $4 / 20 / 92$ & B065 $\times 5$ & & & & $20.00 \mathrm{U}$ \\
\hline $699-44-43 B$ & $6 / 26 / 92$ & B01MT4 & & & & $20.00 \mathrm{U}$ \\
\hline $699-44-43 B$ & $6 / 26 / 92$ & 807022 & $1.00 \mathrm{U}$ & $20.00 \mathrm{U}$ & & - \\
\hline $699-44-43 B$ & $6 / 26 / 92$ & B07023 & 1.00 & $20.00 \mathrm{U}$ & & \\
\hline $699-44-438$ & $6 / 26 / 92$ & 807026 & & & & $20.00 \mathrm{U}$ \\
\hline $699-44-43 B$ & $1 / 27 / 93$ & BOTV44 & $1.00 \mathrm{U}$ & $20.00 \mathrm{U}$ & & \\
\hline $699-44-43 B$ & $1 / 27 / 93$ & B07v48 & & & & $20.00 \mathrm{U}$ \\
\hline
\end{tabular}

\begin{tabular}{|c|c|c|c|c|c|c|}
\hline & & & EU-154 & $E U-155$ & FLUORID & FLUORIN \\
\hline Hell & Collection & Sample & $140 / \mathrm{DCi} / \mathrm{L}$ & $140 / D C i / L$ & $124 / \mathrm{ppb}$ & 4Gippo \\
\hline Name & Date & Number & .1 & .1 & $100 / 4000$ &.$/ 4000$ \\
\hline י מ & n. & - & 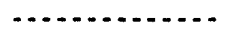 & , n & - & . \\
\hline 299-E18-1 & $8 / 16 / 88$ & H00072T7 & & & & $500.00 \mathrm{U}$ \\
\hline 299-E18-1 & $11 / 10 / 88$ & H0007zV2 & & & & $500.00 \mathrm{U}$ \\
\hline 299-E18-1 & $11 / 10 / 88$ & H00072V5 & & & & $500.00 \mathrm{U}$ \\
\hline 299-E 18-1 & 2/15/89 & H00072v8 & & & & $500.00 \mathrm{U}$ \\
\hline 299-E18-1 & $5 / 26 / 89$ & H0007ZW2 & & & & 500.00 \\
\hline 299-E18-1 & $8 / 08 / 89$ & H0007ZW6 & & & & 600.00 \\
\hline 299-E18-1 & $10 / 31 / 89$ & H0007ZXO & & & & 500.00 \\
\hline 299-E18-1 & $5 / 30 / 90$ & $H 00072 \times 5$ & & & & 500.00 \\
\hline 299-E 18-1 & $7 / 09 / 91$ & H00071X9 & & & 590.00 & \\
\hline
\end{tabular}


(sheet 64 of ${ }^{\star}$ )

\begin{tabular}{|c|c|c|c|c|c|c|}
\hline & & & $E U-154$ & $E U-155$ & FLUORID & FLUORIN \\
\hline Well & Collection & Sample & $140 / \mathrm{DCi} / \mathrm{L}$ & $140 / \mathrm{PCi} / \mathrm{L}$ & $124 / \mathrm{ppb}$ & 46/ppb \\
\hline Name & Date & Number & .1 &.$/$ & $100 / 4000$ &.$/ 4000$ \\
\hline n. & , n & $\ldots$ & (n. & . & - & $\ldots$ \\
\hline $299-E 18-1$ & $9 / 06 / 91$ & B0OLB6 & $-1.58 U$ & 6.01 & & \\
\hline 299-E18-1 & $1 / 24 / 92$ & 801059 & & & 500.00 & \\
\hline 299-E18-1 & $6 / 03 / 92$ & В06РH8 & & & 500.00 & \\
\hline 299-E18-1 & $12 / 16 / 92$ & B07532 & & & 500.00 & \\
\hline $299-E 32-4$ & $9 / 27 / 88$ & H0008Z88 & & & & $500.00 \mathrm{U}$ \\
\hline 299-E32-4 & $12 / 28 / 88$ & H0008ZC2 & & & & 600.00 \\
\hline $299-E 32-4$ & $3 / 01 / 89$ & H0008ZC6 & & & & 500.00 \\
\hline 299-E32-4 & $3 / 13 / 89$ & H0OOBZDO & & & & 600.00 \\
\hline $299-E 32-4$ & $6 / 16 / 89$ & H00082D4 & & & & 600.00 \\
\hline $299-E 32-4$ & $7 / 19 / 89$ & 40008ZD8 & & & & 580.00 \\
\hline $299-E 32-4$ & $9 / 08 / 89$ & H0008ZF6 & & & & 600.00 \\
\hline $299-E 32-4$ & $1 / 17 / 90$ & H00082GO & & & & 500.00 \\
\hline $299-E 32-4$ & $5 / 09 / 90$ & H0008ZG9 & & & & 600.00 \\
\hline $299-E 32-4$ & $8 / 05 / 91$ & $H 0007264$ & $7.92 \mathrm{U}$ & $-3.29 U$ & & \\
\hline $299-E 32-4$ & $9 / 23 / 91$ & B00LK5 & 6.32 & $-.73 \mathrm{U}$ & & \\
\hline $299-E 32-4$ & $1 / 15 / 92$ & B010K6 & & & 600.00 & \\
\hline $299-E 32-4$ & $4 / 06 / 92$ & B06696 & & & 600.00 & \\
\hline $299-E 32-4$ & $4 / 09 / 92$ & B065B6 & & & 600.00 & \\
\hline $299-E 32-4$ & $7 / 14 / 92$ & 807173 & & & 700.00 & \\
\hline $699-40-36$ & $12 / 21 / 92$ & B07TB1 & & & 900.00 & \\
\hline $699-40-36$ & $2 / 22 / 93$ & B08717 & & & 900.00 & \\
\hline $699-40-39$ & $12 / 05 / 89$ & H0OOOBX2 & & & & 700.00 \\
\hline $699-40-39$ & $1 / 25 / 90$ & $H 00008 \times 6$ & & & & 700.00 \\
\hline $699-40-39$ & $4 / 25 / 90$ & HOOOOBYO & & & & 700.00 \\
\hline $699-40-39$ & $7 / 08 / 91$ & H00079Y4 & & & 900.00 & \\
\hline $699-40-39$ & $1 / 31 / 92$ & B01065 & & & 800.00 & \\
\hline $699-40-39$ & $4 / 17 / 92$ & B065P2 & & & $800.00 \mathrm{D}$ & \\
\hline $699-40-39$ & $6 / 24 / 92$ & B062T7 & & & 700.00 & \\
\hline $699-40-39$ & $1 / 14 / 93$ & B07TX4 & & & 700.00 & \\
\hline $699-40-40 \mathrm{~A}$ & $1 / 24 / 92$ & B01T62 & & & 800.00 & \\
\hline $699-40-40 A$ & $4 / 22 / 92$ & B06508 & & & 900.00 & \\
\hline $699-40-40 A$ & $6 / 25 / 92$ & B06ZV2 & & & 800.00 & \\
\hline $699-40-40 \mathrm{~A}$ & $10 / 21 / 92$ & B07JK3 & & & 900.00 & \\
\hline $699-40-40 A$ & $1 / 26 / 93$ & $807 \times 49$ & & & 800.00 & \\
\hline $699-40-40 B$ & $1 / 24 / 92$ & B01T64 & & & 600.00 & \\
\hline $699-40-40 B$ & $4 / 22 / 92$ & B065s0 & & & 800.00 & \\
\hline $699-40-40 B$ & $6 / 29 / 92$ & B06ZW2 & & & 600.000 & \\
\hline $699-40-40 B$ & $10 / 21 / 92$ & B07JK8 & & & 500.00 & \\
\hline $699-40-40 B$ & $1 / 26 / 93$ & BO7V54 & & & 500.00 & \\
\hline $699-41-35$ & $12 / 21 / 92$ & В07т89 & & & 800.00 & \\
\hline $699-41-35$ & $2 / 22 / 93$ & B08707 & & & 1000.00 & \\
\hline $699-41-40$ & $12 / 05 / 89$ & HOOODD 44 & & & & 600.00 \\
\hline $699-41-40$ & $1 / 25 / 90$ & $H 0000048$ & & & & 600.00 \\
\hline
\end{tabular}


(sheet 65 of $*$ )

\begin{tabular}{|c|c|c|c|c|c|c|}
\hline & & & EU-154 & EU-155 & FLUORID & FLUORIN \\
\hline $\begin{array}{l}\text { Hell } \\
\text { Name }\end{array}$ & $\begin{array}{c}\text { Collection } \\
\text { Date }\end{array}$ & $\begin{array}{l}\text { Sample } \\
\text { Number }\end{array}$ & $\begin{array}{c}140 / \mathrm{pCi} / \mathrm{L} \\
. /\end{array}$ & $\begin{array}{c}140 / P C i / L \\
. / .\end{array}$ & $\begin{array}{l}\text { 124/ppb } \\
100 / 4000\end{array}$ & $\begin{array}{l}\text { 46/ppb } \\
.14000\end{array}$ \\
\hline (n) & $\cdots$ & . & $\cdots$ & $\ldots$ & 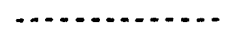 & $\cdots$ \\
\hline $699-41-40$ & $4 / 19 / 90$ & H0000052 & & & & 500.00 \\
\hline $699-49-40$ & $7 / 10 / 91$ & Ho0071Y1 & & & 790.00 & \\
\hline $699-41-40$ & $1 / 31 / 92$ & B010C8 & & & 700.00 & \\
\hline $699-41-40$ & $4 / 28 / 92$ & B065s5 & & & $700.00 \mathrm{D}$ & \\
\hline $699-41-40$ & $4 / 28 / 92$ & 806556 & & & $700.00 \mathrm{D}$ & \\
\hline $699-41-40$ & $6 / 24 / 92$ & $8062 \times 2$ & & & 700.00 & \\
\hline $699-41-40$ & $1 / 14 / 93$ & $807 \times 9$ & & & 600.00 & \\
\hline $699-41-42$ & $1 / 08 / 93$ & B07V59 & & & 600.00 & \\
\hline $699-42-37$ & $12 / 22 / 92$ & B077C4 & & & 700.00 & \\
\hline $699-42-37$ & $2 / 23 / 93$ & B08712 & & & 900.00 & \\
\hline $699-42-39 A$ & $1 / 23 / 92$ & $801 T 66$ & & & $600.00 \mathrm{P}$ & \\
\hline $699-42-39 A$ & $4 / 17 / 92$ & B065T1 & & & $900.00 \mathrm{P}$ & \\
\hline $699 \cdot 42 \cdot 39 A$ & $6 / 25 / 92$ & B062×7 & & & $700.00 \mathrm{P}$ & \\
\hline $699-42 \cdot 39 A$ & $10 / 21 / 92$ & B07JL3 & & & $700.00 \mathrm{P}$ & \\
\hline $699-42-39 A$ & $1 / 27 / 93$ & B07v64 & & & $800.00 P$ & \\
\hline $699-42-398$ & $1 / 23 / 92$ & B01T68 & & & 500.00 & \\
\hline $699-42-398$ & $4 / 17 / 92$ & $8065 T 6$ & & & 900.00 & \\
\hline $699-42-39 B$ & $6 / 25 / 92$ & B062Y2 & & & 700.00 & \\
\hline $699-42-39 B$ & $10 / 28 / 92$ & B07JJ2 & & & 800.00 & \\
\hline $699-42-398$ & $10 / 28 / 92$ & B07JJ3 & & & 800.00 & \\
\hline $699-42-39 B$ & $1 / 25 / 93$ & B07v69 & & & 700.00 & \\
\hline $699-42-40 A$ & $8 / 22 / 85$ & H0OODF 11 & & & & 620.00 \\
\hline $699-42-40 A$ & $5 / 12 / 86$ & H0OODF27 & & & & $500.00 \mathrm{U}$ \\
\hline $699-42-40 A$ & $8 / 05 / 86$ & H0000F33 & & & & $500.00 \mathrm{U}$ \\
\hline $699-42-40 A$ & $1 / 08 / 88$ & H0000F55 & & & & $500.00 \mathrm{U}$ \\
\hline $699-42-40 A$ & $11 / 22 / 88$ & $H 0000 F 60$ & & & & $500.00 \mathrm{U}$ \\
\hline $699-42-40 A$ & $2 / 15 / 89$ & $H 0000 F 65$ & & & & $500.00 \mathrm{U}$ \\
\hline $699-42-40 A$ & $5 / 31 / 89$ & HOOOOF 70 & & & & $500.00 \mathrm{U}$ \\
\hline $699-42-40 \mathrm{~A}$ & $8 / 10 / 89$ & HOOOOF 74 & & & & 500.00 \\
\hline $699-42-40 \mathrm{~A}$ & $1 / 26 / 90$ & HOOODF 78 & & & & $500.00 \mathrm{U}$ \\
\hline $699-42-40 A$ & $7 / 08 / 91$ & H0O071Y2 & & & 180.00 & \\
\hline $699-42-40 A$ & $1 / 23 / 92$ & 801061 & & & $100.00 \mathrm{U}$ & \\
\hline $699-42-40 A$ & $6 / 25 / 92$ & B062Y7 & & & 100.00 & \\
\hline $699-42-41$ & $1 / 24 / 92$ & B01T70 & & & $100.00 P$ & \\
\hline $699-42-41$ & 4/17/92 & B065V1 & & & $200.00 \mathrm{P}$ & \\
\hline $699-42-41$ & $6 / 29 / 92$ & 806222 & & & $100.00 \mathrm{PD}$ & \\
\hline $699-42-41$ & $1 / 25 / 93$ & B07724 & & & 100.00 UP & \\
\hline $699-42-428$ & $11 / 22 / 88$ & HOOODFT3 & & & & $500.00 \mathrm{U}$ \\
\hline $699-42-42 B$ & $2 / 24 / 89$ & HOOODFT7 & & & & $500.00 \mathrm{U}$ \\
\hline $699-42-42 B$ & $6 / 16 / 89$ & HOOODFVI & & & & 600.00 \\
\hline $699-42-42 B$ & $6 / 16 / 89$ & HOOODFV4 & & & & 600.00 \\
\hline $699-42-428$ & $8 / 09 / 89$ & H0OODFV5 & & & & $500.00 \mathrm{U}$ \\
\hline $699-42-42 B$ & $7 / 08 / 91$ & H00071Y3 & & & 560.00 & \\
\hline
\end{tabular}


(sheet 66 of ${ }^{\star *}$ )

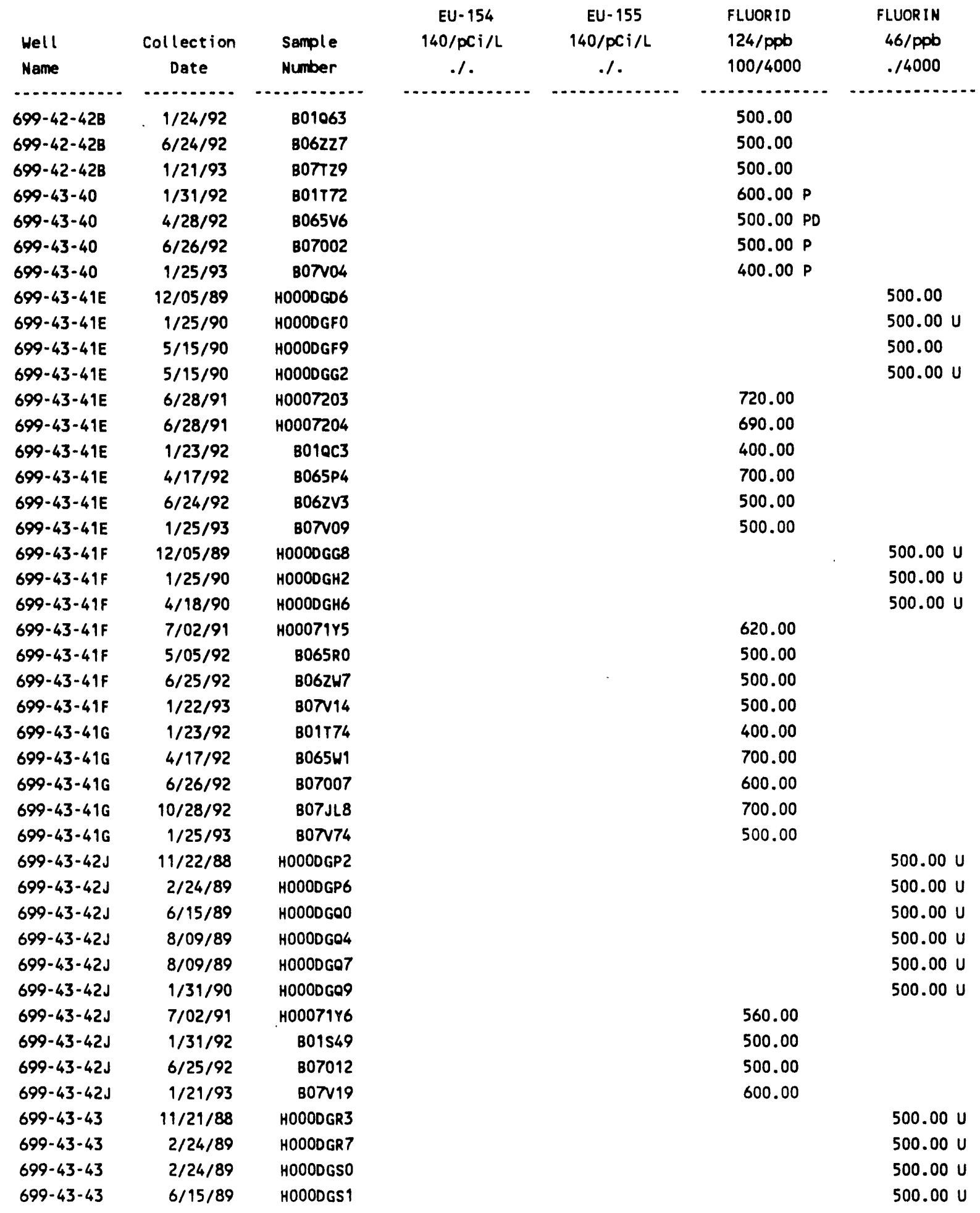


(sheet 67 of $\star$ )

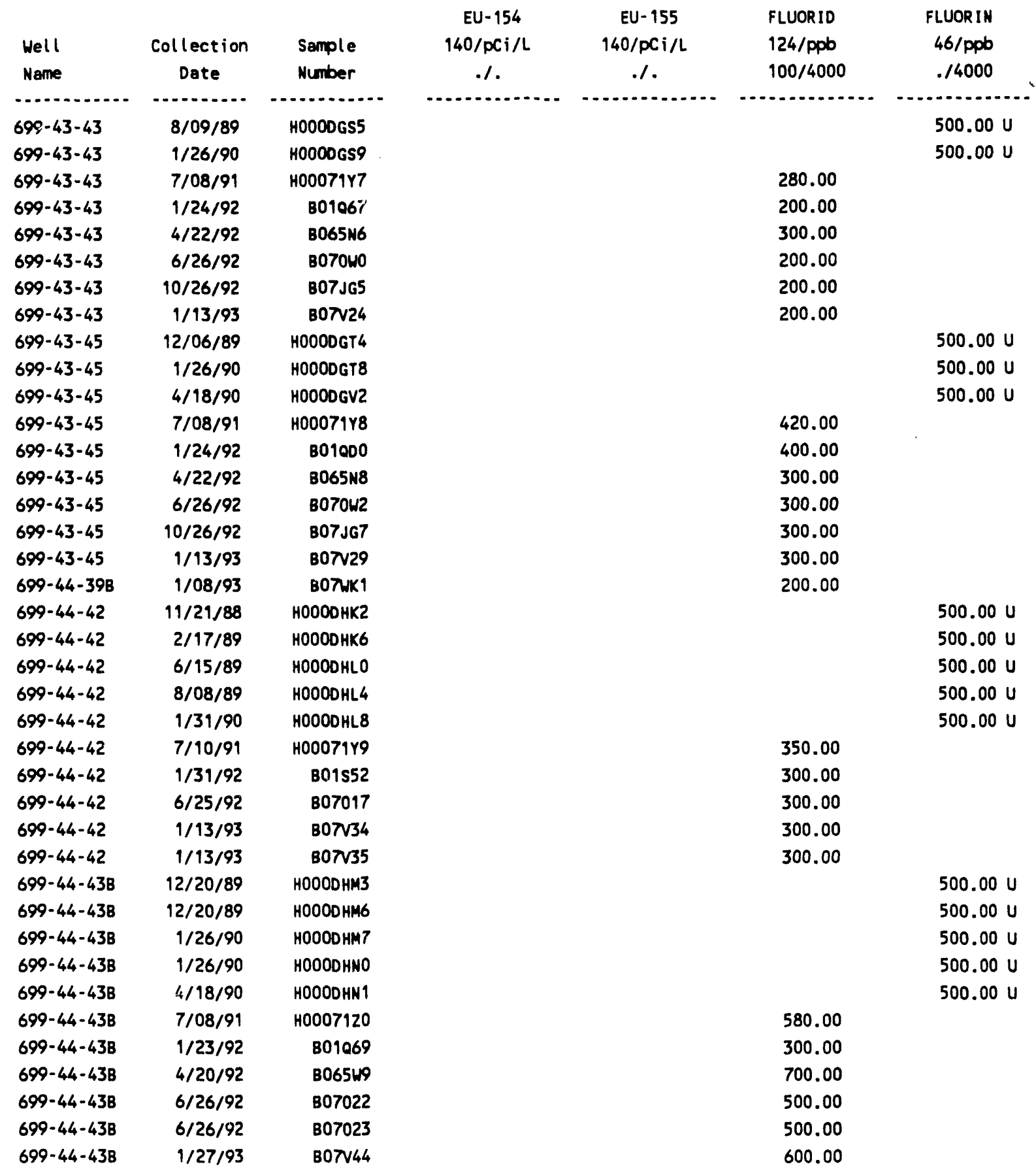


(sheet 68 of $\star$ )

\begin{tabular}{|c|c|c|c|c|c|c|}
\hline Well & Collection & Sample & $\begin{array}{c}\text { ALPHA } \\
135 / D C i / L\end{array}$ & $\begin{array}{l}\text { ALPHA } \\
\pi / D C i / L\end{array}$ & $\begin{array}{c}\text { BETA } \\
136 / \mathrm{pCi} / \mathrm{L}\end{array}$ & $\begin{array}{c}\text { BETA } \\
77 / \mathrm{pCi} / \mathrm{L}\end{array}$ \\
\hline Name & Date & Number &.$/ 15$ &.$/ 15$ &.$/ 50$ & .150 \\
\hline - & $\ldots$ & n. & (n) & n & (n) & -- \\
\hline $299-E 18-1$ & $8 / 16 / 88$ & H00072T7 & & 2.21 & & 3.89 \\
\hline 299-E18-1 & $11 / 10 / 88$ & H0007ZV2 & & 3.83 & & 8.45 \\
\hline 299-E18-1 & $11 / 10 / 88$ & H00072v5 & & 3.90 & & 10.70 \\
\hline 299-E18-1 & $2 / 15 / 89$ & H00072v8 & & 4.87 & & 6.85 \\
\hline 299-E18-1 & $5 / 26 / 89$ & H0007ZW2 & & 5.53 & & 6.58 \\
\hline 299-E18-1 & $8 / 08 / 89$ & H00072W6 & & 5.53 & & 7.46 \\
\hline 299-E18-1 & $10 / 31 / 89$ & $H 00072 \times 0$ & & 4.52 & & 8.50 \\
\hline 299-E18-1 & $9 / 06 / 91$ & BOOLB6 & 1.62 & & 6.29 & \\
\hline 299-E18-1 & $6 / 03 / 92$ & В06РH8 & 1.68 & & 7.49 & \\
\hline 299-E18-1 & $12 / 16 / 92$ & B07\$32 & 4.71 & & 8.46 & \\
\hline $299-E 32-4$ & $9 / 27 / 88$ & H0008ZB8 & & 4.59 & & 9.22 \\
\hline $299-E 32-4$ & $12 / 28 / 88$ & H00082C2 & & 2.09 & & 6.50 \\
\hline $299-E 32-4$ & $3 / 01 / 89$ & H00082C6 & & 4.25 & & 5.99 \\
\hline $299-E 32-4$ & $3 / 13 / 89$ & $H 0008200$ & & 5.89 & & 3.72 \\
\hline $299-E 32-4$ & $6 / 16 / 89$ & $\mathrm{H} 0008 \mathrm{ZD} 4$ & & 4.82 & & 9.12 \\
\hline $299-E 32-4$ & $7 / 19 / 89$ & H0008ZD8 & & 7.93 & & 10.00 \\
\hline $299-E 32-4$ & $9 / 08 / 89$ & H00082F6 & & 3.00 & & 6.57 \\
\hline 299-E32-4 & $1 / 17 / 90$ & $\mathrm{H} 00082 \mathrm{GO}$ & & 6.76 & & 5.31 \\
\hline $299-E 32-4$ & $5 / 09 / 90$ & H0008ZG9 & & 6.93 & & 8.81 \\
\hline 299-E32-4 & $8 / 05 / 91$ & 10007264 & 4.66 & & 10.10 & \\
\hline 299-E32-4 & $9 / 23 / 91$ & BOOLK5 & 5.85 & & 7.49 & \\
\hline $299-E 32-4$ & $1 / 15 / 92$ & B010K6 & 2.79 & & 7.19 & \\
\hline 299-E32-4 & $4 / 06 / 92$ & B06696 & 3.28 & & 4.46 & \\
\hline 299-E32-4 & $7 / 14 / 92$ & 807173 & 2.76 & & 6.82 & \\
\hline $699-40-36$ & $12 / 21 / 92$ & 807TB1 & 4.44 & & 8.24 & \\
\hline $699-40-36$ & $2 / 22 / 93$ & B08717 & 1.47 & & 8.77 & \\
\hline $699-40-39$ & $12 / 05 / 89$ & H00ODBX2 & & 3.74 & & 5.98 \\
\hline $699-40-39$ & $1 / 25 / 90$ & H0OODBX6 & & 2.62 & & 5.43 \\
\hline $699-40-39$ & $4 / 25 / 90$ & HOOOOBYO & & 3.13 & & 5.52 \\
\hline $699-40-39$ & $7 / 08 / 91$ & HOOOTIY4 & 1.88 & & 6.22 & \\
\hline $699-40-39$ & $9 / 11 / 91$ & B00LG1 & 2.09 & & 5.87 & \\
\hline $699-40-39$ & $1 / 31 / 92$ & $B 01065$ & 2.84 & & 4.47 & \\
\hline $699-40-39$ & $4 / 17 / 92$ & $B 065 P 2$ & 2.36 & & 4.32 & \\
\hline $699-40-39$ & $6 / 24 / 92$ & B062T7 & 1.79 & & 3.33 & \\
\hline $699-40-39$ & $1 / 14 / 93$ & $8077 \times 4$ & 3.27 & & 5.08 & \\
\hline $699-40-40 \mathrm{~A}$ & $1 / 24 / 92$ & 801т62 & 2.89 & & 7.44 & \\
\hline $699-40-40 \mathrm{~A}$ & $4 / 22 / 92$ & B06508 & $.49 \mathrm{U}$ & & 5.27 & \\
\hline $699-40-40 \mathrm{~A}$ & $6 / 25 / 92$ & B062V2 & 1.80 & & 6.73 & \\
\hline $699-40-40 \mathrm{~A}$ & $10 / 21 / 92$ & B07JK3 & $1.07 \mathrm{U}$ & & 5.61 & \\
\hline $699-40-40 \mathrm{~A}$ & $1 / 26 / 93$ & $807 \times 49$ & $.11 \mathrm{U}$ & & 7.14 & \\
\hline $699-40-40 B$ & $1 / 24 / 92$ & $801 T 64$ & 5.87 & & 13.10 & \\
\hline $699-40-40 B$ & $4 / 22 / 92$ & 806550 & 1.69 & & 4.72 & \\
\hline $699-40-408$ & $6 / 29 / 92$ & B062W2 & $.89 \mathrm{U}$ & & 4.37 & \\
\hline
\end{tabular}


(sheet 69 of $* *$ )

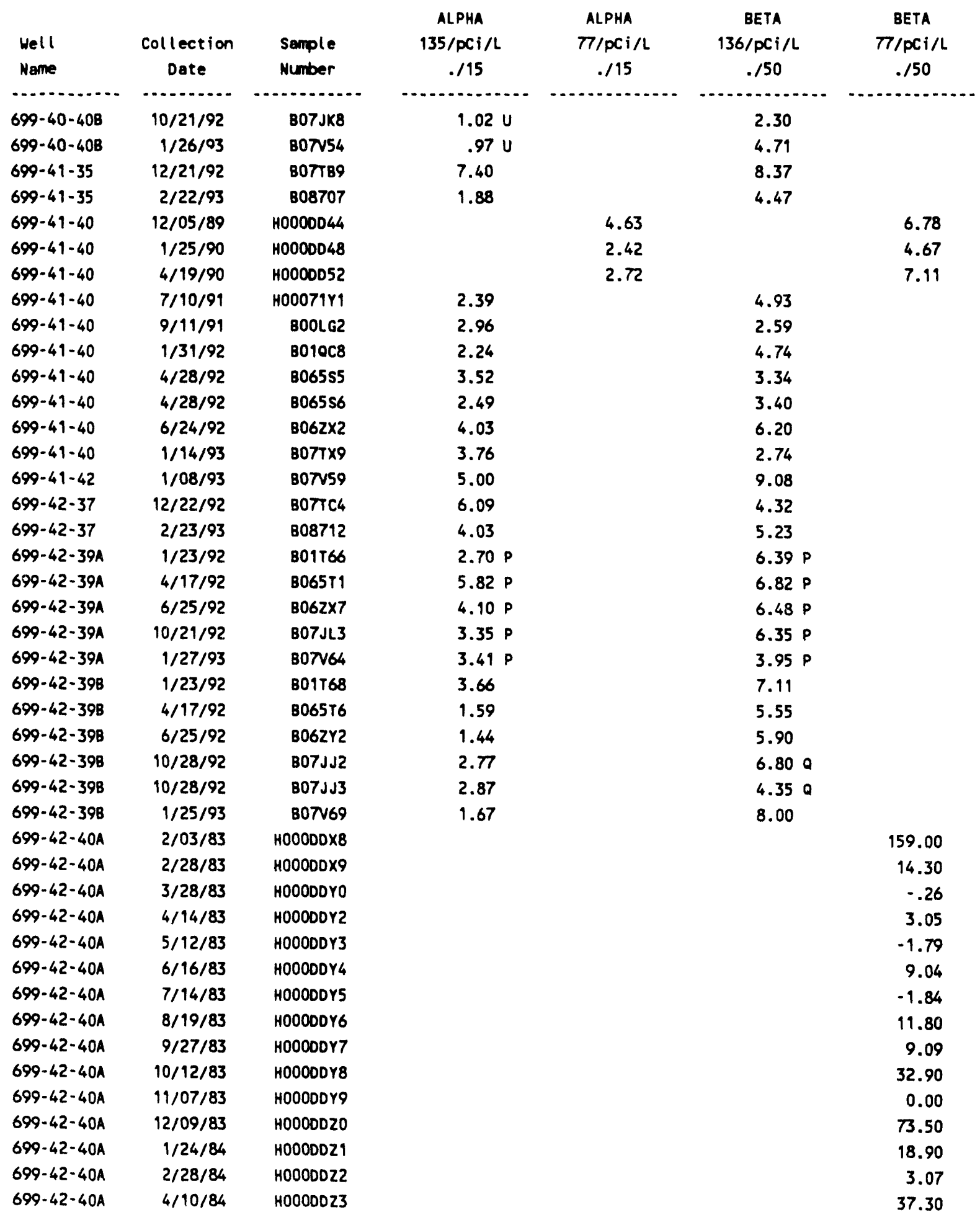


(sheet 70 of $\star *$ )

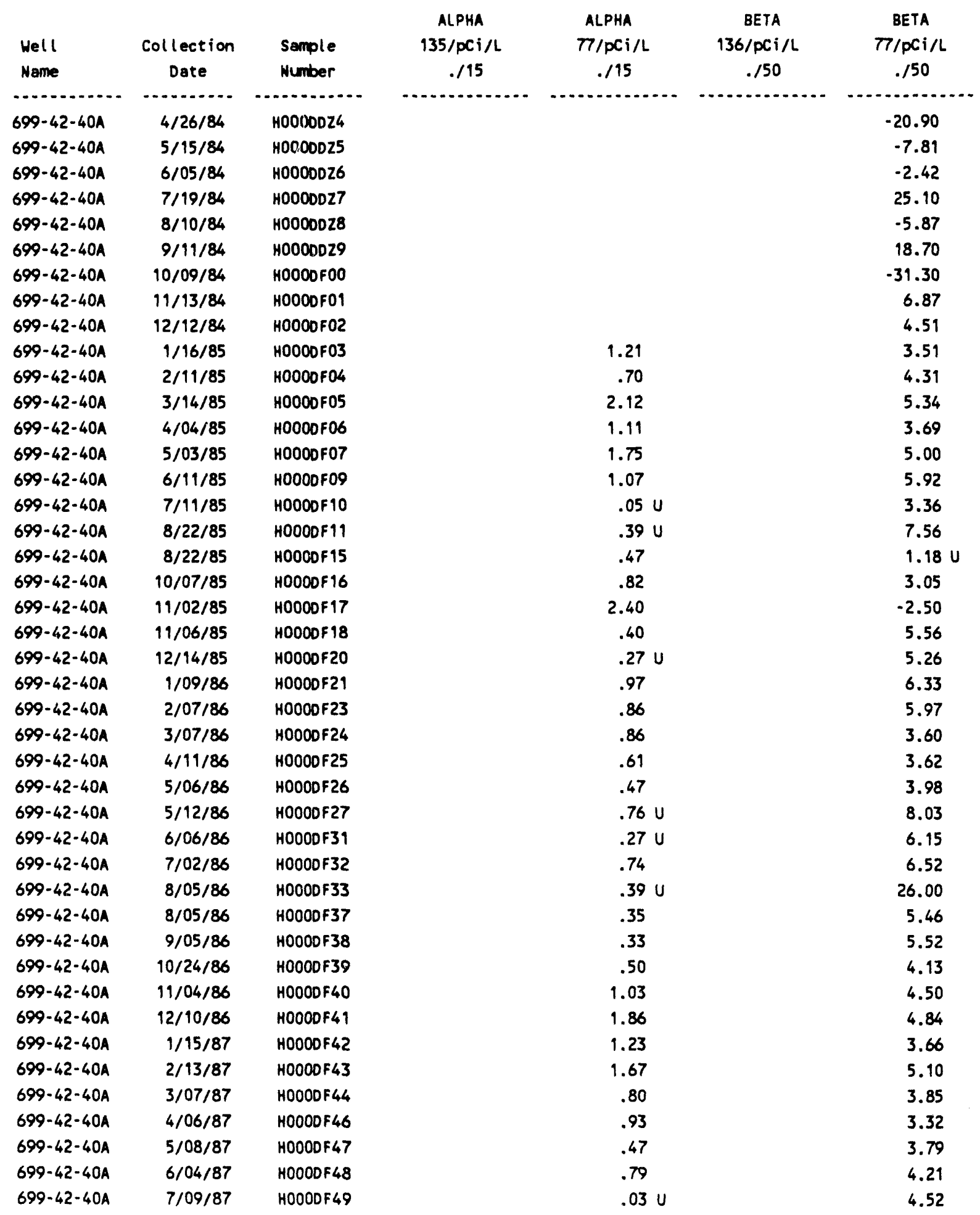


(sheet 71 of $\star *$ )

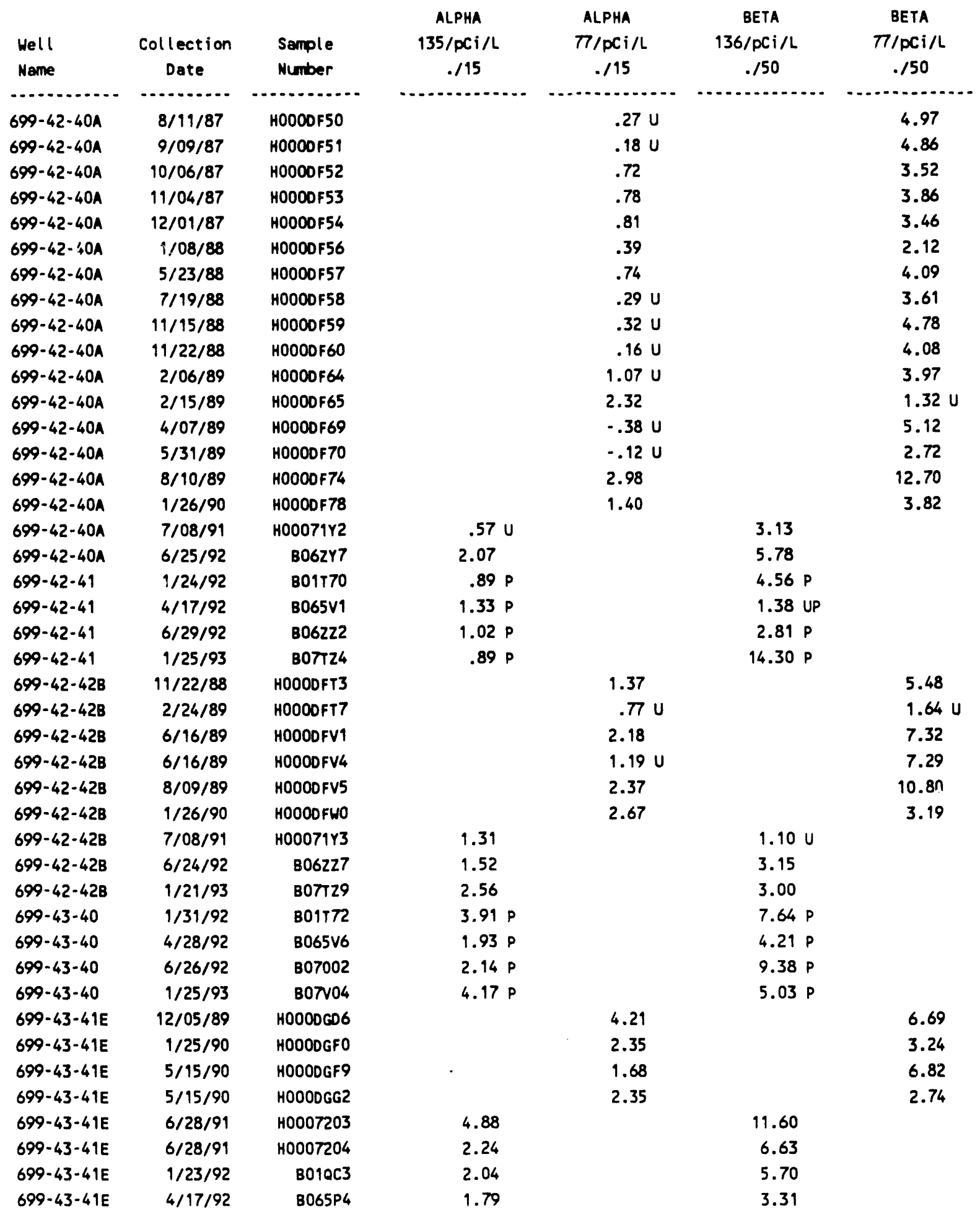


(sheet 72 of $\star \star$ )

\begin{tabular}{|c|c|c|c|c|c|c|}
\hline $\begin{array}{l}\text { Hell } \\
\text { Name }\end{array}$ & $\begin{array}{c}\text { Collection } \\
\text { Date }\end{array}$ & $\begin{array}{l}\text { Sample } \\
\text { Number }\end{array}$ & $\begin{array}{c}\text { ALPHA } \\
135 / \text { pCi/L } \\
. / 15\end{array}$ & $\begin{array}{c}\text { ALPHA } \\
\text { 77/PCi/L } \\
.115\end{array}$ & $\begin{array}{c}\text { BETA } \\
136 / \text { PCi } / L \\
.150\end{array}$ & $\begin{array}{c}\text { BETA } \\
77 / \mathrm{pCi} / \mathrm{L} \\
.150\end{array}$ \\
\hline - n & - & n & 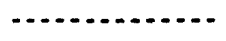 & 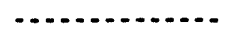 & 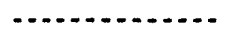 & . \\
\hline $699-43-41 E$ & $6 / 24 / 92$ & B062V3 & 1.94 & & 7.13 & \\
\hline $699-43-41 E$ & $1 / 25 / 93$ & BOTV09 & 2.33 & & 6.01 & \\
\hline $699-43-41 F$ & $12 / 05 / 89$ & HOOOOGG8 & & 3.11 & & 10.20 \\
\hline $699-43-41 F$ & $1 / 25 / 90$ & HOOOOGH2 & & 2.09 & & $2.19 \mathrm{U}$ \\
\hline $699-43-41 F$ & $4 / 18 / 90$ & HOOODGH6 & & 4.44 & & 5.94 \\
\hline $699-43-41 F$ & $7 / 02 / 91$ & H00071Y5 & 2.86 & & 5.48 & \\
\hline $699-43-41 F$ & $5 / 05 / 92$ & B065RO & 2.23 & & $2.13 \mathrm{U}$ & \\
\hline $699-43-41 F$ & $6 / 25 / 92$ & B062W7 & 2.78 & & 3.45 & \\
\hline $699-43-41 F$ & $1 / 22 / 93$ & Bo7v14 & 1.79 & & 3.21 & \\
\hline $699-43-416$ & $1 / 23 / 92$ & B01T74 & 2.15 & & 10.80 & \\
\hline $699-43-410$ & $4 / 17 / 92$ & 8065W1 & 2.41 & & 3.73 & \\
\hline $699-43-41 G$ & $6 / 26 / 92$ & 807007 & 2.14 & & 4.93 & \\
\hline $699-43-410$ & $10 / 28 / 92$ & B07JL8 & $.96 \mathrm{U}$ & & 4.60 & \\
\hline $699-43-416$ & $1 / 25 / 93$ & Bo7v74 & 2.69 & & 7.00 & \\
\hline $699-43-42 \mathrm{~J}$ & $11 / 22 / 88$ & HOOODGP2 & & $.71 \mathrm{U}$ & & 8.01 \\
\hline $699-43-42 J$ & $2 / 24 / 89$ & HOOODGPG & & 2.34 & & 4.52 \\
\hline $699-43-42 J$ & $6 / 15 / 89$ & HOOODGOO & & 1.62 & & 7.18 \\
\hline $699-43-42 J$ & $8 / 09 / 89$ & H0OOOCO4 & & 1.03 & & 5.85 \\
\hline $699-43-42 J$ & $8 / 09 / 89$ & HOOOOGQ7 & & 1.91 & & 5.57 \\
\hline $699-43-42 \mathrm{~J}$ & $1 / 31 / 90$ & H0000GQ9 & & $.20 \mathrm{U}$ & & 4.02 \\
\hline $699-43-42 \mathrm{~J}$ & $7 / 02 / 91$ & H00071Y6 & 1.74 & & 4.29 & \\
\hline $699-43-42 \mathrm{~J}$ & $1 / 31 / 92$ & 801549 & $.64 \mathrm{U}$ & & 2.30 & \\
\hline $699-43-42 J$ & $6 / 25 / 92$ & B07012 & 2.25 & & 4.35 & \\
\hline $699-43-42 \mathrm{~J}$ & $1 / 21 / 93$ & B0T19 & 2.87 & & 4.56 & \\
\hline $699-43-43$ & $11 / 21 / 88$ & HOOOOGR3 & & .96 & & 7.05 \\
\hline $699-43-43$ & $2 / 24 / 89$ & HOOOOGR7 & & $.30 \mathrm{U}$ & & 3.99 \\
\hline $699-43-43$ & $2 / 24 / 89$ & HOOODGSO & & $.41 \mathrm{U}$ & & 4.23 \\
\hline $699-43-43$ & $6 / 15 / 89$ & HOOODGS1 & & $-.04 \mathrm{U}$ & & 4.08 \\
\hline $699-43-43$ & $8 / 09 / 89$ & H0OODGS5 & & $.53 U$ & & 11.90 \\
\hline $699-43-43$ & $1 / 26 / 90$ & HOOODGSO & & $.64 \mathrm{U}$ & & 6.29 \\
\hline $699-43-43$ & $7 / 08 / 91$ & H00071Y7 & .97 & & 4.82 & \\
\hline $699-43-43$ & $1 / 24 / 92$ & 801T83 & 1.51 & & 6.02 & \\
\hline $699-43-43$ & $4 / 22 / 92$ & B065N6 & 2.17 & & 3.22 & \\
\hline $699-43-43$ & $6 / 26 / 92$ & BO70wO & 1.16 & & 5.50 & \\
\hline $699-43-43$ & $10 / 26 / 92$ & B07JG5 & 1.66 & & 8.02 & \\
\hline $699-43-43$ & $1 / 13 / 93$ & BorN24 & $.74 \mathrm{U}$ & & 6.64 & \\
\hline $699-43-45$ & $12 / 06 / 89$ & HOOODGT4 & & 2.59 & & 6.86 \\
\hline $699-43-45$ & $1 / 26 / 90$ & H0000GT8 & & 1.47 & & 5.84 \\
\hline $699-43-45$ & $4 / 18 / 90$ & HOOODGV2 & & 1.97 & & 6.60 \\
\hline $699-43-45$ & $7 / 08 / 91$ & H00071Y8 & 1.03 & & 4.67 & \\
\hline $699-43-45$ & $9 / 11 / 91$ & B00LG5 & $.69 \mathrm{U}$ & & 6.36 & \\
\hline $699-43-45$ & $1 / 24 / 92$ & $B 01000$ & $.81 \mathrm{U}$ & & $1.69 \mathrm{U}$ & \\
\hline $699-43-45$ & $4 / 22 / 92$ & B065N8 & 1.96 & & 4.18 & \\
\hline
\end{tabular}


(sheet 73 of $*$ )

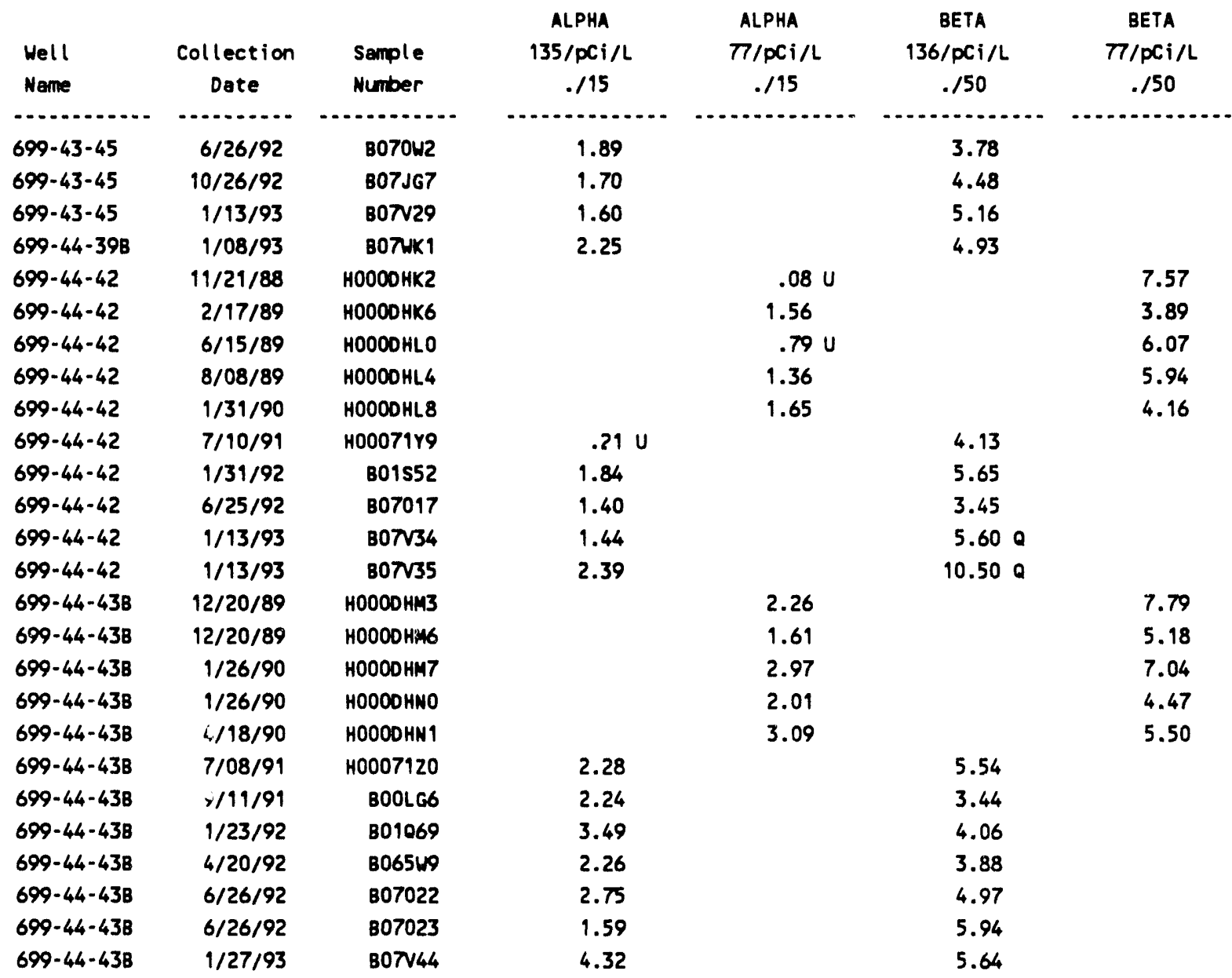

\begin{tabular}{|c|c|c|c|c|c|c|}
\hline & & & I-129 & IRON & IRON & FIRON \\
\hline $\begin{array}{l}\text { Well } \\
\text { Name }\end{array}$ & $\begin{array}{c}\text { Collection } \\
\text { Date }\end{array}$ & $\begin{array}{l}\text { Sample } \\
\text { Number }\end{array}$ & $\begin{array}{c}139 / \mathrm{pC} \mathrm{i} / \mathrm{L} \\
. /\end{array}$ & $\begin{array}{r}34 / p p b \\
20 / 300 s\end{array}$ & $\begin{array}{l}35 / p p b \\
. / 300 \mathrm{~s}\end{array}$ & $\begin{array}{l}34 / \mathrm{ppb} \\
20 / 300 \mathrm{~s}\end{array}$ \\
\hline . & $\cdots$ & - n & (n. & $\cdots$ & n......... & (n) \\
\hline 299-E18-1 & $8 / 16 / 88$ & но0072T7 & & & 1250.00 & \\
\hline 299-E18-1 & $8 / 16 / 88$ & H00072T7 & & & & 33.00 \\
\hline 299-E18-1 & $9 / 22 / 88$ & H0007ZV1 & & & 1810.00 & \\
\hline 299-E18-1 & $9 / 22 / 88$ & HoOOZZVI & & & & $30.00 \mathrm{U}$ \\
\hline 299-E18-1 & $11 / 10 / 88$ & H00072V2 & & . & 355.00 & \\
\hline 299-E 18-1 & $11 / 10 / 88$ & H0OOTZV2 & & & & $30.00 \mathrm{U}$ \\
\hline 299-E18-1 & $11 / 10 / 88$ & H00072V5 & & & 265.00 & \\
\hline 299-E18-1 & $11 / 10 / 88$ & H00072V5 & & & & $30.00 \mathrm{U}$ \\
\hline $299-E 18-1$ & $2 / 15 / 89$ & H0007ZV8 & & & 162.00 & \\
\hline 299-E18-1 & $2 / 15 / 89$ & H00072v8 & & & & $30.00 \mathrm{u}$ \\
\hline
\end{tabular}


(sheet 74 of $\star$ )

\begin{tabular}{|c|c|c|}
\hline $\begin{array}{l}\text { Well } \\
\text { Name }\end{array}$ & $\begin{array}{c}\text { Collection } \\
\text { Date }\end{array}$ & $\begin{array}{l}\text { Sample } \\
\text { Number }\end{array}$ \\
\hline , & & \\
\hline 299-E18-1 & $5 / 26 / 89$ & H0007ZH2 \\
\hline 299-E18-1 & $5 / 26 / 89$ & H0007ZW2 \\
\hline 299-E18-1 & $8 / 08 / 39$ & H0007ZW6 \\
\hline 299-E18-1 & $8 / 08 / 89$ & H0007ZH6 \\
\hline 299-E18-1 & $10 / 31 / 89$ & H0007ZXO \\
\hline $299-E 18-1$ & $10 / 31 / 89$ & H0007ZXO \\
\hline 299-E18-1 & $7 / 09 / 91$ & H00071X9 \\
\hline 299-E18-1 & $7 / 09 / 91$ & H00071X9F \\
\hline 299-E18-1 & $9 / 06 / 91$ & B00LB6 \\
\hline 299-E18-1 & $9 / 06 / 91$ & B00LB6F \\
\hline 299-E18-1 & $1 / 24 / 92$ & 801059 \\
\hline 299-E18-1 & $1 / 24 / 92$ & B01060 \\
\hline 299-E18-1 & $6 / 03 / 92$ & B06PC7 \\
\hline 299-E18-1 & $6 / 03 / 92$ & B06PH8 \\
\hline 299-E18-1 & $6 / 03 / 92$ & B06PJ2 \\
\hline 299-E18-1 & $12 / 16 / 92$ & 807532 \\
\hline $249-E 18-1$ & $12 / 16 / 92$ & 807536 \\
\hline $299-E 32-4$ & $9 / 27 / 88$ & H0008ZB8 \\
\hline $299-E 32-4$ & $9 / 27 / 88$ & H0008ZB8 \\
\hline $299-E 32-4$ & $12 / 28 / 88$ & H0008ZC2 \\
\hline $299-E 32-4$ & $12 / 28 / 88$ & H0008ZC2 \\
\hline 299-E32-4 & $3 / 01 / 89$ & H00082C6 \\
\hline $299-E 32-4$ & $3 / 01 / 89$ & H00082C6 \\
\hline 299-E32-4 & $3 / 13 / 89$ & $H 0008200$ \\
\hline $299-E 32-4$ & $3 / 13 / 89$ & HOOOBZDO \\
\hline $299-E 32-4$ & $6 / 16 / 89$ & H0008204 \\
\hline $299-E 32-4$ & $6 / 16 / 89$ & H00082D4 \\
\hline $299-E 32-4$ & $7 / 19 / 89$ & H0008ZD8 \\
\hline $299-E 32-4$ & $7 / 19 / 89$ & H0008208 \\
\hline $299-E 32-4$ & $9 / 08 / 89$ & H00082F6 \\
\hline 299-E32-4 & $9 / 08 / 89$ & H00082F6 \\
\hline $299-E 32-4$ & $1 / 17 / 90$ & H00082GO \\
\hline $299-E 32-4$ & $1 / 17 / 90$ & HOOOBZGO \\
\hline $299-E 32-4$ & $8 / 05 / 91$ & HOOOTIYO \\
\hline $299-E 32-4$ & $8 / 05 / 91$ & HOOO71YOF \\
\hline 299-E32-4 & $8 / 05 / 91$ & 40007264 \\
\hline $299-E 32-4$ & $8 / 05 / 91$ & H0007264F \\
\hline $299-E 32-4$ & $9 / 23 / 91$ & B0OLK5 \\
\hline $299-E 32-4$ & $9 / 23 / 91$ & B00LK5F \\
\hline 299-E32-4 & $1 / 15 / 92$ & B010K6 \\
\hline 299-E32-4 & $1 / 15 / 92$ & $8010 K 8$ \\
\hline 299-E32-4 & $4 / 06 / 92$ & B06696 \\
\hline 299-E32-4 & 4/06/92 & B06697 \\
\hline
\end{tabular}

\begin{tabular}{|c|c|c|c|}
\hline $1-129$ & IRON & IRON & FIRON \\
\hline $139 / \mathrm{DCi} / \mathrm{L}$ & $34 / \mathrm{ppb}$ & 35/ppb & $34 / \mathrm{ppb}$ \\
\hline .1 & $20 / 300 \mathrm{~s}$ &.$/ 300 \mathrm{~s}$ & $20 / 300 \mathrm{~s}$ \\
\hline \multirow{13}{*}{ (n) } & . & n. & - \\
\hline & & 546.00 & \\
\hline & & & $30.00 \mathrm{U}$ \\
\hline & & 531.00 & \\
\hline & & & $30.00 \mathrm{U}$ \\
\hline & & 802.00 & \\
\hline & & & 35.00 \\
\hline & 1100.00 & & \\
\hline & & & 49.00 \\
\hline & 600.00 & & \\
\hline & & & 31.00 \\
\hline & $430.00 \mathrm{D}$ & & \\
\hline & & & 40.000 \\
\hline \multirow[t]{31}{*}{$-.10 \mathrm{U}$} & & & \\
\hline & 290.00 & & \\
\hline & & & 56.00 \\
\hline & 910.00 & & \\
\hline & & & 30.00 \\
\hline & & 123.00 & \\
\hline & & & 34.00 \\
\hline & & 197.00 & \\
\hline & & & $30.00 \mathrm{U}$ \\
\hline & & 299.00 & \\
\hline & & & $30.00 \mathrm{U}$ \\
\hline & & 267.00 & \\
\hline & & & 41.00 \\
\hline & & 899.00 & \\
\hline & & & $30.00 \mathrm{U}$ \\
\hline & & 368.00 & \\
\hline & & & 32.00 \\
\hline & & 399.00 & \\
\hline & & & $30.00 \mathrm{U}$ \\
\hline & & 844.00 & \\
\hline & & & 38.00 \\
\hline & $1700.00 \mathrm{D}$ & & \\
\hline & & & 78.00 \\
\hline & $1400.00 Q D$ & & \\
\hline & & & $200.00 Q$ \\
\hline & 300.00 & & \\
\hline & & & 24.00 \\
\hline & 550.000 & & \\
\hline & & & $33.00 Q$ \\
\hline & 190.00 & & \\
\hline & & & $20.00 \mathrm{U}$ \\
\hline
\end{tabular}


(sheet $\pi$ of $\star *$ )

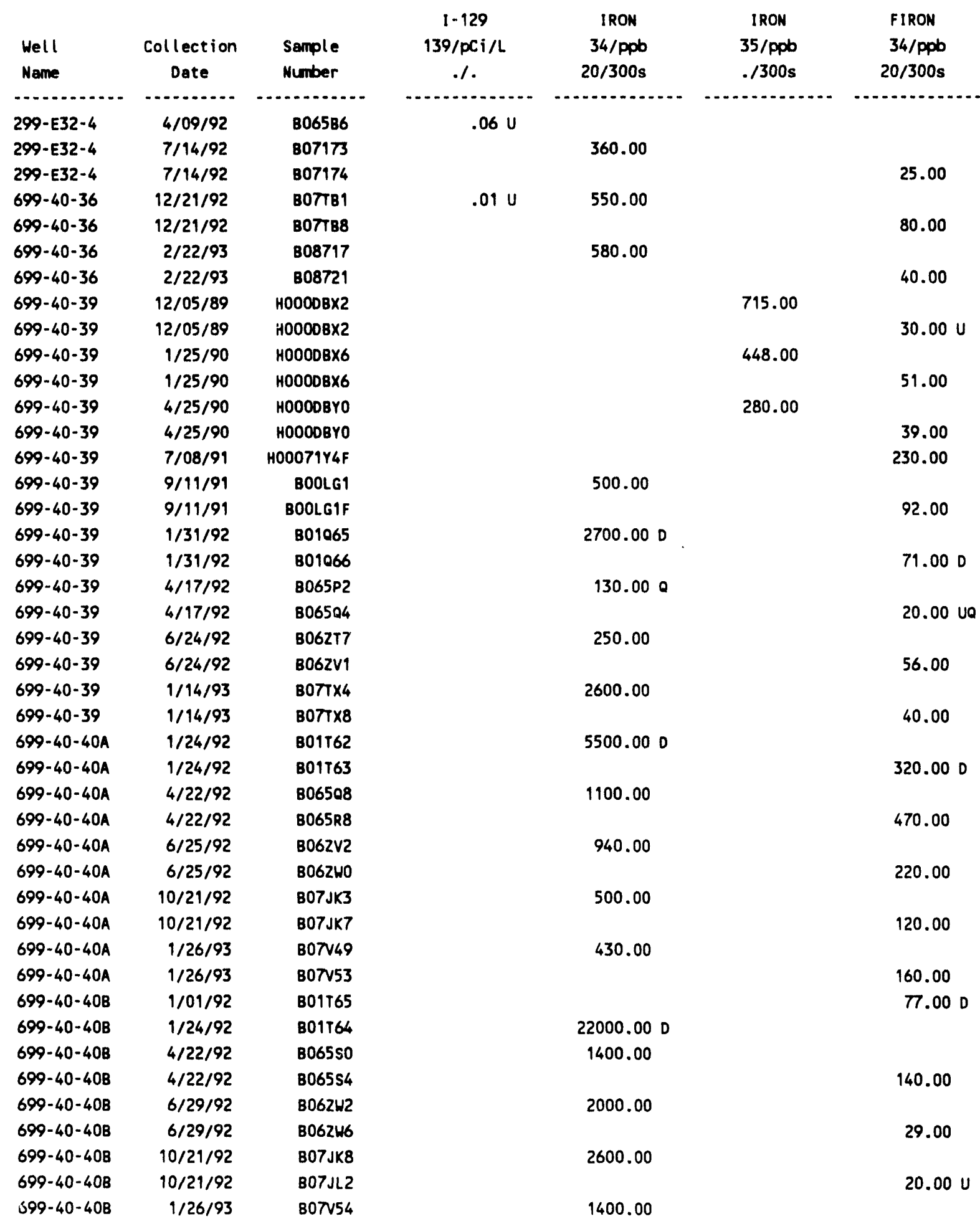


(sheet 76 of **)

\begin{tabular}{|c|c|c|c|c|c|c|}
\hline Hell & Collection & Sample & $\begin{array}{c}1 * 129 \\
139 / p C i / L\end{array}$ & $\begin{array}{c}\text { IRON } \\
34 / p p b\end{array}$ & $\begin{array}{c}\text { IRON } \\
35 / \mathrm{ppb}\end{array}$ & $\begin{array}{l}\text { FIRON } \\
34 / \mathrm{ppb}\end{array}$ \\
\hline Name & Date & Number & .1 & $20 / 300 \mathrm{~s}$ &.$/ 300 \mathrm{~s}$ & $20 / 300 \mathrm{~s}$ \\
\hline - & $\cdots$ & (n) & and & 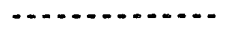 & (n) & 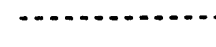 \\
\hline $699-40-40 B$ & $1 / 26 / 93$ & 807N58 & & & & 100.00 \\
\hline $699-41-35$ & $12 / 21 / 92$ & B07т89 & $-.03 \mathrm{U}$ & 300.00 & & \\
\hline $699-49-35$ & $12 / 21 / 92$ & B07TC3 & & & & $20.00 \mathrm{U}$ \\
\hline $699-41-35$ & $2 / 22 / 93$ & B08707 & & 270.00 & & \\
\hline $69 y-41-35$ & $2 / 22 / 93$ & B08711 & & & & 30.00 \\
\hline $699-41-40$ & $12 / 05 / 89$ & $H 0000044$ & & & 98.00 & \\
\hline $699-41-40$ & $12 / 05 / 89$ & $H 0000044$ & & & & $30.00 \mathrm{U}$ \\
\hline $699-41-40$ & $1 / 25 / 90$ & $H 0000048$ & & & 795.00 & \\
\hline $699-41-40$ & $1 / 25 / 90$ & 10000048 & & & & 47.00 \\
\hline $699-41-40$ & $4 / 19 / 90$ & H0000052 & & & 499.00 & \\
\hline $699-41-40$ & $4 / 19 / 90$ & H0000052 & & & & 164.00 \\
\hline $699-41-40$ & $7 / 10 / 91$ & H00071Y1 & & 650.00 & & \\
\hline $699-41-40$ & $7 / 10 / 91$ & H0007IY1F & & & & 140.00 \\
\hline $699-41-40$ & $9 / 11 / 91$ & BOOLG2 & & 570.00 & & \\
\hline $699-41-40$ & $9 / 11 / 91$ & BOOLG2F & & & & 66.00 \\
\hline $699-41-40$ & $1 / 71 / 92$ & B010C8 & & 2700.000 & & \\
\hline $699-41-40$ & $1 / 31 / 92$ & B010C9 & & & & 63.000 \\
\hline $699-41-40$ & $4 / 28 / 92$ & B065S5 & & 250.00 & & \\
\hline $699-41-40$ & $4 / 28 / 92$ & B06556 & & 270.00 & & \\
\hline $699-49-40$ & $4 / 28 / 92$ & B065S9 & & & & $20.00 \mathrm{U}$ \\
\hline $699-41-40$ & $4 / 28 / 92$ & B065TO & & & & $20.00 \mathrm{U}$ \\
\hline $699-49-40$ & $6 / 24 / 92$ & B062X2 & & 370.00 & & \\
\hline $699-41-40$ & $6 / 24 / 92$ & $8062 \times 6$ & & & & 21.00 \\
\hline $699-41-40$ & $1 / 14 / 93$ & $8077 \times 9$ & & 1200.00 & & \\
\hline $699-41-40$ & $1 / 14 / 93$ & B07TY3 & & & & $20.00 \mathrm{U}$ \\
\hline $699-41-42$ & $1 / 08 / 93$ & Bo7v59 & & 360.00 & & \\
\hline $699-41-42$ & $1 / 08 / 93$ & B07V63 & & & & 30.00 \\
\hline $699-42-37$ & $12 / 22 / 92$ & B07TC4 & .43 & 1200.00 & & \\
\hline $699-42-37$ & $12 / 22 / 92$ & B07TC8 & & & & 60.00 \\
\hline $699-42-37$ & $2 / 23 / 93$ & B08712 & & 870.00 & & \\
\hline $699-42-37$ & $2 / 23 / 93$ & B08716 & & & & 40.00 \\
\hline $699-42-39 A$ & $1 / 23 / 92$ & B01T66 & & $910.00 \mathrm{P}$ & & \\
\hline $699-42-39 A$ & $1 / 23 / 92$ & B01T67 & & & & $25.00 \mathrm{P}$ \\
\hline $699-42-39 A$ & $4 / 17 / 92$ & B065T1 & & $5300.00 \mathrm{PQ}$ & & \\
\hline $699-42-39 A$ & $4 / 17 / 92$ & B065TS & & & & 20.00 UP \\
\hline $699-42-39 A$ & $6 / 25 / 92$ & $8062 \times 7$ & & $4000.00 P$ & & \\
\hline $699-42-39 A$ & $6 / 25 / 92$ & B06ZY1 & & & & $47.00 \mathrm{P}$ \\
\hline $699-42-39 A$ & $10 / 21 / 92$ & - B07JL3 & & $4300.00 \mathrm{P}$ & & \\
\hline $699-42-39 A$ & $10 / 21 / 92$ & BOTJL7 & & & & $80.00 P$ \\
\hline $699-42-39 A$ & $1 / 27 / 93$ & B07v64 & & $1800.00 \mathrm{P}$ & & \\
\hline $699-42-39 A$ & $1 / 27 / 93$ & BOTV68 & & & & $20.00 \mathrm{UF}$ \\
\hline $699-42-39 B$ & $1 / 23 / 92$ & B01T68 & & 1900.00 & & \\
\hline $699-42-398$ & $1 / 23 / 92$ & B01T69 & & & & 150.00 \\
\hline
\end{tabular}


(sheet 77 of $* *$ )

\begin{tabular}{|c|c|c|c|c|c|c|}
\hline Well & Collection & Sample & $\begin{array}{c}1-129 \\
139 / \mathrm{pCi} / L\end{array}$ & $\begin{array}{c}\text { IRON } \\
34 / \mathrm{ppb}\end{array}$ & $\begin{array}{c}\text { IRON } \\
\text { 35/ppb }\end{array}$ & $\begin{array}{l}\text { FIRON } \\
\text { 34/ppb }\end{array}$ \\
\hline Name & Date & Number & .1 & $20 / 300 \mathrm{~s}$ & $.1300 \mathrm{~s}$ & $20 / 300$ s \\
\hline - & 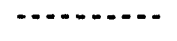 & n & . & - & - & . \\
\hline $699-42-398$ & $4 / 17 / 92$ & B065T6 & & 2600.00 & & \\
\hline $699-42-398$ & $4 / 17 / 92$ & B065Vo & & & & 20.00 Ua \\
\hline $699-42-398$ & $6 / 25 / 92$ & B06zY2 & & 1600.00 & & \\
\hline $699-42-398$ & $6 / 25 / 92$ & $8062 Y 6$ & & & & 64.00 \\
\hline $699-42-398$ & $10 / 28 / 92$ & B07JJ2 & & 560.00 & & \\
\hline $699-42-393$ & $10 / 28 / 92$ & $807 J J 3$ & & 580.00 & & \\
\hline $699-42-398$ & $10 / 28 / 92$ & $807 J J 6$ & & & & $30.00 \mathrm{OF}$ \\
\hline $699-42-39 B$ & $10 / 28 / 92$ & B07JJ7 & & & & $310.00 \mathrm{QF}$ \\
\hline $699-42-39 B$ & $1 / 25 / 93$ & B07N69 & & 1100.00 & & \\
\hline $699-42-39 B$ & $1 / 25 / 93$ & B07v73 & & & & $20.00 \mathrm{U}$ \\
\hline $699-42-40 A$ & $8 / 22 / 85$ & HOOODF11 & & & 610.00 & \\
\hline $699-42-40 A$ & $5 / 12 / 86$ & H00ODF27 & & & 184.00 & \\
\hline $699-42-40 A$ & $8 / 05 / 86$ & H000DF33 & & & 433.00 & \\
\hline $699-42-40 A$ & $1 / 08 / 88$ & H0000F55 & & & 155.00 & \\
\hline $699-42-40 A$ & $1 / 08 / 88$ & H0OODF55 & & & & 171.00 \\
\hline $699-42-40 A$ & $11 / 22 / 88$ & HOOODF60 & & & 309.00 & \\
\hline $699-42-40 A$ & $11 / 22 / 88$ & $H 0000 F 60$ & & & & 57.00 \\
\hline $699-42-40 A$ & $2 / 15 / 89$ & H0000F65 & & & 130.00 & \\
\hline $699-42-40 A$ & $2 / 15 / 89$ & $H 0000 F 65$ & & & & 53.00 \\
\hline $699-42-40 A$ & $5 / 31 / 89$ & HOOODF70 & & & 124.00 & \\
\hline $699-42-40 A$ & $5 / 31 / 89$ & HOOODF 70 & & & & 46.00 \\
\hline $699-42-40 \mathrm{~A}$ & $8 / 10 / 89$ & H0OODF 74 & & & 521.00 & \\
\hline $699-42-40 A$ & $8 / 10 / 89$ & H000DF74 & & & & 44.00 \\
\hline $699-42-40 A$ & $1 / 26 / 90$ & HOOODF78 & & & 175.00 & \\
\hline $699-42-40 \mathrm{~A}$ & $1 / 26 / 90$ & HOOODF78 & & & & 49.00 \\
\hline $699-42-40 A$ & $7 / 08 / 91$ & H00071Y2 & & 1100.00 & & \\
\hline $699-42-40 \mathrm{~A}$ & $7 / 08 / 91$ & H00071Y2F & & & & 70.00 \\
\hline $699-42-40 \mathrm{~A}$ & $1 / 08 / 92$ & B07TY8 & & 4600.00 & & \\
\hline $699-42-40 A$ & $1 / 08 / 92$ & B07T23 & & & & 180.00 \\
\hline $699-42-40 A$ & $1 / 23 / 92$ & B01061 & & 22000.00 & & \\
\hline $699-42-40 A$ & $1 / 23 / 92$ & B01062 & & & & 63.00 \\
\hline $699-42-40 A$ & $6 / 25 / 92$ & B062Y7 & & 6900.00 & & \\
\hline $699-42-40 \mathrm{~A}$ & $6 / 25 / 92$ & B06221 & & & & 190.00 \\
\hline $699-42-41$ & $1 / 24 / 92$ & B01T70 & & $910.00 \mathrm{PD}$ & & \\
\hline $699-42-41$ & $1 / 24 / 92$ & B01T71 & & & & $23.00 \mathrm{PD}$ \\
\hline $699-42-41$ & $4 / 17 / 92$ & $8065 \mathrm{~V} 1$ & & $500.00 \mathrm{PQ}$ & & \\
\hline $699-42-41$ & $4 / 17 / 92$ & $8065 V 5$ & & & & 20.00 UPQ \\
\hline $699-42-41$ & $6 / 29 / 92$ & 806222 & & $1000.00 \mathrm{P}$ & & \\
\hline $699-42-41$ & $6 / 29 / 92$ & 806226 & & & & 20.00 UP \\
\hline $699-42-41$ & $1 / 25 / 93$ & B07T24 & & $100.00 \mathrm{P}$ & & \\
\hline $699-42-41$ & $1 / 25 / 93$ & B07TZ8 & & & & 20.00 UP \\
\hline $699-42-42 B$ & $11 / 22 / 88$ & HOOODFT3 & & & 137.00 & \\
\hline $699-42-42 B$ & $11 / 22 / 88$ & HOOODFT3 & & & & $30.00 \mathrm{U}$ \\
\hline
\end{tabular}


(sheet 78 of $\star$ )

\begin{tabular}{|c|c|c|c|c|c|c|}
\hline $\begin{array}{l}\text { Well } \\
\text { Name }\end{array}$ & $\begin{array}{c}\text { Collection } \\
\text { Date }\end{array}$ & $\begin{array}{l}\text { Sample } \\
\text { Number }\end{array}$ & $\begin{array}{c}1-129 \\
139 / p C i / L \\
. /\end{array}$ & $\begin{array}{c}\text { IRON } \\
34 / \text { ppb } \\
20 / 300 \text { s }\end{array}$ & $\begin{array}{c}\text { IRON } \\
35 / \mathrm{ppb} \\
. / 300 \mathrm{~s}\end{array}$ & $\begin{array}{c}\text { FIRON } \\
34 / \mathrm{ppb} \\
20 / 300 \mathrm{~s}\end{array}$ \\
\hline ( & . & $\ldots$ & - & - nan. & (n) & 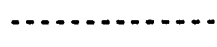 \\
\hline $699-42-42 B$ & $2 / 24 / 89$ & H0O0OFT7 & & & 221.00 & \\
\hline $699-42-42 B$ & $2 / 24 / 89$ & HOOODFT7 & & & & $30.00 \mathrm{U}$ \\
\hline $699-42-42 B$ & $6 / 16 / 89$ & HOOODFVI & & & 229.00 & \\
\hline $699-42-42 B$ & $6 / 16 / 89$ & HOOODFVI & & & & $30.00 \mathrm{U}$ \\
\hline $699-42-42 B$ & $6 / 16 / 89$ & HOOODFV4 & & & 237.00 & \\
\hline $699-42-42 B$ & $6 / 16 / 8 ?$ & HOOOOFV4 & & & & $30.00 \mathrm{U}$ \\
\hline $699-42-42 B$ & $8 / 09 / 89$ & H0OODFVS & & & 291.00 & \\
\hline $699-42-42 B$ & $8 / 09 / 89$ & H000DFV5 & & & & $30.00 \mathrm{U}$ \\
\hline $699-42-42 B$ & $7 / 08 / 91$ & H00071Y3 & & 420.00 & & \\
\hline $699-42-42 B$ & $7 / 08 / 91$ & H00071Y3F & & & & 37.00 \\
\hline $699-42-42 B$ & $1 / 24 / 92$ & B01063 & & 180.000 & & \\
\hline $699-42-42 B$ & $1 / 24 / 92$ & 801064 & & & & 61.000 \\
\hline $699-42-42 B$ & $6 / 24 / 92$ & B06227 & & 89.00 & & \\
\hline $699-42-42 B$ & $6 / 24 / 92$ & B07001 & & & & 49.00 \\
\hline $699-42-42 B$ & $1 / 21 / 93$ & B07T29 & & 290.00 & & \\
\hline $699 \cdot 42-428$ & $1 / 21 / 93$ & Borv03 & & & & $20.00 \mathrm{U}$ \\
\hline $699-43-40$ & $1 / 31 / 92$ & $801 T 72$ & & $1200.00 \mathrm{PD}$ & & \\
\hline $699-43-40$ & $1 / 31 / 92$ & B01т73 & & & & $30.00 \mathrm{PD}$ \\
\hline $699-43-40$ & $4 / 28 / 92$ & B065V6 & & $500.00 \mathrm{P}$ & & \\
\hline $699-43-40$ & $4 / 28 / 92$ & B065WO & & & & 20.00 UP \\
\hline $699-43-40$ & $6 / 26 / 92$ & B07002 & & $130.00 \mathrm{P}$ & & \\
\hline $699-43-40$ & $6 / 26 / 92$ & B07006 & & & & $41.00 \mathrm{P}$ \\
\hline $699-43-40$ & $1 / 25 / 93$ & B07N04 & & $350.00 \mathrm{P}$ & & \\
\hline $699-43-40$ & $1 / 25 / 93$ & B07N08 & & & & 20.00 UP \\
\hline $699-43-41 E$ & $12 / 05 / 89$ & HOOODGD6 & & & 417.00 & \\
\hline $699-43-41 E$ & $12 / 05 / 89$ & HOOODGD6 & & & & 30.00 \\
\hline $699-43-41 E$ & $1 / 25 / 90$ & HOOODGFO & & & 903.00 & \\
\hline $699-43-41 E$ & $1 / 25 / 90$ & HOOODGFO & & & & 37.00 \\
\hline $699-43-41 E$ & $6 / 28 / 91$ & H0007203 & & $550.00 \mathrm{D}$ & & \\
\hline $699-43-41 E$ & $6 / 28 / 91$ & H0007203F & & & & 110.000 \\
\hline $699-43-41 E$ & $6 / 28 / 91$ & H0007204 & & $450.00 \mathrm{D}$ & & \\
\hline $699-43-41 E$ & $6 / 28 / 91$ & H0007204F & & & & 77.000 \\
\hline $699-43-41 E$ & $1 / 23 / 92$ & B010C3 & & 24.00 & & \\
\hline $699-43-41 E$ & $1 / 23 / 92$ & B010C4 & & & & $2300.00 \mathrm{~F}$ \\
\hline $699-43-41 E$ & 4/17/92 & B065P4 & & 1700.000 & & \\
\hline $699-43-41 E$ & $4 / 17 / 92$ & B06506 & & & & $20.00 \mathrm{ve}$ \\
\hline $699-43-41 E$ & $6 / 24 / 92$ & B062V3 & & 380.00 & & \\
\hline $699-43-41 E$ & $6 / 24 / 92$ & B062W1 & & & & 39.00 \\
\hline $699-43-41 E$ & $1 / 25 / 93$ & B07v09 & & 550.00 & & \\
\hline $699-43-41 E$ & $1 / 25 / 93$ & Bo7v13 & & & & $20.00 \mathrm{U}$ \\
\hline $699-43-41 F$ & $12 / 05 / 89$ & H000DGG8 & & & 1540.00 & \\
\hline $699-43-41 F$ & $12 / 05 / 89$ & HOOODGG8 & & & & 157.00 \\
\hline $699-43-41 F$ & $1 / 25 / 90$ & HOOODGH2 & & & 925.00 & \\
\hline
\end{tabular}


(sheet 79 of $\star *$ )

\begin{tabular}{|c|c|c|c|c|c|c|}
\hline $\begin{array}{l}\text { Hell } \\
\text { Name }\end{array}$ & $\begin{array}{c}\text { Collection } \\
\text { Date }\end{array}$ & $\begin{array}{l}\text { Sample } \\
\text { Number }\end{array}$ & $\begin{array}{c}1-129 \\
139 / p c i / L \\
.1\end{array}$ & $\begin{array}{c}\text { IRON } \\
\text { 34/ppb } \\
20 / 300 \text { s }\end{array}$ & $\begin{array}{l}\text { IRON } \\
35 / \mathrm{ppb} \\
. / 300 \mathrm{~s}\end{array}$ & $\begin{array}{l}\text { FIRON } \\
34 / \text { ppb } \\
20 / 300 \text { s }\end{array}$ \\
\hline 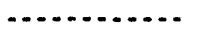 & 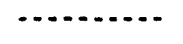 & . & - & . & . & . \\
\hline $699-43-41 F$ & $1 / 25 / 90$ & HOOODGH2 & & & & 63.00 \\
\hline $699-43-41 F$ & $4 / 18 / 90$ & H0OODGH6 & & & 2820.00 & \\
\hline $699-43-41 F$ & $4 / 18 / 90$ & HOOODGH6 & & & & 747.00 \\
\hline $699-43-41 F$ & $7 / 02 / 91$ & H00079Y5 & & $470.00 \mathrm{D}$ & & \\
\hline $699-43-41 F$ & $7 / 02 / 91$ & H00071Y5F & & & & 120.00 \\
\hline $699-43-41 F$ & $5 / 05 / 92$ & 8065RO & & 540.00 & & \\
\hline $699-43-41 F$ & $5 / 05 / 92$ & B065R9 & & & & 26.00 \\
\hline $699-43-41 F$ & $6 / 25 / 92$ & 806247 & & 2100.00 & & \\
\hline $699-43-41 F$ & $6 / 25 / 92$ & $8062 \times 1$ & & & & 58.00 \\
\hline $699-43-41 F$ & $1 / 22 / 93$ & BOTV14 & & 30.00 & & \\
\hline $699-43-41 F$ & $1 / 22 / 93$ & B07V18 & & & & $20.00 \mathrm{U}$ \\
\hline $699-43-41 G$ & $1 / 23 / 92$ & B01T74 & & 1900.00 & & \\
\hline $699-43-41 G$ & $1 / 23 / 92$ & B01T75 & & & & $20.00 \mathrm{U}$ \\
\hline $699-43-41 G$ & $4 / 17 / 92$ & B065H1 & & 2500.000 & & \\
\hline $699-43-41 G$ & $4 / 17 / 92$ & B065146 & & & & 20.00 UQ \\
\hline $699-43-41 G$ & $6 / 26 / 92$ & B07007 & & 190.00 & & \\
\hline $699-43-416$ & $6 / 26 / 92$ & B07011 & & & & 49.00 \\
\hline $699-43-416$ & $10 / 28 / 92$ & B07JL8 & & 250.00 & & \\
\hline $699-43-410$ & $10 / 28 / 92$ & B07JM2 & & & & 30.00 \\
\hline $699-43-41 G$ & $1 / 25 / 93$ & B07v74 & & 270.00 & & \\
\hline $699-43-41 G$ & $1 / 25 / 93$ & Bo7v78 & & & & $20.00 \mathrm{U}$ \\
\hline $699-43-42 J$ & $11 / 22 / 88$ & H0OOOGP2 & & & 153.00 & \\
\hline $699-43-42 \mathrm{~J}$ & $11 / 22 / 88$ & HOOODGP2 & & & & $30.00 \mathrm{U}$ \\
\hline $699-43-42 \mathrm{~J}$ & $2 / 24 / 89$ & HOOODGPG & & & 216.00 & \\
\hline $699-43-42 \mathrm{~J}$ & $2 / 24 / 89$ & HOOODGPG & & & & 33.00 \\
\hline $699-43-42 J$ & $6 / 15 / 89$ & HOOOOGOO & & & 199.00 & \\
\hline $699-43-42 J$ & $6 / 15 / 89$ & HOOOOGOO & & & & $30.00 \mathrm{U}$ \\
\hline $699-43-42 J$ & $8 / 09 / 89$ & H0OOOGO4 & & & 795.00 & \\
\hline $699-43-42 \mathrm{~J}$ & $8 / 09 / 89$ & H0OOOGO4 & & & & $30.00 \mathrm{U}$ \\
\hline $699-43-42 J$ & $8 / 09 / 89$ & H0OODGO7 & & & 436.00 & \\
\hline $699-43-42 \mathrm{~J}$ & $8 / 09 / 89$ & H0OOOG07 & & & & $30.00 \mathrm{U}$ \\
\hline $699-43-42 \mathrm{~J}$ & $7 / 02 / 91$ & H00071Y6 & & 170.000 & & \\
\hline $699-43-42 \mathrm{~J}$ & $7 / 02 / 91$ & H00071Y6F & & & & 54.00 \\
\hline $699-43-42 \mathrm{~J}$ & $1 / 31 / 92$ & B01549 & & $730.00 \mathrm{D}$ & & \\
\hline $699-43-42 \mathrm{~J}$ & $1 / 31 / 92$ & B01S51 & & & & $25.00 \mathrm{D}$ \\
\hline $699-43-42 \mathrm{~J}$ & $6 / 25 / 92$ & 807012 & & 910.00 & & \\
\hline $699-43-42 \mathrm{~J}$ & $6 / 25 / 92$ & B07016 & & & & 83.00 \\
\hline $699-43-42 \mathrm{~J}$ & $1 / 21 / 93$ & Bo7v19 & & 370.00 & & \\
\hline $699-43-42 \mathrm{~J}$ & $1 / 21 / 93$ & B07v23 & & & & $20.00 \mathrm{U}$ \\
\hline $699-43-43$ & $11 / 21 / 88$ & HOOOOGR3 & & & 231.00 & \\
\hline $699-43-43$ & $11 / 21 / 88$ & HOOODGR3 & & & & $30.00 \mathrm{U}$ \\
\hline $699 \cdot 43-43$ & $2 / 24 / 8 ?$ & HOOODGR7 & & & 132.00 & \\
\hline $699-43-43$ & $2 / 24 / 89$ & HOOODGR 7 & & & & $30.00 \mathrm{U}$ \\
\hline
\end{tabular}


(sheet 80 of $\star$ )

\begin{tabular}{|c|c|c|c|c|c|c|}
\hline $\begin{array}{l}\text { Well } \\
\text { Name }\end{array}$ & $\begin{array}{c}\text { Collection } \\
\text { Date }\end{array}$ & $\begin{array}{l}\text { Semple } \\
\text { Number }\end{array}$ & $\begin{array}{c}1-129 \\
139 / \mathrm{pCi} / \mathrm{L} \\
. /\end{array}$ & $\begin{array}{c}\text { IRON } \\
\text { 34/ppb } \\
20 / 300 \text { s }\end{array}$ & $\begin{array}{l}\text { IRON } \\
\text { 35/ppb } \\
. / 300 \mathrm{~s}\end{array}$ & $\begin{array}{c}\text { FIRON } \\
34 / \text { ppb } \\
20 / 300 \text { s }\end{array}$ \\
\hline . & . & . & . & - & $\ldots$ & - \\
\hline $699-43-43$ & $2 / 24 / 89$ & HOOOOGSO & & & 98.00 & \\
\hline $699-43-43$ & $2 / 24 / 89$ & HOOOOGSO & & & & 31.00 \\
\hline $699-43-43$ & $6 / 15 / 89$ & HOOODGS1 & & & 58.00 & \\
\hline $699-43-43$ & $6 / 15 / 89$ & HOOODGS1 & & & & $30.00 \mathrm{U}$ \\
\hline $699-43-43$ & $8 / 09 / 89$ & H0000GS5 & & & 73.00 & \\
\hline $699-43-43$ & $8 / 09 / 89$ & HOOODGS5 & & & & $30.00 \mathrm{U}$ \\
\hline $699-43-43$ & $1 / 26 / 90$ & HOOODGS9 & & & 144.00 & \\
\hline $699-43-43$ & $1 / 26 / 90$ & H0000GS9 & & & & $30.00 \mathrm{U}$ \\
\hline $699-43-43$ & $7 / 08 / 91$ & H00071Y7 & & 340.00 & & \\
\hline $699-43-43$ & $7 / 08 / 91$ & H00071Y7F & & & & 61.00 \\
\hline $699-43-43$ & $1 / 24 / 92$ & 801067 & & 150.000 & & \\
\hline $699-43-43$ & $1 / 24 / 92$ & 801068 & & & & $97.00 \mathrm{D}$ \\
\hline $699-43-43$ & $4 / 22 / 92$ & B065N6 & & 350.00 & & \\
\hline $699-43-43$ & $4 / 22 / 92$ & B065N7 & & & & 27.00 \\
\hline $699-43-43$ & $6 / 26 / 92$ & Bo70w0 & & 150.000 & & \\
\hline $699-43-43$ & $6 / 26 / 92$ & Bo70W1 & & & & 44.00 \\
\hline $699-43-43$ & $10 / 26 / 92$ & B07JG5 & . & 390.00 & & \\
\hline $699-43-43$ & $10 / 26 / 92$ & B07JG6 & & & & $20.00 \mathrm{U}$ \\
\hline $699-43-43$ & $1 / 13 / 93$ & Bo7v24 & & 180.00 & & \\
\hline $699-43-43$ & $1 / 13 / 93$ & BOTV28 & & & & $20.00 \mathrm{U}$ \\
\hline $699-43-45$ & $12 / 06 / 89$ & HOOODGT4 & & & 265.00 & \\
\hline $699-43-45$ & $12 / 06 / 89$ & H0000GT4 & & & & $30.00 \mathrm{U}$ \\
\hline $699-43-45$ & $1 / 26 / 90$ & H0000GT8 & & & 479.00 & \\
\hline $699-43-45$ & $1 / 26 / 90$ & H0000GT8 & & & & $30.00 \mathrm{U}$ \\
\hline $699-43-45$ & $4 / 18 / 90$ & HOOODGV2 & & & 343.00 & \\
\hline $699-43-45$ & $4 / 18 / 90$ & H0000GV2 & & & & $30.00 \mathrm{U}$ \\
\hline $699-43-45$ & $7 / 08 / 91$ & H00071Y8 & & 650.00 & & \\
\hline $699-43-45$ & $7 / 08 / 91$ & H00071Y8F & & & & 22.00 \\
\hline $699-43-45$ & $9 / 11 / 91$ & B0OLG5 & & 330.00 & & \\
\hline $699-43-45$ & $9 / 11 / 91$ & BOOLGSF & & & & 59.00 \\
\hline $699-43-45$ & $1 / 24 / 92$ & 801000 & & 640.000 & & \\
\hline $699-43-45$ & $1 / 24 / 92$ & 801001 & & & & 23.000 \\
\hline $699-43-45$ & $4 / 22 / 92$ & B065N8 & & 430.00 & & \\
\hline $699-43-45$ & $4 / 22 / 92$ & 8065N9 & & & & $20.00 \mathrm{U}$ \\
\hline $699-43-45$ & $6 / 26 / 92$ & B070W2 & & $66.00 \mathrm{D}$ & & \\
\hline $699-43-45$ & $6 / 26 / 92$ & B070W3 & & & & 38.00 \\
\hline $699-43-45$ & $10 / 26 / 92$ & B07JG7 & & 500.00 & & \\
\hline $699-43-45$ & $10 / 26 / 92$ & B07JG8 & & & & $20.00 \mathrm{U}$ \\
\hline $699-43-45$ & $1 / 13 / 93$ & BOTN29 & & 400.00 & & \\
\hline $699-43-45$ & $1 / 13 / 93$ & B07V33 & & & & $20.00 \mathrm{U}$ \\
\hline $699-44-398$ & $1 / 08 / 93$ & BOTNK1 & & 120.00 & & \\
\hline $699-44-39 B$ & $9 / 08 / 83$ & B07NK5 & & & & $20.00 \mathrm{U}$ \\
\hline $699-44-42$ & $11 / 21 / 88$ & H0OODHK2 & & & 104.00 & \\
\hline
\end{tabular}


(sheet 81 of **)

\begin{tabular}{|c|c|c|c|c|c|c|}
\hline $\begin{array}{l}\text { Well } \\
\text { Name }\end{array}$ & $\begin{array}{c}\text { Collection } \\
\text { Date }\end{array}$ & $\begin{array}{l}\text { Sample } \\
\text { Number }\end{array}$ & $\begin{array}{c}1-129 \\
139 / p C i / L \\
. /\end{array}$ & $\begin{array}{c}\text { IRON } \\
\text { 34/Ppb } \\
20 / 300 \text { s }\end{array}$ & $\begin{array}{c}\text { IRON } \\
35 / \mathrm{ppb} \\
. / 300 \mathrm{~s}\end{array}$ & $\begin{array}{l}\text { FIRON } \\
\text { 34/ppb } \\
20 / 300 \text { s }\end{array}$ \\
\hline (n) & 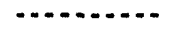 & (n) & nan & . & - & , n \\
\hline $699-44-42$ & $11 / 21 / 88$ & H0000HK2 & & & & $30.00 \mathrm{U}$ \\
\hline $699-44-42$ & $2 / 17 / 89$ & H0OOOHKG & & & 44.00 & \\
\hline $699-44-42$ & $2 / 17 / 89$ & H0000HK6 & & & & $30.00 \mathrm{U}$ \\
\hline $699-44-42$ & $6 / 15 / 89$ & HOOOOHLO & & & 71.00 & \\
\hline $699-44-42$ & $6 / 15 / 89$ & HOOOOHLO & & & & $30.00 \mathrm{U}$ \\
\hline $699-44-42$ & $8 / 08 / 89$ & HOOODHL 4 & & & 127.00 & \\
\hline $699-44-42$ & $8 / 08 / 89$ & HOOOOHL 4 & & & & $30.00 \mathrm{U}$ \\
\hline $699-44-42$ & $1 / 31 / 90$ & HOOOOHL8 & & & 231.00 & \\
\hline $699-44-42$ & $1 / 31 / 90$ & HOOODHL8 & & & & $30.00 \mathrm{U}$ \\
\hline $699-44-42$ & $7 / 10 / 91$ & H00071Y9 & & 190.00 & & \\
\hline $699-44-42$ & $7 / 10 / 91$ & H00071Y9F & & & & 34.00 \\
\hline $699-44-42$ & $1 / 31 / 92$ & B01552 & & $290.00 \mathrm{D}$ & & \\
\hline $699-44-42$ & $1 / 31 / 92$ & B01554 & & & & 21.000 \\
\hline $699-44-42$ & $6 / 25 / 92$ & B07017 & & 590.00 & & \\
\hline $699-44-42$ & $6 / 25 / 92$ & B07021 & · & & & 67.00 \\
\hline $699-44-42$ & $1 / 13 / 93$ & $807 \sqrt{34}$ & & 130.000 & & \\
\hline $699-44-42$ & $1 / 13 / 93$ & B07v35 & & 80.000 & & \\
\hline $699-44-42$ & $1 / 13 / 93$ & BOTN42 & & & & $20.00 \mathrm{U}$ \\
\hline $699-44-42$ & $1 / 13 / 93$ & $807 N 43$ & & & & $20.00 \mathrm{U}$ \\
\hline $699-44-43 B$ & $12 / 20 / 89$ & HOOODHM3 & & & 368.00 & \\
\hline $699-44-43 B$ & $12 / 20 / 89$ & HOOOOHM3 & & & & 157.00 \\
\hline $699-44-43 B$ & $12 / 20 / 89$ & HОOОDHM6 & & & 562.00 & \\
\hline $699-44-43 B$ & $12 / 20 / 89$ & HOOODHMG & & & & 318.00 \\
\hline $699-44-43 B$ & $1 / 26 / 90$ & HOOODHM7 & & & 417.00 & \\
\hline $699-44-43 B$ & $1 / 26 / 90$ & HOOODHM7 & & & & $30.00 \mathrm{U}$ \\
\hline $699-44-43 B$ & $1 / 26 / 90$ & HOOODHNO & & & 463.00 & \\
\hline $699-44-43 B$ & $1 / 26 / 90$ & HOOODHNO & & & & 64.00 \\
\hline $699-44-43 B$ & $4 / 18 / 90$ & HOOODHN1 & & & 1060.00 & \\
\hline $699-44-43 B$ & $4 / 18 / 90$ & HOOODHN1 & & & & $30.00 \mathrm{U}$ \\
\hline $699-44-43 B$ & $7 / 08 / 91$ & HO00712O & & 580.00 & & \\
\hline $699-44-438$ & $7 / 08 / 91$ & HO0071ZOF & & & & 640.00 \\
\hline $699-44-43 B$ & $9 / 11 / 91$ & B00LG6 & & 290.00 & & \\
\hline $699-44-43 B$ & $9 / 11 / 91$ & BOOLG6F & & & & 52.00 \\
\hline $699-44-43 B$ & $1 / 23 / 92$ & B01069 & & $20.00 \mathrm{U}$ & & \\
\hline $699-44-438$ & $1 / 23 / 92$ & B01070 & & & & $680.00 \mathrm{~F}$ \\
\hline $699-44-43 B$ & $4 / 20 / 92$ & B065W9 & & 380.00 & & \\
\hline $699-44-43 B$ & $4 / 20 / 92$ & B065X5 & & & & 49.00 \\
\hline $699-44-438$ & $6 / 26 / 92$ & B01MT4 & & & & $20.00 \mathrm{U}$ \\
\hline $699-44-43 B$ & $6 / 26 / 92$ & B07022 & & 150.00 & & \\
\hline $699-44-43 B$ & $6 / 26 / 92$ & 807023 & & 160.00 & & \\
\hline $699-44-43 B$ & $6 / 26 / 92$ & B07026 & & & & $20.00 \mathrm{U}$ \\
\hline $699-44-43 B$ & $1 / 27 / 93$ & B07N44 & & 320.00 & & \\
\hline $699-44-43 B$ & $1 / 27 / 93$ & $807 N 48$ & & & & $20.00 \mathrm{U}$ \\
\hline
\end{tabular}


(sheet 82 of $\star *$ )

\begin{tabular}{|c|c|c|c|c|c|c|}
\hline $\begin{array}{l}\text { Well } \\
\text { Name }\end{array}$ & $\begin{array}{c}\text { Collection } \\
\text { Date }\end{array}$ & $\begin{array}{l}\text { Sample } \\
\text { Number }\end{array}$ & $\begin{array}{c}I-129 \\
139 / \mathrm{DCi} / \mathrm{L} \\
. /\end{array}$ & $\begin{array}{c}\text { IRON } \\
\text { 34/ppb } \\
20 / 300 \mathrm{~s}\end{array}$ & $\begin{array}{c}\text { IRON } \\
35 / \mathrm{ppb} \\
. / 300 \mathrm{~s}\end{array}$ & $\begin{array}{l}\text { FIRON } \\
\text { 34/ppb } \\
20 / 300 \text { s }\end{array}$ \\
\hline \multirow{2}{*}{ - } & $\ldots$ & (n) & . & n & (n) & . \\
\hline & & & LEAD & LEAD & FLEAD & PB212 \\
\hline Hell & Collection & Sample & 40/ppb & 76/ppb & 40/ppb & 140/pCi/L \\
\hline Name & Date & Number & $5 / 50$ & .1 & $5 / 50$ & .1 \\
\hline$\ldots$ & (n.............. & (n) & . & (n) & 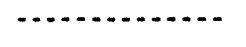 & $\cdots$ \\
\hline $299-E 18-1$ & $8 / 16 / 88$ & H00072T7 & & $5.00 \mathrm{U}$ & & \\
\hline $299-E 18-1$ & $8 / 16 / 88$ & H0007217 & & & $5.00 \mathrm{U}$ & \\
\hline 299-E18-1 & $11 / 10 / 88$ & H0007ZV2 & & $5.00 \mathrm{U}$ & & \\
\hline $299-E 18-1$ & $11 / 10 / 88$ & H0007Zv2 & & & $5.00 \mathrm{U}$ & \\
\hline 299-E18-1 & $11 / 10 / 88$ & H0007ZV5 & & $5.00 \mathrm{U}$ & & \\
\hline 299-E18-1 & $11 / 10 / 88$ & H00072V5 & & & $5.00 \mathrm{U}$ & \\
\hline 299-E18-1 & $2 / 15 / 89$ & H0007Zv8 & & $5.00 \mathrm{U}$ & & \\
\hline 299-E18-1 & $2 / 15 / 89$ & H0007Zv8 & & & $5.00 \mathrm{U}$ & \\
\hline 299-E18-1 & $5 / 26 / 89$ & H0OOTZW2 & & $5.00 \mathrm{U}$ & & \\
\hline 299-E18-1 & $5 / 26 / 89$ & H0007ZW2 & & & $5.00 \mathrm{U}$ & \\
\hline $299-E 18-1$ & $8 / 08 / 89$ & H0007ZW6 & & $5.00 \mathrm{U}$ & & \\
\hline 299-E18-1 & $8 / 08 / 89$ & H00072W6 & & & $5.00 \mathrm{U}$ & \\
\hline $299-E 18-1$ & $10 / 31 / 89$ & $H 00072 \times 0$ & & $5.00 \mathrm{U}$ & & \\
\hline 299-E18-1 & $10 / 31 / 89$ & $H 00072 \times 0$ & & & $5.00 \mathrm{U}$ & \\
\hline $299-E 18-1$ & $9 / 06 / 91$ & BOOLB6 & & & & 10.30 \\
\hline $299-E 18-1$ & $6 / 03 / 92$ & B06PH8 & $5.00 \mathrm{U}$ & & & \\
\hline $299-E 18-1$ & $6 / 03 / 92$ & B06PJ2 & & & $5.00 \mathrm{U}$ & \\
\hline 299-E18-1 & $12 / 16 / 92$ & BO7SNO & $5.00 \mathrm{U}$ & & & \\
\hline 299-E18-1 & $12 / 16 / 92$ & B07SN1 & & & $5.00 \mathrm{U}$ & \\
\hline $299-E 32-4$ & $9 / 27 / 88$ & H0008288 & & $5.00 \mathrm{U}$ & & \\
\hline $299-E 32-4$ & $9 / 27 / 88$ & H00082B8 & & & $5.00 \mathrm{U}$ & \\
\hline $299-E 32-4$ & $12 / 28 / 88$ & HOOOBZC2 & & $5.00 \mathrm{U}$ & & \\
\hline $299-E 32-4$ & $12 / 28 / 88$ & H0008zC2 & & & $5.00 \mathrm{U}$ & \\
\hline 299-E32-4 & $3 / 01 / 89$ & H0008ZC6 & & 5.00 & & \\
\hline $299-E 32-4$ & $3 / 01 / 89$ & H0008ZC6 & & & $5.00 \mathrm{U}$ & \\
\hline $299-E 32-4$ & $3 / 13 / 89$ & $H 00082 D O$ & & $5.00 \mathrm{U}$ & & \\
\hline 299-E32-4 & $3 / 13 / 89$ & $H 0008200$ & & & $5.00 \mathrm{U}$ & \\
\hline 299-E32-4 & $6 / 16 / 89$ & H0OOBZD 4 & & $5.00 \mathrm{U}$ & & \\
\hline 299-E32-4 & $6 / 16 / 89$ & H0008ZD & & & $5.00 \mathrm{U}$ & \\
\hline 299-E32-4 & $7 / 19 / 89$ & H0008ZD8 & & 8.00 & & \\
\hline 299-E32-4 & $7 / 19 / 89$ & H0008ZD8 & & & $5.00 \mathrm{U}$ & \\
\hline $299-E 32-4$ & $9 / 08 / 89$ & H00082F6 & & 6.00 & & \\
\hline 299-E32-4 & $9 / 08 / 89$ & H0008zF6 & & & $5.00 \mathrm{U}$ & \\
\hline 299-E32-4 & $1 / 17 / 90$ & HOOOBZGO & & 10.00 & & \\
\hline $299-E 32-4$ & $1 / 17 / 90$ & $H 00082 G 0$ & & & $5.00 \mathrm{U}$ & \\
\hline $299-E 32-4$ & $1 / 15 / 92$ & B010K6 & $5.00 \mathrm{U}$ & & & \\
\hline
\end{tabular}


(sheet 83 of $\star$ )

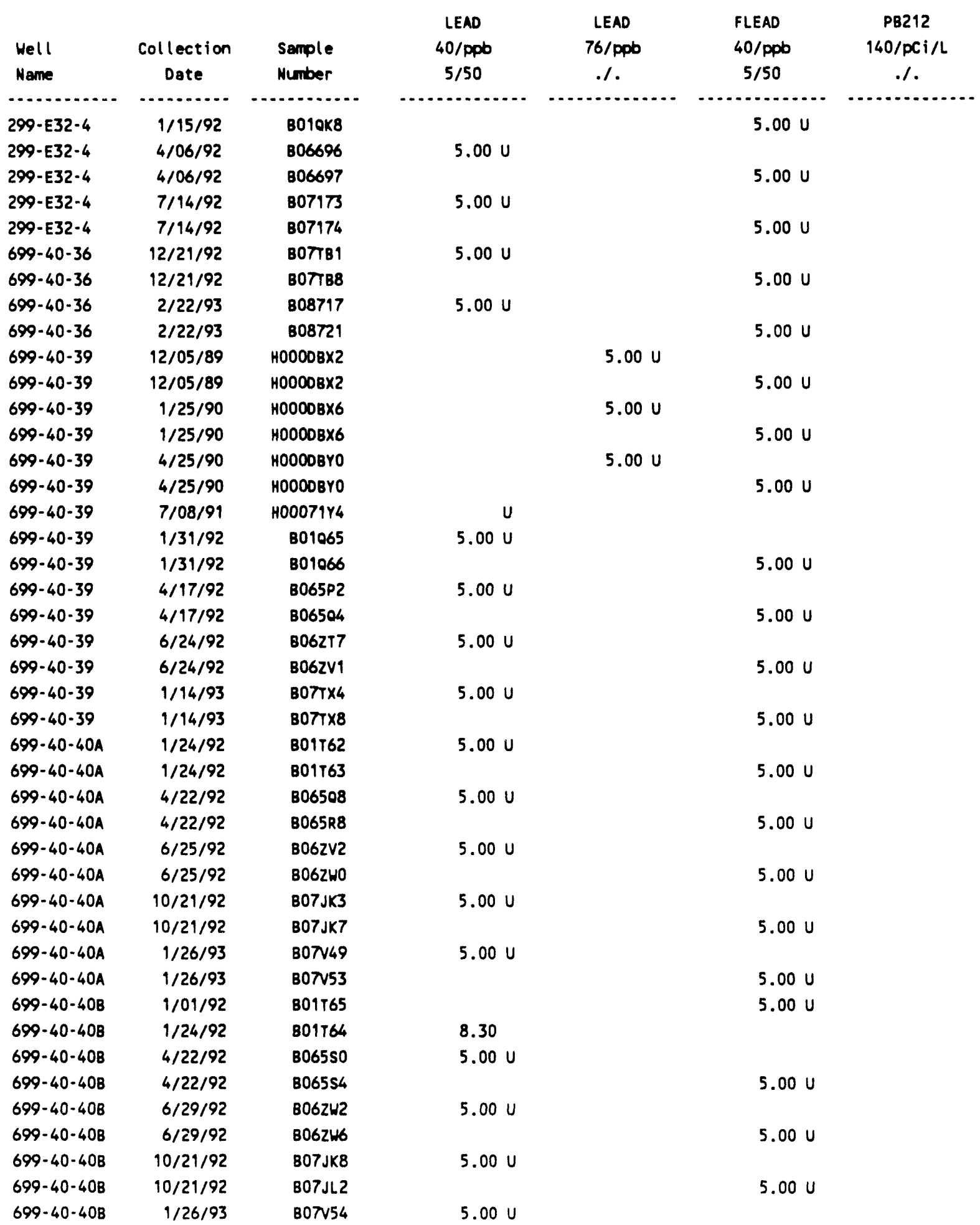


(sheet 84 of

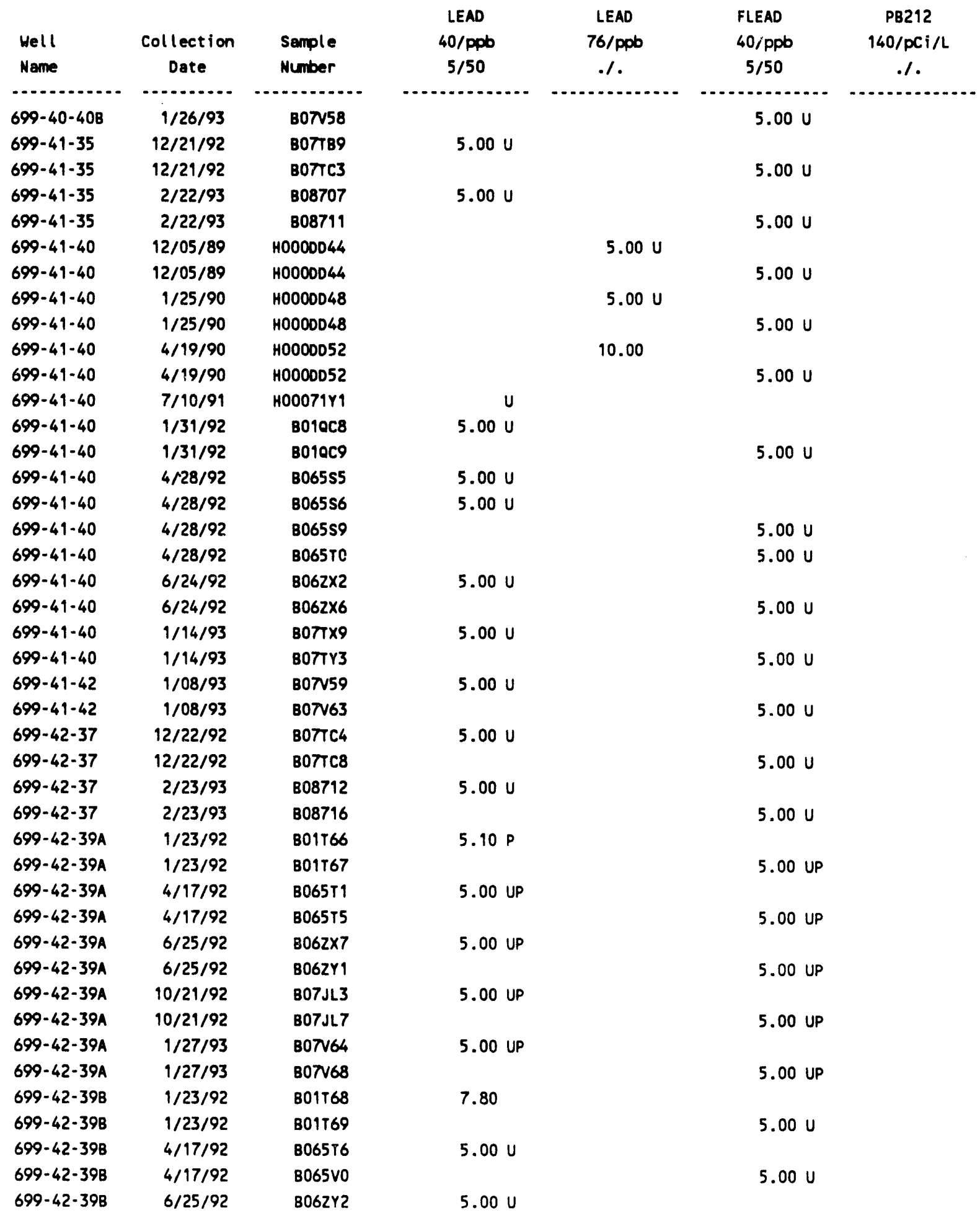


(sheet 85 of $\star *$ )

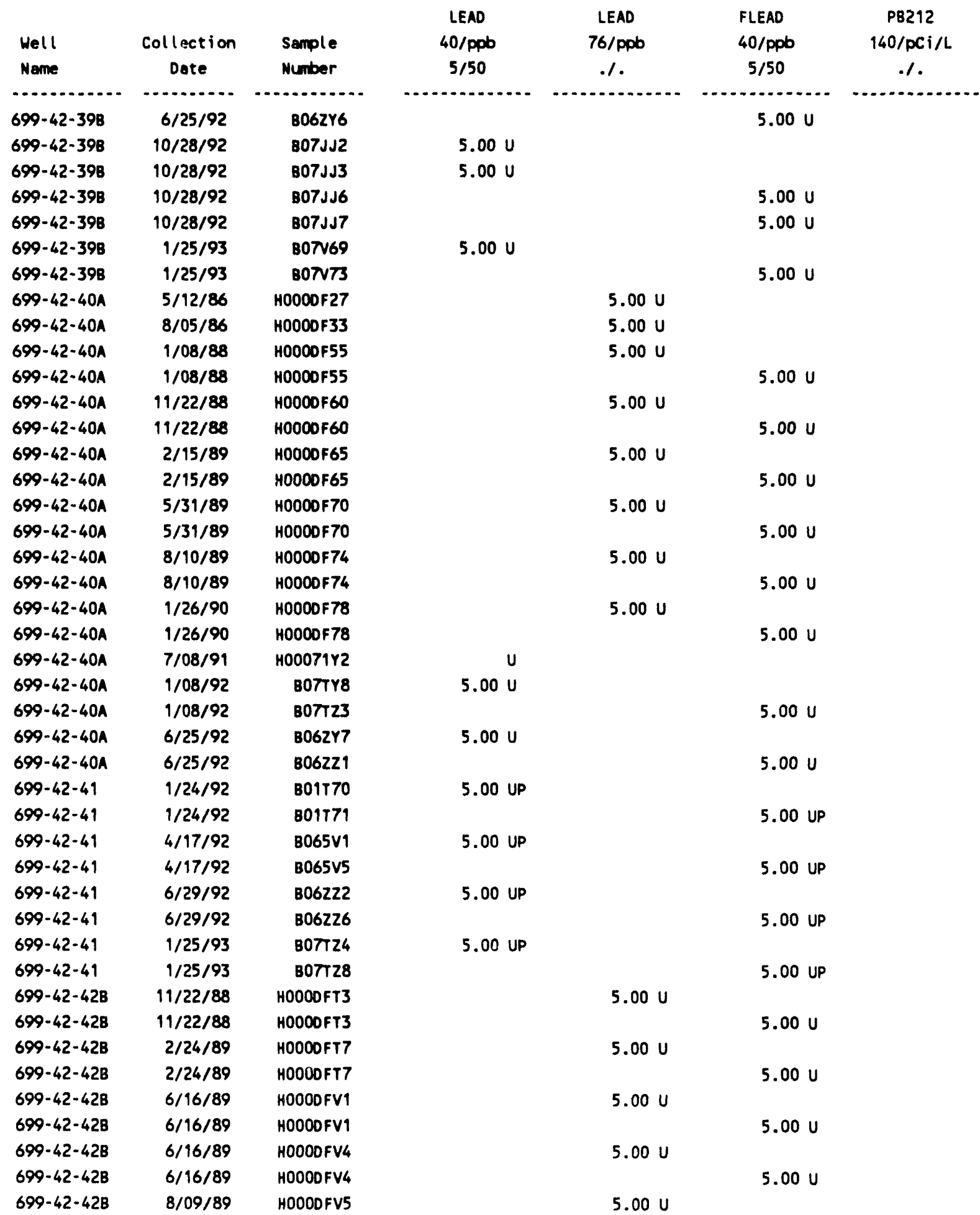


(sheet 86 of $\star *$ )

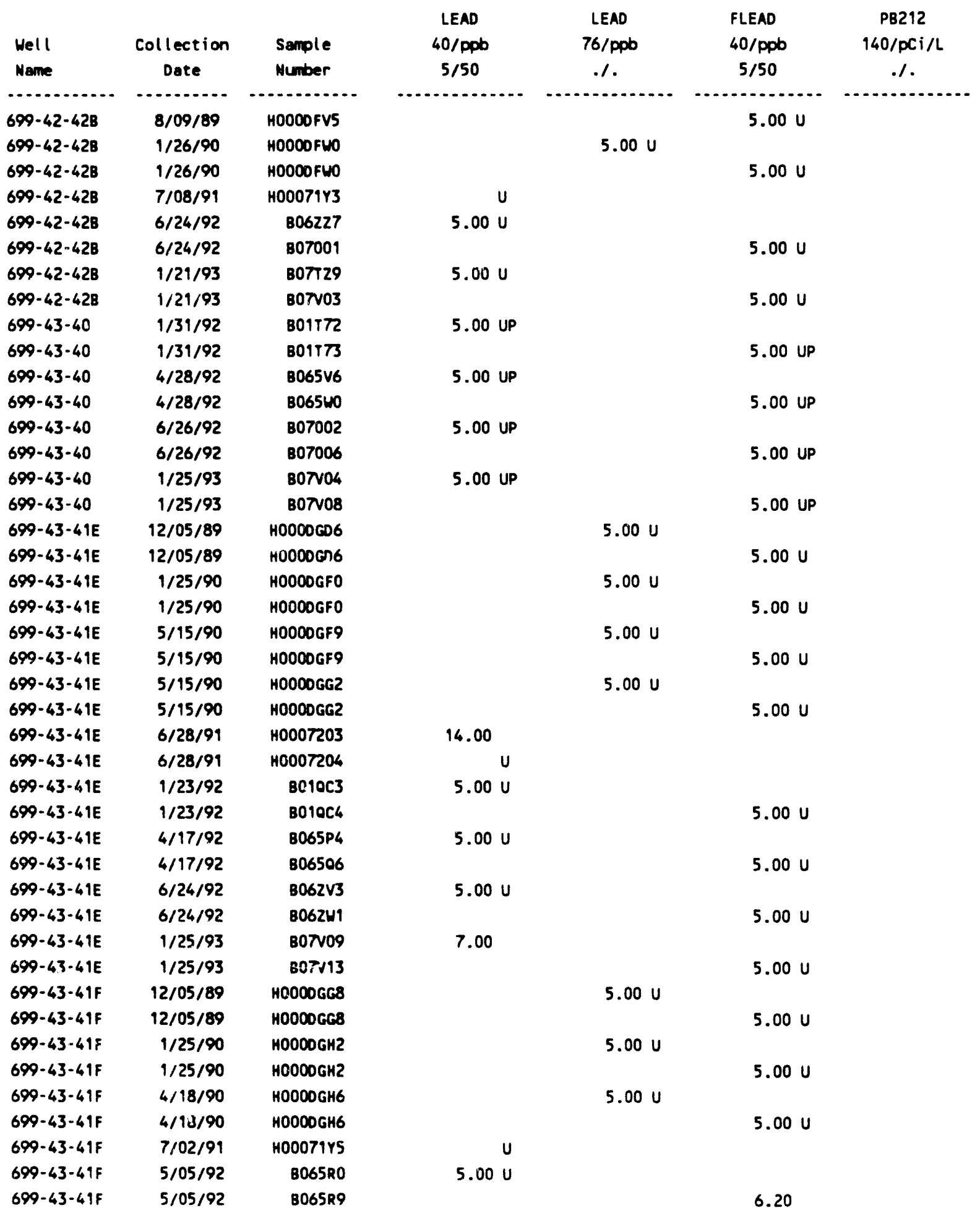


(sheet 87 of $\star$ )

\begin{tabular}{|c|c|c|c|c|c|c|}
\hline $\begin{array}{l}\text { Well } \\
\text { Nane }\end{array}$ & $\begin{array}{c}\text { Collection } \\
\text { Date }\end{array}$ & $\begin{array}{l}\text { Sample } \\
\text { Number }\end{array}$ & $\begin{array}{l}\text { LEAD } \\
\text { 40/ppb } \\
5 / 50\end{array}$ & $\begin{array}{l}\text { LEAD } \\
76 / p p b \\
.1\end{array}$ & $\begin{array}{l}\text { FLEAD } \\
\text { 40/ppb } \\
5 / 50\end{array}$ & $\begin{array}{c}\text { PB212 } \\
140 / p C i / L \\
. /\end{array}$ \\
\hline - & 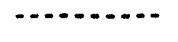 & , n & - & . & - & $\cdots$ \\
\hline $699-43-41 F$ & $6 / 25 / 92$ & B062U7 & $5.00 \mathrm{U}$ & & & \\
\hline $699-43-41 F$ & $6 / 25 / 92$ & $8062 \times 1$ & & & $5.00 \mathrm{U}$ & \\
\hline $699-43-41 F$ & $1 / 22 / 93$ & B07N14 & $5.00 \mathrm{U}$ & & & \\
\hline $699-43-41 F$ & $1 / 22 / 93$ & $807 v 18$ & & & $5.00 \mathrm{U}$ & \\
\hline $699-43-416$ & $1 / 23 / 92$ & $801 T 74$ & $5.00 \mathrm{U}$ & & & \\
\hline $699-43-416$ & $1 / 23 / 92$ & B01T75 & & & $5.00 \mathrm{U}$ & \\
\hline $699-43-416$ & $4 / 17 / 92$ & B065H1 & $5.00 \mathrm{U}$ & & & \\
\hline $699-43-416$ & $4 / 17 / 92$ & B065U6 & & & $5.00 \mathrm{U}$ & \\
\hline $699-43-416$ & $6 / 26 / 92$ & B07007 & $5.00 \mathrm{U}$ & & & \\
\hline $699-43-416$ & $6 / 26 / 92$ & 807019 & & & $5.00 \mathrm{U}$ & \\
\hline $699-43-416$ & $10 / 28 / 92$ & B07JL8 & $5.00 \mathrm{U}$ & & & \\
\hline $699-43-416$ & $10 / 28 / 92$ & B07JM2 & & & $5.00 \mathrm{U}$ & \\
\hline $699-43-416$ & $1 / 25 / 93$ & Bo7v74 & $5.00 \mathrm{U}$ & & & \\
\hline $699-43-416$ & $1 / 25 / 93$ & B07v78 & & & $5.00 \mathrm{U}$ & \\
\hline $699-43-42 \mathrm{~J}$ & $11 / 22 / 88$ & HOOOOGP2 & & $5.00 \mathrm{U}$ & & \\
\hline $699-43-42 \mathrm{~J}$ & $11 / 22 / 88$ & H0OOOGP2 & & & $5.00 \mathrm{U}$ & \\
\hline $699-43-42 J$ & $2 / 24 / 89$ & HOOODGP6 & & $5.00 \mathrm{U}$ & & \\
\hline $699-43-42 J$ & $2 / 24 / 89$ & HOOODGPG & & & $5.00 u$ & \\
\hline $699-43-42 J$ & $6 / 15 / 89$ & HOOOOGOO & & $5.00 \mathrm{U}$ & & \\
\hline $699-43-42 \mathrm{~J}$ & $6 / 15 / 89$ & HOOODGOO & & & $5.00 \mathrm{U}$ & \\
\hline $699-43-42 \mathrm{~J}$ & $8 / 09 / 89$ & HOOOOGO4 & & $5.00 \mathrm{U}$ & & \\
\hline $699-43-42 J$ & $8 / 09 / 89$ & HOOODGO4 & & & $5.00 \mathrm{U}$ & \\
\hline $699-43-42 J$ & $8 / 09 / 89$ & H0000G07 & & $5.00 \mathrm{U}$ & & \\
\hline $699-43-42 J$ & $8 / 09 / 89$ & H0000Ga7 & & & $5.00 \mathrm{U}$ & \\
\hline $699-43-42 J$ & $1 / 31 / 90$ & H0000G09 & & $5.00 \mathrm{U}$ & & \\
\hline $699-43-42 J$ & $1 / 31 / 90$ & H0OOOGO9 & & & $5.00 \mathrm{U}$ & \\
\hline $699-43-42 J$ & $7 / 02 / 91$ & H00071Y6 & $u$ & & & \\
\hline $699-43-42 \mathrm{~J}$ & $1 / 31 / 92$ & 801549 & $5.00 \mathrm{U}$ & & & \\
\hline $699-43-42 J$ & $1 / 31 / 92$ & 801551 & & & $5.00 \mathrm{U}$ & \\
\hline $699-43-42 J$ & $6 / 25 / 92$ & 807012 & $5.00 \mathrm{U}$ & & & \\
\hline $699-43-42 \mathrm{~J}$ & $6 / 25 / 92$ & B07016 & & & $5.00 \mathrm{U}$ & \\
\hline $699-43-42 \mathrm{~J}$ & $1 / 21 / 93$ & Botv19 & $5.00 \mathrm{U}$ & & & \\
\hline $699-43-42 \mathrm{~J}$ & $1 / 21 / 93$ & BoTV23 & & & $5.00 \mathrm{U}$ & \\
\hline $699-43-43$ & $11 / 21 / 88$ & HOOOOGR3 & & $5.00 \mathrm{U}$ & & \\
\hline $699-43-43$ & $11 / 21 / 88$ & HOOOOGR3 & & & $5.00 \mathrm{U}$ & \\
\hline $699-43-43$ & $2 / 24 / 89$ & HOOOOGR7 & & $5.00 \mathrm{U}$ & & \\
\hline $699-43-43$ & $2 / 24 / 89$ & HOOODGR7 & & & $5.00 \mathrm{U}$ & \\
\hline $699-43-43$ & $2 / 24 / 89$ & HOOOOGSO & & $5.00 \mathrm{U}$ & & \\
\hline $699-43-43$ & $2 / 24 / 89$ & HOOODGSO & & & $5.00 \mathrm{U}$ & \\
\hline $699-43-43$ & $6 / 15 / 89$ & HOOODGS 1 & & $5.00 \mathrm{U}$ & & \\
\hline $699-43-43$ & $6 / 15 / 89$ & H0000GS 1 & & & $5.00 \mathrm{U}$ & \\
\hline $699-43-43$ & $8 / 09 / 89$ & HOOODGS5 & & $5.00 \mathrm{U}$ & & \\
\hline $699-43-43$ & $8 / 09 / 89$ & H0OODGS5 & & & $5.00 \mathrm{U}$ & \\
\hline
\end{tabular}


(sheet 88 of $* *$ )

\begin{tabular}{|c|c|c|c|c|c|c|}
\hline & & & LEAD & LEAD & FLEAD & PB212 \\
\hline Hell & Collection & Sample & 40/ppb & 76/ppob & 40/ppb & $140 / \mathrm{PCi} / \mathrm{L}$ \\
\hline Name & Date & Number & $5 / 50$ &.$/$ & $5 / 50$ &.$/$ \\
\hline , & - n & . & (n) & . & . & \\
\hline $699-43-43$ & $1 / 26 / 90$ & HOOODGS9 & & $5.00 \mathrm{U}$ & & \\
\hline $699-43-43$ & $1 / 26 / 90$ & H0OOOGS9 & & & $5.00 \mathrm{U}$ & \\
\hline $699-43-43$ & $7 / 08 / 91$ & H00071Y7 & $U$ & & & \\
\hline $699-43-43$ & $1 / 24 / 92$ & B01T83 & $5.00 \mathrm{U}$ & & & \\
\hline $699-43-43$ & $1 / 24 / 92$ & B01T84 & & & $5.00 \mathrm{U}$ & \\
\hline $699-43-43$ & $4 / 22 / 92$ & B065N6 & $5.00 \mathrm{U}$ & & & \\
\hline $699-43-43$ & $4 / 22 / 92$ & B065N7 & & & $5.00 \mathrm{U}$ & \\
\hline $699-43-43$ & $6 / 26 / 92$ & B070w0 & $5.00 \mathrm{U}$ & & & \\
\hline $699-43-43$ & $6 / 26 / 92$ & B070w1 & & & $5.00 \mathrm{U}$ & \\
\hline $699-43-43$ & $10 / 26 / 92$ & B07JG5 & $5.00 \mathrm{U}$ & & & \\
\hline $699-43-43$ & $10 / 26 / 92$ & B07JG6 & & & $5.00 \mathrm{U}$ & \\
\hline $699-43-43$ & $1 / 13 / 93$ & $807 v 24$ & $5.00 \mathrm{U}$ & & & \\
\hline $699-43-43$ & $1 / 13 / 93$ & B07V28 & & & $5.00 \mathrm{U}$ & \\
\hline $699-43-45$ & $12 / 06 / 89$ & H0OOOGT4 & & $5.00 \mathrm{U}$ & & \\
\hline $699-43-45$ & $12 / 06 / 89$ & HOOOOGT4 & & & $5.00 \mathrm{U}$ & \\
\hline $699-43-45$ & $1 / 26 / 90$ & HOOODGT8 & & $5.00 \mathrm{U}$ & & \\
\hline $699-43-45$ & $1 / 26 / 90$ & HOOODGT8 & & & $5.00 \mathrm{U}$ & \\
\hline $699-43-45$ & $4 / 18 / 90$ & H0OODGV2 & & $5.00 \mathrm{U}$ & & \\
\hline $699-43-45$ & $4 / 18 / 90$ & HOOOOGV2 & & & $5.00 \mathrm{U}$ & \\
\hline $699-43-45$ & $7 / 08 / 91$ & H00079Y8 & u & & & \\
\hline $699-43-45$ & $1 / 24 / 92$ & $B 01000$ & 7.00 & & & \\
\hline $699-43-45$ & $1 / 24 / 92$ & B01001 & & & $5.00 \mathrm{U}$ & \\
\hline $699-43-45$ & $4 / 22 / 92$ & B065H8 & $5.00 \mathrm{U}$ & & & \\
\hline $699-43-45$ & $4 / 22 / 92$ & B065N9 & & & $5.00 \mathrm{U}$ & \\
\hline $699-43-45$ & $6 / 26 / 92$ & B070W2 & $5.00 \mathrm{U}$ & & & \\
\hline $699-43-45$ & $6 / 26 / 92$ & B070W3 & & & $5.00 \mathrm{U}$ & \\
\hline $699-43-45$ & $10 / 26 / 92$ & B07JG7 & $5.00 \mathrm{U}$ & & & \\
\hline $699-43-45$ & $10 / 26 / 92$ & B07JG8 & & & $5.00 \mathrm{U}$ & \\
\hline $699-43-45$ & $1 / 13 / 93$ & B07V29 & $5.00 \mathrm{U}$ & & & \\
\hline $699-43-45$ & $1 / 13 / 93$ & B07V33 & & & $5.00 \mathrm{U}$ & \\
\hline $699-44-398$ & $1 / 08 / 93$ & B07NK1 & $5.00 \mathrm{U}$ & & & \\
\hline $699-44-39 B$ & $1 / 08 / 93$ & B07UK5 & & & $5.00 \mathrm{U}$ & \\
\hline $699-44-42$ & $11 / 21 / 88$ & HOOODHK2 & & $5.00 \mathrm{U}$ & & \\
\hline $699-44-42$ & $11 / 21 / 88$ & HOOODHK2 & & & $5.00 \mathrm{U}$ & \\
\hline $699-44-42$ & $2 / 17 / 89$ & H0OODHKG & & $5.00 \mathrm{U}$ & & \\
\hline $699-44-42$ & $2 / 17 / 89$ & HOOOOHKG & & & $5.00 \mathrm{U}$ & \\
\hline $699-44-42$ & $6 / 15 / 89$ & HOOODHLO & & $5.00 \mathrm{U}$ & & \\
\hline $699-44-42$ & $6 / 15,89$ & HOOOOHLO & & & $5.00 \mathrm{U}$ & \\
\hline $699-44-42$ & $8 / 08,8 \bar{y}$ & HOOODHL 4 & & $5.00 \mathrm{U}$ & & \\
\hline $699-44-42$ & $8 / 08 / 89$ & HOOODHL 4 & & & $5.00 \mathrm{U}$ & \\
\hline $699-44-42$ & $1 / 31 / 90$ & HOOODHL 8 & & $5.00 \mathrm{U}$ & & \\
\hline $699-44-42$ & $1 / 31 / 90$ & HOOODHL8 & & & $5.00 \mathrm{U}$ & \\
\hline $699-44-42$ & $7 / 10 / 91$ & H00071Y9 & $U$ & & & \\
\hline
\end{tabular}


(sheet 89 of $\star$ )

\begin{tabular}{|c|c|c|c|c|c|c|}
\hline $\begin{array}{l}\text { Well } \\
\text { Name }\end{array}$ & $\begin{array}{c}\text { Collection } \\
\text { Date }\end{array}$ & $\begin{array}{l}\text { Sample } \\
\text { Number }\end{array}$ & $\begin{array}{l}\text { LEAD } \\
\text { 40/ppb } \\
5 / 50\end{array}$ & $\begin{array}{l}\text { LEAD } \\
76 / p p b \\
.1\end{array}$ & $\begin{array}{l}\text { FLEAD } \\
\text { 40/ppb } \\
5 / 50\end{array}$ & $\begin{array}{c}\text { PB212 } \\
140 / \mathrm{DC} i / L \\
. /\end{array}$ \\
\hline - & . & n & . & - & - & - \\
\hline $699-44-42$ & $1 / 31 / 92$ & B01552 & $5.00 \mathrm{U}$ & & & \\
\hline $699-44-42$ & $1 / 31 / 92$ & B01554 & & & $5.00 \mathrm{U}$ & \\
\hline $699-44-42$ & $6 / 25 / 92$ & 807017 & $5.00 \mathrm{U}$ & & & \\
\hline $699-44-42$ & $6 / 25 / 92$ & B07021 & & & $5.00 \mathrm{U}$ & \\
\hline $699-44-42$ & $1 / 13 / 93$ & B07v34 & $5.00 \mathrm{U}$ & & & \\
\hline $699-44-42$ & $1 / 13 / 93$ & $807 \sqrt{35}$ & $5.00 \mathrm{U}$ & & & \\
\hline $699-44-42$ & $1 / 13 / 93$ & $807 v 42$ & & & $5.00 \mathrm{U}$ & \\
\hline $699-44-42$ & $1 / 13 / 93$ & B07v43 & & & $5.00 \mathrm{U}$ & \\
\hline $699-44-43 B$ & $12 / 20 / 89$ & H0000HM3 & & $5.00 \mathrm{U}$ & & \\
\hline $699-44-43 B$ & $12 / 20 / 89$ & HOOODHM3 & & & $5.00 \mathrm{U}$ & \\
\hline $699-44-43 B$ & $12 / 20 / 89$ & HOOODHMG & & $5.00 \mathrm{U}$ & & \\
\hline $699-44-43 B$ & $12 / 20 / 89$ & НООООНМ6 & & & $5.00 \mathrm{U}$ & \\
\hline $699-44-43 B$ & $1 / 26 / 90$ & HOOOOHM7 & & $5.00 \mathrm{U}$ & & \\
\hline $699-44-43 B$ & $1 / 26 / 90$ & HOOODHM7 & & & $5.00 \mathrm{U}$ & \\
\hline $699-44-438$ & $1 / 26 / 90$ & НООООНКО & & $5.00 \mathrm{U}$ & & \\
\hline $699-44-43 B$ & $1 / 26 / 90$ & НООООНМО & & & $5.00 \mathrm{U}$ & \\
\hline $699-44-43 B$ & $4 / 18 / 90$ & HOOODHN1 & & $5.00 \mathrm{U}$ & & \\
\hline $699-44-43 B$ & $4 / 18 / 90$ & HOOOOHN1 & & & $5.00 \mathrm{U}$ & \\
\hline $699-44-438$ & $7 / 08 / 91$ & H0007120 & U & & & \\
\hline $699-44-43 B$ & $1 / 23 / 92$ & B01069 & 5.20 & & & \\
\hline $699-44-43 B$ & $1 / 23 / 92$ & B01070 & & & $5.00 \mathrm{U}$ & \\
\hline $699-44-438$ & $4 / 20 / 92$ & B065W9 & $5.00 \mathrm{U}$ & & & \\
\hline $699-44-43 B$ & $4 / 20 / 92$ & $8065 \times 5$ & & & $5.00 \mathrm{U}$ & \\
\hline $699-44-43 B$ & $6 / 26 / 92$ & B01MT4 & & & $5.00 \mathrm{U}$ & \\
\hline $699-44-43 B$ & $6 / 26 / 92$ & B07022 & $5.00 \mathrm{U}$ & & & \\
\hline $699-44-438$ & $6 / 26 / 92$ & B07023 & 5.70 & & & \\
\hline $699-44-43 B$ & $6 / 26 / 92$ & B07026 & & & $5.00 \mathrm{U}$ & \\
\hline $699-44-43 B$ & $1 / 27 / 93$ & B07V44 & $5.00 \mathrm{U}$ & & & \\
\hline $699-44-43 B$ & $1 / 27 / 93$ & B07 448 & & & $5.00 \mathrm{U}$ & \\
\hline
\end{tabular}

\begin{tabular}{|c|c|c|c|c|c|c|}
\hline Hell & Collection & Samole & $\begin{array}{l}\text { FLITHIU } \\
34 / \mathrm{Dob}\end{array}$ & $\begin{array}{l}\text { LITHIUM } \\
35 / \text { pob }\end{array}$ & $\begin{array}{l}\text { MAGNES } \\
34 / \mathrm{pDb}\end{array}$ & $\begin{array}{l}\text { MAGNES } \\
35 / 006\end{array}$ \\
\hline Name & Date & Number & .1 &.$/$ & $100 /$ & .1 \\
\hline , n & - & - & 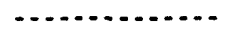 & . & . & $\cdots$ \\
\hline 299-E18-1 & $8 / 16 / 88$ & H0007ZT7 & & & & 15300.00 \\
\hline 299-E 18-1 & $9 / 22 / 88$ & H00072V1 & & & & 17000.00 \\
\hline $299-E 18-1$ & $11 / 10 / 88$ & H0OOZZV2 & & & & 15200.00 \\
\hline 299-E18-1 & $11 / 10 / 88$ & Ho0072v5 & & & & 14700.00 \\
\hline 299-E18-1 & $2 / 15 / 89$ & H00072V8 & & $10.00 \mathrm{U}$ & & 13900.00 \\
\hline 299-E18-1 & $2 / 15 / 89$ & H00072V8 & $10.00 \mathrm{U}$ & & & \\
\hline $299-E 18-1$ & $5 / 26 / 89$ & H0OOZZW2 & & $10.00 \mathrm{U}$ & & 14600.00 \\
\hline
\end{tabular}


(sheet 90 of $* \star$ )

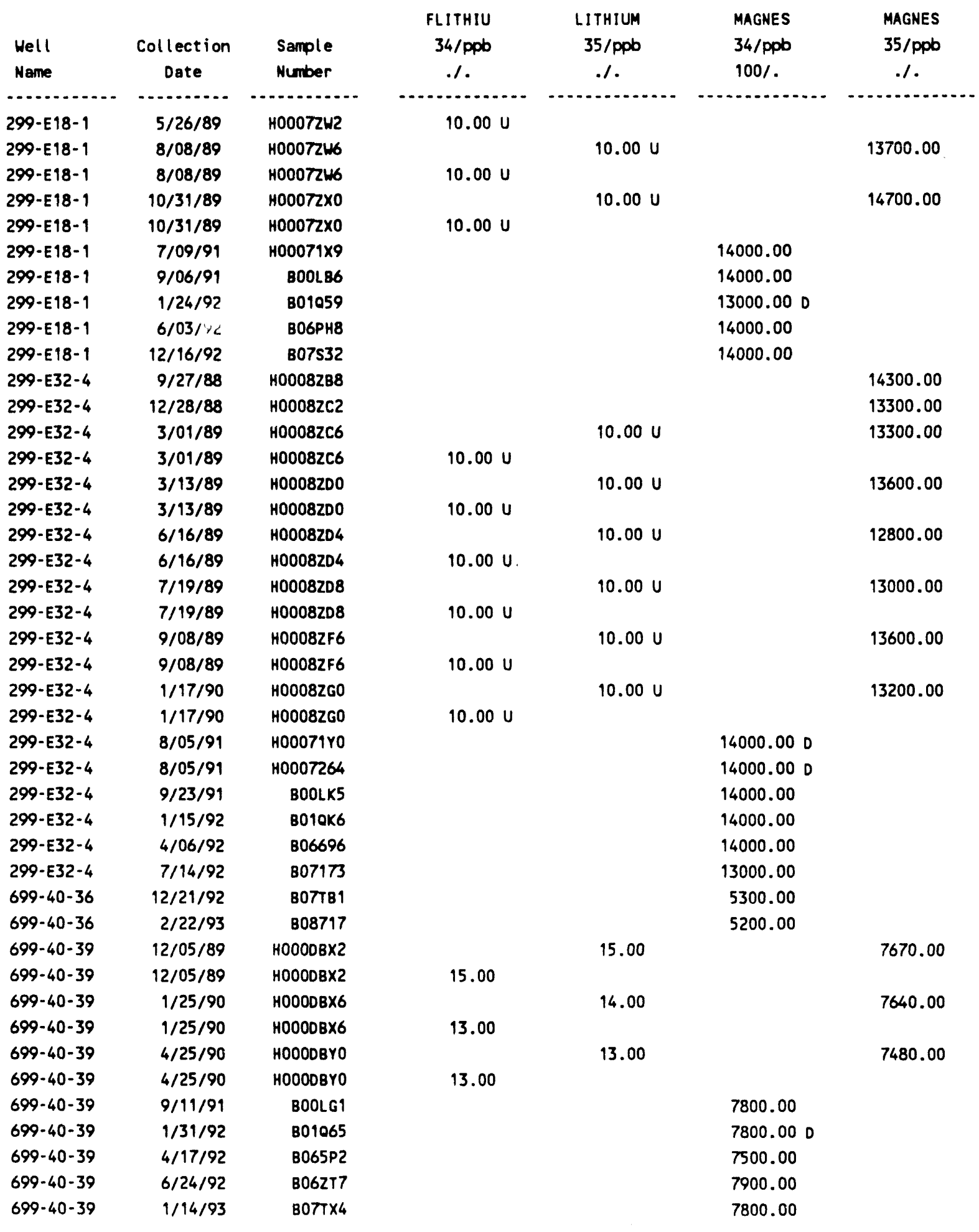


(sheet 91 of $\star *$ )

\begin{tabular}{|c|c|c|c|c|c|c|}
\hline Hell & Collection & Semple & $\begin{array}{l}\text { FLITHIU } \\
34 / \mathrm{ppb}\end{array}$ & $\begin{array}{l}\text { LITHIUM } \\
\text { 35/ppo }\end{array}$ & $\begin{array}{l}\text { MAGNES } \\
34 / \mathrm{ppb}\end{array}$ & $\begin{array}{l}\text { MAGNES } \\
35 / p p b\end{array}$ \\
\hline Name & Date & Number & .1 & .1 & $100 \%$ &.$/$ \\
\hline 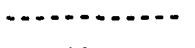 & - & 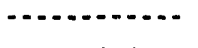 & $\cdots$ & $\cdots$ & . & \\
\hline $699-40-40 \mathrm{~A}$ & $1 / 24 / 92$ & 801762 & & & $8300.00 \mathrm{D}$ & \\
\hline $699-40-40 \mathrm{~A}$ & $4 / 22 / 92$ & B06508 & & & 7500.00 & \\
\hline $699-40-40 A$ & $6 / 25 / 92$ & B062V2 & & & 7300.00 & \\
\hline $699-40-401$ & $10 / 21 / 92$ & $807 J K 3$ & & & 7100.00 & \\
\hline $699-40-40 \mathrm{~A}$ & $1 / 26 / 93$ & B07N49 & & & 7200.00 & \\
\hline $699-40-40 B$ & $1 / 24 / 92$ & B01T64 & & & 10000.000 & \\
\hline $699-40-40 B$ & $4 / 22 / 92$ & B065SO & & & 6300.00 & \\
\hline $699-40-40 B$ & $6 / 29 / 92$ & B062W2 & & & 5800.00 & \\
\hline $699-40-408$ & $10 / 21 / 92$ & B07JK8 & & & 6200.00 & \\
\hline $699-40-40 B$ & $1 / 26 / 93$ & B07v54 & & & 6300.00 & \\
\hline $699-41-35$ & $12 / 21 / 92$ & 807TB9 & & & 6900.00 & \\
\hline $699-41-35$ & $2 / 22 / 93$ & B08707 & & & 6600.00 & \\
\hline $699-41-40$ & $12 / 05 / 89$ & H0O0OD44 & & 10.00 & & 10400.00 \\
\hline $699-41-40$ & $12 / 05 / 89$ & H0OOOD 44 & 10.00 & & & \\
\hline $699-41-40$ & $1 / 25 / 90$ & 40000048 & & 11.00 & & 10000.00 \\
\hline $699-41-40$ & $1 / 25 / 90$ & H0000D48 & 11.00 & & & \\
\hline $699-41-40$ & $4 / 19 / 90$ & H0000052 & & 10.00 & & 10600.00 \\
\hline $699-41-40$ & $4 / 19 / 90$ & H0000052 & $10.00 \mathrm{U}$ & & & \\
\hline $699-41-40$ & $7 / 10 / 91$ & H00071Y1 & & & 12000.00 & \\
\hline $699-41-40$ & $9 / 11 / 91$ & B0OLG2 & & & 11000.00 & \\
\hline $699-41-40$ & $1 / 31 / 92$ & B010C8 & & & $11000.00 \mathrm{D}$ & \\
\hline $699-41 \cdot 40$ & $4 / 28 / 92$ & B065s5 & & & 11000.00 & \\
\hline $699-41-40$ & $4 / 28 / 92$ & B065S6 & & & 11000.00 & \\
\hline $699-41-40$ & $6 / 24 / 92$ & $8062 \times 2$ & & & 11000.00 & \\
\hline $699-41-40$ & $1 / 14 / 93$ & B07TX9 & & & 11000.00 & \\
\hline $699-41-42$ & $1 / 08 / 93$ & B07V59 & & & 6900.00 & \\
\hline $699-42-37$ & $12 / 22 / 92$ & BOTTC4 & & & 9800.00 & \\
\hline $699-42-37$ & $2 / 23 / 93$ & 808712 & & & 10000.00 & \\
\hline $699-42-39 A$ & $1 / 23 / 92$ & 801166 & & & $11000.00 \mathrm{P}$ & \\
\hline $699-42-39 A$ & $4 / 17 / 92$ & B065T1 & & & $12000.00 \mathrm{P}$ & \\
\hline $699-42-39 A$ & $6 / 25 / 92$ & $8062 \times 7$ & & & $11000.00 P$ & \\
\hline $699-42-39 A$ & $10 / 21 / 92$ & B07JL3 & & & $12000.00 P$ & \\
\hline $699-42-39 A$ & $1 / 27 / 93$ & BOTV64 & & & $11000.00 \mathrm{P}$ & \\
\hline $699-42-39 B$ & $1 / 23 / 92$ & В01T68 & & & 10000.00 & \\
\hline $699-42-39 B$ & $4 / 17 / 92$ & B065T6 & & & 10000.00 & \\
\hline $699-42-398$ & $6 / 25 / 92$ & B06ZYZ & & & 10000.00 & \\
\hline $699-42-398$ & $10 / 28 / 92$ & B07JJ2 & & & 11000.00 & \\
\hline $699-42-398$ & $10 / 28 / 92$ & B07JJ3 & & & 11000.00 & \\
\hline $699-42-398$ & $1 / 25 / 93$ & B07N69 & & & 10000.00 & \\
\hline $699-42-40 A$ & $8 / 05 / 86$ & H0OODF33 & & & & 4200.00 \\
\hline $699-42-40 A$ & $1 / 08 / 88$ & H0000F55 & & & & 5590.00 \\
\hline $699-42-40 A$ & $11 / 22 / 88$ & $H 000 D F 60$ & & & & 4700.00 \\
\hline $699-42-40 A$ & $2 / 15 / 89$ & $H 0000 F 65$ & & $10.00 \mathrm{U}$ & & 5230.00 \\
\hline
\end{tabular}


(sheet 92 of $\star *$ )

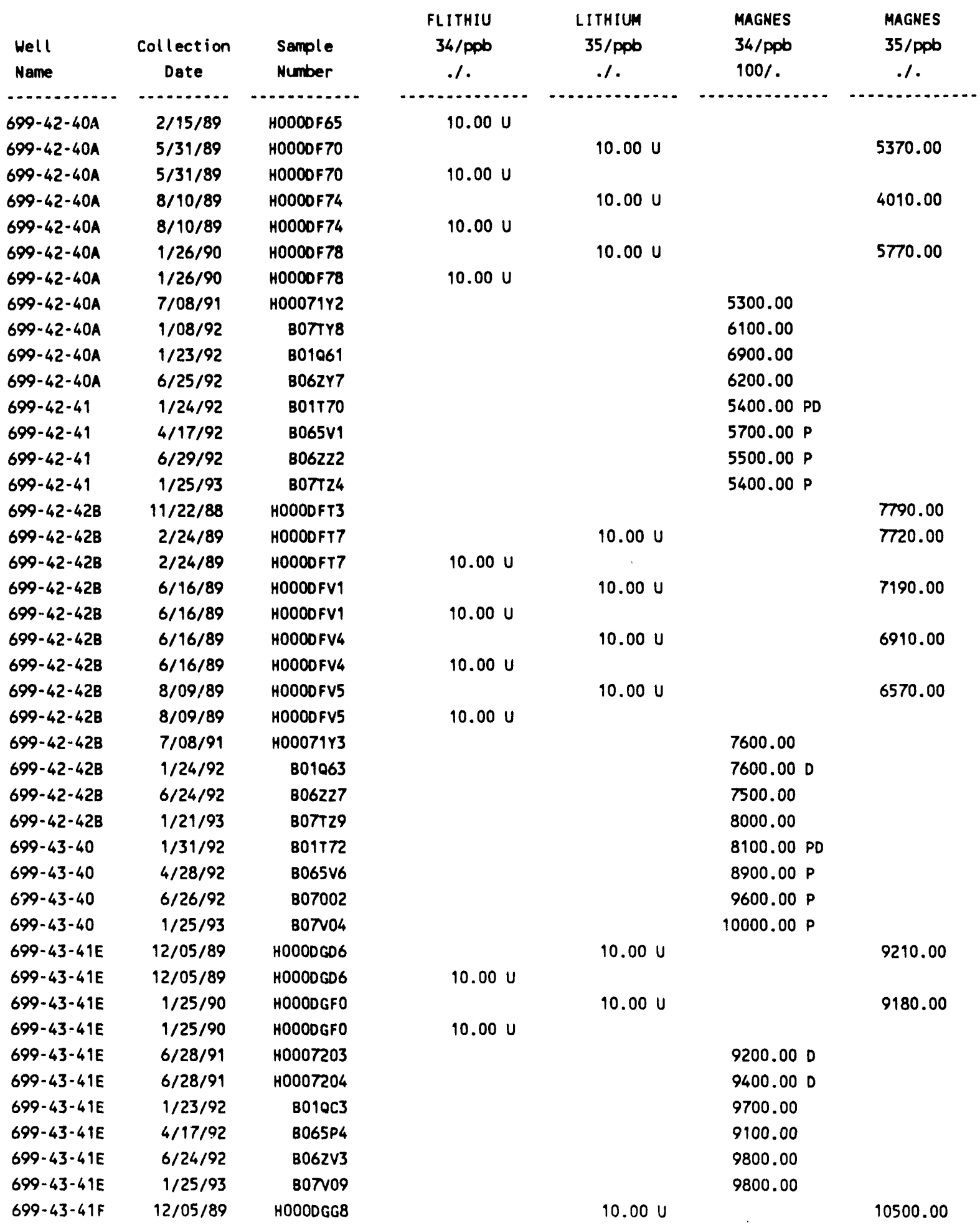


(sheet 93 of ${ }^{* *}$ )

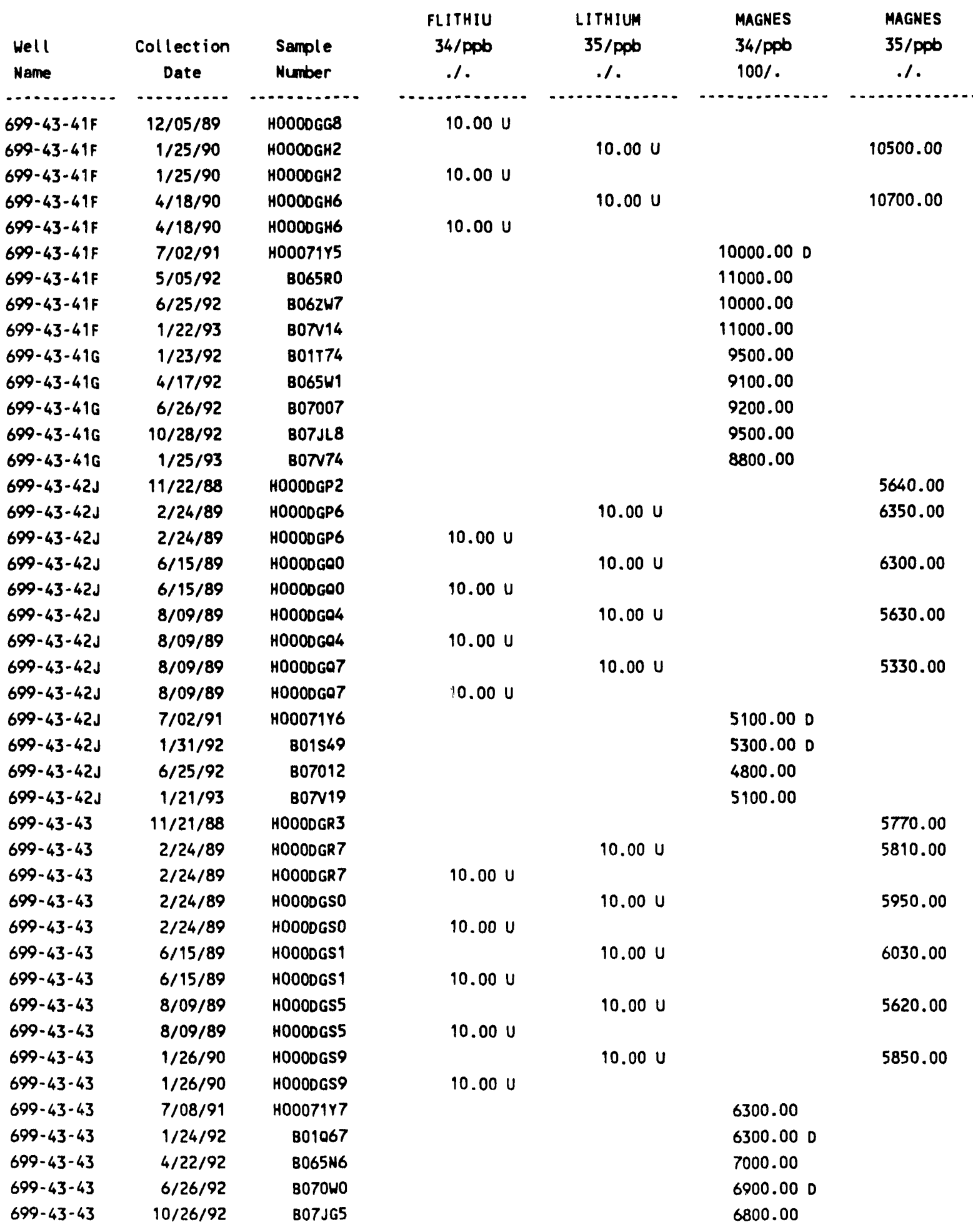


(sheet 94 of $\#$ )

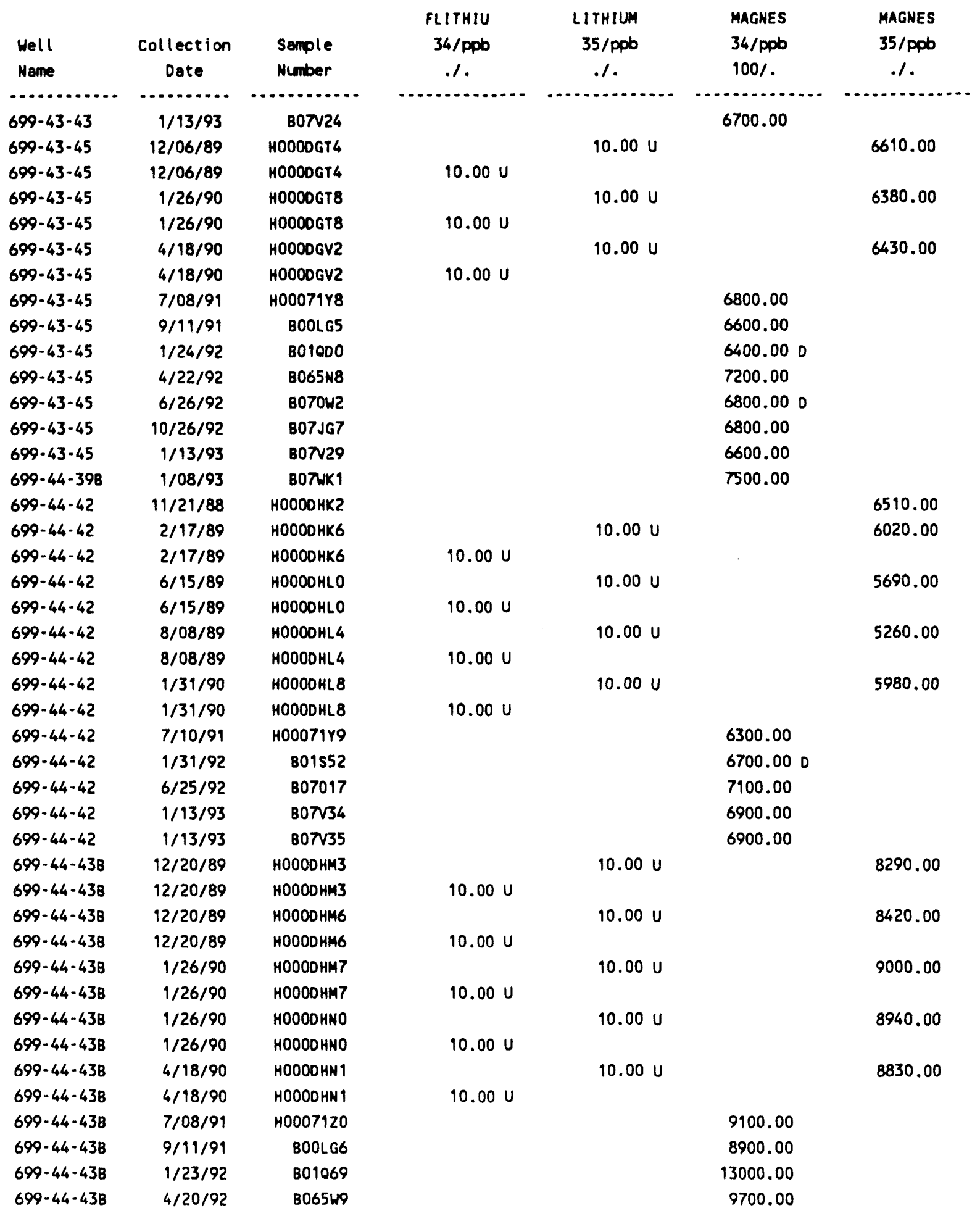


(sheet 95 of **)

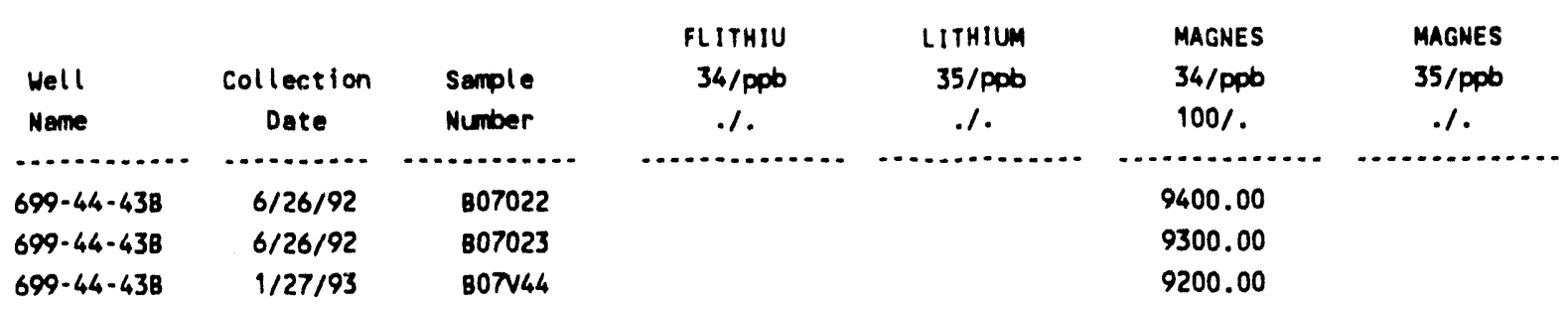

\begin{tabular}{|c|c|c|c|c|c|c|}
\hline $\begin{array}{l}\text { Well } \\
\text { Name }\end{array}$ & $\begin{array}{c}\text { Collection } \\
\text { Date }\end{array}$ & $\begin{array}{l}\text { Sample } \\
\text { Number }\end{array}$ & $\begin{array}{l}\text { FMAGNES } \\
34 / p p b \\
100 /\end{array}$ & $\begin{array}{r}\text { MANGESE } \\
34 / \mathrm{pob} \\
10 / 50 \mathrm{~s}\end{array}$ & $\begin{array}{c}\text { MANGESE } \\
35 / \mathrm{ppb} \\
.150 \mathrm{~s}\end{array}$ & $\begin{array}{l}\text { FMANGAN } \\
34 / \text { ppto } \\
10 / 50 \mathrm{~s}\end{array}$ \\
\hline (n) & $\cdots$ & - & 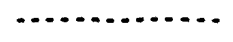 & 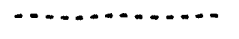 & . & \\
\hline 299-E18-1 & $8 / 16 / 88$ & H0007ZT7 & & & 70.00 & \\
\hline 299-E १8-1 & $8 / 16 / 88$ & H00072T7 & 17100.00 & & & 51.00 \\
\hline $299-E 18-1$ & $9 / 22 / 88$ & HooOTZV1 & & & 46.00 & \\
\hline 299-E18-1 & $9 / 22 / 88$ & H0007ZV1 & 16500.00 & & & 19.00 \\
\hline $299-E 18-1$ & $11 / 10 / 88$ & H0007ZV2 & & & 12.00 & \\
\hline 299-E18-1 & $11 / 10 / 88$ & H0007ZV2 & 15300.00 & & & $5.00 \mathrm{U}$ \\
\hline 299-E18-1 & $11 / 10 / 88$ & H0007ZV5 & & & 12.00 & \\
\hline 299-E18-1 & $11 / 10 / 88$ & Ho007zVs & 14700.00 & & & $5.00 \mathrm{U}$ \\
\hline 299-E18-1 & $2 / 15 / 89$ & H0007ZV8 & & & $5.00 \mathrm{U}$ & \\
\hline 299-E18-1 & $2 / 15 / 89$ & H0007Zv8 & 14400.00 & & & $5.00 \mathrm{U}$ \\
\hline $299-E 18-1$ & $5 / 26 / 89$ & H0007ZW2 & & & 12.00 & \\
\hline 299-E18-1 & $5 / 26 / 89$ & H0007ZW2 & 15100.00 & & & $5.00 \mathrm{U}$ \\
\hline 299-E18-1 & $8 / 08 / 89$ & H0007zW6 & & & 12.00 & \\
\hline 299-E18-1 & $8 / 08 / 89$ & H00072W6 & 16200.00 & & & $5.00 \mathrm{U}$ \\
\hline $299-E 18-1$ & $10 / 31 / 89$ & $400072 \times 0$ & & & 18.00 & \\
\hline 299-E $18-1$ & $10 / 31 / 89$ & $100072 \times 0$ & 15500.00 & & & $5.00 \mathrm{U}$ \\
\hline $299-E 18-1$ & $7 / 09 / 91$ & H00071X9 & & 26.00 & & \\
\hline 299-E18-1 & $7 / 09 / 91$ & H00071X9F & 14000.00 & & & $10.00 \mathrm{U}$ \\
\hline $299-E 18-1$ & $9 / 06 / 91$ & BOOLBG & & 16.00 & & \\
\hline $299-E 18-1$ & $9 / 06 / 91$ & BOOLB6F & 14000.00 & & & $10.00 \mathrm{U}$ \\
\hline $299-E 18-1$ & $1 / 24 / 92$ & B01059 & & 10.00 UD & & \\
\hline $299-E 18-1$ & $1 / 24 / 92$ & 801060 & 13000.000 & & & 10.00 UD \\
\hline 299-E 18-1 & $6 / 03 / 92$ & В06РH8 & & $10.00 \mathrm{U}$ & & \\
\hline 299-E18-1 & $6 / 03 / 92$ & B06PJ2 & 14000.00 & & & $10.00 \mathrm{U}$ \\
\hline $299-E 18-1$ & $12 / 16 / 92$ & B07\$32 & & 20.00 & & \\
\hline $299-E 18-1$ & $12 / 16 / 92$ & B07536 & 14000.00 & & & $10.00 \mathrm{U}$ \\
\hline $299-E 32-4$ & $9 / 27 / 88$ & H00082B8 & & & $5.00 \mathrm{U}$ & \\
\hline $299-E 32-4$ & $9 / 27 / 88$ & H0008288 & 12900.00 & & & $5.00 \mathrm{U}$ \\
\hline $299-E 32-4$ & $12 / 28 / 88$ & $\mathrm{H} 00082 \mathrm{CZ}$ & & & 5.00 & \\
\hline $299-E 32-4$ & $12 / 28 / 88$ & H0008ZC2 & 14000.00 & & & $5.00 \mathrm{U}$ \\
\hline $299-E 32-4$ & $3 / 01 / 89$ & H0008ZC6 & & & 8.00 & \\
\hline $299-E 32-4$ & $3 / 01 / 89$ & $\mathrm{H} 00082 \mathrm{CG}$ & 13400.00 & & & $5.00 \mathrm{U}$ \\
\hline 299-E32-4 & $3 / 13 / 89$ & H0008Z0O & & & 5.00 & \\
\hline
\end{tabular}


(sheet 96 of **)

\begin{tabular}{|c|c|c|c|c|c|c|}
\hline $\begin{array}{l}\text { Well } \\
\text { Name }\end{array}$ & $\begin{array}{c}\text { Collection } \\
\text { Date }\end{array}$ & $\begin{array}{l}\text { Semple } \\
\text { Number }\end{array}$ & $\begin{array}{l}\text { FMAGNES } \\
34 / \text { ppb } \\
100 /\end{array}$ & $\begin{array}{r}\text { MANGESE } \\
34 / \mathrm{ppb} \\
10 / 50 \mathrm{~s}\end{array}$ & $\begin{array}{l}\text { MANGESE } \\
35 / \mathrm{ppb} \\
.150 \mathrm{~s}\end{array}$ & $\begin{array}{r}\text { FMANGAN } \\
34 / \text { ppb } \\
10 / 50 \mathrm{~s}\end{array}$ \\
\hline 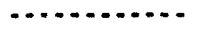 & . & . & . & 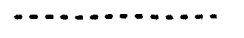 & - & $\cdots \ldots$ \\
\hline $299-E 32-4$ & $3 / 13 / 89$ & $H 0008200$ & 13500.00 & & & $5.00 \mathrm{U}$ \\
\hline $299-E 32-4$ & $6 / 16 / 89$ & $H 0008204$ & & & 13.00 & \\
\hline $299-E 32-4$ & $6 / 16 / 89$ & $\mathrm{H} 0008204$ & 12800.00 & & & $5.00 \mathrm{U}$ \\
\hline $299-E 32-4$ & $7 / 19 / 89$ & H0008208 & & & 7.00 & \\
\hline $299-E 32-4$ & $7 / 19 / 89$ & H0008208 & 12600.00 & & & $5.00 \mathrm{U}$ \\
\hline $299-E 32-4$ & $9 / 08 / 89$ & H00082F6 & & & 13.00 & \\
\hline $299-E 32-4$ & $9 / 08 / 89$ & H00082F6 & 12200.00 & & & $5.00 \mathrm{U}$ \\
\hline 299-E32-4 & $1 / 17 / 90$ & $H 0008260$ & & & 17.00 & \\
\hline 299-E32-4 & $1 / 17 / 90$ & H00082GO & 13300.00 & & & $5.00 \mathrm{U}$ \\
\hline $299-E 32-4$ & $8 / 05 / 91$ & HOOOT1YO & & $26.00 \mathrm{D}$ & & \\
\hline 299-E32-4 & $8 / 05 / 91$ & HOOO71YOF & 14000.00 & & & $10.00 \mathrm{U}$ \\
\hline 299-E32-4 & $8 / 05 / 91$ & 10007264 & & $23.00 \mathrm{D}$ & & \\
\hline 299-E32-4 & $8 / 05 / 91$ & H0007264F & 14000.00 & & & $10.00 \mathrm{U}$ \\
\hline 299-E32-4 & $9 / 23 / 91$ & B00LK5 & & $10.00 \mathrm{U}$ & & \\
\hline $299-E 32-4$ & $9 / 23 / 91$ & 800LK5F & 14000.00 & & & $10.00 \mathrm{U}$ \\
\hline 299-E32-4 & $1 / 15 / 92$ & 8010K6 & & 11.00 & & \\
\hline 299-E32-4 & $1 / 15 / 92$ & 8010K8 & 14000.00 & & & $10.00 \mathrm{U}$ \\
\hline 299-E32-4 & $4 / 06 / 92$ & B06696 & & $10.00 \mathrm{U}$ & & \\
\hline $299-E 32-4$ & $4 / 06 / 92$ & 806697 & 14000.00 & & & $10.00 \mathrm{U}$ \\
\hline $299-E 32-4$ & $7 / 14 / 92$ & B07173 & & $10.00 \mathrm{U}$ & & \\
\hline $299-E 32-4$ & $7 / 14 / 92$ & 807174 & 13000.00 & & & $10.00 \mathrm{U}$ \\
\hline $699-40-36$ & $12 / 21 / 92$ & B07т81 & & 120.00 & & \\
\hline $699-40-36$ & $12 / 21 / 92$ & 807788 & 5300.00 & & & 110.00 \\
\hline $699-40-36$ & $2 / 22 / 93$ & B08717 & & 170.00 & & \\
\hline $699-40-36$ & $2 / 22 / 93$ & 808721 & 5800.00 & & & 150.00 \\
\hline $699-40-39$ & $12 / 05 / 89$ & $400008 \times 2$ & & & 222.00 & \\
\hline $699-40-39$ & $12 / 05 / 89$ & $400008 \times 2$ & 7740.00 & & & 208.00 \\
\hline $699-40-39$ & $1 / 25 / 90$ & $H 00008 \times 6$ & & & 252.00 & \\
\hline $699-40-39$ & $1 / 25 / 90$ & H000DBX6 & 7230.00 & & & 231.00 \\
\hline $699-40-39$ & $4 / 25 / 90$ & HOOODBYO & & & 182.00 & \\
\hline $699-40-39$ & $4 / 25 / 90$ & HOOODBYO & 7440.00 & & & 175.00 \\
\hline $699-40-39$ & $7 / 08 / 91$ & H00079Y4F & 8000.00 & & & 120.00 \\
\hline $699-40-39$ & $9 / 11 / 91$ & BOOLG1 & & 90.00 & & \\
\hline $699-40-39$ & $9 / 11 / 91$ & BOOLG1F & 7600.00 & & & 88.00 \\
\hline $699-40-39$ & $1 / 31 / 92$ & 801065 & & 140.000 & & \\
\hline $699-40-39$ & $1 / 31 / 92$ & B01066 & 7500.000 & & & 57.000 \\
\hline $699-40-39$ & 4/17/92 & B065P2 & & 110.00 & & \\
\hline $699-40-39$ & $4 / 17 / 92$ & B06504 & 7200.00 & & & 83.00 \\
\hline $699-40-39$ & $6 / 24 / 92$ & B06217 & & 83.00 & & \\
\hline $699-40-39$ & $6 / 24 / 92$ & B062V1 & 7900.00 & & & 34.00 \\
\hline $699-40-39$ & $1 / 14 / 93$ & B07TX4 & & 110.00 & & \\
\hline $699-40-39$ & $1 / 14 / 93$ & B077X8 & 7900.00 & & & 50.00 \\
\hline $699-40-40 A$ & $1 / 24 / 92$ & B01T62 & & $370.00 \mathrm{D}$ & & \\
\hline
\end{tabular}


( sheet 97 of *)

\begin{tabular}{|c|c|c|c|c|c|c|}
\hline $\begin{array}{l}\text { Well } \\
\text { Name }\end{array}$ & $\begin{array}{c}\text { Collection } \\
\text { Date }\end{array}$ & $\begin{array}{l}\text { Sample } \\
\text { Number }\end{array}$ & $\begin{array}{c}\text { FMAGNES } \\
34 / \mathrm{ppb} \\
100 /\end{array}$ & $\begin{array}{r}\text { MANGESE } \\
\text { 34/ppb } \\
\text { 10/50s }\end{array}$ & $\begin{array}{c}\text { MANGESE } \\
35 / \mathrm{ppb} \\
.150 \mathrm{~s}\end{array}$ & $\begin{array}{r}\text { FMANGAN } \\
34 / \text { ppb } \\
10 / 50 \mathrm{~s}\end{array}$ \\
\hline . & ................. & $\ldots$ & 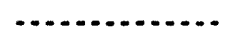 & (n) & . & . \\
\hline $699-40-40 A$ & $1 / 24 / 92$ & B01T63 & 7400.000 & & & 260.000 \\
\hline $699-40-40 \mathrm{~A}$ & $4 / 22 / 92$ & 806508 & & 220.00 & & \\
\hline $699-40-40 \mathrm{~A}$ & $4 / 22 / 92$ & B065R8 & 7600.00 & & & 210.00 \\
\hline $699-40-40 \mathrm{~A}$ & $6 / 25 / 92$ & $8062 \mathrm{~V} 2$ & & 240.00 & & \\
\hline $699-40-40 A$ & $6 / 25 / 92$ & 806240 & 7100.00 & & & 190.00 \\
\hline $699-40-40 A$ & $10 / 21 / 92$ & $807 \mathrm{JK} 3$ & & 200.00 & & \\
\hline $699-40-40 A$ & $10 / 21 / 92$ & 807JK7 & 7100.00 & & & 160.00 \\
\hline $699-40-40 \mathrm{~A}$ & $1 / 26 / 93$ & $807 \times 49$ & & 180.00 & & \\
\hline $699-40-40 A$ & $1 / 26 / 93$ & Bo7v53 & 7100.00 & & & 160.00 \\
\hline $699-40-40 B$ & $1 / 01 / 92$ & B01T65 & $5800.00 \mathrm{D}$ & & & $300.00 \mathrm{D}$ \\
\hline $699-40-408$ & $1 / 24 / 92$ & B01T64 & & 640.000 & & \\
\hline $699-40-40 B$ & $4 / 22 / 92$ & B065SO & & 320.00 & & \\
\hline $699-40-40 B$ & $4 / 22 / 92$ & B065S4 & 5800.00 & & & 270.00 \\
\hline $699-40-408$ & $6 / 29 / 92$ & B06ZW2 & & 300.00 & & \\
\hline $699-40-40 B$ & $6 / 29 / 92$ & B062116 & 5400.00 & & & 250.00 \\
\hline $699-40-40 B$ & $10 / 21 / 92$ & B07JK8 & & 340.00 & & \\
\hline $699-40-408$ & $10 / 21 / 92$ & B07JL2 & 6300.00 & & & 290.00 \\
\hline $699-40-40 B$ & $1 / 26 / 93$ & BOTV54 & & 280.00 & & \\
\hline $699-40-408$ & $1 / 26 / 93$ & B07V58 & 6300.00 & & & 260.00 \\
\hline $699-49-35$ & $12 / 21 / 92$ & во7тв9 & & 180.00 & & \\
\hline $699-41-35$ & $12 / 21 / 92$ & $807 T C 3$ & 6400.00 & & & 170.00 \\
\hline $699-41-35$ & $2 / 22 / 93$ & 808707 & & 150.00 & & \\
\hline $699-41-35$ & $2 / 22 / 93$ & B08711 & 8300.00 & & & 170.00 \\
\hline $699-41-40$ & $12 / 05 / 89$ & $H 0000044$ & & & 107.00 & \\
\hline $699-41-40$ & $12 / 05 / 89$ & 10000044 & 10300.00 & & & 93.00 \\
\hline $699-41-40$ & $1 / 25 / 90$ & $H 0000048$ & & & 89.00 & \\
\hline $699-41-40$ & $1 / 25 / 90$ & 10000048 & 10400.00 & & & $\pi 5.00$ \\
\hline $699-41-40$ & $4 / 19 / 90$ & 40000052 & & & 44.00 & \\
\hline $699-41-40$ & $4 / 19 / 90$ & H0000052 & 9960.00 & & & 35.00 \\
\hline $699-41-40$ & $7 / 10 / 91$ & H00071Y1 & & 19.00 & & \\
\hline $699-41-40$ & $7 / 10 / 91$ & H00071Y1F & 12000.00 & & & 11.00 \\
\hline $699-41-40$ & $9 / 11 / 91$ & $800 L G 2$ & & 21.00 & & \\
\hline $699-41-40$ & $9 / 11 / 91$ & BOOLG2F & 11000.00 & & & $10.00 \mathrm{U}$ \\
\hline $699 \cdot 41 \cdot 40$ & $1 / 31 / 92$ & B010C8 & & 60.000 & & \\
\hline $699-41-40$ & $1 / 31 / 92$ & 8010C9 & $11000.00 \mathrm{D}$ & & & 10.00 UD \\
\hline $699-41-40$ & $4 / 28 / 92$ & 806555 & & $10.00 \mathrm{U}$ & & \\
\hline $699-41 \cdot 40$ & $4 / 28 / 92$ & B065S6 & & $10.00 \mathrm{U}$ & & \\
\hline $699 \cdot 41-40$ & $4 / 28 / 92$ & B06559 & 11000.00 & & & $10.00 \mathrm{U}$ \\
\hline $699-41-40$ & $4 / 28 / 92$ & B065TO & 11000.00 & & & $10.00 \mathrm{U}$ \\
\hline $699-41-40$ & $6 / 24 / 92$ & $8062 \times 2$ & & 16.00 & & \\
\hline $699-41-40$ & $6 / 24 / 92$ & $B 062 \times 6$ & 11000.00 & & & $10.00 \mathrm{U}$ \\
\hline $699-41-40$ & $1 / 14 / 93$ & $807 \pi \times 9$ & & 30.00 & & \\
\hline $699-41 \cdot 40$ & $1 / 14 / 93$ & $8077 Y 3$ & 11000.00 & & & 10.00 \\
\hline
\end{tabular}


(sheet 98 of $\star \star$ )

\begin{tabular}{|c|c|c|c|c|c|c|}
\hline $\begin{array}{l}\text { Well } \\
\text { Name }\end{array}$ & $\begin{array}{c}\text { Collection } \\
\text { Date }\end{array}$ & $\begin{array}{l}\text { Sample } \\
\text { Number }\end{array}$ & $\begin{array}{l}\text { FMAGNES } \\
34 / \mathrm{ppb} \\
100 /\end{array}$ & $\begin{array}{r}\text { MANGESE } \\
34 / \mathrm{ppb} \\
10 / 50 \mathrm{~s}\end{array}$ & $\begin{array}{l}\text { MANGESE } \\
35 / \mathrm{ppb} \\
. / 50 \mathrm{~s}\end{array}$ & $\begin{array}{l}\text { FMANGAN } \\
34 / \mathrm{ppb} \\
10 / 50 \mathrm{~s}\end{array}$ \\
\hline n & . & 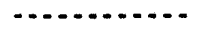 & - & 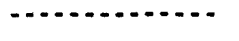 & 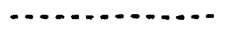 & . \\
\hline $699-41-42$ & $1 / 08 / 93$ & B07V59 & & $10.00 \mathrm{U}$ & & \\
\hline $699-41-42$ & $1 / 08 / 93$ & B07v63 & 6700.00 & & & $10.00 \mathrm{U}$ \\
\hline $699-42-37$ & $12 / 22 / 92$ & BoTtC4 & & 140.00 & & \\
\hline $699-42-37$ & $12 / 22 / 92$ & B07TC8 & 9400.00 & & & 120.00 \\
\hline $699-42-37$ & $2 / 23 / 93$ & B08712 & & 130.00 & & \\
\hline $699-42-37$ & $2 / 23 / 93$ & 808716 & 10000.00 & & & 120.00 \\
\hline $699-42-39 A$ & $1 / 23 / 92$ & B01T66 & & $56.00 \mathrm{P}$ & & \\
\hline $699-42-39 A$ & $1 / 23 / 92$ & $801 T 67$ & $11000.00 \mathrm{P}$ & & & $47.00 P$ \\
\hline $699-42-39 A$ & $4 / 17 / 92$ & B065T1 & & $170.00 \mathrm{P}$ & & \\
\hline $699-42-39 A$ & $4 / 17 / 92$ & B065T5 & $11000.00 \mathrm{P}$ & & & $79.00 P$ \\
\hline $699-42-39 A$ & $6 / 25 / 92$ & $8062 \times 7$ & & $110.00 \mathrm{P}$ & & \\
\hline $699-42-39 A$ & $6 / 25 / 92$ & B06ZY1 & $11000.00 \mathrm{P}$ & & & $24.00 \mathrm{P}$ \\
\hline $699-42-391$ & $10 / 21 / 92$ & B07JL3 & & $140.00 \mathrm{P}$ & & \\
\hline $699-42-39 A$ & $10 / 21 / 92$ & 807JL7 & $11000.00 \mathrm{P}$ & & & $10.00 P$ \\
\hline $699-42-39 A$ & $1 / 27 / 93$ & B07v64 & & $40.00 \mathrm{P}$ & & \\
\hline $699-42-39 A$ & $1 / 27 / 93$ & B07N68 & $11000.00 \mathrm{P}$ & & & 10.00 UP \\
\hline $699-42-398$ & $1 / 23 / 92$ & B01T68 & & 660.00 & & \\
\hline $699-42-398$ & $1 / 23 / 92$ & В01T69 & 11000.00 & & & 630.00 \\
\hline $699-42-398$ & $4 / 17 / 92$ & $8065 T 6$ & & 570.00 & & \\
\hline $699-42-398$ & $4 / 17 / 92$ & B065VO & 10000.00 & & & 520.00 \\
\hline $699-42-398$ & $6 / 25 / 92$ & B06ZY2 & & 460.00 & & \\
\hline $699-42-398$ & $6 / 25 / 92$ & B062Y6 & 9500.00 & & & 360.00 \\
\hline $699-42-398$ & $10 / 28 / 92$ & B07JJ2 & & 320.00 & & \\
\hline $699-42-39 B$ & $10 / 28 / 92$ & $807 J J 3$ & & 320.00 & & \\
\hline $699-42-39 B$ & $10 / 28 / 92$ & B07JJ6 & 10000.00 & & & 280.00 \\
\hline $699-42-398$ & $10 / 28 / 92$ & B07JJ7 & 11000.00 & & & 310.00 \\
\hline $699-42-398$ & $1 / 25 / 93$ & B07v69 & & 290.00 & & \\
\hline $699-42-39 B$ & $1 / 25 / 93$ & B07N73 & 10000.00 & & & 270.00 \\
\hline $699-42-40 A$ & $8 / 22 / 85$ & HOOODF 11 & & & 33.00 & \\
\hline $699-42-40 A$ & $5 / 12 / 86$ & HOOODF27 & & & 6.00 & \\
\hline $699-42-40 \mathrm{~A}$ & $8 / 05 / 86$ & H000DF33 & & & 19.00 & \\
\hline $699-42-40 A$ & $1 / 08 / 88$ & H000DF55 & & & $5.00 \mathrm{U}$ & \\
\hline $699-42-40 A$ & $1 / 08 / 88$ & H0000F55 & 5630.00 & & & 11.00 \\
\hline $699-42-40 A$ & $11 / 22 / 88$ & H000DF60 & & & 12.00 & \\
\hline $699-42-40 A$ & $11 / 22 / 88$ & $H 000 D F 60$ & 4430.00 & & & $5.00 \mathrm{U}$ \\
\hline $699-42-40 A$ & 2/15/89 & $H 0000 F 65$ & & & 8.00 & \\
\hline $699-42-40 A$ & $2 / 15 / 89$ & H0000F65 & 5680.00 & & & 5.00 \\
\hline $699-42-40 A$ & $5 / 31 / 89$ & HOOODF70 & & & 8.00 & \\
\hline $699-42-40 A$ & $5 / 31 / 89$ & HOOODF 70 & 5190.00 & & & 5.00 \\
\hline $699-42-40 A$ & $8 / 10 / 89$ & HOOODF74 & & & 9.00 & \\
\hline $699-42-40 A$ & $8 / 10 / 89$ & H0OODF74 & 4950.00 & & & 8.00 \\
\hline $699-42-40 A$ & $1 / 26 / 90$ & HOOODF78 & & & 15.00 & \\
\hline $699-42-40 \mathrm{~A}$ & $1 / 26 / 90$ & HOOODF 78 & 5740.00 & & & 7.00 \\
\hline
\end{tabular}


(sheet 99 of $* *$ )

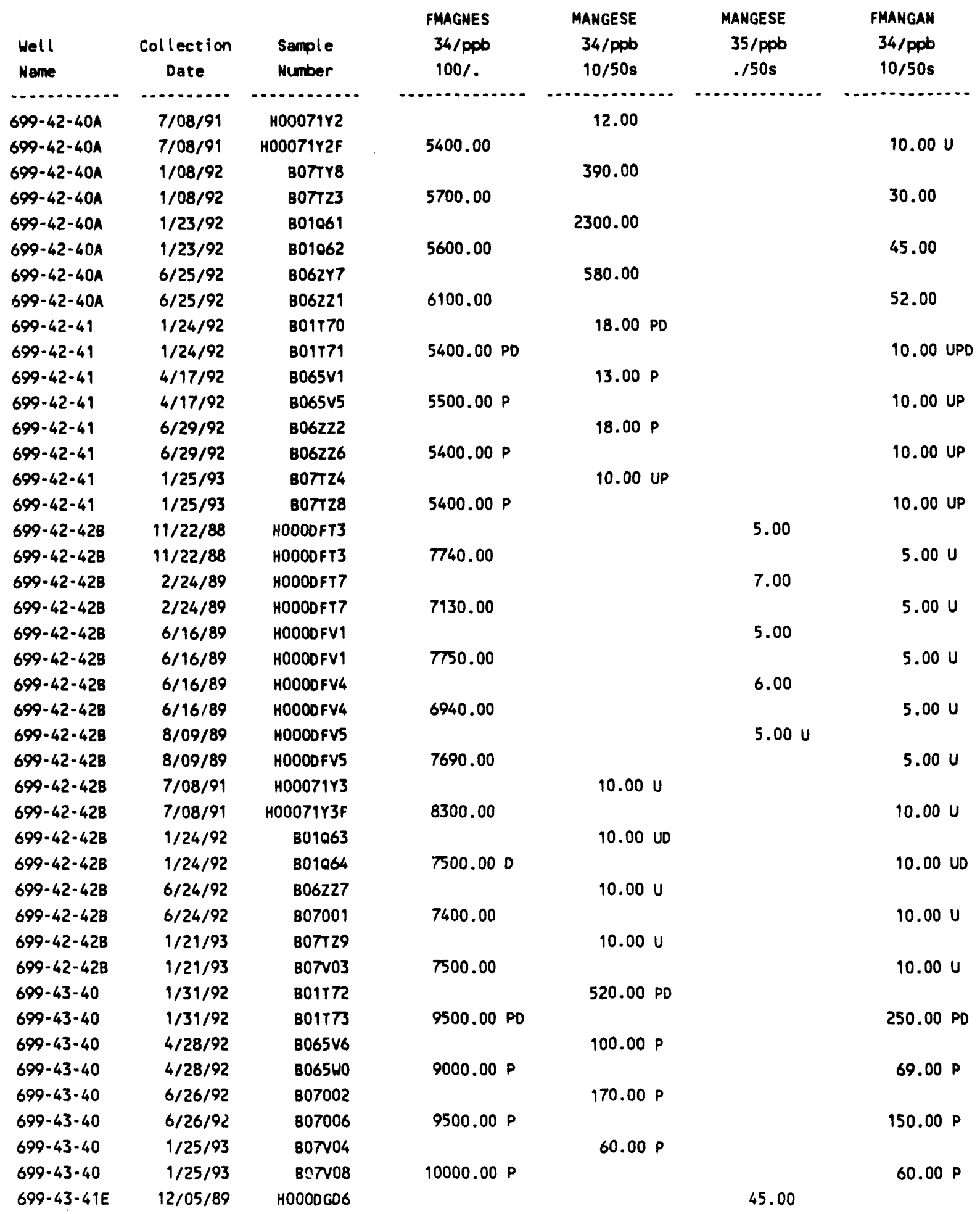


(sheet ** of **)

\begin{tabular}{|c|c|c|c|c|c|c|}
\hline $\begin{array}{l}\text { Well } \\
\text { Nane }\end{array}$ & $\begin{array}{l}\text { Collection } \\
\text { Date }\end{array}$ & $\begin{array}{l}\text { Sample } \\
\text { Number }\end{array}$ & $\begin{array}{l}\text { FMAGNES } \\
34 / \mathrm{ppb} \\
100 /\end{array}$ & $\begin{array}{r}\text { MANGESE } \\
34 / \mathrm{ppb} \\
10 / 50 \mathrm{~s}\end{array}$ & $\begin{array}{l}\text { MANGESE } \\
35 / \mathrm{ppb} \\
.150 \mathrm{~s}\end{array}$ & $\begin{array}{l}\text { FMANGAN } \\
34 / \text { ppb } \\
\text { 10/50s }\end{array}$ \\
\hline (n) & . & 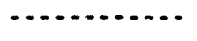 & 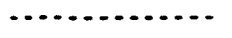 & (n) & - & . \\
\hline $699-43-41 E$ & $12 / 05 / 89$ & H0000CD6 & 8900.00 & & & 33.00 \\
\hline $699-43-41 E$ & $1 / 25 / 90$ & HOOOOGFO & & & 34.00 & \\
\hline $699-43-41 E$ & $1 / 25 / 90$ & HOOOOGFO & 8890.00 & & & 16.00 \\
\hline $699-43-41 E$ & $6 / 28 / 91$ & н0007203 & & $12.00 \mathrm{D}$ & & \\
\hline $699-43-41 E$ & $6 / 28 / 91$ & H0007203F & 9100.00 & & & $10.00 \mathrm{U}$ \\
\hline $699-43-41 E$ & $6 / 28 / 91$ & H0007204 & & $12.00 \mathrm{D}$ & & \\
\hline $699-43-41 E$ & $6 / 28 / 91$ & H0007204F & 9200.00 & & & $10.00 \mathrm{U}$ \\
\hline $699-43-41 E$ & $1 / 23 / 92$ & $8010 c 3$ & & $10.00 \mathrm{U}$ & & \\
\hline $699-43-41 E$ & $1 / 23 / 92$ & B010C4 & 9900.00 & & & 51.00 \\
\hline $699-43-41 E$ & $4 / 17 / 92$ & B065P4 & & 38.00 & & \\
\hline $699-43-41 E$ & $4 / 17 / 92$ & 806506 & 9300.00 & & & $10.00 \mathrm{U}$ \\
\hline $699-43-41 E$ & $6 / 24 / 92$ & $8062 \sqrt{3}$ & & 12.00 & & \\
\hline $699-43-41 E$ & $6 / 24 / 92$ & 8062W1 & 9600.00 & & & $10.00 \mathrm{U}$ \\
\hline $699-43-41 E$ & $1 / 25 / 93$ & Borv09 & & 10.00 & & \\
\hline $699-43-41 E$ & $1 / 25 / 93$ & B07N13 & 9800.00 & & & $10.00 \mathrm{U}$ \\
\hline $699-43-41 F$ & $12 / 05 / 89$ & H00006C8 & & & 154.00 & \\
\hline $699-43-41 F$ & $12 / 05 / 89$ & H0000GG8 & 10600.00 & & & 216.00 \\
\hline $699-43-41 F$ & $1 / 25,90$ & HOOOOGHZ & & & 90.00 & \\
\hline $699-43-41 F$ & $1 / 25 / 90$ & H0OOOGH2 & 10000.00 & & & 79.00 \\
\hline $699-43-41 F$ & $4 / 18 / 90$ & HOOODGH6 & & & 116.00 & \\
\hline $699-43-41 F$ & $4 / 18 / 90$ & H0000GH6 & 10300.00 & & & 89.00 \\
\hline $699-43-41 F$ & $7 / 02 / 91$ & H0007IY5 & & $23.00 \mathrm{D}$ & & \\
\hline $699-43-41 F$ & $7 / 02 / 91$ & H00079Y5F & 10000.00 & & & 21.00 \\
\hline $699-43-41 F$ & $5 / 05 / 92$ & B065RO & & 20.00 & & \\
\hline $699-43-41 F$ & $5 / 05 / 92$ & $8065 R 9$ & 11000.00 & & & $10.00 \mathrm{U}$ \\
\hline $699-43-41 F$ & $6 / 25 / 92$ & $8062 W 7$ & & 40.00 & & \\
\hline $699-43-49 F$ & $6 / 25 / 92$ & $8062 \times 1$ & 10000.00 & & & $10.00 \mathrm{U}$ \\
\hline $699-43-41 F$ & $1 / 22 / 93$ & 807v14 & & $10.00 \mathrm{U}$ & & \\
\hline $699-43-49 F$ & $1 / 22 / 93$ & Borvi8 & 11000.00 & & & $10.00 \mathrm{U}$ \\
\hline $699-43-416$ & $1 / 23 / 92$ & 801T74 & & 360.00 & & \\
\hline $699-43-416$ & $1 / 23 / 92$ & Bo1r7s & 9500.00 & & & 310.00 \\
\hline $699-43-416$ & $4 / 17 / 92$ & $8065 W 1$ & & 320.00 & & \\
\hline $699-43-416$ & $4 ; i 7 / 92$ & B065 16 & 9100.00 & & & 320.00 \\
\hline $649-43-416$ & $6 / 26 / 92$ & 807007 & & 220.00 & & \\
\hline $699-43-416$ & $6 / 26 / 92$ & B07011 & 9200.00 & & & 210.00 \\
\hline $699-43-416$ & $10 / 28 / 92$ & B07JL8 & & 130.00 & & \\
\hline $699-43-416$ & $10 / 28 / 92$ & B07JM2 & 9600.00 & & & 130.00 \\
\hline $699-43-416$ & $1 / 25 / 93$ & BOTV74 & & 110.00 & & \\
\hline $699-43-416$ & $1 / 25 / 93$ & B07N78 & 9500.00 & & & 140.00 \\
\hline $699-43-42 J$ & $11 / 22 / 88$ & HOOOOGP2 & & & $5.00 \mathrm{U}$ & \\
\hline $699-43-42 J$ & $11 / 22 / 88$ & HOOOOGPZ & 5850.00 & & & $5.00 \mathrm{U}$ \\
\hline $699-43-42 J$ & $2 / 24 / 89$ & HOOOOGPG & & & 8.00 & \\
\hline $699-43-42 J$ & $2 / 24 / 89$ & HOOODGP6 & 6380.00 & & & 5.00 \\
\hline
\end{tabular}


(sheet $*$ of $*$ )

\begin{tabular}{|c|c|c|c|c|c|c|}
\hline $\begin{array}{l}\text { Well } \\
\text { Name }\end{array}$ & $\begin{array}{c}\text { Collection } \\
\text { Dete }\end{array}$ & $\begin{array}{l}\text { Sample } \\
\text { Number }\end{array}$ & $\begin{array}{l}\text { FMAGNES } \\
34 / \text { ppb } \\
100 /\end{array}$ & $\begin{array}{r}\text { MANGESE } \\
34 / \text { ppb } \\
10 / 50 \text { s }\end{array}$ & $\begin{array}{c}\text { MANGESE } \\
35 / \mathrm{ppb} \\
.150 \mathrm{~s}\end{array}$ & $\begin{array}{l}\text { FMANGAN } \\
34 / \mathrm{ppb} \\
10 / 50 \text { s }\end{array}$ \\
\hline $699-43-42 \mathrm{~J}$ & $6 / 15 / 89$ & HOOOOGQO & (n) & (n) & 7.00 & \\
\hline $699-43-42 J$ & $6 / 15 / 89$ & HOOOOCOO & 6600.00 & & & 5.00 \\
\hline $699-43-42 J$ & $8 / 09 / 89$ & H0O0OGO4 & & & 18.00 & \\
\hline $699-43-42 \mathrm{~J}$ & $8 / 09 / 89$ & HOOOOGO4 & 6070.00 & & & $5.00 \mathrm{U}$ \\
\hline $699-43-42 J$ & $8 / 09 / 89$ & H0OOOGO7 & & & 12.00 & \\
\hline $699-43-42 J$ & $8 / 09 / 89$ & H0000G07 & 6290.00 & & & 5.00 \\
\hline $699-43-42 J$ & $7 / 02 / 91$ & H00071Y6 & & 10.00 UD & & \\
\hline $699-43-42 \mathrm{~J}$ & $7 / 02 / 91$ & H00071Y6F & 5000.00 & & & $10.00 \mathrm{U}$ \\
\hline $699-43-42 \mathrm{~J}$ & $1 / 31 / 92$ & 801549 & & $16.00 \mathrm{D}$ & & \\
\hline $699-43-42 \mathrm{~J}$ & $1 / 31 / 92$ & B01551 & $5100.00 \mathrm{D}$ & & & 10.00 UD \\
\hline $699-43-42 \mathrm{~J}$ & $6 / 25 / 92$ & B07012 & & 21.00 & & \\
\hline $699-43-42 \mathrm{~J}$ & $6 / 25 / 92$ & B07016 & 4000.00 & & & $10.00 \mathrm{U}$ \\
\hline $699-43-42 J$ & $1 / 21 / 93$ & BoTv19 & & 10.00 & & \\
\hline $699-43-42 \mathrm{~J}$ & $1 / 21 / 93$ & Bo7v23 & 5000.00 & & & $10.00 \mathrm{U}$ \\
\hline $699-43-43$ & $11 / 21 / 88$ & H0OOOGR3 & & & $5.00 \mathrm{U}$ & \\
\hline $699-43-43$ & $11 / 21 / 88$ & HOOOOGR3 & 5270.00 & & & $5.00 \mathrm{U}$ \\
\hline $699-43-43$ & $2 / 24 / 89$ & HOOODGR7 & & & $5.00 U$ & \\
\hline $699-43-43$ & $2 / 24 / 89$ & HOOOOGR7 & 5430.00 & & & $5.00 \mathrm{U}$ \\
\hline $699-43-43$ & $2 / 24 / 89$ & HOOODGSO & & & $5.00 \mathrm{U}$ & \\
\hline $699-43-43$ & $2 / 24 / 89$ & HOOODGSO & 5370.00 & & & $5.00 \mathrm{U}$ \\
\hline $699-43-43$ & $6 / 15 / 89$ & H00ODGS1 & & & 8.00 & \\
\hline $699-43-43$ & $6 / 15 / 89$ & H0000GS1 & 5960.00 & & & 5.00 \\
\hline $699-43-43$ & $8 / 09 / 89$ & H0OODGS5 & & & $5.00 \mathrm{U}$ & \\
\hline $699-43-43$ & $8 / 09 / 89$ & H0000GS5 & 6070.00 & & & $5.00 \mathrm{U}$ \\
\hline $699-43-43$ & $1 / 26 / 90$ & HOOODGSO & & & $5.00 \mathrm{U}$ & \\
\hline $699-43-43$ & $1 / 26 / 90$ & HOOODGS9 & 5960.00 & & & $5.00 \mathrm{U}$ \\
\hline $699-43-43$ & $7 / 08 / 91$ & H00071Y7 & & $10.00 \mathrm{U}$ & & \\
\hline $699-43-43$ & $7 / 08 / 91$ & H00071Y7F & 6100.00 & & & $10.00 \mathrm{U}$ \\
\hline $699-43-43$ & $1 / 24 / 92$ & B01067 & & 10.00 UD & & \\
\hline $699-43-43$ & $1 / 24 / 92$ & 801068 & 6400.000 & & & 10.00 UD \\
\hline $699-43-43$ & $4 / 22 / 92$ & 8065N6 & & $10.00 \mathrm{U}$ & & \\
\hline $699-43-43$ & $4 / 22 / 92$ & 8065N7 & 6600.00 & & & $10.00 \mathrm{U}$ \\
\hline $699-43-43$ & $6 / 26 / 92$ & BO70w0 & & 10.00 UD & & \\
\hline $699-43-43$ & $6 / 26 / 92$ & B070W1 & 6700.00 & & & $10.00 \mathrm{U}$ \\
\hline $699-43-43$ & $10 / 26 / 92$ & B07JG5 & & $10.00 \mathrm{U}$ & & \\
\hline $699-43-43$ & $10 / 26 / 92$ & B07JG6 & 6800.00 & & & $10.00 \mathrm{U}$ \\
\hline $699-43-43$ & $1 / 13 / 93$ & BOTV24 & & $10.00 \mathrm{U}$ & & \\
\hline $699-43-43$ & $1 / 13 / 93$ & B07V28 & 6400.00 & & & $10.00 \mathrm{U}$ \\
\hline $699-43-45$ & $12 / 06 / 89$ & HOOOOGT4 & & & 6.00 & \\
\hline $699-43-45$ & $12 / 06 / 89$ & HOOOOGT4 & 6580.00 & & & $5.00 \mathrm{U}$ \\
\hline $699-43-45$ & $1 / 26 / 90$ & HOOODGT8 & & & 11.00 & \\
\hline $699-43-45$ & $1 / 26 / 90$ & HOOODGT 8 & 6270.00 & & & $5.00 \mathrm{U}$ \\
\hline $699-43-45$ & $4 / 18 / 90$ & H0000GV2 & & & 7.00 & \\
\hline
\end{tabular}


(sheet * of **)

\begin{tabular}{|c|c|c|c|c|c|c|}
\hline $\begin{array}{l}\text { Well } \\
\text { Name }\end{array}$ & $\begin{array}{c}\text { Collection } \\
\text { Date }\end{array}$ & $\begin{array}{l}\text { Semple } \\
\text { Number }\end{array}$ & $\begin{array}{l}\text { FMAGNES } \\
34 / \mathrm{ppb} \\
100 /\end{array}$ & $\begin{array}{r}\text { MANGESE } \\
34 / \mathrm{ppb} \\
10 / 50 \mathrm{~s}\end{array}$ & $\begin{array}{c}\text { MANGESE } \\
35 / \mathrm{ppb} \\
. / 50 \mathrm{~s}\end{array}$ & $\begin{array}{l}\text { FMANGAN } \\
34 / \text { ppb } \\
10 / 50 \text { s }\end{array}$ \\
\hline , n & (n) & n & (n) & 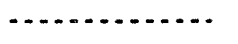 & $\ldots . .$. & 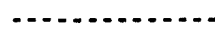 \\
\hline $699-43-45$ & $4 / 48 / 90$ & H0OODGV2 & 6510.00 & & & $5.00 \mathrm{U}$ \\
\hline $699-43-45$ & $7 / 08 / 91$ & H00071Y8 & & 15.00 & & \\
\hline $699-43-45$ & $7 / 08 / 91$ & H00079Y8F & 6800.00 & & & $10.00 \mathrm{U}$ \\
\hline $699-43-45$ & $9 / 11 / 91$ & B00LG5 & & $10.00 \mathrm{U}$ & & \\
\hline $699-43-45$ & $9 / 11 / 91$ & BOOLG5F & 6800.00 & & & $10.00 \mathrm{U}$ \\
\hline $699-43-45$ & $1 / 24 / 92$ & 801000 & & $15.00 \mathrm{D}$ & & \\
\hline $699-43-45$ & $1 / 24 / 92$ & B01001 & $6400.00 \mathrm{D}$ & & & 10.00 UD \\
\hline $699-43-45$ & $4 / 22 / 92$ & B065N8 & & 12.00 & & \\
\hline $699-43-45$ & $4 / 22 / 92$ & B065N9 & 7100.00 & & & $10.00 \mathrm{U}$ \\
\hline $699-43-45$ & $6 / 26 / 92$ & BO70W2 & & 10.00 UD & & \\
\hline $699-43-45$ & $6 / 26 / 92$ & B070、13 & 6900.00 & & & $10.00 \mathrm{U}$ \\
\hline $699-43-45$ & $10 / 26 / 92$ & 807JG7 & & 10.00 & & \\
\hline $699-43-45$ & $10 / 26 / 92$ & B07JG8 & 6800.00 & & & $10.00 \mathrm{U}$ \\
\hline $699-43-45$ & $1 / 13 / 93$ & B07V29 & & 10.00 & & \\
\hline $699-43-45$ & $1 / 13 / 93$ & $807 \sqrt{33}$ & 6400.00 & & & $10.00 \mathrm{U}$ \\
\hline $699-44-398$ & $1 / 08 / 93$ & B07NK1 & & $10.00 \mathrm{U}$ & & \\
\hline $699-44-39 B$ & $1 / 08 / 93$ & BO7NK5 & 7700.00 & & & $10.00 \mathrm{U}$ \\
\hline $699-44-42$ & $11 / 21 / 88$ & HOOODHK2 & & & $5.00 \mathrm{U}$ & \\
\hline $699-44-42$ & $11 / 21 / 88$ & HOOOOHK2 & 6450.00 & & & $5.00 \mathrm{U}$ \\
\hline $699-44-42$ & $2 / 17 / 89$ & HOOODHKG & & & $5.00 \mathrm{U}$ & \\
\hline $699-44-42$ & $2 / 17 / 89$ & HOOOOHK6 & 6230.00 & & & $5.00 \mathrm{U}$ \\
\hline $699-44-42$ & $6 / 15 / 89$ & HOOOOHLO & & & $5.00 \mathrm{U}$ & \\
\hline $699-44-42$ & $6 / 15 / 89$ & HOOOOHLO & 5610.00 & & & $5.00 \mathrm{U}$ \\
\hline $699-44-42$ & $8 / 08 / 89$ & HOOOOHL 4 & & & $5.00 \mathrm{U}$ & \\
\hline $699-44-42$ & $8 / 08 / 89$ & HOOOOHL 4 & 5750.00 & & & $5.00 \mathrm{U}$ \\
\hline $699-44-42$ & $1 / 31 / 90$ & HOOOOHL8 & & & 6.00 & \\
\hline $699-44-42$ & $1 / 31 / 90$ & HOOODHL8 & 5950.00 & & & $5.00 \mathrm{U}$ \\
\hline $699-44-42$ & $7 / 10 / 91$ & HOOO71Y9 & & $10.00 \mathrm{U}$ & & \\
\hline $699-44-42$ & $7 / 10 / 91$ & H0007IY9F & 3400.00 & & & $10.00 \mathrm{U}$ \\
\hline $699-44-42$ & $1 / 31 / 92$ & 801552 & & 10.00 UD & & \\
\hline $699-44-42$ & $1 / 31 / 92$ & B01S54 & $6900.00 \mathrm{D}$ & & & 10.00 UD \\
\hline $699-44-42$ & $6 / 25 / 92$ & B07017 & & 12.00 & & \\
\hline $699-44-42$ & $6 / 25 / 92$ & B07021 & 7000.00 & & & $10.00 \mathrm{U}$ \\
\hline $699-44-42$ & $1 / 13 / 93$ & $807 \sqrt{34}$ & & $10.00 \mathrm{U}$ & & \\
\hline $699-44-42$ & $1 / 13 / 93$ & Bo7v35 & & $10.00 \mathrm{U}$ & & \\
\hline $699-44-42$ & $1 / 13 / 93$ & B0TV42 & 7100.00 & & & $10.00 \mathrm{U}$ \\
\hline $699-44-42$ & $1 / 13 / 93$ & B07N43 & 6900.00 & & & $10.00 \mathrm{U}$ \\
\hline $699-44-43 B$ & $12 / 20 / 89$ & HОOODHM3 & & & 9.00 & \\
\hline $699-44-438$ & $12 / 20 / 89$ & HOOODHM3 & 8830.00 & & & $5.00 \mathrm{U}$ \\
\hline $699-44-43 B$ & $12 / 20 / 89$ & HOOODHMG & & & 11.00 & \\
\hline $699-44-43 B$ & $12 / 20 / 89$ & HOOODHMG & 8890.00 & & & 7.00 \\
\hline $699-44-43 B$ & $1 / 26 / 90$ & HOOODHM7 & & & 8.00 & \\
\hline $699-44-43 B$ & $1 / 26 / 90$ & HOOUDHM7 & 8770.00 & & & $5.00 \mathrm{U}$ \\
\hline
\end{tabular}


(sheet * of *)

\begin{tabular}{|c|c|c|c|c|c|c|}
\hline $\begin{array}{l}\text { Well } \\
\text { Name }\end{array}$ & $\begin{array}{c}\text { Collection } \\
\text { Date }\end{array}$ & $\begin{array}{l}\text { Sample } \\
\text { Number }\end{array}$ & $\begin{array}{c}\text { FMAGNES } \\
\text { 34/ppb } \\
100 /\end{array}$ & $\begin{array}{l}\text { MANGESE } \\
34 / \mathrm{ppb} \\
10 / 50 \mathrm{~s}\end{array}$ & $\begin{array}{c}\text { MANGESE } \\
35 / \mathrm{ppb} \\
. / 50 \mathrm{~s}\end{array}$ & $\begin{array}{r}\text { FMANGAN } \\
34 / \text { ppb } \\
10 / 50 s\end{array}$ \\
\hline (n) & n......... & $\cdots$ & - & 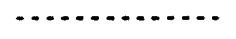 & 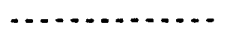 & ............ \\
\hline $699-44-43 B$ & $1 / 26 / 90$ & HOOOOHNO & & & 9.00 & \\
\hline $699-44-43 B$ & $1 / 26 / 90$ & HOOOOHNO & 8760.00 & & & $5.00 \mathrm{U}$ \\
\hline $699-44-438$ & $4 / 18 / 90$ & HOOOOHN1 & & & 19.00 & \\
\hline $699-44-43 B$ & $4 / 18 / 90$ & HOOODHN1 & 8820.00 & & & $5.00 \mathrm{U}$ \\
\hline $699-44-438$ & $7 / 08 / 91$ & H000712O & & 13.00 & & \\
\hline $699-44-438$ & $7 / 08 / 91$ & H0007120F & 9300.00 & & & 10.00 \\
\hline $699-44-438$ & $9 / 11 / 91$ & BOOLG6 & & $10.00 \mathrm{U}$ & & \\
\hline $699-44-43 B$ & $9 / 11 / 91$ & $B 00 L G 6 F$ & 8800.00 & & & $10.00 \mathrm{U}$ \\
\hline $699-44-43 B$ & $1 / 23 / 92$ & 801069 & & $10.00 \mathrm{U}$ & & \\
\hline $699-44-438$ & $1 / 23 / 92$ & 801070 & 9600.00 & & & 13.00 \\
\hline $699-44-43 B$ & $4 / 20 / 92$ & 806510 & & $10.00 \mathrm{U}$ & & \\
\hline $699-44-438$ & $4 / 20 / 92$ & $8065 \times 5$ & 9500.00 & & & $10.00 \mathrm{U}$ \\
\hline $699-44-43 B$ & $6 / 26 / 92$ & B01MT4 & 9100.00 & & & $10.00 \mathrm{U}$ \\
\hline $699-44-438$ & $6 / 26 / 92$ & 807022 & & $10.00 \mathrm{U}$ & & \\
\hline $699-44-43 B$ & $6 / 26 / 92$ & B07023 & & $10.00 \mathrm{U}$ & & \\
\hline $699-44-438$ & $6 / 26 / 92$ & B07026 & 9100.00 & & & $10.00 \mathrm{U}$ \\
\hline $699-44-438$ & $1 / 27 / 93$ & Bo7v44 & & $10.00 \mathrm{U}$ & & \\
\hline $699-44-43 B$ & $1 / 27 / 93$ & B07N48 & 9200.00 & & & $10.00 \mathrm{U}$ \\
\hline
\end{tabular}

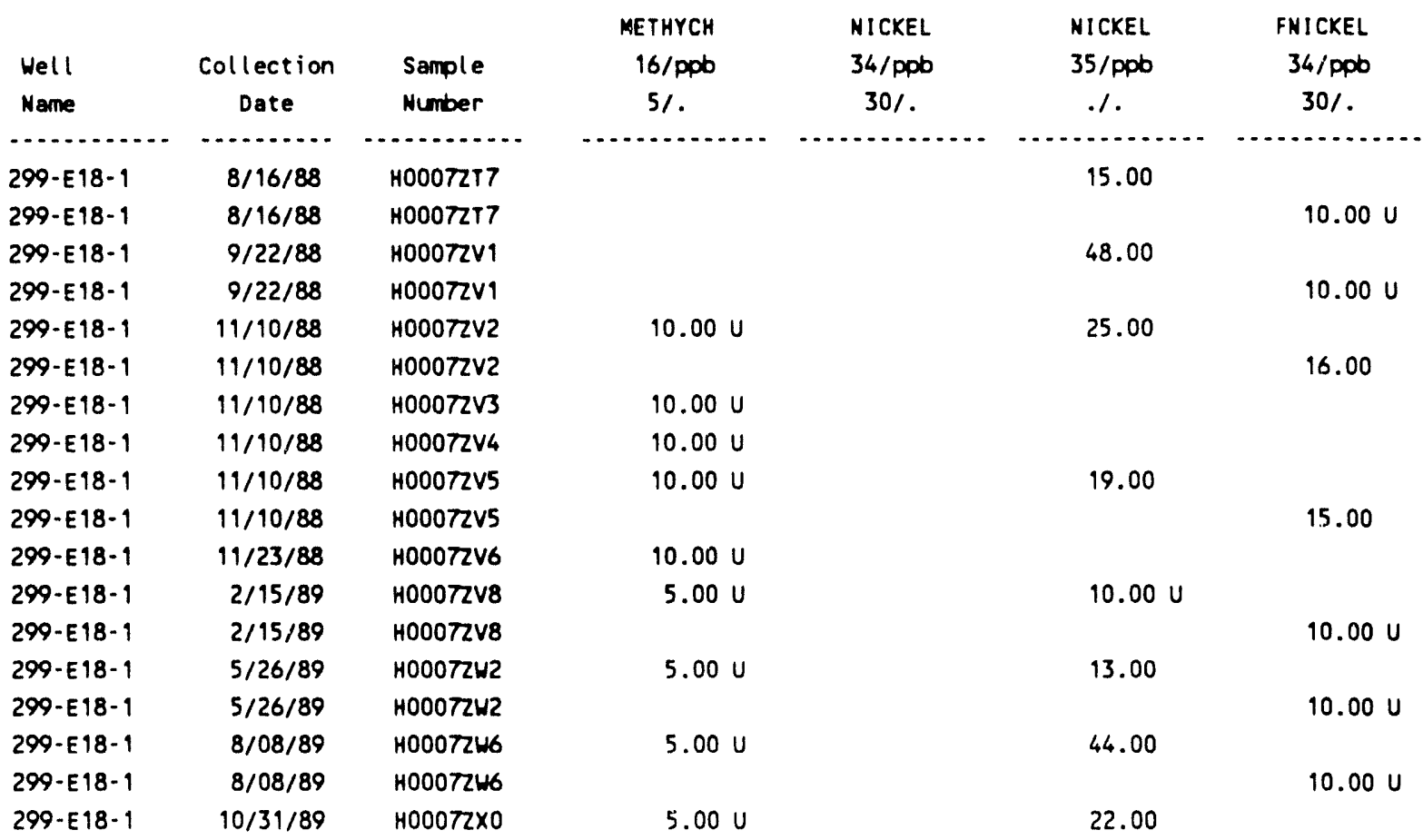


(sheet $\star$ of $\star \star$ )

\begin{tabular}{|c|c|c|c|c|c|c|}
\hline $\begin{array}{l}\text { Hell } \\
\text { Name }\end{array}$ & $\begin{array}{c}\text { Collection } \\
\text { Date }\end{array}$ & $\begin{array}{l}\text { Sample } \\
\text { Number }\end{array}$ & $\begin{array}{c}\text { METHYCH } \\
\text { 16/PpD } \\
5 \%\end{array}$ & $\begin{array}{l}\text { NICKEL } \\
34 / \mathrm{ppb} \\
30 \%\end{array}$ & $\begin{array}{c}\text { NICKEL } \\
35 / \text { ppb } \\
. /\end{array}$ & $\begin{array}{c}\text { ENICKEL } \\
34 / \text { Ppb } \\
30 \%\end{array}$ \\
\hline 299-E18-1 & $10 / 31 / 89$ & H0007ZXO & 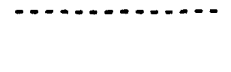 & $\cdots$ & & $10.00 \mathrm{U}$ \\
\hline 299-E18-1 & $7 / 09 / 91$ & H00071X9 & & 67.00 & & \\
\hline 299-E18-1 & $7 / 09 / 91$ & H00071×9F & & & & $30.00 \mathrm{U}$ \\
\hline 299-E18-1 & 9/06/91 & B00LB6 & & 42.00 & & \\
\hline 299-E18-1 & 9/06/91 & BO0LB6F & & & & $30.00 \mathrm{U}$ \\
\hline 299-E 18-1 & $1 / 24 / 92$ & B01059 & & 30.00 UD & & \\
\hline 299-E 18-1 & $1 / 24 / 92$ & $B 01060$ & & & & 30.00 UD \\
\hline 299-E18-1 & 6/03/92 & В06РH8 & $5.00 \mathrm{U}$ & $30.00 \mathrm{U}$ & & \\
\hline 299-E18-1 & $6 / 03 / 92$ & B06PJ2 & & & & $30.00 \mathrm{U}$ \\
\hline 299-E18-1 & $12 / 16 / 92$ & 807532 & & 50.00 & & \\
\hline 299-E18-1 & $12 / 16 / 92$ & B07536 & & & & $30.00 \mathrm{U}$ \\
\hline $299-\varepsilon 32-4$ & $9 / 27 / 88$ & H00082B8 & $10.00 \mathrm{U}$ & & $10.00 \mathrm{U}$ & \\
\hline $299-E 32-4$ & $9 / 27 / 88$ & H00082B8 & & & & $10.00 \mathrm{U}$ \\
\hline $299-E 32-4$ & $12 / 28 / 88$ & H00082C2 & $2.00 \mathrm{U}$ & & 29.00 & \\
\hline 299-E32-4 & $12 / 28 / 88$ & H00082C2 & & & & $10.00 \mathrm{U}$ \\
\hline $299-E 32-4$ & $3 / 01 / 89$ & H0008zC6 & $5.00 \mathrm{U}$ & & 15.00 & \\
\hline $299-E 32-4$ & $3 / 01 / 89$ & H0008zC6 & & & & $10.00 \mathrm{U}$ \\
\hline $299-E 32-4$ & $3 / 13 / 89$ & HOOOBZDO & $5.00 \mathrm{U}$ & & 22.00 & \\
\hline $299-E 32-4$ & $3 / 13 / 89$ & H0008zDO & & & & $10.00 \mathrm{U}$ \\
\hline $299-E 32-4$ & $6 / 16 / 89$ & 40008204 & & & 34.00 & \\
\hline $299-E 32-4$ & $6 / 16 / 89$ & H00082D 4 & & & & $10.00 \mathrm{U}$ \\
\hline $299-E 32-4$ & $7 / 19 / 89$ & H0008208 & $5.00 U$ & & 25.00 & \\
\hline 299-E32-4 & $7 / 19 / 89$ & H0008ZD8 & & & & $10.00 \mathrm{U}$ \\
\hline $299-E 32-4$ & $9 / 08 / 89$ & H00082F6 & $5.00 \mathrm{U}$ & & 19.00 & \\
\hline $299-E 32-4$ & $9 / 08 / 89$ & H00082F6 & & & & 12.00 \\
\hline $299-E 32-4$ & $1 / 17 / 90$ & H0008ZGO & $5.00 \mathrm{U}$ & & 43.00 & \\
\hline 299-E32-4 & $1 / 17 / 90$ & $H 0008260$ & & & & $10.00 \mathrm{U}$ \\
\hline 299-E32-4 & $5 / 09 / 90$ & H00082G9 & $5.00 \mathrm{U}$ & & & \\
\hline $299-E 32-4$ & $8 / 05 / 91$ & HODOT1YO & & 98.000 & & \\
\hline $299-E 32-4$ & $8 / 05 / 91$ & HOOO71YOF & & & & $30.00 \mathrm{U}$ \\
\hline $299-E 32-4$ & $8 / 05 / 91$ & H0007264 & & $85.00 \mathrm{D}$ & & \\
\hline $299-E 32-4$ & $8 / 05 / 91$ & $H 0007264 \mathrm{~F}$ & & & & $30.00 \mathrm{U}$ \\
\hline $299-E 32-4$ & 9/23/91 & B00LK5 & & $30.00 \mathrm{U}$ & & \\
\hline $299-E 32-4$ & $9 / 23 / 91$ & B00LK5F & & & & $30.00 \mathrm{U}$ \\
\hline $299-E 32-4$ & $1 / 15 / 92$ & B010K6 & $5.00 \mathrm{U}$ & 44.00 & & \\
\hline $299-E 32-4$ & $1 / 15 / 92$ & $8010 k 8$ & & & & $30.00 \mathrm{U}$ \\
\hline $299-E 32-4$ & $4 / 06 / 92$ & 806696 & $5.00 \mathrm{U}$ & $30.00 \mathrm{U}$ & & \\
\hline $299-E 32-4$ & $4 / 06 / 92$ & $B 06697$ & & & & $30.00 \mathrm{U}$ \\
\hline $299-E 32-4$ & $7 / 14 / 92$ & 807173 & $5.00 \mathrm{U}$ & 36.00 & & \\
\hline $299-E 32-4$ & $7 / 14 / 92$ & B07174 & & & & $30.00 \mathrm{U}$ \\
\hline $699-40-36$ & $12 / 21 / 92$ & B07T81 & & $30.00 \mathrm{U}$ & & \\
\hline $699-40-36$ & 12/21/92 & B07тB8 & & & & $30.00 \mathrm{U}$ \\
\hline $699-40-36$ & $2 / 22 / 93$ & B08717 & & $30.00 \mathrm{U}$ & & \\
\hline
\end{tabular}


(sheet * of $*$ )

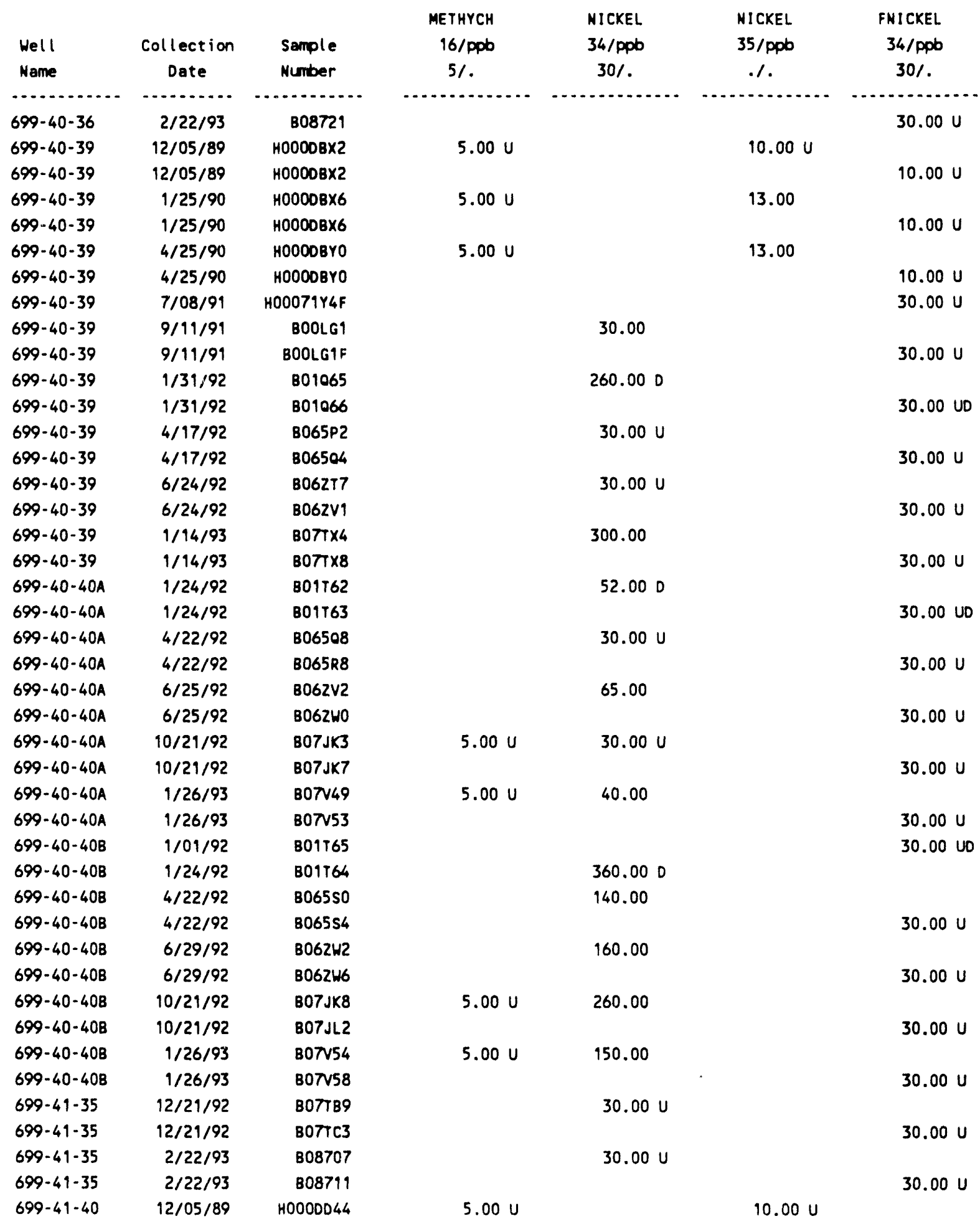


(sheet $\star \star$ of $\star \star)$

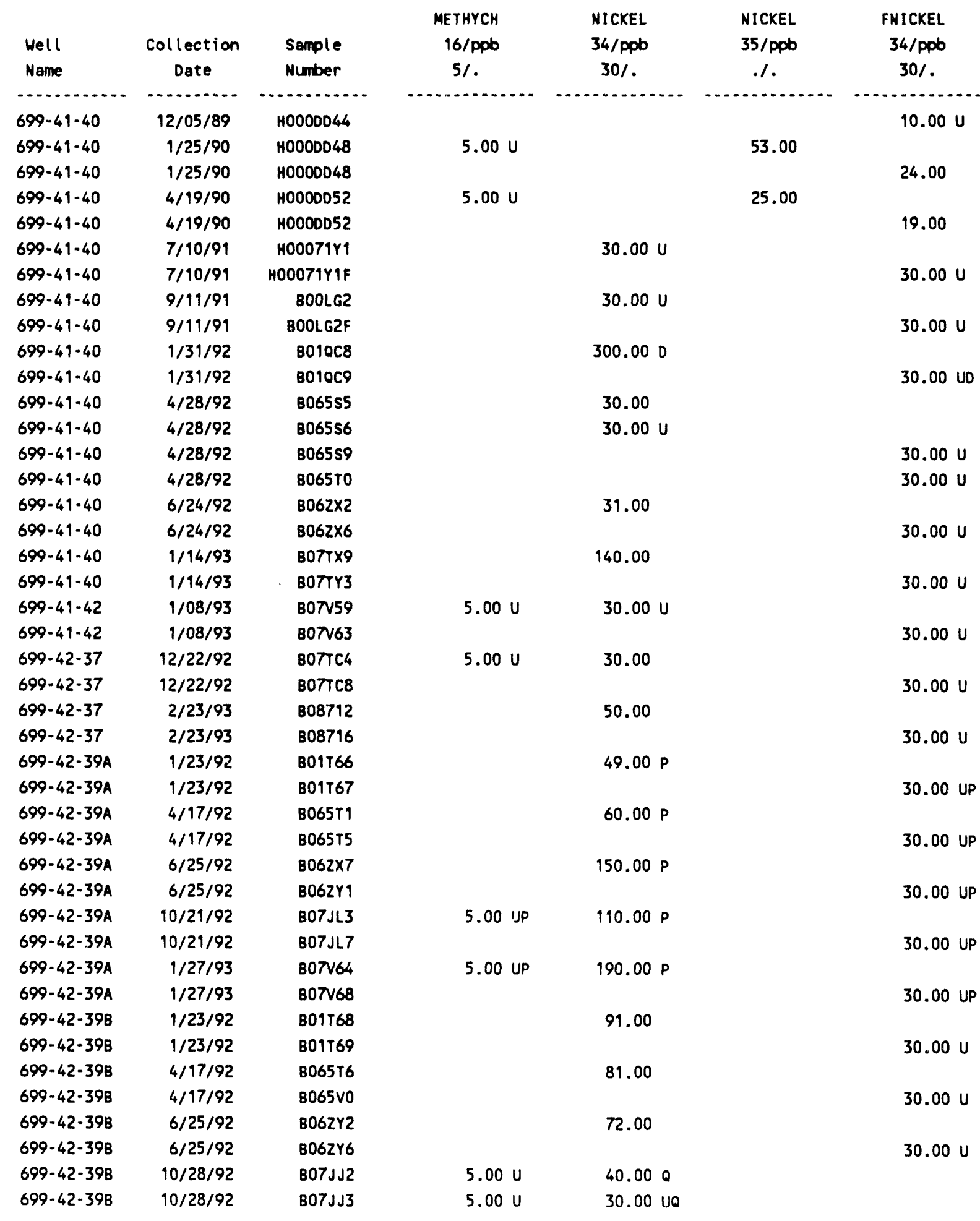


(sheet $\star *$ of $\star *)$

\begin{tabular}{|c|c|c|c|c|c|c|}
\hline $\begin{array}{l}\text { Well } \\
\text { Name }\end{array}$ & $\begin{array}{c}\text { Collection } \\
\text { Date }\end{array}$ & $\begin{array}{l}\text { Sample } \\
\text { Number }\end{array}$ & $\begin{array}{c}\text { METHYCH } \\
\text { 16/ppb } \\
5 / .\end{array}$ & $\begin{array}{c}\text { NICKEL } \\
34 / \mathrm{ppb} \\
30 /\end{array}$ & $\begin{array}{c}\text { MICKEL } \\
35 / \mathrm{ppb} \\
.1\end{array}$ & $\begin{array}{c}\text { FNICKEL } \\
34 / \mathrm{ppb} \\
30 \%\end{array}$ \\
\hline , n & $\cdots$ & , n & - & - & (n) & (n) \\
\hline $699-42-398$ & $10 / 28 / 92$ & B07JJ6 & & & & $30.00 u$ \\
\hline $699-42-398$ & $10 / 28 / 92$ & B07JJ7 & & & & $30.00 \mathrm{U}$ \\
\hline $699-42-39 B$ & $1 / 25 / 93$ & B07N69 & $5.00 \mathrm{U}$ & 120.00 & & \\
\hline $699-42-398$ & $1 / 25 / 93$ & BOTNT3 & & & & $30.00 \mathrm{U}$ \\
\hline $699-42-40 A$ & $8 / 22 / 85$ & HOOODF11 & & & $10.00 \mathrm{U}$ & \\
\hline $699-42-40 A$ & $2 / 07 / 86$ & H0OODF22 & $10.00 \mathrm{U}$ & & & \\
\hline $699-42-40 A$ & $5 / 12 / 86$ & H0OODF27 & & & $10.00 \mathrm{U}$ & \\
\hline $699-42-40 A$ & $8 / 05 / 86$ & H000DF33 & $10.00 \mathrm{U}$ & & $10.00 \mathrm{U}$ & \\
\hline $699-42-40 A$ & $1 / 08 / 88$ & H0OODF55 & $10.00 \mathrm{U}$ & & $10.00 \mathrm{U}$ & \\
\hline $699-42-40 A$ & $1 / 08 / 88$ & H000DF55 & & & & $10.00 \mathrm{U}$ \\
\hline $699-42-40 A$ & $11 / 22 / 88$ & HOOODF60 & $10.00 \mathrm{U}$ & & $10.00 \mathrm{U}$ & \\
\hline $699-42-40 A$ & $11 / 22 / 88$ & HOOODF 60 & & & & $10.00 \mathrm{U}$ \\
\hline $699-42-40 A$ & $2 / 15 / 89$ & H0OODF65 & $5.00 \mathrm{U}$ & & $10.00 \mathrm{U}$ & \\
\hline $699-42-40 A$ & $2 / 15 / 89$ & H0000F65 & & & & $10.00 \mathrm{U}$ \\
\hline $699-42-40 A$ & $5 / 31 / 89$ & HOOODF 70 & $5.00 \mathrm{U}$ & & $10.00 \mathrm{U}$ & \\
\hline $699-42-40 \mathrm{~A}$ & $5 / 31 / 89$ & HOOODF 70 & & & & $10.00 \mathrm{U}$ \\
\hline $699-42-40 \mathrm{~A}$ & $8 / 10 / 89$ & HOOODF 74 & $5.00 \mathrm{U}$ & & $10.00 \mathrm{U}$ & \\
\hline $699-42-40 A$ & $8 / 10 / 89$ & HOOODF 74 & & & & $10.00 \mathrm{U}$ \\
\hline $699-42-40 A$ & $1 / 26 / 90$ & H0OODF 78 & $5.00 \mathrm{U}$ & & $10.00 \mathrm{U}$ & \\
\hline $699-42-40 \mathrm{~A}$ & $1 / 26 / 90$ & HOOODF78 & & & & $10.00 \mathrm{U}$ \\
\hline $699-42-40 A$ & $7 / 08 / 91$ & H00079Y2 & & $30.00 \mathrm{U}$ & & \\
\hline $699-42-40 A$ & $7 / 08 / 91$ & H00071Y2F & & & & $30.00 \mathrm{U}$ \\
\hline $699-42-40 A$ & $1 / 08 / 92$ & B07TY8 & & $30.00 \mathrm{U}$ & & \\
\hline $699-42-40 A$ & $1 / 08 / 92$ & B07TZ3 & & & & $30.00 \mathrm{U}$ \\
\hline $699-42-40 A$ & $1 / 23 / 92$ & B01061 & & $30.00 \mathrm{U}$ & & \\
\hline $699-42-40 A$ & $1 / 23 / 92$ & 801062 & & & & $30.00 \mathrm{U}$ \\
\hline $699-42-40 A$ & $6 / 25 / 92$ & $8062 Y 7$ & & $30.00 \mathrm{U}$ & & \\
\hline $699-42-40 A$ & $6 / 25 / 92$ & B06221 & & & & $30.00 \mathrm{U}$ \\
\hline $699-42-41$ & $1 / 24 / 92$ & B01T70 & & $38.00 \mathrm{PD}$ & & \\
\hline $699-42-41$ & $1 / 24 / 92$ & 801т71 & & & & 30.00 UPD \\
\hline $699-42-41$ & $4 / 17 / 92$ & B065V1 & & $37.00 \mathrm{P}$ & & \\
\hline $699-42-41$ & $4 / 17 / 92$ & $8065 V 5$ & & & & 30.00 UP \\
\hline $699-42-41$ & $6 / 29 / 92$ & B06zZ2 & & 30.00 UP & & \\
\hline $699-42-41$ & $6 / 29 / 92$ & 806226 & & & & 30.00 UP \\
\hline $699-42-41$ & $1 / 25 / 93$ & B07TZ4 & & 30.00 UP & & \\
\hline $699-42-41$ & $1 / 25 / 93$ & B07T28 & & & & 30.00 UP \\
\hline $699-42-42 B$ & $11 / 22 / 88$ & HOOODFT3 & $10.00 \mathrm{U}$ & & $10.00 \mathrm{U}$ & \\
\hline $699-42-42 B$ & $11 / 22 / 88$ & HOOODFT3 & & & & $10.00 \mathrm{U}$ \\
\hline $699-42-428$ & $2 / 24 / 89$ & HOOODFT7 & $5.00 \mathrm{U}$ & & 22.00 & \\
\hline $699-42-42 B$ & $2 / 24 / 89$ & HOOOOFT7 & & & & $10.00 \mathrm{U}$ \\
\hline $699-42-42 B$ & $6 / 16 / 89$ & HOOODFVI & $5.00 \mathrm{U}$ & & $10.00 \mathrm{U}$ & \\
\hline $699-42-42 B$ & $6 / 16 / 89$ & HOOODFVI & & & & $10.00 \mathrm{U}$ \\
\hline $699-42-42 B$ & $6 / 16 / 89$ & HOOODFV 4 & $5.00 \mathrm{U}$ & & 11.00 & \\
\hline
\end{tabular}


(sheet $* *$ of $* *$ )

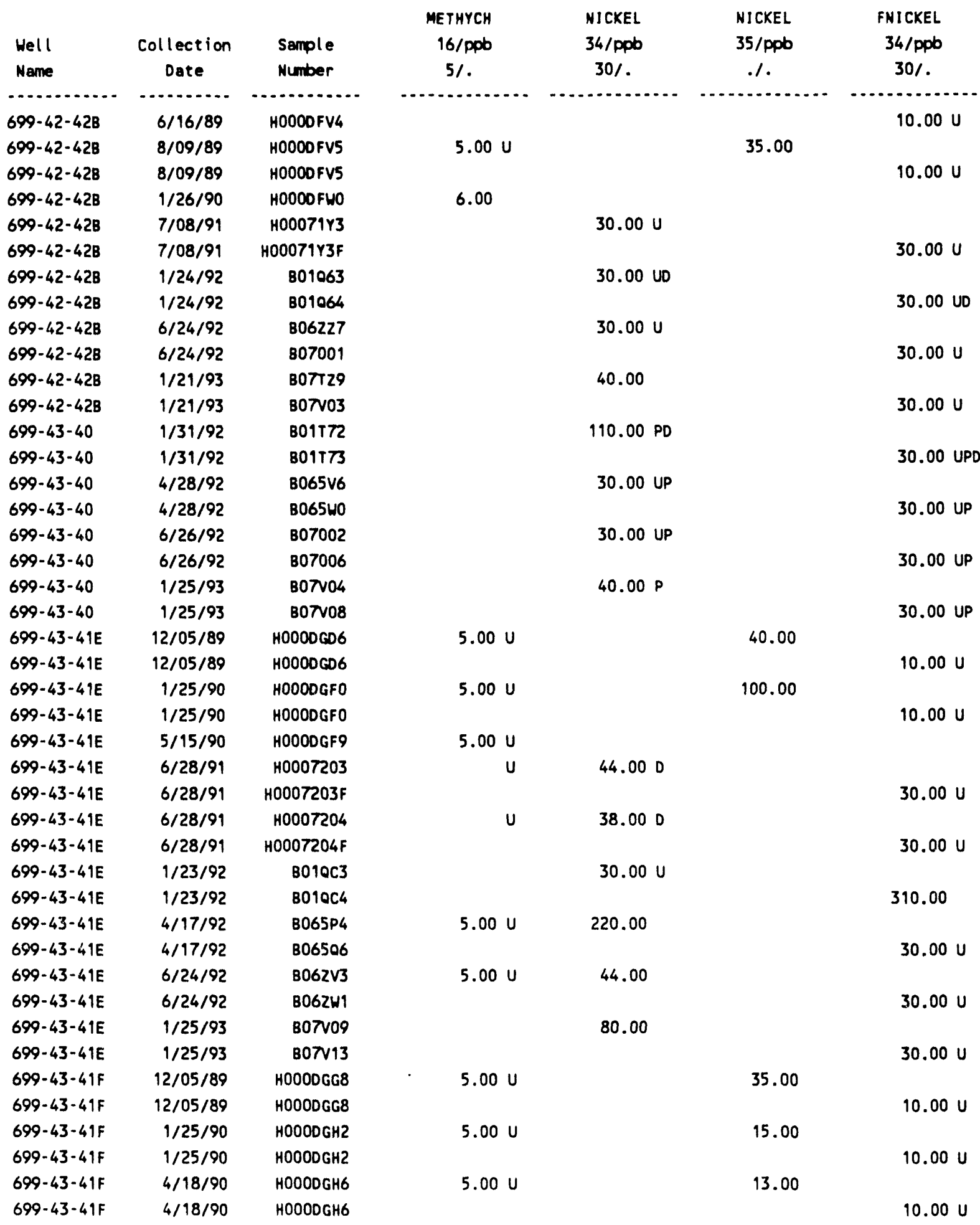


(sheet $*$ of $\star *)$

\begin{tabular}{|c|c|c|c|c|c|c|}
\hline $\begin{array}{l}\text { Well } \\
\text { Name }\end{array}$ & $\begin{array}{c}\text { Collection } \\
\text { Date }\end{array}$ & $\begin{array}{l}\text { Sample } \\
\text { Number }\end{array}$ & $\begin{array}{c}\text { ME THYCH } \\
16 / p p b \\
5 / .\end{array}$ & $\begin{array}{c}\text { NICKEL } \\
34 / \text { ppb } \\
30 / .\end{array}$ & $\begin{array}{c}\text { NICKEL } \\
\text { 35/ppb } \\
. /\end{array}$ & $\begin{array}{c}\text { FNICKEL } \\
34 / \mathrm{ppb} \\
30 /\end{array}$ \\
\hline - & ............... & . & 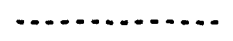 & an. & 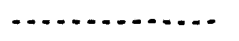 & \\
\hline $699-43-41 F$ & $7 / 02 / 91$ & H00071Y5 & $u$ & 30.00 UD & & \\
\hline $699-43-41 F$ & $7 / 02 / 91$ & H00071Y5F & & & & $30.00 \mathrm{U}$ \\
\hline $699-43-41 F$ & $5 / 05 / 92$ & B065RO & $5.00 \mathrm{U}$ & 55.00 & & \\
\hline $699-43-41 F$ & $5 / 05 / 92$ & B065R9 & & & & $30.00 \mathrm{U}$ \\
\hline $699-43-41 F$ & $6 / 25 / 92$ & B062W7 & $5.00 \mathrm{U}$ & 130.00 & & \\
\hline $099-43-41 F$ & $6 / 25 / 92$ & $8062 \times 1$ & & & & $30.00 \mathrm{U}$ \\
\hline $699-43-41 F$ & $1 / 22 / 93$ & Bo7v14 & & $30.00 \mathrm{U}$ & & \\
\hline $699-43-41 F$ & $1 / 22 / 93$ & BOTV18 & & & & $30.00 \mathrm{U}$ \\
\hline $699-43-416$ & $1 / 23 / 92$ & B01T74 & & $30.00 \mathrm{U}$ & & \\
\hline $699-43-416$ & $1 / 23 / 92$ & B01T75 & & & & $30.00 \mathrm{U}$ \\
\hline $699-43-416$ & $4 / 17 / 92$ & B065W1 & & 100.00 & & \\
\hline $699-43-416$ & $4 / 17 / 92$ & B065W6 & & & & $30.00 \mathrm{U}$ \\
\hline $699-43-416$ & $6 / 26 / 92$ & 807007 & & $30.00 \mathrm{U}$ & & \\
\hline $699-43-416$ & $6 / 26 / 92$ & B07011 & & & & $30.00 \mathrm{U}$ \\
\hline $699-43-416$ & $10 / 28 / 92$ & B07JL8 & $5.00 \mathrm{U}$ & $30.00 \mathrm{U}$ & & \\
\hline $699-43-416$ & $10 / 28 / 92$ & B07JM2 & & & & $30.00 \mathrm{U}$ \\
\hline $699-43-416$ & $1 / 25 / 93$ & BOTV74 & $5.00 \mathrm{U}$ & 40.00 & & \\
\hline $699-43-416$ & $1 / 25 / 93$ & B07V78 & 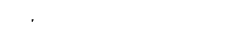 & & & $30.00 \mathrm{U}$ \\
\hline $699-43-42 \mathrm{~J}$ & $11 / 22 / 88$ & H0OOOGP2 & $10.00 \mathrm{U}$ & & 19.00 & \\
\hline $699-43-42 \mathrm{~J}$ & $11 / 22 / 88$ & H0000GP2 & & & & $10.00 \mathrm{U}$ \\
\hline $699-43-42 \mathrm{~J}$ & $2 / 24 / 89$ & HOOODGPG & $5.00 \mathrm{U}$ & & 29.00 & \\
\hline $699-43-42 \mathrm{~J}$ & $2 / 24 / 89$ & H0000GP6 & & & & 12.00 \\
\hline $699-43-42 \mathrm{~J}$ & $6 / 15 / 89$ & HOOOOGOO & $5.00 \mathrm{U}$ & & 34.00 & \\
\hline $699-43-42 \mathrm{~J}$ & $6 / 15 / 89$ & HOOOOGOO & & & & $10.00 \mathrm{U}$ \\
\hline $699-43-42 \mathrm{~J}$ & $8 / 09 / 89$ & H0OOOGO4 & $5.00 \mathrm{U}$ & & 98.00 & \\
\hline $699-43-42 \mathrm{~J}$ & $8 / 09 / 89$ & HOOOOGO4 & & & & $10.00 \mathrm{U}$ \\
\hline $699-43-42 \mathrm{~J}$ & $8 / 09 / 89$ & H0OOOGO7 & $5.00 \mathrm{U}$ & & 57.00 & \\
\hline $699-43-42 \mathrm{~J}$ & $8 / 09 / 89$ & H0OOOGOT & & & & $10.00 \mathrm{U}$ \\
\hline $699-43-42 \mathrm{~J}$ & $1 / 31 / 90$ & H0OOOGOS & $5.00 \mathrm{U}$ & & & \\
\hline $699-43-42 \mathrm{~J}$ & $7 / 02 / 91$ & H00071YG & & 30.00 UD & & \\
\hline $699-43-42 \mathrm{~J}$ & $7 / 02 / 91$ & H00079Y6F & & & & $30.00 \mathrm{U}$ \\
\hline $699-43-42 \mathrm{~J}$ & $1 / 31 / 92$ & $B 01549$ & & 70.000 & & \\
\hline $699-43-42 \mathrm{~J}$ & $1 / 31 / 92$ & B01551 & & & & 30.00 UD \\
\hline $699-43-42 \mathrm{~J}$ & $6 / 25 / 92$ & B07012 & & 110.00 & & \\
\hline $699-43-42 \mathrm{~J}$ & $6 / 25 / 92$ & B07016 & & & & $30.00 \mathrm{U}$ \\
\hline $699-43-42 \mathrm{~J}$ & $1 / 21 / 93$ & Bo7v19 & & 50.00 & & \\
\hline $699-43-42 \mathrm{~J}$ & $1 / 21 / 93$ & BOTN23 & & & & $30.00 \mathrm{U}$ \\
\hline $699-43-43$ & $11 / 21 / 88$ & HOOODGR3 & $10.00 \mathrm{U}$ & & 25.00 & \\
\hline $699-43 \cdot 43$ & $11 / 21 / 88$ & HOOODGR3 & & & & $10.00 \mathrm{U}$ \\
\hline $699-43-43$ & $2 / 24 / 89$ & HOOODGR 7 & $5.00 \mathrm{U}$ & & 20.00 & \\
\hline $699-43-43$ & $2 / 24 / 89$ & HOOOOGRT & & & & $10.00 \mathrm{U}$ \\
\hline $699-43-43$ & $2 / 24 / 89$ & HOOODGSO & $5.00 \mathrm{U}$ & & 16.00 & \\
\hline $699 \cdot 43-43$ & $2 / 24 / 89$ & HOOOOGSO & & & & $10.00 \mathrm{U}$ \\
\hline
\end{tabular}


(sheet ** of **)

\begin{tabular}{|c|c|c|c|c|c|c|}
\hline $\begin{array}{l}\text { Hell } \\
\text { Name }\end{array}$ & $\begin{array}{c}\text { Collection } \\
\text { Date }\end{array}$ & $\begin{array}{l}\text { Sample } \\
\text { Number }\end{array}$ & $\begin{array}{c}\text { METHYCH } \\
16 / p p b \\
5 / .\end{array}$ & $\begin{array}{c}\text { NICKEL } \\
34 / \mathrm{ppb} \\
30 /\end{array}$ & $\begin{array}{c}\text { NICKEL } \\
35 / \mathrm{ppb} \\
.1\end{array}$ & $\begin{array}{c}\text { FNICKEL } \\
34 / \mathrm{ppb} \\
30 \%\end{array}$ \\
\hline (n) & ................ & .................... & 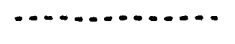 & 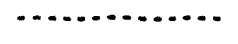 & 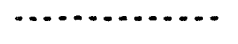 & $\cdots$ \\
\hline $699 \cdot 43-43$ & $6 / 15 / 89$ & HOOODGS1 & $5.00 \mathrm{U}$ & & $10.00 \mathrm{U}$ & \\
\hline $699-43-43$ & $6 / 15 / 89$ & H0OOOGS1 & & & & $10.00 \mathrm{U}$ \\
\hline $699-43-43$ & $8 / 09 / 89$ & H0OOOGS5 & $5.00 \mathrm{U}$ & & $10.00 \mathrm{U}$ & \\
\hline $699-43-43$ & $8 / 09 / 89$ & H0OOOGS5 & & & & $10.00 \mathrm{U}$ \\
\hline $699-43-43$ & $1 / 26 / 90$ & H0OOOGS9 & $5.00 \mathrm{U}$ & & 16.00 & \\
\hline $699-43-43$ & $1 / 26 / 90$ & HOOOOGS9 & & & & $10.00 \mathrm{U}$ \\
\hline $699-43-43$ & $7 / 08 / 91$ & H00071Y7 & & 32.00 & & \\
\hline $699-43-43$ & $7 / 08 / 91$ & H00079Y7F & & & & $30.00 \mathrm{U}$ \\
\hline $699-43-43$ & $1 / 24 / 92$ & 801067 & & 30.00 vo & & \\
\hline $699-43-43$ & $1 / 24 / 92$ & $B 01068$ & & & & 30.00 UD \\
\hline $699-43-43$ & $4 / 22 / 92$ & B065N6 & & 37.00 & & \\
\hline $699-43-43$ & $4 / 22 / 92$ & B065N7 & & & & $30.00 \mathrm{U}$ \\
\hline $699-43-43$ & $6 / 26 / 92$ & 8070w0 & & 30.0040 & & \\
\hline $699-43-43$ & $6 / 26 / 92$ & B070W1 & & & & $30.00 \mathrm{U}$ \\
\hline $699-43-43$ & $10 / 26 / 92$ & B07JG5 & & 40.00 & & \\
\hline $699-43-43$ & $10 / 26 / 92$ & B07JG6 & & & & $30.00 \mathrm{U}$ \\
\hline $699-43-43$ & $1 / 13 / 93$ & $807 v 24$ & & $30.00 \mathrm{U}$ & & \\
\hline $699-43-43$ & $1 / 13 / 93$ & B07V28 & & & & $30.00 \mathrm{U}$ \\
\hline $699-43-45$ & $12 / 06 / 89$ & HOOOOGT4 & $5.00 \mathrm{U}$ & & 20.00 & \\
\hline $699-43-45$ & $12 / 06 / 89$ & HOOODGT4 & & & & $10.00 \mathrm{U}$ \\
\hline $699-43-45$ & $1 / 26 / 90$ & HOOODGTB & $5.00 \mathrm{U}$ & & 27.00 & \\
\hline $699-43-45$ & $1 / 26 / 90$ & HOOOOGT8 & & & & $10.00 \mathrm{U}$ \\
\hline $699-43-45$ & $4 / 18 / 90$ & H0000GV2 & $5.00 \mathrm{U}$ & & 29.00 & \\
\hline $699-43-45$ & $4 / 18 / 90$ & HOOOOGV2 & & & & $10.00 \mathrm{U}$ \\
\hline $699-43-45$ & $7 / 08 / 91$ & H00071Y8 & & 40.00 & & \\
\hline $699-43-45$ & $7 / 08 / 91$ & H00071Y8F & & & & $30.00 \mathrm{U}$ \\
\hline $699-43-45$ & $9 / 11 / 91$ & B00LG5 & & $30.00 \mathrm{U}$ & & \\
\hline $699-43 \cdot 45$ & $9 / 11 / 91$ & BOOLG5F & & & & $30.00 \mathrm{U}$ \\
\hline $699-43-45$ & $1 / 24 / 92$ & $B 01000$ & & $64.00 \mathrm{D}$ & & \\
\hline $699-43-45$ & $1 / 24 / 92$ & 801001 & & & & 30.00 UD \\
\hline $699-43-45$ & $4 / 22 / 92$ & B065N8 & & 45.00 & & \\
\hline $699-43-45$ & $4 / 22 / 92$ & B065N9 & & & & $30.00 \mathrm{U}$ \\
\hline $699-43-45$ & $6 / 26 / 92$ & B070W2 & & 30.00 UD & & \\
\hline $699-43-45$ & $6 / 26 / 92$ & B070W3 & & & & $30.00 \mathrm{U}$ \\
\hline $699-43-45$ & $10 / 26 / 92$ & B07JG7 & & 40.00 & & \\
\hline $699-43-45$ & $10 / 26 / 92$ & B07JG8 & & & & $30.00 \mathrm{U}$ \\
\hline $699-43-45$ & $1 / 13 / 93$ & B07v29 & & 50.00 & & \\
\hline $699-43-45$ & $1 / 13 / 93$ & B07V33 & 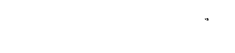 & & & $30.00 \mathrm{U}$ \\
\hline $699-44-398$ & $1 / 08 / 93$ & BOTWK1 & $5.00 \mathrm{U}$ & $30.00 \mathrm{U}$ & & \\
\hline $699-44-398$ & $1 / 08 / 93$ & BOTWK5 & & & & $30.00 \mathrm{U}$ \\
\hline $699-44-42$ & $11 / 21 / 88$ & HOOODHK2 & $10.00 \mathrm{U}$ & & $10.00 \mathrm{U}$ & \\
\hline $699-44-42$ & $11 / 21 / 88$ & HOOODHK2 & & & & $10.00 \mathrm{U}$ \\
\hline $699-44-42$ & $2 / 17 / 89$ & HOOOOHKG & $5.00 \mathrm{U}$ & & $10.00 \mathrm{U}$ & \\
\hline
\end{tabular}


(sheet *t of $*$ )

\begin{tabular}{|c|c|c|c|c|c|c|}
\hline $\begin{array}{l}\text { Hell } \\
\text { Name }\end{array}$ & $\begin{array}{c}\text { Collection } \\
\text { Date }\end{array}$ & $\begin{array}{l}\text { Semple } \\
\text { Number }\end{array}$ & $\begin{array}{l}\text { METHYCH } \\
\text { 16/ppb } \\
5 /\end{array}$ & $\begin{array}{c}\text { NICKEL } \\
34 / \mathrm{ppb} \\
30 /\end{array}$ & $\begin{array}{c}\text { NICKEL } \\
35 / \text { pob } \\
. /\end{array}$ & $\begin{array}{c}\text { FHICKEL } \\
34 / \mathrm{ppb} \\
30 \%\end{array}$ \\
\hline $699-44.42$ & $2 / 17 / 89$ & HOOOOHKG & $\cdots$ & 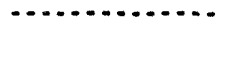 & $\cdots$ & $10.00 \mathrm{U}$ \\
\hline $699-44-42$ & $6 / 15 / 89$ & HOOOOHLO & $5.00 \mathrm{U}$ & & $10.00 \mathrm{U}$ & \\
\hline $699-44-42$ & $6 / 15 / 89$ & HOOOOHLO & & & & $10.00 \mathrm{U}$ \\
\hline $699-44-42$ & $8 / 08 / 89$ & HOOOOHL 4 & $5.00 \mathrm{U}$ & & 15.00 & \\
\hline $699-44-42$ & $8 / 08 / 89$ & HOOOOHL 4 & & & & $10.00 \mathrm{U}$ \\
\hline $699-44-42$ & $1 / 31 / 90$ & HOOOOHL8 & $5.00 \mathrm{U}$ & & 25.00 & \\
\hline $699-44-42$ & $1 / 31 / 90$ & HOOOOHL 8 & & & & $10.00 \mathrm{U}$ \\
\hline $699-44-42$ & $7 / 10 / 91$ & HoOOZ1Y9 & & $30.00 \mathrm{U}$ & & \\
\hline $699-44-42$ & $7 / 10 / 91$ & HOOO71Y9F & & & & $30.00 \mathrm{U}$ \\
\hline $699-44-42$ & $1 / 31 / 92$ & B01S52 & & 30.00 UD & & \\
\hline $699-44-42$ & $1 / 31 / 92$ & 801554 & & & & 30.00 UD \\
\hline $699-44-42$ & $6 / 25 / 92$ & 807017 & & 59.00 & & \\
\hline $699-44-42$ & $6 / 25 / 92$ & B07021 & & & & $30.00 \mathrm{U}$ \\
\hline $699-44-42$ & $1 / 13 / 93$ & $807 \sqrt{34}$ & & $30.00 \mathrm{U}$ & & \\
\hline $699-44-42$ & $1 / 13 / 93$ & B07N35 & $\cdot$ & $30.00 \mathrm{U}$ & & \\
\hline $699-44-42$ & $1 / 13 / 93$ & $807 v 42$ & & & & $30.00 \mathrm{U}$ \\
\hline $699-44-42$ & $1 / 13 / 93$ & B07v43 & & & & $30.00 \mathrm{U}$ \\
\hline $699-44-438$ & $12 / 20 / 89$ & HOOOOHM3 & $5.00 \mathrm{U}$ & & 21.00 & \\
\hline $699-44-43 B$ & $12 / 20 / 89$ & HOOOOHM3 & & & & $10.00 \mathrm{U}$ \\
\hline $699-44-43 B$ & $12 / 20 / 89$ & HOOOOHMG & $5.00 \mathrm{U}$ & & 16.00 & \\
\hline $699-44-43 B$ & $12 / 20 / 89$ & HOOODHMG & & & & $10.00 \mathrm{U}$ \\
\hline $699-44-43 B$ & $1 / 26 / 90$ & HOOODHM7 & $5.00 \mathrm{U}$ & & $10.00 \mathrm{U}$ & \\
\hline $699-44-438$ & $1 / 26 / 90$ & HOOODHM7 & & & & $10.00 \mathrm{U}$ \\
\hline $699-44-43 B$ & $1 / 26 / 90$ & HOOOOHNO & & & 13.00 & \\
\hline $699-44-43 B$ & $1 / 26 / 90$ & HOOOOHNO & & & & $10.00 \mathrm{U}$ \\
\hline $699-44-43 B$ & $4 / 18 / 90$ & HOOODHN1 & $5.00 \mathrm{U}$ & & 13.00 & \\
\hline $699-44-43 B$ & $4 / 18 / 90$ & HОOООНN1 & & & & $10.00 \mathrm{U}$ \\
\hline $699-44-43 B$ & $7 / 08 / 91$ & H000712O & & 39.00 & & \\
\hline $699-44-43 B$ & $7 / 08 / 91$ & H000712OF & & & & $30.00 \mathrm{U}$ \\
\hline $699-44-43 B$ & $9 / 11 / 91$ & BOOLG6 & & $30.00 \mathrm{U}$ & & \\
\hline $699-44-43 B$ & $9 / 11 / 91$ & BOOLGGF & & & & $30.00 \mathrm{U}$ \\
\hline $699-44-43 B$ & $1 / 23 / 92$ & 801069 & & $30.00 \mathrm{U}$ & & \\
\hline $699-44-43 B$ & $1 / 23 / 92$ & 801070 & & & & 69.00 \\
\hline $699-44-43 B$ & $4 / 20 / 92$ & 806519 & & 46.00 & & \\
\hline $699-44-438$ & $4 / 20 / 92$ & $8065 \times 5$ & & & & $30.00 \mathrm{U}$ \\
\hline $699-44-43 B$ & $6 / 26 / 92$ & B01MTL & & & & $30.00 \mathrm{U}$ \\
\hline $699-44-438$ & $6 / 26 / 92$ & B07022 & & $30.00 \mathrm{U}$ & & \\
\hline $699-44-438$ & $6 / 26 / 92$ & 807023 & & $30.00 \mathrm{U}$ & & \\
\hline $699-44-43 B$ & $6 / 26 / 92$ & 807026 & & & & $30.00 \mathrm{U}$ \\
\hline $699-44-438$ & $1 / 27 / 93$ & Borv44 & & 50.00 & & \\
\hline $699-44-43 B$ & $1 / 27 / 93$ & $807 \sim 48$ & & & & $30.00 \mathrm{U}$ \\
\hline
\end{tabular}




\begin{tabular}{|c|c|c|c|c|c|c|}
\hline $\begin{array}{l}\text { Well } \\
\text { Name }\end{array}$ & $\begin{array}{c}\text { Collection } \\
\text { Date }\end{array}$ & $\begin{array}{l}\text { Sample } \\
\text { Number }\end{array}$ & $\begin{array}{c}\text { METHYCH } \\
16 / \mathrm{PPD} \\
5 /\end{array}$ & $\begin{array}{c}\text { NICKEL } \\
34 / \mathrm{ppb} \\
30 /\end{array}$ & $\begin{array}{c}\text { NICKEL } \\
35 / \text { ppb } \\
. /\end{array}$ & $\begin{array}{c}\text { FNICKEL } \\
34 / \mathrm{ppb} \\
30 \%\end{array}$ \\
\hline - & and & 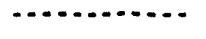 & . & n & n & 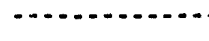 \\
\hline & & & NITRATE & NITRATE & NITRATE & NITRATE \\
\hline Hell & Collection & Sample & 124/ppb & 130/ppb & 46/ppb & 76/ppm \\
\hline Name & Date & Number & $200 / 45000$ & $200 / 45000$ & .145000 &.$/$ \\
\hline$\ldots$ & .............. & n & 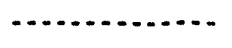 & n & - & n. \\
\hline $299-E 18-1$ & $8 / 16 / 88$ & H0007ZT7 & & & 10100.00 & \\
\hline $299-E 18-1$ & $11 / 10 / 88$ & HoOOTZV2 & & & 8400.00 & \\
\hline $299-E 18-1$ & $11 / 10 / 88$ & H0007ZV5 & & & 8400.00 & \\
\hline 299-E 18-1 & $2 / 15 / 89$ & H0007ZV8 & & & 11400.00 & \\
\hline $299-E 18-1$ & $5 / 26 / 89$ & HOOOTZWZ & & & 12000.00 & \\
\hline $299-E 18-1$ & $8 / 08 / 89$ & H00072W6 & & & 12500.00 & \\
\hline 299-E18-1 & $10 / 31 / 89$ & $H 00072 \times 0$ & & & 12200.00 & \\
\hline 299-E18-1 & $5 / 30 / 90$ & $400072 \times 5$ & & & 12600.00 & \\
\hline 299-E18-1 & $7 / 09 / 91$ & $H 00071 \times 9$ & & 13300.00 & & \\
\hline 299-E18-1 & $9 / 06 / 91$ & B00LB6 & & 11400.00 & & \\
\hline 299-E 18-1 & $1 / 24 / 92$ & 801059 & 13000.00 & & & \\
\hline 299-E18-1 & $6 / 03 / 92$ & В06Рн8 & 12000.00 & & & \\
\hline 299-E18-1 & $12 / 16 / 92$ & 807532 & 13000.00 & & & \\
\hline $299-E 32-4$ & $9 / 27 / 88$ & H00082B8 & & & 25000.00 & \\
\hline 299-E32-4 & $12 / 28 / 88$ & HoOOBZC2 & & & 24200.00 & \\
\hline $299-E 32-4$ & $3 / 01 / 89$ & $\mathrm{H} 00082 \mathrm{CG}$ & & & 24600.00 & \\
\hline $299-E 32-4$ & $3 / 13 / 89$ & H0008ZDO & & & 24800.00 & \\
\hline 299-E32-4 & $6 / 16 / 89$ & H00082D4 & & & 29000.00 & \\
\hline 299-E32-4 & $7 / 19 / 89$ & H0008ZD8 & & & 29600.00 & \\
\hline $299-E 32-4$ & $9 / 08 / 89$ & H00082Fo & & & 24500.00 & \\
\hline $299-E 32-4$ & $1 / 17 / 90$ & $\mathrm{H} 00082 \mathrm{GO}$ & & & 29600.00 & \\
\hline 299-E32-4 & $5 / 09 / 90$ & H0008ZG9 & & & 29300.00 & \\
\hline $299-E 32-4$ & $8 / 05 / 91$ & H0007IYO & & 27200.00 & & \\
\hline $299-E 32-4$ & $8 / 05 / 91$ & H0007264 & & 27000.00 & & \\
\hline $299-E 32-4$ & $9 / 23 / 91$ & B00LK5 & & 27000.00 & & \\
\hline $299-E 32-4$ & $1 / 15 / 92$ & B010K6 & 5300.00 & & & \\
\hline $299-E 32-4$ & $4 / 06 / 92$ & 806696 & 23000.00 & & & \\
\hline $299-E 32-4$ & $4 / 09 / 92$ & B06586 & $24000.00 \mathrm{P}$ & & & \\
\hline $299-E 32-4$ & $7 / 14 / 92$ & 807173 & 25000.00 & & & \\
\hline $699-40-36$ & $12 / 21 / 92$ & B07781 & $200.00 \mathrm{U}$ & & & \\
\hline $699-40-36$ & $2 / 22 / 93$ & 808717 & $200.00 \mathrm{U}$ & & & \\
\hline $699-40-39$ & $12 / 05 / 89$ & HOOODBX2 & & & $500.00 \mathrm{U}$ & \\
\hline $699-40-39$ & $1 / 25 / 90$ & $H 0000 B \times 6$ & & & $500.00 \mathrm{U}$ & \\
\hline $699-40-39$ & $4 / 25 / 90$ & HOOODBYO & & & $500.00 \mathrm{U}$ & \\
\hline $699-40-39$ & $7 / 08 / 91$ & H00071Y4 & & 280.00 & & \\
\hline $699-40-39$ & $9 / 11 / 91$ & B00LG1 & & 220.00 & & \\
\hline
\end{tabular}


(sheet ** of *)

\begin{tabular}{|c|c|c|c|c|c|c|}
\hline $\begin{array}{l}\text { Well } \\
\text { Name }\end{array}$ & $\begin{array}{c}\text { Collection } \\
\text { Date }\end{array}$ & $\begin{array}{l}\text { Sample } \\
\text { Number }\end{array}$ & $\begin{array}{l}\text { NITRATE } \\
\text { 124/PpD } \\
200 / 45000\end{array}$ & $\begin{array}{l}\text { NITRATE } \\
\text { 130/ppb } \\
200 / 45000\end{array}$ & $\begin{array}{l}\text { NITRATE } \\
\text { 46/Ppb } \\
.145000\end{array}$ & $\begin{array}{c}\text { NITRATE } \\
\text { 76/PPm } \\
.1\end{array}$ \\
\hline$\ldots$ & $\cdots \cdots \cdots$ & $\cdots$ & n. & $\cdots$ & n & $\cdots$ \\
\hline $699-40-39$ & $1 / 31 / 92$ & 801065 & 500.00 & & & \\
\hline $699-40-39$ & $4 / 17 / 92$ & $8065 P 2$ & 1700.000 & & & \\
\hline $699 \cdot 40 \cdot 39$ & $6 / 24 / 92$ & B062T7 & 300.00 & & & \\
\hline $699-40-39$ & $1 / 14 / 93$ & $807 \pi \times 4$ & 300.00 & & & \\
\hline $699-40-40 A$ & $1 / 24 / 92$ & B01T62 & 1900.00 & & & \\
\hline $699-40-40 A$ & $4 / 22 / 92$ & B06508 & 3200.00 & & & \\
\hline $699-40-40 \mathrm{~A}$ & $6 / 25 / 92$ & B062V2 & 2600.00 & & & \\
\hline $699-40-40 \mathrm{~A}$ & $10 / 21 / 92$ & B07JK3 & 1900.00 & & & \\
\hline $699-40-40 A$ & $1 / 26 / 93$ & B07N49 & 2100.00 & & & \\
\hline $699-40-40 B$ & $1 / 24 / 92$ & B01T64 & 700.00 & & & \\
\hline $699-40-40 B$ & $4 / 22 / 92$ & B06550 & $200.00 \mathrm{U}$ & & & \\
\hline $699-40-40 B$ & $6 / 29 / 92$ & B062W2 & $600.00 \mathrm{D}$ & & & \\
\hline $699-40-40 B$ & $10 / 21 / 92$ & B07JK8 & 600.00 & & & \\
\hline $699-40-408$ & $1 / 26 / 93$ & B07v54 & 800.00 & & & \\
\hline $699-41 \cdot 35$ & $12 / 21 / 92$ & в07тв9 & 500.00 & & & \\
\hline $699-41-35$ & $2 / 22 / 93$ & B08707 & $200.00 \mathrm{U}$ & & & \\
\hline $699-41-40$ & $12 / 05 / 89$ & $H 0000044$ & & & 18800.00 & \\
\hline $699-41-40$ & $1 / 25 / 90$ & 10000048 & & & 22500.00 & \\
\hline $699-41-40$ & $4 / 19 / 90$ & H0000052 & & & 19600.00 & \\
\hline $699-41 \cdot 40$ & $7 / 10 / 91$ & H00071Y1 & & 20600.00 & & \\
\hline $699-41-40$ & $9 / 11 / 91$ & BOOLG2 & & 20000.00 & & \\
\hline $699-41-40$ & $1 / 31 / 92$ & B010C8 & 20000.00 & & & \\
\hline $699-41-40$ & $4 / 28 / 92$ & 806555 & 20000.000 & & & \\
\hline $699-41-40$ & $4 / 28 / 92$ & 806556 & 20000.000 & & & \\
\hline $699-41 \cdot 40$ & $6 / 24 / 92$ & $8062 \times 2$ & 20000.00 & & & \\
\hline $699-41-40$ & $1 / 14 / 93$ & $8077 \times 9$ & 22000.00 & & & \\
\hline $699-41 \cdot 42$ & $1 / 08 / 93$ & Borv59 & 5000.00 & & & \\
\hline $699 \cdot 42 \cdot 37$ & $12 / 22 / 92$ & BotTC4 & 4300.00 & & & \\
\hline $699 \cdot 42 \cdot 37$ & $2 / 23 / 93$ & B08712 & 3900.00 & & & \\
\hline $699-42-39 A$ & $1 / 23 / 92$ & B01T66 & $2400.00 \mathrm{P}$ & & & \\
\hline $699-42 \cdot 39 A$ & $4 / 17 / 92$ & B065T1 & $13000.00 \mathrm{P}$ & & & \\
\hline $699-42-39 A$ & $6 / 25 / 92$ & $8062 \times 7$ & $13000.00 \mathrm{P}$ & & & \\
\hline $699-42-39 A$ & $10 / 21 / 92$ & B07JL3 & $12000.00 \mathrm{P}$ & & & \\
\hline $699-42-39 A$ & $1 / 27 / 93$ & B07N64 & $11000.00 \mathrm{P}$ & & & \\
\hline $699-42-398$ & $1 / 23 / 92$ & B01T68 & 2600.00 & & & \\
\hline $699-42-398$ & $4 / 17 / 92$ & B065T6 & 14000.00 & & & \\
\hline $699-42-398$ & $6 / 25 / 92$ & B062Y2 & 11000.00 & & & \\
\hline $699-42-398$ & $10 / 28 / 92$ & B07JJ2 & 12000.00 & & & \\
\hline $699-42 \cdot 398$ & $10 / 28 / 92$ & B07JJ3 & 12000.00 & & & \\
\hline $699-42-398$ & $1 / 25 / 93$ & B07N69 & 9700.00 & & & \\
\hline $699-42-40 A$ & $3 / 29 / 83$ & H00000Y9 & & & & 10.60 \\
\hline $699-42-40 A$ & $6 / 16 / 83$ & HOOODDY4 & & & & 6.00 \\
\hline $699-42-40 A$ & $9 / 27 / 83$ & H0OODDY7 & & & & 3.07 \\
\hline
\end{tabular}


(sheet *t of **)

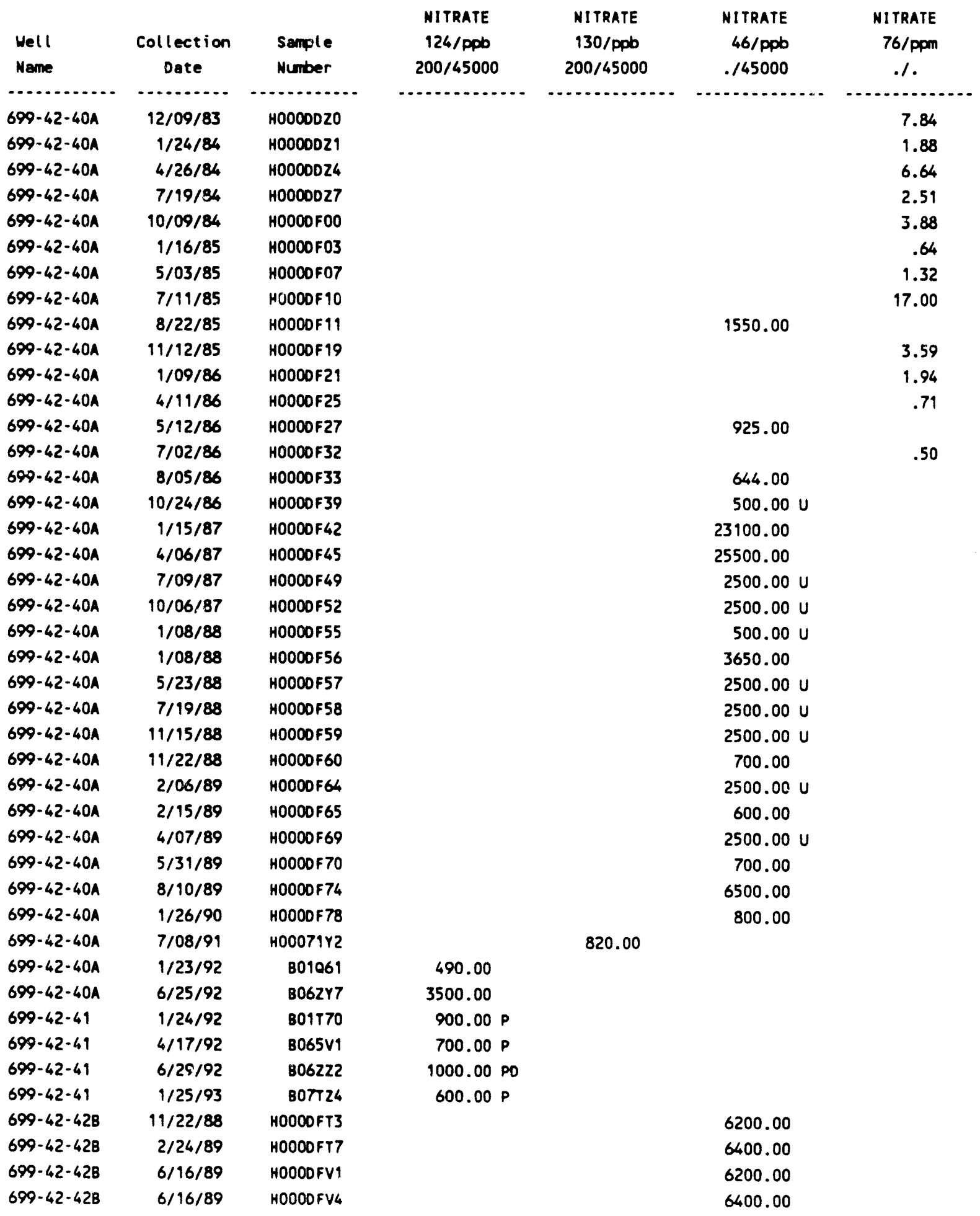


(sheet $*$ of $\star *$ )

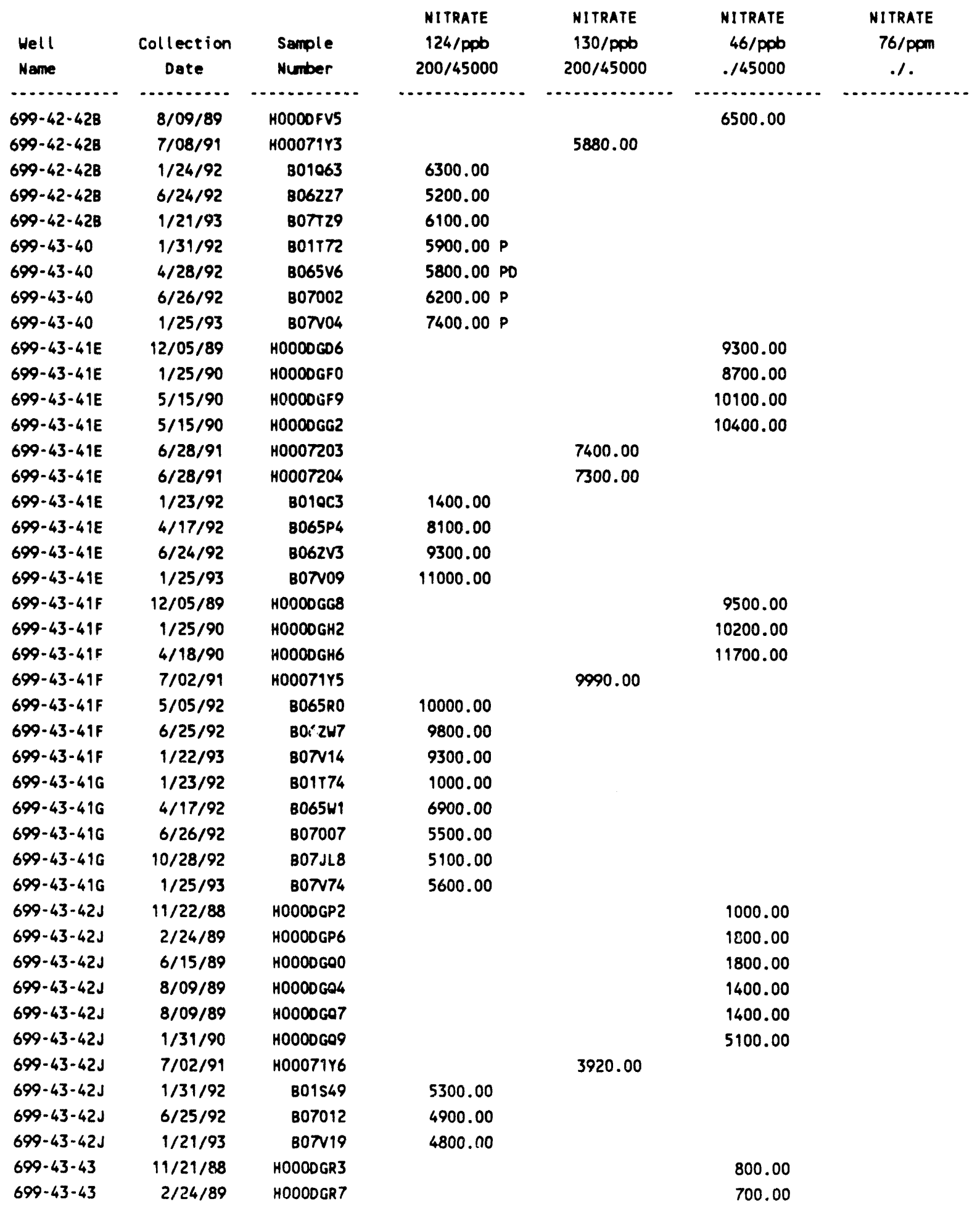


(sheet $* *$ of $* *$ )

\begin{tabular}{|c|c|c|c|c|c|c|}
\hline & & & NITRATE & NITRATE & NITRATE & NITRATE \\
\hline Well & Collection & Sample & 124/ppb & 130/ppb & 46/ppb & 76/ppm \\
\hline Name & Dote & Number & $200 / 45000$ & $200 / 45000$ & .145000 & .1 \\
\hline (n) & 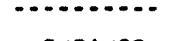 & . & 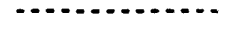 & , & . & \\
\hline $699-43-43$ & $2 / 24 / 89$ & HOOOOGSO & & & 700.00 & \\
\hline $699-43-43$ & $6 / 15 / 89$ & H0OOOGS1 & & & 1100.00 & \\
\hline $699-43-43$ & $8 / 09 / 89$ & HOOOOGS5 & & & 1100.00 & \\
\hline $699-43-43$ & $1 / 26 / 90$ & HOOODGS9 & & & 1000.00 & \\
\hline $699-43-43$ & $7 / 08 / 91$ & H00071Y7 & & 820.00 & & \\
\hline $699-43-43$ & $1 / 24 / 92$ & B01067 & 1100.00 & & & \\
\hline $699-43-43$ & $4 / 22 / 92$ & B065N6 & 1100.00 & & & \\
\hline $699-43-43$ & $6 / 26 / 92$ & BO70wO & 1000.00 & & & \\
\hline $699-43-43$ & $10 / 26 / 92$ & B07JG5 & $61000.00 \mathrm{~F}$ & & & \\
\hline $699-43-43$ & $1 / 13 / 93$ & B07V24 & 1100.00 & & & \\
\hline $699-43-45$ & $12 / 06 / 89$ & HOOODGT4 & & & 1000.00 & \\
\hline $699-43-45$ & $1 / 26 / 90$ & H0000GT8 & & & 1200.00 & \\
\hline $699-43-45$ & $4 / 18 / 90$ & HOOOOGV2 & & & 1500.00 & \\
\hline $699-43-45$ & $7 / 08 / 91$ & H00071Y8 & & 1170.00 & & \\
\hline $699-43-45$ & $9 / 11 / 91$ & BOOLG5 & & 1180.00 & & \\
\hline $699-43-45$ & $1 / 24 / 92$ & 801000 & 1400.00 & & & \\
\hline $699-43-45$ & $4 / 22 / 92$ & B065N8 & 1200.00 & & & \\
\hline $699-43-45$ & $6 / 26 / 92$ & B070W2 & 1200.00 & & & \\
\hline $699-43-45$ & $10 / 26 / 92$ & B07JG7 & 1100.00 & & & \\
\hline $699-43-45$ & $1 / 13 / 93$ & Borv29 & 900.00 & & & \\
\hline $699-44-39 B$ & $1 / 08 / 93$ & BOTWK1 & 1200.00 & & & \\
\hline $699-44-42$ & $11 / 21 / 88$ & HOOODHK2 & & & 1100.00 & \\
\hline $699-44-42$ & $2 / 17 / 89$ & HOOODHKG & & & 1400.00 & \\
\hline $699-44-42$ & $6 / 15 / 89$ & HOOODHLO & & & 1300.00 & \\
\hline $699-44-42$ & $8 / 08 / 89$ & HOOOOHL 4 & & & 1500.00 & \\
\hline $699-44-42$ & $1 / 31 / 90$ & HOOOOHL8 & & & 1400.00 & \\
\hline $699-44-42$ & $7 / 10 / 91$ & HO0071Y9 & & 1340.00 & & \\
\hline $699-44-42$ & $1 / 31 / 92$ & B01S52 & 1600.00 & & & \\
\hline $699-44-42$ & $6 / 25 / 92$ & B07017 & 1600.00 & & & \\
\hline $699-44-42$ & $1 / 13 / 93$ & B07v34 & 1300.00 & & & \\
\hline $699-44-42$ & $1 / 13 / 93$ & B07N35 & 1400.00 & & & \\
\hline $699-44-43 B$ & $12 / 20 / 89$ & HOOODHM3 & & & 7000.00 & \\
\hline $699-44-43 B$ & $12 / 20 / 89$ & HOOODHMG & & & 7200.00 & \\
\hline $699-44-438$ & $1 / 26 / 90$ & HOOODHM7 & & & 7600.00 & \\
\hline $699-44-43 B$ & $1 / 26 / 90$ & HOOODHNO & & & 8300.00 & \\
\hline $699-44-43 B$ & $4 / 18 / 90$ & HOOODHN1 & & & 6600.00 & \\
\hline $699-44-43 B$ & $7 / 08 / 91$ & H0007120 & & 6180.00 & & \\
\hline $699-44-43 B$ & $9 / 11 / 91$ & BOOLG6 & & 4400.00 & & \\
\hline $699-44-438$ & $1 / 23 / 92$ & B01069 & 940.00 & & & \\
\hline $699-44-43 B$ & $4 / 20 / 92$ & $8065 W 9$ & 5000.00 & & & \\
\hline $699-44-438$ & $6 / 26 / 92$ & 807022 & 5500.00 & & & \\
\hline $699-44-438$ & $6 / 26 / 92$ & B07023 & 4800.00 & & & \\
\hline $699-44-43 B$ & $1 / 27 / 93$ & B07V44 & 4100.00 & & & \\
\hline
\end{tabular}


(sheet $\star \star$ of $\star *$ )

\begin{tabular}{|c|c|c|c|c|c|c|}
\hline $\begin{array}{l}\text { Hell } \\
\text { Name }\end{array}$ & $\begin{array}{c}\text { Collection } \\
\text { Date }\end{array}$ & $\begin{array}{l}\text { Sample } \\
\text { Number }\end{array}$ & $\begin{array}{l}\text { NITRATE } \\
\text { 124/Ppb } \\
200 / 45000\end{array}$ & $\begin{array}{l}\text { NITRATE } \\
\text { 130/ppb } \\
200 / 45000\end{array}$ & $\begin{array}{r}\text { NITRATE } \\
46 / \mathrm{ppb} \\
.145000\end{array}$ & $\begin{array}{c}\text { NITRATE } \\
\text { 76/ppm } \\
. /\end{array}$ \\
\hline \multirow{2}{*}{ - } & $\cdots$ & 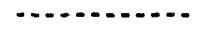 & - nen. & n. & (n) & 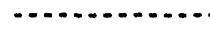 \\
\hline & & & LPHENOL & PHORATE & PHOSPHA & PHOSPHA \\
\hline Well & Collection & Sample & $30 / p p b$ & 29/ppb & 124/ppb & 46/ppb \\
\hline Name & Date & Number & $1 /$ & 21 & $400 /$ & .1 \\
\hline$\ldots$ & n & $\cdots$ & n. & $\cdots$ & (n) & n \\
\hline 299-E18-1 & $8 / 16 / 88$ & H0007ZT7 & $10.00 \mathrm{U}$ & & & $1000.00 \mathrm{U}$ \\
\hline 299-E18-1 & $11 / 10 / 88$ & H0007ZV2 & & & & $1000.00 \mathrm{U}$ \\
\hline 299-E18-1 & $11 / 10 / 88$ & H0007ZV5 & & & & $1000.00 \mathrm{U}$ \\
\hline 299-E18-1 & $2 / 15 / 89$ & H0007ZV8 & $10.00 \mathrm{U}$ & & & $1000.00 \mathrm{U}$ \\
\hline 299-E18-1 & $5 / 26 / 89$ & H0007ZW2 & $10.00 \mathrm{U}$ & & & $1000.00 \mathrm{U}$ \\
\hline 299-E18-1 & $8 / 08 / 89$ & H0007ZW6 & $10.00 \mathrm{U}$ & & & $1000.00 \mathrm{U}$ \\
\hline 299-E18-1 & $10 / 31 / 89$ & $H 00072 \times 0$ & & $2.00 \mathrm{U}$ & & $1000.00 \mathrm{U}$ \\
\hline 299-E18-1 & $5 / 30 / 90$ & $H 00072 \times 5$ & & & & $1000.00 \mathrm{U}$ \\
\hline 299-E18-1 & $7 / 09 / 91$ & H00071X9 & $u$ & & $U$ & \\
\hline 299-E१8-1 & $1 / 24 / 92$ & B01059 & 1.00 Ua & & $400.00 \mathrm{U}$ & \\
\hline 299-E18-1 & $6 / 03 / 92$ & В06PH8 & $1.00 \mathrm{U}$ & & $400.00 \mathrm{U}$ & \\
\hline 299-E18-1 & $12 / 16 / 92$ & B07532 & & & $400.00 \mathrm{U}$ & \\
\hline 299-E18-1 & $12 / 16 / 92$ & BO7SNO & $1.00 \mathrm{U}$ & & & \\
\hline $299-E 32-4$ & $9 / 27 / 88$ & $H 0008288$ & & & & $1000.00 \mathrm{U}$ \\
\hline $299-E 32-4$ & $12 / 28 / 88$ & H0008ZC2 & $10.00 \mathrm{U}$ & & & $1000.00 \mathrm{U}$ \\
\hline $299-E 32-4$ & $3 / 01 / 89$ & H0008ZC6 & $10.00 \mathrm{U}$ & & & $1000.00 \mathrm{U}$ \\
\hline $299-E 32-4$ & $3 / 13 / 89$ & $H 0008200$ & $10.00 \mathrm{U}$ & & & $1000.00 \mathrm{U}$ \\
\hline $299-E 32-4$ & $6 / 16 / 89$ & H0008ZD4 & $10.00 \mathrm{U}$ & & & $1000.00 \mathrm{U}$ \\
\hline $299-E 32-4$ & $7 / 19 / 89$ & H0008ZDB & $10.00 \mathrm{U}$ & & & $1000.00 \mathrm{U}$ \\
\hline $299-E 32-4$ & $9 / 08 / 89$ & H0008ZF6 & $10.00 \mathrm{U}$ & & & $1000.00 \mathrm{U}$ \\
\hline $299-E 32-4$ & $1 / 17 / 90$ & $\mathrm{H} 0008 \mathrm{ZGO}$ & $10.00 \mathrm{U}$ & & & $1000.00 \mathrm{U}$ \\
\hline $299-E 32-4$ & $5 / 09 / 90$ & H0008ZG9 & $10.00 \mathrm{U}$ & & & $1000.00 \mathrm{U}$ \\
\hline $299-E 32-4$ & $1 / 15 / 92$ & B010K6 & $1.00 \mathrm{U}$ & & $400.00 \mathrm{U}$ & \\
\hline $299-E 32-4$ & $4 / 06 / 92$ & B06696 & $1.00 \mathrm{U}$ & & $400.00 \mathrm{U}$ & \\
\hline $299-E 32-4$ & $4 / 09 / 92$ & $8065 B 6$ & & & 400.00 UP & \\
\hline $299-E 32-4$ & $7 / 14 / 92$ & 807173 & $1.00 \mathrm{U}$ & & $400.00 \mathrm{U}$ & \\
\hline $699-40-36$ & $12 / 21 / 92$ & B07TB1 & & & $400.00 \mathrm{U}$ & \\
\hline $699-40-36$ & $2 / 22 / 93$ & B08717 & & & $400.00 \mathrm{U}$ & \\
\hline $699-40-39$ & $12 / 05 / 89$ & $40000 B \times 2$ & & $2.00 \mathrm{U}$ & & $1000.00 \mathrm{U}$ \\
\hline $699-40-39$ & $1 / 25 / 90$ & H0000BX6 & $10.00 \mathrm{U}$ & & & $1000.00 \mathrm{U}$ \\
\hline $699-40-39$ & $4 / 25 / 90$ & HOOODBYO & $10.00 \mathrm{U}$ & & & $1000.00 \mathrm{U}$ \\
\hline $699-40-39$ & $7 / 08 / 91$ & H00071Y4 & $u$ & & U & \\
\hline $699-40-39$ & $1 / 31 / 92$ & 801065 & $1.00 \mathrm{U}$ & & $400.00 \mathrm{U}$ & \\
\hline $699-40-39$ & $4 / 17 / 92$ & B065P2 & $1.00 \mathrm{UD}$ & & 400.00 UD & \\
\hline $699-40-39$ & $6 / 24 / 92$ & 806217 & $1.00 \mathrm{U}$ & & $400.00 \mathrm{U}$ & \\
\hline $699-40-39$ & $1 / 14 / 93$ & $8077 \times 4$ & $1.00 \mathrm{U}$ & & $400.00 \mathrm{U}$ & \\
\hline
\end{tabular}


(sheet $\star *$ of $*$ )

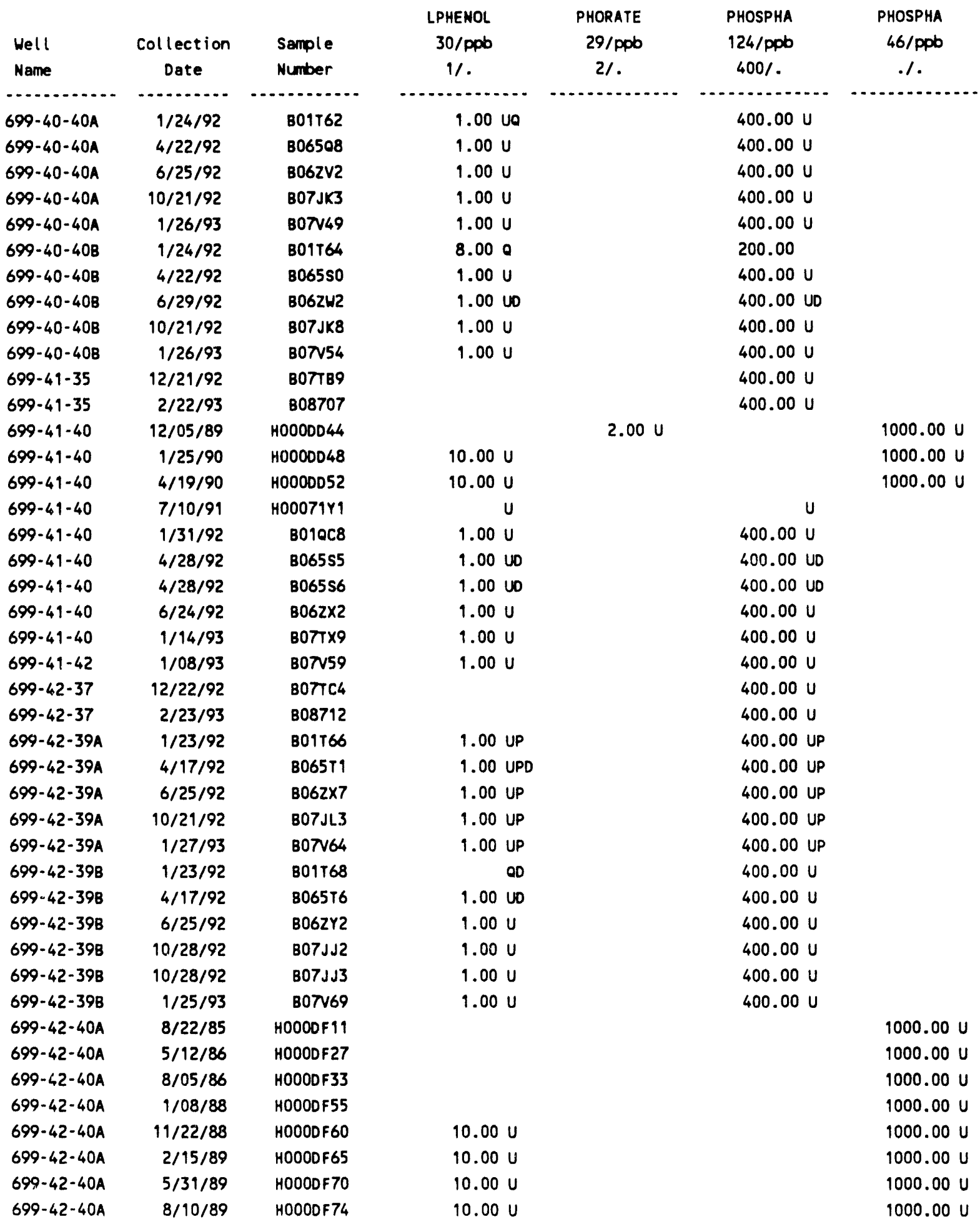


(sheet ** of *)

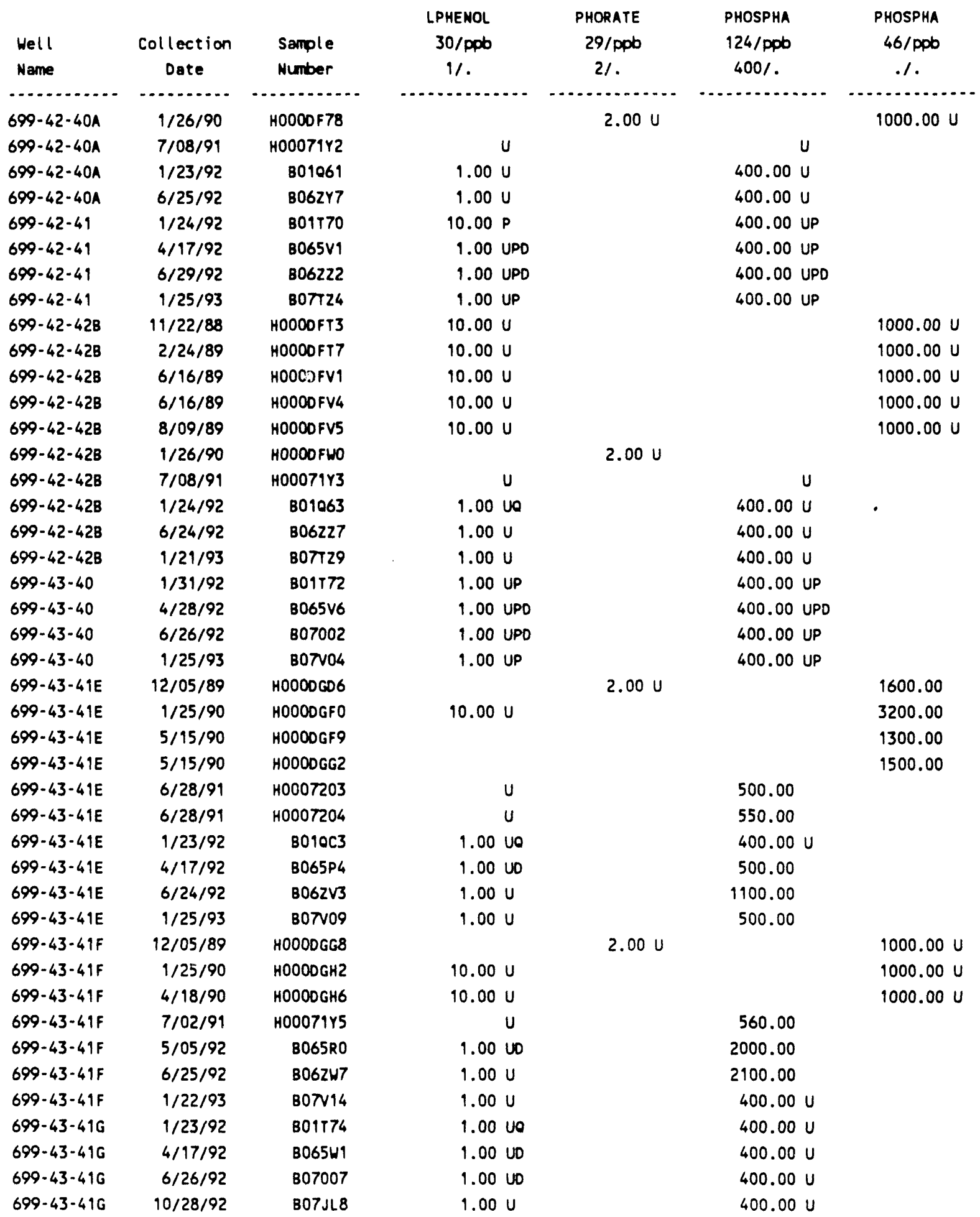


(sheet ** of $\star *$ )

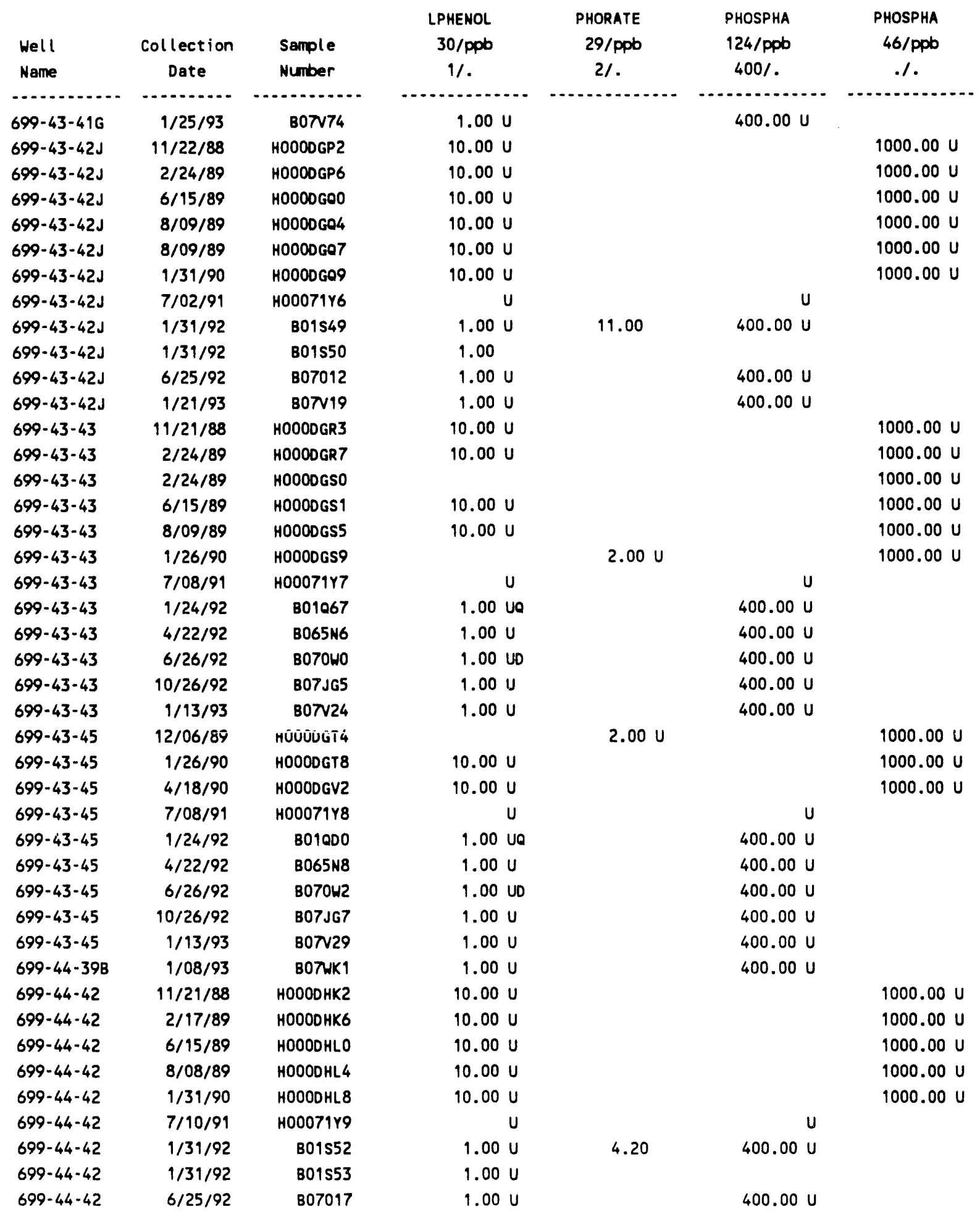


*t of $\star *$ )

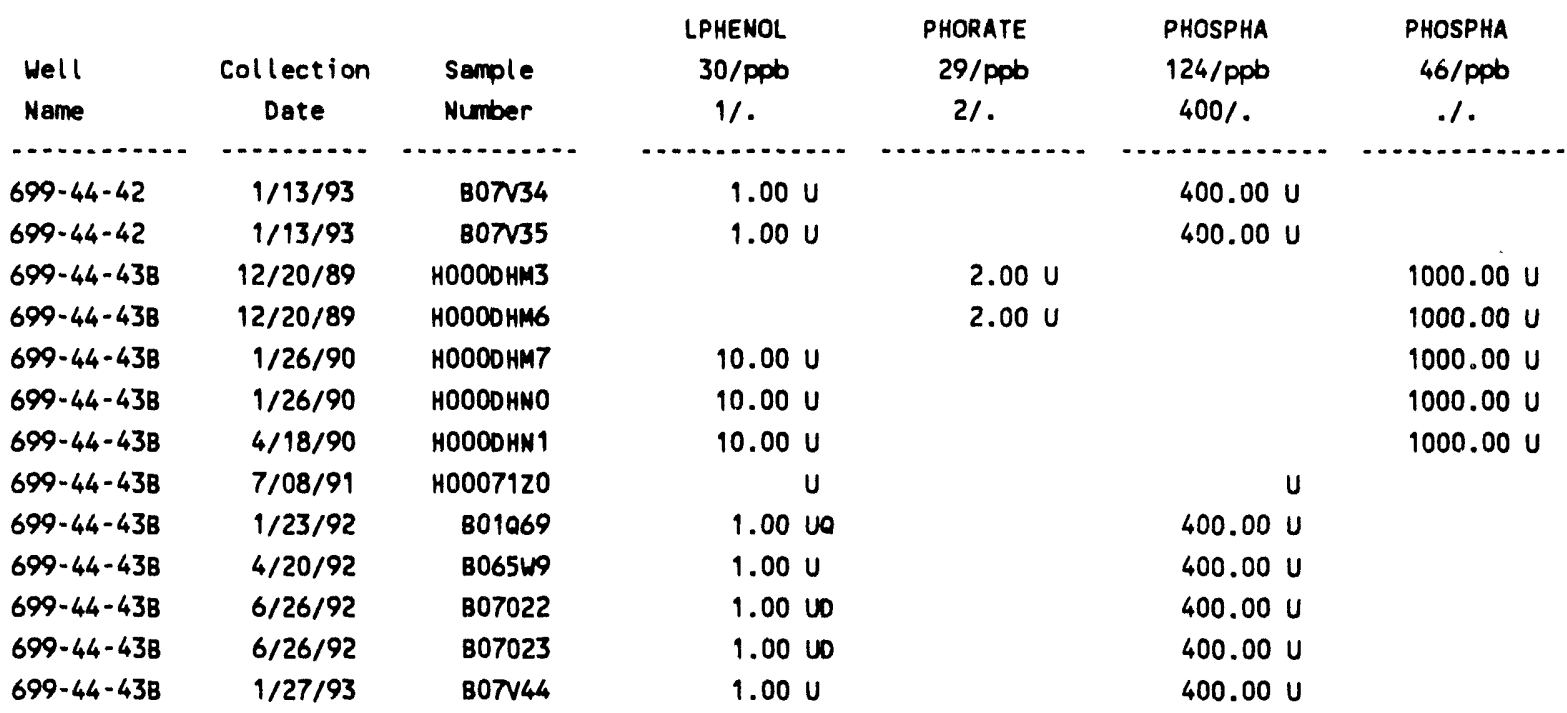

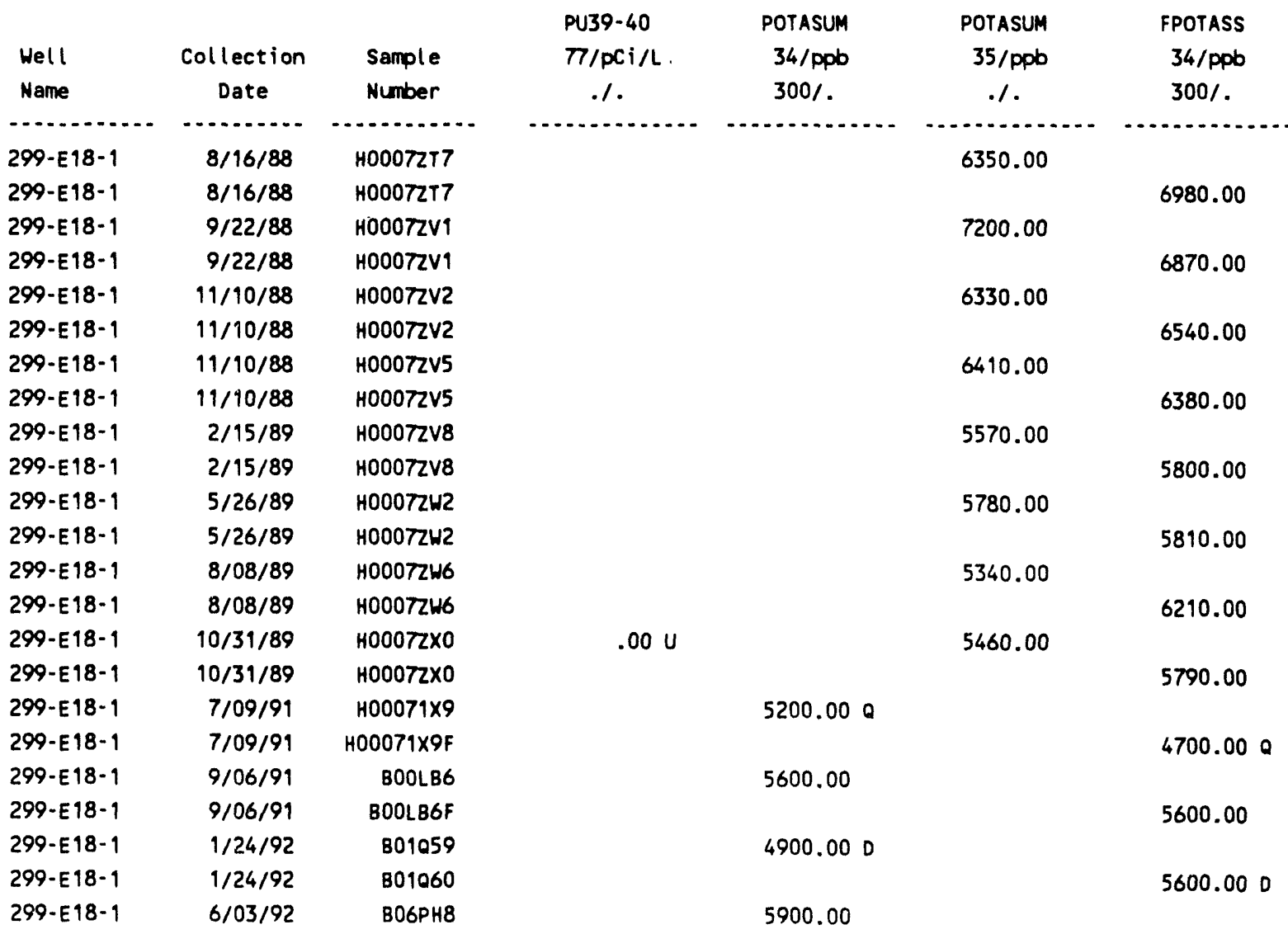


(sheet * of $* *$ )

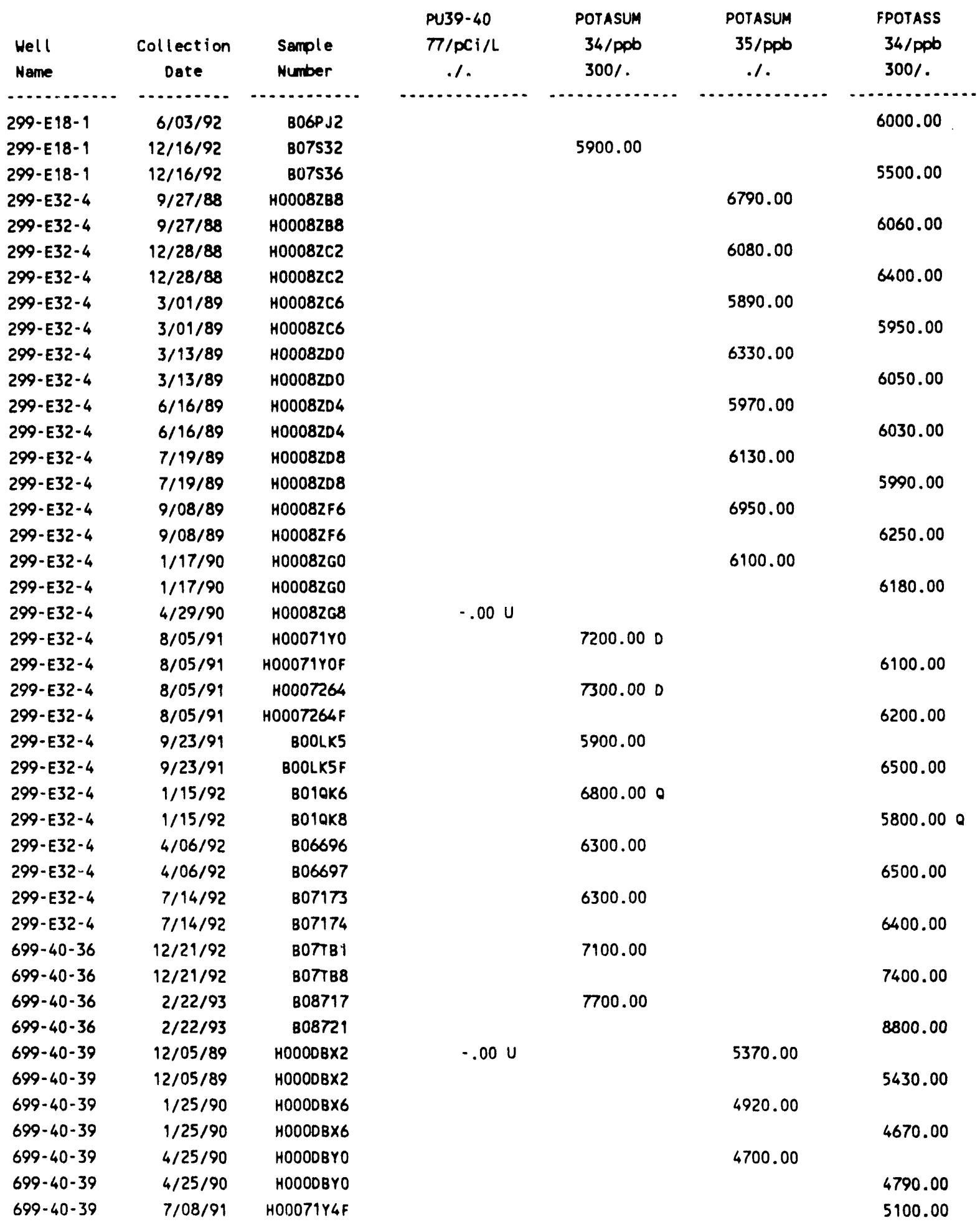


(sheet $*$ of $*$ )

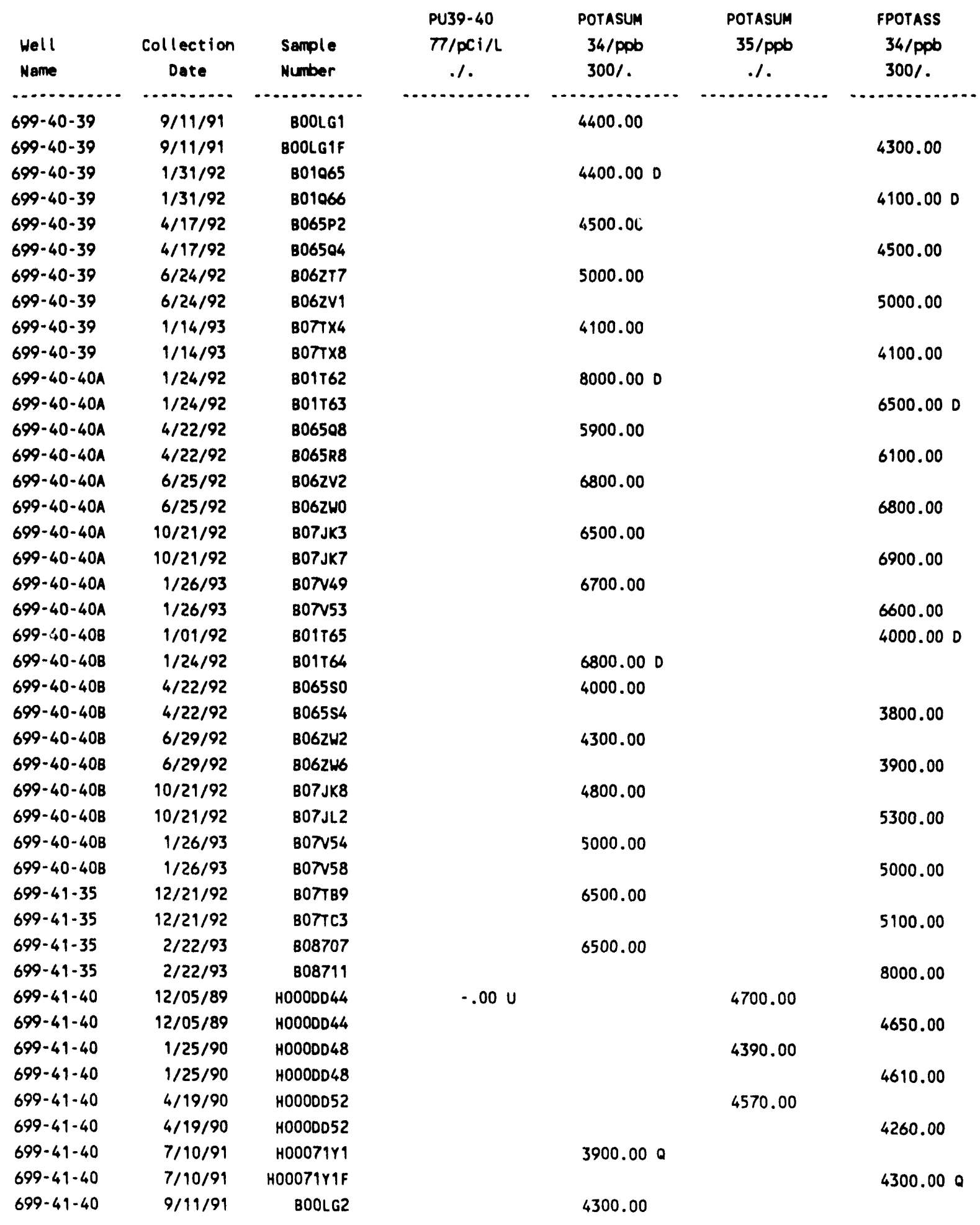


(sheet ** of **)

\begin{tabular}{|c|c|c|c|c|c|c|}
\hline $\begin{array}{l}\text { Well } \\
\text { Name }\end{array}$ & $\begin{array}{c}\text { Collection } \\
\text { Date }\end{array}$ & $\begin{array}{l}\text { Sample } \\
\text { Number }\end{array}$ & $\begin{array}{c}\text { PU39-40 } \\
7 / p C i / L \\
. / .\end{array}$ & $\begin{array}{l}\text { POTASUM } \\
34 / \text { pPb } \\
300 \%\end{array}$ & $\begin{array}{l}\text { POTASUM } \\
35 / p p b \\
.1\end{array}$ & $\begin{array}{l}\text { FPOTASS } \\
34 / \mathrm{ppb} \\
300 /\end{array}$ \\
\hline 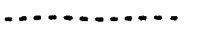 & . & 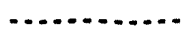 & 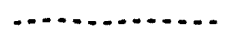 & 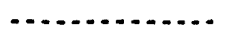 & . & $\ldots$ \\
\hline $699-41-40$ & $9 / 11 / 91$ & BOOLG2F & & & & 4900.00 \\
\hline $699-41-40$ & $1 / 31 / 92$ & B010C8 & & $3800.00 \mathrm{D}$ & & \\
\hline $699-41-40$ & $1 / 31 / 92$ & B010c9 & & & & $4100.00 \mathrm{D}$ \\
\hline $699-41-40$ & $4 / 28 / 92$ & B065s5 & & 4700.00 & & \\
\hline $699-49-40$ & $4 / 28 / 92$ & 806556 & & 4400.00 & & \\
\hline $699-41-40$ & $4 / 28 / 92$ & B06559 & & & & 4700.00 \\
\hline $699-41-40$ & $4 / 28 / 92$ & B065TO & & & & 4400.00 \\
\hline $699-41-40$ & $6 / 24 / 92$ & $B 062 \times 2$ & & 4400.00 & & \\
\hline $699-41-40$ & $6 / 24 / 92$ & $B 062 \times 6$ & & & & 4500.00 \\
\hline $699-41 \cdot 40$ & $1 / 14 / 93$ & $8077 \times 9$ & & 3300.00 & & \\
\hline $699-41-40$ & $1 / 14 / 93$ & B07TY3 & & & & 3500.00 \\
\hline $699-41-42$ & $1 / 08 / 93$ & Bo7v59 & & 6000.00 & & \\
\hline $699-41-42$ & $1 / 08 / 93$ & B07N63 & & & & 6100.00 \\
\hline $699-42-37$ & $12 / 22 / 92$ & B07TC4 & & 4600.00 & & \\
\hline $699-42-37$ & $12 / 22 / 92$ & Botrc8 & & & & 4800.00 \\
\hline $699-42 \cdot 37$ & $2 / 23 / 93$ & B08712 & & 5100.00 & & \\
\hline $699-42-37$ & $2 / 23 / 93$ & 808716 & & & & 4600.00 \\
\hline $699-42-39 A$ & $1 / 23 / 92$ & B01T66 & & $4900.00 \mathrm{P}$ & & \\
\hline $699-42-39 A$ & $1 / 23 / 92$ & $801 T 67$ & & & & $4700.00 \mathrm{P}$ \\
\hline $699-42-39 A$ & $4 / 17 / 92$ & B065T1 & & $4300.00 \mathrm{P}$ & & \\
\hline $699-42-39 A$ & $4 / 17 / 92$ & $8065 T 5$ & & & & $4300.00 P$ \\
\hline $699-42-39 A$ & $6 / 25 / 92$ & $8062 \times 7$ & & $5000.00 \mathrm{P}$ & & \\
\hline $699-42-39 A$ & $6 / 25 / 92$ & B062Y1 & & & & $4900.00 \mathrm{P}$ \\
\hline $699-42-39 A$ & $10 / 21 / 92$ & B07JL3 & & $4900.00 \mathrm{P}$ & & \\
\hline $699-42 \cdot 39 A$ & $10 / 21 / 92$ & B07JL7 & & & & $4500.00 \mathrm{P}$ \\
\hline $699-42-39 A$ & $1 / 27 / 93$ & B07v64 & & $5000.00 \mathrm{PQ}$ & & \\
\hline $699-42-39 A$ & $1 / 27 / 93$ & B07N68 & & & & $4300.00 \mathrm{PQ}$ \\
\hline $699-42-39 B$ & $1 / 23 / 92$ & B01T68 & & 4900.00 & & \\
\hline $699-42-39 B$ & $1 / 23 / 92$ & B01T69 & & & & 5500.00 \\
\hline $699-42-39 B$ & $4 / 17 / 92$ & B065T6 & & 5100.00 & & \\
\hline $699-42-39 B$ & $4 / 17 / 92$ & B065Vo & & & & 5100.00 \\
\hline $699-42-398$ & $6 / 25 / 92$ & $8062 Y 2$ & & 5600.00 & & \\
\hline $699-42-398$ & $6 / 25 / 92$ & B062Y6 & & & & 5600.00 \\
\hline $699-42-398$ & $10 / 28 / 92$ & B07JJ2 & & 5500.00 & & \\
\hline $699-42-39 B$ & $10 / 28 / 92$ & B07JJ3 & & 5900.00 & & \\
\hline $699-42-398$ & $10 / 28 / 92$ & B07JJ6 & & & & 5700.00 \\
\hline $699-42-39 B$ & $10 / 28 / 92$ & B07JJ7 & & & & 5700.00 \\
\hline $699-42-39 B$ & $1 / 25 / 93$ & B07N69 & & 5200.00 & & \\
\hline $699-42-398$ & $1 / 25 / 93$ & $807 v 73$ & & & & 4700.00 \\
\hline $699-42-40 A$ & $8 / 22 / 85$ & H0OODF11 & & & 4180.00 & \\
\hline $699-42-40 A$ & $5 / 12 / 86$ & HOOOOF27 & & & 3680.00 & \\
\hline $699-42-40 A$ & $8 / 05 / 86$ & H0OODF33 & & & 4060.00 & \\
\hline $699-42-40 A$ & $1 / 08 / 88$ & H0OODF55 & & & 2850.00 & \\
\hline
\end{tabular}


(sheet *t of $\star *$ )

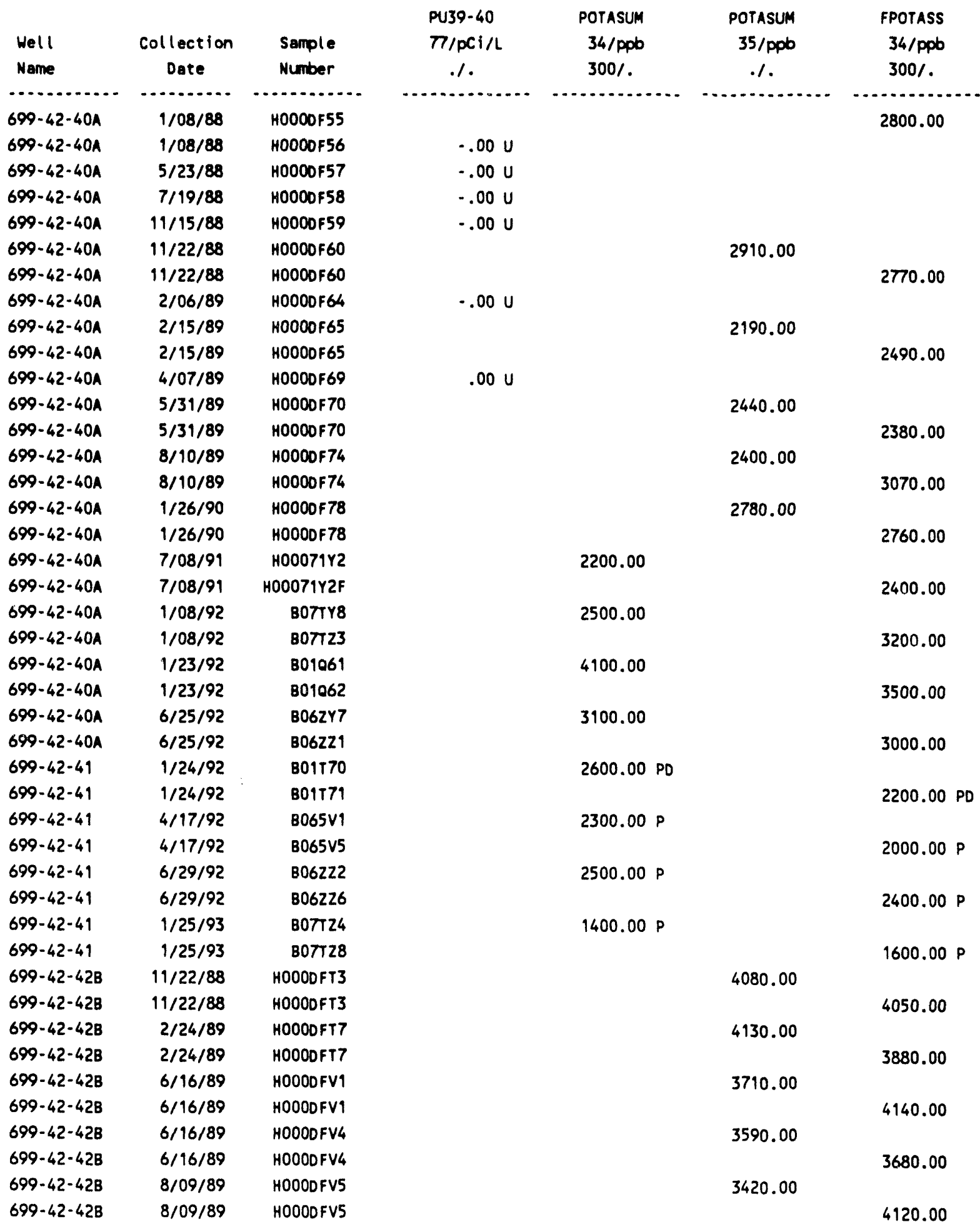


(sheet * of *)

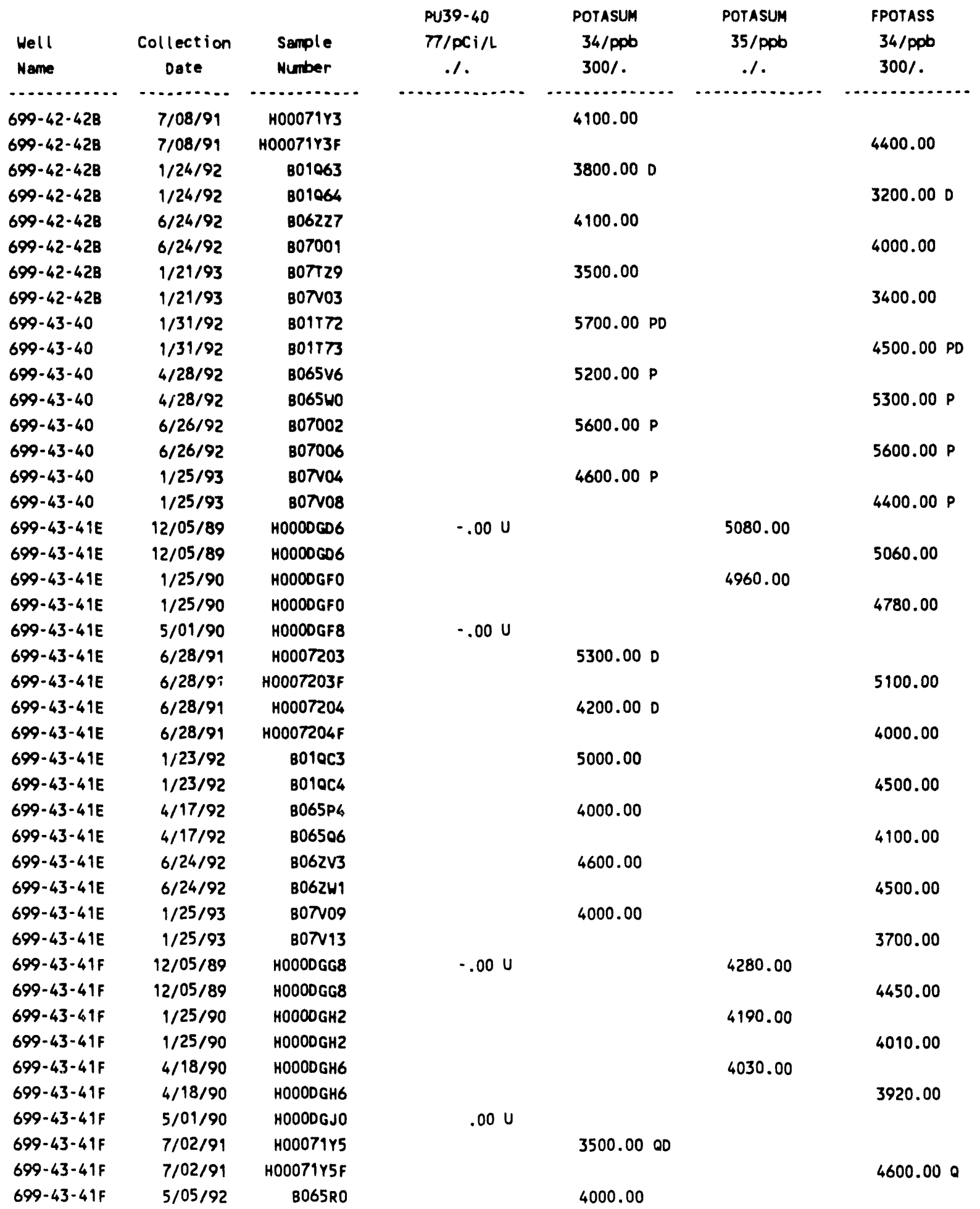


(sheet $\star \star$ of $\star \star$ )

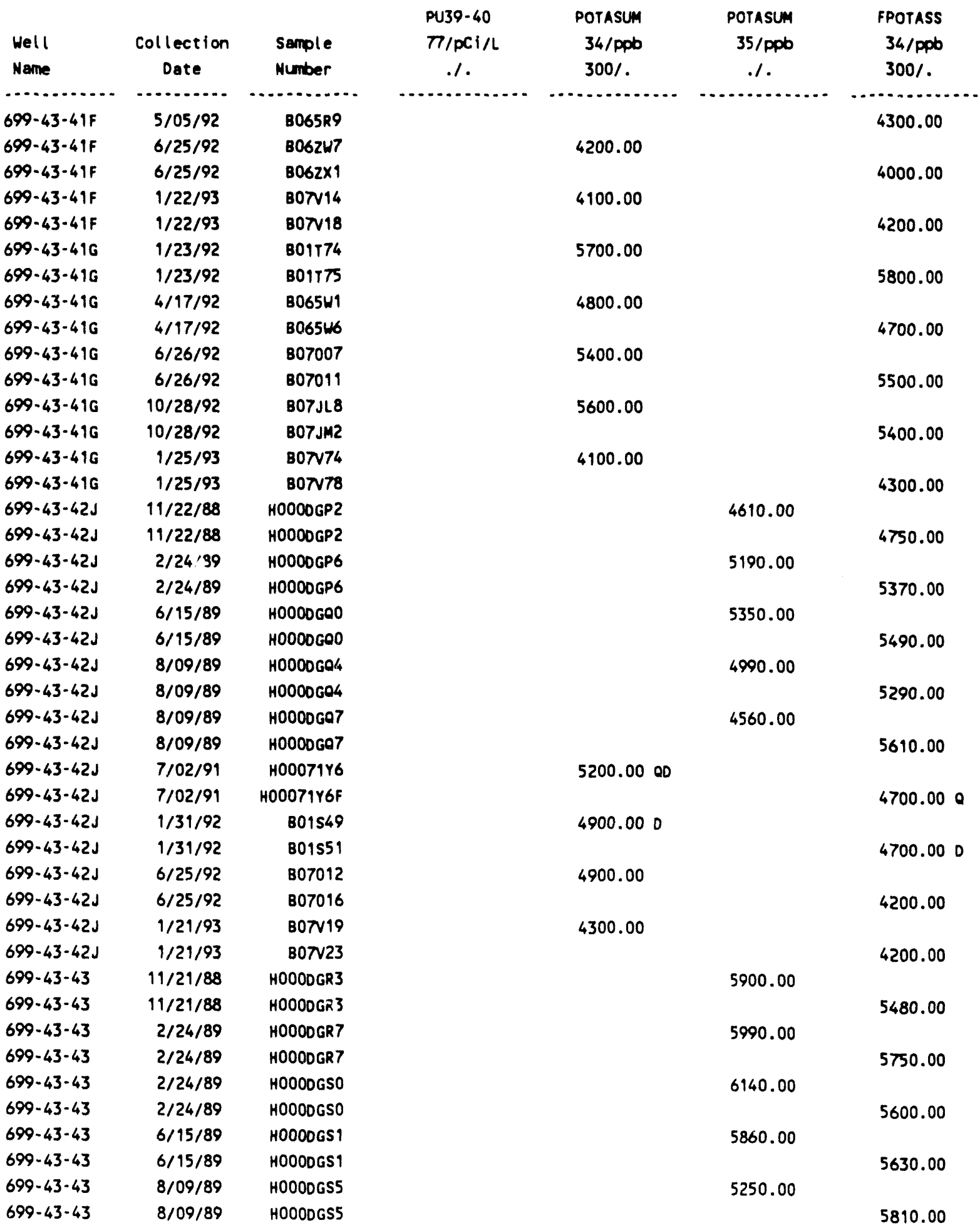


(sheet $\star \star$ of $\star *$ )

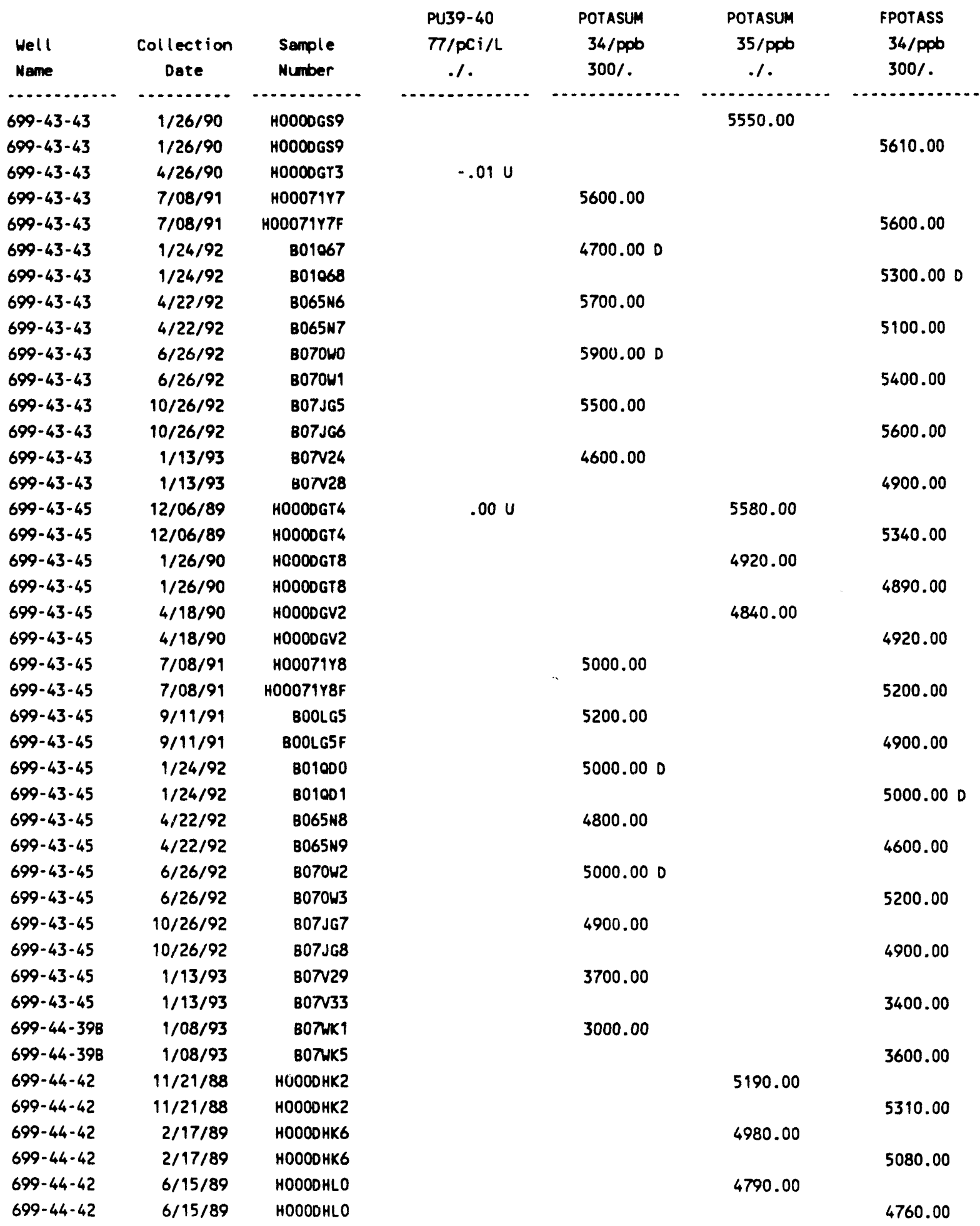


(sheet $\star$ of $\star$ )

\begin{tabular}{|c|c|c|c|c|c|c|}
\hline $\begin{array}{l}\text { Hell } \\
\text { Name }\end{array}$ & $\begin{array}{c}\text { Collection } \\
\text { Date }\end{array}$ & $\begin{array}{l}\text { Sample } \\
\text { Number }\end{array}$ & $\begin{array}{c}\text { Pu39-40 } \\
77 / p c i / L \\
. / .\end{array}$ & $\begin{array}{l}\text { POTASUM } \\
34 / \mathrm{ppb} \\
300 /\end{array}$ & $\begin{array}{c}\text { POTASUM } \\
35 / p p b \\
. /\end{array}$ & $\begin{array}{l}\text { FPOTASS } \\
34 / \text { ppb } \\
300 /\end{array}$ \\
\hline . & . & . & . & - & - & $\ldots$ \\
\hline $699-44-42$ & $8 / 08 / 89$ & HOOODHL 4 & & & 4550.00 & \\
\hline $699-44-42$ & $8 / 08 / 89$ & HOOOOHL 4 & & & & 4810.00 \\
\hline $699-44-42$ & $1 / 31 / 90$ & HOOOOHL 8 & & & 4950.00 & \\
\hline $699-44-42$ & $1 / 31 / 90$ & HOOOOHL8 & & & & 4920.00 \\
\hline $699-44-42$ & $4 / 26 / 90$ & HOOOOHM2 & $-.01 \mathrm{U}$ & & & \\
\hline $699-44-42$ & $7 / 10 / 91$ & H00071Y9 & & 4500.000 & & \\
\hline $699-44-42$ & $7 / 10 / 91$ & HOOOZ1Y9F & & & & 4200.000 \\
\hline $699-44-42$ & $1 / 31 / 92$ & B01552 & & $4400.00 \mathrm{D}$ & & \\
\hline $699-44-42$ & $1 / 31 / 92$ & 801554 & & & & 4500.000 \\
\hline $699-44-42$ & $6 / 25 / 92$ & B07017 & & 4900.00 & & \\
\hline $699-44-42$ & $6 / 25 / 92$ & B07021 & & & & 4900.00 \\
\hline $699-44-42$ & $1 / 13 / 93$ & B07v34 & & 4000.00 & & \\
\hline $699-44-42$ & $1 / 13 / 93$ & B07v35 & & 3600.00 & & \\
\hline $699-44-42$ & $1 / 13 / 93$ & $807 v 42$ & & & & 4100.00 \\
\hline $699-44-42$ & $1 / 13 / 93$ & B07v43 & & & & 3700.00 \\
\hline $699-44-43 B$ & $12 / 20 / 89$ & HOOODHM3 & .02 & & 4530.00 & \\
\hline $699-44-43 B$ & $12 / 20 / 89$ & HООООНMЗ & & & & 4810.00 \\
\hline $699-44-43 B$ & $12 / 20 / 89$ & HOOOOHM6 & $-.00 \mathrm{U}$ & & 4570.00 & \\
\hline $699-44-43 B$ & $12 / 20 / 89$ & HOOOOHMG & & & & 4730.00 \\
\hline $699-44-43 B$ & $1 / 26 / 90$ & HOOODHM7 & & & 4960.00 & \\
\hline $699-44-43 B$ & $1 / 26 / 90$ & HOOODHM7 & & & & 4830.00 \\
\hline $699-44-43 B$ & $1 / 26 / 90$ & HOOOOHNO & & & 4930.00 & \\
\hline $699-44-43 B$ & $1 / 26 / 90$ & HOOODHNO & & & & 4840.00 \\
\hline $699-44-43 B$ & $4 / 18 / 90$ & HOOODHNI & & & 4620.00 & \\
\hline $699-44-43 B$ & $4 / 18 / 90$ & HOOODHN1 & & & & 4640.00 \\
\hline $699-44-43 B$ & $4 / 26 / 90$ & HOOODHN5 & $-.00 \mathrm{U}$ & & & \\
\hline $699-44-43 B$ & $7 / 08 / 91$ & H000712O & & 4900.00 & & \\
\hline $699-44-43 B$ & $7 / 08 / 91$ & H0007120F & & & & 4600.00 \\
\hline $699-44-43 B$ & $9 / 11 / 91$ & B00LG6 & & 5300.00 & & \\
\hline $699-44-438$ & $9 / 11 / 91$ & BOOLGGF & & & & 5100.00 \\
\hline $699-44-43 B$ & $1 / 23 / 92$ & B01069 & & 5200.00 & & \\
\hline $699-44-43 B$ & $1 / 23 / 92$ & 801070 & & & & 3500.00 \\
\hline $699-44-43 B$ & $4 / 20 / 92$ & B065W9 & & 4900.00 & & \\
\hline $699-44-43 B$ & $4 / 20 / 92$ & $8065 \times 5$ & & & & 4800.00 \\
\hline $699-44-43 B$ & $6 / 26 / 92$ & B01MT4 & & & & 5000.00 \\
\hline $699-44-43 B$ & $6 / 26 / 92$ & B07022 & & 5100.00 & & \\
\hline $699-44-438$ & $6 / 26 / 92$ & B07023 & & 5100.00 & & \\
\hline $699-44-43 B$ & $6 / 26 / 92$ & B07026 & & & & 5000.00 \\
\hline $699-44-43 B$ & $1 / 27 / 93$ & BOTV44 & & 5700.000 & & \\
\hline $699-44-43 B$ & $1 / 27 / 93$ & BOTN48 & & & & $5800.00 Q$ \\
\hline
\end{tabular}


(sheet ** of **)

\begin{tabular}{|c|c|c|c|c|c|c|}
\hline Well & Collection & Sample & $\begin{array}{c}x-40 \\
140 / p C i / L\end{array}$ & $\begin{array}{l}\text { RADIUM } \\
137 / D C i / L\end{array}$ & $\begin{array}{l}\text { RADIUM } \\
\text { T7/pCi/L }\end{array}$ & $\begin{array}{c}R U-106 \\
77 / p C i / L\end{array}$ \\
\hline Name & Date & Number & .1 & .1 & .15 & .1 \\
\hline n & . & n & . & - & - & $\cdots$ \\
\hline 299-E18-1 & $8 / 16 / 88$ & H0007ZT7 & & & 2.15 & \\
\hline 299-E18-1 & $11 / 10 / 88$ & H0007ZV2 & & & .27 & \\
\hline 299-E18-1 & $11 / 10 / 88$ & H0007ZV5 & & & .21 & \\
\hline 299-E18-1 & $2 / 15 / 89$ & H0007Zv8 & & & .25 & \\
\hline $299-E 18-1$ & $5 / 26 / 89$ & H0007ZWZ & & & .47 & \\
\hline 299-E18-1 & $8 / 08 / 89$ & H0007ZW6 & & & .31 & \\
\hline $299-E 18-1$ & $10 / 31 / 89$ & H0007ZXO & & & .25 & $-26.20 \mathrm{U}$ \\
\hline 299-E18-1 & $9 / 06 / 91$ & B00LB6 & $159.00 \mathrm{~F}$ & $.09 \mathrm{U}$ & & \\
\hline $299-E 18-1$ & $6 / 03 / 92$ & В06РH8 & & $-.02 \mathrm{U}$ & & \\
\hline 299-E18-1 & $12 / 16 / 92$ & B07SNO & & $.12 \mathrm{U}$ & & \\
\hline 299-E32-4 & $9 / 27 / 88$ & H0008ZB8 & & & $.02 \mathrm{U}$ & $0.00 \mathrm{U}$ \\
\hline 299-E32-4 & $12 / 28 / 88$ & H0008ZC2 & & & $.05 \mathrm{U}$ & \\
\hline 299-E32-4 & $3 / 01 / 89$ & H0008zC6 & & & .25 & \\
\hline $299-E 32-4$ & $3 / 13 / 89$ & $H 0008200$ & & & $.01 \mathrm{U}$ & $-15.00 \mathrm{U}$ \\
\hline 299-E32-4 & $6 / 16 / 89$ & H00082D4 & & & $.07 \mathrm{u}$ & \\
\hline 299-E32-4 & $7 / 19 / 89$ & H0008208 & & & .41 & $-32.50 \mathrm{U}$ \\
\hline $299-E 32-4$ & $9 / 08 / 89$ & H0008ZFG & & & $.10 \mathrm{U}$ & $17.00 \mathrm{U}$ \\
\hline $299-E 32-4$ & $1 / 17 / 90$ & H00082GO & & & $.09 \mathrm{U}$ & $22.60 \mathrm{U}$ \\
\hline 299-E32-4 & $5 / 09 / 90$ & H0008ZG9 & & & .28 & $-18.20 \mathrm{U}$ \\
\hline $299-E 32-4$ & $8 / 05 / 91$ & $H 0007264$ & 58.90 UF & .19 & & \\
\hline $299-E 32-4$ & $9 / 23 / 91$ & B00LK5 & 16.30 UF & $.07 \mathrm{U}$ & & \\
\hline 299-E32-4 & $1 / 15 / 92$ & B010K6 & & .20 & & \\
\hline 299-E32-4 & $4 / 06 / 92$ & 806696 & & $.07 \mathrm{U}$ & & \\
\hline $299-E 32-4$ & $7 / 14 / 92$ & $B 07173$ & & $.01 \mathrm{U}$ & & \\
\hline $699-40-39$ & $12 / 05 / 89$ & HOOODBX2 & & & .37 & $6.95 U$ \\
\hline $699-40-39$ & $1 / 25 / 90$ & HOOODBX6 & & & $.11 \mathrm{U}$ & \\
\hline $699-40-39$ & $4 / 25 / 90$ & HOOODBYO & & & $.09 \mathrm{U}$ & \\
\hline $699-40-39$ & $7 / 08 / 91$ & H00071Y4 & & $.14 \mathrm{U}$ & & \\
\hline $699-40-39$ & $9 / 11 / 91$ & BOOLG1 & & $.08 \mathrm{U}$ & & \\
\hline $699-40-39$ & $1 / 31 / 92$ & B01065 & & $.07 \mathrm{U}$ & & \\
\hline $699-40-39$ & $4 / 17 / 92$ & B065P2 & & $.00 \mathrm{U}$ & & \\
\hline $699-40-39$ & $6 / 24 / 92$ & $8062 T 7$ & & $.02 \mathrm{U}$ & & \\
\hline $699-40-39$ & $1 / 14 / 93$ & $8077 \times 4$ & & $.03 \mathrm{U}$ & & \\
\hline $699-40-40 \mathrm{~A}$ & $1 / 24 / 92$ & B01T62 & & .15 & & \\
\hline $699-40-40 \mathrm{~A}$ & $4 / 22 / 92$ & B06508 & & $.01 \mathrm{U}$ & & \\
\hline $699-40-40 \mathrm{~A}$ & $6 / 25 / 92$ & B06ZV2 & & $.01 \mathrm{U}$ & & \\
\hline $699-40-40 \mathrm{~A}$ & $10 / 21 / 92$ & B07JK3 & & $.09 \mathrm{U}$ & & \\
\hline $699-40-40 \mathrm{~A}$ & $1 / 26 / 93$ & BOTV49 & & $.03 \mathrm{U}$ & & \\
\hline $699-40-40 B$ & $1 / 24 / 92$ & B01T64 & & .67 & & \\
\hline $699-40-40 B$ & $4 / 22 / 92$ & B065SO & & $.12 \mathrm{U}$ & & \\
\hline $699-40-40 B$ & $6 / 29 / 92$ & B06ZW2 & & .23 & & \\
\hline $699-40-40 B$ & $10 / 21 / 92$ & B07JK8 & & .16 & & \\
\hline $699-40-40 B$ & $1 / 26 / 93$ & B07N54 & & .18 & & \\
\hline
\end{tabular}


(sheet $\star \star$ of $\star \star$ )

\begin{tabular}{|c|c|c|c|c|c|c|}
\hline & & & $k-40$ & RADIUM & RADIUM & RU-106 \\
\hline $\begin{array}{l}\text { Hell } \\
\text { Name }\end{array}$ & $\begin{array}{c}\text { Collection } \\
\text { Date }\end{array}$ & $\begin{array}{l}\text { Sample } \\
\text { Number }\end{array}$ & $\begin{array}{c}140 / \mathrm{pCi} / \mathrm{L} \\
. / .\end{array}$ & $\begin{array}{c}137 / \mathrm{pC} \mathrm{i} / \mathrm{L} \\
. / .\end{array}$ & $\begin{array}{c}\text { r/pCill } \\
. / 5\end{array}$ & $\begin{array}{l}\text { 17pcis } \\
. / .\end{array}$ \\
\hline 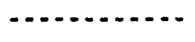 & 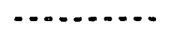 & - n & $\cdots$ & - & , n & - \\
\hline $699-41-40$ & $12 / 05 / 89$ & $\mathrm{H} 0000044$ & & & .18 & $12.60 \mathrm{U}$ \\
\hline $699-49-40$ & $1 / 25 / 90$ & 10000048 & & & .30 & \\
\hline $699-41-40$ & $4 / 19 / 90$ & H0000052 & & & .24 & \\
\hline $699-41-40$ & $7 / 10 / 91$ & H00071Y1 & & .12 & & \\
\hline $699-41-40$ & $9 / 11 / 91$ & BOOLG2 & & $.04 \mathrm{U}$ & & \\
\hline $699-41-40$ & $1 / 31 / 92$ & B010C8 & & $-.00 \mathrm{U}$ & & \\
\hline $699-41-40$ & $4 / 28 / 92$ & $B 065 S 5$ & & $.03 \mathrm{U}$ & & \\
\hline $699-41-40$ & $4 / 28 / 92$ & B065S6 & & $.09 \mathrm{U}$ & & \\
\hline $699-41-40$ & $6 / 24 / 92$ & $B 062 \times 2$ & & .16 & & \\
\hline $699-41-40$ & $1 / 14 / 93$ & $807 \pi \times 9$ & & $.06 \mathrm{U}$ & & \\
\hline $699-41-42$ & $1 / 08 / 93$ & B07v59 & & .38 & & \\
\hline $699-42-39 A$ & $1 / 23 / 92$ & $B 01 T 66$ & & .05 UP & & \\
\hline $699-42-39 A$ & $4 / 17 / 92$ & $8065 T 1$ & & $.31 \mathrm{P}$ & & \\
\hline $699-42 \cdot 39 A$ & $6 / 25 / 92$ & $8062 \times 7$ & & $.22 \mathrm{P}$ & & \\
\hline $699-42 \cdot 39 A$ & $10 / 21 / 92$ & B07JL3 & & $.22 \mathrm{P}$ & & \\
\hline $699-42-39 A$ & $1 / 27 / 93$ & BOTV64 & & .14 UP & & \\
\hline $699-42-398$ & $1 / 23 / 92$ & $801 T 68$ & & .17 & & \\
\hline $699-42-398$ & $4 / 17 / 92$ & $8065 T 6$ & & $.10 \mathrm{U}$ & & \\
\hline $699-42-39 B$ & $6 / 25 / 92$ & B06ZYZ & & .24 & & \\
\hline $699-42-39 B$ & $10 / 28 / 92$ & B07JJ2 & & .15 & & \\
\hline $699-42-398$ & $10 / 28 / 92$ & $B 07 \mathrm{JJ} 3$ & & $.05 \mathrm{U}$ & & \\
\hline $699-42-39 B$ & $1 / 25 / 93$ & B07N69 & & .17 & & \\
\hline $699-42-40 A$ & $2 / 03 / 83$ & $100000 \times 8$ & & & & -17.70 \\
\hline $699-42-40 A$ & $2 / 28 / 83$ & HOOODDX9 & & & & 45.50 \\
\hline $699-42-40 A$ & $3 / 28 / 83$ & HOOODDYO & & & & -49.60 \\
\hline $699-42-40 A$ & $4 / 14 / 83$ & H0OODOYZ & & & & 37.70 \\
\hline $699-42-40 A$ & $5 / 12 / 83$ & HOOOODY3 & & & & 12.70 \\
\hline $699-42-40 A$ & $6 / 16 / 83$ & HOOOODY4 & & & & -31.00 \\
\hline $699-42-40 A$ & $7 / 14 / 83$ & H000DDYS & & & & -9.86 \\
\hline $699-42-40 A$ & $8 / 19 / 83$ & H0OODOYG & & & & 4.90 \\
\hline $699-42-40 \mathrm{~A}$ & $9 / 27 / 83$ & H0OODDY7 & & & & 13.10 \\
\hline $699-42-40 A$ & $10 / 12 / 83$ & HOOODDY8 & & & & -102.00 \\
\hline $699-42-40 A$ & $11 / 07 / 83$ & HOOODOY9 & & & & 12.80 \\
\hline $699-42-40 A$ & $12 / 09 / 93$ & $H 0000020$ & & & & 18.00 \\
\hline $699-42-40 \mathrm{~A}$ & $1 / 24 / 84$ & H0000021 & & & & 29.20 \\
\hline $699-42-40 \mathrm{~A}$ & $2 / 28 / 84$ & HOOODDZZ & & & & 63.40 \\
\hline $699-42-40 A$ & $4 / 10 / 84$ & HOOODDZ3 & & & & 15.90 \\
\hline $699-42-40 \mathrm{~A}$ & $4 / 26 / 84$ & $H 0000024$ & & & & -35.40 \\
\hline $699-42-40 \mathrm{~A}$ & $5 / 15 / 84$ & $H 0000025$ & & & & -26.80 \\
\hline $699-42-40 \mathrm{~A}$ & $6 / 05 / 84$ & 40000026 & & & & 18.30 \\
\hline $699-42-40 A$ & $7 / 19 / 84$ & $H 0000027$ & & & & -35.90 \\
\hline $699-42-40 A$ & $8 / 10 / 84$ & 40000028 & & & & 34.40 \\
\hline $699-42-40 A$ & $9 / 11 / 84$ & 40000029 & & & & -8.85 \\
\hline
\end{tabular}


(sheet ** of $\star *$ )

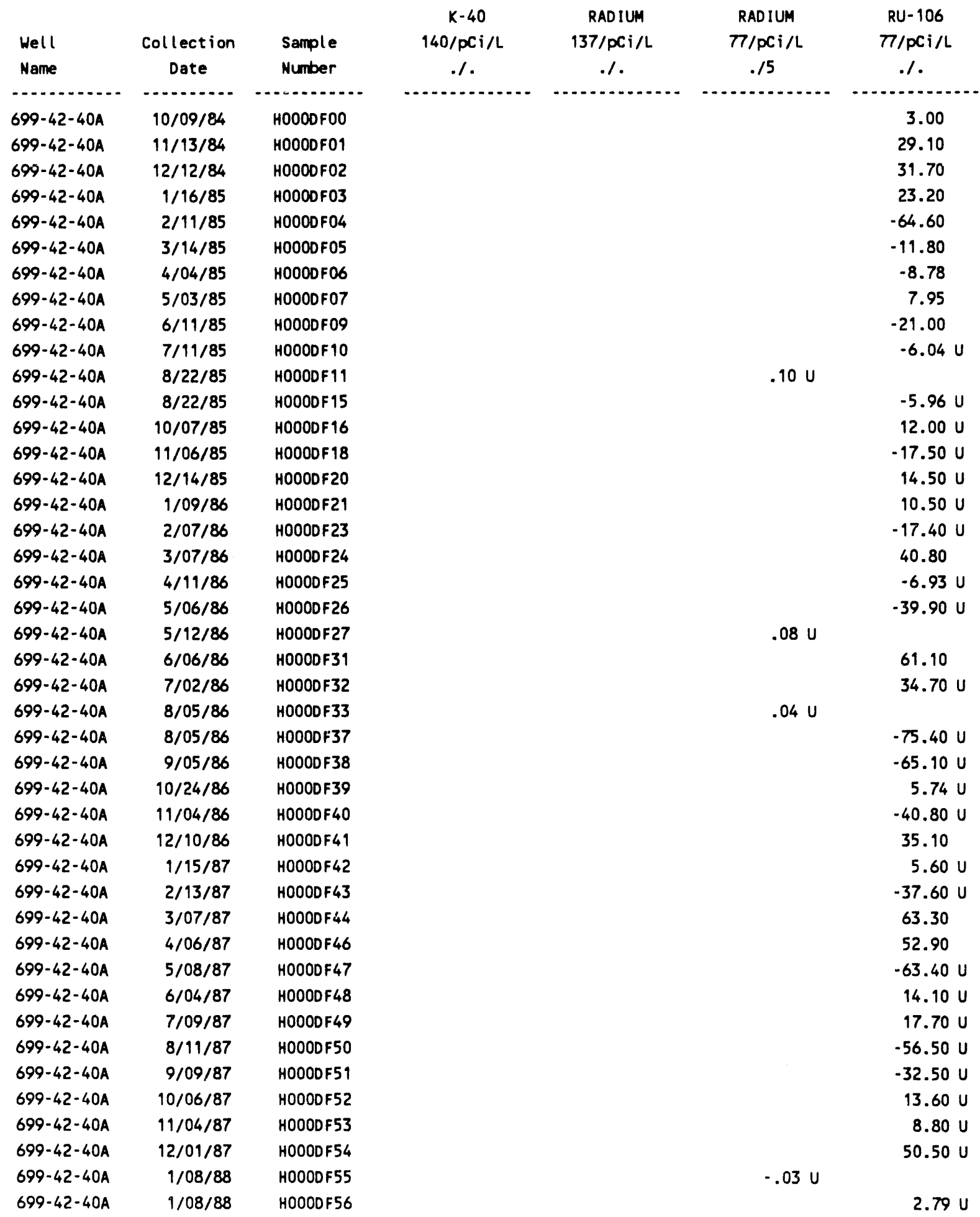


(sheet $* \star$ of $\star \star$ )

\begin{tabular}{|c|c|c|c|c|c|c|}
\hline & & & $\begin{array}{c}k-40 \\
140 / \mathrm{Cj} /\end{array}$ & $\begin{array}{l}\text { RADIUM } \\
137 / \mathrm{DCi} / \mathrm{L}\end{array}$ & $\begin{array}{l}\text { RADIUM } \\
\pi 7 / p C i / L\end{array}$ & $\begin{array}{l}\text { RU-106 } \\
77 / p C i / L\end{array}$ \\
\hline $\begin{array}{l}\text { Well } \\
\text { Name }\end{array}$ & $\begin{array}{c}\text { Collection } \\
\text { Date }\end{array}$ & $\begin{array}{l}\text { Semple } \\
\text { Number }\end{array}$ & $\begin{array}{c}140 / \mathrm{DCi} / \mathrm{L} \\
. / .\end{array}$ & $\begin{array}{c}137 / \mathrm{PCi} / \mathrm{L} \\
. / .\end{array}$ & $\begin{array}{c}7 / D_{1} 1 / L \\
. / 5\end{array}$ & .1 \\
\hline$\cdots$ & . & . & …n. & - & ............. & \\
\hline $699-42-40 A$ & $5 / 23 / 88$ & H000DF57 & & & & $-18.90 U$ \\
\hline $699-42-40 A$ & $7 / 19 / 88$ & H0000F58 & & & & $-50.80 U$ \\
\hline $699-42-40 A$ & $11 / 15 / 88$ & H0OOOF59 & & & & $-7.31 U$ \\
\hline $699-42-40 A$ & $11 / 22 / 88$ & $H 0000 F 60$ & & & $.10 \mathrm{U}$ & \\
\hline $699-42-40 A$ & $2 / 06 / 89$ & H000DF 64 & & & & $12.50 \mathrm{U}$ \\
\hline $699-42-40 A$ & $2 / 15 / 89$ & HOOODF65 & & & $.08 \mathrm{U}$ & \\
\hline $699-42-40 A$ & $4 / 07 / 89$ & H0000F69 & & & & $-25.40 \mathrm{U}$ \\
\hline $699-42-40 A$ & $5 / 31 / 89$ & HOOODF 70 & & & $.02 \mathrm{U}$ & \\
\hline $699-42-40 \mathrm{~A}$ & $8 / 10 / 89$ & HOOODF 74 & & & $.04 \mathrm{U}$ & \\
\hline $699-42-40 A$ & $1 / 26 / 90$ & HOOODF78 & & & $-.09 \mathrm{U}$ & \\
\hline $699-42-40 A$ & $7 / 08 / 91$ & H00071Y2 & & $.09 \mathrm{U}$ & & \\
\hline $699-42-40 A$ & $6 / 25 / 92$ & $8062 Y 7$ & & .28 & & \\
\hline $699-42-41$ & $1 / 24 / 92$ & B01T70 & & .00 UP & & \\
\hline $699-42-41$ & $4 / 17 / 92$ & B065V1 & & .06 UP & & \\
\hline $699-42-41$ & $6 / 29 / 92$ & B06222 & & $.17 \mathrm{P}$ & & \\
\hline $699-42-41$ & $1 / 25 / 93$ & BOTTZ4 & & .00 UP & & \\
\hline $699-42-42 B$ & $11 / 22 / 88$ & HOOODFT3 & & & $.19 \mathrm{U}$ & \\
\hline $699-42-42 B$ & $2 / 24 / 89$ & HOOODFT7 & & & .51 & \\
\hline $699-42-428$ & $6 / 16 / 89$ & HOOODFVI & & & $-.01 \mathrm{U}$ & \\
\hline $699-42-42 B$ & $6 / 16 / 89$ & HOOODFV4 & & & .15 & \\
\hline $699-42-428$ & $8 / 09 / 89$ & H00ODFVS & & & .31 & \\
\hline $699-42-428$ & $1 / 26 / 90$ & HOOOOFWO & & & $.09 \mathrm{U}$ & \\
\hline $699-42-42 B$ & $7 / 08 / 91$ & H00071Y3 & & $.08 \mathrm{U}$ & & \\
\hline $699-42-42 B$ & $6 / 24 / 92$ & 806227 & & $-.01 \mathrm{U}$ & & \\
\hline $699-42-428$ & $1 / 21 / 93$ & BOT7Z9 & & $.07 \mathrm{U}$ & & \\
\hline $699-43-40$ & $1 / 31 / 92$ & B01T72 & & $.24 \mathrm{P}$ & & \\
\hline $699-43-40$ & $4 / 28 / 92$ & B065V6 & & $.27 \mathrm{P}$ & & \\
\hline $699-43-40$ & $6 / 26 / 92$ & B07002 & & $.35 P$ & & \\
\hline $699-43-40$ & $1 / 25 / 93$ & BOTV04 & & $.34 P$ & & \\
\hline $699-43-41 E$ & $12 / 05 / 89$ & HOOODGD 6 & & & .42 & $-23.00 \mathrm{U}$ \\
\hline $699-43-41 E$ & $1 / 25 / 90$ & HOOODGFO & & & .29 & \\
\hline $699-43-41 E$ & $6 / 28 / 91$ & H0007203 & & .25 & & \\
\hline $699-43-41 E$ & $6 / 28 / 91$ & H0007204 & & .16 & & \\
\hline $699-43-41 E$ & $1 / 23 / 92$ & B010C3 & & $.10 \mathrm{U}$ & & \\
\hline $699-43-41 E$ & $4 / 17 / 92$ & B065P4 & & $.11 \mathrm{U}$ & & \\
\hline $699-43-41 E$ & $6 / 24 / 92$ & $8062 \sqrt{3}$ & & $.07 \mathrm{U}$ & & \\
\hline $699-43-41 E$ & $1 / 25 / 93$ & B07v09 & & $.10 \mathrm{U}$ & & \\
\hline $699-43-41 F$ & $12 / 05 / 89$ & H000DGG8 & & & $.09 \mathrm{U}$ & $13.00 \mathrm{U}$ \\
\hline $699-43-41 F$ & $1 / 25 / 90$ & HOOODGH2 & & & .22 & \\
\hline $699-43-41 F$ & $4 / 18 / 90$ & HOOODGH6 & & & .41 & \\
\hline $699-43-41 F$ & $7 / 02 / 91$ & H00071Y5 & & .15 & & \\
\hline $699-43-41 F$ & $5 / 05 / 92$ & B065RO & & .18 & & \\
\hline $699-43-41 F$ & $6 / 25 / 92$ & B062W7 & & .24 & & \\
\hline
\end{tabular}


(sheet $\star \star$ of $\star \star$ )

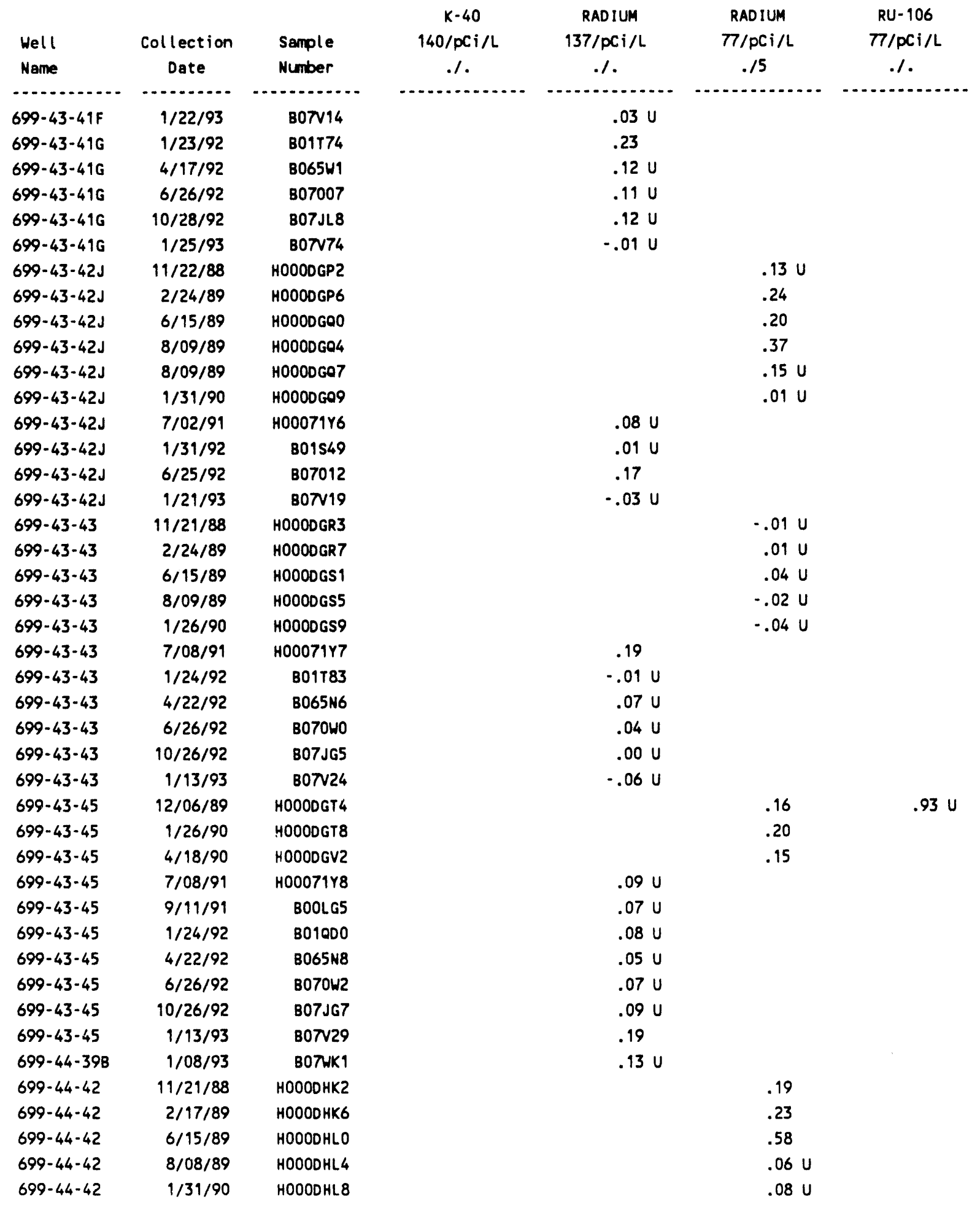


(sheet $\star \star$ of $\star \star)$

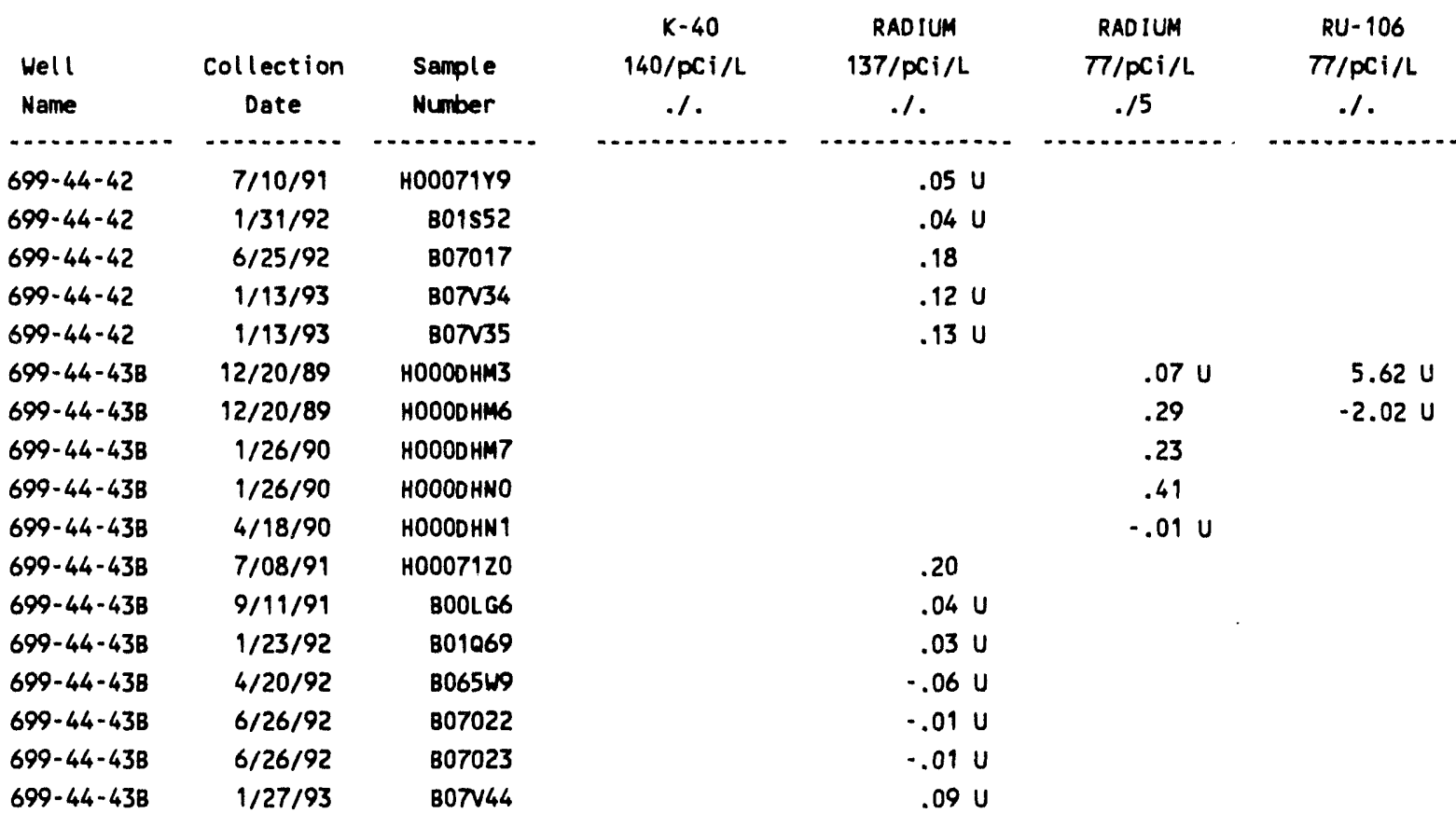

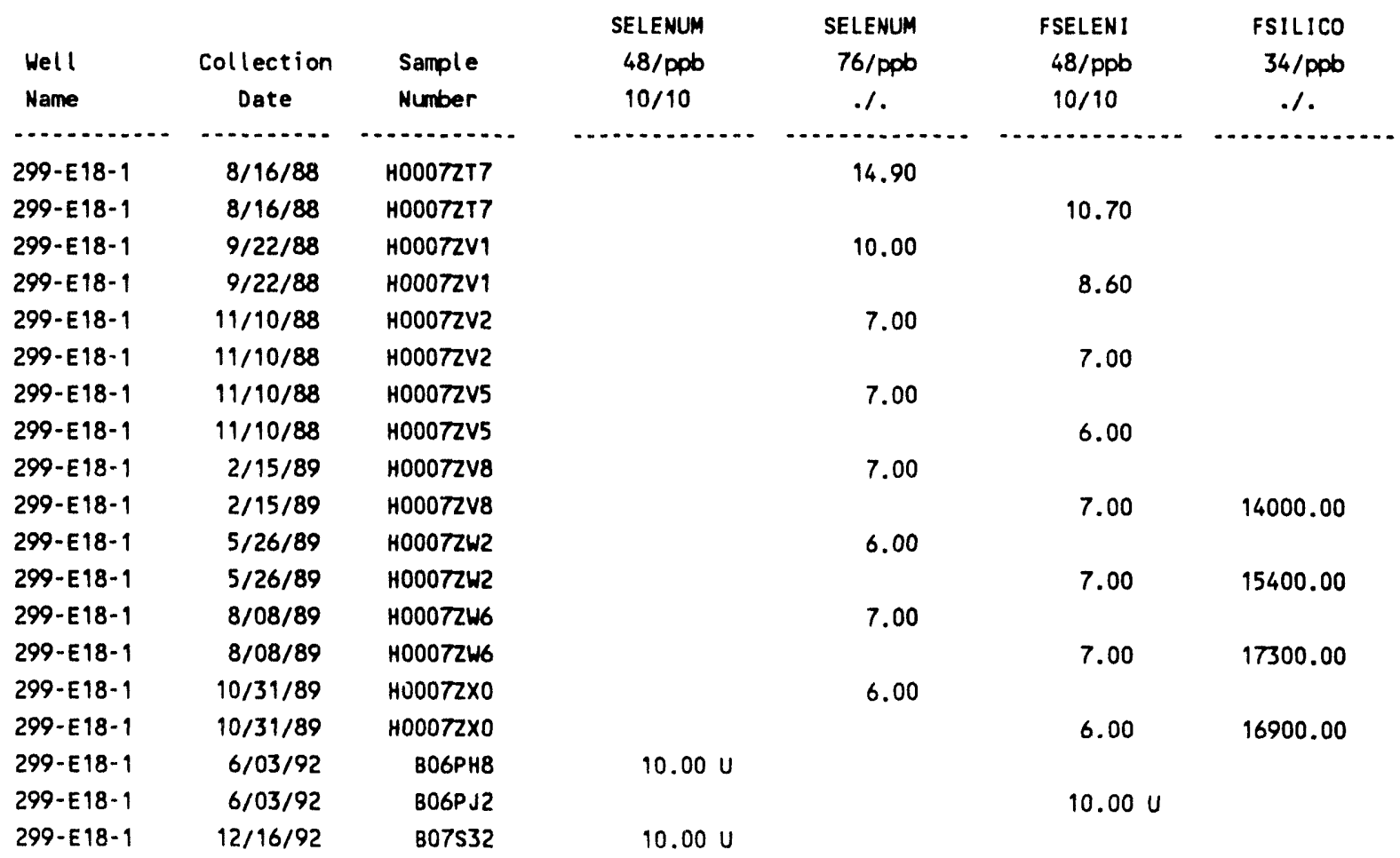


(sheet $\star \star$ of $\star *$ )

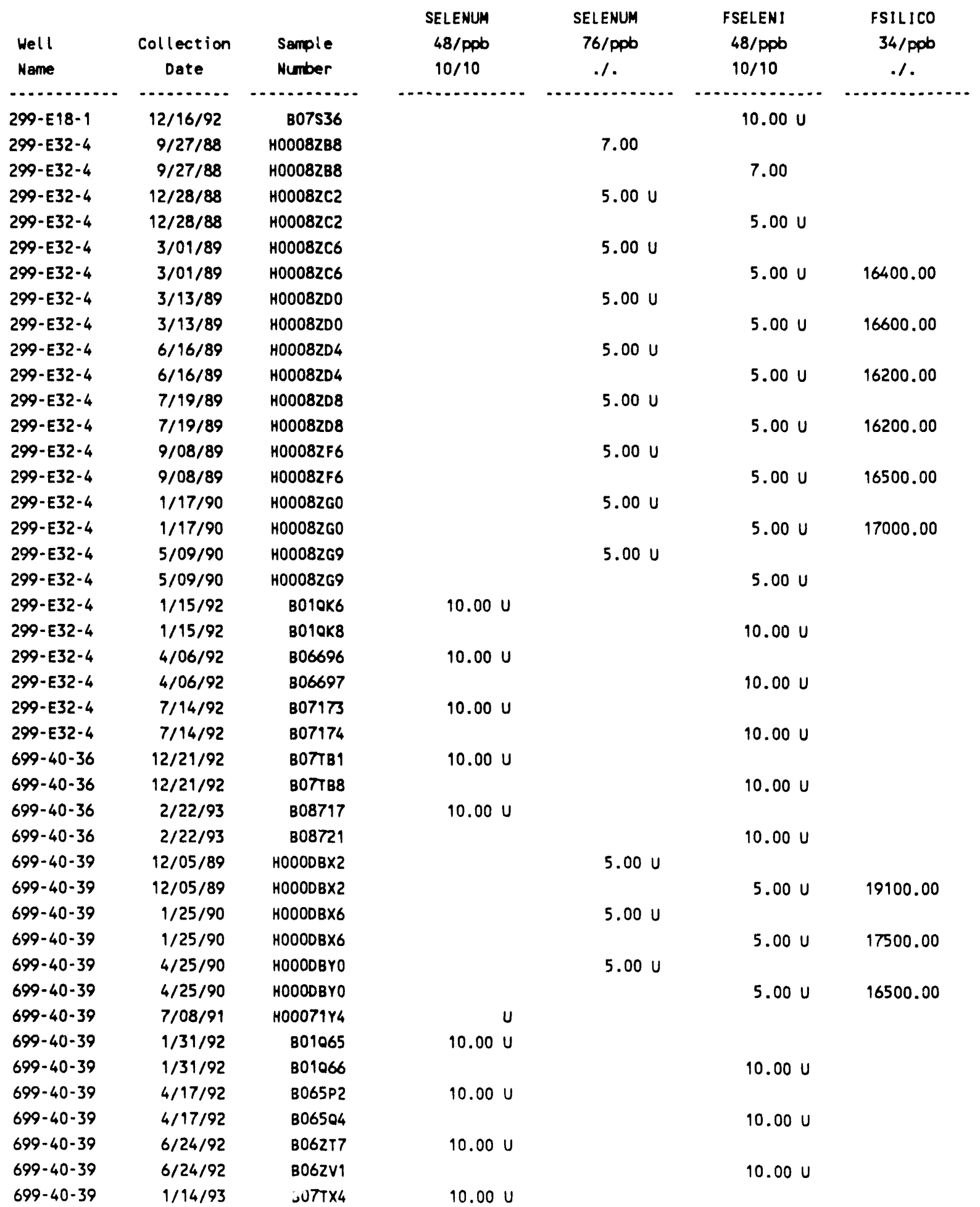


(sheet ** of $\star *$ )

\begin{tabular}{|c|c|c|c|c|c|c|}
\hline $\begin{array}{l}\text { Well } \\
\text { Name }\end{array}$ & $\begin{array}{c}\text { Collection } \\
\text { Dete }\end{array}$ & $\begin{array}{l}\text { Sample } \\
\text { Number }\end{array}$ & $\begin{array}{l}\text { SELENUM } \\
48 / \mathrm{ppo} \\
10 / 10\end{array}$ & $\begin{array}{c}\text { SELENUM } \\
76 / \mathrm{ppb} \\
. /\end{array}$ & $\begin{array}{l}\text { FSELENI } \\
48 / \mathrm{ppb} \\
10 / 10\end{array}$ & $\begin{array}{c}\text { FSILICO } \\
34 / \mathrm{ppb} \\
.1\end{array}$ \\
\hline - & . & . & . & . & . & \\
\hline $699 \cdot 40-39$ & $1 / 14 / 93$ & B077X8 & & & $10.00 \mathrm{U}$ & \\
\hline $699-40-40 \mathrm{~A}$ & $1 / 24 / 92$ & B01T62 & $10.00 \mathrm{U}$ & & & \\
\hline $699-40-40 \mathrm{~A}$ & $1 / 24 / 92$ & B01T63 & & & $10.00 \mathrm{U}$ & \\
\hline $699-40-40 \mathrm{~A}$ & $4 / 22 / 92$ & B06508 & $10.00 \mathrm{U}$ & & & \\
\hline $699-40-40 A$ & $4 / 22 / 92$ & B065R8 & & & $10.00 \mathrm{U}$ & \\
\hline $699-40-40 \mathrm{~A}$ & $6 / 25 / 92$ & B06zV2 & $10.00 \mathrm{U}$ & & & \\
\hline $699-40-40 \mathrm{~A}$ & $6 / 25 / 92$ & B06ZWO & & & $10.00 \mathrm{U}$ & \\
\hline $699-40-40 A$ & $10 / 21 / 92$ & 807JK3 & $10.00 \mathrm{U}$ & & & \\
\hline $699-40-40 A$ & $10 / 21 / 92$ & B07JK7 & & & $10.00 \mathrm{U}$ & \\
\hline $699-40-40 \mathrm{~A}$ & $1 / 26 / 93$ & BOTV49 & $10.00 \mathrm{U}$ & & & \\
\hline $699-40-40 \mathrm{~A}$ & $1 / 26 / 93$ & Bo7v53 & & & $10.00 \mathrm{U}$ & \\
\hline $699-40-408$ & $1 / 01 / 92$ & $801 T 65$ & & & $10.00 \mathrm{U}$ & \\
\hline $699-40-40 B$ & $1 / 24 / 92$ & B01T64 & $10.00 \mathrm{U}$ & & & \\
\hline $699-40-40 B$ & $4 / 22 / 92$ & 806550 & $10.00 \mathrm{U}$ & & & \\
\hline $699-40-408$ & $4 / 22 / 92$ & B065S4 & & & $10.00 \mathrm{U}$ & \\
\hline $699-40-40 B$ & $6 / 29 / 92$ & 806242 & $10.00 \mathrm{U}$ & & & \\
\hline $699-40-40 B$ & $6 / 29 / 92$ & B062W6 & & & $10.00 \mathrm{U}$ & \\
\hline $699-40-40 B$ & $10 / 21 / 92$ & B07JK8 & $10.00 \mathrm{U}$ & & & \\
\hline $699-40-40 B$ & $10 / 21 / 92$ & B07JL2 & & & $10.00 \mathrm{U}$ & \\
\hline $699-40-40 B$ & $1 / 26 / 93$ & B07V54 & $10.00 \mathrm{U}$ & & & \\
\hline $699-40-40 B$ & $1 / 26 / 93$ & B07v58 & & & $10.00 \mathrm{U}$ & \\
\hline $699-41-35$ & $12 / 21 / 92$ & B07T89 & $10.00 \mathrm{U}$ & & & \\
\hline $699-41-35$ & $12 / 21 / 92$ & B07TC3 & & & $10.00 \mathrm{U}$ & \\
\hline $699-41-35$ & $2 / 22 / 93$ & B08707 & $10.00 \mathrm{U}$ & & & \\
\hline $699-41-35$ & $2 / 22 / 93$ & B08711 & & & $10.00 \mathrm{U}$ & \\
\hline $699-41-40$ & $12 / 05 / 89$ & H0OODD44 & & $5.00 \mathrm{U}$ & & \\
\hline $699-41-40$ & $12 / 05 / 89$ & 10000044 & & & $5.00 \mathrm{U}$ & 14000.00 \\
\hline $699-41-40$ & $1 / 25 / 90$ & H0OODD 48 & & $5.00 \mathrm{U}$ & & \\
\hline $699-41-40$ & $1 / 25 / 90$ & $H 000 D 048$ & & & $5.00 \mathrm{U}$ & 15900.00 \\
\hline $699-41-40$ & $4 / 19 / 90$ & H000DD52 & & $5.00 \mathrm{U}$ & & \\
\hline $699-41-40$ & $4 / 19 / 90$ & H000DD52 & & & $5.00 \mathrm{U}$ & 13900.00 \\
\hline $699-41-40$ & $7 / 10 / 91$ & H00071Y1 & $U$ & & & \\
\hline $699-41-40$ & $1 / 31 / 92$ & B010C8 & $10.00 \mathrm{U}$ & & & \\
\hline $699-41-40$ & $1 / 31 / 92$ & B010C9 & & & $10.00 \mathrm{U}$ & \\
\hline $699-41-40$ & $4 / 28 / 92$ & B065S5 & $10.00 \mathrm{U}$ & & & \\
\hline $699-41-40$ & $4 / 28 / 92$ & 806556 & $10.00 \mathrm{U}$ & & & \\
\hline $699-41-40$ & $4 / 28 / 92$ & B065s9 & & & $10.00 \mathrm{U}$ & \\
\hline $699-41-40$ & $4 / 28 / 92$ & 8065TO & & & $10.00 \mathrm{U}$ & \\
\hline $699-41-40$ & $6 / 24 / 92$ & $8062 \times 2$ & $10.00 \mathrm{U}$ & & & \\
\hline $699-41-40$ & $6 / 24 / 92$ & $8062 \times 6$ & & & $10.00 \mathrm{U}$ & \\
\hline $699-41-40$ & $1 / 14 / 93$ & $8077 \times 9$ & $10.00 \mathrm{U}$ & & & \\
\hline $699-41-40$ & $1 / 14 / 93$ & B07TY3 & & & $10.00 \mathrm{U}$ & \\
\hline $699-41-42$ & $1 / 08 / 93$ & B07V59 & $10.00 \mathrm{U}$ & & & \\
\hline
\end{tabular}


(sheet $*$ of $* *$ )

\begin{tabular}{|c|c|c|c|c|c|c|}
\hline $\begin{array}{l}\text { Well } \\
\text { Name }\end{array}$ & $\begin{array}{c}\text { Collection } \\
\text { Date }\end{array}$ & $\begin{array}{l}\text { Sample } \\
\text { Number }\end{array}$ & $\begin{array}{c}\text { SELENUM } \\
48 / \mathrm{ppb} \\
10 / 10\end{array}$ & $\begin{array}{c}\text { SELENUM } \\
\text { 76/ppb } \\
. /\end{array}$ & $\begin{array}{c}\text { FSELENI } \\
48 / \mathrm{ppb} \\
10 / 10\end{array}$ & $\begin{array}{c}\text { FSILICO } \\
34 / \mathrm{ppb} \\
.1\end{array}$ \\
\hline . & 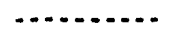 & . & . & . & - & . \\
\hline $699-41-42$ & $1 / 08 / 93$ & B07N63 & & & $10.00 \mathrm{U}$ & \\
\hline $699-42-37$ & $12 / 22 / 92$ & Bo7TC4 & $10.00 \mathrm{U}$ & & & \\
\hline $699-42 \cdot 37$ & $12 / 22 / 92$ & $\mathrm{~B} 07 \mathrm{TC}$ & & & $10.00 \mathrm{U}$ & \\
\hline $699-42-37$ & $2 / 23 / 93$ & 808712 & $10.00 \mathrm{U}$ & & & \\
\hline $699-42-37$ & $2 / 23 / 93$ & B08716 & & & $10.00 \mathrm{U}$ & \\
\hline $699-42-39 A$ & $1 / 23 / 92$ & B01T66 & 10.00 UP & & & \\
\hline $699-42-39 A$ & $1 / 23 / 92$ & B01T67 & & & 10.00 UP & \\
\hline $699-42-39 A$ & $4 / 17 / 92$ & B065T1 & 10.00 UP & & & \\
\hline $699-42-39 A$ & $4 / 17 / 92$ & B065T5 & & & 10.00 UP & \\
\hline $699-42-39 A$ & $6 / 25 / 92$ & $B 062 \times 7$ & 10.00 UP & & & \\
\hline $699-42-39 A$ & $6 / 25 / 92$ & B06ZY1 & & & 10.00 UP & \\
\hline $699-42-39 A$ & $10 / 21 / 92$ & B07JL3 & 10.00 UP & & & \\
\hline $699-42-39 A$ & $10 / 21 / 92$ & B07JL7 & & & 10.00 UP & \\
\hline $699-42-39 A$ & $1 / 27 / 93$ & Bo7v64 & 10.00 UP & & & \\
\hline $699-42-39 A$ & $1 / 27 / 93$ & B07N68 & & & 10.00 UP & \\
\hline $699-42-39 B$ & $1 / 23 / 92$ & B01T68 & $10.00 \mathrm{U}$ & & & \\
\hline $699-42-398$ & $1 / 23 / 92$ & В01T69 & & & $10.00 \mathrm{U}$ & \\
\hline $699-42-398$ & $4 / 17 / 92$ & B065T6 & $10.00 \mathrm{U}$ & & & \\
\hline $699-42-39 B$ & $4 / 97 / 92$ & B065V0 & & & $10.00 \mathrm{U}$ & \\
\hline $699-42-398$ & $6 / 25 / 92$ & B06ZY2 & $10.00 \mathrm{U}$ & & & \\
\hline $699-42-398$ & $6 / 25 / 92$ & $8062 Y 6$ & & & $10.00 \mathrm{U}$ & \\
\hline $699-42-398$ & $10 / 28 / 92$ & B07JJ2 & $10.00 \mathrm{U}$ & & & \\
\hline $699-42-39 B$ & $10 / 28 / 92$ & B07JJ3 & $10.00 \mathrm{U}$ & & & \\
\hline $699-42-398$ & $10 / 28 / 92$ & 807JJ6 & & & $10.00 \mathrm{U}$ & \\
\hline $699-42-398$ & $10 / 28 / 92$ & B07JJ7 & & & $10.00 \mathrm{U}$ & \\
\hline $699-42-39 B$ & $1 / 25 / 93$ & B07N69 & $10.00 \mathrm{U}$ & & & \\
\hline $699-42-39 B$ & $1 / 25 / 93$ & BOTVT3 & & & $10.00 \mathrm{U}$ & \\
\hline $699-42-40 A$ & $8 / 22 / 85$ & HOOODF 11 & & $5.00 \mathrm{U}$ & & \\
\hline $699-42-40 A$ & $5 / 12 / 86$ & HOOODF27 & & $5.00 \mathrm{U}$ & & \\
\hline $699-42-40 A$ & $8 / 05 / 86$ & H0OODF33 & & $5.00 \mathrm{U}$ & & \\
\hline $699-42-40 A$ & $1 / 08 / 88$ & H0OODF55 & & $5.00 \mathrm{U}$ & & \\
\hline $699-42-40 A$ & $1 / 08 / 88$ & H0OODF55 & & & $5.00 \mathrm{U}$ & \\
\hline $699-42-40 A$ & $11 / 22 / 88$ & HOOODF 60 & & $5.00 \mathrm{U}$ & & \\
\hline $699-42-40 A$ & $11 / 22 / 88$ & HOOODF60 & & & $5.00 \mathrm{U}$ & \\
\hline $699-42-40 A$ & $2 / 15 / 89$ & H0OODF65 & & $5.00 \mathrm{U}$ & & \\
\hline $699-42-40 A$ & $2 / 15 / 89$ & H000OF65 & & & $5.00 \mathrm{U}$ & 3950.00 \\
\hline $699-42-40 \mathrm{~A}$ & $5 / 31 / 89$ & HOOODF 70 & & $5.00 \mathrm{U}$ & & \\
\hline $699-42-40 A$ & $5 / 31 / 89$ & HOOODF7O & & & $5.00 \mathrm{U}$ & 4420.00 \\
\hline $699-42-40 A$ & $8 / 10 / 89$ & HOOODF74 & & $5.00 \mathrm{U}$ & & \\
\hline $699-42-40 A$ & $8 / 10 / 89$ & HOOODF74 & & & $5.00 \mathrm{U}$ & 6850.00 \\
\hline $699-42-40 A$ & $1 / 26 / 90$ & H0OODF 78 & & $5.00 \mathrm{U}$ & & \\
\hline $699-42-40 A$ & $1 / 26 / 90$ & HOOODF78 & & & $5.00 \mathrm{U}$ & 5300.00 \\
\hline $699-42-40 A$ & $7 / 08 / 91$ & H00079Y2 & $u$ & & & \\
\hline
\end{tabular}


(sheet $\star$ of $\star *$ )

\begin{tabular}{|c|c|c|c|c|c|c|c|}
\hline Well & Collection & Semple & $\begin{array}{l}\text { SELENUM } \\
\text { 48/ppb }\end{array}$ & & $\begin{array}{r}\text { SELENUM } \\
76 / p p b\end{array}$ & $\begin{array}{l}\text { FSELENI } \\
48 / \mathrm{ppb}\end{array}$ & $\begin{array}{r}\text { FSILICO } \\
34 / p p b\end{array}$ \\
\hline Name & Date & Number & $10 / 10$ & &.$/$ & $10 / 10$ & .1 \\
\hline - & . & - & . & $\cdots$ & .............. & . & \\
\hline $699-42-40 A$ & $1 / 08 / 92$ & $80 \pi Y 8$ & 10.00 & $u$ & & & \\
\hline $699-42-40 A$ & $1 / 08 / 92$ & $807 \pi 23$ & & & & $10.00 \mathrm{U}$ & \\
\hline $699-42-40 A$ & $6 / 25 / 92$ & B062Y7 & 10.00 & $u$ & & & \\
\hline $699-42-40 A$ & $6 / 25 / 92$ & $B 06221$ & & & & $10.00 \mathrm{U}$ & \\
\hline $699-42-41$ & $1 / 24 / 92$ & B01T70 & 10.00 & UP & & & \\
\hline $699-42-41$ & $1 / 24 / 92$ & B01T71 & & & & 10.00 UP & \\
\hline $699-42-41$ & $4 / 17 / 92$ & B065V1 & 10.00 & UP & & & \\
\hline $699-42-41$ & $4 / 17 / 92$ & B065V5 & & & & 10.00 UP & \\
\hline $699-42-41$ & $6 / 29 / 92$ & 806222 & 10.00 & UP & & & \\
\hline $699-42-41$ & $6 / 29 / 92$ & 806226 & & & & 10.00 UP & \\
\hline $699-42-41$ & $1 / 25 / 93$ & B07T24 & 10.00 & UP & & & \\
\hline $699-42-41$ & $1 / 25 / 93$ & B07T28 & & & & 10.00 UP & \\
\hline $699-42-42 B$ & $11 / 22 / 88$ & HOOODFT3 & & & $5.00 \mathrm{U}$ & & \\
\hline $699-42-42 B$ & $11 / 22 / 88$ & H0000FT3 & & & & $5.00 \mathrm{U}$ & \\
\hline $699-42-428$ & $2 / 24 / 89$ & H0O0OFT7 & & & $5.00 \mathrm{U}$ & & \\
\hline $699-42 \cdot 428$ & $2 / 24 / 89$ & HOOODFT7 & & & & $5.00 \mathrm{U}$ & 18000.00 \\
\hline $699-42-42 B$ & $6 / 16 / 89$ & H0000FV1 & & & $5.00 \mathrm{U}$ & & \\
\hline $699-42-42 B$ & $6 / 16 / 89$ & H0000FV1 & & & & $5.00 \mathrm{U}$ & 19100.00 \\
\hline $699-42-42 B$ & $6 / 16 / 89$ & HOOODFV4 & & & $5.00 \mathrm{U}$ & & \\
\hline $699-42-42 B$ & $6 / 16 / 89$ & HOOODFV 4 & & & & $5.00 \mathrm{U}$ & 17200.00 \\
\hline $699-42-42 B$ & $8 / 09 / 89$ & H000OFV5 & & & $5.00 \mathrm{U}$ & & \\
\hline $699-42-42 B$ & $8 / 09 / 89$ & H0OODFV5 & & & & $5.00 \mathrm{U}$ & 20000.00 \\
\hline $699-42-42 B$ & $1 / 26 / 90$ & HOOODFWO & & & $5.00 \mathrm{U}$ & & \\
\hline $699-42-42 B$ & $1 / 26 / 90$ & HOOODFWO & & & & $5.00 \mathrm{U}$ & \\
\hline $699-42-42 B$ & $7 / 08 / 91$ & H00071Y3 & & u & & & \\
\hline $699-42-42 B$ & $6 / 24 / 92$ & 806227 & 10.00 & $u$ & & & \\
\hline $699-42-42 B$ & $6 / 24 / 92$ & B07001 & & & & $10.00 \mathrm{U}$ & \\
\hline $699-42-42 B$ & $1 / 21 / 93$ & B07T29 & 10.00 & $U$ & & & \\
\hline $699-42-42 B$ & $1 / 21 / 93$ & BO7v03 & & & & $10.00 \mathrm{U}$ & \\
\hline $699-43-40$ & $1 / 31 / 92$ & В01т72 & 10.00 & UP & & & \\
\hline $699-43-40$ & $1 / 31 / 92$ & B01T73 & & & & 10.00 UP & \\
\hline $699-43-40$ & $4 / 28 / 92$ & B065V6 & 10.00 & UP & & & \\
\hline $699-43-40$ & $4 / 28 / 92$ & B065WO & & & & 10.00 UP & \\
\hline $699-43-40$ & $6 / 26 / 92$ & B07002 & 10.00 & UP & & & \\
\hline $699-43-40$ & $6 / 26 / 92$ & B07006 & & & & 10.00 UP & \\
\hline $699-43-40$ & $1 / 25 / 93$ & BOTV04 & 10.00 & UP & & & \\
\hline $699-43-40$ & $1 / 25 / 93$ & B07v08 & & & & 10.00 UP & \\
\hline $699-43-41 E$ & $12 / 05 / 89$ & HODODGD6 & $\cdot$ & & $5.00 \mathrm{U}$ & & \\
\hline $699-43-41 E$ & $12 / 05 / 89$ & H0000GD6 & & & & $5.00 \mathrm{U}$ & 10400.00 \\
\hline $699: 43-41 E$ & $1 / 25 / 90$ & HOOOOGFO & & & $5.00 \mathrm{U}$ & & \\
\hline $699-43-41 E$ & $1 / 25 / 90$ & HOOODGFO & & & & $5.00 \mathrm{U}$ & 9960.00 \\
\hline $699-43-41 E$ & $6 / 28 / 91$ & H0007203 & & U & & & \\
\hline $699-43-41 E$ & $6 / 28 / 91$ & H0OOT2O4 & & $u$ & & & \\
\hline
\end{tabular}


(sheet ** of $\star *$ )

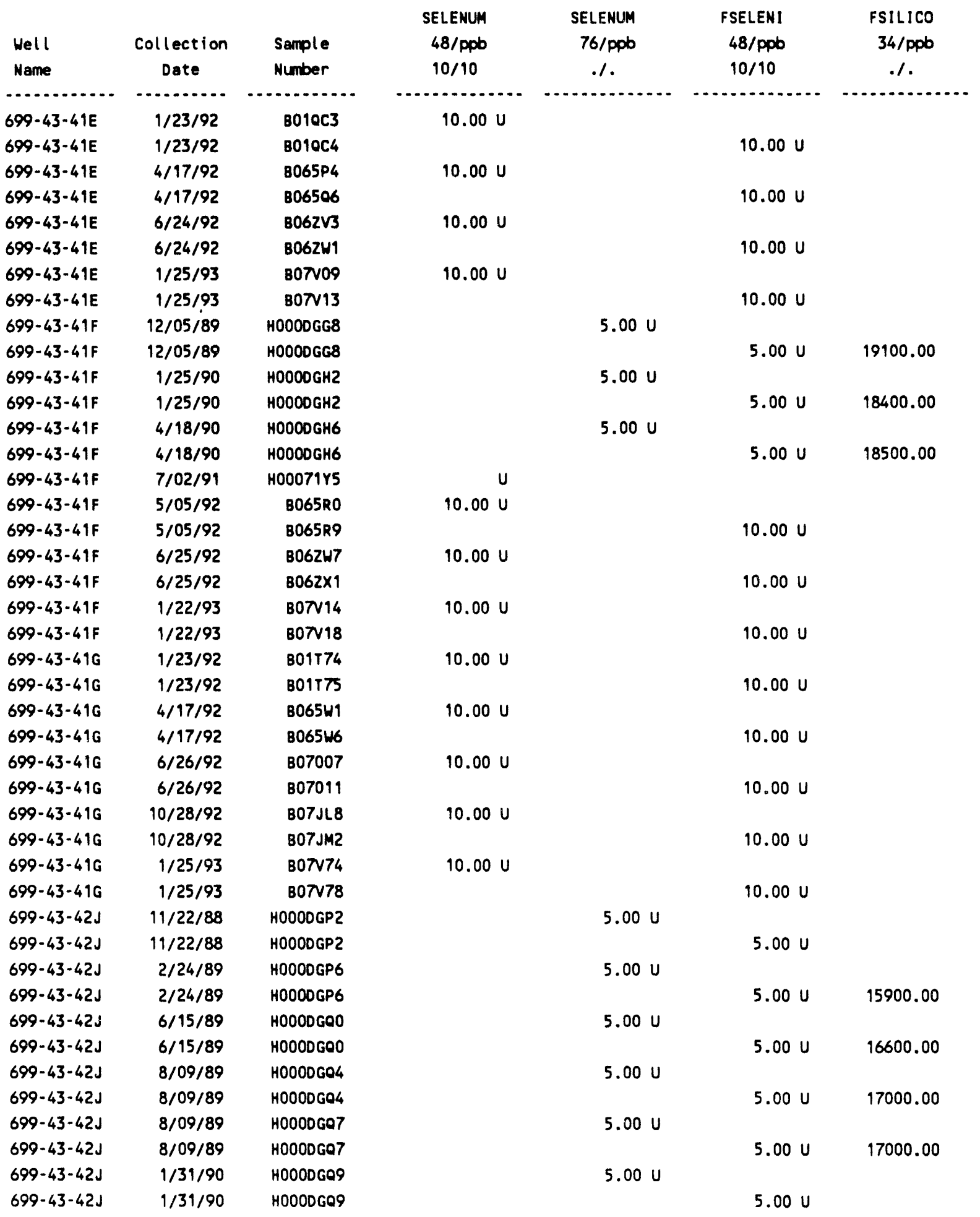


(sheet $* *$ of $* *$ )

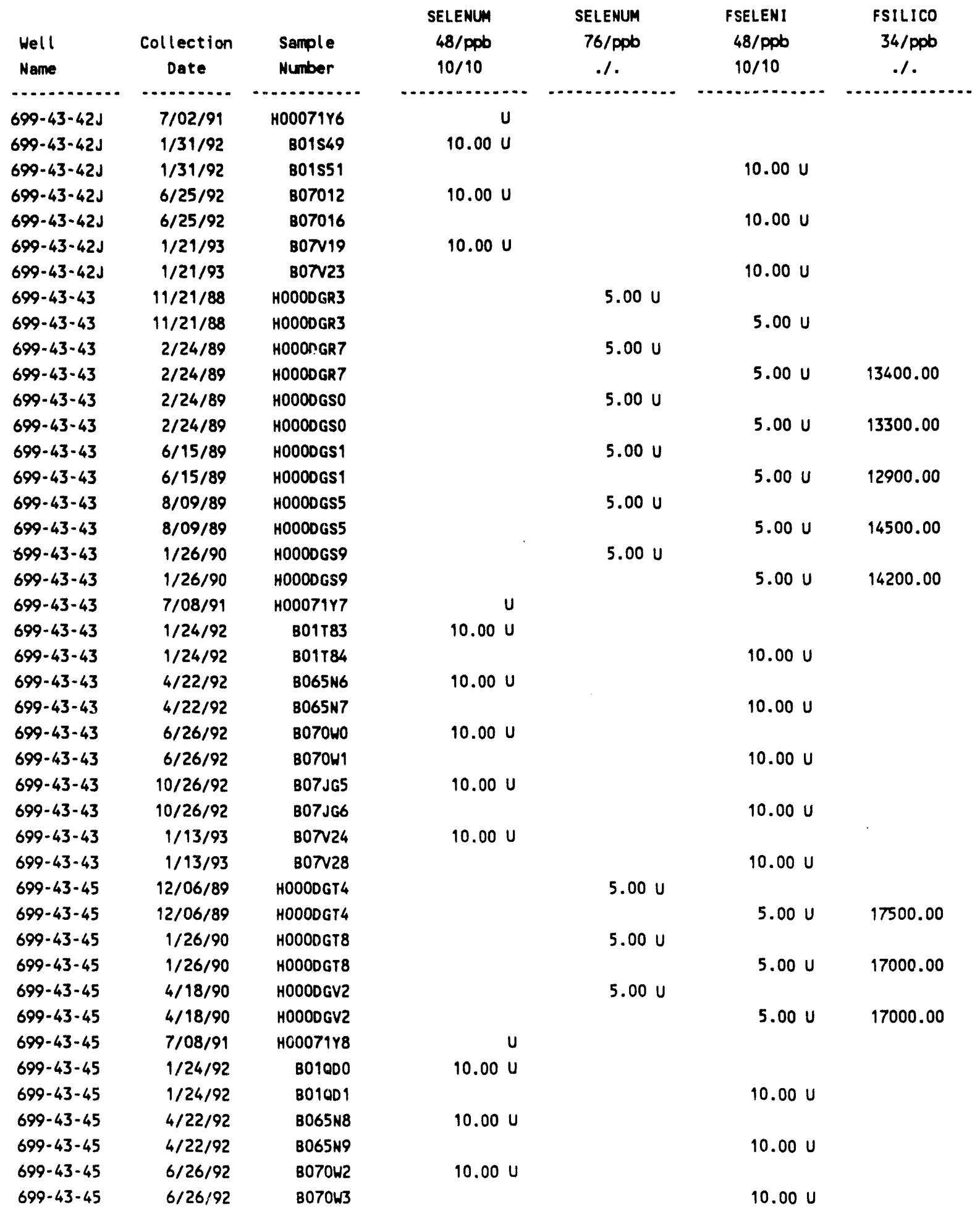


(sheet $\star \star$ of $\star \star$ )

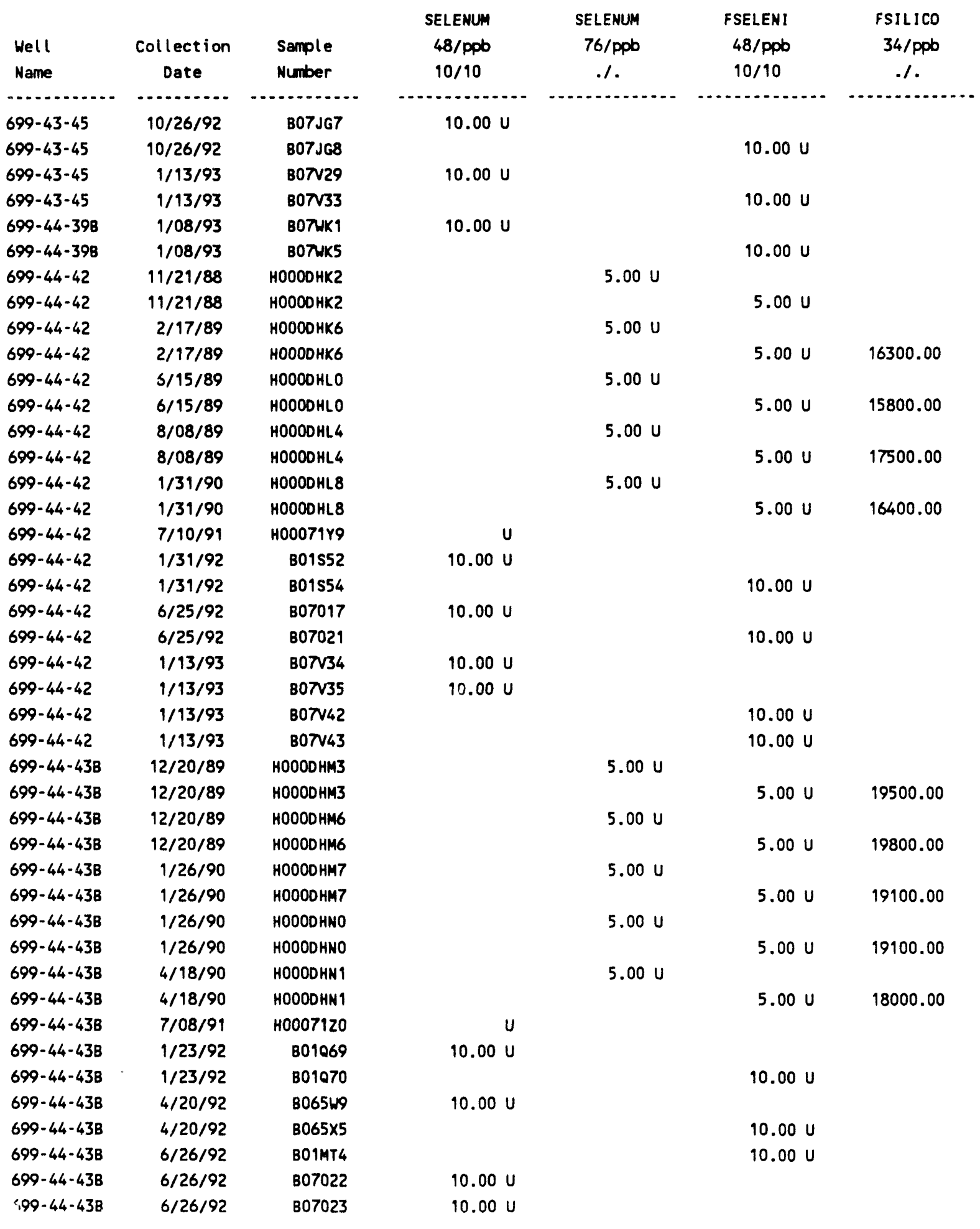


(sheet ** of **)

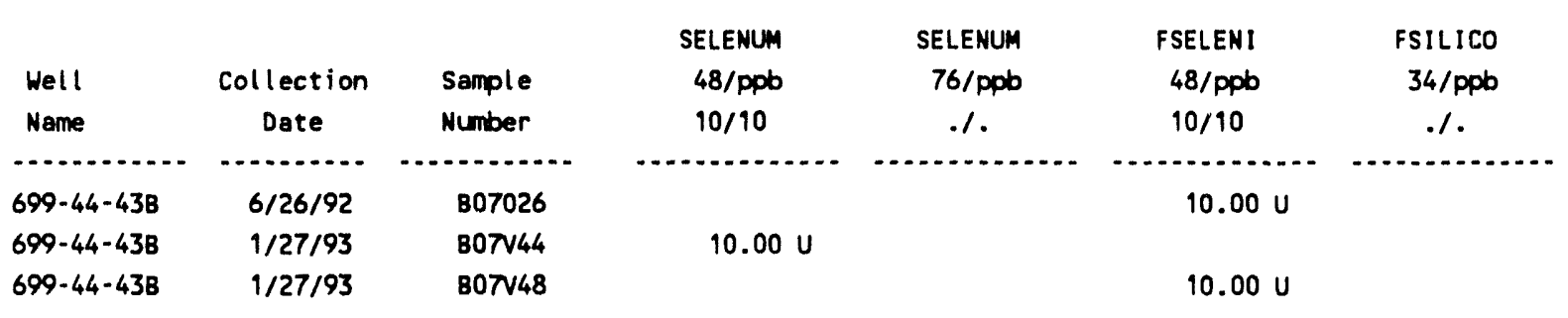

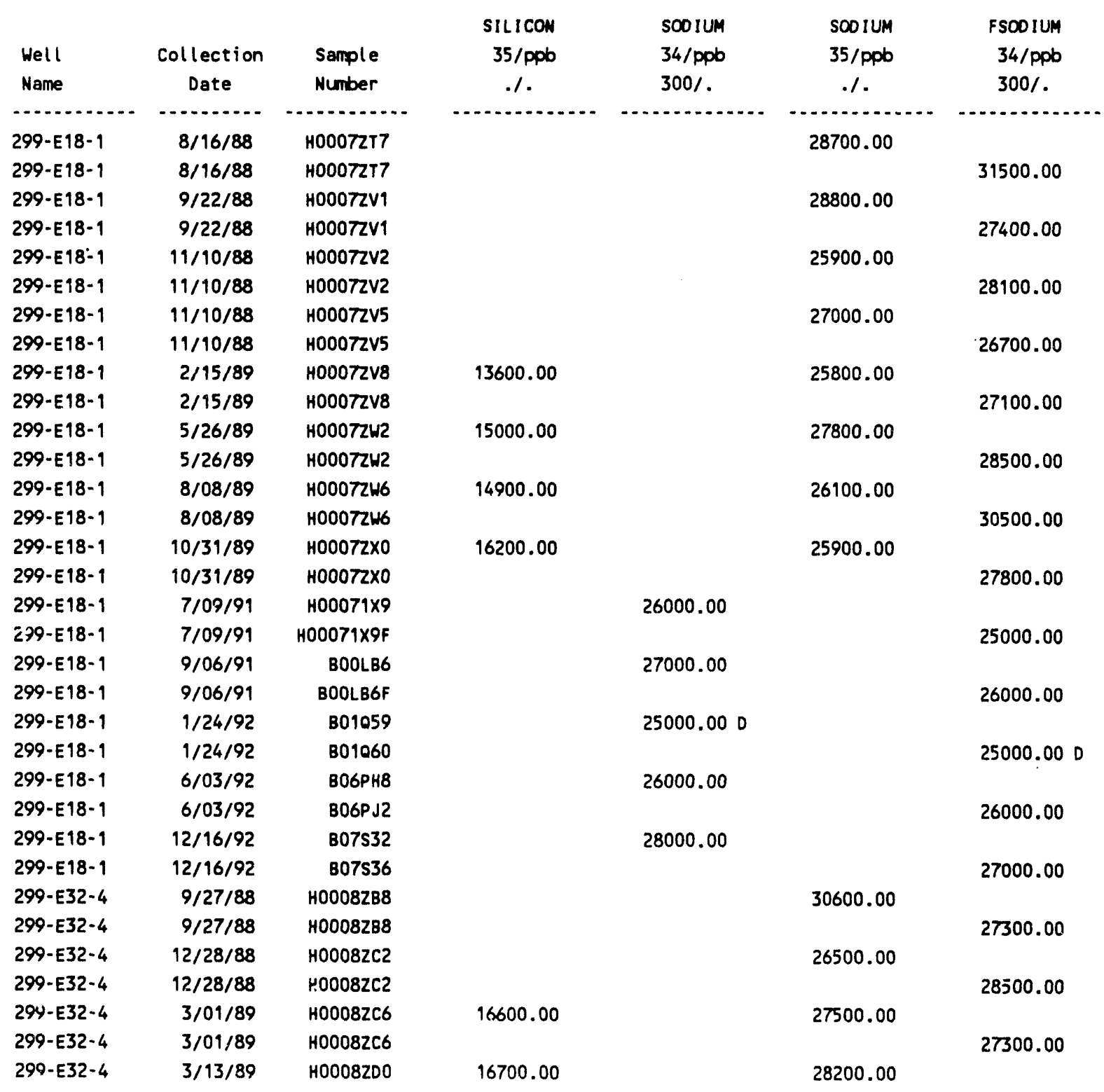


(sheet ** of $*$ )

\begin{tabular}{|c|c|c|c|c|c|c|}
\hline & & & SILICON & SOOIUM & SOOIUM & FSOOIUM \\
\hline Well & Collection & Sample & 35/ppb & 34/ppb & 35/ppb & 34/ppb \\
\hline Name & Date & Nunber & .1 & $300 /$ & .1. & $300 /$ \\
\hline (n) & n. & . & - & (n) & 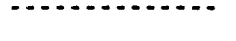 & - \\
\hline $299-E 32-4$ & $3 / 13 / 89$ & $H 0008200$ & & & & 27000.00 \\
\hline $299-E 32-4$ & $6 / 16 / 89$ & H0O08ZD4 & 16700.00 & & 26300.00 & \\
\hline $299-E 32-4$ & $6 / 16 / 89$ & H0008ZD4 & & & & 26000.00 \\
\hline $299-E 32-4$ & $7 / 19 / 89$ & H0008ZD8 & 17000.00 & & 25900.00 & \\
\hline $299-E 32-4$ & $7 / 19 / 89$ & H0008208 & & & & 24700.00 \\
\hline 299-E32-4 & $9 / 08 / 89$ & H0008ZF6 & 18800.00 & & 29100.00 & \\
\hline $299-E 32-4$ & $9 / 08 / 89$ & H0008ZF6 & & & & 26300.00 \\
\hline $299-E 32-4$ & $1 / 17 / 90$ & H0008ZGO & 17200.00 & & 26300.00 & \\
\hline $299-E 32-4$ & $1 / 17 / 90$ & HoOOBZGO & & & & 26400.00 \\
\hline 299-E32-4 & $8 / 05 / 91$ & HOOOTIYO & & $28000.00 Q D$ & & \\
\hline 299-E32-4 & $8 / 05 / 91$ & HOOOT1YOF & & & & 27000.000 \\
\hline 299-E32-4 & $8 / 05 / 91$ & H0007264 & & 27000.0000 & & \\
\hline $299-E 32-4$ & $8 / 05 / 91$ & H0007264F & & & & 27000.000 \\
\hline $299-E 32-4$ & $9 / 23 / 91$ & 800LK5 & & 26000.00 & & \\
\hline $299-E 32-4$ & $9 / 23 / 91$ & BOOLK5F & & & & 26000.00 \\
\hline 299-E32-4 & $1 / 15 / 92$ & B010K6 & & 27000.00 & & \\
\hline $299-E 32-4$ & $1 / 15 / 92$ & B010K8 & & & & 27000.00 \\
\hline $299-E 32-4$ & $4 / 06 / 92$ & $B 06696$ & & 27000.00 & & \\
\hline $299-E 32-4$ & $4 / 06 / 92$ & 806697 & & & & 28000.00 \\
\hline 299-E32-4 & $7 / 14 / 92$ & 807173 & & 27000.00 & & \\
\hline 299-E32-4 & $7 / 14 / 92$ & B07974 & & & & 27000.00 \\
\hline $699-40-36$ & $12 / 21 / 92$ & 807TB1 & & 45000.00 & & \\
\hline $699-40-36$ & $12 / 21 / 92$ & B07TB8 & & & & 48000.00 \\
\hline $699 \cdot 40 \cdot 36$ & $2 / 22 / 93$ & B08717 & & 47000.00 & & \\
\hline $699-40-36$ & $2 / 22 / 93$ & 808721 & & & & 54000.00 \\
\hline $699-40-39$ & $12 / 05 / 89$ & HOOODBX2 & 19100.00 & & 33900.00 & \\
\hline $699-40-39$ & $12 / 05,89$ & HOOODBX2 & & & & 34500.00 \\
\hline $699-40-39$ & $1 / 25 / 90$ & H0OODBX6 & 18600.00 & & 34100.00 & \\
\hline $699-40-39$ & $1 / 25 / 90$ & H0OODBX6 & & & & 32300.00 \\
\hline $699-40-39$ & $4 / 25 / 90$ & HOOODBYO & 16500.00 & & 32700.00 & \\
\hline $699-40-39$ & $4 / 25 / 90$ & HOOODBYO & & & & 33400.00 \\
\hline $699-40 \cdot 39$ & $7 / 08 / 91$ & H00071Y4F & & & & 34000.00 \\
\hline $699-40-39$ & $9 / 11 / 91$ & BOOLG1 & & 33000.00 & & \\
\hline $699-40-39$ & $9 / 11 / 91$ & BOOLGIF & & & & 33000.00 \\
\hline $699-40-39$ & $1 / 31 / 92$ & B01065 & & $32000.00 \mathrm{D}$ & & \\
\hline $699-40-39$ & $1 / 31 / 92$ & 801066 & & & & $31000.00 \mathrm{D}$ \\
\hline $699-40-39$ & $4 / 17 / 92$ & B065P2 & & 32000.00 & & \\
\hline $699-40-39$ & $4 / 17 / 92$ & B06504 & & & & 32000.00 \\
\hline $699-40-39$ & $6 / 24 / 92$ & B062T7 & & 33000.00 & & \\
\hline $699-40-39$ & $6 / 24 / 92$ & B062V1 & & & & 33000.00 \\
\hline $699-40-39$ & $1 / 14 / 93$ & $8077 \times 4$ & & 33000.00 & & \\
\hline $699-40-39$ & $1 / 14 / 93$ & $8077 \times 8$ & & & & 33000.00 \\
\hline $699-40-40 A$ & $1 / 24 / 92$ & B01T62 & & 39000.000 & & \\
\hline
\end{tabular}


(sheet ** of **)

\begin{tabular}{|c|c|c|c|c|c|c|}
\hline & & & SILICON & SOOIUM & SODIUM & FSOOIUM \\
\hline Well & Collection & Sample & 35/ppb & 34/ppob & 35/ppb & 34/ppb \\
\hline Name & Date & Number & .1 & $300 \%$ & .1 & $300 /$ \\
\hline , n & , & $\cdots$ & (n) & 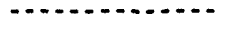 & (n) & 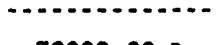 \\
\hline $699-40-40 A$ & $1 / 24 / 92$ & $801 T 63$ & & & & $38000.00 \mathrm{D}$ \\
\hline $699-40-40 \mathrm{~A}$ & $4 / 22 / 92$ & 806508 & & 37000.00 & & \\
\hline $699-40-40 \mathrm{~A}$ & $4 / 22 / 92$ & B065R8 & & & & 38000.00 \\
\hline $699-40-40 A$ & $6 / 25 / 92$ & 8062V2 & & 39000.00 & & \\
\hline $699-40-40 A$ & $6 / 25 / 92$ & B06ZWO & & & & 40000.00 \\
\hline $699-40-40 \mathrm{~A}$ & $10 / 21 / 92$ & B07JK3 & & 39000.00 & & \\
\hline $699-40-40 A$ & $10 / 21 / 92$ & B07JK7 & & & & 40000.00 \\
\hline $699-40-40 \mathrm{~A}$ & $1 / 26 / 93$ & $807 V 49$ & & 40000.00 & & \\
\hline $699-40-40 A$ & $1 / 26 / 93$ & B07V53 & & & & 39000.00 \\
\hline $699-40-40 B$ & $1 / 01 / 92$ & $801 T 65$ & & & & 37000.000 \\
\hline $699-40-40 B$ & $1 / 24 / 92$ & B01T64 & & $40000.00 \mathrm{D}$ & & \\
\hline $699-40-40 B$ & $4 / 22 / 92$ & 806550 & & 35000.00 & & \\
\hline $699-40-40 B$ & $4 / 22 / 92$ & 806554 & & & & 32000.00 \\
\hline $699-40-40 B$ & $6 / 29 / 92$ & 8062W2 & & 35000.00 & & \\
\hline $699-40-40 B$ & $6 / 29 / 92$ & B06Z146 & & & & 34000.00 \\
\hline $699-40-40 B$ & $10 / 21 / 92$ & B07JK8 & & 36000.00 & & \\
\hline $699-40-40 B$ & $10 / 21 / 92$ & B07JL2 & & & & 36000.00 \\
\hline $699-40-40 B$ & $1 / 26 / 93$ & 80754 & & 35000.00 & & \\
\hline $699-40-40 B$ & $1 / 26 / 93$ & B07V58 & & & & 34000.00 \\
\hline $699-41-35$ & $12 / 21 / 92$ & В07T89 & & 47000.00 & & \\
\hline $699 \cdot 41-35$ & $12 / 21 / 92$ & B07TC3 & & & & 39000.00 \\
\hline $699-41 \cdot 35$ & $2 / 22 / 93$ & B08707 & & 45000.00 & & \\
\hline $699-41-35$ & $2 / 22 / 93$ & 808711 & & & & 53000.00 \\
\hline $699-41-40$ & $12 / 05 / 89$ & $H 0000044$ & 14600.00 & & 30600.00 & \\
\hline $699-41-40$ & $12 / 05 / 89$ & $H 0000044$ & & & & 30000.00 \\
\hline $699-41-40$ & $1 / 25 / 90$ & $H 0000048$ & 15300.00 & & 29900.00 & \\
\hline $699-41-40$ & $1 / 25 / 90$ & $H 0000048$ & & & & 31900.00 \\
\hline $699-49-40$ & $4 / 19 / 90$ & H0OODD52 & 14600.00 & & 31100.00 & \\
\hline $699-41-40$ & $4 / 19 / 90$ & H0OODD52 & & & & 29000.00 \\
\hline $699-41-40$ & $7 / 10 / 91$ & H0007IY1 & & 30000.00 & & \\
\hline $699-41-40$ & $7 / 10 / 91$ & H00071Y1F & & & & 31000.00 \\
\hline $699-41-40$ & $9 / 91 / 91$ & BOOLG2 & & 31000.00 & & \\
\hline $699-41-40$ & $9 / 11 / 91$ & BOOLG2F & & & & 31000.00 \\
\hline $699-41-40$ & $1 / 31 / 92$ & B010C8 & & $29000.00 \mathrm{D}$ & & \\
\hline $699-41-40$ & $1 / 31 / 92$ & B010C9 & & & & $29000.00 \mathrm{D}$ \\
\hline $699-41-40$ & $4 / 28 / 92$ & B06555 & & 31000.00 & & \\
\hline $699-41-40$ & $4 / 28 / 92$ & B065S6 & & 30000.00 & & \\
\hline $699-41-40$ & $4 / 28 / 92$ & B065S9 & & & & 30000.00 \\
\hline $699-41-40$ & $4 / 28 / 92$ & B065TO & & & & 30000.00 \\
\hline $699-41-40$ & $6 / 24 / 92$ & $8062 \times 2$ & & 31000.00 & & \\
\hline $699-41-40$ & $6 / 24 / 92$ & $8062 \times 6$ & & & & 31000.00 \\
\hline $699-41-40$ & $1 / 14 / 93$ & B07TX9 & & 31000.00 & & \\
\hline $699-41-40$ & $1 / 14 / 93$ & BOTTY3 & & & & 30000.00 \\
\hline
\end{tabular}


(sheet $\star$ of $\star \star)$

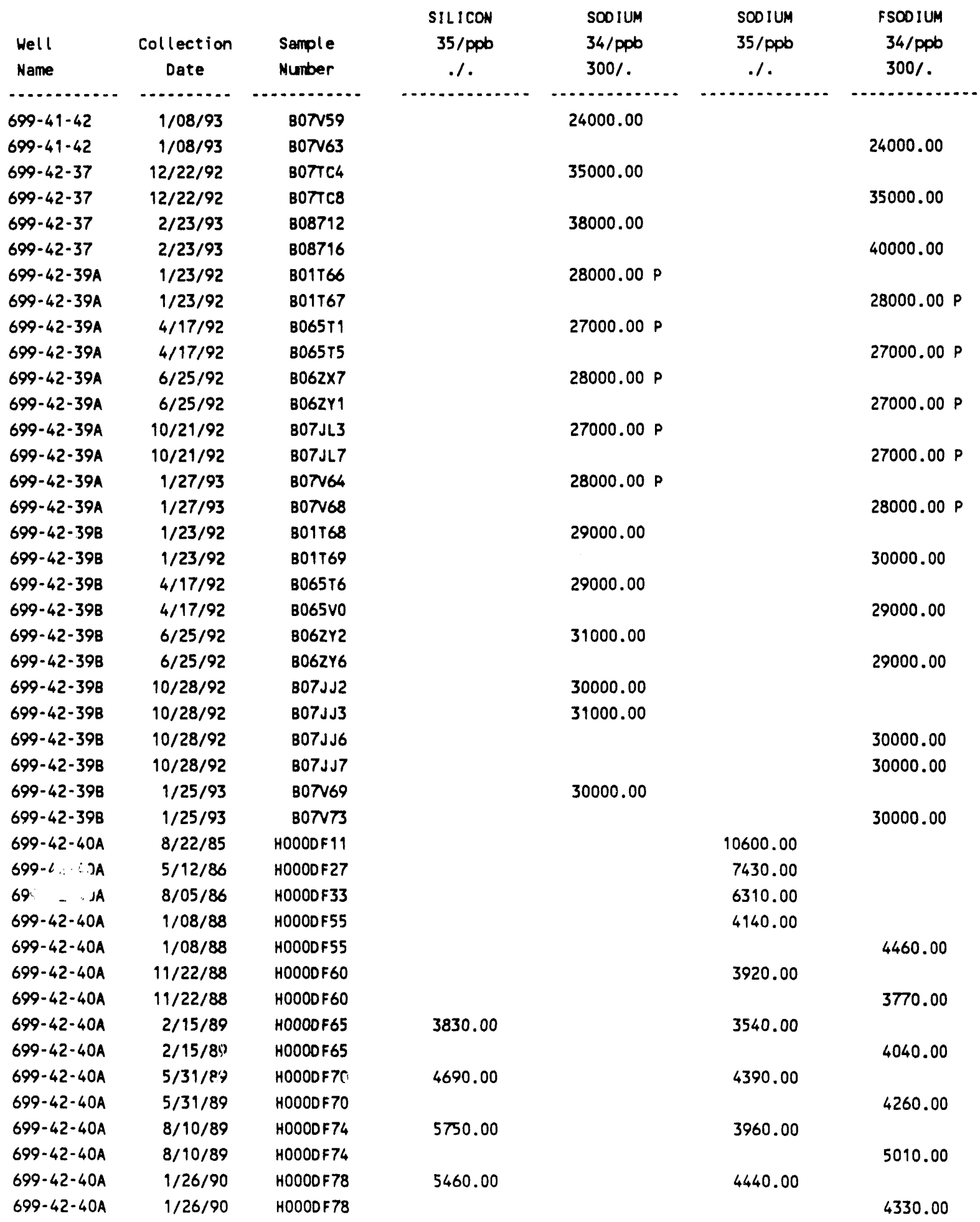


(sheet ** of $* *$ )

\begin{tabular}{|c|c|c|c|c|c|c|}
\hline & & & SILICON & SOOIUM & SODIUM & FSOOIUM \\
\hline Hell & Collection & Sample & 35/ppb & 34/ppb & 35/ppb & 34/ppb \\
\hline Name & Date & Number & .1 & $300 /$ & .1 & $300 /$ \\
\hline . & $\ldots$ & 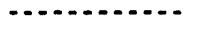 & . & - & $\cdots$ & - \\
\hline $699-42-40 \mathrm{~A}$ & $7 / 08 / 91$ & H00071Y2 & & 4600.00 & & \\
\hline $699-42-40 A$ & $7 / 08 / 91$ & H0007IYZF & & & & 5300.00 \\
\hline $699-42-40 A$ & $1 / 08 / 92$ & BOTTY8 & & 4600.00 & & \\
\hline $699-42-40 A$ & $1 / 08 / 92$ & B07T23 & & & & 4500.00 \\
\hline $699-42-40 A$ & $1 / 23 / 92$ & B01061 & & 5100.00 & & \\
\hline $699-42-40 A$ & $1 / 23 / 92$ & 801062 & & & & 4900.00 \\
\hline $699-42-40 A$ & $6 / 25 / 92$ & B062Y7 & & 4800.00 & & \\
\hline $699-42-40 A$ & $6 / 25 / 92$ & 806221 & & & & 4800.00 \\
\hline $699-42-41$ & $1 / 24 / 92$ & B01T70 & & $3900.00 \mathrm{PD}$ & & \\
\hline $699-42-41$ & $1 / 24 / 92$ & B01T71 & & & & $3800.00 \mathrm{PD}$ \\
\hline $699-42-41$ & $4 / 17 / 92$ & B065V1 & & $4200.00 \mathrm{P}$ & & \\
\hline $699-42-41$ & $4 / 17 / 92$ & B065V5 & & & & $3900.00 \mathrm{P}$ \\
\hline $699-42-41$ & $6 / 29 / 92$ & 806222 & & $4400.00 \mathrm{P}$ & & \\
\hline $699-42-41$ & $6 / 29 / 92$ & 806226 & & & & $4300.00 \mathrm{P}$ \\
\hline $699-42-41$ & $1 / 25 / 93$ & BOT7Z4 & & $3500.00 \mathrm{P}$ & & \\
\hline $699-42-41$ & $1 / 25 / 93$ & BOTTZ8 & & & & $3500.00 \mathrm{P}$ \\
\hline $699-42-428$ & $11 / 22 / 88$ & HOOODFT3 & & & 21800.00 & \\
\hline $699-42-428$ & $11 / 22 / 88$ & HOOODFT3 & & & & 22600.00 \\
\hline $699-42-42 B$ & $2 / 24 / 89$ & HOOODFT7 & 19200.00 & & 20200.00 & \\
\hline $699-42-42 B$ & $2 / 24 / 89$ & HOOODFT7 & & & & 19600.00 \\
\hline $699-42-42 B$ & $6 / 16 / 89$ & HOOODFV1 & 17800.00 & & 18800.00 & \\
\hline $699-42-42 B$ & $6 / 16 / 89$ & HOOODFV1 & & & & 21600.00 \\
\hline $699-42-42 B$ & $6 / 16 / 89$ & HOOOOFV4 & 17200.00 & & 18200.00 & \\
\hline $699-42-42 B$ & $6 / 16 / 89$ & H0OODFV4 & & & & 19100.00 \\
\hline $699-42-42 B$ & $8 / 09 / 89$ & H00ODFV5 & 16600.00 & & 17600.00 & \\
\hline $699-42-42 B$ & $8 / 59 / 89$ & H000DFV5 & & & & 21500.00 \\
\hline $699-42-42 B$ & $7 / 08 / 91$ & H00071Y3 & & 19000.00 & & \\
\hline $699-42-42 B$ & $7 / 08 / 91$ & H00071Y3F & & & & 18000.00 \\
\hline $699-42-42 B$ & $1 / 24 / 92$ & B01063 & & $18000.00 \mathrm{D}$ & & \\
\hline $699-42-428$ & $\{/ 24 / 92$ & 801064 & & & & $18000.00 \mathrm{D}$ \\
\hline $699-42-42 B$ & $6 / 24 / 92$ & B06227 & & 19000.00 & & \\
\hline $699-42-42 B$ & $6 / 24 / 92$ & В07001 & & & & 19000.00 \\
\hline $699-42-42 B$ & $1 / 21 / 93$ & B07T29 & & 18000.00 & & \\
\hline $699-42-42 B$ & $1 / 21 / 93$ & B07v03 & & & & 18000.00 \\
\hline $699-43-40$ & $1 / 31 / 92$ & B01T72 & & $21000.00 \mathrm{PD}$ & & \\
\hline $699-43-40$ & $1 / 31 / 92$ & B01T73 & & & & $20000.00 \mathrm{PD}$ \\
\hline $699-43-40$ & $4 / 28 / 92$ & B065V6 & & $19000.00 \mathrm{P}$ & & \\
\hline $699-43-40$ & $4 / 28 / 92$ & 806540 & & & & $20000.00 P$ \\
\hline $699-43-40$ & $6 / 26 / 92$ & 807002 & & $21000.00 \mathrm{P}$ & & \\
\hline $699-43-40$ & $6 / 26 / 92$ & B07006 & & & & $21000.00 \mathrm{P}$ \\
\hline $699-43-40$ & $1 / 25 / 93$ & $807 v 04$ & & $21000.00 P$ & & \\
\hline $699-43-40$ & $1 / 25 / 93$ & B07v08 & & & & $21000.00 \mathrm{P}$ \\
\hline $699-43-41 E$ & $12 / 05 / 89$ & H0000GDG & 10400.00 & & 26900.00 & \\
\hline
\end{tabular}


(sheet $* \star$ of $* *)$

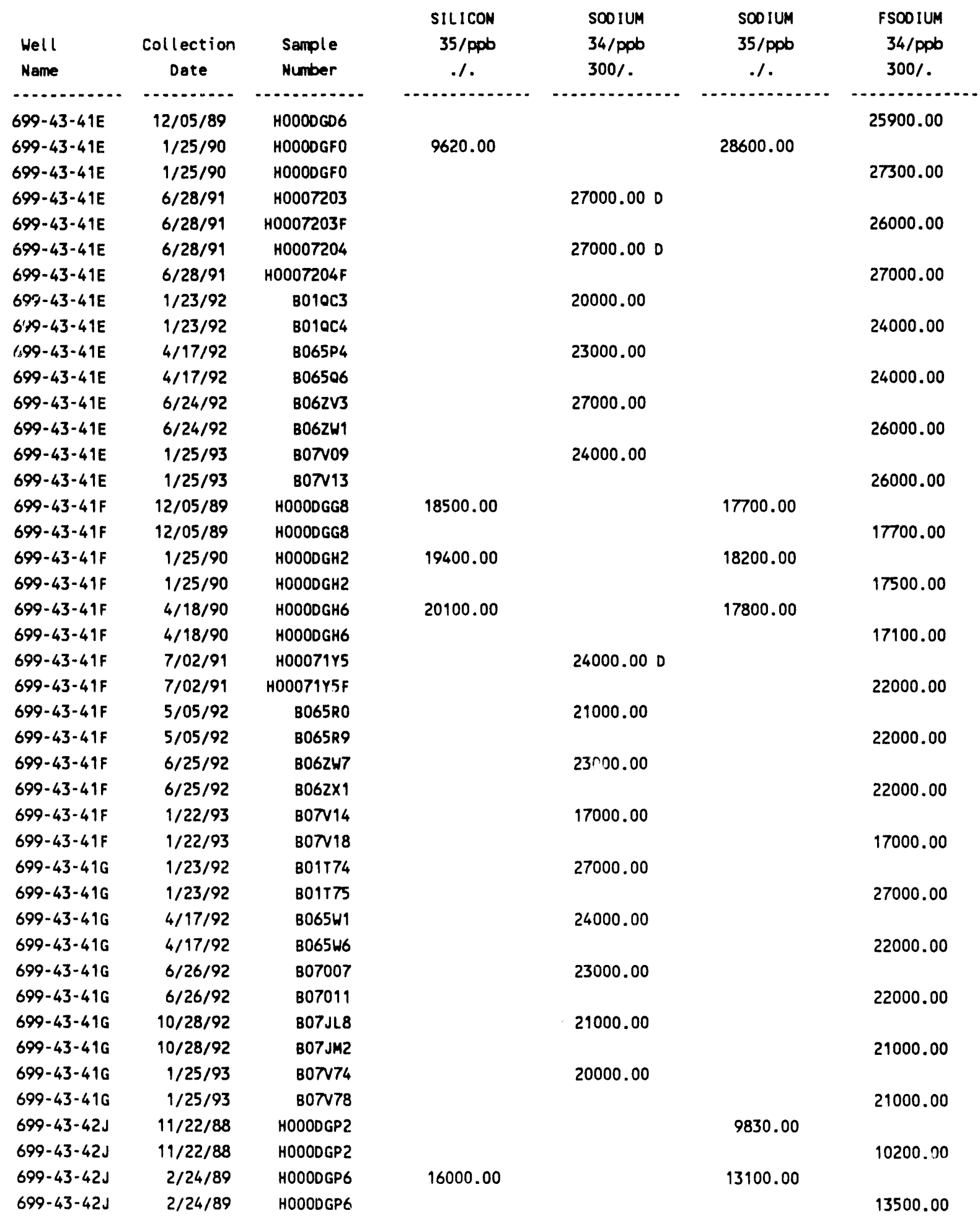


(sheet ** of $\star *$ )

\begin{tabular}{|c|c|c|c|c|c|c|}
\hline $\begin{array}{l}\text { Well } \\
\text { Name }\end{array}$ & $\begin{array}{c}\text { Collection } \\
\text { Date }\end{array}$ & $\begin{array}{l}\text { Sample } \\
\text { Number }\end{array}$ & $\begin{array}{c}\text { SILICON } \\
35 / \mathrm{ppb} \\
. /\end{array}$ & $\begin{array}{l}\text { S00 IUM } \\
34 / \mathrm{ppb} \\
300 / .\end{array}$ & $\begin{array}{c}\text { SOO IUM } \\
35 / p p b \\
. /\end{array}$ & $\begin{array}{l}\text { FSOO IUH } \\
34 / \mathrm{ppb} \\
300 /\end{array}$ \\
\hline - & . & (n) & . & - & - & 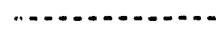 \\
\hline $699-43-42 J$ & $6 / 15 / 89$ & HOOOOGOO & 16100.00 & & 16400.00 & \\
\hline $699-43-42 \mathrm{~J}$ & $6 / 15 / 89$ & HOOOOGOO & & & & 16500.00 \\
\hline $699-43-42 J$ & $8 / 09 / 89$ & H0OOOGO4 & 15600.00 & & 14000.00 & \\
\hline $699-43-42 J$ & $8 / 09 / 89$ & HOOOOGO4 & & & & 15100.00 \\
\hline $699-43-42 \mathrm{~J}$ & $8 / 09 / 89$ & H0000G07 & 15000.00 & & 12700.00 & \\
\hline $699-43-42 \mathrm{~J}$ & $8 / 09 / 89$ & HOOODGO7 & & & & 15900.00 \\
\hline $699-43-42 \mathrm{~J}$ & $7 / 02 / 91$ & H00071Y6 & & $28000.00 \mathrm{D}$ & & \\
\hline $699-43-42 \mathrm{~J}$ & $7 / 02 / 91$ & H00079Y6F & & & & 27000.00 \\
\hline $699-43-42 J$ & $1 / 31 / 92$ & 801549 & & 34000.000 & & \\
\hline $699-43-42 J$ & $1 / 31 / 92$ & B01551 & & & & $33000.00 \mathrm{D}$ \\
\hline $699-43-42 \mathrm{~J}$ & $6 / 25 / 92$ & B07012 & & 34000.00 & & \\
\hline $699-43-42 J$ & $6 / 25 / 92$ & B07016 & & & & 29000.00 \\
\hline $699-43-42 J$ & $1 / 21 / 93$ & B07N19 & & 36000.00 & & \\
\hline $699-43-42 J$ & $1 / 21 / 93$ & 807 23 & & & & 35000.00 \\
\hline $699-43-43$ & $11 / 21 / 88$ & HOOODGR3 & & & 7450.00 & \\
\hline $699-43-43$ & $11 / 21 / 88$ & HOOODGR3 & & & & 7020.00 \\
\hline $699-43-43$ & $2 / 24 / 89$ & HOOODGR7 & 14500.00 & & 7860.00 & \\
\hline $699-43-43$ & $2 / 24 / 89$ & HOOODGR7 & & & & 7510.00 \\
\hline $699-43-43$ & $2 / 24 / 89$ & HOOODGSO & 14900.00 & & 8050.00 & \\
\hline $699-43-43$ & $2 / 24 / 89$ & HOOODGSO & & & & 7290.00 \\
\hline $699-43-43$ & $6 / 15 / 89$ & HOOODGS1 & 13400.00 & & 8180.00 & \\
\hline $699-43-43$ & $6 / 15 / 89$ & H000DGS1 & & & & 7740.00 \\
\hline $699-43-43$ & $8 / 09 / 89$ & HOOODGS5 & 11400.00 & & 7440.00 & \\
\hline $699-43-43$ & $8 / 09 / 89$ & H0000GS5 & & & & 8330.00 \\
\hline $699-43-43$ & $1 / 26 / 90$ & H0OODGS9 & 14000.00 & & 7400.00 & \\
\hline $699-43-43$ & $1 / 26 / 90$ & HOOODGS9 & & & & $\pi 50.00$ \\
\hline $699-43-43$ & $7 / 08 / 91$ & H00079Y7 & & 7800.00 & & \\
\hline $699-43-43$ & $7 / 08 / 91$ & H00071Y7F & & & & 7800.00 \\
\hline $699-43-43$ & $1 / 24 / 92$ & 801067 & & $7900.00 \mathrm{D}$ & & \\
\hline $699-43-43$ & $1 / 24 / 92$ & B01068 & & & & $7900.00 \mathrm{D}$ \\
\hline $699-43-43$ & $4 / 22 / 92$ & $8065 N 6$ & & 7700.00 & & \\
\hline $699-43-43$ & $4 / 22 / 92$ & $8065 N 7$ & & & & 7400.00 \\
\hline $699-43-43$ & $6 / 26 / 92$ & Bo70w0 & & $8500.00 \mathrm{D}$ & & \\
\hline $699-43-43$ & $6 / 26 / 92$ & B070W1 & & & & 8300.00 \\
\hline $699-43-43$ & $10 / 26 / 92$ & B07JG5 & & 8300.00 & & \\
\hline $699-43-43$ & $10 / 26 / 92$ & B07JG6 & & & & 8300.00 \\
\hline $699-43-43$ & $1 / 13 / 93$ & BO7v24 & & 8100.00 & & \\
\hline $699-43-43$ & $1 / 13 / 93$ & B07N28 & & & & 8700.00 \\
\hline $699-43-45$ & $12 / 06 / 89$ & HOOODGT 4 & 17800.00 & & 11000.00 & \\
\hline $699-43-45$ & $12 / 06 / 89$ & H0OODGT4 & & & & 10500.00 \\
\hline $699-43-45$ & $1 / 26 / 90$ & H000DGT8 & 17600.00 & & 10300.00 & \\
\hline $699-43-45$ & $1 / 26 / 90$ & H000DGT8 & & & & 10300.00 \\
\hline $699-43-45$ & $4 / 18 / 90$ & HOOODGV2 & 16600.00 & & 10300.00 & \\
\hline
\end{tabular}


(sheet ** of **)

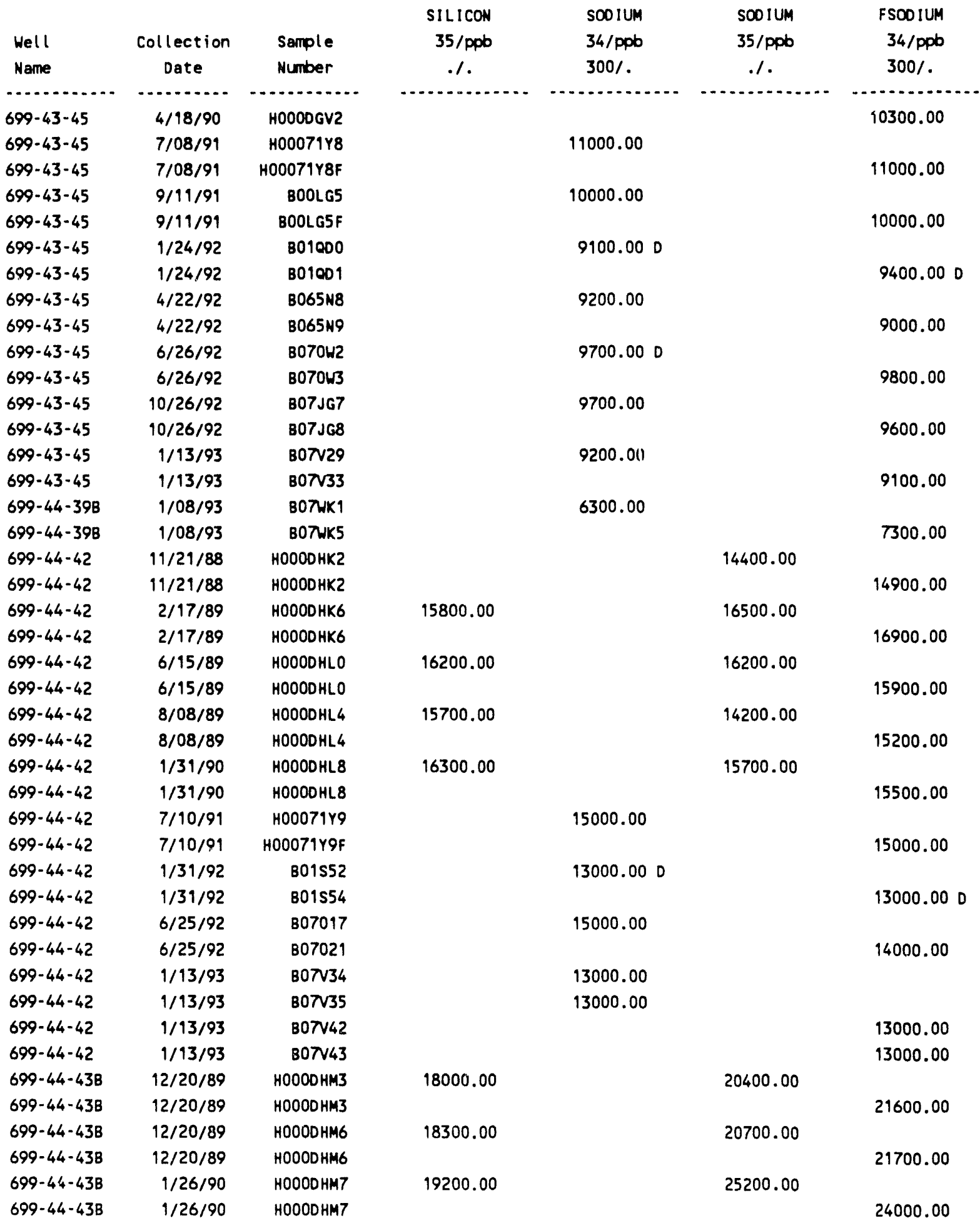


(sheet $\star \star$ of $\star *$ )

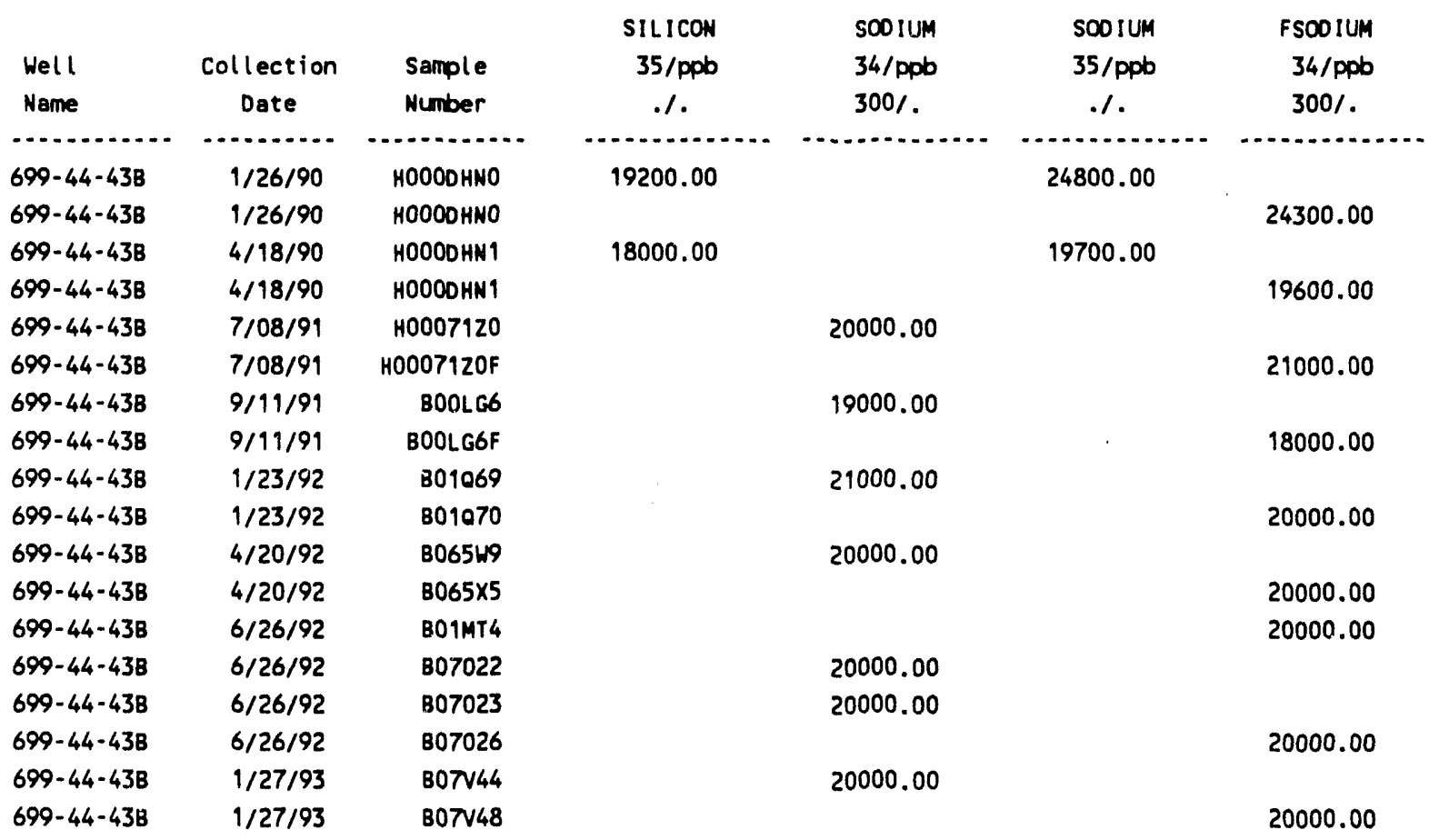

\begin{tabular}{|c|c|c|c|c|c|c|}
\hline Hell & Collection & Sample & $\begin{array}{l}\text { STRONUM } \\
\text { 35/ppb }\end{array}$ & $\begin{array}{l}\text { FSTRONUM } \\
34 / \mathrm{ppb}\end{array}$ & $\begin{array}{l}S R-90 \\
\pi / P C i / L\end{array}$ & $\begin{array}{l}\text { SULFATE } \\
\text { 124/ppD }\end{array}$ \\
\hline Name & Date & Number &.$/$ & .1 & .18 & $500 / 250000 \mathrm{~s}$ \\
\hline - & . & - & , n & , & - . . & 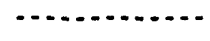 \\
\hline 299-E18-1 & $8 / 16 / 88$ & H00072T7 & 249.00 & & & \\
\hline $299-E 18-1$ & $8 / 16 / 88$ & H00072T7 & & 277.00 & & \\
\hline $299-E 18-1$ & $11 / 10 / 88$ & HoOOTZV2 & 249.00 & & & \\
\hline 299-E18-1 & $11 / 10 / 88$ & H0007ZV2 & & 255.00 & & \\
\hline 299-E18-1 & $11 / 10 / 88$ & H0OOTZV5 & 241.00 & & & \\
\hline $299-E 18-1$ & $11 / 10 / 88$ & H0007zV5 & & 241.00 & & \\
\hline 299-E18-1 & $2 / 15 / 89$ & H0007ZV8 & 240.00 & & & \\
\hline $299-E 18-1$ & $2 / 15 / 89$ & H0007ZV8 & & 241.00 & & \\
\hline $299-E \uparrow 8-1$ & $5 / 26 / 89$ & H0007ZW2 & 257.00 & & & \\
\hline 299-E18-1 & $5 / 26 / 89$ & HOOOTZWZ & & 259.00 & & \\
\hline 299-E18-1 & $8 / 08 / 89$ & H0OOTZW6 & 231.00 & & & \\
\hline 299-E18-1 & $8 / 08 / 89$ & H00072W6 & & 283.00 & & \\
\hline 299-E18-9 & $10 / 31 / 89$ & H00072X0 & 250.00 & & $.43 \mathrm{U}$ & \\
\hline 299-E18-i & $10 / 31 / 89$ & H0007ZXO & & 265.00 & & \\
\hline $299-E 18-1$ & $7 / 09 / 91$ & H00071X9 & & & & 130000.00 \\
\hline 299-E18-1 & $1 / 24 / 92$ & B01059 & & & & 140000.00 \\
\hline 299-E18-1 & $6 / 03 / 92$ & B06PH8 & & & & 130000.00 \\
\hline 299-E18-1 & $12 / 16 / 92$ & B07S32 & & & & 130000.00 \\
\hline
\end{tabular}


(sheet $\star \star$ of $\star *$ )

\begin{tabular}{|c|c|c|c|c|c|c|}
\hline Hell & Collection & Samole & $\begin{array}{l}\text { STRONUM } \\
35 \text { Db }\end{array}$ & $\begin{array}{l}\text { FSTRONUM } \\
34 / \mathrm{pOb}\end{array}$ & $\begin{array}{l}\text { SR-90 } \\
77 / \mathrm{DCi} / \mathrm{L}\end{array}$ & $\begin{array}{l}\text { SULFATE } \\
124 / \mathrm{pob}\end{array}$ \\
\hline Name & Date & Number & .1 & .1 &.$/ 8$ & $500 / 250000 \mathrm{~s}$ \\
\hline - & $\ldots$ & 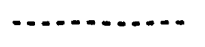 & $\ldots$ & - & - & . \\
\hline 299-E32-4 & $9 / 27 / 88$ & H0008ZB8 & 234.00 & & $.37 \mathrm{U}$ & \\
\hline $299-E 32-4$ & $9 / 27 / 88$ & H0008ZB8 & & 214.00 & & \\
\hline $299-E 32-4$ & $12 / 28 / 88$ & H0008ZC2 & 209.00 & & $-.05 U$ & \\
\hline 299-E32-4 & $12 / 28 / 88$ & H0008ZC2 & & 215.00 & & \\
\hline $299-E 32-4$ & $3 / 01 / 89$ & H0008ZC6 & 233.00 & & & \\
\hline 299-E32-4 & $3 / 01 / 89$ & H0008ZC6 & & 230.00 & & \\
\hline $299-E 32-4$ & $3 / 13 / 89$ & H0008ZDO & 236.00 & & $-.34 \mathrm{U}$ & \\
\hline $299-E 32-4$ & $3 / 13 / 89$ & $H 0008200$ & & 231.00 & & \\
\hline 299-E32-4 & $6 / 16 / 89$ & H0008Z204 & 220.00 & & & \\
\hline $299-E 32-4$ & $6 / 16 / 89$ & H0OOBZD 4 & & 216.00 & & \\
\hline 299-E32-4 & $7 / 19 / 89$ & H0008Z08 & 228.00 & & $-.17 \mathrm{U}$ & \\
\hline $299-E 32-4$ & $7 / 19 / 89$ & H0008ZD8 & & 217.00 & & \\
\hline $299-E 32-4$ & $9 / 08 / 89$ & H00082F6 & 238.00 & & $-.35 U$ & \\
\hline 299-E32-4 & $9 / 08 / 89$ & H00082F6 & & 212.00 & & \\
\hline 299-E32-4 & $1 / 17 / 90$ & H0008ZGO & 227.00 & & $.23 \mathrm{U}$ & \\
\hline 299-E32-4 & $1 / 17 / 90$ & H00082GO & & 230.00 & & \\
\hline $299-E 32-4$ & $1 / 15 / 92$ & B010K6 & & & & 59000.00 \\
\hline $299-E 32-4$ & $4 / 06 / 92$ & B06696 & & & & 56000.00 \\
\hline $299-E 32-4$ & $4 / 09 / 92$ & B06586 & & & & 57000.00 \\
\hline $299-E 32-4$ & $7 / 14 / 92$ & B07173 & & & & 60000.00 \\
\hline $699-40-36$ & $12 / 21 / 92$ & B07TB1 & & & & 7300.00 \\
\hline $699-40-36$ & $2 / 22 / 93$ & B08717 & & & & 17000.00 \\
\hline $699-40-39$ & $12 / 05 / 89$ & HOOODBX2 & 169.00 & & $-.05 \mathrm{U}$ & \\
\hline $699-40-39$ & $12 / 05 / 89$ & HOOOOBX2 & & 169.00 & & \\
\hline $699-40-39$ & $1 / 25 / 90$ & HOOODBX6 & 173.00 & & & \\
\hline $699-40-39$ & $1 / 25 / 90$ & HOOODBX6 & & 163.00 & & \\
\hline $699-40-39$ & $4 / 25 / 90$ & HOOODBYO & 170.00 & & & \\
\hline $699-40-39$ & $4 / 25 / 90$ & HOOODBYO & & 175.00 & & \\
\hline $699-40-39$ & $7 / 08 / 91$ & H0OO71Y4 & & & & 3500.00 \\
\hline $699-40-39$ & $1 / 31 / 92$ & 801065 & & & & 3900.00 \\
\hline $699-40-39$ & $4 / 17 / 92$ & B065P2 & & & & $3900.00 \mathrm{D}$ \\
\hline $699-40-39$ & $6 / 24 / 92$ & B06217 & & & & 3600.00 \\
\hline $699-40-39$ & $1 / 14 / 93$ & $8077 \times 4$ & & & & 3900.00 \\
\hline $699-40-40 \mathrm{~A}$ & $1 / 24 / 92$ & В01T62 & & & & 17000.00 \\
\hline $699-40-40 \mathrm{~A}$ & $4 / 22 / 92$ & 806508 & & & & 16000.00 \\
\hline $699-40-40 A$ & $6 / 25 / 92$ & B062V2 & & & & 16000.00 \\
\hline $699-40-40 \mathrm{~A}$ & $10 / 21 / 92$ & B07JK3 & & & & 13000.00 \\
\hline $699-40-40 \mathrm{~A}$ & $1 / 26 / 93$ & $807 \times 49$ & & & & 18000.00 \\
\hline $699-40-40 B$ & $1 / 24 / 92$ & Bu1T64 & & & & 21000.00 \\
\hline $699-40-40 B$ & $4 / 22 / 92$ & 806550 & & & & 17000.00 \\
\hline $699-40-40 B$ & $6 / 29 / 92$ & $8062 \mathrm{W2}$ & & & & $16000.00 \mathrm{D}$ \\
\hline $699-40-40 B$ & $10 / 21 / 92$ & B07JK8 & & & & 16000.00 \\
\hline $699-40-40 B$ & $1 / 26 / 93$ & Bo7v54 & & & & 16000.00 \\
\hline
\end{tabular}


(sheet ** of **)

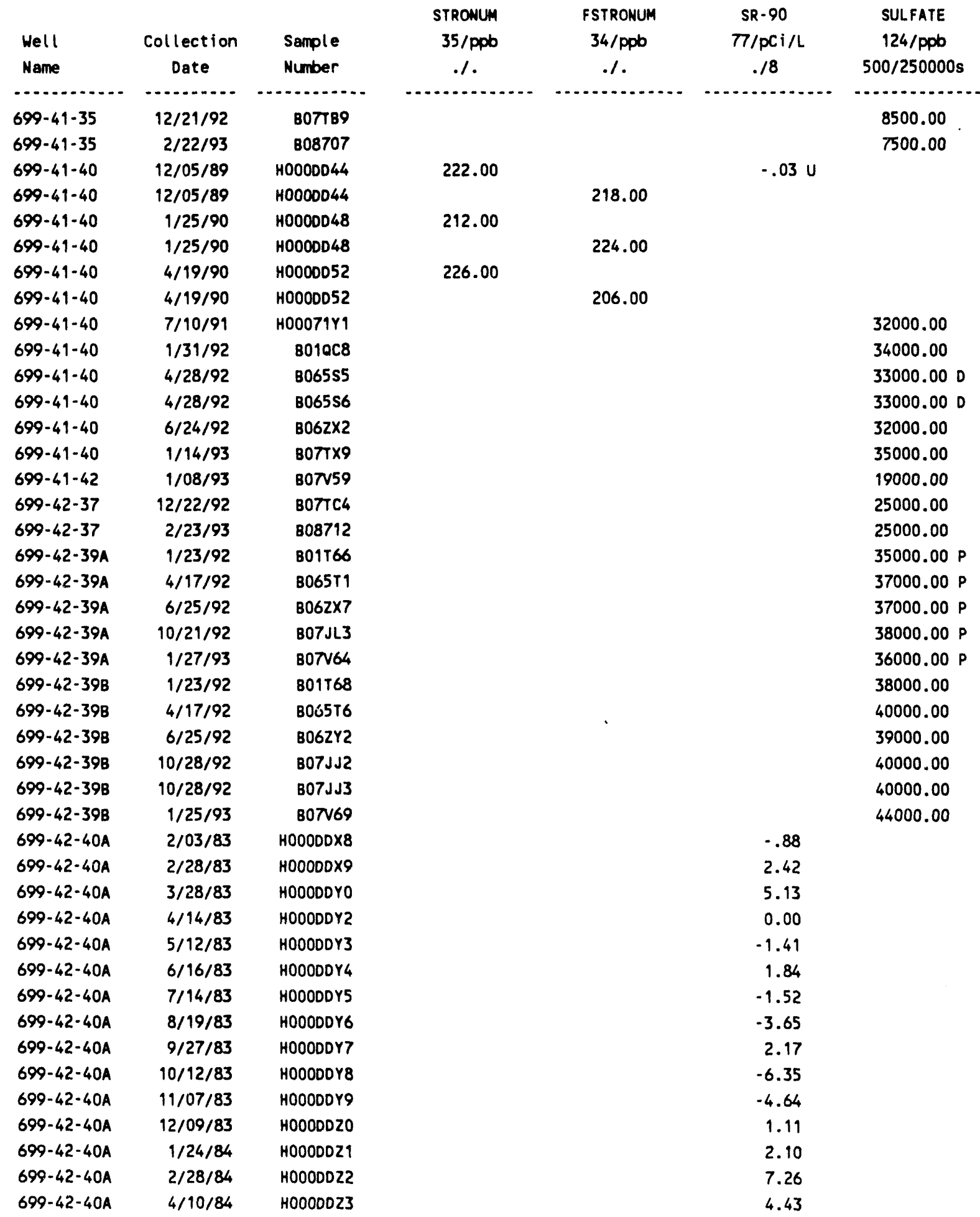


(sheet $\star \star$ of $\star \star$ )

\begin{tabular}{|c|c|c|}
\hline $\begin{array}{l}\text { Well } \\
\text { Name }\end{array}$ & $\begin{array}{c}\text { Collection } \\
\text { Date }\end{array}$ & $\begin{array}{l}\text { Sample } \\
\text { Number }\end{array}$ \\
\hline . & $\cdots$ & n \\
\hline $699-42-40 A$ & $4 / 26 / 84$ & HOOODDZ4 \\
\hline $699-42-40 A$ & $5 / 15 / 84$ & H0000DZ5 \\
\hline $699-42-40 A$ & $6 / 05 / 84$ & H000DDZ6 \\
\hline $699-42-40 A$ & $7 / 19 / 84$ & HOOODDZ7 \\
\hline $699-42-40 \mathrm{~A}$ & $8 / 10 / 84$ & $H 0000028$ \\
\hline $699-42-40 A$ & $9 / 11 / 84$ & HOOODOZ29 \\
\hline $699-42-40 A$ & $10 / 09 / 84$ & HOOODFOO \\
\hline $699-42-40 A$ & $11 / 13 / 84$ & HOOODFO1 \\
\hline $699-42-40 A$ & $12 / 12 / 84$ & HOOODFO2 \\
\hline $699-42-40 A$ & $1 / 16 / 85$ & HOOODFO3 \\
\hline $699-42-40 A$ & $2 / 11 / 85$ & $\mathrm{HOOODFO4}$ \\
\hline $699-42-40 A$ & $3 / 14 / 85$ & H0000F05 \\
\hline $699-42-40 A$ & $4 / 04 / 85$ & HOOODF06 \\
\hline $699-42-40 A$ & $5 / 03 / 85$ & H0OODF07 \\
\hline $699-42-40 A$ & $6 / 11 / 85$ & HOOODFO8 \\
\hline $699-42-40 A$ & $7 / 11 / 85$ & HOOODF 10 \\
\hline $699-42-40 A$ & $8 / 22 / 85$ & HOOODF 11 \\
\hline $699-42-40 A$ & $8 / 22 / 85$ & HOOODF 15 \\
\hline $699-42-40 A$ & $10 / 07 / 85$ & HOOODF 16 \\
\hline $699-42-40 A$ & $11 / 02 / 85$ & HOOODF 17 \\
\hline $699-42-40 A$ & $11 / 06 / 85$ & HOOODF 18 \\
\hline $699-42-40 A$ & $12 / 14 / 85$ & HOOODF2O \\
\hline $699-42-40 A$ & $1 / 09 / 86$ & HOOODF21 \\
\hline $699-42-40 A$ & $2 / 07 / 86$ & HOOODF23 \\
\hline $699-42-40 A$ & $3 / 07 / 86$ & HOOODF24 \\
\hline $699-42-40 A$ & $5 / 06 / 86$ & HOOODF26 \\
\hline $699-42-40 A$ & $5 / 12 / 86$ & HOOODF27 \\
\hline $699-42-40 A$ & $6 / 06 / 86$ & HOOODF31 \\
\hline $699-42-40 A$ & $7 / 02 / 86$ & HOOODF32 \\
\hline $699-42-40 A$ & $8 / 05 / 86$ & HOOODF33 \\
\hline $699-42-40 A$ & $8 / 05 / 86$ & H0OODF37 \\
\hline $699-42-40 A$ & $9 / 05 / 86$ & HOOODF38 \\
\hline $699-42-40 A$ & $10 / 24 / 86$ & HOOODF39 \\
\hline $699-42-40 A$ & $11 / 04 / 86$ & $H 0 O O D F 40$ \\
\hline $699-42-40 A$ & $12 / 10 / 86$ & $H 000 D F 41$ \\
\hline $699-42-40 A$ & $1 / 15 / 87$ & HOOODF42 \\
\hline $699-42-40 A$ & $4 / 06 / 87$ & $H 0000 F 46$ \\
\hline $699-42-40 A$ & $7 / 09 / 87$ & HOOODF49 \\
\hline $699-42-40 \mathrm{~A}$ & $10 / 06 / 87$ & H0OODF52 \\
\hline $699-42-40 A$ & $1 / 08 / 88$ & H000DF55 \\
\hline $699-42-40 A$ & $1 / 08 / 88$ & H0OODF56 \\
\hline $699-42-40 A$ & $5 / 23 / 88$ & HOOODF57 \\
\hline $699-42-40 A$ & $7 / 19 / 88$ & HOOODF58 \\
\hline
\end{tabular}

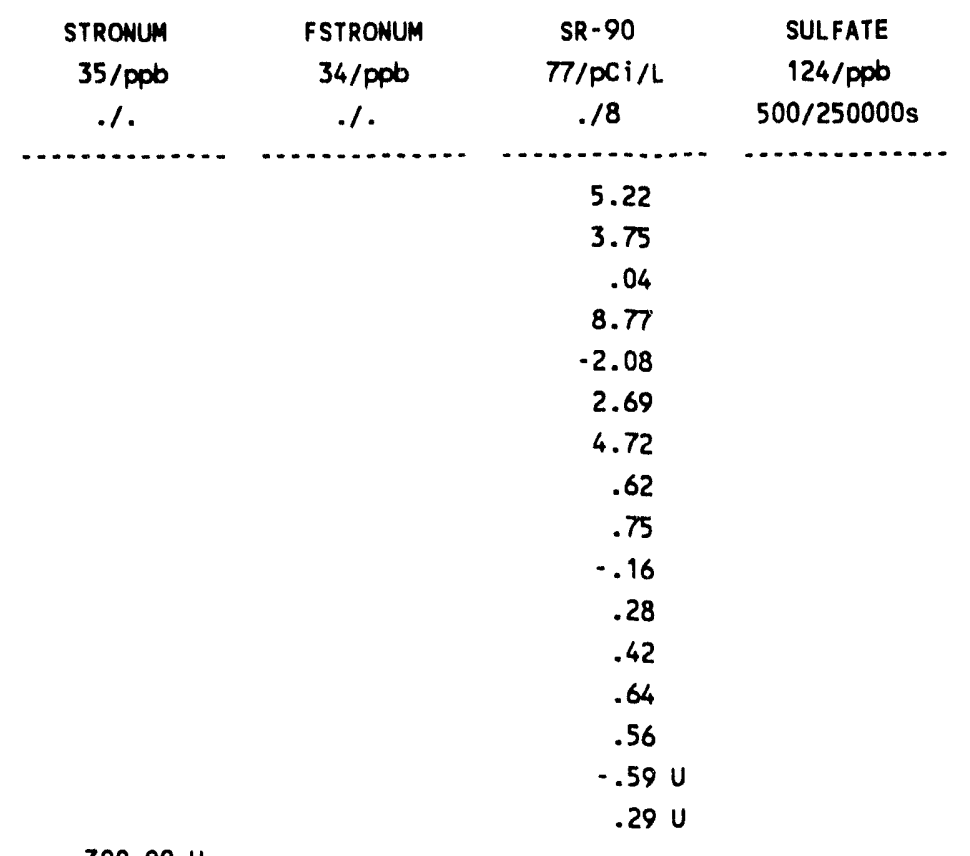

$300.00 \mathrm{U}$

$.30 \mathrm{U}$

$.14 \mathrm{U}$

16.30

1.77

$.33 \mathrm{U}$

$.01 \mathrm{U}$

$.38 \mathrm{U}$

1.65

$.55 \mathrm{U}$

$300.00 \mathrm{U}$

$.10 \mathrm{U}$

$.45 \mathrm{U}$

$300.00 \mathrm{U}$

$.03 \mathrm{U}$

$.30 \mathrm{U}$

$-.06 \mathrm{U}$

$.28 \mathrm{U}$

$.35 \mathrm{U}$

$.83 \mathrm{U}$

$.01 \mathrm{U}$

$.27 \mathrm{U}$

$-.26 U$

104.00

$.18 \mathrm{U}$
$.29 \mathrm{U}$
$.31 \mathrm{U}$ 
(sheet ** of **)

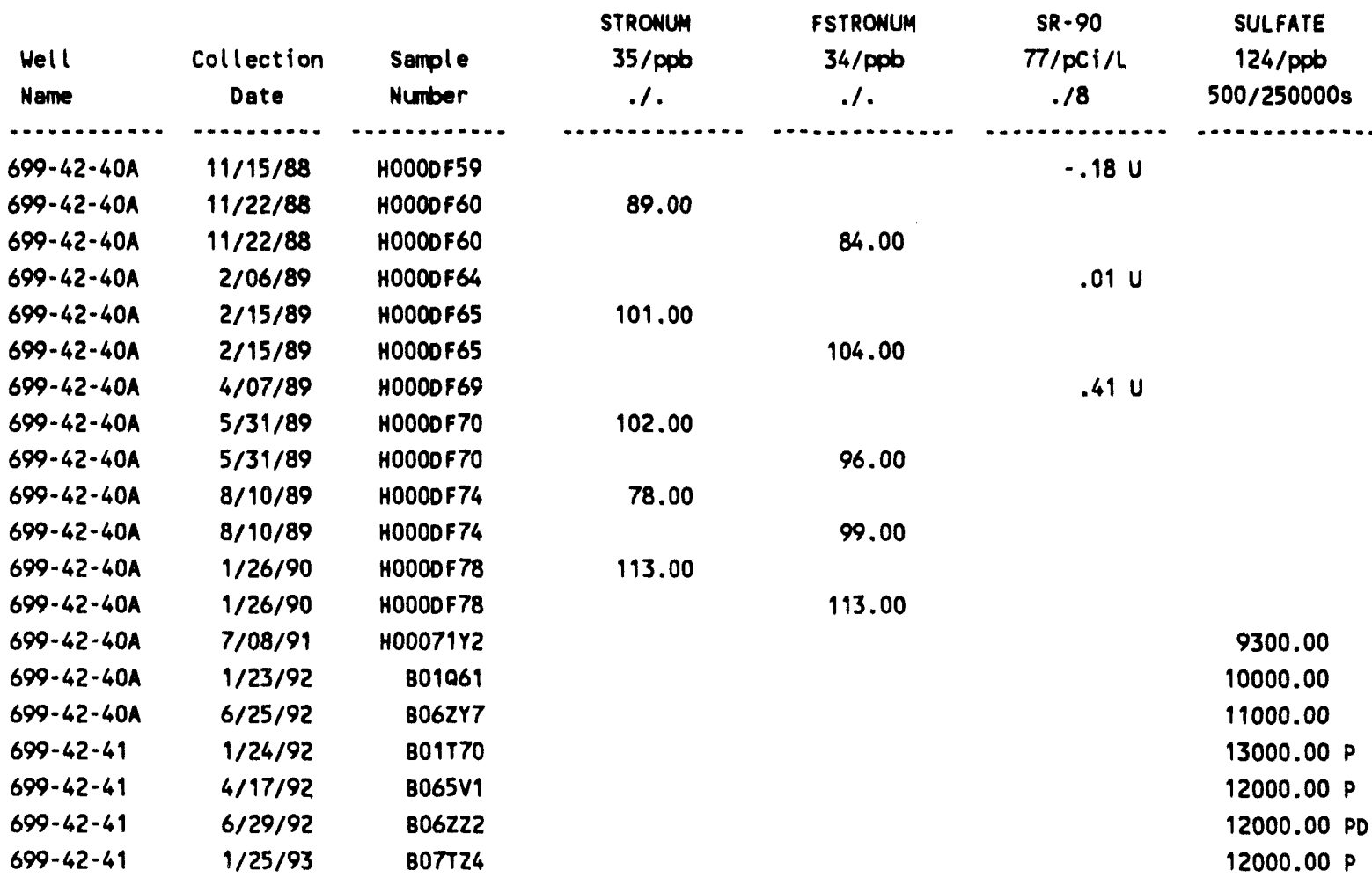

\begin{tabular}{|c|c|c|}
\hline $699-42-42 B$ & $11 / 22 / 88$ & HOOODFT3 \\
\hline $639-42-42 B$ & $11 / 22 / 88$ & HOOODFT3 \\
\hline $699-42-42 B$ & $2 / 24 / 89$ & H0OODFT7 \\
\hline $699-42-42 B$ & $2 / 24 / 89$ & HOOODFT7 \\
\hline $699-42-42 B$ & $6 / 16 / 89$ & H000DFVI \\
\hline $699-42-42 B$ & $6 / 16 / 89$ & HOOODFVI \\
\hline $699-42-42 B$ & $6 / 16 / 89$ & HOOODFV4 \\
\hline $699-42-42 B$ & $6 / 16 / 89$ & HOOODFV4 \\
\hline $699-42-42 B$ & $8 / 09 / 89$ & H0OODFV5 \\
\hline $699-42-42 B$ & $8 / 09 / 89$ & H000DFV5 \\
\hline $699-42-42 B$ & $7 / 08 / 91$ & H00071Y3 \\
\hline $699-42-42 B$ & $1 / 24 / 92$ & B01063 \\
\hline $699-42-42 B$ & $6 / 24 / 92$ & $80622^{7}$ \\
\hline $699-42-42 B$ & $1 / 21 / 93$ & B07тZ9 \\
\hline $699-43-40$ & $1 / 31 / 92$ & B01T72 \\
\hline $699-43-40$ & $4 / 28 / 92$ & B065V6 \\
\hline $699-43-40$ & $6 / 26 / 92$ & B07002 \\
\hline $699-43-40$ & $1 / 25 / 93$ & B07N04 \\
\hline $699-43-41 E$ & $12 / 05 / 89$ & H0OODGDG \\
\hline $699-43-41 E$ & $12 / 05 / 89$ & H0000G06 \\
\hline $699-43-41 E$ & $1 / 25 / 90$ & HOOODGFO \\
\hline $699-43-41 E$ & $1 / 25 / 90$ & HOOODGFO \\
\hline $699-43-41 E$ & $6 / 28 / 91$ & H0007203 \\
\hline
\end{tabular}

156.00

153.00

162.00

150.00

151.00

159.00

145.00

142.00

130.00

163.00

19000.00

19000.00

17000.00

16000.00

$25000.00 P$ 26000.00 PD $26000.00 P$ $32000.00 P$

185.00 $.10 \mathrm{U}$

185.00

177.00

181.00

30000.00 


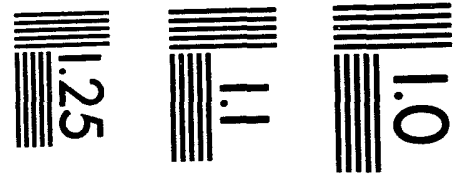

$$
\begin{aligned}
& \text { 春背市 }
\end{aligned}
$$

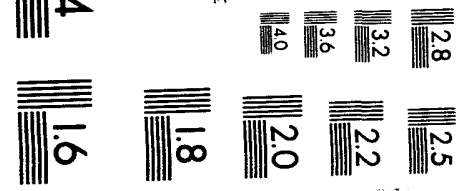



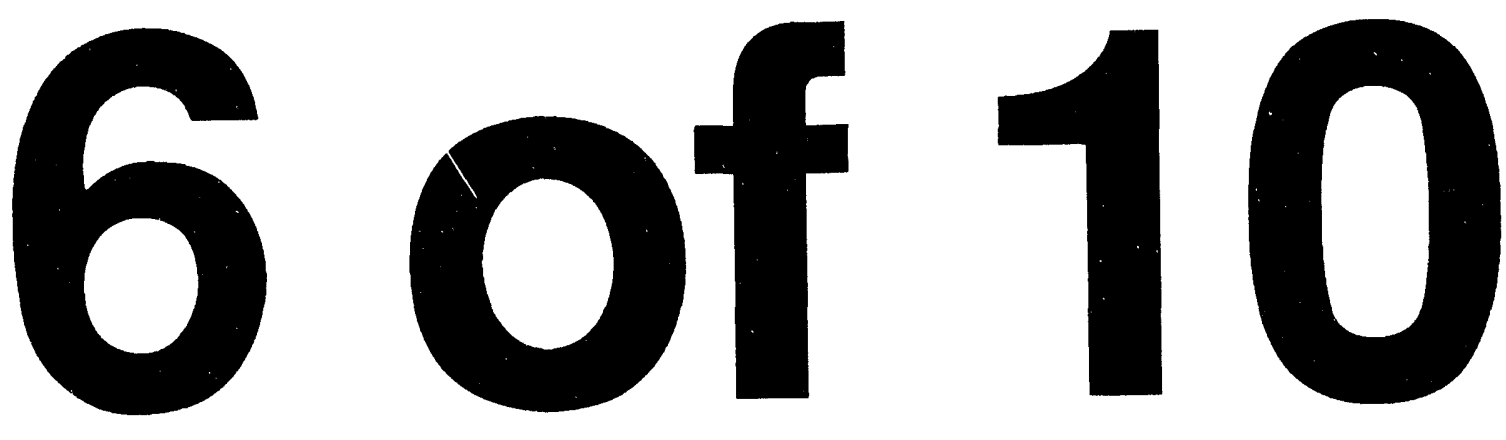
(sheet ** of **)

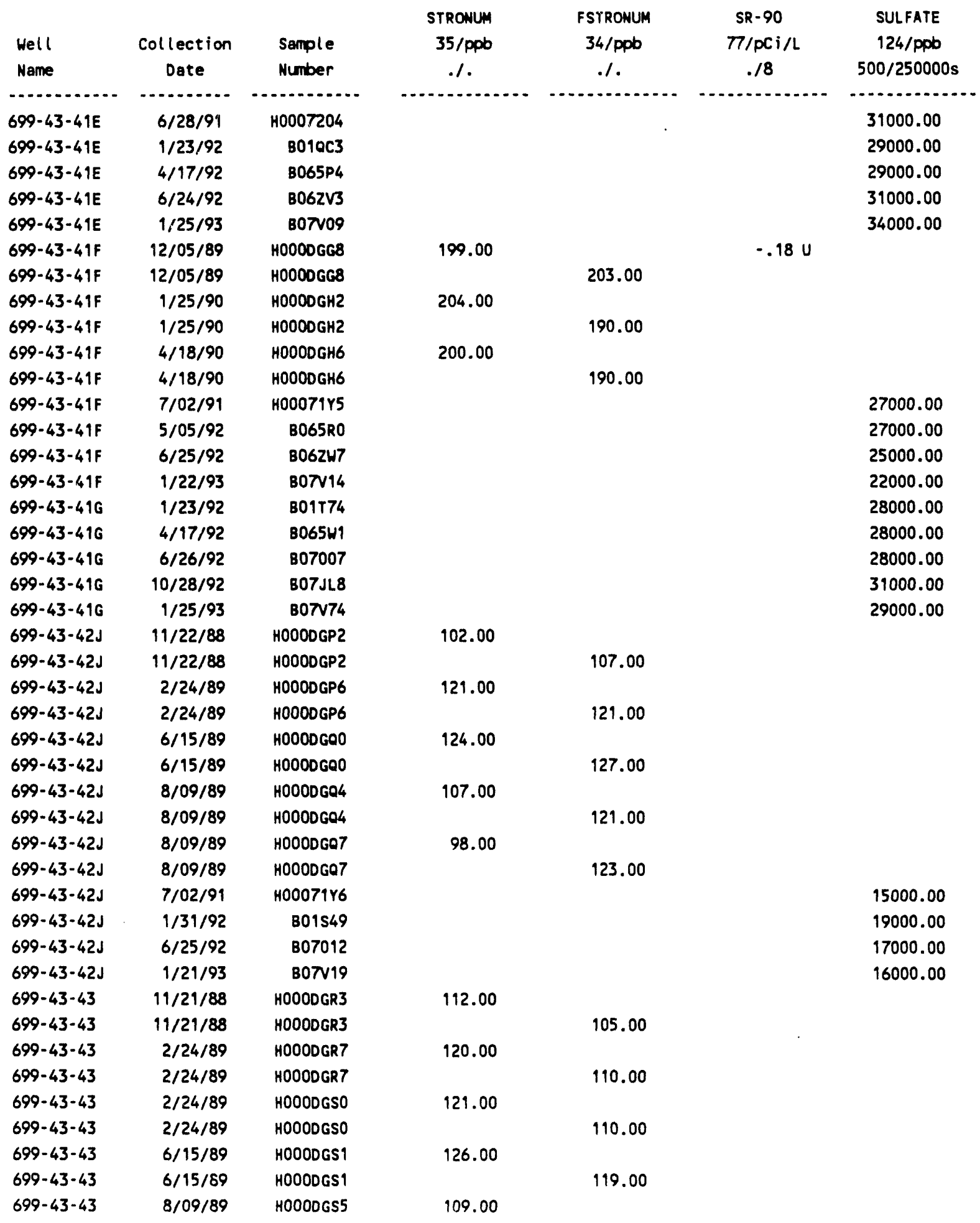


(sheet $\star *$ of $* *$ )

\begin{tabular}{|c|c|c|c|c|c|c|}
\hline $\begin{array}{l}\text { Hell } \\
\text { Name }\end{array}$ & $\begin{array}{c}\text { Collection } \\
\text { Date }\end{array}$ & $\begin{array}{l}\text { Sample } \\
\text { Number }\end{array}$ & $\begin{array}{c}\text { STRONUM } \\
\text { 35/ppb } \\
.1\end{array}$ & $\begin{array}{l}\text { FSTRONUM } \\
34 / \mathrm{ppb} \\
.1\end{array}$ & $\begin{array}{c}\text { SR- } 90 \\
77 / P C i / L \\
. / 8\end{array}$ & $\begin{array}{c}\text { SULFATE } \\
124 / \text { ppb } \\
500 / 250000 \mathrm{~s}\end{array}$ \\
\hline$\ldots$ & ................. & $\ldots$ & - & (n) & (n) & . \\
\hline $699-43-43$ & $8 / 09 / 89$ & H0000GS5 & & 126.00 & & \\
\hline $699-43-43$ & $1 / 26 / 90$ & HOOODGS9 & 121.00 & & & \\
\hline $699-43-43$ & $1 / 26 / 90$ & HOOODGSO & & 122.00 & & \\
\hline $699-43-43$ & $7 / 08 / 91$ & H00079Y7 & & & & 9700.00 \\
\hline $699-43-43$ & $1 / 24 / 92$ & B01067 & & & & 8000.00 \\
\hline $699-43-43$ & $4 / 22 / 92$ & B065NG & & & & 8700.00 \\
\hline $699-43-43$ & $6 / 26 / 92$ & BO7OWO & & & & 8600.00 \\
\hline $699-43-43$ & $10 / 26 / 92$ & B07JG5 & & & & 7600.00 \\
\hline $699-43-43$ & $1 / 13 / 93$ & 807V24 & & & & 8600.00 \\
\hline $699-43-45$ & $12 / 06 / 89$ & HOOODGT 4 & 142.00 & & $-.06 \mathrm{U}$ & \\
\hline $699-43-45$ & $12 / 06 / 89$ & H0OODGT4 & & 138.00 & & \\
\hline $699-43-45$ & $1 / 26 / 90$ & HOOOOGT8 & 135.00 & & & \\
\hline $699-43-45$ & $1 / 26 / 90$ & HOOOOGT8 & & 136.00 & & \\
\hline $699-43-45$ & $4 / 18 / 90$ & HOOODGV2 & 133.00 & & & \\
\hline $699-43-45$ & $4 / 18 / 90$ & H000OGV2 & & 133.00 & & \\
\hline $699-43-45$ & $7 / 08 / 91$ & H00071Y8 & & & & 11000.00 \\
\hline $699-43-45$ & $1 / 24 / 92$ & BO10DO & & & & 9400.00 \\
\hline $699-43-45$ & $4 / 22 / 92$ & B065N8 & & & & 9000.00 \\
\hline $699-43 \cdot 45$ & $6 / 26 / 92$ & B070w2 & & & & 9300.00 \\
\hline $699-43-45$ & $10 / 26 / 92$ & B07JG7 & & & & 11000.00 \\
\hline $699-43-45$ & $1 / 13 / 93$ & BOTV29 & & & & 9800.00 \\
\hline $699-44-398$ & $1 / 08 / 93$ & BOTWKI & & & & 13000.00 \\
\hline $699-44-42$ & $11 / 21 / 88$ & HOOODHK2 & 128.00 & & & \\
\hline $699-44-42$ & $11 / 21 / 88$ & HOOODHK2 & & 129.00 & & \\
\hline $699-44-42$ & $2 / 17 / 89$ & HOOODHK6 & 125.00 & & & \\
\hline $699-44-42$ & $2 / 17 / 89$ & HOOOOHKG & & 128.00 & & \\
\hline $699-44-42$ & $6 / 15 / 89$ & HOOOOHLO & 121.00 & & & \\
\hline $699-44-42$ & $6 / 15 / 89$ & HOOOOHLO & & 116.00 & & \\
\hline $699-44-42$ & $8 / 08 / 89$ & HOOODHL4 & 108.00 & & & \\
\hline $699-44-42$ & $8 / 08 / 89$ & HOOODHL 4 & & 123.00 & & \\
\hline $699-44-42$ & $1 / 31 / 90$ & HOOODHL8 & 125.00 & & & \\
\hline $699-44-42$ & $1 / 31 / 90$ & HOOODHL8 & & 125.00 & & \\
\hline $699-44-42$ & $7 / 10 / 91$ & H00071Y9 & & & & 12000.00 \\
\hline $699-44-42$ & $1 / 31 / 92$ & B01S52 & & & & 11000.00 \\
\hline $699-44-42$ & $6 / 25 / 92$ & B07017 & & & & 12000.00 \\
\hline $699-44-42$ & $1 / 13 / 93$ & B07v34 & & & & 11000.00 \\
\hline $699-44-42$ & $1 / 13 / 93$ & B07V35 & & & & 11000.00 \\
\hline $699-44-43 B$ & $12 / 20 / 89$ & HOOODHM3 & 168.00 & & $-.49 \mathrm{U}$ & \\
\hline $699-44-43 B$ & $12 / 20 / 89$ & HOOODHM3 & & 179.00 & & \\
\hline $699-44-43 B$ & $12 / 20 / 89$ & HOOODHMG & 168.00 & & $-.23 \mathrm{u}$ & \\
\hline $699-44-43 B$ & $12 / 20 / 89$ & HООООНM6 & & 182.00 & & \\
\hline $699-44-43 B$ & $1 / 26 / 90$ & HOOOOHM7 & 185.00 & & & \\
\hline $699-44-43 B$ & $1 / 26 / 90$ & HOOODHM7 & & 179.00 & & \\
\hline
\end{tabular}


(sheet $* \star$ of $* \star$ )

\begin{tabular}{|c|c|c|c|c|c|c|}
\hline Holl & & Samole & STRONUM & FSTRONUM & $\begin{array}{l}\text { SR-90 } \\
7 / \text { OCi } / L\end{array}$ & $\begin{array}{l}\text { SULFATE } \\
124 / 00 b\end{array}$ \\
\hline Name & Date & Number & .1 & .1 & .18 & $500 / 250000 \mathrm{~s}$ \\
\hline , n & . & . & . & 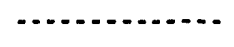 & - & (n) \\
\hline $699-44-43 B$ & $1 / 26 / 90$ & НООООНNО & 184.00 & & & \\
\hline $699-44-43 B$ & $1 / 26 / 90$ & HOOODHNO & & 179.00 & & \\
\hline $699-44-43 B$ & $4 / 18 / 90$ & HOOOOHN1 & 171.00 & & & \\
\hline $699-44-43 B$ & $4 / 18 / 90$ & HOOODHN1 & & 171.00 & & \\
\hline $699-44-43 B$ & $7 / 08 / 91$ & H00071ZO & & & & 24000.00 \\
\hline $699-44-43 B$ & $1 / 23 / 92$ & 801069 & & & & 24000.00 \\
\hline $699-44-43 B$ & $4 / 20 / 92$ & B065W9 & & & & 23000.00 \\
\hline $699-44-43 B$ & $6 / 26 / 92$ & 807022 & & & & 21000.00 \\
\hline $699-44-43 B$ & $6 / 26 / 92$ & B07023 & & & & 21000.00 \\
\hline $699-44-43 B$ & $1 / 27 / 93$ & B07N44 & & & & 20000.00 \\
\hline
\end{tabular}

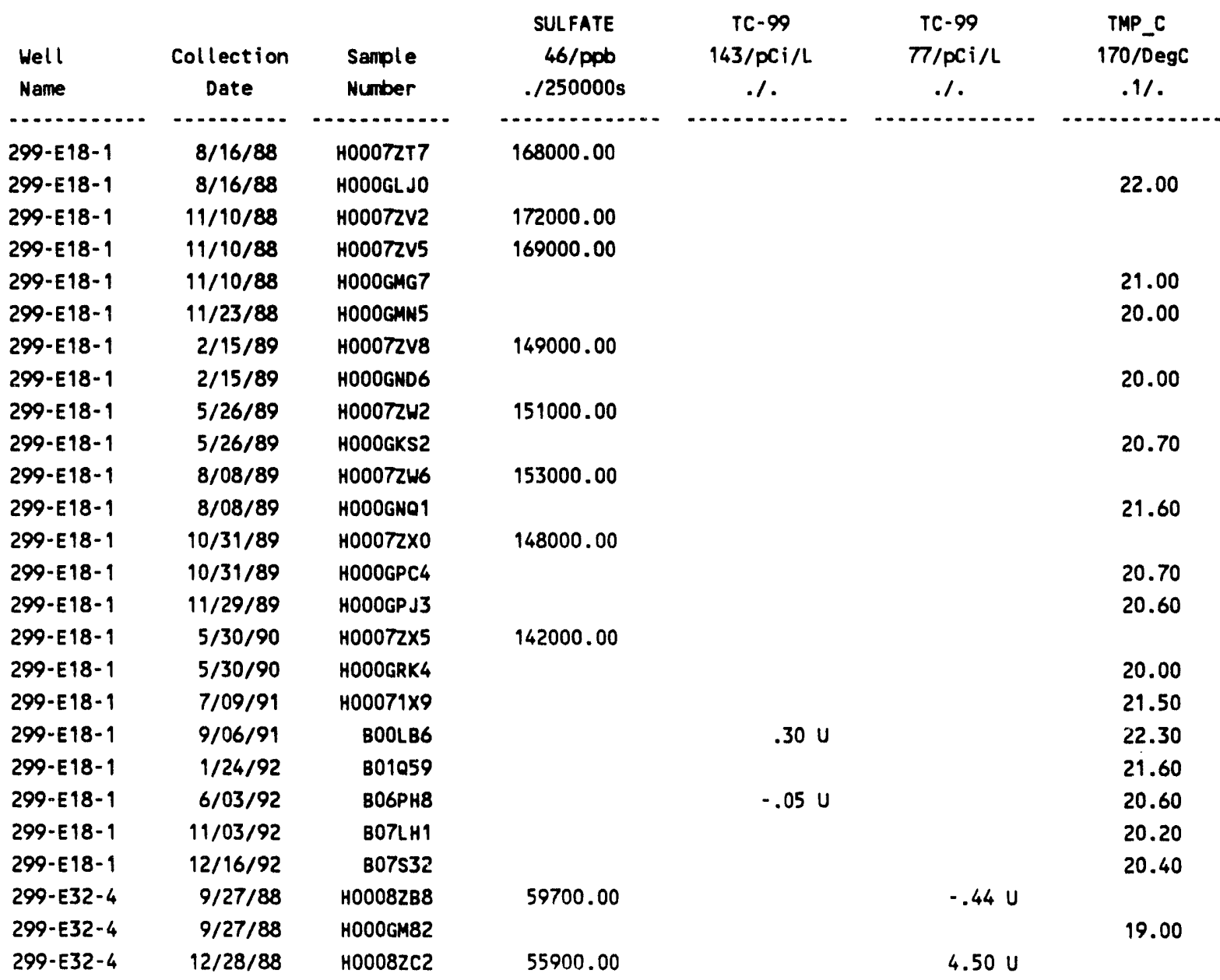


(sheet $\star \star$ of $\star \star$ )

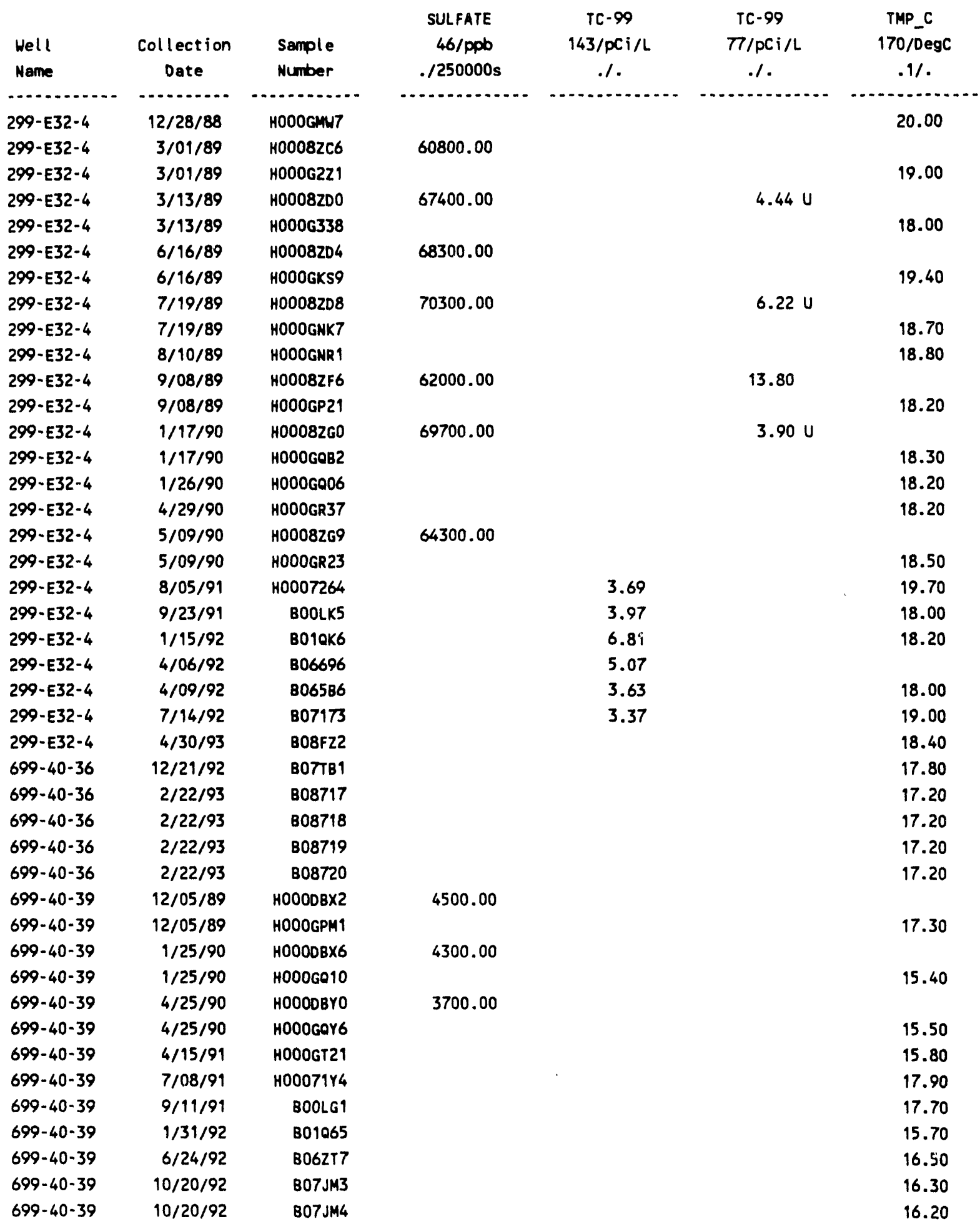


(sheet $\star \star$ of $\star \star$ )

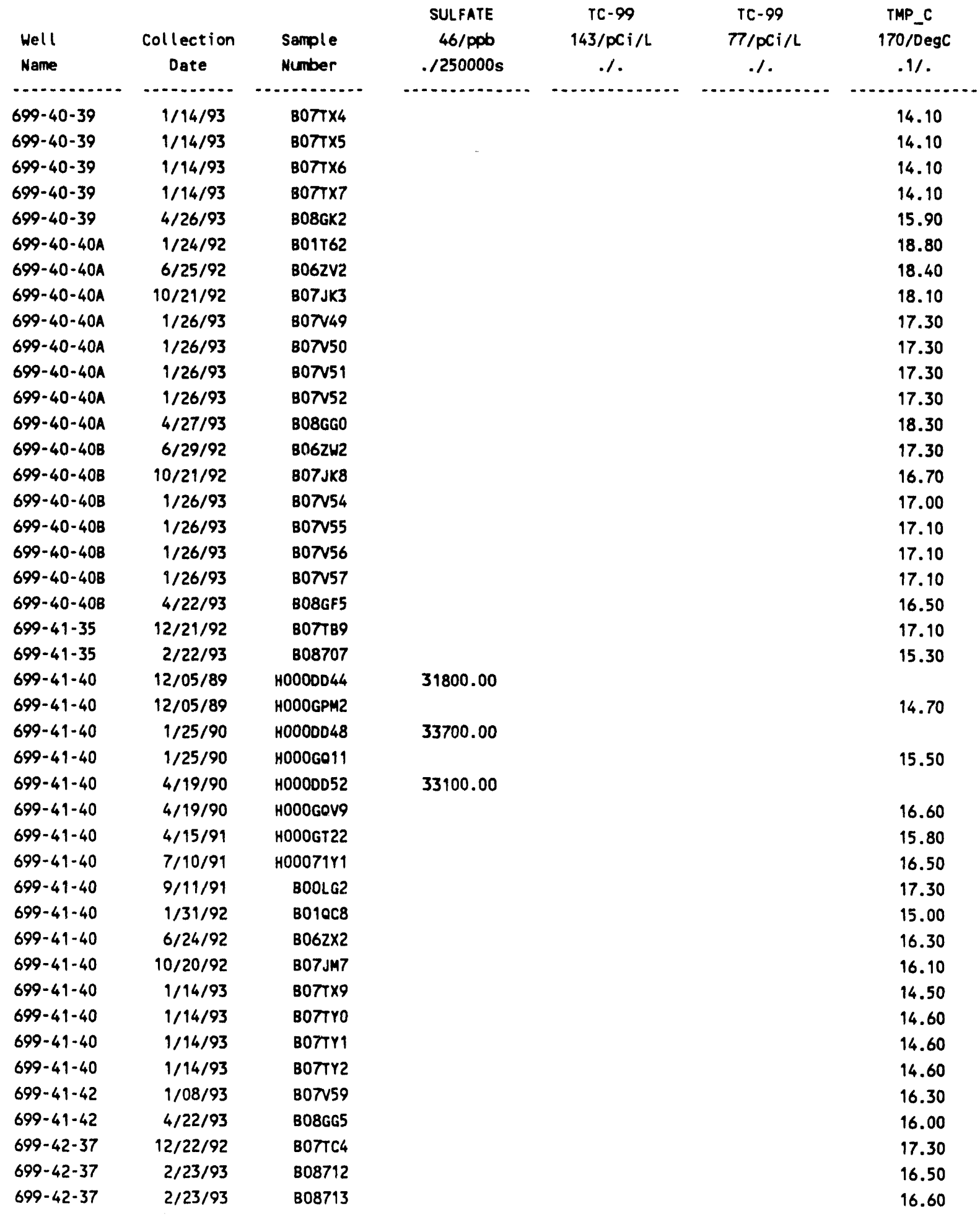


(sheet $\star *$ of $\star *$ )

\begin{tabular}{|c|c|c|c|c|c|c|}
\hline $\begin{array}{l}\text { Well } \\
\text { Name }\end{array}$ & $\begin{array}{c}\text { Collection } \\
\text { Date }\end{array}$ & $\begin{array}{l}\text { Sample } \\
\text { Number }\end{array}$ & $\begin{array}{c}\text { SULFATE } \\
46 / \text { ppb } \\
.1250000 \mathrm{~s}\end{array}$ & $\begin{array}{c}\text { rC- } 99 \\
143 / p C i / L \\
. /\end{array}$ & $\begin{array}{c}\text { TC- } 99 \\
77 / \mathrm{pCi} / \mathrm{L} \\
. /\end{array}$ & $\begin{array}{c}\text { TMP_C } \\
170 / \text { DegC } \\
.1 /\end{array}$ \\
\hline - & $\ldots$ & - & - & (n. & - & . \\
\hline $699-42-37$ & $2 / 23 / 93$ & $B 08714$ & & & & 16.60 \\
\hline $699-42-37$ & $2 / 23 / 93$ & B08715 & & & & 16.60 \\
\hline $699-42-39 A$ & $1 / 23 / 92$ & $801 T 66$ & & & & $14.80 \mathrm{P}$ \\
\hline $699-42-39 A$ & $6 / 25 / 92$ & $8062 \times 7$ & & & & $16.60 \mathrm{P}$ \\
\hline $699-42-39 A$ & $10 / 21 / 92$ & B07JL3 & & & & 16.40 \\
\hline $699-42-39 A$ & $1 / 27 / 93$ & B07N64 & & & & 14.00 \\
\hline $699-42-39 A$ & $1 / 27 / 93$ & B07v65 & & & & 14.30 \\
\hline $699-42-39 A$ & $1 / 27 / 93$ & B07N66 & & & & 14.40 \\
\hline $699-42-39 A$ & $1 / 27 / 93$ & B07N67 & & & & 14.40 \\
\hline $699-42-39 B$ & $1 / 23 / 92$ & B01T68 & & & & 17.50 \\
\hline $699-42-39 B$ & $6 / 25 / 92$ & B06ZYZ & & & & 17.00 \\
\hline $699-42-398$ & $10 / 28 / 92$ & B07JJ2 & & & & 16.80 \\
\hline $699-42-39 B$ & $10 / 28 / 92$ & B07JJ3 & & & & 16.80 \\
\hline $699-42-39 B$ & $10 / 28 / 92$ & B07JJ4 & & & & 16.80 \\
\hline $699-42-398$ & $10 / 28 / 92$ & B07JJJ5 & & & & 16.80 \\
\hline $699-42-39 B$ & $1 / 25 / 93$ & 807N69 & & & & 15.90 \\
\hline $699-42-40 \mathrm{~A}$ & $8 / 22 / 85$ & HOOODF99 & 16000.00 & & & \\
\hline $699-42-40 \mathrm{~A}$ & $8 / 22 / 85$ & HOOOGFT8 & & & & 20.60 \\
\hline $699-42-40 A$ & $8 / 22 / 85$ & H000GGB6 & & & & 20.00 \\
\hline $699-42-40 A$ & $2 / 07 / 86$ & HOOOGFSO & & & & 9.10 \\
\hline $699-42-40 A$ & $5 / 12 / 86$ & HOOODF 27 & 14600.00 & & & \\
\hline $699-42-40 A$ & $5 / 12 / 86$ & H00OGFH8 & & & & 13.80 \\
\hline $699-42-40 A$ & $8 / 05 / 86$ & H0000F33 & 11800.00 & & & \\
\hline $699-42-40 A$ & $8 / 05 / 86$ & HOOOGGJ6 & & & & 20.70 \\
\hline $699-42-40 A$ & $1 / 08 / 88$ & H000DF55 & 11500.00 & & & \\
\hline $699-42-40 \mathrm{~A}$ & $1 / 08 / 88$ & HOOOGJP1 & & & & 10.00 \\
\hline $699-42-40 A$ & $11 / 22 / 88$ & H0000F60 & 12200.00 & & & \\
\hline $699-42-40 \mathrm{~A}$ & $11 / 22 / 88$ & HOOOGMN2 & & & & 18.00 \\
\hline $699-42-40 \mathrm{~A}$ & $2 / 15 / 89$ & H0O0DF65 & 13500.00 & & & \\
\hline $699-42-40 \mathrm{~A}$ & $2 / 15 / 89$ & HODOGNFI & & & & 12.00 \\
\hline $699-42-40 \mathrm{~A}$ & $5 / 31 / 89$ & HOOODF7O & 13700.00 & & & \\
\hline $699-42-40 \mathrm{~A}$ & $5 / 31 / 89$ & HOOOGKNO & & & & 13.20 \\
\hline $699-42-40 A$ & $8 / 10 / 89$ & HOOODF 74 & 19100.00 & & & \\
\hline $699-42-40 A$ & $8 / 10 / 89$ & HOOOGNRO & & & & 16.60 \\
\hline $699-42-40 A$ & $1 / 26 / 90$ & HOOODF 78 & 13200.00 & & & \\
\hline $699-42-40 A$ & $1 / 26 / 90$ & H0OOGQ07 & & & & 16.60 \\
\hline $699-42-40 A$ & $7 / 08 / 91$ & H00071YZ & & & & 17.00 \\
\hline $699-42-40 \mathrm{~A}$ & $1 / 08 / 92$ & B07TY8 & & & & 16.10 \\
\hline $699-42-40 \mathrm{~A}$ & $1 / 08 / 92$ & BOTT 20 & & & & 16.00 \\
\hline $699-42-40 \mathrm{~A}$ & $1 / 08 / 92$ & B07TZ1 & & & & 16.00 \\
\hline $699-42-40 \mathrm{~A}$ & $1 / 08 / 92$ & B07T22 & & & & 16.10 \\
\hline $699-42-40 \mathrm{~A}$ & $1 / 23 / 92$ & 801061 & & & & 15.30 \\
\hline $699-42-40 \mathrm{~A}$ & $6 / 25 / 92$ & B06ZY7 & & & & 16.40 \\
\hline
\end{tabular}


(sheet $\star \star$ of $\star \star$ )

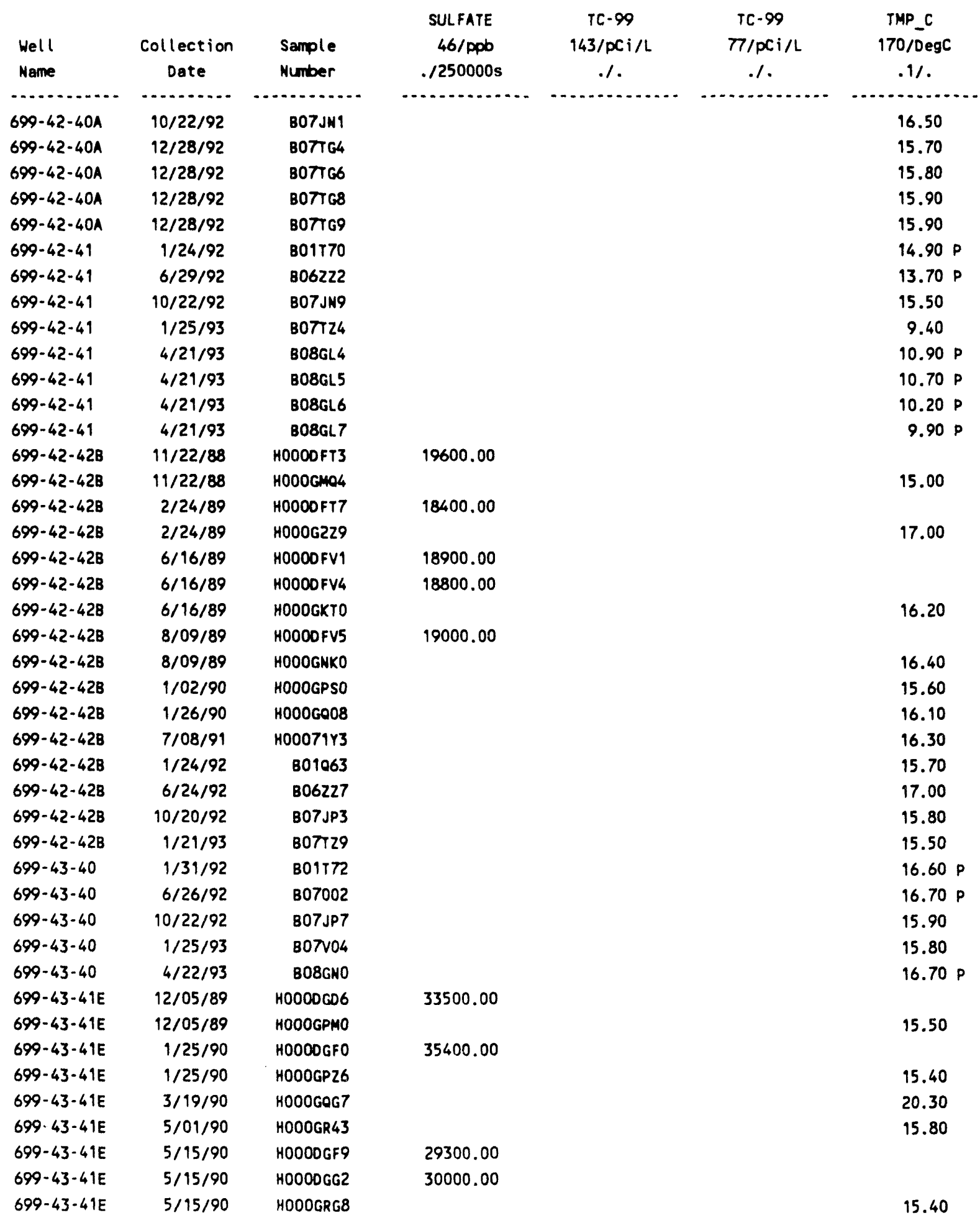


(sheet *t of **)

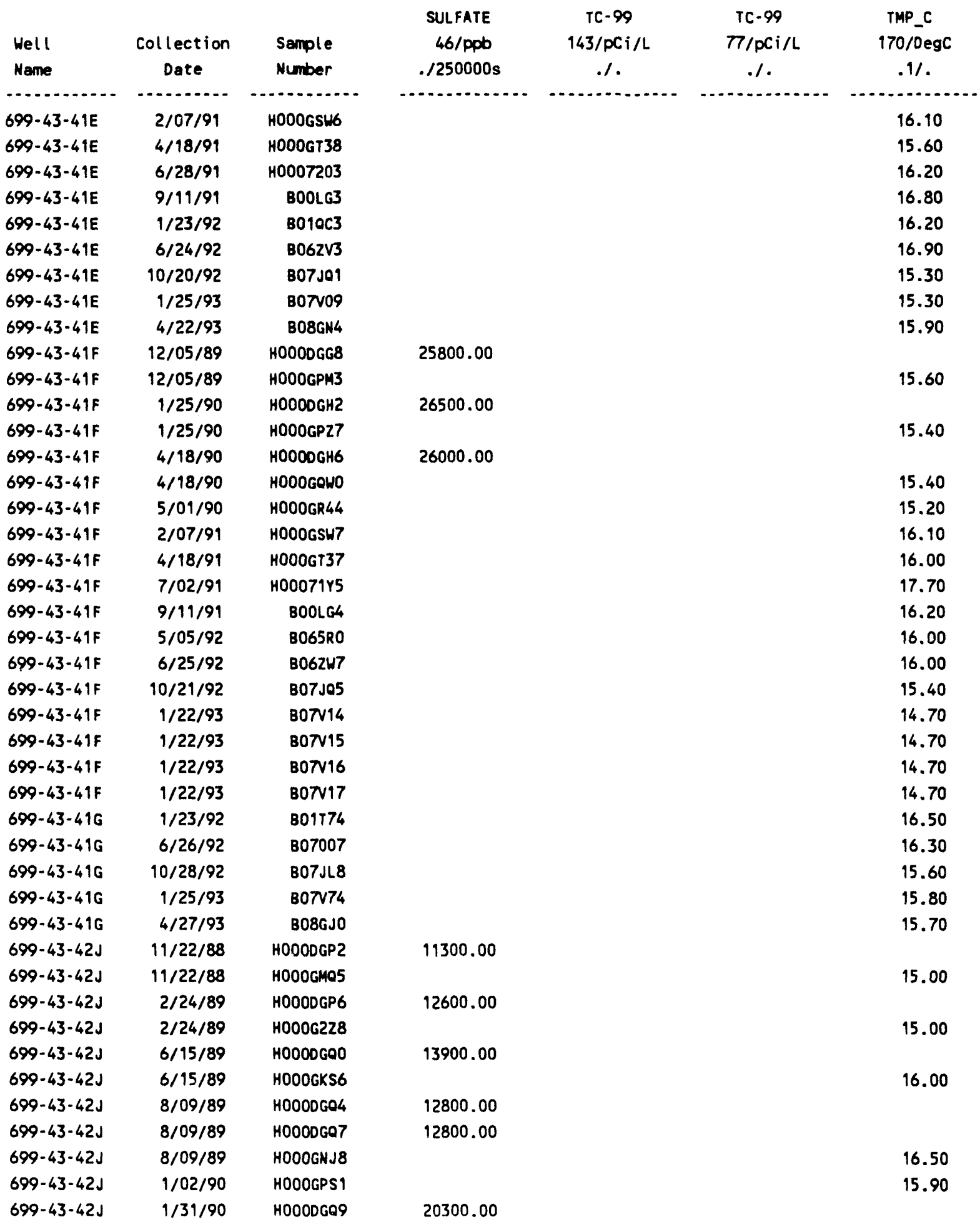


(sheet ** of **)

\begin{tabular}{|c|c|c|c|c|c|c|}
\hline & & & SULFATE & TC-99 & TC-99 & TMP_C \\
\hline Hell & Collection & Sample & 46/ppb & 143/PCi/L & $77 / p C i / L$ & 170/DegC \\
\hline Name & Date & Number &.$/ 250000 \mathrm{~s}$ & .1 & .1 & $.1 /$ \\
\hline - & n. & - & n. & $\cdots$ & $\cdots$ & - \\
\hline $699-43-42 J$ & $1 / 31 / 90$ & H0OOGPZ3 & & & & 15.10 \\
\hline $699-43-42 \mathrm{~J}$ & $7 / 02 / 91$ & H00071Y6 & & & & 17.40 \\
\hline $699-43-42 \mathrm{~J}$ & $1 / 31 / 52$ & B01549 & & & & 16.00 \\
\hline $699-43-42 \mathrm{~J}$ & $2 / 25 / 92$ & B05Y96 & & & & 14.90 \\
\hline $699-43-42 \mathrm{~J}$ & $6 / 25 / 92$ & 807012 & & & & 15.60 \\
\hline $699-43-42 \mathrm{~J}$ & $10 / 22 / 92$ & B07J09 & & & & 15.80 \\
\hline $699-43-42 J$ & $12 / 28 / 92$ & ВотTно & & & & 15.20 \\
\hline $699-43-42 \mathrm{~J}$ & $12 / 28 / 92$ & B07TH1 & & & & 15.20 \\
\hline $699-43-42 \mathrm{~J}$ & $12 / 28 / 92$ & 807тн2 & & & & 15.00 \\
\hline $699-43-42 J$ & $12 / 28 / 92$ & B07TH3 & & & & 15.00 \\
\hline $699-43-42 J$ & $1 / 21 / 93$ & B07N19 & & & & 15.20 \\
\hline $699-43-43$ & $11 / 21 / 88$ & HOOODGR3 & 9300.00 & & & \\
\hline $699-43-43$ & $11 / 21 / 88$ & H0OOGMO3 & & & & 18.00 \\
\hline $699-43-43$ & $2 / 24 / 89$ & HOOOOGR7 & 11000.00 & & & \\
\hline $699-43-43$ & $2 / 24 / 89$ & HOOOOGSO & 11000.00 & & & \\
\hline $699-43-43$ & $2 / 24 / 89$ & HOOOG30O & & & & 18.00 \\
\hline $699-43-43$ & $6 / 15 / 89$ & HOOODGS1 & 12100.00 & & & \\
\hline $699-43-43$ & $6 / 15 / 89$ & H000GKS7 & & & & 16.40 \\
\hline $699-43-43$ & $8 / 09 / 89$ & HOOODGS5 & 10600.00 & & & \\
\hline $699-43-43$ & $8 / 09 / 89$ & HOOOGNJ9 & & & & 17.00 \\
\hline $699-43-43$ & $1 / 26 / 90$ & HOOODGSO & 10400.00 & & & \\
\hline $699-43-43$ & $1 / 26 / 90$ & H000G009 & & & & 17.00 \\
\hline $699-43-43$ & $4 / 26 / 90$ & H0OOGR45 & & & & 16.00 \\
\hline $699-43-43$ & $7 / 08 / 91$ & Ho0071Y7 & & & & 17.10 \\
\hline $699-43-43$ & $1 / 24 / 92$ & 801067 & & & & 16.60 \\
\hline $699-43-43$ & $6 / 26 / 92$ & 8070w0 & & & & 16.20 \\
\hline $699-43-43$ & $10 / 26 / 92$ & B07JG5 & & & & 15.60 \\
\hline $699-43 \cdot 43$ & $1 / 13 / 93$ & BOTN24 & & & & 14.00 \\
\hline $699-43-43$ & $1 / 13 / 93$ & BOTV25 & & & & 14.00 \\
\hline $699-43-43$ & $1 / 13 / 93$ & B07v26 & & & & 14.00 \\
\hline $699-43-43$ & $1 / 13 / 93$ & 807v27 & & & & 14.00 \\
\hline $699-43-45$ & $12 / 06 / 89$ & HOOODGT 4 & 14500.00 & & & \\
\hline $699-43-45$ & $12 / 06 / 89$ & HOOOGPL9 & & & & 19.10 \\
\hline $699-43-45$ & $1 / 26 / 90$ & HOOODGT8 & 14900.00 & & & \\
\hline $699-43-45$ & $1 / 26 / 90$ & H000GQ12 & & & & 19.10 \\
\hline $699-43-45$ & $4 / 18 / 90$ & HOOODGV2 & 14300.00 & & & \\
\hline $699-43-45$ & $4 / 18 / 90$ & HOOOGOW1 & & & & 19.40 \\
\hline $699-43-45$ & $4 / 29 / 90$ & HOOOGR48 & & & & 19.40 \\
\hline $699-43-45$ & $7 / 08 / 91$ & H00071Y8 & & & & 19.20 \\
\hline $699-43-45$ & $9 / 11 / 91$ & BOOLG5 & & & & 18.90 \\
\hline $699-43-45$ & $1 / 24 / 92$ & B01000 & & & & 18.80 \\
\hline $699-43-45$ & $6 / 26 / 92$ & B062T2 & & & & 18.70 \\
\hline $699-43-45$ & $10 / 26 / 92$ & B07JG7 & & & & 18.10 \\
\hline
\end{tabular}


(sheet $\star \star$ of $\star \star$ )

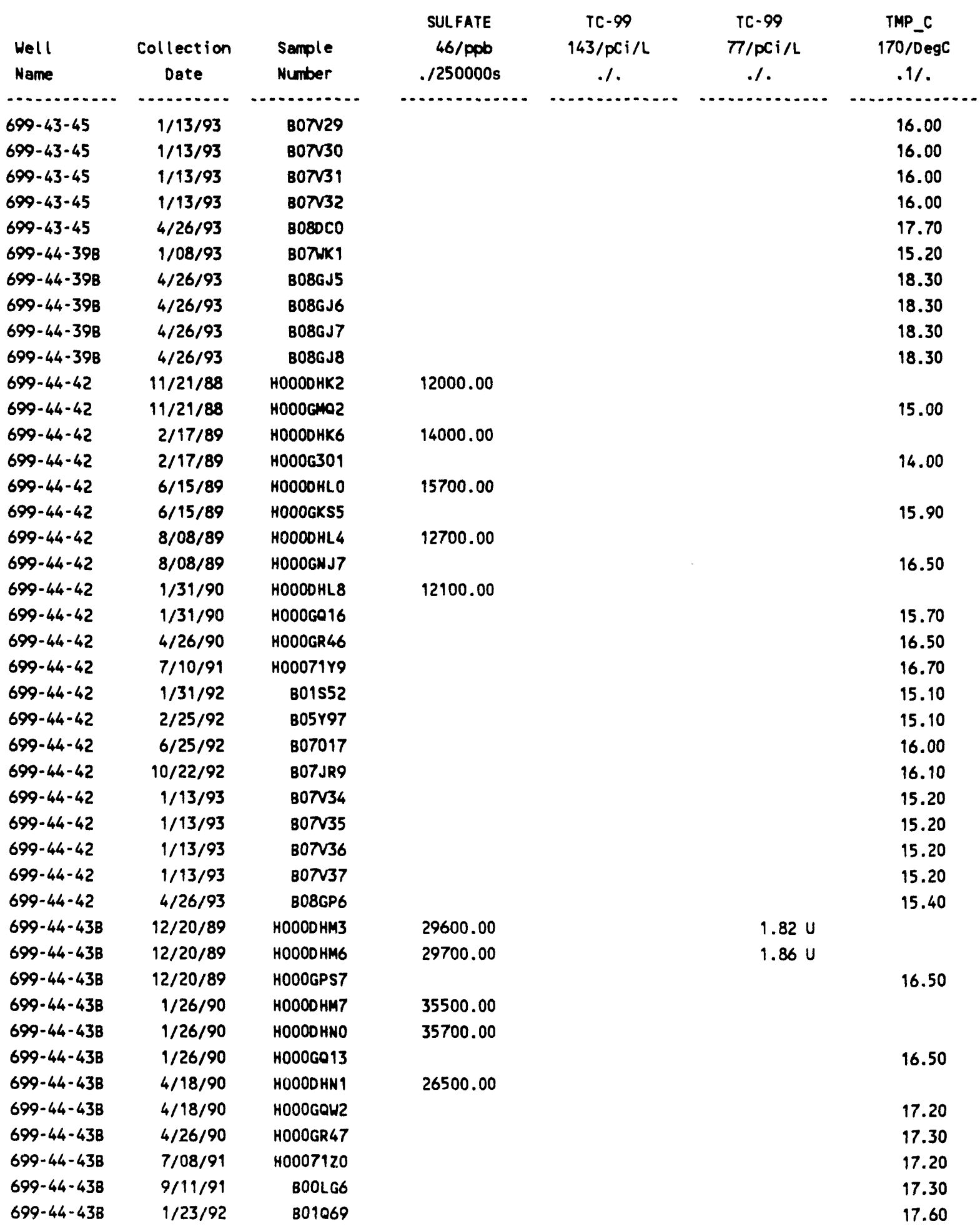


(sheet $\star \star$ of $\star \star$ )

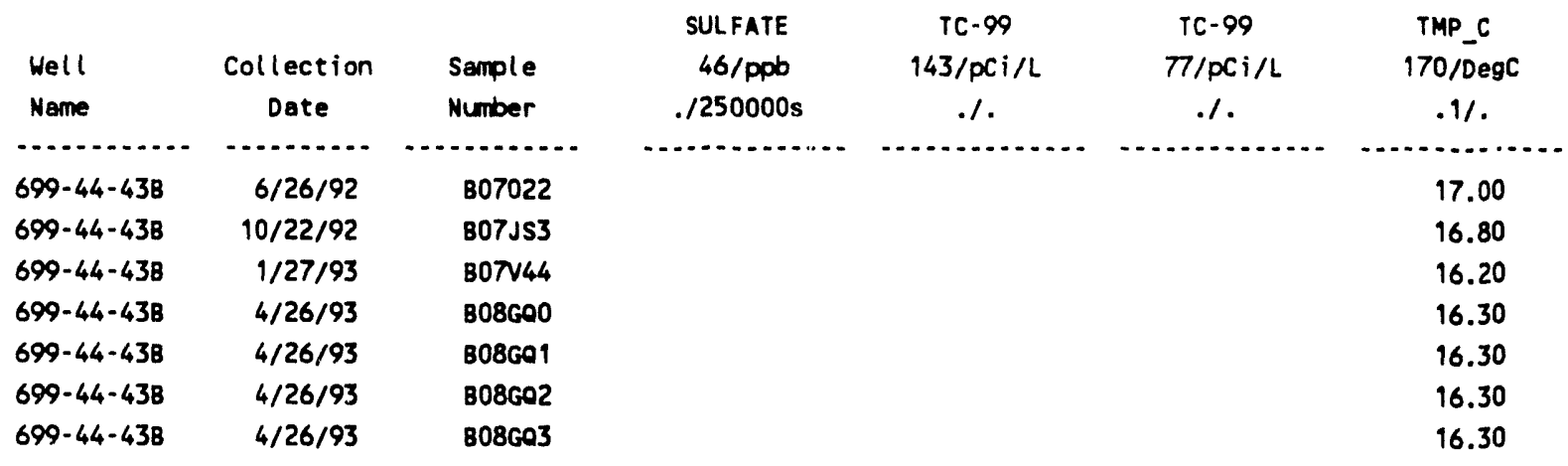

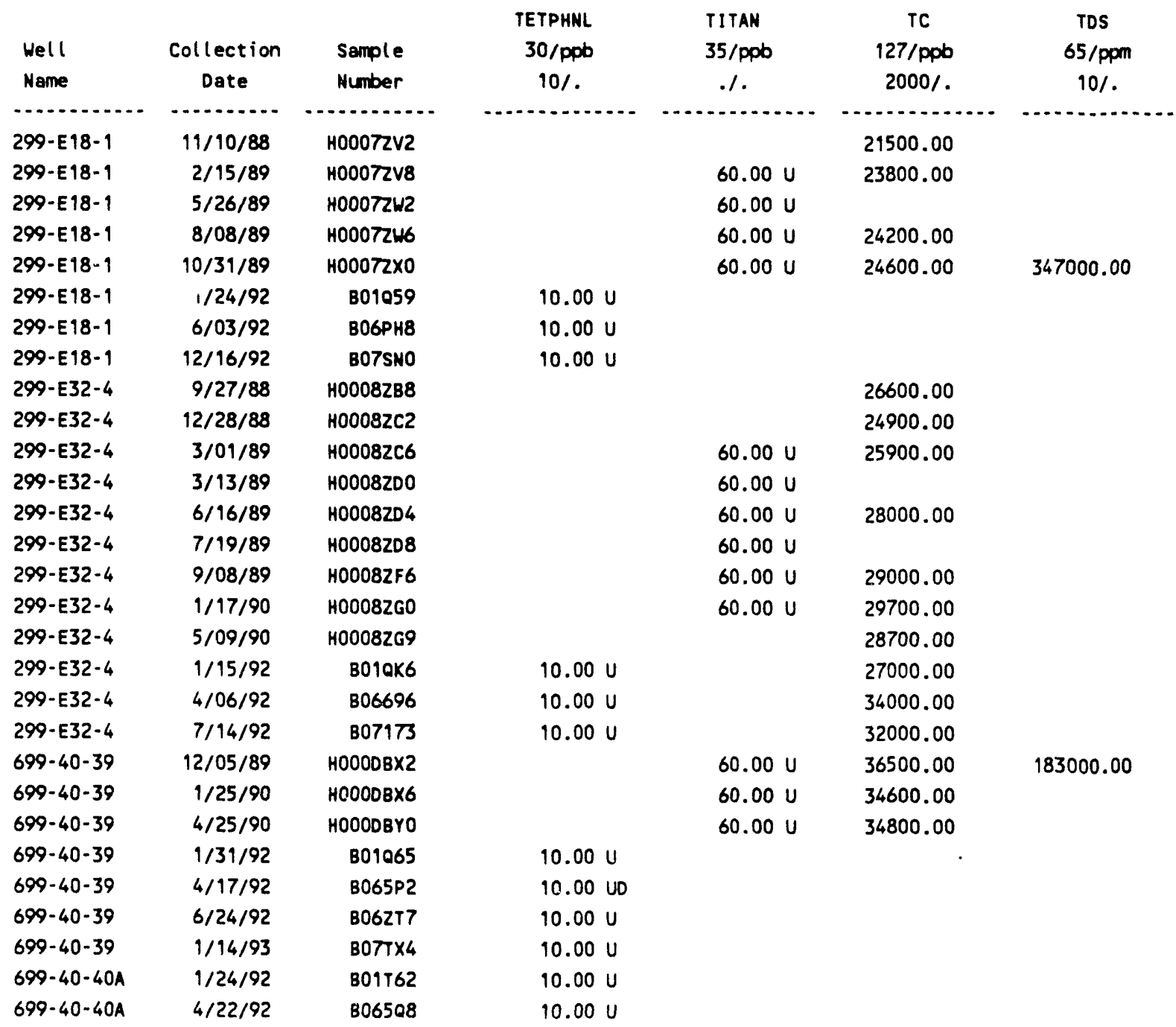


(sheet $\star *$ of $\star$ )

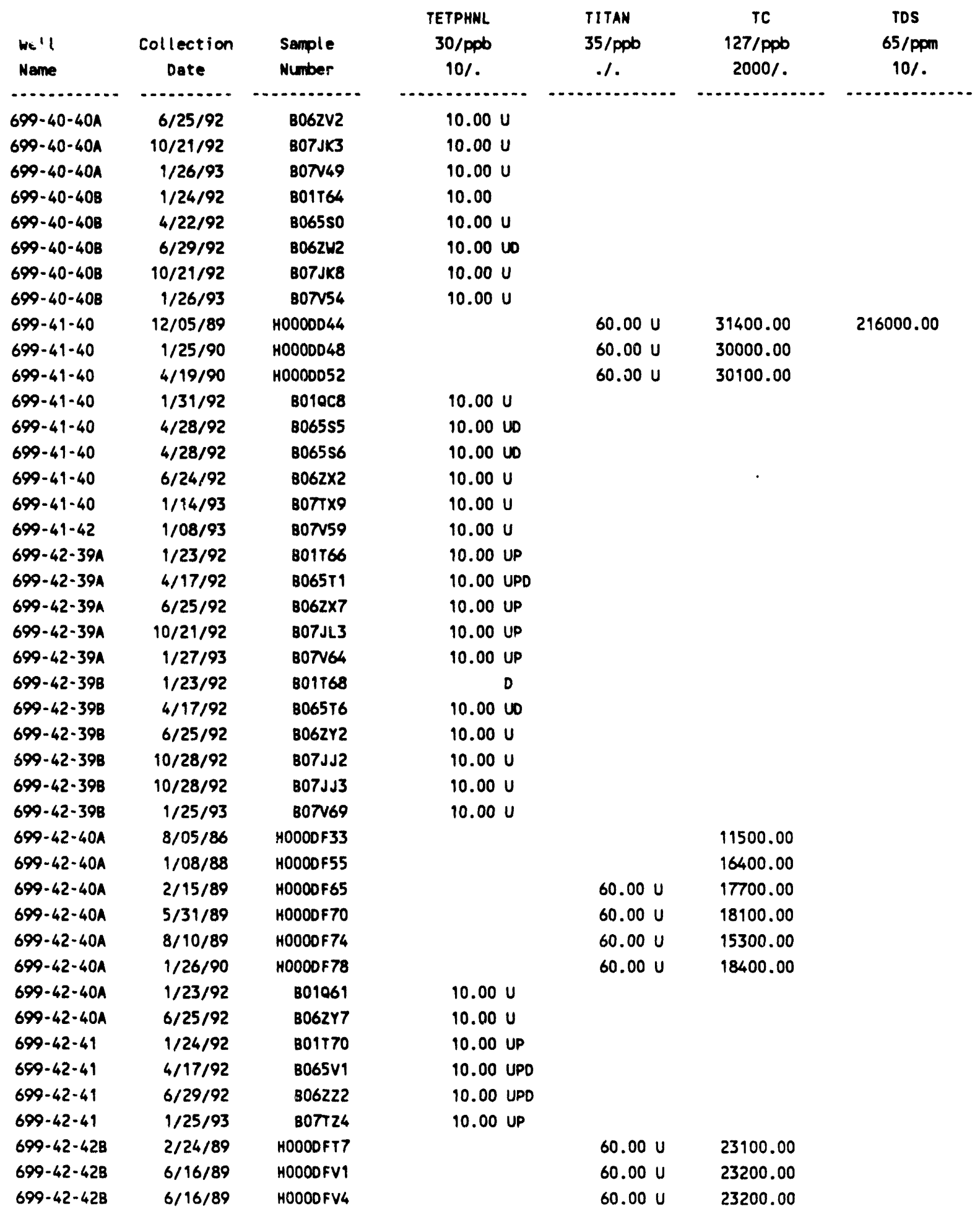


(sheet ** of **)

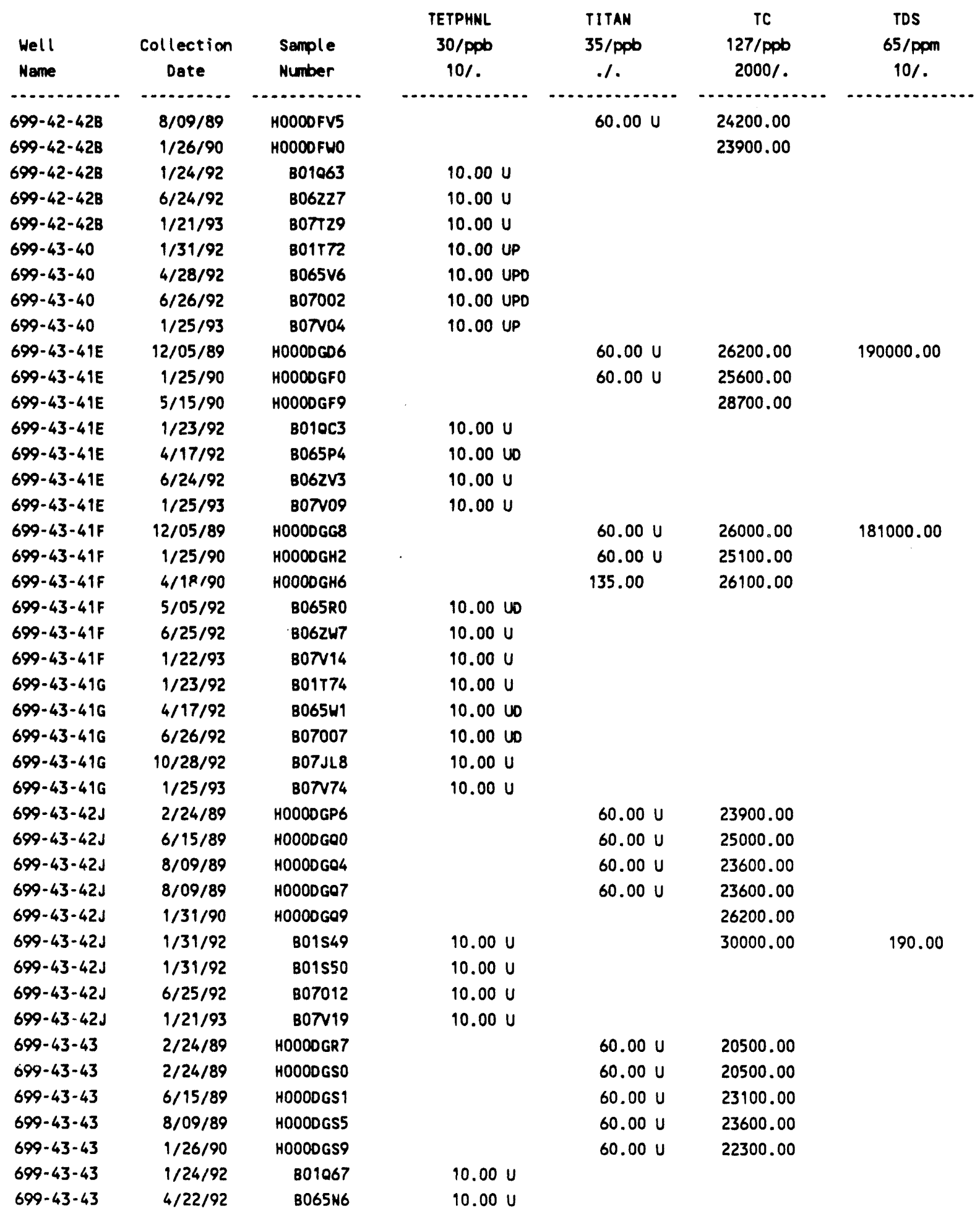


(sheet $\star \star$ of $\star *$ )

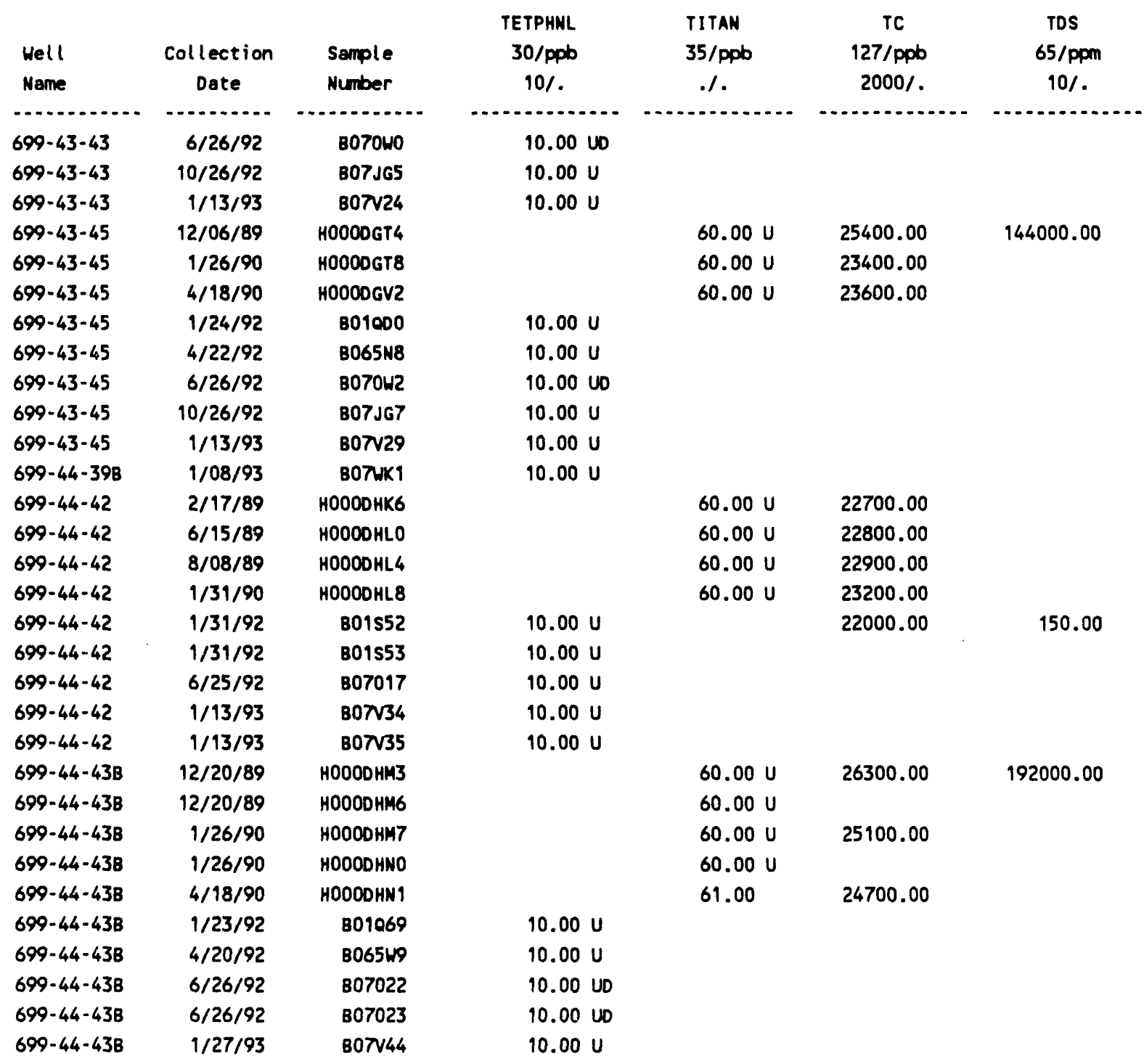

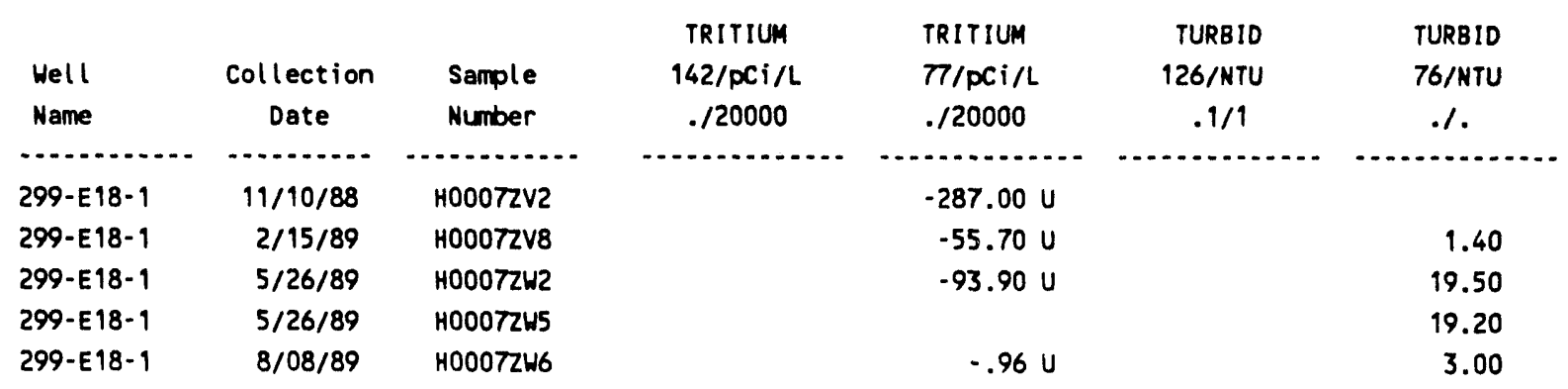


(sheet ** of **)

\begin{tabular}{|c|c|c|c|c|c|c|}
\hline & & & TRITIUM & TRITIUM & TURBID & TURB ID \\
\hline Hell & Collection & Sample & $142 / \mathrm{pCi} / \mathrm{L}$ & $77 / p c i / L$ & 126/NTU & 76/NTU \\
\hline Name & Date & Number &.$/ 20000$ &.$/ 20000$ & $.1 / 1$ & .1 \\
\hline - & - n & - & - & - & $\cdots$ & 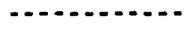 \\
\hline 299-E18-1 & $10 / 31 / 89$ & H0007ZXO & & $86.30 \mathrm{U}$ & & 11.00 \\
\hline 299-E18-1 & $5 / 30 / 90$ & $100072 \times 5$ & & & & 3.50 \\
\hline 299-E18-1 & $7 / 09 / 91$ & H0007207 & 25300.00 & & & \\
\hline 299-E18-1 & $9 / 06 / 91$ & B00LB6 & $-150.00 U$ & & & \\
\hline 299-E 18-1 & $1 / 24 / 92$ & B01059 & $58.20 \mathrm{U}$ & & & \\
\hline 299-E18-1 & $6 / 03 / 92$ & В06Рн8 & $108.00 \mathrm{U}$ & & .80 & \\
\hline 299-E18-1 & $12 / 16 / 92$ & B07532 & & & 1.80 & \\
\hline 299-E18-1 & $12 / 16 / 92$ & BOTSNO & 483.00 & & & \\
\hline $299-E 32-4$ & $9 / 27 / 88$ & H00082B8 & & 1850.00 & & \\
\hline 299-E32-4 & $12 / 28 / 88$ & H0008ZC2 & & 1890.00 & & \\
\hline $299-E 32-4$ & $3 / 01 / 89$ & H0008ZC6 & & 5650.00 & & .95 \\
\hline $299-E 32-4$ & $3 / 13 / 89$ & H0008ZDO & & 5590.00 & & \\
\hline 299-E32-4 & $6 / 16 / 89$ & H0008ZD4 & & 24700.00 & & 4.00 \\
\hline $299-E 32-4$ & $7 / 19 / 89$ & H0008ZD8 & & 41700.00 & & \\
\hline $299-E 32-4$ & $9 / 08 / 89$ & H0008ZF6 & • & 320.00 & & 4.40 \\
\hline 299-E32-4 & $1 / 17 / 90$ & H0008ZGO & & 21500.00 & & 9.60 \\
\hline $299-E 32-4$ & $5 / 09 / 90$ & H0008269 & & & & 8.80 \\
\hline $299-E 32-4$ & $8 / 05 / 91$ & $H 0007264$ & 7490.00 & & & \\
\hline $299-E 32-4$ & $9 / 23 / 91$ & B00LK5 & 6030.00 & & & \\
\hline $299-E 32-4$ & $1 / 15 / 92$ & B010K6 & 1300.00 & & .70 & \\
\hline $299-E 32-4$ & $4 / 06 / 92$ & B06696 & 1510.00 & & 1.10 & \\
\hline $299-E 32-4$ & $4 / 09 / 92$ & B065B6 & 1030.00 & & & \\
\hline $299-E 32-4$ & $7 / 14 / 92$ & B07173 & 959.00 & & 1.60 & \\
\hline $699-40-36$ & $12 / 21 / 92$ & В07TB1 & $26.80 \mathrm{U}$ & & & \\
\hline $699-40-36$ & $2 / 22 / 93$ & B08717 & $-86.50 u$ & & & \\
\hline $699-40-39$ & $12 / 05 / 89$ & HOOODBX2 & & 57700.00 & & 10.50 \\
\hline $699-40-39$ & $1 / 25 / 90$ & HOOODBX6 & & 334.00 & & 3.40 \\
\hline $699-40-39$ & $4 / 25 / 90$ & HOOODBYO & & $20.20 \mathrm{U}$ & & 1.10 \\
\hline $699-40-39$ & $4 / 15 / 91$ & H0007335 & $226000.00 \mathrm{~F}$ & & & \\
\hline $699-40-39$ & $7 / 08 / 91$ & H00071Y4 & $-59.60 \mathrm{U}$ & & 4.50 & \\
\hline $699-40-39$ & $9 / 11 / 91$ & BOOLG1 & $457.00 \mathrm{~F}$ & & & \\
\hline $699-40-39$ & $1 / 31 / 92$ & B01065 & $36.10 \mathrm{U}$ & & 4.40 & \\
\hline $699-40-39$ & $4 / 17 / 92$ & B065P2 & $-139.00 \mathrm{U}$ & & 2.20 & \\
\hline $699-40-39$ & $6 / 24 / 92$ & B062T7 & $-6.72 U$ & & 3.90 & \\
\hline $699-40-39$ & $1 / 14 / 93$ & $807 \pi \times 4$ & $45.20 \mathrm{U}$ & & .90 & \\
\hline $699-40-40 A$ & $1 / 24 / 92$ & B01T62 & 739.00 & & 36.00 & \\
\hline $699-40-40 \mathrm{~A}$ & $4 / 22 / 92$ & B06508 & 1150.00 & & 2.50 & \\
\hline $699-40-40 A$ & $6 / 25 / 92$ & B062V2 & 791.00 & & 2.80 & \\
\hline $699-40-40 A$ & $10 / 21 / 92$ & B07JK3 & 635.00 & & 1.50 & \\
\hline $699-40-40 \mathrm{~A}$ & $1 / 26 / 93$ & BOTN49 & 643.00 & & D & \\
\hline $699-40-408$ & $1 / 24 / 92$ & B01T64 & $91.40 \mathrm{U}$ & & 60.00 & \\
\hline $699-40-40 B$ & $4 / 22 / 92$ & B065SO & 7230.00 & & 1.60 & \\
\hline $699-40-40 B$ & $6 / 29 / 92$ & B06ZW2 & $16.30 \mathrm{U}$ & & 3.50 & \\
\hline
\end{tabular}


(sheet ** of **)

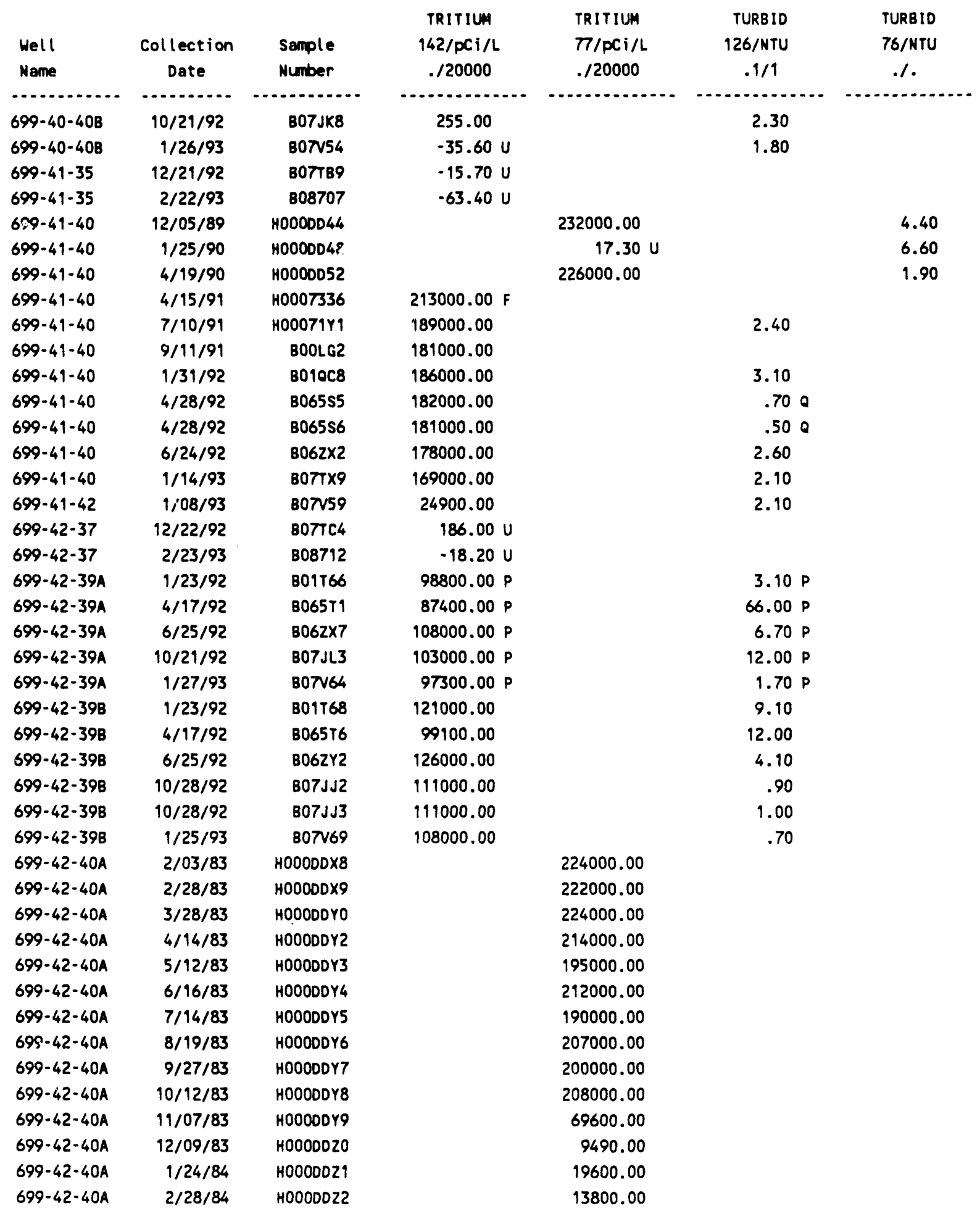


(sheet $\star \star$ of $\star *$ )

\begin{tabular}{|c|c|c|c|c|c|c|}
\hline Yell & Collection & Samole & $\begin{array}{l}\text { TRITIUM } \\
142 / 0 \mathrm{Cj} / \mathrm{L}\end{array}$ & TRITIUM & $\begin{array}{r}\text { TURBID } \\
\text { 126/NTU }\end{array}$ & $\begin{array}{l}\text { TURBID } \\
\text { 76/NTU }\end{array}$ \\
\hline Name & $\begin{array}{l}\text { Date } \\
\text { Dation }\end{array}$ & Number & $\begin{array}{l}14 \angle / 1001 / L \\
. / 20000\end{array}$ &.$/ 20000$ & $.1 / 1$ & .1 \\
\hline - & - & - & 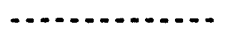 & - & . & n \\
\hline $699-42-40 A$ & $4 / 10 / 84$ & H0000DZZ3 & & 5990.00 & & \\
\hline $699-42-40 A$ & $4 / 26 / 84$ & H0O0DDZ24 & & 3030.00 & & \\
\hline $699-42-40 A$ & $5 / 15 / 84$ & H0OODDZ5 & & 5350.00 & & \\
\hline $699-42-40 A$ & $6 / 05 / 84$ & 40000026 & & 21200.00 & & \\
\hline $699-42-40 A$ & $7 / 19 / 84$ & H0000D27 & & 371.00 & & \\
\hline $699-42-40 A$ & $8 / 90 / 84$ & H00000Z8 & & 9790.00 & & \\
\hline $699-42-40 A$ & $9 / 11 / 84$ & H00000Z9 & & 822.00 & & \\
\hline $699-42-40 \mathrm{~A}$ & $10 / 09 / 84$ & HOOODFOO & & 11400.00 & & \\
\hline $699-42-40 A$ & $11 / 13 / 84$ & HOOODFO1 & & 1190.00 & & \\
\hline $699-42-40 \mathrm{~A}$ & $12 / 12 / 84$ & H0OODFO2 & & 1180.00 & & \\
\hline $699-42-40 A$ & $1 / 16 / 85$ & HOOODFO3 & & 1410.00 & & \\
\hline $699-42-40 A$ & $2 / 11 / 85$ & HOOODFO4 & & 13200.00 & & \\
\hline $699-42-40 A$ & $3 / 14 / 85$ & HOOODFOS & & 3630.00 & & \\
\hline $699-42-40 A$ & $4 / 04 / 85$ & HOOODFO6 & & 1870.00 & & \\
\hline $699-42-40 A$ & $5 / 03 / 85$ & H000DF07 & & 1040.00 & & \\
\hline $699-42-40 A$ & $6 / 11 / 85$ & HOOODF08 & & $1080.00 \mathrm{U}$ & & \\
\hline $699-42-40 \mathrm{~A}$ & $7 / 11 / 85$ & HOOODF 10 & & $391.00 \mathrm{U}$ & & \\
\hline $699-42-40 A$ & $8 / 22 / 85$ & HOOODF 15 & & $273.00 \mathrm{U}$ & & \\
\hline $699-42-40 A$ & $10 / 07 / 85$ & HOOODF 16 & & 2210.00 & & \\
\hline $699-42-40 A$ & $11 / 02 / 85$ & H0OODF 97 & & 1600.00 & & \\
\hline $699-42-40 A$ & $11 / 06 / 85$ & HOOODF 18 & & 2380.00 & & \\
\hline $699-42-40 A$ & $12 / 14 / 85$ & $H 0000 F 20$ & & $376.00 \mathrm{U}$ & & \\
\hline $699-42-40 A$ & $1 / 09 / 86$ & HOOODF29 & & $1210.00 \mathrm{U}$ & & \\
\hline $699-42-40 \mathrm{~A}$ & $2 / 07 / 86$ & H0OODF23 & & $1270.00 \mathrm{U}$ & & \\
\hline $699-42-40 \mathrm{~A}$ & $3 / 07 / 86$ & HOOODF24 & & $-57.30 \mathrm{U}$ & & \\
\hline $699-42-40 \mathrm{~A}$ & $4 / 11 / 86$ & HOOODF 25 & & $619.00 \mathrm{U}$ & & \\
\hline $699-42-40 \mathrm{~A}$ & $5 / 06 / 86$ & H000DF26 & & 416.00 & & \\
\hline $699-42-40 \mathrm{~A}$ & $6 / 06 / 86$ & H000DF31 & & 4650.00 & & \\
\hline $699-42-40 \mathrm{~A}$ & $7 / 02 / 86$ & H0OODF32 & & $627.00 \mathrm{U}$ & & \\
\hline $699-42-40 A$ & $8 / 05 / 86$ & HOOODF37 & & $53.80 \mathrm{U}$ & & \\
\hline $699-42-40 A$ & $9 / 05 / 86$ & H0OODF38 & & $-1120.00 \mathrm{U}$ & & \\
\hline $699-42-40 A$ & $10 / 24 / 86$ & HOOODF39 & & $-61.10 \mathrm{U}$ & & \\
\hline $699-42-40 A$ & $11 / 04 / 86$ & $H 0000 F 40$ & & $424.00 \mathrm{U}$ & & \\
\hline $699-42-40 A$ & $12 / 10 / 86$ & HOOODF41 & & $151.00 \mathrm{U}$ & & \\
\hline $699-42-40 \mathrm{~A}$ & $1 / 15 / 87$ & $H 0000 F 42$ & & 590.00 & & \\
\hline $699-42-40 A$ & $2 / 13 / 87$ & $H 0000 F 43$ & & $239.00 \mathrm{U}$ & & \\
\hline $699-42-40 A$ & $3 / 07 / 87$ & HOOODF 44 & & 389.00 & & \\
\hline $699-42-40 \mathrm{~A}$ & $4 / 06 / 87$ & $H 000 D F 46$ & & $240.00 \mathrm{U}$ & & \\
\hline $699-42-40 A$ & $5 / 08 / 87$ & H0OODF 47 & & 306.00 & & \\
\hline $699-42-40 A$ & $6 / 04 / 87$ & H0OODF 48 & & $185.00 \mathrm{U}$ & & \\
\hline $699-42-40 \mathrm{~A}$ & $7 / 09 / 87$ & HOOODF49 & & 466.00 & & \\
\hline $699-42-40 \mathrm{~A}$ & $8 / 11 / 87$ & H0OODF50 & & 544.00 & & \\
\hline $699-42-40 A$ & $9 / 09 / 87$ & H000DF51 & & 700.00 & & \\
\hline
\end{tabular}


(sheet ** of **)

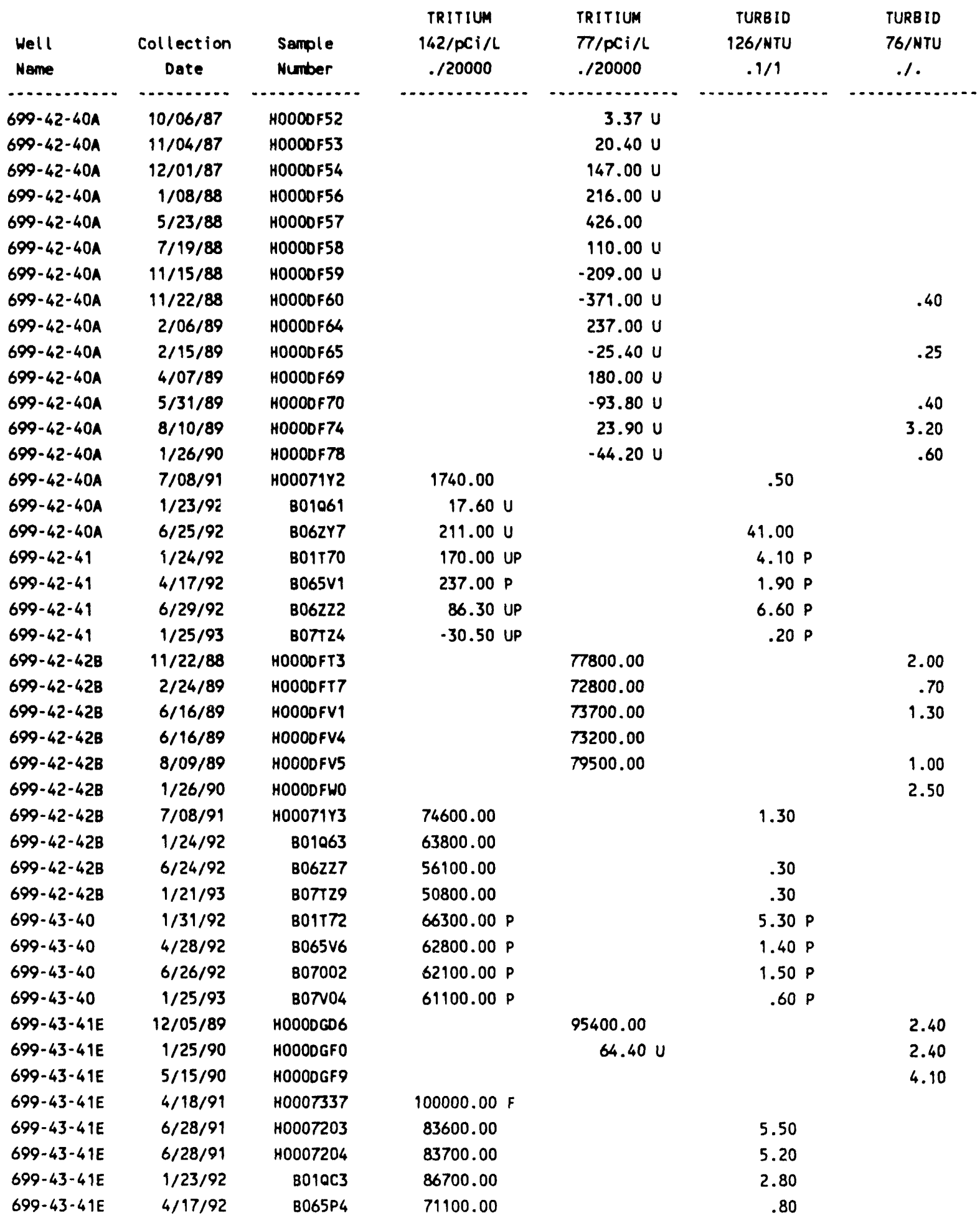


(sheet ** of **)

\begin{tabular}{|c|c|c|c|c|c|c|}
\hline & & & TRITIUM & TRITIUM & TURBID & TURBID \\
\hline Well & Collection & Sample & $142 / \mathrm{pCi} / \mathrm{L}$ & $\pi / D C i / L$ & 126/NTU & 76/NTU \\
\hline Name & Date & Number &.$/ 20000$ &.$/ 20000$ & $.1 / 1$ & .1 \\
\hline - & . & n & . & 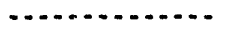 & . & $\cdots$ \\
\hline $699-43-41 E$ & $6 / 24 / 92$ & B062V3 & 78500.00 & & .90 & \\
\hline $699-43-41 E$ & $1 / 25 / 93$ & Bo7v09 & 78100.00 & & .40 & \\
\hline $699-43-41 F$ & $12 / 05 / 89$ & H0OODGG8 & & $31.90 \mathrm{U}$ & & 27.00 \\
\hline $699-43-41 F$ & $1 / 25 / 90$ & H0OOOGH2 & & $-65.30 U$ & & 6.80 \\
\hline $699-43-41 F$ & $4 / 18 / 90$ & H0OOOGH6 & & 58500.00 & & 10.70 \\
\hline $699-43-41 F$ & $4 / 18 / 91$ & H0007338 & $60400.00 \mathrm{~F}$ & & & \\
\hline $699-43-41 F$ & $7 / 02 / 91$ & H00079Y5 & $51200.00 \mathrm{~F}$ & & 1.40 & \\
\hline $699-43-41 F$ & $5 / 05 / 92$ & B065RO & 52900.00 & & 2.20 & \\
\hline $699-43-41 F$ & $6 / 25 / 92$ & B062W7 & 53500.00 & & 7.10 & \\
\hline $699-43-41 F$ & $1 / 22 / 93$ & BOTV14 & 52600.00 & & .80 & \\
\hline $699-43-416$ & $1 / 23 / 92$ & $801 T 74$ & 72300.00 & & 28.00 & \\
\hline $699-43-41 G$ & $4 / 17 / 92$ & B065W1 & 70000.00 & & 13.00 & \\
\hline $699-43-41 G$ & $6 / 26 / 92$ & B07007 & 71100.00 & & 4.10 & \\
\hline $699-43-416$ & $10 / 28 / 92$ & B07JL8 & 67500.00 & & .40 & \\
\hline $699-43-41 G$ & $1 / 25 / 93$ & Bo7v74 & 62600.00 & & .30 & \\
\hline $699-43-42 J$ & $11 / 22 / 88$ & HOOODGP2 & & 1200.00 & & 1.10 \\
\hline $699-43-42 \mathrm{~J}$ & $2 / 24 / 89$ & HOOODGPG & & 2620.00 & & 1.50 \\
\hline $699-43-42 \mathrm{~J}$ & $6 / 15 / 89$ & HOOOOGOO & & 1790.00 & & 1.00 \\
\hline $699-43-42 \mathrm{~J}$ & $8 / 09 / 89$ & H0OOOGO4 & & 1080.00 & & .80 \\
\hline $699-43-42 \mathrm{~J}$ & $8 / 09 / 89$ & H0OODGO7 & & 1160.00 & & \\
\hline $699-43-42 \mathrm{~J}$ & $1 / 31 / 90$ & HOOODGOQ & & 13000.00 & & 2.00 \\
\hline $699-43-42 \mathrm{~J}$ & $7 / 02 / 91$ & H00071Y6 & 7370.00 & & .70 & \\
\hline $699-43-42 \mathrm{~J}$ & $1 / 31 / 92$ & B01549 & 12900.00 & & .70 & \\
\hline $699-43-42 \mathrm{~J}$ & $6 / 25 / 92$ & B07012 & 13500.00 & & 1.00 & \\
\hline $699-43-42 J$ & $1 / 21 / 93$ & B07V19 & 11200.00 & & & \\
\hline $699-43-43$ & $11 / 21 / 88$ & HOOOOGR3 & & 539.00 & & .80 \\
\hline $699-43-43$ & $2 / 24 / 89$ & HOOOOGR7 & & 338.00 & & .50 \\
\hline $699-43-43$ & $2 / 24 / 89$ & HOOODGSO & & 432.00 & & \\
\hline $699-43-43$ & $6 / 15 / 89$ & HOOODGS 1 & & 283.00 & & .30 \\
\hline $699-43-43$ & $8 / 09 / 89$ & H00ODGS5 & & 287.00 & & .40 \\
\hline $699-43-43$ & $1 / 26 / 90$ & HOOODGS9 & & 349.00 & & .40 \\
\hline $699-43-43$ & $7 / 08 / 91$ & H00071Y7 & 394.00 & & .30 & \\
\hline $699-43-43$ & $1 / 24 / 92$ & B01067 & 467.00 & & & \\
\hline $699-43-43$ & $1 / 24 / 92$ & $801 T 83$ & & & .20 & \\
\hline $699-43-43$ & $4 / 22 / 92$ & B065N6 & $303.00 \mathrm{U}$ & & .20 & \\
\hline $699-43-43$ & $6 / 26 / 92$ & BO7ONO & 479.00 & & .30 & \\
\hline $699-43-43$ & $10 / 26 / 92$ & B07JG5 & $138.00 \mathrm{U}$ & & .20 & \\
\hline $699-43-43$ & $1 / 13 / 93$ & Bo7v24 & 342.00 & & .20 & \\
\hline $699-43-45$ & $12 / 06 / 89$ & HOOODGT4 & & 342.00 & & .80 \\
\hline $699-43-45$ & $1 / 26 / 90$ & НО00DGT8 & & 392.00 & & 3.80 \\
\hline $699-43-45$ & $4 / 18 / 90$ & HOOODGV2 & & 506.00 & & .60 \\
\hline $699-43-45$ & $7 / 08 / 91$ & H00071Y8 & 444.00 & & 1.00 & \\
\hline $699-43-45$ & $9 / 11 / 91$ & B00LG5 & 429.00 & & & \\
\hline
\end{tabular}


(sheet $\star *$ of $\star *$ )

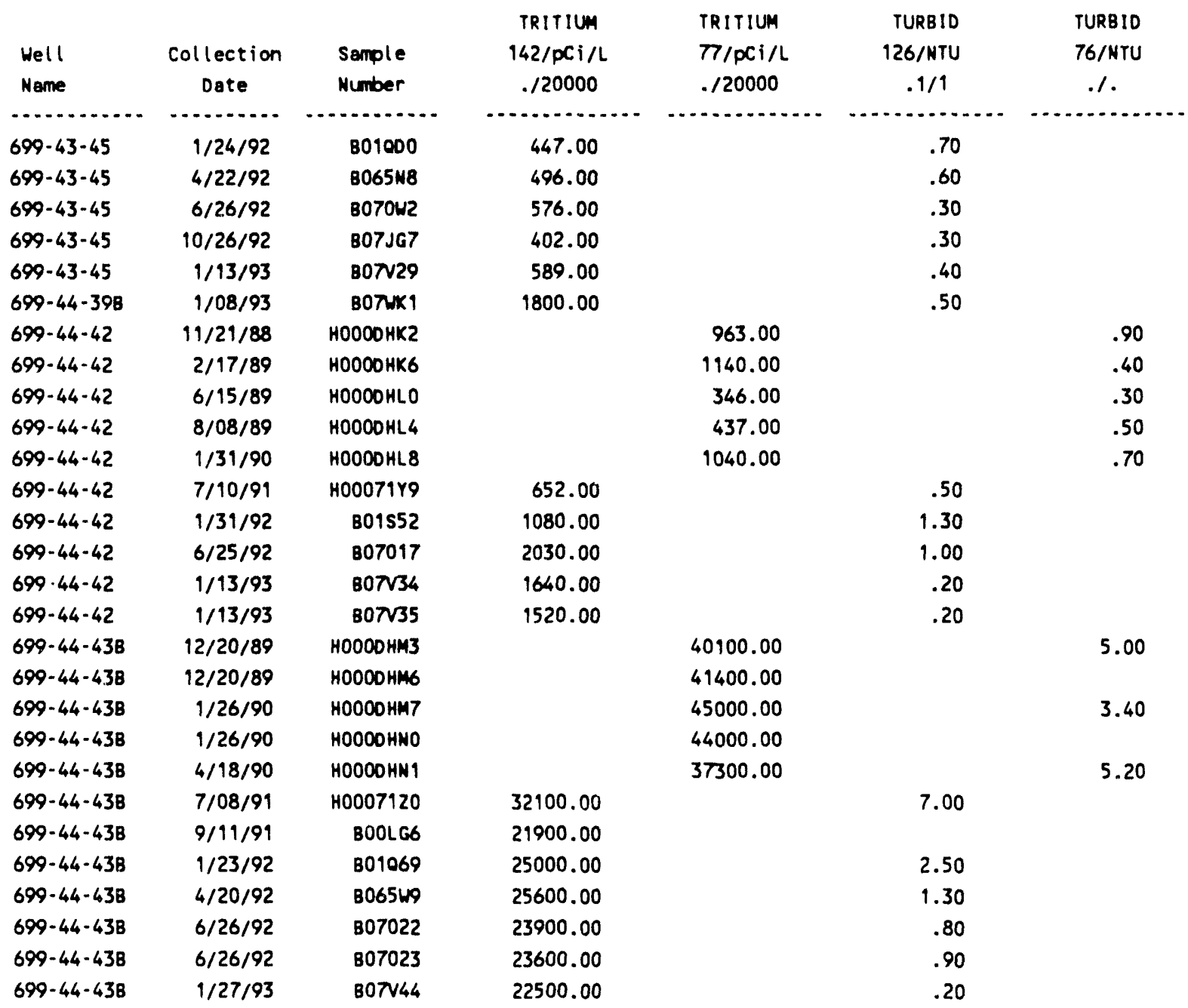

\begin{tabular}{|c|c|c|c|c|c|c|}
\hline & & & UNKNOWN & UNKALI & URANIUM & URANIUM \\
\hline Well & Collection & Sample & 76/ppb & 76/ppb & 145/ppb & $\pi / p C i / L$ \\
\hline Name & Date & Number & .1 & .1 & .1 & .1 \\
\hline . & $\ldots \ldots$ & . & - & , & 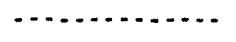 & $\ldots$ \\
\hline 299-E18-1 & $10 / 31 / 89$ & H0007ZXO & & & & 4.56 \\
\hline 299-E18-1 & $9 / 06 / 91$ & B00LB6 & & & 6.13 & \\
\hline 299-E18-1 & $6 / 03 / 92$ & В06РН8 & & & 5.84 & \\
\hline 299-E18-1 & $12 / 16 / 92$ & B07532 & & & 6.78 & \\
\hline $299-E 32-4$ & $9 / 27 / 88$ & H0008z88 & & & & 7.73 \\
\hline $299-E 32-4$ & $12 / 28 / 88$ & H0008ZC2 & & 6.00 & & 2.46 \\
\hline $299-E 32 \cdot 4$ & $3 / 01 / 89$ & H0008zC6 & & & & 4.15 \\
\hline $299-E 32-4$ & $3 / 13 / 89$ & H0008200 & & & & 4.27 \\
\hline
\end{tabular}


(sheet * of $* *$ )

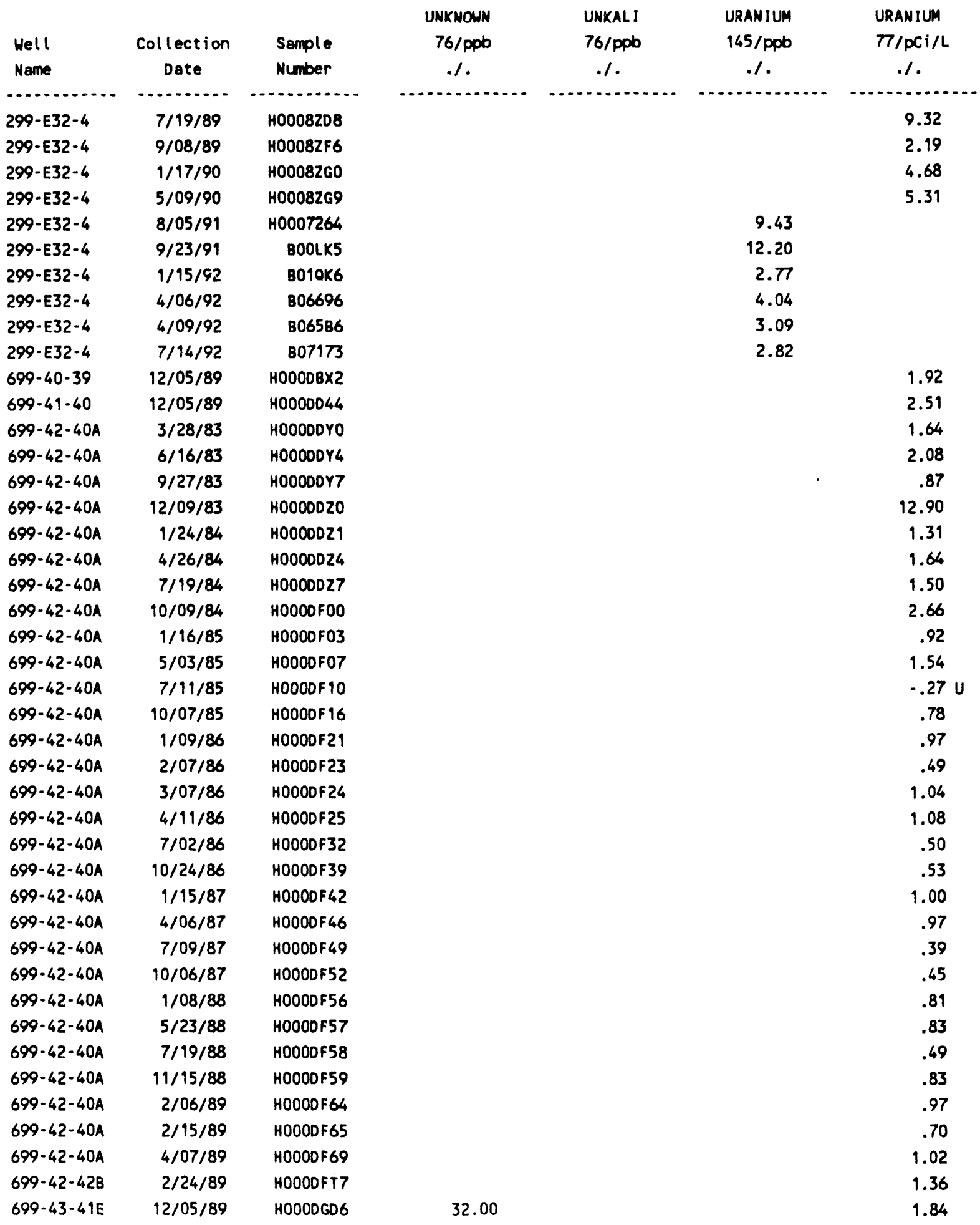




\begin{tabular}{|c|c|c|c|c|c|c|}
\hline & & & UNKMONN & UNKALI & URANIUM & URANIUM \\
\hline Well & Collection & Sample & 76/ppb & 76/ppb & 145/ppb & $77 / p C i / L$ \\
\hline Neme & Date & Number & .1 & .1 & .1 & .1 \\
\hline . & $\ldots$ & 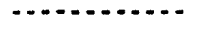 & 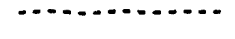 & 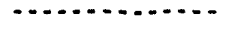 & $\cdots$ & \\
\hline $699-43-41 F$ & $12 / 05 / 89$ & HOOOOGG8 & & & & 2.39 \\
\hline $699-43-42 \mathrm{~J}$ & $2 / 24 / 89$ & HOOOOGPG & & & & 1.51 \\
\hline $699-43-45$ & $12 / 06 / 89$ & HOOODGT4 & & & & 1.21 \\
\hline $699-44-438$ & $12 / 20 / 89$ & НООООНАЗ & & & & 1.51 \\
\hline $699-44-438$ & $12 / 20 / 89$ & HOOODHM6 & & & & 1.89 \\
\hline & & & $U \cdot 234$ & $U-235$ & $U-238$ & VANADUM \\
\hline Hell & Collection & Sample & $77 / p C i / L$ & $\pi / p c i / L$ & $77 / p C i / L$ & 34/ppb \\
\hline Name & Date & Number & .1 & .1 & .1 & $30 \%$ \\
\hline - & (n) & , n & (n) & (n) & (n) & - \\
\hline 299-E18-1 & $7 / 09 / 91$ & H00071X9 & & & & $30.00 \mathrm{U}$ \\
\hline 299-E18-1 & $9 / 06 / 91$ & BOOLB6 & & & & $30.00 \mathrm{U}$ \\
\hline 299-E18-1 & $1 / 24 / 92$ & 801059 & & & & 30.00 UD \\
\hline 299-E18-1 & $6 / 03 / 92$ & В06PH8 & & & & $30.00 \mathrm{U}$ \\
\hline 299-E18-1 & $12 / 16 / 92$ & B07532 & & & & $30.00 \mathrm{U}$ \\
\hline $299-E 32-4$ & $8 / 05 / 91$ & HOOOZIYO & & & & 30.00 UD \\
\hline $299-E 32-4$ & $8 / 05 / 91$ & H0007264 & & & & 30.00 UD \\
\hline 299-E32-4 & $9 / 23 / 91$ & BOOLK5 & & & & $30.00 \mathrm{U}$ \\
\hline 299-E32-4 & $1 / 15 / 92$ & B010K6 & & & & $30.00 \mathrm{U}$ \\
\hline $299-E 32-4$ & $4 / 06 / 92$ & $B 06696$ & & & & $30.00 \mathrm{U}$ \\
\hline $299-E 32-4$ & $7 / 14 / 92$ & B07173 & & & & $30.00 \mathrm{U}$ \\
\hline $699-40-36$ & $12 / 21 / 92$ & B07TB1 & & & & $30.00 \mathrm{U}$ \\
\hline $699-40-36$ & $2 / 22 / 93$ & B08717 & & & & $30.00 \mathrm{U}$ \\
\hline $699-40-39$ & $9 / 11 / 91$ & B00LG1 & & & & $30.00 \mathrm{U}$ \\
\hline $699-40-39$ & $1 / 31 / 92$ & B01065 & & & & 30.00 UD \\
\hline $699-40-39$ & $4 / 17 / 92$ & B065P2 & & & & $30.00 \mathrm{U}$ \\
\hline $699-40-39$ & $6 / 24 / 92$ & B06217 & & & & $30.00 \mathrm{U}$ \\
\hline $699-40-39$ & $1 / 14 / 93$ & B07TX4 & & & & $30.00 \mathrm{U}$ \\
\hline $699-40-40 A$ & $1 / 24 / 92$ & B01T62 & & & & 30.00 UD \\
\hline $699-40-40 A$ & $4 / 22 / 92$ & B06508 & & & & $30.00 \mathrm{U}$ \\
\hline $699-40-40 A$ & $6 / 25 / 92$ & B062V2 & & & & $30.00 \mathrm{U}$ \\
\hline $699-40-40 A$ & $10 / 21 / 92$ & B07JK3 & & & & $30.00 \mathrm{U}$ \\
\hline $699-40-40 A$ & $1 / 26 / 93$ & BOTV49 & & & & $30.00 \mathrm{U}$ \\
\hline $699-40-408$ & $1 / 24 / 92$ & $801 T 64$ & & & & 33.000 \\
\hline $699-40-408$ & $4 / 22 / 92$ & 8065 S0 & & & & $30.00 \mathrm{U}$ \\
\hline $699-40-408$ & $6 / 29 / 92$ & BO6ZW2 & & & & $30.00 \mathrm{U}$ \\
\hline $699-40-40 B$ & $10 / 21 / 92$ & B07JK8 & & & & $30.00 \mathrm{U}$ \\
\hline $699-40-408$ & $1 / 26 / 93$ & Bo7v54 & & & & $30.00 \mathrm{U}$ \\
\hline $699-41-35$ & $12 / 21 / 92$ & B07TB9 & & & & $30.00 \mathrm{U}$ \\
\hline $699-41 \cdot 35$ & $2 / 22 / 93$ & B08707 & & & & $30.00 \mathrm{U}$ \\
\hline $699-41-40$ & $7 / 10 / 91$ & HOOOTIY1 & & & & $30.00 \mathrm{U}$ \\
\hline
\end{tabular}


(sheet $* *$ of $\star *$ )

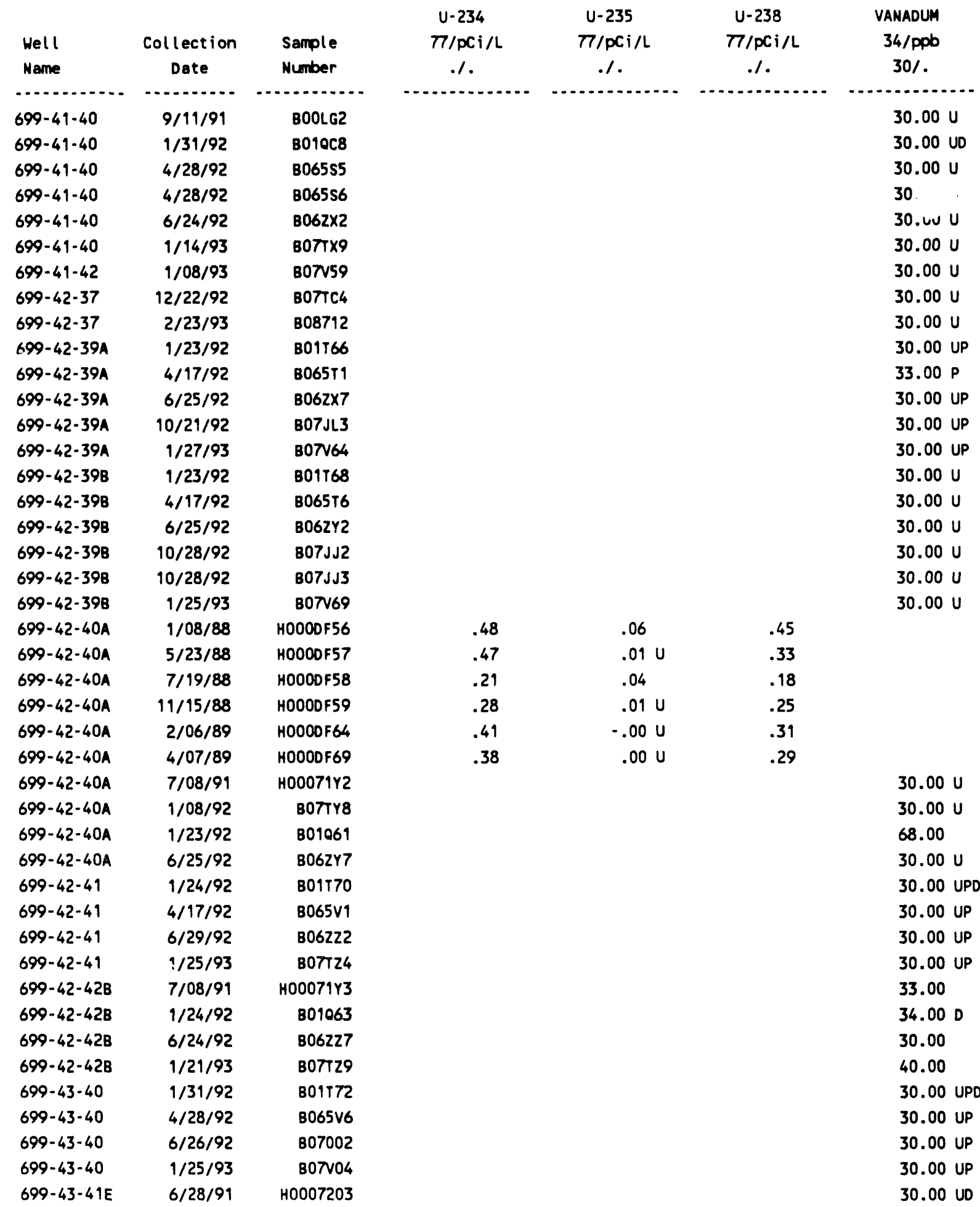


(sheet $\star$ of $\star \star$ )

\begin{tabular}{|c|c|c|c|c|c|c|}
\hline $\begin{array}{l}\text { Well } \\
\text { Name }\end{array}$ & $\begin{array}{c}\text { Collection } \\
\text { Date }\end{array}$ & $\begin{array}{l}\text { Sample } \\
\text { Number }\end{array}$ & $\begin{array}{c}U-234 \\
\pi / D C i / L \\
.1\end{array}$ & $\begin{array}{c}u-235 \\
77 / p C i / L \\
. /\end{array}$ & $\begin{array}{c}u-238 \\
\pi / p C i / L \\
. /\end{array}$ & $\begin{array}{c}\text { VANADUM } \\
34 / \mathrm{ppb} \\
30 /\end{array}$ \\
\hline - & 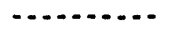 & - & 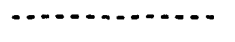 & - & . & $\cdots$ \\
\hline $699-43-41 E$ & $6 / 28 / 91$ & H0007204 & & & & 30.00 UD \\
\hline $699-43-41 E$ & $1 / 23 / 92$ & B010C3 & & & & 41.00 \\
\hline $699-43-41 E$ & $4 / 17 / 92$ & $8065 P 4$ & & & & $30.00 \mathrm{U}$ \\
\hline $699-43-41 E$ & $6 / 24 / 92$ & $8062 V 3$ & & & & $30.00 \mathrm{U}$ \\
\hline $699-43-41 E$ & $1 / 25 / 93$ & B07V09 & & & & $30.00 \mathrm{U}$ \\
\hline $699-43-41 F$ & $7 / 02 / 91$ & H00079Y5 & & & & 30.00 UD \\
\hline $699-43-41 F$ & $5 / 05 / 92$ & 8065RO & & & & $30.00 \mathrm{U}$ \\
\hline $699-43-41 F$ & $6 / 25 / 92$ & $8062 W 7$ & & & & $30.00 \mathrm{U}$ \\
\hline $699-43-41 F$ & $1 / 22 / 93$ & BOTV14 & & & & $30.00 \mathrm{U}$ \\
\hline $699-43-416$ & $1 / 23 / 92$ & B01T74 & & & & $30.00 \mathrm{U}$ \\
\hline $699-43-416$ & $4 / 17 / 92$ & B065W1 & & & & $30.00 \mathrm{U}$ \\
\hline $699-43-416$ & $6 / 26 / 92$ & 807007 & & & & $30.00 \mathrm{U}$ \\
\hline $699-43-416$ & $10 / 28 / 92$ & 807JL8 & & & & $30.00 \mathrm{U}$ \\
\hline $699-43-416$ & $1 / 25 / 93$ & B07V74 & & & & $30.00 \mathrm{U}$ \\
\hline $699-43-42 J$ & $7 / 02 / 91$ & H00071Y6 & & & & $65.00 \mathrm{D}$ \\
\hline $699-43-42 J$ & $1 / 31 / 92$ & 801549 & & & & $65.00 \mathrm{D}$ \\
\hline $699-43-42 J$ & $6 / 25 / 92$ & B07012 & & & & 70.00 \\
\hline $699-43-42 J$ & $1 / 21 / 93$ & BoTV19 & & & & 60.00 \\
\hline $699-43-43$ & $7 / 08 / 91$ & H00071Y7 & & & & 33.00 \\
\hline $699-43-43$ & $1 / 24 / 92$ & B01067 & & & & 39.000 \\
\hline $699-43-43$ & $4 / 22 / 92$ & B065N6 & & & & 39.00 \\
\hline $699-43-43$ & $6 / 26 / 92$ & Bo70w0 & & & & 38.000 \\
\hline $699-43-43$ & $10 / 26 / 92$ & B07JG5 & & & & 40.00 \\
\hline $699-43-43$ & $1 / 13 / 93$ & BOTV24 & & & & 50.00 \\
\hline $699-43-45$ & $7 / 08 / 91$ & H00071Y8 & & & & 33.00 \\
\hline $699-43-45$ & $9 / 11 / 91$ & BOOLG5 & & & & 31.00 \\
\hline $699-43-45$ & $1 / 24 / 92$ & $B 01000$ & & & & 39.000 \\
\hline $699-43-45$ & $4 / 22 / 92$ & B065N8 & & & & $30.00 \mathrm{U}$ \\
\hline $699-43-45$ & $6 / 26 / 92$ & 8070w2 & & & & $34.00 \mathrm{D}$ \\
\hline $699-43-45$ & $10 / 26 / 92$ & B07JG7 & & & & 30.00 \\
\hline $699-43-45$ & $1 / 13 / 93$ & 807 29 & & & & 40.00 \\
\hline $699-44-39 B$ & $1 / 08 / 93$ & BOTNK1 & & & & $30.00 \mathrm{U}$ \\
\hline $699-44-42$ & $7 / 10 / 91$ & H00071Y9 & & & & 56.00 \\
\hline $699-44-42$ & $1 / 31 / 92$ & B01552 & & & & $46.00 \mathrm{D}$ \\
\hline $699-44-42$ & $6 / 25 / 92$ & B07017 & & & & 45.00 \\
\hline $699-44-42$ & $1 / 13 / 93$ & $807 \sqrt{34}$ & & & & 30.000 \\
\hline $699-44-42$ & $1 / 13 / 93$ & B07v35 & & & & $40.00 a$ \\
\hline $699-44-438$ & $7 / 08 / 91$ & H00071ZO & & & & 37.00 \\
\hline $699-44-438$ & $9 / 11 / 91$ & BOOLG6 & & & & 33.00 \\
\hline $699-44-438$ & $1 / 23 / 92$ & B01069 & & & & $30.00 \mathrm{U}$ \\
\hline $699-44-438$ & $4 / 20 / 92$ & B065 W9 & & & & 39.00 \\
\hline $699-44-43 B$ & $6 / 26 / 92$ & B07022 & & & & 38.00 \\
\hline $699-44-43 B$ & $6 / 26 / 92$ & B07023 & & & & 35.00 \\
\hline
\end{tabular}


1

(sheet ** of **)

\begin{tabular}{|c|c|c|c|c|c|c|}
\hline & & & $U-234$ & U-235 & $U-238$ & VANADUM \\
\hline Well & Collection & Sample & $\pi / p c i / L$ & $\pi / p C i / L$ & $\pi / p C i / L$ & $34 / p p b$ \\
\hline Name & Date & Number & .1. & .1 & .1 & $30 \%$ \\
\hline $699-44-43 B$ & $1 / 27 / 93$ & B07N44 & 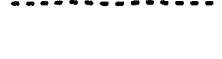 & - & 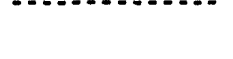 & 40.00 \\
\hline
\end{tabular}

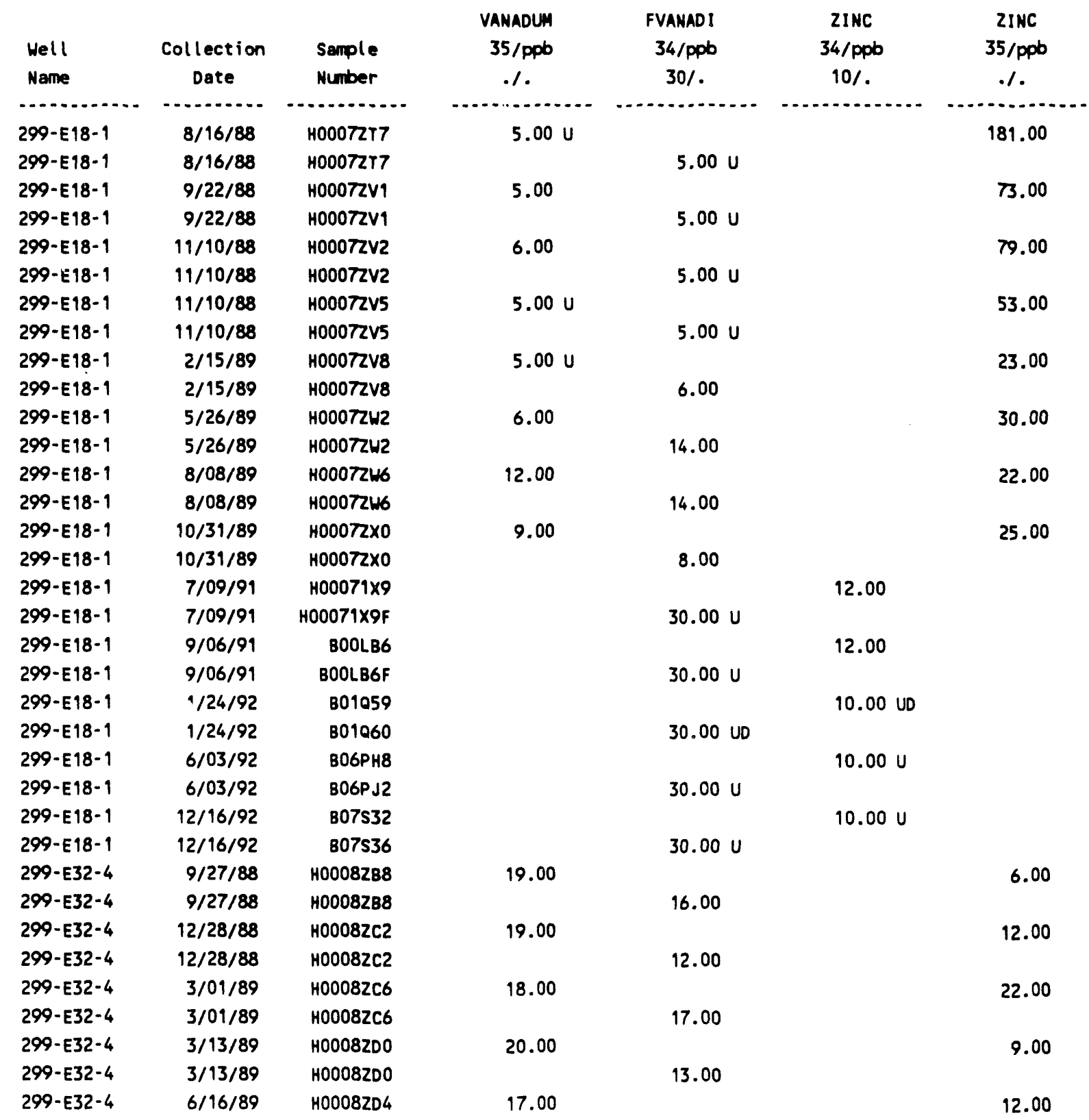


sheet $\star *$ of $\star *$ )

\begin{tabular}{|c|c|c|c|c|c|c|}
\hline $\begin{array}{l}\text { Hell } \\
\text { Mame }\end{array}$ & $\begin{array}{l}\text { Collection } \\
\text { Date }\end{array}$ & $\begin{array}{l}\text { Sample } \\
\text { Number }\end{array}$ & $\begin{array}{c}\text { VANADUM } \\
35 / p p b \\
. /\end{array}$ & $\begin{array}{c}\text { FVANADI } \\
34 / \mathrm{ppb} \\
30 \%\end{array}$ & $\begin{array}{c}\text { 2INC } \\
34 / \mathrm{ppb} \\
10 \%\end{array}$ & $\begin{array}{c}\text { ZINC } \\
35 / p p b \\
.1\end{array}$ \\
\hline 299-E32-4 & $6 / 16 / 89$ & 40008204 & (n) & 13.00 & - & $\cdots$ \\
\hline $299-E 32-4$ & $7 / 19 / 89$ & N0008208 & 17.00 & & & $5.00 \mathrm{U}$ \\
\hline $299-E 32-4$ & $7 / 19 / 89$ & H0008ZDB & & 16.00 & & \\
\hline 299-E32-4 & $9 / 08 / 89$ & H00082F6 & 22.00 & & & 9.00 \\
\hline $299-E 32-4$ & $9 / 08 / 89$ & H0008ZF6 & & 18.00 & & \\
\hline 299-E32-4 & $1 / 17 / 90$ & H00082GO & 16.00 & & & 13.00 \\
\hline $299-E 32-4$ & $1 / 17 / 90$ & H00082GO & & 14.00 & & \\
\hline 299-E32-4 & $8 / 05 / 91$ & HO0071YO & & & $23.00 \mathrm{D}$ & \\
\hline $299-E 32-4$ & $8 / 05 / 91$ & HOOOTIYOF & & $30.00 \mathrm{U}$ & & \\
\hline 299-E32-4 & $8 / 05 / 91$ & H0007264 & & & 21.000 & \\
\hline $299-E 32-4$ & $8 / 05 / 91$ & H0007264F & & $30.00 \mathrm{U}$ & & \\
\hline $299-E 32-4$ & $9 / 23 / 91$ & $800 \mathrm{LK5}$ & & & $10.00 \mathrm{U}$ & \\
\hline $299-E 32-4$ & $9 / 23 / 91$ & B0OLK5F & & $30.00 \mathrm{U}$ & & \\
\hline $299-E 32-4$ & $1 / 15 / 92$ & 8010K6 & & & 10.00 vo & \\
\hline $299-E 32-4$ & $1 / 15 / 92$ & $8010 \times 8$ & & $30.00 \mathrm{U}$ & & \\
\hline $299-E 32-4$ & $4 / 06 / 92$ & 806696 & & & 14.00 & \\
\hline 299-E32-4 & $4 / 06 / 92$ & 806697 & & $30.00 \mathrm{U}$ & & \\
\hline $299-E 32-4$ & $7 / 14 / 92$ & B07173 & & & $10.00 \mathrm{U}$ & \\
\hline $299-E 32-4$ & $7 / 14 / 92$ & B07174 & & $30.00 \mathrm{U}$ & & \\
\hline $699-40-36$ & $12 / 21 / 92$ & B07TB1 & & & 100.00 & \\
\hline $699-40-36$ & $12 / 21 / 92$ & B07T88 & & $30.00 \mathrm{U}$ & & \\
\hline $699-40-36$ & $2 / 22 / 93$ & B08717 & & & 690.00 & \\
\hline $699-40-36$ & $2 / 22 / 93$ & 808721 & & $30.00 \mathrm{U}$ & & \\
\hline $699-40-39$ & $12 / 05 / 89$ & $100008 \times 2$ & 6.00 & & & 31.00 \\
\hline $699-40-39$ & $12 / 05 / 89$ & H0000BX2 & & 7.00 & & \\
\hline $699-40-39$ & $1 / 25 / 90$ & H0000BX6 & $5.00 \mathrm{U}$ & & & 30.00 \\
\hline $699-40-39$ & $1 / 25 / 90$ & $100008 \times 6$ & & $5.00 \mathrm{U}$ & & \\
\hline $699-40-39$ & $4 / 25 / 90$ & HOOODBYO & 5.00 & & & 18.00 \\
\hline $699-40-39$ & $4 / 25 / 90$ & HOOOOBYO & & 6.00 & & \\
\hline $699-40-39$ & $7 / 08 / 91$ & H00071Y4F & & $30.00 \mathrm{U}$ & & \\
\hline $699-40-39$ & $9 / 11 / 91$ & BOOLGI & & & 20.00 & \\
\hline $699-40 \cdot 39$ & $9 / 11 / 91$ & BOOLGIF & & $30.00 \mathrm{U}$ & & \\
\hline $699 \cdot 40-39$ & $1 / 31 / 92$ & $B 01065$ & & & $24.00 \mathrm{D}$ & \\
\hline $699-40-39$ & $1 / 31 / 92$ & 801066 & & 30.00 UD & & \\
\hline $699-40-39$ & $4 / 17 / 92$ & B065P2 & & & 24.00 & \\
\hline $699-40-39$ & $4 / 17 / 92$ & B06504 & & $30.00 \mathrm{U}$ & & \\
\hline $699-40-39$ & $6 / 24 / 92$ & 806217 & & & 23.00 & \\
\hline $699-40-39$ & $6 / 24 / 92$ & B062VI & & $30.00 \mathrm{U}$ & & \\
\hline $699-40-39$ & $1 / 14 / 93$ & $8077 \times 4$ & & & $10.00 \mathrm{U}$ & \\
\hline $699-40-39$ & $1 / 14 / 93$ & $8077 \times 8$ & & $30.00 \mathrm{U}$ & & \\
\hline $699-40-40 A$ & $1 / 24 / 92$ & $801 T 62$ & & & $490.00 \mathrm{D}$ & \\
\hline $699-40-40 A$ & $1 / 24 / 92$ & $801 T 63$ & & 30.00 UD & & \\
\hline $699-40-40 \mathrm{~A}$ & $4 / 22 / 92$ & B06508 & & & 23.00 & \\
\hline
\end{tabular}


(sheet $\star *$ of $\star \star$ )

\begin{tabular}{|c|c|c|c|c|c|c|}
\hline $\begin{array}{l}\text { Well } \\
\text { Name }\end{array}$ & $\begin{array}{c}\text { Collection } \\
\text { Date }\end{array}$ & $\begin{array}{l}\text { Sample } \\
\text { Number }\end{array}$ & $\begin{array}{l}\text { VANADUM } \\
35 / \text { ppb } \\
.1\end{array}$ & $\begin{array}{l}\text { FVANADI } \\
34 / \mathrm{ppb} \\
30 /\end{array}$ & $\begin{array}{c}\text { ZINC } \\
34 / \text { ppb } \\
10 /\end{array}$ & $\begin{array}{c}21 N C \\
35 / \mathrm{ppb} \\
.1\end{array}$ \\
\hline$\cdots$ & ................. & 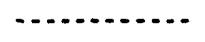 & 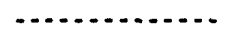 & . & - & - n. \\
\hline $699-40-40 A$ & $4 / 22 / 92$ & B065R8 & & $30.00 \mathrm{U}$ & & \\
\hline $699-40-40 A$ & $6 / 25 / 92$ & B062V2 & & & 28.00 & \\
\hline $699-40-40 A$ & $6 / 25 / 92$ & 806240 & & $30.00 \mathrm{U}$ & & \\
\hline $699-40-40 \mathrm{~A}$ & $10 / 21 / 92$ & B07JK3 & & & 20.00 & \\
\hline $699-40-40 A$ & $10 / 21 / 92$ & $807 J K 7$ & & $30.00 \mathrm{U}$ & & \\
\hline $699-40-40 \mathrm{~A}$ & $1 / 26 / 93$ & Bo7v49 & & & $10.00 \mathrm{U}$ & \\
\hline $699-40-40 \mathrm{~A}$ & $1 / 26 / 93$ & Bo7v53 & & $30.00 \mathrm{U}$ & & \\
\hline $699-40-40 B$ & $1 / 01 / 92$ & B01T65 & & 30.00 UD & & \\
\hline $699-40-40 B$ & $1 / 24 / 92$ & B01T64 & & & $1000.00 \mathrm{D}$ & \\
\hline $699-40-40 B$ & $4 / 22 / 92$ & B065s0 & & & 91.00 & \\
\hline $699-4 n-108$ & $4 / 22 / 92$ & B065S4 & & $30.00 \mathrm{U}$ & & \\
\hline $699-40-40 B$ & $6 / 29 / 92$ & B06ZW2 & & & 240.00 & \\
\hline $699-40-40 B$ & $6 / 29 / 92$ & B062166 & & $30.00 \mathrm{U}$ & & \\
\hline $699-40-40 B$ & $10 / 21 / 92$ & B07JK8 & & & 380.00 & \\
\hline $699-40-40 B$ & $10 / 21 / 92$ & B07JL2 & & $30.00 \mathrm{U}$ & & \\
\hline $699-40-40 B$ & $1 / 26 / 93$ & B07v54 & & & 420.00 & \\
\hline $699-40-40 B$ & $1 / 26 / 93$ & B07v58 & & $30.00 \mathrm{U}$ & & \\
\hline $699-41-35$ & $12 / 21 / 92$ & В07т89 & & & 20.00 & \\
\hline $699-41-35$ & $12 / 21 / 92$ & BoTTC3 & & $30.00 \mathrm{U}$ & & \\
\hline $699-41-35$ & $2 / 22 / 73$ & 808707 & & & 40.00 & \\
\hline $699-41-35$ & $2 / 22 / 93$ & B08711 & & $30.00 \mathrm{U}$ & & \\
\hline $699-41-40$ & $12 / 05 / 89$ & H0OOOD 44 & 8.00 & & & 14.00 \\
\hline $699-41-40$ & $12 / 05 / 89$ & HOOOODD 44 & & 9.00 & & \\
\hline $699-41-40$ & $1 / 25 / 90$ & HOOODD 68 & 9.00 & & & 20.00 \\
\hline $699-41-40$ & $1 / 25 / 90$ & $H 0000048$ & & 10.00 & & \\
\hline $699-41-40$ & $4 / 19 / 90$ & H0000052 & 10. n & & & 15.00 \\
\hline $699-41-40$ & $4 / 19 / 90$ & 40000052 & & 7.00 & & \\
\hline $699-41-40$ & $7 / 10 / 91$ & H00079Y1 & & & $10.00 \mathrm{U}$ & \\
\hline $699-41-40$ & $7 / 10 / 91$ & HOOOT1Y1F & & $30.00 \mathrm{U}$ & & \\
\hline $699-41-40$ & $9 / 11 / 91$ & B0OLG2 & & & 16.00 & \\
\hline $699-49 \cdot 40$ & $9 / 11 / 91$ & $800 L G 2 F$ & & $30.00 \mathrm{U}$ & & \\
\hline $699-41-40$ & $1 / 31 / 92$ & B010C8 & & & 10.00 UD & \\
\hline $699-41-40$ & $1 / 31 / 92$ & B010C9 & & 30.00 UD & & \\
\hline $699-41-40$ & $4 / 28 / 92$ & 806555 & & & $10.00 \mathrm{U}$ & \\
\hline $699-41-40$ & $4 / 28 / 92$ & B065S6 & & & $10.00 \mathrm{U}$ & \\
\hline $699-41-40$ & $4 / 28 / 92$ & B06559 & & $30.00 \mathrm{U}$ & & \\
\hline $699-41-40$ & $4 / 28 / 92$ & B065TO & & $30.00 \mathrm{U}$ & & \\
\hline $699-41-40$ & $6 / 24 / 92$ & $8062 \times 2$ & & & 17.00 & \\
\hline $699-41-40$ & $6 / 24 / 92$ & $8062 \times 6$ & & $30.00 \mathrm{U}$ & & \\
\hline $699-41-40$ & $1 / 14 / 93$ & $80 \pi 7 \times 9$ & & & $10.00 \mathrm{U}$ & \\
\hline $699-41-40$ & $1 / 14 / 83$ & Bot7Y3 & & $30.00 \mathrm{U}$ & & \\
\hline $699-41-42$ & $1 / 08 / 93$ & BOTV59 & & & $10.00 \mathrm{U}$ & \\
\hline $699-41-42$ & $1 / 08 / 93$ & B07N63 & & $30.00 \mathrm{U}$ & & \\
\hline
\end{tabular}


(sheet $\star *$ of $\star *$ )

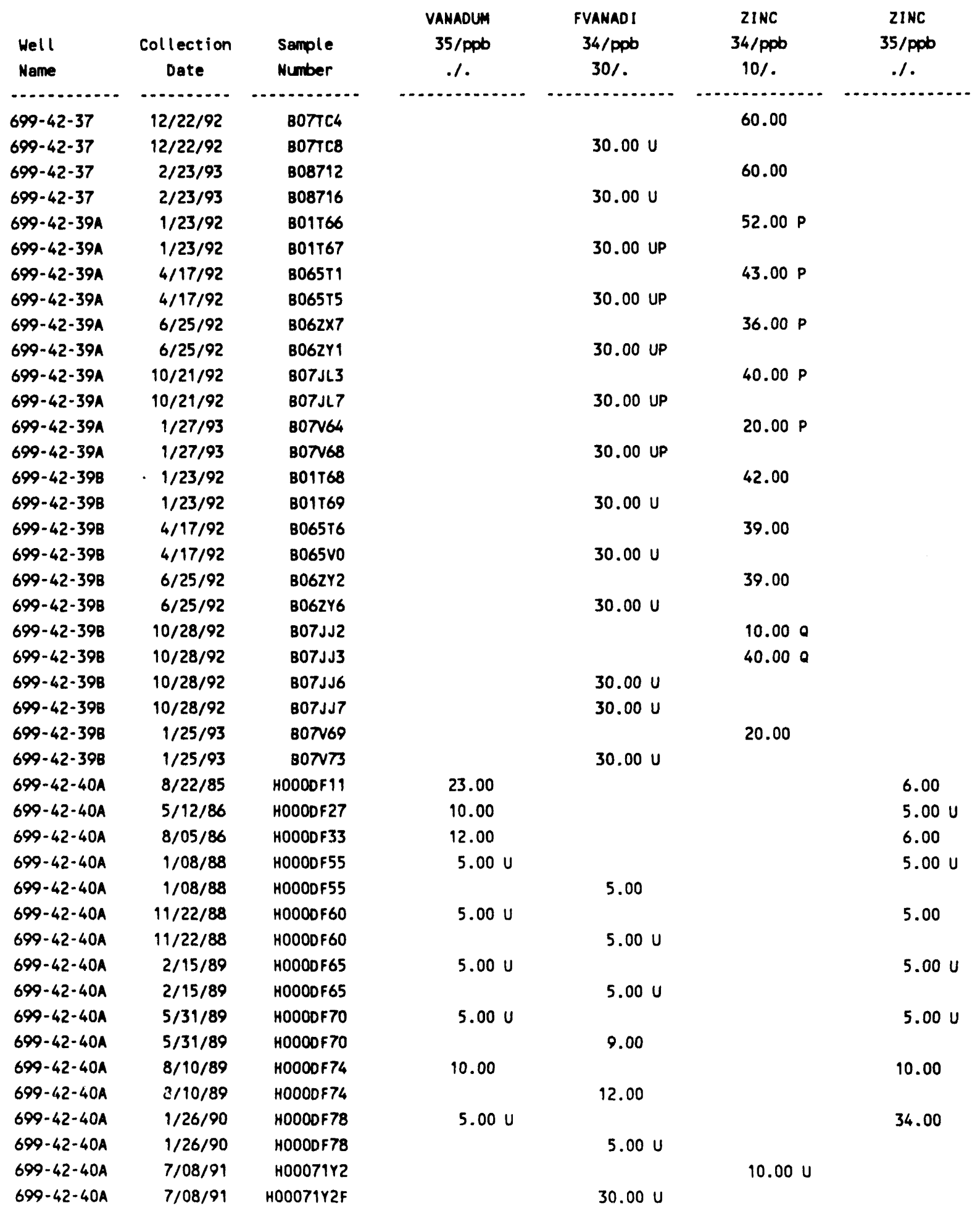


(sheet *\# of $\star$ )

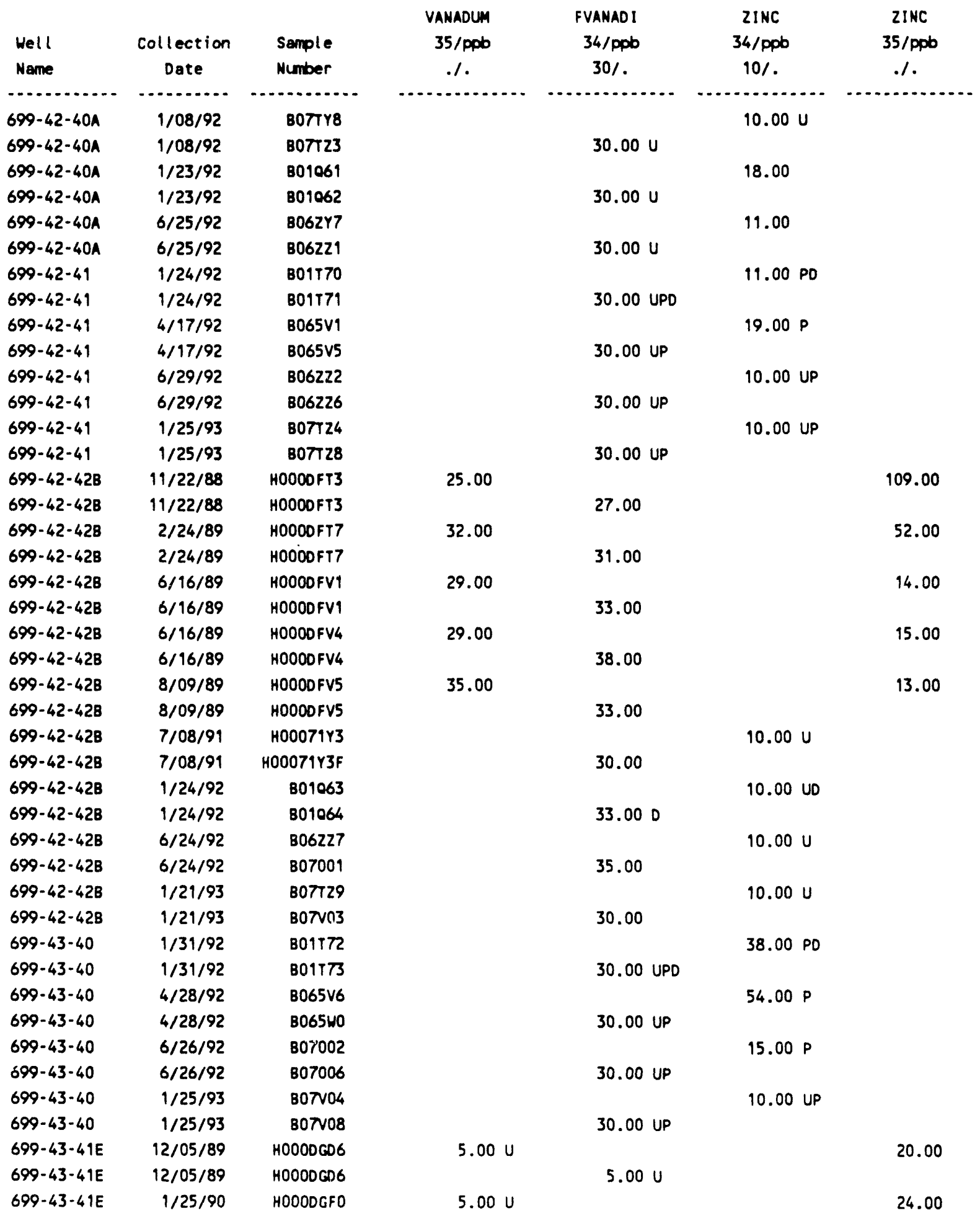


(sheet $\star *$ of $\star *$ )

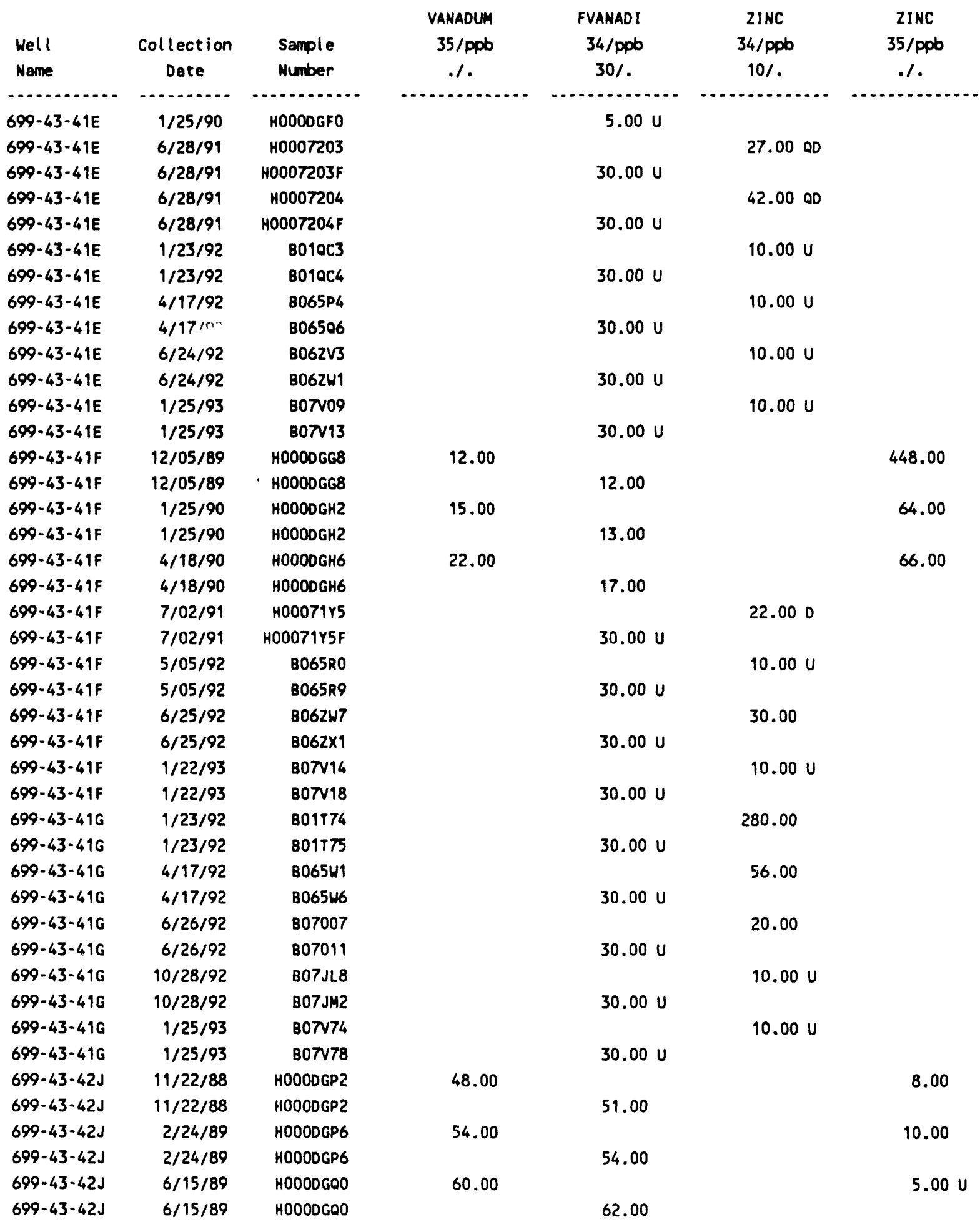


(sheet ** of *)

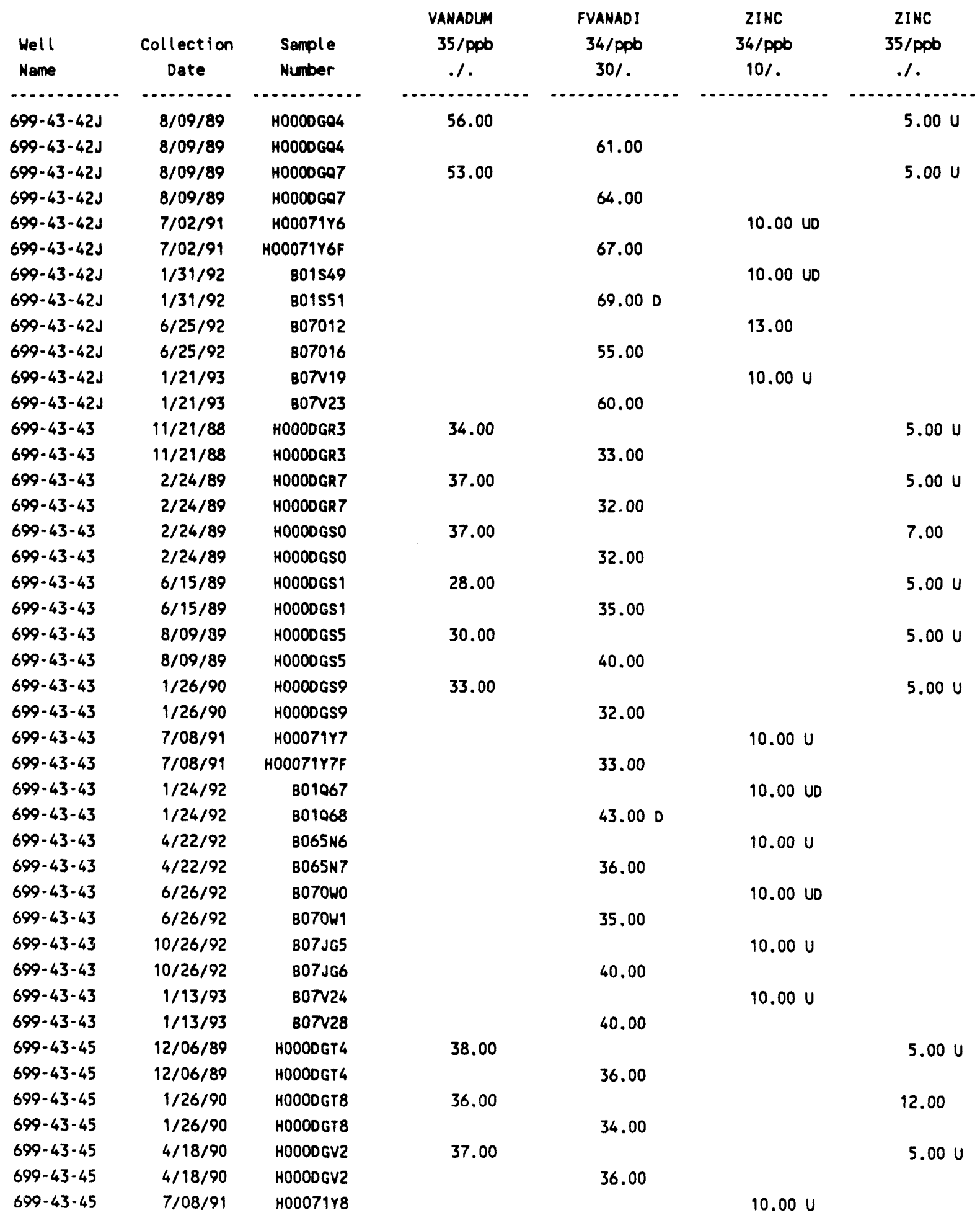


(sheet $\star$ of $\star \star$ )

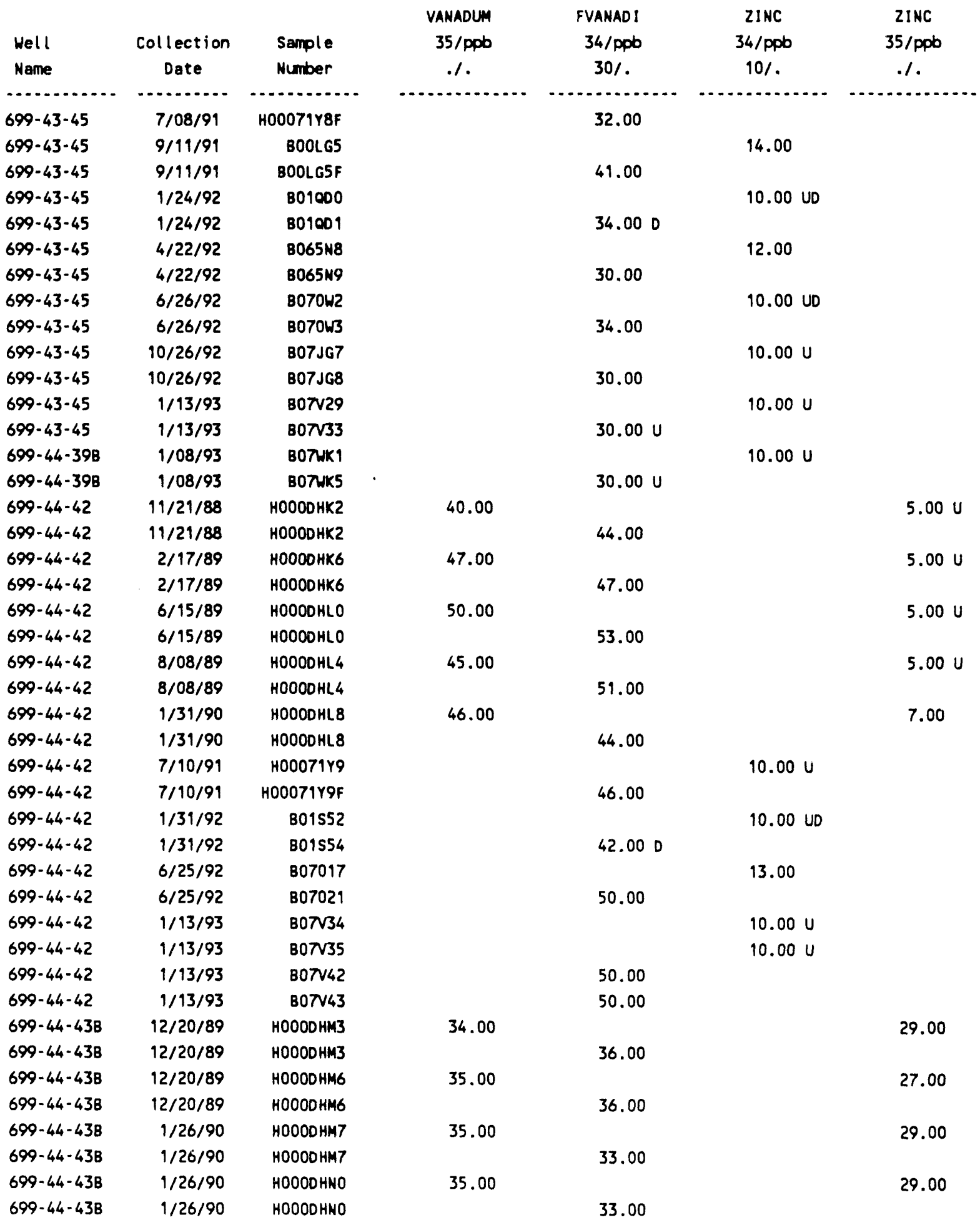


(sheet $*$ of $\star *$ )

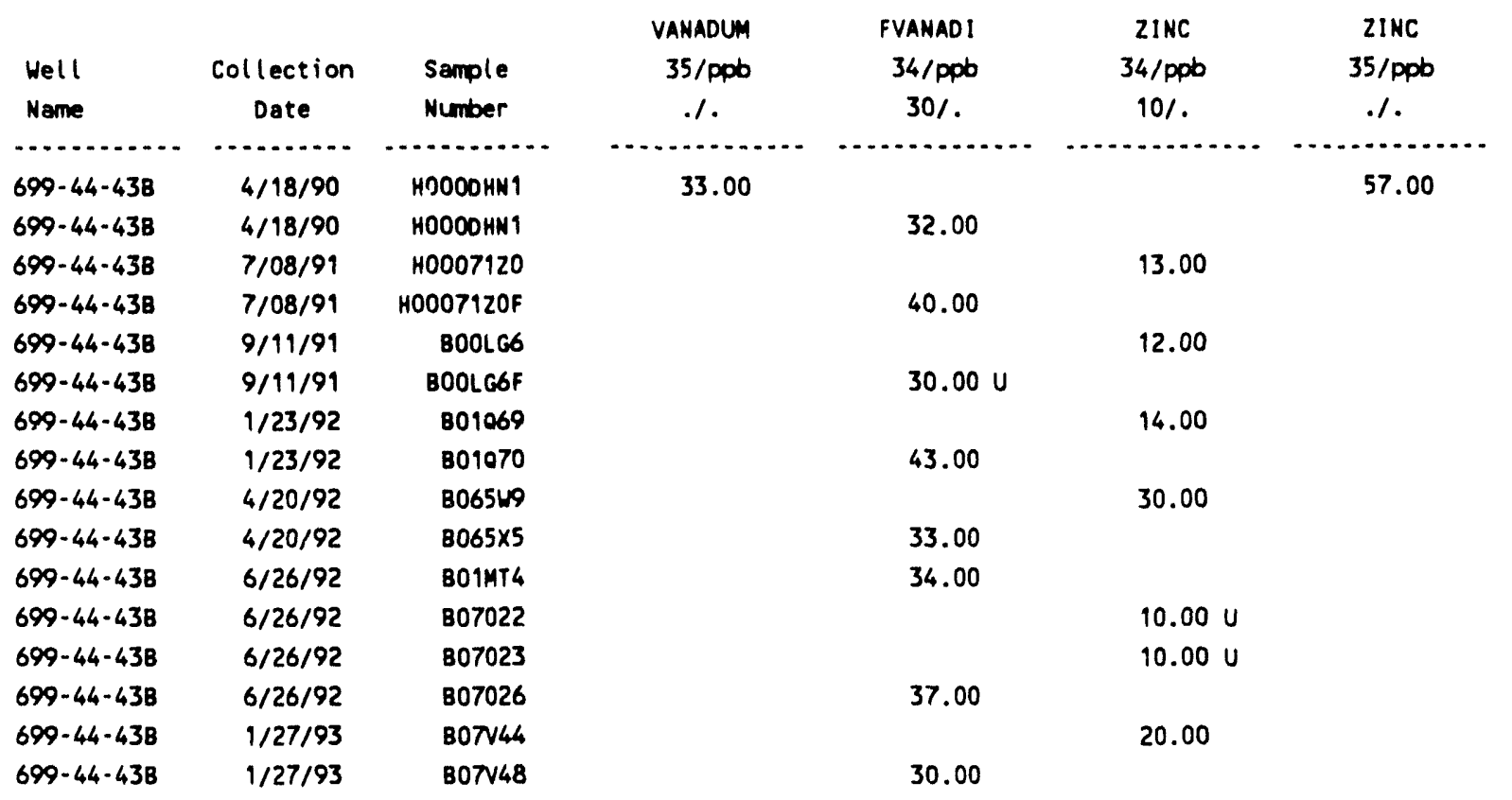

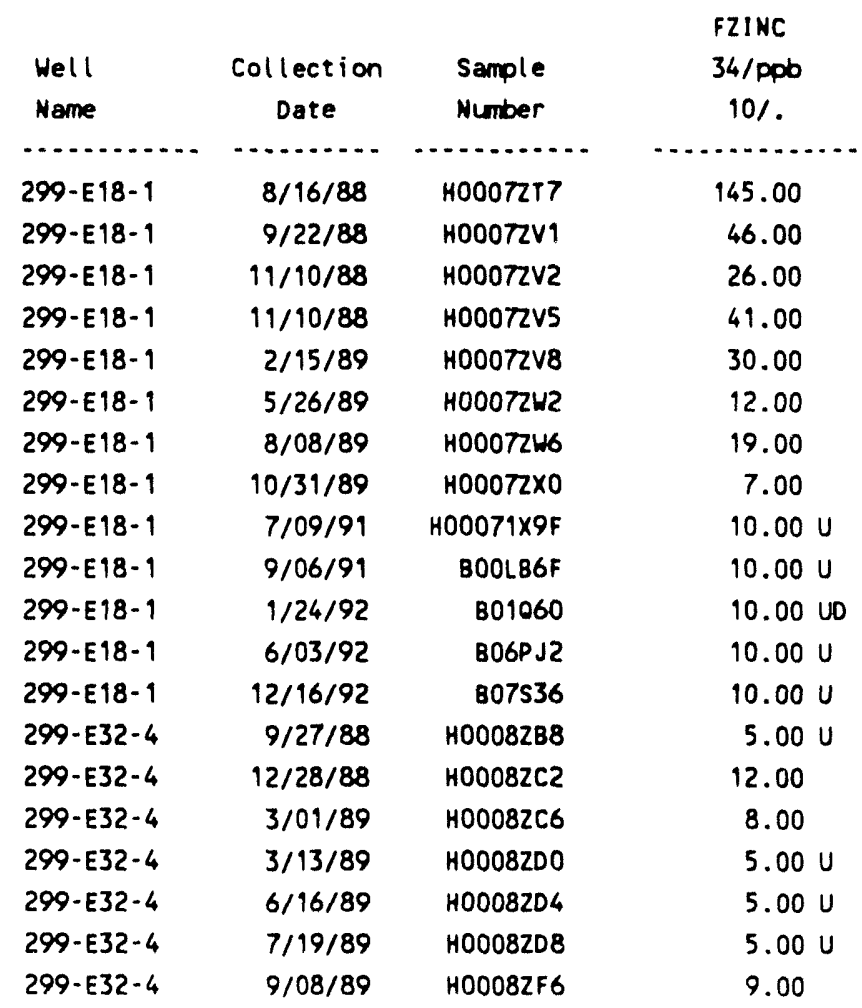


(sheet $\star \star$ of $\star \star)$

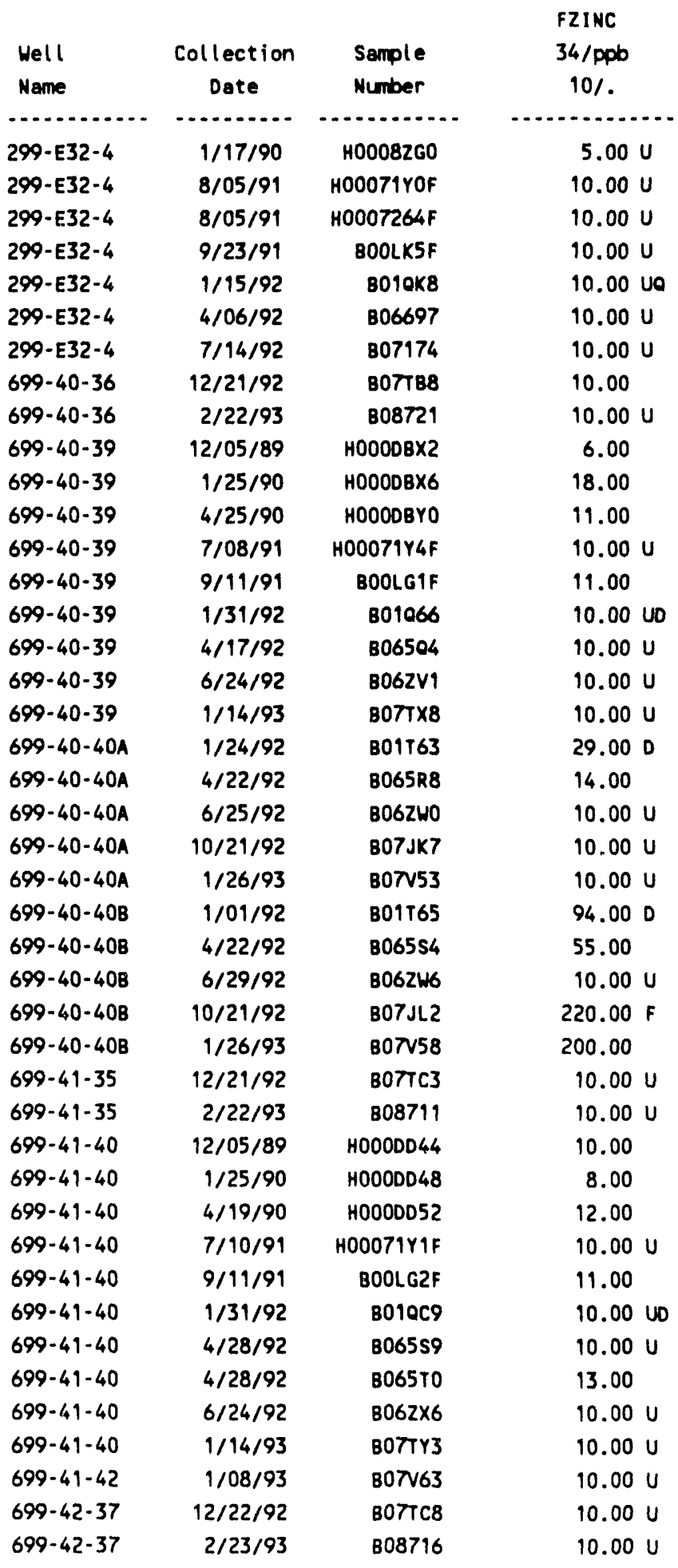


(sheet $* *$ of $*$ )

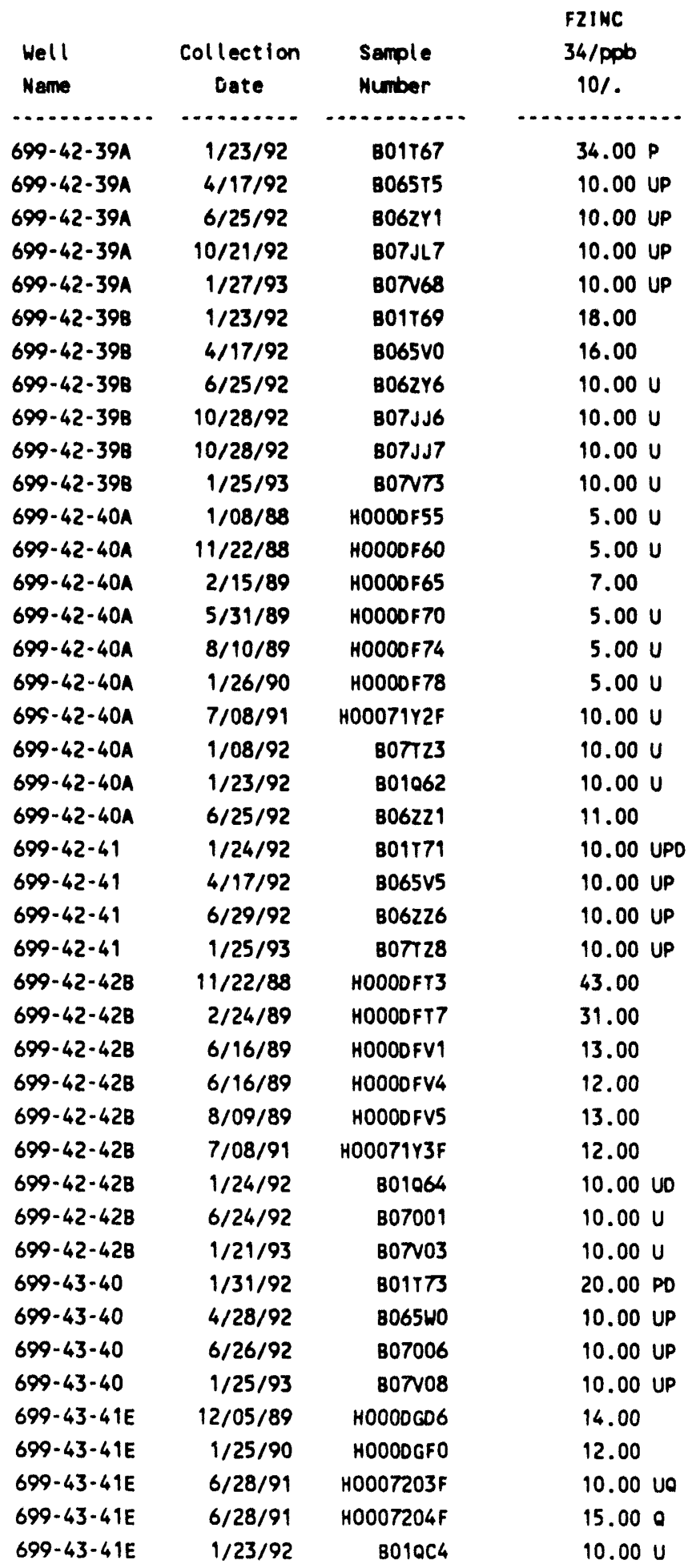


(sheet $\star \star$ of $\star \star$ )

\begin{tabular}{|c|c|c|c|}
\hline $\begin{array}{l}\text { Hell } \\
\text { Neme }\end{array}$ & $\begin{array}{c}\text { Collection } \\
\text { Date }\end{array}$ & $\begin{array}{l}\text { Sample } \\
\text { Number }\end{array}$ & $\begin{array}{c}\text { F2INC } \\
34 / \mathrm{ppb} \\
10 / .\end{array}$ \\
\hline$\cdots$ & $\cdots$ & $\cdots+\cdots$ & 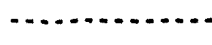 \\
\hline $699-43-41 E$ & 4/17/92 & 806506 & $10.00 \mathrm{U}$ \\
\hline $699-43-41 E$ & $6 / 24 / 92$ & B062W1 & 15.00 \\
\hline $699-43-41 E$ & $1 / 25 / 93$ & $807 v 13$ & $10.00 \mathrm{U}$ \\
\hline $699-43-41 F$ & $12 / 05 / 89$ & H0OOOGG8 & 89.00 \\
\hline $699-43-41 F$ & $1 / 25 / 90$ & HOOOOGH2 & 36.00 \\
\hline $699-43-41 F$ & $4 / 18 / 90$ & HOOODGHG & 45.00 \\
\hline $699-43-41 F$ & $7 / 02 / 91$ & H0007IY5F & 17.00 \\
\hline $699-43-41 F$ & $5 / 05 / 92$ & B065R9 & 11.00 \\
\hline $699-43-41 F$ & $6 / 25 / 92$ & $8062 \times 1$ & 11.00 \\
\hline $699-43-41 F$ & $1 / 22 / 93$ & B07N18 & $10.00 \mathrm{U}$ \\
\hline $699-43-416$ & $1 / 23 / 92$ & B01TTS & $10.00 \mathrm{U}$ \\
\hline $699-43-416$ & $4 / 17 / 92$ & B065W6 & $10.00 \mathrm{U}$ \\
\hline $699-43-410$ & $6 / 26 / 92$ & B07011 & $10.00 \mathrm{U}$ \\
\hline $699-43-41 G$ & $10 / 28 / 92$ & B07JM2 & $10.00 \mathrm{U}$ \\
\hline $699-43-416$ & $1 / 25 / 93$ & BoTV78 & $10.00 \mathrm{U}$ \\
\hline $699-43-42 \mathrm{~J}$ & $11 / 22 / 88$ & HOOOOGPZ & 8.00 \\
\hline $699-43-42 \mathrm{~J}$ & $2 / 24 / 89$ & HOOOOGPG & $5.00 \mathrm{U}$ \\
\hline $699-43-42 \mathrm{~J}$ & $6 / 15 / 89$ & HOOOOGOO & $5.00 \mathrm{U}$ \\
\hline $699-43-42 \mathrm{~J}$ & $8 / 09 / 89$ & HOOOOGO4 & $5.00 \mathrm{U}$ \\
\hline $699-43-42 \mathrm{~J}$ & $8 / 09 / 89$ & H0OODGO7 & $5.00 \mathrm{U}$ \\
\hline $699-43-42 \mathrm{~J}$ & $7 / 02 / 91$ & H00071Y6F & $10.00 \mathrm{U}$ \\
\hline $699-43-42 \mathrm{~J}$ & $1 / 31 / 92$ & 801551 & $10.00 \mathrm{vo}$ \\
\hline $699-43-42 \mathrm{~J}$ & $6 / 25 / 92$ & 807016 & $10.00 \mathrm{U}$ \\
\hline $699-43-42 \mathrm{~J}$ & $1 / 21 / 93$ & Borv23 & $10.00 \mathrm{U}$ \\
\hline $699-43-43$ & $11 / 21 / 88$ & H0OODGR3 & $5.00 \mathrm{U}$ \\
\hline $699-43-43$ & $2 / 24 / 89$ & HOOODGR7 & $5.00 \mathrm{U}$ \\
\hline $699-43-43$ & $2 / 24 / 89$ & HOOODGSO & $5.00 \mathrm{U}$ \\
\hline $699-43-43$ & $6 / 15 / 89$ & H0OOOGS1 & $5.00 \mathrm{U}$ \\
\hline $699-43-43$ & $8 / 09 / 89$ & H0000GS5 & $5.00 \mathrm{U}$ \\
\hline $699-43-43$ & $1 / 26 / 90$ & HOOODGS9 & $5.00 \mathrm{U}$ \\
\hline $699-43-43$ & $7 / 08 / 91$ & H00071Y7F & 58.00 \\
\hline $699-43-43$ & $1 / 24 / 92$ & $B 01068$ & 10.00 UD \\
\hline $699-43-43$ & $4 / 22 / 92$ & B065N7 & $10.00 \mathrm{U}$ \\
\hline $699-43-43$ & $6 / 26 / 92$ & BO70W1 & $10.00 \mathrm{U}$ \\
\hline $699-43-43$ & $10 / 26 / 92$ & $807 J 66$ & $10.00 \mathrm{U}$ \\
\hline $699-43-43$ & $1 / 13 / 93$ & B07v28 & $10.00 \mathrm{U}$ \\
\hline $699-43-45$ & $12 / 06 / 89$ & HOOODGT4 & $5.00 \mathrm{U}$ \\
\hline $699-43-45$ & $1 / 26 / 90$ & HOOODGT8 & $5.00 \mathrm{U}$ \\
\hline $699-43-45$ & $4 / 18 / 90$ & HOOODGV2 & $5.00 \mathrm{U}$ \\
\hline $699-43-45$ & $7 / 08 / 91$ & H00071Y8F & $10.00 \mathrm{U}$ \\
\hline $699 \cdot 43-45$ & $9 / 11 / 91$ & BOOLGSF & $10.00 \mathrm{U}$ \\
\hline $699-43-45$ & $1 / 24 / 92$ & 801009 & 10.00 vo \\
\hline $699 \cdot 43-45$ & $4 / 22 / 92$ & B065N9 & $10.00 \mathrm{U}$ \\
\hline
\end{tabular}


(sheet $\star \star$ of $* \star$ )

\begin{tabular}{|c|c|c|c|}
\hline $\begin{array}{l}\text { Hell } \\
\text { Neme }\end{array}$ & $\begin{array}{c}\text { Collection } \\
\text { Date }\end{array}$ & $\begin{array}{l}\text { Sample } \\
\text { Number }\end{array}$ & $\begin{array}{c}\text { F2INC } \\
34 / \mathrm{ppb} \\
10 /\end{array}$ \\
\hline 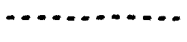 & $\ldots$ & n. & $\ldots$ \\
\hline $699-43-45$ & $6 / 26 / 92$ & B070w3 & $10.00 \mathrm{U}$ \\
\hline $699-43-45$ & $10 / 26 / 92$ & BO7JG8 & $10.00 \mathrm{U}$ \\
\hline $699-43-45$ & $1 / 13 / 93$ & Bo7v33 & $10.00 \mathrm{U}$ \\
\hline $699-44-398$ & $1 / 08 / 93$ & BOTUK5 & $10.00 \mathrm{U}$ \\
\hline $699-44-42$ & $11 / 21 / 88$ & HOOOOHK2 & $5.00 \mathrm{U}$ \\
\hline $699-44-42$ & $2 / 17 / 89$ & HOOOOHK 6 & $5.00 \mathrm{U}$ \\
\hline $699-44-42$ & $6 / 15 / 89$ & HOOOOHLO & $5.00 \mathrm{U}$ \\
\hline $699-44-42$ & $8 / 08 / 89$ & HOOOOHL 4 & 16.00 \\
\hline $699-44-42$ & $1 / 31 / 90$ & HOOOOHL 8 & $5.00 \mathrm{U}$ \\
\hline $699-44-42$ & $7 / 10 / 91$ & Ho0071Y9F & $10.00 \mathrm{U}$ \\
\hline $699-44-42$ & $1 / 31 / 92$ & B01554 & $10.00 \mathrm{vo}$ \\
\hline $699-44-42$ & $6 / 25 / 92$ & B07021 & $10.00 \mathrm{U}$ \\
\hline $699-44-42$ & $1 / 13 / 93$ & BOTV42 & $10.00 \mathrm{U}$ \\
\hline $699-44-42$ & $1 / 13 / 93$ & B07N43 & $10.00 \mathrm{U}$ \\
\hline $699-44-438$ & $12 / 20 / 89$ & H0OОOHMЗ & 44.00 \\
\hline $699-44-438$ & $12 / 20 / 89$ & HОOOOHMG & 25.00 \\
\hline $699-44-43 B$ & $1 / 26 / 90$ & HООООНМ7 & 16.00 \\
\hline $699-44-43 B$ & $1 / 26 / 90$ & НООООНNO & 20.00 \\
\hline $699-44-43 B$ & $4 / 18 / 90$ & H0OOOHN1 & 21.00 \\
\hline $699-44-43 B$ & $7 / 08 / 91$ & Ho00712OF & 20.00 \\
\hline $699-44-43 B$ & $9 / 11 / 91$ & BOOLG6F & $10.00 \mathrm{U}$ \\
\hline $699-44-43 B$ & $1 / 23 / 92$ & 801070 & 20.00 \\
\hline $699-44-43 B$ & $4 / 20 / 92$ & $B 065 \times 5$ & $10.00 \mathrm{U}$ \\
\hline $699-44-43 B$ & $6 / 26 / 92$ & B01MT4 & $10.00 \mathrm{U}$ \\
\hline $699-44-43 B$ & $6 / 26 / 92$ & 807026 & $10.00 \mathrm{U}$ \\
\hline $699-44-43 B$ & $1 / 27 / 93$ & B07N48 & $10.00 \mathrm{U}$ \\
\hline
\end{tabular}

For explanation of this table, see Section 1.4 of report. 
DOE/RL 89-28, Rev. 1

$12 / 15 / 93$

\section{APPENDIX C}

216-B-3 POND SYSTEM PHASE 1 SOIL AND SEDIMENT SAMPLING 
DOE/RL 89-28, Rev. 1

$12 / 15 / 93$

This page intentionally left blank. 


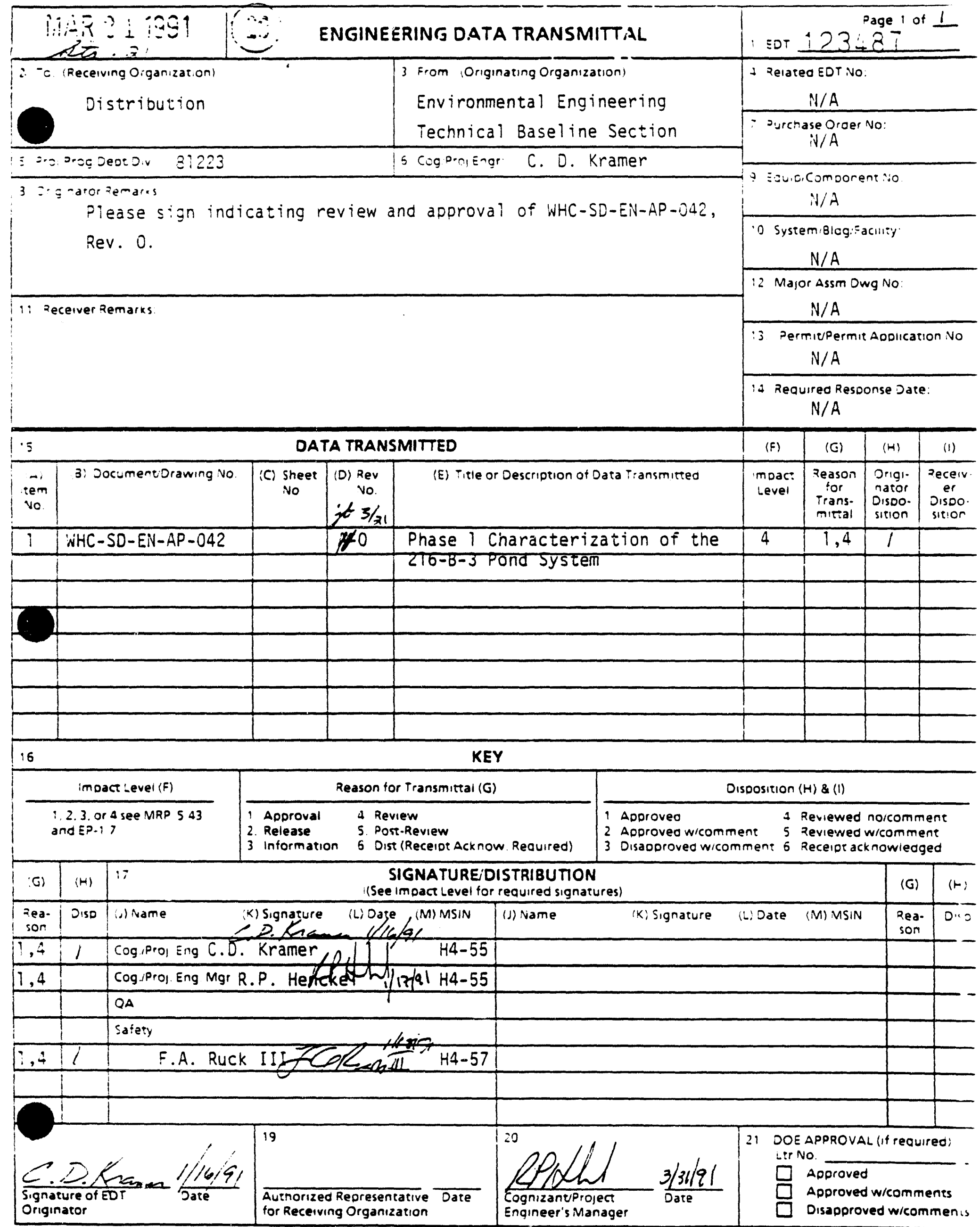




\title{
INSTRUCTIONS FOR COMPLETION OF THE ENGINEERING DATA TRANSMITTAL
}

\author{
(USE BLACY INK OR TYDE)
}

\begin{tabular}{|c|c|}
\hline BLOCK & TITLE \\
\hline 19 & EDT \\
\hline (2) & Oo (Receivino Organiza:ion) \\
\hline (3) & $\begin{array}{l}\text { From: Orginating } \\
\text { Organization }\end{array}$ \\
\hline (4) & Related EDT \\
\hline$(5)^{*}$ & $\begin{array}{l}\text { Prolect/Program/ } \\
\text { Dept/Div }\end{array}$ \\
\hline (6) & $\begin{array}{l}\text { Cognizant Proiect } \\
\text { Engineer }\end{array}$ \\
\hline (7) & Purchase Order No \\
\hline$(8)^{*}$ & Originator Remarks \\
\hline (9) & Equ:pment/Component No \\
\hline$(: 0)$ & System/Bido /Facility \\
\hline$(\because)$ & Recelver Remarks \\
\hline$(i 2)$ & Major Assm Dwg No \\
\hline$(: 3)$ & Dermie/Permit Applicarion No \\
\hline (14) & Required Response Date \\
\hline
\end{tabular}

(15)* Data Trarsmitred

(A)" Item Number
(B)" Document
Drawing No
(C)" Sheet No
(D)" Rev No
(E) Title or Descridtion of
Data Transmitted
(F) Impact Level
(G) Reason for Submitral
(H) Originator DisDosition
(I) Receiver Disposition

(16) Key

- Enter the assigned EDT numbe.

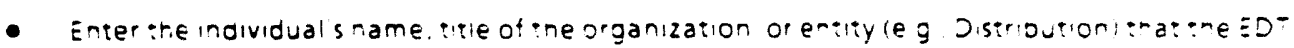
is being :ransmittec :0

- Enter the title of the organization originating anc transmiting ine EDT

- Enter EDT numbers whicn relate to ine cata deing transmitrec

- Enter the Project/Program/Department/Division title or Project/Program acronym or Drojec: Number Work Order Number or Organization Code

- Enter the name of the individual identified as being responsible for coordinating disposition of the EDT

- Enter related Purchase Order ( $P$ ) Number, if avaliable

- Enter special or additional comments concerning transmitta or "Key" retrieval worcs may de entered

- Enter equidment/component number of affected item if aporodriate

- Enter approprlate system. building or tacility number, if appropriate

- Enter special or additional comments concerning transmittal

- Enter applicable drawing number of major assembly, if appropriate.

- Enter applicable permit or permit application number, if appropriate

- Enter the date a response is requirent from individuals identified in Block 17 (Signature/Distribution)

- Enter sequential number, beginning with 1, of the information listed on EDT

- Enter the unique identification number assigned to the document or orawing being transmitted

- Enter the sheet number of the information being transmirted if no sheet number, leave olar

- Enter the revision number of the information being transmitted. If no revision number, leave blank

- Enter the title of the document or drawing or a brief description of the subject it no titie is identified.

- Enter the appropriate Impact Level (Block 15) Use NA for non-engineering documents

- Enter the appropriate code to identify the purpose of the data transmitial (see Block 16)

- Enter the appropriate disposition code (see Block 16)

- Enter the appropriate disposition code (see Block 16)

- Number cooes used in completion of Blocks $15(G),(H)$, and $(1)$, and $: 7(G),(H)$ (Signature/Distrioution)

(17) Signature/Distribution

(G) Reason
(H) Disposition
(J) Name
(L) Date
(M) MSIN

(18) Signature of EDT Originator

(9) Autnorized Representative OorReceiving Organizarion

(20)* Cognizantiprojec Manager

(21) DOE Approval

- Enter the code of the reason for transmittal (Block 16)

- Enter the code for the disposition (Block 16)

- Enter the signature of the individual completing the Disposition 17(H)iand ine Transmitta

- Enter date signature is obtained

- Enter MSIN Note: if Distribution Sheet is used, show entire distribution (including that indicated on Page 1 of the EDT) on the Distribution Sheet

- Enter the signature and date of the individual originating the EDT (entered prior to transmittal to Receiving Organization) if the EDT originator is the Cognizant/Project Engineer, sign dotn Blocks 17 and 18

- Enter the signature and date of the individual identified by the Receiving Organization as authorized:0 aporove 0isDos:ion of ine EDT and acceptance of the data :ransmirec. as applicade

- Enter the signature and date of the Cognizant,project Engineers manager (This signature is authorization for release ;

- Enter DOE approval (if required) by letter number and indicate DOE acrion

- Asterisk denote the requireo minimum items checked by Engineering Document Control prior to release; these are the minimum release requirements 
SUPPORTING DOCUMENT

1. Total Pages

2. Title

Phase I Characterization of the 216-8-3 Pond System

5. Key Woras 216-B-3 Pond Closure, 8 Pond, Phase I

Characterization, Soil, Sediment, RCRA

\begin{tabular}{|c|c|}
\hline $\begin{array}{l}\text { 3. Number } \\
\text { WHC-SD } E N-A P-042\end{array}$ & 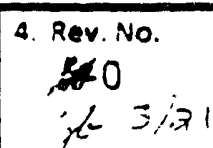 \\
\hline
\end{tabular}

6. Autnor

C. D. Kramer

Name (Type or Princ)

signature P Kanes

$81223<\equiv K^{2}, R_{1}$

Organizationicharge Code

7. Abstract

The 216-B-3 Pond System is undergoing closure as a Resource Conservation and Recovery Act of 1976 treatment, storage, or disposal unit. Characterization of the soil and sediment of the facility is being performed in a phased approach. Phase 1, reported herein, involved sampling nearsurface soil and sediment. Organic constituents of interest were not found in meaningful quantities. The appropriateness and knowledge of background is limited to clearly define inorganic pollution on this basis alone. Background soil composition in the undisturbed native area surrounding the facility was different than an adjacent unused Contingency Pond. Many analytes exceed threshold values derived from the native background, but not those derived from the excavated Contingency Pond area. Reference to typical soil concentrations suggests lead, mercury, and cadmium are the most significant observations greater than their threshold values. Even these are far below hazardous levels as defined by the characteristic of extraction procedure toxicity. The data suggest that the soil or sediment at any sampled location would not be classified as dangerous waste under current Washington

Administrative Code 173-303, Dangeroos Waste Regulations.

PURPOSE AND USE OF DOCUMENit This Jocument was Dreafed for use within

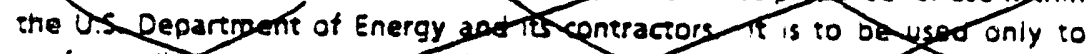

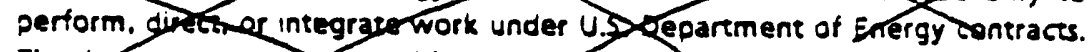
This decument is not aspoved for publicrelease until reviewed.

PATSET STATUS - This docynnent copy, since $y$ is transmitted in adannce of patent cleacence. is made urailable in contigencesojely sor use in pertermance Wh of work onder togtrags wrth the U.S. Deporment of Energy. This docubent is 7 not tobe published.tor is contents otyerwise disseminated f used for purpores i orger than speghed above before patent approval foy buch reledre or use has been secucod. upon request. flom the U.S. Degartment of Energy, Patent Attorney, Richland Operations OHfice, Richland, WA.

DISCLAIMER - This report was prepared as an account of work sponsored by an agency of the United States Government. Nesther the United States Government nor any agency thereof, nor any of their employees, nor any of their contraciors, subcontractors or their employees. makes any warranty, express or implied. or assumes any legal liability or responsibility for the accuracy, completeness, or any chird party's use or the results of such use of any information, apparatus. product, or process disclosed. or represents that its use would not infringe privately owned rights. Reference herein to any specific commercial product. process, or service by trade name, trademark, manufacturer, or otherwise, does not necessarity constitute or imply its endorsement, recommendation. or favoring by the United States Government or any agency thereof of its contraceors or subcontraciors. The views and opinions of authors expressed herein do not recessarily state or reflec :hose of the United States Government or any agency thereof.

9. Impact Level

A.
$: 0$

R.P. Henckel

Auzhorized Mankger's Name (Type or Print)

Authorized

Authorized Manager's Signature

Spesify Oistribution Limit ExTExilitL

11

RELEASE STAMP

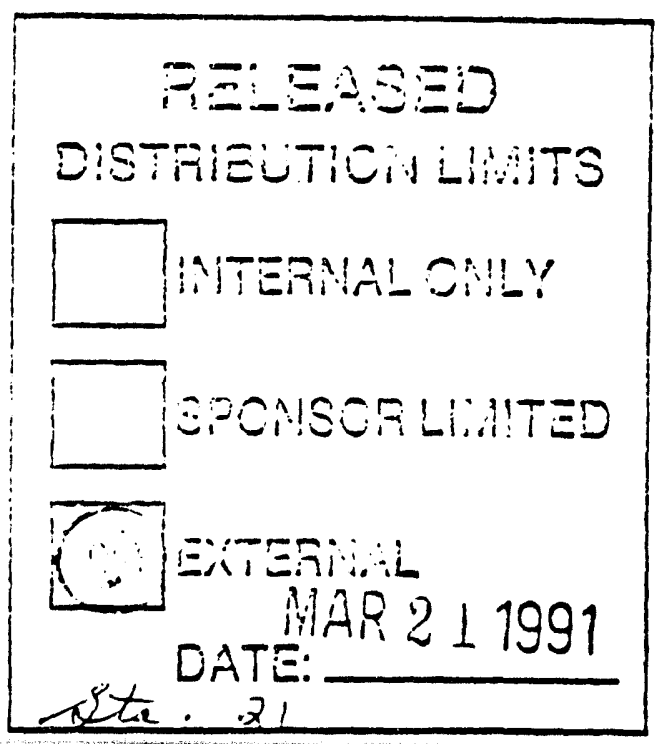




\section{SUPPORTING DOCUMENT COVER SHEET COMPLETION INSTRUCTIONS}

i. TOTALPAGES Sheet. - Enter total page count, including the Supporting Document Cover

2. TTLE - Enter the title of the Supporting Document to be released.

3. NUMBER - Enter the unique document identification number obtained from Engineering Document Control.

4. REV. NO. - Enter the current revision number of the Supporting Document to be released.

5. KEY WORDS - Enter specific words that are input to a database that will aid in future retrieval of the document, e.g., project, task, selected words from the title, etc.

6. AUTHOR - Enter the printed/typed name of the Supporting Document author, his signature, the author's organization code, and charge code (if different from the organization code).

7. ABSTRACT - Enter a brief summary of the document content.

8. CAVEATS - Reminders to the user(s) and those on distribution that the Supporting Document is not approved for public release until proper reviews/approvals have been obtained.

9. IMPACT LEVEL - Enter the applicable Impact Level for the Supporting Document. Reference MRP 5.43 and EP-1.7.

10. AUTHORIZED MANAGER - Enter the name and signature of the individual identified as being responsible for the in-process classification/sensitive information review. The Authorized Manager indicates the appropriate distribution limit on the line provided.

11. RELEASE STAMP - The release/distribution limits stamp is affixed by Engineering Document Control to certify that the Supporting Document is approved for the intended use, is cleared for the appropriate distribution indicated, and is accountable and retrievable. 
WHC-SD-EN-AP-042, REV. 0

\section{CONTENTS}

1.0 INTRODUCTION

1.1 BACKGROUND

1.2 SETTING

2.0 PRESAMPLING ACTIVITIES . . . . . . . . . . . . . . . . . 5

2.1 OBJECTIVES . . . . . . . . . . . . . 5

2.2 SITE GRID AND ALLOCATION FOR SOIL/SEDIMENT SAMPLING . . . . . . . . 5

2.3 EQUIPMENT PREPARATION ................... 6

2.4 SITE EXPLORATION ...................... . . 8

3.0 SAMPLING SOILS/SEDIMENTS . . . . . . . . . . . . . . . . . 8

3.1 COLLECTION . . . . . . . . . . . . . . . . . 8

3.2 QUALITY ASSURANCE SAMPLES . . . . . . . . . . . . . . . . 14

3.3 REQUESTED ANALYSES . . . . . . . . . . . . . . . . . . 14

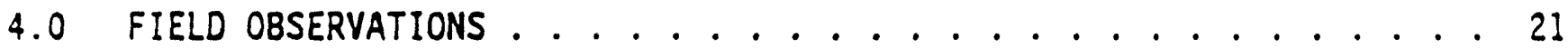

4.1 WILDLIFE . . . . . . . . . . . . . . . . . . 21

4.2 VEGETATION ......................... 21

4.3 WEATHER ............................ . 21

4.4 GEOLOGY ............................ . . 22

4.5 MISCELLANEOUS . . . . . . . . . . . . . . . . . . . . . 22

5.0 DISCUSSION OF BACKGROUND . . . . . . . . . . . . . . . . . . . . 22

6.0 COMPARISONS TO BACKGROUND . . . . . . . . . . . . . . . . . . . 24

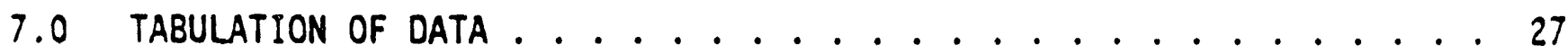

7.1 DETECTION LIMIT AND OTHER QA FLAGS . . . . . . . . . . . . . . 27

7.2 ACCURACY AND PRECISION ESTIMATES . . . . . . . . . . . . . . . 28

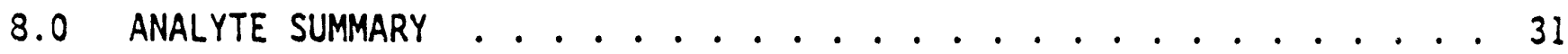

8.1 SUMMARY OF METAL ANALYSES . . . . . . . . . . . . . . . . 31

8.1.1 Cadmium . . . . . . . . . . . . . . . . 32

8.1.2 Lead .. . . . . . . . . . . . . . . . . . . . . . . 33

8.1.3 Mercury ....................... 34

8.2 IONS . . . . . . . . . . . . . . . . . . 34

8.2.1 Ammonium . . . . . . . . . . . . . . . . . . . . . 34

8.2.2 Bromide ......................... 35

8.2.3 Chloride..................... . 35

8.2.4 Cyanide ....................... . . . . 35

8.2.5 fluoride ...................... . . 35

8.2.6 Nitrate, Nitrite.................. . 35

8.2.7 Phosphate .................. . 36 
8.2.8 Sulfate .................. . . . 36

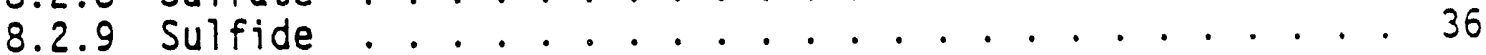

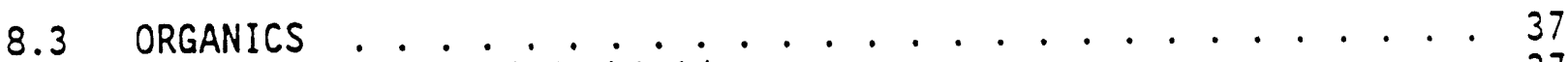

8.3.1 Chlorinated Herbicides . . . . . . . . . . . . . 37

8.3.2 Chloropesticides . . . . . . . . . . . . 37

8.3.3 Phosphorous Pesticides . . . . . . . . . . . . . 38

8.3 .4 Polychlorinated Biphenyls . . . . . . . . . . . . 38

8.3 .5 Semivolatiles ............... . . . 38

8.3 .6 Volatile organics ............. . . 39

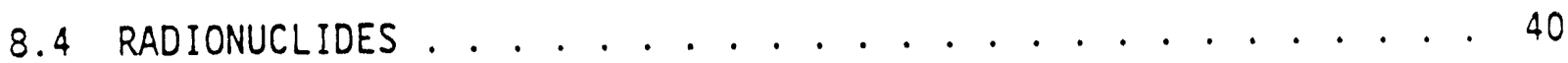

9.0 CONCLUSIONS ......................... 40

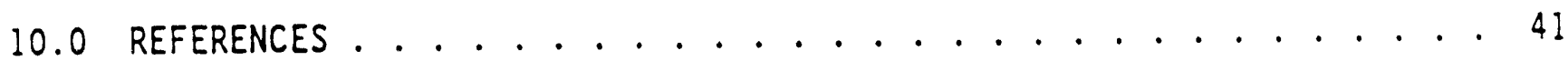

APPENDICES:

A. Observations Exceeding Background Tolerance Limit . . . . . . . A-1

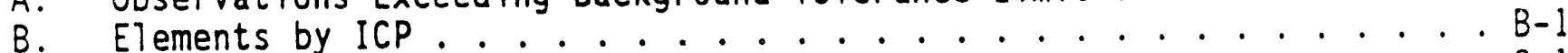

C. Selected Data Other than ICP Analyses . . . . . . . . . . . . . C-1

D. Field Duplicate Graphs .................... . D-1

\section{FIGURES:}

1. Map of the Hanford Site . . . . . . . . . . . . . . 2

2. Aerial Photograph of the 216-8-3 Pond System and

Surrounding Areas . . . . . . . . . . . . . . . . . . . . . 3

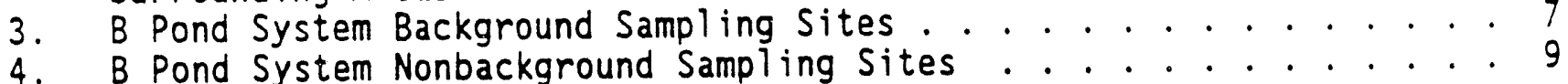

\section{TABLES:}

1. B Pond Phase l Sample Key ........ . . . . . . . . . . 10

2a. Requested Analyses, Individual Samples . . . . . . . . . 15

2b. Metals Analyses Using Methods 3050/6010 . . . . . . . . . . . . . . . 17

3. Requested Analyses, Composite Samples ............ 18

4. Shapiro-Wilk W Test for Normality $\left(W_{0.05}\right) . \ldots 26$

5. Summary of Matrix Spike/Matrix Spike Duplicate Results . . . . . . . 29

6a. Field Duplicates/Precision B Pond Phase 1 Soil/Sediment

Samples (11 Duplicate Pairs) . . . . . . . . . . . . 30

6b. Field Duplicates/Precision Water Samples (One Duplicate Pair) . . . . 31

7. Metal Concentrations in Soils ................. 33

8. Groundwater Monitoring List Metals ............... . 33

9. Semivolatile Spike Recoveries .................. 39 
WHC-SD-EN-AP-042, REV. $O$

\subsection{INTRODUCTION}

\subsection{BACXGROUND}

The 216-B-3 Pond System (hereinafter referred to as $B$ Pond) is undergoing evaluation to characterize the potential hazards that may be present in the soil and sediments. The dangerous chemical and radionuclide inventory of the soils and sediments is relatively unknown. Information gathered will assist in evaluating closure and/or remediation activities. The $B$ Pond is part of the 200-8P-11 operable unit (WHC 1989a, P A-35).

A Westinghouse Hanford Company (Westinghouse Hanford) sampling plan, 216-8-3 Pond Characterization of the Hazardous Waste Inventory in the NearSurface Soil and Sediments (Roos and Woodworth 1989), governs the characterization effort. The sampling plan sets forth a phased approach toward characterizing the soils and sediments of B Pond. Phase 1 is an initial sampling effort assessing near-surface soil contamination within the 216-8-3 Pond, the 216-8-3-3 Ditch, and the three expansion ponds (216-8-3A, $216-8-3 B$, and $216-8-3 C)$. This phase includes the estimation of background soil concentrations in the vicinity of the site. Phase 2 is to be an extension of the characterization work utilizing data and knowledge from Phase 1. Phase 3 will examine the vertical distribution of contaminants beneath the surface soil.

This document summarizes the sampling activities undertaken and the analytical results obtained in Phase I of the soil and sediment sampling of 8 Pond.

\subsection{SETIING}

The $B$ Pond is located adjacent to the 200 East Area on the Hanford Site in southeast Washington (Figure 1), is classified as a RCRA TSD unit, and for the purposes of this study, comprises the following (Figure 2):

- Open section of the 216-8-3-3 Ditch, approximately 3,700 feet

- 216-B-3 Pond (B-3 Pond), approximately 35 acres

- 216-8-3A Pond (hereinafter referred to as $3 A$ Pond), approximateiy 11 acres

- 216-B-3B Pond (hereinafter referred to as $3 B$ Pond), approximately 11 acres

- 216-8-3C Pond (hereinafter referred to as $3 C$ Pond), approximately 41 acres. 


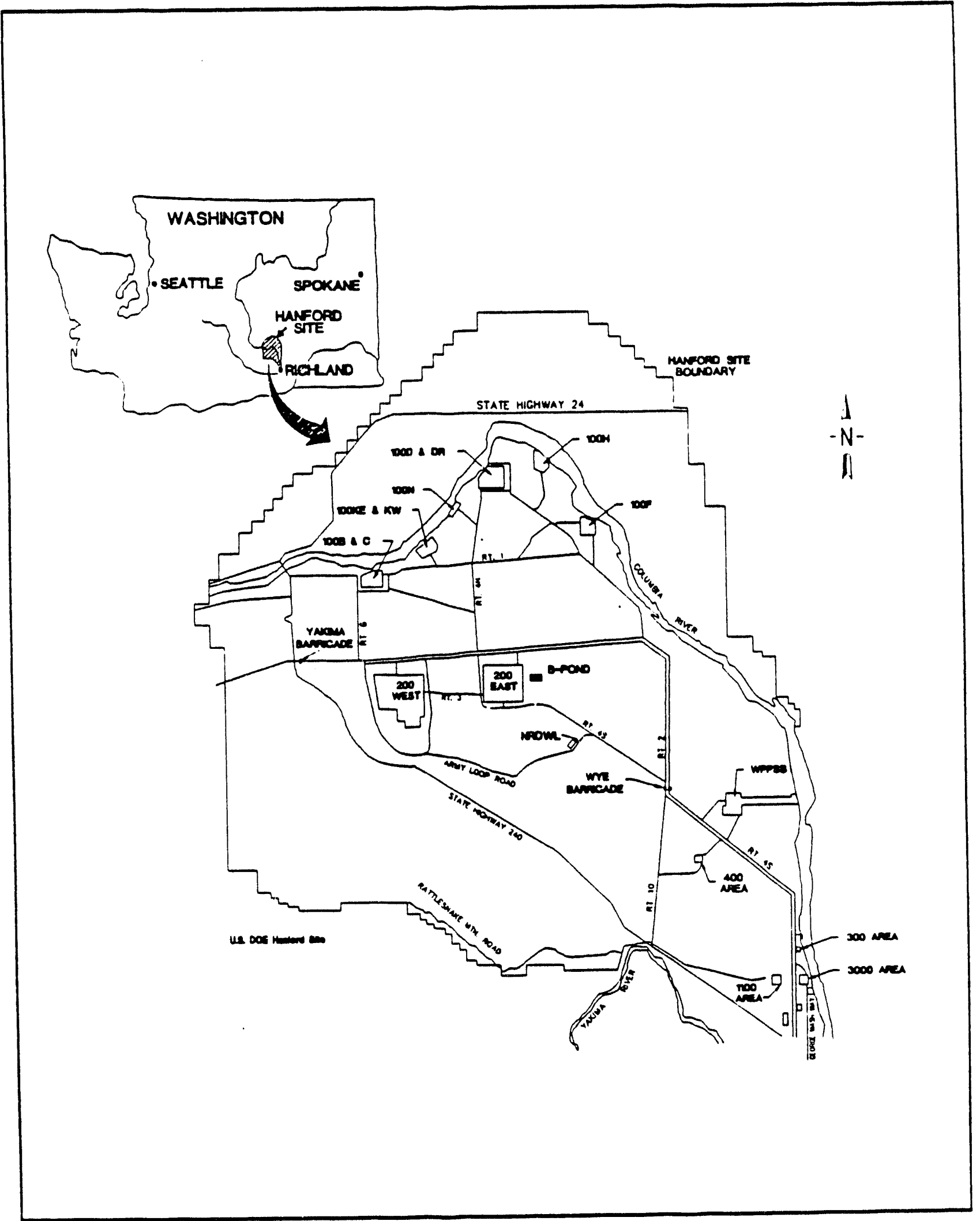

Figure 1. Map of the Hanford Site. 


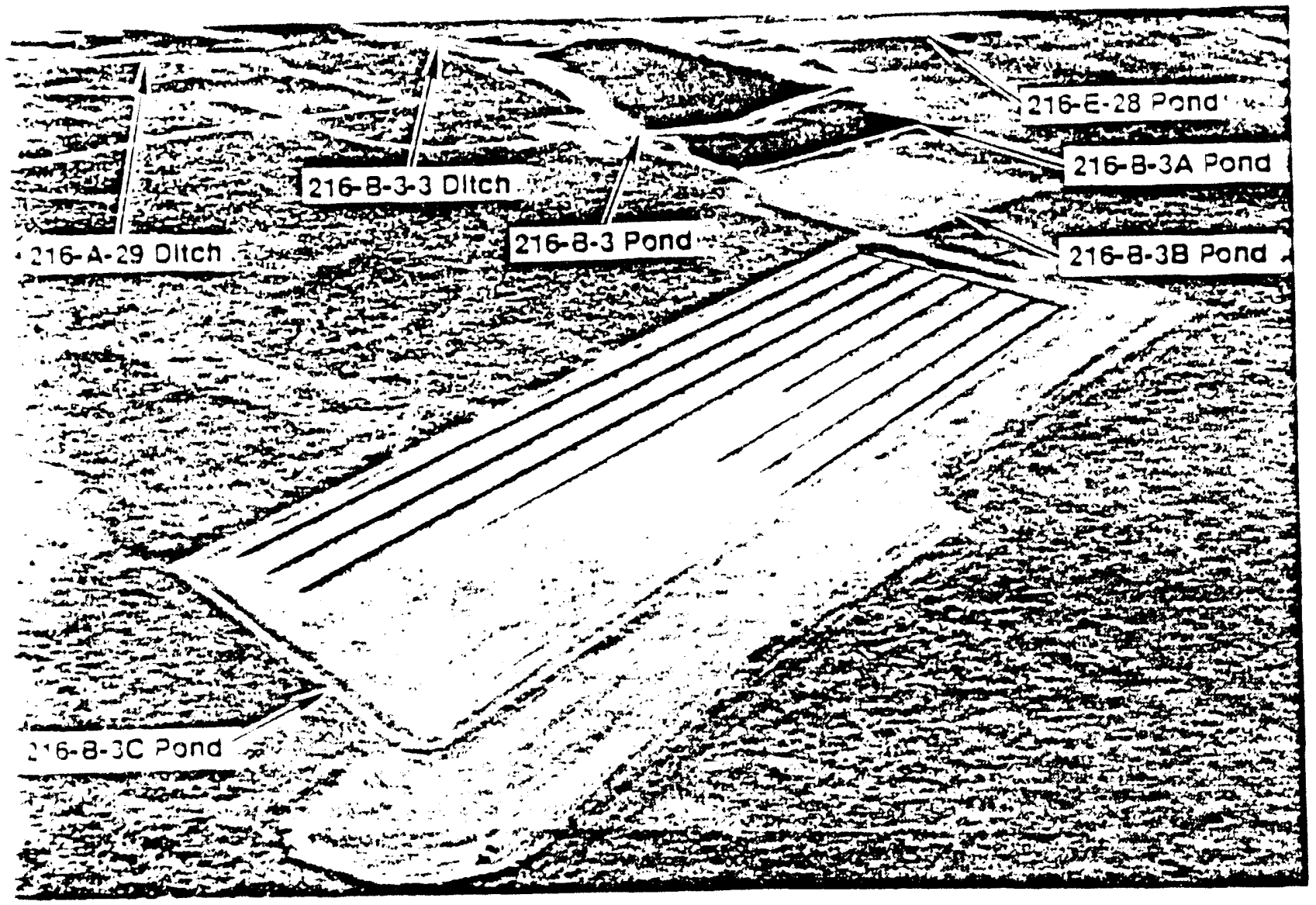

Figure 2. Aerial Photograph of the 216-8-3 Pond System and Surrounding Areas (1988). 
Water flows into the $B-3$ Pond through the 216-B-3-3 Ditch. The $B-3$ Pond and $3 A$ Pond are normally full of water. Flow to $3 A$ Pond is controlled at the east end of the B-3 Pond. Water from $3 A$ Pond can go to $3 B$ Pond or $3 C$ Pond; currently, 3B Pond is not in use. Although this document uses the term pond, the 3B Pond and the Contingency Pond (1abeled 216-E-28 Pond in Figure 2) are actually dry basins. The $3 C$ Pond has a series of eight parallel infiltration trenches into which water from $3 A$ Pond is usually channelled. The water in $3 C$ Pond has never been above the tops of the trenches, which cover a much smaller total area than the pond itself. The trenches are not usually wet along their entire length. The wet area varies with water level.

The Contingency Pond was constructed to provide emergency overflow capability for B Pond. It lies north and slightly west of the B-3 Pond. This facility was constructed in 1987. The area is dry and has not been utilized for waste disposal. Sagebrush and native plants populate the undisturbed areas around $B$ Pond. Both the unused, but man-impacted Contingency Pond area, and the area of native desert vegetation were utilized in Phase 1 as sources for background samples.

The $B$ Pond area has received liquid effluent from activities in the 200 East Area since 1945. Effluent originating within the 200 East Area flows into open ditches upon exit. This liquid effluent provides water to $B$ Pond. The B-3 Pond (sometimes referred to as the main pond) is the oldest pond in the system and contains the largest volume of water; the level of the pond and the inflow have changed with time. Originally, B-3 pond was supplied through the 216-B-3-1 Ditch. In 1964, the 216-B-3-1 Ditch was replaced by the 216-B-3-2 Ditch. In 1970, the 216-B-3-2 Ditch was replaced by the present 216-B-3-3 Ditch. Both the 216-B-3-1 and 216-B-3-2 Ditches were removed from service due to radioactive contamination and filled with soil to reduce contaminant mobility. The three expansion ponds ( $3 A$, 3B, and $3 C$ ) were placed in service in 1983, 1984, and 1985, respectively. Since taken out of service in May 1985, several feet of soil have been removed from the former $3 B$ Pond bottom in an attempt to increase percolation during future use. The material removed was piled adjacent to the B-3 Pond.

The B Pond primarily received steam condensate, cooling water, chemical sewer discharges, and process waste water. Some mixed waste has been discharged to $B$ Pond. Administrative and physical controls have been implemented to eliminate dangerous waste discharges. The B Pond is still in use for nondangerous waste water disposal and is undergoing closure in accordance with RCRA. The 216-B-3 Pond System Closure/Postclosure Plan (DOE-RL 1990) provides a broader perspective of this closure and includes chapters on process information and waste characteristics (Chapters 3-4, p 3-1 to 4-14). 
WHC-SD-EN-AP-042, REV. 0

\subsection{PRESAMPLING ACTIVITIES}

\subsection{OBJECTIVES}

The 216-8-3 Pond Systen Closure/Postclosure Plan (DOE-RL 1990, p 7-4) stated four major objectives for Phase 1 :

- Assess near-surface soil contamination within tíle B-3 Pond, 216-8-3-3 Ditch, and three expansion ponds ( $3 A, 38$, and $3 C$ )

- Estimate background values

- Identify constituents of concern

- Estimate the variability of concentrations present at the sites.

\subsection{SITE GRID AND ALLOCATION FOR SOIL/SEDIMENT SAMPLING}

Sampling sites for Phase 1 were set forth in the sampling plan document (Roos and Woodworth 1989). Reference to that document is appropriate for those desiring the rationale for site selection. The procedure utilized was intended to provide representative sample locations for each of the units of B Pond. Additionally, a small number of sites was selected because information about specific locations was also desired.

A site grid was established to assist in defining the sampling locations within each unit of interest. The perimeters of the 216-8-3 Pond, $3 A$ Pond, $3 B$ Pond, and the Contingency Pond were surveyed and staked relative to the Hanford site coordinate system.

Most sites within the TSO unit were selected randomly; the sites sampled include the following:

- Nine sites in the 216-8-3-3 Ditch

- Twenty sites in the B-3 Pond

- Seven sites in $3 A$ Pond

- Five sites in $3 B$ Pond

- Eight sites in $3 C$ Pond.

A BASIC random number generator was used to select the sample sites from among a population of grid coordinate intercepts falling within the boundaries of each unit of interest. In the B-3 Pond, a square grid system of 100-foot intervals was used. In $3 A$ and $3 B$ Ponds, the lines of the grid were set at 50 -foot intervals due to the smaller acreage. The point $N 42600$, W43600 of the Hanford Site coordinate system corresponded to 0,0 of the B-3 Pond grid. The point N42350, W41750 was the origin for the $3 A$ Pond grid, and N42250, W41100 was the origin for the $3 B$ Pond grid. Randomization in $3 A$ Pond was performed in two blocks. Three locations were randomly allocated from the trenched area, and four locations were randomly allocated from the remainder of the pond. There are eight long infiltration trenches in $3 \mathrm{C}$ Pond. In both $3 \mathrm{C}$ Pond and the 216-B-3-3 Ditch, potential sampling points were at 100-foot intervals 
in the channels. Randomization in $3 C$ Pond was restricted to one random location per ditch for a total of eight sites. These sites were referenced from the northwest end of the 2,200-foot trenches. Locations in the 216-B-3-3 Ditch were randomly allocated within two blocks. After the sampling was initiated, the scope of the project was changed with respect to the 216-B-3-3 Ditch. Sampling was extended upstream from the confluence of the 216-A-29 and 216-B-3-3 Ditches. Four locations were randomly selected from among points at 100-foot intervals in the lower section of the ditch. Five additional random samples were likewise selected from the upper section of the ditch. Locations were referenced from the confluence of the two ditches in the lower section and from the beginning of the 216-8-3-3 Ditch in the upper section.

In addition to randomily allocated sites, samples were to be collected from the following locations:

- The closest possible point to the head end of the 216-B-3-3 Ditch

- The intersection of the 216-B-3-3 and 216-A-29 ditches

- The present inlet area of the B-3 Pond

- The deepest area of the B-3 Pond.

Background samples were to be collected from two types of sites. Five representative samples were to be selected from the Contingency Pond area. This area was surveyed at 100-foot intervals, and the sampled locations were randomly selected from among the population of intercepts within the Contingency Pond. This area was selected for background sampling based on the fact that it has not received influent, is a manmade basin, and is constructed in an adjacent area and fashion. Five additional background samples were to be chosen at sites surrounding $B$ Pond. These sites were recorded in the field logbook using compass headings of several permanent landmarks. It was intended that these samples would provide information concerning the composition and variability of background soil in the area. These samples were taken from areas of native vegetation several hundred feet from the TSO. These locations all appear to be typical of the presystem environment, and were selected by professional judgement on that basis. Figure 3 shows the background sample locations.

\subsection{EQUIPMENT PREPARATION}

A sampling platform was constructed for use in the B-3 Pond and $3 A$ Pond by connecting two 14-foot, flat-bottom aluminum boats. Stainless-stee] scoopulas, spoons, bowls, shovels, and augers were prepared for use in accordance with the laboratory decontamination of field equipment specified in environmental investigation instruction (EII) 5.5, "Decontamination of Equipment for RCRA/CERCLA Sampling" (WHC 1989b). Cleaned equipment was wrapped in aluminum foil by cleaning personnel and remained wrapped until use. Precleaned sample containers were purchased and used for all samples. The containers come presealed from the manufacturer with tamper-indicating seals affixed. 


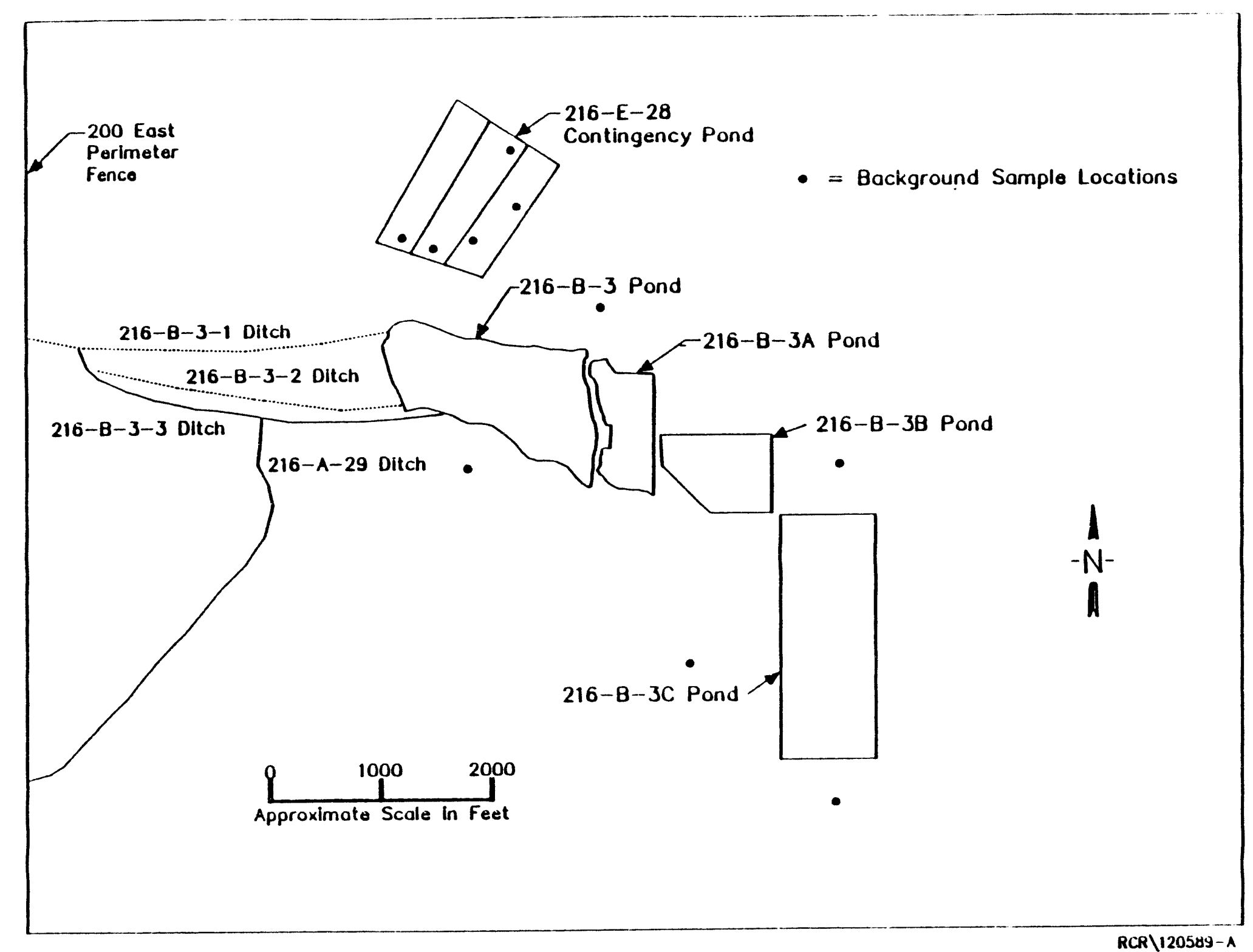

Figure 3. B Pond System Background Sampling Sites. 
WHC-SD-EN-AP-042, REV. 0

\subsection{SITE EXPLORATION}

Before sample collection in the 8-3 Pond, a survey of water and sediment depth was performed. A check of 28 points in the pond showed a maximum water depth of about 12 feet. Sediment depth was assessed by hand-forced penetration of a 0.5 -inch-diameter metal rod. The maximum penetration found was 1 foot with an average of about 4 inches. This survey was performed to provide the sampling team with some knowledge of conditions in the 35-acre B-3 Pond prior to initiating the actual sediment sample collection.

\subsection{SAMPLING SOILS/SEDIMENTS}

\subsection{COLLECTION}

Table 1 is a sample key for all samples submitted in Phase 1. The table lists sample numbers, date collected, area, coordinates, and sample type. The type category gives additional information about the sample. Replicate samples are those split into two or more portions during the measurement process. Samples from a single location, divided upon collection, and sent to the primary laboratory, are referred to as field duplicates. Split samples were those where a replicate was sent to an alternate laboratory. All samples are soil or sediment samples with the exception of the B-206 through B-211 water samples $\left(\mathrm{H}_{2} \mathrm{O}\right.$ is attached to the type designation to identify water samples). Field conditions prevented sampling at a small number of predesignated locations, so sampling was performed at the closest possible site to that predetermined point, and the new location was documented in the field log. The actual sampled location appears in Table 1 . All nonbackground sampling sites for $B$ Pond are shown in Figure 4.

Sampling was conducted between August 3 and September 21, 1989, and collection was performed in accordance with EII 5.2, "Soil and Sediment Sampling" (WHC 1989b). Personnel collecting the samples wore disposable vinyl gloves in addition to other clean protective clothing specified in the approved health and safety plan. These gloves were shed after each sample in an effort to minimize the potential for cross-contamination between samples. All sample collection tools were cleaned before use by standard procedures EII 5.5, "Decontamination of Equipment for RCRA/CERCLA Sampling" (WHC 1989b). Cleaned tools which would contact the sample material remained wrapped in aluminum foil until use. Only large stainless-steel shovels were decontaminated in the field and reused. Other equipment was decontaminated in the laboratory. Clean equipment was used at each sample collection point.

Health and Safety personnel provided and operated an HNU* photoionization detector to detect organic vapors in addition to wind velocity and wet and dry-bulb temperature monitoring. Radiation protection personnel provided monitoring of radiological conditions with Geiger-Mueller counters.

*HNU is a trademark of HNU Systems, Inc. 


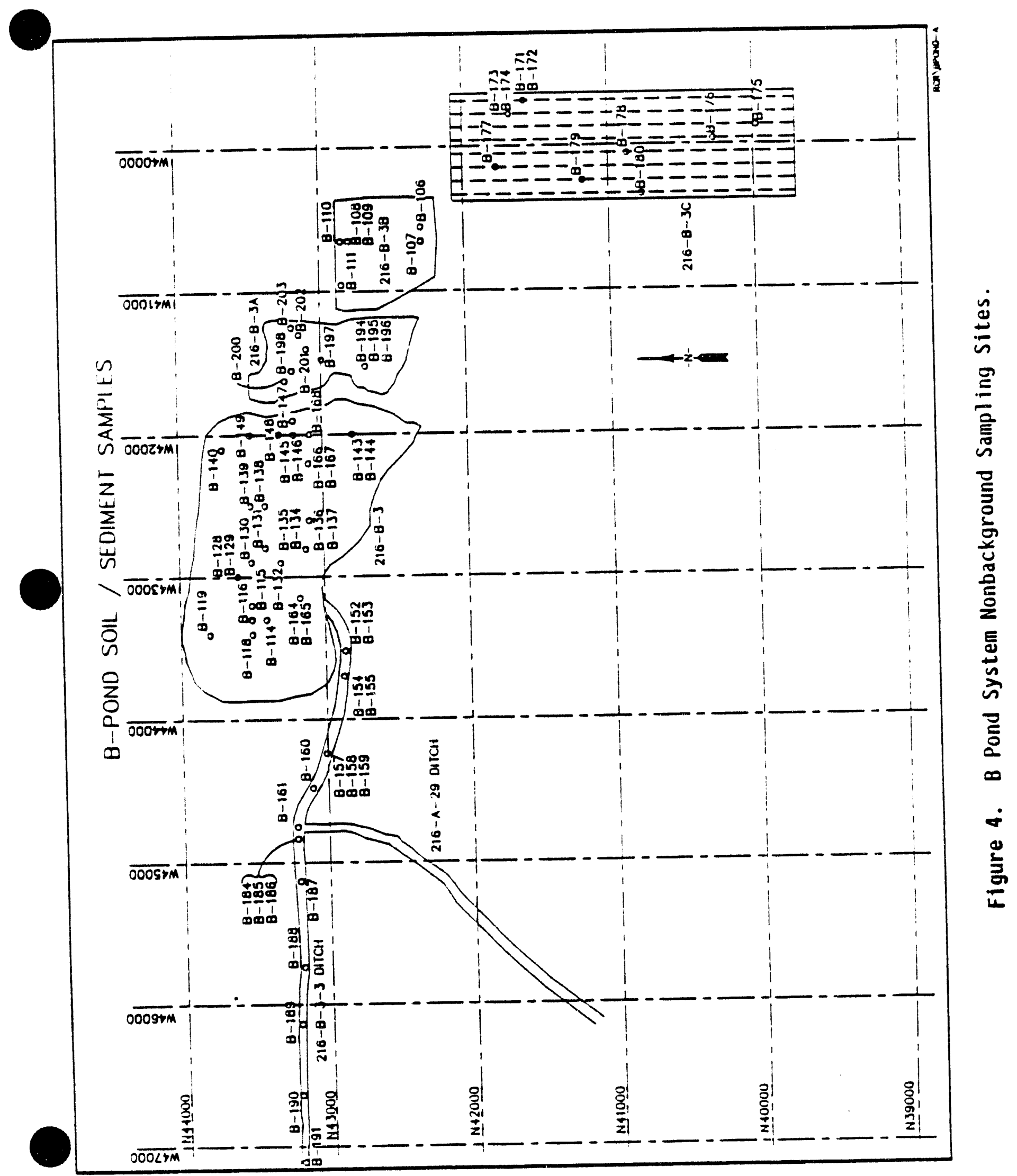


WHC-SD-EN-AP-042, REV. 0

Table 1. B Pond Phase 1 Sample Key. (Sheet 1 of 3)

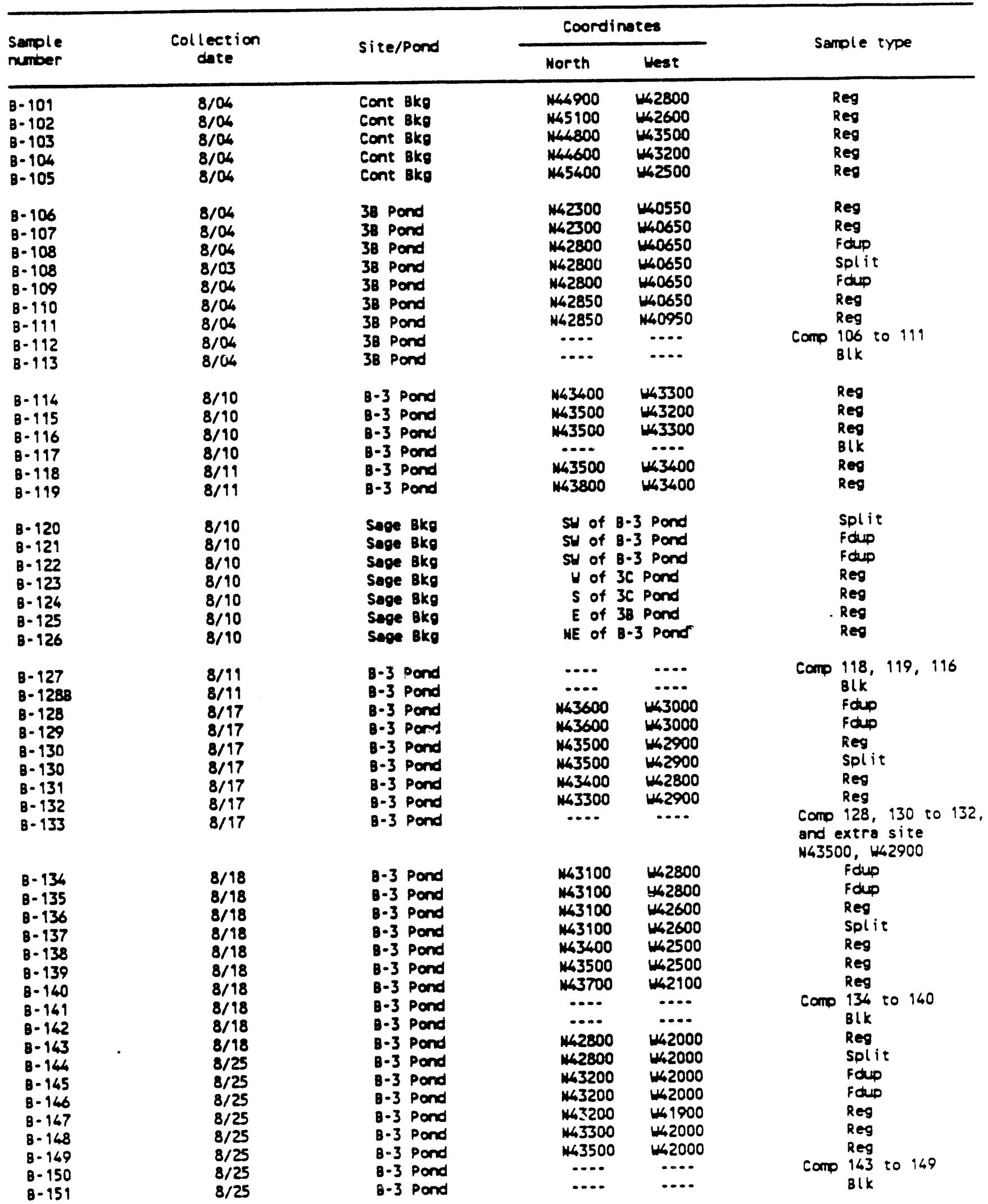


WHC-SD-EN-AP-042, REV. 0

Table 1. B Pond Phase 1 Sample Key. (Sheet 2 of 3)

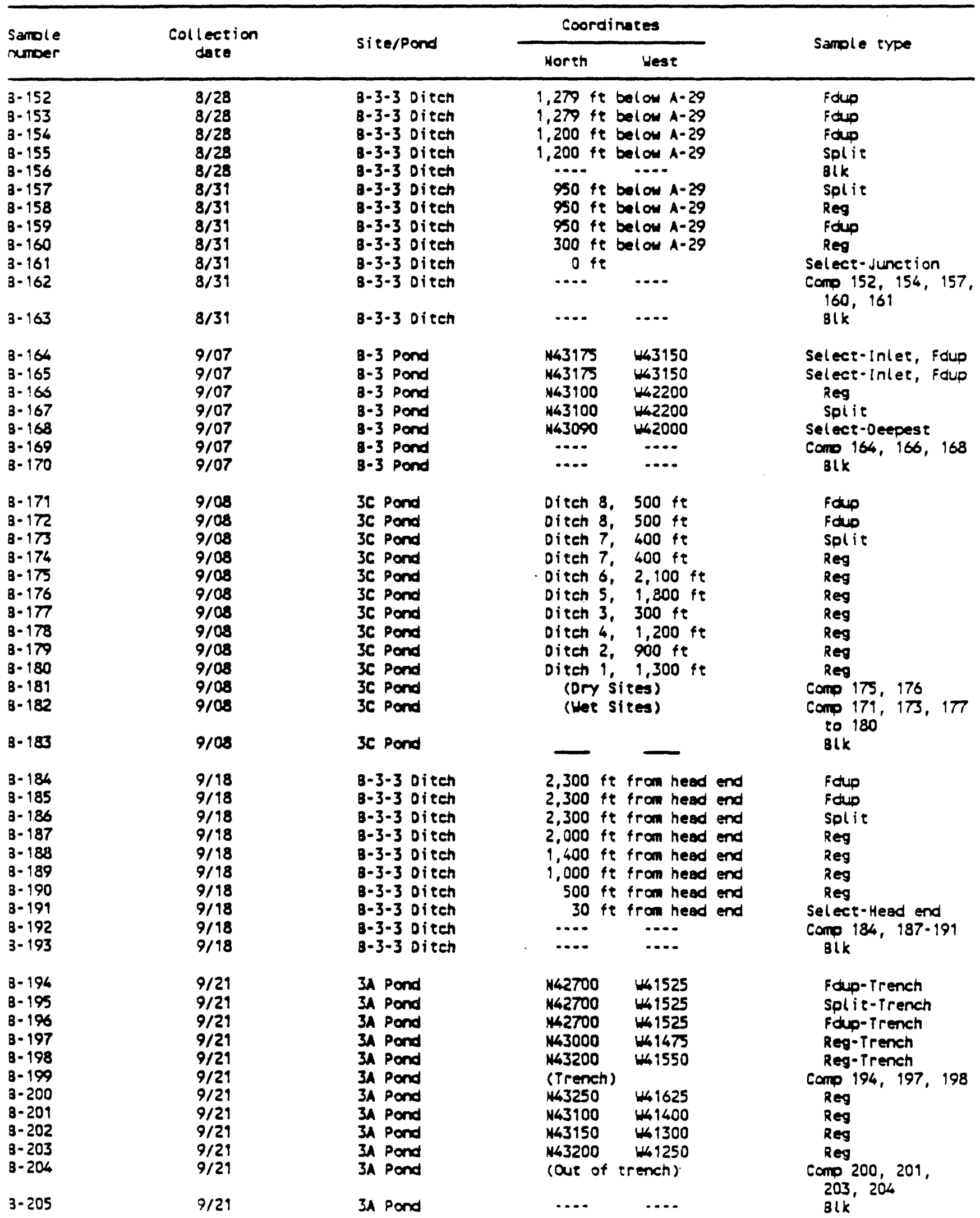


WHC-SD-EN-AP-042, REV. 0

Table 1. B Pond Phase 1 Sample Key. (Sheet 3 of 3)

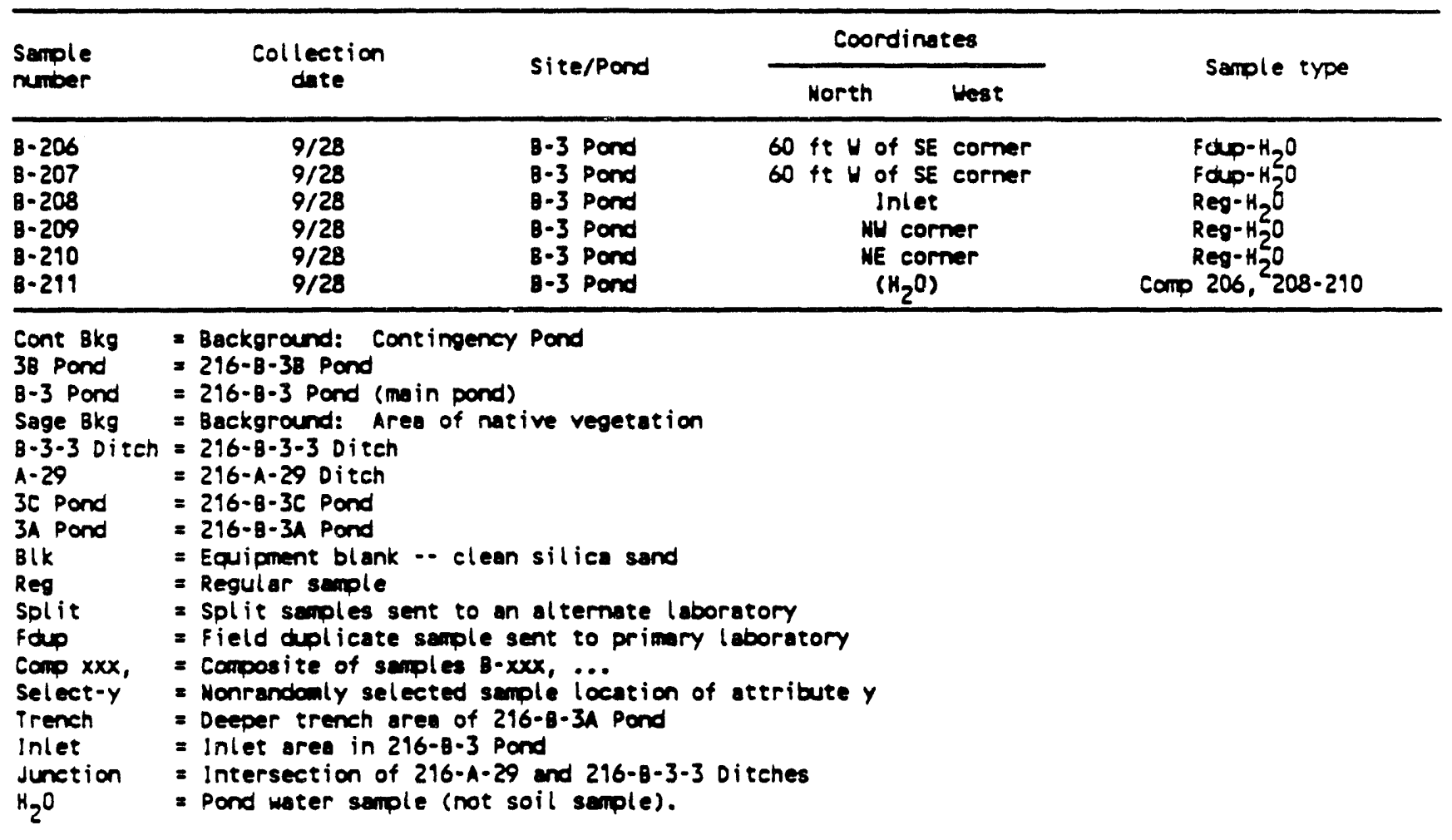


Dry soil samples were collected by removing approximately $\sigma$ inches of surface soil prior to sample collection. This was specified in the sampling plan to minimize the influence of any surface disturbances (e.g., windblown material, vegetation) and to obtain a representative sample of the site (Roos and Woodworth 1989). Stainless-steel scoopulas, spoons, trowels, and shovels were used in the sample collection, as appropriate. Tools used to remove overburden were separate from those used to collect the sample (clean tools were used at each location). Soil exposed at the bottom of the hole was immediately collected for volatile organic analysis. Containers appropriate to the rest of the requested analyses were filled as rapidly as possibie. All samples from the Contingency Pond, the native background sites, and $3 B$ Pond were dry samples. Samples B-175, B-176, and their composite B-181 were dry samples taken from $3 C$ Pond. Other sampling points in $3 C$ Pond were wet.

Sediment samples were collected from $3 A$ Pond, $B-3$ Pond, and the 216-B-3-3 Ditch using a $3 \times 12$-inch $i . d$. soil recovery auger. $A 3 \times 30$-inch auger was tried during early efforts in the B-3 Pond, but was never superior for collecting deeper sediment samples than the 12-inch auger. Multiple borings were necessary to obtain sufficient quantities of material for all the requested analyses. These were always commingled in a stainless-steel bowl prior to allocation to the individual sample analysis containers sent to the Taboratories.

Sediment collection at the water-covered sites of $3 C$ Pond was performed with stainless-steel shovels. Some samples in the lower 216-B-3-3 Ditch were also collected by shovel because of the rocky nature of the sediments. All sediment material collected at a specific sampling location was placed in a large stainless-steel bowl, the excess water was decanted, and the sample was homogenized and packed into containers. As with the dry soil samples, the handiing of material submitted for volatile organic analysis was kept to an absolute minimum.

Composite samples were usually collected at a frequency of one per sampling day in accordance with the sampling plan (Roos and Woodworth 1989). They were composed of soil/sediment split from each sample within a particular pond (or ditch) area. Prior to compositing, the material was kept on ice in clean sealed sample jars $(125 \mathrm{~mL})$. Upon taking the final sample of the day or area, the respective jars were emptied into a stainless-steel bowl, mixed, and dispensed into sample containers.

Once sample containers were filled, the exterior was wiped and/or rinsed clean, labeled, sealed in plastic bags, and placed on ice. Prior to transport to the laboratory, a tamper-indicating seal was placed on every sample container. Each sample was double checked for proper seal and labeling. Sample number and location were verified as properly recorded in the field logbook. Chain-of-custody and sample-analysis-request forms were completed and checked. All samples were rebagged (double bags) after label verification and placed on ice for transport to the laboratory the same day by collection personnel. 
WHC-SD-EN-AP-042, REV. 0

\subsection{QUALITY ASSURANCE SAMPLES}

The approved sampling plan called for at least one pair of split samples and one pair of duplicates for every 20 samples or one per day, whichever resulted in the greater number of quality assurance (QA) samples. Three types of QA samples were submitted from the field.

- Duplicate samples were defined in this project as samples from the same location submitted as two separate samples for separate analysis at a single laboratory.

- Split samples were defined identical to duplicates except that one sample would be analyzed at one laboratory and the second of the pair would be analyzed at an independent laboratory.

- Equipment blanks of clean silica sand were also submitted for analysis daily. These blanks were prepared by mixing an aliquot of silica sand under field conditions with decontaminated equipment.

Duplicate samples would be used to assess the variability inherent in the solitary estimate available for most sample collection points. Split samples were to serve as interlaboratory comparison. Equipment blanks were used to indicate errors of contamination in the measurement system.

Additional laboratory $Q A$ measures included reporting matrix spikes, matrix spike duplicates, blanks, and, in the case of organic analytes -surrogate recoveries (surrogates are synthetic compounds added by the laboratory to monitor method performance).

\subsection{REQUESTED ANALYSES}

Table 2 a summarizes the types of analyses originally requested for individual soil/sediment samples. Later, it was determined that comparison to background would be more appropriate if the strong acid digestion Method 3050 (EPA 1986) was employed instead of the acetic acid digestion used for Extraction Procedure (EP) toxicity determinations. In February 1990, this analysis was requested on samples held in storage by the laboratory.

Analytical results were reported for those elements listed in Table $2 b$. The method yielded higher concentrations of analytes for the comparisons. In each method, the soils are processed in a digestion procedure, and the extract analyzed. The amounts extracted by the two methods can differ by orders of magnitude due to the different strength of the acids employed. The majority of all site and background values were below the corresponding required contract detection limit (CDL) for the EP-toxicity digestion. This makes comparisons to background error prone due to the uncertainty of quantification. The characteristic of EP toxicity is determined by comparison to regulatory limits using the prescribed EP-toxicity extraction. The only elements regulated or even defined for EP toxicity are arsenic, barium, cadmium, lead, chromium, mercury, selenium, and silver. Because the objective of this study involves comparison to background values, results of other elements listed in the sampling plan under the category of "EP-Toxic Metals, Enhanced" will not be the presented by that digestion method. 
Table 2a. Requested Analyses, Individual Samples. (sheet 1 of 2)

\begin{tabular}{|c|c|c|}
\hline Const i tuent & Hethod & $\operatorname{col}^{a}$ \\
\hline 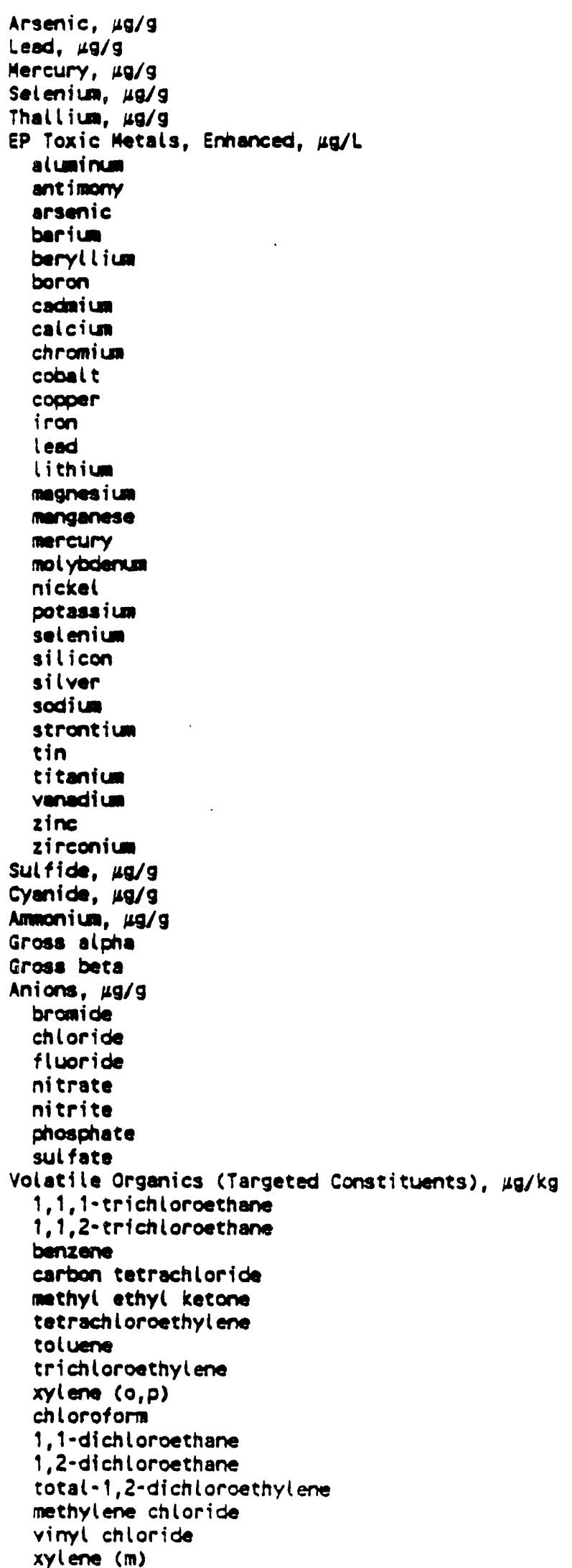 & $\begin{array}{l}9030^{b} \\
9010^{b} \\
1426-C / 0^{c} \\
A-703^{C} \\
A-703^{c} \\
300^{b}\end{array}$ & $\begin{array}{r}0.5 \\
0.5 \\
0.2 \\
0.5 \\
1.0 \\
\\
1,500 \\
1,000 \\
500 \\
1.000 \\
50 \\
100 \\
100 \\
500 \\
500 \\
200 \\
100 \\
300 \\
500 \\
100 \\
500 \\
50 \\
20 \\
400 \\
100 \\
100 \\
1.000 \\
500 \\
500 \\
50\end{array}$ \\
\hline
\end{tabular}


Table 2a. Requested Analyses, Individual Samples. (sheet 2 of 2)

\begin{tabular}{|c|c|c|}
\hline Const i tuent & Method & $\cos$ \\
\hline 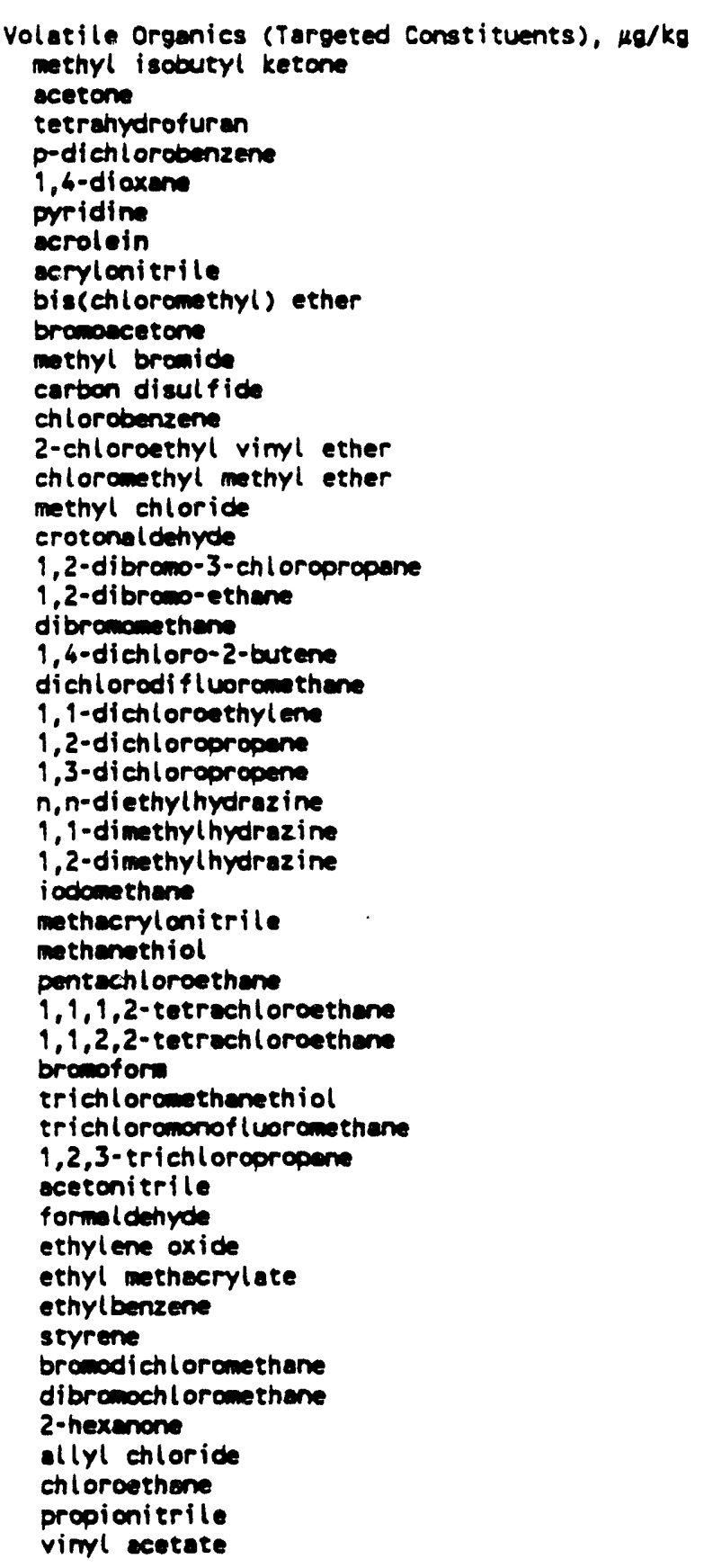 & $8240^{b}$ & $\begin{array}{r}10 \\
10 \\
10 \\
5 \\
500 \\
500 \\
10 \\
10 \\
5 \\
5 \\
10 \\
10 \\
5 \\
5 \\
10 \\
10 \\
10 \\
10 \\
10 \\
10 \\
10 \\
10 \\
10 \\
5 \\
5 \\
10 \\
10 \\
10 \\
10 \\
10 \\
10 \\
10 \\
10 \\
5 \\
5 \\
10 \\
10 \\
10 \\
10 \\
500 \\
10 \\
10 \\
5 \\
5 \\
5 \\
5 \\
50 \\
100 \\
10 \\
5 \\
5\end{array}$ \\
\hline
\end{tabular}

¿COL for EP-toxic matals are listed as concentration in the preecribed extract

CEPA 1986

CASTM 1987

CDL = contract detection limit

$E P=$ Extraction Procedure

$N / A$ a standard reference not ovailable. 
WHC-SD-EN-AP-042, REV. 0

Table 2b. Metals Analyses Using Methods 3050/6010

\begin{tabular}{|c|c|c|c|}
\hline Const i tuent & $\infty L^{b}$ & Const i tuent & $\cos ^{b}$ \\
\hline 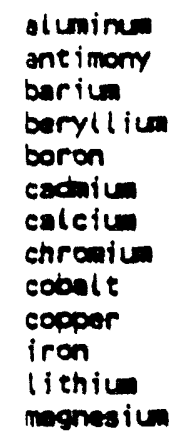 & $\begin{array}{r}15.0 \\
10.0 \\
0.6 \\
0.5 \\
1.0 \\
0.2 \\
5.0 \\
1.0 \\
2.0 \\
1.0 \\
5.0 \\
10.0 \\
5.0\end{array}$ & $\begin{array}{l}\text { menganese } \\
\text { molytodemm } \\
\text { nicxel } \\
\text { potassium } \\
\text { silicon } \\
\text { silver } \\
\text { sodium } \\
\text { strontium } \\
\text { tin } \\
\text { titanium } \\
\text { venadium } \\
\text { zine } \\
\text { zireonium }\end{array}$ & $\begin{array}{r}0.5 \\
4.0 \\
1.0 \\
10.0 \\
20.0 \\
1.0 \\
20.0 \\
1.0 \\
3.0 \\
6.0 \\
0.5 \\
0.5 \\
5.0\end{array}$ \\
\hline
\end{tabular}

Instead, the data for digestion Method 3050/inductively coupled plasma (ICP) spectroscopy analysis 6010 (EPA 1986) is presented. Elements not reported by the aforementioned method (arsenic, lead, mercury, selenium, thallium) are those for which a total metal determination was already requested by a more sensitive method.

Composite samples were screened for a broader array of organic analytes than individual samples as verification of waste stream characterization. The list of analytes for composite samples is given in Table 3.

Lists of organic compounds routinely reported by the contract laboratory are included in Tables $2 \mathrm{a}, 2 \mathrm{~b}$, and 3 . Additional compounds may be reported. The 'other' compounds may be identified or listed as unknowns (a search of the EPA/NIH Mass Spectral Data Base is included in the analysis).

Tables $2 a$ and 3 reference standard methods and give minimum required COLs. These limits were set forth in the project QA plan, Appendix $C$, of the sampling plan (Roos and Woodworth 1989). These limits correspond to the administratively determined COLS of the primary laboratory. The CDLs given are for soil matrices. Water matrices may have different CDLs. Generally, CDLs correspond to the recommended limits of the referenced method when they exist. At times, they are below a practical quantitation limit (PQL).

The primary laboratory analyzed one-half of the total split samples as regular samples. The al ternate laboratory performed EP toxicity, sulfide, cyanide, ammonium, and anion analyses on the remaining split samples. Analysis of matrix spikes (MS), matrix spike duplicates (MSD), blanks, calibration, and/or verification standards were not reported. The results of the 11 split samples delivered to the 325 Laboratory lacked sufficient QA information for Westinghouse Hanford data validation. Data from the these split samples are, therefore, not included with this report. 
WHC-SD-EN-AP-042, REV. 0

Table 3. Requested Analyses, Composite Samples. (sheet 1 of 3)

\begin{tabular}{|c|c|c|c|}
\hline Const i tuent & $C D L$ & Const i tuent & $\infty$ \\
\hline 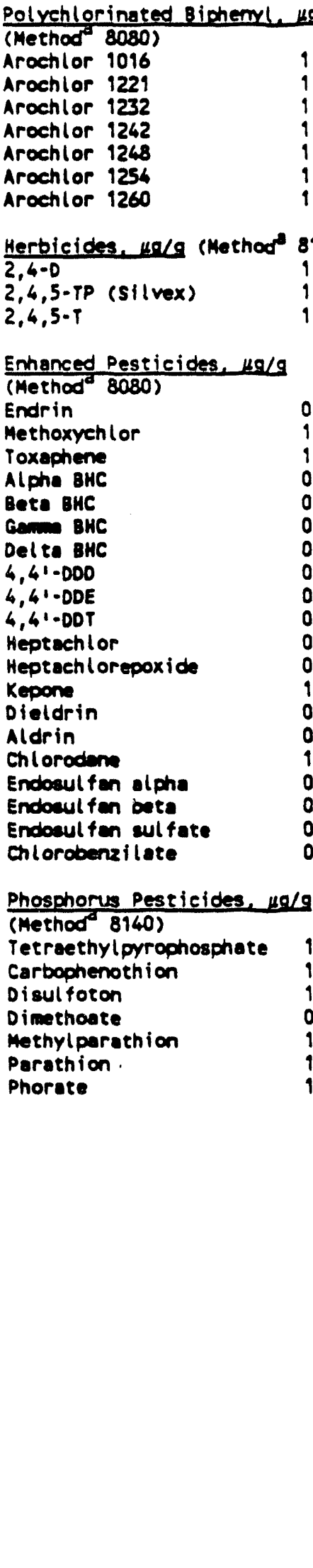 & $\begin{array}{l}0.01 \\
1.0 \\
1.0 \\
0.01 \\
0.01 \\
0.01 \\
0.01 \\
0.01 \\
0.01 \\
0.01 \\
0.01 \\
0.01 \\
1.0 \\
0.01 \\
0.01 \\
1.0 \\
0.01 \\
0.01 \\
0.05 \\
0.3 \\
49 \\
1.0 \\
1.0 \\
1.0 \\
0.2 \\
1.0 \\
1.0 \\
1.0\end{array}$ & 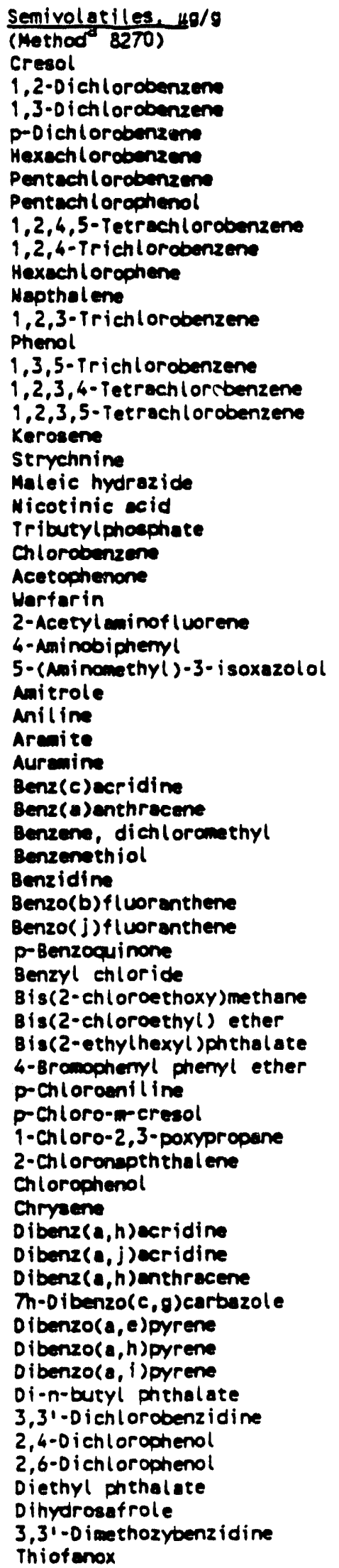 & $\begin{array}{l}1.0 \\
1.0 \\
1.0 \\
1.0 \\
1.0 \\
1.0 \\
5.0 \\
1.0 \\
1.0 \\
1.0 \\
1.0 \\
1.0 \\
1.0 \\
1.0 \\
1.0 \\
1.0 \\
1.000 \\
5.0 \\
50.0 \\
10.0 \\
1.0 \\
1.0 \\
1.0 \\
1.0 \\
1.0 \\
1.0 \\
1.0 \\
1.0 \\
1.0 \\
1.0 \\
1.0 \\
1.0 \\
1.0 \\
1.0 \\
1.0 \\
1.0 \\
1.0 \\
1.0 \\
1.0 \\
1.0 \\
1.0 \\
1.0 \\
1.0 \\
1.0 \\
1.0 \\
1.0 \\
1.0 \\
1.0 \\
1.0 \\
1.0 \\
1.0 \\
1.0 \\
1.0 \\
1.0 \\
1.0 \\
1.0 \\
1.0 \\
1.0\end{array}$ \\
\hline
\end{tabular}


Table 3. Requested Analyses, Composite Samples. (sheet 2 of 3)

\begin{tabular}{|c|c|c|c|}
\hline Conse f tuent & $\infty \mathbf{L}$ & Constituent & CDL \\
\hline \multicolumn{4}{|l|}{ Semivolariles (Cont.) } \\
\hline Dimethyl phenalace & 1.0 & 2-Cyelonexyl-4,6-dinitrophenol & 1.0 \\
\hline $\begin{array}{l}\text { m-Dinitrobenzem } \\
\text { 4,6-0initro-0-eresol }\end{array}$ & $\begin{array}{l}1.0 \\
1.0\end{array}$ & $\begin{array}{l}\text { 7, 12-Dimethylbenz (a) anthracene } \\
\text { Alpho, olpha-dimehyl }\end{array}$ & 1.0 \\
\hline 2.6-0initrooshenol & 1.0 & phenothylamine & 1.0 \\
\hline 2.4-0initrotoluen & 1.0 & 6, 4- - wethylenebis(2-chloro & \\
\hline $\begin{array}{l}\text { 2,6-0initrotolume } \\
\text { oi-n-octyl phthalate }\end{array}$ & 1.0 & & 1.0 \\
\hline & 1.0 & $\begin{array}{l}\text { 2-hothol-2-(mathylthio) } \\
\text { propionaldahyde-o- }\end{array}$ & \\
\hline 1,2-0iphemyinydrazin & 1.0 & (mothylcarbomyl soxim & 1.0 \\
\hline $\begin{array}{l}\text { Di-n-propylnitrosanine } \\
\text { Ethyl envinin }\end{array}$ & $\begin{array}{l}1.0 \\
1.0\end{array}$ & $\begin{array}{l}0,0,0 \text {-iriethyl phosphorothioate } \\
\text { tris }(2,3 \text {-0 ibromoprooyl) }\end{array}$ & 1.0 \\
\hline Ethyl methenesulfonate & 1.0 & $\begin{array}{l}\text { tris(2,3-0ibromopropy() } \\
\text { phospente }\end{array}$ & 1.0 \\
\hline Fluorantien & 1.0 & bis(2-chloro-1-methylethyl) & \\
\hline Mexach l orobut adi ene & 1.0 & other & 1.0 \\
\hline Hexach lorocycl opentadiene & 1.0 & sym-irini trobenzene & 1.0 \\
\hline Hexechlorosthan & 1.0 & Benzo(a)pyrente & 1.0 \\
\hline Ideno $(1,2,3$-cd)pyrene & 1.0 & Chlornaphaz in & 1.0 \\
\hline Isosafrole & 1.0 & bis(2-Chloroisoprooyl) ether & 1.0 \\
\hline Malononitrile & 1.0 & Hexech loropropene & 1.0 \\
\hline Molphalan & 1.0 & Isophorone & 1.0 \\
\hline Aatheoprilane & 1.0 & Acenephthen & 1.0 \\
\hline Butyl benzyl phthalate & 1.0 & Fllorene & 1.0 \\
\hline 2-sec-outyl-4,6-dinitro phenol & 1.0 & Anthrecens & 1.0 \\
\hline Chloroalkyl ethers & 1.0 & Pyrene & 1.0 \\
\hline 2-Methyll actonitrile & 1.0 & O-Mierophenol & 1.0 \\
\hline Metholomi & 1.0 & 2-Hethyl naph thal ene & 1.0 \\
\hline 2-Hethylaziridine & 1.0 & Phenenthrene & 1.0 \\
\hline 3-Methyleholenthrene & 1.0 & Benzyl alcohol & 1.0 \\
\hline 2,4,6-Trichlorophenol & 1.0 & Benzo(k) f luoranthene & 1.0 \\
\hline Mathyl methecrylate & 1.0 & Benzo(ghi) parylene & 1.0 \\
\hline Methyl methanesulfonen & 1.0 & Dinoseb & 1.0 \\
\hline 1,6-Hephehoquinom & $1.0^{\circ}$ & Disllate & 1.0 \\
\hline 1-Mephthylemine & 1.0 & $N$-Nitrosodiphemy lamine & 1.0 \\
\hline 2- Wephthyl awing & 1.0 & Dibenzofuran & 1.0 \\
\hline p-Nitraenilin & 1.0 & Acenephthalens & 1.0 \\
\hline Nitrobenzem & 1.0 & $0,0-0$ iethyl 0-2-pyrazimyl & \\
\hline p-llitrophenol & 1.0 & phosphoroth ionare & 1.0 \\
\hline N-Nitrosodi-n-butyl amine & 1.0 & Isodrin & 1.0 \\
\hline N-Nitrosodi ethenol anine & 1.0 & o-Mitraniline & 1.0 \\
\hline$N$-Nitrosodiethylamine & 1.0 & n-Witroeniline & 1.0 \\
\hline N-Nitrosodimethylamine & 1.0 & 4-Nitroquinol ine-1-oxide & 1.0 \\
\hline N-Ni trosonethylethyl anine & 1.0 & Acetone & 1.0 \\
\hline N-Nitroso-n-msehylurethane & 1.0 & Thiuran & 1.0 \\
\hline$N$-Ni troscanthyivimylanine & 1.0 & Methylthiouracil & 1.0 \\
\hline N-Nitrosanorohol ine & 1.0 & p-oimathyl aminoazobenzene & 1.0 \\
\hline N-Nitrrosiperidine & 1.0 & 3,31-0 ime thybenzidine & 1.0 \\
\hline N-Nierosopyrrol idine & 1.0 & $2,4,5$ irichlorophenol & 1.0 \\
\hline 5-Nitro-o-toluidino & 1.0 & Toluenedi amine & 1.0 \\
\hline Pentachloroni trobenzene & 1.0 & & \\
\hline Phenacet in & 1.0 & & \\
\hline p-Pherylenedianin & 9.0 & & \\
\hline $\begin{array}{l}\text { Phehalic acid esters } \\
\text { 2-picol in }\end{array}$ & $\begin{array}{l}1.0 \\
1.0\end{array}$ & & \\
\hline $\begin{array}{l}\text { 2-picoline } \\
\text { Reserpine }\end{array}$ & 1.0 & & \\
\hline Resoreinol & 1.0 & & \\
\hline o-Toluidine & 1.0 & & \\
\hline $\begin{array}{l}\text { Sofrole } \\
2,3,4,6 \text {-Tetrackilorophenol }\end{array}$ & $\begin{array}{l}1.0 \\
1.0\end{array}$ & & \\
\hline & & & \\
\hline
\end{tabular}




\section{WHC-SD-EN-AP-042, REV. 0}

Table 3. Requested Analyses, Composite Samples. (sheet 3 of 3)

\begin{tabular}{|c|c|c|c|}
\hline Consti tuent & $\infty$ & Const i tuent & $\cos$ \\
\hline 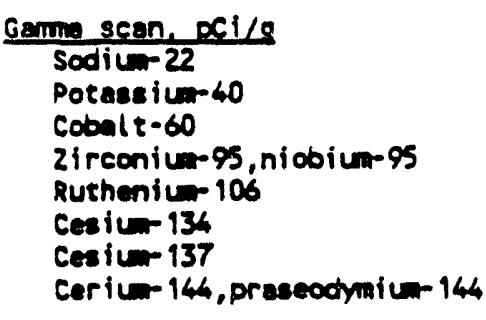 & $\begin{array}{l}0.02 \\
0.35 \\
0.02 \\
0.03 \\
0.17 \\
0.02 \\
0.02 \\
0.18\end{array}$ & & \\
\hline $\begin{array}{l}\text { (others relative to energy } \\
\text { and photo yield of } \\
\text { cesium-137) }\end{array}$ & & & \\
\hline Strontium-90, $\times$ xi/s & 0.005 & & \\
\hline
\end{tabular}

${ }^{8}$ EPA 1986

BHC = benzene hexachloride

CDL = contract detection limit

$D D D=$ dichlorodiphempldichloroethen

DDE a dichlorodiphemyldichloroethylene

DOT = dichlorodipheryltrichloroetheme 
WHC-SD-EN-AP-042, REV. 0

\subsection{FIELD OBSERVATIONS}

\subsection{WILDLIFE}

Numerous waterfowl use the wet areas of $B$ Pond. The sampling period did not coincide with the peak periods of waterfowl populations in the area. Nevertheless, the presence of very young Coots indicated some waterfowl were utilizing the site for nesting. Great Blue Herons were frequently observed in the $3 C$ Pond trenches. Small goldfish were readily available there. Minnows were also observed while sampling the upper portion of the 216-8-3-3 Ditch. Clams were also present in the ditch. Notable emergences of mayfly adults took place from the B-3 Pond during the sampling effort, but there was a lack of ichthyic surface activity. One snake was observed. Deer tracks could be found in the vicinity of the site. No wildiife was observed within the dry engineered confines of either the $3 B$ Pond or the Contingency Pond.

\subsection{VEGETATION}

Plant communities bordering and within the sampled areas did not appear highly unusual or indicative of adverse environmental effects due to waterborne contaminates. Vegetation was virtually absent in the Contingency Pond and $3 B$ Pond; however, there was also a lack of topsoil in these areas. Vegetation was clearly less developed in association with $3 A$ and $3 C$ Ponds (newer structures) than around the B-3 Pond. There was a lack of vegetation on the higher ground between the trenches in $3 C$ Pond as well as the drier ends of the trenches. Though sampling took place in the latter part of the summer, there were no significant algal blooms observed. Some submerged macrophytes were visible from the sampling platform in the B-3 Pond. Periphyton appeared thickest in the shallow, warm infiltration trenches of $3 C$ Pond.

The plant community at the native background sample sites differed significantly from those of the pond areas. Plants in the native areas were those common to the surrounding desert -- drought tolerant and drought avoidant species. The vegetation was composed of riparian and aquatic species in the TSD. The differing vegetation not only emphasized that the physical environments were characteristically different, but that both the physical and biological influences on the soil were also different. At the native background sites, the soil was undisturbed. Topsoil was in place. Coarse and fine sand constituted a larger proportion of the total mass than the other areas. There was notably less cobble than within the engineered confines of $B$ Pond or Contingency Pond.

\subsection{WEATHER}

During sampling collection, the weather was very dry with temperatures generally in the $80^{\circ} \mathrm{F}$ range. Winds were usually below 15 miles per hour, but at times, particularly as $3 C$ Pond sampling was being completed, ranged 
to approximately 25 miles per hour. Use of the sampling craft on the B-3 Pond and $3 A$ Pond was restricted by practical and safety concerns to periods with winds less than 10 miles per hour.

\subsection{GEOLOGY}

The sediment sampled in the B-3 Pond and $3 A$ Pond consisted primarily of medium to coarse sand overlain by fine sands and silts. Fine sand and silt were more prevalent at these sites than in the rockier 216-B-3-3 Ditch and 3C Pond. The Contingency Pond and $3 B$ Pond structures are mostly cobble gravel with relatively small fractions of sand. Throughout B Pond, organic matter was much more prevalent where water was available (216-B-3-3 Ditch, B-3 Pond, $3 A$ Pond, and the trenches of $3 C$ Pond). Background sites in undisturbed native areas surrounding $B$ Pond lacked the abundance of cobbles, which were chiefly composed of sand and silty sand.

The overlying soil of the Hanford Site is a very young soil by pedogenic standards. The arid climate reduces mineral weathering and soil forming processes. Lack of rainfall reduces the transport of ions to lower horizons in the soil profile. Evaporation can leave enhanced concentrations of easily exchanged elements on or near the surface.

Major minerals in the general area of $B$ Pond as determined from thin section microscopic analysis (Westinghouse geological determination) and $x$-ray florescence analysis (Hooper and Swanson 1990, $p$ 71) are polycrystalline and monocrystalline quartz, potassium feldspars, plagioclase, and basaits. Major elements found in the minerals of Hanford Site soils include magnesium, calcium, sodium, aluminum, potassium, iron, titanium, and silicon. As rocks decompose from weathering to form soil, the elements change in concentration, proportional composition, and structural arrangement.

\subsection{MISCELLANEOUS}

The water present in $B$ Pond was clear. The current was strong in the 216-B-3-3 Ditch and the inflow to the infiltration trenches of $3 C$ Pond. No unusual colors or odors were associated with the water; however, a decaying organic odor was noticed while collecting the samples from $3 A$ Pond. An HNU photoionization detector showed an inconsistent reading as high as 1 part per million (the instrument detects total concentrations of many organic and some inorganic gases, but compound identification is not possible). Another sample from the B-3 Pond in about 10 feet of water was also noted as having an organic odor.

\subsection{DISCUSSION OF BACXGROUND}

The physical and temporal boundaries of background, the representativeness of the TSD, and whether or not the differences between values from the site and the defined background imply a detrimental 
WHC-SD-EN-AP-042, REV. 0

condition need to be considered. This section highlights how some of the 'background' issues have been addressed to this point in Phase I sampling and analysis.

The waste disposal operations related to $B$ Pond are the reason for the attention of this study to characterize the sediments. RCRA closure requires that action be taken. Site characterization and removal of all waste from the site, and/or isolation of waste detrimental to human health or the environment has been described as the generic goal of the overall RCRA closure activity.

The concentrations derived from a defined background are one possible type of criteria by which the need for action can be assessed. The desirability of background for defining contamination makes some assumptions. One of these is that organisms have at least a tolerance for this background condition. The ecology of a waste site will always be different than that of background. Value judgments are inherent in defining contamination. Cleanup equaling loss of a nutrient source, loss of habitat, reproductive failure, loss of symbionts, changes in microclimate, etc., can be more significant to individual populations than legal definitions of contamination. Definitions of contamination that only reference maximum chemical concentrations are incomplete in an ecological context. All life forms have different susceptibilities, tolerances, and optimum concentration ranges of any given potential 'pollutant'. Even though a given pollutant may not affect a target population directly, it may have significant indirect effects.

For Phase 1, the criterion of contamination was to be background as determined by sampling from sites adjacent to the TSO. One type of site was a dry 2-year old excavated cobbly basin adjacent to the TSD. This is the area referred to as the Contingency Pond. It has never had waste water delivered to it. It is an aitered natural environment, constructed similar to most of the B Pond facility and in the same area, but unused for waste disposal. The second type of background site was the native desert environment peripheral to 8 Pond. These sites are frequently referred to as sagebrush sites to differentiate them from the Contingency Pond. The soit was not exposed to the waste water delivered to the pond areas. None of the sampled soils had been visibly altered by human activities. The chosen sample collection points were more widely spread about the TSD than the first type of background site. Five locations from each background area were selected for sampling.

It was not anticipated that the chemical composition would be different between the two areas. Both sites were believed to be derived from the same parent material, and part of the same geologic formation. Analytical results, however, did show different elemental compositions between the random Contingency Pond sites and those selected by professional judgement from the native desert. Calcium serves as one example of the differences. From the five sites in the Contingency Pond, reported values were 6,830 to $9,923 \mathrm{\mu g} / \mathrm{g}$ (mean 8,700 , coefficient of variation $17.2 \%$ ). From the five sage sites, values ranged from 3,172 to $3,872 \mu \mathrm{g} / \mathrm{g}$, (mean 3,555 , coefficient of variation $8.02 \%$ ). An equal number of sites were examined in each case, but the data suggested that the sampled parent populatiuns were not equivalent. 
Variability is inherent in nature. Both variability and concentration figure into the calculation of pollution defining threshold values. The fact that the two selected backgrounds were compositionally different should not automatically eliminate consideration of each. Some of the natural factors that affect soil composition are parent material, physical and chemical weathering, wind and water transport, geologic processes, climate, plants, and animals -- including microscopic species of the latter two.

For this report, it was determined that the values from the native sagebrush habitat would be utilized for TSD site comparisons with threshold values from the Contingency Pond available for user comparison. The choice of comparing to background values derived from the sagebrush sites is more conservative than using those values derived from the Contingency Pond. The majority of analytes have lower threshold values when calculated from the sagebrush background. For instance, of all the compared ICP total metals, only aluminum and chromium have higher threshold values. This is not an unbiased comparison to background. It may result in flagging locations that are not abnormal in terms of a broader background population. Both are local backgrounds. Neither background is recent pond sediment. Nutrient cycling, weathering, primary productivity, and physical environment are all drasticaliy different between the surrounding desert and an aquatic environment.

\subsection{COMPARISONS TO BACKGROUND}

Comparisons to background were made using a tolerance interval approach. Analysis followed a scheme similar to that outlined in the EPA guidance Statistical Analysis of Groundwater Monitoring Data at RCRA Facilities (EPA 1989a, p 5-19 to 5-22). An analysis of variance (ANOVA) approach was not used because individual values are of prime concern; ANOVA is concerned with mean concentrations.

The tolerance interval approach allows comparison of individual values. It is most useful where there are not large natural spatial variations in the analytes of interest. The tolerance interval approach uses the background data to generate a confidence interval estimate of a quantile. For a one-sided confidence interval, a value is established to below which at least a specified proportion of the population lies with a specified confidence coefficient. EPA recommends using a $95 \%$ coverage ratio with a 95\% confidence coefficient for RCRA groundwater monitoring (EPA 1989a, p 5-19). Tolerance intervals can be constructed assuming that the data or the transformed data are normally distributed. Nonparametric tolerance intervals can be constructed, but require such a large number of observations for similar coverage and confidence as to be impractical. The parametric tolerance interval is sensitive to departures from the assumed distribution. 
The assumption that the data are normally distributed with an unspecified mean and variance may be tested using the Shapiro-Wilk test statistic. A discussion of the computation and use of statistic is provided by Gilbert (1987). Table 4 displays the Shapiro-Wilk test statistic for many of the analytes of the Phase 1 sagebrush area background samples. Unfortunately, the small number of Phase 1 background observations do not provide much data for definitive conclusions. For those analytes where all or nearly all background values are below CDL, the statistic was not calculated. Based on the available data, the assumption of a normal distribution was rejected for ammonium, zinc, and zirconium. If the normal assumption was rejected a lognormal assumption was tested. In this case, the test was applied to the natural logarithms of the observations. Ammonium values may be lognormally distributed. The lognormal assumption is rejected for zinc and zirconium.

The upper tolerance limit is calculated for most samples based on the normal assumption. This means that, given the assumption of a normal distribution and a $95 \%$ level of confidence, at least $95 \%$ of the background population is expected to be less than the tolerance limit. Using this approach, the upper tolerance 1 imit is equal to the sum of the background average and a factor $(K)$ times the background standard deviation. The value used for $K$ is 4.210 and corresponds to a sample size of five for the stated coverage and confidence (Gilbert 1987, $p$ 256). The calculated upper tolerance limits will be used as the threshold values. For ammonium, the natural antilog of the threshold value based on natural logarithm transformed data is compared to site values. In the cases of zinc and zirconium, a nonparametric approach is used. Here, the threshold value is set equal to the highest of the five observed background concentrations. The coverage and confidence is much less than using the normal assumption for the same sample size. Using a nonparametric, one-sided tolerance interval based on only five random samples, it could be expected with 95\% confidence that at least $50 \%$ of the background population is less than the observed maximum value. Coverage of $95 \%$ and a confidence level of $95 \%$ would require a sample size of 59 (Conover 1980, p 447).

When data below the administratively determined CDL were available for calculating a limit, they were used with caution. The threshold values based on such data may have associated relative errors larger than those analytes for which quantitation is more certain. This is a matter of degree. The absolute errors may still be quite small. Substitution of arbitrary values for real data is not a preferable alternative (see Gilbert 1987, p 178). If the calculated threshold value was below a respective CDL, the COL became the defacto threshold value since the project had established these a priori as minimum required levels (the project QA plan [Roos and Woodworth 1989] established minimum project requirements). The laboratory was accountable for individual values to that limit. When the threshold value exceeded the COL, the comparisons were made in the usual fashion. 
WHC-SD-EN-AP-042, REV. 0

Table 4. Shapiro-Wilk W Test for Normality $\left(W_{0.05}\right)$.

\begin{tabular}{|c|c|c|c|c|}
\hline \multirow{2}{*}{ Analyte } & \multicolumn{3}{|c|}{ W-statistic } & \multirow{2}{*}{$\begin{array}{l}\text { Anolyces not } \\
\text { calculated }\end{array}$} \\
\hline & Raw dat & $1 a^{a}$ & Los values b & \\
\hline $\begin{array}{l}\text { Amonium } \\
\text { Arsenic } \\
\text { Lead } \\
\text { Sulfide } \\
\text { Chloride } \\
\text { Mitrite } \\
\text { Mitrate } \\
\text { Phosphate } \\
\text { Sulfate } \\
\text { Gross olphe } \\
\text { Gross beta } \\
\text { Aluminu } \\
\text { Cadmium } \\
\text { Calcium } \\
\text { Chromiun } \\
\text { Cobalt } \\
\text { Copper } \\
\text { Iron } \\
\text { Lithiu } \\
\text { Mognesium } \\
\text { Manganese } \\
\text { Mickel } \\
\text { Potassium } \\
\text { Silver } \\
\text { Sodium } \\
\text { Strontiun } \\
\text { Titanium } \\
\text { Venadium } \\
\text { Zinc } \\
\text { Zirconium } \\
\text { Acetone }\end{array}$ & 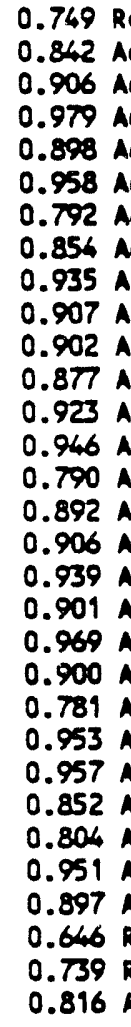 & $\begin{array}{l}\text { Re ject } \\
\text { Accept } \\
\text { Accept } \\
\text { Accept } \\
\text { Accept } \\
\text { Accept } \\
\text { Accept } \\
\text { Accept } \\
\text { Accept } \\
\text { Accept } \\
\text { Accept } \\
\text { Accept } \\
\text { Accept } \\
\text { Accept } \\
\text { Accept } \\
\text { Accept } \\
\text { Accept } \\
\text { Accept } \\
\text { Accept } \\
\text { Accept } \\
\text { Accept } \\
\text { Accept } \\
\text { Accept } \\
\text { Aceept } \\
\text { Accept } \\
\text { Accept } \\
\text { Accept } \\
\text { Accept } \\
\text { Re ject } \\
\text { Re ject } \\
\text { Accept }\end{array}$ & $\begin{array}{l}0.650 \text { Reject } \\
0.745 \text { Reject }\end{array}$ & 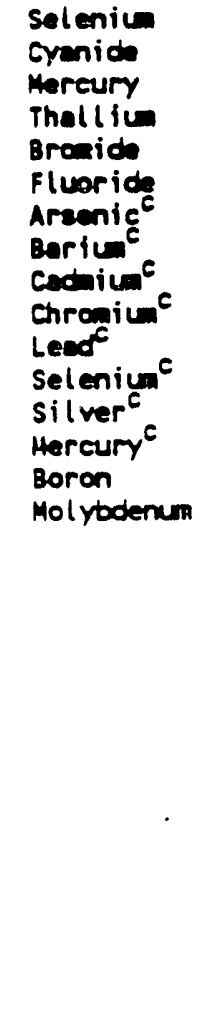 \\
\hline
\end{tabular}

Gull hypothesis: Distribution normal

Gull hypothesis: Distribution Ioonormal

EEP toxicity.

Multiple observations (field and/or laboratory duplicates) from a single jar or bowl of soil were not used as independent estimates of the overall site population parameters. Most locations in the study were represented by a single estimate. When multiple values were available, they were used to generate estimates of the population from which they were randomly allocated by using their mean. Laboratory duplicates represented the multiple observations on the individual sample. Likewise, field duplicates represented muitiple observations at the specific sampling location. Thus, if sampling point values for a hypothetical analyte were $22,10,44,25$, and at a field-duplicated point ( 48 and 46 ), the overall population mean and standard deviation would be calculated based on the first four values and 47 as the representative fifth value.

The background threshold value for each analyte is recorded in Appendix A. Each was compared to every observed value. All observations exceeding their threshold value were recorded. Background observations from the unused dry contingency bas in were also compared for reference. Only sample observations exceeding the threshold value are recorded in the list. 
WHC-SD-EN-AP-042, REY. 0

An asterisk in the far right-hand column of Appendix A denotes those field and/or laboratory duplicate samples whose respective average was less than the threshold value.

\subsection{TABULATION OF DATA}

\subsection{DETECTION LIMIT AND OTHER QA FLAGS}

Appendix $B$ is a compilation of total metals data using a strong acid digestion and analysis by ICP. Appendix C contains data collected for other analyses. Not included in the summaries are data for those analytes that were entirely below detection limits. "Detection limit" as used throughout this report refers to a CDL, except where noted. A CDL is commonily used as a minimum goal required by a laboratory hired to do chemical analyses. In many cases this limit is derived directly from the prescribed standard procedure.

There are several ways of defining detection limits. The limit of detection ( $L O D)$ is a commonly used term referring to the mean plus three standard deviations of the signal from a reagent blank (this definition is clearly limited to those determinations that do not involve subtraction of a blank). The term method detection limit (MOL) is another form of detection limit definition based on a sample that actually contains the analyte at low levels. The EPA uses a multiple of the standard deviation of such observations to define MDL (EPA 1986, Revision 1, p one-16). The limit of quantitation (LOQ) is calculated from reagent blanks like an LOD but is a factor of 10 standard deviations from the mean of the blanks instead of three. Ideally, all measurements would be in excess of a quantitation limit for the method. Data in the appendices are flagged based on reagent blanks analyzed during the same period as Phase 1 data, and on the silica sand field blanks.

This report has attempted to present all data for those analytes above COLs and appearing as potential contributors to any hazardous waste inventory at $B$ Pond. Beryllium, barium; antimony, silicon, and tin are not 1 isted among the elements disposed at $B$ Pond according to the 216-B-3 closure plan (DOE-RL 1990, $p$ 4-1 to 4-14). These five anajytes are only considered in the Analyte Summary (Section 8), with the exception of EP-toxicity barium. In some cases, analytes are shown even though all site data were below CDL (most such data are summarized in Section 8). Much of the data presented in the appendices are below CDLs and flagged as such. The information was obtained from chemist bench sheets and should be considered as auxiliary, semi-quantitative information. Values calculated need to be used appropriately. Information below these limits can be useful to the data analyst. 
Reagent blank data for the period of analyses, adjusted for nominal soil sample size, and data from the silica sand field blanks were scrutinized for evidence as to whether or not the contract laboratory was meeting CDL goals. There is evidence that the CDLs for total lead, mercury, sulfide, and selenium were ambitious. Except mercury, each estimated LOD for these analytes was below it's CDL, but LOQs were slightly in excess of these limits. Background noise on which $L O D$ and $L O Q$ are dependent can become magnified by dilution factors or inversely sample size used in the analysis and subsequent calculations. This has significance in the case of $B$ Pond total mercury estimates. Based on nine reagent blanks and a nominal sample size of $0.2 \mathrm{~g}$, mercury had an LOD of $0.39 \mu \mathrm{g} / \mathrm{g}$ and an LOQ of $2.92 \mu \mathrm{g} / \mathrm{g}-$ both in excess of the $0.2 \mu \mathrm{g} / \mathrm{g} \mathrm{CDL}$.

Another purpose of the data tabies in Appendices $B$ and $C$ are to help integrate a variety of $Q A$ flags with the numerical data. Reagent blanks, field blanks, MS/MSD, estimates of detection or quantitation fimits, surrogate recoveries, etc., are used in constructing the tables. Laboratory quality control (QC) was not performed on a sample delivery batch basis but on a process basis. Because sample delivery groups were not traceable through the analytical process, flags for blanks and matrix recoveries were done on a per-analytical-day basis. Field blanks, though collected with a sample, were not necessarily analyzed the same day as associated samples, which makes batch interpretation very difficult. A single problem with a $Q A$ sample may generate flags on multiple analytical dates, unless there was contrary evidence to disassociate that $Q A$ anomaly with collection, extraction, and analytical dates. Holding times originate from the RCRA groundwater monitoring limits. The holding times are based upon liquid samples.

\subsection{ACCURACY AND PRECISION ESTIMATES}

Accuracy was assessed by MS and MSD on a project basis. Table 5 lists accuracy achieved on samples submitted in Phase 1. The average percent recovery, standard deviation of the percent recovery, and number of spikes (observations) is displayed. The laboratory determined which samples to spike as part of their routine QC.

Precision was assessed by field duplicates. No field duplicates were submitted for the analyses done on composite samples. Precision estimates are shown in Tables $6 a$ and $6 b$. Both standard deviation and relative standard deviation are shown. Relative variability increases dramatically below the CDL, but is usually stable over a wider range than absolute variability. For those analytes where variability markedly trends upward with concentration, a graph is provided in Appendix $D$ to help assess precision at the concentration of interest. A normal regression curve is not drawn through the points because standard deviation would not be expected to be normally distributed. 
Table 5. Summary of Matrix Spike/Matrix Spike Duplicate Results.

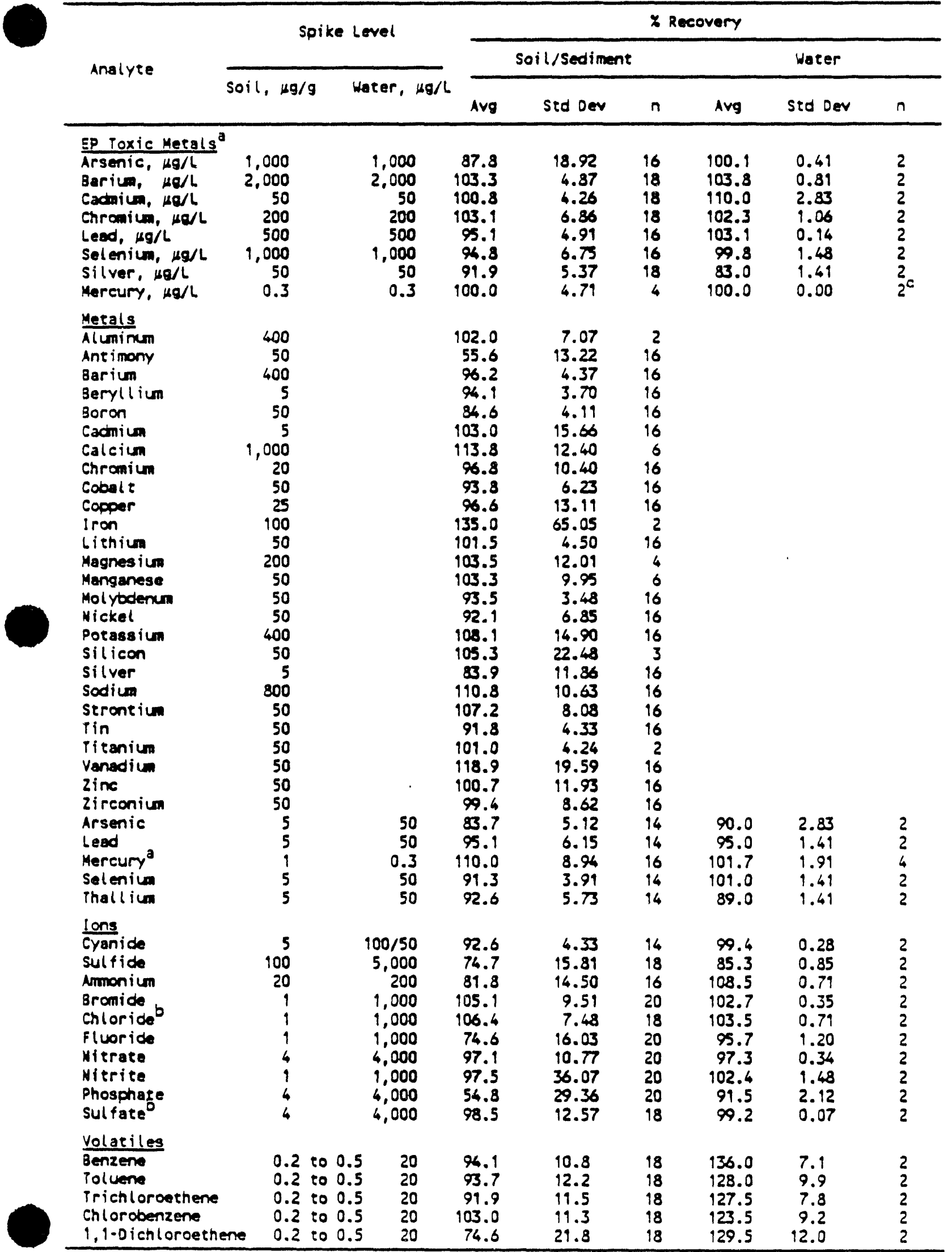

astatistics for water matrices derived from contract laboratory ac report for first quarter fy90. (Matrix spike recoveries were not reported for 8 Pond-specific water samoles.)

Excludes 8-105 soil matrix spike/matrix spike duplicates due to level in sample. 
Table 6a. Field Duplicates/Precision

B Pond Phase 1 Soil/Sediment Samples (11 Duplicate Pairs).

\begin{tabular}{|c|c|c|c|}
\hline Analyte & Absolute Std Dev & Relative std Dev, & Comments \\
\hline $\begin{array}{l}\text { EP Toxic Metals, } \mu \mathrm{g} / \mathrm{s} \\
\text { Arsenic } \\
\text { Bariun } \\
\text { Cadmiun } \\
\text { Chromium } \\
\text { Lead } \\
\text { Seleniun } \\
\text { silver } \\
\text { Mercury }\end{array}$ & $\begin{array}{c}8.42 \\
20.1 \\
4.21 \\
1.67 \\
3.81 \\
13.1 \\
0.52 \\
\text { NC }\end{array}$ & $\begin{array}{l}\text { NC } \\
9.79 \\
76.2 \\
\text { NC } \\
\text { NC } \\
\text { NC } \\
\text { NC } \\
\text { NC }\end{array}$ & $\begin{array}{l}\text { All below CDL } \\
\text { All below CDL } \\
\text { All belOW CDL } \\
\text { All below CDL } \\
\text { All below CDL } \\
\text { All below COL } \\
\text { All below CDL } \\
\text { Reported as }<C D L\end{array}$ \\
\hline 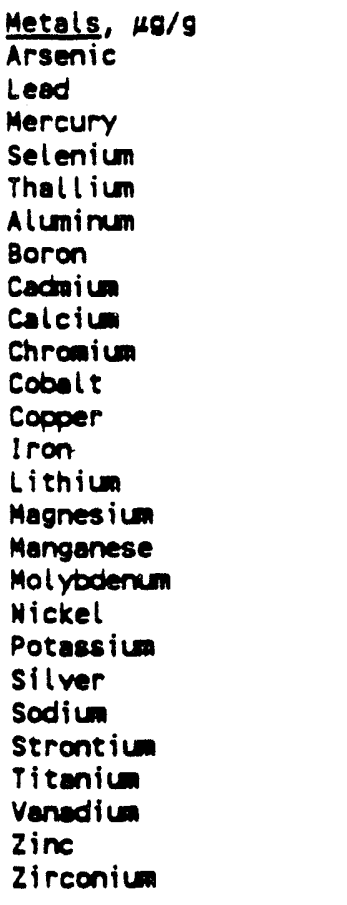 & $\begin{array}{c}0.41 \\
35.6 \\
0.33 \\
0.06 \\
0.05 \\
963.0 \\
0.1 \\
0.690 \\
532.0 \\
1.85 \\
0.795 \\
1.62 \\
273.0 \\
0.823 \\
454.0 \\
54.3 \\
1.6 \\
1.77 \\
159.0 \\
0.20 \\
26.4 \\
1.97 \\
201.0 \\
5.90 \\
8.60 \\
2.84\end{array}$ & $\begin{array}{c}21.7 \\
31.7 \\
39.6 \\
58.0 \\
45.7 \\
15.0 \\
M C \\
9.76 \\
9.36 \\
21.5 \\
10.0 \\
10.6 \\
9.58 \\
12.5 \\
9.20 \\
14.7 \\
M C \\
18.9 \\
17.8 \\
90.3 \\
10.2 \\
8.08 \\
91.8 \\
12.3 \\
14.8 \\
12.5\end{array}$ & $\begin{array}{l}\text { See Appendix } 0 \\
\text { See Section } 8.1 .3 \\
\text { All belOw CDL } \\
\text { All below COL } \\
\text { All below COL }\end{array}$ \\
\hline $\begin{array}{l}\text { lons, } \mu g / 9 \\
\text { Cyanide } \\
\text { sulfide } \\
\text { Ammoniuma } \\
\text { Bromide } \\
\text { Chloride } \\
\text { Fluoride } \\
\text { Nitrote } \\
\text { Nitrite } \\
\text { Phosphate } \\
\text { Sulfate }\end{array}$ & $\begin{array}{l}0.013 \\
0.778 \\
1.17 \\
0.00 \\
0.457 \\
0.082 \\
0.179 \\
0.022 \\
0.347 \\
8.61\end{array}$ & $\begin{array}{l}27.3 \\
147.0 \\
50.8 \\
N C \\
29.6 \\
18.4 \\
68.3 \\
14.7 \\
19.1 \\
19.4\end{array}$ & $\begin{array}{c}\text { All below } C D L \\
\text { All below CDL } \\
\text { See Appendix } D \\
\text { All below COL } \\
\text { See Appendix } 0 \\
\text { All below COL } \\
\text { All below COL with two exceptions } \\
\text { All below COL } \\
\text { All below COL with one exception } \\
\text { see Appendix D }\end{array}$ \\
\hline $\begin{array}{l}\text { Rediological, PCi/g } \\
\text { Grose lpha } \\
\text { Groas beta }\end{array}$ & $\begin{array}{l}0.655 \\
3.46\end{array}$ & $\begin{array}{l}39.0 \\
5.89\end{array}$ & \\
\hline $\begin{array}{l}\text { Volatiles } \\
\text { (All }<\mathrm{SW}-846 \mathrm{MO} / \mathrm{g} \\
\text { Acetone } \\
\text { Methyl ethyl ketone }\end{array}$ & $\begin{array}{l}0.036 \\
0.0024\end{array}$ & $\begin{array}{l}63.7 \\
5.61\end{array}$ & $\begin{array}{c}7 \text { of } 22 \text { observations }<C D L \\
\text { All below CDL }\end{array}$ \\
\hline
\end{tabular}

avalues given are on the untransformed data. The standard deviation and coefficient of variation on the natural-log transformation of the data are 0.299 and $42.9 \%$, respectively.

based on nine paired duplicates (two pair lost due to freezing).

COL = contract detection limit.

NC = not calculated.

POL = prectical quentitation limit. 
WHC-SD-EN-AP-042, REV. 0

Table 6b. Field Duplicates/Precision

Water Samples (One Duplicate Pair)a.

\begin{tabular}{|c|c|c|c|c|c|}
\hline Analyes & $\begin{array}{l}\text { Absolute } \\
\text { Std Dev, } \mu g / L\end{array}$ & $\begin{array}{l}\text { Relative } \\
\text { std Dev, } x\end{array}$ & Analyee & $\begin{array}{l}\text { Absolute } \\
\text { std Dev, } 2 \mathrm{~g} / \mathrm{L}\end{array}$ & $\begin{array}{l}\text { Relative } \\
\text { Std Dov, * }\end{array}$ \\
\hline \multicolumn{3}{|c|}{ EP Toxic Metals } & lons & & \\
\hline $\begin{array}{l}\text { Arsenic } \\
\text { Barium } \\
\text { Cacteiun } \\
\text { Chromiun } \\
\text { Leed } \\
\text { Selenium } \\
\text { sllver } \\
\text { Mercury }\end{array}$ & $\begin{array}{l}2.83 \\
1.41 \\
0.00 \\
0.00 \\
8.49 \\
0.71 \\
0.79 \\
0.00\end{array}$ & $\begin{array}{c}20.2 \\
4.79 \\
\text { MC } \\
\text { MC } \\
169.0 \\
4.29 \\
141.0 \\
\text { MC }\end{array}$ & $\begin{array}{l}\text { Oyanide } \\
\text { Sulfide } \\
\text { Anmonic } \\
\text { Bronide } \\
\text { Chloride } \\
\text { Fluoride } \\
\text { Mitrate } \\
\text { Mitrite } \\
\text { Sulfate }\end{array}$ & $\begin{array}{c}\text { NC } \\
\text { NC } \\
\text { NC } \\
\text { NC } \\
53.0 \\
2.1 \\
149.0 \\
N C \\
25.5\end{array}$ & $\begin{array}{l}\text { MC } \\
\text { NC } \\
\text { MC } \\
\text { NC } \\
2.0 \\
1.5 \\
64.4 \\
M C \\
0.0\end{array}$ \\
\hline
\end{tabular}

Merals

\begin{tabular}{|c|c|c|c|c|c|}
\hline \multirow{3}{*}{$\begin{array}{l}\text { Arsenic } \\
\text { Lead } \\
\text { Mercury } \\
\text { Seleniun } \\
\text { Thallium }\end{array}$} & \multirow{3}{*}{$\begin{array}{l}0.0007 \\
0.0007 \\
0.00 \\
0.0007 \\
0.0007\end{array}$} & \multirow{2}{*}{$\begin{array}{r}47.1 \\
141.0 \\
N C \\
141.0 \\
20.2\end{array}$} & \multicolumn{3}{|c|}{ Radiological $\propto x i / L$} \\
\hline & & & $\begin{array}{l}\text { Gross alpha } \\
\text { Gross beta }\end{array}$ & $\begin{array}{l}0.54 \\
2.16\end{array}$ & $\begin{array}{c}19.0 \mathrm{~b} \\
101.6^{b}\end{array}$ \\
\hline & & & Volatiles & - det & \\
\hline
\end{tabular}

Data used to compute precision were <COL except for chloride, sulfate, and gross alpha bon of two lab-estimated analyeical error (2 sigma)

CDL = contract detection limit.

\subsection{ANALYTE SUMMARY}

\subsection{SUMMARY OF METAL ANALYSES}

Metals requested for analysis (Tables $2 a$ and $2 b$ ) will be described relative to holding time, concentrations exceeding the threshold value, and COL. According to RCRA, B Pond is categorized as a surface impoundment, which is a depression or diked area used for storage, treatment, and disposal of hazardous waste in liquid or semisolid form. The compliance of such a facility is influenced by 40 CFR 264 (EPA 1989b). Metals 1 isted in Groundwater Monitoring List, 40 CFR 264, Appendix IX, will be of priority concern. The following list represents those metals requested for analys is using ICP analysis, Method 3050/6010; atomic absorption/graphite furnace analysis, Method 7421; and cold vapor atomic absorption analys is, Method 7470 . The metals of the EPA groundwater monitoring list (EPA 1989b) are underlined.

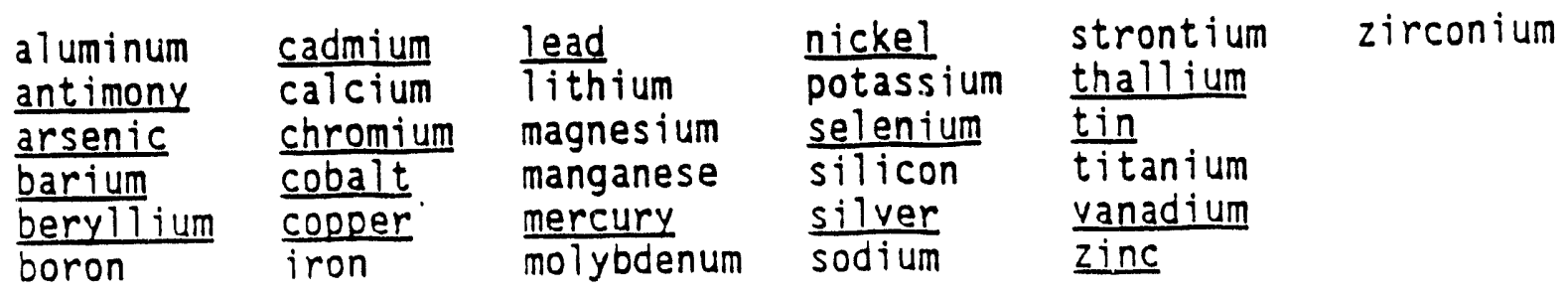


Aluminum, boron, calcium, iron, lithium, magnesium, manganese, molybdenum, potassium, silicon, strontium, titanium, and zirconium are metals that are common to most soils in concentrations less toxic than other metals. These metals are also easily complexed by other soil components. For these reasons, these metals have been omitted or not included in the Groundwater Monitoring List, 40 CFR 264, (EPA 1989b, Appendix IX). These elements are naturally occurring in soil and geologic minerals that eventually undergo dissolution and become components of the soil. Table 7 lists these elements in typical soil concentration ranges throughout the world (Clark and Washington 1924, Swaine 1955, Vinogradov 1959, Jackson 1964, Mitchell 1964, Taylor 1964, Bowen 1966, Lindsay 1979, Barber 1984, and Bohn et al. 1985). The far right column represents the highest value above the background level for that particular element in $B$ Pond.

Apparent from comparing the two sets of data in Table 7 , concentrations of those elements, determined by ICP Method 3050/6010 for B Pond, are within normal soil concentration ranges. Amended by the omission from the EPA groundwater monitoring list (EPA 1989b, Appendix IX), the above soil concentrations pose little threat for human, animal, or plant health of $B$ Pond.

The metals from the groundwater monitoring list are listed in Table 8 with respective typical soil concentration ranges throughout the world (Clark and Washington 1924, Swaine 1955, Vinogradov 1959, Jackson 1964 , Mitchel1 1964, Taylor 1964, Bowen 1966, Lindsay 1979, Barber 1984, Bowen 1979, and Bohn et al. 1985). The far right column represents the highest observed value for that particular element in $B$ Pond. Apparent from comparing the two sets of data in Table 8, cadmium, lead, and mercury total metal concentrations for $B$ Pond are higher than the upper limits of the common ranges for soils and higher than background levels of $B$ Pond. Neither these elements nor arsenic, barium, chromium, selenium, or silver were close to levels demonstrating the characteristic of EP toxicity. Only a single sample in Phase 1 exceeded any respective EP toxic CDL. Except for selenium, CDLs were an order of magnitude below the EP toxic defined levels. The selenium CDL was one-half of the EP toxic defined concentration. A discussion of total cadmium, lead, and mercury, as differentiated from EP leachable, is presented relative to the threshold values and common concentration ranges.

\subsubsection{Cadmium}

Holding times for the sagebrush site samples were slightly exceeded. This should not significantly affect the results. Concentrations exceeding the threshold value were found in the $3 A$ Pond, $B-3$ Pond, and B-3-3 Ditch. of the eight samples taken from the $3 A$ Pond, one was above the threshold value. Of the 30 samples taken from the $B-3$ Pond, $70 \%$ were above the threshold value. Of the 15 samples taken from the B-3-3 Ditch, 20\% were above the threshold value. Numerous sites in the $3 A$ Pond, $B-3$ Pond, and the B-3-3 Ditch exceeded the upper common soil range $(7.0 \mu \mathrm{g} / \mathrm{g})$ found in referenced literature. Background observations were close to this referenced value. 
WHC-SD-EN-AP-042, REV. 0

Table 7. Metal Concentrations in Soils.

\begin{tabular}{|c|c|c|}
\hline Element & $\begin{array}{l}\text { common rense } \\
\text { for soils, } \\
\mu e / g\end{array}$ & $\begin{array}{l}\text { Higheat doberved } \\
\text { value (Method 3050) } \\
\text { He/g }\end{array}$ \\
\hline 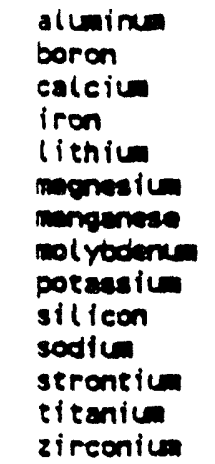 & $\begin{array}{rll}10,000 & \text { to } & 300,000 \\
2 & \text { to } & 100 \\
7,000 & \text { to } & 500,000 \\
7,000 & \text { to } & 550,000 \\
5 & t 0 & 200 \\
600 & \text { to } & 10,200 \\
20 & \text { to } & 3,000 \\
0.2 & t 0 & 5 \\
400 & t 0 & 30,000 \\
230,000 & t 0 & 350,000 \\
750 & t 0 & 7,500 \\
50 & t 0 & 1,000 \\
1,000 & \text { to } & 10,000 \\
60 & t 0 & 2,000\end{array}$ & $\begin{array}{c}16,699 \\
<1.0 \mathrm{cDL} \\
16,510 \\
37,479 \\
16 \\
7,423 \\
856 \\
4.0 \mathrm{col} \\
2,867 \\
2,093 \\
465 \\
46 \\
2,917 \\
39\end{array}$ \\
\hline
\end{tabular}

Table 8. Groundwater Monitoring List Metals (EPA 1989a).

\begin{tabular}{|c|c|c|}
\hline El enent & $\begin{array}{l}\text { common range } \\
\text { for soils, } \\
\mu \mathrm{N} / \mathrm{g}\end{array}$ & $\begin{array}{l}\text { Highest observed } \\
\text { value (Method 3050), } \\
\text { He/9 }\end{array}$ \\
\hline 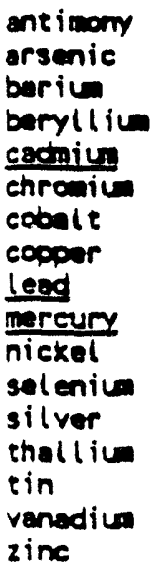 & $\begin{array}{rll}0.2 & t 0 & 10 \\
1 & t 0 & 50 \\
100 & t 0 & 3,000 \\
0.1 & t 0 & 40 \\
0.01 & t 0 & 7 \\
1 & t 0 & 1,000 \\
1 & t 0 & 40 \\
2 & t 0 & 100 \\
2 & t 0 & 200 \\
0.01 & t 0 & 0.3 \\
5 . & t 0 & 500 \\
0.1 & t 0 & 2 \\
0.01 & t 0 & 5 \\
0.1 & t 0 & 0.8 \\
2 & t 0 & 200 \\
20 & t 0 & 500 \\
10 & 20 & 300\end{array}$ & $\begin{array}{l}<10.0 \mathrm{COL} \\
\text { <background of } 4.9 \\
116.4 \\
<0.5 \mathrm{COL} \\
\frac{22.6}{34.5} \\
11.2 \\
43.1 \\
\frac{618.0}{15.6} \\
\frac{19.2}{19.2} \\
<1.0 \mathrm{CO} \\
5.1 \\
<1.0 \mathrm{OL} \\
11.8 \\
81.8 \\
119.3\end{array}$ \\
\hline
\end{tabular}

\subsubsection{Lead}

Lead was determined using Method 7421, atomic absorption/graphite furnace analysis. This analysis also employs Method 3050 extraction technique. Concentrations exceeding the threshold value were found in B-3 Pond. of the 30 samples taken from B-3 Pond, $70 \%$ were above the threshold value. Three of the 22 sample collection points were above the upper limit of $200 \mathrm{\mu g} / \mathrm{g}$ lead for soils. 


\subsubsection{Mercury}

Mercury was determined using cold vapor atomic absorption analysis. For the five sage site samples, all values for mercury analys is were less than the CDL of $0.2 \mu \mathrm{g} / \mathrm{g}$. All values less than this were reported by the laboratory only as less-than values. For computation of precision statistics, all mercury less-than values were assigned a value equal to $0.2 \mu \mathrm{g} / \mathrm{g}$. Values exceeding the CDL were found in the $B-3$ Pond and the B-3-3 Ditch. Of the 30 samples taken from the B-3 Pond, $73 \%$ were above the threshold values. Of this $73 \%$, 95\% were above the upper limit of $0.3 \mathrm{\mu g} / \mathrm{g}$ mercury for soils. Of the 15 samples taken from B-3-3 Ditch, 20\% were above the threshold values. Of this $20 \%, 33 \%$ were above the upper limit of $0.3 \mathrm{\mu g} / \mathrm{g}$ mercury for soils. Only two observations from the main pond $(7.0$ and $15.6 \mu \mathrm{g} / \mathrm{g})$ were above both a dilution adjusted LOQ and LOD.

\subsection{IONS}

\subsubsection{Ammonium}

Many holding times were exceeded for this analysis. All background samples exceeded the 28-day allowed holding time by approximately 2 weeks. The threshold value may be biased by the affect of holding time. The MS/MSD associated with these background samples was also the lowest recorded, (average $=57.5 \%$ ).

Sampling site values in $3 A$ Pond and B-3 Pond exceed the threshold value estimated from available data. All water samples from the main pond were found to have ammonium levels below the $50 \mathrm{\mu g} / \mathrm{L} \mathrm{CDL}$.

Ammonium compounds were among those known to have been disposed of in $B$ Pond. It is doubtful that these contributed to any elevated levels in the present-day sediments at the TSO. Ammonium readily undergoes physical and biological transformations. Ammonia is generated by heterotrophic bacteria as the primary end product of decomposition of organic matter (it is also a major excretory product of aquatic animals). Ammonia in solution is present primarily as ammonium. The measurement procedure does not differentiate between these two forms of nitrogen. High ammonium levels are typically associated with poliution from degradable organic matter. This type of poliution is not a viable concern given the types of effluents disposed of in $B$ Pond. Normal sediment ammonium concentrations still need definition. Ammonification in pond sediments and subsequent sorption to the sediments, as well as accumulation in the interstitial water, would normaliy contribute to higher concentrations of ammonium in pond sediments than in a desert. Wetzel (1975, p 196) reports fixed and exchangeable ammonium in Wisconsin hard water oligotrophic lake sediments at $66 \mathrm{mg} / \mathrm{kg}$ each (total $132 \mathrm{mg} / \mathrm{kg}$ ). Eutrophic lakes have higher total sediment ammonium concentrations. The maximum concentration found in Phase 1 samples was $16.2 \mu \mathrm{g} / \mathrm{g}$. This concentration does not appear abnormally high for sediment. Production and decomposition of organic material in either the dry $3 B$ Pond, the dry Contingency Pond, or native desert are inhibited by a lack of moisture. 


\subsubsection{Bromide}

All bromide results were far below the $1.0 \mu \mathrm{g} / \mathrm{g}$ CDL. Accuracy on spike recoveries in soil averaged 105\%. Precision on field duplicates was not calculated because all values were equal to zero according to chemist sheets. Clearly this is not to be a future constituent of concern.

\subsubsection{Chloride}

Chloride was the second most frequently detected anion behind sulfate. Chloride data are presented in Appendix C, Table C-5. The chloride values of the background sagebrush areas are below reliable detection levels. Chloride is introduced via water to $B$ Pond. It does not appear that it is anywhere close to levels of environmental significance. The highest levels were actually found in samples from the dry unused Contingency Pond background site.

\subsubsection{Cyanide}

Al1 cyanide measurements were below their respective CDL $(0.5 \mu \mathrm{g} / \mathrm{g}$ soil, $10 \mathrm{\mu g} / \mathrm{L}$ water). Holding timus were exceeded for all sample numbers prior to B-144. This included all background samples and all samples from 38 Pond. The holding time is 14 days. Some samples were held as long as 28 days and three were held for 5 weeks. Samples not exceeding holding times were consistent with those that did exceed holding times - no detectable cyanide. There was no detectable concentration of cyanide in the B-3 Pond water samples. All MS recoveries were acceptable.

\subsubsection{Fiuoride}

Data for fluoride are displayed in Appendix C, Table C-6. Virtually all the data are below the CDL. The only samples reported above $1 \mu \mathrm{g} / \mathrm{g}$ were those with matrix effects. The one exception to this is a $1.3 \mu \mathrm{g} / \mathrm{g}$ value from a sample in the B-3-3 Ditch. Fluoride is not at hazardous levels in the near-surface soils and sediments of $B$ Pond.

\subsubsection{Nitrate, Nitrite}

The nitrate and nitrite data are presented in Table C-7 of Appendix $C$. Nitrate is the predominate form of the two. There are no observed concentrations greater than the threshold value in $B$ Pond. Levels are clearly higher in the dry sites of $3 B$ Pond, the background sites, and the two dry sample sites of $3 C$ Pond. The highest nitrate concentration was associated with a native background site. 


\subsubsection{Phosphate}

Phosphate data are displayed in Table C-8 of Appendix C. All site data are below CDL. There are no observed concentrations greater than the threshold values at the site. Levels are higher in the native sage, area than the soils and sediments of $B$ Pond. Phosphate should no longer be an analyte of concern in the near-surface soils and sediments of $B$ Pond.

\subsubsection{Sulfate}

Sulfate data are displayed in Appendix C, Table C-9. The graph of field duplicates, Appendix $D$, shows a strong correlation between variability and concentration over the ranges found at B Pond. Under the normal distribution, the mean and standard deviation are uncorrelated. If the mean and standard deviation estimates generated from repeated sampling are proportional to each other, then the parent population is not normally distributed. A lognormal tolerance interval would be a better choice to apply in this case. Although field duplicate data were not restricted to background sites, they suggest that the tolerance interval should not be based on a normal distribution. A lognomal distribution would result in a higher threshold value. Only observations associated with the 8-3 Pond would exceed value. Note that in either case, the unused contingency Pond is far higher in sulfate than the TSD unit. This anion can be found in higher concentrations from natural weathering of soil materials and other processes than is found in B Pond.

\subsubsection{Sulfide}

Only two samples were above the CDL $(10 \mu \mathrm{g} / \mathrm{g})$ among all sites. Sample B-179 from $3 C$ Pond was reported at $10.9 \mu \mathrm{g} / \mathrm{g}$ and sample $B-198$ from $3 A$ Pond was reported at 25.7. All background samples were analyzed 1 to 2 weeks after holding times had expired. Both associated pairs of MS/MSD analyzed that day had low-spike recoveries (58\%/60\% and 50\%/49\%). The low recovery was attributed by the laboratory to a matrix effect. The average of either type of background site was below one-half the CDL. A LOD calculated from the five reagent blanks, (average $+3 s$ ), is below the CDL, but an LOQ (average + $10 \mathrm{~s}$ ) is equal to $16.7 \mathrm{\mu g} / \mathrm{g}$.

The holding time of 7 days was exceeded by 1 to 2 weeks for samples B-101 through B-142. Samples B-152 to B-163 and B-184 to B-193 exceeded the holding time by 1 to 4 days. This problem affects all measurements from either background, 3B Pond, and the B-3-3 Ditch. Sample B-118, a sample from the B-3 Pond analyzed 28 days after collection, also had low spike recoveries attributed to matrix effects. Another sediment sample from the B-3 Pond analyzed on the same day had satisfactory recoveries. A1l water samples analyzed for sulfide were reported below CDL $(1 \mu \mathrm{g} / \mathrm{mL})$.

The data are weak, but do not indicate dangerous concentrations of sulfide. It is a naturally occurring compound in pond sediments and would be consistent with observed concentrations of sulfate in excess of that observed from the sagebrush sites. 
WHC-SD-EN-AP-042, REY. 0

\subsection{ORGANICS}

\subsubsection{Chlorinated Herbicides}

A11 composite sampies were tested for the herbicides 2,4-D, 2,4,5-T, and 2,4,5-TP (Silvex). The CDL were $1.0 \mu \mathrm{g} / \mathrm{g}$ for each analyte in soil samples and $2.0 \mu \mathrm{g} / \mathrm{L}$ in water. None of the herbicides were found present in any of the samples. The surrogate 2,4-DB was reported slightly out of limits for sample B-162 (60\%) and B-153 (44\%) versus the $63 \%$ to $151 \%$ allowable range. Sample B-162 was the composite sample from the lower part of the 8-3-3 Ditch. Sample B-169 was a composite containing material from the inlet area of the pond, the deepest sampling location, and one other site. Another aliquot of this sample was reextracted and reanalyzed, and the results were consistent. The laboratory attributed the low surrogate recovery to a matrix effect. The sample was noted to have formed an emulsion during the extraction process. The MS/MSD analyses are not available for B Pond samples. Method performance for soil matrices appears very poor based on reported spike recoveries for the scant data several months prior to and after analys is of B Pond samples. The allowed QC limits referred to previously were established by the laboratory, but it is not clear from the available data that the method was capable of meeting those limits. Phase 1 data do not contradict that the site is clean with respect to the aforementioned herbicides, but the analytical evidence is not conclusive. The volume of water passing through the system and site disposal practices argue against significant n...ntities of these herbicides being present in the sediments of the pond.

\subsubsection{Chloropesticides}

Analysis for the chloropesticides consisted of all the analytes listed in Table 3 under the heading "Pesticides, Enhanced". Respective soit and. water matrix minimum CDL are also given in Table 3 . Several samples required raising the reported less-than value due sample specific matrix effects. Samples $8-150$, one of five composite sediment samples from the main pond, was associated with a twentyfold increase in reported less-than levels for a 11 analytes. Samples B-133, B-141, and B-169 had detection levels increased tenfold for those analytes with retention times less than 10 minutes. These three composite samples were also from B-3 Pond. Analytes reported to higher detection limits included all four benzene hexachloride (BHC) compounds, heptachlor, heptachlorepoxide, aldrin, and alpha endosulfan. Samples B-199 and B-204 were reported likewise. Additionally, DDE was reported as less than a tenfold increased limit rue to matrix effects in these two samples from $3 A$ Pond. Surrogate recoveries for dibutylchlorendate and/or 2,4,5,6-tetrachloro-meta-xylene were all within acceptable limits. A MS/MSO was performed on sample B-181. Spikes of endrin, lindane (gamma BHC), DDT, heptachlor, dieldrin, and aldrin at 0.2 to $0.5 \mathrm{\mu g}, \mathrm{g}$ were performed. Recoveries of endrin were high; however, the problem was later traced to interference in the standard (high chlorobenzilate concentration). All remaining spikes had acceptable recoveries that anged between 95 and $126 \%$. Phase 1 data supports the initial perceptions that the chloropesticides are not a serious constituent of concern in the soil and sediments of $B$ Pond. 


\subsubsection{Phosphorous Pesticides}

Phosphorous pesticides analyzed for include tetraethylpyrophosphate, carbophenothion, disulfoton, dimethoate, methylparathion, parathion, and phorate. The soil CDL was $1.0 \mu \mathrm{g} / \mathrm{g}$ for all except dimethoate, which was $2.0 \mu \mathrm{g} / \mathrm{g}$. Water COLs were $2.0 \mathrm{\mu g} / \mathrm{L}$ for all compounds. No compound was reported at or above it's respective limit. A MS/MSD was performed on sample $B-181$. The respective recoveries were an acceptable 76 and $88 \%$ using a spike level of $2.0 \mathrm{\mu g} / \mathrm{g}$. A spike was not performed on the single B Pond water sample submitted for this analysis, but the laboratory QC-report for the respective quarter shows 10 MS during the quarter; all were acceptable and ranged 88 to $118 \%$. All holding times were met.

The organophosphate pesticides are known to degrade rapidly in soil, and the rate of degradation increases with moisture content (Guenzi 1974). According to Pionke and Chesters (1973) most organophosphorus insecticides, with the exception of diazanon which degrades in acid, are hydrolyzed in water at alkaline pH. Phase 1 sampling confirmed that the above phosphorus pesticides are not a constituent of concern in the sediments of $B$ Pond.

\subsubsection{Polychlorinated Biphenyls}

Polychlorinated biphenyls tested for included arochlors 1016, 1221 , $1232,1242,1248,1254$, and 1260. The minimum CDL for soil is $1.0 \mu \mathrm{g} / \mathrm{g}$ and the minimum for water is $1.0 \mathrm{\mu g} / \mathrm{L}$. Matrix effects required dilution and upward adjustment of the reported less-than values twentyfold on samples B-150 (for arochlors 1016-1254), and B-199 (for arochlors 1221, 1232, 1242, and 1260). Tenfold adjustments were required on sample B-204 for the same arochlors adjusted in reporting sample $B-199$. Fivefold dilutions were required due to high background noise in samples $B-133$ and $B-141$ for the above arochlors. The remaining seven composite samples did not require dilutions. All samples were reported as less than their respective detection limits. A MS/MSD was run on sample B-192 using arochlor 1254 . The recoveries of 116 and $120 \%$ were well within the acceptable limits. All surrogate recoyeries for each sample were within acceptable limits with one exception. Sample B-127, a composite of three samples from the B-3 Pond, had a low recovery for surrogate dibutylchlorendate (1.3\%) and a high surrogate recovery for $2,4,5,6$-tetrachloro-meta-xylene (289\%). Typical recoveries range 20 to $150 \%$. Other composite samples from the B-3 Pond showed no evidence of contamination. Surrogate recoveries for the single composite water sample from the B-3 Pond were acceptable. A MS was not done on this specific sample, but all six water sample MS reported in the laboratory $Q C$ report for the respective quarter were acceptable. Phase 1 data do not indicate polychlorinated biphenyls contamination in the nearsurface sediments of $B$ Pond.

\subsubsection{Semivolatiles}

Bis(2-ethylhexyl)phthalate was the only compound identified from the entire target 1 ist of Table 3 for either soil, sediment, or water samples. It was identified at $2.4 \mu \mathrm{g} / \mathrm{g}$ in sample $\mathrm{B}-169,3.5 \mu \mathrm{g} / \mathrm{g}$ in $\mathrm{B}-181$, and 
$6.7 \mu \mathrm{g} / \mathrm{g}$ in B-182. Al1 three results are considered qualified nondetects due to associated blank contamination at $8.0 \mu \mathrm{g} / \mathrm{g}$. Six compounds were used as surrogates in the analysis, (2-f7uorophenol, phenol-05, nitrobenzene-05, 2-fiuorobipheny 1, 2,4,6-tribromophenol, and p-terpheny1). A11 surrogate recoveries were within acceptable limits as determined by EPA methods (EPA 1986).

Matrix spikes were run on sediment sample B-127 for several compounds as shown in Table 9 . Spike recovery for one compound was less than $10 \%$ over its respective advisory limit. All other spike recoveries are within guideline limits. There is no indication that any of the long list of compounds analyzed by this method should continue to be constituents of concern in the near-surface sediments of $B$ Pond.

Table 9. Semivolatile Spike Recoveries.

\begin{tabular}{|c|c|c|c|}
\hline \multirow{2}{*}{ Compound } & \multirow{2}{*}{$\begin{array}{l}\text { Spike } \\
\text { added, no }\end{array}$} & \multicolumn{2}{|c|}{ * Rec } \\
\hline & & MS & MSO \\
\hline 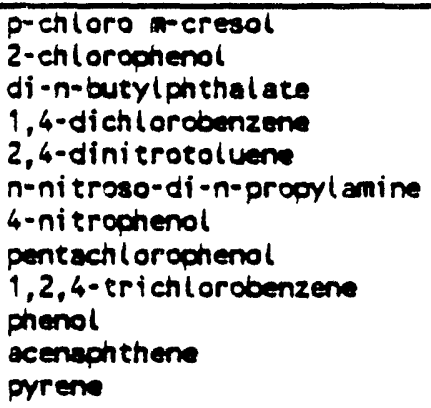 & $\begin{array}{r}100 \\
100 \\
50 \\
50 \\
50 \\
50 \\
100 \\
100 \\
50 \\
100 \\
50 \\
50\end{array}$ & $\begin{array}{l}55.6 \\
49.8 \\
127.40 \\
39.8 \\
79.6 \\
47.4 \\
71.2 \\
93.3 \\
61.0 \\
39.7 \\
54.0 \\
63.6\end{array}$ & $\begin{array}{l}54.0 \\
60.3 \\
72.8 \\
45.4 \\
59.2 \\
60.2 \\
80.3 \\
79.0 \\
54.2 \\
36.3 \\
89.4 \\
65.6\end{array}$ \\
\hline
\end{tabular}

aspike recovery outside atvisory oc limits for this compound from water.

\subsubsection{Volatile Organics}

Volatile organics found were generally insignificant. Data for the volatiles are shown in Appendix $C$, Tables $\mathrm{C}-10$ through $\mathrm{C}-13$. Acetone was present in more samples than any other organic compound. None was reported in the Contingency Pond samples, but all other categories including the field equipment sand blanks, samples from the native sagebrush area, and laboratory blanks had some samples with acetone above the $10 \mu \mathrm{g} / \mathrm{kg} \mathrm{CDL}$.

The two highest concentrations of acetone reported were from samples $B-115(333 \mu \mathrm{g} / \mathrm{kg})$ and $B-129(160 \mu \mathrm{g} / \mathrm{kg})$; both samples were from the B-3 Pond. Neither is believed to be representative of actual field conditions. Sample B-129 was a field duplicate. Acetone reported in it's respective pair (B-128) was less than the $10 \mu \mathrm{g} / \mathrm{kg}$ CDL (moisture considered). Sample B-115 not only had the highest reported concentration for acetone, but al so the other common laboratory contaminants. The sample had the highest reported values for methyl ethyl ketone and methylene chloride. Some methyl ethyl ketone was thought to originate from fresh paint in one of the laboratory rooms according to the quarterly QC report 
supplied by the contract laboratory. Methylene chloride is a common laboratory solvent. The reported sample was run on August 22, 1989; however, the MS/MSD were run prior to this date on August 16, 1989. There are no reported sample results for this date. With the exception of problem sample B-115, all other compounds found in the B-3 Pond are below the practical quantitation guidelines of EPA (1986, Revision 1).

The contract laboratory program guidelines use a $10 x$ rule for evaluating common laboratory contaminants in environmental samples. If an associated blank is noted to have a certain level of a common laboratory contaminant, the data are qualified as a nondetect when they are above the CDL but within 10 times the concentration found in the blank.

A tentatively identified compound (1,3-dichlorobenzene) was found in two 3B Pond samples. One of these samples was a field duplicate. It's respective pair had no detectable trace of the compound. This compound has also been reported in the laboratory $Q C$ report as one of several present in water matrix (volatile organic analysis) blanks during the respective quarter and in a soil (volatile organic analysis) blank in the following quarter. The fact that it is at a very low level was not present in any of the other samples from $3 B$ Pond and is known to have potential as a laboratory contaminant suggest it is an artifact of the measurement system.

\subsection{RADIONUCLIDES}

The data on gross alpha, gross beta, strontium-90 concentration, and gamma activities are 1 isted in Appendix C, Tables C-14 and C-15. These parameters are not regulated under current RCRA regulations. The data are presented in the appendix because they were collected as part of the Phase 1 $B$ Pond investigations. Background samples were not collected, nor were comparisons made. Levels of radioactivity were surprisingly low in the sampled material. The highest observed gross beta measurement $(718 \mathrm{pCi} / \mathrm{g})$ was from a $3 C$ Pond sample.

\subsection{SONCLUSIONS}

Phase 1 characterization efforts show additional work is needed to define acceptable levels of many naturally occurring compounds; particularly where the background is not strictly comparable. Natural spatial and seasonal differences in background may be poorly represented in highly localized background measurements.

Many analytes were investigated in Phase 1. These compounds do not appear present at hazardous levels in the sampled near-surface soils and sediments of $B$ Pond. There are many observations greater than native background in the B-3 Pond. Lead, cadmium, and mercury are believed to be the most significant. Each element was far below levels exhibiting the characteristic of EP toxicity. None of the data indicate that the nearsurface soil/sediment would be classified dangerous waste under any of the WAC 173-303, Dangerous Waste Regulations (Ecology 1989). Further 
characterization activities of the soil profile with depth should pay close attention to QA for volatile organic analysis sampling. Sampling for other organic analyses is not justified based on Phase 1 results.

\subsection{REFEREYCES}

ASTM, 1986, Annual Book of ASTM Standards, D-1426 C/D and A-703, American Society of Testing and Materials, Philadelphia, Pennsylvania.

Barber, S. A., 1984, Soil Nutrient Bioavailability, John Wiley \& Sons, Inc., New York.

Bohn H., B. McNeal, and G. O'Conner, 1985, Soil Chemistry, 2nd edition, John Wiley \& Sons, Inc., New York.

Bowen, H. J. M., 1966, Trace Elements in Biochemistry, Academic Press, New York.

Bowen, H. J. M., 1979, Environmental Chemistry of the Elements, Academic Press, New York.

Clark, F. W. and J. W. Washington, 1924, The Composition of the Earth's Crust, U.S. Geological Survey Paper 127.

Conover, W. J., 1980, Practical Nonparametric Statistics, John Wiley \& Sons, Inc., New York.

DOE-RL, 1990, 216-8-3 Pond Systen Closure/Postclosure P1an, DOE-RL-89-28, Rev. 0, U.S. Department of Energy-Richland Operations Office, Richland, Washington.

Ecology, 1989, Dangerous Waste Regulations, Washington Administrative Code (WAC 173-303), Washington Department of Ecology, Olympia, Washington.

EPA, 1986. Test Methods for Evaluating Solid Waste, Physical/Chemical Me $\ldots$, SW-846, Third Edition, U.S. Environmental Protection Agency, Washington, D.C.

EPA, 1989a, Statistical Analysis of Groundwater Monitoring Data at RCRA Facilities, Interim Final Guidance, Feb. 1989, U.S. Environmental Protection Agency, Washington, D.C.

EPA, 1989b, Standards for Owne:ns and Operators of Hazardous Waste Treatment, Storage, and Disposal Facilities, Title 40, Code of Federal

Regulations, Part 264, as amended, U.S. Environmental Protection Agency, Washington, D.C.

Gilbert, R. 0., 1987 Statistical Methods for Environmental Pollution Monitoring, Van Nostrand Reinhold, New York. 
Guenzi, W. D., editor, 1974, Pesticides in Soil and Water, Soil Science Society of America, Inc., Madison, Wisconsin.

Hooper, P. R., and Swanson, D. A., 1990, Geology of the Blue Mountains Region of Oregon, Idaho, and Washington: Cenozoic Geology of the Blue Mountains Region, U.S. Geological Survey Paper 1437.

Jackson, M. L., 1964, "Chemical Composition of Soils," Chemistry of the Soil, F. E. Bear, editor, 2nd edition, Reinhold, New York, pp. 71 to 141 .

Lindsay, W. L., 1979, Chemical Equilibria in Soils, John Wiley \& Sons, Inc., New York.

Mitchell, R. L., 1964, "Trace Elements in Soils," Chemistry of the Soil, F. E. Bear, editor, 2nd edition, Reinhold, New York, Pp. 320 to 368 .

Pionke, H. B. and G. Chesters, 1973, Pesticide - Sediment - Water Interactions, Journal of Environmental Quality 2:29-45.

Roos, R. C. and K. A. Woodworth, 1989, 216-B-3 Pond Characterization of the Hazardous Waste Inventory in the Near-Surface Soi is and Sediments, WHC-SD-EN-AP-016, Rev. 1, Westinghouse Hanford Company, Richland, Washington.

Swaine, D. J., 1955, The Trace Element Content of Soils, Commonwealth bur. Soil Sci. Tech. Comm., No. 48, Herald Printing, York, England.

Taylor, S. R., 1964, The Abundance of Chemical Elements in the Continental Crust-A New Table, Geochim. Cosomochim., Acta 28: 145 to 146.

Vinogradov, A. P., 1959, The Geochemistry of Rare and Dispersed Chemical Elements in Soils, 2nd edition, translation from Russian, Consultants Bureau, New York.

WHC, 1989a, Preliminary Operable Units Designation Project, WHC-EP-0216, Westinghouse Hanford Company, Richland, Washington.

WHC, 1989b, Environmental Investigations and Site Characterization Manual, WHC-CM-7-7, Westinghouse Hanford Company, Richland, Washington. 
WHC-SO-EN-AP-042, REV. 0

APPENDIX A

OBSERVATIONS EXCEEDING BACXGROUND TOLERANCE LIMIT

$A-i$ 
WHC-SD-EN-AP-042, REV. 0

This page intentionally left blank.

A i i 


\section{APPENDIX A \\ OBSERVATIONS EXCEEDING BACXGROUND TOLERANCE LIMIT}

Appendix A contains a list of observations exceeding a soil background tolerance limit, or when applicable, a regulatory or contract detection limit (CDL). Each observation was compared to determine if it exceeded the stated value. Where possible, an alternate background limit from the contingency pond data is provided. Inorganic analytes appear first in alphabetical order. An asterisk in "Type" column denotes those field and/or laboratory duplicate samples whose respective duplicate average is below the threshold value. (The type "Select" is used to denote those samples from judgement selected locations, i.e., nonrandom). The designation "EP" denotes results of the extraction procedure toxicity analyses for those elements previously defined for that waste characteristic. The EP results immediately follow total metal determinations where applicable. The list concludes with the organic analytes in the following order: volatile organics, semivolatiles, herbicides, pesticides, phosphorous pesticides, and polychiorinated biphenyls.

\section{INORGANIC ANALYTES}

Aluminum--Threshold value: $11,238 \mu \mathrm{g} / \mathrm{g}$

(Aiternate background 1imit: $10,090 \mu \mathrm{g} / \mathrm{g}$ )

\begin{tabular}{|c|c|c|c|c|c|}
\hline Area & Sample & $\mu g / g$ & Coordi & ates & Type \\
\hline $\begin{array}{l}B-3 \text { Pond } \\
B-3 \text { Pond } \\
B-3 \text { Pond } \\
B-3 \text { Pond } \\
B-3 \text { Pond } \\
B-3 \text { Pond } \\
B-3 \text { Pond } \\
B-3 \text { Pond } \\
B-3 \text { Pond } \\
B-3 \text { Pond } \\
B-3 \text { Pond } \\
B-3-3 \text { Ditch }\end{array}$ & $\begin{array}{l}B-114 \\
B-129 \\
B-130 \\
B-132 \\
B-134 \\
B-135 \\
B-145 \\
B-146 \\
B-147 \\
B-147 \\
B-148 \\
B-191\end{array}$ & $\begin{array}{l}12,189 \\
12,327 \\
14,913 \\
13,370 \\
12,052 \\
12,537 \\
11,424 \\
12,381 \\
14,119 \\
16,699 \\
11,384 \\
11,747\end{array}$ & $\begin{array}{l}N 43400 \\
N 43600 \\
N 43500 \\
N 43300 \\
N 43100 \\
N 43100 \\
N 43200 \\
N 43200 \\
N 43200 \\
N 43200 \\
N 43300 \\
30^{\prime} \text { fro }\end{array}$ & $\begin{array}{l}W 43300 \\
W 43000 \\
W 42900 \\
W 42900 \\
W 42800 \\
W 42800 \\
W 42000 \\
W 42000 \\
W 41900 \\
W 41900 \\
W 42000 \\
W \text { head end }\end{array}$ & $\begin{array}{l}\text { Regular } \\
\text { Field duplicate* } \\
\text { Regular } \\
\text { Regular } \\
\text { Field duplicate } \\
\text { Field duplicate } \\
\text { Field duplicate } \\
\text { Field duplicate } \\
\text { Laboratory duplicate } \\
\text { Laboratory duplicate } \\
\text { Regular } \\
\text { Select }\end{array}$ \\
\hline
\end{tabular}

Ammonium--Threshold value: $6.26 \mu \mathrm{g} / \mathrm{g} ;$ lognormal TI used (Alternate background limit: $13.98 \mu \mathrm{g} / \mathrm{g}$, lognormal TI)

\begin{tabular}{|c|c|c|c|c|}
\hline Area & Sample & $\mu g / g$ & Coord & lates \\
\hline $\begin{array}{l}3 A \text { Pond } \\
3 A \text { Pond } \\
B-3 \text { Pond } \\
B-3 \text { Pond } \\
B-3 \text { Pond } \\
B-3 \text { Pond }\end{array}$ & $\begin{array}{l}B-198 \\
8-203 \\
8-114 \\
B-115 \\
B-116 \\
B-118\end{array}$ & $\begin{array}{l}7.59 \\
7.79 \\
7.39 \\
8.31 \\
9.62 \\
9.46\end{array}$ & $\begin{array}{l}N 43200 \\
N 43200 \\
N 43400 \\
N 43500 \\
N 43500 \\
N 43500\end{array}$ & $\begin{array}{l}W 41550 \\
W 41250 \\
W 43300 \\
W 43200 \\
W 43300 \\
W 43400\end{array}$ \\
\hline
\end{tabular}

Type

Regular

Regular

Regular

Regular

Regular

Regular 
WHC-SD-EN-AP-042, REV. 0

Armonium (Cont)

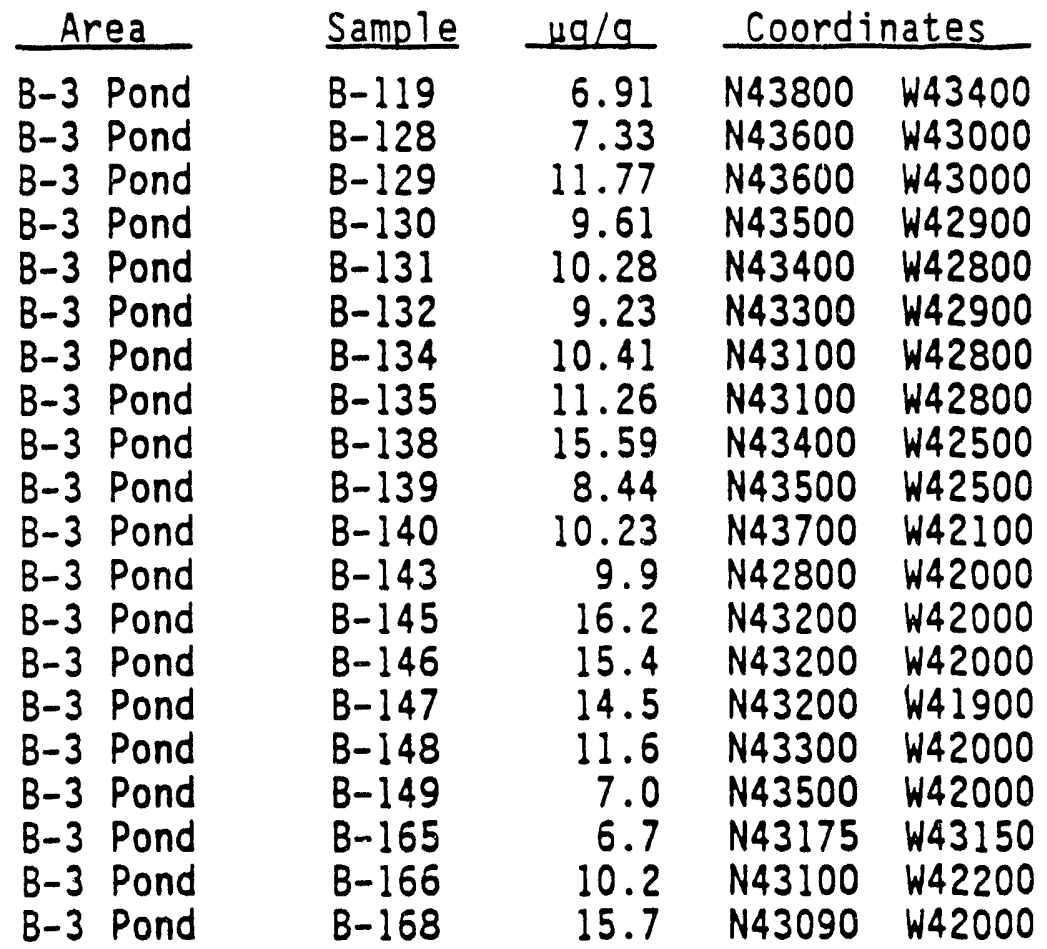

Type

Regular

Field duplicate

Field duplicate

Regular

Regular

Regular

Field duplicate

Field duplicate

Regular

Regular

Regular

Regular

Field duplicate

Field duplicate

Regular

Regular

Regular

Select

Regular

Select

Arsenic--Threshold value: $4.91 \mathrm{\mu g} / \mathrm{g}$

(Alternate background limit: $7.59 \mu \mathrm{g} / \mathrm{g}$ )

All observations below threshold

Arsenic, (EP)--Regulatory threshold value: $5 \mathrm{mg} / \mathrm{L}$

$\mathrm{CDL}=500 \mu \mathrm{g} / \mathrm{L}$

No observations $>\mathrm{CDL}$

Barium, (EP)--Regulatory threshold value: $100 \mathrm{mg} / \mathrm{L}$ $C D L=1,000 \mu \mathrm{g} / \mathrm{L}$

No observations $>C D L$

Boron--Regulatory threshold value: not calculated (NC)

All values $\angle C D L$

Bromide--Threshold value: NC

Al1 values $\angle C D L$

Cadmium--Threshold value: $8.23 \mu \mathrm{g} / \mathrm{g}$

(Alternate background limit: $9.58 \mu \mathrm{g} / \mathrm{g}$ )

\begin{tabular}{|c|c|c|c|c|}
\hline Area & Sample & $\mathrm{kg} / \mathrm{q}$ & Coord & nates \\
\hline $\begin{array}{l}3 A \text { Pond } \\
B-3 \text { Pond } \\
B-3 \text { Pond } \\
B-3 \text { Pond } \\
B-3 \text { Pond } \\
B-3 \text { Pond } \\
B-3 \text { Pond }\end{array}$ & $\begin{array}{l}B-196 \\
B-114 \\
B-115 \\
B-115 \\
B-116 \\
B-118 \\
B-119\end{array}$ & $\begin{array}{r}8.7 \\
9.9 \\
8.8 \\
8.6 \\
9.8 \\
8.8 \\
22.6\end{array}$ & $\begin{array}{l}N 42700 \\
N 43400 \\
N 43500 \\
N 43500 \\
N 43500 \\
N 43500 \\
N 43800\end{array}$ & \\
\hline
\end{tabular}

Type

Field duplicate*

Regular

Laboratory duplicate Laboratory duplicate

Regular

Regular

Laboratory duplicate 
WHC-SD-EN-AP-042, REV. 0

Cadmium (Cont)

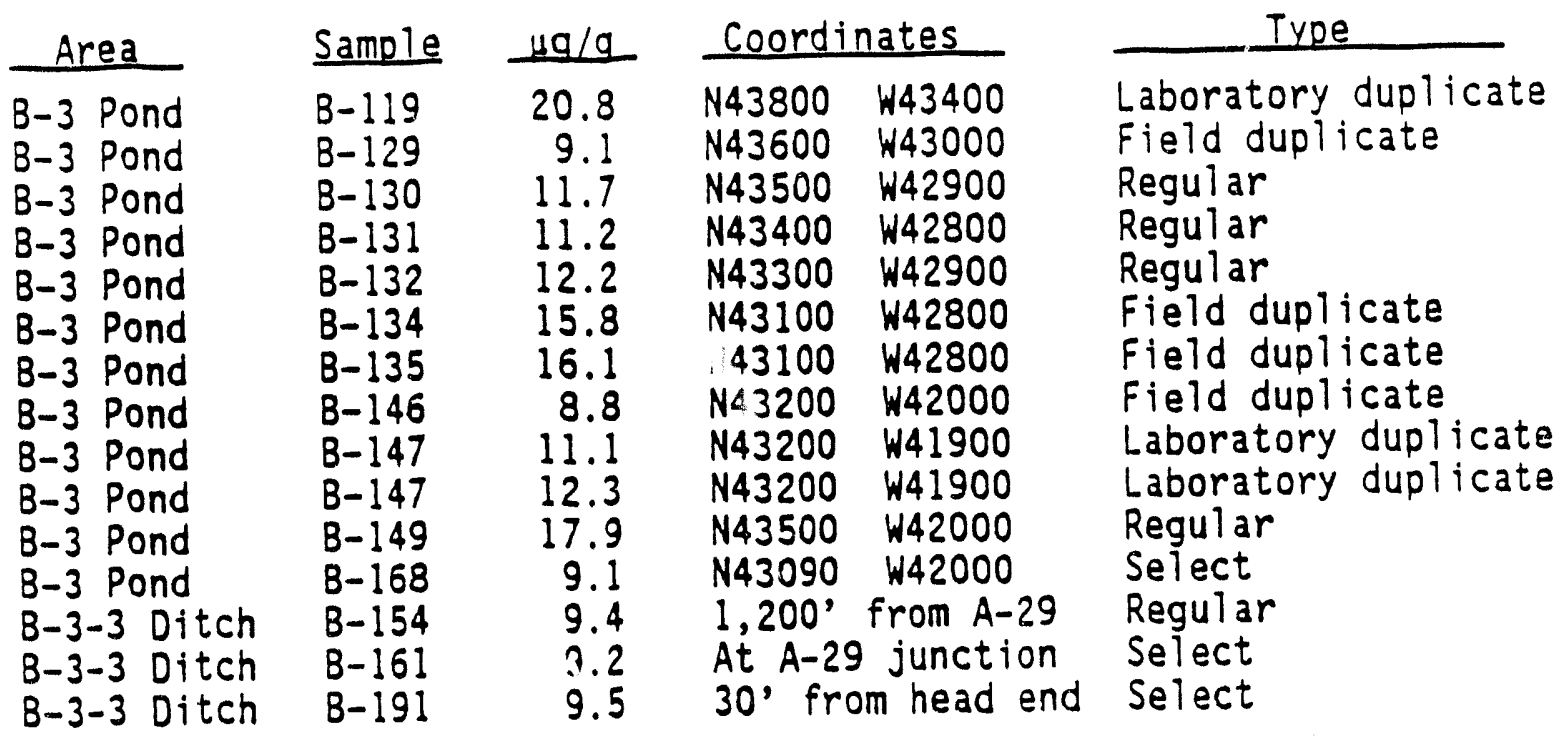

Cadmium, (EP)--Regulatory threshold value: $1 \mathrm{mg} / \mathrm{L}$

$C O L=100 \mu g / L$

One observation >CDL; none exceeding regulatory 1 imit

$\frac{\text { Area }}{B-3 \text { Pond }} \frac{\text { Sample }}{\text { B-119 }} \frac{\mu / L}{259} \frac{\text { Coordinates }}{\text { N43800 W43400 }}$

Calcium--Threshold value: $4,755 \mu \mathrm{g} / \mathrm{g}$

(Alternate background limit: $14,997 \mu \mathrm{g} / \mathrm{g}$ )

\begin{tabular}{|c|c|c|c|c|c|}
\hline Area & Sample & $\mu q / g$ & Coordi & nates & Type \\
\hline $\begin{array}{l}3 A \text { Pond } \\
3 A \text { Pond } \\
3 A \text { Pond } \\
3 A \text { Pond } \\
3 A \text { Pond } \\
3 A \text { Pond } \\
3 A \text { Pond } \\
3 B \text { Pond } \\
3 B \text { Pond } \\
3 B \text { Pond } \\
3 B \text { Pond } \\
3 B \text { Pond } \\
3 B \text { Pond } \\
3 C \text { Pond } \\
3 C \text { Pond } \\
3 C \text { Pond } \\
3 C \text { Pond } \\
3 C \text { Pond } \\
B-3 \text { Pond } \\
B-3 \text { Pond } \\
B-3 \text { Pond } \\
B-3-3 \text { Ditch }\end{array}$ & $\begin{array}{l}B-194 \\
B-196 \\
B-197 \\
B-200 \\
B-201 \\
B-202 \\
B-203 \\
B-106 \\
B-107 \\
B-108 \\
B-109 \\
B-110 \\
B-111 \\
B-171 \\
B-172 \\
B-175 \\
B-176 \\
B-178 \\
B-146 \\
B-147 \\
B-147 \\
B-152\end{array}$ & $\begin{array}{r}5,200 \\
5,948 \\
9,463 \\
16,510 \\
9,684 \\
11,808 \\
8,265 \\
9,331 \\
7,683 \\
7,704 \\
7,366 \\
9,099 \\
6,986 \\
5,154 \\
5,326 \\
4,788 \\
5,331 \\
5,818 \\
4,906 \\
5,315 \\
5,400 \\
5,090\end{array}$ & $\begin{array}{l}N 42700 \\
N 42700 \\
N 43000 \\
N 43250 \\
N 43100 \\
N 43150 \\
N 43200 \\
N 42300 \\
N 42300 \\
N 42800 \\
N 42800 \\
N 42850 \\
N 42850 \\
D i t c h 8 \\
D i t c h 8 \\
D i t c h 6 \\
D i t c h 5 \\
D i t c h 4 \\
N 43200 \\
N 43200 \\
N 43200 \\
1,279\end{array}$ & $\begin{array}{l}W 41525 \\
W 41525 \\
W 41475 \\
W 41625 \\
W 41400 \\
W 41300 \\
W 42500 \\
W 40550 \\
W 40650 \\
W 40650 \\
W 40650 \\
W 40650 \\
W 40950 \\
500 \\
3,500 \\
5,2,100 \\
1,800^{\prime} \\
1,200 \\
\text { W42000 } \\
W 41900 \\
W 41900 \\
\text { from A-29 }\end{array}$ & $\begin{array}{l}\text { Field dupl icate } \\
\text { Fiald duplicate } \\
\text { Regular } \\
\text { Regular } \\
\text { Regular } \\
\text { Regular } \\
\text { Regular } \\
\text { Regular } \\
\text { Regular } \\
\text { Field dupl icate } \\
\text { Field duplicate } \\
\text { Regular } \\
\text { Regular } \\
\text { Field dupl icate } \\
\text { Field duplicate } \\
\text { Regular } \\
\text { Regular } \\
\text { Regular } \\
\text { Field duplicate* } \\
\text { Laboratory duplicate } \\
\text { Laboratory duplicate } \\
\text { Field duplicate }\end{array}$ \\
\hline
\end{tabular}


WHC-SD-EN-AP-042, REV. 0

Calcium (Cont)

\begin{tabular}{|c|c|c|c|c|}
\hline Area & Sample & $\mu g / g$ & Coordinates & Type \\
\hline $\begin{array}{ll}\text { B-3-3 } & \text { Ditch } \\
\text { B-3-3 } & \text { Ditch } \\
\text { B-3-3 } & \text { Ditch }\end{array}$ & $\begin{array}{l}B-153 \\
B-154 \\
B-158\end{array}$ & $\begin{array}{l}7,211 \\
9,381 \\
5,419\end{array}$ & $\begin{array}{l}1,279^{\circ} \text { from } A-29 \\
1,200^{\circ} \text { from } A-29 \\
950^{\prime} \text { from } A-29\end{array}$ & $\begin{array}{l}\text { Field duplicate } \\
\text { Regular } \\
\text { Field duplicate, } \\
\text { Laboratory duplicate }\end{array}$ \\
\hline B-3-3 Ditch & $B-158$ & 4,885 & 950' from $A-29$ & $\begin{array}{l}\text { Field duplicate, } \\
\text { Laboratory duplicate }\end{array}$ \\
\hline $\begin{array}{ll}\text { B-3-3 } & \text { Ditch } \\
\text { B-3-3 } & \text { Ditch }\end{array}$ & $\begin{array}{l}B-159 \\
B-189\end{array}$ & $\begin{array}{l}4,889 \\
5,259\end{array}$ & $\begin{array}{l}950 \text { ' from } A-29 \\
1,000 \text { ' from } \\
\text { head end }\end{array}$ & $\begin{array}{l}\text { Field duplicate } \\
\text { Regular }\end{array}$ \\
\hline $\begin{array}{l}\text { B-3-3 Ditch } \\
\text { Cont. Bkg. } \\
\text { Cont. Bkg. } \\
\text { Cont. Bkg. } \\
\text { Cont. Bkg. } \\
\text { Cont. Bkg. } \\
\text { Cont. Bkg. }\end{array}$ & $\begin{array}{l}B-191 \\
B-101 \\
B-102 \\
B-103 \\
B-104 \\
B-105 \\
B-105\end{array}$ & $\begin{array}{l}5,064 \\
6,830 \\
9,831 \\
9,923 \\
7,328 \\
9,764 \\
9,416\end{array}$ & $\begin{array}{ll}30 ' \text { from head end } \\
N 44900 & W 42800 \\
N 45100 & W 42600 \\
N 44800 & W 43500 \\
N 44600 & W 43200 \\
N 45400 & W 42500 \\
N 45400 & W 42500\end{array}$ & $\begin{array}{l}\text { Select } \\
\text { Regular } \\
\text { Regular } \\
\text { Regular } \\
\text { Regular } \\
\text { Laboratory duplicate } \\
\text { Laboratory duplicate }\end{array}$ \\
\hline
\end{tabular}

Chloride--Threshold value: $1.47 \mu \mathrm{g} / \mathrm{g}$

(Alternate background 1imit: $97.0 \mu \mathrm{g} / \mathrm{g}$; excluding indeterminate results) NOTE: All sagebrush background observations are <CDL

\begin{tabular}{|c|c|c|c|c|c|}
\hline Area & Sample & $\mu \mathrm{g} / \mathrm{q}$ & Coordin & nates & Type \\
\hline $\begin{array}{l}3 A \text { Pond } \\
3 A \text { Pond } \\
3 A \text { Pond } \\
3 C \text { Pond } \\
B-3 \text { Pond } \\
B-3 \text { Pond } \\
B-3 \text { Pond } \\
B-3 \text { Pond } \\
B-3 \text { Pond } \\
B-3 \text { Pond } \\
B-3 \text { Pond } \\
B-3 \text { Pond } \\
B-3 \text { Pond } \\
B-3 \text { Pond } \\
B-3 \text { Pond } \\
B-3 \text { Pond } \\
B-3 \text { Pond } \\
B-3 \text { Pond } \\
B-3-3 \text { Ditch } \\
B-3-3 \text { Ditch } \\
B-3-3 \text { Ditch } \\
\text { Cont. Bkg. } \\
\text { Cont. Bkg. }\end{array}$ & $\begin{array}{l}B-198 \\
B-201 \\
B-203 \\
B-177 \\
B-114 \\
B-115 \\
B-116 \\
B-119 \\
B-130 \\
B-131 \\
B-132 \\
B-134 \\
B-135 \\
B-136 \\
B-140 \\
B-143 \\
B-147 \\
B-168 \\
B-154 \\
B-161 \\
B-191 \\
B-101 \\
B-104\end{array}$ & $\begin{array}{l}1.49 \\
3.71 \\
1.67 \\
7.90 \\
4.04 \\
1.63 \\
2.01 \\
2.05 \\
2.56 \\
5.58 \\
3.60 \\
1.81 \\
3.80 \\
4.22 \\
2.13 \\
1.51 \\
4.74 \\
1.93 \\
1.84 \\
1.83 \\
2.00 \\
21.7 \\
17.6\end{array}$ & $\begin{array}{l}N 43200 \\
N 43100 \\
N 43200 \\
\text { Ditch } 3, \\
N 43400 \\
N 43500 \\
N 43500 \\
N 43800 \\
N 43500 \\
N 43400 \\
N 43300 \\
N 43100 \\
N 43100 \\
N 43100 \\
N 43700 \\
N 42800 \\
N 43200 \\
N 43090 \\
1,200^{\prime} \\
0^{\prime} \text { from } \\
30 \text { from } \\
N 44900 \\
N 44600\end{array}$ & $\begin{array}{l}W 41550 \\
W 41400 \\
W 42500 \\
300 \\
W 43300 \\
W 43200 \\
W 43300 \\
W 43400 \\
W 42900 \\
W 42800 \\
W 42900 \\
W 42800 \\
W 42800 \\
W 42600 \\
W 42100 \\
W 42000 \\
W 41900 \\
W 42000 \\
\text { from A-29 } \\
\text { A-29 } \\
\text { head and } \\
W 42800 \\
\text { W43200 }\end{array}$ & $\begin{array}{l}\text { Regular } \\
\text { Regular } \\
\text { Regular } \\
\text { Regular } \\
\text { Regular } \\
\text { Regular } \\
\text { Regular } \\
\text { Regular } \\
\text { Regular } \\
\text { Regular } \\
\text { Regular } \\
\text { Field duplicate } \\
\text { Field duplicate } \\
\text { Regular } \\
\text { Regular } \\
\text { Regular } \\
\text { Regular } \\
\text { Select } \\
\text { Regular } \\
\text { Select } \\
\text { Select } \\
\text { Regular } \\
\text { Regular }\end{array}$ \\
\hline
\end{tabular}

Cont. Bkg. = Contingency pond background. 
Chromium--Threshold value: $12.86 \mu \mathrm{g} / \mathrm{g}$

(Alternate background limit: $8.78 \mu \mathrm{g} / \mathrm{g}$ )

\begin{tabular}{|c|c|c|c|c|c|}
\hline Area & Sample & $\mu q / q$ & Coordi & lates & Type \\
\hline $\begin{array}{l}B-3 \text { Pond } \\
B-3 \text { Pond } \\
B-3 \text { Pond } \\
B-3 \text { Pond } \\
B-3 \text { Pond } \\
B-3 \text { Pond } \\
B-3 \text { Pond } \\
B-3 \text { Pond } \\
B-3 \text { Pond } \\
B-3 \text { Pond } \\
B-3 \text { Pond } \\
B-3 \text { Pond } \\
B-3 \text { Pond } \\
B-3-3 \text { Ditch }\end{array}$ & $\begin{array}{l}B-115 \\
B-115 \\
B-116 \\
B-130 \\
B-131 \\
B-132 \\
B-135 \\
B-138 \\
B-138 \\
B-145 \\
B-146 \\
B-147 \\
B-147 \\
B-191\end{array}$ & $\begin{array}{l}13.6 \\
12.9 \\
13.1 \\
34.5 \\
18.5 \\
18.1 \\
13.5 \\
13.2 \\
12.9 \\
19.5 \\
25.5 \\
25.2 \\
29.1 \\
18.6\end{array}$ & $\begin{array}{l}N 43500 \\
N 43500 \\
N 43500 \\
N 43500 \\
N 43400 \\
N 43300 \\
N 43100 \\
N 43400 \\
N 43400 \\
N 43200 \\
N 43200 \\
N 43200 \\
N 43200 \\
30^{\prime} \text { fro }\end{array}$ & $\begin{array}{l}W 43200 \\
W 43200 \\
W 43300 \\
W 42900 \\
W 42800 \\
W 42900 \\
W 42800 \\
W 42500 \\
W 42500 \\
W 42000 \\
W 42000 \\
W 41900 \\
W 41900 \\
\text { n head end }\end{array}$ & $\begin{array}{l}\text { Laboratory duplicate } \\
\text { Laboratory duplicate } \\
\text { Regular } \\
\text { Regular } \\
\text { Regular } \\
\text { Regular } \\
\text { Field duplicate } \\
\text { Laboratory duplicate } \\
\text { Laboratory duplicate } \\
\text { Field duplicate } \\
\text { Field duplicate } \\
\text { Laboratory duplicate } \\
\text { Laboratory duplicate } \\
\text { Select }\end{array}$ \\
\hline
\end{tabular}

Chromium, (EP)--Regulatory threshold value: $5 \mathrm{mg} / \mathrm{L}$ $\mathrm{COL}=500 \mu \mathrm{g} / \mathrm{L}$

No observations $>C D L$

Cobalt--Threshold value: $9.7 \mu \mathrm{g} / \mathrm{g}$

(Alternate background limit: $12.8 \mu \mathrm{g} / \mathrm{g}$ )

\begin{tabular}{|c|c|c|c|c|c|}
\hline Area & Sample & $\mu g / q$ & Coord & nates & Type \\
\hline $\begin{array}{l}B-3 \text { Pond } \\
B-3 \text { Pond } \\
B-3 \text { Pond } \\
B-3 \text { Pond } \\
B-3 \text { Pond } \\
B-3-3 \text { Ditch } \\
B-3-3 \text { Ditch }\end{array}$ & $\begin{array}{l}8-138 \\
B-145 \\
B-146 \\
B-147 \\
B-147 \\
B-152 \\
B-189\end{array}$ & $\begin{array}{r}9.7 \\
10.2 \\
10.5 \\
9.8 \\
10.6 \\
11.2 \\
9.9\end{array}$ & $\begin{array}{l}N 43400 \\
N 43200 \\
N 43200 \\
N 43200 \\
N 43200 \\
1,279^{\prime} \\
1,000^{\prime}\end{array}$ & $\begin{array}{l}W 42500 \\
W 42000 \\
W 42000 \\
W 41900 \\
W 41900 \\
\text { from } A-29 \\
\text { from }\end{array}$ & $\begin{array}{l}\text { Laboratory duplicate } \\
\text { Field duplicate } \\
\text { Field duplicate } \\
\text { Laboratory duplicate } \\
\text { Laboratory duplicate } \\
\text { Field duplicate } \\
\text { Regular }\end{array}$ \\
\hline B-3-3 Ditch & $B-191$ & 10.3 & & & Select \\
\hline
\end{tabular}

Copper--Threshold value: $15.96 \mu \mathrm{g} / \mathrm{g}$

(Alternate background limit: $22.76 \mu \mathrm{g} / \mathrm{g}$ )

\begin{tabular}{|c|c|c|c|c|}
\hline Area & Sample & $\mu g / g$ & Coordi & lates \\
\hline $\begin{array}{l}3 A \text { Pond } \\
3 A \text { Pond } \\
3 A \text { Pond } \\
3 B \text { Pond } \\
3 C \text { Pond } \\
3 C \text { Pond } \\
3 C \text { Pond } \\
3 C \text { Pond } \\
3 C \text { Pond } \\
B-3 \text { Pond }\end{array}$ & $\begin{array}{l}B-196 \\
B-201 \\
B-202 \\
B-108 \\
B-171 \\
B-172 \\
B-177 \\
B-180 \\
B-180 \\
B-114\end{array}$ & $\begin{array}{l}17.2 \\
18.6 \\
20.1 \\
16.1 \\
16.3 \\
17.9 \\
18.5 \\
16.9 \\
16.2 \\
20.4\end{array}$ & $\begin{array}{l}N 42700 \\
N 43100 \\
N 43150 \\
N 42800 \\
\text { Ditch } 8 \\
\text { Ditch } 8 \\
\text { Ditch } 3 \\
\text { Ditch } 1 \\
\text { Ditch } 1 \\
\text { N43400 }\end{array}$ & $\begin{array}{l}W 41525 \\
W 41400 \\
W 41300 \\
W 40650 \\
500 \\
500 \\
300 \\
1,300 \\
1,300 \\
W 43300\end{array}$ \\
\hline
\end{tabular}

Type

Field duplicate*

Regular

Regular

Field duplicate*

Field duplicate

Field duplicate

Regular

Laboratory duplicate Laboratory duplicate

Regular 
WHC-SD-EN-AP-042, REV. 0

Copper (Cont)

\begin{tabular}{|c|c|c|c|c|c|}
\hline \multirow{13}{*}{$\begin{array}{l}\text { Area } \\
\\
B-3 \text { Pond } \\
B-3 \text { Pond } \\
B-3 \text { Pond } \\
B-3 \text { Pond } \\
B-3 \text { Pond } \\
B-3 \text { Pond } \\
B-3 \text { Pond } \\
B-3 \text { Pond } \\
B-3 \text { Pond } \\
B-3 \text { Pond } \\
B-3 \text { Pond } \\
B-3 \text { Pond } \\
B-3 \text { Pond } \\
B-3 \text { Pond } \\
B-3 \text { Pond } \\
B-3 \text { Pond } \\
B-3-3 \text { Ditch } \\
B-3-3 \text { Ditch } \\
B-3-3 \text { Ditch }\end{array}$} & \multirow{13}{*}{$\begin{array}{l}\text { Sample } \\
\text { B-115 } \\
B-115 \\
B-116 \\
B-128 \\
B-130 \\
B-131 \\
B-132 \\
B-135 \\
B-138 \\
B-138 \\
B-145 \\
B-146 \\
B-147 \\
B-147 \\
B-148 \\
B-164 \\
B-154 \\
B-161 \\
B-188\end{array}$} & $\mu g / g$ & \multicolumn{2}{|c|}{ Coordinates } & Type \\
\hline & & 19.2 & & & Laboratory duplicate \\
\hline & & 17.7 & N43500 & & $\begin{array}{l}\text { Regular } \\
\text { Reory auplicate }\end{array}$ \\
\hline & & $\begin{array}{l}17 . \\
32 .\end{array}$ & & & $\begin{array}{l}\text { ield duplicate } \\
\text { Regular }\end{array}$ \\
\hline & & & & & \\
\hline & & & & & duplicate \\
\hline & & & & & ry duplica \\
\hline & & & & & duplic \\
\hline & & & & & duplic \\
\hline & & & & & $\begin{array}{l}\text { atory duplicate } \\
\text { atory duplicate }\end{array}$ \\
\hline & & & $\begin{array}{l}N 43300 \\
N 43175\end{array}$ & & \\
\hline & & & & & \\
\hline & & & & & \\
\hline -3-3 Ditch & $B-189$ & 17.6 & & & Regular \\
\hline & & & & & \\
\hline & & & hea & & \\
\hline $\begin{array}{l}\text { B-3-3 Ditch } \\
\text { Cont. Bkg. } \\
\text { Cont. Bkg. } \\
\text { Cont. Bkg. }\end{array}$ & $\begin{array}{l}B-191 \\
B-103 \\
B-104 \\
B-105\end{array}$ & $\begin{array}{l}43.1 \\
18.1 \\
16.4 \\
16.2\end{array}$ & $\begin{array}{l}30^{\prime} \text { fro } \\
N 44800 \\
N 44600 \\
N 45400\end{array}$ & $\begin{array}{l}\text { Im head end } \\
\text { W43500 } \\
W 43200 \\
\text { W42500 }\end{array}$ & $\begin{array}{l}\text { Select } \\
\text { Regular } \\
\text { Regular } \\
\text { Laboratory duplicate* }\end{array}$ \\
\hline
\end{tabular}

Cyanide--Threshold value: NC

All values $\angle C D L$

Fluoride--Threshold Value: < CDL

Default to CDL, $1.0 \mu \mathrm{g} / \mathrm{g}$

NOTE: All sagebrush background observations are $<1 / 2$ CDL. All

contingency pond background observations are $\angle C D L$ or have matrix

interferences.

\begin{tabular}{|c|c|c|c|c|}
\hline Area & Sample & $\mu \mathrm{g} / \mathrm{O}_{-}$ & Coordinates & Type \\
\hline B-3-3 Ditch & B-161 & 1.29 & $0^{\prime}$ & Select \\
\hline
\end{tabular}

Iron--Threshold value: $29,437 \mathrm{\mu g} / \mathrm{g}$

(Alternate background limit: $40,909 \mu \mathrm{g} / \mathrm{g}$ )

\begin{tabular}{|c|c|c|c|c|c|}
\hline Area & Sample & $\mu q / q$ & Coordi & pates & Type \\
\hline $\begin{array}{l}B-3 \text { Pond } \\
B-3 \text { Pond } \\
B-3 \text { Pond }\end{array}$ & $\begin{array}{l}B-129 \\
B-131 \\
B-132\end{array}$ & $\begin{array}{l}30,750 \\
30,250 \\
35,716\end{array}$ & $\begin{array}{l}N 43600 \\
N 43400 \\
N 43300\end{array}$ & $\begin{array}{l}W 43000 \\
W 42800 \\
W 42900\end{array}$ & $\begin{array}{l}\text { Field duplicate* } \\
\text { Regular } \\
\text { Regular }\end{array}$ \\
\hline
\end{tabular}




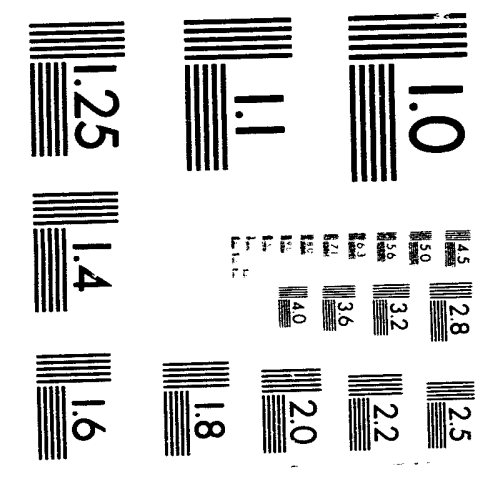



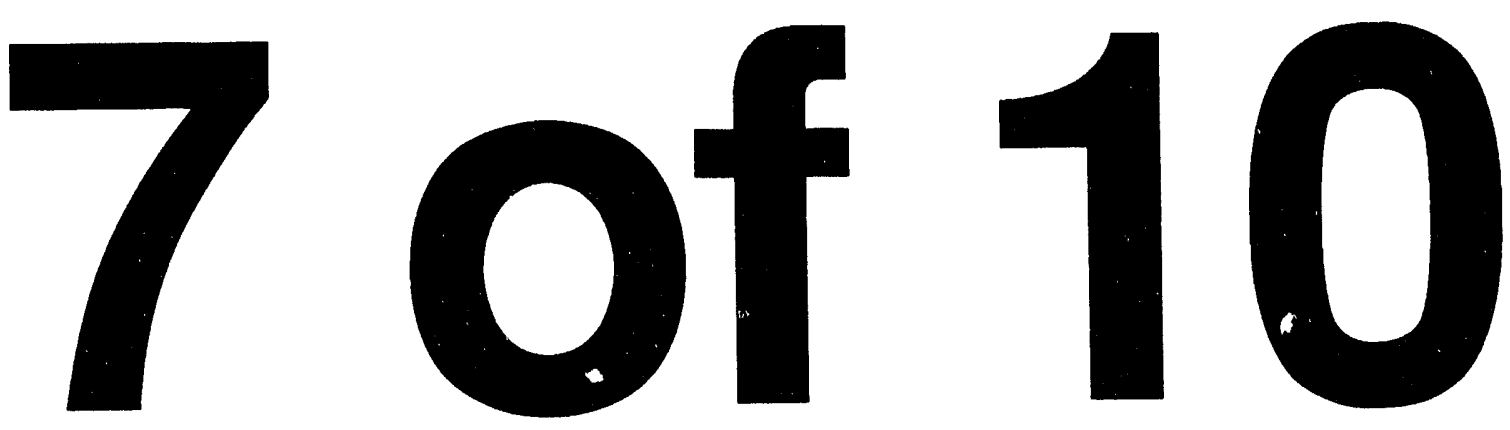
WHC-SD-EN-AP-042, REY. 0

Iron (Cont)

\begin{tabular}{|c|c|c|c|c|c|}
\hline Area & Sample & $\mu q / q$ & Coordin & lates & Type \\
\hline $\begin{array}{l}B-3 \text { Pond } \\
B-3 \text { Pond } \\
B-3 \text { Pond } \\
B-3 \text { Pond } \\
B-3 \text { Pond } \\
B-3 \text { Pond } \\
\text { B-3 Pond } \\
\text { B-3-3 Ditch } \\
\text { Cont. Bkg. }\end{array}$ & $\begin{array}{l}B-135 \\
B-138 \\
B-138 \\
B-146 \\
B-147 \\
B-147 \\
B-148 \\
B-191 \\
B-103\end{array}$ & $\begin{array}{l}29,724 \\
31,085 \\
29,511 \\
30,006 \\
32,099 \\
36,021 \\
32,809 \\
37,479 \\
29,671\end{array}$ & $\begin{array}{l}N 43100 \\
N 43400 \\
N 43400 \\
N 43200 \\
N 43200 \\
N 43200 \\
N 43300 \\
30 \text { fron } \\
N 44800\end{array}$ & $\begin{array}{l}W 42800 \\
W 42500 \\
W 42500 \\
W 42000 \\
W 41900 \\
W 41900 \\
W 42000 \\
\text { head end } \\
\text { W43500 }\end{array}$ & $\begin{array}{l}\text { Field duplicate* } \\
\text { Laboratory duplicate } \\
\text { Laboratory duplicate } \\
\text { Field duplicate } \\
\text { Laboratory duplicate } \\
\text { Laboratory duplicate } \\
\text { Regular } \\
\text { Select } \\
\text { Regular }\end{array}$ \\
\hline
\end{tabular}

Lead--Threshold value: $15.16 \mu \mathrm{g} / \mathrm{g}$

(Alternate background limit: $7.13 \mu \mathrm{g} / \mathrm{g}$ )

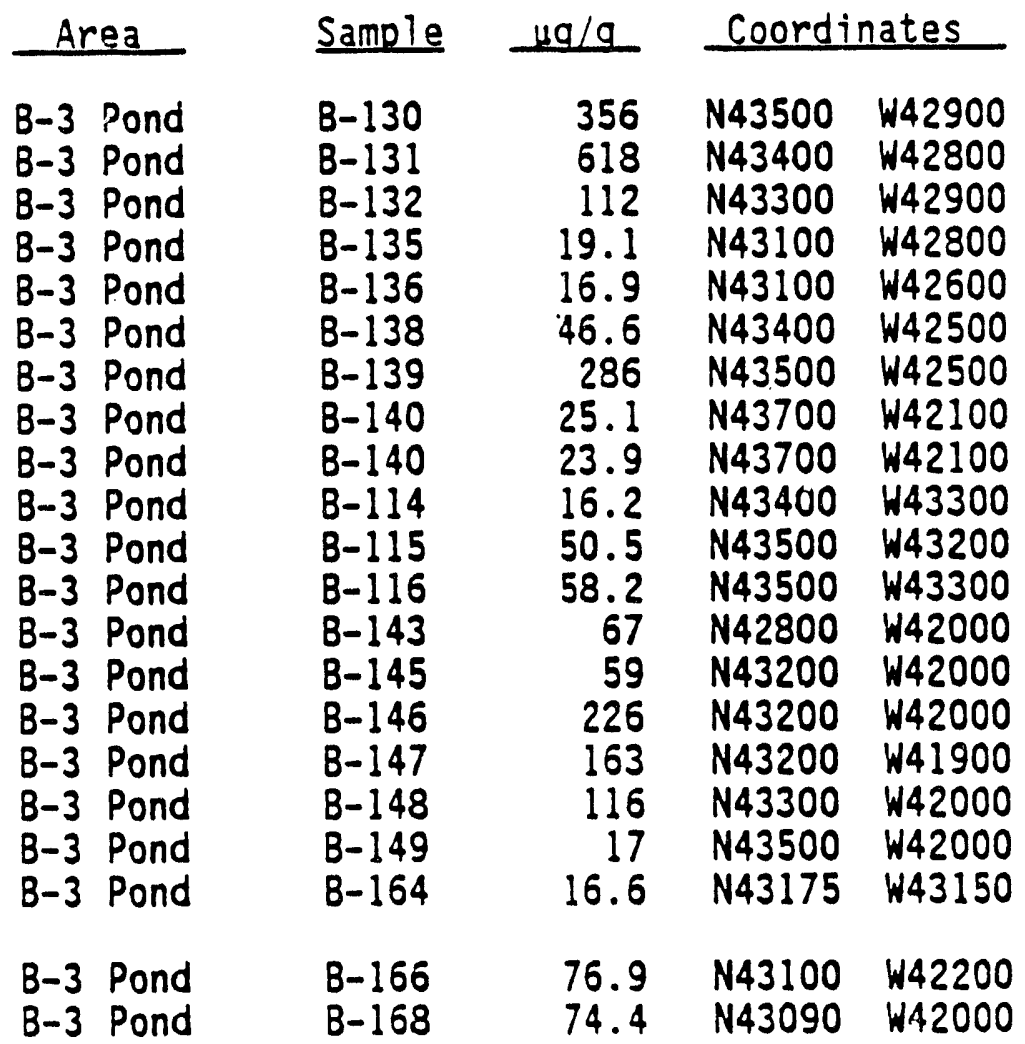

\begin{tabular}{l} 
Type \\
\hline Regular \\
Regular \\
Regular \\
Field dupl icate \\
Regular \\
Regular \\
Regular \\
Laboratory duplicate \\
Laboratory duplicate \\
Regular \\
Regular \\
Regular \\
Regular \\
Field duplicate \\
Field duplicate \\
Regular \\
Regular \\
Regular \\
Select-Field \\
duplicate* \\
Regular \\
Select
\end{tabular}

Lead, (EP)--Regulatory threshold value: $5 \mathrm{mg} / \mathrm{L}$

$\mathrm{CDL}=500 \mu \mathrm{g} / \mathrm{L}$

No observations $>\mathrm{CDL}$

Lithium--Threshold value: $10.2 \mu \mathrm{g} / \mathrm{g}$

(Alternate background limit: $11.9 \mu \mathrm{g} / \mathrm{g}$ )

NOTE: All background observations are slightly below the $10 \mu \mathrm{g} / \mathrm{g} \mathrm{CDL}$

\begin{tabular}{|c|c|c|c|c|}
\hline Area & Sample & $\mathrm{\mu g} / \mathrm{g}$ & Coordinates & Tyoe \\
\hline $\begin{array}{l}B-3 \text { Pond } \\
B-3 \text { Pond }\end{array}$ & $\begin{array}{l}8-114 \\
8-129\end{array}$ & $\begin{array}{l}11.8 \\
10.8\end{array}$ & $\begin{array}{ll}N 43400 & W 43300 \\
N 43600 & W 43000\end{array}$ & $\begin{array}{l}\text { Regular } \\
\text { Field duplicate* }\end{array}$ \\
\hline
\end{tabular}


WHC-SD-EN-AP-042, REV. 0

Lithium (Cont)

\begin{tabular}{|c|c|c|c|c|}
\hline Area & Sample & $\mu \mathrm{g} / \mathrm{Q}$ & Coordinates & Type \\
\hline $\begin{array}{l}\text { B-3 Pond } \\
B-3 \text { Pond } \\
B-3 \text { Pond } \\
B-3 \text { Pond } \\
B-3 \text { Pond } \\
B-3 \text { Pond } \\
B-3 \text { Pond } \\
B-3-3 \text { Ditch } \\
B-3-3 \text { Ditch }\end{array}$ & $\begin{array}{l}B-130 \\
B-131 \\
B-132 \\
B-134 \\
B-135 \\
B-147 \\
B-147 \\
B-154 \\
B-191\end{array}$ & $\begin{array}{l}16.1 \\
11.4 \\
11.8 \\
10.6 \\
11.4 \\
13.0 \\
13.9 \\
10.8 \\
10.8\end{array}$ & $\begin{array}{ll}N 43500 & W 42900 \\
N 43400 & W 42800 \\
N 43300 & W 42900 \\
N 43100 & W 42800 \\
N 43100 & W 42800 \\
N 43200 & W 41900 \\
N 43200 & W 41900 \\
1,200, & \text { from A-29 } \\
30^{\prime}, \text { from head end }\end{array}$ & $\begin{array}{l}\text { Regular } \\
\text { Regular } \\
\text { Regular } \\
\text { Field duplicate } \\
\text { Field duplicate } \\
\text { Laboratory duplicate } \\
\text { Laboratory duplicate } \\
\text { Regular } \\
\text { Select }\end{array}$ \\
\hline
\end{tabular}

Magnesium--Threshold value: $6,408 \mu \mathrm{g} / \mathrm{g}$

(Alternate background limit: $9,027 \mu \mathrm{g} / \mathrm{g}$ )

\begin{tabular}{|c|c|c|c|c|c|}
\hline Area & Sample & $\mu \mathrm{g} / \mathrm{g}$ & Coord & nates & Type \\
\hline $\begin{array}{l}3 A \text { Pond } \\
B-3 \text { Pond } \\
B-3 \text { Pond } \\
B-3 \text { Pond } \\
B-3 \text { Pond } \\
B-3-3 \text { Ditch }\end{array}$ & $\begin{array}{l}B-200 \\
B-135 \\
B-147 \\
B-147 \\
B-148 \\
B-154\end{array}$ & $\begin{array}{l}6,546 \\
6,439 \\
6,553 \\
7,423 \\
6,649 \\
6,635\end{array}$ & $\begin{array}{l}N 43250 \\
N 43100 \\
N 43200 \\
N 43200 \\
N 43300 \\
1,200\end{array}$ & $\begin{array}{l}W 41625 \\
W 42800 \\
W 41900 \\
W 41900 \\
W 42000 \\
\text { from A-29 }\end{array}$ & $\begin{array}{l}\text { Regular } \\
\text { Field duplicate* } \\
\text { Laboratory duplicate } \\
\text { Laboratory duplicate } \\
\text { Regular } \\
\text { Regular }\end{array}$ \\
\hline
\end{tabular}

Manganese--Threshold value: $391 \mathrm{\mu g} / \mathrm{g}$

(Alternate background limit: $585 \mu \mathrm{g} / \mathrm{g}$ )

\begin{tabular}{|c|c|c|c|c|c|}
\hline Area & Sample & $\mu \mathrm{g} / \mathrm{q}$ & Coord & inates & Type \\
\hline $\begin{array}{l}3 A \text { Pond } \\
3 A \text { Pond } \\
3 A \text { Pond } \\
B-3-3 \text { Ditch } \\
B-3-3 \text { Ditch }\end{array}$ & $\begin{array}{l}B-194 \\
B-200 \\
B-201 \\
B-152 \\
B-188\end{array}$ & $\begin{array}{l}518 \\
427 \\
856 \\
427 \\
427\end{array}$ & \multirow{4}{*}{\multicolumn{2}{|c|}{$\begin{array}{l}N 42700 \text { W41525 } \\
N 43250 \text { W41625 } \\
\text { N43100 W41400 } \\
1,279^{\prime} \text { from A-29 } \\
1,400^{\prime} \text { from } \\
\text { head end } \\
1,000^{\prime} \text { from } \\
\text { head end } \\
500^{\prime} \text { from } \\
\text { head end } \\
\text { N44800 W43500 }\end{array}$}} & $\begin{array}{l}\text { Field duplicate } \\
\text { Regular } \\
\text { Regular } \\
\text { Field duplicate* } \\
\text { Regular }\end{array}$ \\
\hline B-3-3 Ditch & $B-189$ & 395 & & & Regular \\
\hline B-3-3 Ditch & $B-190$ & 570 & & & Regular \\
\hline Cont. Bkg. & $B-103$ & 398 & & & Regular \\
\hline
\end{tabular}

Mercury--Threshold value: NC

Default to CDL, $0.2 \mu \mathrm{g} / \mathrm{g}$

NOTE: Based on nine reagent blanks -- $L O D=0.39 \mu \mathrm{g} / \mathrm{g} ; \quad L O Q=2.92 \mu \mathrm{g} / \mathrm{g}$

All values including background censored by laboratory below CDL

Sagebrush sites -- 0 of $5>\mathrm{CDL}$

Contingency pond area -- 0 of $5>\mathrm{CDL}$

18 of 22 sites in the $B-3$ Pond $>C D L$ (22 of 18 observations)

3 of 11 sites in the $B-3-3$ Ditch $>C D L$ ( 3 of 15 observations) 
WHC-SD-EN-AP-042, REV. 0

Mercury (Cont)

\begin{tabular}{|c|c|c|c|c|}
\hline Area & Sampie & $\mu g / q$ & Coordi & nates \\
\hline $\begin{array}{l}B-3 \text { Pond } \\
B-3 \text { Pond } \\
B-3 \text { Pond } \\
B-3 \text { Pond } \\
B-3 \text { Pond } \\
B-3 \text { Pond } \\
B-3 \text { Pond } \\
B-3 \text { Pond } \\
B-3 \text { Pond } \\
B-3 \text { Pond } \\
B-3 \text { Pond } \\
B-3 \text { Pond } \\
B-3 \text { Pond } \\
B-3 \text { Pond } \\
B-3 \text { Pond } \\
B-3 \text { Pond } \\
B-3 \text { Pond } \\
B-3 \text { Pond } \\
B-3 \text { Pond } \\
B-3 \text { Pond } \\
B-3 \text { Pond } \\
B-3 \text { Pond } \\
B-3-3 \text { Ditch } \\
B-3-3 \text { Ditch } \\
B-3-3 \text { Ditch }\end{array}$ & $\begin{array}{l}B-114 \\
B-114 \\
B-115 \\
B-116 \\
B-130 \\
B-131 \\
B-132 \\
B-134 \\
B-135 \\
B-136 \\
B-138 \\
B-139 \\
B-140 \\
B-143 \\
B-143 \\
B-145 \\
B-147 \\
B-148 \\
B-164 \\
B-165 \\
B-166 \\
B-168 \\
B-154 \\
B-161 \\
B-188\end{array}$ & $\begin{array}{r}1.7 \\
1.4 \\
2.4 \\
3.2 \\
11.6 \\
7.0 \\
15.6 \\
0.7 \\
1.1 \\
1.7 \\
1.7 \\
1.4 \\
0.7 \\
1.2 \\
1.0 \\
1.6 \\
3.7 \\
1.2 \\
0.8 \\
0.3 \\
0.6 \\
0.7 \\
0.2 \\
0.6 \\
0.4\end{array}$ & $\begin{array}{l}N 43400 \\
N 43400 \\
N 43500 \\
N 43500 \\
N 43500 \\
N 43400 \\
N 43300 \\
N 43100 \\
N 43100 \\
N 43100 \\
N 43400 \\
N 43500 \\
N 43700 \\
N 42800 \\
N 42800 \\
N 43200 \\
N 43200 \\
N 43300 \\
N 43175 \\
N 43175 \\
N 43100 \\
N 43090 \\
1,200 \\
A t A-29 \\
1,400^{\prime} \\
\text { head }\end{array}$ & $\begin{array}{l}W 43300 \\
W 43300 \\
W 43200 \\
W 43300 \\
W 42900 \\
W 42800 \\
W 42900 \\
W 42800 \\
W 42800 \\
W 42600 \\
W 42500 \\
W 42500 \\
W 42100 \\
W 42000 \\
W 42000 \\
W 42000 \\
W 41900 \\
W 42000 \\
W 43150 \\
W 43150 \\
W 42200 \\
W 42000 \\
\text { from A-29 } \\
\text { junction } \\
\text { from } \\
\text { end }\end{array}$ \\
\hline
\end{tabular}

Type
Laboratory dupl icate
Laboratory duplicate
Regular
Regular
Regular
Regular
Regular
Field duplicate
Field dupl icate
Regular
Regular
Regular
Regular
Laboratory duplicate
Laboratory duplicate
Field duplicate
Regular
Regular
Select-Field duplicate
Select-Field duplicate
Regular
Select
Regular
Select
Regular

Mercury, (EP)--Regulatory threshold value: $0.2 \mathrm{mg} / \mathrm{L}$ $\mathrm{CDL}=20 \mu \mathrm{g} / \mathrm{L}$

No observations $>C D L$

Molybdenum--Threshold value: NC

All values $\angle C D L$

Nickel--Threshold value: $12.3 \mu \mathrm{g} / \mathrm{g}$

(Alternate background 1imit: $22.0 \mu \mathrm{g} / \mathrm{g}$ )

\begin{tabular}{|c|c|c|c|c|}
\hline Area & Sample & $\mu \mathrm{g} / \mathrm{g}$ & Coordinates & Tyoe \\
\hline $\begin{array}{l}\text { B-3 Pond } \\
\text { B-3 Pond } \\
B-3 \text { Pond } \\
B-3-3 \text { Ditch }\end{array}$ & $\begin{array}{l}B-130 \\
B-147 \\
B-147 \\
B-184\end{array}$ & $\begin{array}{l}14.6 \\
13.7 \\
15.0 \\
13.5\end{array}$ & $\begin{array}{l}N 43500 \text { W42900 } \\
N 43200 \text { W41900 } \\
N 43200 \text { W41900 } \\
2,300^{\prime} \text { from } \\
\text { head end }\end{array}$ & $\begin{array}{l}\text { Regular } \\
\text { Laboratory duplicate } \\
\text { Laboratory duplicate } \\
\text { Field duplicate* }\end{array}$ \\
\hline $\begin{array}{l}\text { B-3-3 Ditch } \\
\text { Cont. Bkg. }\end{array}$ & $\begin{array}{l}8-191 \\
8-102\end{array}$ & $\begin{array}{l}19.2 \\
13.9\end{array}$ & $\begin{array}{l}30^{\prime} \text { from head end } \\
N 45100 \text { W42600 }\end{array}$ & $\begin{array}{l}\text { Select } \\
\text { Regular }\end{array}$ \\
\hline
\end{tabular}

Nitrate--Threshold value: $22.7 \mathrm{\mu g} / \mathrm{g}$

(Alternate background 1imit: $5.33 \mu \mathrm{g} / \mathrm{g}$ )

No observations above threshold 
Nitrite--Threshold value: $2.44 \mathrm{\mu g} / \mathrm{g}$

(Alternate background limit: NC; all values <1/2 CDL)

No observations above threshold

NOTE: Most sagebrush background observations <CDL

Phosphate--Threshold value: $4.56 \mu \mathrm{g} / \mathrm{g}$

(A7ternate background 1 imit: default to $\mathrm{CDL}, 2.0 \mu \mathrm{g} / \mathrm{g}$ )

No observations above threshold

Potassium--Threshold value: $1,758 \mu \mathrm{g} / \mathrm{g}$

(Alternate background limit: $1,883 \mu \mathrm{g} / \mathrm{g}$ )

\begin{tabular}{|c|c|c|c|c|c|}
\hline Area & Sample & $\mu \mathrm{g} / \mathrm{a}$ & Coordi & ates & Type \\
\hline $\begin{array}{l}B-3 \text { Pond } \\
B-3 \text { Pond } \\
B-3 \text { Pond } \\
B-3 \text { Pond } \\
B-3 \text { Pond } \\
B-3 \text { Pond } \\
B-3 \text { Pond } \\
B-3 \text { Pond } \\
B-3 \text { Pond } \\
B-3 \text { Pond }\end{array}$ & $\begin{array}{l}B-114 \\
B-129 \\
B-130 \\
B-132 \\
B-134 \\
B-135 \\
B-140 \\
B-146 \\
B-147 \\
B-147\end{array}$ & $\begin{array}{l}1,841 \\
2,019 \\
2,021 \\
2,276 \\
1,851 \\
1,939 \\
1,827 \\
1,884 \\
2,522 \\
2,867\end{array}$ & $\begin{array}{l}N 43400 \\
N 43600 \\
N 43500 \\
N 43300 \\
N 43100 \\
N 43100 \\
N 43700 \\
N 43200 \\
N 43200 \\
N 43200\end{array}$ & $\begin{array}{l}W 43300 \\
W 43000 \\
W 42900 \\
W 42900 \\
W 42800 \\
W 42800 \\
W 42100 \\
W 42000 \\
W 41900 \\
W 41900\end{array}$ & $\begin{array}{l}\text { Regular } \\
\text { Field duplicate } \\
\text { Regular } \\
\text { Regular } \\
\text { Field duplicate } \\
\text { Field duplicate } \\
\text { Regular } \\
\text { Field duplicate } \\
\text { Laboratory duplicate } \\
\text { Laboratory duplicate }\end{array}$ \\
\hline
\end{tabular}

Selenium--Threshold value: NC

All values $\angle C D L$

Selenium, (EP)--Regulatory threshold value: $1 \mathrm{mg} / \mathrm{L}$ $C D L=500 \mu g / L$

No observations >CDL

Silver--Threshold value: NC

Default to CDL, $1.0 \mu \mathrm{g} / \mathrm{g}$

Sagebrush sites -- 0 of $5>1 / 2$ CDL

Contingency pond area -- 0 of 5 sites $>1 / 2$ CDL

Based on reagent blanks -- $L O D=0.45 \mu \mathrm{g} / \mathrm{g} ; L O Q=1.45 \mu \mathrm{g} / \mathrm{g}$

1 of 8 sites in the $3 C$ Pond $>C D L$, ( 1 of 10 observations)

11 of 22 sites in main pond >CDL, (16 of 30 observations)

\begin{tabular}{|c|c|c|c|c|}
\hline Area & Sample & $\mu \alpha / q$ & Coordinates & Type \\
\hline $\begin{array}{l}3 C \text { Pond } \\
B-3 \text { Pond } \\
B-3 \text { Pond } \\
B-3 \text { Pond } \\
B-3 \text { Pond } \\
B-3 \text { Pond } \\
B-3 \text { Pond } \\
B-3 \text { Pond } \\
B-3 \text { Pond } \\
B-3 \text { Pond } \\
B-3 \text { Pond } \\
B-3 \text { Pond }\end{array}$ & $\begin{array}{l}B-177 \\
B-115 \\
B-115 \\
B-116 \\
B-130 \\
B-131 \\
B-132 \\
B-135 \\
B-138 \\
B-138 \\
B-139 \\
B-145\end{array}$ & $\begin{array}{l}1.2 \\
2.5 \\
2.1 \\
1.7 \\
4.6 \\
3.6 \\
2.2 \\
1.2 \\
1.0 \\
1.2 \\
2.1 \\
2.0\end{array}$ & $\begin{array}{ll}\text { Ditch } 3, & 300 \\
N 43500 & W 43200 \\
N 43500 & W 43200 \\
N 43500 & W 43300 \\
N 43500 & W 42900 \\
N 43400 & W 42800 \\
N 43300 & W 42900 \\
N 43100 & W 42800 \\
N 43400 & W 42500 \\
N 43400 & W 42500 \\
N 43500 & W 42500 \\
N 43200 & W 42000\end{array}$ & $\begin{array}{l}\text { Regular } \\
\text { Laboratory duplicate } \\
\text { Laboratory duplicate } \\
\text { Regular } \\
\text { Regular } \\
\text { Regular } \\
\text { Regular } \\
\text { Field duplicate } \\
\text { Laboratory duplicate } \\
\text { Laboratory duplicate } \\
\text { Regular } \\
\text { Field duplicate }\end{array}$ \\
\hline
\end{tabular}


WHC-SD-EN-AP-042, REY. 0

Silver (Cont)

\begin{tabular}{|c|c|c|c|c|c|}
\hline Area & Sample & $\mu \mathrm{g} / \mathrm{q}$ & Coord & nates & Type \\
\hline $\begin{array}{l}B-3 \text { Pond } \\
B-3 \text { Pond } \\
B-3 \text { Pond } \\
B-3 \text { Pond } \\
B-3 \text { Pond }\end{array}$ & $\begin{array}{l}B-146 \\
B-147 \\
8-147 \\
B-148 \\
B-168\end{array}$ & $\begin{array}{l}2.0 \\
3.5 \\
5.1 \\
1.1 \\
1.0\end{array}$ & $\begin{array}{l}\text { N43200 } \\
\text { N43200 } \\
\text { N43200 } \\
\text { N43300 } \\
\text { N43090 }\end{array}$ & $\begin{array}{l}W 42000 \\
W 41900 \\
W 41900 \\
W 42000 \\
W 42000\end{array}$ & $\begin{array}{l}\text { Field duplicate } \\
\text { Laboratory duplicate } \\
\text { Laboratory duplicate } \\
\text { Regular } \\
\text { Select }\end{array}$ \\
\hline
\end{tabular}

Silvor, (EP)--Regulatory threshold value: $5 \mathrm{mg} / \mathrm{L}$ $\mathrm{CDL}=500 \mu \mathrm{g} / \mathrm{L}$

No observations $>C D L$

Sodium--Threshold value: $280.2 \mathrm{\mu g} / \mathrm{g}$

(Alternate background limit: $493.5 \mu \mathrm{g} / \mathrm{g}$ )

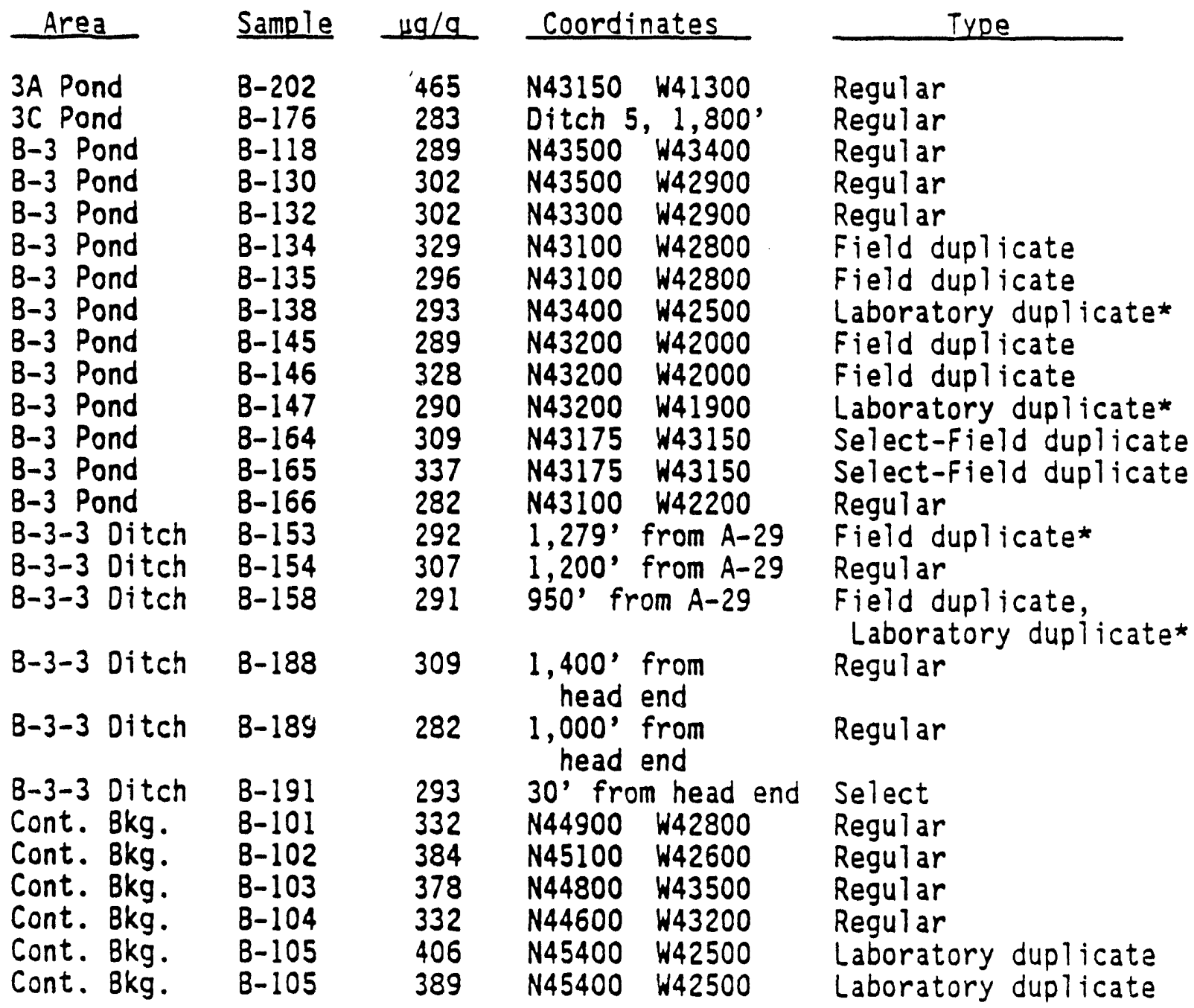


WHC-SD-EN-AP-042, REV. 0

Strontium--Threshold value: $30.1 \mathrm{\mu g} / \mathrm{g}$

(Alternate background limit: $33.1 \mu \mathrm{g} / \mathrm{g}$ )

\begin{tabular}{|c|c|c|c|c|c|}
\hline Area & Sample & $\mu \mathrm{g} / \mathrm{q}$ & Coordi & nates & Type \\
\hline $\begin{array}{l}3 A \text { Pond } \\
3 A \text { Pond } \\
3 A \text { Pond } \\
3 A \text { Pond } \\
B-3 \text { Pond } \\
B-3 \text { Pond } \\
B-3 \text { Pond } \\
B-3-3 \text { Ditch }\end{array}$ & $\begin{array}{l}B-197 \\
B-200 \\
B-201 \\
B-202 \\
B-130 \\
B-147 \\
B-147 \\
B-154\end{array}$ & $\begin{array}{l}30.6 \\
46.1 \\
31.0 \\
31.7 \\
34.7 \\
31.5 \\
33.7 \\
34.8\end{array}$ & $\begin{array}{l}N 43000 \\
N 43250 \\
N 43100 \\
N 43150 \\
N 43500 \\
N 43200 \\
N 43200 \\
1,200\end{array}$ & $\begin{array}{l}W 41475 \\
W 41625 \\
W 41400 \\
W 41300 \\
W 42900 \\
W 41900 \\
W 41900 \\
\text { from A-29 }\end{array}$ & $\begin{array}{l}\text { Regular } \\
\text { Regular } \\
\text { Regular } \\
\text { Regular } \\
\text { Regular } \\
\text { Laboratory duplicate } \\
\text { Laboratory duplicate } \\
\text { Regular }\end{array}$ \\
\hline
\end{tabular}

Sulfate--Threshold value: $5.55 \mu \mathrm{g} / \mathrm{g}$

(Alternate background limit: $3,347 \mu \mathrm{g} / \mathrm{g}$ )

Alternate threshold value: $68.8 \mu \mathrm{g} / \mathrm{g}$

(Based on lognormal tolerance interval, see text.)

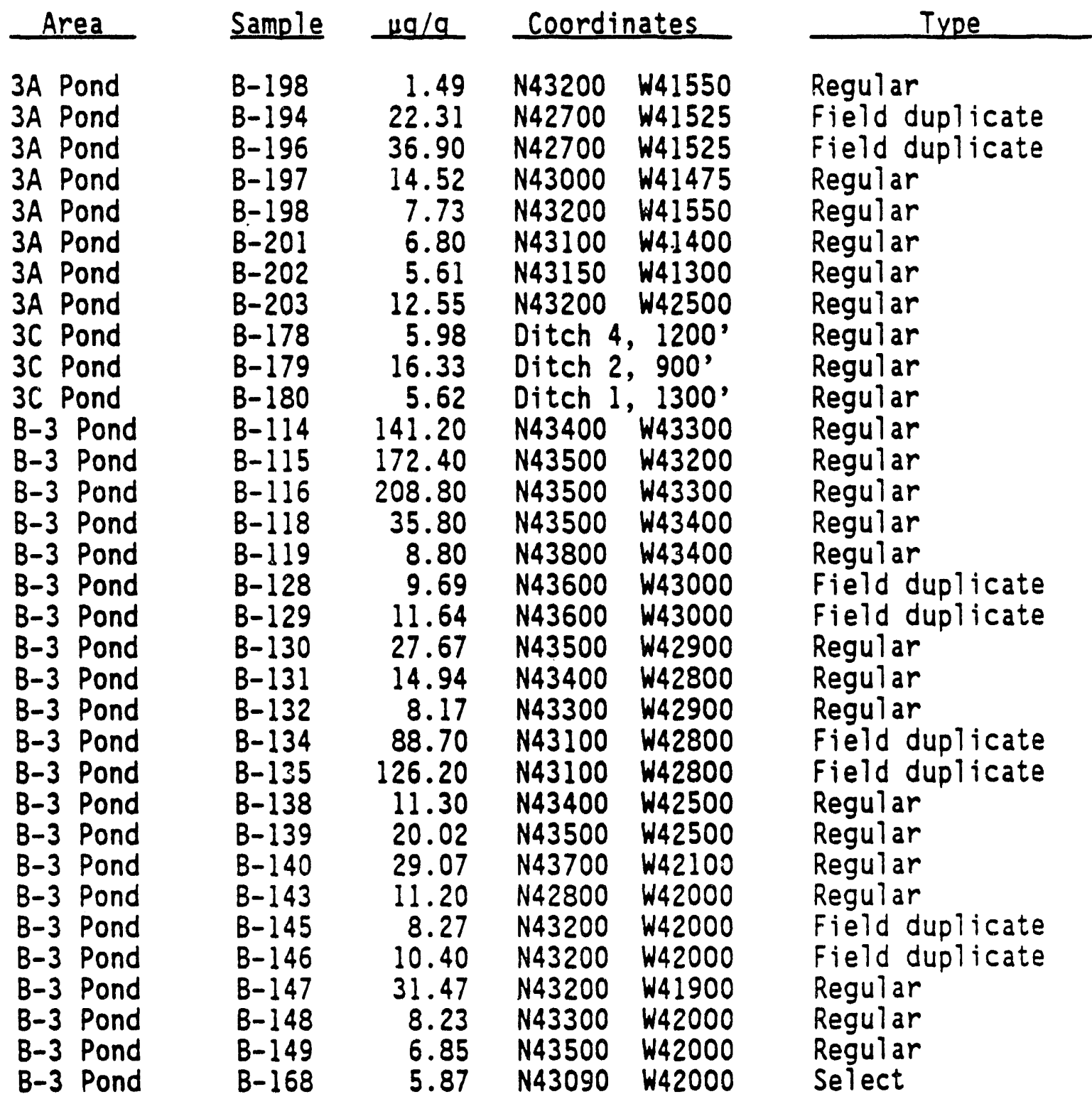


WHC-SD-EN-AP-042, REV. 0

Sulfate (Cont)

\begin{tabular}{|c|c|c|c|c|}
\hline Area & Sample & $\mu \mathrm{g} / \mathrm{g}$ & Coordinates & Tyoe \\
\hline $\begin{array}{l}\text { B-3-3 Ditch } \\
\text { B-3-3 Ditch } \\
\text { Cont. Bkg. } \\
\text { Cont. Bkg. } \\
\text { Cont. Bkg. } \\
\text { Cont. Bkg. }\end{array}$ & $\begin{array}{l}B-161 \\
B-191 \\
B-101 \\
B-103 \\
B-104 \\
B-105\end{array}$ & $\begin{array}{l}6.94 \\
7.12 \\
84.2 \\
1,664 \\
281 \\
192\end{array}$ & 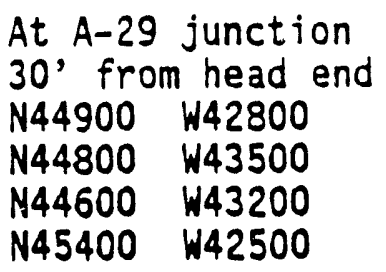 & $\begin{array}{l}\text { Select } \\
\text { Select } \\
\text { Regular } \\
\text { Regular } \\
\text { Regular } \\
\text { Regular }\end{array}$ \\
\hline
\end{tabular}

Sulfide--Threshold value: NC

All values <CDL except two

Default to CDL, $10 \mu \mathrm{g} / \mathrm{g}$

Sagebrush sites -- 0 of $5<1 / 2 \mathrm{CDL}$

Contingency pond area - 0 of 5 sites $<1 / 2 \mathrm{COL}$

Based on reagent blanks -- $L O D=5.63 \mu \mathrm{g} / \mathrm{g} ; \mathrm{LOQ}=16.7 \mathrm{\mu g} / \mathrm{g}$

1 of 7 sites in the $3 A$ Pond $>C D L$, ( 1 of 8 observations)

1 of 8 sites in $3 C$ Pond $>C D L$, ( 1 of 9 observations)

\begin{tabular}{|c|c|c|c|}
\hline Area & Sample & $\mu g / q$ & Coordinates \\
\hline $\begin{array}{l}3 A \text { Pond } \\
3 C \text { Pond }\end{array}$ & $\begin{array}{l}B-198 \\
B-179\end{array}$ & $\begin{array}{l}25.7 \\
10.9\end{array}$ & $\begin{array}{l}N 43200 \text { W41550 } \\
\text { Ditch 2, } 900^{\prime}\end{array}$ \\
\hline
\end{tabular}

Type

Regular Regular

Thallium--Threshold value: NC

Alt values $<C D L$

Titanium--Threshold value: $2,552 \mu \mathrm{g} / \mathrm{g}$

(A1ternate background limit: $3,931 \mathrm{\mu g} / \mathrm{g}$ )

\begin{tabular}{|c|c|c|c|c|}
\hline Area & Sample & $\mu \mathrm{g} / \mathrm{g}$ & \multicolumn{2}{|c|}{ Coordinates } \\
\hline $\begin{array}{l}3 B \text { Pond } \\
B-3 \text { Pond } \\
B-3 \text { Pond } \\
B-3 \text { Pond } \\
B-3 \text { Pond } \\
B-3 \text { Pond } \\
B-3 \text { Pond } \\
B-3 \text { Pond } \\
B-3 \text { Pond } \\
B-3-3 \text { Ditch } \\
\text { Cont. Bkg. } \\
\text { Cont. Bkg. } \\
\text { Cont. Bkg. }\end{array}$ & $\begin{array}{l}B-106 \\
B-129 \\
B-132 \\
B-138 \\
B-138 \\
B-139 \\
B-145 \\
B-146 \\
B-148 \\
B-153 \\
B-103 \\
B-105 \\
B-105\end{array}$ & $\begin{array}{l}2,599 \\
2,620 \\
2,848 \\
2,864 \\
2,821 \\
2,917 \\
2,748 \\
2,668 \\
2,646 \\
2,560 \\
2,714 \\
2,806 \\
2,762\end{array}$ & $\begin{array}{l}N 42300 \\
N 43600 \\
N 43300 \\
N 43400 \\
N 43400 \\
N 43500 \\
N 43200 \\
N 43200 \\
N 43300 \\
1,279 \\
N 44800 \\
N 45400 \\
N 45400\end{array}$ & $\begin{array}{l}W 40550 \\
W 43000 \\
W 42900 \\
W 42500 \\
W 42500 \\
W 42500 \\
W 42000 \\
W 42000 \\
W 42000 \\
\text { from A-29 } \\
W 43500 \\
W 42500 \\
W 42500\end{array}$ \\
\hline
\end{tabular}

Type

Regular

Field duplicate*

Regular

Laboratory duplicate

Laboratory duplicate

Regular

Field duplicate

Field duplicate

Regular

Field duplicate*

Regular

Laboratory duplicate

Laboratory duplicate

Vanadium--Threshold value: $63.8 \mathrm{\mu g} / \mathrm{g}$

(Alternate background limit: $95.3 \mu \mathrm{g} / \mathrm{g}$ )

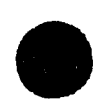

\begin{tabular}{|c|c|c|c|}
\hline Area & Sample & $\mu g / g$ & Coordinates \\
\hline $\begin{array}{l}38 \text { Pond } \\
38 \text { Pond }\end{array}$ & $\begin{array}{l}B-106 \\
B-107\end{array}$ & $\begin{array}{l}71.1 \\
68.1\end{array}$ & $\begin{array}{l}N 42300 \\
N 42300\end{array}$ \\
\hline
\end{tabular}

Type
Regular
Regular


WHC-SD-EN-AP-042, REV. 0

Vanadium (Cont)

\begin{tabular}{|c|c|c|c|c|}
\hline Area & Sample & $\mu a / a$ & \multicolumn{2}{|c|}{ Coordinates } \\
\hline 3B Pond & $B-108$ & 70.9 & $N 42800$ & $W 40650$ \\
\hline$B-3$ Pond & $B-118$ & 65.0 & $N 43500$ & $W 43400$ \\
\hline B-3 Pond & $B-119$ & 67.2 & N43800 & $W 43400$ \\
\hline B-3 Pond & $B-129$ & 69.3 & $N 43600$ & $W 43000$ \\
\hline B-3 Pond & $B-131$ & 66.3 & N43400 & $W 42800$ \\
\hline B-3 Pond & $B-132$ & 81.8 & N43300 & W42900 \\
\hline B-3 Pond & $B-134$ & 65.3 & $N 43100$ & $W 42800$ \\
\hline B-3 Pond & B-135 & 68.8 & $N 43100$ & $W 42800$ \\
\hline B-3 Pond & $B-138$ & 76.8 & $N 43400$ & $W 42500$ \\
\hline B-3 Pond & $B-138$ & 72.5 & $N 43400$ & $W 42500$ \\
\hline B-3 Pond & $B-139$ & 73.5 & $N 43500$ & $W 42500$ \\
\hline B-3 Pond & 140 & 65.6 & N43700 & $W 42100$ \\
\hline B-3 Pond & & 70.6 & N43200 & $W 42000$ \\
\hline B-3 Pond & & .6 & $N 43200$ & $W 42000$ \\
\hline B-3 Pond & & 5.5 & $N 43200$ & W41900 \\
\hline B-3 Pond & & .7 & $N 43200$ & $W 41900$ \\
\hline -3-3 Ditch & $0: 0$ & 65.6 & $1,279^{\circ}$ & from $A-29$ \\
\hline $2,0 \mathrm{n}+\mathrm{b}^{2}$ & $B-18$ & 69.4 & $1,000^{\prime}$ & from \\
\hline Cont. Bkg. & $B-103$ & 68.7 & N44800 & $W 43500$ \\
\hline Cont. Bkg. & $B-105$ & 72.4 & N45400 & $W 42500$ \\
\hline Cont. Bkg. & & 73.2 & N45400 & $W 42500$ \\
\hline
\end{tabular}

Type
Field dupl icate
Regular
Laboratory duplicate
Field duplicate
Regular
Regular
Field duplicate
Field duplicate
Laboratory duplicate
Laboratory duplicate
Regular
Regular
Field duplicate
Field duplicate
Laboratory duplicate
Laboratory duplicate
Field duplicate
Regular
Regular
Laboratory duplicate
Laboratory duplicate

Zinc--Threshold value: maximum of five background values, $41.3 \mathrm{\mu g} / \mathrm{g}$

(Alternate background maximum: $44 \mu \mathrm{g} / \mathrm{g}$ )

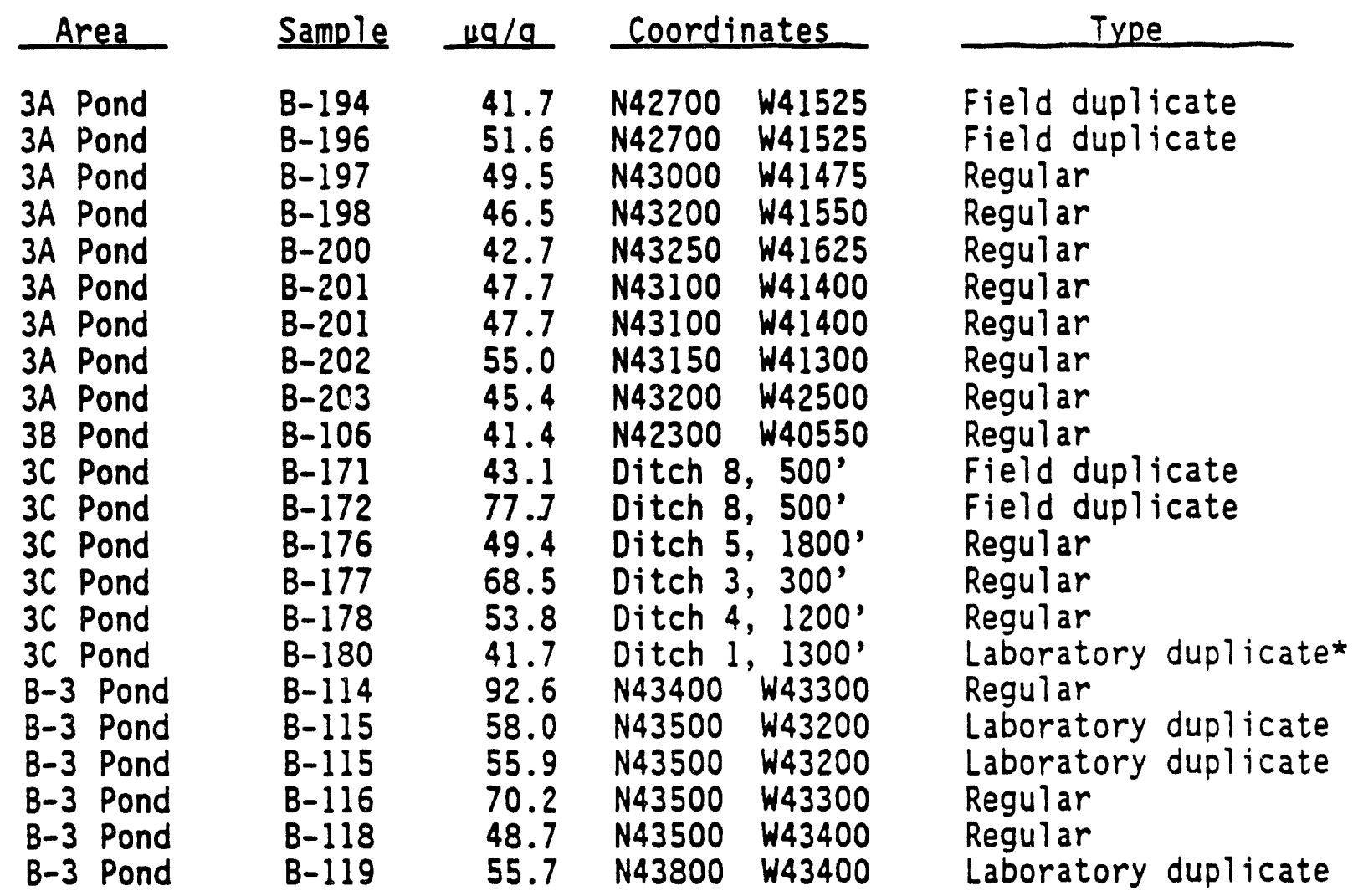


WHC-SD-EN-AP-042, REY. 0

Zinc (Cont)

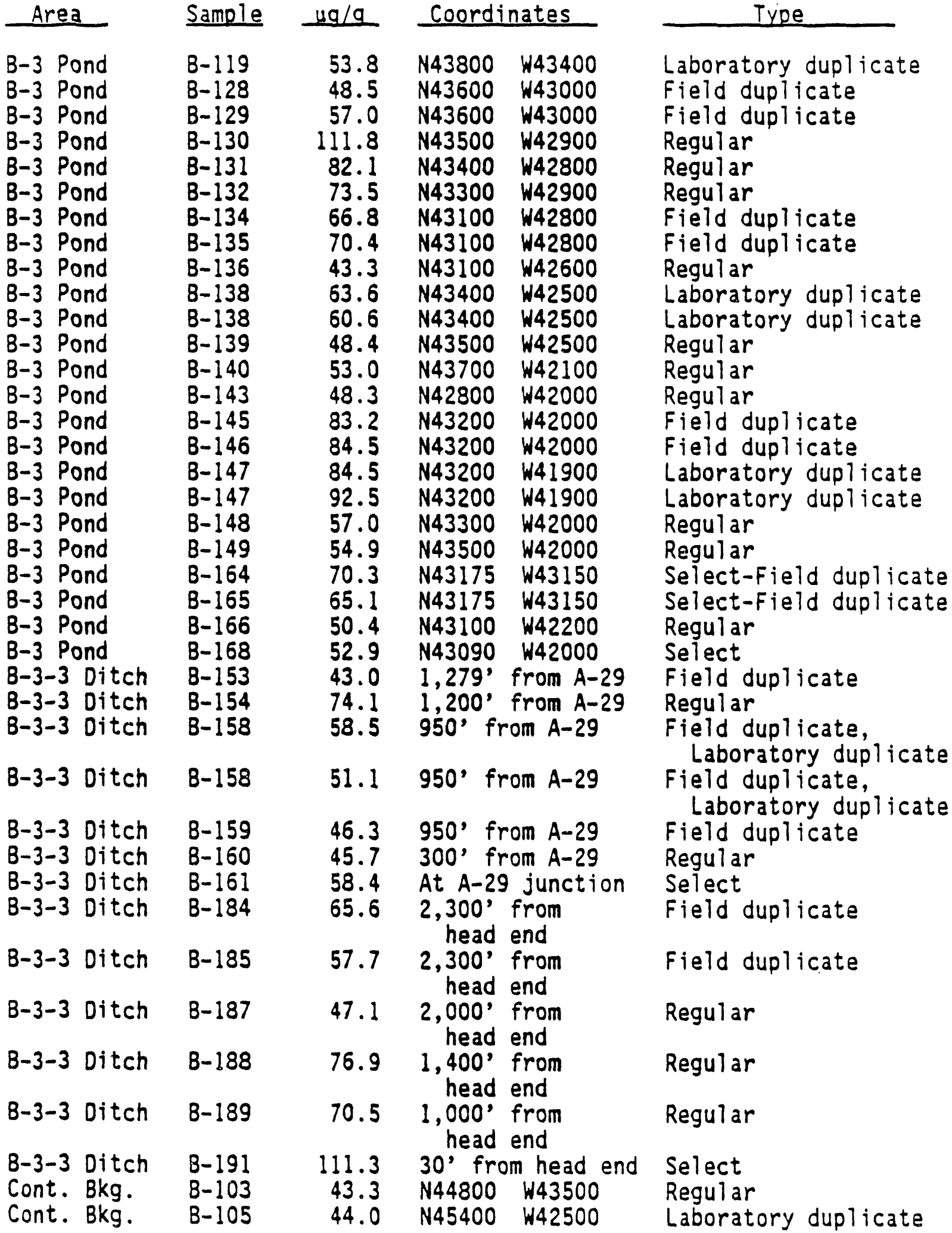


WHC-SD-EN-AP-042, REV. 0

Zirconium--Threshold value: maximum of five background values, $23.1 \mathrm{\mu g} / \mathrm{g}$ (Alternate background maximum: $28.7 \mu \mathrm{g} / \mathrm{g}$ )

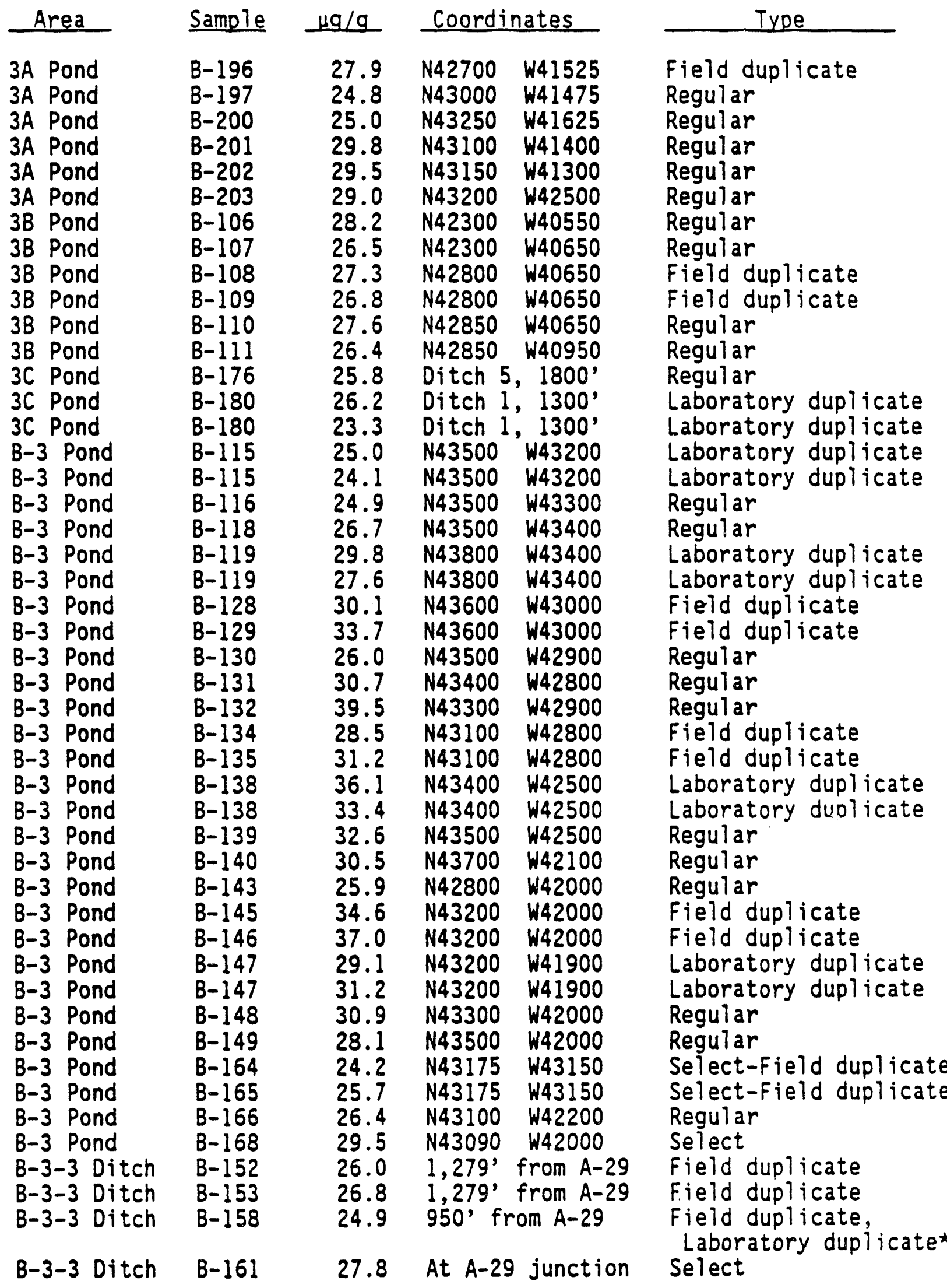


WHC-SD-EN-AP-042, REY. 0

Zirconium (Cont)

\begin{tabular}{|c|c|c|c|c|c|}
\hline Area & Sample & $\mu \mathrm{g} / \mathrm{q}$ & \multicolumn{2}{|c|}{ Coordinates } & Type \\
\hline B-3-3 Ditch & $B-188$ & 26.1 & $1,400^{\prime}$ & from & Regular \\
\hline B-3-3 Ditch & B-189 & 25.5 & 1,000, & & Regular \\
\hline $\begin{array}{l}\text { B-3-3 Ditch } \\
\text { Cont. Bkg. } \\
\text { Cont. Bkg. } \\
\text { Cont. Bkg. } \\
\text { Cont. Bkg. } \\
\text { Cont. Bkg. }\end{array}$ & $\begin{array}{l}B-191 \\
B-102 \\
B-103 \\
B-104 \\
B-105 \\
B-105\end{array}$ & $\begin{array}{l}26.8 \\
23.8 \\
28.7 \\
27.8 \\
28.5 \\
27.8\end{array}$ & $\begin{array}{l}30 \text { fro } \\
\text { N45100 } \\
\text { N44800 } \\
\text { N44600 } \\
\text { N45400 } \\
\text { N45400 }\end{array}$ & $\begin{array}{l}m \text { head end } \\
W 42600 \\
W 43500 \\
W 43200 \\
W 42500 \\
W 42500\end{array}$ & $\begin{array}{l}\text { Select } \\
\text { Regular } \\
\text { Regular } \\
\text { Regular } \\
\text { Laboratory duplicate } \\
\text { Laboratory duplicate }\end{array}$ \\
\hline
\end{tabular}

\section{VOLATILE ORGANICS}

Acetone--Threshold value: $218 \mu \mathrm{g} / \mathrm{kg}$

(Alternate background limit: acetone nondetectable)

$\mathrm{SW}-846 \mathrm{PQL}=100 \mathrm{\mu g} / \mathrm{kg}$

Area $\frac{\text { Sample }}{\text { B-3 Pond }}$ B-115 $_{333} \frac{\text { Coordinates }}{N 43500 \text { W43200 Regular }}$

Carbon Disulfide--Threshold value: $\angle C O L$

Default tu CDL, $10 \mu \mathrm{g} / \mathrm{kg}$

Observed in a single sample; $<1 / 2 \mathrm{SW}-846 \mathrm{PQL}$

$S W-846 P Q L=100 \mu g / k g$

$\frac{\text { Area }}{\text { B-3 Pond }} \quad \frac{\text { Sample }}{\text { B-114 }} \frac{\mu \mathrm{g} / \mathrm{kg}}{34} \frac{\text { Coordinates }}{N 43400 W 43300} \frac{\text { Type }}{\text { Regular }}$

1,3 Dichlorobenzene--Threshold value: $26 \mu \mathrm{g} / \mathrm{kg}$; maximum of five background sites.

(Alternate background limit: nondetectable)

No observations above threshold

Methylene chioride--Threshold value: $\angle C D L$

Default to $\mathrm{COL}, 5 \mu \mathrm{g} / \mathrm{kg}$

1 of 8 sites in $3 C$ Pond $>C D L$ ( 1 of 9 observations)

3 of 22 sediment sites in $B-3$ Pond $>C D L$, ( 3 of 25 observations)

1 of 11 sites in the B-3-3 ditch $>C D L$ ( 1 of 13 observations)

1 of 5 sites in the contingency pond >nondetect, $(3 \mu \mathrm{g} / \mathrm{kg})$, but $\angle C D L$

2 of 11 silica sand blanks >nondetect, $(3,4 \mu \mathrm{g} / \mathrm{kg})$, but $<\mathrm{CDL}$

$\mathrm{SW}-846 \mathrm{PQL}=5 \mu \mathrm{g} / \mathrm{kg}$ 
WHC-SD-EN-AP-042, REV. 0

Methylene chloride (Cont)

\begin{tabular}{|c|c|c|c|c|}
\hline Area & Sample & $\mu g / k g$ & Coordinates & Type \\
\hline $\begin{array}{l}3 C \text { Pond } \\
\text { B-3 Pond } \\
\text { B-3 Pond } \\
\text { B-3 Pond } \\
\text { B-3-3 Ditch }\end{array}$ & $\begin{array}{l}B-178 \\
B-115 \\
B-131 \\
B-143 \\
B-154\end{array}$ & $\begin{array}{r}6 \\
92 \\
7 \\
6 \\
14^{b}\end{array}$ & $\begin{array}{l}\text { Ditch } 4,1,200^{\prime} \\
N 43500 \text { W43200 } \\
N 43400 \text { W42800 } \\
N 42800 \text { W42000 } \\
1,20 J^{\prime} \text { from A-29 }\end{array}$ & $\begin{array}{l}\text { Regular } \\
\text { Regular } \\
\text { Regular } \\
\text { Regular } \\
\text { Regular }\end{array}$ \\
\hline
\end{tabular}

Methyl ethyl ketone--Threshold value: $\angle C D L$

(Alternate background limit: $12.5 \mathrm{\mu g} / \mathrm{kg}$ )

Default to $\mathrm{CDL}, 10 \mu \mathrm{g} / \mathrm{kg}$

SW-846 PQL $100 \mu \mathrm{g} / \mathrm{kg}$

\begin{tabular}{|c|c|c|c|c|}
\hline Area & Sampie & $\mu \mathrm{g} / \mathrm{kg}$ & Coordinates & Type \\
\hline $\begin{array}{l}B-3 \text { Pond } \\
3 C \text { Pond } \\
B-3 \text { Pond } \\
B-3 \text { Pond } \\
B-3 \text { Pond } \\
B-3-3 \text { Ditch }\end{array}$ & $\begin{array}{l}B-114 \\
B-177 \\
B-114 \\
B-115 \\
B-147 \\
B-191\end{array}$ & $\begin{array}{l}34 \\
12^{b} \\
13 \\
74 \\
19^{\circ} \\
11\end{array}$ & $\begin{array}{l}\text { N43400 W43300 } \\
\text { Ditch } 3,300^{\prime} \\
\text { N43400 W43300 } \\
N 43500 \text { W43200 } \\
\text { N43200 W41900 } \\
30^{\circ} \text { from head end }\end{array}$ & $\begin{array}{l}\text { Regular } \\
\text { Regular } \\
\text { Regular } \\
\text { Regular } \\
\text { Regular } \\
\text { Select }\end{array}$ \\
\hline
\end{tabular}

\section{SEMIVOLATILES}

Bis (2-ethylhexyl) phthalate--Threshold Value: NC Background not tested for semivolatiles

All observations $>C D L(1.0 \mu \mathrm{g} / \mathrm{g})$ are 1 isted. All observations $>C D L$ are qualified due to problems with their associated laboratory reagent blanks

\begin{tabular}{|c|c|c|c|}
\hline Area & Sample & $\mu \mathrm{g} / \mathrm{g}$ & Type \\
\hline $\begin{array}{l}B-3 \text { Pond } \\
3 C \text { Pond } \\
3 C \text { Pond }\end{array}$ & $\begin{array}{l}B-169 \\
B-181 \\
B-182\end{array}$ & $\begin{array}{l}2.4^{a} \\
3.5^{b} \\
6.7^{b}\end{array}$ & $\begin{array}{l}\text { Composite of B-164, 166, } 168 \\
\text { Composite of B-175, 176 } \\
\text { Composite of B-171, 173,177 to } 180\end{array}$ \\
\hline
\end{tabular}

\section{OTHER ORGANIC ANALYTES}

Herbicides--Threshold value: NC, all values nondetectable.

Pesticides, Enhanced--Threshold value: NC, all values nondetectable.

Pesticides, Phosphorous--Threshold value: NC, all values nondetectable.

Polychlorinated Biphenyls--Threshold value: NC, all values nondetectable.

\footnotetext{
- Associated laboratory reagent blank not identifiable for this sample. Denotes qualification as a nondetect due to the occurrence of the analyte at least $1 / 10$ th the listed concentration in an associated.blank.
} 
WHC-SD-EN-AP-042, REY. 0

APPENDIX B

ELEMENTS BY ICP 

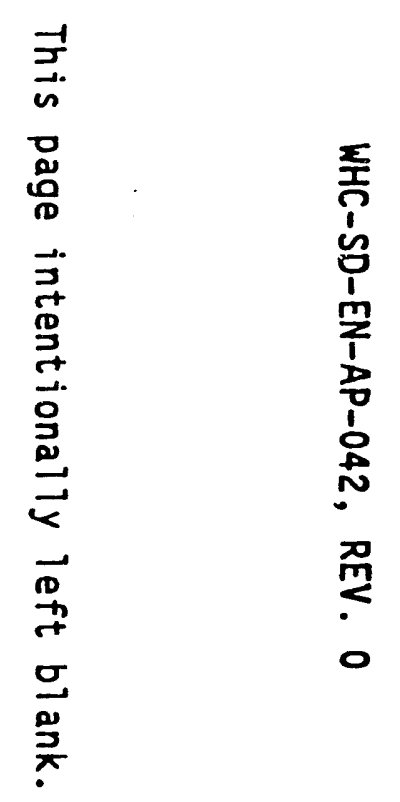
WHC-SD-EN-AP-042, REV. 0

Table B-1. Elements by ICP (EPA Method 3050/6010) 3A Pond.

\begin{tabular}{|c|c|c|c|c|c|c|c|c|c|}
\hline Samole & Aluminum & Cadmium & Calcium & Chromium & Cobalt & Copoer & Iron & Magnesium & Manganese \\
\hline \multirow[t]{2}{*}{$\begin{array}{l}3-194 \\
3-196 \\
3-197 \\
8-198 \\
8-200 \\
8-201 \\
8-202 \\
8-203\end{array}$} & $\begin{array}{rr}4953 & 020 \\
6750 & 020 \\
4789 & 020 \\
5299 & 020 \\
7091 & 020 \\
9741 & 020 \\
10339 & 020 \\
9404 & 020\end{array}$ & $\begin{array}{l}7.0 \\
8.7 \\
8.0 \\
7.3 \\
7.2 \\
7.6 \\
7.8 \\
7.3\end{array}$ & $\begin{array}{rl}5200 & \\
5948 & \\
9463 & 020 \\
4739 & \\
16510 & 020 \\
9684 & 020 \\
11808 & 020 \\
8265 & 020\end{array}$ & $\begin{array}{ll}5.4 & \mathrm{~B} \\
6.9 & \mathrm{~B} \\
3.9 & \mathrm{~B} \\
5.6 & \mathrm{~B} \\
7.1 & \mathrm{~B} \\
9.4 & \mathrm{~B} \\
9.7 & \mathrm{~B} \\
9.0 & \mathrm{~B}\end{array}$ & $\begin{array}{l}6.6 \\
7.8 \\
6.4 \\
6.7 \\
8.4 \\
9.4 \\
9.4 \\
8.5\end{array}$ & $\begin{array}{l}12.8 \\
17.2 \\
14.8 \\
15.6 \\
15.1 \\
18.6 \\
20.9 \\
14.9\end{array}$ & $\begin{array}{ll}19530 & 020 \\
26449 & 020 \\
21457 & 020 \\
21656 & 020 \\
26363 & 020 \\
28566 & 020 \\
27854 & 020 \\
28470 & 020\end{array}$ & $\begin{array}{ll}4296 & 020 \\
4649 & 020 \\
3838 & 020 \\
3760 & 020 \\
6546 & 020 \\
6113 & 020 \\
6026 & 020 \\
6088 & 020\end{array}$ & $\begin{array}{l}517.3 \\
335.9 \\
308.6 \\
212.7 \\
426.8 \\
856.4 \\
342.1 \\
294.3\end{array}$ \\
\hline & Nickel & Potassium & Sodium & strontiun & ritanium & Vanadium & zinc & zirconium & \\
\hline $\begin{array}{l}8-194 \\
8-196 \\
B-197 \\
B-198 \\
8-200 \\
3-201 \\
B-202 \\
B-203\end{array}$ & $\begin{array}{r}10.5 \\
7.6 \\
5.2 \\
6.0 \\
8.3 \\
19.4 \\
10.6 \\
9.7\end{array}$ & $\begin{array}{r}643.3 \\
673.1 \\
498.9 \\
579.2 \\
1099.1 \\
1637.1 \\
1541.7 \\
1492.9\end{array}$ & 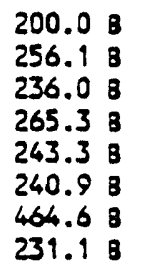 & $\begin{array}{l}25.6 \\
28.9 \\
30.6 \\
18.4 \\
46.1 \\
39.0 \\
31.7 \\
29.8\end{array}$ & $\begin{array}{ll}1458 & 020 \\
2101 & 020 \\
1767 & 020 \\
1694 & 020 \\
2119 & 020 \\
1955 & 020 \\
1938 & 020 \\
2279 & 020\end{array}$ & $\begin{array}{l}40.9 \\
56.3 \\
43.4 \\
45.9 \\
53.7 \\
52.1 \\
55.5 \\
57.5\end{array}$ & $\begin{array}{l}41.7 \\
51.6 \\
49.5 \\
46.5 \\
42.7 \\
47.7 \\
55.0 \\
45.4\end{array}$ & $\begin{array}{l}18.5 \\
27.9 \\
24.8 \\
21.8 \\
25.0 \\
29.8 \\
29.5 \\
29.0\end{array}$ & \\
\hline
\end{tabular}

Sampling Parameters

\begin{tabular}{|c|c|c|c|c|c|}
\hline Sample & $\begin{array}{c}\text { Collect } \\
\text { date }\end{array}$ & $\begin{array}{c}\text { Digest } \\
\text { date } \\
\end{array}$ & $\begin{array}{c}\text { Analysis } \\
\text { date } \\
\end{array}$ & $\begin{array}{c}\text { Days } \\
\text { el apsed }\end{array}$ & Iype \\
\hline $\begin{array}{l}8-194 \\
B-196 \\
B-197 \\
8-198 \\
8-200 \\
8-201 \\
8-202 \\
B-203\end{array}$ & $\begin{array}{l}9 / 21 / 89 \\
9 / 21 / 89 \\
9 / 21 / 89 \\
9 / 21 / 89 \\
9 / 21 / 89 \\
9 / 21 / 89 \\
9 / 21 / 89 \\
9 / 21 / 89\end{array}$ & $\begin{array}{l}03 / 06 \\
03 / 06 \\
03 / 06 \\
03 / 06 \\
03 / 06 \\
03 / 06 \\
03 / 06 \\
03 / 06\end{array}$ & $\begin{array}{l}03 / 07 / 90 \\
03 / 07 / 90 \\
03 / 07 / 90 \\
03 / 07 / 90 \\
03 / 07 / 90 \\
03 / 07 / 90 \\
03 / 07 / 90 \\
03 / 07 / 90\end{array}$ & $\begin{array}{l}167 \\
167 \\
167 \\
167 \\
167 \\
167 \\
167 \\
167\end{array}$ & $\begin{array}{l}\text { Foup } \\
\text { Foup } \\
\text { Reg } \\
\text { Reg } \\
\text { Reg } \\
\text { Reg } \\
\text { Reg } \\
\text { Reg }\end{array}$ \\
\hline
\end{tabular}

Reggent 8 lanks Greater than COL

\begin{tabular}{|c|c|c|c|c|c|}
\hline Analyte & Date & Value $\mu \mathrm{g} / \mathrm{g}$ & GI & LI & $C D L \mu g / g$ \\
\hline $\begin{array}{l}\text { Chromium } \\
\text { Sodium } \\
\text { Sodiun }\end{array}$ & $\begin{array}{l}3 / 07 / 90 \\
3 / 07 / 90 \\
3 / 07 / 90\end{array}$ & $\begin{array}{r}1.1 \\
26.7 \\
24.1\end{array}$ & $\begin{array}{l}1 \\
2 \\
-\end{array}$ & $\begin{array}{l}3 \\
2 \\
-\end{array}$ & $\begin{array}{r}1.0 \\
20.0\end{array}$ \\
\hline
\end{tabular}

\footnotetext{
$B=A$ reagent blank was grester than (GT) the contract detection limit (COL).

$D X$ a Sample further diluted by $x$ then anolyzed.

Fodu = Field Ouplicate.

Reg = Regular sample.

+ a Chosen by lab for matrix spike.
} 
Table B-2. Elements by ICP (EPA Method 3050/6010) 3B Pond.

\begin{tabular}{|c|c|c|c|c|c|c|c|c|c|}
\hline Sample & Aluminum & Cacmium & Calcium & Chromium & Cobalt & Cogper & Iron & Magnesium & Manganese \\
\hline \multirow[t]{2}{*}{$\begin{array}{l}B-106 \\
B-107 \\
8-108 \\
8-109 \\
8-110 \\
8-111\end{array}$} & $\begin{array}{ll}5428 & 020 \\
5269 & 020 \\
6211 & 020 \\
5735 & 020 \\
6265 & 020 \\
5062 & 020\end{array}$ & $\begin{array}{l}6.3 \\
6.2 \\
7.0 \\
5.9 \\
6.5 \\
5.8\end{array}$ & $\begin{array}{l}9339 \text { D2: } \\
7683 \\
7704 \\
7366 \\
9099 \text { 020 } \\
6986\end{array}$ & $\begin{array}{l}4.7 \\
5.6 \\
6.5 \\
5.3 \\
5.5 \\
6.2\end{array}$ & $\begin{array}{l}9.4 \\
8.4 \\
8.9 \\
8.8 \\
8.9 \\
8.2\end{array}$ & $\begin{array}{l}15.3 \\
14.4 \\
16.9 \\
15.0 \\
13.9 \\
13.7\end{array}$ & $\begin{array}{ll}27397 & 020 \\
26473 & 020 \\
29081 & 020 \\
25847 & 020 \\
27210 & 020 \\
23855 & 020\end{array}$ & 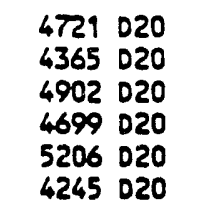 & $\begin{array}{l}319.8 \\
290.6 \\
332.0 \\
301.8 \\
342.5 \\
293.2\end{array}$ \\
\hline & Nickel & Potassium & Sodiun & strontium & Iitanium & Vanadium & zine & zirconium & \\
\hline $\begin{array}{l}B-106 \\
8-107 \\
8-108 \\
8-109 \\
8-110 \\
8-111\end{array}$ & $\begin{array}{l}7.9 \\
6.9 \\
8.3 \\
6.8 \\
6.6 \\
6.6\end{array}$ & $\begin{array}{r}780.6 \mathrm{HM} \\
779.9 \mathrm{HM} \\
1068.2 \mathrm{HM} \\
879.6 \mathrm{HM} \\
1071.7 \mathrm{HM} \\
842.8 \mathrm{HM}\end{array}$ & $\begin{array}{l}249.2 \\
206.1 \\
207.3 \\
198.5 \\
223.3 \\
210.4\end{array}$ & $\begin{array}{l}27.1 \\
23.8 \\
26.4 \\
24.6 \\
27.3 \\
25.9\end{array}$ & $\begin{array}{ll}2599 & 020 \\
2515 & 020 \\
2354 & 020 \\
2211 & 020 \\
2402 & 020 \\
2324 & 020\end{array}$ & $\begin{array}{l}79.9 \\
68.9 \\
70.9 \\
63.6 \\
63.5 \\
61.8\end{array}$ & $\begin{array}{l}41.4 \\
39.0 \\
49.9 \\
49.0 \\
41.2 \\
38.5\end{array}$ & $\begin{array}{l}28.2 \\
26.5 \\
27.3 \\
26.8 \\
27.6 \\
26.4\end{array}$ & \\
\hline
\end{tabular}

Sampling Paremeters

\begin{tabular}{|c|c|c|c|c|c|}
\hline Sample & $\begin{array}{c}\text { Collect } \\
\text { date } \\
\end{array}$ & $\begin{array}{c}\text { - Digest } \\
\text { date }\end{array}$ & $\begin{array}{l}\text { Analysis } \\
\text { date }\end{array}$ & $\begin{array}{c}\text { Days } \\
\text { elapsed } \\
\end{array}$ & Iype \\
\hline $\begin{array}{l}8-106 \\
8-107 \\
8-108 \\
8-109 \\
8-190 \\
8-191\end{array}$ & $\begin{array}{l}8 / 4 / 89 \\
8 / 4 / 89 \\
8 / 4 / 89 \\
8 / 4 / 89 \\
8 / 4 / 89 \\
8 / 4 / 89\end{array}$ & $\begin{array}{l}02 / 20 \\
02 / 20 \\
02 / 20 \\
02 / 20 \\
02 / 20 \\
02 / 20\end{array}$ & $\begin{array}{l}02 / 23 / 90 \\
02 / 23 / 90 \\
02 / 23 / 90 \\
02 / 23 / 90 \\
02 / 23 / 90 \\
02 / 23 / 90\end{array}$ & $\begin{array}{ll}203 & H \\
203 & H \\
203 & H \\
203 & H \\
203 & H \\
203 & H\end{array}$ & $\begin{array}{l}\text { Reg } \\
\text { Reg } \\
\text { Foup } \\
\text { Fodup } \\
\text { Reg + } \\
\text { Reg }\end{array}$ \\
\hline
\end{tabular}

$B=$ Sample further diluted by $x$ when analyzed.

Fodp = Field cuplicate.

HW = Associated matrix recovery high; see Table B-9.

$H=$ Holding time exceeded (6 months).

Reg = Regular sample.

+ = Chosen by lab for matrix spike. 
WHC-SD-EN-AP-042, REV. 0

Table B-3. Elements by ICP (EPA Method 3050/6010) 3C Pond.

\begin{tabular}{|c|c|c|c|c|c|c|c|c|c|}
\hline Samole & Aluminum & Cacmiun & Calcium & Chromiun & Cobalt & Copoer & Iron & Magnes iun & Manganese \\
\hline $\begin{array}{l}8-179 \\
8-172 \\
8-174 \\
8-175 \\
8-176 \\
8-177 \\
8-178 \\
8=179 \\
8-180 \\
8-180\end{array}$ & $\begin{array}{ll}3920 & 020 \\
6850 & 020 \\
4925 & 020 \\
4811 & 020 \\
6386 & 020 \\
4448 & 020 \\
4866 & 020 \\
3743 & 020 \\
4746 & 020 \\
5003 & 020\end{array}$ & $\begin{array}{l}5.2 \\
4.2 \\
5.1 \\
5.3 \\
6.3 \\
2.0 \\
4.9 \\
4.0 \\
5.4 \\
5.5\end{array}$ & $\begin{array}{l}5154 \\
5326 \\
4649 \\
4788 \\
5331 \\
3403 \\
5898 \\
3977 \\
4535 \\
4140\end{array}$ & $\begin{array}{l}3.3 \\
7.2 \\
4.3 \\
3.5 \\
6.1 \\
6.1 \\
4.5 \\
4.3 \\
4.0 \\
5.5\end{array}$ & $\begin{array}{l}8.4 \\
6.2 \\
7.5 \\
6.6 \\
8.5 \\
3.0 \\
6.2 \\
5.3 \\
7.5 \\
6.4\end{array}$ & $\begin{array}{l}16.3 \\
17.9 \\
12.5 \\
13.4 \\
15.4 \\
18.5 \\
13.0 \\
11.10 \\
16.9 \\
16.2\end{array}$ & $\begin{array}{rl}20739 & 020 \\
17097 & 020 \\
21496 & 020 \\
20927 & 020 \\
24957 & 020 \\
7291 & 020 \\
18849 & 020 \\
15874 & 020 \\
21308 & 020 \\
20368 & 020\end{array}$ & $\begin{array}{ll}3649 & 020 \\
4403 & 020 \\
4280 & 020 \\
3958 & 020 \\
4787 & 020 \\
2130 & 020 \\
3586 & 020 \\
3920 & 020 \\
3875 & 020 \\
3963 & 020\end{array}$ & $\begin{array}{l}253.9 \\
305.8 \\
287.7 \\
230.8 \\
287.4 \\
101.4 \\
281.9 \\
176.1 \\
248.6 \\
228.9\end{array}$ \\
\hline & Nickel & Potassium & silver & Sodium & strontium & Iiranium & Vanadium & zine & zirconium \\
\hline $\begin{array}{l}8-179 \\
8-172 \\
8-174 \\
8-175 \\
8-176 \\
8-177 \\
8-178 \\
8-179 \\
8-180 \\
B-180\end{array}$ & $\begin{array}{l}5.3 \\
7.9 \\
8.2 \\
5.5 \\
7.8 \\
4.9 \\
5.5 \\
5.0 \\
5.9 \\
6.7\end{array}$ & $\begin{array}{r}480.4 \\
1038.6 \\
559.3 \\
657.5 \\
912.8 \\
637.8 \\
638.7 \\
385.1 \\
426.4 \\
472.7\end{array}$ & $\begin{array}{l}0.0: \\
0.3: \\
0.1 \\
0.0 \\
0.1 \\
1.2: \\
0.1 \\
0.2: \\
0.2: \\
0.1\end{array}$ & $\begin{array}{ll}279.3 & B \\
224.0 & B \\
243.0 & B \\
230.3 & 8 \\
282.5 & 8 \\
129.5 & 8 \\
229.9 & B \\
198.1 & 8 \\
246.4 & B \\
270.5 & B\end{array}$ & $\begin{array}{ll} & 29.0 \\
& 26.1 \\
& 29.0 \\
& 20.7 \\
\text { HM } & 25.9 \\
\text { HM } & 14.9 \\
\text { HM } & 22.5 \\
\text { HM } & 18.9 \\
\text { HM } & 18.8 \\
\text { HM } & 19.4\end{array}$ & $\begin{array}{rr}1521 & 020 \\
1072 & 020 \\
1965 & 020 \\
1541 & 020 \\
1934 & 020 \\
401 & \\
1567 & 020 \\
1182 & 020 \\
1868 & 020 \\
1642 & 020\end{array}$ & $\begin{array}{l}48.6 \mathrm{HM} \\
32.5 \mathrm{HM} \\
49.2 \mathrm{HM} \\
46.0 \mathrm{HM} \\
53.2 \mathrm{HM} \\
12.8 \mathrm{HM} \\
41.1 \mathrm{HM} \\
32.2 \mathrm{HM} \\
47.7 \mathrm{HM} \\
45.8 \mathrm{HM}\end{array}$ & $\begin{array}{l}43.9 \\
77.7 \\
38.6 \\
33.6 \\
49.4 \\
68.6 \\
53.8 \\
33.9 \\
49.7 \\
40.3\end{array}$ & $\begin{array}{l}21.2 \\
15.8 \\
22.3 \\
20.5 \\
25.8 \\
6.9 \\
20.5 \\
15.5 \\
26.2 \\
23.3\end{array}$ \\
\hline
\end{tabular}

Sampling Parameters

\begin{tabular}{|c|c|c|c|c|c|}
\hline Samole & $\begin{array}{c}\text { Collect } \\
\text { dare. }\end{array}$ & $\begin{array}{l}\text { Digest } \\
\text { dare } \\
\end{array}$ & $\begin{array}{c}\text { Analysis } \\
\text { date }\end{array}$ & $\begin{array}{c}\text { Days } \\
\text { elapsed }\end{array}$ & Iype \\
\hline $\begin{array}{l}8-171 \\
8-172 \\
8-174 \\
8-175 \\
8-176 \\
8-177 \\
8-178 \\
8-179 \\
8-180 \\
8-180\end{array}$ & $\begin{array}{l}9 / 8 / 89 \\
9 / 8 / 89 \\
9 / 8 / 89 \\
9 / 8 / 89 \\
9 / 8 / 89 \\
9 / 8 / 89 \\
9 / 8 / 89 \\
9 / 8 / 89 \\
9 / 8 / 89 \\
9 / 8 / 89\end{array}$ & $\begin{array}{l}03 / 08 \\
03 / 08 \\
03 / 08 \\
03 / 08 \\
03 / 05 \\
03 / 05 \\
03 / 05 \\
03 / 05 \\
03 / 05 \\
03 / 05\end{array}$ & $\begin{array}{l}03 / 10 / 90 \\
03 / 10 / 90 \\
03 / 10 / 90 \\
03 / 10 / 90 \\
03 / 12 / 90 \\
03 / 12 / 90 \\
03 / 12 / 90 \\
03 / 12 / 90 \\
03 / 12 / 90 \\
03 / 12 / 90\end{array}$ & $\begin{array}{l}183 \\
183 \\
183 \\
183 \\
185 \\
185 \\
185 \\
185 \\
185 \\
185 \\
185 \\
185 \\
18\end{array}$ & $\begin{array}{l}\text { Foup } \\
\text { Fdup } \\
\text { Reg } \\
\text { Reg } \\
\text { Reg } \\
\text { Reg } \\
\text { Reg } \\
\text { Reg } \\
\text { Ldup } \\
\text { Ldup }\end{array}$ \\
\hline
\end{tabular}

Reagent Blanks Greater than CDL

\begin{tabular}{|c|c|c|c|c|c|}
\hline Analyte & Date & Value ug/a & GI & $L T$ & $C D L+19 / 9$ \\
\hline $\begin{array}{l}\text { Sodium } \\
\text { Sodium } \\
\text { sodium }\end{array}$ & $\begin{array}{l}3 / 10 / 90 \\
3 / 10 / 90 \\
3 / 12 / 90\end{array}$ & $\begin{array}{l}22.8 \\
22.7 \\
23.4\end{array}$ & 2 & : & 20.0 \\
\hline
\end{tabular}

\footnotetext{
8 = A reagent blank was greater than (GT) the contract detection limit (COL) on the date of analysis. The number of <COL blanks on that day is shown in the less than (LT) colum above.

$D x=$ Sample further diluted by $x$ when onalyzed.

Fdup = Field duplicate.

$H=$ Holding time exceeded ( 6 months).

HM = Associated matrix recovery high; see Table 8-9. Ldup a Lab dol icate.

$Q=$ Sample is above the contract detection limit (COL) but below a limit of quantitation based on reagent blanks.

Reg a Regular sample.

- = Chosen by lab for matrix spike.

- Sample is below the laboratory col.
} 
WHC-SD-EN-AP-042, REV. 0

Table B-4. Elements by ICP (EPA Method 3050/6010) B-3 Pond. (sheet 1 of 2)

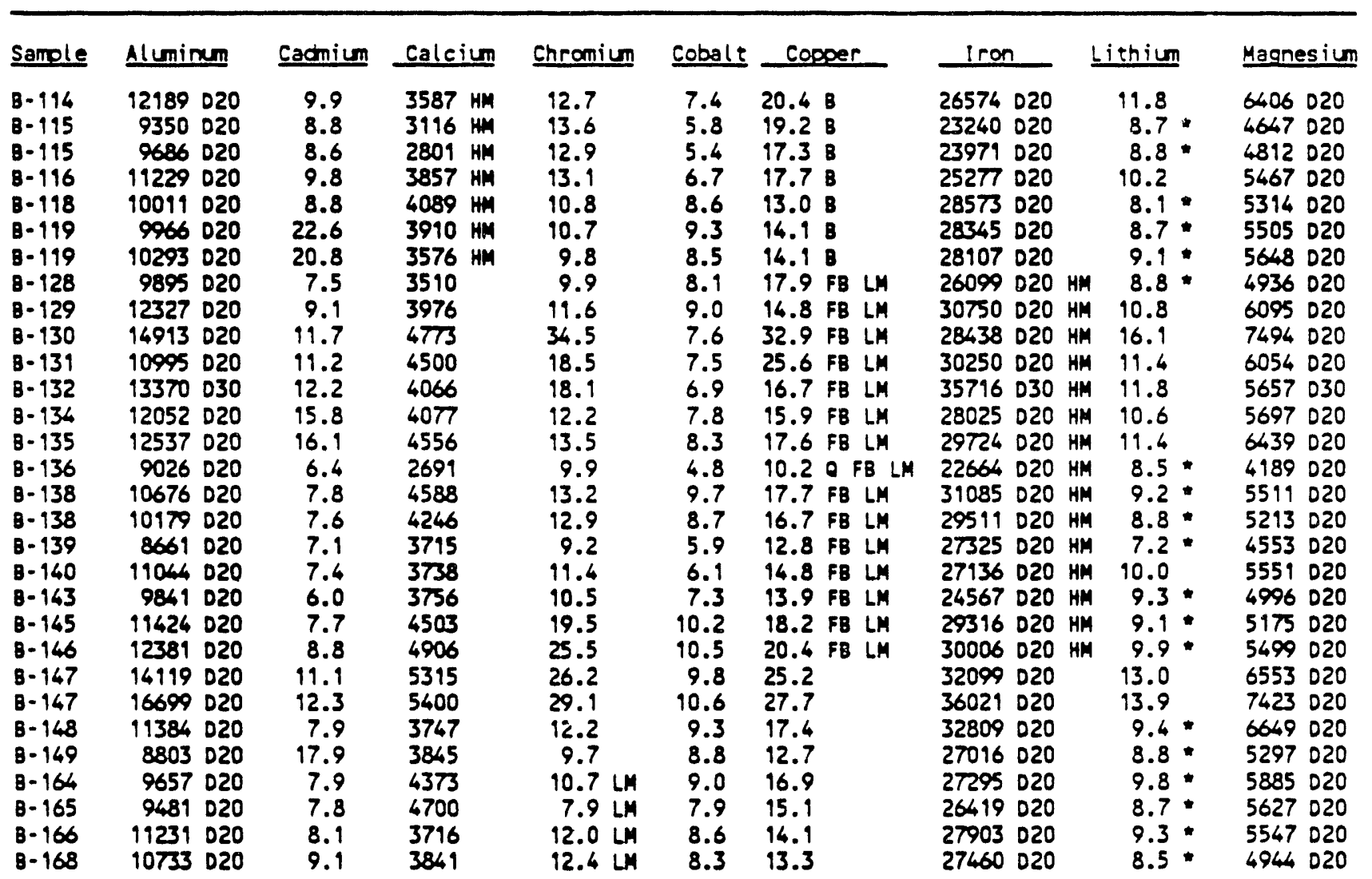

Manganese Nickel Potassiun

\begin{tabular}{|c|c|c|c|}
\hline 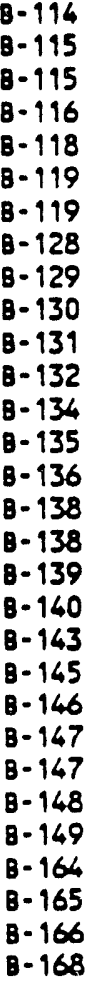 & $\begin{array}{l}198.6 \\
167.5 \\
163.9 \\
174.5 \\
274.0 \\
233.3 \\
238.4 \\
203.1 \\
225.1 \\
233.7 \\
214.4 \\
255.8 \\
212.4 \\
226.7 \\
185.9 \\
257.0 \\
232.8 \\
195.7 \\
189.2 \\
206.2 \\
241.3 \\
257.3 \\
353.1 \\
353.5 \\
252.3 \\
248.0 \\
291.6 \\
267.2 \\
229.5 \\
220.8\end{array}$ & $\begin{array}{r}11.6 \\
9.6 \\
8.8 \\
10.1 \\
10.6 \\
9.7 \\
10.0 \\
9.7 \\
11.0 \\
14.6 \\
10.6 \\
11.2 \\
10.7 \\
12.1 \\
7.7 \\
10.6 \\
9.5 \\
7.3 \\
9.0 \\
8.2 \\
11.6 \\
19.6 \\
13.7 \\
15.0 \\
10.5 \\
10.0 \\
11.0 \\
9.5 \\
19.1 \\
10.0\end{array}$ & $\begin{array}{l}1849 \\
1491 \\
1526 \\
1732 \\
1442 \\
1608 \\
1616 \\
1684 \\
2019 \\
2021 \\
1358 \\
2276 \\
1851 \\
1930 \\
1521 \\
1699 \\
1637 \\
1235 \\
1827 \\
1569 \\
1649 \\
1884 \\
2522 \mathrm{HM} \\
2867 \mathrm{HM} \\
1678 \mathrm{HM} \\
1455 \mathrm{HM} \\
1140 \mathrm{HM} \\
1142 \mathrm{HM} \\
1580 \mathrm{HM} \\
1580 \mathrm{HM}\end{array}$ \\
\hline
\end{tabular}

silver sodium strontium

$1.0 \mathrm{OLM} 268.6$

2.5 LM 216.6

2.1 LH 213.7

1.7 OLM 261.9

0.2 LM 289.0

$0.3 \cdot \operatorname{LM} 235.5$

0.6 LM 230.5

$0.0 \cdot \ln 225.1$

$0.3 *$ LM 245.3

4.6 LM 302.2

3.6 LM 262.3

2.2 LM 302.2

0.8 LM 328.9

1.2 OLM 296.4

0.4 LL 299.3

1.0 OLM 293.4

1.2 OLM 256.3

2.1 LM 256.8

0.8 LM 258.9

$0.7 \cdot$ LM 263.0

2.0 LM 289.3

2.0 LM 328.2

$3.5 \quad 243.0$

$5.1 \quad 290.4$

$1.10 \quad 181.7$

0.3 .193 .6

308.9 HM

$0.0 * 336.9 \mathrm{HM} 25.8$

$0.7 \quad 281.7 \mathrm{HM} 25.8$

$1.00 \quad 261.8 \mathrm{HM} 24.0$

\section{2}

21.3

(1.

26.2

24.1

22.6

21.9

23.9

34.7

27.7

29.8

20.1

23.8

21.5

18.3

23.0

23.2

26.8

31.5

33.7

20.4

21.0

6.7

5.8

\section{Titanium}

1737020

1908020

1962020

1968020

2312020

2390020

2299020

2353020

2620020

1633

2473020

2848030

2299020

2445020

1732

2864020

2821020

2917020

2431020

2079

2748020

2668020

2996020

2462020

2646020

2242020

2226020

2248020

2283020

2279020
Vanadium zinc zirconium

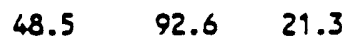

$56.5 \quad 58.0 \quad 25.0$

$56.9 \quad 55.9 \quad 24.9$

$\begin{array}{lll}56.7 & 70.2 & 24.9\end{array}$

$\begin{array}{lll}65.0 & 48.7 & 26.7\end{array}$

$\begin{array}{lll}67.2 & 55.7 & 29.8\end{array}$

$60.7 \quad 53.8 \quad 27.6$

$\begin{array}{lll}61.0 & 48.5 & 30.1\end{array}$

$69.3 \quad 57.0 \quad 33.7$

$\begin{array}{lll}51.0 & 191.8 & 26.0\end{array}$

$\begin{array}{lll}66.3 & 82.1 & 30.7\end{array}$

$\begin{array}{lll}81.8 & 73.5 & 39.5\end{array}$

$\begin{array}{lll}65.3 & 66.8 & 28.5\end{array}$

$\begin{array}{lll}68.8 & 70.4 & 31.2\end{array}$

$\begin{array}{lll}52.0 & 43.3 & 22.1\end{array}$

$\begin{array}{lll}76.8 & 63.6 & 36.1\end{array}$

$\begin{array}{lll}72.5 & 60.6 & 33.4\end{array}$

$\begin{array}{lll}73.5 & 48.4 \quad 32.6\end{array}$

$\begin{array}{lll}65.6 & 53.0 \quad 30.5\end{array}$

$\begin{array}{lll}59.4 & 48.3 \quad 25.9\end{array}$

$70.6 \quad 83.2 \quad 34.6$

$\begin{array}{lll}72.6 & 84.5 & 37.0\end{array}$

$\begin{array}{lll}65.5 & 84.5 & 29.1\end{array}$

$67.7 \quad 92.5 \quad 39.2$

$60.5 \quad 57.0 \quad 30.9$

$62.2 \quad 54.9 \quad 28.1$

58.9 HM $70.3 \quad 24.2$

60.0 HM $65.9 \quad 25.7$

$58.5 \mathrm{HM} 50.4 \quad 26.4$

59.0 HM $52.9 \quad 29.5$ 
WHC-SD-EN-AP-042, REV. 0

Table B-4. Elements by ICP (EPA Method 3050/6010) B-3 Pond. (sheet 2 of 2)

\section{Sampling Parameters}

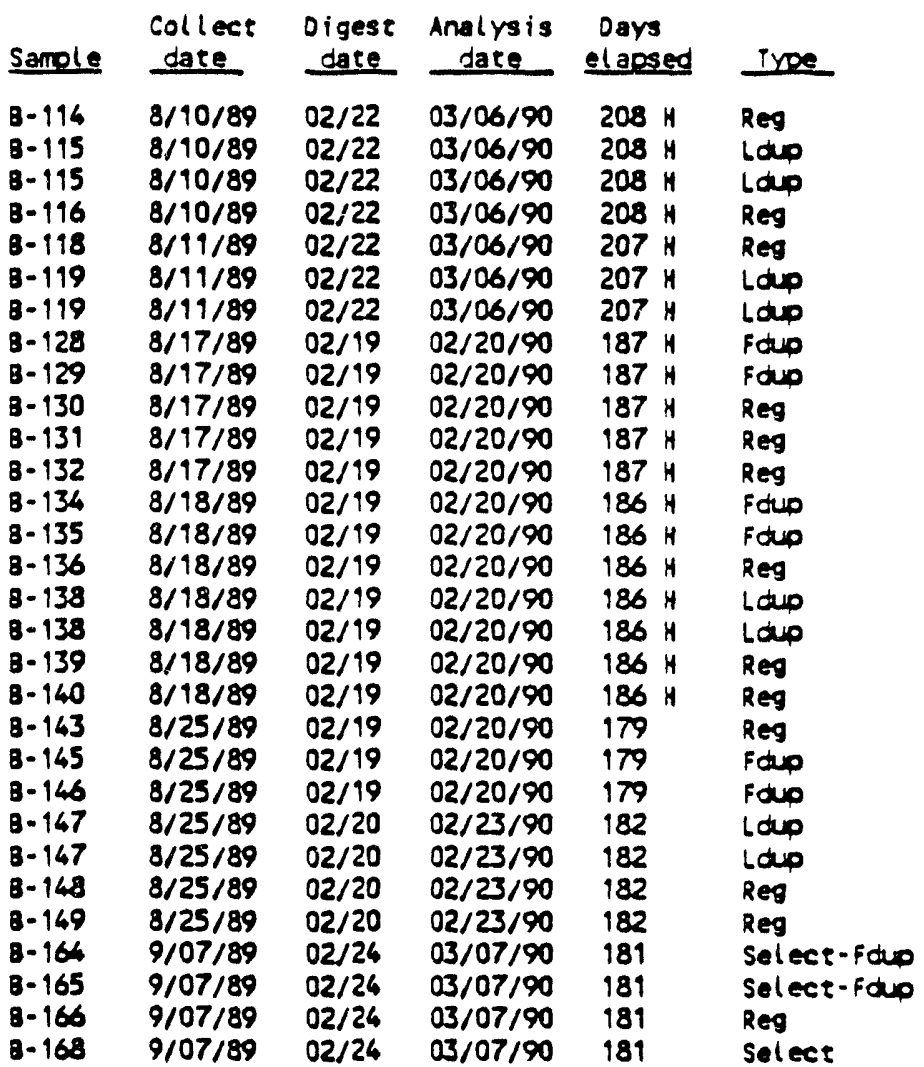

Reagent Blanks Greater than COL

\begin{tabular}{|c|c|c|c|c|c|}
\hline Analyre & Date & Value $\mu \mathrm{g} / \mathrm{g}$ & GT & $L T$ & $C O L \quad y g / g$ \\
\hline Copper & $3 / 06 / 90$ & 1.3 & 1 & 1 & 1.0 \\
\hline
\end{tabular}

8 a A reagent blank was greater than (GT) the contract detection limit (CDL) on the date of analysis. The number of <CDL blanks on that day is shoun in the less than (LI) column above.

$D X=$ Sample further diluted by $x$ when analyzed.

FB = Field blank high collected z/or analyzed on the same date; see Table B-8.

Foup a Field duplicate.

HA = Associated matrix recovery high; see Table 8-9.

$H=$ Holding time exceeded (6 months).

Ldup = Lab duplicace.

$L M=$ Associated matrix recovery low; see Table B-9.

- Sample is above the contract detection limit (COL) but below a limit of quentitation based on reagent blanks.

Reg a Regular sample.

Select = A nonrandomly selected sample.

- = Semple is belaw the laboratory contract detection limit. 
Table B-5. Elements by ICP (EPA Method 3050/6010) B-3-3 Ditch. (sheet 1 of 2)

\begin{tabular}{|c|c|c|c|c|c|c|c|c|c|c|c|c|}
\hline Samole & Aluminum & Cacmiun & Calc & ium & Chr & omiun & Cobalt & Cooper & Iron & Lithium & Magnesium & \\
\hline \multirow[t]{2}{*}{$\begin{array}{l}B-152 \\
B-153 \\
B-154 \\
B-158 \\
B-158 \\
B-159 \\
B-160 \\
B-161 \\
8-184 \\
B-185 \\
B-187 \\
B-188 \\
B-189 \\
B-190 \\
B-191\end{array}$} & $\begin{array}{rr}4906 & 020 \\
5906 & 020 \\
9823 & 020 \\
6978 & 020 \\
5965 & 020 \\
6456 & 020 \\
6060 & 020 \\
7439 & 020 \\
6409 & 020 \\
6379 & 020 \\
5306 & 020 \\
9024 & 020 \\
6780 & 020 \\
6158 & 020 \\
11747 & 020\end{array}$ & $\begin{array}{l}7.0 \\
7.5 \\
9.4 \\
7.3 \\
6.5 \\
6.2 \\
6.6 \\
9.2 \\
5.4 \\
5.2 \\
5.2 \\
6.5 \\
6.2 \\
5.2 \\
9.5\end{array}$ & $\begin{array}{l}5090 \\
7211 \\
9381 \\
5419 \\
4885 \\
4889 \\
4107 \\
3703 \\
4253 \\
4192 \\
3925 \\
4674 \\
5259 \\
3900 \\
5064\end{array}$ & $\begin{array}{l}\text { D20 } \\
020 \\
F B \\
F B \\
F B \\
F B \\
F B\end{array}$ & \multicolumn{2}{|c|}{$\begin{array}{r}4.4 \\
5.0 \\
19.0 \\
6.5 \\
6.1 \\
7.5 \\
5.2 \\
8.4 \\
7.9 \\
5.5 \\
8.4 \\
8.7 \\
9.4 \\
9.3 \\
18.6\end{array}$} & $\begin{array}{l}19.2 \\
9.3 \\
9.9 \\
7.6 \\
7.4 \\
6.6 \\
6.1 \\
6.9 \\
7.2 \\
6.6 \\
6.1 \\
9.1 \\
9.9 \\
6.6 \\
10.3\end{array}$ & $\begin{array}{l}12.8 \\
14.3 \\
23.5 \\
15.7 \\
14.5 \\
12.4 \\
11.7 \\
19.7 \\
14.7 \\
14.7 \\
12.1 \\
17.5 \\
17.6 \\
19.4 \\
43.1\end{array}$ & $\begin{array}{ll}26106 & 020 \\
27866 & 020 \\
26168 & 020 \\
25207 & 020 \\
20943 & 020 \\
21672 & 020 \\
20979 & 020 \\
25511 & 020 \\
20904 & 020 \\
21743 & 020 \\
20482 & 020 \\
26393 & 020 \\
27627 & 020 \\
20563 & 020 \\
37479 & 020\end{array}$ & $\begin{array}{c}4.2 \\
5.2 \\
10.8 \\
6.1 \\
6.5 \\
6.6 \\
6.2 \\
6.4 \\
7.4 \\
6.6 \\
6.3 \\
9.6 \\
6.9 \\
6.9 \\
10.8\end{array}$ & 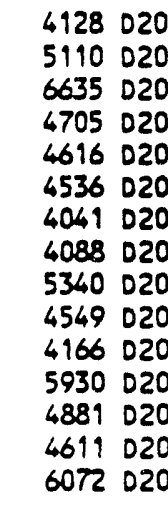 & $\begin{array}{l}\text { FB } \\
\text { FB } \\
\text { FB } \\
\text { FB } \\
\text { FB }\end{array}$ \\
\hline & Manganese & Nickel & \multicolumn{2}{|c|}{ Potassium } & \multicolumn{2}{|c|}{ Sodium } & strontium & ritanium & Vanadium & $\underline{\text { zinc }}$ & zirconium & \\
\hline \multirow[t]{4}{*}{$\begin{array}{l}B-152 \\
8-153 \\
B-154 \\
B-158 \\
8-158 \\
8-159 \\
B-160 \\
\theta-161 \\
B-184 \\
B-185 \\
8-187 \\
8-188 \\
B-189 \\
B-190 \\
B-191\end{array}$} & $\begin{array}{l}426.7 \\
309.1 \\
336.8 \\
282.0 \\
273.8 \\
262.9 \\
254.1 \\
345.4 \\
381.1 \\
270.1 \\
263.6 \\
426.6 \\
395.1 \\
570.1 \\
262.0\end{array}$ & $\begin{array}{r}7.3 \\
7.8 \\
11.8 \\
7.4 \\
7.5 \\
7.4 \\
6.5 \\
7.3 \\
13.5 \\
6.9 \\
8.0 \\
9.9 \\
8.5 \\
11.0 \\
19.2\end{array}$ & $\begin{array}{r}519 . \\
616 . \\
1388 . \\
845 . \\
731 . \\
878 . \\
671 . \\
832 . \\
767 . \\
645 . \\
479 . \\
1032 . \\
749 . \\
721 . \\
1584 .\end{array}$ & & & $\begin{array}{l}.0 \\
.7 \\
.3 \\
.3 \\
.1 \\
.6 \\
.5 \\
.2 \\
.3 \mathrm{BHM} \\
.0 \mathrm{BHM} \\
.6 \mathrm{BHM} \\
.9 \mathrm{BHH} \\
.5 \mathrm{BHM} \\
.8 \mathrm{BHM} \\
.9 \mathrm{BHM}\end{array}$ & $\begin{array}{l}22.9 \\
25.5 \\
34.8 \\
25.9 \\
23.6 \\
23.7 \\
21.3 \\
21.6 \\
23.6 \\
21.8 \\
97.8 \\
28.0 \\
23.3 \\
22.9 \\
30.0\end{array}$ & $\begin{array}{ll}2491 & 020 \\
2560 & 020 \\
1889 & 020 \\
2266 & 020 \\
1739 & 020 \\
1885 & 020 \\
1706 & 020 \\
2491 & 020 \\
1647 & 020 \\
1648 & 020 \\
1390 & 020 \\
2042 & 020 \\
2291 & 020 \\
1379 & 020 \\
1863 & 020\end{array}$ & $\begin{array}{l}65.6 \\
63.0 \\
53.0 \\
60.9 \\
48.5 \\
50.1 \\
48.5 \\
56.9 \\
44.4 \mathrm{HI} \\
42.3 \mathrm{HI} \\
40.4 \mathrm{HI} \\
52.5 \mathrm{HI} \\
69.4 \mathrm{HI} \\
40.9 \mathrm{HI} \\
54.9 \mathrm{HI}\end{array}$ & $\begin{array}{r}40.1 \\
.33 .0 \\
76.1 \\
53.5 \\
51.1 \\
46.3 \\
45.7 \\
58.4 \\
65.6 \\
57.7 \\
47.1 \\
76.9 \\
70.5 \\
41.3 \\
119.3\end{array}$ & $\begin{array}{l}26.0 \\
26.8 \\
22.5 \\
24.9 \\
20.6 \\
19.6 \\
20.2 \\
27.8 \\
17.8 \\
19.4 \\
20.6 \\
26.1 \\
25.5 \\
15.2 \\
26.8\end{array}$ & \\
\hline & \multicolumn{11}{|c|}{ Sampl ine Parameters } & \\
\hline & & & Sample & $\begin{array}{l}\text { Coll } \\
\text { dat }\end{array}$ & & $\begin{array}{l}\text { Digest } \\
\text { date }\end{array}$ & $\begin{array}{c}\text { Analysis } \\
\text { date }\end{array}$ & $\begin{array}{l}\text { Days } \\
\text { elapsed }\end{array}$ & Trpe & & & \\
\hline & & & $\begin{array}{l}8-152 \\
8-153 \\
8-154 \\
8-158 \\
8-158 \\
8-159 \\
8-160 \\
8-161 \\
8-184 \\
8-185 \\
8-187 \\
8-188 \\
8-189 \\
8-190 \\
8-191\end{array}$ & $\begin{array}{l}8 / 28 \\
8 / 28 \\
8 / 28 \\
8 / 3 \\
8 / 3 \\
8 / 3 \\
8 / 3 \\
8 / 3 \\
9 / 18 \\
9 / 18 \\
9 / 18 \\
9 / 18 \\
9 / 18 \\
9 / 18 \\
9 / 18\end{array}$ & $\begin{array}{l}3 / 89 \\
3 / 89 \\
3 / 89 \\
1 / 89 \\
1 / 89 \\
1 / 89 \\
1 / 89 \\
1 / 89 \\
3 / 89 \\
3 / 89 \\
3 / 89 \\
3 / 89 \\
3 / 89 \\
3 / 89 \\
3 / 89\end{array}$ & $\begin{array}{l}02 / 24 \\
02 / 24 \\
02 / 24 \\
02 / 24 \\
02 / 24 \\
02 / 24 \\
02 / 24 \\
02 / 24 \\
03 / 05 \\
03 / 05 \\
03 / 05 \\
03 / 05 \\
03 / 10 \\
03 / 05 \\
03 / 05\end{array}$ & $\begin{array}{l}03 / 07 / 90 \\
03 / 07 / 90 \\
03 / 07 / 90 \\
03 / 07 / 90 \\
03 / 07 / 90 \\
03 / 07 / 90 \\
03 / 07 / 90 \\
03 / 07 / 90 \\
03 / 12 / 90 \\
03 / 12 / 90 \\
03 / 92 / 90 \\
03 / 12 / 90 \\
03 / 12 / 90 \\
03 / 12 / 90 \\
03 / 12 / 90\end{array}$ & $\begin{array}{l}191 \mathrm{H} \\
191 \mathrm{H} \\
191 \mathrm{H} \\
188 \mathrm{H} \\
188 \mathrm{H} \\
188 \mathrm{H} \\
188 \mathrm{H} \\
188 \mathrm{H} \\
175 \\
175 \\
175 \\
175 \\
175 \\
175 \\
175\end{array}$ & $\begin{array}{l}\text { Foup } \\
\text { Fdup } \\
\text { Reg } \\
\text { Fdup, Lo } \\
\text { Foup, Lo } \\
\text { Fdup } \\
\text { Reg } \\
\text { Select } \\
\text { Fdup } \\
\text { Fdup } \\
\text { Reg } \\
\text { Reg } \\
\text { Reg } \\
\text { Reg } \\
\text { Select }\end{array}$ & & & \\
\hline
\end{tabular}


WHC-SD-EN-AP-042, REV. 0

Table B-5. Elements by ICP (EPA Method 3050/6010) B-3-3 Ditch. (sheet 2 of 2)

Regent Blanks Greater than COL

$\begin{array}{llllll}\text { Analyte } & \text { Date } & \text { Value ug/a } & \text { GI } & \text { CDL ng/9 } \\ \text { Sodiun } & 3 / 12 / 90 & 23.4 & 1 & 2 & 20.0\end{array}$
$B$ - A reegent blank wa greater then (GT) contract datection linit (COL) on the date of analysis. The nuber of <COL blenks on thet doy is shom in the less then (LT) colum above.
Dx a Sample further diluted by $x$ then analyzed.

FB = Field blank high collected L/or analyzed on the sam dete; see Table 8-8.

Fop a Fietd duplicate.

$H=$ Holding time exceeded (6 months).

HM = Associated matrix recovery high; see Table 8-9.

Loup = Lab cupl icate.

Reg = Regular sample.

- chosen by lab for matrix spike.

- = Sample is below the laboratory contract detection limit. 
Table B-6. Elements by ICP (EPA Method 3050/6010) Background 1 - Contingency Pond.

\begin{tabular}{|c|c|c|c|c|c|c|c|c|c|c|}
\hline Sample & Aluminum & Cacmium & Calcium & Chromium & Cobalt & Copoer & Iron & Lithium & Magnesium & Manganese \\
\hline \multirow[t]{2}{*}{$\begin{array}{l}8-101 \\
8-102 \\
8-103 \\
8-104 \\
8-105 \\
8-105\end{array}$} & $\begin{array}{ll}5118 & 020 \\
6120 & 020 \\
7650 & 020 \\
5925 & 020 \\
5590 & 020 \\
5682 & 020\end{array}$ & $\begin{array}{l}5.3 \\
6.2 \\
7.3 \\
6.7 \\
6.7 \\
6.7\end{array}$ & $\begin{array}{ll}6830 & \\
9831 & 020 \\
9923 & 020 \\
7328 & \\
9764 & 020 \\
9416 & 020\end{array}$ & $\begin{array}{l}4.1 \\
5.2 \\
6.3 \\
5.8 \\
5.4 \\
5.0\end{array}$ & $\begin{array}{l}6.8 \\
8.9 \\
9.4 \\
8.9 \\
8.8 \\
8.8\end{array}$ & $\begin{array}{l}14.1 \\
14.1 \\
18.1 \\
16.4 \\
16.2 \\
15.0\end{array}$ & $\begin{array}{ll}21232 & 020 \\
26085 & 020 \\
29671 & 020 \\
27353 & 020 \\
28433 & 020 \\
29369 & 020\end{array}$ & $\begin{array}{l}5.7: \\
7.9 \\
8.7 \\
6.9 \\
6.0 \\
6.1\end{array}$ & $\begin{array}{ll}4284 & 020 \\
6308 & 020 \\
6260 & 020 \\
5154 & 020 \\
5715 & 020 \\
5108 & 020\end{array}$ & $\begin{array}{l}243.7 \\
377.0 \\
397.7 \\
313.5 \\
336.6 \\
318.6\end{array}$ \\
\hline & Nickel & Potassium & silver & Sodium & Strontium & Iitanium & Vanadium & $\underline{\text { ince }}$ & 2irconium & \\
\hline $\begin{array}{l}8-101 \\
8-102 \\
8-103 \\
8-104 \\
8-105 \\
8-105\end{array}$ & $\begin{array}{r}5.4 \\
13.9 \\
8.5 \\
7.5 \\
19.0 \\
6.8\end{array}$ & $\begin{array}{r}899.9 \\
1216.8 \\
1350.0 \\
999.9 \\
970.3 \\
961.9 \mathrm{HM}\end{array}$ & $\begin{array}{l}0.0: \\
0.2: \\
0.0= \\
0.0: \\
0.1: \\
0.3 .\end{array}$ & $\begin{array}{l}331.6 \\
383.5 \\
378.2 \\
331.9 \\
405.5 \\
388.8\end{array}$ & $\begin{array}{l}21.9 \\
25.1 \\
23.6 \\
25.4 \\
24.9 \\
28.0\end{array}$ & $\begin{array}{ll}1884 & 020 \\
2312 & 020 \\
2714 & 020 \\
2310 & 020 \\
2806 & 020 \\
2762 & 020\end{array}$ & $\begin{array}{l}53.3 \\
60.6 \\
68.7 \\
62.5 \\
72.4 \\
73.2\end{array}$ & $\begin{array}{l}33.1 \\
38.7 \\
43.3 \\
42.1 \\
42.1 \\
44.0\end{array}$ & $\begin{array}{l}21.9 \\
23.8 \\
28.7 \\
27.8 \\
28.5 \\
27.8\end{array}$ & \\
\hline
\end{tabular}

Sampl ing Parameters

\begin{tabular}{|c|c|c|c|c|c|}
\hline Semole & $\begin{array}{c}\text { Collect } \\
\text { dete } \\
\end{array}$ & $\begin{array}{l}\text { Digest } \\
\text { date }\end{array}$ & $\begin{array}{c}\text { Analysis } \\
\text { dete }\end{array}$ & $\begin{array}{c}\text { Days } \\
\text { el apsed } \\
\end{array}$ & Iype \\
\hline $\begin{array}{l}8-101 \\
8-102 \\
8-103 \\
8-104 \\
8-105 \\
8-105\end{array}$ & $\begin{array}{l}8 / 04 / 89 \\
8 / 04 / 89 \\
8 / 04 / 89 \\
8 / 04 / 89 \\
8 / 04 / 89 \\
8 / 04 / 89\end{array}$ & $\begin{array}{l}02 / 20 \\
02 / 20 \\
02 / 20 \\
02 / 20 \\
02 / 20 \\
02 / 20\end{array}$ & $\begin{array}{l}02 / 21 / 90^{1} \\
02 / 21 / 90 \\
02 / 21 / 90 \\
02 / 21 / 90 \\
02 / 21 / 90 \\
02 / 23 / 90\end{array}$ & $\begin{array}{ll}201 & H \\
201 & H \\
201 & H \\
201 & H \\
201 & H \\
203 & H\end{array}$ & $\begin{array}{l}\text { Reg } \\
\text { Reg } \\
\text { Reg } \\
\text { Reg } \\
\text { Ldup } \\
\text { Ldup }\end{array}$ \\
\hline
\end{tabular}

\footnotetext{
$D x=$ sample further diluted by $x$ then analyzed.

$H=$ Holding time exceeded ( 6 months.)

in = Associated matrix recovery high; see Table B-9.

Ldup = Lab duplicate.

Reg = Regular sample.

- Semple is below the laboratory contract detection limit.
}

1 No matrix spike (nor matrix spike duplicate) was reported for samples analyzed on $02 / 21 / 90$. One of the B-105 1 ab duplicates was analyzed on $2 / 23 / 90$ and supported by MS/MSD data. 
Table B-7. Elements by ICP (EPA Method 3050/6010) Background 2 - Undisturbed Native Area.

\begin{tabular}{|c|c|c|c|c|c|c|c|c|c|c|}
\hline Sample & Aluminum & Cacnium & Calcium & Chromiun & Cobsite & Cogoer & Iron & Lithium & Magnesium & Manganese \\
\hline $\begin{array}{l}8-121 \\
8-122 \\
8-123 \\
8-126 \\
8-125 \\
8-126\end{array}$ & $\begin{array}{ll}8076 & 020 \\
8162 & 020 \\
7695 & 020 \\
9204 & 020 \\
7948 & 020 \\
9027 & 020\end{array}$ & $\begin{array}{l}6.4 \\
6.5 \\
7.2 \\
7.0 \\
6.4 \\
6.8\end{array}$ & $\begin{array}{l}3138 \mathrm{HM} \\
3206 \mathrm{HM} \\
3872 \mathrm{HM} \\
3726 \mathrm{HM} \\
3354 \mathrm{HM} \\
3649 \mathrm{HM}\end{array}$ & $\begin{array}{l}8.2 \\
9.7 \\
6.8 \\
9.1 \\
7.4 \\
9.1\end{array}$ & $\begin{array}{l}7.2 \\
7.3 \\
7.1 \\
8.3 \\
6.9 \\
7.5\end{array}$ & $\begin{array}{rr}9.6 & 08 \\
10.6 & 08 \\
9.9 & 08 \\
11.8 & 8 \\
8.7 & 08 \\
11.7 & B\end{array}$ & $\begin{array}{ll}22324 & 020 \\
22231 & 020 \\
24139 & 020 \\
25620 & 020 \\
22676 & 020 \\
24242 & 020\end{array}$ & $\begin{array}{l}7.3: \\
7.4= \\
6.4= \\
7.5= \\
6.0= \\
7.8\end{array}$ & $\begin{array}{ll}4334 & 020 \\
4692 & 020 \\
4577 & 020 \\
4970 & 020 \\
4142 & 020 \\
5193 & 020\end{array}$ & $\begin{array}{r}312.2 \\
318.9 \\
309.5 \\
345.8 \\
314.7 \\
1.5\end{array}$ \\
\hline & Nickel & Potassiun & silver & Sodiun & strontiun & Iitaniun & Vanadium & zine & zirconium & \\
\hline $\begin{array}{l}8-121 \\
8-122 \\
8-123 \\
8-124 \\
8-125 \\
8-126\end{array}$ & $\begin{array}{r}8.8 \\
10.0 \\
7.8 \\
9.5 \\
8.2 \\
9.5\end{array}$ & $\begin{array}{l}1445 \\
1505 \\
1443 \\
1538 \\
1404 \\
1561\end{array}$ & $\begin{array}{l}0.3 \cdot L M \\
0.2 \cdot L M \\
0.5 \cdot L M \\
0.4 \cdot L M \\
0.3 \cdot L M \\
0.2 \cdot L M\end{array}$ & $\begin{array}{l}185.2 \\
188.7 \\
196.4 \\
226.2 \\
188.4 \\
299.6\end{array}$ & $\begin{array}{l}19.9 \\
20.6 \\
21.7 \\
23.9 \\
24.0 \\
24.9\end{array}$ & $\begin{array}{ll}1799 & 020 \\
1755 & 020 \\
2943 & 020 \\
2032 & 020 \\
1870 & 020 \\
1888 & 020\end{array}$ & $\begin{array}{l}49.9 \\
48.6 \\
52.9 \\
56.3 \\
50.1 \\
50.7\end{array}$ & $\begin{array}{l}37.5 \\
37.6 \\
37.5 \\
37.8 \\
37.9 \\
41.3\end{array}$ & $\begin{array}{l}21.4 \\
21.3 \\
21.6 \\
23.1 \\
21.5 \\
21.2\end{array}$ & \\
\hline
\end{tabular}

\section{Sampling Parameters}

\begin{tabular}{|c|c|c|c|c|c|}
\hline Sanole & $\begin{array}{c}\text { Collect } \\
\text { date } \\
\end{array}$ & $\begin{array}{l}\text { Digest } \\
\text { date }\end{array}$ & $\begin{array}{c}\text { Analysis } \\
\text { date }\end{array}$ & $\begin{array}{c}\text { Days } \\
\text { el aosed } \\
\end{array}$ & Iyoe \\
\hline $\begin{array}{l}8-121 \\
8-122 \\
8-123 \\
8-126 \\
8-125 \\
8-126\end{array}$ & $\begin{array}{l}8 / 10 / 89 \\
8 / 10 / 89 \\
8 / 10 / 89 \\
8 / 10 / 89 \\
8 / 10 / 89 \\
8 / 10 / 89\end{array}$ & $\begin{array}{l}02 / 22 \\
02 / 22 \\
02 / 22 \\
02 / 22 \\
02 / 22 \\
02 / 22\end{array}$ & $\begin{array}{l}03 / 06 / 90 \\
03 / 06 / 90 \\
03 / 06 / 90 \\
03 / 06 / 90 \\
03 / 06 / 90 \\
03 / 06 / 90\end{array}$ & $\begin{array}{ll}208 & H \\
208 & H \\
208 & H \\
208 & H \\
208 & H \\
208 & H\end{array}$ & $\begin{array}{l}\text { Fotup } \\
\text { Foup } \\
\text { Reg } \\
\text { Reg } \\
\text { Reg } \\
\text { Reg }\end{array}$ \\
\hline
\end{tabular}

\section{Reggent Blanks Greater than COL}

Anolyte

\begin{tabular}{|c|c|c|c|c|}
\hline Date & Value us $/ 9$ & GI & LI & $\operatorname{col} 4 \mathrm{~g} / \mathrm{g}$ \\
\hline $3 / 06 / 90$ & 1.3 & 1 & 1 & 1.0 \\
\hline
\end{tabular}

\footnotetext{
$B=A$ reagent blank was greater than (GT) CDL on the date of analysis. The number of <CDL blanks on that day is shown in the less than (LT) colum above.

$D x=$ Sample further diluted by $x$ when analyzed.

Four a Field dupl icate.

$H$ = Holding time exceeded.

HW = Associated motrix recovery high; see Table B.9.

LM = Associated matrix recovery low; see Table B-9.

- Sample is above the contract detection limit $(C D L)$ but below a limit of auantitation based on reagent blanks.

Reg a Regular sample.

- I Sample is below the laboratory COL.

+ a chosen by lab for matrix spike.
} 
Table B-8. Elements by ICP (EPA Method 3050/6010) Silica Sand Field Blanks. (sheet 1 of 2)

\begin{tabular}{|c|c|c|c|c|c|c|c|c|c|}
\hline Sample & Aluminum & Cacmiun & Calcium & Chromium & Cobalt & Cogoer & iron & Lithium & Magnesium \\
\hline \multirow[t]{2}{*}{$\begin{array}{l}8-113 \\
8-117 \\
8-162 \\
8-151 \\
B-156 \\
B-163 \\
B-170 \\
8-170 \\
8-193 \\
8-193 \\
8-205\end{array}$} & $\begin{array}{l}227.8 \\
159.5 \\
159.9 \\
131.9 \\
202.4 \\
158.2 \\
165.0 \\
152.8 \\
165.3 \\
147.0 \\
152.3\end{array}$ & $\begin{array}{l}0.2: \\
0.0: \\
0.0: \\
0.4: \\
0.70 \\
0.5: \\
0.8: \\
0.1: \\
0.0: \\
0.0: \\
0.1\end{array}$ & $\begin{array}{l}43.2 \text { OHM } \\
28.0 \mathrm{OHM} \\
25.40 \\
27.00 \\
37.70 \\
346.4 \mathrm{FB} \\
35.00 \\
32.60 \\
38.00 \\
28.40 \\
31.90\end{array}$ & 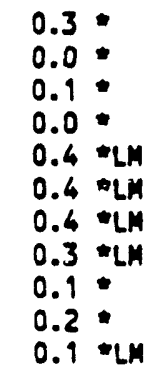 & $\begin{array}{l}0.2 \div 0 \\
0.0=0 \\
0.0=0 \\
0.3=0 \\
0.1=0 \\
0.1=0 \\
0.6=0 \\
0.0=0 \\
0.0=0 \\
0.1 \div 0 \\
0.3=0\end{array}$ & $\begin{array}{l}1.3: B \text { LD } \\
0.5: 8 \\
5.7: F B L M \\
0.6: \\
0.3: \\
0.3: \\
0.6: \\
0.2: \\
0.3: \\
0.2: \\
0.9:\end{array}$ & $\begin{array}{l}302.0 \\
205.4 \\
186.7 \mathrm{HM} \\
924.0 \\
517.7 \\
212.2 \\
845.2 \\
188.6 \\
203.6 \\
194.1 \\
613.1\end{array}$ & $\begin{array}{l}0.2: \\
0.1: \\
0.1: \\
0.1: \\
0.3: \\
0.2: \\
0.2: \\
0.1: \\
0.1: \\
0.0: \\
0.1\end{array}$ & $\begin{array}{l}35.6 \\
17.9 \\
15.9 \\
15.3 \\
23.9 \\
86.0 \quad F B \\
19.7 \\
17.5 \\
19.8 \\
16.8 \\
18.8\end{array}$ \\
\hline & Nickel & Potassium & Silver & Sodium & Strontium & m Titaniun & Vanadium & Zine & zirconium \\
\hline $\begin{array}{l}8-113 \\
8-117 \\
8-142 \\
8-151 \\
8-156 \\
8-163 \\
8-170 \\
8-170 \\
8-193 \\
8-193 \\
8-205\end{array}$ & $\begin{array}{l}0.4: \\
0.3: \\
0.1: \\
0.3: \\
0.8: \\
0.8: \\
0.8: \\
0.5: \\
0.2: \\
0.3: \\
0.0\end{array}$ & $\begin{array}{l}44.6 \\
42.9 \\
38.2 \\
30.8 \\
43.9 \mathrm{HM} \\
40.9 \mathrm{HM} \\
60.0 \mathrm{HM} \\
34.4 \mathrm{HM} \\
38.5 \\
34.8 \\
31.8 \mathrm{HM}\end{array}$ & $\begin{array}{l}0.2 \div \mathrm{LM} \\
0.0 \div \mathrm{LM} \\
0.0 \div \\
0.2: \\
0.0: \\
0.0: \\
0.0: \\
0.1: \\
0.0: \\
0.3: \\
0.1\end{array}$ & 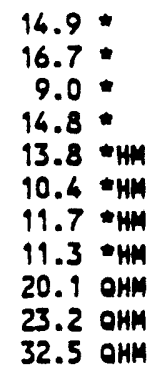 & $\begin{array}{ll} & 0.7: \\
& 0.5= \\
& 0.6= \\
& 0.5= \\
B & 0.7= \\
B & 0.6= \\
B & 0.7= \\
B & 0.5: \\
B & 0.5: \\
B & 0.6 \\
B & 0.6\end{array}$ & 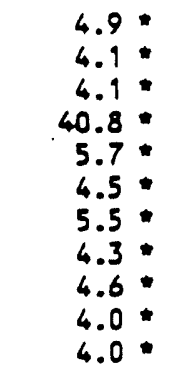 & $\begin{array}{l}0.6 \\
0.0 \\
0.1 \\
0.8 \\
0.4 \\
0.3 \\
0.4 \\
0.2 \\
0.5 \\
0.5 \\
0.4\end{array}$ & 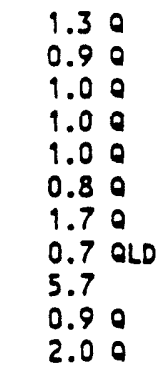 & $\begin{array}{l}1.2: \\
0.7: \\
0.8: \\
0.6= \\
0.9: \\
0.8: \\
0.9= \\
0.7: \\
0.7= \\
0.3: \\
0.7\end{array}$ \\
\hline
\end{tabular}

Sanol ing Paranaters

\begin{tabular}{|c|c|c|c|c|c|}
\hline Semple & $\begin{array}{c}\text { collect } \\
\text { date }\end{array}$ & $\begin{array}{l}\text { Digest } \\
\text { date }\end{array}$ & $\begin{array}{c}\text { Analyois } \\
\text { date }\end{array}$ & $\begin{array}{c}\text { Days } \\
\text { el apsed }\end{array}$ & Iype \\
\hline $\begin{array}{l}8-193 \\
B-197 \\
B-142 \\
B-151 \\
B-156 \\
B-163 \\
B-170 \\
8-170 \\
8-193 \\
8-193 \\
B-205\end{array}$ & $\begin{array}{l}8 / 04 / 89 \\
8 / 10 / 89 \\
8 / 18 / 89 \\
8 / 25 / 89 \\
8 / 28 / 89 \\
8 / 31 / 89 \\
9 / 07 / 89 \\
9 / 07 / 89 \\
9 / 18 / 89 \\
9 / 18 / 89 \\
9 / 21 / 89\end{array}$ & $\begin{array}{l}2 / 22 \\
2 / 22 \\
2 / 19 \\
2 / 20 \\
2 / 24 \\
2 / 24 \\
2 / 24 \\
2 / 24 \\
3 / 05 \\
3 / 05 \\
3 / 06\end{array}$ & $\begin{array}{l}3 / 06 / 90 \\
3 / 06 / 90 \\
2 / 20 / 90 \\
2 / 21 / 90^{2} \\
3 / 07 / 90 \\
3 / 07 / 90 \\
3 / 07 / 90 \\
3 / 07 / 90 \\
3 / 92 / 90 \\
3 / 12 / 90 \\
3 / 07 / 90\end{array}$ & $\begin{array}{l}216 H \\
208 H \\
186 H \\
180 \\
191 H \\
188 H \\
181 \\
189 \\
175 \\
175 \\
167\end{array}$ & $\begin{array}{l}\text { Blk } \\
\text { Blk } \\
\text { Blk + } \\
\text { Blk } \\
\text { Blk } \\
\text { Blk } \\
\text { Blk-Ldup } \\
\text { Blk-Ldup } \\
\text { Blk-Ldup } \\
\text { Blk-Ldup } \\
\text { Blk }\end{array}$ \\
\hline
\end{tabular}


WHC-SD-EN-AP-042, REV. 0

Table B-8. Elements by ICP (EPA Method 3050/6010)

Silita Sand Field Blanks. (sheet 2 of 2 )

\section{Reggent Blanks Greater than COL}

Analyte Date Value ug/g GI LI COL ig/g

$\begin{array}{lrrrrr}\text { Coppr } & 3 / 06 / 90 & 1.3 & 1 & 1 & 1.0 \\ \text { Sodium } & 3 / 07 / 90 & 26.7 & 2 & 2 & 20.0 \\ \text { Sodium } & 3 / 07 / 90 & 24.1 & 2 & . & \\ \text { Sodium } & 3 / 12 / 90 & 23.4 & 1 & 2 & \end{array}$

$B=A$ reagent blank was greater than (GT) COL on date of andysis. The number of <COL blanks on that day is shown on the following page in the less then (LT) colum.

$B / k=$ silica sand field blank.

FB = Field blank high--exceeds poth percentile of the distribution.

$H=$ Holding time exceeded ( 6 months).

HM = Associated matrix recovery high; see Table 8.9.

$L D=$ Sample is above col but below a limit of detection, (avg $+3 s$ ), based on reagent blanks.

Ldup = Lab depl icate.

LA = Associated metrix recovery low; see Table 8-9.

0 = Sample is above contract detection limit (ODL) but below a limit of quantitation, (avg + 10s), based on reagent blanks.

- = Sample is bolon COL limit.

+ = Chosen by lab for merix spike.

2 No matrix spike (nor matrix spike duplicate) was reported for samples analyzed on $02 / 21 / 90$. 
WHC-SD-EN-AP-042, REV. 0

Table B-9. Matrix Spike/Matrix Spike Duplicate Anomaliy Summary for ICP Analytes.

\begin{tabular}{|c|c|c|c|c|c|c|}
\hline Sanple & $\begin{array}{l}\text { Digest } \\
\text { Date }\end{array}$ & $\begin{array}{l}\text { Analysis } \\
\text { Date }\end{array}$ & $\begin{array}{l}\text { Low } \\
\text { Recovery }\end{array}$ & $\begin{array}{c}\text { Anolyte } \\
\text { High Recovery }\end{array}$ & $\begin{array}{l}\text { Spike Level } \\
\text { Ingropropriate }\end{array}$ & $\begin{array}{c}\text { Sample Spikes } \\
\text { site/Source }\end{array}$ \\
\hline $\begin{array}{l}8 \cdot 13359 \\
B-13352\end{array}$ & $\begin{array}{l}2 / 19 \\
2 / 19\end{array}$ & $\begin{array}{l}2 / 20 / 90 \\
2 / 20 / 90\end{array}$ & $A \theta(72 x)$ & & $\begin{array}{l}\text { Al, Fe, wo, Ti } \\
\text { Al, Fe, Ti }\end{array}$ & Composite fr. 8.3 Pand \\
\hline $\begin{array}{l}8-14259 \\
8-14252\end{array}$ & $\begin{array}{l}2 / 19 \\
2 / 19\end{array}$ & $\begin{array}{l}2 / 20 / 90 \\
2 / 20 / 90\end{array}$ & $\begin{array}{l}\operatorname{cu}(73 x) \\
\operatorname{cu}(75 x)\end{array}$ & Fe(181x) & & silice send blank \\
\hline $\begin{array}{l}8-11051 \\
8-11052\end{array}$ & $\begin{array}{l}2 / 20 \\
2 / 20\end{array}$ & $\begin{array}{l}2 / 23 / 90 \\
2 / 23 / 90\end{array}$ & & $K(128 \%)$ & $\begin{array}{l}\text { Ca, Al, Fe, Mg, Ti } \\
\text { Ca, Al, Fe, Mg, Ti }\end{array}$ & 38 Pond \\
\hline $\begin{array}{ll}8-123 & 51 \\
8-123 & 52\end{array}$ & $\begin{array}{l}2 / 22 \\
2 / 22\end{array}$ & $\begin{array}{l}3 / 06 / 90 \\
3 / 06 / 90\end{array}$ & $\begin{array}{l}A g(71 x) \\
A g(74 x)\end{array}$ & $\begin{array}{l}\operatorname{Ca}(128 \%) \\
\operatorname{Ca}(129 \%)\end{array}$ & $\begin{array}{l}\text { Al, m, Fe, Mg, Ti } \\
\text { Al, Mn, Fe, Ti }\end{array}$ & Background (Sage. site) \\
\hline $\begin{array}{ll}8-152 & 51 \\
8-152 & 52\end{array}$ & $\begin{array}{l}2 / 24 \\
2 / 24\end{array}$ & $\begin{array}{l}3 / 07 / 90 \\
3 / 07 / 90\end{array}$ & & & $\begin{array}{l}\mathrm{Ca}, \mathrm{Al}, \mathrm{m}, \mathrm{Fe}, \mathrm{Mg}, \mathrm{Ti} \\
\mathrm{Ca}, \mathrm{Al}, \mathrm{Mn}, \mathrm{Fe}, \mathrm{Mg}, \mathrm{Ti}\end{array}$ & B-3-3 Ditch \\
\hline $8-16252$ & $2 / 24$ & $3 / 07 / 90$ & $\operatorname{cr}(73 x)$ & $\begin{array}{l}\operatorname{Cd}(130 x), \\
\text { Ma(130x), } \\
V(152 x), \\
K(131 x) \\
\operatorname{Cd}(130 x), \\
\text { Ma(128x), } \\
V(147 x), \\
K(143 x)\end{array}$ & $\begin{array}{l}\text { Ca, Al, Fe, Mg, Ti } \\
\text { Ca, Al, Mn, Fe, Mg, Ti }\end{array}$ & $\begin{array}{l}\text { Composite fr. } \\
\text { B-3-3 Diteh }\end{array}$ \\
\hline $\begin{array}{l}8-19851 \\
8-19852\end{array}$ & $\begin{array}{l}3 / 06 \\
3 / 06\end{array}$ & $\begin{array}{l}3 / 07 / 90 \\
3 / 07 / 90\end{array}$ & & & $\begin{array}{l}\text { Ca, Al, m, Fe, Mg, Ti } \\
\mathrm{Ca}_{1} \text { Al, Fe, } \mathrm{Mg}, \mathrm{Ti}\end{array}$ & 3A Pond \\
\hline $\begin{array}{l}8-175 s 1 \\
8-175 s 2\end{array}$ & $\begin{array}{l}3 / 08 \\
3 / 08\end{array}$ & $\begin{array}{l}3 / 10 / 90 \\
3 / 10 / 90\end{array}$ & & $\begin{array}{l}V(136 x) \\
V(131 \%)\end{array}$ & $\begin{array}{l}\text { Ca, Al, Mn, FE, Mg, } T i \\
\text { Ca, Al, Mn, Fe, Mg, } T i\end{array}$ & $3 c$ Pond (dry site) \\
\hline $\begin{array}{l}8-187 s 1 \\
8-18752\end{array}$ & $\begin{array}{l}3 / 05 \\
3 / 05\end{array}$ & $\begin{array}{l}3 / 12 / 90 \\
3 / 12 / 90\end{array}$ & & $\begin{array}{l}\operatorname{Ma}(126 x), \\
V(161 x) \\
V(167 x)\end{array}$ & $\begin{array}{l}\text { Ca, Al, Mn, Fe, Mg, Ti } \\
\text { Co, Al, Mn, Fe, Mg, Ti }\end{array}$ & 8-3-3 Diteh \\
\hline
\end{tabular}

- Acceptable guidel ine recoveries are 75 to $125 \%$. 
WHC-SD-EN-AP-042, REV. 0

APPENDIX $C$

SELECTED DATA OTHER THAN ICP ANALYSES

$r-i$ 
WHC-SD-EN-AP-042, REV. 0

This page intentionally left blank. 


\section{APPENDIX C}

\section{SELECTED DATA OTHER THAN ICP ANALYSES}

Appendix $C$ contains tabulations of total metals by atomic absorption, ammonium, common anions by liquid chromatography, volatile organics by gas chromatography/mass spectrometry, and radioactivity measurements. Many analytes investigated in Phase 1 were below concentrations measurable by the referenced procedures. Those selected for display in this appendix generally include analytes reported above the contract detection limit (CDL) in at least some samples and not listed in the previous appendix. Analytes are presented in the following order: arsenic, lead, mercury, ammonium, chloride, fluoride, nitrate, nitrite, phosphate, sulfate, volatile organics, gross alpha, gross beta, strontium-90, and radionuclides by gamma scan.

\section{Key to sample type abbreviations of Appendix $C$}

$$
\begin{array}{ll}
\text { Fdup } & =\text { Field duplicate } \\
\text { Ldup } & =\text { Laboratory duplicate } \\
\text { Reg } & =\text { Regular sample } \\
\text { Select } & =\text { Nonrandomly selected sample } \\
B l k & =\text { Silica sand field blank } \\
H_{2} O & =\text { Pond water sample } \\
M S & =\text { Matrix spike sample } \\
M S D & =\text { Matrix spike duplicate sample. }
\end{array}
$$


Table C-1. Arsenic Data (EPA Method 7060)

Soil $C D L=0.5 \mu \mathrm{g} / \mathrm{g}$. (sheet 1 of 2)

\begin{tabular}{|c|c|c|c|c|c|c|c|}
\hline site & Sample & $\begin{array}{l}\text { Arsenic } \\
(\mu g / g)\end{array}$ & oc-flags & Collect date & Digest date & Analysis date & Type \\
\hline $\begin{array}{l}3 A \text { Pond } \\
3 A \text { Pond } \\
3 A \text { Pond } \\
3 A \text { Pond } \\
3 A \text { Pond } \\
3 A \text { Pand } \\
3 A \text { Pond } \\
3 A \text { Pond } \\
3 A \text { Pond }\end{array}$ & $\begin{array}{l}B-194 \\
8-196 \\
B-197 \\
B-197 \\
8-198 \\
8-200 \\
8-201 \\
8-202 \\
8-203\end{array}$ & $\begin{array}{l}1.10 \\
0.97 \\
0.84 \\
0.89 \\
1.07 \\
4.69 \\
2.66 \\
1.35 \\
2.12\end{array}$ & & $\begin{array}{l}9 / 29 \\
9 / 21 \\
9 / 29 \\
9 / 21 \\
9 / 21 \\
9 / 21 \\
9 / 21 \\
9 / 21 \\
9 / 21\end{array}$ & $\begin{array}{l}9 / 25 \\
9 / 25 \\
9 / 25 \\
9 / 25 \\
9 / 25 \\
9 / 25 \\
9 / 25 \\
9 / 25 \\
9 / 25\end{array}$ & $\begin{array}{l}9 / 26 \\
9 / 26 \\
9 / 26 \\
9 / 26 \\
9 / 26 \\
9 / 26 \\
9 / 26 \\
9 / 26 \\
9 / 26\end{array}$ & $\begin{array}{l}\text { Fdup } \\
\text { Fdup } \\
\text { Ldup } \\
\text { Ldup } \\
\text { Reg } \\
\text { Reg } \\
\text { Reg } \\
\text { Reg } \\
\text { Reg }\end{array}$ \\
\hline $\begin{array}{l}38 \text { Pond } \\
38 \text { Pond } \\
38 \text { Pond } \\
38 \text { Pond } \\
38 \text { Pond } \\
38 \text { Pond } \\
38 \text { Pond }\end{array}$ & $\begin{array}{l}B-106 \\
B-106 \\
B-107 \\
B-108 \\
8-109 \\
8-110 \\
B-111\end{array}$ & $\begin{array}{l}1.64 \\
2.54 \\
1.92 \\
1.87 \\
2.26 \\
3.43 \\
1.78\end{array}$ & & $\begin{array}{l}8 / 04 \\
8 / 04 \\
8 / 04 \\
8 / 04 \\
8 / 04 \\
8 / 04 \\
8 / 04\end{array}$ & $\begin{array}{l}8 / 39 \\
8 / 31 \\
8 / 31 \\
8 / 39 \\
9 / 05 \\
9 / 05 \\
9 / 05\end{array}$ & $\begin{array}{l}9 / 05 \\
9 / 05 \\
9 / 05 \\
9 / 05 \\
9 / 08 \\
9 / 08 \\
9 / 08\end{array}$ & $\begin{array}{l}\text { Ldup } \\
\text { Ldup } \\
\text { Reg } \\
\text { Fdup } \\
\text { Fdup } \\
\text { Reg } \\
\text { Reg }\end{array}$ \\
\hline $\begin{array}{l}3 C \text { Pond } \\
3 C \text { Pand } \\
3 C \text { Pond } \\
3 C \text { Pond } \\
3 C \text { Pond } \\
3 C \text { Pond } \\
3 C \text { Pond } \\
3 C \text { Pand } \\
3 C \text { Pond } \\
3 C \text { Pond }\end{array}$ & $\begin{array}{l}8-179 \\
8-172 \\
B-174 \\
8-175 \\
8-176 \\
8-176 \\
8-177 \\
8-178 \\
8-179 \\
B-180\end{array}$ & $\begin{array}{l}0.97 \\
2.20 \\
0.99 \\
1.95 \\
1.14 \\
1.32 \\
0.94 \\
0.83 \\
1.13 \\
0.84\end{array}$ & & $\begin{array}{l}9 / 08 \\
9 / 08 \\
9 / 08 \\
9 / 08 \\
9 / 08 \\
9 / 08 \\
9 / 08 \\
9 / 08 \\
9 / 08 \\
9 / 08\end{array}$ & $\begin{array}{l}9 / 13 \\
9 / 13 \\
9 / 13 \\
9 / 13 \\
9 / 13 \\
9 / 13 \\
9 / 13 \\
9 / 13 \\
9 / 13 \\
9 / 13\end{array}$ & $\begin{array}{l}9 / 15 \\
9 / 15 \\
9 / 15 \\
9 / 15 \\
9 / 15 \\
9 / 15 \\
9 / 15 \\
9 / 15 \\
9 / 15 \\
9 / 15\end{array}$ & $\begin{array}{l}\text { Fodp } \\
\text { Fdup } \\
\text { Reg } \\
\text { Reg } \\
\text { Ldup } \\
\text { Ldup } \\
\text { Reg } \\
\text { Reg } \\
\text { Reg } \\
\text { Reg }\end{array}$ \\
\hline $\begin{array}{l}8-3 \text { Pond } \\
8-3 \text { Pond } \\
8-3 \text { Pond } \\
8-3 \text { Pond } \\
8-3 \text { Pond } \\
8-3 \text { Pond } \\
8-3 \text { Pond } \\
8-3 \text { Pond } \\
8-3 \text { Pond } \\
8-3 \text { Pond } \\
8-3 \text { Pond } \\
8-3 \text { Pond } \\
8-3 \text { Pond } \\
8-3 \text { Pond } \\
8-3 \text { Pond } \\
8-3 \text { Pond } \\
8-3 \text { Pond } \\
8-3 \text { Pond } \\
8-3 \text { Pond } \\
8-3 \text { Pond } \\
8-3 \text { Pond } \\
8-3 \text { Pond } \\
8-3 \text { Pond } \\
8-3 \text { Pond } \\
8-3 \text { Pond } \\
8-3 \text { Pond } \\
8-3 \text { Pond }\end{array}$ & $\begin{array}{l}B-114 \\
8-115 \\
B-116 \\
8-118 \\
8-119 \\
8-128 \\
B-129 \\
B-130 \\
8-139 \\
8-132 \\
B-134 \\
B-135 \\
B-136 \\
B-138 \\
8-139 \\
8-140 \\
8-140 \\
B-143 \\
8-145 \\
B-146 \\
B-147 \\
8-148 \\
B-149 \\
B-164 \\
B-165 \\
8-166 \\
B-168\end{array}$ & $\begin{array}{l}2.24 \\
1.75 \\
1.57 \\
2.67 \\
2.17 \\
1.54 \\
1.60 \\
2.32 \\
2.36 \\
2.46 \\
2.18 \\
3.10 \\
2.32 \\
1.38 \\
1.13 \\
1.52 \\
1.40 \\
1.15 \\
1.32 \\
1.23 \\
2.05 \\
3.34 \\
2.65 \\
2.63 \\
2.91 \\
1.45 \\
1.56\end{array}$ & & $\begin{array}{l}8 / 10 \\
8 / 10 \\
8 / 10 \\
8 / 19 \\
8 / 19 \\
8 / 17 \\
8 / 17 \\
8 / 17 \\
8 / 17 \\
8 / 17 \\
8 / 18 \\
8 / 18 \\
8 / 18 \\
8 / 18 \\
8 / 18 \\
8 / 18 \\
8 / 18 \\
8 / 25 \\
8 / 25 \\
8 / 25 \\
8 / 25 \\
8 / 25 \\
8 / 25 \\
9 / 07 \\
9 / 07 \\
9 / 07 \\
9 / 07\end{array}$ & $\begin{array}{l}9 / 05 \\
9 / 05 \\
9 / 05 \\
9 / 15 \\
9 / 15 \\
9 / 15 \\
9 / 15 \\
9 / 15 \\
9 / 15 \\
9 / 15 \\
9 / 21 \\
9 / 21 \\
9 / 21 \\
9 / 21 \\
9 / 21 \\
9 / 21 \\
9 / 21 \\
8 / 29 \\
8 / 29 \\
8 / 29 \\
8 / 29 \\
8 / 29 \\
8 / 29 \\
9 / 13 \\
9 / 13 \\
9 / 13 \\
9 / 13\end{array}$ & $\begin{array}{l}9 / 08 \\
9 / 08 \\
9 / 08 \\
9 / 18 \\
9 / 18 \\
9 / 18 \\
9 / 18 \\
9 / 18 \\
9 / 18 \\
9 / 18 \\
9 / 22 \\
9 / 22 \\
9 / 22 \\
9 / 22 \\
9 / 22 \\
9 / 22 \\
9 / 22 \\
8 / 30 \\
8 / 30 \\
8 / 30 \\
8 / 30 \\
8 / 30 \\
8 / 30 \\
9 / 15 \\
9 / 15 \\
9 / 15 \\
9 / 15\end{array}$ & $\begin{array}{l}\text { Reg } \\
\text { Reg } \\
\text { Reg } \\
\text { Reg } \\
\text { Reg } \\
\text { Fdup } \\
\text { Fdup } \\
\text { Reg } \\
\text { Reg } \\
\text { Reg } \\
\text { Fdup } \\
\text { fdup } \\
\text { Reg } \\
\text { Reg } \\
\text { Reg } \\
\text { Ldup } \\
\text { Ldup } \\
\text { Reg } \\
\text { Fdup } \\
\text { Fdup } \\
\text { Reg } \\
\text { Reg } \\
\text { Reg } \\
\text { Select-Fdup } \\
\text { Select-Fdup } \\
\text { Reg } \\
\text { Select }\end{array}$ \\
\hline $\begin{array}{l}8-3-3 \text { Dit. } \\
8-3-3 \text { Dit. } \\
8-3-3 \text { Dit. } \\
8-3-3 \text { Dit. } \\
8-3-3 \text { Dit. } \\
8-3-3 \text { Dit. } \\
8-3-3 \text { Dit. }\end{array}$ & $\begin{array}{l}B-152 \\
8-153 \\
8-154 \\
B-158 \\
8-159 \\
8-160 \\
B-161\end{array}$ & $\begin{array}{l}1.59 \\
1.22 \\
3.09 \\
2.56 \\
1.86 \\
1.28 \\
1.29\end{array}$ & & $\begin{array}{l}8 / 28 \\
8 / 28 \\
8 / 28 \\
8 / 31 \\
8 / 31 \\
8 / 39 \\
8 / 31\end{array}$ & $\begin{array}{l}8 / 31 \\
8 / 31 \\
8 / 31 \\
9 / 05 \\
9 / 05 \\
9 / 05 \\
9 / 05\end{array}$ & $\begin{array}{l}9 / 05 \\
9 / 05 \\
9 / 05 \\
9 / 08 \\
9 / 08 \\
9 / 08 \\
9 / 08\end{array}$ & $\begin{array}{l}\text { Fodup } \\
\text { Fdup } \\
\text { Reg } \\
\text { Fdup } \\
\text { foup } \\
\text { Reg } \\
\text { Select }\end{array}$ \\
\hline
\end{tabular}


WHC-SD-EN-AP-042, REV. 0

Table C-1. Arsenic Data (EPA Method 7060)

Soil $C D L=0.5 \mu \mathrm{g} / \mathrm{g}$. (sheet 2 of 2)

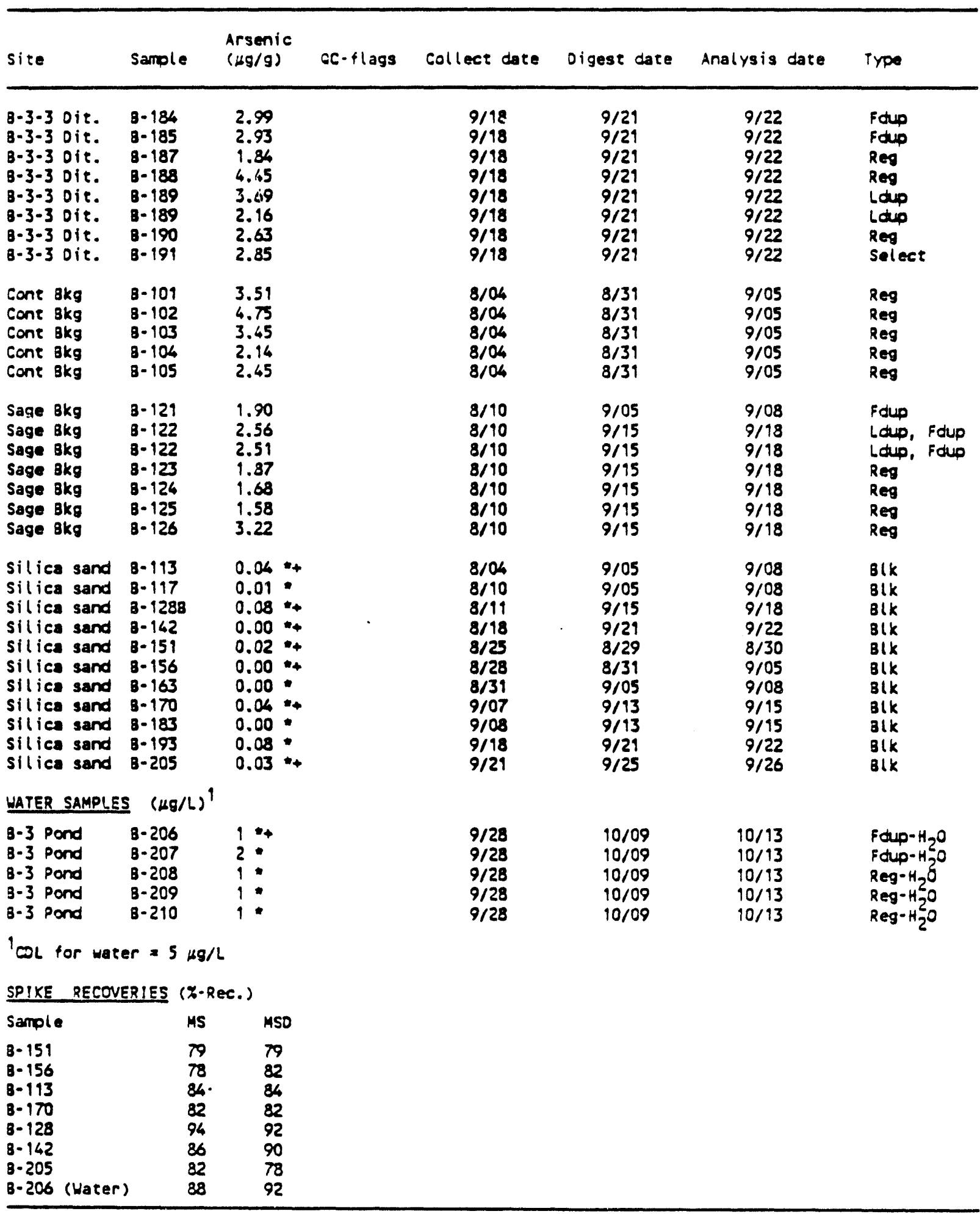

- I Estimated value $<C D L$.

- = Sarpole chosen by laboratory for MS/MSD. 
Table C-2. Lead Data (EPA Method 7421) So il $\mathrm{CDL}=0.5 \mu \mathrm{g} / \mathrm{g}$. (sheet 1 of 2 )

\begin{tabular}{|c|c|c|c|c|c|c|c|c|}
\hline site & semple & $\begin{array}{l}\text { Leed } \\
(\mu \sigma / g)\end{array}$ & OC. & flags & Colleet date & Digest dare & Analysis date & Type \\
\hline $\begin{array}{l}3 A \text { Pond } \\
3 A \text { Pond } \\
3 A \text { Pand } \\
3 A \text { Pand } \\
3 A \text { Pand } \\
3 A \text { Pond } \\
3 A \text { Pand } \\
3 A \text { Pond } \\
3 A \text { Pond }\end{array}$ & $\begin{array}{l}B-194 \\
B-196 \\
B-197 \\
B-197 \\
B-198 \\
B-200 \\
B-201 \\
B-202 \\
B-203\end{array}$ & $\begin{array}{l}4.41 \\
4.29 \\
2.97 \\
4.01 \\
5.22 \\
6.28 \\
7.29 \\
3.76 \\
6.36\end{array}$ & & & $\begin{array}{l}9 / 21 \\
9 / 21 \\
9 / 21 \\
9 / 21 \\
9 / 21 \\
9 / 21 \\
9 / 21 \\
9 / 21 \\
9 / 21\end{array}$ & $\begin{array}{l}9 / 25 \\
9 / 25 \\
9 / 25 \\
9 / 25 \\
9 / 25 \\
9 / 25 \\
9 / 25 \\
9 / 25 \\
9 / 25\end{array}$ & $\begin{array}{l}9 / 26 \\
9 / 26 \\
9 / 26 \\
9 / 26 \\
9 / 26 \\
9 / 26 \\
9 / 26 \\
9 / 26 \\
9 / 26\end{array}$ & $\begin{array}{l}\text { Foup } \\
\text { Foup } \\
\text { Lodp } \\
\text { Lodp } \\
\text { Reg } \\
\text { Reg } \\
\text { Reg } \\
\text { Reg } \\
\text { Reg }\end{array}$ \\
\hline $\begin{array}{l}38 \text { Pond } \\
38 \text { Pond } \\
38 \text { Pond } \\
38 \text { Pond } \\
38 \text { Pond } \\
38 \text { Pond } \\
38 \text { Pond }\end{array}$ & $\begin{array}{l}8-106 \\
8-106 \\
8-107 \\
8-108 \\
8-109 \\
8-110 \\
8-111\end{array}$ & $\begin{array}{l}2.63 \\
3.11 \\
2.92 \\
3.12 \\
3.84 \\
3.03 \\
2.07\end{array}$ & $\begin{array}{l}\mathrm{FE} \\
\mathrm{FE} \\
\mathrm{FE}\end{array}$ & & $\begin{array}{l}8 / 04 \\
8 / 04 \\
8 / 04 \\
8 / 04 \\
8 / 04 \\
8 / 04 \\
8 / 04\end{array}$ & $\begin{array}{l}8 / 39 \\
8 / 39 \\
8 / 31 \\
8 / 31 \\
9 / 05 \\
9 / 05 \\
9 / 05\end{array}$ & $\begin{array}{l}9 / 06 \\
9 / 06 \\
9 / 06 \\
9 / 06 \\
9 / 07 \\
9 / 07 \\
9 / 07\end{array}$ & $\begin{array}{l}\text { Loup } \\
\text { Ldup } \\
\text { Reg } \\
\text { Fdup } \\
\text { Fdup } \\
\text { Reg } \\
\text { Reg }\end{array}$ \\
\hline $\begin{array}{l}3 C \text { Pond } \\
3 C \text { Pond } \\
3 C \text { Pond } \\
3 C \text { Pond } \\
3 C \text { Pond } \\
3 C \text { Pond } \\
3 C \text { Pond } \\
3 C \text { Pond } \\
3 C \text { Pond } \\
3 C \text { Pond }\end{array}$ & $\begin{array}{l}8-179 \\
8-172 \\
8-174 \\
8-175 \\
8-176 \\
8-176 \\
8-177 \\
8-178 \\
B=179 \\
8=180\end{array}$ & $\begin{array}{l}3.37 \\
5.22 \\
2.92 \\
4.65 \\
3.48 \\
3.31 \\
6.09 \\
3.30 \\
3.84 \\
3.04\end{array}$ & & & $\begin{array}{l}9 / 08 \\
9 / 08 \\
9 / 08 \\
9 / 08 \\
9 / 08 \\
9 / 08 \\
9 / 08 \\
9 / 08 \\
9 / 08 \\
9 / 08\end{array}$ & $\begin{array}{l}9 / 13 \\
9 / 13 \\
9 / 13 \\
9 / 13 \\
9 / 13 \\
9 / 13 \\
9 / 13 \\
9 / 13 \\
9 / 13 \\
9 / 13\end{array}$ & $\begin{array}{l}9 / 14 \\
9 / 14 \\
9 / 14 \\
9 / 14 \\
9 / 14 \\
9 / 14 \\
9 / 14 \\
9 / 14 \\
9 / 14 \\
9 / 14\end{array}$ & $\begin{array}{l}\text { Fodp } \\
\text { foup } \\
\text { Reg } \\
\text { Reg } \\
\text { Ldup } \\
\text { Ldup } \\
\text { Reg } \\
\text { Reg } \\
\text { Reg } \\
\text { Reg. }\end{array}$ \\
\hline $\begin{array}{l}8-3 \text { Pond } \\
8-3 \text { Pond } \\
8-3 \text { Pond } \\
8-3 \text { Pond } \\
8-3 \text { Pond } \\
8-3 \text { Pond } \\
8-3 \text { Pond } \\
8-3 \text { Pond } \\
8-3 \text { Pond } \\
8-3 \text { Pond } \\
8-3 \text { Pond } \\
8-3 \text { Pond } \\
8-3 \text { Pond } \\
8-3 \text { Pond } \\
8-3 \text { Pond } \\
8-3 \text { Pond } \\
8-3 \text { Pand } \\
8-3 \text { Pand } \\
8-3 \text { Pond } \\
8-3 \text { Pond } \\
8-3 \text { Pond } \\
8-3 \text { Pond } \\
8-3 \text { Pond } \\
8-3 \text { Pand } \\
8-3 \text { Pand } \\
8-3 \text { Pond } \\
8-3 \text { Pond }\end{array}$ & $\begin{array}{l}B-114 \\
B-115 \\
B-116 \\
B-118 \\
B-119 \\
B-128 \\
B-129 \\
B-130 \\
B-131 \\
8-132 \\
B-134 \\
8-135 \\
8-136 \\
8-138 \\
8-139 \\
B-140 \\
B-140 \\
B-143 \\
B-145 \\
B-146 \\
8-147 \\
B-148 \\
B-149 \\
B-164 \\
B-165 \\
8-166 \\
8-168\end{array}$ & $\begin{array}{r}16.20 \\
50.50 \\
58.20 \\
8.14 \\
9.60 \\
13.50 \\
13.00 \\
356.00 \\
618.00 \\
112.00 \\
14.50 \\
19.10 \\
16.90 \\
46.60 \\
286.00 \\
25.10 \\
23.90 \\
67.00 \\
59.00 \\
226.00 \\
163.00 \\
116.00 \\
17.00 \\
16.60 \\
13.00 \\
76.90 \\
74.40\end{array}$ & $\begin{array}{l}010 F t \\
050 F t \\
010 F t \\
010 \\
010 \\
010 \\
010 \\
0100 \\
0100 \\
0100 \\
010 \\
010 \\
010 \\
010 \\
0100 \\
010 \\
010 \\
010 \\
010 \\
0100 \\
0100 \\
0100 \\
010 \\
010 \\
010 \\
010 \\
010\end{array}$ & ${ }_{8}^{B} E$ & $\begin{array}{l}8 / 10 \\
8 / 10 \\
8 / 10 \\
8 / 19 \\
8 / 11 \\
8 / 17 \\
8 / 17 \\
8 / 17 \\
8 / 17 \\
8 / 17 \\
8 / 18 \\
8 / 18 \\
8 / 18 \\
8 / 18 \\
8 / 18 \\
8 / 18 \\
8 / 18 \\
8 / 25 \\
8 / 25 \\
8 / 25 \\
8 / 25 \\
8 / 25 \\
8 / 25 \\
9 / 07 \\
9 / 07 \\
9 / 07 \\
9 / 07\end{array}$ & $\begin{array}{l}9 / 05 \\
9 / 05 \\
9 / 05 \\
9 / 15 \\
9 / 15 \\
9 / 15 \\
9 / 15 \\
9 / 15 \\
9 / 15 \\
9 / 15 \\
9 / 21 \\
9 / 21 \\
9 / 21 \\
9 / 21 \\
9 / 21 \\
9 / 21 \\
9 / 21 \\
8 / 29 \\
8 / 29 \\
8 / 29 \\
8 / 29 \\
8 / 29 \\
8 / 29 \\
9 / 13 \\
9 / 13 \\
9 / 13 \\
9 / 13\end{array}$ & $\begin{array}{l}9 / 09 \\
9 / 09 \\
9 / 09 \\
9 / 18 \\
9 / 18 \\
9 / 18 \\
9 / 18 \\
9 / 20 \\
9 / 20 \\
9 / 20 \\
9 / 22 \\
9 / 22 \\
9 / 22 \\
9 / 22 \\
9 / 23 \\
9 / 22 \\
9 / 22 \\
8 / 31 \\
8 / 39 \\
9 / 01 \\
9 / 01 \\
9 / 01 \\
8 / 31 \\
9 / 16 \\
9 / 16 \\
9 / 16 \\
9 / 16\end{array}$ & $\begin{array}{l}\text { Reg } \\
\text { Reg } \\
\text { Reg } \\
\text { Reg } \\
\text { Res } \\
\text { Fdup } \\
\text { fdup } \\
\text { Reg } \\
\text { Reg } \\
\text { Reg } \\
\text { Fdup } \\
\text { Fdup } \\
\text { Reg } \\
\text { Reg } \\
\text { Reg } \\
\text { Ldup } \\
\text { Ldup } \\
\text { Reg } \\
\text { Fdup } \\
\text { Fdup } \\
\text { Reg } \\
\text { Reg } \\
\text { Reg } \\
\text { Select-Fdup } \\
\text { Select -Fdup } \\
\text { Reg } \\
\text { Select }\end{array}$ \\
\hline $\begin{array}{l}\text { B-3-3 Dit. } \\
8-3-3 \text { Dit. } \\
\text { B-3-3 Dit. } \\
\text { B-3-3 Dit. } \\
\text { B-3-3 Dit. } \\
\text { B-3-3 Dit. }\end{array}$ & $\begin{array}{l}B-152 \\
B-153 \\
B-154 \\
B-158 \\
B-159 \\
B-160\end{array}$ & $\begin{array}{l}3.22 \\
2.38 \\
8.65 \\
5.69 \\
4.51 \\
5.62\end{array}$ & & & $\begin{array}{l}8 / 28 \\
8 / 28 \\
8 / 28 \\
8 / 31 \\
8 / 31 \\
8 / 31\end{array}$ & $\begin{array}{l}8 / 3 i \\
8 / 3 i \\
8 / 31 \\
9 / 05 \\
9 / 05 \\
9 / 05\end{array}$ & $\begin{array}{l}9 / 06 \\
9 / 06 \\
9 / 06 \\
9 / 07 \\
9 / 07 \\
9 / 07\end{array}$ & $\begin{array}{l}\text { Fdup } \\
\text { Fdup } \\
\text { Reg } \\
\text { Fdup } \\
\text { Fdup } \\
\text { Reg }\end{array}$ \\
\hline
\end{tabular}


WHC-SD-EN-AP-042, REV. 0

Table C-2. Lead Data (EPA Method 7421)

Soil $\mathrm{COL}=0.5 \mu \mathrm{g} / \mathrm{g}$. (sheet 2 of 2 )

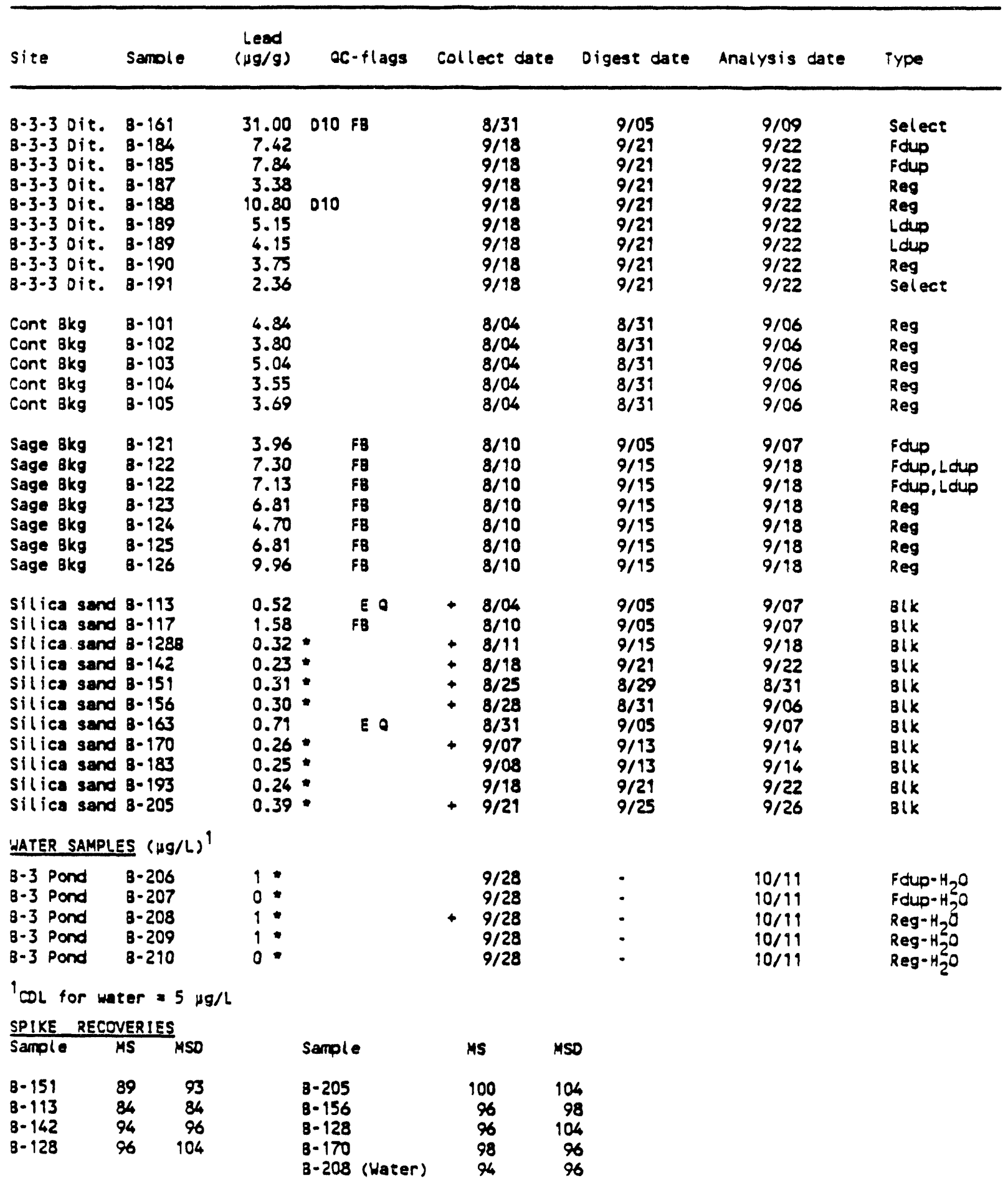

$D x=$ Sample diluted during analysis by an extra factor of $x$.

$E=$ Estimate is greater than a dilution-adjusted $C D L$, but $<3$ times the standard deviation of the field blanks multiplied by any additional dilution factor.

$F B=$ Assoc. Field blank high .. exceeds 99 th percentile of the $\underline{t}$ distribution.

0 = Estimate is greater than a dilution-adjusted COL, but below an LCO derived from the mean and standard deviation of reagent blanks, (avg. + 10s), and adjusted for nominal samole size/dilution; $L \infty=0.73 \mu g / g$.

+ a Samole chosen by laboratories for MS/MSO.

- Estimated value below COL. 
WHC-SD-EN-AP-042, REV. 0

Table C-3. Mercury Data (EPA Methods 7470 and 7471)

Soil CDL $=0.2 \mu \mathrm{g} / \mathrm{g}$. (sheet 1 of 2)

\begin{tabular}{|c|c|c|c|c|c|c|c|}
\hline site & Sample & $\begin{array}{l}\text { Mercury } \\
(\mu \sigma / g)\end{array}$ & ac-flags & Collect date & Analysis date & Days elapsed & Type \\
\hline $\begin{array}{l}3 A \text { Pond } \\
3 A \text { Pond } \\
3 A \text { Pond } \\
3 A \text { Pond } \\
3 A \text { Pond } \\
3 A \text { Pond } \\
3 A \text { Pond } \\
3 A \text { Pond }\end{array}$ & $\begin{array}{l}8-194 \\
8-196 \\
8-197 \\
8-198 \\
8-200 \\
8-201 \\
8-202 \\
8-203\end{array}$ & $\begin{array}{ll}< & 0.2 \\
< & 0.2 \\
< & 0.2 \\
< & 0.2 \\
< & 0.2 \\
< & 0.2 \\
< & 0.2 \\
< & 0.2\end{array}$ & & $\begin{array}{r}9 / 21 \\
9 / 29 \\
9 / 29 \\
9 / 21 \\
9 / 29 \\
9 / 21 \\
+\quad 9 / 21 \\
9 / 21\end{array}$ & $\begin{array}{l}9 / 26 \\
9 / 26 \\
9 / 26 \\
9 / 26 \\
9 / 26 \\
9 / 26 \\
9 / 26 \\
9 / 26\end{array}$ & $\begin{array}{l}5 \\
5 \\
5 \\
5 \\
5 \\
5 \\
5 \\
5\end{array}$ & $\begin{array}{l}\text { Fdup } \\
\text { Fdup } \\
\text { Reg } \\
\text { Reg } \\
\text { Reg } \\
\text { Reg } \\
\text { Reg } \\
\text { Reg }\end{array}$ \\
\hline $\begin{array}{l}38 \text { Pond } \\
38 \text { Pond } \\
38 \text { Pond } \\
38 \text { Pond } \\
38 \text { Pond } \\
38 \text { Pand }\end{array}$ & $\begin{array}{l}B-106 \\
B-107 \\
8-108 \\
8-109 \\
B-110 \\
8-119\end{array}$ & $\begin{array}{ll}< & 0.2 \\
< & 0.2 \\
< & 0.2 \\
< & 0.2 \\
< & 0.2 \\
< & 0.2\end{array}$ & & $\begin{array}{l}8 / 04 \\
8 / 04 \\
8 / 04 \\
8 / 04 \\
8 / 04 \\
8 / 04\end{array}$ & $\begin{array}{l}8 / 91 \\
8 / 19 \\
8 / 91 \\
8 / 19 \\
8 / 99 \\
8 / 19\end{array}$ & $\begin{array}{l}7 \\
7 \\
7 \\
7 \\
7 \\
7\end{array}$ & $\begin{array}{l}\text { Reg } \\
\text { Reg } \\
\text { Fdup } \\
\text { Fdup } \\
\text { Reg } \\
\text { Reg }\end{array}$ \\
\hline $\begin{array}{l}3 C \text { Pond } \\
3 C \text { Pond } \\
3 C \text { Pond } \\
3 C \text { Pond } \\
3 C \text { Pond } \\
3 C \text { Pand } \\
3 C \text { Pond } \\
3 C \text { Pond } \\
3 C \text { Pond }\end{array}$ & $\begin{array}{l}8-179 \\
8-172 \\
8-174 \\
8-175 \\
8-176 \\
8-177 \\
8-178 \\
8-179 \\
8-180\end{array}$ & $\begin{array}{l}<0.2 \\
<0.2 \\
<0.2 \\
<0.2 \\
<0.2 \\
<0.2 \\
<0.2 \\
<0.2 \\
<0.2\end{array}$ & & $\begin{array}{r}9 / 08 \\
9 / 08 \\
9 / 08 \\
9 / 08 \\
+9 / 08 \\
9 / 08 \\
9 / 08 \\
9 / 08 \\
9 / 08\end{array}$ & $\begin{array}{l}9 / 14 \\
9 / 14 \\
9 / 14 \\
9 / 14 \\
9 / 14 \\
9 / 18 \\
9 / 18 \\
9 / 18 \\
9 / 18\end{array}$ & $\begin{array}{c}6 \\
6 \\
6 \\
6 \\
6 \\
10 \\
10 \\
10 \\
10\end{array}$ & $\begin{array}{l}\text { Fodp } \\
\text { Fdup } \\
\text { Reg } \\
\text { Reg } \\
\text { Reg } \\
\text { Reg } \\
\text { Reg } \\
\text { Reg } \\
\text { Reg }\end{array}$ \\
\hline $\begin{array}{l}8-3 \text { Pond } \\
8-3 \text { Pond } \\
8-3 \text { Pond } \\
8-3 \text { Pond } \\
8-3 \text { Pond } \\
8-3 \text { Pond } \\
8-3 \text { Pond } \\
8-3 \text { Pond } \\
8-3 \text { Pond } \\
8-3 \text { Pond } \\
8-3 \text { Pond } \\
8-3 \text { Pond } \\
8-3 \text { Pond } \\
8-3 \text { Pond } \\
8-3 \text { Pond } \\
8-3 \text { Pond } \\
8-3 \text { Pond } \\
8-3 \text { Pond } \\
8-3 \text { Pond } \\
8-3 \text { Pond } \\
8-3 \text { Pond } \\
8-3 \text { Pand } \\
8-3 \text { Pond } \\
8-3 \text { Pond } \\
8-3 \text { Pond } \\
8-3 \text { Pond } \\
8-3 \text { Pond } \\
8-3 \text { Pond }\end{array}$ & $\begin{array}{l}B-114 \\
8-114 \\
B-115 \\
8-116 \\
8-118 \\
8-119 \\
8-128 \\
8-129 \\
8-130 \\
8-131 \\
8-132 \\
8-134 \\
8-135 \\
8-136 \\
8-138 \\
B-139 \\
8-140 \\
8-143 \\
8-143 \\
8-145 \\
B-146 \\
8-147 \\
8-148 \\
B-149 \\
B-164 \\
8-165 \\
B-166 \\
B-168\end{array}$ & 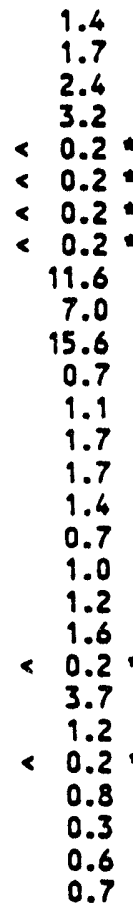 & 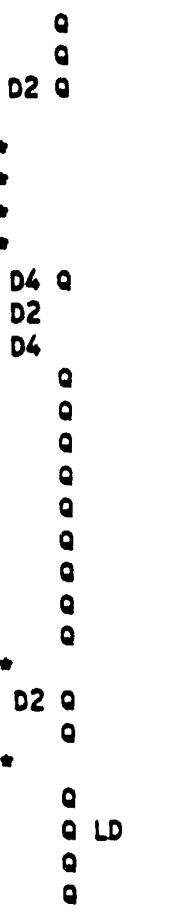 & $\begin{array}{r}8 / 10 \\
8 / 10 \\
+8 / 10 \\
8 / 10 \\
8 / 11 \\
8 / 11 \\
8 / 17 \\
8 / 17 \\
8 / 17 \\
8 / 17 \\
8 / 17 \\
8 / 18 \\
8 / 18 \\
8 / 18 \\
8 / 18 \\
8 / 18 \\
8 / 18 \\
8 / 25 \\
8 / 25 \\
8 / 25 \\
8 / 25 \\
8 / 25 \\
8 / 25 \\
8 / 25 \\
9 / 07 \\
9 / 07 \\
9 / 07 \\
9 / 07\end{array}$ & $\begin{array}{l}8 / 24 \\
8 / 24 \\
8 / 29 \\
8 / 24 \\
8 / 24 \\
8 / 24 \\
8 / 24 \\
8 / 24 \\
8 / 29 \\
8 / 29 \\
8 / 29 \\
8 / 24 \\
8 / 24 \\
8 / 24 \\
8 / 24 \\
8 / 24 \\
8 / 24 \\
8 / 29 \\
8 / 29 \\
8 / 29 \\
8 / 29 \\
8 / 30 \\
8 / 29 \\
8 / 29 \\
9 / 14 \\
9 / 14 \\
9 / 14 \\
9 / 14\end{array}$ & $\begin{array}{r}14 \\
14 \\
19 \\
14 \\
13 \\
13 \\
7 \\
7 \\
12 \\
12 \\
12 \\
6 \\
6 \\
6 \\
6 \\
6 \\
6 \\
4 \\
4 \\
4 \\
4 \\
5 \\
4 \\
4 \\
7 \\
7 \\
7 \\
7\end{array}$ & $\begin{array}{l}\text { Ldup } \\
\text { Ldup } \\
\text { Reg } \\
\text { Reg } \\
\text { Reg } \\
\text { Reg } \\
\text { Fdup } \\
\text { Fdup } \\
\text { Reg } \\
\text { Reg } \\
\text { Reg } \\
\text { fdup } \\
\text { Fdup } \\
\text { Reg } \\
\text { Reg } \\
\text { Reg } \\
\text { Reg } \\
\text { Ldup } \\
\text { Ldup } \\
\text { Fdup } \\
\text { Fdup } \\
\text { Reg } \\
\text { Reg } \\
\text { Reg } \\
\text { Select -Fdup } \\
\text { Select-Fdup } \\
\text { Reg } \\
\text { Select }\end{array}$ \\
\hline $\begin{array}{l}\text { B-3-3 Dit. } \\
B-3-3 \text { Dit. } \\
B-3-3 \text { Dit. } \\
8-3-3 \text { Dit. } \\
B-3-3 \text { Dit. } \\
B-3-3 \text { Dit. } \\
\text { B-3-3 Dit. } \\
\text { B-3-3 Dit. } \\
\text { B-3-3 Dit. } \\
\text { B-3-3 Dit. }\end{array}$ & $\begin{array}{l}B-152 \\
B-153 \\
B-154 \\
B-158 \\
B-158 \\
B-159 \\
B-160 \\
B-161 \\
8-184 \\
B-185\end{array}$ & $\begin{array}{ll}< & 0.2 \\
< & 0.2 \\
& 0.2 \\
< & 0.2 \\
< & 0.2 \\
< & 0.2 \\
< & 0.2 \\
& 0.6 \\
< & 0.2 \\
< & 0.2\end{array}$ & Q LD & $\begin{array}{l}8 / 28 \\
8 / 28 \\
8 / 28 \\
8 / 39 \\
8 / 31 \\
8 / 31 \\
8 / 31 \\
8 / 31 \\
9 / 18 \\
9 / 18\end{array}$ & $\begin{array}{l}8 / 30 \\
8 / 30 \\
8 / 30 \\
9 / 05 \\
9 / 05 \\
9 / 05 \\
9 / 05 \\
9 / 05 \\
9 / 22 \\
9 / 22\end{array}$ & $\begin{array}{l}2 \\
2 \\
2 \\
5 \\
5 \\
5 \\
5 \\
5 \\
4 \\
4\end{array}$ & $\begin{array}{l}\text { Fdup } \\
\text { Fdup } \\
\text { Reg } \\
\text { Ldup, Fdup } \\
\text { Ldup, fdup } \\
\text { Fdup } \\
\text { Reg } \\
\text { Select } \\
\text { Fdup } \\
\text { Fdup }\end{array}$ \\
\hline
\end{tabular}


Table C-3. Mercury Data (EPA Method 7470) Soil $\mathrm{COL}=0.2 \mathrm{\mu g} / \mathrm{g}$. (sheet 2 of 2 )

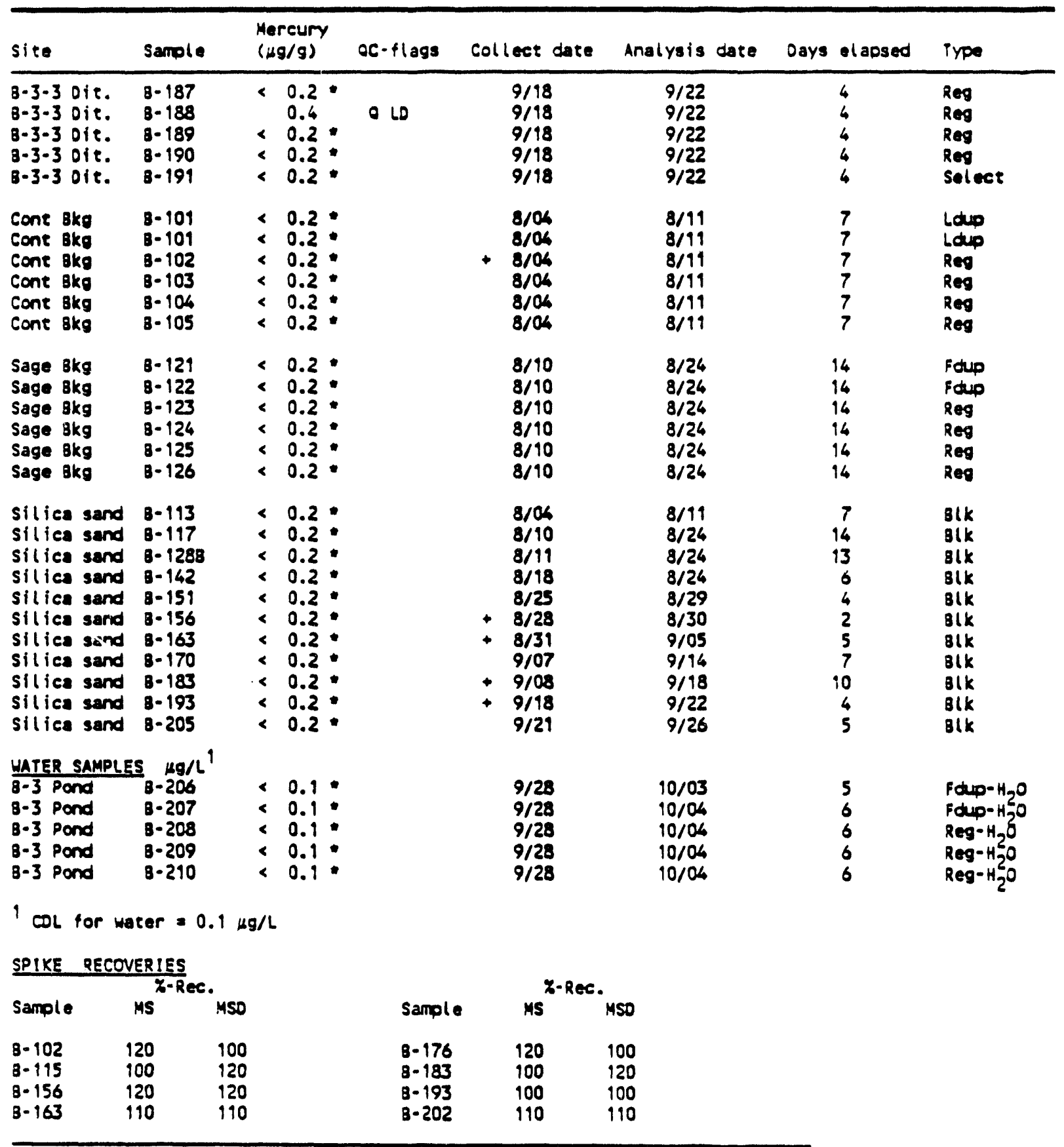

$0 x$ - Sample size rectuced in analysis by an extra factor of $x$.

$L D$ - Estimate is greater than a dilution adjusted $\infty \mathrm{L}$, but below a limit of detection, (LO), derived from the mean and standard deviation of resgent blanks, (avg. \$3s), and adjusted for nominal sample size/dilution. $L \infty=0.4 \mu \mathrm{g} / \mathrm{g}$

- Estimate is greater than a dilution adjusted $\infty L$, but below a limit of quantification, (LD), derived from the man and standard deviation of reagent blanks, (avg. + 10s), and adjusted for nominal sample size/dilution. $L D=2.9 \mu \mathrm{g} / \mathrm{g}$

- Sample chosen by lab for matrix spike MS/MSO.

- Estimated value below COL. 
Table C-4. Ammonium Data (ASTM-D-1426 C/D) Soil $\mathrm{CDL}=0.5 \mu \mathrm{g} / \mathrm{g}$. (sheet 1 of 2)

\begin{tabular}{|c|c|c|c|c|c|c|c|c|}
\hline \multicolumn{2}{|c|}{ site } & \multirow[b]{2}{*}{$\begin{array}{l}\text { Semple } \\
B-196 \\
8-196 \\
8-197 \\
8-198 \\
8-200 \\
8-201 \\
8-202 \\
8-203\end{array}$} & \multirow{2}{*}{$\begin{array}{c}\begin{array}{c}\text { Ammonium } \\
(\mu \sigma / g)\end{array} \\
2.96 \\
1.46 \\
2.09 \\
7.59 \\
0.25 \\
3.47 \\
3.17 \\
7.79\end{array}$} & oc-flags & \multirow[t]{2}{*}{ Collect date } & \multirow[t]{2}{*}{ Analysis date } & \multirow[b]{2}{*}{$\begin{array}{c}\text { Days elapsed } \\
5 \\
5 \\
5 \\
5 \\
5 \\
5 \\
5 \\
5\end{array}$} & \multirow[b]{2}{*}{$\begin{array}{l}\text { Type } \\
\text { Fodp } \\
\text { Fdup } \\
\text { Reg } \\
\text { Reg } \\
\text { Reg } \\
\text { Reg } \\
\text { Reg } \\
\text { Reg }\end{array}$} \\
\hline $\begin{array}{l}3 A \\
3 A \\
3 A \\
3 A \\
3 A \\
3 A \\
3 A \\
3 A\end{array}$ & $\begin{array}{l}\text { Pond } \\
\text { Pond } \\
\text { Pond } \\
\text { Pond } \\
\text { Pond } \\
\text { Pond } \\
\text { Pond } \\
\text { Pond }\end{array}$ & & & & & & & \\
\hline $\begin{array}{l}38 \\
38 \\
38 \\
38 \\
3 B \\
38\end{array}$ & $\begin{array}{l}\text { Pond } \\
\text { Pond } \\
\text { Pond } \\
\text { Pond } \\
\text { Pond } \\
\text { Pond }\end{array}$ & $\begin{array}{l}8-106 \\
8-107 \\
8-108 \\
8-109 \\
8-110 \\
8-111\end{array}$ & $\begin{array}{r}1.00 \\
0.90 \\
0.40 \\
0.40 \\
0.04 \\
0.00\end{array}$ & $\begin{array}{l}H \\
H \\
H \\
H \\
H \\
H\end{array}$ & $\begin{array}{l}8 / 04 \\
8 / 04 \\
8 / 04 \\
8 / 04 \\
8 / 04 \\
8 / 04\end{array}$ & $\begin{array}{l}9 / 18 \\
9 / 18 \\
9 / 18 \\
9 / 18 \\
9 / 18 \\
9 / 18\end{array}$ & $\begin{array}{l}45 \\
45 \\
45 \\
45 \\
45 \\
45\end{array}$ & $\begin{array}{l}\text { Reg } \\
\text { Reg } \\
\text { fdup } \\
\text { Foup } \\
\text { Reg } \\
\text { Reg }\end{array}$ \\
\hline $\begin{array}{l}3 c \\
3 c \\
3 c \\
3 c \\
3 C \\
3 c \\
3 c \\
3 c \\
3 c\end{array}$ & $\begin{array}{l}\text { Pond } \\
\text { Pond } \\
\text { Pond } \\
\text { Pond } \\
\text { Pand } \\
\text { Pond } \\
\text { Pand } \\
\text { Pond } \\
\text { Pond }\end{array}$ & $\begin{array}{l}B=171 \\
8-172 \\
8-176 \\
8-175 \\
8-176 \\
B-177 \\
B-178 \\
8=179 \\
B=180\end{array}$ & $\begin{array}{l}3.00 \\
3.50 \\
-0.09 \\
5.60 \\
0.80 \\
0.20 \\
0.20 \\
2.70 \\
0.20\end{array}$ & + & $\begin{array}{l}9 / 08 \\
9 / 08 \\
9 / 08 \\
9 / 08 \\
9 / 08 \\
9 / 08 \\
9 / 08 \\
9 / 08 \\
9 / 08\end{array}$ & $\begin{array}{l}9 / 11 \\
9 / 19 \\
9 / 19 \\
9 / 19 \\
9 / 19 \\
9 / 19 \\
9 / 11 \\
9 / 91 \\
9 / 19\end{array}$ & $\begin{array}{l}3 \\
3 \\
3 \\
3 \\
3 \\
3 \\
3 \\
3 \\
3\end{array}$ & $\begin{array}{l}\text { Fodup } \\
\text { Fdup } \\
\text { Reg } \\
\text { Reg } \\
\text { Reg } \\
\text { Reg } \\
\text { Reg } \\
\text { Reg } \\
\text { Reg }\end{array}$ \\
\hline $\begin{array}{l}8-3 \\
B-3 \\
8-3 \\
8-3 \\
8-3 \\
8-3 \\
8-3 \\
8-3 \\
8-3 \\
B-3 \\
8-3 \\
B-3 \\
8-3 \\
8-3 \\
B-3 \\
8-3 \\
8-3 \\
8-3 \\
8-3 \\
8-3 \\
8-3 \\
B-3 \\
8-3 \\
8-3 \\
8-3 \\
B-3\end{array}$ & $\begin{array}{l}3 \text { Pond } \\
3 \text { Pond } \\
3 \text { Pond } \\
3 \text { Pond } \\
3 \text { Pond } \\
3 \text { Pond } \\
3 \text { Pond } \\
3 \text { Pond } \\
3 \text { Pond } \\
3 \text { Pond } \\
3 \text { Pond } \\
3 \text { Pond } \\
3 \text { Pond } \\
3 \text { Pond } \\
3 \text { Pond } \\
3 \text { Pond } \\
3 \text { Pond } \\
3 \text { Pond } \\
3 \text { Pond } \\
3 \text { Pond } \\
3 \text { Pond } \\
3 \text { Pand } \\
3 \text { Pond } \\
3 \text { Pond } \\
3 \text { Pond } \\
3 \text { Pand }\end{array}$ & 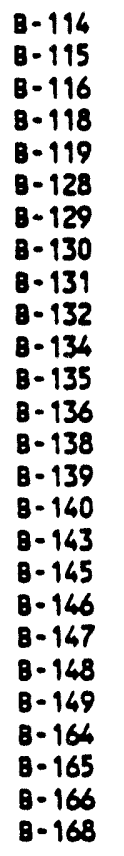 & $\begin{array}{r}7.39 \\
8.31 \\
9.62 \\
9.46 \\
6.91 \\
7.33 \\
19.77 \\
9.61 \\
10.28 \\
9.23 \\
10.41 \\
11.26 \\
3.83 \\
15.59 \\
8.44 \\
10.23 \\
9.90 \\
16.20 \\
15.40 \\
14.50 \\
19.60 \\
7.00 \\
4.40 \\
6.70 \\
10.20 \\
15.70\end{array}$ & 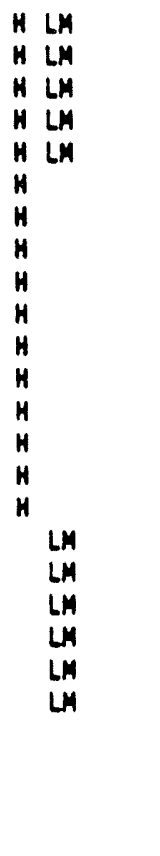 & $\begin{array}{l}8 / 10 \\
8 / 10 \\
8 / 90 \\
8 / 11 \\
8 / 19 \\
8 / 17 \\
8 / 17 \\
8 / 17 \\
8 / 17 \\
8 / 17 \\
8 / 18 \\
8 / 18 \\
8 / 18 \\
8 / 18 \\
8 / 18 \\
8 / 18 \\
8 / 25 \\
8 / 25 \\
8 / 25 \\
8 / 25 \\
8 / 25 \\
8 / 25 \\
9 / 07 \\
9 / 07 \\
9 / 07 \\
9 / 07\end{array}$ & $\begin{array}{l}9 / 23 \\
9 / 23 \\
9 / 23 \\
9 / 23 \\
9 / 23 \\
9 / 27 \\
9 / 27 \\
9 / 27 \\
9 / 27 \\
9 / 27 \\
9 / 27 \\
9 / 27 \\
9 / 27 \\
9 / 27 \\
9 / 27 \\
9 / 27 \\
9 / 01 \\
9 / 01 \\
9 / 01 \\
9 / 01 \\
9 / 01 \\
9 / 01 \\
9 / 11 \\
9 / 11 \\
9 / 19 \\
9 / 11\end{array}$ & $\begin{array}{l}44 \\
44 \\
44 \\
43 \\
43 \\
49 \\
49 \\
41 \\
49 \\
49 \\
40 \\
40 \\
40 \\
40 \\
40 \\
40 \\
7 \\
7 \\
7 \\
7 \\
7 \\
7 \\
4 \\
4 \\
6 \\
4\end{array}$ & $\begin{array}{l}\text { Reg } \\
\text { Reg } \\
\text { Reg } \\
\text { Reg } \\
\text { Reg } \\
\text { fdup } \\
\text { Fdup } \\
\text { Reg } \\
\text { Reg } \\
\text { Reg } \\
\text { Fdup } \\
\text { fdup } \\
\text { Reg } \\
\text { Reg } \\
\text { Reg } \\
\text { Reg } \\
\text { Reg } \\
\text { Fdup } \\
\text { fdup } \\
\text { Reg } \\
\text { Reg } \\
\text { Reg } \\
\text { Select-Fdup } \\
\text { Select-Fdup } \\
\text { Reg } \\
\text { Select }\end{array}$ \\
\hline $\begin{array}{l}8-3 \\
8-3 \\
8-3 \\
8-3 \\
8-3\end{array}$ & $\begin{array}{l}\text { 3-3 Dit. } \\
\text { 3-3 Dit. } \\
\text { 3-3 Dit. } \\
\text { 3-3 Dit. } \\
\text { 3-3 Dit. }\end{array}$ & $\begin{array}{l}B-152 \\
B-153 \\
8-156 \\
8-158 \\
B-159\end{array}$ & $\begin{array}{l}0.40 \\
0.20 \\
0.40 \\
0.30 \\
0.00\end{array}$ & $\begin{array}{l}L M \\
L M \\
L M \\
L M\end{array}$ & $\begin{array}{l}8 / 28 \\
8 / 28 \\
8 / 28 \\
8 / 31 \\
8 / 31\end{array}$ & $\begin{array}{l}9.101 \\
9 / 01 \\
9 / 01 \\
9 / 01 \\
9 / 01\end{array}$ & $\begin{array}{l}4 \\
6 \\
4 \\
1 \\
1\end{array}$ & $\begin{array}{l}\text { Fodp } \\
\text { Foup } \\
\text { Reg } \\
\text { Fdup } \\
\text { Fdup }\end{array}$ \\
\hline
\end{tabular}


Table C-4. Ammonium Data (ASTM-0-1426 C/D) Soil $C D L=0.5 \mu \mathrm{g} / \mathrm{g}$. (sheet 2 of 2 )

\begin{tabular}{|c|c|c|c|c|c|c|c|}
\hline site & Samole & $\begin{array}{l}\text { Anmonium } \\
(\mu g / g)\end{array}$ & oc- flags & Collect date & Analysis date & Days elapsed & inpe \\
\hline $\begin{array}{l}3-3-3 \text { oit. } \\
8-3-3 \text { oit. } \\
8-3-3 \text { oit. } \\
8-3-3 \text { oit. } \\
8-3-3 \text { Dit. } \\
8-3-3 \text { oit. } \\
8-3-3 \text { oit. } \\
8-3-3 \text { Dit. } \\
8-3-3 \text { Dit. }\end{array}$ & $\begin{array}{l}8-160 \\
B-161 \\
B-184 \\
8-185 \\
8-187 \\
8-188 \\
8-189 \\
8-190 \\
8-191\end{array}$ & $\begin{array}{l}0.00 \\
0.10 \\
0.72 \\
0.79 \\
0.73 \\
0.62 \\
0.70 \\
0.56 \\
0.89\end{array}$ & $L_{L M}$ & $\begin{array}{l}8 / 31 \\
8 / 39 \\
9 / 18 \\
9 / 18 \\
9 / 18 \\
9 / 18 \\
9 / 18 \\
9 / 18 \\
9 / 18\end{array}$ & $\begin{array}{l}9 / 01 \\
9 / 01 \\
9 / 23 \\
9 / 23 \\
9 / 23 \\
9 / 23 \\
9 / 23 \\
9 / 23 \\
9 / 23\end{array}$ & $\begin{array}{l}1 \\
1 \\
5 \\
5 \\
5 \\
5 \\
5 \\
5 \\
5\end{array}$ & $\begin{array}{l}\text { Reg } \\
\text { Seleet } \\
\text { Foup } \\
\text { Foup } \\
\text { Reg } \\
\text { Reg } \\
\text { Reg } \\
\text { Reg } \\
\text { Select }\end{array}$ \\
\hline $\begin{array}{l}\text { Cont 8kg } \\
\text { Cont 8kg } \\
\text { Cont 8kg } \\
\text { Cont 8kg } \\
\text { Cont 3kg }\end{array}$ & $\begin{array}{l}8-109 \\
8-102 \\
8-103 \\
8=104 \\
8=105\end{array}$ & $\begin{array}{l}0.40 \\
0.40 \\
0.70 \\
0.30 \\
2.00\end{array}$ & $\begin{array}{l}H \\
H \\
H \\
H \\
H\end{array}$ & $\begin{array}{l}8 / 04 \\
8 / 04 \\
8 / 04 \\
8 / 06 \\
8 / 04\end{array}$ & $\begin{array}{l}9 / 18 \\
9 / 18 \\
9 / 18 \\
9 / 18 \\
9 / 18\end{array}$ & $\begin{array}{l}45 \\
45 \\
45 \\
45 \\
45\end{array}$ & $\begin{array}{l}R e g \\
R e g \\
R e g \\
R e g \\
R e g\end{array}$ \\
\hline $\begin{array}{l}\text { Sage Bkg } \\
\text { Sage Bkg } \\
\text { Sage Bkg } \\
\text { Sage Bkg } \\
\text { Sage Bkg } \\
\text { Sage Bkg. }\end{array}$ & $\begin{array}{l}8-121 \\
8-122 \\
8-123 \\
8-126 \\
8-125 \\
8-126\end{array}$ & $\begin{array}{l}2.06 \\
1.11 \\
0.68 \\
0.62 \\
0.75 \\
0.61\end{array}$ & $\begin{array}{ll}H & L M \\
H & \text { LM } \\
H & \text { LM } \\
H & \text { LM } \\
H & \text { LA } \\
H & \text { LAH }\end{array}$ & $\begin{array}{l}8 / 10 \\
8 / 10 \\
8 / 10 \\
8 / 10 \\
8 / 10 \\
8 / 10\end{array}$ & $\begin{array}{l}9 / 23 \\
9 / 23 \\
9 / 23 \\
9 / 23 \\
9 / 23 \\
9 / 23\end{array}$ & $\begin{array}{l}44 \\
46 \\
46 \\
46 \\
46\end{array}$ & $\begin{array}{l}\text { Foup } \\
\text { Foup } \\
R \in g \\
R \in g \\
R \in g \\
R \in g\end{array}$ \\
\hline $\begin{array}{l}\text { silica sand } \\
\text { silica sand } \\
\text { silica sand } \\
\text { silica sand } \\
\text { silica sand } \\
\text { silica sand } \\
\text { silica sand } \\
\text { silica sand } \\
\text { silica sand } \\
\text { silice sand } \\
\text { silice sand }\end{array}$ & $\begin{array}{l}8-113 \\
8-117 \\
8-1288 \\
8-142 \\
8-151 \\
8-156 \\
8-163 \\
8-170 \\
8-183 \\
8-193 \\
8-205\end{array}$ & $\begin{array}{r}0.20 \\
0.15 \\
-0.05 \\
0.16 \\
0.20 \\
0.30 \\
0.20 \\
0.04 \\
0.10 \\
0.06 \\
0.64\end{array}$ & 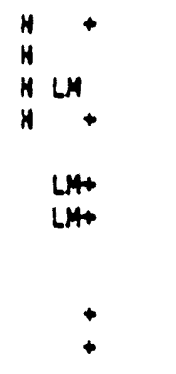 & $\begin{array}{l}8 / 04 \\
8 / 10 \\
8 / 17 \\
8 / 18 \\
8 / 25 \\
8 / 28 \\
8 / 31 \\
9 / 07 \\
9 / 08 \\
9 / 18 \\
9 / 21\end{array}$ & $\begin{array}{l}9 / 18 \\
9 / 23 \\
9 / 23 \\
9 / 27 \\
9 / 01 \\
9 / 01 \\
9 / 01 \\
9 / 11 \\
9 / 11 \\
9 / 23 \\
9 / 26\end{array}$ & $\begin{array}{r}45 \\
46 \\
37 \\
40 \\
7 \\
4 \\
1 \\
4 \\
3 \\
5 \\
5\end{array}$ & $\begin{array}{l}81 k \\
81 k \\
81 k \\
81 k \\
81 k \\
81 k \\
81 k \\
81 k \\
81 k \\
B 1 k \\
81 k\end{array}$ \\
\hline $\begin{array}{l}\text { WATER SAMPLE: } \\
8 \cdot 3 \text { Pond } \\
8-3 \text { Pand } \\
8-3 \text { Pond } \\
8-3 \text { Pand } \\
8-3 \text { Pand }\end{array}$ & $\begin{array}{l}\mu g / L^{1} \\
8-206 \\
B-207 \\
8-208 \\
B-209 \\
8-210\end{array}$ & $\begin{array}{l}<50: \\
<50: \\
<50: \\
<50 . \\
<50 .\end{array}$ & + & $\begin{array}{l}9 / 28 \\
9 / 28 \\
9 / 28 \\
9 / 28 \\
9 / 28\end{array}$ & $\begin{array}{l}10 / 02 \\
10 / 02 \\
10 / 02 \\
10 / 02 \\
10 / 02\end{array}$ & $\begin{array}{l}4 \\
4 \\
4 \\
4 \\
4\end{array}$ & $\begin{array}{l}\text { Fdup }-\mathrm{H}_{2} \mathrm{O} \\
\text { Fdup- } \mathrm{H}_{2} \mathrm{O} \\
\mathrm{Reg}-\mathrm{H}_{2} \mathrm{O} \\
\operatorname{Reg}-\mathrm{H}_{2} \mathrm{O} \\
\operatorname{Reg}-\mathrm{H}_{2} \mathrm{O}\end{array}$ \\
\hline $\begin{array}{l}1 \text { COL for wat } \\
\text { SPIXE RECOV }\end{array}$ & $\begin{array}{l}=50 \\
\text { RIES }\end{array}$ & & & & & & \\
\hline Samole & & $M S^{x-R}$ & IC. MSD & & & & \\
\hline $\begin{array}{l}8-176 \\
3-126 \\
8-113 \\
8-142 \\
8-156 \\
8-163 \\
8-193 \\
8-205 \\
8-209 \text { (Water) }\end{array}$ & & $\begin{array}{r}87.0 \\
56.5 \\
78.0 \\
103.0 \\
69.5 \\
73.0 \\
97.5 \\
85.5 \\
109.0\end{array}$ & $\begin{array}{r}80.0 \\
58.5 \\
81.0 \\
102.0 \\
72.0 \\
73.5 \\
100.0 \\
91.0 \\
108.0\end{array}$ & & & & \\
\hline
\end{tabular}

$H=$ Holding time exceeded, (28 days)

LM a Associated matrix spike recovery low $\cdots$ outside CLP guidelines (+/. 25\%).

+ a Sample chosen by lab for MS/MSO.

- Estimated value below COL. 
WHC-SD-EN-AP-042, REV. 0

Table C-5. Chloride Data (EPA Method 300)

So il $\mathrm{CDL}=1.0 \mu \mathrm{g} / \mathrm{g}$. (sheet 1 of 2)

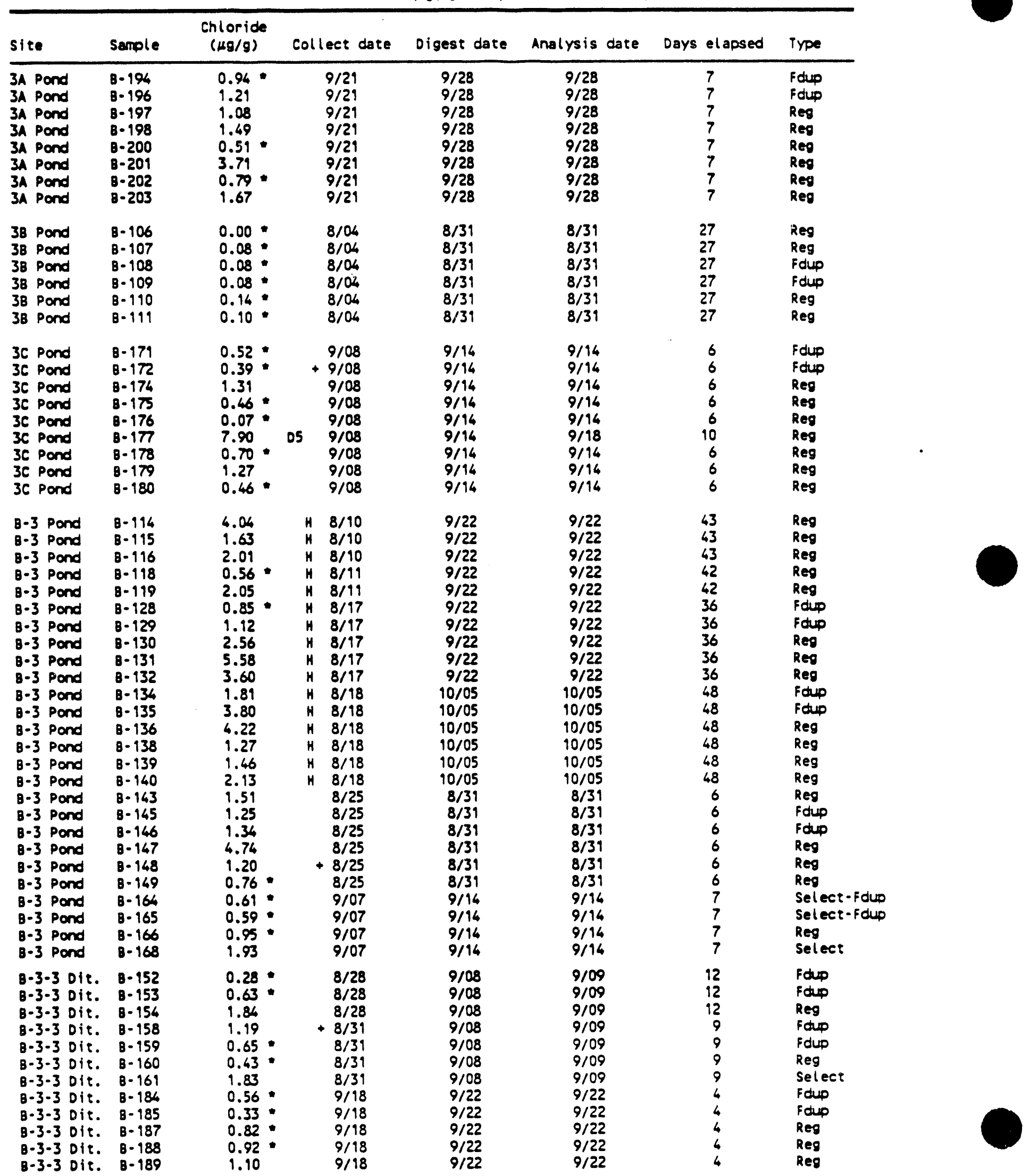


Table C-5. Chloride Data (EPA Method 300)

Soil $\mathrm{CDL}=1.0 \mu \mathrm{g} / \mathrm{g}$. (sheet 2 of 2 )

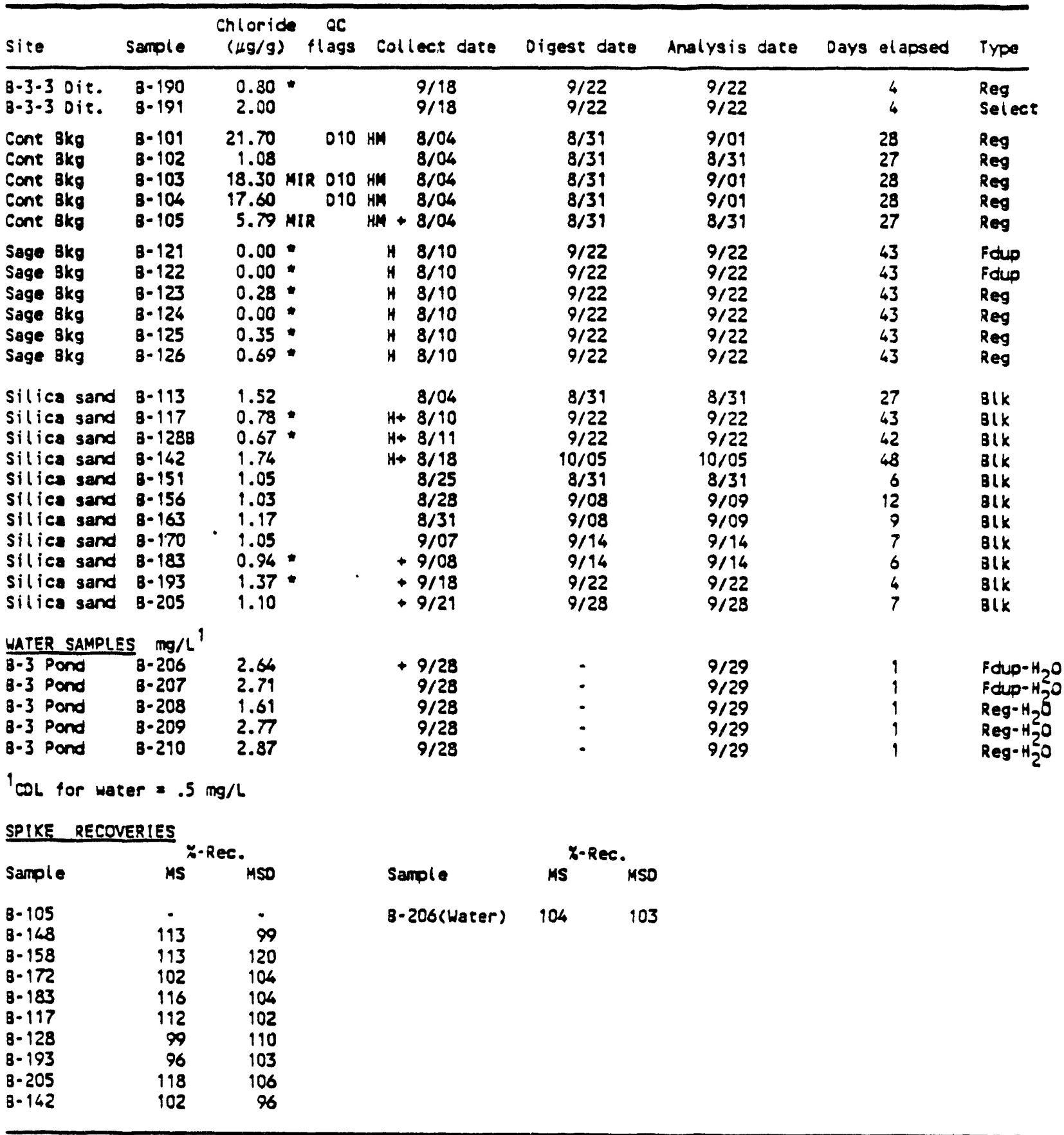

$O x=$ Sample diluted during analysis by an extra factor of $x$.

HM = Associated matrix spike recovery high--outside CLP guidelines $(+1 \cdot 25 \%)$.

$H$ = Holding time exceeded, (28 days)

- Sample chosen by lab for MS/MSO.

- Estimated value below COL.

MIR = Matrix effect, indeterminate result. A matrix effect innibits accurace quantification of the analyte according to laboratory chemist. 
Table C-6. Fluoride Data (EPA Method 300)

Soil $\mathrm{COL}=1.0 \mu \mathrm{g} / \mathrm{g}$. (sheet 1 of 2 )

\begin{tabular}{|c|c|c|c|c|c|c|c|c|c|c|}
\hline \multicolumn{2}{|c|}{ site } & \multirow[b]{2}{*}{$\begin{array}{c}\text { Sample } \\
B-196 \\
B-196 \\
B-197 \\
B-198 \\
8-200 \\
B-201 \\
8-202 \\
8-203\end{array}$} & \multicolumn{2}{|c|}{$\begin{array}{c}\text { Fluoride } \\
\text { (1sg/g) }\end{array}$} & \multicolumn{2}{|c|}{ Collect date } & Digest date & Anolysis date & Days elapsed & \multirow[b]{2}{*}{$\begin{array}{l}\text { Type } \\
\text { Foup } \\
\text { Fodo } \\
\text { Reg } \\
\text { Reg } \\
\text { Reg } \\
\text { Reg } \\
\text { Reg } \\
\text { Reg }\end{array}$} \\
\hline $\begin{array}{l}3 A \\
3 A \\
3 A \\
3 A \\
3 n \\
3 n \\
3 n \\
3 n\end{array}$ & $\begin{array}{l}\text { Pand } \\
\text { Pond } \\
\text { Pond } \\
\text { Pond } \\
\text { Pond } \\
\text { Pand } \\
\text { Pond } \\
\text { Pand }\end{array}$ & & $\begin{array}{l}0.2: \\
0.2: \\
0.2: \\
0.2: \\
0.1: \\
1.4: \\
0.2: \\
0.2:\end{array}$ & 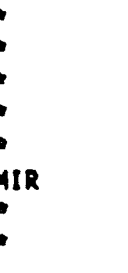 & & $\begin{array}{l}9 / 29 \\
9 / 29 \\
9 / 21 \\
9 / 29 \\
9 / 21 \\
9 / 21 \\
9 / 21 \\
9 / 21\end{array}$ & $\begin{array}{l}9 / 28 \\
9 / 28 \\
9 / 28 \\
9 / 28 \\
9 / 28 \\
9 / 28 \\
9 / 28 \\
9 / 28\end{array}$ & $\begin{array}{l}9 / 28 \\
9 / 28 \\
9 / 28 \\
9 / 28 \\
9 / 28 \\
9 / 28 \\
9 / 28 \\
9 / 28\end{array}$ & $\begin{array}{l}7 \\
7 \\
7 \\
7 \\
7 \\
7 \\
7 \\
7\end{array}$ & \\
\hline $\begin{array}{l}38 \\
38 \\
38 \\
38 \\
38 \\
38\end{array}$ & $\begin{array}{l}\text { Pand } \\
\text { Pond } \\
\text { Pond } \\
\text { Pond } \\
\text { Pond } \\
\text { Pond }\end{array}$ & $\begin{array}{l}8-106 \\
B-107 \\
8-108 \\
8-109 \\
8-110 \\
8-111\end{array}$ & $\begin{array}{l}0.3: \\
0.2: \\
0.4: \\
0.5: \\
0.5: \\
0.3\end{array}$ & & $\begin{array}{l}L M \\
L M \\
L M \\
L M \\
L M\end{array}$ & $\begin{array}{l}8 / 04 \\
8 / 04 \\
8 / 04 \\
8 / 04 \\
8 / 04 \\
8 / 04\end{array}$ & $\begin{array}{l}8 / 31 \\
8 / 31 \\
8 / 31 \\
8 / 31 \\
8 / 31 \\
8 / 31\end{array}$ & $\begin{array}{l}8 / 31 \\
8 / 39 \\
8 / 39 \\
8 / 31 \\
8 / 39 \\
8 / 31\end{array}$ & $\begin{array}{l}27 \\
27 \\
27 \\
27 \\
27 \\
27\end{array}$ & $\begin{array}{l}\text { Reg } \\
\text { Reg } \\
\text { Foup } \\
\text { Foup } \\
\text { Reg } \\
\text { Reg }\end{array}$ \\
\hline $\begin{array}{l}3 c \\
3 C \\
3 C \\
3 C \\
3 C \\
3 C \\
3 C \\
3 C \\
3 C\end{array}$ & $\begin{array}{l}\text { Pond } \\
\text { Pond } \\
\text { Pond } \\
\text { Pond } \\
\text { Pand } \\
\text { Pond } \\
\text { Pond } \\
\text { Pond } \\
\text { Pond }\end{array}$ & $\begin{array}{l}B-179 \\
8-172 \\
8-174 \\
8-175 \\
8-176 \\
8-177 \\
8-178 \\
8-179 \\
B=180\end{array}$ & $\begin{array}{r}0.9: \\
1.3 \\
0.0 \\
0.2 \\
0.0 \\
19.0 \\
0.0 \\
0.3: \\
0.1\end{array}$ & IR 010 & $\operatorname{LM}_{L M}$ & $\begin{array}{l}9 / 08 \\
9 / 08 \\
9 / 08 \\
9 / 08 \\
9 / 08 \\
9 / 08 \\
9 / 08 \\
9 / 08 \\
9 / 08\end{array}$ & $\begin{array}{l}9 / 14 \\
9 / 14 \\
9 / 14 \\
9 / 16 \\
9 / 14 \\
9 / 14 \\
9 / 16 \\
9 / 14 \\
9 / 14\end{array}$ & $\begin{array}{l}9 / 14 \\
9 / 14 \\
9 / 14 \\
9 / 14 \\
9 / 14 \\
9 / 15 \\
9 / 14 \\
9 / 14 \\
9 / 14\end{array}$ & $\begin{array}{l}6 \\
6 \\
6 \\
6 \\
6 \\
7 \\
6 \\
6 \\
6\end{array}$ & $\begin{array}{l}\text { Fodp } \\
\text { Fodp } \\
\text { Reg } \\
\text { Reg } \\
\text { Reg } \\
\text { Reg } \\
\text { Reg } \\
\text { Reg } \\
\text { Reg }\end{array}$ \\
\hline $\begin{array}{l}8-3 \\
8-3 \\
8-3 \\
8-3 \\
8-3 \\
8-3 \\
8-3 \\
8-3 \\
8-3 \\
8-3 \\
8-3 \\
8-3 \\
8-3 \\
8-3 \\
8-3 \\
8-3 \\
8-3 \\
8-3 \\
8-3 \\
8-3 \\
8-3 \\
8-3 \\
8-3 \\
8-3 \\
B-3 \\
8-3\end{array}$ & $\begin{array}{l}\text { Pond } \\
\text { Pond } \\
\text { Pond } \\
\text { Pand } \\
\text { Pond } \\
\text { Pand } \\
\text { Pond } \\
\text { Pond } \\
\text { Pond } \\
\text { Pond } \\
3 \text { Pond } \\
3 \text { Pond } \\
3 \text { Pand } \\
3 \text { Pond } \\
3 \text { Pond } \\
3 \text { Pond } \\
3 \text { Pand } \\
3 \text { Pond } \\
3 \text { Pond } \\
3 \text { Pond } \\
3 \text { Pond } \\
3 \text { Pond } \\
3 \text { Pond } \\
3 \text { Pond } \\
3 \text { Pand }\end{array}$ & $\begin{array}{l}8-116 \\
8-115 \\
8-116 \\
8-118 \\
8-119 \\
8-128 \\
8-129 \\
8-130 \\
8-131 \\
8-132 \\
8-136 \\
8-135 \\
B-136 \\
8-138 \\
8-139 \\
8-160 \\
8-163 \\
8-145 \\
8-146 \\
8-167 \\
8-148 \\
8-169 \\
8-164 \\
8-165 \\
8-166 \\
B-168\end{array}$ & 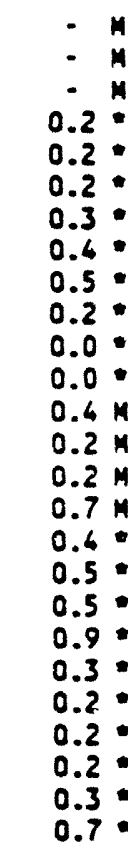 & $\begin{array}{l}\text { IIR } \\
\text { ilR } \\
\text { UIR } \\
: \\
:\end{array}$ & $\begin{array}{l}H \\
H \\
H \\
H \\
H \\
H \\
H \\
H \\
H \\
H \\
H \\
H \\
H \\
H \\
H \\
H \\
L M \\
L M \\
L M \\
L M \\
L M\end{array}$ & $\begin{array}{l}8 / 10 \\
8 / 10 \\
8 / 10 \\
8 / 19 \\
8 / 11 \\
8 / 17 \\
8 / 17 \\
8 / 17 \\
8 / 17 \\
8 / 17 \\
8 / 18 \\
8 / 18 \\
8 / 18 \\
8 / 18 \\
8 / 18 \\
8 / 18 \\
8 / 25 \\
8 / 25 \\
8 / 25 \\
8 / 25 \\
8 / 25 \\
8 / 25 \\
9 / 07 \\
9 / 07 \\
9 / 07 \\
9 / 07\end{array}$ & $\begin{array}{l}9 / 22 \\
9 / 22 \\
9 / 22 \\
9 / 22 \\
9 / 22 \\
9 / 22 \\
9 / 22 \\
9 / 22 \\
9 / 22 \\
9 / 22 \\
10 / 05 \\
10 / 05 \\
10 / 05 \\
10 / 05 \\
10 / 05 \\
10 / 05 \\
8 / 31 \\
8 / 31 \\
8 / 31 \\
8 / 31 \\
8 / 31 \\
8 / 31 \\
9 / 14 \\
9 / 14 \\
9 / 14 \\
9 / 14\end{array}$ & $\begin{array}{l}9 / 22 \\
9 / 22 \\
9 / 22 \\
9 / 22 \\
9 / 22 \\
9 / 22 \\
9 / 22 \\
9 / 22 \\
9 / 22 \\
9 / 22 \\
10 / 05 \\
10 / 05 \\
10 / 05 \\
10 / 05 \\
10 / 05 \\
10 / 05 \\
8 / 31 \\
8 / 31 \\
8 / 31 \\
8 / 31 \\
8 / 31 \\
8 / 31 \\
9 / 14 \\
9 / 14 \\
9 / 14 \\
9 / 14\end{array}$ & $\begin{array}{l}43 \\
43 \\
43 \\
42 \\
42 \\
36 \\
36 \\
36 \\
36 \\
36 \\
48 \\
48 \\
48 \\
48 \\
48 \\
48 \\
6 \\
6 \\
6 \\
6 \\
6 \\
6 \\
7 \\
7 \\
7 \\
7\end{array}$ & $\begin{array}{l}\text { Reg } \\
\text { Reg } \\
\text { Reg } \\
\text { Reg } \\
\text { Reg } \\
\text { Fdup } \\
\text { Fdup } \\
\text { Reg } \\
\text { Reg } \\
\text { Reg } \\
\text { Fdup } \\
\text { Fdup } \\
\text { Reg } \\
\text { Reg } \\
\text { Reg } \\
\text { Reg } \\
\text { Reg } \\
\text { Fdp } \\
\text { Fdip } \\
\text { Reg } \\
\text { Reg } \\
\text { Reg } \\
\text { Select - Fdup } \\
\text { Select-Fdup } \\
\text { Reg } \\
\text { Select }\end{array}$ \\
\hline $\begin{array}{l}8-3 \\
8-3 \\
8-3 \\
8-3 \\
8-3 \\
8-3 \\
8-3 \\
8-3 \\
8-3 \\
8-3 \\
8-3 \\
8-3\end{array}$ & $\begin{array}{l}3-3 \text { Dit. } \\
3-3 \text { Dit. } \\
3-3 \text { Dit. } \\
3-3 \text { Dit. } \\
3-3 \text { Dit. } \\
3-3 \text { oit. } \\
3-3 \text { Dit. } \\
3-3 \text { oit. } \\
3-3 \text { Dit. } \\
3-3 \text { Dit. } \\
\text { 3-3 Dit. } \\
\text { 3-3 Dit. }\end{array}$ & $\begin{array}{l}B-152 \\
8-153 \\
B-154 \\
B-158 \\
B-159 \\
B-160 \\
8-161 \\
B-184 \\
B-185 \\
B-187 \\
8-188 \\
B-189\end{array}$ & $\begin{array}{l}0.2 \\
0.1 \\
0.2 \\
0.2 \\
0.2 \\
0.1 \\
1.3 \\
0.2 \\
0.2 \\
0.1 \\
0.1 \\
0.1\end{array}$ & : & $\begin{array}{l}\text { LM } \\
L M \\
L M \\
L M \\
L M \\
L M \\
L M\end{array}$ & $\begin{array}{l}8 / 28 \\
8 / 28 \\
8 / 28 \\
8 / 31 \\
8 / 31 \\
8 / 31 \\
8 / 31 \\
9 / 18 \\
9 / 18 \\
9 / 18 \\
9 / 18 \\
9 / 18\end{array}$ & $\begin{array}{l}9 / 08 \\
9 / 08 \\
9 / 08 \\
9 / 08 \\
9 / 08 \\
9 / 08 \\
9 / 08 \\
9 / 22 \\
9 / 2 c \\
9 / 22 \\
9 / 22 \\
9 / 22\end{array}$ & $\begin{array}{l}9 / 09 \\
9 / 09 \\
9 / 09 \\
9109 \\
9 / 09 \\
9 / 09 \\
9109 \\
9 / 22 \\
9 / 22 \\
9 / 22 \\
9 / 22 \\
9 / 22\end{array}$ & $\begin{array}{r}12 \\
12 \\
12 \\
9 \\
9 \\
9 \\
9 \\
4 \\
6 \\
4 \\
4 \\
6\end{array}$ & $\begin{array}{l}\text { Fodp } \\
\text { Foup } \\
\text { Reg } \\
\text { Foup } \\
\text { Fdup } \\
\text { Reg } \\
\text { Select } \\
\text { Fods } \\
\text { Fdip } \\
\text { Reg } \\
\text { Reg } \\
\text { Reg }\end{array}$ \\
\hline
\end{tabular}


Table C-6. FTuoride Data (EPA Method 300)

Soil $\mathrm{CDL}=1.0 \mu \mathrm{g} / \mathrm{g}$. (sheet 2 of 2$)$

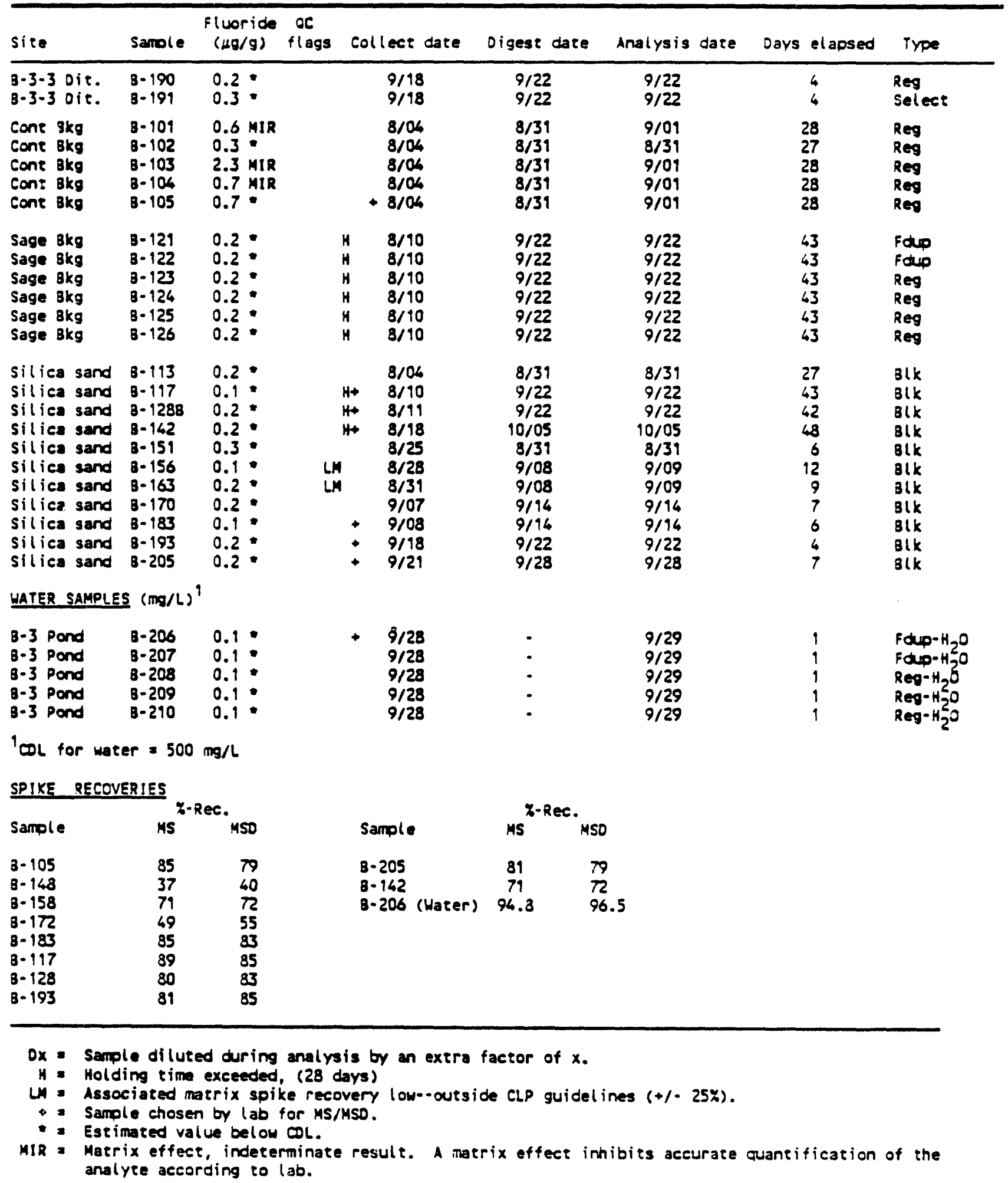


Table C-7. Nitrate-Nitrite Data (EPA Method 300)

Soll $\mathrm{COL}=1.0 \mu \mathrm{g} / \mathrm{g}$ each. (sheet 1 of 3 )

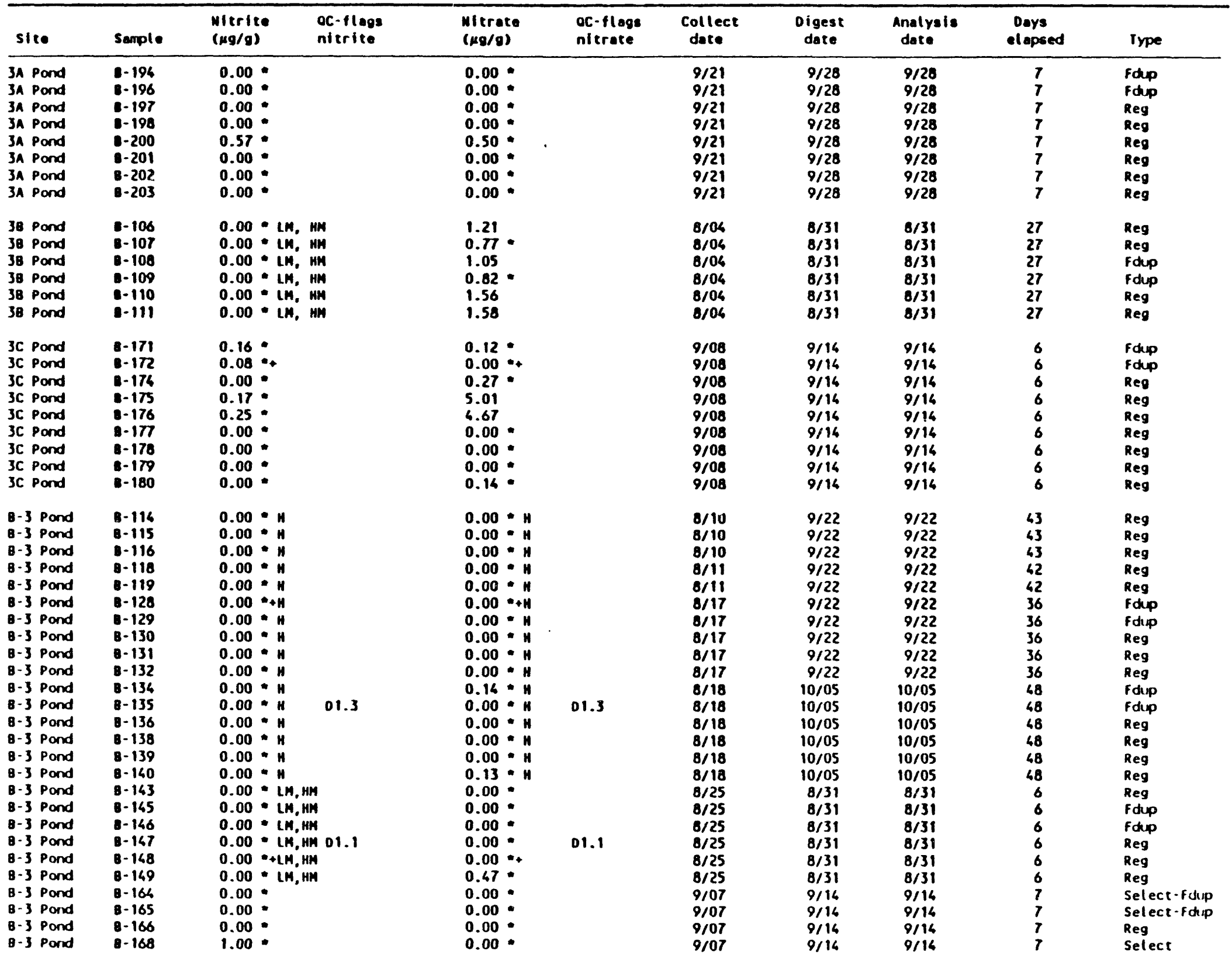


Table C-7. Nitrate-Nitrite Data (EPA Method 300)

Soil $\mathrm{CDL}=1.0 \mu \mathrm{g} / \mathrm{g}$ each. (sheet 2 of 3 )

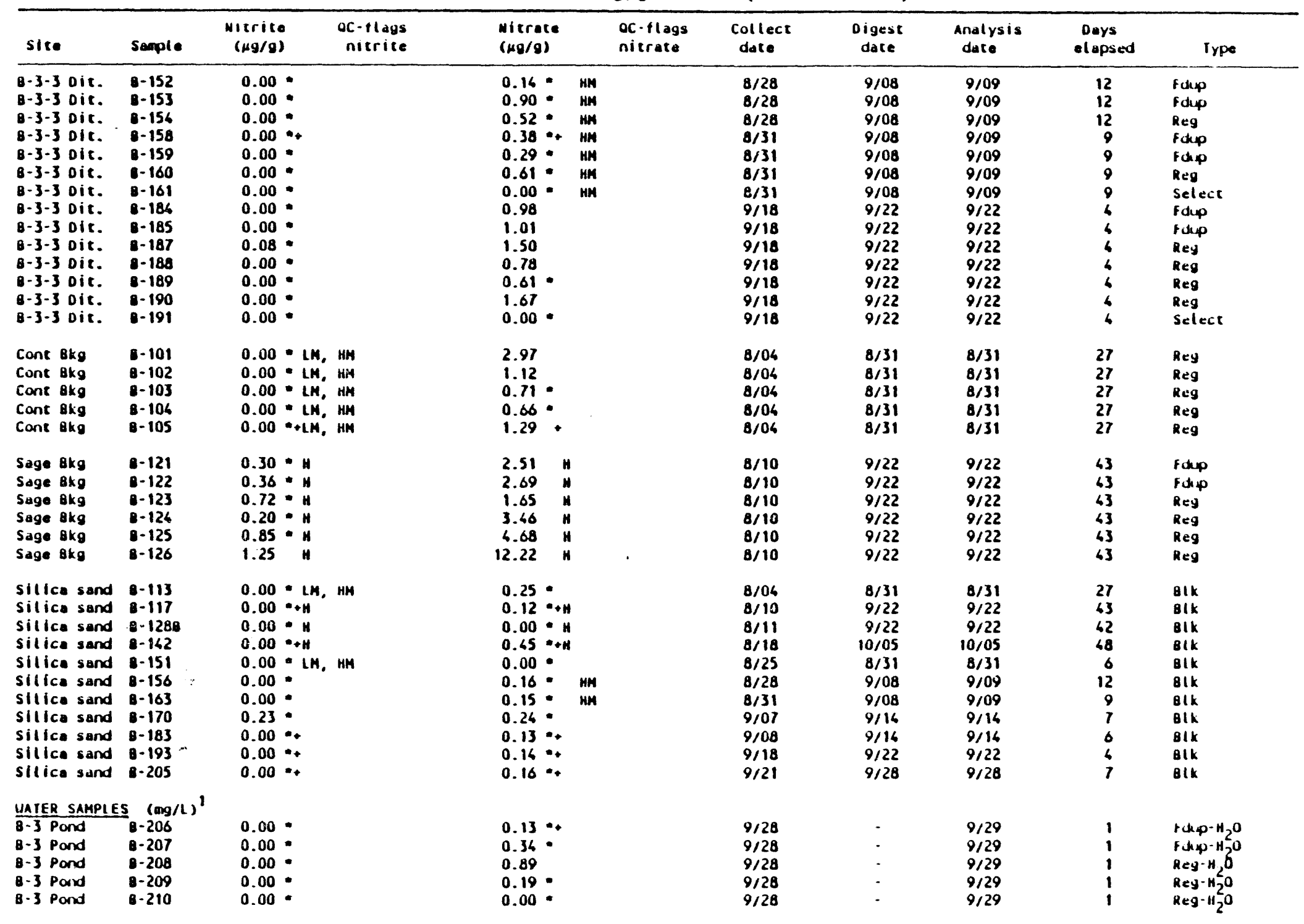

1 COL for water $=0.5 \mathrm{arg} / \mathrm{L}$ 
Table C-7. Nitrate-Nitrite Data (EPA Method 300)

Soil $\mathrm{COL}=1.0 \mu \mathrm{g} / \mathrm{g}$ each. (sheet 3 of 3 )

\begin{tabular}{|c|c|c|c|c|c|c|c|c|c|c|}
\hline site & Sample & $\begin{array}{l}\text { Mitrite } \\
(\mu g / g)\end{array}$ & $\begin{array}{c}\text { oc-flogs } \\
\text { nitrite }\end{array}$ & $\begin{array}{l}\text { Mitrate } \\
(\mu g / g)\end{array}$ & $\begin{array}{l}\text { oc-flags } \\
\text { nitrate }\end{array}$ & $\begin{array}{l}\text { Collect } \\
\text { date }\end{array}$ & $\begin{array}{l}\text { Digest } \\
\text { date }\end{array}$ & $\begin{array}{l}\text { Analysis } \\
\text { date }\end{array}$ & $\begin{array}{l}\text { Days } \\
\text { el apsed }\end{array}$ & Type \\
\hline
\end{tabular}

SPIXE RECOVERIES

\begin{tabular}{|c|c|c|}
\hline & XRec NOS & XRec $N 02$ \\
\hline Sample & MS $\quad$ HSO & HS MSO \\
\hline
\end{tabular}

$\begin{array}{rrrrr}8-105 & 109.0 & 99.8 & 0.0 & 0.0 \\ 8-148 & 93.8 & 97.8 & 148.0 & 137.0 \\ 8-158 & 125.3 & 121.8 & 115.0 & 120.0 \\ 8-172 & 82.8 & 81.0 & 116.0 & 115.0 \\ 8-183 & 98.0 & 95.8 & 98.0 & 99.0 \\ 8-117 & 96.0 & 93.0 & 103.0 & 190.0 \\ 8-128 & 94.3 & 94.5 & 95.0 & 100.0 \\ 8-193 & 91.8 & 92.5 & 97.0 & 102.0 \\ 8-205 & 97.8 & 95.8 & 100.0 & 99.0 \\ 8-146 & 91.5 & 89.5 & 102.0 & 103.0 \\ \text { B-206(Hater) } & 97.5 & 97.0 & 103.4 & 101.3\end{array}$

$0 x=$ Sample diluted during analysis by an extre fector of $x$.

$H$ " Holding time, (28 days), for combined reporting of Witrate, Mitrite exceeded.

HA - Associated motrix spike recovery high -. outside CLP guidel ines $(+/-25 x)$.

LIN - Associated metrix spike recovery lon .. outside CLP guidelines $(+/-25 X)$.

- Semple chosen by lob for metrix spike MS/HSO.

- Estimated value below COL. 
WHC-SD-EN-AP-042, REV. 0

Table C-8. Phosphate Data (EPA Method 300)

Soil $\mathrm{CDL}=2.0 \mu \mathrm{g} / \mathrm{g}$. (sheet 1 of 2)

\begin{tabular}{|c|c|c|c|c|c|c|c|c|}
\hline site & Sample & $\begin{array}{l}\text { Phosphate } \\
(\mu \mathrm{g} / \mathrm{g})\end{array}$ & $\stackrel{\text { OC }}{f \text { lags }}$ & $\begin{array}{l}\text { Collect } \\
\text { date }\end{array}$ & $\begin{array}{c}\text { Oigest } \\
\text { date }\end{array}$ & $\begin{array}{l}\text { Analysis } \\
\text { date }\end{array}$ & $\begin{array}{l}\text { Days } \\
\text { elapsed }\end{array}$ & Type \\
\hline $\begin{array}{l}3 A \text { Pond } \\
3 A \text { Pond } \\
3 A \text { Pond } \\
3 A \text { Pond } \\
3 A \text { Pond } \\
3 A \text { Pond } \\
3 A \text { Pond } \\
3 A \text { Pond }\end{array}$ & $\begin{array}{l}8-194 \\
8-196 \\
8-197 \\
8-198 \\
8-200 \\
8-201 \\
8-202 \\
8-203\end{array}$ & $\begin{array}{l}0.0: \\
0.0: \\
0.0 \\
0.0 \\
0.0 \\
0.0 \\
0.0 \\
0.0\end{array}$ & & $\begin{array}{l}9 / 21 \\
9 / 21 \\
9 / 21 \\
9 / 21 \\
9 / 21 \\
9 / 21 \\
9 / 21 \\
9 / 29\end{array}$ & $\begin{array}{l}9 / 28 \\
9 / 28 \\
9 / 28 \\
9 / 28 \\
9 / 28 \\
9 / 28 \\
9 / 28 \\
9 / 28\end{array}$ & $\begin{array}{l}9 / 28 \\
9 / 28 \\
9 / 28 \\
9 / 28 \\
9 / 28 \\
9 / 28 \\
9 / 28 \\
9 / 28\end{array}$ & $\begin{array}{l}7 \\
7 \\
7 \\
7 \\
7 \\
7 \\
7 \\
7\end{array}$ & $\begin{array}{l}\text { Foup } \\
\text { Foup } \\
\text { Reg } \\
\text { Reg } \\
\text { Reg } \\
\text { Reg } \\
\text { Reg } \\
\text { Reg }\end{array}$ \\
\hline $\begin{array}{l}38 \text { Pand } \\
38 \text { Pand } \\
38 \text { Pond } \\
38 \text { Pond } \\
38 \text { Pond } \\
38 \text { Pond }\end{array}$ & $\begin{array}{l}8-106 \\
8-107 \\
8-108 \\
8-109 \\
8-110 \\
8-119\end{array}$ & $\begin{array}{l}0.0 \\
0.0 \\
0.0 \\
0.0 \\
0.0 \\
0.0\end{array}$ & $\begin{array}{l}\text { LM } \\
\text { LM } \\
\text { LM } \\
\text { LM }\end{array}$ & $\begin{array}{l}8 / 04 \\
8 / 04 \\
8 / 04 \\
8 / 04 \\
8 / 04 \\
8 / 04\end{array}$ & $\begin{array}{l}8 / 31 \\
8 / 31 \\
8 / 31 \\
8 / 31 \\
8 / 31 \\
8 / 31\end{array}$ & $\begin{array}{l}8 / 39 \\
8 / 39 \\
8 / 39 \\
8 / 39 \\
8 / 39 \\
8 / 39\end{array}$ & $\begin{array}{l}27 \\
27 \\
27 \\
27 \\
27 \\
27\end{array}$ & $\begin{array}{l}\text { Reg } \\
\text { Reg } \\
\text { Fdup } \\
\text { Fdup } \\
\text { Reg } \\
\text { Reg }\end{array}$ \\
\hline $\begin{array}{l}3 C \text { Pond } \\
3 C \text { Pond } \\
3 C \text { Pond } \\
3 C \text { Pond } \\
3 C \text { Pond } \\
3 C \text { Pond } \\
3 C \text { Pond } \\
3 C \text { Pond } \\
3 C \text { Pond }\end{array}$ & $\begin{array}{l}8-179 \\
8-172 \\
8-174 \\
8-175 \\
8=176 \\
8-177 \\
8-178 \\
8=179 \\
8=180\end{array}$ & $\begin{array}{l}0.0 \\
0.0 \\
0.0 \\
0.7 \\
0.0 \\
0.0 \\
0.0 \\
0.0 \\
0.0\end{array}$ & $\begin{array}{l}L M \\
L M+ \\
L M \\
L M \\
L M \\
L M \\
L M \\
L M \\
L M\end{array}$ & $\begin{array}{l}9 / 08 \\
9 / 08 \\
9 / 08 \\
9 / 08 \\
9 / 08 \\
9 / 08 \\
9 / 08 \\
9 / 08 \\
9 / 08\end{array}$ & $\begin{array}{l}9 / 14 \\
9 / 14 \\
9 / 14 \\
9 / 14 \\
9 / 14 \\
9 / 14 \\
9 / 14 \\
9 / 14 \\
9 / 14\end{array}$ & $\begin{array}{l}9 / 14 \\
9 / 14 \\
9 / 14 \\
9 / 14 \\
9 / 14 \\
9 / 18 \\
9 / 14 \\
9 / 14 \\
9 / 14\end{array}$ & $\begin{array}{l}6 \\
6 \\
6 \\
6 \\
6 \\
10 \\
6 \\
6 \\
6\end{array}$ & $\begin{array}{l}\text { Fdup } \\
\text { fdup } \\
\text { Reg } \\
\text { Reg } \\
\text { Reg } \\
\text { Reg } \\
\text { Reg } \\
\text { Reg } \\
\text { Reg }\end{array}$ \\
\hline $\begin{array}{l}8-3 \text { Pond } \\
8-3 \text { Pond } \\
8-3 \text { Pand } \\
8-3 \text { Pond } \\
8-3 \text { Pond } \\
8-3 \text { Pond } \\
8-3 \text { Pond } \\
8-3 \text { Pond } \\
8-3 \text { Pond } \\
8-3 \text { Pond } \\
8-3 \text { Pond } \\
8-3 \text { Pond } \\
8-3 \text { Pond } \\
8-3 \text { Pond } \\
8-3 \text { Pond } \\
8-3 \text { Pond } \\
8-3 \text { Pond } \\
8-3 \text { Pond } \\
8-3 \text { Pond } \\
8-3 \text { Pond } \\
8.3 \text { Pond } \\
8-3 \text { Pond } \\
8-3 \text { Pond } \\
8.3 \text { Pond } \\
8-3 \text { Pond } \\
8-3 \text { Pond }\end{array}$ & $\begin{array}{l}8-114 \\
8-115 \\
8-116 \\
8-118 \\
8-119 \\
8-128 \\
8-129 \\
8-130 \\
8-139 \\
8-132 \\
8-134 \\
8-135 \\
8-136 \\
8-138 \\
8-139 \\
B-140 \\
8-143 \\
B-145 \\
B-146 \\
B-147 \\
8-148 \\
B-149 \\
8-164 \\
B-165 \\
8-166 \\
8-168\end{array}$ & 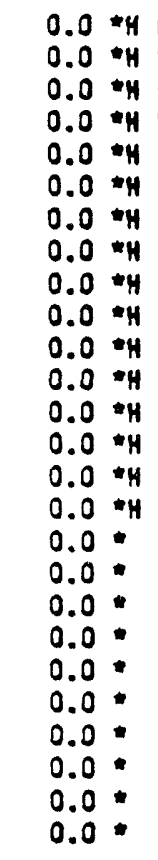 & $\begin{array}{l}L M \\
L M \\
L M \\
L M \\
L M \\
L M \\
L M \\
L M \\
L M \\
L M \\
L M \\
L M \\
L M \\
L M \\
L M \\
L M \\
L M \\
L M\end{array}$ & $\begin{array}{l}8 / 10 \\
8 / 10 \\
8 / 10 \\
8 / 19 \\
8 / 11 \\
8 / 17 \\
8 / 17 \\
8 / 17 \\
8 / 17 \\
8 / 17 \\
8 / 18 \\
8 / 18 \\
8 / 18 \\
8 / 18 \\
8 / 18 \\
8 / 18 \\
8 / 25 \\
8 / 25 \\
8 / 25 \\
8 / 25 \\
8 / 25 \\
8 / 25 \\
9 / 07 \\
9 / 07 \\
9 / 07 \\
9 / 07\end{array}$ & $\begin{array}{l}9 / 22 \\
9 / 22 \\
9 / 22 \\
9 / 22 \\
9 / 22 \\
9 / 22 \\
9 / 22 \\
9 / 22 \\
9 / 22 \\
9 / 22 \\
10 / 05 \\
10 / 05 \\
10 / 05 \\
10 / 05 \\
10 / 05 \\
10 / 05 \\
8 / 31 \\
8 / 31 \\
8 / 31 \\
8 / 31 \\
8 / 31 \\
8 / 31 \\
9 / 14 \\
9 / 14 \\
9 / 14 \\
9 / 14\end{array}$ & $\begin{array}{l}9 / 22 \\
9 / 22 \\
9 / 22 \\
9 / 22 \\
9 / 22 \\
9 / 22 \\
9 / 22 \\
9 / 22 \\
9 / 22 \\
9 / 22 \\
10 / 05 \\
10 / 05 \\
10 / 05 \\
10 / 05 \\
10 / 05 \\
10 / 05 \\
8 / 31 \\
8 / 31 \\
8 / 31 \\
8 / 31 \\
8 / 39 \\
8 / 31 \\
9 / 14 \\
9 / 14 \\
9 / 14 \\
9 / 94\end{array}$ & $\begin{array}{l}43 \\
43 \\
43 \\
42 \\
42 \\
36 \\
36 \\
36 \\
36 \\
36 \\
48 \\
48 \\
48 \\
48 \\
48 \\
48 \\
6 \\
6 \\
6 \\
6 \\
6 \\
6 \\
7 \\
7 \\
7 \\
7\end{array}$ & $\begin{array}{l}\text { Reg } \\
\text { Reg } \\
\text { Reg } \\
\text { Reg } \\
\text { Reg } \\
\text { Fdup } \\
\text { Fdup } \\
\text { Reg } \\
\text { Reg } \\
\text { Reg } \\
\text { Fdup } \\
\text { Fdup } \\
\text { Reg } \\
\text { Reg } \\
\text { Reg } \\
\text { Reg } \\
\text { Reg } \\
\text { Fdup } \\
\text { Fdup } \\
\text { Reg } \\
\text { Reg } \\
\text { Reg } \\
\text { Select-Fdup } \\
\text { Select-Fdup } \\
\text { Reg } \\
\text { Select }\end{array}$ \\
\hline $\begin{array}{l}8-3-3 \text { Dit. } \\
8-3-3 \text { Dit. } \\
8-3-3 \text { Dit. } \\
8-3-3 \text { Dit. } \\
3-3-3 \text { Dit. } \\
8-3-3 \text { oit. } \\
8-3-3 \text { Dit. } \\
8-3-3 \text { Dit. } \\
8-3-3 \text { Dit. } \\
8-3-3 \text { oit. } \\
\text { B-3-3 Dit. }\end{array}$ & $\begin{array}{l}B-152 \\
B-153 \\
B-154 \\
B-158 \\
B-159 \\
8-160 \\
B-161 \\
B-184 \\
8-185 \\
8-187 \\
B-188\end{array}$ & $\begin{array}{l}0.0: \\
0.0: \\
0.0: \\
0.0: \\
0.0: \\
0.0: \\
0.0: \\
0.0: \\
0.0: \\
0.0: \\
0.0 .\end{array}$ & $\begin{array}{l}\text { LM } \\
\text { LM } \\
\text { LM } \\
\text { LMt } \\
\text { LM } \\
\text { LM } \\
\text { LM } \\
\text { LM } \\
\text { LM } \\
\text { LM } \\
\text { LM }\end{array}$ & $\begin{array}{l}8 / 28 \\
8 / 28 \\
8 / 28 \\
8 / 31 \\
8 / 31 \\
8 / 31 \\
8 / 31 \\
9 / 18 \\
9 / 18 \\
9 / 18 \\
9 / 18\end{array}$ & $\begin{array}{l}9 / 08 \\
9 / 08 \\
9 / 08 \\
9 / 08 \\
9 / 08 \\
9 / 08 \\
9 / 08 \\
9 / 22 \\
9 / 22 \\
9 / 22 \\
9 / 22\end{array}$ & $\begin{array}{l}9 / 09 \\
9 / 09 \\
9 / 09 \\
9 / 09 \\
9 / 09 \\
9 / 09 \\
9 / 09 \\
9 / 22 \\
9 / 22 \\
9 / 22 \\
9 / 22\end{array}$ & $\begin{array}{r}12 \\
12 \\
12 \\
9 \\
9 \\
9 \\
9 \\
4 \\
4 \\
4 \\
4\end{array}$ & $\begin{array}{l}\text { Fodp } \\
\text { Fdup } \\
\text { Reg } \\
\text { Fdup } \\
\text { Fdup } \\
\text { Reg } \\
\text { Select } \\
\text { Foup } \\
\text { Foup } \\
\text { Reg } \\
\text { Reg }\end{array}$ \\
\hline
\end{tabular}


Table C-8. Phosphate Data (EPA Method 300) Soil CDL $=2.0 \mu \mathrm{g} / \mathrm{g}$. (sheet 2 of 2)

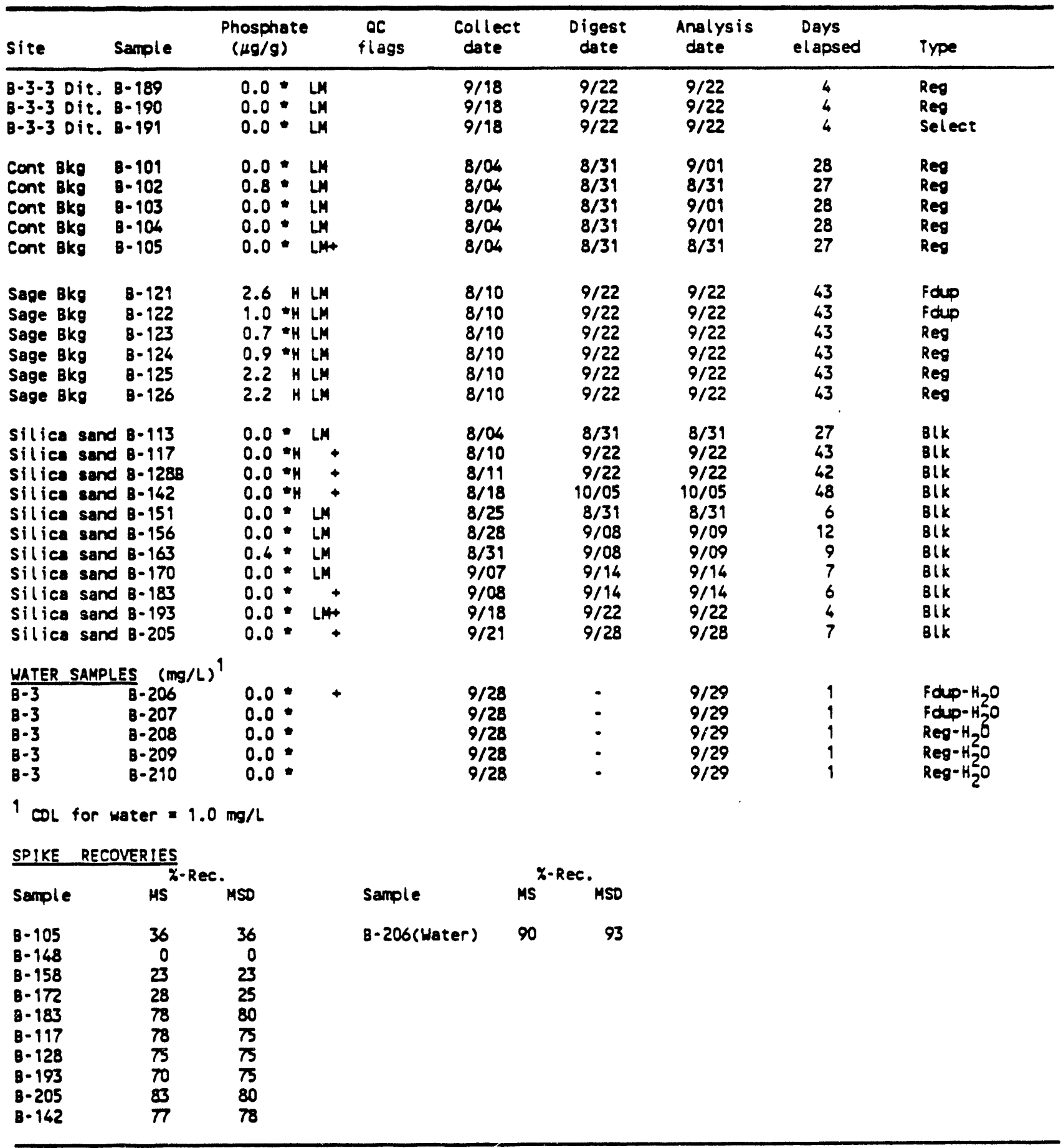

- Estimated value below COL.

H - Holding time exceeded, (28 days).

LM = Associated matrix spike recovery low--outside CLP guidel ines $(+/-25 \%)$.

- Sample chosen by lab for MS/MSO. 
Table C-9. Sulfate Data (EPA Method 300) So i1 $\mathrm{COL}=1.0 \mu \mathrm{g} / \mathrm{g}$. (sheet 1 of 2)

\begin{tabular}{|c|c|c|c|c|c|c|c|c|c|c|}
\hline Site & & Samole & $\begin{array}{l}\text { Sulfat } \\
(\mu g / g)\end{array}$ & & $\begin{array}{c}\text { OC } \\
\text { flags }\end{array}$ & $\begin{array}{l}\text { Collect } \\
\text { date }\end{array}$ & $\begin{array}{l}\text { Digest } \\
\text { date }\end{array}$ & $\begin{array}{l}\text { Analysis } \\
\text { date }\end{array}$ & $\begin{array}{l}\text { Days } \\
\text { elapsed }\end{array}$ & Type \\
\hline $\begin{array}{l}3 A \\
3 A \\
3 A \\
3 A \\
3 A \\
3 A \\
3 A \\
3 A\end{array}$ & $\begin{array}{l}\text { Pond } \\
\text { Pond } \\
\text { Pond } \\
\text { Pand } \\
\text { Pand } \\
\text { Pand } \\
\text { Pand } \\
\text { Pand }\end{array}$ & $\begin{array}{l}8-194 \\
8-196 \\
8-197 \\
8-198 \\
8-200 \\
8-201 \\
8-202 \\
8-203\end{array}$ & $\begin{array}{r}22.3 \\
36.9 \\
14.5 \\
7.7 \\
4.1 \\
6.8 \\
5.6 \\
12.6\end{array}$ & 010 & & $\begin{array}{l}9 / 21 \\
9 / 21 \\
9 / 21 \\
9 / 21 \\
9 / 21 \\
9 / 21 \\
9 / 21 \\
9 / 21\end{array}$ & $\begin{array}{l}9 / 28 \\
9 / 28 \\
9 / 28 \\
9 / 28 \\
9 / 28 \\
9 / 28 \\
9 / 28 \\
9 / 28\end{array}$ & $\begin{array}{l}9 / 28 \\
9 / 28 \\
9 / 28 \\
9 / 28 \\
9 / 28 \\
9 / 28 \\
9 / 28 \\
9 / 28\end{array}$ & $\begin{array}{l}7 \\
7 \\
7 \\
7 \\
7 \\
7 \\
7 \\
7\end{array}$ & $\begin{array}{l}\text { Foup } \\
\text { Fdup } \\
\text { Reg } \\
\text { Reg } \\
\text { Reg } \\
\text { Reg } \\
R e g \\
R e g\end{array}$ \\
\hline $\begin{array}{l}38 \\
38 \\
38 \\
38 \\
38 \\
38\end{array}$ & $\begin{array}{l}\text { Pond } \\
\text { Pond } \\
\text { Pond } \\
\text { Pond } \\
\text { Pand } \\
\text { Pond }\end{array}$ & $\begin{array}{l}8-106 \\
8-107 \\
3-108 \\
8-109 \\
8-110 \\
8-111\end{array}$ & $\begin{array}{l}0.8 \\
1.0 \\
1.2 \\
1.2 \\
1.8 \\
1.5\end{array}$ & • & & $\begin{array}{l}8 / 04 \\
8 / 04 \\
8 / 04 \\
8 / 04 \\
8 / 04 \\
8 / 06\end{array}$ & $\begin{array}{l}8 / 31 \\
8 / 31 \\
8 / 31 \\
8 / 31 \\
8 / 31 \\
8 / 31\end{array}$ & $\begin{array}{l}8 / 31 \\
8 / 31 \\
8 / 31 \\
8 / 31 \\
8 / 31 \\
8 / 31\end{array}$ & $\begin{array}{l}27 \\
27 \\
27 \\
27 \\
27 \\
27\end{array}$ & $\begin{array}{l}\text { Reg } \\
\text { Reg } \\
\text { Fdup } \\
\text { fdup } \\
\text { Reg } \\
\text { Reg }\end{array}$ \\
\hline $\begin{array}{l}3 C \\
3 C \\
3 C \\
3 C \\
3 C \\
3 C \\
3 C \\
3 C \\
3 C\end{array}$ & $\begin{array}{l}\text { Pond } \\
\text { Pand } \\
\text { Pond } \\
\text { Pand } \\
\text { Pand } \\
\text { Pond } \\
\text { Pond } \\
\text { Pand } \\
\text { Pond }\end{array}$ & $\begin{array}{l}3-171 \\
8-172 \\
3-176 \\
8-175 \\
8-176 \\
8-177 \\
8-178 \\
8-179 \\
8-180\end{array}$ & $\begin{array}{r}3.0 \\
2.6 \\
5.6 \\
2.3 \\
1.7 \\
3.8 \\
6.0 \\
16.3 \\
5.6\end{array}$ & & & $\begin{array}{r}9 / 08 \\
+9 / 08 \\
9 / 08 \\
9108 \\
9108 \\
9108 \\
9108 \\
9 / 08 \\
9108\end{array}$ & $\begin{array}{l}9 / 14 \\
9 / 14 \\
9 / 14 \\
9 / 14 \\
9 / 14 \\
9 / 14 \\
9 / 14 \\
9 / 14 \\
9 / 14\end{array}$ & $\begin{array}{l}9 / 14 \\
9 / 14 \\
9 / 14 \\
9 / 14 \\
9 / 14 \\
9 / 14 \\
9 / 14 \\
9 / 14 \\
9 / 14\end{array}$ & $\begin{array}{l}6 \\
6 \\
6 \\
6 \\
6 \\
6 \\
6 \\
6 \\
6\end{array}$ & $\begin{array}{l}\text { Fdup } \\
\text { Foup } \\
R e g \\
R e g \\
\text { Reg } \\
R e g \\
R e g \\
\text { Reg } \\
\text { Reg }\end{array}$ \\
\hline $\begin{array}{l}8-3 \\
8-3 \\
8-3 \\
8-3 \\
8-3 \\
8-3 \\
8-3 \\
8-3 \\
8-3 \\
8-3 \\
8-3 \\
8-3 \\
8-3 \\
8-3 \\
8-3 \\
8-3 \\
8-3 \\
8-3 \\
8-3 \\
8-3 \\
8-3 \\
8-3 \\
8-3 \\
8-3 \\
8-3 \\
8-3\end{array}$ & $\begin{array}{l}\text { Pond } \\
\text { Pand } \\
\text { Pand } \\
\text { Pand } \\
\text { Pand } \\
\text { Pond } \\
\text { Pond } \\
\text { Pand } \\
\text { Pand } \\
\text { Pand } \\
\text { Pand } \\
\text { Pond } \\
\text { Pond } \\
\text { Pond } \\
\text { Pand } \\
\text { Pand } \\
\text { Pond } \\
\text { Pond } \\
\text { Pand } \\
\text { Pond } \\
3 \text { Pond } \\
\text { Pand } \\
3 \text { Pond } \\
3 \text { Pand } \\
3 \text { Pand } \\
3 \text { Pand }\end{array}$ & $\begin{array}{l}8-114 \\
8-115 \\
8-116 \\
8-118 \\
8-119 \\
8-128 \\
8-129 \\
8-130 \\
8-131 \\
8-132 \\
8-134 \\
8-135 \\
8-136 \\
8-138 \\
8-139 \\
8-140 \\
8-143 \\
8-145 \\
8-146 \\
8-147 \\
8-148 \\
8-149 \\
8-164 \\
8-165 \\
8-166 \\
8-168\end{array}$ & $\begin{array}{r}141.2 \\
172.4 \\
208.8 \\
35.8 \\
8.8 \\
9.7 \\
11.6 \\
27.7 \\
14.9 \\
8.2 \\
88.7 \\
126.2 \\
1.7 \\
11.3 \\
20.0 \\
29.1 \\
11.2 \\
8.3 \\
10.4 \\
31.5 \\
8.2 \\
6.9 \\
3.5 \\
3.1 \\
3.2 \\
5.9\end{array}$ & $\begin{array}{rr}010 & H \\
010 & H \\
010 & H \\
05 & H \\
& H \\
& H \\
& H \\
& H \\
& H \\
& H \\
010 & H \\
010 & H \\
& H \\
& H \\
& H \\
& H \\
& H\end{array}$ & $\begin{array}{l}A \\
4 \\
4 \\
4 \\
4 \\
H \\
4 \\
H \\
H \\
H \\
H \\
H\end{array}$ & $\begin{array}{l}8 / 10 \\
8 / 10 \\
8 / 10 \\
8 / 11 \\
8 / 11 \\
8 / 17 \\
8 / 17 \\
8 / 17 \\
8 / 17 \\
8 / 17 \\
8 / 18 \\
8 / 18 \\
8 / 18 \\
8 / 18 \\
8 / 18 \\
8 / 18 \\
8 / 25 \\
8 / 25 \\
8 / 25 \\
8 / 25 \\
+8 / 25 \\
8 / 25 \\
9 / 07 \\
9 / 07 \\
9 / 07 \\
9 / 07\end{array}$ & $\begin{array}{c}9 / 22 \\
9 / 22 \\
9 / 22 \\
9 / 22 \\
9 / 22 \\
9 / 22 \\
9 / 22 \\
9 / 22 \\
9 / 22 \\
9 / 22 \\
10 / 05 \\
10 / 05 \\
10 / 05 \\
10 / 05 \\
10 / 05 \\
10 / 05 \\
8 / 31 \\
8 / 31 \\
8 / 31 \\
8 / 31 \\
8 / 31 \\
8 / 31 \\
9 / 14 \\
9 / 14 \\
9114 \\
9 / 14\end{array}$ & $\begin{array}{l}9 / 22 \\
9 / 22 \\
9 / 22 \\
9 / 22 \\
9 / 22 \\
9 / 22 \\
9 / 22 \\
9 / 22 \\
9 / 22 \\
9 / 22 \\
10 / 05 \\
10 / 05 \\
10 / 05 \\
10 / 05 \\
10 / 05 \\
10 / 05 \\
8 / 31 \\
8 / 31 \\
8 / 31 \\
8 / 31 \\
8 / 31 \\
8 / 31 \\
9 / 14 \\
9 / 14 \\
9 / 14 \\
9 / 14\end{array}$ & $\begin{array}{l}43 \\
43 \\
43 \\
42 \\
42 \\
36 \\
36 \\
36 \\
36 \\
36 \\
48 \\
48 \\
48 \\
48 \\
48 \\
48 \\
6 \\
6 \\
6 \\
6 \\
6 \\
6 \\
7 \\
7 \\
7 \\
7\end{array}$ & $\begin{array}{l}\text { Reg } \\
\text { Reg } \\
\text { Reg } \\
\text { Reg } \\
\text { Reg } \\
\text { Fdup } \\
\text { fdup } \\
\text { Reg } \\
\text { Reg } \\
\text { Reg } \\
\text { Foup } \\
\text { foup } \\
\text { Reg } \\
\text { Reg } \\
\text { Reg } \\
\text { Reg } \\
\text { Reg } \\
\text { fdup } \\
\text { foup } \\
\text { Reg } \\
\text { Reg } \\
\text { Reg } \\
\text { Select-Fotud } \\
\text { Select - Fotup } \\
\text { Reg } \\
\text { Select }\end{array}$ \\
\hline $\begin{array}{l}8-3 \\
8-3 \\
8-3 \\
8-3 \\
8-3 \\
8-3 \\
8-3 \\
8-3 \\
8-3 \\
8-3\end{array}$ & 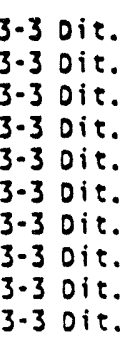 & $\begin{array}{l}8-152 \\
8-153 \\
8-154 \\
8-158 \\
B-159 \\
B-160 \\
B-161 \\
3-184 \\
3-185 \\
3-127\end{array}$ & $\begin{array}{l}1.6 \\
2.0 \\
4.7 \\
3.1 \\
2.2 \\
2.7 \\
6.9 \\
3.3 \\
2.3 \\
3.2\end{array}$ & $\begin{array}{l}H \\
H \\
H \\
H \\
H \\
H \\
H\end{array}$ & $\begin{array}{l}\text { HM } \\
\text { HM } \\
\text { HM } \\
\text { HM } \\
\text { HM } \\
\text { HM }\end{array}$ & $\begin{array}{r}8 / 28 \\
8 / 28 \\
8 / 28 \\
+8 / 31 \\
8 / 31 \\
8 / 31 \\
8 / 31 \\
9 / 18 \\
9 / 18 \\
9 / 18\end{array}$ & $\begin{array}{l}9 / 08 \\
9 / 08 \\
9 / 08 \\
9 / 08 \\
9 / 08 \\
9 / 08 \\
9 / 08 \\
9 / 22 \\
9 / 22 \\
9 / 22\end{array}$ & $\begin{array}{l}9 / 09 \\
9 / 09 \\
9 / 09 \\
9 / 09 \\
9 / 09 \\
9 / 09 \\
9 / 09 \\
7 / 22 \\
9 / 22 \\
7 / 22\end{array}$ & $\begin{array}{r}12 \\
12 \\
12 \\
9 \\
9 \\
9 \\
9 \\
4 \\
4 \\
4\end{array}$ & $\begin{array}{l}\text { Foup } \\
\text { Fdup } \\
\text { Reg } \\
\text { Fdup } \\
\text { Fdup } \\
\text { Reg } \\
\text { Select } \\
\text { Fdup } \\
\text { Fdup } \\
\text { Reg }\end{array}$ \\
\hline
\end{tabular}


WHC-SD-EN-AP-042, REV. 0

Table C-9. Sulfate Data (EPA Method 300)

Soil $\mathrm{CDL}=1.0 \mu \mathrm{g} / \mathrm{g}$. (sheet 2 of 2)

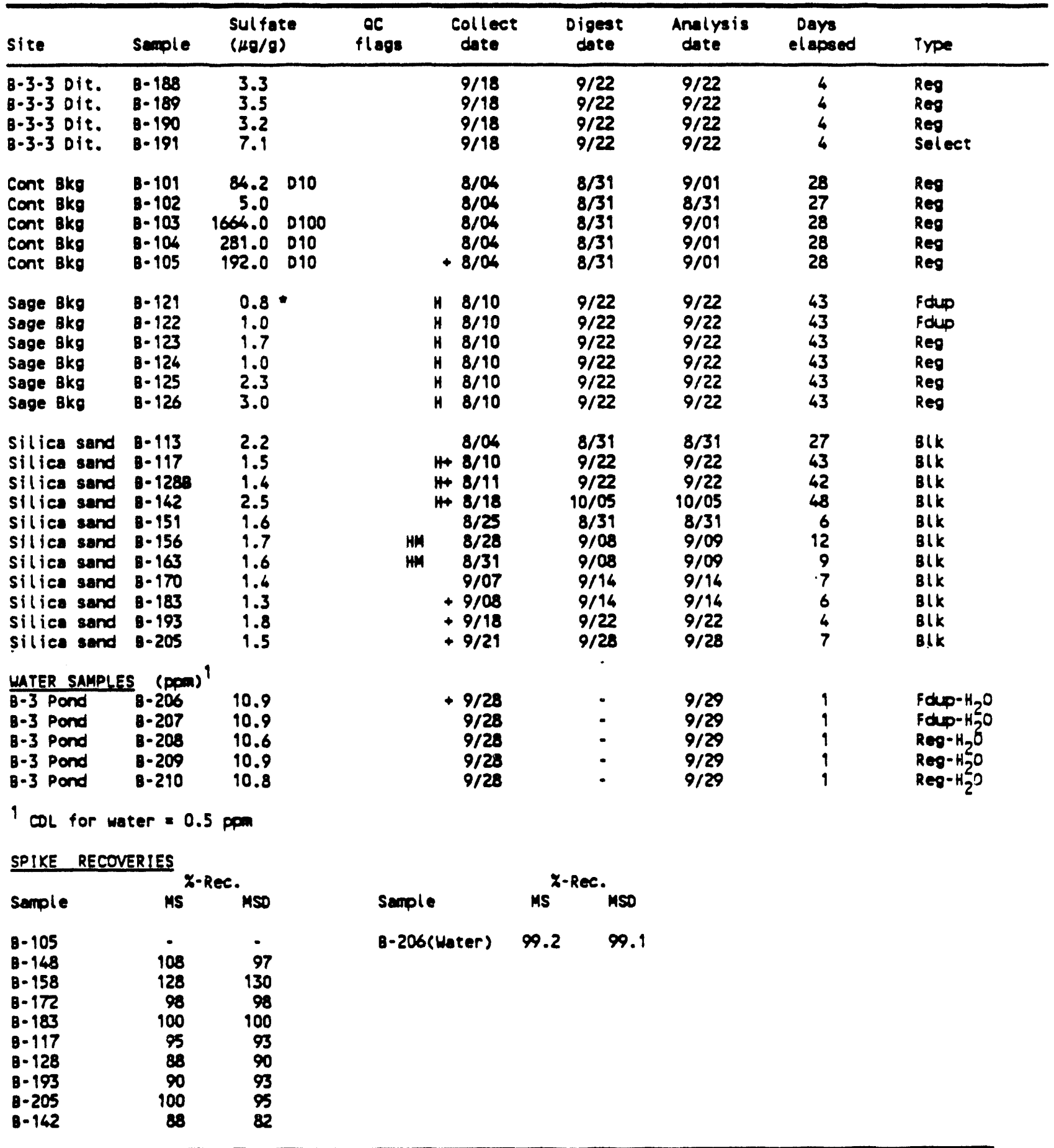

Dx = Sample diluted during analysis by an extra factor of $x$.

HM a Associated matrix spike recovery high-ooutside CLP guidelines $(+/-25 \%)$.

$H$ = Holding time exceeded, (28 days).

- Estimared value below CDL.

+ Semple chosen by lab for MS/MSO. 
Table C-10. Volatile Organic Analysis Summary (EPA Method 8240) $\mu \mathrm{g} / \mathrm{kg}$. (sheet 1 of 2)

\begin{tabular}{|c|c|c|c|c|c|c|c|}
\hline \multirow[b]{2}{*}{ site } & \multirow[b]{2}{*}{ Samole } & \multicolumn{3}{|c|}{ Analyes Codes } & \multirow{2}{*}{$\begin{array}{l}\text { Collect } \\
\text { dote }\end{array}$} & \multirow{2}{*}{$\begin{array}{c}\text { Analys is } \\
\text { dace }\end{array}$} & \multirow[b]{2}{*}{ Type } \\
\hline & & Metione & Ace & tone & & & \\
\hline $\begin{array}{l}3 A \text { Pond } \\
3 A \text { Pond } \\
3 A \text { Pond } \\
3 A \text { Pond } \\
3 A \text { Pond } \\
3 A \text { Pond } \\
3 A \text { Pond }\end{array}$ & $\begin{array}{l}8-194 \\
8-196 \\
B-197 \\
8-198 \\
8-200 \\
8-201 \\
B-203\end{array}$ & 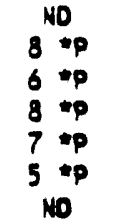 & $\begin{array}{l}26 \\
42 \\
29 \\
20 \\
11 \\
13 \\
13\end{array}$ & $\begin{array}{l}P 8 \\
P B \\
P 8 \\
P B \\
P 8 \\
P 8 \\
P 8\end{array}$ & $\begin{array}{l}9 / 21 \\
9 / 21 \\
9 / 21 \\
9 / 29 \\
9 / 21 \\
9 / 21 \\
9 / 29\end{array}$ & $\begin{array}{l}9 / 22 \\
9 / 22 \\
9 / 22 \\
9 / 22 \\
9 / 22 \\
9 / 22 \\
9 / 22\end{array}$ & $\begin{array}{l}\text { Fodup } \\
\text { Foup } \\
\text { Reg } \\
\text { Reg } \\
\text { Reg } \\
\text { Reg } \\
\text { Reg }\end{array}$ \\
\hline
\end{tabular}

$3 A$ Pond ( 1 other sample.. all anolyees ND)

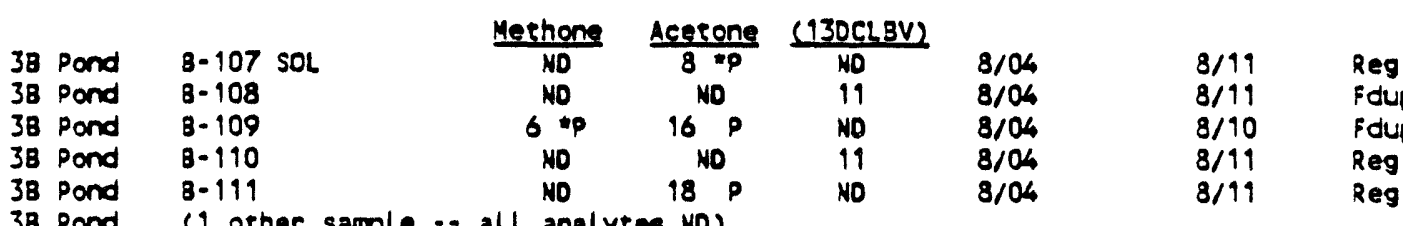

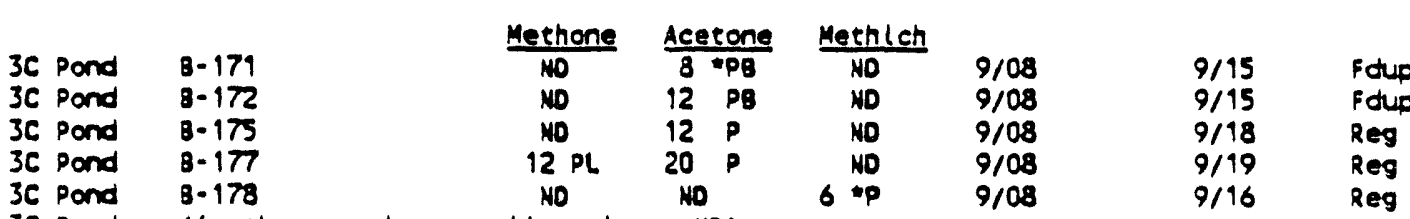

3C Pond (4 other samples -. all analytes NO)

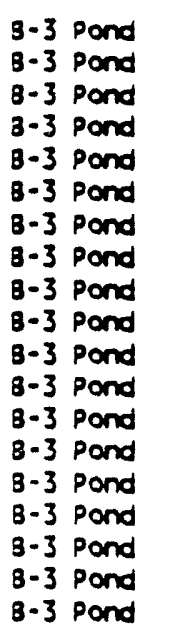

8. 114

B- $115+$

$8-128$

B-129+

B- 130

8- 131

$8-134$

$8-135$

8- 136

B- 138

8- 139

$8-143$

B- 146

8-147 SOL

B- 148 SOL

8- 149

$\frac{\text { Methone Carbide Methych }}{13}$

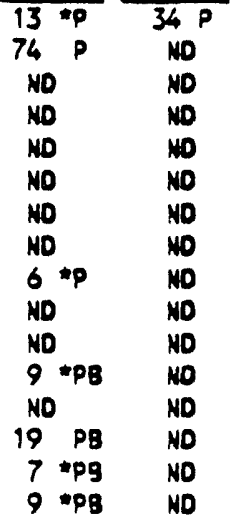

8-210

samples

- all

\begin{tabular}{|c|c|c|}
\hline & & \\
\hline $\begin{array}{l}\text { ND } \\
92\end{array}$ & $\begin{array}{r}21 \\
333\end{array}$ & $P$ \\
\hline ND & 10 & $P$ \\
\hline NO & 160 & \\
\hline No & 10 & $P$ \\
\hline $7 * p$ & 8 & $\oplus p$ \\
\hline No & 8 & 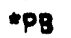 \\
\hline NO & 6 & $\triangle P B$ \\
\hline NO & NO & \\
\hline ND & 8 & $\bullet \rho 8$ \\
\hline NO & 6 & -PB \\
\hline $6 \circ$ & 27 & PBL \\
\hline No & 11 & $\mathrm{~PB}$ \\
\hline ND & 82 & PBL \\
\hline ND & 42 & PBL \\
\hline NO & 54 & PBL \\
\hline
\end{tabular}

( 4 other water samples ... all analytes ND)

0 PQ

B-3-3 Dit Mechone

B-3-3 Dit. B-152 H7 ND 8-3-3 Dit. $8-154 \mathrm{H} 4$ NO B-3-3 Dit. $8-158$ 8-3-3 Dit. $8-160$ 8-3-3 Dit. $8-161$

\begin{tabular}{l} 
Methych \\
\hline NO \\
148 \\
NO \\
ND \\
ND
\end{tabular}

\begin{tabular}{rr}
\multicolumn{3}{c}{ Acerone } \\
\hline 11 & $P 8$ \\
$N 0$ & 8 \\
29 & $P 8$ \\
28 & $P B$ \\
54 & $P 8$
\end{tabular}

\begin{tabular}{l} 
(OMOS) \\
\hline 19 \\
NO \\
NO \\
NO \\
NO
\end{tabular}

\section{Contract Detection Limit}

Acetone Carbide Methone Methlch (130CLBV) (DMOS)

\section{Acetone}

Carbon disulfide Methyl ethyl ketone Methyl chloride

1,3-0ichl orabenzene D imethyldisulfide

$10 \mu g / k g$
$10 \mu g / k g$
$10 \mu g / k g$
$10 \mu g / k g$
$N / A$
$H / A$

$10 \mu \mathrm{kg} / \mathrm{kg}$

$10 \mathrm{\mu g} / \mathrm{kg}$

N/A

A tentatively identified compound.

A tentatively identified compound.

$100 \mathrm{pg} / \mathrm{kg}$

$100 \mathrm{Hg} / \mathrm{kg}$

$100 \mathrm{ng} / \mathrm{kg}$

$10 \mathrm{He} / \mathrm{kg}$
$8 / 10$

$8 / 10$

$8 / 17$

$8 / 17$

$8 / 17$

$8 / 17$

$8 / 98$

$8 / 18$

$8 / 18$

$8 / 18$

$8 / 18$

$8 / 25$

$8 / 25$

$8 / 25$

$8 / 25$

$8 / 25$

$9 / 28$

SH-846 POL

$\begin{array}{ll}8 / 16 & \text { Reg } \\ 8 / 22 & \text { Reg } \\ 8 / 29 & \text { Fdup } \\ 8 / 29 & \text { Fdup } \\ 8 / 29 & \text { Reg } \\ 8 / 23 & \text { Reg } \\ 8 / 29 & \text { Fdup } \\ 8 / 30 & \text { Fdup } \\ 8 / 30 & \text { Reg } \\ 8 / 29 & \text { Reg } \\ 8 / 30 & \text { Reg } \\ 9 / 01 & \text { Reg } \\ 8 / 31 & \text { Fdup } \\ 9 / 01 & \text { Reg } \\ 9 / 01 & \text { Reg } \\ 9 / 01 & \text { Reg }\end{array}$

$10 / 04 \quad \mathrm{Reg}-\mathrm{H}_{2} \mathrm{O}$

$9 / 18 \quad$ Reg

$9 / 15 \quad R e g$

$9 / 06$ Foup

$9 / 06$ Reg

$9 / 06$ Select 
WHC-SD-EN-AP-042, REV. 0

Table C-10. Volatile Organic Analys is $\mu \mathrm{g} / \mathrm{kg}$ Summary (EPA Method 8240). (sheet 2 of 2)

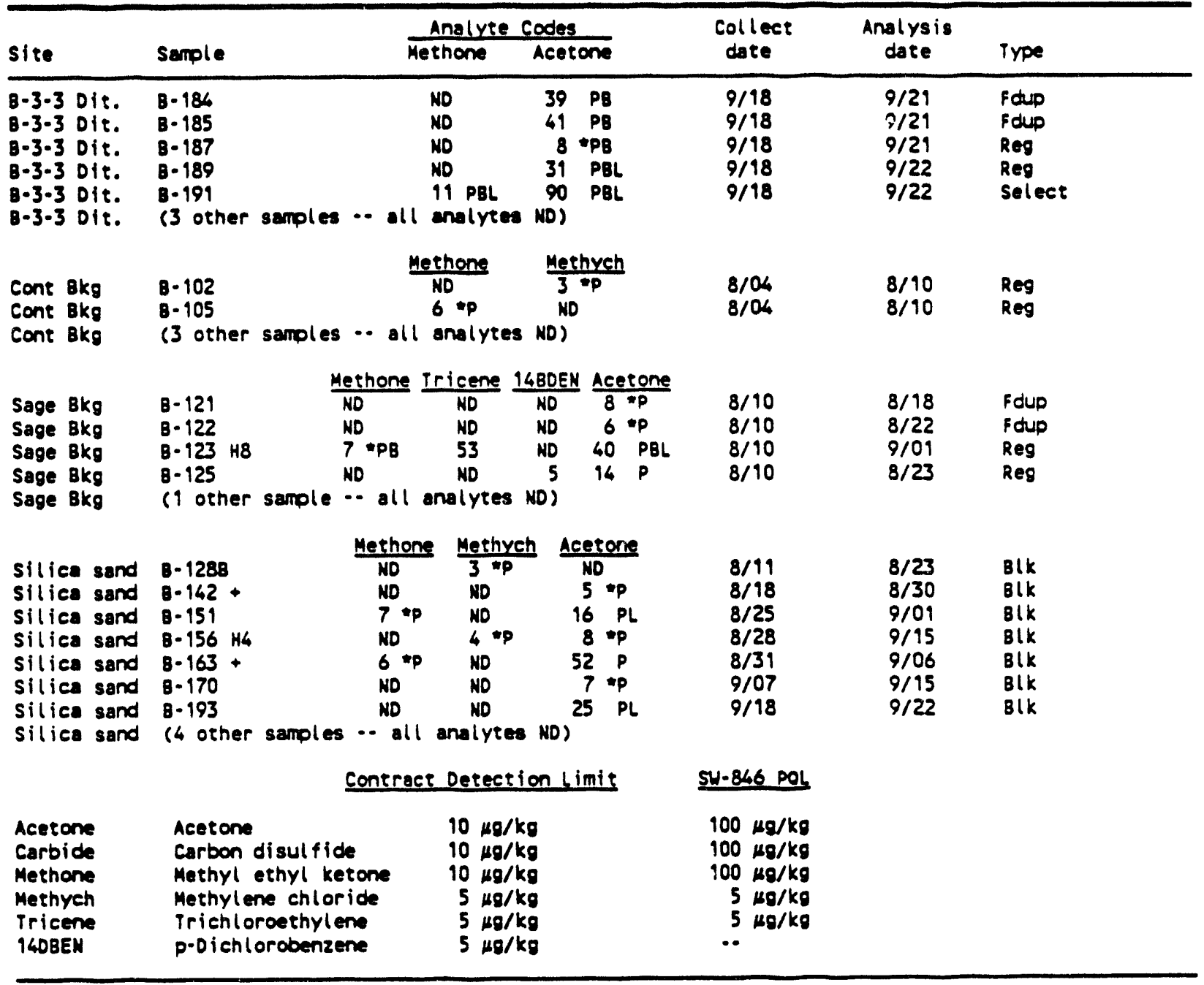

$B=$ Analyte >NO in a field blank collected and/or analyzed on the listed day.

$H x=$ Holding time, ( 14 days), exceeded by $x$ days for all analytes.

$L=$ Lab reagent blank contamination noted by chenist (see table $C-12$ ).

ND = Non-detectable.

$P$ a Result is below SW-846 (December 1987) Practical Quantitation Limit (POL) guidelines. PQLs listed in SW-846 for soil/sediment are based on wet weight sample size. PaLs for comparison were adjusted upward based on sample moisture since results shown are on a dry weight basis.

SOL = Surragate out of limits (see Table C-12).

- Estimated value below COL, (adjusted for dry semple size).

+ Sample chosen by lab for MS/MSO.

'only eamples with an analyte >ND displayed) 
WHC-SD-EN-AP-042, REV. 0

Table C-11. Volatile Organic Analysis

Lab Reagent B1anks for the Period 8/89 - 9/89.

\begin{tabular}{|c|c|c|}
\hline Analysis Date & Constituent Identified & Result (Dob) \\
\hline $\begin{array}{l}8 / 03 / 89 \\
8 / 09 / 89 \\
8 / 10 / 89 \\
8 / 11 / 89 \\
8 / 16 / 89 \\
8 / 17 / 89 \\
8 / 21 / 89 \\
8 / 22 / 89 \\
8 / 23 / 89 \\
8 / 28 / 89 \\
8 / 29 / 89 \\
8 / 30 / 89 \\
8 / 31 / 89 \\
9 / 01 / 89 \\
9 / 06 / 89 \\
9 / 16 / 89 \\
9 / 18 / 89 \\
9 / 19 / 89 \\
9 / 20 / 89 \\
9 / 21 / 89 \\
9 / 22 / 89 \\
9 / 2 \\
9 / 22 / 89 \\
9 / 28 / 89\end{array}$ & 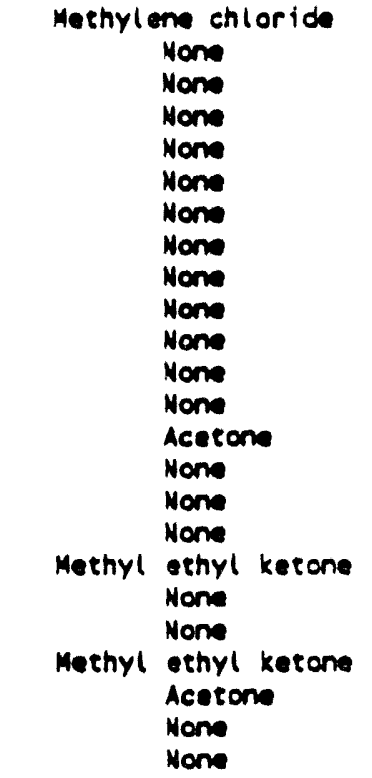 & $\begin{array}{l}3 \\
: \\
: \\
: \\
: \\
: \\
: \\
: \\
: \\
: \\
: \\
6 \\
: \\
6 \\
6 \\
:\end{array}$ \\
\hline
\end{tabular}


Table C-12. Volatile Organic Analysis Holding Times and Surrogate Recoveries. (sheet 1 of 2)

\begin{tabular}{|c|c|c|c|c|c|c|c|c|}
\hline Lobe & Semple & $\begin{array}{l}\text { Collect } \\
\text { date }\end{array}$ & $\begin{array}{l}\text { Anslysis } \\
\text { date }\end{array}$ & $\begin{array}{l}\text { El apsed } \\
\text { days }\end{array}$ & $\overline{120 \mathrm{CAD4}}$ & $\frac{x \text { - ReC. }}{\text { TOLLOS }}$ & $\overline{B F B}$ & Type \\
\hline $\begin{array}{l}3 A \text { Pond } \\
3 A \text { Pond } \\
3 A \text { Pond } \\
3 A \text { Pond } \\
3 A \text { Pond } \\
3 A \text { Pand } \\
3 A \text { Pond } \\
3 A \text { Pand }\end{array}$ & $\begin{array}{l}8-196 \\
8-196 \\
B-197 \\
8-198 \\
8-200 \\
8-201 \\
8-202 \\
8-203\end{array}$ & $\begin{array}{l}9 / 21 \\
9 / 29 \\
9 / 21 \\
9 / 21 \\
9 / 21 \\
9 / 29 \\
9 / 21 \\
9 / 21\end{array}$ & $\begin{array}{l}9 / 22 \\
9 / 22 \\
9 / 22 \\
9 / 22 \\
9 / 22 \\
9 / 22 \\
9 / 28 \\
9 / 22\end{array}$ & $\begin{array}{l}1 \\
1 \\
1 \\
1 \\
1 \\
1 \\
? \\
1\end{array}$ & $\begin{array}{l}98 \\
96 \\
92 \\
108 \\
90 \\
94 \\
90 \\
96\end{array}$ & $\begin{array}{r}100 \\
100 \\
100 \\
102 \\
100 \\
100 \\
98 \\
100\end{array}$ & $\begin{array}{l}92 \\
94 \\
96 \\
92 \\
96 \\
96 \\
94 \\
96\end{array}$ & $\begin{array}{l}\text { Fdup } \\
\text { Fdup } \\
\text { Reg } \\
\text { Reg } \\
\text { Reg } \\
\text { Reg } \\
\text { Reg } \\
\text { Reg }\end{array}$ \\
\hline $\begin{array}{l}38 \text { Pond } \\
38 \text { Pond } \\
38 \text { Pond } \\
38 \text { Pond } \\
38 \text { Pond } \\
38 \text { Pond }\end{array}$ & $\begin{array}{l}8-106 \\
8-107 \\
8-108 \\
8-109 \\
8-110 \\
8-111\end{array}$ & $\begin{array}{l}8 / 04 \\
8 / 04 \\
8 / 04 \\
8 / 04 \\
8 / 04 \\
8 / 04\end{array}$ & $\begin{array}{l}8 / 11 \\
8 / 11 \\
8 / 11 \\
8 / 10 \\
8 / 11 \\
8 / 11\end{array}$ & $\begin{array}{l}7 \\
7 \\
7 \\
6 \\
7 \\
7\end{array}$ & $\begin{array}{r}104 \\
95 \\
92 \\
87 \\
88 \\
90\end{array}$ & $\begin{array}{r}112 \\
85 \\
107 \\
103 \\
105 \\
107\end{array}$ & $\begin{array}{r}107 \\
104 \\
102 \\
99 \\
104 \\
97\end{array}$ & $\begin{array}{l}\text { Reg } \\
\text { Reg } \\
\text { Foup } \\
\text { fdup } \\
\text { Reg } \\
\text { Reg }\end{array}$ \\
\hline $\begin{array}{l}3 C \text { Pond } \\
3 C \text { Pond } \\
3 C \text { Pond } \\
3 C \text { Pond } \\
3 C \text { Pond } \\
3 C \text { Pand } \\
3 C \text { Pand } \\
3 C \text { Pond } \\
3 C \text { Pond }\end{array}$ & $\begin{array}{l}8-171 \\
8-172 \\
B-174 \\
8-175 \\
8-176 \\
8-177 \\
8-178 \\
8-179 \\
8-180\end{array}$ & $\begin{array}{l}9 / 08 \\
9 / 08 \\
9 / 08 \\
9 / 08 \\
9 / 08 \\
9 / 08 \\
9108 \\
9 / 08 \\
9 / 08\end{array}$ & $\begin{array}{l}9 / 15 \\
9 / 15 \\
9 / 15 \\
9 / 18 \\
9 / 18 \\
9 / 19 \\
9 / 16 \\
9 / 18 \\
9 / 16\end{array}$ & $\begin{array}{c}7 \\
7 \\
7 \\
10 \\
10 \\
11 . \\
8 \\
10 \\
8\end{array}$ & $\begin{array}{r}118 \\
110 \\
112 \\
100 \\
100 \\
88 \\
118 \\
118 \\
106\end{array}$ & $\begin{array}{r}100 \\
102 \\
98 \\
108 \\
108 \\
106 \\
106 \\
106 \\
104\end{array}$ & $\begin{array}{r}104 \\
102 \\
104 \\
112 \\
112 \\
96 \\
108 \\
114 \\
106\end{array}$ & $\begin{array}{l}\text { Foup } \\
\text { Fdup } \\
\text { Fdup } \\
\text { Reg } \\
\text { Reg } \\
\text { Reg } \\
\text { Reg } \\
\text { Reg } \\
\text { Reg }\end{array}$ \\
\hline $\begin{array}{l}8-3 \text { Pond } \\
8-3 \text { Pond } \\
8-3 \text { Pond } \\
8-3 \text { Pond } \\
8-3 \text { Pond } \\
8-3 \text { Pond } \\
8-3 \text { Pand } \\
8-3 \text { Pond } \\
8-3 \text { Pond } \\
8-3 \text { Pond } \\
8-3 \text { Pond } \\
8-3 \text { Pond } \\
8-3 \text { Pond } \\
8-3 \text { Pond } \\
8-3 \text { Pond } \\
8-3 \text { Pond } \\
8-3 \text { Pond } \\
8-3 \text { Pond } \\
8-3 \text { Pond } \\
8-3 \text { Pond } \\
8-3 \text { Pond } \\
8-3 \text { Pond } \\
8-3 \text { Pond } \\
8-3 \text { Pond } \\
8-3 \text { Pond } \\
8-3 \text { Pond } \\
8-3 \text { Pond } \\
8-3 \text { Pond } \\
8-3 \text { Pond } \\
8-3 \text { Pond }\end{array}$ & $\begin{array}{l}B-114 \\
B-115 \\
B-116 \\
B-118 \\
B-119 \\
B-128 \\
B-129 \\
B-130 \\
8-131 \\
B-132 \\
B-134 \\
8-135 \\
8-136 \\
B-138 \\
B-139 \\
8-140 \\
B-143 \\
B-145 \\
B-146 \\
B-147 \\
B-148 \\
B-149 \\
B-165 \\
B-166 \\
8-168 \\
B-206 \\
B-207 \\
B-208 \\
B-209 \\
B-210\end{array}$ & $\begin{array}{l}8 / 10 \\
8 / 10 \\
8 / 10 \\
8 / 91 \\
8 / 19 \\
8 / 17 \\
8 / 17 \\
8 / 17 \\
8 / 17 \\
8 / 97 \\
8 / 18 \\
8 / 18 \\
8 / 18 \\
8 / 18 \\
8 / 18 \\
8 / 18 \\
8 / 25 \\
8 / 25 \\
8 / 25 \\
8 / 25 \\
8 / 25 \\
8 / 25 \\
9 / 07 \\
9 / 07 \\
9 / 07 \\
9 / 28 \\
9 / 28 \\
9 / 28 \\
9 / 28 \\
9 / 28\end{array}$ & $\begin{array}{l}8 / 16 \\
8 / 22 \\
8 / 22 \\
8 / 23 \\
8 / 23 \\
8 / 29 \\
8 / 29 \\
8 / 29 \\
8 / 31 \\
8 / 23 \\
8 / 29 \\
8 / 30 \\
8 / 30 \\
8 / 29 \\
8 / 30 \\
8 / 29 \\
9 / 01 \\
8 / 31 \\
8 / 31 \\
9 / 01 \\
9 / 01 \\
9 / 01 \\
9 / 15 \\
9 / 15 \\
9 / 15 \\
10 / 04 \\
10 / 04 \\
10 / 04 \\
10 / 04 \\
10 / 04\end{array}$ & $\begin{array}{c}6 \\
12 \\
12 \\
12 \\
12 \\
12 \\
12 \\
12 \\
16 \\
6 \\
11 \\
12 \\
12 \\
11 \\
12 \\
11 \\
7 \\
6 \\
6 \\
7 \\
7 \\
7 \\
8 \\
8 \\
8 \\
6 \\
6 \\
6 \\
6 \\
6\end{array}$ & $\begin{array}{r}103 \\
111 \\
150 \\
96 \\
115 \\
101 \\
114 \\
107 \\
93 \\
135 \\
109 \\
74 \\
102 \\
116 \\
94 \\
109 \\
118 \\
110 \\
114 \\
130 \\
128 \\
118 \\
112 \\
112 \\
106 \\
95 \\
93 \\
91 \\
93 \\
88\end{array}$ & $\begin{array}{r}92 \\
113 \\
112 \\
98 \\
103 \\
100 \\
100 \\
9 ? \\
108 \\
111 \\
103 \\
100 \\
96 \\
105 \\
100 \\
99 \\
100 \\
104 \\
104 \\
104 \\
106 \\
102 \\
102 \\
100 \\
102 \\
102 \\
100 \\
100 \\
101 \\
101\end{array}$ & $\begin{array}{r}102 \\
95 \\
102 \\
88 \\
94 \\
97 \\
101 \\
101 \\
84 \\
123 \\
104 \\
98 \\
112 \\
103 \\
100 \\
102 \\
92 \\
100 \\
108 \\
104 \\
110 \\
106 \\
102 \\
102 \\
104 \\
105 \\
105 \\
106 \\
105 \\
102\end{array}$ & $\begin{array}{l}\text { Reg } \\
\text { Reg } \\
\text { Reg } \\
\text { Reg } \\
\text { Reg } \\
\text { Fdup } \\
\text { Fdup } \\
\text { Reg } \\
\text { Reg } \\
\text { Reg } \\
\text { Fdup } \\
\text { Fdup } \\
\text { Reg } \\
\text { Reg } \\
\text { Reg } \\
\text { Reg } \\
\text { Reg } \\
\text { Fdup } \\
\text { Fdup } \\
\text { Reg } \\
\text { Reg } \\
\text { Reg } \\
\text { Select } \\
\text { Fdup } \\
\text { Select } \\
\text { Fdup- } \mathrm{H}_{2} \mathrm{O} \\
\text { Fdup- } H_{2} \mathrm{O} \\
\text { Reg- } \mathrm{H}_{2} \text { O } \\
\text { Reg- } \mathrm{H}_{2} \mathrm{O} \\
\text { Reg- } \mathrm{H}_{2} \mathrm{O}\end{array}$ \\
\hline $\begin{array}{l}8-3-3 \text { oit. } \\
8-3-3 \text { Dit. } \\
8-3-3 \text { Dit. } \\
8-3-3 \text { Dit. } \\
8-3-3 \text { Dit. } \\
8-3-3 \text { Dit. }\end{array}$ & $\begin{array}{l}8-152 \\
8-154 \\
B-158 \\
8-159 \\
B-160 \\
8-161\end{array}$ & $\begin{array}{l}8 / 28 \\
8 / 28 \\
8 / 31 \\
8 / 31 \\
8 / 31 \\
8 / 31\end{array}$ & $\begin{array}{l}9 / 18 \\
9 / 15 \\
9 / 06 \\
9 / 06 \\
9 / 06 \\
9 / 06\end{array}$ & $\begin{array}{l}21 \\
18 \\
6 \\
6 \\
6 \\
6\end{array}$ & $\begin{array}{l}102 \\
102 \\
106 \\
102 \\
110 \\
106\end{array}$ & $\begin{array}{r}101 \\
102 \\
100 \\
106 \\
98 \\
102\end{array}$ & $\begin{array}{r}102 \\
102 \\
90 \\
98 \\
102 \\
94\end{array}$ & $\begin{array}{l}\text { Foup } \\
\text { Reg } \\
\text { Fdup } \\
\text { Fdup } \\
\text { Reg } \\
\text { Select }\end{array}$ \\
\hline
\end{tabular}


Table C-12. Volatile Organic Analysis Holding Times and Surrogate Recoveries. (sheet 2 of 2)

\begin{tabular}{|c|c|c|c|c|c|c|c|c|}
\hline Labe & Sample & $\begin{array}{l}\text { Collect } \\
\text { date }\end{array}$ & $\begin{array}{c}\text { Analysis } \\
\text { date }\end{array}$ & $\begin{array}{c}\text { El apsed } \\
\text { days }\end{array}$ & $120 \mathrm{CAO4}$ & $\frac{* \text { Pec. }}{\text { TOLU108 }}$ & $\overline{3 F B}$ & iype \\
\hline $\begin{array}{l}8-3-3 \text { oit. } \\
8-3-3 \text { oit. } \\
8-3-3 \text { oit. } \\
8-3-3 \text { oit. } \\
8-3-3 \text { oit. } \\
8-3-3 \text { Dit. } \\
8-3-3 \text { Dit. }\end{array}$ & $\begin{array}{l}B-184 \\
8-185 \\
B-187 \\
B-188 \\
B-189 \\
B-190 \\
8-191\end{array}$ & $\begin{array}{l}9 / 18 \\
9 / 18 \\
9 / 18 \\
9 / 18 \\
9 / 18 \\
9 / 18 \\
9 / 18\end{array}$ & $\begin{array}{l}9 / 21 \\
9 / 29 \\
9 / 21 \\
9 / 21 \\
9 / 22 \\
9 / 22 \\
9 / 22\end{array}$ & $\begin{array}{l}3 \\
3 \\
3 \\
3 \\
4 \\
4 \\
4\end{array}$ & $\begin{array}{r}100 \\
98 \\
106 \\
112 \\
116 \\
94 \\
100\end{array}$ & $\begin{array}{r}98 \\
98 \\
100 \\
96 \\
96 \\
100 \\
96\end{array}$ & $\begin{array}{l}102 \\
100 \\
106 \\
100 \\
112 \\
98 \\
92\end{array}$ & $\begin{array}{l}\text { Foup } \\
\text { Foup } \\
\text { Reg } \\
\text { Reg } \\
\text { Red } \\
\text { Reg } \\
\text { Select }\end{array}$ \\
\hline $\begin{array}{l}\text { Cont Bkg. } \\
\text { Cont Bkg. } \\
\text { Cont 3kg. } \\
\text { Cont Bkg. } \\
\text { Cont 8kg. }\end{array}$ & $\begin{array}{l}8-101 \\
8-102 \\
8-103 \\
8-104 \\
8-105\end{array}$ & $\begin{array}{l}8 / 06 \\
8 / 06 \\
8 / 06 \\
8 / 06 \\
8 / 06\end{array}$ & $\begin{array}{l}8 / 09 \\
8 / 10 \\
8 / 09 \\
8 / 10 \\
8 / 10\end{array}$ & $\begin{array}{l}5 \\
6 \\
5 \\
6 \\
6\end{array}$ & $\begin{array}{r}95 \\
99 \\
100 \\
88 \\
85\end{array}$ & $\begin{array}{r}99 \\
97 \\
106 \\
91 \\
101\end{array}$ & $\begin{array}{r}108 \\
99 \\
96 \\
94 \\
97\end{array}$ & $\begin{array}{l}\text { Reg } \\
\text { Reg } \\
\text { Reg } \\
\text { Reg } \\
\text { Reg }\end{array}$ \\
\hline $\begin{array}{l}\text { Sage 3kg. } \\
\text { Sage Bkg. } \\
\text { Sage Bkg. } \\
\text { Sage Bkg. } \\
\text { Sage Bkg. } \\
\text { Sage Bkg. }\end{array}$ & $\begin{array}{l}8-129 \\
B-122 \\
8-123 \\
B-126 \\
8-125 \\
B-126\end{array}$ & $\begin{array}{l}8 / 10 \\
8 / 10 \\
8 / 10 \\
8 / 10 \\
3 / 10 \\
8 / 10\end{array}$ & $\begin{array}{l}8 / 18 \\
8 / 22 \\
9 / 01 \\
8 / 23 \\
8 / 23 \\
8 / 23\end{array}$ & $\begin{array}{r}8 \\
12 \\
22 \\
13 \\
13 \\
13\end{array}$ & $\begin{array}{l}101 \\
115 \\
116 \\
115 \\
117 \\
97\end{array}$ & $\begin{array}{l}105 \\
103 \\
112 \\
103 \\
115 \\
106\end{array}$ & $\begin{array}{r}109 \\
105 \\
78 \\
111 \\
110 \\
84\end{array}$ & $\begin{array}{l}\text { Folp } \\
\text { Fodup } \\
\text { Reg } \\
\text { Reg } \\
\text { Reg } \\
\text { Reg }\end{array}$ \\
\hline $\begin{array}{l}\text { silica sand } \\
\text { silica sand } \\
\text { silica sand } \\
\text { silica sand } \\
\text { silica sand } \\
\text { silica sand } \\
\text { silica sand } \\
\text { silica sand } \\
\text { silica sand } \\
\text { silice sand } \\
\text { silica sand }\end{array}$ & $\begin{array}{l}8-113 \\
8-117 \\
8-1288 \\
8-162 \\
8-151 \\
8-156 \\
8-163 \\
8-170 \\
8-183 \\
8-193 \\
8-205\end{array}$ & $\begin{array}{l}8 / 04 \\
8 / 10 \\
8 / 11 \\
8 / 18 \\
8 / 25 \\
8 / 28 \\
8 / 31 \\
9 / 07 \\
9 / 08 \\
9 / 18 \\
9 / 21\end{array}$ & $\begin{array}{l}8 / 17 \\
8 / 17 \\
8 / 23 \\
8 / 30 \\
9 / 01 \\
9 / 15 \\
9 / 06 \\
9 / 15 \\
9 / 18 \\
9 / 22 \\
9 / 28\end{array}$ & $\begin{array}{r}13 \\
7 \\
12 \\
12 \\
7 \\
18 \\
6 \\
8 \\
10 \\
4 \\
7\end{array}$ & $\begin{array}{l}119 \\
101 \\
100 \\
100 \\
106 \\
108 \\
106 \\
108 \\
98 \\
102 \\
92\end{array}$ & $\begin{array}{l}104 \\
106 \\
104 \\
102 \\
104 \\
102 \\
100 \\
104 \\
108 \\
100 \\
88\end{array}$ & $\begin{array}{r}107 \\
110 \\
104 \\
98 \\
96 \\
104 \\
98 \\
106 \\
106 \\
102 \\
104\end{array}$ & $\begin{array}{l}81 k \\
31 k \\
31 k \\
31 k \\
81 k \\
81 k \\
81 k \\
31 k \\
31 k \\
81 k \\
81 k\end{array}$ \\
\hline
\end{tabular}

120CAD4 = 1,2-0ichloroethane-04.

TOLU08 = Tolvene-08.

BFB = 4-8romofllwrobenzene. 
Table C-13. Volatile Organic Analysis Spike and Surrogate Recoveries.

\begin{tabular}{|c|c|c|c|c|c|c|c|c|c|c|}
\hline \multirow[b]{2}{*}{ Somple } & & \multirow[b]{2}{*}{ Eenzerse } & \multicolumn{4}{|c|}{ Matrix Spike Recoverles (x) } & \multirow{2}{*}{$\begin{array}{c}\text { Analysie } \\
\text { Dete }\end{array}$} & \multicolumn{3}{|c|}{ Surrogafe Recoveries $(x)$} \\
\hline & & & Tolverl & Trlchloroethene & Chlorobenzens & 1,1-Dichloroethene & & 1,2-0lchl or oethane-04 & Toluene-08 & 6-Bromofluorabenzene \\
\hline $8-103$ & $\begin{array}{l}\text { MS } \\
\text { MSD }\end{array}$ & $\begin{array}{r}95.8 \\
117.6\end{array}$ & $\begin{array}{l}100.4 \\
109.2\end{array}$ & $\begin{array}{l}105.8 \\
109.4\end{array}$ & $\begin{array}{l}101.6 \\
116.6\end{array}$ & $\begin{array}{l}102.6 \\
111.8\end{array}$ & $\begin{array}{l}0 / 09 / 89 \\
8 / 09 / 89\end{array}$ & $\begin{array}{l}95.8 \\
90.6\end{array}$ & $\begin{array}{l}103.2 \\
95\end{array}$ & $\begin{array}{r}101.6 \\
89.6\end{array}$ \\
\hline $8-115$ & $\begin{array}{l}\text { MS } \\
\text { MSO }\end{array}$ & $\begin{array}{l}115 \\
100\end{array}$ & $\begin{array}{r}115 \\
95\end{array}$ & $\begin{array}{l}115 \\
105\end{array}$ & $\begin{array}{l}130 \\
115\end{array}$ & $\begin{array}{r}105 \\
85\end{array}$ & $\begin{array}{l}8 / 16 / 89 \\
8 / 16 / 89\end{array}$ & $\begin{array}{r}106 \\
98\end{array}$ & $\begin{array}{l}94 \\
92\end{array}$ & $\begin{array}{r}106 \\
96\end{array}$ \\
\hline $0-121$ & $\begin{array}{l}\text { MS } \\
\text { MSO }\end{array}$ & $\begin{array}{c}96 \\
106.5\end{array}$ & $\begin{array}{l}101.5 \\
109\end{array}$ & $\begin{array}{c}86 \\
107.5\end{array}$ & $\begin{array}{l}106 \\
118.5\end{array}$ & $\begin{array}{c}85.5 \\
107\end{array}$ & $\begin{array}{l}8 / 18 / 89 \\
8 / 21 / 89\end{array}$ & $\begin{array}{r}99.2 \\
115.6\end{array}$ & $\begin{array}{r}109.6 \\
99.6\end{array}$ & $\begin{array}{r}107.6 \\
98.6\end{array}$ \\
\hline $8-129$ & $\begin{array}{l}\text { MS } \\
\text { MSO }\end{array}$ & $\begin{array}{l}90 \\
63\end{array}$ & $\begin{array}{l}90 \\
87\end{array}$ & $\begin{array}{l}80 \\
81\end{array}$ & $\begin{array}{l}98 \\
96\end{array}$ & $\begin{array}{l}52 \\
53\end{array}$ & $\begin{array}{l}8 / 28 / 89 \\
8 / 28 / 89\end{array}$ & $\begin{array}{r}98 \\
100\end{array}$ & $\begin{array}{l}100 \\
100\end{array}$ & $\begin{array}{l}100 \\
100\end{array}$ \\
\hline $8-162$ & $\begin{array}{l}\text { MS } \\
\text { MSO }\end{array}$ & $\begin{array}{l}24 \\
98\end{array}$ & $\begin{array}{r}92 \\
102\end{array}$ & $\begin{array}{l}28 \\
96\end{array}$ & $\begin{array}{l}102 \\
112\end{array}$ & $\begin{array}{l}70 \\
74\end{array}$ & $\begin{array}{l}8 / 30 / 89 \\
8 / 30 / 49\end{array}$ & $\begin{array}{r}112 \\
98\end{array}$ & $\begin{array}{l}104 \\
100\end{array}$ & $\begin{array}{l}118 \\
108\end{array}$ \\
\hline $8 \cdot 163$ & $\begin{array}{l}\text { MS } \\
\text { MSO }\end{array}$ & $\begin{array}{r}100 \\
86\end{array}$ & $\begin{array}{l}62 \\
78\end{array}$ & $\begin{array}{l}88 \\
76\end{array}$ & $\begin{array}{l}96 \\
86\end{array}$ & $\begin{array}{l}74 \\
62\end{array}$ & $\begin{array}{l}9 / 06 / 89 \\
9 / 06 / 89\end{array}$ & $\begin{array}{l}116 \\
112\end{array}$ & $\begin{array}{l}66 \\
86\end{array}$ & $\begin{array}{r}96 \\
110\end{array}$ \\
\hline $8-176$ & $\begin{array}{l}\text { MS } \\
\text { MSO }\end{array}$ & $\begin{array}{l}28 \\
86\end{array}$ & $\begin{array}{l}96 \\
96\end{array}$ & $\begin{array}{l}86 \\
84\end{array}$ & $\begin{array}{r}102 \\
98\end{array}$ & $\begin{array}{l}56 \\
46\end{array}$ & $\begin{array}{l}9 / 15 / 89 \\
9 / 18 / 89\end{array}$ & $\begin{array}{l}112 \\
110\end{array}$ & $\begin{array}{l}100 \\
106\end{array}$ & $\begin{array}{l}102 \\
108\end{array}$ \\
\hline $8-190$ & $\begin{array}{l}\text { MS } \\
\text { MSO }\end{array}$ & $\begin{array}{l}78 \\
92\end{array}$ & $\begin{array}{l}84 \\
90\end{array}$ & $\begin{array}{l}84 \\
88\end{array}$ & $\begin{array}{l}96 \\
94\end{array}$ & $\begin{array}{l}60 \\
76\end{array}$ & $\begin{array}{l}9 / 22 / 89 \\
9 / 22 / 89\end{array}$ & $\begin{array}{l}108 \\
102\end{array}$ & $\begin{array}{l}96 \\
98\end{array}$ & $\begin{array}{l}96 \\
96\end{array}$ \\
\hline $8 \cdot 201$ & $\begin{array}{l}\text { MS } \\
\text { MSO }\end{array}$ & $\begin{array}{l}80 \\
92\end{array}$ & $\begin{array}{l}90 \\
92\end{array}$ & $\begin{array}{l}82 \\
86\end{array}$ & $\begin{array}{l}96 \\
98\end{array}$ & $\begin{array}{l}74 \\
72\end{array}$ & $\begin{array}{l}9 / 23 / 89 \\
9 / 23 / 89\end{array}$ & $\begin{array}{l}94 \\
96\end{array}$ & $\begin{array}{r}100 \\
98\end{array}$ & $\begin{array}{l}96 \\
96\end{array}$ \\
\hline $\begin{array}{l}\text { Averag } \\
\text { Std. } 0 \\
x C y\end{array}$ & ev. & $\begin{array}{l}96.1 \\
10.8 \\
11.5\end{array}$ & $\begin{array}{l}93.7 \\
12.2 \\
13.0\end{array}$ & $\begin{array}{l}91.9 \\
11.5 \\
12.5\end{array}$ & $\begin{array}{r}103.0 \\
11.3 \\
11.0\end{array}$ & $\begin{array}{l}74.6 \\
21.8 \\
29.2\end{array}$ & & & & \\
\hline $\begin{array}{l}\text { B-206 } \\
\text { (Hoter }\end{array}$ & $\begin{array}{l}\text { MS } \\
\text { 2MSD }\end{array}$ & $\begin{array}{l}161 \\
131\end{array}$ & $\begin{array}{l}135 \\
121\end{array}$ & $\begin{array}{l}133 \\
122\end{array}$ & $\begin{array}{l}130 \\
117\end{array}$ & $\begin{array}{l}138 \\
121\end{array}$ & $\begin{array}{l}10 / 4 / 89 \\
10 / 4 / 89\end{array}$ & $\begin{array}{l}93.8 \\
88.4\end{array}$ & 109.2 & $\begin{array}{l}106 \\
106\end{array}$ \\
\hline
\end{tabular}


WHC-SD-EN-AP-042, REV. 0

Table C-14. Radioactivity, $\mathrm{PCi} / \mathrm{g}$. (sheet 1 of 2)

\begin{tabular}{|c|c|c|c|c|}
\hline site looe & Sample number & Gross alphe & Gross beta & Type \\
\hline $\begin{array}{l}3 A \text { Pond } \\
3 A \text { Pond } \\
3 A \text { Pond } \\
3 A \text { Pand } \\
3 A \text { Pond } \\
3 A \text { Pond } \\
3 A \text { Pand } \\
3 A \text { Pond }\end{array}$ & $\begin{array}{l}3-196 \\
B-196 \\
3-197 \\
B-198 \\
B-200 \\
B-201 \\
B-202 \\
8-203\end{array}$ & $\begin{array}{l}3.3 \\
4.0 \\
5.3 \\
6.3 \\
4.8 \\
1.0 \\
3.9 \\
4.9\end{array}$ & $\begin{array}{l}51.8 \\
55.5 \\
42.7 \\
68.1 \\
23.6 \\
21.6 \\
18.8 \\
18.5\end{array}$ & $\begin{array}{l}\text { Foup } \\
\text { Fdup } \\
\text { Reg } \\
\text { Reg } \\
\text { Reg } \\
\text { Reg } \\
\text { Reg } \\
\text { Reg }\end{array}$ \\
\hline $\begin{array}{l}38 \text { Pand } \\
38 \text { Pond } \\
38 \text { Pand } \\
38 \text { Pand } \\
38 \text { Pand } \\
38 \text { Pand }\end{array}$ & $\begin{array}{l}8-106 \\
8-107 \\
8-108 \\
8-109 \\
8-110 \\
8-111\end{array}$ & $\begin{array}{l}2.5 \\
1.3 \\
3.2 \\
0.6 \\
4.4 \\
6.4\end{array}$ & $\begin{array}{l}16.8 \\
20.2 \\
18.6 \\
18.3 \\
17.1 \\
18.6\end{array}$ & $\begin{array}{l}\text { Reg } \\
\text { Reg } \\
\text { Foup } \\
\text { Foup } \\
\text { Reg } \\
\text { Reg }\end{array}$ \\
\hline $\begin{array}{l}3 C \text { Pond } \\
3 C \text { Pand } \\
3 C \text { Pond } \\
3 C \text { Pond } \\
3 C \text { Pand } \\
3 C \text { Pand } \\
3 C \text { Pond } \\
3 C \text { pand } \\
3 C \text { pond }\end{array}$ & $\begin{array}{l}3-179 \\
8-172 \\
8-174 \\
8-175 \\
8-176 \\
8-177 \\
3-178 \\
8-179 \\
8-180\end{array}$ & $\begin{array}{r}6.5 \\
7.6 \\
7.8 \\
6.2 \\
4.7 \\
18.6 \\
13.5 \\
10.6 \\
3.3\end{array}$ & $\begin{array}{r}399.0 \\
393.0 \\
31.2 \\
139.0 \\
153.0 \\
488.0 \\
718.0 \\
343.0 \\
159.0\end{array}$ & $\begin{array}{l}\text { Fdup } \\
\text { Fdup } \\
\text { Reg } \\
R e g \\
R e g \\
R e g \\
R e g \\
R e g \\
R e g\end{array}$ \\
\hline $\begin{array}{l}3-3 \text { Pond } \\
8-3 \text { Pond } \\
3-3 \text { Pond } \\
8-3 \text { Pond } \\
3-3 \text { Pond } \\
8-3 \text { Pond } \\
8-3 \text { Pand } \\
8-3 \text { Pond } \\
8-3 \text { Pond } \\
8-3 \text { Pond } \\
8-3 \text { Pond } \\
8-3 \text { Pond } \\
8-3 \text { Pond } \\
8-3 \text { Pond } \\
8-3 \text { Pond } \\
8-3 \text { Pond } \\
8-3 \text { Pond } \\
8-3 \text { Pond } \\
8-3 \text { Pond } \\
8-3 \text { Pond } \\
8-3 \text { Pond } \\
8-3 \text { Pond } \\
8-3 \text { Pand } \\
8-3 \text { Pond } \\
3-3 \text { Pond } \\
3-3 \text { Pand }\end{array}$ & $\begin{array}{l}8-114 \\
8-115 \\
8-116 \\
8-118 \\
8-119 \\
8-128 \\
8-129 \\
8-130 \\
8-139 \\
8-132 \\
8-136 \\
B-135 \\
8-136 \\
8-138 \\
8-139 \\
8-140 \\
8-143 \\
8-145 \\
8-146 \\
8-147 \\
8-148 \\
8-149 \\
8-164 \\
8-165 \\
8-166 \\
B-168\end{array}$ & $\begin{array}{r}13.1 \\
11.2 \\
13.4 \\
6.3 \\
7.9 \\
3.0 \\
11.5 \\
17.7 \\
14.1 \\
13.2 \\
8.3 \\
9.7 \\
10.4 \\
8.6 \\
6.1 \\
9.5 \\
5.4 \\
11.3 \\
11.5 \\
5.8 \\
2.9 \\
5.0 \\
8.6 \\
10.1 \\
6.6 \\
2.9\end{array}$ & $\begin{array}{r}84.5 \\
36.1 \\
66.9 \\
24.8 \\
36.3 \\
33.9 \\
34.0 \\
334.0 \\
71.8 \\
91.9 \\
35.4 \\
43.0 \\
31.7 \\
34.4 \\
55.0 \\
30.1 \\
161.0 \\
222.0 \\
208.0 \\
194.0 \\
167.0 \\
181.0 \\
270.0 \\
271.0 \\
155.0 \\
190.0\end{array}$ & $\begin{array}{l}\text { Reg } \\
\text { Reg } \\
\text { Reg } \\
\text { Reg } \\
\text { Reg } \\
\text { Fdup } \\
\text { Fdup } \\
\text { Reg } \\
\text { Reg } \\
\text { Reg } \\
\text { Fdup } \\
\text { fdup } \\
\text { Reg } \\
\text { Reg } \\
\text { Reg } \\
\text { Reg } \\
\text { Reg } \\
\text { Fdup } \\
\text { Fdup } \\
\text { Reg } \\
\text { Reg } \\
\text { Reg } \\
\text { Select-Fdup } \\
\text { Select-Fdup } \\
\text { Reg } \\
\text { Select }\end{array}$ \\
\hline $\begin{array}{l}\text { 8-3-3 Dit. } \\
8-3-3 \text { Dit. } \\
8-3-3 \text { Dit. } \\
8-3-3 \text { Dit. } \\
\text { 8-3-3 Dit. } \\
8-3-3 \text { Dit. } \\
\text { 8-3-3 Dit. } \\
\text { B-3-3 Dit. } \\
\text { B-3-3 Dit. } \\
8-3-3 \text { Dit. } \\
8-3-3 \text { Dit. } \\
\text { B-3-3 Dit. } \\
8-3-3 \text { Dit. } \\
\text { B-3-3 Dit. }\end{array}$ & 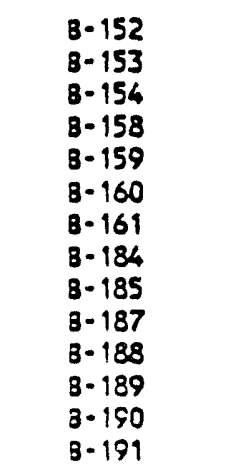 & $\begin{array}{r}2.3 \\
2.0 \\
5.8 \\
7.8 \\
8.6 \\
6.4 \\
11.8 \\
9.8 \\
8.3 \\
4.6 \\
6.2 \\
2.3 \\
7.3 \\
5.0\end{array}$ & $\begin{array}{l}29.9 \\
25.4 \\
64.4 \\
57.7 \\
58.0 \\
73.3 \\
69.3 \\
76.3 \\
80.6 \\
35.6 \\
67.6 \\
93.4 \\
77.1 \\
493.0\end{array}$ & $\begin{array}{l}\text { Foup } \\
\text { Foup } \\
\text { Reg } \\
\text { Foup } \\
\text { Foup } \\
\text { Reg } \\
\text { Select } \\
\text { Foup } \\
\text { Foup } \\
\text { Reg } \\
\text { Reg } \\
\text { Reg } \\
\text { Reg } \\
\text { Select }\end{array}$ \\
\hline
\end{tabular}


WHC-SD-EN-AP-042, REV. 0

Table C-14. Radioactivity, $\mathrm{pCi} / \mathrm{g}$. (sheet 2 of 2 )

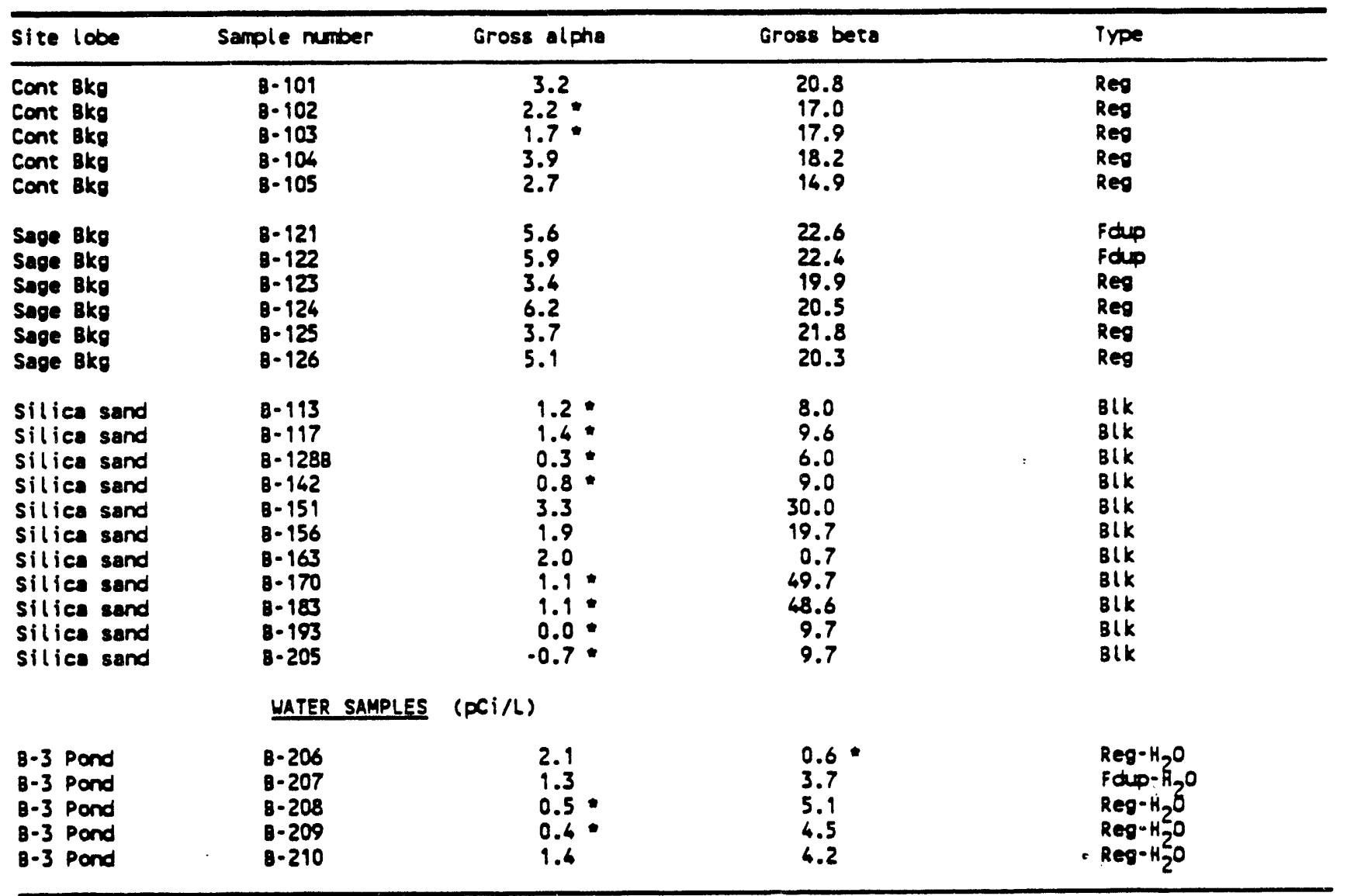

- Result less then the lab-estimated andytical error, (2 sigma). (All samples met 6 month holding time (imits.) 


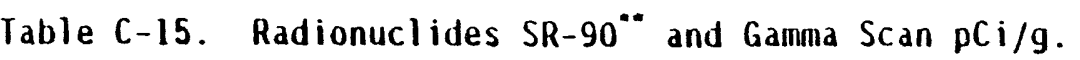

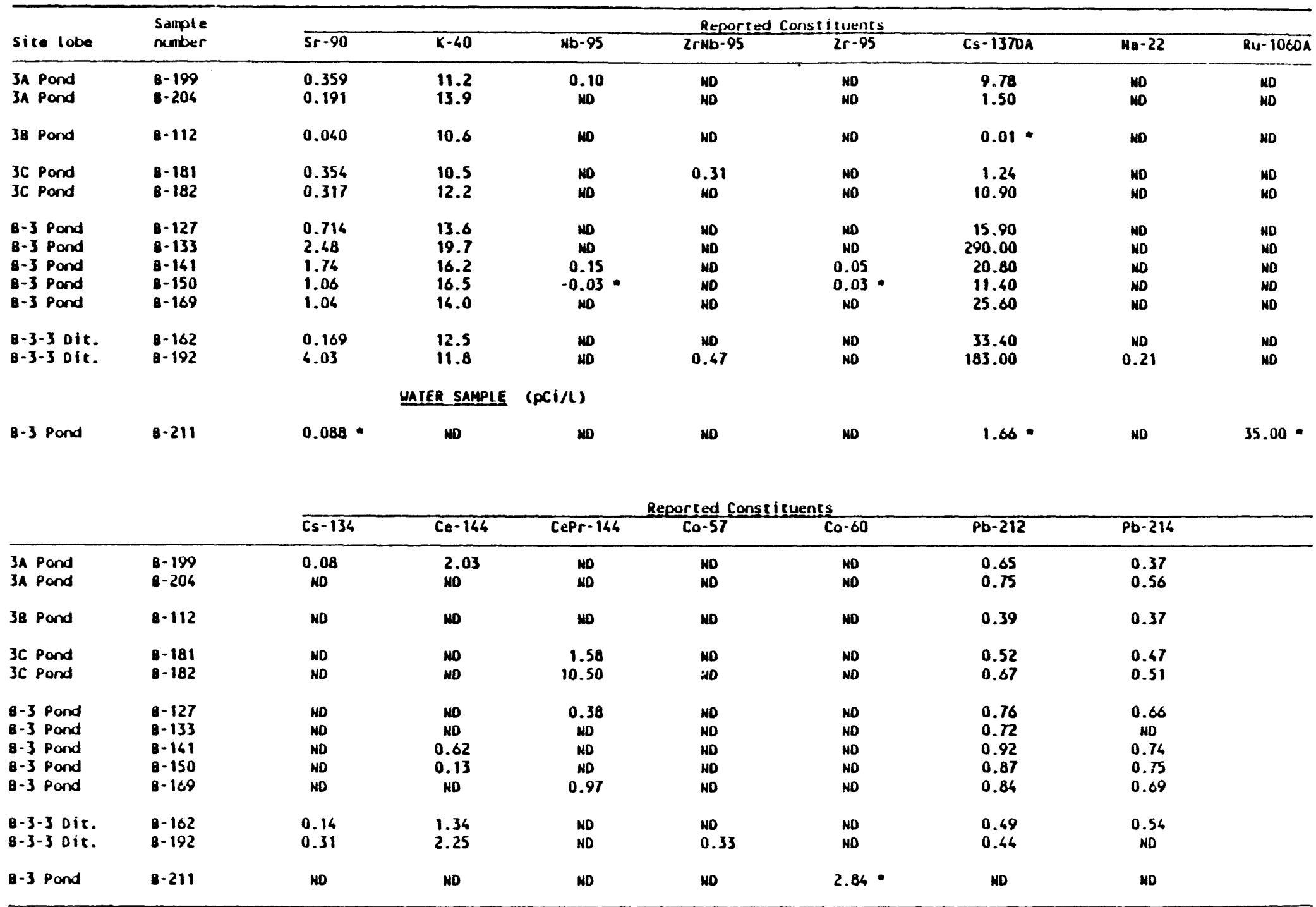

- Denotes result less than lab-estimated 2 signa.

- Strontium-90 is determined separately.

HD a Mon-detectable.

DA a May include unresolved daughters. 
WHC-SD-EN-AP-042, REV. 0

APPENDIX D

FIELD DUPLICATE GRAPHS 
WHC-SD-EN-AP-042, REV. 0

This page intentionally left blank. 
WHC-SD-EN-AP-042, REV. 0

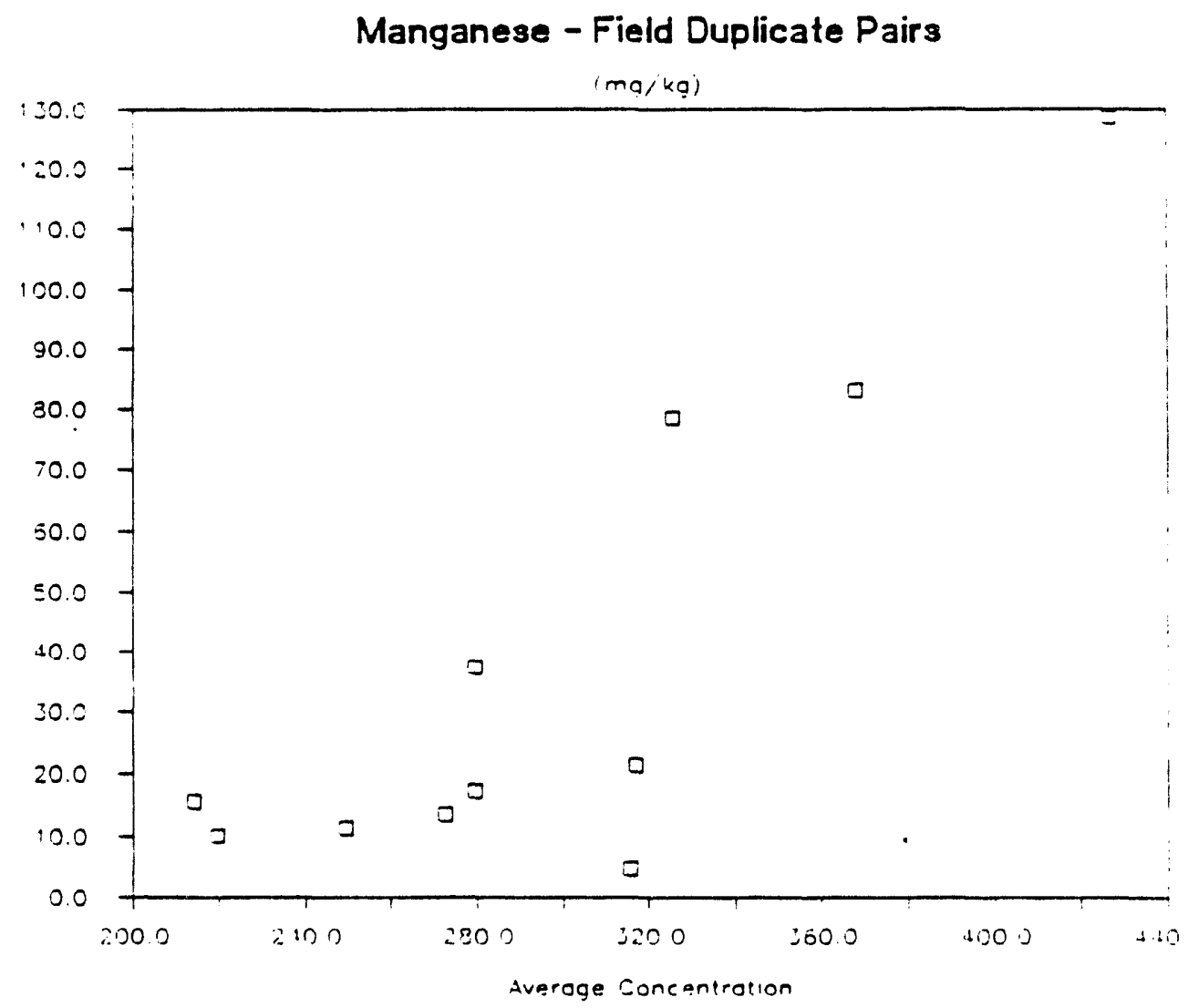

Lead - Field Duplicate Pairs

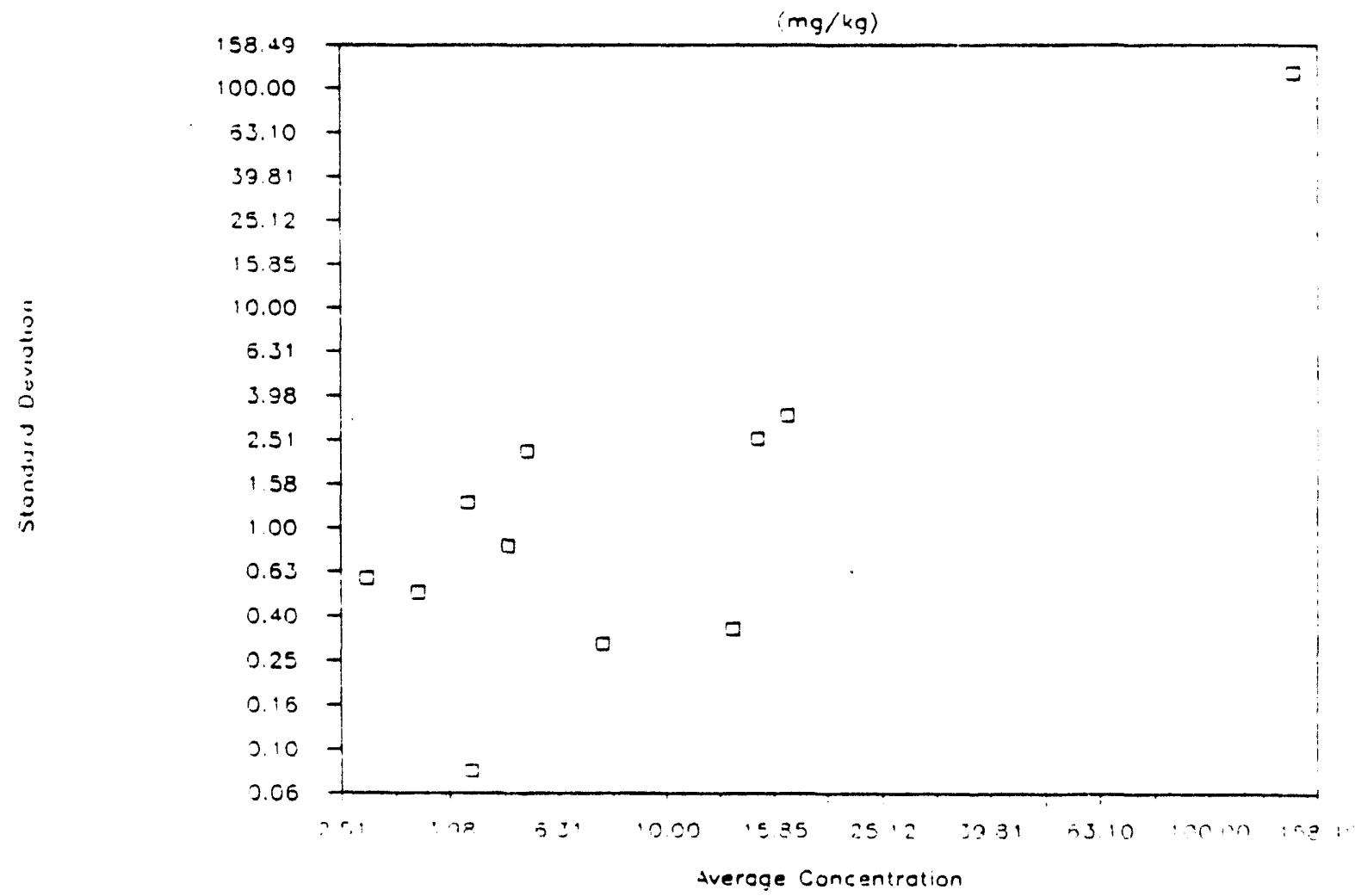

D-1 
WHC-SD-EN-AP-042, REV. 0

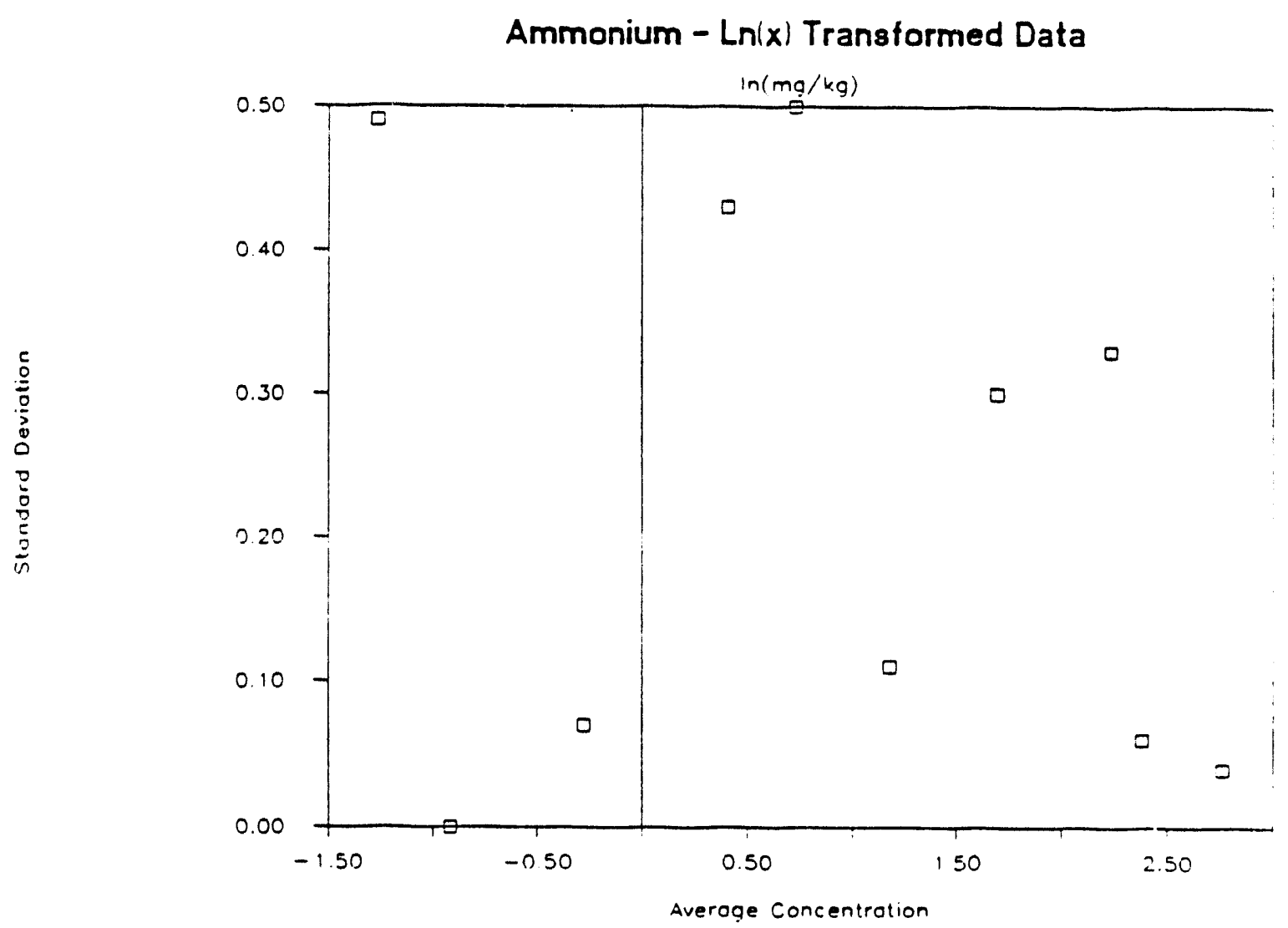

Ammonium - Untransformed Data

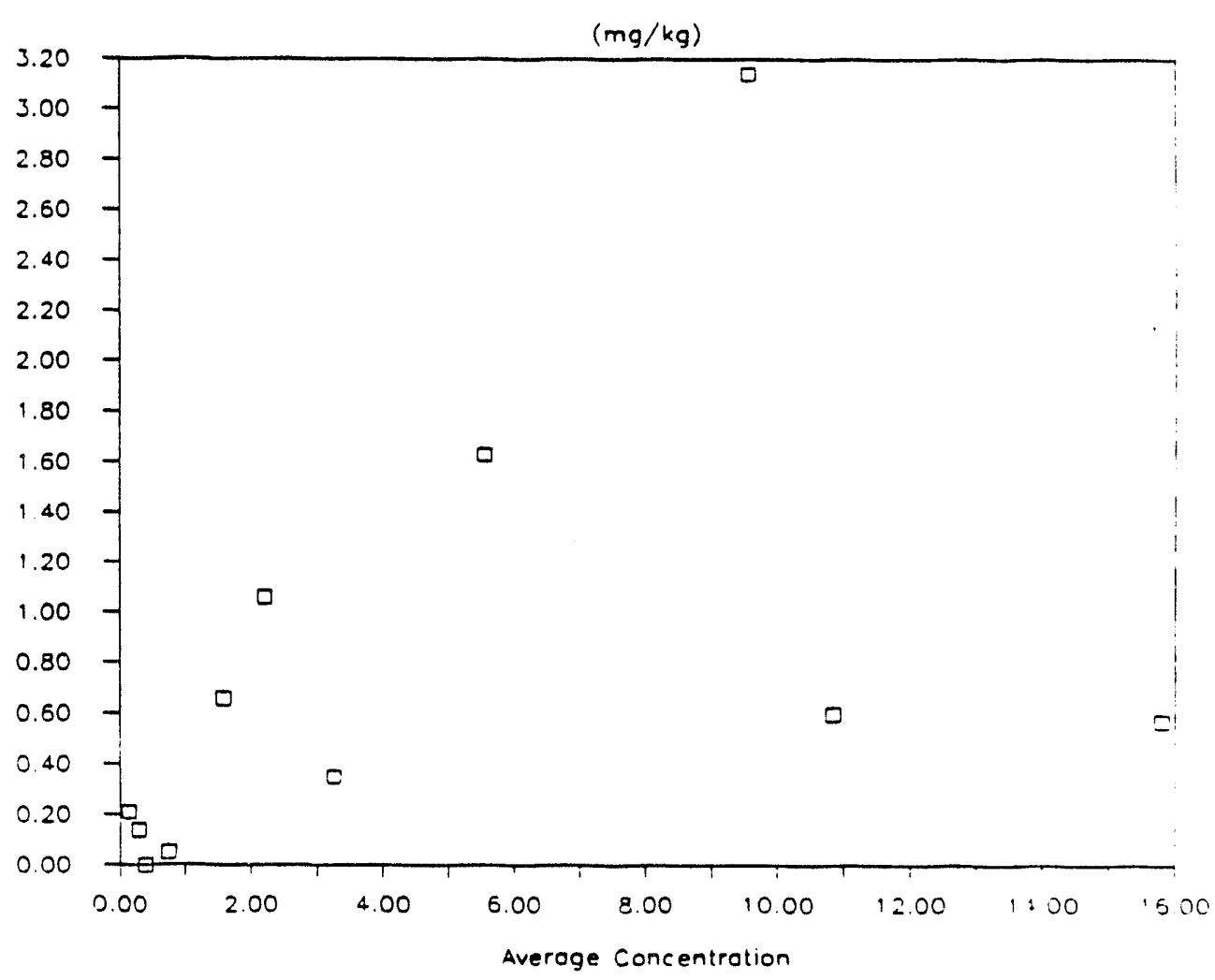

$D-2$ 
WHC-SD-EN-AP-042, REY. 0

\section{Chloride - Field Duplicate Pairs}

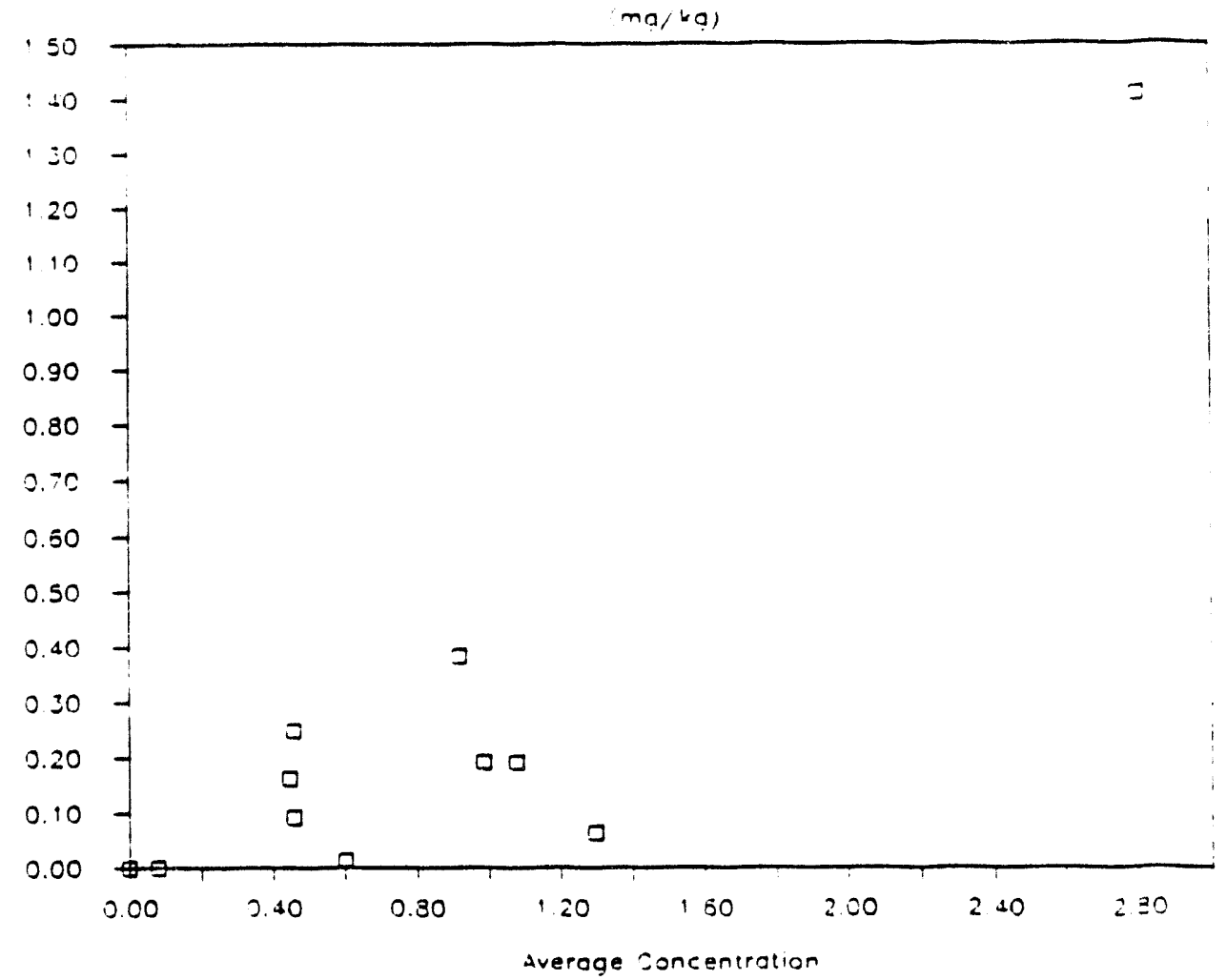

Fluoride - Fieid Duplicate Pairs

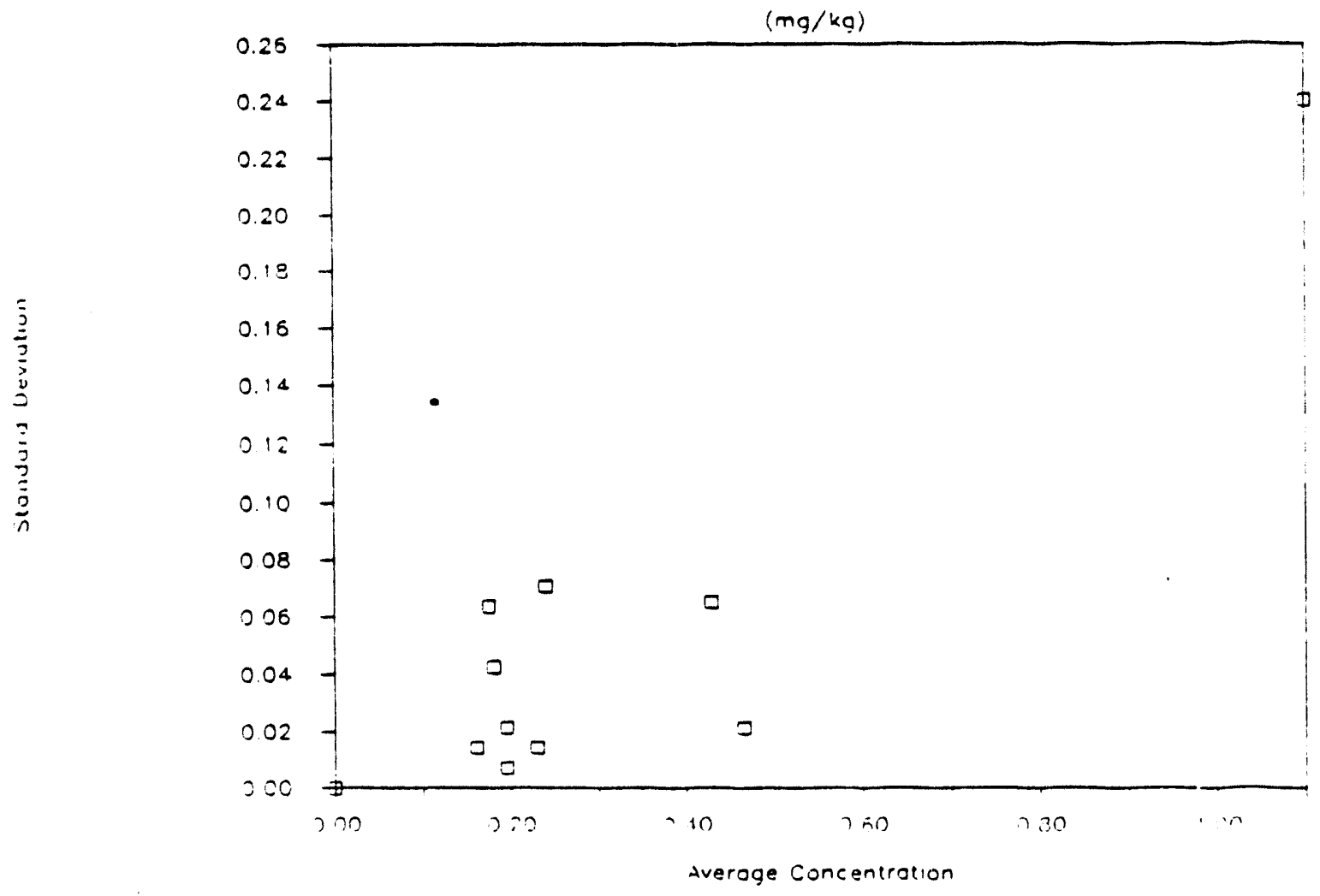




\section{Sulfate - Field Duplicate Pairs}

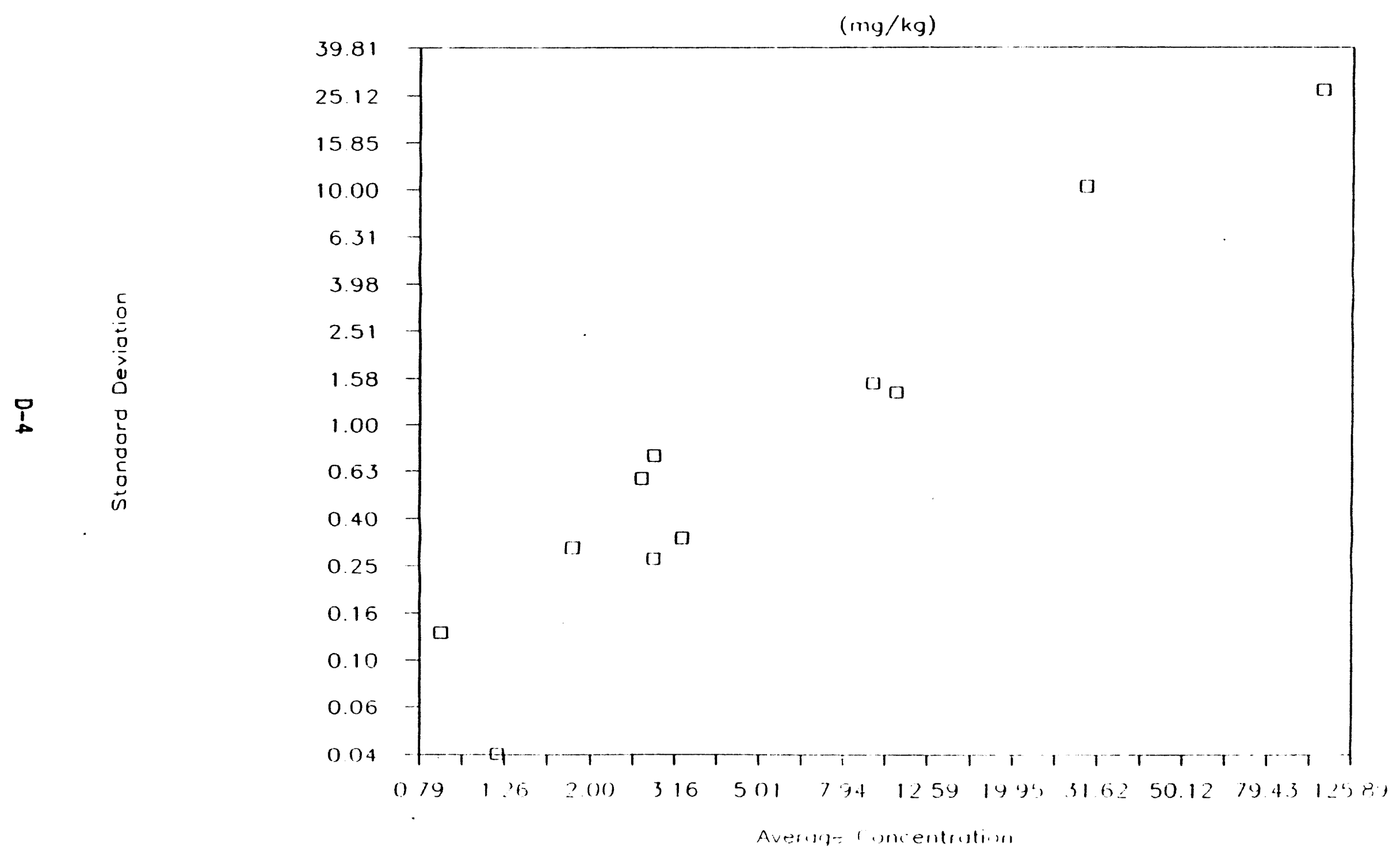


DOE/RL 89-28, Rev. 1

$12 / 15 / 93$

\section{APPENDIX D}

\section{6-B-3 POND SYSTEM PHASE 2 SOIL AND SEDIMENT SAMPLING}

OF A, B, AND C LOBES 
DOE/RL 89-28, Rev. 1

$12 / 15 / 93$

This page intentionally left blank. 
WHC-SD-EN-AP-137, Rev. 0

\section{ACRONYMS}

CERCLA

CFR

CLP

DOE

Ecology

EPA

HEIS

ICP

LOD

LOQ

MTCA

$P C B$

$Q A / Q C$

RCRA

RPD

SOW

Tri-Party

TSD

VOA

WAC

Comprehensive Environmental Response, Compensation, and Liability Act of 1980

Code of Federal Regulations

Contract Laboratory Program

U.S. Department of Energy

Washington State Department of Ecology

U.S. Environmental Protection Agency

Hanford Environmental Information System

inductively coupled plasma

Limit of Detection

Limit of Quantification

Model Toxics Control Act

polychlorinated biphenyl

Quality Assurance/Quality Control

Resource Conservation and Recovery Act of 1976

relative percent difference

statement of work

Hanford Federal Facility Agreement and Consent Order

treatment, storage, and disposal

volatile organics analysis

Washington Administrative Code 
WHC-SD-EN-AP-137, Rev. 0

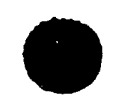


WHC-SD-EN-AP-137, Rev. 0

\section{CONTENTS}

1.0 INTRODUCTION . . . . . . . . . . . . . . . . . . . 1

1.1 REGULATORY BACKGROUND . . . . . . . . . . . . . . . . . . . . . . 1

1.2 BACKGROUND . . . . . . . . . . . . . . . . . . . . . . . 2

1.3 SETTING . . . . . . . . . . . . . . . . . . . . . . . 2

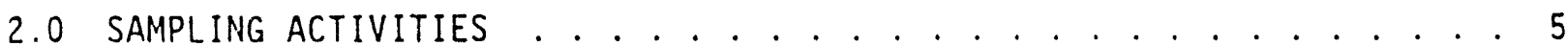

2.1 PHASE 1........................... 5

2.2 PHASE 3.......................... . . 7

2.3 PHASE 2 . . . . . . . . . . . . . . . . . . . . . . . . . . 7

2.3.1 Sample Location . . . . . . . . . . . . . . . . . . . . 7

2.3.2 Sample Collection .................. . . 10

2.3.3 Field Quality Assurance/Quality Control . . . . . . . . . 11

2.3.4 Sample Analysis . . . . . . . . . . . . . . . . . 11

3.0 DATA VALIDATION . . . . . . . . . . . . . . . . . . . . . . . 14

3. I WESTON LABORATORIES . . . . . . . . . . . . . . . . . . . . . . . 15

3.2 TMA LABURATORIES . . . . . . . . . . . . . . . . . . . . . . . . 16

4.0 ANALYTICAL RESULTS AND DATA TABULATION . . . . . . . . . . . . . . . . 18

4.1 DATA SUMMARY . . . . . . . . . . . . . . . . . . . . . . . . . . 24

4.1.1 Organic Analytes . . . . . . . . . . . . . . . . . . . . . 24

4.1.2 Metal Analytes..................... . . 24

4.1.3 Radionuclide Analyses . . . . . . . . . . . . . . . 26

5.0 CONCLUSIONS . . . . . . . . . . . . . . . . . . . . . . 27

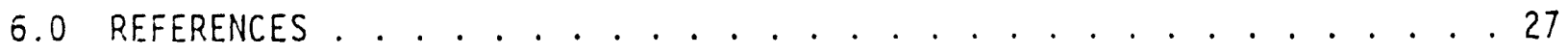

\section{APPENDIXES:}

A Method-Specific Analyte List and Associated Typical

Detection Limits . . . . . . . . . . . . . . . . . . . . . A-1

B Maxima and 95/95 Reference Threshold Values for Hanford Site Soil Background .................. B-1

C Typical Ranges for Metals in Soils . . . . . . . . . . . . . . C-1

Washington Administrative Code Model Toxics Control Act
Method B Cleanup Standards . . . . . . . . . . . . . . . . 1

\section{FIGURES:}

1. Map of the Hanford Sice . . . . . . . . . . . . . . . . . . 3

2. Aerial Photograph of the 216-B-3 Pond System
and Surrounding Areas $(1988) . . . . . . . . . . . . . .4$

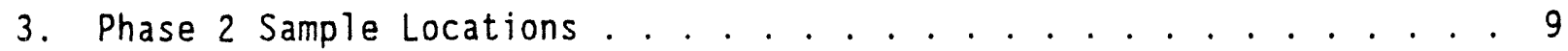




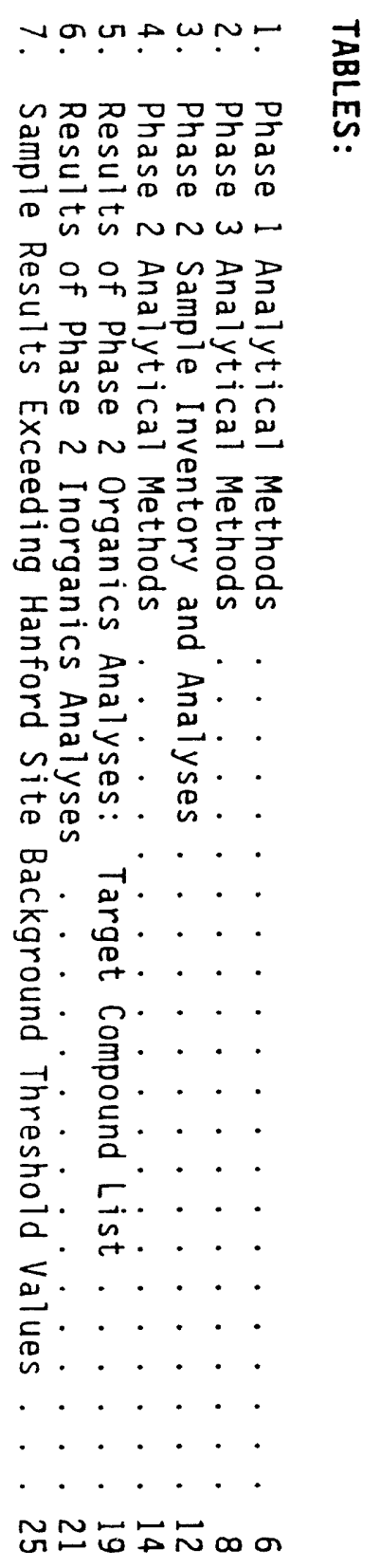


WHC-SD-EN-AP-1.37, ReV. 0

\subsection{INTRODUCTION}

This report summarizes the sampling activities undertaken and the analytical results obtained in a soil and sediment sampling study performed at the three expansion ponds in the 216-B-3 Pond ( $B$ Pond) System. This sampling effort, referred to as the Phase 2 characterization study, was performed to confirm the results of previous sampling efforts at the B Pond system.

Results were compared to Hanford Site Background thresholds for soils and the Model Toxics Control Act (MTCA) residential limits. No organic compounds or inorganic constituents were found in sufficient concentrations to cause the investigated soil and sediment to be regulated as dangerous waste. The results of the Phase 2 study are consistent with the earlier findings.

While this sampling event focused on soil and sediments at the 216-B-3 Pond System, at the request of the Washington State Department of Ecology (Ecology), i iquid samples were taken from the two expansions ponds that contained water and the results also are reported in this document.

\subsection{REGULATORY BACKGROUND}

The U.S. Environmental Protection Agency (EPA) and Ecology jointly administer the Resource Conservation and Recovery Act of 1976 (RCRA) in the State of Washington. The EPA retains oversight authority while delegating to Ecology enforcement of a state program that is consistent with or more stringent than the corresponding federal program. The implementing regulations can be found in the Washington Administrative Code (WAC) 173-303, "Dangerous Waste Regulations," and Title 40, Code of Federal Regulations (CFR), Parts 260-270. Ecology's authorization includes administering treatment, storage, and disposal (TSD) closures. However, the state currently is not authorized to enforce the federal Hazardous and Solid Waste Amendments of 1984, which includes RCRA corrective-action provisions.

The U.S. Department of Energy (DOE), EPA, and Ecology have entered into an agreement called the Hanford Federal Facility Agreement and Consent order (Ecology et al. 1989), commonly referred to as the Tri-Party Agreement. This agreement affects environmental regulation at the Hanford Site. One purpose of this agreement is to ensure environmental impacts associated with past activities are investigated and appropriate response actions taken as necessary to protect human health and the environment. The agreement seeks to promote this goal, in part, by identifying TSD units, identifying which units will undergo closure, and promoting compliance with relevant RCRA permitting requirements.

B Pond is identified as a RCRA TSD unit that will be closed in accordance with applicable laws and regulations. B Pond is considered an interim status, surface impoundment disposal unit (DOE-RL 1990). Clean closure is the planned option for the portion of $B$ Pond addressed by this report: the 216-B-3A expansion pond, the 216-B-3B expansion pond, and the 216-B-3C expansion pond (DOE-RL 1990). 


\subsection{BACKGROUND}

The $B$ Pond is undergoing evaluation to characterize the potential hazards that may be present in the soil and sediments. The potential dangerous chemical and radionuclide inventory of the soils and sediments is known only from information about past discharges to the ponds and previous sampling efforts. Information gathered wi1l assist in evaluating closure options. $B$ Pond is part of the 200-BP-11 operable unit (WHC 1989b).

A sampling plan, 216-8-3 Pond Characterization of the Hazardous Waste Inventory in the Near-Surface Soil and Sediments (Roos and Woodworth 1989), governs the characterization effort. The sampling plan sets forth a phased approach toward characterizing the soils and sediments of B Pond. Phase 1 was an initial sampling effort assessing near-surface soil contamination within the 216-B-3 Pond, the 216-B-3-3 Ditch, and the three expansion ponds $(216-B-3 A, 216-B-3 B$, and $216-B-3 C)$. This phase includes the estimation of background soil concentrations in the vicinity of the site. Phase 2 is an extension of the characterization work using data and knowledge from Phase 1. Phase 3 examined the vertical distribution of contaminants beneath the surface soit.

\subsection{SETTING}

$B$ Pond is located adjacent to the 200 East Area on the Hanford Site in southeast Washington State (Figure 1). B Pond is composed of the following units (Figure 2):

- Open section of the 216-B-3-3 Ditch, approximately 3,700 ft

- 216-B-3 Pond ( $B-3$ Pond), approximately 35 acres

- 216-B-3A Pond ( $3 A$ Pond), approximately 11 acres

- 216-B-3B Pond (3B Pond), approximately 11 acres

- $216-B-3 C$ Pond ( $3 C$ Pond), approximately 41 acres.

The B-3 Pond is the oldest pond in the system. It contains the largest volume of water. The level of the pond and the inflow have changed with time.

Originally the pond was supplied through the 216-8-3-1 Ditch. In 1964, this ditch was replaced by the 216-B-3-2 Ditch. This second ditch was replaced in 1970 by the present 216-B-3-3 Ditch. Both the 216-8-3-1 and 216-B-3-2 Ditches were removed from service due to radioactive contamination and were filled with soil to reduce contaminant mobility. The three expansion ponds, 216-B-3A $(3 A), 216-B-3 B(3 B)$, and $216-B-3 C(3 C)$, were placed in service in 1983,1984 , and 1985, respectively. The $3 B$ Pond has not been used since taken out of service in May 1985. Several feet of material were subsequently removed from the former pond bottom in an attempt to increase percolation should the pond be used again. 
WHC-SO-EN-AP-137, Rev. 0

Figure 1. Map of the Hanford Site.

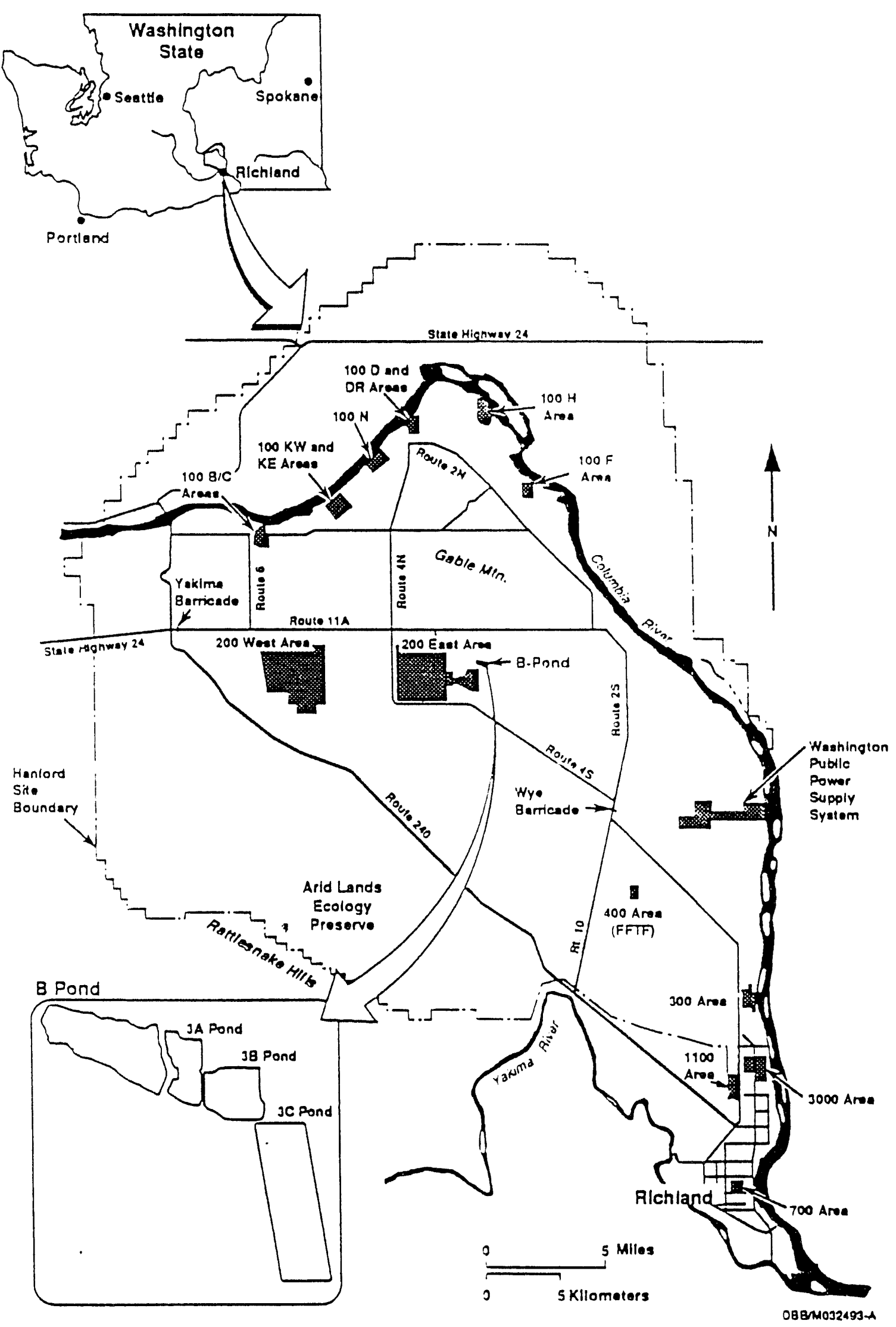


Fiqure 2. Aerial Photograph of the 215-B-3 Pond system and Surrounding Areas (1988).

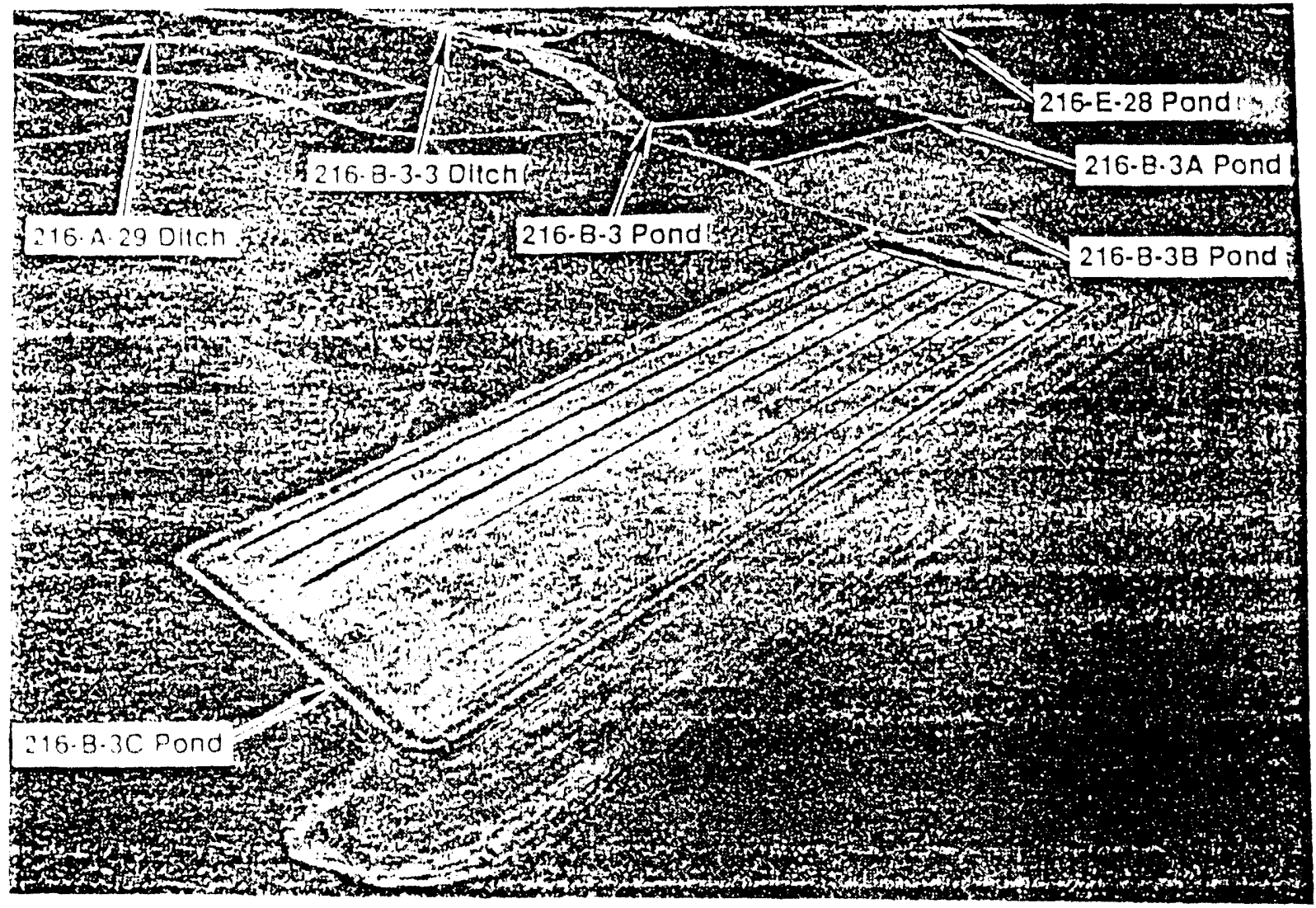

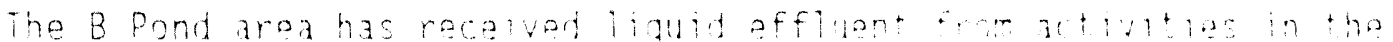
200 East. Araa since 1945. B Pond primarily has para vet stean rondonsato. cooling water. chomical sawer discharges. and procoss wastevator. sumo miod waste also has bean jlscharged to 3 Pond. Administrative and physcal controls have beon molemented to eiminate dangeras was dischargos $B$ Pond is still in use for nondangerous wastewater fisposal. With racoact to hazardous waste. it is undoraing closure in acoordanco with acan. Tho 216-B-3 Pona System Closuro Postclosure plan (COE-RL 1990) providos a bradar perspective of this closure and aciudes chaptors on arocoss information and waste characteristics (hapters $3-4, p p .3-1$ to $1-1.4$ )

Water flows into the 3 -3 Cond through the 216-8-3-3 Oitch. Flow from the B-3 Pond to the 3A Pond is controlled at the east eme of the B-3 pond. iha B-3 Pond and the $3 A$ pond normally contain water. Water from the $3 A$ Pond currently 15 dirocted to the 36 Pond. The $3 B$ Pond currantly is not in 15 ? The 36 Pond has a series of eight parallel infitration trenches into whloh water usually is channelled. The water in the 36 pond has never been above the tops of the trenches. which cover a much smallar total araa than the pond itself. The trenches usually ara not wet along thoir antire length. The wet area varies with water level 
WHC-SD-EN-AP-137, Rev. 0

The Contingency Pond, 216-E-28, was constructed in 1987 to provide emergency overflow capability for $B$ Pond. It lies north and slightly west of the B-3 Pond. The area is dry and has not been used for waste disposal. Both the unused contingency pond area and an area of native desert vegetation (sagebrush and native plants) were used in Phase 1 as sources for background soil samples. For the purposes of this study, only the $3 A, 3 B$, and $3 C$ Ponds underwent sampling during Phase 2. Although this document uses the term 'pond', the reader should keep in mind that the $3 \mathrm{~B}$ Pond and the Contingency pond are actually dry basins.

\subsection{SAMPLING ACTIVITIES}

Characterization of the $B$ Pond System was accomplished by a three-phase sampling approach. Phase 1 was conducted from August through September 1989. Phase 1 results are described in Phase 1 Characterization of the 216-8-3 Pond System (WHC 1991). Phase 3, examination of the vadose zone, was conducted from February through March 1991 . Phase 3 sample results are described in Vadose Zone Investigation of the 216-B-3A, 216-B-3B, and 216-B-3C Ponds (WHC 1992b). The following provides the reader with a brief overview of the phased sampling approach and describes the need for initiating Phase 2 for the $B$ Pond characterization effort.

\subsection{PHASE 1}

Phase 1 was an initial sampling effort assessing near-surface soil contamination within the B-3 Pond, the 216-B-3-3 Bitch, and the three expansion ponds. The objectives of Phase 1 also included estimating background values, identifying constituents of concern, and estimating contamination variability. All but four sample locations within the TSD unit were selected randomly. Randomly allocated sample locations included sites in the 216-B-3-3 Ditch, the B-3 Pond, the 3A Pond, the $3 B$ Pond, and the $3 C$ Pond. Randomly allocated sample locations included sites in the closest possible point to the head end of the 216-B-3-3 Ditch, the intersection of the 216-B-3-3 and 216-A-29 Ditches, the present inlet area of the B-3 Pond, and the deepest area of the B-3 Pond. Sample collection methods are detailed in WHC-SD-EN-AP-042, Phase 1 Characterization of the 216-B-3 Pond System (WHC 1991).

Phase 1 also included measuring constituents in two types of background areas in the vicinity of the site. This involved taking five samples from the never-used 216-E-28 Contingency Pond and five samples from the area of native desert vegetation.

Characterization of the soils during the Phase 1 study focused on inorganic analytes. Table 1 summarizes the analyses requested for soil/sediment samples. In February 1990 it was decided that comparison to background would be more appropriate if the strong acid digestion method 3050 (EPA 1986) was employed for background and onsite samples instead of the acetic acid digestion used for EP-toxicity determinations. This analysis was requested at that time on samples still held in storage by the laboratory. The method yielded higher concentrations of analytes for the comparisons. 
Table 1. Phase 1 Analytical Methods.

\begin{tabular}{|l|c|l|}
\hline \multicolumn{1}{|c|}{ Constituent } & Method $^{a}$ & \multicolumn{1}{c|}{$\begin{array}{c}\text { Method detection } \\
\text { limit }\end{array}$} \\
\hline Arsenic & 7060 & $0.5 \mu \mathrm{g} / \mathrm{g}$ \\
\hline Lead & 7421 & $0.5 \mu \mathrm{g} / \mathrm{g}$ \\
\hline Mercury & 7470 & $0.2 \mu \mathrm{g} / \mathrm{g}$ \\
\hline Selenium & 7740 & $0.5 \mu \mathrm{g} / \mathrm{g}$ \\
\hline Thallium & 7841 & $1.0 \mu \mathrm{g} / \mathrm{g}$ \\
\hline EP-Tox metals, enhanced & 1310 & $.02-1.5 \mu \mathrm{g} / \mathrm{L}$ \\
\hline Anions & 300 & $1.0 \mu \mathrm{g} / \mathrm{g}$ \\
\hline Volatile organics & 8240 & $5-500 \mathrm{ng} / \mathrm{g}$ \\
\hline Gross alpha & $\mathrm{A}-703^{c}$ & $\mathrm{~N} / \mathrm{A}$ \\
\hline Gross beta & $\mathrm{A}-703^{c}$ & $\mathrm{~N} / \mathrm{A}$ \\
\hline Sulfide & 9030 & $10.0 \mu \mathrm{g} / \mathrm{g}$ \\
\hline Cyanide & 9010 & $.5 \mu \mathrm{g} / \mathrm{g}$ \\
\hline Ammonium & $1426-\mathrm{C} / \mathrm{O}^{c}$ & $.5 \mu \mathrm{g} / \mathrm{g}$ \\
\hline Metals & $3050 / 6010$ & $.5-300 \mu \mathrm{g} / \mathrm{g}$ \\
\hline
\end{tabular}

$N / A=$ not applicable (standard reference not available).

aEPA (1986), unless noted.

Laboratory-specific method consisting of EP-Tox analysis with additional analyses.

${ }^{c}$ ASTM (1987).

Analytical results for site samples were compared to threshold values derived from the two limited background sampling efforts. Contractually defined detection limits, as set forth in the quality assurance project plan (Roos and Woodworth 1989), were used for some comparisons. In these cases, the constituents were not found in concentrations great enough to calculate threshold values. Organic constituents were not found in reliably measurable quantities. Background soil composition in the undisturbed native area surrounding the facility was different than an adjacent background area of anthropic influence. Many analytes exceed threshold values derived from the native background, but not those derived from an unused contingency pond area. Reference to typical soil concentrations suggests lead, mercury, and cadmium are the most significant exceedances. Even these are far below hazardous levels as defined by the characteristic of EP-toxicity. The data suggest that the soil or sediment at any sampled location would not be classified as dangerous waste under any of the WAC-173-303 Dangerous Waste Regulations. 
WHC-SD-EN-AP-137, Rev. 0

\subsection{PHASE 3}

The objective of Phase 3 characterization sampling was to collect data addressing the issue of potential vadose zone chemical contamination with dangerous waste and examine the vertical distribution of potential contaminants beneath the surface soil. Efforts focused on the subsurface of the three expansion ponds. The investigation was limited to the vadose zone; it did not address groundwater. The investigation involved the construction of three temporary characterization boreholes, designated as $699-43-41 \mathrm{H}$. 699-42-41B, and 699-41-41 in the 3A, 3B, and $3 C$ Ponds, respectively. Samples were collected as described in WHC-SD-EN-AP-104, Vadose Zone Investigation of the 216-B-3A, 216-B-3B, and 216-B-3C Ponds (WHC 1992b).

Table 2 summarizes the analyses requested for borehole soil/sediment samples.

The $B$ Pond Phase 3 vadose zone investigation did not indicate that hazardous levels of waste constituents exist in the vadose zone of the $216-B-3 A, 216-B-3 B$, or 216-B-3C Ponds. No organic compounds or inorganic constituents were found in sufficient representative concentrations to cause the investigated vadose soils to be regulated as a dangerous waste.

\subsection{PHASE 2}

Phase 2 soil and sediment sampling was initiated to assess the possibility of surface soil contamination in the $B$ Pond expansion ponds. In addition, Ecology expressed concern over the quality control and data validation associated with the Phase 1 soil and sediment sampling results. Documentation received from the laboratory was not sufficient to perform the level of data validation requested by Ecology. This Phase 2 sampling effort is, in part, to substantiate the conclusions that were based on the Phase 1 sampling effort.

\subsubsection{Sample Location}

Because of the different nature of the $3 A, 3 B$, and $3 C$ Ponds, each pond was sampled as a separate entity. However, the same basic sampling pattern was used for each of the three expansion ponds (WHC 1992a). All sample points are referenced in Figure 3. The sampling strategy identified the following three sample points for each pond.

- One sample was collected at the influent point of each pond. This location would be expected to be contaminated with any heavy solids, should any contamination be present.

- A second sample was collected from the deepest point in the pond. Should any contamination be present, 1 ight materials and fines would be expected to settle at this point.

- A third sample was collected at a point expected to contain high levels of the analytes of concern (relative to other locations), as determined by an evaluation of Phase 1 sample results (WHC 1991) and by field observation. 


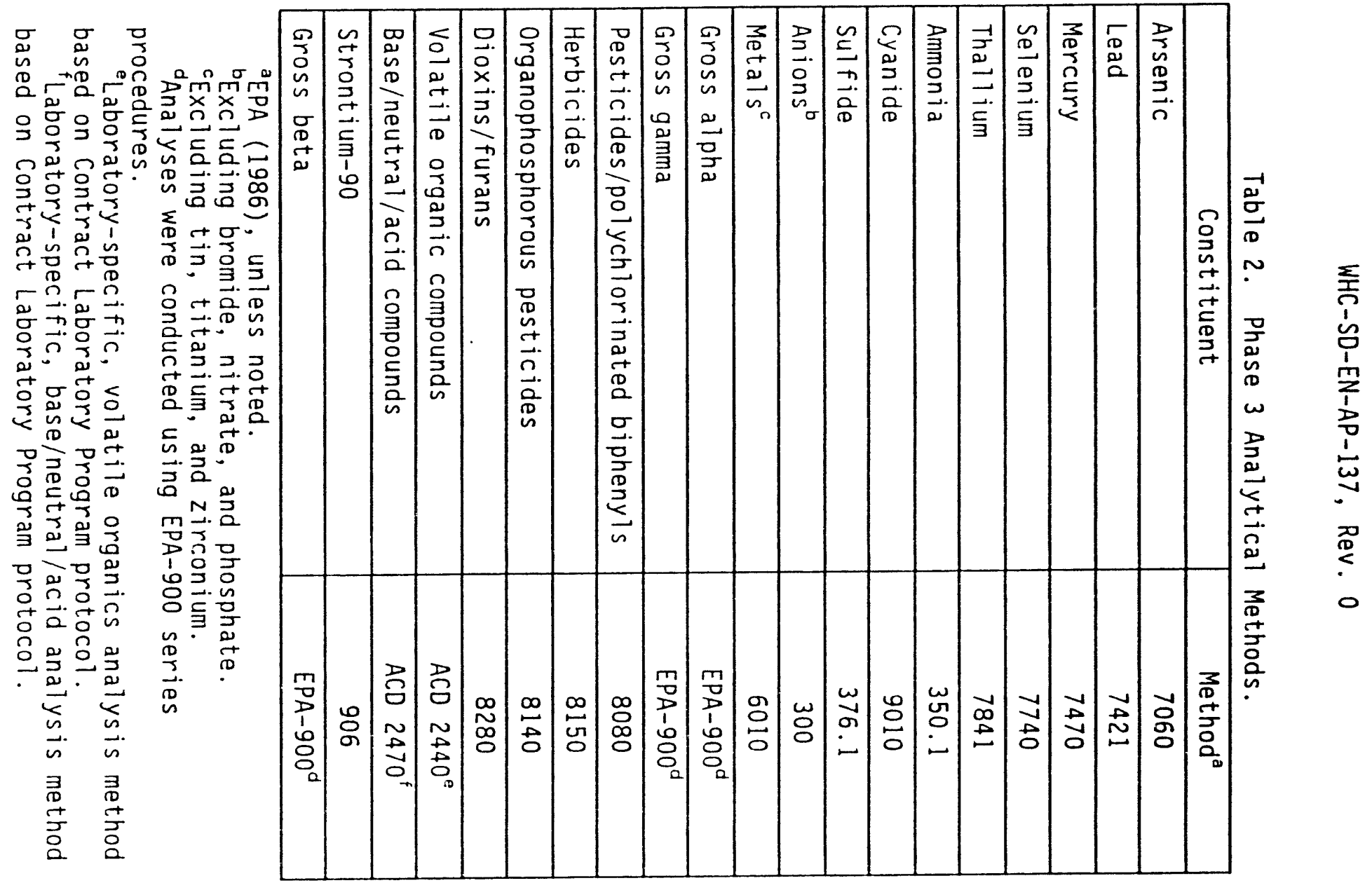


WHC-SD-EN-AP-137, Rev. 0

Figure 3. Phase 2 Sample Locations.

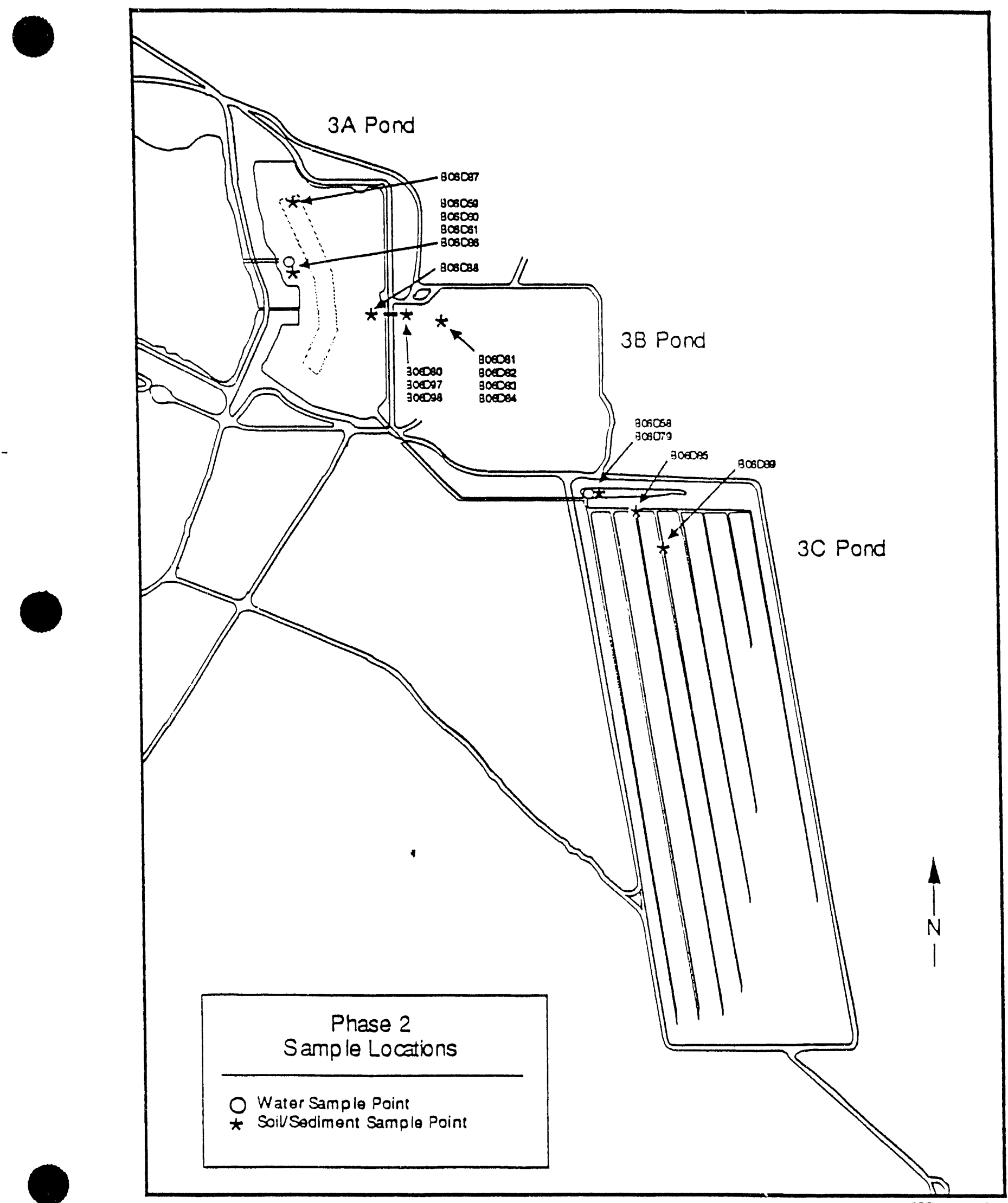


In the $3 A$ and $3 C$ Ponds, which are wet ponds, the location of the second sample point (deepest point) was determined by measuring the water depth visually and then confirming the relative depth with a probe. The probe consisted of conduit pipe with marks at $1-\mathrm{ft}$ increments.

Additionally, while this sampling event focused on soil and sediments at the 216-B-3 Pond System, at the request of Ecology water samples were taken from the two wet ponds.

In the $3 A$ Pond, the first sample point was located at the influent point at which water from the 216-3-B (main) Pond entered the $3 A$ Pond. Water samples also were taken at this point. A second soil/sediment sample was taken from the deepest portion of the pond. This point was located at the north end of the underwater trench running through the $3 \mathrm{~A}$ Pond. A water sample also was taken in this vicinity. The third soil/sediment sample point was located at the east side of the pond near the outfall to the dry 38 Pond. Sedimentation was found to be unusually heavy at this location.

The "deep point" of the $3 B$ Pond was not sampled because stabilization of the pond had made it impractical. The location of the "deep point" of the $3 B$ Pond could not be determined. A sample of soil/sediments was taken near the pond influent gates, approximately $10 \mathrm{ft}$ east of the surface contamination area. The next sample point was a location approximately $100 \mathrm{ft}$ east and $15 \mathrm{ft}$ south of the influent gates. The gradual downslope of the terrain suggested that settleable contaminants would have been likely to deposit at this point while the pond was in use. Discrete samples of surface soils and underlying soils were taken at this point.

Three sample points were identified for the $3 C$ Pond. The first point sampled was located $70 \mathrm{ft}$ downstream and $15 \mathrm{ft}$ north of the $3 \mathrm{C}$ Pond influent pipe. This area was characterized by heavy sedimentation. A water sample also was taken at this location. The high flowrate of the influent made sampling in the direct vicinity of the influent pipe impractical.

Soil/sediment samples were taken at the intersection of the third north/south trench and the main east/west feed trench. A visual inspection of the pond determined this location to be the deepest point in the pond. A final sample was taken of dry sediments located approximately $100 \mathrm{ft}$ down (south of the feed trench) the fourth trench.

\subsubsection{Sample Collection}

Samples were collected in the same manner as for the Phase 1 sampling effort. The sampling equipment used included a long pole and a 3.25-in. by 12-in. soil recovery auger. Multiple borings were necessary to obtain sufficient quantities of material for all the requested analyses. These were always commingled in a stainless steel bowl prior to allocation to the individual sample analys is containers sent to the laboratories. Stainless steel shovels were used to collect samples in the northern portion of $3 \mathrm{C}$ Pond, near the influent point. Stainless steel scoopulas, spoons, bowls, shovels, and augers were prepared for use in accordance with the laboratory decontamination of field equipment specified in Environmental Investigations Instruction 5.5, "Decontamination of Equipment for RCRA/CERCLA Sampling" (WHC 1989a). Cleaned equipment was wrapped in aluminum foil by the cleaning personnel and maintained wrapped until used. Precleaned sample containers 
WHC-SD-EN-AP-137, Rev. 0

were purchased and used for all samples. The containers come presealed from the manufacturer with tamper-indicating seals affixed to the packaging.

Personnel collecting the samples wore disposable vinyl gloves in addition to other clean protective clothing. These gloves were shed after each sample in an effort to minimize the potential for cross-contamination between samples. Only the large stainless steel shovels were decontaminated in the field and reused. Sample media were monitored for radiation. Work was performed according to the applicable description of work (WHC 1992b).

For samples collected in the $3 A$ Pond, samplers were permitted to sample from a flat-bottom aluminum boat. Health Physics coverage was supplied from a similar adjacent boat. The two boats were stabilized by securing the oar locks together with rope.

\subsubsection{Field Quality Assurance/Quality Control}

Field quality assurance/quality control (QA/QC) is used to provide the sampler with a basis by which laboratory accuracy and reproducibility can be measured. Field duplicates and equipment blanks are used to assess precision and bias of sampling. The estimated precision and bias will contain components of the laboratory's precision and bias, but alone cannot be used to assess those factors for the laboratory. Field splits are used to assess laboratory reproducibility. Additional information with regards to laboratory cleanliness and sample handling protocol can be inferred by the results to blank analysis. Trip blanks are used to provide information with regards to sample handling and shipping prior to receipt by the laboratory. Field duplicates, splits, and blanks were prepared to address issues related to laboratory $Q A / Q C$.

A water sample duplicate was taken and a split was made at the $3 A$ Pond. A soil/sediment sample duplicate was taken and a split was made at the $3 B$ Pond for chemical and radiological analyses. Two equipment blanks were prepared, one for the water matrix and one for the soil matrix. Trip blanks in the water matrix were shipped with all sample shipping containers. All shipping containers containing soil/sediment samples were shipped with trip blanks of clean silica sand. Table 3 summarizes sample identification, location, and $Q A / Q C$ designation.

\subsubsection{Sample Analys is}

Table 4 summarizes the analyses requested for water and soil/sediment samples.

For each sample, Table 3 lists the laboratory that performed the analyses and the analyses performed on each sample. Trip blanks were analyzed for volatile organics only. The majority of the samples were analyzed by Roy $F$. Weston, Inc., Lionville Analytical Laboratory (Weston) in Lionville, Pennsylvania. TMA/NORCAL (TMA) in Richmond, California, was used as a split laboratory. Appendix A lists all analytes for each specific analytical method as well as the detection limits reported for each laboratory. 


\begin{tabular}{|c|c|c|c|c|c|c|c|}
\hline $\begin{array}{l}\text { HEIS } \\
\text { Number }\end{array}$ & Location & Matrix & $\begin{array}{l}\text { Field } Q A / Q C \\
\text { designation }\end{array}$ & Laboratory & Analysis requested & & \\
\hline B06058 & Influent to $3 \mathrm{C}$ Pond & Water & Rout ine & Weston & $\begin{array}{l}\text { VOA, Semi-VOA, PCB/Pest, ICP, } \\
\text { GFAA, Hq, CN, rad }\end{array}$ & $\overrightarrow{\underline{g}}$ & \\
\hline B06059 & Influent to $3 \mathrm{~A}$ Pond & Water & Rout ine & Weston & $\begin{array}{l}\text { VOA, Semi-VOA, PCB/Pest, ICP, } \\
\text { GFAA, Hg, CN, rad }\end{array}$ & $\omega$ & \\
\hline B06060 & Influent to $3 \mathrm{~A}$ Pond & Water & Duplicate of 806059 & Westion & $\begin{array}{l}\text { VOA, Seini-VOA, PCB/Pest, ICP, } \\
\text { GFAA, } \mathrm{Hg}, \mathrm{CN}, \mathrm{rad}\end{array}$ & 菅 & \\
\hline B05061 & Influent to $3 \mathrm{~A}$ Pond & Water & Split of $B 06059$ & TMA & $\begin{array}{l}\text { VOA, Semi-VOA, PCB/Pest, ICP, } \\
\text { liFAA, Hy, CN, rad }\end{array}$ & n & \\
\hline B06062 & $N / A$ & Water & Equipment blank & Weston & $\begin{array}{l}\text { VOA, Semi-VOA, PCB/Pest, ICP, } \\
\text { liFAA, Hg, CN, rad }\end{array}$ & $\frac{\text { 岁 }}{\frac{\partial}{\mathrm{d}}}$ & $\frac{2}{2}$ \\
\hline B06063 & $N / A$ & Water & Trip blank & Weston & VOA & $\overrightarrow{3}$ & c \\
\hline B06064 & $N / A$ & Water & Trip blank & Weston & VOA & \$ & $\overbrace{1}$ \\
\hline B06076 & $N / A$ & Water & Trip blank & Weston & VOA & $\stackrel{8}{0}$ & $\frac{x}{2}$ \\
\hline B06077 & $N / A$ & Water & Trip blank & TMA & VOA & & to \\
\hline B06078 & $N / A$ & Water & Trip blank & Weston & VOA & בె & - \\
\hline B06079 & Influent to $3 \mathrm{C}$ Pond & Soil & Rout ine & Weston & $\begin{array}{l}\text { VOA, Senli-VOA, PCB/Pest, ICP, } \\
\text { GFAA, Hg, LN, rad }\end{array}$ & 㺃 & $\stackrel{\substack{\pi \\
:}}{<}$ \\
\hline B06D80 & Influent to $3 \mathrm{~B}$ Pond & Soil & Rout ine & Weston & $\begin{array}{l}\text { VOA, Selli-VOA, PCB/Pest, ICP, } \\
\text { GFAA, Ily, CN, rad }\end{array}$ & 芯 & c \\
\hline B06081 & 3B Pond, surface & Soil & Rout ine & Weston & $\begin{array}{l}\text { VOA, Seni-VOA, PCB/Pest, ICP, } \\
\text { GFAA, Hy, CN, rad }\end{array}$ & $\widehat{n}$ & \\
\hline B06082 & $3 \mathrm{~B}$ Pond & Soil & Rout ine & Weston & $\begin{array}{l}\text { VOA, Semi-YOA, PCB/Pest, ICP, } \\
\text { GFAA, } \mathrm{Hg}, \mathrm{CN}\end{array}$ & 勇 & \\
\hline B06D83 & 3B Pond & Soil & Duplicate of $B 06082$ & Weston & $\begin{array}{l}\text { VOA, Semi-VOA, PCB/Pest, ICP, } \\
\text { GFAA, } \mathrm{Hg}, C N\end{array}$ & $\stackrel{\varpi}{\rightarrow}$ & \\
\hline B06084 & $3 B$ Pond & Soil & Split of $B 06082$ & TMA & $\begin{array}{l}\text { VOA, Semi-VOA, PCB/Pest, ICP, } \\
\text { GFAA, } \mathrm{Hg}, C N\end{array}$ & $\simeq$ & \\
\hline B06085 & 3C Pond, dry sediment & Soil & Rouline & Weston & $\begin{array}{l}\text { VOA, Semi-VOA, PCB/Pest, ICP, } \\
\text { GFAA, Hg, CN }\end{array}$ & & \\
\hline
\end{tabular}




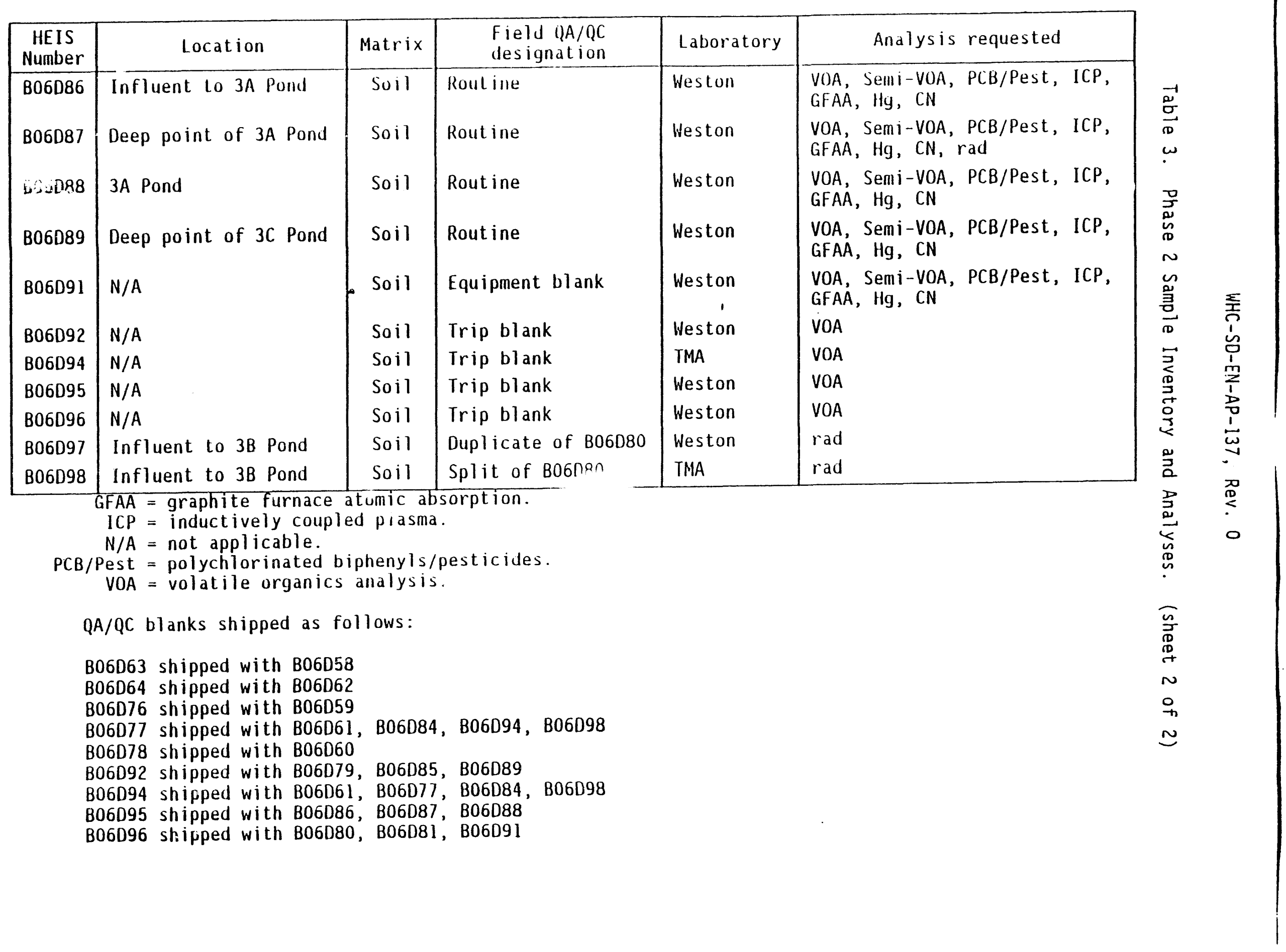


Table 4. Phase 2 Analytical Methods.

\begin{tabular}{|l|c|}
\hline \multicolumn{1}{|c|}{ Constituent } & Method $^{\text {a }}$ \\
\hline Volatile organics & 8240 \\
\hline $\begin{array}{l}\text { Pesticides/polychlorinated } \\
\text { biphenyls }\end{array}$ & 8080 \\
\hline Inductively coupled plasma metals & 6010 \\
\hline Strontium-90 & $b$ \\
\hline Gross alpha & $b$ \\
\hline Gross gamma & $b$ \\
\hline Semivolatile organics & 8270 \\
\hline $\begin{array}{l}\text { Graphite furnace atomic } \\
\text { absorption metals }\end{array}$ & $7000^{c}$ \\
\hline Mercury & 7471 \\
\hline Cyanide & 9010 \\
\hline Gross beta & $b$ \\
\hline
\end{tabular}

${ }^{a}$ EPA (1986).

baboratory-specific. (No standard methods have been established.)

${ }^{c}$ Analyses were conducted using EPA-7000 series procedures.

\subsection{DATA VALIDATION}

Analytical results underwent data validation by the Hanford Analytical Services Management organization. Data validation activities were performed in accordance with the RCRA procedure (Level B) contained within the Sample Management and Administration Manual, WHC-CM-5-3 (WHC 1990). This section summarizes procedures used for validation of data received from the laboratories. Further information on the procedures and details of how these procedures are applied are available in WHC-CM-5-3 (WHC 1990).

The data $v i$ lidation process included a review of the following QC elements performed by the laboratories and reported in the associated data deliverables:

- Holding times

- Blank analyses

- Surrogates

- Matrix spikes

- Duplicates. 
The validation procedure establishes the following qualifiers and definitions to describe the associated data:

$U$ The material was analyzed for, but was not detected. The associated value is the detection/quantitation limit.

UJ The material was analyzed for, but was not detected. The associated detection/quantitation limit is an estimated value.

$J$ The associated value is estimated.

$R$ The data are unusable.

Phase 2 sample results with appropriate data qualifiers are displayed in Chapter 3.0 .

\subsection{WESTON LABORATORIES}

After completion of the validation process, all data received from Weston were determined to be acceptable with the exception of the initial semivolatile organic analys is of sample $B 06080$. Initial results for sample $B 06080$ were qualified as unusable due to very low surrogate recoveries. Because of the problems with the initial analysis, results from a re-extraction of sample B06080 are reported in Chapter 3.0. Based on the results of B06D81 and sampling done in Phase 1 , it is unlikely that semivolatile organic compounds are present in detectable levels in the $3 \mathrm{~B}$ Pond.

All holding time criteria were met for both water and soil samples analyzed by Weston with the exception of semivolatile and pesticide/PCB extraction criteria (exceeded by 1 day) for sample B06058. No holding times were established for the semivolatile analysis of soils. This is considered to have a minimal impact on the analysis, and the results were qualified accordingly.

Weston prepared and analyzed laboratory blanks for both the soil and water sample matrices. Analyses of the blanks identified some potential laboratory contamination for the following compounds:

- Volatile organics

- Acetone (soil blanks only)

- Methylene chloride

- Semivolatile organics

- Di-n-butylphthalate

- Bis-(2-ethylhexy1)-phthalate

- Metals

- Copper, lead, and zinc.

Compounds detected in the organics blanks were below the contract-required quantitation limit and are estimated values. Analytes detected in tha metals blanks were at levels less than the contract-required detection limit. When evidence of blank contamination was present, blank validation criteria were applied to determine appropriate qualification for associated sample results. 
Weston prepared and analyzed matrix spike samples and reported the results as percent recovery as an indication of accuracy. Matrix spike recovery is used as a general correlation for all samples in the analytical batch based on the fact that the samples are related to the same site and have relatively similar analyte concentrations. Spiked sample results generally were within control limits for percent recovery. Matrix spike recovery for thallium, lead, and silver were low in one or more of the Weston delivery groups. Weston also analyzed surrogate compounds for organics analyses and reported results in terms of percent recovery as another indication of accuracy. Surrogate recoveries provide an indication of accuracy for laboratory sample preparation and determinative procedures. Reported surrogate recoveries were outside control limits for several volatile, semivolatile, and pesticide/PCB samples in one or more of the Weston delivery groups. Results that fell outside of the applicable control limits were qualified according to the validation procedure. No indication of significant matrix effects were observed in the sample results.

Duplicate samples were prepared and analyzed, and data were reported as relative percent difference (RPD) by Weston as an indication of laboratory precision. For organics analyses, RPD calculations were made between matrix spike/matrix spike duplicate samples. For inorganics analyses, RPD

calculations were made between initial and duplicate sample results. Reported RPDs for duplicate samples were high for aluminum, magnesium, and zinc in one or more of the Weston delivery groups. Results that fell outside of the applicable control limits were qualified according to the validation procedure.

Weston used Contract Laboratory Program (CLP 3/90) protocols to perform sample analyses instead of the requested SW-846 methods. The use of CLP protocols is expected to have minimal impact on the data. The detection levels achieved using CLP were adequate for making decisions regarding $B$ Pond closure. It is concluded that the data are acceptable with the qualifiers listed. These qualifiers were taken into account in further evaluations of the data set performed by project personnel.

\subsection{TMA LABORATORIES}

After completion of the validation process, all data received from TMA were determined to be acceptable with the exception of the antimony result for sample B06D84. The antimony result for tne subject sample was qualified as unusable due to a very low matrix spike recovery.

Holding time criteria were met for the analysis of soil and water samples with the following exception of cyanide for samples B06061 and B06084. Based on criteria established for water samples, the nolding times for these cyanide analyses were exceeded by 42 days. The reported results have been qualified accordingly. In addition, both cyanide samples were split samples, and cyanide data, from the samples analyzed within holding time, exist in the Weston data for both sampling locations. Therefore, any limitations on the use of the cyanide resulits for these samples are expected to have minimal impact on data interpretation. 
TMA prepared and analyzed laboratory blanks for both the soil and water sample matrices. Analyses of the blanks identified some potential laboratory contamination for the following compounds:

- Volatile organics

- Acetone

- Benzene

- Semivolatile organics

- Butylbenzylphthalate

- Metals

- Aluminum, calcium, copper, iron, magnesium, mercury, silver, sodium, vanadium, and zinc.

Target compounds and tentatively identified compounds detected in the organics blanks were below the contract-required quantitation limit and are estimated values. Analytes detected in metals blanks were at levels less than the contract-required detection limit. When evidence of blank contamination was present, blank validation criteria were applied to determine appropriate qualification for associated sample results.

TMA prepared and analyzed matrix spike samples and reported the results as percent recovery as an indication of accuracy. Spiked sample results were generally within control limits for percent recovery. Aluminum, cadmium, iron, thallium, antimony, and zinc matrix spike recoveries were outside control limits in one or more of the TMA QC samples. TMA also analyzed surrogate compounds for organics analyses and reported results in terms of percent recovery as another indication of accuracy. Results that fell outside of the applicable control limits were qual ified according to the validation procedure. No indication of significant matrix effects was observed in the sample results.

Duplicate samples were prepared and analyzed, and data were reported as RPD by TMA as an indication of Taboratory precision. For organics analyses, RPD calculations were made between matrix spike/matrix spike duplicate samples. For inorganics analyses, RPD calculations were made between initial and duplicate sample results. Reported RPDs for duplicate samples were high for aluminum, barium, iron, arsenic, lead, and sodium in one or more of the TMA QC samples. Results that fell outside of the applicable control limits were nlified according to the validation procedure.

TMA analyzed samples using SW-846 protocols. 


\subsection{ANALYTICAL RESULTS AND DATA TABULATION}

Analytical results are summarized and evaluated in this chapter. Analytical results were compared to background levels and health-based limits. For background, both the Hanford Site Background threshold values and the local background concentrations determined during the Phase 1 sampling effort were used. Hanford Site Background threshold values are from the Hanford Site Background: Part 1, Soil Background for Nonradioactive Analytes, Rev. 1 (DOE-RL 1993), and are listed in Appendix B. For health-based levels WAC-173-340, the Model Toxics Control Act (MTCA) Cleanup Regulations, was used. Calculations for these health-based levels are described in Appendix $D$.

Hanford Site Background is a Site-wide approach to determining background levels and was developed as an alternative to local unit-based background determinations at the Hanford Site. Using local backgrounds for each unit can lead to different definitions of contamination and different assessments of remediation goals and risk for different units. The Hanford Site Background approach is based on the premise that all of the waste management units are part of a common sequence of vadose zone sediments, and that the basic characteristics that control the chemical composition of these sediments are similar throughout the Hanford Site. The range of natural soil compositions is then used to establish a single set of soil background data. Use of the Hanford Site Background for environmental restoration at the Hanford Site is technically preferable to the use of the unit-based background because it more accurately represents the range of natural variability in soil composition, and also provides a more consistent, credible, and efficient basis for evaluating contamination in soil.

The Hanford Site Background threshold values are summarized in Appendix B of this report. The background threshold is the concentration level defining the upper limit of what is considered part of the background population. Background thresholds are based on a tolerance interval approach. The calculated threshold levels depend on the confidence interval and percentile used in the calculation. The WAC 173-340-708(11)(d) specifies a tolerance coefficient of $95 \%$ and a coverage of $95 \%$. The Hanford Site Background threshold values are based on a 95/95 confidence interval. Statistical calculations are described in the source document.

Tables 5 and 6 summarize results from the analyses performed on samples from Phase 2 sampling. Table 6 also provides the range of concentrations detected in soils from the Phase 1 sampling of the three expansion ponds, the contingency pond, and the local background area. Table 6 includes tre MTCA cleanup levels (Appendix D) for reference. Appendix $C$ provides a quick reference table indicating common elemental concentration ranges in soils (Dragun 1988). An examination of the results indicates that none of the analytes detected were present at levels regulated by the Washington State Administrative Code. The data suggest that the soil or sediment at any sampled location would not be classified as dangerous waste under any of the WAC-173-303 Dangerous Waste Regulations. 
WHC-SD-EN-AP-137, Rev. 0

Table 5. Results of Phase 2 Organics Analyses: Target Compound List. (sheet 1 of 2)

\begin{tabular}{|c|c|c|c|}
\hline \multirow{2}{*}{$\begin{array}{l}\text { HEIS } \\
\text { Number }\end{array}$} & \multicolumn{2}{|c|}{ Organic constituents } & \multirow{2}{*}{$\begin{array}{l}\text { Pesti- } \\
\text { cides and } \\
\text { PCBs }\end{array}$} \\
\hline & Volatile organics & Semivolatile organics & \\
\hline 806058 & ND & 5 Methoxyethoxyethanol $^{\mathrm{J}}$ & ND \\
\hline B06059 & ND & 3 Methoxyethoxyethanol $^{\mathrm{J}}$ & ND \\
\hline$B 06060$ & ND & 3 Methylcyclopentanol ${ }^{\mathrm{J}}$ & ND \\
\hline B06D61 & ND & ND & ND \\
\hline B06D62 & ND & 4 Methoxyethoxyethanol $^{\mathrm{J}}$ & ND \\
\hline 806063 & ND & NR & NR \\
\hline 806064 & ND & NR & NR \\
\hline B06076 & ND & NR & NR \\
\hline$B 06077$ & ND & NR & NR \\
\hline 0.06078 & ND & NR & NR \\
\hline 306079 & ND & ND & ND \\
\hline $\mathrm{B} 06080$ & ND & ND & ND \\
\hline B06081 & 370 Toluene & ND & ND \\
\hline B06082 & 2 Toluene & $\overline{N D}$ & ND \\
\hline B06083 & 2 Toluene & ND & ND \\
\hline B06084 & ND & ND & ND \\
\hline$B 06085^{*}$ & $\begin{array}{l}150 \text { Methylene chloride } \\
86 \text { Acetone } \\
\text { J } 120 \text { Toluene }\end{array}$ & ND & ND \\
\hline B06D85RE & $\begin{array}{l}140 \text { Methylene chloride } \\
77 \text { Acetone, } 160 \text { Toluene }\end{array}$ & -- & -- \\
\hline B06086 & 8 Toluene & ND & ND \\
\hline B06087 & ND & ND & ND \\
\hline $\mathrm{B} 06088$ & ND & ND & ND \\
\hline B06089 & ND & ND & ND \\
\hline 806091 & ND & ND & ND \\
\hline B06092 & ND & NR & NR \\
\hline B06094 & $\begin{array}{ll}1 & \text { Chloroform } \\
1 & 111-\mathrm{TCA}^{\mathrm{J}}, 5 \text { Toluene, } \\
3 & \text { Chlorobenzene } \\
2 & \text { Xylene } \\
2 & \text { Trichloroethane } \\
\end{array}$ & NR & NR \\
\hline 806095 & ND & NR & NR \\
\hline B06096 & ND & NR & NR \\
\hline
\end{tabular}


WHC-SD-EN-AP-137, Rev. 0

Table 5. Results of Phase 2 Organics Analyses: Target Compound List. (sheet 2 of 2)

\begin{tabular}{|c|l|l|c|}
\hline \multirow{2}{*}{$\begin{array}{c}\text { HEIS } \\
\text { Number }\end{array}$} & \multicolumn{2}{|c|}{ Organic constituents } & $\begin{array}{c}\text { Pesti- } \\
\text { cides and } \\
\text { PCBs }\end{array}$ \\
\hline B06097 & NR & Semivolatile organics & NR \\
\hline B06098 & NR & NR & NR \\
\hline
\end{tabular}

NOTE: Concentrations in $\mu \mathrm{g} / \mathrm{L}$ (water matrix) and $\mu \mathrm{g} / \mathrm{kg}$ (soil matrix); TICs (Tentatively Identified Compounds) are not 1 isted.

For VOA analysis: sample B06D85 internal standards were outside of limits. Sample was reanalyzed. Results from the reanalysis, B06085RE, were qualified as estimated due to poor surrogate recoveries.

$N D=$ non-detect.

$N R=$ not requested .

${ }^{J}$ Estimated concentration.

${ }^{D}$ Sample dilution was required, surrogate recoveries unavailable. 
WHC-SD-EN-AP-137, Rev. 0

Table 6. Results of Phase 2 Inorganics Analyses. (sheet 1 of 3 )

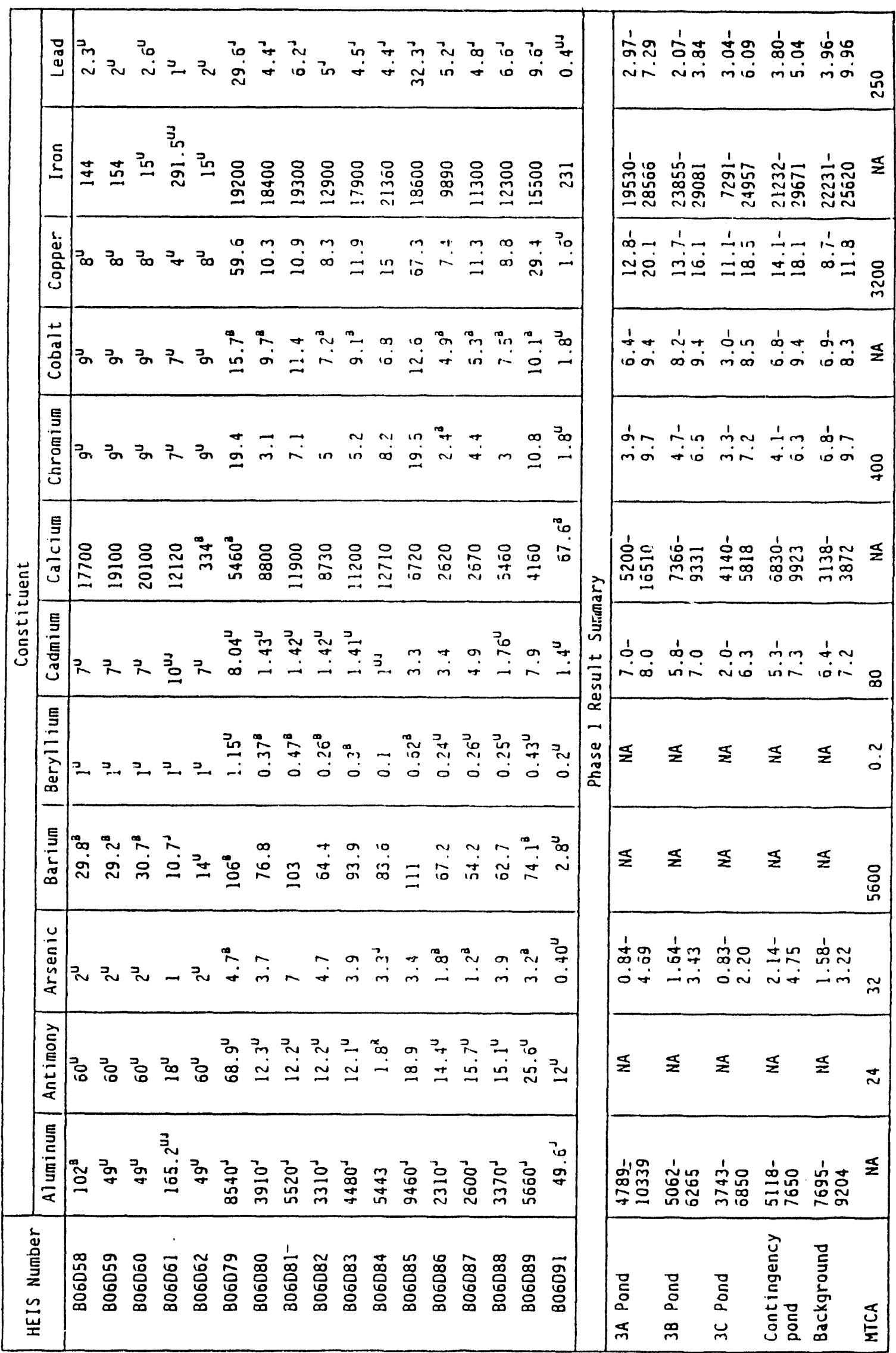




\begin{tabular}{|c|c|c|}
\hline 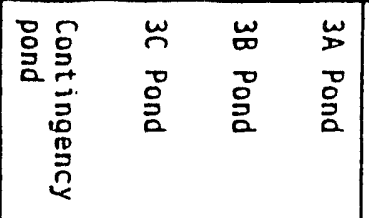 & 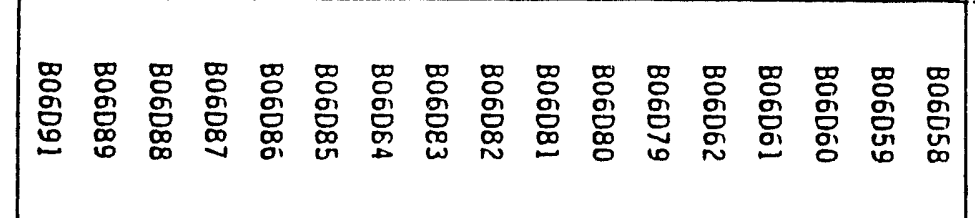 & 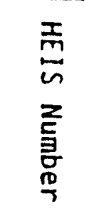 \\
\hline 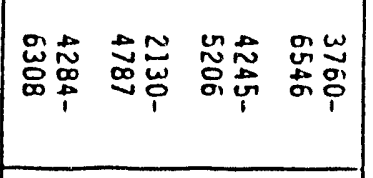 & 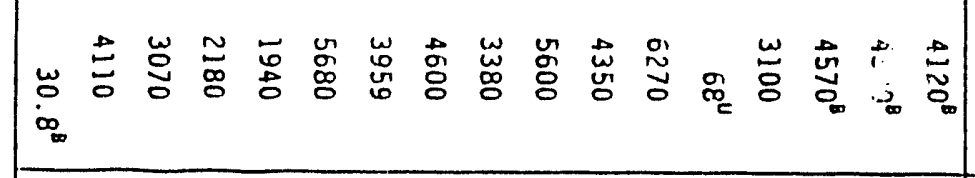 & 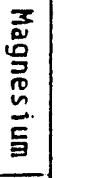 \\
\hline 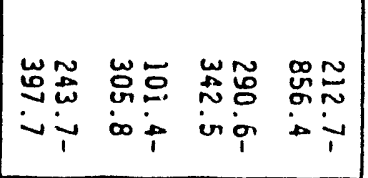 & 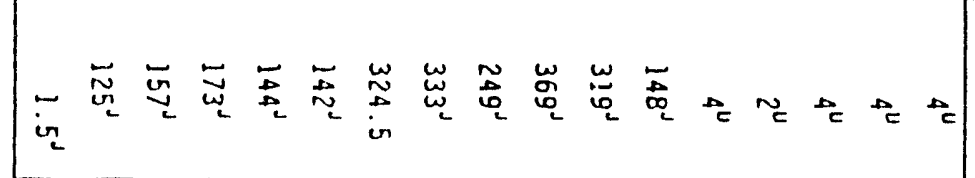 & 蕞 \\
\hline$z z z \quad \begin{array}{ll}0 \\
i \\
c\end{array}$ & 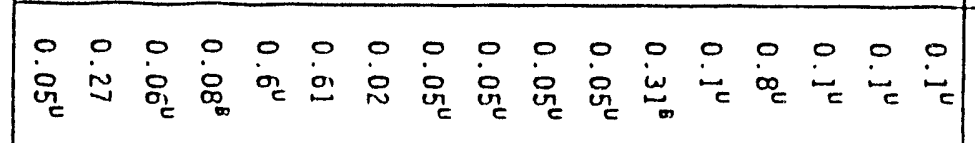 & 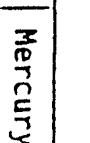 \\
\hline 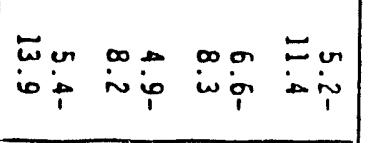 & 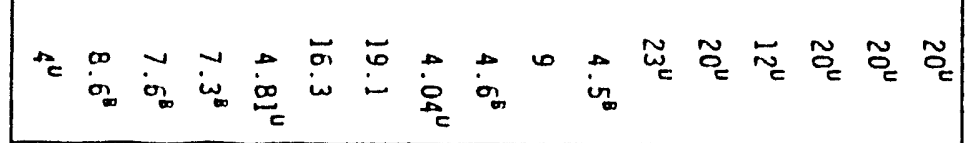 & 吕. \\
\hline 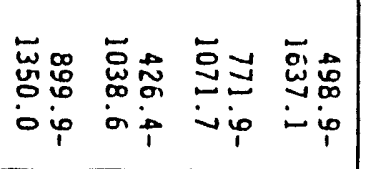 & 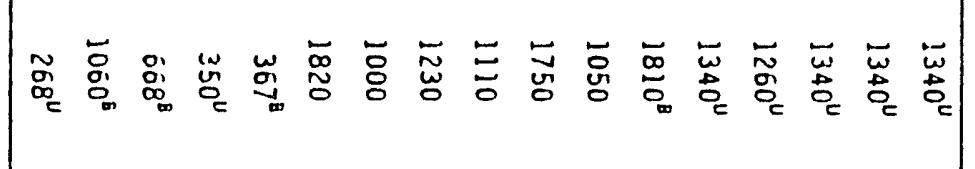 & 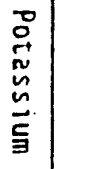 \\
\hline$z z z z$ & 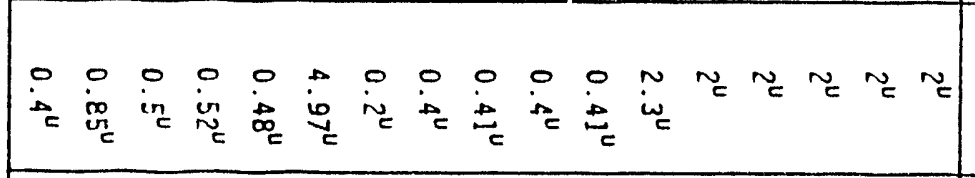 & 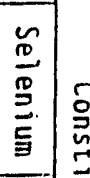 \\
\hline$z z z z$ & 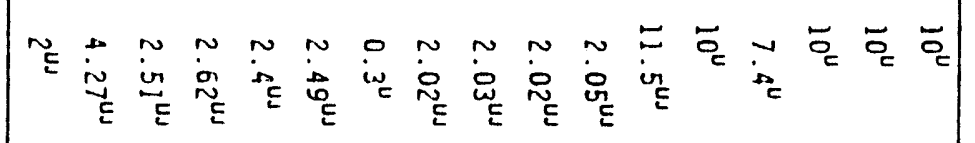 & 竞 \\
\hline 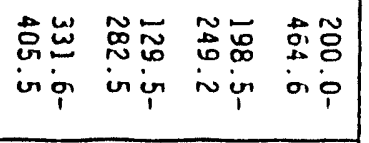 & 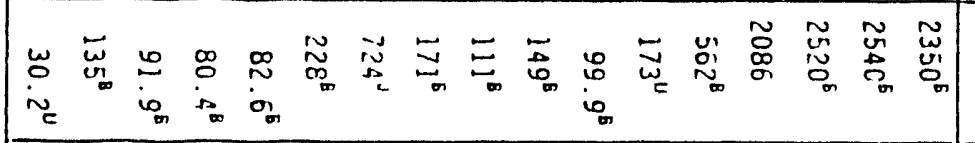 & 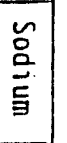 \\
\hline$z z$ & 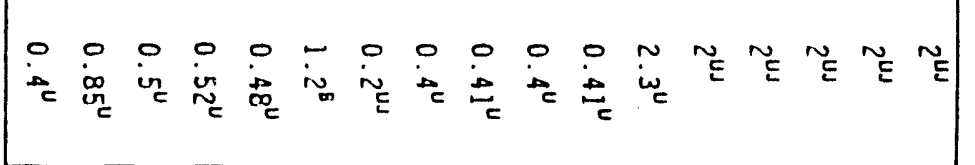 & | \\
\hline 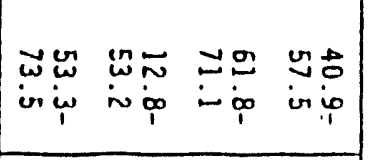 & 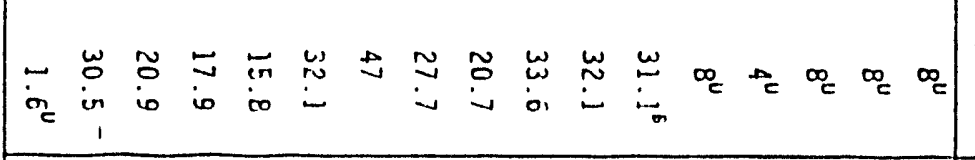 & 誉 \\
\hline 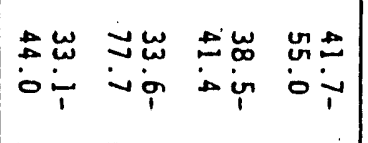 & 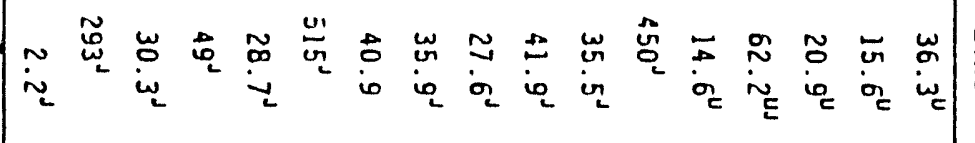 & 岂 \\
\hline$z$ & 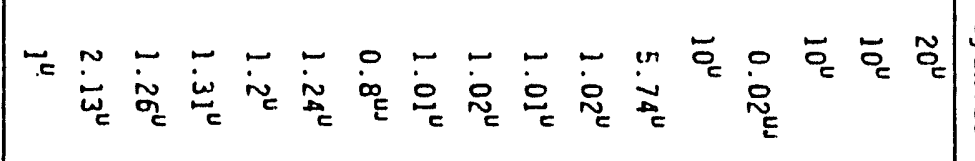 & 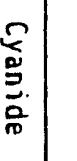 \\
\hline
\end{tabular}

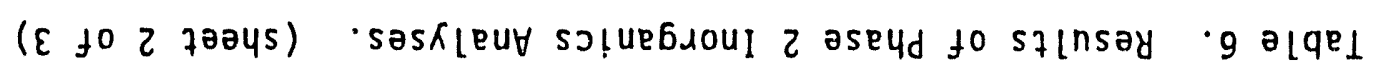




\begin{tabular}{|c|c|c|c|c|c|c|c|c|c|c|c|c|}
\hline \multirow{2}{*}{$\begin{array}{c}\text { HEIS } \\
\text { Number }\end{array}$} & \multicolumn{12}{|c|}{ Ezristituent } \\
\hline & Magnesium & Manganese & Mercury & $N)=K \equiv i$ & 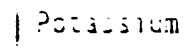 & $\sum=\vdots=n i$ um & Silizer & | EuJ1:in & Tr.si::Un & Varisulum & Zinc & Cyanide \\
\hline \multicolumn{13}{|c|}{ Praje ! kesuli juñáary (cont.) } \\
\hline Background & $\begin{array}{l}4142- \\
5193\end{array}$ & $\begin{array}{l}306.7- \\
345.8\end{array}$ & NO & $\begin{array}{l}7.3- \\
10.1\end{array}$ & $\begin{array}{l}\text { ito4- } \\
\text { i5ol }\end{array}$ & NA & ili & $\mid \begin{array}{l}: 85.2 \\
\vdots 25.2\end{array}$ & HA & $\begin{array}{l}+3.5- \\
50.3\end{array}$ & $\begin{array}{l}37.5- \\
41.3\end{array}$ & NA \\
\hline MTCA & MA & 11200 & 1.0 & 1600 & 4000 & 400 & 400 & NA & 72 & 500 & 16000 & $1 \overline{000}$ \\
\hline
\end{tabular}

NOTES:

1. Phase 1 results added for comparison.

2. Concentrations in $\mathrm{mg} / \mathrm{L}$ (water matrix) and $\mathrm{mg} / \mathrm{kg}$ (soil matrix).

3. B qualifiers for inorganic analyses indicate the relation of the reported values to the Contract Requirea Detaction Limit (CROL); values noted with a 8 qualifier are less than the CROL. A B qualirier does not represent a ilmitation on the use of the data.

Material was analyzed for but not detected. Associated value is the detection/quancitition limit.

${ }^{u s}$ Material was analyzed for but not detected. Associated detection/quantitation limit is an estimated vaiue.

Associated value is estimated.

Data are not useable.

$N A=$ not available. 
WHC-SD-EN-AP-137, Rev. 0

\subsection{DATA SUMMARY}

Detectable analyte concentrations were not observed for most samples. The organic analytes detected were dismissed due to their low concentrations and status as common laboratory contaminants. Metal analytes found in levels detectable by the laboratory instrumentation were compared to the Hanford Site Background (DOE-RL 1993), to previously determined local background levels (from Phase 1 sampling), and to health-based standards. Of the analyses that showed levels above detection limits, none are considered to indicate contamination. Appendix 0 provides the MTCA cleanup levels for reference.

\subsubsection{Organic Analytes}

No volatile organic compounds ivere detected in any of the water samples. of the compounds found in the soil samples, all the compounds found only in the trip blank were disregarded ivith respect to determining contamination. The remaining analytes detected. toluene, methylene chloride, and acetone. ar: considered to be common laboratory contaminants and, with the exception of two toluene hits, were found only in very low concentrations. The two toluene vaiuez of possible concern. greater than $100 \mu \mathrm{k} / \mathrm{kg}$, were found in very dry suriace soils samples of the $3 B$ Pond. These values can be compared to the MTCA cleanup levels, WAC-173-340-740 (3) (Appendix D; all reported values are significantly below the cleanup levels.

No semivolatile organic compounds were detected in any of the soil samples. All semivolatile organic compounds found in the water samples were at very low levels. The methoxyethoxyethanol was found in two routine samples at concentrations less than or equal to that found in the trip blanks. Therefore, this compound was attributed to contamination after sampling. Thu: methylcyclopentanol was found in a duplicate sample but was not reported in the original analyses.

No pesticides or polychlorinated biphenyls (PCBs) were detected in any samples.

Volatile and semivolatile organic compounds as well as PCBs and pesticides typically were not detected in the Hanford Site Background samples; therefore, sample result comparison to Hanford Site Background values is not possibie.

\subsubsection{Metal Analytes}

Metal analyses reported above-laboratory instrument detection limits were first compared to Hanford Site Background values [(DOE-RL 1993) (Appendix B)]. In the calculation of threshold values, certain soil classes such as topsoil and volcanic ash were excluded. Results exceeding Hanford Site Background threshold values are summarized in Table 7. Only copper, lead, zinc, antimony, and cadmium were found in concentrations exceeding the Hanford site Background threshold. These analytes then were compared to the local area background determined during the Phase 1 study, to common concentrations found in soils, and to MTCA Method B cleanup levels, except for lead, which was compared to the more stringent Method A cleanup level. MTCA Method A levels 
WHC-SD-EN-AP-137, Rev. 0

Table 7. Sample Results Exceeding Hanford Site Background Threshold Values.

\begin{tabular}{|c|c|c|c|}
\hline $\begin{array}{l}\text { HEIS } \\
\text { Number }\end{array}$ & $\begin{array}{l}\text { Analyte } \\
\text { of } \\
\text { concern }\end{array}$ & $\begin{array}{c}\text { Concentration } \\
(\mathrm{mg} / \mathrm{kg})\end{array}$ & $\begin{array}{c}\text { Background } \\
\text { threshold } \\
\text { value } \\
\text { (mg/kg) }\end{array}$ \\
\hline B06079 & $\begin{array}{l}\text { Copper } \\
\text { Lead } \\
\text { Zinc }\end{array}$ & $\begin{array}{r}59.6 \\
29.6 \\
450\end{array}$ & $\begin{array}{l}30 \\
14.9 \\
79\end{array}$ \\
\hline 806085 & $\begin{array}{l}\text { Antimony } \\
\text { radmilim } \\
\text { Copper } \\
\text { l.ead } \\
\text { 7.inc }\end{array}$ & $\begin{array}{r}18.9 \\
3.3 \\
67.3 \\
32.3 \\
515\end{array}$ & $\begin{array}{c}15.7 / 52.2^{0} \\
0.24 / 0.79^{\circ} \\
30 \\
14.9 \\
79\end{array}$ \\
\hline $806080^{\circ}$ & Cadmium & 3.4 & $0.24 / 0.79^{\circ}$ \\
\hline 806037 & Cadmium & 4.9 & $0.24,0.79^{\circ}$ \\
\hline BODOSO3 & Cadmium & 1.75 & $0.24,0.73^{\circ}$ \\
\hline 806089 & $\operatorname{linc}$ & 293 & 79 \\
\hline
\end{tabular}

Data qualifiers listed in Table 6.

"Threchold values not calculated; numbers represent statistically calculated "Limit of Detection" /"Limit of Quantification."

were used for comnorison to lead concentrations because data for the Method $B$ cleanup level calculation were not available. It is concluded that none of these analytes arn prosent in concentrations of concern. In addition, copper, lead, and zinc in not. ineet the designation criteria for dangernus waste according to $\mathrm{HAC}$ 1/3-303-9904.

4.1.2.1 Copper. Tivl analytical results for copper, $59.6 \mathrm{mg} / \mathrm{kg}$ and $67.3 \mathrm{mg} / \mathrm{kg}$ (Table 7), are above the Hanford Site Background threshold. Both of these values were found in the $3 C$ Pond. The highest value found in topsoil during the Hanford Site Background study was $40.3 \mathrm{mg} / \mathrm{kg}$. The highest value found in all types of soil analyzed during the Hanford Site Background study was $61 \mathrm{mg} / \mathrm{kg}$. The highest value reported during the Phase 1 study for the $3 \mathrm{C}$ Pondwas $18.5 \mathrm{mg} / \mathrm{kg}$. The threshold value calculated in Phase 1 was $15.96 \mathrm{mg} / \mathrm{kg}$ (WHC 1991). The common range for copper for soils throughout the world is 2 to $100 \mathrm{mg} / \mathrm{kg}$ (Dragun 1988). In addition, the MTCA Method B cleanup level is $3,200 \mathrm{mg} / \mathrm{kg}$, which is far greater than the highest reported value in this study, $67.3 \mathrm{mg} / \mathrm{kg}$.

4.1.2.2 Lead. Two analytical result.s for 1 ead, $29.6 \mathrm{mg} / \mathrm{kg}$ and $32.3 \mathrm{mg} / \mathrm{kg}$ (Table 7), are above the Hanford Site Background threshold. Both values were derived for $3 C$ Pond samples, which also contained elevated concentrations of copper. The highest reported value for lead during the Hanford Site Background study was $74.1 \mathrm{mg} / \mathrm{kg}$, found in topsoil. Other exceedances of the Hanford Site Background threshold limit for lead in topsoil reported in the Hanford Site Background document ranged from $19.9 \mathrm{mg} / \mathrm{kg}$ to $74.1 \mathrm{mg} / \mathrm{kg}$, with the majority being greater than $35 \mathrm{mg} / \mathrm{kg}$. The threshold value calculated in 
Phase 1 was $15.16 \mathrm{mg} / \mathrm{kg}$ (WHC 1991). The common range for lead for soils throughout the world is 2 to $200 \mathrm{mg} / \mathrm{kg}$ (Dragun 1988). In addition, the MTCA Method A cleanup level for lead is $250 \mathrm{mg} / \mathrm{kg}$, which is far greater than the highest reported value in this study, $32.3 \mathrm{mg} / \mathrm{kg}$. Because they are well below commonly found concentrations of lead or levels of concern, the reported values should not be considered an indication of contamination.

4.1.2.3 Zinc. Three values for zinc concentration, $450 \mathrm{mg} / \mathrm{kg}, 515 \mathrm{mg} / \mathrm{kg}$, and $293 \mathrm{mg} / \mathrm{kg}$ (Table 7). are above the Hanford Site Background threshold. All of these samples were collected from the $3 C$ Pond. The highest value reported for zinc in topsoil in the Hanford Site Background study was $366 \mathrm{mg} / \mathrm{kg}$. The highest value reported during the Phase 1 study for the $3 C$ Pond was $77.7 \mathrm{mg} / \mathrm{kg}$. The thrashold value calculated in Phase 1 was $41.3 \mathrm{mg} / \mathrm{kg}$ (,NHC 1991). The ca-man range for zinc for soils throughout the worldi is io :us $300 \mathrm{mg} / \mathrm{kg}$ (Dragun : $\Xi \Xi \Xi$. The ilTCA Method B cleanup level for zinc is $15,000 \mathrm{mg} / \mathrm{kg}$, which is nuch higher than the highest concentration reported for the $3 \mathrm{C}$ Pond. $515 \mathrm{~kg} \mathrm{~kg}$

4.1.2.4 Antimony. The concentrition of antimony is $18.9 \mathrm{mg} / \mathrm{kg}$, which is chly slightly above the Hanford Site Background Limit of Detection (LOD) at. $: \Xi .7 \mathrm{mg} / \mathrm{kg}$. The associated Limit of iuantitation (LOQ) is $52.2 \mathrm{mg} / \mathrm{kg}$. For inalytical results reported betiven the LOD and LOQ, detection is considerand reliable; however, the concentration value is in question. The maximum reported value for antimony collected from towsoil during the Hanford Site Background study was $29.1 \mathrm{mg} / \mathrm{kg}$. The MTCA Method B cleanup level for antimony is $32 \mathrm{mg} / \mathrm{kg}$, which is higher than the $18.9 \mathrm{mg} / \mathrm{kg}$ value found in this study. Because there is only one detected concentration reported for antimony and this value is only slightly above the LOD, it should not be considered an indication of contamination.

4.1.2.5 Cadmium. Values found for cadmium is this study ranged from $3.3 \mathrm{mg} / \mathrm{kg}$ to $7.9 \mathrm{mg} / \mathrm{kg}$. The Hinford Site Background LOD value for cadmiun i:s $0.24 \mathrm{mg} / \mathrm{kg}$ ard the LOQ value $1 ; 0.7 \mathrm{ng} / \mathrm{kg}$. The highest cadmium value reported for :zosoil during the Hanjurd Site Background study was $3.1 \mathrm{mg} / \mathrm{kg}$. The local backgrounds reported in the B Pond Phase 1 study were $8.23 \mathrm{mg} / \mathrm{kg}$ for the sagebrush site and $9.58 \mathrm{mg} / \mathrm{kg}$ for the contingency pond. The threshold value calculated in Phase 1 was $8.23 \mathrm{mg} / \mathrm{kg}$ (WHC 1991). Several local backgrounds described in the Hanford Site Background document showed values of Cadmium above the values reported here. The 1324-N local background ranged from 6.1 to $7.9 \mathrm{mg} / \mathrm{kg}$. The $183-\mathrm{H}$ local background ranged from 4.7 to $3.9 \mathrm{mg} / \mathrm{kg}$. The common range for cadmium for soils throughout the world is 0.01 to $7 \mathrm{mg} / \mathrm{kg}$ (Dragun 1988). The MTCA Method B cleanup level For cadmium is $80 \mathrm{mg} / \mathrm{kg}$, which is again much higher than the concentrations found in this study.

\subsubsection{Radionuclide Analyses}

Radionuclide analyses were performed on several samples. A report describing the results of the radionuclide analysis will be prepared separately. 


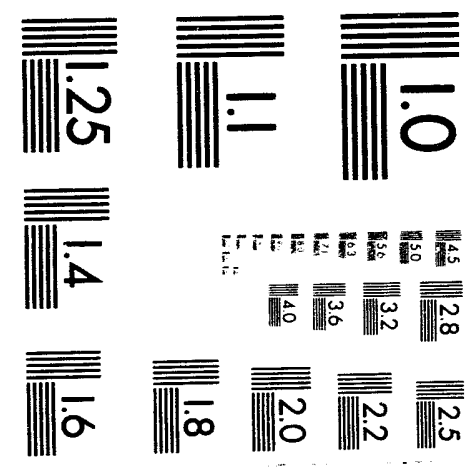



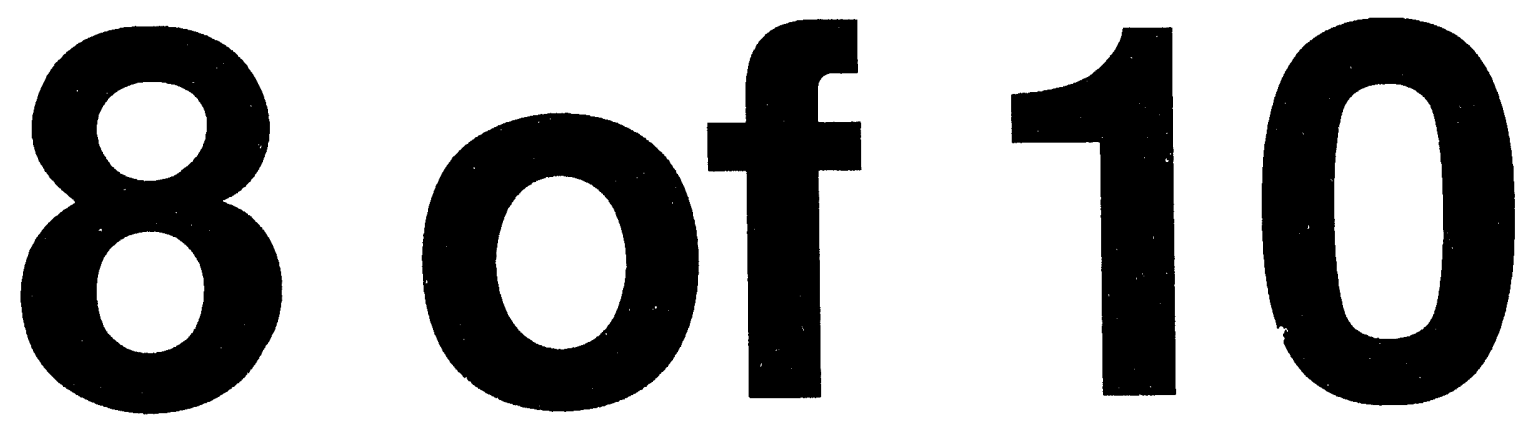
WHC-SD-EN-AP-137, Rev. 0

\subsection{CONCLUSIONS}

Most analytes were reported undetected in the sample results. The organic analytes detected were dismissed due to their low concentrations and status as common laboratory contaminants. Metals analytes detected by the laboratories were compared to the Hanford Site Background, to previously determined local background levels (from Phase 1 sampling), and to healthbased standards. Of the analyses that showed levels above detection limits, none are considered to indicate contamination relative to local background levels.

All detarto! anilutes were compared to the MTCA cleanup standards. Method B was used to calculate the appropriate soil cleanup levels (Appendix D). In cases where sufficient information for calculating cleanup levels was not aviliable, MTCA Residential (Method A) standards were used instead. MTCA Rosidential standards may be considered inappropriate for the closure of the $B$ Pond expansion ponds. The cleanup levels will depend on the eventual land ise. This area may not be released for residential use. However, the MTCA Residential standards used here are meant to illustrate the relatively low loveli; of inetals when compared to regulatory sisndards.

Beryllium results were reported at levels that exceeded the MTCA Method $B$ cleanup standards but. below the Hanford Site Background threshold value. In this case, beryllium concentration was compared to the soil cleanup level for carcinogens $(0.2 \mathrm{mg} / \mathrm{kg})$. Based on the regional background beryllium concentration and the limited number of sample data, there is insubstantial evidence to conclude that the $B$ Pond expansion ponds contain regulated levels of beryllium.

of all the organic compounds or inorganic constituents detected within the samples from the B Pond expansion ponds, none were found in levels regulated under the Wishington Administrative Codes. The findings of Phase 2 are consistent with the findings of Phase 1 and Phase 3 . No crganic compounds or inorganic constituent.s were found in sufficient concentrations to cause the investigated soil to be regulated as dangerous waste.

\subsection{REFERENCES}

ASTM, 1987, Annual Book of ASTM Standards, D1426-D, American Society of Testing and Materials, Philadelphia, Pennsylvania.

DOE-RL, 1990, 216-B-3 Pond System Closure/Postclosure Plan, DOE/RL 89-28, Rev. 0, U.S. Department of Energy, Richland Field Office, Richland, Washington.

DOE-RL, 1993, Hanford Site Background: Part 1, Soi7 Background for Nonradioactive Analytes, DOE/RL-92-24, Rev. 1, U.S. Department of Energy, Richland Field Office, Richland, Washington. 
Dragun, James, 1988, The Soil Chemistry of Hazardous Materials, The Hazardous Materials Research Institute, Silver Springs, Maryland.

Ecology, EPA, and DOE, 1989, Hanford Federal Facility Agreement and Consent Order, 2 vols., as amended, Washington State Department of Ecology, U.S. Environmental Protection Agency, and the U.S. Department of Energy, Olympia, Washington.

EPA, 1986, Test Methods for Evaluating Solid Waste, Physical/Chemical Methods, SW-846. Third Edition, U.S. Environmental Protection Agency, Washington, D.C.

Roos, R. C. and K. A. Woodworth. 1989, 216-B-3 Pond Characterization of the Hazardous Waste In!entory in the Near-Surface Soils and Sediments, WHC-SD-EN-AP-OIj. Rev. 1, Westinghouse Hanford Company, Richland, Washington.

WAC 173-303, 1992, "Dangerous Waste Regulations," Wasirington Administrative Code, as amended.

iAC 173-340, 1992, "The Model Toxics Control Act Cleanup Regulations," ivashington Administrative Code, as amended.

WHC, 1989a, Environmental Investigations and Site Characterization Manual. WHC-CM-7-7, Westinghouse Hanford Company, Richland, Washington.

WHC, 1989b, Preliminary Operable Units Designation Project, WHC-EP-0216, Westinghouse Hanford Company, Richland, Washington.

iHC, 1990, Sample Management and Administration Manual, WHC-CM-5-3, Westinghouse Hanford Company, Richland, Washington.

WHC, 1991, Phase 1 Characterization of the 216-8-3 Pond System, WHC-SD-EN-AF-042, Rev. 1, Westinghouse Hanford Company, Richland, Washington.

WHC, 1992a, Description of Work for Phase 2 Sampling of the 216-B-3A, -3B, and 3C Expansion Ponds, WHC-SD-EN-AP-106, Rev. 0, Westinghouse Hanford Company, Richland, Washington.

VHC, 1992b, Vadose Zone Investigation of the 216-B-3A, 216-8-3B, and 216-B-3C Ponds, WHC-SD-EN-AP-104, Rev. 0, Westinghouse Hanford Company, Richland, Washington.

40 CFR 260, "Hazardous Waste Management System - General, " Code of Federal Regulations, as amended.

40 CFR 261, "Identification and Listing of Hazardous Waste," Code of Federal Regulations, as amended.

40 CFR 265, "Interim Status Standards for Owners and Operators of Hazardous Waste Treatment, Storage, and Disposal Facilities, "Code of Federal Regulations, as amended. 
WrL-sU-cir-hr-1s/, KeV. U

40 CFR 264, "Standards for Owners and Operators of Hazardous Haste Treatment, Storage, and Disposal Facilities," Code of Federal Regulations, as amended. 
WHC-SD-EN-AP-137, Rev. 0 
WHC-SD-EN-AP-137, Rev. 0

\section{APPENDIX A}

METHOD-SPECIFIC ANALYTE LIST AND ASSOCIATED TYPICAL DETECTION LIMITS 
VHC-SD-EN-AP-137, Rev. 0

A-2 


\section{APPENDIX A \\ METHOD-SPECIFIC ANALYTE LIST AND ASSOCIATED TYPICAL DETECTION LIMITS}

The following table lists detection/quantitation limits typically reported by ach laboratory. Detection/quantitation limits listed for organic analytes are sample quantitation limits. Detection/quantitation limits listed for inorganic analytes are instrument detection limits. More specific information such a's the effects of data qualifiers on detection/quantitation limits of a barticular sample may be found in the source documentation along; with the speclic justicication of such qualifiers.

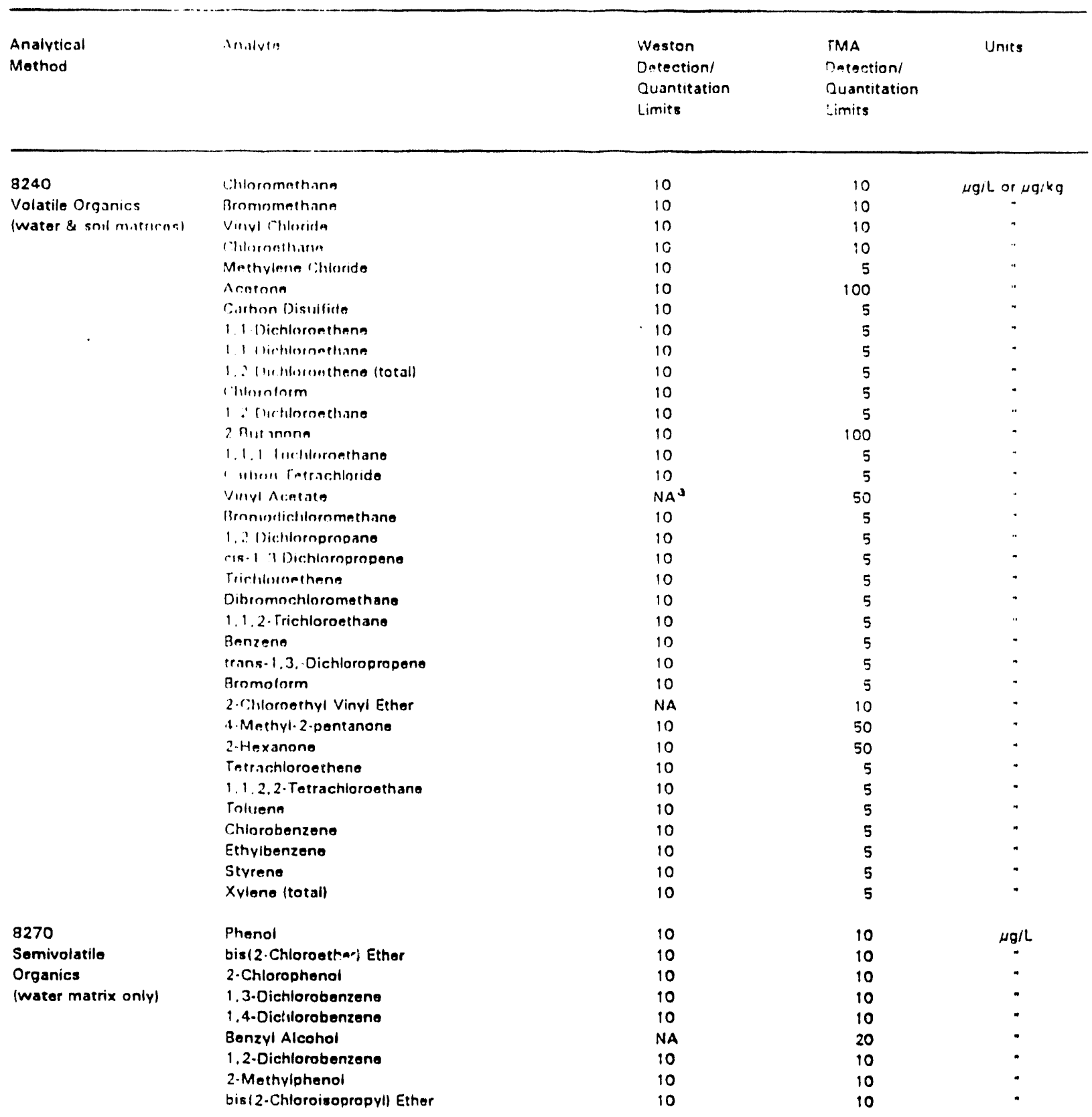


WHC-SD-EN-AP-137, Rev. 0

\begin{tabular}{|c|c|c|c|c|}
\hline $\begin{array}{l}\text { Anolytical } \\
\text { Mothod }\end{array}$ & Analyto & $\begin{array}{l}\text { Weston } \\
\text { Dotection/ } \\
\text { Quantitation } \\
\text { Limits }\end{array}$ & $\begin{array}{l}\text { TMA } \\
\text { Dotection/ } \\
\text { Quantitation } \\
\text { Limits }\end{array}$ & Units \\
\hline
\end{tabular}

4-Methylphenol

N-Nitroso-Di-n-Propylamine

Hexachloroethane

Nitrobenzene

sophorane

2. Nitrootienal

2.4.Dimethylnhennl

Banzole Aced

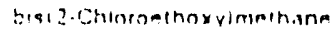

idacinalena

A.C.horoaniline

Hexachlornbutadiene

S. Ethiorn.? nethyiphanul

¿ Malnylnupthaiens

Hexachlororyclonemproniene

2.4. 6. Trichiorohonent

2.4.5. Trichloropnenol

2-Chloronaphehalerin

2. Nitroamiline

Oimethyishehishese

Acenaphehylene

1.2.4-Trichlorobenzens

3. Nitronanilina

Acenaphthene

2.4-Dinitrophenol

4. Nitrophenol

Dibenzofuran

2.4-Dinitrotoliınne

2.6-Dinitrntalierin

Diethylohthal.spe

4-Chlorophenviphenvielhe.e

Fluorene

A.Nitroanaline

4.6-Dinitro-2-mathulpliani,il

ij-ivitrosodiphnnyi.urmerna"

4-Bromoghenyi-ghanimither

Hexachlorobenzenn

Pontachlorophenol

Phenonthrene

Anthracenn

Carbazoln

Di-N-Butylphthalate

Fluoranthene

Pyrene

Butylbenzylphthalate

3. 3'-Dichlorebenzidine

Benzo(a) anthracens

bis (2. Ethythexyl)phthalate

Chrysene

Di-n.oc:yl Phthalate

Benzo(b)fluaranthene

Benzo(k)fluorantheno

Benzolalpyreno

Indeno(1.2.3-cdl Pyrene

Dibenz(a,h) Anthracena

Benzolg.h.ilperylene

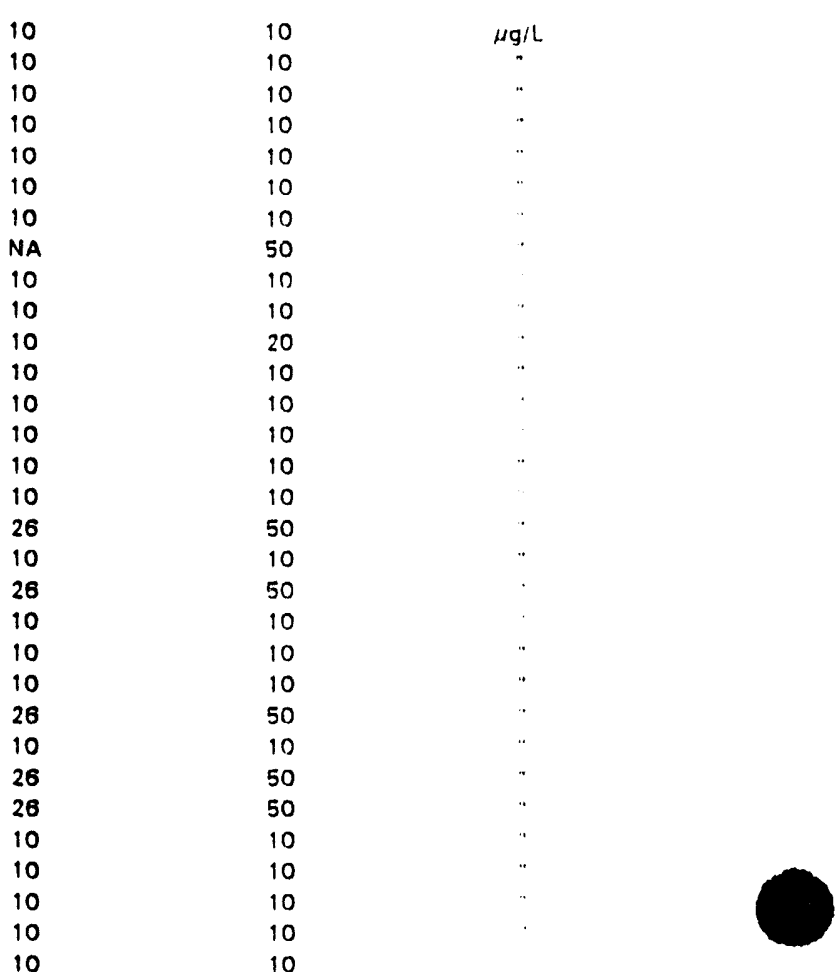


WHC-SD-EN-AP-137, Rev. 0

\begin{tabular}{|c|c|c|c|}
\hline $\begin{array}{l}\text { Analvitical } \\
\text { Mothod }\end{array}$ & Anaiyte & $\begin{array}{l}\text { Weston } \\
\text { Detection/ } \\
\text { Quantitation } \\
\text { Limit: }\end{array}$ & $\begin{array}{l}\text { TMA } \\
\text { Detection/ } \\
\text { Quantitation } \\
\text { Limits }\end{array}$ \\
\hline
\end{tabular}

\begin{tabular}{|c|c|c|c|c|}
\hline 8270 & Phenol & $330.1900^{c}$ & 330 & $\mu \mathrm{g} / \mathrm{kg}$ \\
\hline Semivolatile & bis(2. Chloroether) Ether & 330.1900 & 330 & 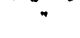 \\
\hline Organics & 2-Chiorophenol & 330.1900 & 330 & $\cdot$ \\
\hline \multirow[t]{60}{*}{ (soil matrix only) } & 1.3.Dichlorobenzene & $330 \cdot 1900$ & 330 & $\cdot$ \\
\hline & 1. 1.Dichlorobenzene & NA & 330 & $\cdot$ \\
\hline & Benzyl Alcohol & $330-1900$ & 650 & $\cdot$ \\
\hline & 1. . Dirchinrnbenzene & $330-1900$ & 330 & $\cdot$ \\
\hline & 2.Mathvintianol & $330-1900$ & 330 & $\cdot$ \\
\hline & hisi2 Chiteroisopropyll Ether & 330.1900 & 330 & $\cdot$ \\
\hline & : isurthylohenol & 330.1900 & 330 & $\cdot$ \\
\hline & N-P'itroso-Di-n-Propylamine & $330 \cdot 1900$ & 330 & $\cdot$ \\
\hline & Hexisctiloroethane & 330.1900 & 330 & $\cdot$ \\
\hline & Nitratienrene & 330.1900 & 330 & $\cdot$ \\
\hline & 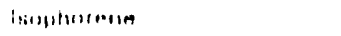 & 330.1900 & 330 & $\cdot$ \\
\hline & $\therefore$ Nirrnohenol & 330.1900 & 330 & $\cdot$ \\
\hline & I. A Dimethylphenal & 330.1900 & 330 & $\cdot$ \\
\hline & Bunzour: Acid & NA & 1600 & $\cdot$ \\
\hline & bis/2 Ghlornethoxylmethane & $330 \cdot 1900$ & 330 & $\cdot$ \\
\hline & Alanthilient & 330.1900 & 330 & . \\
\hline & 1.t.liturn.iniline & 330.1900 & 650 & $\cdot$ \\
\hline & innxu:hinmbutadiene & $330 \cdot 1900$ & 330 & $"$ \\
\hline & 4. (illorn-3) mechyiphenol & $330 \cdot 1900$ & 650 & $"$ \\
\hline & 2 Methyinapthaiene & 330.1900 & 330 & $"$ \\
\hline & Ilexichlormcyclonentadiene & $330 \cdot 1900$ & 330 & $\cdot$ \\
\hline & $\therefore 4$ is rictiloroonenol & $330 \cdot 1900$ & 330 & $"$ \\
\hline & 2.4.5. Trichlorophenol & 830.4600 & 1600 & $\cdot$ \\
\hline & 2. Chiornnaphthalene & $330 \cdot 1900$ & 330 & $"$ \\
\hline & 2.Nitronniline & 830.4600 & 1600 & $"$ \\
\hline & Dimuthylohthalate & 330.1900 & 330 & $"$ \\
\hline & Aren.unhthylene & 330.1900 & 330 & 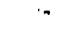 \\
\hline & 1 2.4. Trichlorobenzene & 330.1900 & 330 & 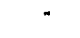 \\
\hline & 3 ilitro.moline & 830.4600 & 1600 & $\cdot$ \\
\hline & Aisnnophthene & $330 \cdot 1900$ & 330 & " \\
\hline & $\therefore$ Inintrophenol & 830.4600 & 1600 & $\cdot$ \\
\hline & 1. Nifrophenol & 830.4600 & 1600 & • \\
\hline & 1sheriznturan & 330.1900 & 330 & $\cdot$ \\
\hline & $\therefore A$ Dinitrotoluene & $330-1900$ & 330 & ' \\
\hline & 2.ti. Binitrntoluene & 330.1900 & 330 & $\cdot$ \\
\hline & Dinthylnhthaiate & 330.1900 & 330 & $\cdot$ \\
\hline & 1.1 Whrophenylphenylether & 330.1900 & 330 & " \\
\hline & Fluorene & 330.1900 & 330 & ${ }^{*}$ \\
\hline & 4. Nitroanaline & 830.4600 & 1600 & $\cdot$ \\
\hline & 4.6-Dinitro-2.methyiphanol & 830.4600 & 1600 & $*$ \\
\hline & N.Nitrosodiphenylamine ${ }^{b}$ & 330.1900 & 330 & $\cdot$ \\
\hline & A. Bromophenyl-ohenylether & $330 \cdot 1900$ & 330 & • \\
\hline & Hexachiorobenzene & $330-1900$ & 330 & • \\
\hline & Pentachlorophenoi & 830.4600 & 1600 & $\cdot$ \\
\hline & Phenanthrene & $330-1300$ & 330 & $\cdot$ \\
\hline & Anthracene & 330.1900 & 330 & $\cdot$ \\
\hline & Carbozole & 330.1900 & NA & 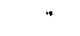 \\
\hline & Di-N-Butylphthaiate & 330.1900 & 330 & • \\
\hline & Fluoranthene & $330-1900$ & 330 & $\cdot$ \\
\hline & Pyrene & 330.1900 & 330 & “ \\
\hline & Butylbenzyiphthalate & 330.1900 & 330 & $\cdot$ \\
\hline & 3., $3^{\prime}$-Dichiorobenzidine & $330-1900$ & 1600 & " \\
\hline & Benzolalanthraceno & 330.1900 & 330 & $\cdot$ \\
\hline & bis(2-Ethylhexyl)phthalate & 330.1900 & 330 & $\cdot$ \\
\hline & Chrveene & 330.1900 & 330 & $\cdot$ \\
\hline & Di-n-octyl Phthalato & $330-1900$ & 330 & • \\
\hline & Benzo(b)fluoranthene & $330-1900$ & 330 & " \\
\hline & Benzo(k) fluoranthene & 330.1900 & 330 & " \\
\hline & Benzolalpyrene & $330-1900$ & 330 & $\cdot$ \\
\hline & Indeno(1.2.3-cd) Pyrene & $330-1900$ & 330 & $\cdot$ \\
\hline
\end{tabular}


WHC-SD-EN-AP-137, Rev. 0

\begin{tabular}{|c|c|c|c|c|}
\hline $\begin{array}{l}\text { Analytical } \\
\text { Mothod }\end{array}$ & Analyte & $\begin{array}{l}\text { Weston } \\
\text { Detection/ } \\
\text { Quantitation } \\
\text { Limits }\end{array}$ & $\begin{array}{l}\text { TMA } \\
\text { Dotection/ } \\
\text { Quantitation } \\
\text { Limits }\end{array}$ & Units \\
\hline & $\begin{array}{l}\text { Dibenzla,h) Anthracene } \\
\text { Benzolg,h,i)perylene }\end{array}$ & $\begin{array}{l}330-1900 \\
330.1900\end{array}$ & $\begin{array}{l}330 \\
330\end{array}$ & $\mu q / \mathrm{kg}$ \\
\hline 8080 & Alona.BHC & $0.05 \cdot 0.10$ & 0.05 & $\mu(1 ; 1$. \\
\hline P.CBs and & B.Ta.BHC & $0.05 \cdot 0.10$ & 005 & " \\
\hline Pesticides & Ceita.BHC & $0.05 \cdot 0.10$ & 0.05 & $\cdot$ \\
\hline \multirow[t]{25}{*}{ (water ratrix sniv) } & G.umma-BHC Ilind.inel & $0.05-0.10$ & 005 & $\cdot$ \\
\hline & Haptuchlor & $0.05 \cdot 0.10$ & 005 & $\cdot$ \\
\hline & $\therefore+$ in & $0.05 \cdot 0.10$ & 045 & \\
\hline & & & 0.05 & . \\
\hline & $\begin{array}{l}\text { Endesuitin I } \\
\text { Sieldrin }\end{array}$ & $\begin{array}{l}\text { NA } \\
0.10 \cdot 0.20\end{array}$ & $\begin{array}{l}0.115 \\
0.10\end{array}$ & . \\
\hline & $\triangle \because D D E$ & $0.10 \cdot 0.20$ & n in & . \\
\hline & En:den & $0.10 \cdot 0.20$ & $0.11)$ & \\
\hline & Endosulfan $\|$ & $0.10-0.20$ & 010 &. \\
\hline & .4 .000 & $0.10 \cdot 0.20$ & 0.10 & . \\
\hline & Endosisifan Sulfats & NA & 010 & . \\
\hline & $44.00 T$ & NA & 010 &. \\
\hline & Methoxvi:hini & $0.50 \cdot 1.0$ & 0451 & \\
\hline & Endrine Katone & $0.10-0.20$ & 010 & \\
\hline & Enurin Aldehydis & $0.10 \cdot 0.20$ & 0.10 & . \\
\hline & Chlordann & NA & 10 & $\cdot$ \\
\hline & aloha. Chlordana & $0.05 \cdot 0.10$ & NA & $\cdot$ \\
\hline & gamma-Chlnedinn & $0.05-0.10$ & NA & \\
\hline & Toxaphene & $5.0 \cdot 10.0$ & 5.0 & " \\
\hline & Arocior 1016 & $1.0 \cdot 2.0$ & 1.0 & . \\
\hline & Aroclor 1221 & $2.0 \cdot 4.0$ & 10 & $\cdot$ \\
\hline & Aroclar 1232 & 1.0-2.0 & 1.0 & - \\
\hline & Aroclor 12.12 & $\cdot 1.0 \cdot 2.0$ & 10 & $\cdot$ \\
\hline & Arncior 12.413 & $1.0 \cdot 2.0$ & 10 & \\
\hline & Arnclor 125.4 & $1.0 \cdot 2.0$ & 10 & \\
\hline & Aroclor 1260 & $1.0 \cdot 2.0$ & 1.0 & \\
\hline 8080 & Alpha-BHC: & $1.7 \cdot 9.6$ & $i 1$ & แ11!:! \\
\hline PCBs and & Beta-BHC & 1.7.9.6 & 11 & \\
\hline Pesticides & Delia.BHC & $1.7-9.6$ & 1.7 & \\
\hline \multirow[t]{26}{*}{ Isoil matnx only } & Samma-BHC (Lindann) & $1.7 \cdot 9.6$ & 1.7 & . \\
\hline & Heptachlor & $1.7-9.6$ & 1.7 & $\cdot$ \\
\hline & Aldrin & 1.7.9.6 & 1.7 & \\
\hline & Heotuchlor moxiris & $1.7 \cdot 9.6$ & 1.7 & " \\
\hline & Endosulfan I & NA & 1.7 & . \\
\hline & Dieldrin & $3.4-19$ & 3.3 & - \\
\hline & $4,4^{\prime} \cdot 00 E$ & $3.4-19$ & 3.3 & " \\
\hline & Endrin & $3.4-19$ & 3.3 & " \\
\hline & Endosuitan II & $3.4-19$ & 3.3 & - \\
\hline & $4.4^{\circ}-D D D$ & $3.4-19$ & 3.3 & . \\
\hline & Endosuifan Sulfate & NA & 3.3 & - \\
\hline & $4.4^{\prime} \cdot D D T$ & NA & 3.3 & - \\
\hline & Methoxyehlor & 17.96 & 17.0 & - \\
\hline & Endrine Ketone & $3.4 \cdot 19$ & 3.3 & " \\
\hline & Endrin Aldehydo & 3.4 .19 & 3.3 & - \\
\hline & Chlordane & NA & 33.0 & - \\
\hline & sioha-Chlordane & $1.7 \cdot 9.6$ & NA & - \\
\hline & gamma-Chlordane & $1.7 \cdot 9.6$ & NA & $\cdot$ \\
\hline & Toxapheno & $170-960$ & 170 & - \\
\hline & Aroclor 1016 & $34-190$ & 33.0 & • \\
\hline & Aroclor 1221 & 68.380 & 33.0 & - \\
\hline & Aroclor 1232 & $34-190$ & 33.0 & $\cdot$ \\
\hline & Arocior 1242 & $34-190$ & 33.0 & • \\
\hline & Aroclor 1248 & 34.190 & 33.0 & $n$ \\
\hline & Arocior 1254 & $34-190$ & 33.0 & - \\
\hline & Aroclor 1260 & $34-190$ & 33.0 & - \\
\hline
\end{tabular}


WHC-SD-EN-AP-137, Rev. 0

\begin{tabular}{|c|c|c|c|c|}
\hline $\begin{array}{l}\text { Analvitical } \\
\text { Method }\end{array}$ & Analyte & $\begin{array}{l}\text { Woston } \\
\text { Dotection/ } \\
\text { Quantitation } \\
\text { Limits }\end{array}$ & $\begin{array}{l}\text { TMA } \\
\text { Dotection/ } \\
\text { Quantitation } \\
\text { Limit: }\end{array}$ & Unit: \\
\hline Inorganics por & Aluminum & 49.0 & 5 & $\mu \mathrm{g} / \mathrm{L}$ \\
\hline CLP SOW 3:30 & Antimony & 60.0 & 18 & ? \\
\hline IWestonl Ind & Arsonic & 2.0 & 1 & - \\
\hline $15010 ! T M A 1$ & Basrium & 14.0 & 1 & $\cdot$ \\
\hline \multirow[t]{21}{*}{ (water marrix only) } & Beryllium & 1.0 & 1 & $\cdot$ \\
\hline & Bornn & NA & 52 & $"$ \\
\hline & Cadmium & 7.0 & :0 & - \\
\hline & C.alcium & 57.0 & 5 & $\cdot$ \\
\hline & ithromium & $3)$ & $i$ & \\
\hline & Cobalt & 9.0 & 7 & $\cdot$ \\
\hline & Cuoper & $10:$ & 4 & $\cdot$ \\
\hline & $\operatorname{lrnn}$ & 15.0 & 4 & - \\
\hline & land & 2.4 & 1 & $\cdot$ \\
\hline & M.cynesium & 68.2 & 53 & \\
\hline & Manganese & 4.0 & 2 & - \\
\hline & Mercurv & 0.10 & 0.2 & $\cdot$ \\
\hline & Molybdenum & NA & 4 & ' \\
\hline & Por.sssium & $13: 00$ & 1260 & . \\
\hline & intermum & $\therefore 1$ & 2 & $\cdot$ \\
\hline & : Silverer & 107 & 3 & $\cdot$ \\
\hline & Soctilum & 151.0 & 53 & - \\
\hline & Thallium & 2.0 & 2 & - \\
\hline & Vanadium & 16.4 & 4 & $"$ \\
\hline & Zins: & 100 & 4 & $\cdot$ \\
\hline & Cryanide & 10.0 & 2 & $\cdot$ \\
\hline Inorqonics per & Aluminum & 49.0 & 0.5 & $\mathrm{mg} / \mathrm{kg}$ \\
\hline CLP SOW $3 / 90$ & Antimony & 60.0 & 1.8 & 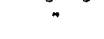 \\
\hline (Westont ind & Arsenic & 2.0 & 0.1 & $\cdot$ \\
\hline 5010$)(T M A)$ & B.arrum & 140 & 0.1 & r \\
\hline \multirow[t]{21}{*}{ |soil mi.strix menly) } & Bnryllium & i.o & 0.1 & $"$ \\
\hline & Bornn & NA & 5.2 & $\cdot$ \\
\hline & Cadmium & 70 & 1 & $\cdot$ \\
\hline & Conlrium & 57.0 & 0.5 & - \\
\hline & Chromium & 3.0 & $0 . i$ & - \\
\hline & robalt & 3.0 & 0.7 & $\cdot$ \\
\hline & Conper & 8.0 & 0.4 & $\cdot$ \\
\hline & Iron & 15.0 & 0.4 & - \\
\hline & Lond & 2.2 & 0.1 & $\cdot$ \\
\hline & Magnnesium & 68.0 & 5.3 & - \\
\hline & Manganeso & 40 & 0.2 & - \\
\hline & Mercury & 0.10 & 0.005 & - \\
\hline & Molybdenum & NA & 0.4 & $\cdot$ \\
\hline & Nickel & 20.0 & 1.2 & . \\
\hline & Potassium & 1340.0 & 125 & - \\
\hline & Solenium & 2.0 & 0.2 & . \\
\hline & Silver & 10.0 & 0.3 & $\cdot$ \\
\hline & Sodium & 151.0 & 5.3 & . \\
\hline & Thallium & 2.0 & 0.2 & $\cdot$ \\
\hline & Vandium & 8.0 & 0.4 & $\cdot$ \\
\hline & Zine & 4.0 & 0.4 & - \\
\hline (9010 (TMA)I & Cyanide & 20.0 & 0.08 & $\cdot$ \\
\hline
\end{tabular}

${ }^{3}$ Not included in analysie.

${ }^{b}$ Cannot be separated from diphenylamine.

Cootection limits typically foll within this range. 
WHC-SD-EN-AP-137, Rev. 0

A-8 
WML-SU-EN-AY-131, Rev. 0

\section{APPENDIX B}

MAXIMA AND 95/95 REFERENCE THRESHOLD VALUES FOR HANFORD SITE SOIL BACKGROUND 
WHC-SD-EN-AP-137, Rev. 0

B-2 
APPENDIX B

\section{MAXIMA AND 95/95 REFERENCE THRESHOLDS FOR HANFORD SITE SOIL BACKGROUND'}

The $95 / 95$ thresholds values represent the upper $95 \%$ confidence interval of the 95th percentile of the distribution. Information on the statistics is provided in the source document.

\begin{tabular}{|c|c|c|c|c|c|}
\hline Analyte & LOD & LOQ & $\begin{array}{c}95 / 95 \\
\text { Threshold } \\
\text { (mg/kg) }\end{array}$ & $\begin{array}{l}\text { Maximum } \\
\text { concentration } \\
\text { (mg/kg) }\end{array}$ & $\begin{array}{l}\text { Sample with maximum } \\
\text { concentration }\end{array}$ \\
\hline Aluininum & 23.8 & 66.1 & 15100 & 28800 & TCPSOIL, P:AYA, E-i \\
\hline Ane imony & 15.7 & 52.2 & NC & 31 & VOLCANIC ASH* \\
\hline Arsenic & N/A & N/A & 9.0 & 27.7 & TCPSOIL, JUNI=ER, E-J \\
\hline Barlun & 0.87 & 2.7 & 175 & 480 & VOLCANIC ISHE \\
\hline $5(\because \cdots, 1, \cdots n$ & $N / A$ & $N / A$ & 1.8 & 10 & VOLGANI: :S"̈" \\
\hline C.admitum & 0.24 & 0.79 & NC & 11 & VOLCANL :S": \\
\hline Calcium & 175 & 470 & 24600 & 105000 & TOPSOIL, GREASENCCD, $\equiv-2$ \\
\hline Chromilum & 1.1 & 3.0 & 28 & 320 & RINGOLD FM* \\
\hline $\cos i^{-}$ & 0.88 & 2.9 & 19 & 110 & VOLCANIC ASH" \\
\hline Escorr & 2.1 & 6.2 & 30 & $s:$ & VOLCANIE ASH* \\
\hline$! n$ & 75.7 & 236 & 38200 & $=8: 20$ & RINGCLD $=M$ \\
\hline Lead & N/A & $N / A$ & 14.7 & 74.9 & TOPSOIL, JUNIPER, E-3 \\
\hline Magnes i um & 18.4 & 57.9 & 9160 & 32300 & TOPSOIL, GREASENOOO, E-? \\
\hline Mangzanesie & 0.63 & 1.8 & $58 j$ & 1110 & TOPSOIL, PLAIA, E-7 \\
\hline Mercury & $N / A$ & N/A & 1.3 & 3.8 & RANDOM SAMPLES, \#15 \\
\hline Nickel & 2.4 & 7.7 & 25 & 200 & RINGOLD FM* \\
\hline Porassiun & 135 & 451 & 3090 & 7900 & TOPSOIL, PLAYA, E-7 \\
\hline Sel一nilln & $N / A$ & $N / A$ & NC & 6 & RANOCM SAMPLES, $=15$ \\
\hline silunr & 2.1 & 4.5 & 2.1 & $: 4.5$ & RANDOM SAMPLES, $\# 6$ \\
\hline Sudium & 50.6 & 140 & $i 390$ & $20 \leqslant 0$ & RANOCM SAMP:ES, $\neq 12$ \\
\hline Thall ilun & $H / A$ & $N / A$ & NC & 3.7 & LA3 วETECT:ZN LIM!T \\
\hline Vanadium & 1.8 & 5.9 & 107 & 140 & $\because O L C A N I C A S H *$ \\
\hline Zine & 6.4 & 15.6 & 79 & 366 & TOPSOIL, JUNIPER, E-3 \\
\hline Mot ybdenum & 1.4 & 4.8 & NC & 6 & RINGOLD FM \\
\hline L. ithium & $N / A$ & N/A & 37 & 38.2 & RANCOM SAMPLES, $=94^{*}$ \\
\hline Titanium & $N / A$ & N/A & 3307 & 3180 & RANOCM SAMPLES, $=6$ \\
\hline zirconium & $N / A$ & $N / A$ & 53 & 34.3 & RANDOM SAMPLES, $=10$ \\
\hline Ammonia & $N / A$ & $N / A$ & 27.4 & 26.4 & RANOOM SAMPLES, $\neq 14$ \\
\hline Alkatinity & $N / A$ & $N / A$ & 20100 & $: 50000$ & TOPSOIL, GREASEWOOO, $\equiv-2$ \\
\hline silicon & $N / A$ & $N / A$ & 239 & 1202.9 & TOPSOIL, PLAYA, E-? \\
\hline Fluoride & N/A & N/A & 13 & 73.3 & RANOOM SAMPLES, $=10$ \\
\hline Chloride & $N / A$ & $\mathrm{~N} / \mathrm{A}$ & 783 & 1480 & RANDOM SAMPLES, $\neq 11$ \\
\hline Nitrite & $N / A$ & $N / A$ & NC & 36.5 & TOPSOIL, GREASE:NOOD, E-2 \\
\hline Nitrate & $N / A$ & N/A & 208 & 906 & HANFORD FM JUDGEMENT, \\
\hline Q-Phosphate & N/A & $N / A$ & 12.7 & 225 & RAMDOM SAMPLES, $=10$ \\
\hline Sulfate & $N / A$ & $N / A$ & 931 & 12600 & TOPSOIL, GREASEWOOD, E-? \\
\hline
\end{tabular}

Adapted from DOE-RL, 1993, Hanford Site 3ackground: Part 1 , Soil Background for Nonradioactive Analytes, DOE/RL-92-24, Rev. 1.

$N ! A=$ Not available.

NC = Not calculated.

* = Offsite. 
WML-دU-LIV-AH-1د/, Kev. U 
WHC-SD-EN-AP-137, Rev. 0

APPENDIX C

TYPICAL RANGES FOR METALS IN SOILS 
WHC-SD-EN-AP-137, Rev. 0 
WHC-SD-EN-AP-137, Rev. 0

APPENDIX C

TYPICAL RANGES FOR METALS IN SOILS

\section{Element}

Common Range in Soils $(\mathrm{mg} / \mathrm{kg}$ )

Aluminum

Antimony

Barium

Beryllium!

Boron

Caclinium

C.alcium

Chromium

Cobalt.

Copper

Iron

Lead

Lithium

Magnesium

Manganese

Mercury

Mol ybdemum

Nickel

Potassium

Selenium

Silicon

Silver

Sodium

Sirontium

Thallium

Titanium

Tin

Vanadium

Zinc

Zirconium

$$
\begin{array}{ccr}
10,000 & \text { to } & 300,000 \\
0.2 & \text { to } & 10 \\
100 & \text { to } & 3,000 \\
0.1 & \text { to } & 40 \\
2 & \text { to } & 100 \\
0.01 & \text { to } & 7 \\
7,000 & \text { to } & 500,000 \\
1 & \text { to } & 1,000 \\
1 & \text { to } & 40 \\
2 & \text { to } & 100 \\
7,000 & \text { to } & 550,000 \\
2 & \text { to } & 200 \\
5 & \text { to } & 200 \\
500 & \text { to } & 10,200 \\
20 & \text { to } & 3,000 \\
0.01 & \text { to } & 0.3 \\
0.2 & \text { to } & 5 \\
5 & \text { to } & 500 \\
400 & \text { to } & 30,000 \\
0.1 & \text { to } & 2 \\
230,000 & \text { to } & 350,000 \\
0.01 & \text { to } & 5 \\
750 & \text { to } & 7,500 \\
50 & \text { to } & 1,000 \\
0.1 & \text { to } & 0.8 \\
1,000 & \text { to } & 10,000 \\
2 & \text { to } & 200 \\
20 & \text { to } & 500 \\
10 & \text { to } & 300 \\
60 & \text { to } & 2,000 \\
& &
\end{array}
$$

Adapted from Dragun, James, 1988, The Soil Chemistry of Hazardous Materials, The Hazardous Materials Research Institute, Silver Springs, Maryland. 
WHC-SD-EN-AP-137, Rev. 0

$$
\text { C-4 }
$$


WHC-SD-EN-AP-137, ReV. 0

\section{APPENDIX D}

WASHINGTON ADMINISTRATIVE CODE MODEL TOXICS CONTROL ACT

CLEANUP STANDARDS

D-1 
WHC-SD-EN-AP-137, Rev. 0

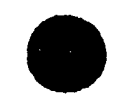

$\bullet$ 


\section{APPENDIX D \\ MODEL TOXICS CONTROL ACT CLEANUP STANDARDS" (sheet 1 of 2)}

The following cleanup standards are derived from MTCA Method A and Method B. MTCA Method $B$ was used to calculate the appropriate soil cleanup levels. In cases where sufficient information for calculating cleanup levels was not available, MTCA Method A standards were used.

\begin{tabular}{|c|c|c|c|c|c|}
\hline Compound & $R f D^{a}$ & $\begin{array}{c}\text { Cleanup } \\
\text { level } \\
(\mathrm{mg} / \mathrm{kg})\end{array}$ & $C P F^{a}$ & $\begin{array}{l}\text { Cleanup } \\
\text { level } \\
(\mathrm{mg} / \mathrm{kg})\end{array}$ & $\begin{array}{c}\text { Carcinogenic } \\
\text { classifi- } \\
\text { catio }\end{array}$ \\
\hline Acetone & 0.1 & 8000.0 & \multirow{8}{*}{$\begin{array}{l}0.0061 \\
0.0075\end{array}$} & NA & 0 \\
\hline Chivoridencente & 0.02 & 1600.0 & & NA & 0 \\
\hline Chloroform & 0.01 & 800.0 & & 163.9 & 82 \\
\hline Methylene chloride & 0.06 & 4800.0 & & 133.3 & B2 \\
\hline Toluene & 0.2 & 16000.0 & & $N A$ & $D$ \\
\hline $1.1 .1-T C A^{b}$ & & $20.0^{c}$ & & NA & 0 \\
\hline Trichluroe thene ${ }^{b}$ & & $0.5^{c}$ & & NA & 0 \\
\hline Xylenes & 2 & 160000.0 & & NA & D \\
\hline Aluminum & \multicolumn{5}{|c|}{ Data Inadequate for Quantitative Risk Analysis } \\
\hline Arsenic & 0.0003 & 24.0 & \multirow{11}{*}{4.3} & NA & $A$ \\
\hline Antimuny ${ }^{-1}$ & $0.0004^{e}$ & 32.0 & & NA & \\
\hline Barium ${ }^{3}$ & 0.07 & 5600.0 & & NA & \\
\hline Beryllium & 0.005 & 400.0 & & 0.2 & B2 \\
\hline Cadmium & 0.001 & 80.0 & & NA & B1 \\
\hline Calcium & & NA & & NA & 0 \\
\hline Chromium (III) & 1 & 80000.0 & & NA & D \\
\hline Chromium (VI) & 0.005 & 400.0 & & NA & $A$ \\
\hline Couait & & NA & & NA & \\
\hline Copperdis & $0.04^{f}$ & 3200.0 & & NA & \\
\hline \multirow{4}{*}{$\begin{array}{l}\text { Cyanide } \\
\text { Irond }^{\text {d }} \\
\text { Lead }^{b} \\
\text { Magnesium }\end{array}$} & 0.02 & 1600.0 & & NA & D \\
\hline & Data & Inadequate & \multicolumn{3}{|c|}{ for Quantitative Risk Analys is } \\
\hline & & $250.0^{c}$ & & NA & \\
\hline & & NA & & NA & \\
\hline Manganese & 0.14 & 11200.0 & & NA & D \\
\hline Mercury & & $1.0^{c}$ & & NA & D \\
\hline Nickel ${ }^{g}$ & $0.02^{e}$ & 1600.0 & & NA & \\
\hline Potassium ${ }^{d}$ & $0.05^{e}$ & 4000.0 & & NA & \\
\hline Selenium & 0.005 & 400.0 & & NA & D \\
\hline Sitver & 0.005 & 400.0 & & NA & 0 \\
\hline Sodium ${ }^{d}$ & & NA & & NA & \\
\hline Tha11 ium & $0.0009^{e}$ & 72.0 & & NA & \\
\hline Vanadiumb,g & $0.007^{e}$ & 560.0 & & NA & \\
\hline Zinc & 0.2 & 16000.0 & & NA & $D$ \\
\hline
\end{tabular}

*See footnotes on page $D-4$.

$N A=$ not available. 


\section{MODEL TOXICS CONTROL ACT CLEANUP STANDARDS* (sheet 2 of 2)}

FOOTNOTES:

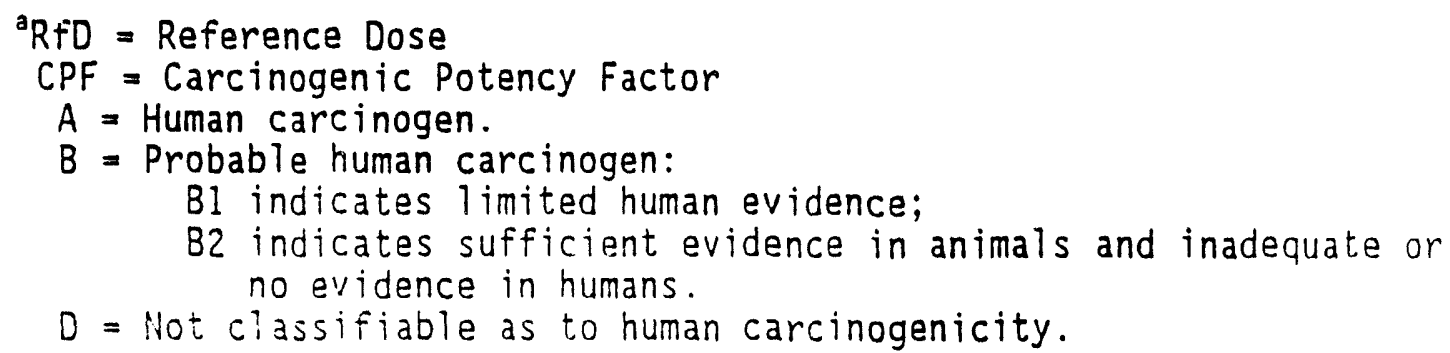

Undergoing EPA RTD Work Group Review at the time of the IRIS Dbase check.

'Cleanup levels obtained from MTCA Method A Cleanup Standards for soil.

${ }^{d}$ IRIS did not contain entries.

${ }^{e}$ RfD values were taken from the Health Effect Summary Tables.

tTaken from the Superfund Technical Support Center.

${ }^{9}$ IRIS did not contain any carcinogenic data.

IRIS, Integrated Risk Information System, is part of the Hazardous Substances Data Bank, National Library of Medicine, Bethesda, Maryland.

MTCA Method B Soil Cleanup Level Calculations:

Soii Cleanup Level (mg/kg)

$=(R F D * A B W * U C F * 40) !(S I P * A B I * F O C)=80,000 * R f d$

Soil Cleanup Level for Carcinogens (mg/kg)

$=(R I S K$ * $A B W * L I F E * U C F) /(C P F * S I R * A B I * D U R * F O C)=1 / C P F$

where:

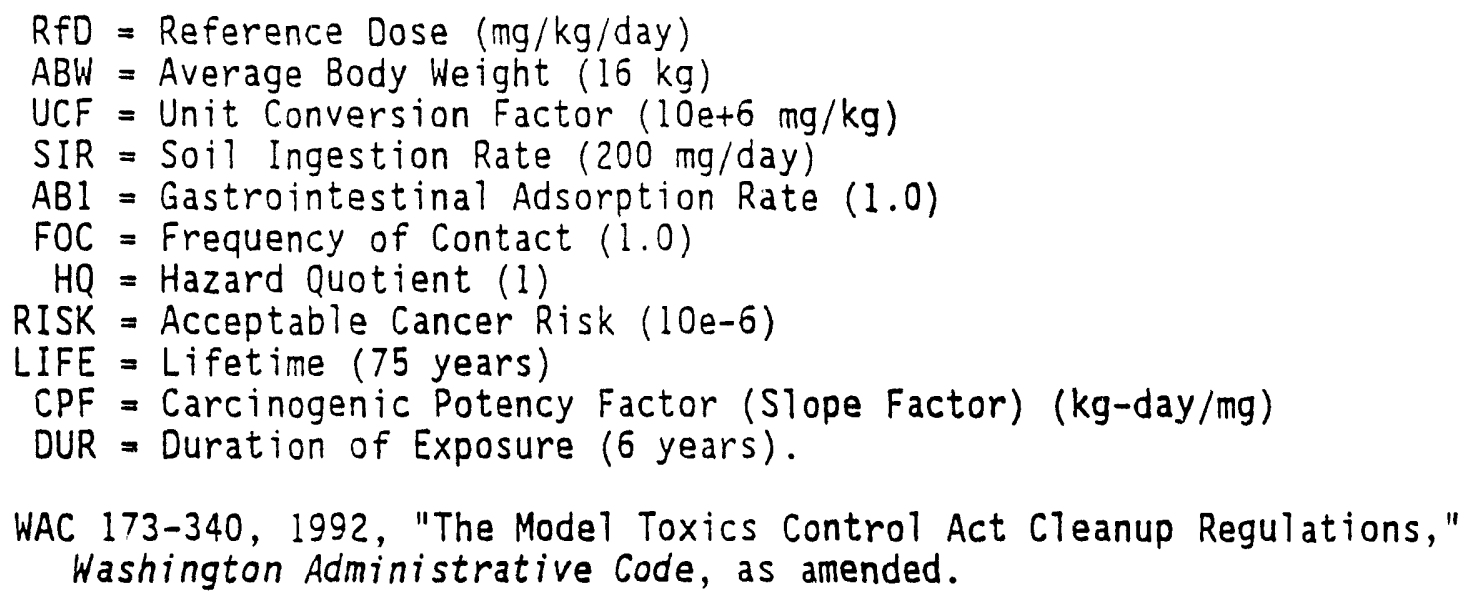


DOE/RL 89-28, Rev. 1

$12 / 15 / 93$

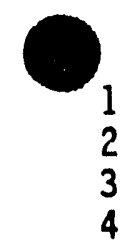

\section{APPENDIX E}

216-B-3 POND SYSTEM PHASE 3 VADOSE ZONE SAMPLING 
DOE/RL 89-28, Rev. 1
$12 / 15 / 93$

This page intentionally left blank. 
2. To: (Receiving Organizotion)

Distribution

S. Proj./Prog./Dept./Div.:

81353

8. Originator Remorks:

Please sign indicating approval of WHC-SD-EN-AP-104, Rev. 0
3. From: (Originating Organization)

Environmental Remediation

Engineering--Site Remediation Management Section

\section{Cog. Engr.:}

C.D. Kramer
4. Related EDT No.:

N/A

7. Purchase Order No.: $N / A$

9. Equip./Component Mo.: $N / A$

10. System/Bldg./Facility: $N / A$

\section{Receiver Remarks:}

12. Major Assm. Dwg. No.: $N / A$

13. Permit/Permit Application No.: $N / A$

14. Required Response Date: $10 / 05 / 92$

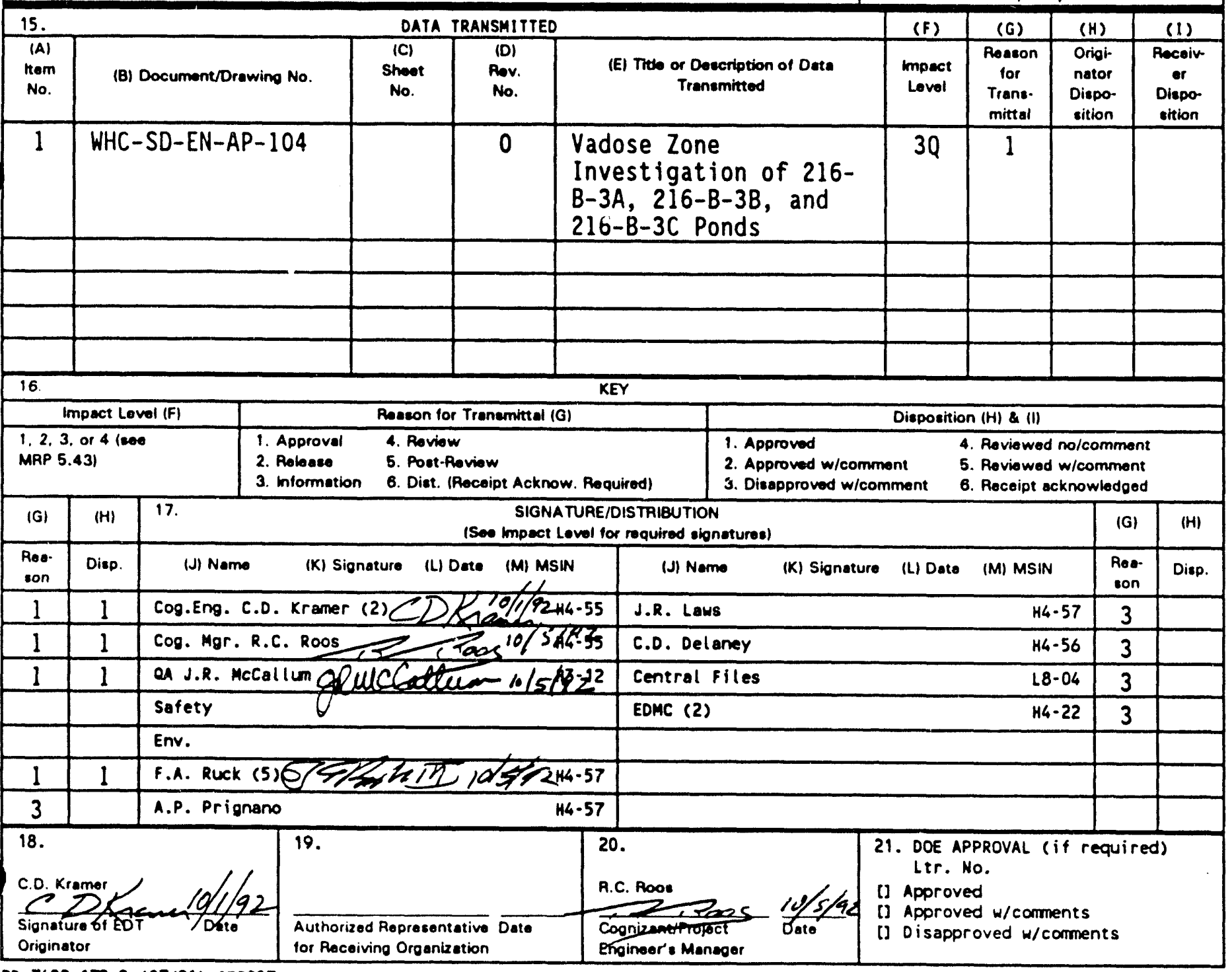




\section{INSTRUCTIONS FOR COMPLETION OF THE ENGINEERING DATA TRANSMITTAL}

(USE BLACK INK OR TYPE)

\begin{tabular}{|c|c|}
\hline BLOCK & TITLE \\
\hline$(1)^{*}$ & EDT \\
\hline (2) & To: (Recoiving Organization) \\
\hline (3) & From: (Originating Orgenizetion) \\
\hline (4) & Rolated EDT No. \\
\hline$(5)^{*}$ & Proj./Prog./Dept./Div. \\
\hline (6)* & Cognizant Engineor \\
\hline (7) & Purchase Order No. \\
\hline$(8)^{*}$ & Originator Remarks \\
\hline (9) & Equipment/Component No. \\
\hline (10) & Systom/Bldg./Facility \\
\hline (11) & Recoiver Romarks \\
\hline (12) & Mojor Assm. Dwg. No. \\
\hline (13) & Pormit/Permit Application No. \\
\hline (14) & Required Response Date \\
\hline
\end{tabular}

(15). Date Transmittod
(A)* Itom Number
(B)" Document/Drawing No.
(C)" Shoot No.
(D) * Rov. No.
(E) Title or Description of Date Tranemitted
(F). Impact Levol
(G) Resson for Transmittal
(H) Originator Disposition
(I) Rocoivor Disposition

(16) Koy

(17) Signoture/Distribution

(G) Resson
(H) Disposition
(J) Nome
(K) Signature
(L) Dete
(M) MSIN

(18) Signature of EDT Originator

(19) Authorized Representative for Rocoiving Organization

(20). Cognizent Manager

(21)* DOE Approval
- Pro-eseigned EDT number.

- Enter the individual's neme, title of the organization, or entity (e.g., Distribution) that the EDT is being tranamitted to.

- Enter the title of the o:ganization originating and transmitting the EDT.

- Enter EDT numbers which relate to the date being trensmitted.

- Enter the Project/Program/Department/Division title or Project/Program acronym or Project Number, Work Order Number or Organization Code.

- Enter the neme of the individual identified as being responsible for coordinating disposition of the EDT.

- Enter rolated Purchase Order (P.O.) Number, if available.

- Enter epecial or additional comments concerning transmittal, or "Key" retrieval words may be entered.

- Enter equipment/componont number of affected item, if appropriate.

- Enter appropriate system, building or facility number, if appropriate.

- Enter special or additional comments concorning trensmittal.

- Enter applicable drewing number of major assembly, if appropriate.

- Enter applicable permit or permit epplication number, if appropriate.

- Enter the date a response is required from individuals identified in Block 17 (Signature/Distribution).

- Enter sequential number, beginning with 1, of the information listed on EDT.

- Enter the unique identification number assigned to the document or drawing being trenemitted.

- Enter the shoot number of the information boing transmitted. If no shoot number, loave blank.

- Enter the revision number of the information being transmitted. If no revision number, leave blank.

- Enter the title of the document or drawing or a brief description of the subject if no title is identified.

- Enter the appropriate Impact Level (Block 15). Also, indicate the appropriate approvals for each item listed, i.e., SQ, ESQ, otc. Use NA for non-engineering documents.

- Enter the appropriate code to identify the purpose of the date transmittal (see Block 16).

- Enter the appropriate disposition code (80e Block 16).

- Enter the appropriate disposition code (seo Block 16).

- Number codes used in completion of Blocks 15 (G), (H), and (I), and 17 (G), (H) (Signature/Distribution).

- Enter the code of the reason for transmittal (Block 16).

- Enter the code for the disposition (Block 16).

- Enter the signature of the individual completing the Disposition $17(\mathrm{H})$ and the Transmittal.

- Obtain appropriate signaturo(s).

- Enter date signature is obtained.

- Enter MSIN. Note: If Distribution Sheot is used, show ontire distribution (including that indicated on Page 1 of the EDT) on the Distribution Sheot.

- Enter the signature and dote of the individual originating the EDT lentered prior to trensmittal to Receiving Orgenization). If the EDT originator is the cognizent engineer, sign both Blocks 17 and 18.

- Enter the signature and date of the individual identified by the Receiving Orgenization as authorized to approve disposition of the EDT and acceptence of the dete transmitted, as applicablo.

- Enter the signature and date of the cognizent manager. (This signature is authorization for roleses.)

- Enter DOE approvel (if required) by lotter number and indicate DOE action.

-Asteriak denote the required minimum items check by Configuration Documentation prior to reloseo; these ere the minimum rolease requirements. 


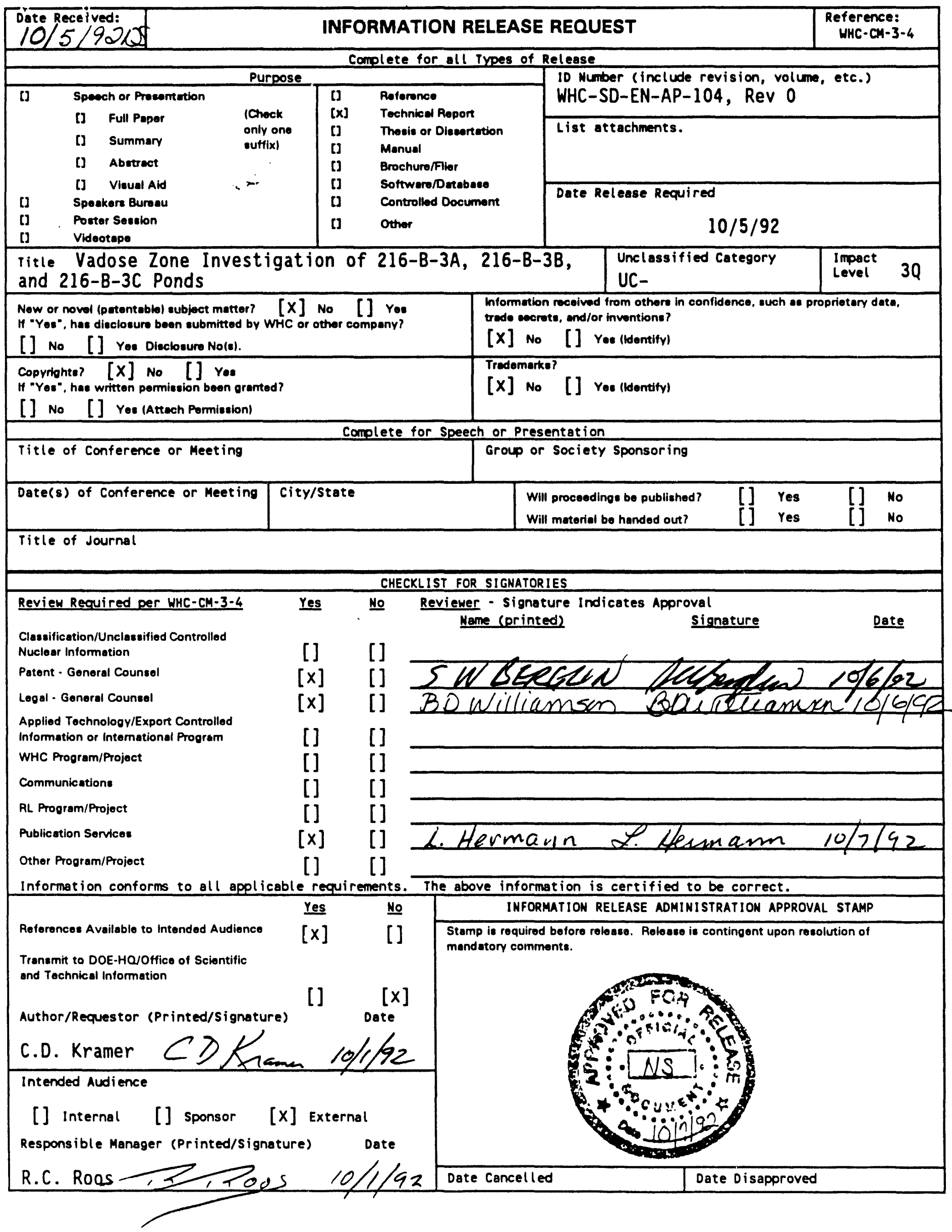


2. Title

Vadose Zone Investigation of 216-B-3A, 216-B-3B, and $216-B-3 C$ Ponds

5. Key Words

Closure, Pond, Characterization, Soil sampling, 216-B-3 Pond, Wastewater

Abstract

\section{APPROVED FOR \\ PUBLICRELFASE}

3. Number

WHC-SD-EN-AP- 104

4. ReV No.

0

\section{Abstract} 1017/9247 dolis

6. Author

Neme: C.D. Kramer

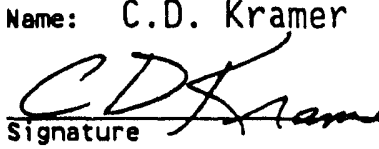

Organization/Charge code

The B-Pond system on the Hanford Site in south-central Washington State is undergoing a series of investigations designed to determine if hazardous or dangerous waste remains in the soils and/or sediments. The pond system has been classified as a Resource Conservation and Recovery Act of 1976 unit, and is undergoing closure under the act. This report summarizes the findings from three temporary borehules constructed to sample soil beneath the 216-B-3A, 216-B-3B, and 216-B-3C Ponds. These field activities comprise Phase 3 investigations as described in 216-B-3 Pond System Closure/Postclosure Plan (DOE 1990). Samples from each borehole were analyzed for a wide variety of organic and inorganic constituents. Representative constituent concentrations indicate vadose zone soils are not contaminated with Resource Conservation and Recovery Act of 1976 regulated hazardous and/or dangerous waste.

8. PU POSE ANO USE OF DOCUMENT - This docume was prepared for use wit in the U.S. Department of gy and its contractors. is to be sed only to perfor direct, or tegrate, the under for pu, ic release y reviewed.

PATENT \& TUS This document copy, singe is transmitted in advance on the clearance, is made avai ole in onfidence solely for use performance of work nder cont cts with the U.S. De tm t of Energy. This dog thit is not to publishes nor its rents herwise disseminat or used for purp es other than spe fied abov before patent proval for such relec or use has in secured, up request, in the Patent Counsel, U.S. Department Energy field ONice, Richrand, WA.

DISCLAIMER - This report was prepared as an account of work sponsored by an agency of the United States Goverment. Neither the United States Goverment nor any agency thereof, nor any of their employees, nor any of their contractors, subcontractors or their employees, makes any warranty, express or implied, or assumes any legal liability or responsibility for the accuracy, completeness, or any third party's use or the results of such use of any information, apparatus, product, or process disclosed, or represents that its use would not infringe privately owned rights. Reference herein to any specific commercial product, process, or service by trade name, trademark, manufacturer, or otherwise, does not necessarily constitute or imply its endorsement, recommendation, or favoring by the United States Goverment or any agency thereof or its contractors or subcontractors. The views and opinions of authors expressed herein do not necessarily state or reflect those of the United States Government or any agency thereof.

9. Impact Level $3 Q$
10. RELEASE STAMP

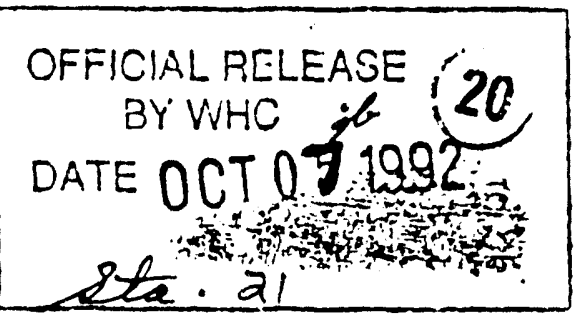


WHC-SD-EN-AP-104 ReV. 0

\section{CONTENTS}

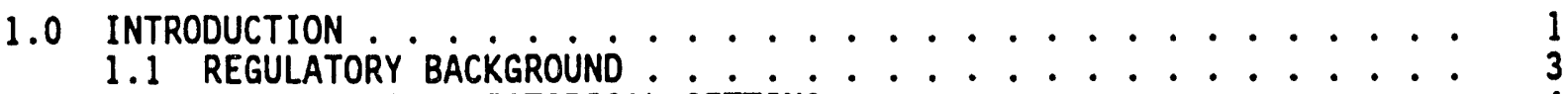

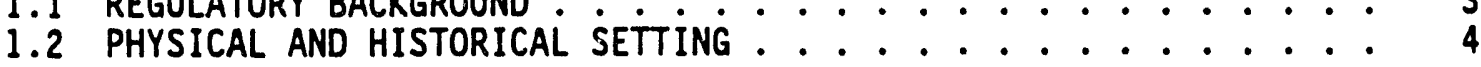

2.0 DISCUSSION OF RECENT WASTE HISTORY . . . . . . . . . . . . . 7

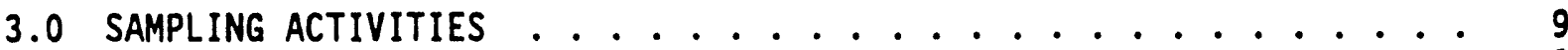

3.1 OBJECTIVE AND SCOPE ................... 9

3.2 ANALYTES INVESTIGATED .................... 9

3.3 DESCRIPTION OF FIELD ACTIVITIES . . . . . . . . . . . . 15

3.3.1 The $3 A$ Pond . . . . . . . . . . . . . . . 15

3.3.2 The $3 B$ Pond ..................... 16

3.3.3 The $3 C$ Pond . . . . . . . . . . . . . . . . 17

4.0 SUMMARY OF RESULTS . . . . . . . . . . . . . . . . . . 19

4.1 ORGANIC CHEMICAL RESULTS ................. . . 19

4.1.1 Pesticides/PCBs ................. 21

4.1.2 Herbicides... . . . . . . . . . . . . . . 24

4.1.3 Organophosphorous Pesticides ............ . 24

4.1.4 Dioxins and Furans................. . 27

4.1.5 Volatile Organic Compounds .. . . . . . . . . . . . 28

4.1.6 Base/Neutral/Acid Compounds .. . . . . . . . . 30

4.2 INORGANIC CHEMICAL RESULTS ................. 33

4.3 RADIOANALYTICAL RESULTS . . . . . . . . . . . . . . . . . . . 42

4.4 GEOLOGY AT THE VADOSE BOREHOLES . . . . . . . . . . . . . . 42

4.5 SOIL PHYSICAL PROPERTIES . . . . . . . . . . . . . . . 43

5.0 DISCUSSION AND COMPARISON TO DANGEROUS WASTE CRITERIA . . . . . 47

6.0 CONCLUSION . . . . . . . . . . . . . . . . . . . 54

7.0 REFERENCES ........................... 55

\section{APPENDICES}

A B-POND PHASE 3 SOIL DATA . . . . . . . . . . . . . . . . . . A- $i$

B ANALYTE VARIABILITY GRAPHS .................... B- . . . .

C ENVIRONMENTAL PROTECTION AGENCY OFFICE OF SOLID WASTE AND EMERGENCY RESPONSE MEMORANDUM $. . . . . . . . . . . . . . . . . . . C-i$ 
WHC-SD-EN-AP-104 ReV. 0

\section{LIST OF FIGURES}

1-1. The Hanford Site and the Study Borehole Locations . . . . . . . 2

\section{LIST OF TABLES}

3-1. Inorganic Parameters ................... 10

3-2. Organic Parameters ..................... 11

3-3. B-Pond Phase 3 Borehole Sample Key ................ 12

4-2. Pesticides/PCB Sample Result Summary -- 31 Regular Samples . . . 22

4-3. Split Sample Results for Pesticides/PCBs . . . . . . . . . . 23

4-4a. Organophosphorous Pesticide Reporting -- 18 Regular Samples (Short List). . . . . . . . . . . . . . . . . 25

4-4b. Organophosphorous Pesticide Reporting -- 13 Regular Samples (Long List) ...................... . 26

4-5. Internal Standard Percent-Recovery Summary

Dioxins and Furans (25 Samples) .............. . 27

4-6. VOA Surrogate Percent-Recovery Summary

(37 Samples--50 $\mu \mathrm{g} / \mathrm{Kg}$ Spikes) . . . . . . . . . . . . . 28

4-7. Semivolatile Surrogate Percent-Recovery Surmary

(37 Primary Laboratory Samples) . . . . . . . . . . . . . 31

4-8. Summary Statistics--Regular Samples ( $\mu \mathrm{g} / \mathrm{g})$. . . . . . . . . . . 34

4-9. Field Duplicate and Split Comparison Summary . . . . . . . . . 40

4-10. Physical Properties B-Pond Phase 3 Soil Samples . . . . . . . . 44

4-11. Grain Size Analysis ..................... . 45

5-1. Evaluation of Inorganic Dangerous Waste Constituents in all Regular Samples . . . . . . . . . . . . . . . . . . . 49 


\section{LIST OF TERMS}

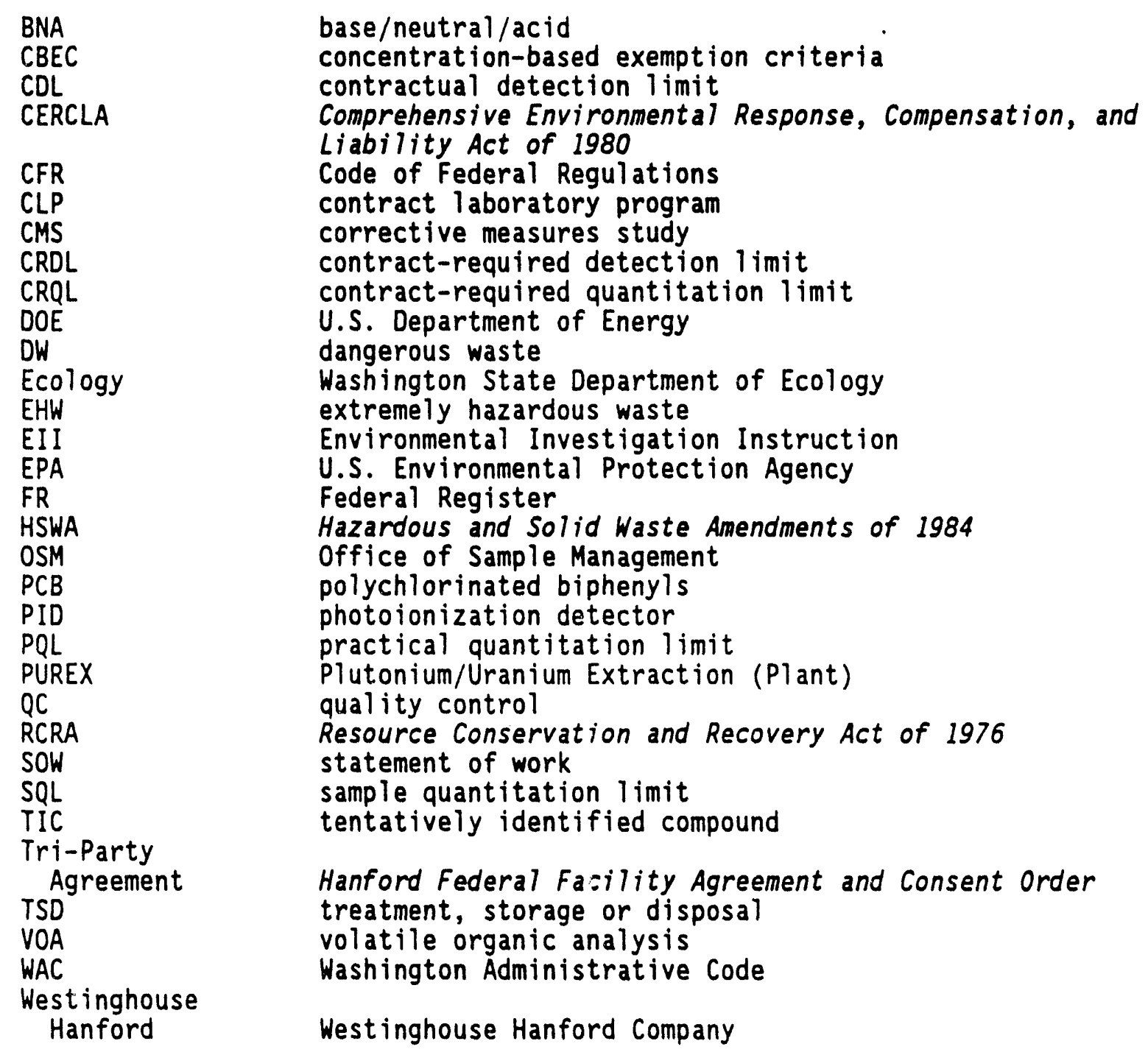


WHC-SD-EN-AP-104 Rev. 0

This page intentionally left blank. 
WHC-SD-EN-AP-104 Rev. 0

\subsection{INTRODUCTION}

A number of waste management units located on the Hanford Site in southcentral Washington State are being physically and/or procedurally closed in accordance with applicable laws, regulations, and agreements. One unit, the 216-B-3 Pond System (B-Pond), consists of one main pond area, three expansion ponds (often referred to as lobes) and the 216-B-3-3 Ditch. This series of ponds lies immediately east of the Hanford Site's 200 East Area (Figure 1-1). The B-Pond has been considered a Resource Conservation and Recovery Act of 1976 (RCRA) treatment, storage, or disposal (TSD) unit (Ecology et al. 1989, $p$ $B-2)$ comprised of the following:

- Open section of the 216-B-3-3 Ditch, approximately 3,700 ft

- 216-B-3 Pond (main pond), approximately 35 acres

- 216-B-3A Pond (hereafter referred to as the $3 A$ Pond), approximately 11 acres

- 216-B-3B Pond (hereafter referred to as the 3B Pond), approximately 11 acres

- 216-B-3C Pond (hereafter referred to as the $3 C$ Pond), approximately 41 acres.

The B-Pond receives wastewater from a variety of sources in the 200 East Area. The system is fully described in the 216-B-3 Pond system

closure/Postclosure Plan (closure plan) (DOE 1990). Wastewater enters the southwest side. of the main pond via the 2.16-B-3-3 Ditch. The system is designed to handle in excess of $28,000,000$ gal/day. The discharge primarily consists of atmospheric condensate, cooling water, potable water, and steam condensate (DOE 1990, p 3-1). In 1989, over 3,000,000,000 gallons of water were discharged to B-Pond (WHC 1990). Much of this is unfiltered, untreated water originating from the Columbia River. Current discharges to B-Pond are considered nonhazardous.

Some past discharges to B-Pond are suspected to have included waste that would currently be regulated under RCRA (DOE 1990, p 1-1). Some discharges have also included radioactive wastes.

Analysis of the pond soil and sediments is being conducted to assess the possible presence and extent of hazardous waste contamination (DOE 1990, $p$ 71). Initial sampling efforts examined surface soil and sediment composition. (For more detail refer to WHC 1991.) Subsequent activities have involved drilling vadose zone boreholes.

This report summarizes the findings of three subsurface (vadose zone) temporary characterization boreholes: 699-43-41H, 699-42-41B, and 699-41-41. Areas investigated include the $3 A$ Pond, the $3 B$ Pond, and the $3 C$ Pond (Figure 1-1). As proposed in the closure plan, one vadose zone borehole was drilled in each lobe (DOE 1990, p 7-16). 
WHC-SD-EN-AP-104 Rev. 0

Figure 1-1. The Hanford Site and the Study Borehole Locations.

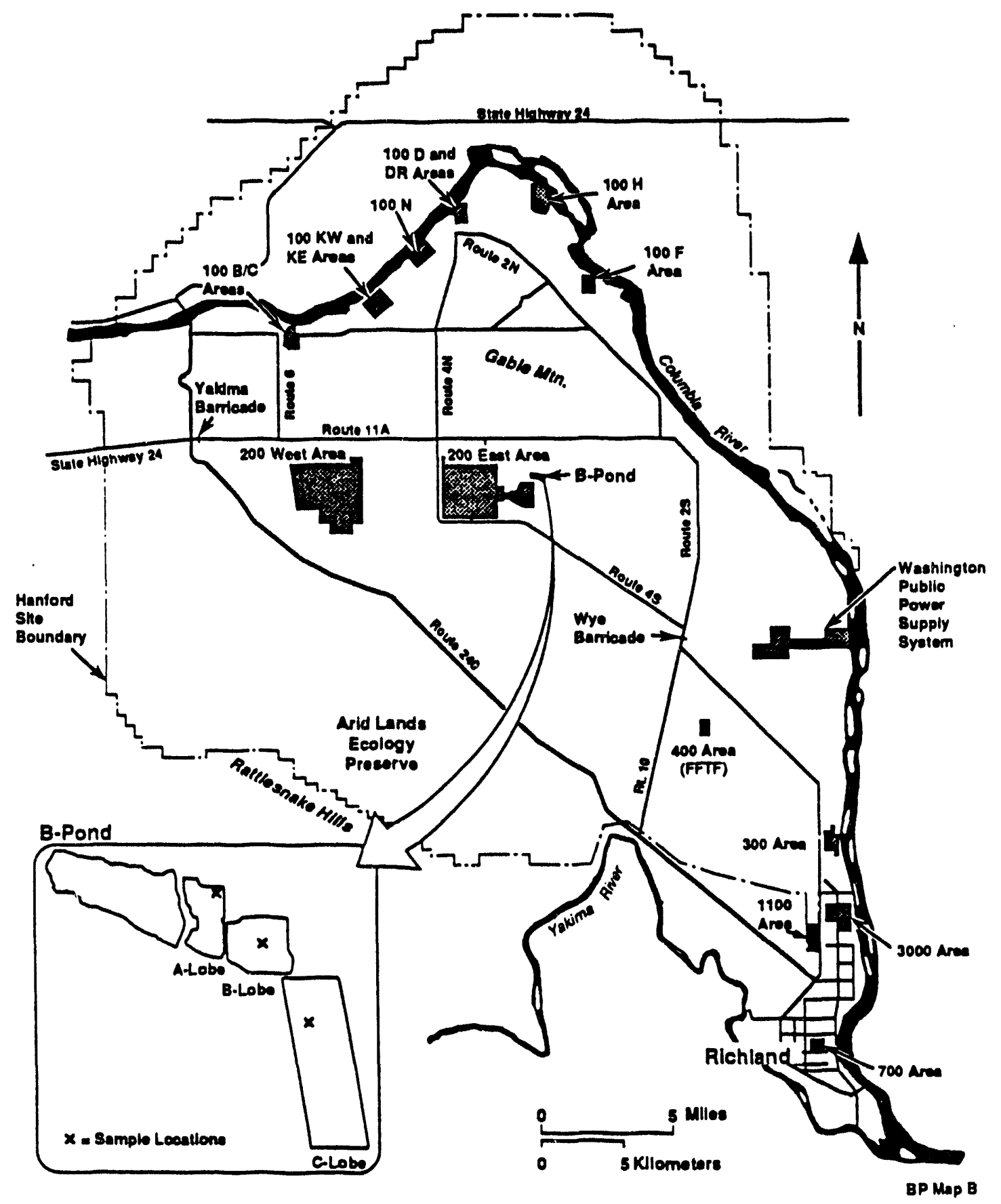


WHC-SD-EN-AP-104 Rev. 0

\subsection{REGULATORY BACKGROUND}

The U.S. Environmental Protection Agency (EPA) and Washington State Department of Ecology (Ecology) jointly administer RCRA in the State of Washington. The EPA retains oversight authority while delegating to Ecology enforcement of a state program consistent with or more stringent than the corresponding federal program. The implementing regulations can be found in the Washington Administrative Code (WAC) 173-303, "Dangerous Waste Regulations", and Title 40, Code of Federal Regulations (CFR), Parts 260-270. Ecology's authorization includes administering TSD closures. However, the state is currently not authorized to enforce the federal Hazardous and Solid Waste Amendments of 1984 (HSWA), which includes RCRA corrective-action provisions.

The U.S. Department of Energy (DOE), EPA, and Ecology have entered into an agreement called the Hanford Federal Facility Agreement and Consent Order (Ecology et al. 1989), commonly referred to as the Tri-Party Agreement. This agreement affects environmental regulation at the Hanford Site. One of purposes of this agreement was to ensure environmental impacts associated with past activities are investigated, and appropriate response actions taken as necessary to protect human health and the environment. The agreement seeks to promote this goal in part, by identifying TSD units, identifying which units will undergo closure and promote compliance with relevant RCRA permitting requirements. The agreement also establishes "operable units" for addressing potential environmental contamination from past practices.

The B-Pond is identified as a RCRA TSD unit that will be closed in accordance with applicable laws and regulations (Ecology et a1. 1989. Appendix $B)$. The B-Pond is considered an interim status, surface impoundment disposal unit (DOE 1990, p 1-1).

Although current liquid discharges to the pond are not considered hazardous or dangerous, RCRA closure has been necessitated by the concern that B-Pond soil and sediments may "contain" hazardous or dangerous waste from past activities. Environmental media such as water, soil, or sediments may be managed as a hazardous waste when they contain a listed waste (EPA Office of Solid Waste and Emergency Response memorandum, Cannon to Jorling, 1989, refer to Appendix C). Generally, regulated hazardous characteristic wastes, for instance wastes that are hazardous solely due to corrosivity, are no longer regulated hazardous wastes when they loose the characteristic that caused them to be managed as such (40 CFR 261.3 (a)(2)(i)). Dilution and neutralization for instance, can render a corrosive hazardous waste as nonhazardous.

Clean closure requires the demonstration that all dangerous and/or hazardous wastes or waste constituents posing any significant hazard to human health or the environment have been removed. The Tri-Party Agreement describes three types of closure: closure as a landfill, clean closure, and procedural closure (Ecology et a1. 1989, Action Plan-Section 6.3). Clean closure is the planned option for the portion of B-Pond addressed by this report: the $3 A, 3 B$, and $3 C$ Ponds (DOE 1990, $p$ 1-2). If a unit no longer contains significant hazardous waste or constituents, no physical closure action may be required.

According to the WAC 173-303, a specific scheme must be followed in determining whether or not a solid waste is a regulated hazardous waste. This 
WHC-SD-EN-AP-104 Rev. 0

scheme requires knowledge of the process by which the waste was generated and the attributes of the waste. Current Washington State designation procedures (WAC 173-303-070), require generators to check their waste per specified criteria in a specific order.

Under the "Dangerous Waste Regulations," a dangerous waste means a solid waste designated via WAC 173-303-070 through 173-303-103 as either dangerous waste (DW) or extremely hazardous waste (EHW). Those regulations use the words "hazardous waste" to mean those solid wastes designated by 40 CFR 261, and regulated as hazardous by the EPA. This document will henceforth be consistent with existing state regulations by using the term "dangerous waste" to mean waste regulated by WAC 173-303, including DW, EHW, and EPA hazardous wastes.

Normally TSD units will have all hazardous substances addressed as part of the TSD closure. However, disposal units such as B-Pond being closed in conjunction with an operable unit may have hazardous substances (including radioactive constituents) addressed under the Comprehensive Environmental Response, Compensation and Liability Act of 1980 (CERCLA) past-practice authority (Ecology et a1. 1989, Action Plan P 6-4). "Hazardous substances" are defined in CERCLA Section 101(14). When investigation shows that a unit no longer contains substantial dangerous waste or constituents, any remaining CERCLA-only materials would be addressed as part of the past-practice process designated for that operable unit (Ecology et al. 1989, Action Plan p 6-4).

The B-Pond is part of the 200-BP-11 operable unit (Ecology et al. 1989, Appendix C).

\subsection{PHYSICAL AND HISTORICAL SETTING}

The B-Pond lies on an arid isolated tract of land near the center of the Hanford Site. Water is supplied to the pond system through a series of lines exiting the Site's 200 East Area. Water presently flows into the approximately 35-acre main pond through the 216-B-3-3 Ditch.

The vicinity of the main pond has received liquid effluent from activities in the 200 East Area since 1945. The level of the pond and the inflow have changed over time. Originally the pond was supplied through the 216-B-3-1 Ditch. In 1964 this ditch was replaced by the 216-B-3-2 Ditch. In 1970 the 216-B-3-2 Ditch was replaced by the 216-B-3-3 Ditch The 216-B-3-3 Ditch is currently operative. Both the 216-B-3-1 and 216-B-3-2 Ditches were radioactively contaminated and were removed from service and filled with soil to reduce potential radioactive contaminant mobility.

The three expansion ponds, the $3 A, 3 B$, and $3 C$ Ponds, were placed in service much later than the main pond. Flow from the main pond is directed to the $3 A$ Pond and then either to the $3 B$ Pond or the $3 C$ Pond. Flow is controlled. Use of the $3 A$ Pond commenced in October 1983 (DOE 1990, p 2-19). The 3B Pond was in service from January 1984 until May 1985. The 3C Pond became operational in 1985.

The $3 \mathrm{~A}$ Pond is a shallow pond approximately 11 acres and $12 \mathrm{ft}$ deep. It was constructed using a cut-and-fill method. In January of 1984 the dike between the $3 A$ and the $3 B$ Ponds and adjacent to the connecting spillway failed 
(DOE 1990, p 2-19). Overflow from the $3 A$ Pond was contained in the previously unused $3 B$ Pond. Flow to $B-P$ ond was reduced, and the $3 A$ and $3 B$ Ponds were removed from service for repairs. A trench approximately $30 \mathrm{ft}$ wide and $5 \mathrm{ft}$ deep was excavated along part of the $3 A$ Pond bottom to increase the pond's infiltration capacity. Discharge was resumed to $3 \mathrm{~A}$ Pond at a temporarily reduced rate in the newly excavated area. A new spilliway was constructed to connect 3B Pond. Debris from the dike failure was removed from 3B Pond. A system of infiltration trenches were excavated in $3 B$ Pond. Both ponds were fully operational by June 1984 .

The 3B Pond, which is currently dry, is al so approximately 11 acres. It has not been used since being removed from service in May 1985 (DOE 1990, p 232). After being removed from service, the area was excavated to a depth below the bottom of the former trenches. According to the closure plan, up to $7 \mathrm{ft}$ of material was excavated from the pond bottom (DOE 1990, p 2-32).

The 3C Pond, approximately 41 acres in total size, has a series of eight partially filled, parallel infiltration trenches into which water from $3 \mathrm{~A}$ Pond is usually channelled. The water in $3 C$ Pond has never risen above the tops of the trenches, which cover a much smaller total area than the pond itself. The trenches are not usually wet along their entire length. The kater level and, therefore, the area wetted longitudinally vary with time.

A contingency pond, 216-E-28, was constructed in 1987 to provide emergency overflow capability for B-Pond. This contingency pond 1 ies north and slightly west of the main pond. The area is dry and has never been used. The contingency pond is mentioned in this report only because it was one of two sites used to generate background values for earlier comparisons (WHC 1991).

Sagebrush and native plants populate the undisturbed areas around B-Pond. Typical littoral vegetation is naturally developing along the edge of the $3 \mathrm{~A}$ Pond and the trenches of the $3 C$ Pond. Each of the three expansion ponds is circumscribed by graveled and/or unimproved roads. Some adjacent areas disturbed by spiliway construction, etc. have been revegetated. 
WHC-SD-EN-AP-104 Rev. 0

This page intentionally left blank. 
WHC-SD-EN-AP-104 Rev. 0

\subsection{DISCUSSION OF RECENT WASTE HISTORY}

This section summarizes dangerous waste releases to B-Pond since October 1983 as described in the closure plan (DOE 1990). The general period of operation for the expansion ponds was as follows:

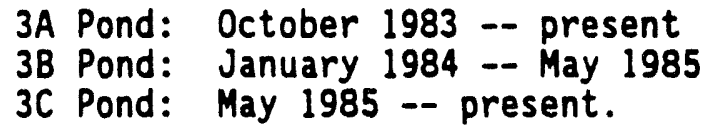

B-Pond had two points of inflow during the period from 1983 through 1992. Water continuously flowed into the 216-8-3-3 Ditch via a pipe at the headend. In addition, midway to the main pond, flow was supplemented by effluent from the 216-A-29 Ditch. Wastewater discharged at the headend of the 216-B-3-3 Ditch since October 1983 has included raw water, sanitary (potable) water, cooling water, steam condensate, filter backwash from the water treatment plant, etc. (DOE 1990, p 3-2). No contributing source has been identified as a dangerous waste.

The unlined 216-A-29 Ditch is a separate TSD unit. It had been used as an open ditch conveying wastewater to B-Pond. In 1991 it was decommissioned and backfilled. Wastewater from the PUREX chemical sewer 1 ine had been routinely released to the 216-A-29 Ditch before entering B-Pond. The open 216-A-29 Ditch extended over 2,000 ft before discharging into the 216-B-3-3 Ditch of B-Pond.

The closure plan (Rev. 0) lists the Plutonium/Uranium Extraction (PUREX) Plant chemical sewer 1 ine as the most likely contributor of any dangerous waste to B-Pond while the expansion ponds were operable (DOE 1990, p 4-3). Documented releases were assessed (DOE 1990, $p$ 4-6). The following chemicals were traceable components of the chemical sewer line wastewater: potassium hydroxide, sodium hydroxide, cadmium nitrate, hydrazine, nitric acid, and sulfuric acid (DOE 1990, Table 4-3). A single documented release to the PUREX chemical sewer of solution containing ammonium fluoride and ammonium nitrate occurred in July 1985 (DOE 1990, p 4-7).

The chemical sewer line wastewater was conservatively judged to be a regulated dangerous waste during some of those documented releases. Applicable designation codes are D002, WTO2, U133, WTO1 and D006. These constitute all dangerous waste numbers listed on Revision 3 of the Part $A$, Form 3, Dangerous Waste Permit Application submitted for B-Pond (DOE 1990, p 1-10). The last chemical sewer discharge suspected of being a dangerous waste occurred in 1986 (DOE 1990, Table 4-3).

Each of the above releases to the 216-A-29 Ditch was designated as a dangerous waste based on characteristics or criteria, except for those releases containing hydrazine, a "listed" discarded chemical product (U133) (DOE 1990, Table 4-3). Wastes designated 0002 are deemed hazardous based on corrosivity; 0006, WTO1 and WTO2 wastes are regulated because of their toxicity. These designations were not made on the average or representative flow, but were based on specific incidences when high concentrations of chemicals were documented to have been released from the chemical sewer line to the 216-A-29 ditch. 
The chemical sewer line wastewater attributes were estimated based on process knowledge, and were not measured nor estimated at the point that the 216-A-29 Ditch empties into the 216-B-3-3 Ditch of B-Pond. The closure plan specifically states that these designations were "at the point the chemical sewer line enters the environment" (DOE 1990, p 4-6). Further attenuation would occur as the liquid waste stream flowed the full length of the 216-A-29 Ditch, mixed with the additional flow of the 216-B-3-3 Ditch, and dispersed in the main lobe before any flow to $3 A, 3 B$, or $3 C$ Ponds. 


\subsection{SAMPLING ACTIVITIES}

A Westinghouse Hanford Company (Westinghouse Hanford) sampling plan, 216-B-3 Pond Characterization of the Hazardous Waste Inventory in the NearSurface Soil and Sediments (WHC 1989a), in conjunction with approved modifications and procedures, has been used in the B-Pond site characterization effort. The sampiing plan sets forth a phased approach toward characterizing the soils and sediments of B-Pond.

Phase 1 was an initial sampling effort assessing near-surface soil contamination within the main pond, the 216-B-3-3 Ditch, and the three expansion ponds. Phase 1 included measuring constituents in two types of background areas in the vicinity of the site. Phase 1 activities are summarized in Phase 1 Characterization of the 216-B-3 Pond System (WHC 1991).

Phase 2 is planned as an extension of the Phase 1 characterization work using data and knowledge gathered from Phase 1 and Phase 3.

Phase 3 , the subject of this report, examines the vertical distribution of potential contaminants beneath the surface soil. Field activities involved drilling one vadose zone borehole in each of the expansion ponds. Soil samples were collected and submitted for chemical analyses similar to those performed in Phase 1. Additionally, some nonchemical data were collected in conjunction with the drilling effort. Each hole was logged by a qualified geologist as drilling was performed. Some samples were submitted for physical analyses, such as grain size. Gross gamma logging was also performed on each borehole.

\subsection{OBJECTIVE AND SCOPE}

The objective of Phase 3 characterization sampling was to collect data addressing the issue of potential vadose zone chemical contamination with dangerous waste. Efforts focused on the subsurface of the three expansion ponds. The current closure plan has proposed to address potential subsurface contamination in the main pond with the remedial activities of the operable unit, 200-BP-11. This report summarizes Phase 3 activities and findings.

This investigation was limited to the vadose zone, the portion of the earth's crust above the water table. "Soil" is meant to be understood in the context of environmental cleanup regulations. This report does not address groundwater.

\subsection{ANALYTES INVESTIGATED}

Although B-Pond was declared a RCRA TSD unit, current discharge to the unit is nondangerous waste. Although releases from the PUREX chemical sewer line to the 216-A-29 Ditch TSD have been documented, existence of the regulated characteristics or criteria in the downstream TSD (B-Pond) have been postulated, but not demonstrated. Substances of concern are concentrations of a potential waste residual that could cause the water, soil/(sediment), or subsoil to be managed as a dangerous waste under Ecology's "Dangerous Waste Regulations," (WAC 173-303). 
Constituents and/or attributes not regulated under the "Dangerous Waste Regulations" are reported as part of the site characterization. It should not be inferred that all analytes are pertinent to determining whether or not a RCRA dangerous waste is present. For instance, the characteristic of radioactivity is not a criterion for determining whether or not a waste is a RCRA dangerous waste; however this information may be applicable to later CERCLA work at the site. With regard to listed waste, generally detection in an environmental media such as soil or sediment is sufficient to be of regulatory concern. However, the EPA has allowed hazardous waste management to cease when the constituents are less than de minimis levels--most commonly those posing no health threat when directly ingested.

Inorganic parameters measured in Phase 3 include those listed in Table 3-1.

Table 3-1. Inorganic Parameters.

\begin{tabular}{||l|c|l|c||}
\hline Analyte & EPA Method & Analyte & EPA Method \\
\hline Aluminum & 6010 & Magnesium & 6010 \\
\hline Ammonia & 350.3 & Manganese & 6010 \\
\hline Antimony & 6010 & Mercury & 7471 \\
\hline Arsenic & 7060 & Molybdenum & 6010 \\
\hline Barium & 6010 & Nickel & 6010 \\
\hline Beryllium & 6010 & Nitrate & 300.0 \\
\hline Boron & 6010 & Potassium & 6010 \\
\hline Cadmium & 6010 & Selenium & 7740 \\
\hline Calcium & 6010 & Silicon & 6010 \\
\hline Chloride & 300.0 & Silver & 6010 \\
\hline Chromium & 6010 & Sodium & 6010 \\
\hline Cobalt & 6010 & Sulfate & 300.0 \\
\hline Copper & 6010 & Sulfide & 376.1 \\
\hline Cyanide & 9010 & Thallium & 7841 \\
\hline Fluoride & 300.0 & Vanadium & 6010 \\
\hline Iron & 6010 & Zinc & 6010 \\
\hline Lead & 7421 & & \\
\hline
\end{tabular}

Spl it samples were analyzed and reported according to Contract Laboratory Program (CLP) protocol found in the March 1990 Statement of Work (SOW) for Inorganic Analysis. The following inorganic analytes were reported for split samples: aluminum, antimony, arsenic, barium, beryllium, cadmium, calcium, chromium, cobalt, copper, cyanide, iron, lead, magnesium, manganese, mercury, nickel, potassium, selenium, silver, sodium, thallium, vanadium, and zinc.

Organic compounds evaluated at the primary laboratory include those listed in Table 3-2. 
WHC-SD-EN-AP-104 Rev. 0

Table 3-2. Organic Parameters.

\begin{tabular}{|c|c|c|c|}
\hline Analytical Class & $\begin{array}{l}\text { EPA/Other } \\
\text { Method }\end{array}$ & Analytical Class & $\begin{array}{l}\text { EPA/Other } \\
\text { Method }\end{array}$ \\
\hline $\begin{array}{l}\text { Pesticides/Polychlorinated } \\
\text { biphenyls (PCBS) }\end{array}$ & 8080 & Dioxins/Furans & 8280 \\
\hline Herbicides & 8150 & $\begin{array}{l}\text { Volatile Organic } \\
\text { Compounds }\end{array}$ & $A C D 2440^{\prime}$ \\
\hline $\begin{array}{l}\text { Organophosphorous } \\
\text { Pesticides }\end{array}$ & 8140 & $\begin{array}{l}\text { Base/Neutral/Acid } \\
\text { (BNA) Compounds }\end{array}$ & $A C D 2470^{2}$ \\
\hline
\end{tabular}

The specific chemicals reported for each of the above categories can be found in Appendix A. These lists contain only those routinely reported compounds in each class. Additional volatile and semivolatile compounds could be reported as tentatively identified compounds (TICS).

Some split samples were also analyzed and reported according to CLP protocol for the following organic analytes:

Target Compound List Volatiles (CLP SOW 2/88--Rev. 5/89)

Target Compound List Semivolatiles (CLP SOW 2/88--Rev. 5/89)

Pesticide and PCB Target Compounds (CLP SOW)

One split, sample BOOGW5, was analyzed for semivolatiles by EPA 8270 .

Radioactivity measurements were al so made on Phase 3 soil samples. Gross alpha, beta activity, ${ }^{90} \mathrm{Sr}$, and gamma activity radiochemical analyses were conducted using EPA-900 series procedures.

A sample key showing sample identification numbers and associated field data can be found in Table 3-3. 
Table 3-3. B-Pond Phase 3 Borehole Sample Key. (3 sheets)

\begin{tabular}{|c|c|c|c|c|c|c|c|}
\hline Semple & Type & Pond & Depth" & $\begin{array}{c}\text { Collection } \\
\text { Date }\end{array}$ & \multicolumn{2}{|c|}{ Interval b } & $\begin{array}{l}\text { Classification } \\
\text { from Borehole Log }\end{array}$ \\
\hline BOOFK6 & Reg & $3 A$ & 6.5 & $2 / 7 / 91$ & 4.95 & 7.55 & silty Sand \\
\hline BOOFK7 & Reg & $3 n$ & 8.5 & $2 / 7 / 91$ & 6.9 & 10.2 & $n$ \\
\hline B00FK8 & $R \in g$ & $3 A$ & 10.5 & $2 / 7 / 91$ & 9.6 & 11.75 & Sand \\
\hline BOOFK9 & Reg & $3 A$ & 13 & $2 / 7 / 91$ & 11.8 & 14.0 & Sandy Gravel \\
\hline BOOFLO & Reg & $3 A$ & 16.5 & $2 / 7 / 91$ & 13.5 & 15.7 & $n$ \\
\hline BOOFLI & Reg & $3 A$ & 16 & $2 / 8 / 91$ & 14.7 & 17.0 & " \\
\hline$B 00 F L 2$ & Phys & $3 A$ & 21.5 & $2 / 11 / 91$ & 20.4 & 23 & $"$ \\
\hline$B 00 F L 3$ & 8 lank & $3 A$ & $\cdots$ & $2 / 11 / 91$ & MA & & $\begin{array}{l}\text { (silica Sand Control } \\
\text { Sample) }\end{array}$ \\
\hline BOOFLL & Reg & $3 A$ & 28 & $2 / 11 / 91$ & 26.4 & 29.3 & Sandy Gravel \\
\hline BOOGR9 & Fodp & $3 A$ & 28 & $2 / 11 / 91$ & 26.4 & 29.3 & " \\
\hline BOOGSO & Reg & $3 A$ & 31.5 & $2 / 11 / 91$ & 30.5 & 32.6 & $n$ \\
\hline BoOGS1 & Reg & $3 A$ & 36.5 & $2 / 12 / 91$ & 35.55 & 37.71 & $\begin{array}{l}\text { Sandy Gravel/ Slighely } \\
\text { silty Sand/ Sand }\end{array}$ \\
\hline BoOGS2 & Reg & $3 A$ & 42 & $2 / 13 / 91$ & 40.4 & 43.25 & Sand \\
\hline BooGs3 & Reg & $3 A$ & 46.5 & $2 / 13 / 91$ & 45.45 & 48.0 & $n$ \\
\hline 800056 & Phys & $3 A$ & $52^{\mathrm{C}}$ & $2 / 14 / 91$ & 51.13 & 54.10 & Silty Sand \\
\hline B00GS4 & Reg & $3 A$ & 52.5 & $2 / 14 / 91$ & 51.13 & 54.10 & Sandy silt \\
\hline 800655 & Split & $3 A$ & 52.5 & $2 / 14 / 91$ & 51.13 & 54.10 & $"$ \\
\hline B00GS7 & Phys & $3 n$ & 54.5 & $2 / 14 / 91$ & 53.0 & 55.6 & Sandy silt/ Sand \\
\hline BOOGSB & Reg & $3 A$ & 57 & $2 / 14 / 91$ & 56 & 58.4 & Sand \\
\hline BOOGSO & Reg & $3 A$ & 66.5 & $2 / 15 / 91$ & 65.35 & 67.65 & Sandy Gravel \\
\hline BOOGTO & Phys & $3 A$ & 68.5 & $2 / 15 / 91$ & 67.5 & 69.65 & Sand \\
\hline BOOGTI & Reg & $3 A$ & $\pi$ & $2 / 19 / 91$ & 75.7 & 77.90 & " \\
\hline B00GT2 & Phys & $3 A$ & $\pi$ & $2 / 19 / 91$ & $\pi .7$ & 77.90 & " \\
\hline B00GT3 & Blank & $3 A$ & $\cdots$ & $2 / 20 / 91$ & MA & & $\begin{array}{l}\text { (silica send Control } \\
\text { Semple) }\end{array}$ \\
\hline 800674 & Reg & $3 A$ & 85.5 & $2 / 21 / 91$ & 84.1 & 86.68 & Send \\
\hline BO0GT5 & Fodp & $3 A$ & 85.5 & $2 / 21 / 91$ & 84.1 & 86.68 & $n$ \\
\hline BOOGT6 & Split & 31 & 85.5 & $2 / 21 / 91$ & 84.1 & 86.68 & $n$ \\
\hline Bo0GT7 & Reg & 31 & 97 & $2 / 21 / 91$ & 95.7 & 98.3 & Sandy Gravel \\
\hline BOOGT8 & Reg & $3 A$ & 102 & $2 / 22 / 91$ & 101.6 & 102.2 & $\begin{array}{l}\text { slightly silty, } \\
\text { slightly Gravelly sand }\end{array}$ \\
\hline BOOGT9 & Phys & $3 A$ & 102 & $2 / 22 / 91$ & 101.6 & 102.2 & $"$ \\
\hline BooGvo & Reg & $3 A$ & 122 & $2 / 26 / 91$ & 120.7 & 123.2 & Sandy Gravel \\
\hline B0OGV1 & Blenk & $3 n$ & $\cdots$ & $2 / 27 / 91$ & $M A$ & & $\begin{array}{l}\text { (silica Sand Control } \\
\text { Sample) }\end{array}$ \\
\hline BoogV2 & Reg & $3 A$ & 131 & 2/27/91 & 129.9 & 132.05 & Sandy Gravel \\
\hline $800 \mathrm{G} \sqrt{3}$ & Fodp & $3 A$ & 131 & $2 / 27 / 91$ & 129.9 & 132.05 & $\omega$ \\
\hline $800 \mathrm{GV}$ & Split & $3 A$ & 131 & $2 / 27 / 91$ & 129.9 & 132.05 & $"$ \\
\hline BooGVs & Reg & $3 A$ & 143.5 & $2 / 28 / 91$ & $142 . \pi 5$ & 163.85 & $"$ \\
\hline $800 \mathrm{GV} 6$ & Reg & 38 & 1 & $3 / 4 / 91$ & 0 & 2 & Silty Sandy Gravel \\
\hline $800 G V 7$ & Reg & $3 B$ & 3.5 & $3 / 4 / 91$ & 2.5 & 4.5 & " \\
\hline $800 G V 8$ & Reg & 38 & 5.5 & $3 / 4 / 91$ & 4 & 6.55 & " \\
\hline
\end{tabular}


WHC-SD-EN-AP-104 Rev. 0

Table 3-3. B-Pond Phase 3 Borehole Sample Key. (3 sheets)

\begin{tabular}{|c|c|c|c|c|c|c|c|}
\hline Sunple & Type & Pond & Depth" & $\begin{array}{c}\text { Collection } \\
\text { Date }\end{array}$ & \multicolumn{2}{|c|}{ interval ${ }^{b}$} & $\begin{array}{l}\text { Classification } \\
\text { from Borehole Log }\end{array}$ \\
\hline Bo06V9 & Blank & 38 & $\cdots$ & $3 / 5 / 91$ & \multicolumn{2}{|l|}{ MA } & $\begin{array}{l}\text { (Sillice Sand Control } \\
\text { sample) }\end{array}$ \\
\hline BOOGNO & Reg & 38 & 7.5 & $3 / 5 / 91$ & 6.2 & 8.4 & Sand \\
\hline 800GW1 & Reg & 38 & 9.5 & $3 / 5 / 91$ & 8.2 & 10.85 & 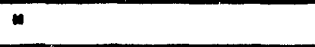 \\
\hline BOOGW2 & Phys & 38 & 9.5 & $3 / 5 / 91$ & 8.2 & 10.85 & $n$ \\
\hline $800 \mathrm{G} / 3$ & Reg & 3B & 13 & $3 / 5 / 91$ & 11.4 & 14.1 & Sendy Gravel \\
\hline BO00W4 & Foup & 38 & 13 & $3 / 5 / 91$ & 11.4 & 14.1 & $"$ \\
\hline 800 GW5 & Spl it & 3B & 13 & $3 / 5 / 91$ & 11.4 & 14.1 & " \\
\hline BOOGW6 & Reg & 38 & 16 & $3 / 5 / 91$ & 14.4 & 17.1 & silty Sandy Gravel \\
\hline $800 \mathrm{GW7}$ & Phys & $3 B$ & 16 & $3 / 5 / 91$ & 14.4 & 17.1 & " \\
\hline BOOGUS & Reg & 38 & 21 & $3 / 6 / 91$ & 19.2 & 22.5 & $"$ \\
\hline BooGw9 & Reg & $3 B$ & 28 & $3 / 6 / 91$ & 25.9 & 29.6 & $n$ \\
\hline$B 00 G \times 0$ & Phys & 3B & 28. & $3 / 6 / 91$ & 25.9 & 29.6 & $n$ \\
\hline $8006 \times 1$ & Phys & 3B & 28 & $3 / 6 / 91$ & 25.9 & 29.6 & $"$ \\
\hline $8006 \times 2$ & Reg & 38 & 31 & $3 / 6 / 91$ & 29.5 & 32.2 & $"$ \\
\hline $8006 \times 3$ & Reg & 38 & 35.5 & $3 / 7 / 91$ & 36.0 & 36.8 & $"$ \\
\hline $8006 \times 4$ & Reg & $3 B$ & 40 & $3 / 7 / 91$ & 38.8 & 49.4 & $\omega$ \\
\hline $8006 \times 5$ & Reg & $3 B$ & 52 & $3 / 8 / 91$ & 50.8 & 52.95 & $\begin{array}{l}\text { Silty Sandy Gravel/ } \\
\text { silty Gravel }\end{array}$ \\
\hline $8006 \times 6$ & Reg & 38 & 61.5 & $3 / 8 / 91$ & 60.0 & 62.6 & $\begin{array}{l}\text { Silty Sandy Gravel/ } \\
\text { Sand }\end{array}$ \\
\hline $8006 \times 7$ & Phys & 38 & 61.5 & $3 / 8 / 91$ & 60.0 & 62.6 & $n$ \\
\hline $8006 \times 8$ & Reg & 38 & 70.5 & $3 / 8 / 91$ & 69.6 & 79.8 & silty Sandy Gravel \\
\hline $8006 \times 9$ & Phys & 38 & 73 & $3 / 11 / 91$ & 72.25 & 74.15 & $\omega$ \\
\hline BOOGYO & Blank & 3B & $\cdots$ & $3 / 12 / 91$ & MA & & $\begin{array}{l}\text { (silica sand Control } \\
\text { Semple) }\end{array}$ \\
\hline $800 G Y 1$ & Reg & $3 B$ & 80.5 & $3 / 12 / 91$ & 79.75 & 81.5 & Gravelly sand \\
\hline BO0GY2 & Foup & 38 & 80.5 & $3 / 12 / 91$ & 79.75 & 81.5 & " \\
\hline 800GY9 & Split & 38 & 80.5 & $3 / 12 / 91$ & 79.73 & 81.5 & " \\
\hline 800620 & Phys & 38 & 84.5 & $3 / 12 / 91$ & 83.0 & 85.9 & Silty Sandy Gravel \\
\hline $800 G 21$ & Phys & 38 & 84.5 & $3 / 12 / 91$ & 83.0 & 85.9 & n \\
\hline 800622 & Reg & 38 & 90.5 & $3 / 12 / 91$ & 89. & 91.85 & 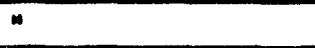 \\
\hline $800 G 23$ & Reg & 38 & 105 & $3 / 14 / 91$ & 103.9 & 106.35 & $n$ \\
\hline 800624 & Phys & 38 & 105 & $3 / 14 / 91$ & 103.9 & 106.35 & $n$ \\
\hline $800 G 25$ & Phys & 38 & 105 & $3 / 14 / 91$ & 103.9 & 106.35 & $n$ \\
\hline$B 00 G 26$ & Reg & 38 & 118.5 & $3 / 15 / 91$ & 117.5 & 119.3 & silt \\
\hline $800 G 27$ & Phys & 38 & 118.5 & $3 / 15 / 91$ & 117.5 & 119.3 & 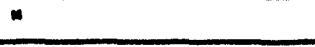 \\
\hline B00G28 & Reg & 38 & 123.5 & $3 / 18 / 91$ & 122.3 & 124.7 & 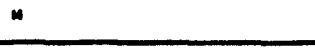 \\
\hline BOOHOO & Reg & $3 c$ & 1 & $3 / 15 / 91$ & 0 & 2 & Sendy Gravel \\
\hline 80OHO1 & $R \in g$ & $3 c$ & 3 & $3 / 15 / 91$ & 1.5 & 4 & $n$ \\
\hline BOOHO2 & Reg & $3 c$ & 5 & $3 / 15 / 91$ & 3.87 & 5.8 & $"$ \\
\hline $\mathrm{BOOHO3}$ & Reg & $3 c$ & 7 & $3 / 18 / 91$ & 5.93 & 7.95 & $n$ \\
\hline $\mathrm{BOOHO4}$ & Reg & $3 c$ & 9 & $3 / 18 / 91$ & 7.93 & 9.73 & $"$ \\
\hline BOOHOS & Fodp & $3 c$ & 9 & $3 / 18 / 91$ & 7.93 & 9.73 & $n$ \\
\hline
\end{tabular}


Table 3-3. B-Pond Phase 3 Borehole Sample Key. (3 sheets)

\begin{tabular}{|c|c|c|c|c|c|c|c|}
\hline semple & Trpe & Pond & Depth & $\begin{array}{l}\text { Collection } \\
\text { Date }\end{array}$ & \multicolumn{2}{|c|}{ Interval b } & $\begin{array}{l}\text { Classification } \\
\text { tram Borehole Log }\end{array}$ \\
\hline BOOHOG & Reg & $3 c$ & 11.5 & $3 / 18 / 91$ & 10.6 & 11.93 & Sandy Gravel/ Sand \\
\hline ВОСН07 & Split & $3 c$ & 11.5 & $3 / 18 / 91$ & 10.6 & 19.93 & $n$ \\
\hline ВООНОВ & Phre & $3 c$ & 12.5 & $3 / 19 / 91$ & 11.7 & 13.7 & Sand \\
\hline 8OOHO9 & Reg & $3 c$ & 16 & $3 / 19 / 91$ & 15.0 & 17.0 & Gravelly Send \\
\hline BOOH1O & Blent & $3 c$ & $\cdots$ & $3 / 20 / 91$ & MA & & $\begin{array}{l}\text { (sillice sand Control } \\
\text { semple) }\end{array}$ \\
\hline BOOH11 & Reg & $3 c$ & 20.5 & $3 / 20 / 91$ & 19.5 & 21.5 & Sandy Gravel \\
\hline $800 H 12$ & Phys & $3 c$ & 26.5 & $3 / 20 / 91$ & 25.6 & 27.8 & Gravel \\
\hline $800 \mathrm{H} 13$ & Phys & $3 c$ & 26.5 & $3 / 21 / 91$ & 25.6 & 27.8 & $n$ \\
\hline BOOH14 & Reg & $3 c$ & 30 & $3 / 21 / 91$ & 29 & 31 & Slightly Gravelly Sand \\
\hline $800 \mathrm{H} 15$ & Reg & $3 c$ & 36 & $3 / 25 / 91$ & 34.8 & 37.6 & Sandy Gravel \\
\hline ВоОН16 & $R=g$ & $3 c$ & 40.5 & $3 / 25 / 91$ & 39 & 41.8 & " \\
\hline $800 \mathrm{H} 17$ & Fodp & $3 c$ & 40.5 & $3 / 25 / 91$ & 39 & 41.8 & " \\
\hline BOOH18 & Reg & $3 c$ & 50 & $3 / 25 / 91$ & 48.8 & 50.8 & $n$ \\
\hline BOOH19 & Reg & $3 c$ & 60 & $3 / 26 / 91$ & 59.3 & 61.1 & $\omega$ \\
\hline $800 \mathrm{H} 20$ & Reg & $3 c$ & 70.5 & $3 / 27 / 91$ & 69.3 & 71.5 & $"$ \\
\hline BOOH21 & Blank & $3 c$ & $\cdots$ & $3 / 27 / 91$ & MA & & $\begin{array}{l}\text { (Silice Sand Control } \\
\text { Sample) }\end{array}$ \\
\hline $800 \mathrm{H} 22$ & Phys & $3 c$ & 78 & $3 / 27 / 91$ & 76.9 & 79.4 & Sancty Gravel \\
\hline $\mathrm{BOOH} 23$ & Reg & $3 c$ & 80 & $3 / 27 / 91$ & 79.4 & 80.9 & $"$ \\
\hline $800 \mathrm{H} 24$ & Split & $3 c$ & 80 & $3 / 27 / 91$ & 79.4 & 80.9 & n \\
\hline
\end{tabular}

- Logbook interval midpoint rounded to the closest $1 / 2-\mathrm{ft}$.

c Source: Project Field Logbook.

semple collected from liners $51.6-52.1$ ft below surface.

Type:

Reg = Regular semple for chemical andysis

Phys a Sample for physical onalysis

Blank = Field originated, equipment "blenk" silice sand semple for chemical analysis

Fdup = Field duplicate semple for chemical enalysis

Split = Split semple for independent chemical enalysis 
WHC-SD-EN-AP-104 Rev. 0

\subsection{DESCRIPTION OF FIELD ACTIVITIES}

\subsubsection{The 3A Pond}

Several months before drilling, clean fill was used to construct a pad extending over a small portion of $3 \mathrm{~A}$ Pond. This pad was located along the north shore of the pond, approximately 25 yd from the east corner.

Field sampling was initiated at the $3 A$ Pond. The borehole, $B H 3 A-1$, (1ater designated 699-43-411) penetrated the former pond bottom. The first sample submitted for chemical analysis was collected February 7, 1991. Samples were planned at 2-ft intervals for the first $10 \mathrm{ft}$ below the former pond bottom and at decreasing intervals thereafter until reaching groundwater. A11 depths were referenced to the ground surface. The pond bottom was encountered at approximately $6.5 \mathrm{ft}$.

A cable tool drilling rig was used to drill the borehole. Drill rigs are decontaminated before use. Samples were collected using a 5-in. outside diameter stainless steel split tube with stainless steel liners. A 10-in. outside diameter, schedule 40 casing was first used, followed by 8- then 6-in. The 10-in. casing string was set at $20.4 \mathrm{ft}$. The $8-i n$. casing was set at $77.7 \mathrm{ft}$. Samples were collected per procedures of the Environmental Investigations and Site Characterization Manual, WHC-CM-7-7 (WHC 1989b). Samples for chemical analysis were placed in supplier-cleaned glass bottles.

Samples were screened for radioactivity using hand-held instruments. A field photoionization detector (PID) was used to monitor for organic vapors. No evidence of radioactive or organic contamination was found. Aliquots submitted to an onsite laboratory also revealed no evidence of radioactive contamination. All aliquots were found to be below applicable administrative limits for release from all radiologic controls. Applicable limits during the project were detectable readings above background with field instruments or laboratory results exceeding either $60 \rho \mathrm{Ci} / \mathrm{g}$ alpha or $200 \rho \mathrm{Ci} / \mathrm{g}$ total activity, including beta/gamma.

Gross gamma logging was performed on three separate days:

\begin{tabular}{lc}
\multicolumn{1}{c}{ DATE } & LOG INTERVAL (FT) \\
February 8, 1991 & $5-19$ \\
February 20, 1991 & $4-79$ \\
March 1, 1991 & $45-142$.
\end{tabular}

Larger cobbles and boulders made drilling difficult at approximately the 100-ft level. After samples BOOGT8 and BOOGT9 were collected (101.0$102.2 \mathrm{ft}$ ), hardtooling was first employed. This required the addition of some raw (Columbia River) water to the borehole. Drilling improved below $105 \mathrm{ft}$, and hardtooling was discontinued. A small amount (approximately 0.5 gal) of raw water was required at $112 \mathrm{ft}$ to get recovery in the core barrel. The next sample interval was 120.7-123.2 ft, sample BOOGVO.

The final sample from the $3 A$ Pond borehole was collected February 28 , 1991 from a recorded depth of 142.75-143.85 ft. Recovery in the split spoon 
WHC-SD-EN-AP-104 ReV. 0

was estimated at only 50 percent. Observations in the field log note the sample as "very wet." The water level was measured at $142.75 \mathrm{ft}$ from the surface. Later, the casing was removed, and the borehole was backfilled, abandoned, and marked according to standard procedures--plugging and Abandoning Characterization Boreholes Environmental Investigation Instruction (EII) 6.5 (WHC 1989b).

\subsubsection{The 3B Pond}

A cleaned cable tool drilling rig was set up at $3 B$ Pond in late February 1991. The borehole, BH 3B-1, (1ater designated 699-42-41B) was located in the center of the dry lobe. Drilling equipment was routinely cleaned per EII 5.4 (WHC 1989b) before delivery/use at the site. Likewise, direct contact sampling equipment (split tube assemblies, bowls, spoons, etc.) is specially cleaned before use per EII 5.5, 1706 KE Laboratory Decontamination of RCRA/CERCLA Sampling Equipment, (WHC 1989b).

Sampling was initiated March 4, 1991. The first sample, BO0GV6, was collected with a split tube over the 0 to 2-ft interval. Recovery of sample BOOGV6 and the next two samples was estimated at 50 percent because of the coarse gravelly nature of the soll. Finer material was found below a depth of $7 \mathrm{ft}$.

Drilling method and sampling frequency were similar to the other two boreholes. Samples were planned at $2-\mathrm{ft}$ intervals for the first $10 \mathrm{ft}$ and at decreasing intervals thereafter until reaching groundwater. Samples were collected as previously described for the 3A Pond, except that there was no fill material overlying the area to be investigated. All depths were referenced to the ground surface. The 10-in. casing string was set at $21.1 \mathrm{ft}$. The $8-i n$. casing was set at $78.2 \mathrm{ft}$. Samples were screened with field instruments for radioactivity and/or hazardous organic vapors. No evidence of radioactivity or organic vapors was found.

Gross gamma logging of the $3 B$ Pond borehole was also performed on the following three separate days:

\section{DATE}

March 6, 1991

March 11, 1991

March 19, 1991
LOG INTERVAL (FT)

5-21

4-79

45-122.

The borehole was advanced by drive barrel to approximately $74 \mathrm{ft}$ before it was necessary to add any water. Only 1 gal of raw water was added to progress drilling. This was about $6 \mathrm{ft}$ above the next sample interval, 79.8 $81.5 \mathrm{ft}$. Two samples, BOOGY1 and BOOGY2, were taken for chemical analys is from the bottom two liners at this next interval.

A sample for physical analysis, BOOGZO, was collected from an interval beginning at $83.0 \mathrm{ft}$. Although recovery in the split tube was good (est. 75 percent), there was insufficient volume for a representative grain size analysis because of the amount of cobble. Sample BOOGZl was subsequently 
WHC-SD-EN-AP-104 Rev. 0

collected from the 5-in-diameter drive-barrel cleanout and submitted for grain size.

Hard-tool drilling was required at 95-103 ft and at 109-113 ft. Thirty gallons of raw water were used. Samples for chemical analysis potentially affected by added raw water are BOOGZ3, BOOGZ4, and BOOGZ6. In each case, several feet of soll remained above the respective intervals when the last of the water was added.

The final sample, BO0GZ8, a wet silt, was collected March 18, 1991. Final depth of the borehole was $124.7 \mathrm{ft}$. The casing was 1 ater pulled and the borehole abandoned per standard procedures (WHC 1989b, EII 6.5).

\subsubsection{The 3C Pond}

Sampling in 3C Pond began on March 15, 1991. The borehole, BH 3C-1, (later designated 699-41-4) was located on dry ground between trenches in the northwest quadrant of the lobe. The water surface in the adjacent trench was several feet below ground level at the borehole. The $3 C$ Pond (a series of trenches) was in active use at the time of this investigation, similar to $3 \mathrm{~A}$ Pond.

Drilling and sampling methods were identical to those previously described. As with boreholes drilled earlier, sampling was more frequent in the top portion of the borehole. Field monitoring of the samples showed no radioactivity or hazardous organic vapors. Five samples were collected in the first $10 \mathrm{ft}$. Samples for chemical analysis were collected using a 5-in. outside-diameter split tube sampler. The 10-in. casing string was set at 32.1 $\mathrm{ft}$. An 8 -in. casing was used for the remainder of the borehole.

Most of the borehole was wet. Early samples were damp, but moisture appeared to increase at about $18 \mathrm{ft}$. When drilling started at $19 \mathrm{ft}$, March 20, there was no standing water in the hole. However, some difficulty was experienced keeping material in the drive barrel. Moisture was a factor. Poor sample recovery limited planned analyses in the 20-25 ft range. On the morning of March 21, there was standing water in the hole. The starting depth was $27.8 \mathrm{ft}$. Moist conditions abated, but did not cease for the remainder of the borehole.

Gross gamma logging at the $3 \mathrm{C}$ Pond was performed on two days as follows:

\section{DATE}

March 22, 1991

March 28, 1991

\section{LOG INTERVAL (FT)}

5-32

$0-77$.

Soil below $74 \mathrm{ft}$ was noticeably wetter. Intermittent saturated zones were experienced to $80 \mathrm{ft}$. It was decided to terminate the borehole at this level because of continuing high moisture conditions. Final depth of the borehole was $80.9 \mathrm{ft}$. 
The casing was removed and the borehole filled and abandoned in accordance with standard procedures (WHC 1989b, EII 6.5). As with previous sites, a brass survey marker was placed at the location.

Sample BOOGS5, originating from the borehole at the $3 C$ Pond, was later reported by the laboratory as sample BOOGS. Based on date of submittal, analyses requested, and review of documentation associated with the sample this was determined to be simply a typographical error on the part of the laboratory and will not affect interpretation of the results. 
WHC-SD-EN-AP-104 Rev. 0

\subsection{SUMMARY OF RESULTS}

\subsection{ORGANIC CHEMICAL RESULTS}

Organic analyses were performed on a subset of project samples in accordance with project plans. All regular samples identified below were analyzed for pesticides/PCBs, herbicides, organophosphorous pesticides, volatile organic compounds, and BNA compounds.

3A Pond: B00FK6, B00FK7, B00FK8, B00FK9, BOOFLO, B00FL1, B00FL4, B00GS4, BOOGS9, BOOGT7, BOOGV5

3B Pond: B00GV6, B00GV7, BO0GV8, B00GW0, B00GW1, B00GW3, B00GW8, B00GX6, BOOGZ2, BOOGZ6, BOOGZ8

3C Pond: BOOHOO, BOOHO1, BOOHO2, ВОOHO3, $800 \mathrm{HO} 4, \mathrm{BOOHO6,} \mathrm{BOOH14,} \mathrm{BOOH19,}$ $\mathrm{BOOH} 23$

A subset of the above were analyzed for dioxin and furan homologs. This included all samples except BOOGX6, BOOGZ2, BOOGZ6, BOOGZ8, BOOHO1, BOOHO4, $\mathrm{BOOHO6}, \mathrm{BOOH} 14, \mathrm{BOOH} 19$, and $\mathrm{BOOH} 23$. More analyses were performed than were requested by Westinghouse Hanford. One planned dioxin analysis (sample BOOHOl from 1.5- to 4-ft level of $3 C$ Pond) was inadvertently omitted by the laboratory. An examination of the Sample Analysis Request forms shows the primary laboratory did not correctly forward requests/samples to their subcontracted laboratory.

Results of silica sand samples (BOOFL3, BOOGV9, BOOH1O), field duplicates (BOOGW4, BOOH05, BOOGR9) and split samples (BOOH07, BOOGW5, BOOGS5) are discussed with each group summary appearing below.

Results of all regular samples analyzed for organic compounds are summarized in Table 4-1. Organic constituents of interest were generally undetected.

Nearly all results have been qualified as estimated, flagged with a "J" by Westinghouse Hanford's Office of Sample Management (OSM). The most common reason is the comparison of sample (soil) holding times before extraction to holding times applicable to water matrices. Compounds not on routine target lists may have been reported as TICS. All TICS were routinely qualified as estimated, "J", by the reporting laboratory. 


\begin{tabular}{|c|c|c|c|c|c|}
\hline Analytical Class & Protocol Used & Pond & $\begin{array}{l}\text { Munber of } \\
\text { Reg. Samples }\end{array}$ & $\begin{array}{l}\text { All Analytes } \\
\text { \& Detection } \\
\text { Limit }\end{array}$ & Remarks \\
\hline \multirow[t]{3}{*}{ Pesticides/PCB } & EPA 8080 & $3 A$ & 11 & Yes & \\
\hline & & 38 & 11 & Yes & \\
\hline & & $3 c$ & 9 & Yes & \\
\hline \multirow[t]{3}{*}{ Herbicides } & EPA DISO & $3 n$ & 11 & res & \\
\hline & & 38 & 11 & Yes & \\
\hline & & $3 c$ & 9 & Yes & \\
\hline \multirow[t]{3}{*}{ Organophosphorous Pesticídes } & EPA 8160 & $3 n$ & 11 & res & List A (App. C) \\
\hline & & 38 & 11 & Yes & Llast A, List \& for 4 lowermost \\
\hline & & $3 c$ & 9 & res & Llst \& (App. C) \\
\hline \multirow[t]{3}{*}{ Dioxins/Fureme } & Modified EPA 8280 & $3 n$ & 11 & Yee & (More analyses then requested) \\
\hline & & 38 & 7 & Yes & \\
\hline & & 3c & 3 & Yes & \\
\hline \multirow[t]{3}{*}{ Volatille Organic Compounds } & $\begin{array}{l}\text { ACD } 2440 \\
\text { (CLP VOA Protocol) }\end{array}$ & $3 A$ & 11 & No & $\begin{array}{l}\text { Low level Acetone, Methylene Chlo- } \\
\text { ride, and 4-Methyi-2-pentanone }\end{array}$ \\
\hline & & 38 & 11 & Mo & Low level 4-Methyl-2-pentanone \\
\hline & & $3 c$ & 8 & No & Lon level Acetone \\
\hline \multirow[t]{3}{*}{$\begin{array}{l}\text { Base/Meutrol/Acid Compounds } \\
\text { (Semivolatifes) }\end{array}$} & $\begin{array}{l}\text { ACD } 2470 \\
\text { (CLP 3MA Protocol) }\end{array}$ & $3 n$ & 11 & No & Mul tiple compounds reported \\
\hline & & 38 & 11 & Mo & Multiple compounds reported \\
\hline & & 3c & 9 & Mo & Mult tiple compounds reported \\
\hline
\end{tabular}


WHC-SD-EN-AP-104 Rev. 0

\subsubsection{Pesticides/PCBs}

Tables 4-2 and 4-3 summarize results of the pesticides/PCB analyses. Table 4-2 is based on the results of the 31 regular soil samples sent to the primary laboratory. Table 4-3 shows the numerical results of each of the three samples sent to the split laboratory. All regular, field duplicate, field split, and silica sand sample results are provided in Appendix $A$.

All pesticides and $P C B$ results were reported as nondetectable by the laboratory, or were qualified as nondetected upon validation. Some laboratory reagent blanks at the primary laboratory contained traces of target analytes (Arochlor-1254, beta-BHC, and Lindane). Some immediately associated B-Pond soil samples also contained those analytes at very low levels--less than the valid sample quantitation limit (SQL). Consistent with established data validation protocol, OSM qualified some data as undetected at the SQL based upon results of laboratory reagent blanks. No other analytes were reported by the laboratory without an undetected ("U") laboratory qualification.

All samples, including silica sand and field duplicates, were extracted outside the 7-day criterion applicable to certain water analyses, and were thus qualified "J" by Westinghouse Hanford. All extracts were analyzed within the allotted 40 days following extraction. High surrogate recovery on sample BOOHOl also contributed to Westinghous: Hanford's "J" qualification for all analytes of that sample, al though no target compounds were found. Recovery was 193 percent, slightly outside the laboratory-reported quality control (QC) limits of 20-150 percent for a $105-\mu \mathrm{g} / \mathrm{Kg}$ nominal spike.

Results of each of the three silica sand and field duplicate samples were consistent with the above. All values were reported as undetected by the laboratory or were qualified as undetected at the SQL. All six samples were reported with sub-SQL concentrations of arochlor-1254, and were qualified as undetected at the SQL. Two silica sand field blanks (BOOFL 3 and $B O O H 1 O$ ) and one field duplicate (BOOGR9) reported by the laboratory with less than SQL traces of lindane were subsequently qualified as undetected at the SQL based on laboratory reagent blank results. The field duplicate BOOGRg contained a trace of beta-BHC $(0.77 \mathrm{~J} \mu \mathrm{g} / \mathrm{Kg})$ that was qualified as undetected at the SQL $(13 \mu \mathrm{g} / \mathrm{Kg})$. No trace of beta-BHC was found in the associated regular sample, BOOFL3; laboratory reported value, $13 \mathrm{U} \mu \mathrm{g} / \mathrm{Kg}$.

Split samples were analyzed according to criteria -et forth in the CLP for pesticide and PCB target compounds. Validated results are shown in Table 4-3. Results confirm those of the primary laboratory. Targeted compounds were undetectable in site samples. Compounds for which there were trace contamination problems at the primary laboratory were undetected in samples analyzed at the split laboratory. One split sample, BOOGS5, was also associated with a high surrogate spike recovery. This was attributed to a co-eluting interference. Seven of 12 matrix spike recoveries were outside EPA QC limits. Although all analytes were undetected, results for B0OGS5 were consequently qualified " $\mathrm{J}$ " by Westinghouse Hanford. 
Table 4-2. Pesticides/PCB Sample Result Summary -- 31 Regular Samples.

\begin{tabular}{|c|c|c|c|c|}
\hline AMALYTE & cas & $\begin{array}{l}\text { ALL RESULTS } \\
\text { < DETECTION } \\
\text { LIMIT? }\end{array}$ & $\begin{array}{c}\text { DETECTION LIMIT } \\
\text { RANGE } \\
\text { Mg/Kg }\end{array}$ & $\begin{array}{l}\text { MEDIAN } \\
\text { MO/Kg }\end{array}$ \\
\hline $4,41-D D E$ & $72 \cdot 55 \cdot 9$ & Yee & $25 \mathrm{UJ} \cdot 310 \mathrm{UJ}$ & $120 \mathrm{UJ}$ \\
\hline $4,41-000$ & $72-54-8$ & Yes & 25 UJ $-310 \mathrm{UJ}$ & 120 UJ \\
\hline $4,4 \cdot-00 T$ & $50 \cdot 29 \cdot 3$ & Yee & $25 \mathrm{UJ} \cdot 310 \mathrm{UJ}$ & $120 \mathrm{UJ}$ \\
\hline Aldrin & $309-00-2$ & res & $13 \mathrm{UJ} \cdot 160 \mathrm{UJ}$ & $62 \mathrm{UJ}$ \\
\hline alphe BHC & $319-84-6$ & Yes & $13 \mathrm{UJ}-160 \mathrm{UJ}$ & $62 \mathrm{UJ}$ \\
\hline bete BHC & $319-85-7$ & Yes & $13 \mathrm{UJ} \cdot 160 \mathrm{UJ}$ & $62 \mathrm{UJ}$ \\
\hline delte BHC & $319-86-8$ & Yes & $13 \mathrm{UJ} \cdot 160 \mathrm{UJ}$ & $62 \mathrm{UJ}$ \\
\hline gamme BHC (Lindane) & $58-89-9$ & Yes & 13 UJ -160 UJ & $62 \mathrm{UJ}$ \\
\hline - lpha-Chl orodane & $5103-71-9$ & Yes & $130 \mathrm{UJ} \cdot 1600 \mathrm{UJ}$ & 620 UJ \\
\hline garma-Chl orodane & $5103-74-2$ & Yes & $130 \mathrm{UJ} \cdot 1600 \mathrm{UJ}$ & $620 \mathrm{UJ}$ \\
\hline Dieldrin & $60-57-1$ & Yes & 25 UJ -310 UJ & $120 \mathrm{UJ}$ \\
\hline Endosulfan I & $959-98-8$ & Yes & $13 \mathrm{UJ} \cdot 160 \mathrm{UJ}$ & $62 \mathrm{UJ}$ \\
\hline Endosul fan II & $33213-65-9$ & Yes & 25 UJ $-310 \mathrm{UJ}$ & $120 \mathrm{UJ}$ \\
\hline Endosulfan sulfate & $1031-07-8$ & Yes & $25 \mathrm{UJ} \cdot 390 \mathrm{UJ}$ & $120 \mathrm{UJ}$ \\
\hline Endr in & $72 \cdot 20 \cdot 8$ & Yes & $25 \mathrm{UJ} \cdot 310 \mathrm{UJ}$ & $120 \mathrm{UJ}$ \\
\hline Endrin Ketone & $53494 \cdot 70-5$ & Yes & $25 \mathrm{UJ}-310 \mathrm{UJ}$ & $120 \mathrm{UJ}$ \\
\hline Heptachlor & $76 \cdot 44 \cdot 8$ & Yes & $13 \mathrm{UJ}-160 \mathrm{UJ}$ & $62 \mathrm{UJ}$ \\
\hline Heptachlor Epoxide & $1024 \cdot 57 \cdot 3$ & Yes & $13 \mathrm{UJ} \cdot 160 \mathrm{UJ}$ & $62 \mathrm{UJ}$ \\
\hline Methoxychlor & $72 \cdot 43 \cdot 5$ & Yes & $130 \mathrm{UJ}=1600 \mathrm{UJ}$ & $620 \mathrm{UJ}$ \\
\hline Toxaphene & $8001-35-2$ & Yes & $250 \mathrm{UJ}-3100 \mathrm{UJ}$ & $1200 \mathrm{UJ}$ \\
\hline Arochlor 1016 & $12674-11-2$ & Yes & $120 \mathrm{UJ} \cdot 180 \mathrm{UJ}$ & $130 \mathrm{UJ}$ \\
\hline Arochlor 1221 & $11104-28-2$ & Yes & $120 \mathrm{UJ} \cdot 180 \mathrm{UJ}$ & $130 \mathrm{UJ}$ \\
\hline Arochlor 1232 & $11141-16-5$ & Yes & $120 \mathrm{UJ}-180 \mathrm{UJ}$ & $130 \mathrm{UJ}$ \\
\hline Arochlor 1242 & $53469-21 \cdot 9$ & Yes & $120 \mathrm{UJ} \cdot 180 \mathrm{UJ}$ & $130 \mathrm{UJ}$ \\
\hline Arochlor 1248 & $12672-29-6$ & Yes & $120 \mathrm{UJ} \cdot 180 \mathrm{UJ}$ & $130 \mathrm{UJ}$ \\
\hline Arochlor 1254 & $11097-69-1$ & Yes & $240 \mathrm{UJ} \cdot 360 \mathrm{UJ}$ & $260 \mathrm{UJ}$ \\
\hline Arochlor 1260 & $11096-82 \cdot 5$ & Yes & $240 \mathrm{UJ} \cdot 360 \mathrm{UJ}$ & $260 \mathrm{UJ}$ \\
\hline
\end{tabular}

$\checkmark$ compound was anolyzed for but not detected at the stated limit.

Indicates on estimated value. 
Table 4-3. Split Sample Results for Pesticides/PCBs.

\begin{tabular}{|c|c|c|c|c|c|}
\hline ANALYTE & cas * & $\begin{array}{l}800 \mathrm{HO7} \\
\mathrm{Mg} / \mathrm{Kg}\end{array}$ & $\begin{array}{l}800 \mathrm{G} / 5 \\
\mathrm{Mg} / \mathrm{Kg}\end{array}$ & $\begin{array}{c}800 G 55^{\circ} \\
\mathrm{mg} / \mathrm{Kg}\end{array}$ & $\begin{array}{l}\text { Median } \\
\text { Regul ar } \\
\text { Semple } \\
\text { Mg/Kg }\end{array}$ \\
\hline $4,41 \cdot 00 E$ & $72-55-9$ & $17 \mathrm{U}$ & 16 US & 19 UJ & 120 UJ \\
\hline $4,41-000$ & $72-54-8$ & $17 \mathrm{U}$ & $16 \mathrm{UJ}$ & $19 \mathrm{UJ}$ & $120 \mathrm{UJ}$ \\
\hline 4,41-00T & $50-29-3$ & $17 \mathrm{U}$ & $16 \mathrm{UJ}$ & 19 UJ & $120 \mathrm{UJ}$ \\
\hline Aldrin & $309-00-2$ & $8.3 \mathrm{UJ}$ & $8.0 \mathrm{UJ}$ & $9.7 \mathrm{WJ}$ & 62 UJ \\
\hline alphe BHC & $319-84-6$ & $8.3 \mathrm{UJ}$ & $8.0 \mathrm{UJ}$ & 9.7 UJ & 62 UJ \\
\hline beta BHC & $319-85-7$ & $8.3 \mathrm{UJ}$ & $8.0 \mathrm{UJ}$ & $9.7 \mathrm{UJ}$ & $62 \mathrm{UJ}$ \\
\hline delta BHC & $319-86-8$ & $8.3 \mathrm{UJ}$ & $8.0 \mathrm{UJ}$ & $9.7 \mathrm{UJ}$ & $62 \mathrm{UJ}$ \\
\hline gamma BHC (Lindane) & $58-89-9$ & $8.3 \mathrm{U}$ & $8.0 \mathrm{UJ}$ & $9.7 \mathrm{UJ}$ & $62 \mathrm{UJ}$ \\
\hline - lpha-Chl orodane & $5103.71 \cdot 9$ & $83 \mathrm{UJ}$ & $80 \mathrm{UJ}$ & 97 UJ & $620 \mathrm{Ud}$ \\
\hline gamma-Chl orodane & $5103-74-2$ & 83 UJ & $80 \mathrm{UJ}$ & $97 \mathrm{UJ}$ & $620 \mathrm{UJ}$ \\
\hline Dieldrin & $60-57-1$ & $17 \mathrm{U}$ & $16 U$ & 19 UJ & $120 \mathrm{UJ}$ \\
\hline Endosul fan I & $959-98-8$ & $8.3 \mathrm{U}$ & $8.0 \mathrm{UJ}$ & $9.7 \mathrm{UJ}$ & $62 \mathrm{UJ}$ \\
\hline Endosul fan II & $33213-65-9$ & $17 \mathrm{U}$ & $16 \mathrm{U}$ & $19 \mathrm{UJ}$ & $120 \mathrm{UJ}$ \\
\hline Endosulfan Sulfate & $1031-07-8$ & $17 \mathrm{U}$ & $16 \mathrm{UJ}$ & 19 US & $120 \mathrm{UJ}$ \\
\hline Endrin & $72-20-8$ & $17 \mathrm{UJ}$ & $16 \mathrm{U}$ & $19 \mathrm{UJ}$ & $120 \mathrm{UJ}$ \\
\hline Endrin Ketone & $53494-70-5$ & $17 \mathrm{U}$ & $16 U$ & 19 UJ & $120 \mathrm{UJ}$ \\
\hline Heptachlor & $76-44-8$ & $8.3 \mathrm{U}$ & $8.0 \mathrm{U}$ & $9.7 \mathrm{UJ}$ & $62 \mathrm{UJ}$ \\
\hline Heptachlor Epoxide & $1024-57-3$ & $8.3 \mathrm{U}$ & $8.0 \mathrm{U}$ & $9.7 \mathrm{UJ}$ & $62 \mathrm{Ud}$ \\
\hline Methoxychlor & $72-43-5$ & $83 U$ & $80 \mathrm{U}$ & 97 UJ & $620 \mathrm{UJ}$ \\
\hline Toxaphene & $8001-35-2$ & $170 \mathrm{U}$ & $160 \mathrm{U}$ & $190 \mathrm{UJ}$ & $1200 \mathrm{UJ}$ \\
\hline Arochlor 1016 & $12674-11-2$ & $83 \mathrm{U}$ & $80 \mathrm{U}$ & $97 \mathrm{UJ}$ & $130 \mathrm{UJ}$ \\
\hline Arochlor 1221 & $11104-28-2$ & $83 U$ & $80 \mathrm{U}$ & $97 \mathrm{UJ}$ & $130 \mathrm{UJ}$ \\
\hline Arochlor 1232 & $11141 \cdot 16 \cdot 5$ & $83 \mathrm{U}$ & $80 \mathrm{U}$ & $97 \mathrm{UJ}$ & $130 \mathrm{UJ}$ \\
\hline Arochlor 1242 & $53469-21-9$ & $83 \mathrm{U}$ & $80 \mathrm{U}$ & 97 Ud & $130 \mathrm{UJ}$ \\
\hline Arochlor 1248 & $12672-29 \cdot 6$ & $83 \mathrm{U}$ & $80 \mathrm{U}$ & 97 UJ & 130 UJ \\
\hline Arochlor 1254 & $11097-69-1$ & $170 \mathrm{U}$ & $160 \mathrm{U}$ & $190 \mathrm{UJ}$ & $260 \mathrm{UJ}$ \\
\hline Arochlor 1260 & $11096-82-5$ & $170 \mathrm{U}$ & $160 \mathrm{U}$ & $190 \mathrm{UJ}$ & $260 \mathrm{UJ}$ \\
\hline
\end{tabular}


WHC-SD-EN-AP-104 ReV. 0

\subsubsection{Herbicides}

Analytical results were reported for 2,4-D (CAS \# 94-75-7) and 2,4,5-TP, also known as Silvex, (CAS \# 93-72-1). Both herbicides were undetected in ail regular site samples, field duplicates and field silica sand samples. Sample reporting limits ranged widely. Validated results ranged from 28 UJ $4900 \mathrm{UJ} \mu \mathrm{g} / \mathrm{Kg}$ for $2,4-\mathrm{D}$, and 3 UJ $-240 \mathrm{UJ} \mu \mathrm{g} / \mathrm{Kg}$ for 2,4,5-TP. The median regular sample result for $2,4-D$ was $150 \mathrm{UJ} \mu \mathrm{g} / \mathrm{Kg}$. The median regular sample result for $2,4,5-T P$ was 15 UJ $\mu \mathrm{g} / \mathrm{Kg}$. All regular, field duplicate, field split and silica sand sample results are shown in Appendix $A$.

All values were qualified by Westinghouse Hanford as " $\mathrm{J}$ " because the preextraction holding time exceeded the 7 day criterion established for water samples. Once extracted, all samples were analyzed within the appropriate 40-day period. 2,4,5-TP was detected in one laboratory reagent blank, but no results were qualified because herbicides were undetected in all site samples.

Split samples were not analyzed for herbicides.

\subsubsection{Organophosphorous Pesticides}

Organophosphorous pesticides were undetected in all soil sampies. All results were qualified by Westinghouse Hanford because extraction was outside the 7-day criterion applicable to certain water analyses. Once extracted, all samples were analyzed within the appropriate 40-day period.

Organopesticide analyses were subcontracted by the primary laboratory. One of the applicable contracts changed during the Phase 3 project. This resulted in an increase in the number of analytes reported for about 40 percent of the samples. All analytes were still undetected. Samples with the increased analyte list include the following:

- All samples from the borehole at the $3 C$ fond

- Samples BOOGX6, BOOGZ2, BOOGZ6, and BOOGZ8 from the 3B Pond

- Silica sand BOOHIO

- Field duplicate BOOHO5.

All regular, field duplicate and silica sand sample results are shown in Appendix A.

Tables 4-4a and 4-4b summarize the reporting limits for all regular field samples and analytes. Silica sand and field duplicates were reported to similar limits. No contaminants were reported in laboratory bianks.

Split samples were not analyzed for organophosphorous pesticides. 
Table 4-4a. Organophosphorous Pesticide Reporting -- 18 Regular Samples (Short List).

\begin{tabular}{|c|c|c|c|c|}
\hline AMALYTE & cas * & $\begin{array}{l}\text { ALL RESULTS } \\
\text { \& OETECTION } \\
\text { LIMIT ? }\end{array}$ & $\begin{array}{c}\text { DETECTION LIMIT } \\
\text { RANGE } \\
\text { WOKG }\end{array}$ & $\begin{array}{c}\text { MEDIAN } \\
m g / K o\end{array}$ \\
\hline Dimethoute & $60.51-5$ & Yes & $0.10 \mathrm{UJ}=0.13 \mathrm{UJ}$ & $0.11 \mathrm{uJ}$ \\
\hline Disulfoton & $298-04-4$ & Yea & $0.05 \mathrm{UJ}=0.06 \mathrm{UJ}$ & $0.05 \mathrm{UJ}$ \\
\hline Parathion ethyl & $156-38-2$ & Yes & $0.10 \mathrm{UJ} \cdot 0.13 \mathrm{UJ}$ & $0.11 \mathrm{us}$ \\
\hline Parathion methyl & $298-00-0$ & Yes & $0.10 \mathrm{UJ}-0.13 \mathrm{UJ}$ & $0.11 \mathrm{uJ}$ \\
\hline Phorate & $298-02-2$ & Yes & $0.05 \mathrm{UJ}=0.06 \mathrm{UJ}$ & $0.05 \mathrm{ud}$ \\
\hline Sul fotepp & $3689-24-5$ & Yes & $0.05 \mathrm{UJ}=0.06 \mathrm{UJ}$ & $0.05 \mathrm{UJ}$ \\
\hline Femphur & $52-85-7$ & Yes & $0.16 \mathrm{UJ} \cdot 0.19 \mathrm{UJ}$ & $0.16 \mathrm{UJ}$ \\
\hline Thionaz in & $297-97-2$ & Yes & $0.05 \mathrm{UJ} \cdot 0.06 \mathrm{UJ}$ & 0.05 UJ \\
\hline $\begin{array}{l}0,0,0-\text { Triethyl } \\
\text { phosphorothioate }\end{array}$ & $126-68-1$ & Yen & $0.03 \mathrm{UJ} \cdot 0.03 \mathrm{Ud}$ & 0.03 UJ \\
\hline
\end{tabular}

$U$ Compound was anslyzed for but not detected at the stated limit.

$J$ Indicates an estimated value. 
Table 4-4b. Organophosphorous Pesticide Reporting -- 13 Regular Samples (Long List).

\begin{tabular}{|c|c|c|c|c|}
\hline aMALYTE & cas * & $\begin{array}{l}\text { ALL RESULTS } \\
\text { < DETECTIOW } \\
\text { LIMIT ? }\end{array}$ & $\begin{array}{c}\text { DETECTION LIMIT } \\
\text { RANGE } \\
\text { m. } / \mathrm{Kg}\end{array}$ & $\begin{array}{c}\text { MED IAN } \\
m=/ K g\end{array}$ \\
\hline Azinphos methly & $86 \cdot 50-0$ & Yes & 0.21 UJ $=0.24$ UJ & $0.21 \mathrm{UJ}$ \\
\hline Chlorpyrifos & $2981-88-2$ & Yee & $0.05 \mathrm{UJ} \cdot 0.06 \mathrm{UJ}$ & $0.05 \mathrm{UJ}$ \\
\hline Chlorpyrifos methyl & $5598-13-0$ & Yes & $0.05 \mathrm{UJ} \cdot 0.06 \mathrm{UJ}$ & $0.05 \mathrm{UJ}$ \\
\hline Coumaphos & $56-72-4$ & Yee & $0.21 \mathrm{UJ} \cdot 0.26 \mathrm{UJ}$ & $0.21 \mathrm{UJ}$ \\
\hline Deneton & $8065-48-3$ & Yes & $0.1 \mathrm{UJ}=0.12 \mathrm{UJ}$ & $0.1 \mathrm{UJ}$ \\
\hline Diazanon & $333-49-5$ & Yes & $0.05 \mathrm{UJ} \cdot 0.06 \mathrm{UJ}$ & $0.05 \mathrm{UJ}$ \\
\hline DDVP (Dichlorvos) & $62 \cdot 73 \cdot 7$ & Yes & $0.1 \mathrm{UJ} \cdot 0.12 \mathrm{UJ}$ & $0.1 \mathrm{UJ}$ \\
\hline Dimethoste & $60-51-5$ & Yes & $0.1 \mathrm{UJ}=0.12 \mathrm{UJ}$ & $0.1 \mathrm{UJ}$ \\
\hline Disulfoton & $298-04-4$ & Yes & 0.05 UJ $-0.06 \mathrm{UJ}$ & $0.05 \mathrm{UJ}$ \\
\hline EPN & $2104-64-5$ & Yes & $0.05 \mathrm{UJ}=0.06 \mathrm{UJ}$ & $0.05 \mathrm{UJ}$ \\
\hline Ethion & $563-12-2$ & Yes & $0.05 \mathrm{UJ} \cdot 0.06 \mathrm{UJ}$ & $0.05 \mathrm{UJ}$ \\
\hline Ethoprop & $13194-78-4$ & Yes & $0.1 \mathrm{UJ}=0.12 \mathrm{UJ}$ & $0.1 \mathrm{UJ}$ \\
\hline Fensul fothion & $115-90-2$ & Yes & $0.1 \mathrm{UJ}=0.12 \mathrm{UJ}$ & $0.1 \mathrm{UJ}$ \\
\hline Fenthion & $55-38-9$ & Yes & $0.05 \mathrm{UJ}=0.06 \mathrm{UJ}$ & $0.05 \mathrm{UJ}$ \\
\hline Malathion & $121 \cdot 75 \cdot 5$ & Yes & $0.05 \mathrm{UJ} \cdot 0.06 \mathrm{UJ}$ & $0.05 \mathrm{UJ}$ \\
\hline Merphos & $150-50-5$ & Yes & $0.1 \mathrm{UJ}=0.12 \mathrm{UJ}$ & $0.1 \mathrm{uJ}$ \\
\hline Mevinphos & $7786-34-7$ & Yes & $0.1 \mathrm{UJ} \cdot 0.12 \mathrm{UJ}$ & $0.1 \mathrm{UJ}$ \\
\hline Monocrotophos & $6923-22-4$ & Yes & 0.21 UJ $=0.24$ UJ & $0.29 \mathrm{UJ}$ \\
\hline Maled & $300-76-5$ & Yes & $0.21 \mathrm{UJ} \cdot 0.24 \mathrm{UJ}$ & $0.21 \mathrm{UJ}$ \\
\hline Parathion, ethyl & $56-38-2$ & YeE & $0.05 \mathrm{UJ} \cdot 0.06 \mathrm{UJ}$ & $0.05 \mathrm{UJ}$ \\
\hline Parathion, wethyl & $298-00-0$ & Yes & $0.05 \mathrm{UJ} \cdot 0.06 \mathrm{UJ}$ & $0.05 \mathrm{UJ}$ \\
\hline Phorate & $298.02-2$ & Yes & $0.05 \mathrm{UJ} \cdot 0.06 \mathrm{UJ}$ & $0.05 \mathrm{UJ}$ \\
\hline Romel & $299-84-3$ & Yes & $0.05 \mathrm{UJ} \cdot 0.06 \mathrm{UJ}$ & $0.05 \mathrm{Ud}$ \\
\hline Sul fotepp & $3689 \cdot 24 \cdot 5$ & Yes & $0.05 \mathrm{UJ} \cdot 0.06 \mathrm{UJ}$ & $0.05 \mathrm{UJ}$ \\
\hline Sulprofos & $35400-43-2$ & Yes & $0.05 \mathrm{UJ} \cdot 0.06 \mathrm{UJ}$ & $0.05 \mathrm{UJ}$ \\
\hline TEPP & $21646-99-1$ & Yes & $0.21 \mathrm{UJ} \cdot 0.24 \mathrm{UJ}$ & 0.21 UJ \\
\hline Tetrach lorvinghos & $22248 \cdot 79-9$ & Yes & $0.26 \mathrm{UJ} \cdot 0.31 \mathrm{UJ}$ & $0.26 \mathrm{UJ}$ \\
\hline Trichloronate & $327-98-0$ & Yes & $0.05 \mathrm{UJ}=0.06 \mathrm{UJ}$ & $0.05 \mathrm{UJ}$ \\
\hline
\end{tabular}

$U$ Compound was anslyzed for but not detected at the stated limit.

$J$ Indicates on estimated value. 
WHC-SD-EN-AP-104 Rev. 0

\subsubsection{Dioxins and Furans}

Some Phase 3 soil samples were submitted for the analysis of total tetra through octa dioxin and furan homologs. These highly specialized analyses were planned for the first few samples from each of the vadose zone boreholes. Evidence has shown that dioxins do not readily migrate through soil and dioxins are not suspected to have been disposed of at the site. Sampling and analysis was intended to demonstrate that the vadose zone was not contaminated with such compounds.

Samples were analyzed using a modified version of SW-846 Method 8280 , (Rev. 0) (EPA 1986). Dioxin analyses, like organophosphorous pesticide analyses, were subcontracted by the primary laboratory. A $10-\mathrm{g}$ al iquot of each sample and laboratory blank (sodium sulfate) were spiked at the analytical laboratory before extraction with an internal standard solution containing, $50 \mathrm{ng}$ each of ${ }_{13} \mathrm{C}-2,3,7,8-T C D D,{ }_{13}^{13} \mathrm{C}-2,3,7,8-\mathrm{TCDF},{ }^{13} \mathrm{C}-\mathrm{PeCDD}$, ${ }^{13} \mathrm{C}-\mathrm{PeCDF},{ }^{13} \mathrm{C}-\mathrm{H} \times \mathrm{CDD},{ }^{13} \mathrm{C}-\mathrm{H} \times \mathrm{CDF},{ }^{13} \mathrm{C}-\mathrm{HPCDD},{ }^{13} \mathrm{C}-\mathrm{HpCDF}$ and ${ }^{13} \mathrm{C}-\mathrm{OCDD}$. A summary of the performance against these internal standards is shown in Table 4-5.

Table 4-5. Internal Standard Percent-Recovery Summary Dioxins and Furans (25 Samples).

\begin{tabular}{|c|c|c|c|c|c|c|c|c|c|}
\hline & $T C D D$ & PeCDD & $H \times C D D$ & HpCDD & OCDD & $T C D F$ & PeCDF & $H \times C D F$ & HpCDF \\
\hline AVERAGE & 65.08 & 66.56 & 68.08 & 59.8 & 63.48 & 59.72 & 62.8 & 79.72 & 72.76 \\
\hline RANGE- Max & 84 & 98 & 85 & 71 & 98 & 83 & 84 & 103 & 92 \\
\hline Min & 37 & 36 & 44 & 43 & 64 & 26 & 49 & 61 & 55 \\
\hline
\end{tabular}

Additional laboratory $Q C$ included blank, matrix spike, and duplicate analyses. Results were within established acceptance limits.

All soil aliquots were extracted outside the 7-day criterion applicable to certain water samples. Results shown in Appendix A were conservatively qualified "UJ" by Westinghouse Hanford because of the time between field sampling and extraction. Periods between sampling and extraction ranged from 3 weeks to 50 days. Once extracted, all samples were analyzed within the 40day criterion established for extracts.

Detection limits were calculated and reported by the laboratory when target compounds were not found. The concentration corresponding to a signalto-noise ratio of 2.5 was reported as the detection limit for each analyte. All results reflect these limits and are reported with "U" qualifiers in Appendix A.

The result for sample $\mathrm{BOOHOl} \mathrm{(see} \mathrm{Section} \mathrm{4.1)} \mathrm{is} \mathrm{missing;} \mathrm{however,} \mathrm{this}$ should have minimal impact on the chemical characterization of $3 \mathrm{C}$ Pond vadose zone. Samples taken above and below BOOHOl were not found to have any detectable dioxin or furan target compounds. (This is also consistent with samples from other areas of B-Pond.) 


\subsubsection{Volatile Organic Compounds}

No volatile organic compounds of significance were found. However, three identifiable compounds were reported in the regular samples: methylene chloride, acetone, and 4-methyl-2-pentanone. Only methylene chloride is known to be a 40 CFR Part 261 Hazardous Constituent and WAC 173-303-9905 Dangerous Waste Constituent. All regular, field duplicate, field split, and silica sand sample results are shown in Appendix $A$.

Traces of three unidentified compounds were reported in sample BO0GV5. This was the deepest $3 A$ Pond borehole sample $(\sim 143.5 \mathrm{ft})$. It was from a saturated zone. (The sample was noted as "very wet" in the field logbook. A percent moisture on the VOA al iquot was not reported.)

Samples were spiked with surrogate compounds to monitor method performance. Recoveries are summarized in Table 4-5. Performance on matrix spike and matrix spike duplicates was also reviewed as part of data validation and found to be within accepted limits. Some VOA results were qualified during data validation based on holding times and laboratory reagent blanks.

Table 4-6. VOA Surrogate Percent-Recovery Summary (37 Samples--50 $\mu \mathrm{g} / \mathrm{Kg}$ Spikes)

\begin{tabular}{|l|c|c|c|c|}
\hline \multicolumn{1}{|c|}{ SURROGATE } & OC LIMITS $(x)$ & MEAN $(x)$ & MXIMUM $(x)$ & MINIMIM $(x)$ \\
\hline \hline Tolvene-d8 & 81.117 & 103.4 & 195.4 & 91.2 \\
\hline Bromofluorobenzene & 74.121 & 101.1 & 109.2 & 91.0 \\
\hline 1,2 -Dichlorethane & 70.121 & 102.0 & 110.7 & 86.9 \\
\hline
\end{tabular}

Methylene chloride was reported in BOOFKT $(4 \mathrm{~J} \mu \mathrm{g} / \mathrm{Kg})$ and BOOFK8 (3 $\mathrm{J}$ $\mu \mathrm{g} / \mathrm{Kg})$. These were the second and third samples, respectively, collected from the $3 A$ Pond borehole. No other suspected traces of this analyte were identified in the 29 other regular site samples, 3 field duplicates, 3 silica sand samples, or 9 laboratory reagent blanks. Methylene chloride in each sample was reported at less than the minimum detection level reported for all other samples. Reporting limits on other samples ranged from $5 \mathrm{U}-8 \mathrm{U} \mu \mathrm{g} / \mathrm{Kg}$, with $5 \mathrm{U} \mu \mathrm{g} / \mathrm{Kg}$ being the most common value.

Methylene chloride was reported by the laboratory (before Westinghouse Hanford validation) with a "J" qualifier flag. This indicates an estimated value. According to CLP protocol and given evidence of detection, some analytes may be reported by the laboratory at levels below the CLP contract detection limit and flagged as estimated. The EPA CLP Statement of Work for Organic Analysis has historically used $10 \mu \mathrm{g} / \mathrm{Kg}$ as a contract-required quantitation limit (CRQL) for methylene chloride in soil. This figure is based on wet weight, and must be adjusted upward based on the percent moisture for comparison to results reported on a dry-weight basis. The reporting methods used by the Phase 3 laboratories are based on this protocol. Results were reported on a dry-weight basis.

Although methylene chloride was not reported in blanks, it is a common laboratory contaminant. It can also diffuse through the septum of VOA sample containers in shipment or storage. Acetone, another common volatile solvent, 
WHC-SD-EN-AP-104 Rev. 0

was also reported in each of the two samples reported with traces of methylene chloride. These samples contained the highest and second highest reported levels of acetone.

Acetone was reported in only 6 of the 37 validated VOA samples analyzed at the primary laboratory. Reported concentrations were $64,55,13,17,27$, and $49 \mu \mathrm{g} / \mathrm{Kg}$. Five of the incidences were associated with two sampling/shipment days (from $3 A$ Pond) and two analytical batches. Sample numbers were BOOFK7, BOOFK8, BOOFLO, BOOFL3 (silica sand blank), and BOOGR9 (field duplicate). The sixth occurrence was in sample BOOH19 from $3 C$ Pond. Not all samples collected and shipped in common were analyzed on the same day. Eight samples shared the characteristic of having been collected/shipped and analyzed in association with a sample where acetone was reported. None of the three immediately associated laboratory blanks showed traces of acetone, although another laboratory blank during the project was reported at $26 \mu \mathrm{g} / \mathrm{Kg}$. One of the eight samples was a silica sand field blank. Acetone was reported in the silica sand blank at $17 \mu \mathrm{g} / \mathrm{kg}$. The other two silica blanks submitted during the project were not reported to contain acetone. Acetone was also not reported in $B O O F L 4$, the regular sample associated with the field duplicate, BOOGR9.

All individual sample results for acetone are less than four times the amount reported in one of the three project silica sand blanks. All acetone results are also below the SW-846 (EPA 1986) practical quantitation limit $(P Q L)$ discussed below. Acetone is highly soluble in water. If acetone was at a quantifiable concentration and originated from percolating wastewater, there should be a positive correlation between sample moisture and acetone content. The evidence does not support correlation.

The compound 4-methyl-2-pentanone, al so known as methyl isobutyl ketone, was reported by the laboratory at $3 \mathrm{~J} \mu \mathrm{g} / \mathrm{Kg}$ in sample BO0GV5, BOOGX6, and BOOGZ2. (The "J" qualifiers have the same meaning as for methylene chloride.) The contract-required quantitation limit (CRQL) and nominal reporting limit of 4-methyl-2-pentanone is the same as methylene chloride, $10 \mu \mathrm{g} / \mathrm{Kg}$. For all other 28 regular samples, 3 field duplicates, and 3 silica sand blanks, 4methyl-2-pentanone was reported as undetected at the adjusted CRQL. Aithough not reported in either of the two immediately associated laboratory blanks, the compound was reported at precisely the same concentration in one of the nine laboratory VOA blanks reported for the project. This rate of occurrence (as well as concentration) is not significantly different from that found for site soil samples. A related compound, the aldol condensate 4-hydroxy-4methyl-2-pentanone, was a chronic contaminant in semivolatile analyses at the primary laboratory. (All occurrences of that compound were qualified as undetected TICS caused by prolific laboratory contamination. Because of this they are not shown in Appendix $A$, but concentrations frequently exceeded $20,000 \mu \mathrm{g} / \mathrm{Kg}$ in many semivolatile analyses.)

The validation procedure used to produce the data listed in Appendix $A$ qualifies data based only on laboratory blanks. Appendix $A$ data have not been qualified based on results of project silica sand field samples. Consistent with EPA validation guidance, the procedure employed to evaluate laboratory blanks uses a $10 x$ rule for evaluating common laboratory contaminants, including acetone. Results less than $10 x$ the concentration in an associated blank are qualified as undetected at the reported concentration. 
Frequently instrument capabilities alone are not the primary limitation of measuring low-level organic compounds. Other aspects of the procedure, such as sample preparation and handling, are important parts of the measurement system. For instance, a single VOA aliquot of sample BOOHIS was collected and shipped for analysis. It was divided by the laboratory and analyzed in triplicate as a regular, matrix spike, and matrix spike duplicate sample. Acetone was measured at 49 and $47 \mu \mathrm{g} / \mathrm{Kg}$ respectively in two portions, yet undetectable $(11 \mathrm{U} \mu \mathrm{g} / \mathrm{Kg})$ in the third.

In recognition of such factors, EPA has established practical quantitation limits (PQLS) for those methods used to determine whether a solid waste is a hazardous waste within the definition of Section 3001 of RCRA. Practical quantitation limits are estimates of the lowest concentrations that can be reliably measured by a given analytical procedure. Washington State "Dangerous Waste Regulations" (WAC 173-303) reference EPA's SW-846 (EPA 1986) manual in setting analytical protocol standards. The EPA has published 5 $\mu \mathrm{g} / \mathrm{Kg}$ as a PQL for methylene chloride in soil measured by SW-846 method 8240 . The corresponding PQLS for acetone and 4-methy7-2-pentanone are 100 and 50 $\mu \mathrm{g} / \mathrm{Kg}$ (EPA 1986). EPA recognizes that PQLs are highly matrix dependent and may not always be achievable. Again, these figures are based on wet weight and must be adjusted when compared to results reported on a dry-weight basis.

Although not currently discussed in the "Dangerous Waste Regulations" (WAC 173-303), regulations under other authority such as Washington State's "Model Toxics Control Act" (WAC 173-340) reference EPA's PQLs in establishing de facto de minimis regulatory limits (see WAC 173-340-707 Analytical

Considerations). Other factors, including toxicity, are al so considered.

The EPA is not known to have issued any general rules on environmental media de minimis levels of 40 CFR Part 261 Appendix VIII hazardous constituents. It has historically been EPA's policy that such levels are determined on a site-specific basis (57 FR 958 et seq.). The EPA's proposed RCRA Corrective Action rules (55 FR 30798 et seq.) give an example of a soil methylene chloride concentration meeting the criteria for a media action level. This action level is a conservative health-based level based on ingestion of contaminated soil. The toxicity of methylene chloride is such that the proposed action level is $90 \mathrm{mg} / \mathrm{kg}$ (equivalent to $90,000 \mu \mathrm{g} / \mathrm{kg}$ ). Likewise, conservative health-based concentration action levels for acetone and 4-methyl-2-pentanone are $8000 \mathrm{mg} / \mathrm{kg}$ and $4000 \mathrm{mg} / \mathrm{kg}$, respectively.

\subsubsection{Base/Neutral/Acid Compounds}

Phase 3 soil samples showed no semivolatile target compounds at concentrations above their respective CRQL. Only two target compounds were reported in site samples, benzoic acid and diethylphthalate. Each occurrence was qualified as estimated, "J", by the laboratory because both had less than CRQL concentrations. Both were also reported in at least one laboratory blank, a) though not the one "associated" with those particular analyses according to the employed data validation procedure. All regular, field duplicate, field split, and silica sand sample results are shown in Appendix A.

Surrogate compounds were used to monitor method performance. All surrogate recoveries were within acceptable limits. A performance summary for 
WHC-SD-EN-AP-104 Rev. 0

all regular, duplicate, and silica sand samples submitted to the primary laboratory is shown in Table 4-7. All matrix spike and duplicate recoveries met $Q C$ specifications.

Table 4-7. Semivolatile Surrogate Percent-Recovery Summary (37 Primary Laboratory Samples).

\begin{tabular}{|c|c|c|c|c|c|c|}
\hline surrogate & $\begin{array}{c}\text { Nitrobenzeme } \\
\text {-ds }\end{array}$ & $\begin{array}{c}1,11-8 \text { iphemyl, } \\
2-f \text { luoro }\end{array}$ & Terpheryl-d14 & Phenol-ds & $\begin{array}{l}\text { 2-Fluoro } \\
\text { phenol }\end{array}$ & $\begin{array}{c}2,4,6-\text { Tribrano } \\
\text { phenol }\end{array}$ \\
\hline $\begin{array}{l}\text { Spike added } \\
(\mu g / K g)\end{array}$ & 100 & 100 & 100 & 200 & 200 & 200 \\
\hline $\begin{array}{l}\text { Mean } \\
\text { percent- } \\
\text { recovery }\end{array}$ & 57.2 & 65.8 & 83.1 & 54.6 & 51.8 & 52.2 \\
\hline $\begin{array}{l}\text { Standord } \\
\text { deviation }\end{array}$ & 17.2 & 20.6 & 14.8 & 16.1 & 13.3 & 17.4 \\
\hline OC limits $x$ & $23 \cdot 120$ & $30-115$ & $18 \cdot 137$ & $26-113$ & $25 \cdot 121$ & $19 \cdot 122$ \\
\hline
\end{tabular}

While benzoic acid is not listed as a RCRA Appendix VIII- or WAC 173-303-9905 Dangerous Waste constituent, benzoic acid was reported in 9 of the 37 samples, (regular, field duplicate, and silica sand samples). In each case, it was reported at less-than-one-fifth of the nominal less-than reporting limit of $5000 \mu \mathrm{g} / \mathrm{Kg}$. Seven occurrences were associated with samples extracted February 24, 1991. All of the samples were from the upper $28 \mathrm{ft}$ of the $3 A$ Pond borehole. The remaining two occurrences were associated with samples extracted March 7, 1991. These were the first two samples from the $3 B$ borehole. Neither immediately associated batch blank was reported with traces of benzoic acid, nor were other site samples in the batches. However, one of seven laboratory blanks reported with Phase 3 samples did contain benzoic acid, estimated at $1500 \mathrm{~J} \mu \mathrm{g} / \mathrm{Kg}$, which is below the CRQL. This concentration is greater than that estimated in the nine validated samples.

Diethylphthalate was reported in only three regular samples and one split sample. Diethylphthalate appears on both the RCRA Appendix VIII and WAC 173303-9905 1ist. All occurrences of diethylphthalate were qualified as estimated, flagged with a "J", because of low concentration. All occurrences were less than half the less-than reporting limit of $1000 \mu \mathrm{g} / \mathrm{Kg}$. Reported concentrations were $170 \mathrm{~J}, 210 \mathrm{~J}$, and $370 \mathrm{~J} \mu \mathrm{g} / \mathrm{Kg}$. One of the independently analyzed split samples was reported at $95 \mathrm{~J} \mu \mathrm{g} / \mathrm{Kg}$. That sample was collected simultaneously to with the regular sample reported at $210 \mathrm{~J} \mu \mathrm{g} / \mathrm{Kg}$ by the primary laboratory. Sample numbers and location are as follows:

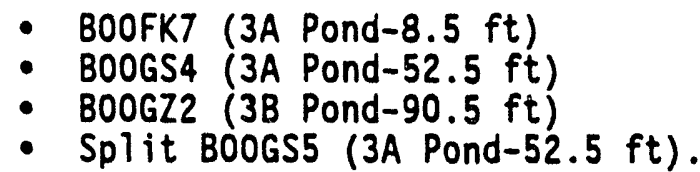

No evidence of the phthalate compound was found in the associated laboratory blanks; however traces were suspected in two of the seven blanks at the primary laboratory, (a higher rate than the samples). The phthalate compound was reported at $670 \mathrm{~J}$ and $540 \mathrm{~J} \mu \mathrm{g} / \mathrm{Kg}$ in those laboratory reagent blanks. As a result, some samples were qualified undetected at the CRQL. None of the three split laboratory blanks or three silica sand samples showed traces of this particular phthalate, though both groups contained other 
phthalates. Phthalates are commonly found at low levels as field or laboratory contaminants.

The EPA CLP SOW for organic analyses has traditionally defined an acceptable semivolatile analytical method blank as one containing a concentration less than or equal to the CLP CRQL, except for target compound phthalate esters. An acceptable blank may contain a concentration of less than or equal to 5X times the target compound phthalates. This reflects the widespread use of phthalate compounds and the difficulty of avoiding sample cross-contamination bias. The key issue of whether a particular single isolated sample is representative must be considered.

The fact that both the regular sample, BOOGS4, and its associated split, BOOGS5 were reported with traces of diethylphthalate suggests at least some of the occurrences may have had a field origin (true or artificial). Although the compound sinks in water, phthalate esters are readily sequestered by or adsorbed on organic residues and solid surfaces in environmental water systems. This should lead to accumulation in the near-surface sediments and subsequent long-term low-level release if wastewater disposal activities are the true source of diethylphthalate. Introduced spurious contamination from a common field source is also a possible source, which would cause such samples to actually be unrepresentative of site conditions.

The few and isolated nature of the occurrences, low concentration, and apparent lack of decreasing concentration with depth suggest that the occurrences are an artifact of the measurement system and not a reflection of site conditions. Although trends with depth are opposite of a pond sediment source, the values are too low to be considered reliable indicators of contamination. The cverall measurement system is simply not capable of reliably characterizing the mean diethylphthalate concentration at such minute levels. From a single split spoon of soil, the sample standard deviation calculated using the two independently anaiyzed samples, BOOGS4 and BOOGS5, is $81.3 \mu \mathrm{g} / \mathrm{Kg}$. A 90-percent one-sided small sample confidence interval for the true mean of the location encompasses zero. Based only on the demonstrated reproducibility at this one location for which two, supposedly positive, independent analyses were performed, one cannot reliably consider the concentration of diethylphthalate different from zero.

Semivolatile results, in contrast to the Phase 1 study results, showed frequent TICs, averaging approximately 13 per sample for the primary laboratory and slightly more than 3 per sample for the split laboratory. In addition, laboratory batch blanks averaged approximately 14 TICs per blank at the primary laboratory; no TICs were seen for blanks at the split laboratory. Most of the TICs were either unidentifiable or only generically identifiable compounds. The large number of TICs reported by the primary laboratory for both samples and blanks suggest that their occurrence must be interpreted with some skepticism.

The majority of TICS were rejected on validation because identical compounds occurred at similar concentrations in the immediately associated laboratory batch blanks. Nevertheless, some TICs remained after validation. A surprisingly similar number of TICs were present in the average validated sample results from the primary and split laboratories--slightly less than four and slightly greater than three, respectively, after validation. Silica sand field blanks were not considered in the employed validation procedure. 
WHC-SD-EN-AP-104 Rev. 0

They were submitted only to the primary laboratory. On average, they contained four validated TICs per sample.

One compound identified as a validated TIC is listed on the RCRA Appendix VIII or WAC 173-303-9905 Dangerous Waste Constituents List. The identified compound is dimethylhydrazine (CAS \# not reported by laboratory). Three occurrences, (BOOFL1, BOOGR9, and BOOFK9), were associated with a single analytical batch; however, BOOFKg was flagged to indicate the analyte was found in an associated laboratory reagent blank. The laboratory did not specifically report this compound in the identified associated laboratory blank, (1ab ID 910225-170). The laboratory has not been able to produce a definitive explanation for this apparent anomaly. Application of validation criteria to TICs resulted in rejection of this particular TIC in sample BOOFK9, but not BOOFLI or BOOGR9--even though all were supposediy in the same analytical batch. Reported concentrations and qual ifiers were $600 \mathrm{JY}$ - and 460 $\mathrm{J}-\mu \mathrm{g} / \mathrm{Kg}$, respectively. No other Phase 3 samples contained this compound.

\subsection{INORGANIC CHEMICAL RESULTS}

All inorganic results with attached data qualifiers are listed in Appendix $A$. The results are summarized by two tables. Calculated statistics can be confirmed using values listed in Appendix A. Further comparisons of these results are made in Section 5 .

All regular samples are summarized in Table 4-8. Values are summarized by showing the total number of samples analyzed, number of less-thandetection-limit values, median, mean, upper 90-percent limit of the mean, standard deviation, percent coefficient of variation, and range for each lobe. A standard deviation, upper confidence limit, and percent-coefficient of variation were not calculated for analytes that were rarely or never at detectable concentrations. For those analytes that were undetected in a minority of samples, analytes were assumed, for summary calculation purposes, to have values equal to their reported "less-than" values. Concentration qualification flags are shown for the minimum and maximum values of each lobe. 


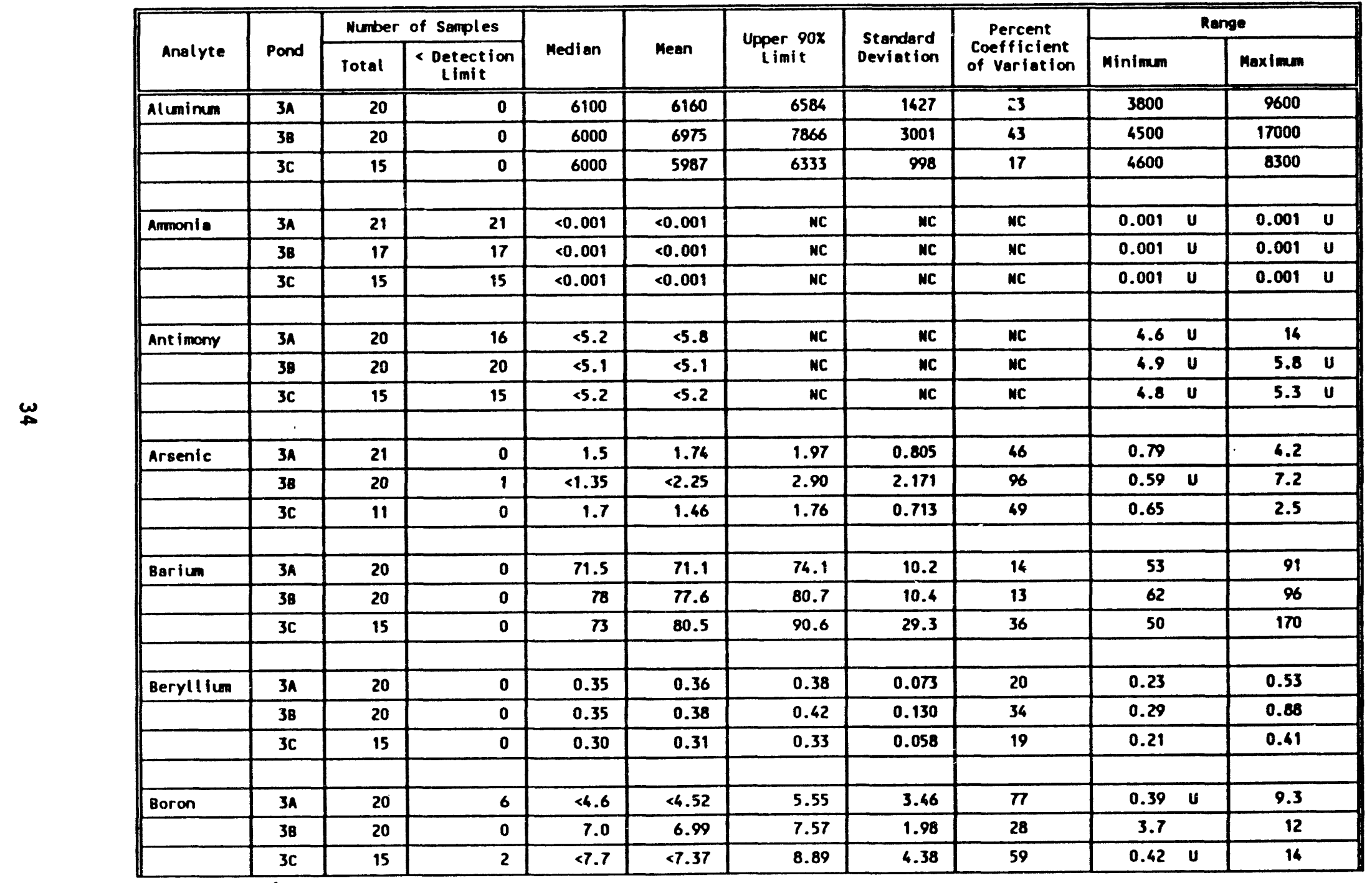

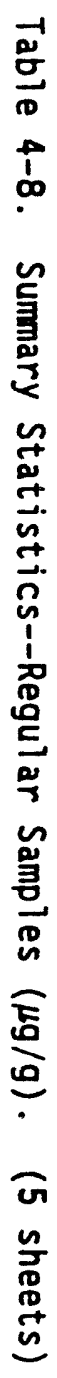




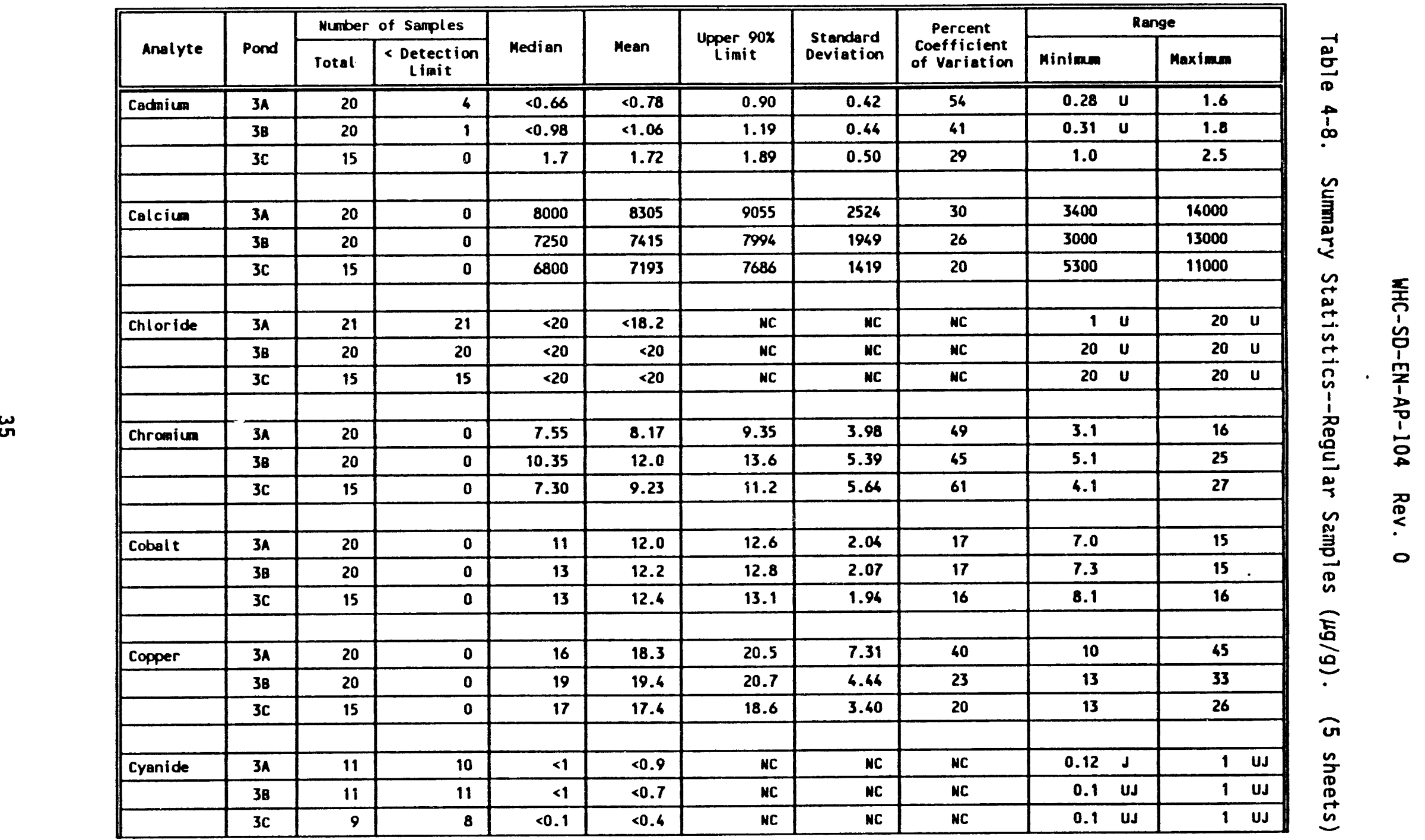




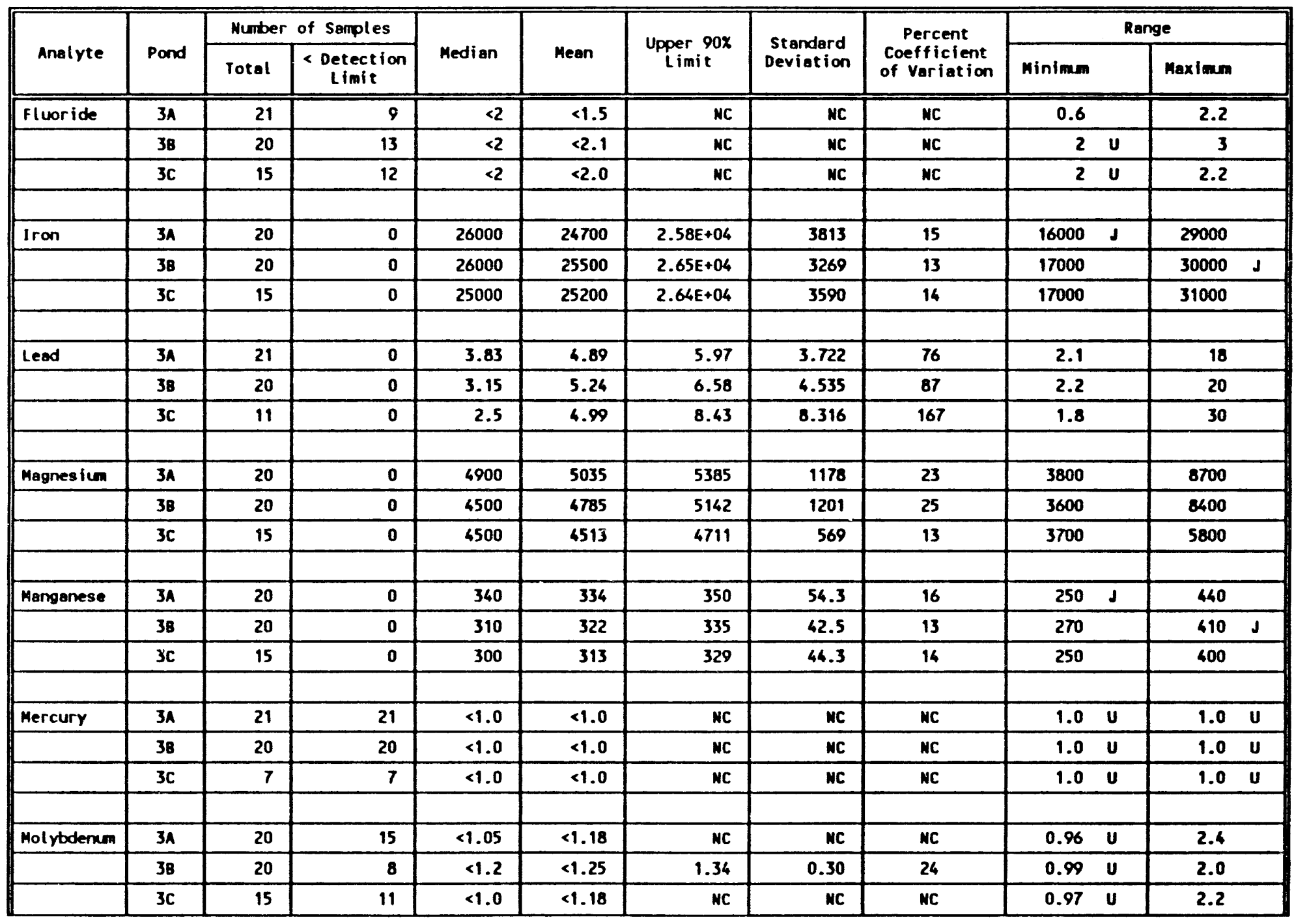




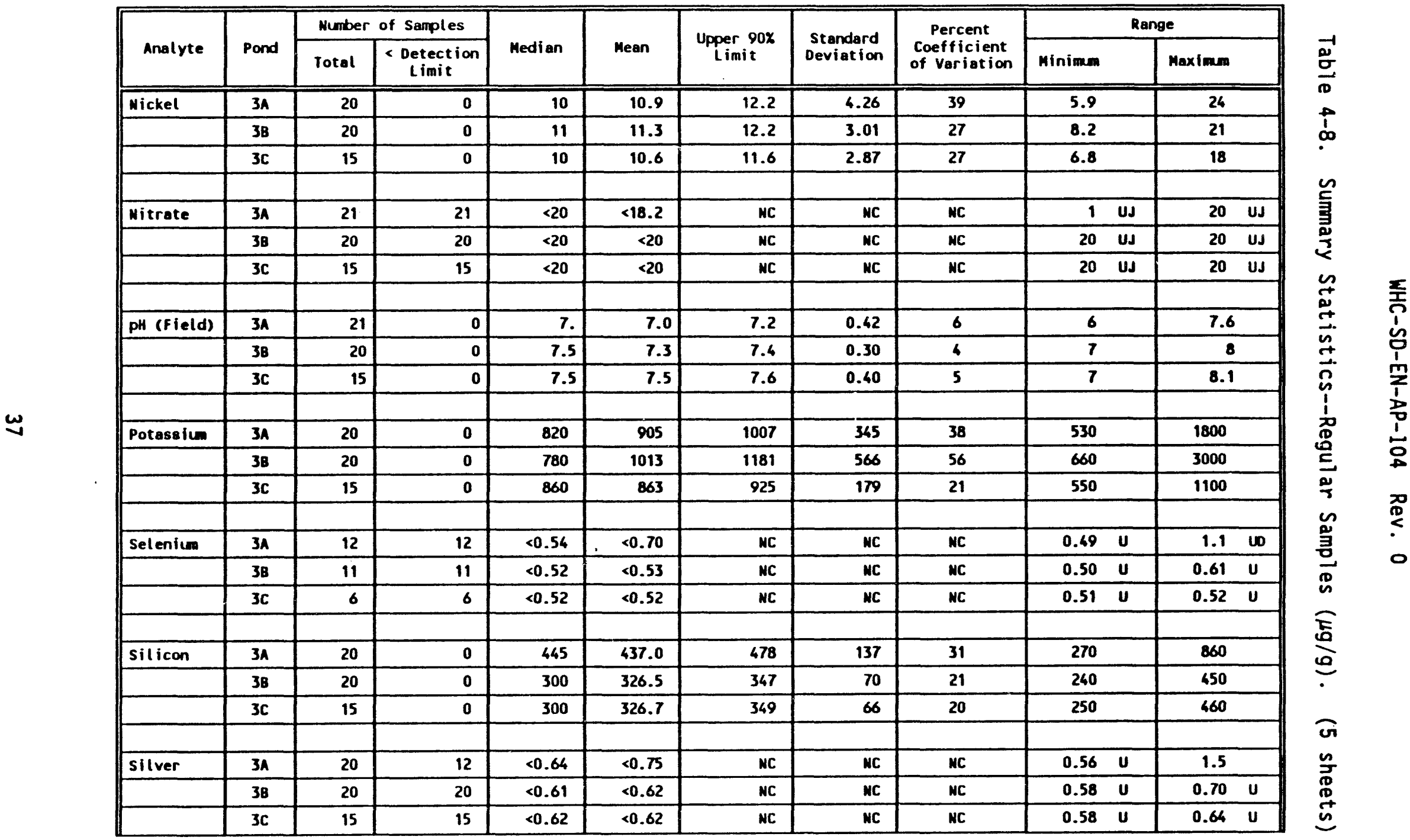




\begin{tabular}{|c|c|c|c|c|c|c|c|c|c|c|}
\hline \multirow[b]{2}{*}{ Analyte } & \multirow[b]{2}{*}{ Pond } & \multicolumn{2}{|c|}{ Number of Samples } & \multirow{2}{*}{ Median } & \multirow{2}{*}{ Mean } & \multirow{2}{*}{$\begin{array}{c}\text { Upper } 90 x \\
\text { Limit }\end{array}$} & \multirow{2}{*}{$\begin{array}{l}\text { Standard } \\
\text { Deviation }\end{array}$} & \multirow{2}{*}{$\begin{array}{c}\text { Percent } \\
\text { Coefficient } \\
\text { of Voriation }\end{array}$} & \multicolumn{2}{|c|}{ Range } \\
\hline & & Total & $\begin{array}{l}\text { <etection } \\
\text { Limit }\end{array}$ & & & & & & Minimum & Maximam \\
\hline \multirow[t]{3}{*}{ Sodium } & $3 A$ & 20 & $\mathbf{0}$ & 280 & 349 & 404 & 186 & 53 & 170 & 810 \\
\hline & 38 & 20 & 0 & 405 & 402 & 445 & 146 & 36 & 180 & 710 \\
\hline & $3 c$ & 15 & 0 & 435 & 479 & 520 & 117 & 24 & 270 & 730 \\
\hline \multirow[t]{3}{*}{ Sulfate } & $3 A$ & 21 & 2 & $<20$ & $<18.4$ & MC & NC & NC & 1 & 24 \\
\hline & 38 & 20 & 5 & $<20$ & $<22.7$ & MC & MC & MC & 20 & 39 \\
\hline & 3c & 15 & 1 & $<20$ & $<20.6$ & NC & NC & NC & 20 & 26 \\
\hline \multirow[t]{3}{*}{ Sulfide } & $\because$ & 11 & 11 & $<0.1$ & $<0.1$ & NC & NC & MC & 0.1 & 0.1 \\
\hline & 38 & 11 & 10 & $<0.1$ & $<0.1$ & MC & NC & WC & 0.1 & 0.1 \\
\hline & $3 c$ & 9 & 9 & $<0.1$ & $<0.1$ & MC & MC & MC & 0.1 & 0.1 \\
\hline \multirow[t]{3}{*}{ Thallium } & $3 A$ & 12 & 12 & $<1.0$ & $<1.04$ & NC & MC & MC & 0.97 & 1.1 \\
\hline & 38 & 11 & 11 & $<1.0$ & $<1.04$ & MC & NC & MC & 1.0 & 1.2 \\
\hline & $3 c$ & 6 & 6 & $<1.0$ & $<1.00$ & NC & MC & MC & 1.0 & 1.0 \\
\hline \multirow[t]{3}{*}{ Vanadium } & $3 A$ & 20 & $\mathbf{0}$ & 67.5 & 64.5 & 68.4 & 13.3 & 21 & 38 & 86 \\
\hline & 38 & 20 & 0 & 70.5 & 66.2 & 70.6 & 14.9 & 22 & 34 & 87 \\
\hline & $3 c$ & 15 & 0 & 68 & 66.9 & 71.1 & 12.1 & 18 & 38 & 85 \\
\hline \multirow[t]{3}{*}{ Zinc } & $3 A$ & 20 & $\overline{0}$ & 49.5 & 47.8 & 49.8 & 6.64 & 14 & 34 & 60 \\
\hline & 38 & 20 & 0 & 47 & 46.6 & 47.9 & 4.67 & 10 & 39 & 56 \\
\hline & $\overline{3 c}$ & 15 & 0 & 47 & 46.3 & 48.5 & 6.50 & 14 & 34 & 57 \\
\hline
\end{tabular}

WC Not calculated, most or all values undetected. See Appendix A data.

D Dilution.

$U$ Analyte was not detected at the stated limit.

$J$ The associated value is on est imated quantity. 
Field duplicates are summarized in Table 4-9. Field duplicate samples aid in evaluating short-term variability of the measurement system processes and of the inherent media variability itself. They provide a second estimate of the representative concentration associated with a particular interval, and thereby allow an estimate of variability within the given measurement system. For the purposes of the Table 4-9 summary, all statistics were calculated only where pairs of values were uncensored by a reporting limit. The following two methods of summarizing variability were used:

- The average sample variance between regular/field duplicate pairs. (The square root of the variance is the standard deviation.)

- The average percent coefficient of variation between regular/field duplicate pairs.

Variability above the detection limit is also graphically displayed in Appendix $B$ for regular/field duplicate and regular/split sample pairs uncensored by a reporting limit. Most analytes show no definitive trend between variability and concentration for results from a single laboratory; however, this is not the case when split samples are considered. This suggests that the coefficient of variation may be the preferred parameter to consider when making interlaboratory comparisons. These comparisons incorporate sources of variability between measurement systems as well as within single-laboratory systems.

Split samples provide an independent analysis to corroborate results of the primary laboratory. Table 4-9 summarizes the average "bias" of the reportable primary laboratory results by assuming that the split laboratory provides the true value. The standard deviation of the bias and number of pairs considered in the calculations are listed. The statistical significance was evaluated by determining if a $95 \%$, two-sided confidence interval around the average also encompassed zero. The interval was based upon the tdistribution, number of bias estimates and their variability. Analyte concentrations were generally lower at the split laboratory than the primary laboratory. Therefore, decisions based on projections from the primary laboratory values should be more conservative and thus be more protective of human health and the environment. If the site is considered sufficiently clean based on these higher values, overestimation of constituents is irrelevant. However, if values suggest that dangerous waste is be present, further evaluation may be in order.

A mean bias and comparison calculations were not made when all values were reported at an undetected censored limit by either laboratory. When values were not censored at a reporting limit, they were considered in the comparisons. Alternatively for arsenic, beryllium, chromium, potassium, sodium, and gross alpha, computations were al so made considering all censored concentrations equivalent to the reporting limit, (example $1.0 U=1$ ). The alternate results are shown in brackets. In the case of sodium, one undetected split was reported at a much higher limit and therefore unduly affected this type of comparison. No comparisons are possible for analytes not measured at both the primary and split laboratories. 


\begin{tabular}{|c|c|c|c|c|c|c|c|c|}
\hline \multirow[b]{2}{*}{$\begin{array}{c}\text { Analyte } \\
(\mu g / g)\end{array}$} & \multicolumn{4}{|c|}{ Field Duplicate: Regular Sample Pairs } & \multicolumn{4}{|c|}{ Regular Minus Associated Field Split Sample } \\
\hline & $\begin{array}{l}\text { Computed } \\
\text { on } x \\
\text { Sample } \\
\text { Pairs }\end{array}$ & $\begin{array}{c}\text { Average } \\
\text { Variance }\left(s^{2}\right)\end{array}$ & $\begin{array}{c}\text { Standard } \\
\text { Deviation } \\
\text { (S) }\end{array}$ & $\begin{array}{l}\text { Average } \\
\text { Percent } \\
\text { Coefficient } \\
\text { of Variation }\end{array}$ & $\begin{array}{l}\text { Mean } \\
\text { Bias } \\
\mu g / g\end{array}$ & $\begin{array}{l}\text { Standard } \\
\text { Deviation } \\
\text { of Bias }\end{array}$ & $\begin{array}{l}\text { Computed } \\
\text { on } x \\
\text { Sample } \\
\text { Pairs }\end{array}$ & $\begin{array}{c}\text { Statistically } \\
\text { Significant? } \\
(\alpha=.05)\end{array}$ \\
\hline Aluminum & 7 & 250714.3 & 500.71 & 6.50 & 4082.86 & 1163.50 & 7 & $\mathbf{r}$ \\
\hline Ammonis & - & MC & NC & MC & MA & ma & - & - \\
\hline Ant imony & - & MC & MC & NC & NC & MC & - & - \\
\hline Arsenic & 6 & 1.503 & 1.226 & 19.9 & $1.426[1.14]$ & $2.37[2.04]$ & $5[7$ & $N$ [N] \\
\hline Berium & 7 & 126.6 & 11.25 & 11.4 & 28.4429 & 13.33 & 7 & $r$ \\
\hline Beryllium & 7 & 0.0 & 0.02 & 6.20 & $0.07[-0.04]$ & $0.11[0.31]$ & $4[7$ & $N$ [N] \\
\hline Boron & 6 & 1.7 & 1.32 & 10.6 & $\mathrm{NA}$ & MA & - & - \\
\hline Cactnium & 7 & 0.3 & 0.51 & 26.8 & MC & MC & - & - \\
\hline Calcium & 7 & 1465714.3 & 1210.67 & 11.4 & 2761.43 & 978.48 & 7 & $r$ \\
\hline Chloride & - & NC & NC & MC & MA & Ma & - & - \\
\hline Chromium & 7 & 12.4 & 3.52 & 27.3 & $14.17[11.04]$ & $6.17[5.50]$ & $3[7]$ & $n[y]$ \\
\hline Cobalt & 7 & 0.2 & 0.48 & 3.09 & 5.25 & 2.74 & 6 & $r$ \\
\hline Copper & 7 & 3.4 & 1.85 & 9.01 & 9.943 & 3.25 & 7 & $\bar{r}$ \\
\hline Cyanide & - & NC & NC & NC & NC & MC & - & - \\
\hline field pH & 7 & 0.0 & 0.0 & 0.0 & MA & WA & - & - \\
\hline Fluoride & - & MC & NC & $M C$ & NA & MA & - & - \\
\hline Iron & 7 & 2214285.7 & 1488.05 & 4.34 & 14927.1 & 3962.73 & 7 & $r$ \\
\hline Lead & 7 & 8.995 & 2.999 & 12.2 & 2.2 & 5.45 & 6 & N \\
\hline Magnesium & 7 & 189285.7 & 435.07 & 8.85 & 2645.71 & 816.37 & 7 & $r$ \\
\hline Mangenese & 7 & 464.3 & 21.55 & 5.38 & 145.6 & 48.27 & 7 & $r$ \\
\hline Mercury & - & NC & NC & NC & MC & NC & - & - \\
\hline Mol ybderum & 3 & 0.3 & 0.57 & 31.5 & MA & MA & - & - \\
\hline Nickel & 7 & 26.9 & 5.18 & 20.3 & 5.62 & 2.43 & 6 & $r$ \\
\hline Mitrate & - & NC & MC & NC & NA & $\mathrm{MA}$ & - & - \\
\hline Potassium & 7 & 8114.3 & 90.08 & 8.76 & $\begin{array}{c}389.75 \\
{[351.28]}\end{array}$ & $74.59\{205.7\}$ & $4(7)$ & $r[y]$ \\
\hline Selenium & - & MC & NC & NC & NC & MC & - & - \\
\hline silicon & 7 & 3828.6 & 61.88 & 12.9 & NA & $\mathrm{MA}$ & - & - \\
\hline
\end{tabular}




\begin{tabular}{|c|c|c|c|c|c|c|c|c|}
\hline \multirow[b]{2}{*}{$\begin{array}{c}\text { Analyte } \\
(\mu \mathrm{g} / \mathrm{g})\end{array}$} & \multicolumn{4}{|c|}{ Field Duplicate: Regular Sample Pairs } & \multicolumn{4}{|c|}{ Regular Minus Associated Field Split Sample } \\
\hline & $\begin{array}{l}\text { Computed } \\
\text { on } x \\
\text { Sample } \\
\text { Pairs }\end{array}$ & $\begin{array}{c}\text { Average } \\
\text { Variance }\left(s^{2}\right)\end{array}$ & $\begin{array}{c}\text { Standard } \\
\text { Deviation } \\
\text { (S) }\end{array}$ & $\begin{array}{c}\text { Average } \\
\text { Percent } \\
\text { Coefficient } \\
\text { of Variation }\end{array}$ & $\begin{array}{l}\text { Mean } \\
\text { Bias } \\
\mu g / g\end{array}$ & $\begin{array}{l}\text { Standard } \\
\text { Deviation } \\
\text { of Bias }\end{array}$ & $\begin{array}{l}\text { Computed } \\
\text { on } x \\
\text { Sample } \\
\text { Pairs } \\
\end{array}$ & $\begin{array}{c}\text { Statistically } \\
\text { significant? } \\
\text { (ax.05) }\end{array}$ \\
\hline Silver & - & MC & NC & MC & NC & MC & - & - \\
\hline Sodium & 7 & 3785.7 & 61.53 & 11.6 & $272.14[151.1]$ & $177.58 \quad[299.35]$ & $5[7$ & $Y[M]$ \\
\hline Sulfate & 2 & 18.5 & 4.30 & 13.3 & MA & MA & - & $\cdot$ \\
\hline Sulfide & - & NC & NC & MC & MA & MA & - & - \\
\hline Thallium & - & HC & NC & NC & NC & NC & - & - \\
\hline Vanadiun & 7 & 13.0 & 3.61 & 4.17 & 45.029 & 14.53 & 7 & $r$ \\
\hline Zinc & 7 & 8.6 & 2.93 & 4.32 & 25.829 & 5.35 & 7 & $r$ \\
\hline \multicolumn{9}{|l|}{$\begin{array}{l}\text { RADIONUCLIDE } \\
\text { DATA }(\rho C I / g)\end{array}$} \\
\hline Gross Alpha & 7 & 1.21 & 1.100 & MC & $-2.7[-1.4]$ & $1.38[1.7]$ & $3[6]$ & $M[N]$ \\
\hline Gross Bete & 7 & 18.78 & 4.334 & $M C$ & -18.35 & 12.88 & 6 & $r$ \\
\hline strontium-90 & 3 & 1.60 & 1.263 & NC & MC & MC & - & - \\
\hline $\begin{array}{l}\text { Gamma: } \\
\text { Cs-137 }\end{array}$ & 2 & 0.015 & 0.121 & MC & MA & MA & - & - \\
\hline $\begin{array}{l}\text { Gamma: } \\
\mathrm{Pa}-234 \mathrm{~m}\end{array}$ & 2 & 1056.25 & 32.500 & NC & MA & MA & $\cdot$ & $\cdot$ \\
\hline $\begin{array}{l}\text { Gamma: } \\
\text { Th-234 }\end{array}$ & 2 & 1.49 & 1.220 & MC & MA & MA & - & - \\
\hline
\end{tabular}

wuw flagged, less-than values excluded except for bracketed al ternate figures computed under the assumption undetected values are equal to the reporting limit, (See text).

NC Not calculated, most or all values undetected--see Appendix $A$ data.

MA Not avail able. 
WHC-SD-EN-AP-104 Rev. 0

\subsection{RADIOANALYTICAL RESULTS}

Radioanalytical work included field screening techniques and both onsite and offsite laboratory determinations. All samples were handled as nonradioactive based on field screening and onsite analyses. Offsite analyses included gross alpha, gross beta, gamma, and ${ }^{90} \mathrm{Sr}$ determinations. The primary laboratory reported EPA 900.0 was used for alpha, beta and gamma, and EPA 906 for ${ }^{90}$ Srdeterminations. Several samples were submitted to the split laboratory for radiologic analyses. These particular analyses were subcontracted to another laboratory. Methods were identified only by the laboratory-specific procedure numbers PRO-032-15 for total alpha or beta determinations, PRO-042-5 for gamma scans, and PRO-032-25 for strontium-90 assays.

The above parameters are not believed to be regulated under current and applicable RCRA regulations. Unvalidated radiological data are presented in Appendix A for information only. Field duplicate and split summaries are presented at the end of Table 4-9. The results of the gamma spectra analyses were not comparable between the two project laboratories. Different radionuclides were reported by the two measurement systems.

Gross gamma borehole logging did not reveal any obvious anomalies. Without radionuclide-specific detection capabilities, it is not possibie to judge whether any areas of slightly elevated gross counts are caused by radionuclide contamination or localized natural background differences.

\subsection{GEOLOGY AT THE VADOSE BOREHOLES}

The geology at the three boreholes consisted of mixed sands, sandy gravels, and gravelly sands typical of the Hanford formation in this area. Lithologic descriptions of the three boreholes were recorded in the project borehole logs. A general classification associated with each sample has been listed in the sample key, Table 3-4.

Soil from the $3 A$ Pond borehole was somewhat sandier and had less gravels than soil from the other locations reflecting the fining westward character of the Hanford formation in the B-Pond area. The water table at the $3 A$ Pond borehole was in a sandy gravel, probably still in the Hanford formation, while at the 3B Pond borehole, a saturated silt lens at $116.5 \mathrm{ft}$ most likely marks the top of the Ringold formation. The $3 C$ Pond borehole did not penetrate deep enough to pass through the Hanford formation into the Ringold, which also underlies this area.

Undisturbed surface soil surrounding the B-Pond system is predominately eolian-deposited material. It lacks the cobble and coarse gravels common to the flood-deposited Hanford formation. Earlier Phase 1 sampling collected one class of background samples from the upper foot of soil in sagebrush areas surrounding the B-Pond system. Other background samples collected, as part of the same study, were from the surface of an adjacent unused contingency pond excavation. These two groups of samples were treated separately in the Phase 1 analysis when it became evident that the values of the combined set differed significantly from a normal distribution. 
WHC-SD-EN-AP-104 Rev. 0

\subsection{SOIL PHYSICAL PROPERTIES}

Characterization work at the three boreholes included a suite of physical properties testing. Samples collected for physical properties testing were not those analyzed for chemical constituents. Testing was performed at an onsite laboratory. Determinations included specific gravity, percent moisture content, grain size distribution by sieve analysis, hydraulic conductivity, and porosity. Deviation from basic theoretical relationships showed moisture retention curve results were not satisfactory.

Six samples were collected from the borehole at the $3 A$ Pond; 11 at the $3 B$ Pond; and 3 at the $3 \mathrm{C}$ Pond. Test requests were not the same for each sample, particularly where similar lithologies were present at several sample horizons. Table 4-10 shows physical properties data for the three boreholes. Some determinations were not performed because the samples were unsuitable. Table 4-11 shows sieve data results. A hydrometer analys is was performed for most samples on fractions passing through a number 200 sieve. This additional data was not included in Table 4-11.

Specific gravity of all samples was well within expected values, ranging from 2.69 to $2.82 \mathrm{~g} / \mathrm{cm}^{3}$. Sieve analysis data showed grain size distributions typical of the Hanford formation in this area. Most samples were classified as sandy gravels and were poorly sorted showing a fairly wide range in grain size. Porosity ranged from 20.50 to 37.71 percent. These values are relatively high, but well within the range for the sandy gravels of the Hanford formation, which are relatively uncompacted and uncemented.

Moisture content varied widely between physical property samples and was not correlated with depth of the sample. Moisture contents of 15 to 18 percent in the $3 \mathrm{~A}$ Pond borehole indicate saturated or nearly saturated sediments at intermediate depths. This borehole was drilled over a filled area on the edge of the $3 A$ Pond. At the $3 B$ Pond borehole, moisture contents were generally lower, between 2.44 and 7.16 percent above the water table and 20.88 percent in the sample taken at the water table. The 38 Pond has not been used for wastewater disposal since 1985. Moisture content in physical samples from the $3 C$ Pond borehole ranged from 1.07 to 9.6 percent.

Hydraulic conductivity values determined in the laboratory reflect the generally coarsening grain size of the Hanford formation from northwest to southeast at the B-Pond area. The $3 A$ Pond borehole, drilled in the northwest, has the finer grain sizes and the lower measured hydraulic conductivity values, around 3 to $5 \mathrm{~cm} / \mathrm{sec}$. Hydraulic conductivity measurements on samples from the $3 \mathrm{~B}$ Pond borehole to the southeast are higher, around $1 \mathrm{E}-4$ to $1 E-3 \mathrm{~cm} / \mathrm{sec}$. One measurement of $3 E-8$ was obtained on the clay silt sample taken at the water table from 3B Pond. No measurements were made on the single $3 C$ Pond sample submitted for this determination because the sample was unsuitable. 
WHC-SD-EN-AP-104 Rev. 0

Table 4-10. Physical Properties B-Pond Phase 3 Soil Samples.

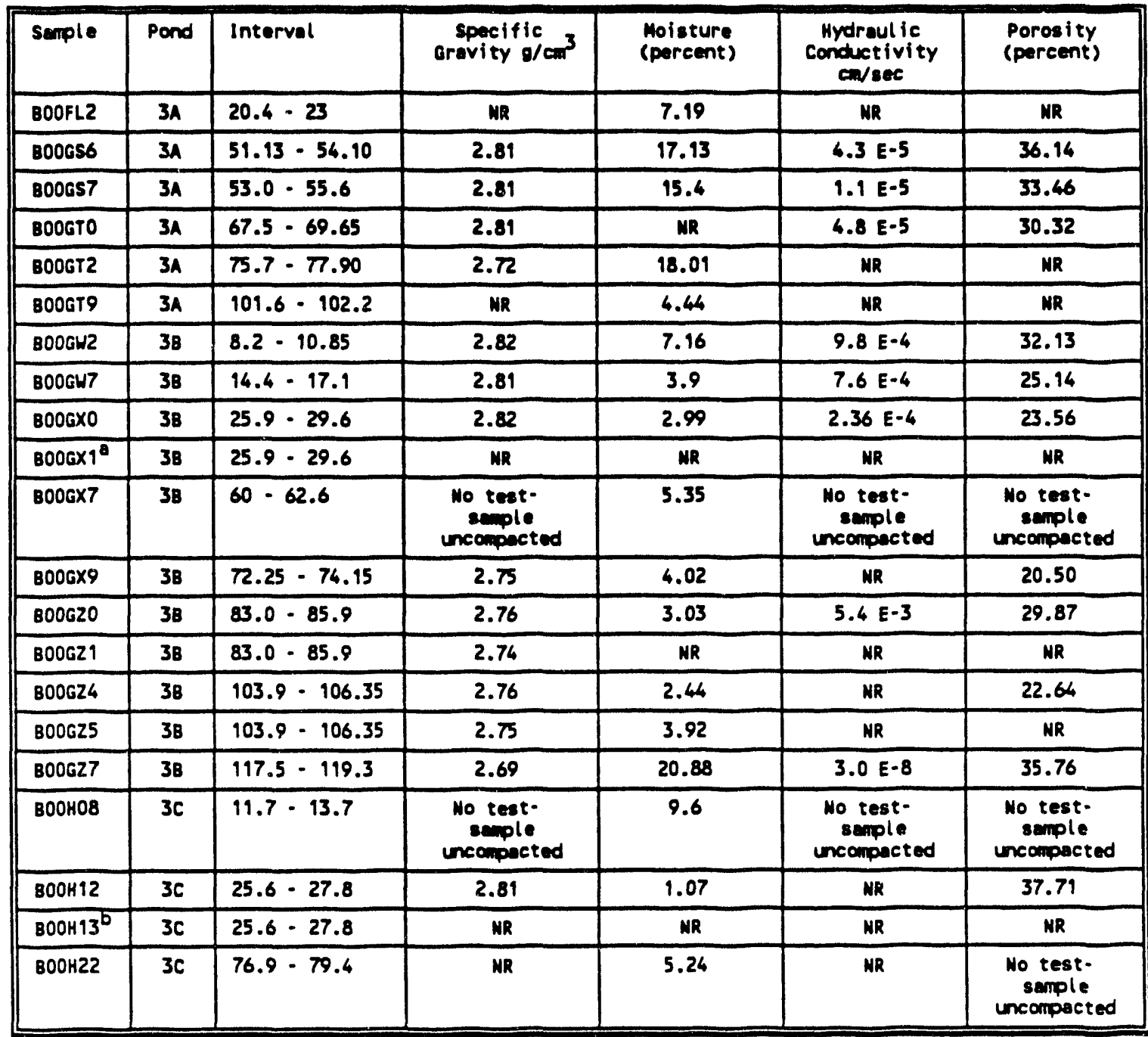

- Semple only submitted for moisture-retention analysis.

Semple only submitted for grain-size analysis.

NR Not requested 


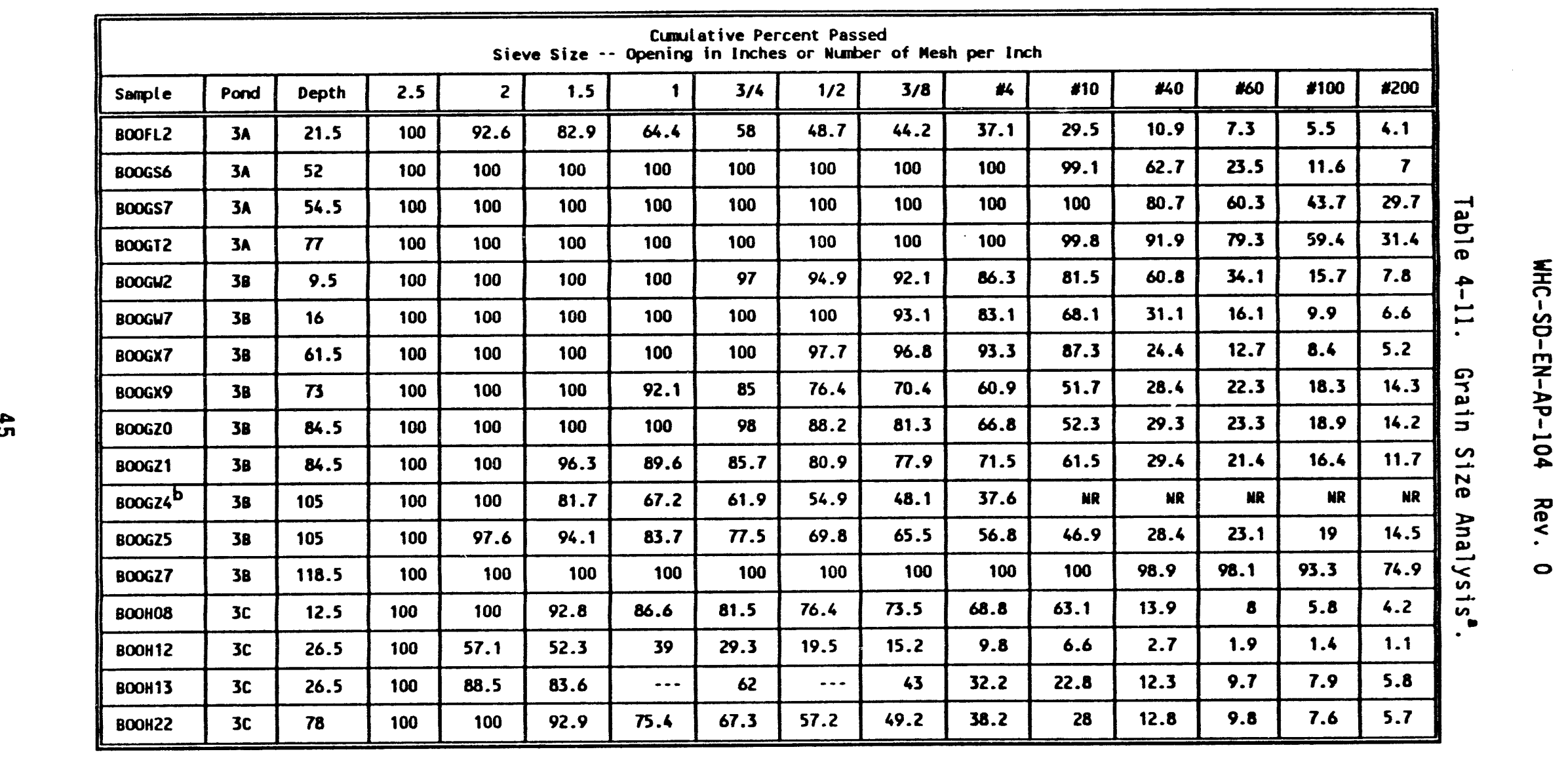

Qushed fine grading also performed for most samples on material finer than Wo. 200 sieve.

sieve analysis not requested but performed to no. 4 for specific gravity determination. 
WHC-SD-EN-AP-104 Rev. 0

This page intentionally left blank. 
WHC-SD-EN-AP-104 Rev. 0

\subsection{DISCUSSION AND COMPARISON TO DANGEROUS WASTE CRITERIA}

The demonstration of clean closure requires that no 40 CFR part 261 Appendix VIII constituents remain in the soils, vadose zone, or groundwater above regulatory agency recommended limits (EPA 1989). These 1 imits include consideration of water quality standards and criteria, health-based limits based on published reference doses or carcinogenic potency factors, or sitespecific agency-approved health advisories (52 FR 8706). The scope of analytical requirements may be reduced from all Appendix VIII constituents when it is reasonable to exclude some based on knowledge of past activities at the unit. In consideration of the potential effect of a waste on human health or the environment, EPA's proposed corrective action rules (55 FR 30798) expand the meaning of the term hazardous constituents to include those identified in 40 CFR Part 264 Appendix IX, commonly known as the Groundwater Monitoring List. Washington State's "Dangerous Waste Constituents List" (WAC 173-303-9905) includes additional constituents not found on the 40 CFR Part 261 Appendix VIII list. Clean closure will require that concentrations of such constituents pose no substantial threat to human health or the environment when left unmanaged.

For several years, two published statements have provided the fullest interpretation of EPA policy currently available concerning requirements applicable to units undergoing clean closure. Those two accounts are in the Federal Register (FR) starting at 52 FR 8704 and again starting at 53 FR 9944. The EPA has been working on issuance of a clean closure guidance document, however it is not known to be available at this time. It is anticipated that many aspects will reflect policy expressed in the proposed RCRA Corrective Action Rule issued July 27, 1990, (55 FR 30798). Recent legal rulings regarding the "mixture" and "derived-from" rule have led EPA to propose a concentration-based exemption criteria (CBEC) that would fundamentally change the application of RCRA Subtitle C (see 57 FR 21450). The proposal will also affect soil contaminated with listed waste, which is currently considered hazardous by the "contained-in" policy.

Surface impoundments containing unremoved regulated hazardous waste cannot remain open to receive nonhazardous waste (54 FR 33388). The $3 \mathrm{~A}$ Pond, 3B Pond, and 3C Pond have been classified part of a RCRA TSD unit; however, no waters, sediments, or soils have demonstrated characteristics or criteria of a dangerous waste. A dangerous waste must meet one or more of the characteristics or criteria described in WAC 173-303.

Compounds listed on the Part A permit as being occasionally discharged into the B-Pond system include common acids and bases. Such chemicals are no longer hazardous when they lose the characteristic that caused them to be a hazard. In the case of corrosivity, a waste is regulated when the $\mathrm{pH}$ is less than or equal to 2 or greater than or equal to 12.5. In the case of solids, regulated status is determined on the solution derived by mixing with an equal weight of water. Both field $\mathrm{pH}$ data and $\mathrm{pH}$ reported in conjunction with BNA analyses at the split laboratory showed $\mathrm{pH}$ within criteria. Also, as evidenced by the aquatic life and vegetation at the unit, the soils would not be expected to exceed these criteria.

Cadmium nitrate was known to have been discharged at least twice since 1983 (during the operation of the B-Pond expansion ponds) to a TSD unit 
feeding B-Pond (DOE 1990, Table 4-3). In sufficient concentration, this compound may cause a waste to be sufficiently toxic for regulation as a dangerous waste. Earlier Phase 1 studies did not indicate elevated total cadmium concent, ations in surface sediments/soils of $3 A, 3 B$, or $3 C$ Ponds (WHC 1991). Phase 3 results found average concentrations at the $3 A, 3 B$, and $3 C$ Ponds boreholes to be $<0.78,<1.06$, and $1.72 \mu \mathrm{g} / \mathrm{g}$, respectively. These figures are well below those found at sagebrush sites and contingency-pond Phase 1 backgrounds. Phase 1 background tolerance limits were established at 8.23 and $9.58 \mu \mathrm{g} / \mathrm{g}$, respectively. No estimate of interlaboratory variability between the laboratories used for Phase 1 and Phase 3 analys is is available. A common cadmium range for soil is $0.1-7 \mu \mathrm{g} / \mathrm{g}$ (Shields 1988, $p 101$ ). Cadmium was undetected in all seven inorganic split samples. All values were reported $\leq 1.0 \mu \mathrm{g} / \mathrm{g}$.

Several compounds designated in the closure plan as having been disposed of at B-Pond include elements such as sodium and potassium, the compound ammonium, or the common anions nitrate, fluoride, and sulfate. These constituents are not listed hazardous waste constituents. They may cause a waste to be regulated as a dangerous waste only when present in extreme (i.e. toxic or deleterious) concentrations or as indicators of specific listed wastes. Phase 3 data demonstrates this is not the case for vadose zone soils in the $3 A, 3 B$, and $3 C$ Ponds.

Table 5-1 lists Phase 3 inorganic analytes that are listed in Washington State's "Dangerous Waste Constituents List" (WAC 173-303-9905).

Concentrations are compared, where available, to two criteria: Phase 1 thresholds and concentrations meeting criteria for action levels under EPA's proposed RCRA Subpart $S$ (Corrective Action for Solid Waste Management Units at Hazardous Waste Management Facilities--55 characterized by a mean concentration ass 98). Each lobe is have a normal distribution of error. (Statistics are based on all regu. ples; field and laboratory QC samples were not included in calculating ave, uyes or maximum values.) An upper 90 percent confidence limit is compared to Phase 1 threshold values. Thresholds were based on Phase 1 surface samples from areas of natural vegetation surrounding the TSD or an unused excavated dry contingency-pond area. For several constituents all Phase 1 samples for each background were undetected at concentrations greater than the contractual detection limit $(C D L)$. In those cases the respective detection limits were given, as footnoted. Though the representative value is clearly defined by regulation and guidance as the average ( 40 CFR 260.10, or SW-846 Ch. 9, [EPA 1986]), a conservative comparison of the maximum reported regular sample value is also compared to EPA's example soil action levels. 


\begin{tabular}{|c|c|c|c|c|c|c|c|c|c|c|}
\hline Analyte & Pond & $\begin{array}{l}\text { Frequency } \\
\text { of Non- } \\
\text { detects }\end{array}$ & Mean & $\begin{array}{l}\text { Upper 90x } \\
\text { Limit }\end{array}$ & $\begin{array}{c}\text { Maximem } \\
\text { Observation }\end{array}$ & $\begin{array}{c}\text { Phase } 1 \\
\text { Threshold } \\
\text { Concentrations } \\
\mu 9 / 9\end{array}$ & $\begin{array}{c}\text { Propose RCRA } \\
\text { Corrective } \\
\text { Actiog Level- } \\
\text { Soil mg/Kg }\end{array}$ & $\begin{array}{c}\text { Typical } \\
\text { Soil Range } \\
\text { (ppm) }\end{array}$ & $\begin{array}{l}\text { Mean Upper } \\
\text { Limlt Above } \\
\text { Both Phase } 1 \\
\text { Thresholds? }\end{array}$ & $\begin{array}{l}\text { Maximum Above } \\
\text { EPA Example } \\
\text { Soll Actjon } \\
\text { Levei? }\end{array}$ \\
\hline & 3B & $20 / 20$ & $<5.1$ & NC & $5.8 \mathrm{U}$ & & & & $\cdots$ & no \\
\hline & $3 c$ & $15 / 15$ & $<5.2$ & NC & $5.3 \mathrm{u}$ & & & & $\cdots$ & no \\
\hline Arsenic & $3 A$ & $0 / 21$ & 1.74 & 1.97 & 4.2 & $4.91 / 7.59$ & 80 & & No & \\
\hline & 38 & $1 / 20$ & $<2.25$ & 2.90 & 7.2 & & & & мо & nо \\
\hline & $3 c$ & $0 / 11$ & 1.46 & 1.76 & 2.5 & & & & no & no \\
\hline & & & & & & & & & & \\
\hline Barium & $3 A$ & $0 / 20$ & 71.1 & 74.1 & 91 & $N c^{c}$ & 4000 & $100-3500$ & $\because$ & No \\
\hline & 38 & $0 / 20$ & $\pi 7.6$ & 80.7 & 96 & & & & $\cdots$ & no \\
\hline & $3 c$ & $0 / 15$ & 80.5 & 90.6 & 170 & & & & - & no \\
\hline & 38 & $0 / 20$ & 0.38 & 0.42 & 0.88 & & & & $\cdots$ & YES \\
\hline & 3c & $0 / 15$ & 0.31 & 0.33 & 0.41 & & & & $\cdots$ & YES \\
\hline & & & & & & & & & & \\
\hline Cadmiun & $3 A$ & $1 / 20$ & $<0.78$ & 0.90 & 1.6 & $8.23 / 9.58$ & 40 & $0.01-7$ & no & no \\
\hline & 38 & $1 / 20$ & $<1.06$ & 1.19 & 1.8 & & & & no & no \\
\hline & $3 c$ & $0 / 15$ & 1.72 & 1.89 & 2.5 & & & & no & no \\
\hline Chromium & $3 n$ & $0 / 20$ & 8.17 & 9.35 & 16 & $12.86 / 8.78$ & 400 & $5 \cdot 3000$ & no & No \\
\hline & 38 & $0 / 20$ & 12.0 & 13.6 & 25 & & (as Cr VI) & & YES & мо \\
\hline & 3c & $0 / 15$ & 9.23 & 11.2 & 27 & & & & No & no \\
\hline Cyanide & $3 A$ & $10 / 11$ & $<0.9$ & MC & $1 \mathrm{us}$ & $<0.5^{b}$ & 2000 & Ma & $\cdots$ & No \\
\hline & 3B & $11 / 11$ & $<0.7$ & NC. & $1 \mathrm{us}$ & & & & -- & no \\
\hline & $3 c$ & $8 / 9$ & $<0.4$ & MC & $1 \mathrm{uJ}$ & & & & - & $\omega$ \\
\hline & 38 & $0 / 20$ & 5.24 & 6.58 & 20 & & & & No & $\cdots$ \\
\hline & 3c & $0 / 11$ & 4.99 & 8.43 & 30 & & & & nо & $\cdots$ \\
\hline
\end{tabular}




\begin{tabular}{|c|c|c|c|c|c|c|c|c|c|c|}
\hline Analyte & Pond & $\begin{array}{l}\text { Frequency } \\
\text { of Won- } \\
\text { detects }\end{array}$ & Mean & $\begin{array}{l}\text { Upper 90x } \\
\text { Limit }\end{array}$ & $\begin{array}{c}\text { Maximum } \\
\text { Observation }\end{array}$ & $\begin{array}{c}\text { Phase 1 } \\
\text { Threshold } \\
\text { Concentrations } \\
\mu \mathrm{g} / \mathrm{g}\end{array}$ & $\begin{array}{c}\text { Propose RCRA } \\
\text { corrective } \\
\text { Actiog Level- } \\
\text { soil Log/Kg }\end{array}$ & $\begin{array}{c}\text { Typical } \\
\text { Soil Range } \\
\text { (ppm) }\end{array}$ & $\begin{array}{l}\text { Mean Upper } \\
\text { Limit Above } \\
\text { Both Phase } 1 \\
\text { Thresholds? }\end{array}$ & $\begin{array}{l}\text { Maximum Above } \\
\text { EPA Exemple } \\
\text { Soll Action } \\
\text { Level? }\end{array}$ \\
\hline \multirow[t]{3}{*}{ Mercury } & $3 n$ & $21 / 21$ & $<1.0$ & NC & $1.0 \mathrm{~V}$ & $<0.2^{6}$ & 20 & $0.01-0.8$ & $-\cdot$ & No \\
\hline & $3 B$ & $20 / 20$ & $<1.0$ & NC & $1.0 \mathrm{U}$ & & & & $\cdots$ & no \\
\hline & $3 c$ & $7 / 7$ & $<1.0$ & NC & $1.0 \mathrm{U}$ & & & & $-\cdot$ & мо \\
\hline \multirow{3}{*}{ Mickel } & $3 n$ & $0 / 20$ & 10.9 & 12.2 & 24 & $12.3 / 22.0$ & 2000 & $5-1000$ & yo & no \\
\hline & 38 & $0 / 20$ & 11.3 & 12.2 & 21 & & & & Mo & no \\
\hline & $\overline{3 c}$ & $0 / 15$ & 10.6 & 11.6 & 18 & & & & no & No \\
\hline & & & & & & & & & & \\
\hline \multirow[t]{3}{*}{ Selenium } & 3n & $12 / 12$ & $<0.70$ & NC & 1.100 & $<1.0^{\mathrm{b}}$ & $m n$ & $0.1-2$ & $\because \cdot$ & $\cdots$ \\
\hline & 38 & $11 / 11$ & $<0.53$ & MC & $0.61 \mathrm{U}$ & & & & $\cdots$ & $-\cdot$ \\
\hline & $3 c$ & $6 / 6$ & $<0.52$ & MC & $0.52 \mathrm{U}$ & & & & $\cdots$ & $\because$ \\
\hline \multirow{3}{*}{ Silver } & $3 A$ & $12 / 20$ & $<0 . \sqrt{3}$ & NC & 1.5 & $<1.0^{6}$ & 200 & $0.01-5$ & .. & no \\
\hline & 38 & $20 / 20$ & $<0.62$ & MC & $0.70 \mathrm{U}$ & & & & -. & no \\
\hline & $3 c$ & $15 / 15$ & $<0.62$ & NC & $0.64 \mathrm{U}$ & & & & 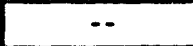 & mo \\
\hline \multirow[t]{3}{*}{ Thallium } & $3 A$ & $12 / 12$ & $<1.04$ & MC & $1.1 \mathrm{U}$ & $<1.0^{6}$ & MA & $0.1-0.8$ & $-\cdot$ & -. \\
\hline & 38 & $11 / 11$ & $<1.04$ & MC & $1.2 \mathrm{U}$ & & & & $\ldots$ & $\because$ \\
\hline & $3 c$ & $6 / 6$ & $<1.00$ & NC & $1.0 \mathrm{v}$ & & & & 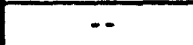 & $\cdots$ \\
\hline
\end{tabular}

b Source: Shields 1988 except for thallium from MHC 1991.

All Phase 1 semples less than the st ted contract detection limit--no threshold calculated.

Threshold not calculated for total barlum. All Phase 1 background values $<105 \mathrm{~kg} / \mathrm{g}$.

55 FR 30798

WA Not applicable.

NC Not calculoted. 
WHC-SD-EN-AP-104 ReV. 0

Action levels are established for hazardous constituents for which data are sufficient to establish protective health- or environmental-based limits. "The Agency believes that it will very rarely be necessary to set action levels at background," (55 FR 30820). Action levels for soil generally assume exposure through consumption of soil contaminated with the hazardous constituent. Exposure assumptions are given in the proposed rule, and are based on a residential use pattern, including long-term direct contact and soil ingestion by children.

Action levels serve as rebuttable conservative presumptions that further study is necessary. Concentrations would "typically be measured on the surface (generally the upper two feet of earth)," (55 FR 30819). The EPA intends to use these levels as a presumption that a corrective measures study (CMS) may be necessary for contaminated deep soils, too. The permittee may attempt to rebut this presumption by demonstrating that there is no threat to human health and the environment from such deep soil contamination, either through direct contact or migration to aquifers or surface water.

Concentrations below capabilities of approved measurement methods designed to determine whether or not a sample contains a given dangerous waste constituent are presumed to be adequately protective of human health and the environment, i.e. satisfy the intent of regulation. Mercury, selenium, thallium, and cyanide were below contractual quantitation limits for all Phase 3 samples. Antimony and silver concentrations in all regular samples from the boreholes of $3 B$ and $3 C$ Ponds were also undetected at the stated limits. Likewise, all Phase I background measurements for all these analytes were below their respective reporting limits.

Antimony was detected in 4 of the 20 regular Phase 3 samples. The median sample value was undetectable (typically $<6 \mathrm{ppm}$ ). For comparison, the March 1990 EPA CLP Statement of Work CRDL for antimony in soil and sediment is 12 $\mathrm{ppm}$. The maximum antimony concentration found in any single Phase 3 sample $(14 \mu \mathrm{g} / \mathrm{g})$, an extreme of the data set, was only slightly above a referenced typical natural range $(0.6-10 \mathrm{ppm})$ and less than half the level EPA has proposed as protective of human health and the environment $(30 \mathrm{mg} / \mathrm{Kg}$ ). (No Phase I TSD or background soil sample was found at or above the CDL of 10.0 $\mu \mathrm{g} / \mathrm{g}$.$) All Phase 3$ split and field duplicate samples were consistent with the associated regular samples; each reported antimony as undetected.

Several other elements of Table 5-1 deserve mention. Beryllium was not found in any Phase 1 site or background samples at or above $0.5 \mu \mathrm{g} / \mathrm{g}$, the CDL. This Phase 3 sampling had lower reporting limits. All regular Phase 3 samples were reported as detects, but values were similar. The vast majority were less than $0.5 \mu \mathrm{g} / \mathrm{g}$. Split sample results suggested no significant primary laboratory bias. The EPA example action level of $0.2 \mathrm{mg} / \mathrm{Kg}$ (55 FR 30798) is frequently exceeded. Concentrations found in the vadose zone samples are entirely within the range of natural concentrations expected in the area based upon ranges found in the Characterization and Use of Soil and Groundwater Background for the Hanford Site (WHC-MR-0246, Rev 1).

Chromium Phase 1 threshold concentrations were frequently exceeded in the vadose zone. The highest average was found beneath the least used pond, the $3 B$ Pond. The pond area used longer, the $3 C$ Pond, had an intermediate concentration, and the oldest and most used of the expansion ponds, the $3 A$ Pond, had the lowest average chromium concentration. This casts doubt on the premise 
that wastewater disposal deposited hazardous concentrations of chromium to the land. The highest reported concentration $(27 \mu \mathrm{g} / \mathrm{g})$ was in the lowest $3 \mathrm{C}$ Pond sample $(\sim 80 \mathrm{ft})$; the associated split $(8.5 \mathrm{~J} \mu \mathrm{g} / \mathrm{g})$ was also the highest of seven splits. The Phase 3 data imply a slight natural increase in concentration with depth at B-Pond, contrary to the pond and near-surface sediments being a hazardous waste. Naturally occurring typical soil ranges have been referenced at 5-3000 ppm (Shields 1988).

High chromium concentrations in a waste may cause it to be regulated because of toxicity. Chromium is considered more toxic when present as $\mathrm{Cr}(V I)$. This is why the action level of Table 5-1 is based on $\mathrm{Cr}(V I)$. Chromium is most stable as $\mathrm{Cr}$ (III). It is most commonly found in oxidation states 0 , III, and VI.

Chromium was analyzed simultaneously with numerous other elements that showed a positive bias against the split laboratory results. A possible interelement correlation may exist because of common measurement system factors, (for example: digestion conditions). Comparisons between laboratories are confounded by left-censored data at the reporting limit. Using only samples that each laboratory found above their respective reporting limits (as if a random sample), insufficient information is available to contradict a null hypothesis of no significant bias; however, most samples at the split laboratory are undetected while corresponding primary laboratory samples are reported much higher. Under the assumption that the true nondetect split sample concentrations equal the reporting limit, the primary positive bias estimate would be minimized. The average bias in this case would be about $11 \mu \mathrm{g} / \mathrm{g}$, which is substantial when compared to the average reported concentrations.

Although validation did not detect accuracy problems via review of laboratory blanks or matrix spike recoveries, the validation did not consider field silica sand samples. A review of the seven silica sand blanks shows two of the seven were reported positive for $\mathrm{Cr}$; one at 1.3 , the other at $7.2 \mu \mathrm{g} / \mathrm{g}$. The remainder were $<1 \mu \mathrm{g} / \mathrm{g}$. Silica sand was not submitted to the split laboratory. However, all 11 Phase 1 values of similar silica sand were $<1 \mu g / g$.

The data suggest a potential positive bias in the concentrations reported by tia primary laboratory. These factors should be considered in comparing Ph. to Phase 3 chromium concentrations. Nevertheless, the important point is not to promote more study but identify if there is a potential threat to human health or the environment. Acceptance of an inflated characteristic concentration will not change the conclusion of "no threat." The reported concentrations are more than an order of magnitude below limits the EPA has quoted as protective trigger levels for further investigation (upper 90 percent 1 imit $=13.6 \mu \mathrm{g} / \mathrm{g}$ total $\mathrm{Cr}$ vs. $400 \mu \mathrm{g} / \mathrm{g}$ all $\mathrm{Cr}[\mathrm{VI}])$. Washington State has determined similar levels to be protective of human health and the environment. The state has promulgated environmental regulations setting "Method A" chromium cleanup levels for industrial soil at $500 \mu \mathrm{g} / \mathrm{Kg}$ (WAC 173340-745). The most critical path is considered to be via inhalation. The level is based on exposure assumptions of breathing contaminated dust at the sites where hazardous chromium compounds were formerly released to the environment. 
No designated, listed wastes are known to have been directly discharged to the B-Pond system while the expansion lobes were in service. Hydrazine is the sole designated, listed waste known to have been potentially discharged indirectly to the B-Pond system during operation of any of the B-Pond expansion ponds (DOE 1990). Five releases of this compound were documented to a TSD unit supplying B-Pond, the 216-A-29 Ditch--the latest in 1986 (DOE 1990). Hydrazine is a strong oxygen scavenger and will react with oxygen in water to form $\mathrm{NH}_{4} \mathrm{OH}$ and nitrogen gas. It was not specifically. addressed in Phase 3 because it was not expected to be present at the expansion ponds because of the extreme dilution and relatively age of the releases. Furthermore, no SW-846 (EPA 1986) method is specified to measure this constituent in soil. Air is the typical medium of concern for this compound. Several studies were found addressing the fate of hydrazine in aquatic environments. In one study, river and pond water were adjusted to the same dissolved oxygen level and temperature, and $5 \mathrm{mg} / \mathrm{L}$ of hydrazine was added. Hydrazine residues in river water containing substantial amounts of organic matter were 22.6 percent, 96 percent, and 100 percent degraded after approximately one hour, one day, and two days, respectively. In the pond water, residues were 20 percent, 74 percent, 80 percent, and 81.6 percent degraded after approximately one $\mathrm{hr}$, one day, two days, and three days, respectively (Slonim and Gisclard 1976). Hydrazine has been used experimentally in vit. o as medication for sickle cell disease (HSOB $1992^{\prime}$ ). It has been found to be a natural product of nitrogen fixation by azotobacter algae (HSDB $1992^{\circ}$ ). It has also been measured in cigarette smoke (HSDB 1992').

Most Appendix VIII (40 CFR 261) and Dangerous Waste (WAC 173-303) constituents are organic compounds. All investigated organic analytes were undetectable at representative site soil concentrations.

There is no indication that any investigated pesticide, PCB, herbicide, organophosphorous pesticide, dioxin, or furan is present in the vadose zone soil at the borehole sites. Several volatile and semivolatile target compounds were occasionally reported at concentrations less than PQL and/or contract required detection limit (CRDL). Tentatively identified volatile and semivolatile compounds were also noted in site samples, but performance on field duplicates, split, and silica sand samples suggests such occurrences are not representative of site soils.

\footnotetext{
SilverPlatter Software Copyright (C), SilverPlatter International N. V.
} 1992 
WHC-SD-EN-AP-104 Rev. 0

\subsection{CONCLUSION}

The $B$-Pond Phase 3 vadose zone investigation does not indicate hazardous levels of waste constituents exist in the vadose zone of the 216-B-3A, 216-B$3 B$, or 216-B-3C Ponds. Furthermore, results do not suggest dangerous, listed wastes exist in detectable, but dilute concentrations in the vadose zone. Nondangerous waste by definition, does not meet the statutory criteria of a "dangerous" or "hazardous" waste. Based on characteristics (ignitability, corrosivity, reactivity, toxicity) or criteria (carcinogenic, persistent, toxic), no compounds, organic or inorganic, were found in sufficient representative concentrations to cause the investigated vadose soils to be reasonably regulated as a dangerous waste. 
WHC-SD-EN-AP-104 ReV. 0

\subsection{REFERENCES}

ASTM, 1986, Annual Book of ASTM Standards, D1426-D, American Society of Testing and Materials, Philadelphia, Pennsylvania.

Comprehensive Environmental Response, Compensation, and Liability Act of 1980, 42 USC 9601 et seq.

DOE, 1990, 216-B-3 Pond System Closure/Postclosure Plan, DOE/RL 89-28 Rev. 0, U.S. Department of Energy, Richland, Washington.

Ecology, EPA, and DOE, 1989, Hanford Federal Facility Agreement and Consent Order, 2 vols., as amended, Washington State Department of Ecology, U.S. Environmental Protection Agency, and the U.S. Department of Energy, Olympia, Washington.

EPA, 1986, Test Methods for Evaluating Solid Waste, Physical/Chemical Methods, SW-846, Third Edition, U.S. Environmental Protection Agency, Washington, D.C.

EPA, 1989, Guidance on Demonstrating Equivalence of Part 265 Clean Closure with Part 264 Requirements, OSWER Policy Directive 9476.00-18, May 12, 1989, U.S. Environmental Protection Agency, Washington, D.C.

HSDB, 1992, Hazardous Substances Data Bank, National Library of Medicine, Bethesda, Maryl and.

Resource Conservation and Recovery Act of 1976, 42 USC 6901, et seq.

Shields, E.J., 1988, Pollution Control Engineer's Handbook, ISBN 0-934165-029, Revised and Expanded Edition, compiled by E.J. Shields, Cahners Publishing Co., Des Plains, Illinois.

Slonim, A.R. and J. B. Gisclard, "Hydrazine Degradation in Aquatic Systems," Bulletin of Environmental Contamination Toxicology 16(a): 301-9 (1976).

WAC 173-303, 1989, "Dangerous Waste Regulations," Washington Administrative Code, as amended.

WAC 173-340, 1990, "The Model Toxics Control Act Cleanup Regulations," Washington Administrative Code, as amended.

WHC, 1989a, 216-8-3 Pond Characterization of the Hazardous Waste Inventory in the Near-Surface Soils and Sediments, WHC-SD-EN-AP-016, Rev. 1, Westinghouse Hanford Company, Richland, Washington.

WHC, 1989b, Environmental Investigations and Site Characterization Manual, WHC-CM-7-7, Westinghouse Hanford Company, Richland, Washington.

WHC, 1990, Westinghouse Hanford Company Effluent Discharges and Solid Waste Management Report for Calendar Year 1989: 200/600 Areas, WHC-EP-0141-2, Westinghouse Hanford Company, Richland, Washington. 
WHC, 1991, Phase 1 Characterization of the 216-B-3 Pond System, WHC-SD-EN-AP-042, Rev. 0, Westinghouse Hanford Company, Richland, Washington.

40 CFR 260, "Hazardous Waste Management System - General, " Code of Federal Regulations, as amended.

40 CFR 261, "Identification and Listing of Hazardous Waste, " Code of Federal Regulations, as amended.

40 CRF 265, "Interim Status Standards for Owners and Operators of Hazardous Waste Treatment, Storage, and Disposal Facilities, " Code of Federal Regulations, as amended.

40 CFR 264, "Standards for Owners and Operators of Hazardous Waste Treatment, Storage, and Disposal Facilities, "Code of Federal Regulations, as amended.

52 FR 8704, 1987, "Interim Status Standards for Owners and Operators of Hazardous Waste Treatment, Storage, and Disposa? Facilities; Final Rule." Federal Register, Vo1. 52, pp. 8704-8707, (March 15').

53 FR 9944, 1988, "Interim Status Standards for Owners and Operators of Hazardous Waste Treatment, Storage, and Disposal Facilities:

Clarification," Federal Register, Vol. 53, p. 9944, (March 28).

54 FR 33388, 1989, "Delay of Closure Period for Hazardous Waste Management Facilities; Final Rule 40 CFR 264, 265, 270." Federal Register, Vol. 54, pp. 33376-33388, (August 14).

55 FR 30798, 1990, "Corrective Action for Solid Waste Management Units (SWMUs) at Hazardous Waste Management Facilities; Proposed Rule," Federal Register, Vol. 55, p 30798, (July 27).

55 FR 30820, 1990, "Corrective Action for Solid Waste Management Units (SWMUs) at Hazardous Waste Management Facilities; Proposed Rule," Federal Register, Vol. 55, p 30820, (July 27).

57 FR 958, 1992, "Land Disposal Restrictions for Newly Listed Wastes and Contaminated Debris; Proposed Rule," Federal Register, Vol. 57, p 958, (January 9).

57 FR 2.1450, 1992, "Hazardous Waste Management System: Identification and Listing of Hazardous Waste; Proposed Rule, "Federal Register, Vo1. 57, p 21450, (May 20). 
WHC-SD-EN-AP-104 Rev: 0

\section{APPENDIX A}

B-POND PHASE 3 SOIL DATA

$$
A-i
$$


WHC-SD-EN-AP-104 Rev. 0

This page intentionally left blank.

$A-i j$ 


\section{CONTENTS}

Introduction ....................... . . A-1

Reasons for Westinghouse Hanford Qualification--

Pesticides/Polychlorinated Biphenyls . . . . . . . . . . . A-11

Reasons for Westinghouse Hanford Company Qualification--Herbicides . . A-13

Reasons for Westinghouse Hanford Company Qual ification--Organophosphorous Pesticides . . . . . . . . . . . . . . . . . A-22

Reasons for Westinghouse Hanford Company Qualification--Dioxins and

Furans . . . . . . . . . . . . . . . . . . A-26

Reasons for Westinghouse Hanford Company Qualification--Volatile

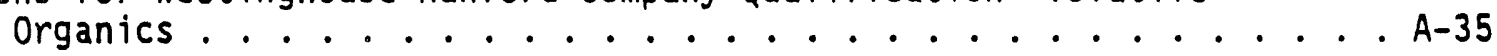

Reasons for Westinghouse Hanford Company Qualification--Semivolatile Organic (Base/Neutral/Acid) Compounds . . . . . . . . . . A-52

Reasons for Westinghouse Hanford Company Qualification--Analytes by Inductively Coupled Plasma (Aluminum-Zinc) . . . . . . . . . . . A-72

Reasons for Westinghouse Hanford Company Qualification--Analytes by Atomic Absorption Spectroscopy.............. . . A-77

Reasons for Westinghouse Hanford Company Qualification--Miscellaneous Analytes................... . A-82

References ..................... . A-88 
WHC-SD-EN-AP-104 Rev. 0

LIST OF TABLES

A-1. B-Pond Phase 3 Pesticide/PCBs ............... . A-3

A-2. B-Pond Phase 3 Herbicide Data . . . . . . . . . . . . A-12

A-3. B-Pond Phase 3 Organophosphorous Pesticides . . . . . . . . . A-14

A-4. B-Pond Phase 3 Dioxins \& Furans ................ . A-23

A-5. Volatile Organic Compounds . . . . . . . . . . . . . A-27

A-6. B-Pond Phase 3 Semivolatiles . . . . . . . . . . . . A-36

A-7. B-Pond Phase 3 Semivolatile Tentatively Identified Compounds . . A-54

A-8a. Analytes by Inductively Coupled Plasma, Aluminum-Calcium . . . . A-60

A-8b. Analytes by Inductively Coupled Plasma, Chromium-Molybdenum . . A-64

A-8c. Analytes by Inductively Coupled Plasma, Nickel-Zinc . . . . . A-68

A-9. Analytes by Atomic Absorption Spectroscopy . . . . . . . . . . A-73

A-10. Miscellaneous Analytes . . . . . . . . . . . . A-78

A-11. List of Radioactivity Data $(\rho \mathrm{C} i / g)$--Unvalidated. . . . . . . . A-83

A-12. Gamma Energy Analysis Unvalidated, Raw Data. . . . . . . . . A-86 
WHC-SD-EN-AP-104 Rev. 0

\section{LIST OF TERMS}

$\begin{array}{ll}\text { AAS } & \text { atomic absorbtion spectroscopy } \\ \text { CLP } & \text { contract laboratory program } \\ \text { CRQL } & \text { contract-required detection limit } \\ \text { ICP } & \text { inductively coupled plasma } \\ \text { MS } & \text { matrix spike } \\ \text { MSD } & \text { matrix spike duplicate } \\ \text { PCB } & \text { polychlorinated biphenyl } \\ \text { TIC } & \text { tentatively identified compound } \\ \text { Westinghouse } & \\ \text { Hanford-OSM } & \text { Westinghouse Hanford Company-Office of Sample Management }\end{array}$




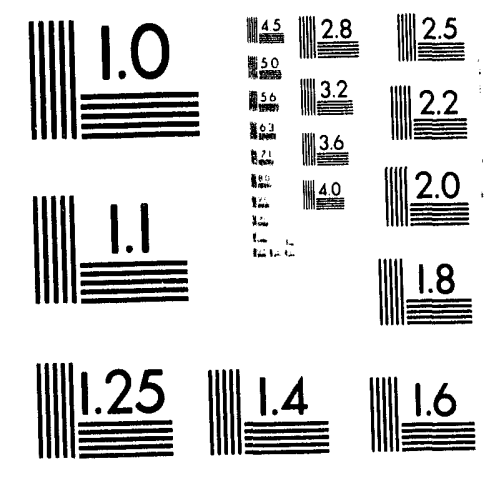



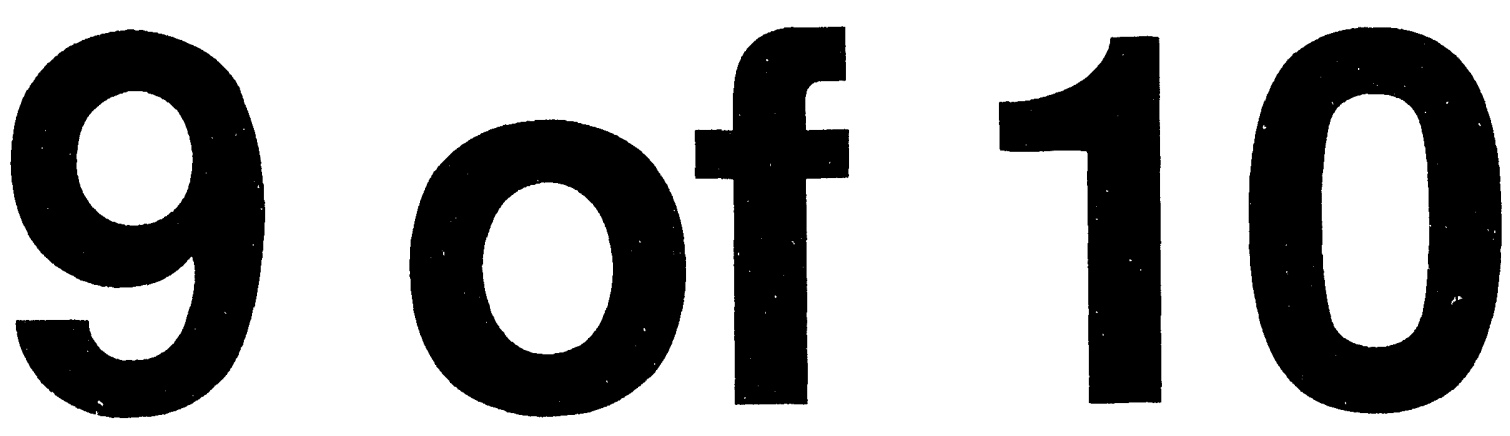
WHC-SD-EN-AP-104 Rev. 0

This page intentionally left blank. 
WHC-SD-EN-AP-104 Rev. 0

\section{Introduction}

Each table in Appendix A typically is several pages long. Samples will be listed along one axis and analytes along the other. Where analytes are listed along the left-hand margin, results from a single group of samples will be visible for several pages before the end of the analyte list is reached. An analyte list appears in the same order for another set of samples until all results are reported and the table ends. In other tables, each analyte is listed along the top of a table and all samples are listed along the left-hand margin for several pages until all are reported and the table ends.

Data appearing in this appendix have been validated lyy the Westinghouse Hanford Company Office of Sample Management (Westinghouse Hanford-OSM). The primary exceptions are radiological characterization data, which are presented as is for information only. Validation is a systematic review of laboratory performance and execution of protocol that may qualify data based on holding time, matrix spike (MS), matrix spike duplicate (MSD) analysis, surrogate recovery, analytical blank performance, calibration, or any other methodspecific requirements. As a result of data validation, qualification flags placed by the reporting laboratory may be replaced, supplemented or deleted. Westinghouse Hanford validation procedures can be found in WHC-CM-5-3 (WHC 1990). Many sample results were qualified according to holding time criteria established for water samples. This represents a conservative approach to validation. It is questionable if these time periods, especially in the case of extraction for organics, for soil matrices affect quality.

Several common concentration flags appear in the following tables. These include:

"U" The analyte was undetected. (The associated number represents an upper bound estimate of an undetected analyte, usually a concentration corresponding to an established sample quantitation limit.)

" $\mathrm{J"}$ The associated value is an estimated quantity. (This may be caused by any of a wide number of factors. It should alert the user that the associated value may have a slightly wider than usual potential for error.)

The above two flags may be combined and/or appear in conjunction with other qualifiers. The meaning of other flags will be listed at the end of each multipage table, as necessary. Results of inorganic constituents from the primary laboratory were reported to Westinghouse Hanford as " $<x \mu \mathrm{g} / \mathrm{g}$ " when undetected. For consistency in this report, these inorganic constituents reported by the primary laboratory are presented as the equivalent " $x U \mu \mathrm{g} / \mathrm{g}$ ". The CLP " $Q$ " (quality) flags and " $M$ " (method) flags reported on contract laboratory program (CLP) Form 1 are not shown for split samples because this information was not reported in the same format for those samples analyzed by SW-846 (EPA 1986) methods at the primary laboratory. Concentration or "C" flags are shown. One laboratory-reported concentration flag appearing ONLY with CLP inorganic split sample results is a "B" flag. This indicates when 
the corresponding inorganic sample result is above an instrument detection limit but below the CLP contract-required detection limit (CRQL).

After each table, a brief summary of the reasons for Westinghouse Hanford data qualification will appear. Only concentration qualifiers added or altered by Westinghouse Hanford-OSM as a result of data validation will be addressed-not explanations for displayed standard laboratory-reported qualifiers. The explanation will first address samples analyzed at the primary laboratory--regular, field duplicate, and silica sand samples--tien, if applicable, the split samples analyzed at an independent laboratory. Split samples were validated to criteria consistent with employed CLP procedure, except for radiological analyses, as already mentioned.

Most tables list some additional information about each reported field sample. Terms used to describe sample type include Regular (Reg), Field Duplicate (FDup), Field Split (Split), and clean Silica Sand (Blank) as described in the attached report. The terms $3 A, 3 B$, and $3 C$ Pond refer to the 216-B-3A Pond, 216-B-3B Pond, and 216-B-3C Pond, respectively. Sample depths are given as depth from the surface at the borehole to a midpoint of the sampled interval. ALL DEPTHS ARE LISTED IN FEET UNLESS SPECIFIED OTHERWISE. 
Table A-1. B-Pond Phase 3 Pesticide/PCBs. $(\mu \mathrm{g} / \mathrm{Kg})$

\begin{tabular}{|c|c|c|c|c|c|c|c|c|c|c|c|}
\hline ANALYTE & CAS* & BO0fK6 & B00FK7 & BOOFK8 & B00FK9 & 800FLO & B00FL1 & BOOFL3 & BOOFL4 & BOOGR9 & B00GS4 \\
\hline & TYPE & Reg & Reg & Reg & Reg & Reg & Reg & Blank & Reg & Folp & Reg \\
\hline & POND & $3 A$ & $3 n$ & $3 A$ & $3 A$ & $3 A$ & $3 n$ & $3 A$ & $3 A$ & $3 n$ & $3 A$ \\
\hline & DEPTH & 6.5 & 8.5 & 10.5 & 13 & 14.5 & 16 & $\cdots$ & 28 & 28 & 52.5 \\
\hline alpha BHC & $319-84-6$ & $14 \mathrm{UJ}$ & $13 \mathrm{UJ}$ & $13 \mathrm{UJ}$ & 13 UJ & $13 \mathrm{UJ}$ & $14 \mathrm{UJ}$ & $12 \mathrm{UJ}$ & $13 \mathrm{UJ}$ & $13 \mathrm{UJ}$ & $16 \mathrm{UJ}$ \\
\hline beta BHC & $319-85-7$ & $14 \mathrm{UJ}$ & 13 UJ & $13 \mathrm{UJ}$ & 13 UJ & $13 \mathrm{UJ}$ & $14 \mathrm{UJ}$ & 12 UJ & 13 Us & $13 \mathrm{UJ}$ & $16 \mathrm{UJ}$ \\
\hline del ta BHC & $319-86-8$ & $14 \mathrm{UJ}$ & $13 \mathrm{UJ}$ & $13 \mathrm{UJ}$ & $13 \mathrm{UJ}$ & $13 \mathrm{UJ}$ & $14 \mathrm{UJ}$ & $12 \mathrm{UJ}$ & 13 UJ & $13 \mathrm{UJ}$ & $16 \mathrm{UJ}$ \\
\hline gamma BHC (Lindane) & $58-89-9$ & $14 \mathrm{UJ}$ & $13 \mathrm{UJ}$ & $13 \mathrm{UJ}$ & 13 UJ & $13 \mathrm{UJ}$ & 14 UJ & $12 \mathrm{UJ}$ & 13 UJ & $13 \mathrm{UJ}$ & $16 \mathrm{UJ}$ \\
\hline Heptachlor & $76-44-8$ & $14 \mathrm{UJ}$ & 13 UJ & $13 \mathrm{UJ}$ & $13 \mathrm{UJ}$ & 13 Us & $14 \mathrm{UJ}$ & $12 \mathrm{UJ}$ & 13 US & 13 UJ & $16 \mathrm{UJ}$ \\
\hline Aldrin & $309-00-2$ & $14 \mathrm{UJ}$ & 13 UJ & $13 \mathrm{UJ}$ & $13 \mathrm{UJ}$ & 13 UJ & $14 \mathrm{UJ}$ & $12 \mathrm{UJ}$ & :3 UJ & 13 UJ & $16 \mathrm{UJ}$ \\
\hline Heptachlor Epoxide & $1024-57-3$ & $14 \mathrm{UJ}$ & $13 \mathrm{UJ}$ & $13 \mathrm{UJ}$ & 13 UJ & $13 \mathrm{UJ}$ & $14 \mathrm{UJ}$ & 12 UJ & $13 \mathrm{UJ}$ & $13 \mathrm{UJ}$ & $16 \mathrm{UJ}$ \\
\hline Endosul fan I & $959-98-8$ & $14 \mathrm{UJ}$ & $13 \mathrm{UJ}$ & $13 \mathrm{UJ}$ & $13 \mathrm{UJ}$ & $13 \mathrm{UJ}$ & $14 \mathrm{UJ}$ & $12 \mathrm{UJ}$ & $13 \mathrm{UJ}$ & 13 UJ & $16 \mathrm{UJ}$ \\
\hline Dieldrin & $60-57-1$ & $27 \mathrm{UJ}$ & $27 \mathrm{UJ}$ & $25 \mathrm{UJ}$ & $26 \mathrm{UJ}$ & $26 \mathrm{UJ}$ & $27 \mathrm{UJ}$ & $26 \mathrm{UJ}$ & 25 UJ & 25 UJ & $31 \mathrm{UJ}$ \\
\hline $4.4 \cdot-D D E$ & $72-55-9$ & $27 \mathrm{uJ}$ & $27 \mathrm{UJ}$ & $25 \mathrm{UJ}$ & $26 \mathrm{UJ}$ & $26 \mathrm{UJ}$ & $27 \mathrm{UJ}$ & $24 \mathrm{UJ}$ & 25 UJ & $25 \mathrm{UJ}$ & 31 UJ \\
\hline Endrin & $72-20-8$ & $27 \mathrm{UJ}$ & 27 US & $25 \mathrm{UJ}$ & $26 \mathrm{UJ}$ & $26 \mathrm{UJ}$ & $27 \mathrm{UJ}$ & $24 \mathrm{UJ}$ & $25 \mathrm{UJ}$ & $25 \mathrm{UJ}$ & $31 \mathrm{UJ}$ \\
\hline Endosulfan 11 & $33213-65-9$ & $27 \mathrm{us}$ & 27 UJ & $25 \mathrm{uJ}$ & $26 \mathrm{UJ}$ & $26 \mathrm{UJ}$ & 27 Us & $24 \mathrm{UJ}$ & $25 \mathrm{Ud}$ & 25 UJ & $31 \mathrm{UJ}$ \\
\hline $4,41-D D D$ & $72-54-8$ & $27 \mathrm{UJ}$ & $27 \mathrm{UJ}$ & $25 \mathrm{UJ}$ & $26 \mathrm{UJ}$ & $26 \mathrm{UJ}$ & $27 \mathrm{UJ}$ & $24 \mathrm{UJ}$ & 25 UJ & $25 \mathrm{UJ}$ & $31 \mathrm{UJ}$ \\
\hline Endosul fan su: rate & $1031-07-8$ & $27 \mathrm{uJ}$ & $27 \mathrm{UJ}$ & $25 \mathrm{UJ}$ & $26 \mathrm{UJ}$ & $26 \mathrm{UJ}$ & $27 \mathrm{UJ}$ & $24 \mathrm{UJ}$ & 25 UJ & 25 UJ & $31 \mathrm{UJ}$ \\
\hline $4,41-0 D T$ & $50-29-3$ & $27 \mathrm{UJ}$ & $27 \mathrm{UJ}$ & 25 UJ & $26 \mathrm{UJ}$ & $26 \mathrm{UJ}$ & 27 UJ & $24 \mathrm{UJ}$ & $25 \mathrm{UJ}$ & 25 UJ & 31 UJ \\
\hline Methoxychlor & $72-43-5$ & $140 \mathrm{UJ}$ & $130 \mathrm{UJ}$ & $130 \mathrm{UJ}$ & 130 us & $130 \mathrm{UJ}$ & $140 \mathrm{UJ}$ & $120 \mathrm{UJ}$ & $130 \mathrm{UJ}$ & $130 \mathrm{UJ}$ & $160 \mathrm{UJ}$ \\
\hline Endrin Ket one & $53494-70-5$ & 27 UJ & $27 \mathrm{UJ}$ & $25 \mathrm{UJ}$ & $26 \mathrm{UJ}$ & $26 \mathrm{UJ}$ & $27 \mathrm{UJ}$ & $24 \mathrm{UJ}$ & $25 \mathrm{UJ}$ & $25 \mathrm{UJ}$ & $31 \mathrm{UJ}$ \\
\hline al pha-chlorodane & $5103-71-9$ & $140 \mathrm{UJ}$ & $130 \mathrm{UJ}$ & $130 \mathrm{UJ}$ & $130 \mathrm{UJ}$ & $130 \mathrm{UJ}$ & $140 \mathrm{UJ}$ & $120 \mathrm{UJ}$ & 130 UJ & $130 \mathrm{UJ}$ & $160 \mathrm{UJ}$ \\
\hline gamma-Chl orodane & $5103-74-2$ & $140 \mathrm{UJ}$ & $130 \mathrm{UJ}$ & $130 \mathrm{UJ}$ & $130 \mathrm{UJ}$ & $130 \mathrm{UJ}$ & $140 \mathrm{UJ}$ & $120 \mathrm{UJ}$ & $130 \mathrm{UJ}$ & $130 \mathrm{UJ}$ & $160 \mathrm{UJ}$ \\
\hline
\end{tabular}

(Page 1 of 8 ) 
Table A-1. B-Pond Phase 3 Pesticide/PCBs. ( $\mu \mathrm{g} / \mathrm{Kg})$

\begin{tabular}{|c|c|c|c|c|c|c|c|c|c|c|c|}
\hline AMALYTE & CASE & B00FK6 & B00FK 7 & BOOFK8 & BOOFK & BOOFLO & B00FL1 & B00FL3 & BOOFL4 & BOOGR9 & B00GS4 \\
\hline & TYPE & Reg & Reg & Reg & Reg & Reg & Reg & Blank & Reg & Fodup & Reg \\
\hline & POND & $3 \AA$ & $3 A$ & $3 A$ & $3 A$ & $3 A$ & $3 n$ & $3 A$ & $3 A$ & $3 A$ & 3A \\
\hline & DEPTH & 6.5 & 8.5 & 10.5 & 13 & 14.5 & 16 & $\cdots$ & 28 & 28 & 52.5 \\
\hline Toxaphene & $8001-35-2$ & 270 UJ & 270 UJ & 250 UJ & 260 UJ & $260 \mathrm{UJ}$ & 270 UJ & 240 UJ & 250 UJ & $250 \mathrm{UJ}$ & $310 \mathrm{UJ}$ \\
\hline Arochlor 1016 & $12674-11-2$ & 140 UJ & $140 \mathrm{UJ}$ & $130 \mathrm{UJ}$ & $130 \mathrm{UJ}$ & $130 \mathrm{UJ}$ & $140 \mathrm{UJ}$ & $120 \mathrm{UJ}$ & 130 UJ & $130 \mathrm{UJ}$ & $160 \mathrm{UJ}$ \\
\hline Arochlor 1221 & $11104-28-2$ & $140 \mathrm{UJ}$ & $140 \mathrm{UJ}$ & 130 UJ & 130 UJ & 130 UJ & 140 UJ & $120 \mathrm{UJ}$ & $130 \mathrm{UJ}$ & 130 UJ & $160 \mathrm{UJ}$ \\
\hline Arochlor 1232 & $11141-16-5$ & $140 \mathrm{lIJ}$ & $140 \mathrm{UJ}$ & $130 \mathrm{UJ}$ & $130 \mathrm{UJ}$ & 130 UJ & $140 \mathrm{UJ}$ & $120 \mathrm{UJ}$ & $130 \mathrm{UJ}$ & 130 US & 160 US \\
\hline Arochlor 1242 & $53469-21-9$ & $140 \mathrm{UJ}$ & $140 \mathrm{UJ}$ & $130 \mathrm{UJ}$ & 130 Us & 130 UJ & $140 \mathrm{UJ}$ & $120 \mathrm{UJ}$ & 130 UJ & 130 UJ & $160 \mathrm{UJ}$ \\
\hline Arochlor 1248 & $12672-29-6$ & $140 \mathrm{UJ}$ & $140 \mathrm{UJ}$ & $130 \mathrm{UJ}$ & $130 \mathrm{UJ}$ & 130 UJ & $140 \mathrm{UJ}$ & 120 UJ & 130 UJ & $130 \mathrm{UJ}$ & $160 \mathrm{UJ}$ \\
\hline Arochlor 1254 & 11097-69-1 & $280 \mathrm{UJ}$ & $280 \mathrm{UJ}$ & $260 \mathrm{UJ}$ & $260 \mathrm{UJ}$ & $260 \mathrm{UJ}$ & 280 UJ & $240 \mathrm{UJ}$ & $260 \mathrm{UJ}$ & $260 \mathrm{UJ}$ & $320 \mathrm{UJ}$ \\
\hline Arochlor 1260 & $11096-82-5$ & $280 \mathrm{UJ}$ & $280 \mathrm{UJ}$ & $260 \mathrm{UJ}$ & $260 \mathrm{UJ}$ & $260 \mathrm{UJ}$ & $280 \mathrm{UJ}$ & $240 \mathrm{UJ}$ & $260 \mathrm{UJ}$ & $260 \mathrm{UJ}$ & $320 \mathrm{UJ}$ \\
\hline
\end{tabular}


Table A-1. B-Pond Phase 3 Pesticide/PCBs. $\quad(\mu \mathrm{g} / \mathrm{Kg})$

\begin{tabular}{|c|c|c|c|c|c|c|c|c|c|c|c|}
\hline ANALYTE & CAS: & BOOGS5 & BOOGS9 & B00GT7 & $800 \mathrm{GVS}$ & BOOGV6 & BooGv7 & B00GV8 & BooGv9 & BOOGWO & B0OGW1 \\
\hline & TYPE & Split & Reg & Reg & Reg & Reg & Reg & Reg & Btank & Reg & Reg \\
\hline & POND & $3 n$ & $3 A$ & $3 A$ & $3 n$ & 38 & 38 & 38 & 3B & 38 & 38 \\
\hline & DEPTH & 53 & 66.5 & 97 & 143.5 & 1 & 3.5 & 5.5 & $\cdots$ & 7.5 & 9.5 \\
\hline alpha BHC & $319-84-6$ & $9.7 \mathrm{uJ}$ & $13 \mathrm{Ud}$ & 13 UJ & $13 \mathrm{UJ}$ & 13 UJ & 13 UJ & $13 \mathrm{UJ}$ & $60 \mathrm{UJ}$ & $60 \mathrm{UJ}$ & $62 \mathrm{UJ}$ \\
\hline beta BHC & $319-85-7$ & $9.7 \mathrm{uJ}$ & $13 \mathrm{UJ}$ & $13 \mathrm{UJ}$ & $13 \mathrm{uJ}$ & 13 UJ & $13 \mathrm{uJ}$ & 13 US & $60 \mathrm{UJ}$ & $60 \mathrm{UJ}$ & $62 \mathrm{UJ}$ \\
\hline del ta BHC & $319-86-8$ & $9.7 \mathrm{UJ}$ & $13 \mathrm{UJ}$ & $13 \mathrm{UJ}$ & 13 UJ & 13 UJ & 13 UJ & 13 UJ & $60 \mathrm{UJ}$ & $60 \mathrm{UJ}$ & $62 \mathrm{UJ}$ \\
\hline garma BHC (Lindane) & $58-89-9$ & $9.7 \mathrm{UJ}$ & $13 \mathrm{UJ}$ & $13 \mathrm{UJ}$ & 13 UJ & 13 UJ & $13 \mathrm{UJ}$ & $13 \mathrm{UJ}$ & $60 \mathrm{UJ}$ & $60 \mathrm{UJ}$ & $62 \mathrm{UJ}$ \\
\hline Heptachlor & $76-44-8$ & $9.7 \mathrm{uJ}$ & $13 \mathrm{UJ}$ & $13 \mathrm{UJ}$ & $13 \mathrm{UJ}$ & $13 \mathrm{UJ}$ & $13 \mathrm{UJ}$ & $13 \mathrm{UJ}$ & $60 \mathrm{UJ}$ & $60 \mathrm{UJ}$ & $62 \mathrm{UJ}$ \\
\hline Aldrín & $309-00-2$ & $9.7 \mathrm{UJ}$ & $13 \mathrm{UJ}$ & $13 \mathrm{UJ}$ & $13 \mathrm{UJ}$ & $13 \mathrm{UJ}$ & $13 \mathrm{UJ}$ & 13 UJ & $60 \mathrm{UJ}$ & $60 \mathrm{UJ}$ & $62 \mathrm{UJ}$ \\
\hline Heptachlor Epoxide & $1024-57-3$ & $9.7 \mathrm{UJ}$ & $13 \mathrm{UJ}$ & $13 \mathrm{UJ}$ & $13 \mathrm{UJ}$ & $13 \mathrm{UJ}$ & $13 \mathrm{UJ}$ & 13 UJ & $60 \mathrm{uJ}$ & $60 \mathrm{UJ}$ & $62 \mathrm{UJ}$ \\
\hline Endosul fan 1 & $959-98-8$ & $9.7 \mathrm{us}$ & 13 UJ & $13 \mathrm{UJ}$ & $13 \mathrm{UJ}$ & 13 UJ & 13 Us & $13 \mathrm{uJ}$ & $60 \mathrm{UJ}$ & $60 \mathrm{UJ}$ & $62 \mathrm{UJ}$ \\
\hline Dieldrín & $60-57-1$ & $19 \mathrm{UJ}$ & $26 \mathrm{UJ}$ & 25 UJ & $26 \mathrm{UJ}$ & 25 UJ & $25 \mathrm{UJ}$ & $25 \mathrm{UJ}$ & $120 \mathrm{UJ}$ & $120 \mathrm{UJ}$ & $120 \mathrm{UJ}$ \\
\hline $4,41-D D E$ & $72-55-9$ & 19 UJ & $26 \mathrm{UJ}$ & $25 \mathrm{UJ}$ & $26 \mathrm{UJ}$ & $25 \mathrm{UJ}$ & $25 \mathrm{UJ}$ & 25 UJ & $120 \mathrm{UJ}$ & $120 \mathrm{UJ}$ & 120 UJ \\
\hline Endrin & $72-20-8$ & $19 \mathrm{uJ}$ & $26 \mathrm{UJ}$ & $25 \mathrm{UJ}$ & $26 \mathrm{UJ}$ & 25 UJ & $25 \mathrm{UJ}$ & 25 US & $120 \mathrm{UJ}$ & 120 UJ & $120 \mathrm{UJ}$ \\
\hline Endosul fan 11 & $33213-65-9$ & 19 UJ & $26 \mathrm{UJ}$ & 25 UJ & $26 \mathrm{UJ}$ & $25 \mathrm{UJ}$ & 25 UJ & 25 UJ & $120 \mathrm{UJ}$ & 120 UJ & $120 \mathrm{UJ}$ \\
\hline $4,4 !-D 0 D$ & $72-54-8$ & $19 \mathrm{UJ}$ & $26 \mathrm{UJ}$ & 25 UJ & $26 \mathrm{UJ}$ & 25 UJ & 25 UJ & 25 UJ & $120 \mathrm{UJ}$ & $120 \mathrm{UJ}$ & $120 \mathrm{UJ}$ \\
\hline Endosul fan Sulfate & $1031-07-8$ & $19 \mathrm{UJ}$ & $26 \mathrm{uJ}$ & 25 us & $26 \mathrm{UJ}$ & $25 \mathrm{UJ}$ & $25 \mathrm{UJ}$ & 25 UJ & $120 \mathrm{UJ}$ & $120 \mathrm{UJ}$ & $120 \mathrm{UJ}$ \\
\hline $4,4 \cdot-\mathrm{DDT}$ & $50-29-3$ & $19 \mathrm{UJ}$ & $26 \mathrm{UJ}$ & $25 \mathrm{UJ}$ & $26 \mathrm{UJ}$ & 25 UJ & $25 \mathrm{UJ}$ & $25 \mathrm{UJ}$ & $120 \mathrm{UJ}$ & $120 \mathrm{UL}$ & $120 \mathrm{UJ}$ \\
\hline Methoxychlor & $72-43-5$ & $97 \mathrm{UJ}$ & $130 \mathrm{UJ}$ & $130 \mathrm{UJ}$ & $130 \mathrm{UJ}$ & $130 \mathrm{UJ}$ & $130 \mathrm{UJ}$ & $130 \mathrm{UJ}$ & $600 \mathrm{UJ}$ & $600 \mathrm{UJ}$ & $620 \mathrm{UJ}$ \\
\hline Endr in Ketone & $53494-70-5$ & $19 \mathrm{UJ}$ & $26 \mathrm{UJ}$ & $25 \mathrm{UJ}$ & $26 \mathrm{UJ}$ & $25 \mathrm{UJ}$ & $25 \mathrm{uJ}$ & $25 \mathrm{UJ}$ & $120 \mathrm{UJ}$ & 120 UJ & $120 \mathrm{UJ}$ \\
\hline alpha-chlorodane & $5103-71-9$ & $97 \mathrm{UJ}$ & $130 \mathrm{UJ}$ & $130 \mathrm{UJ}$ & $130 \mathrm{UJ}$ & $130 \mathrm{UJ}$ & $130 \mathrm{UJ}$ & $130 \mathrm{UJ}$ & $600 \mathrm{UJ}$ & $600 \mathrm{UJ}$ & $620 \mathrm{UJ}$ \\
\hline gamma-Chl orodane & $5103-74-2$ & $97 \mathrm{UJ}$ & $130 \mathrm{UJ}$ & $130 \mathrm{UJ}$ & $130 \mathrm{UJ}$ & $130 \mathrm{UJ}$ & $130 \mathrm{UJ}$ & $130 \mathrm{UJ}$ & $600 \mathrm{UJ}$ & $600 \mathrm{UJ}$ & $620 \mathrm{UJ}$ \\
\hline
\end{tabular}

(Page 3 of 8 ) 
Table A-1. B-Pond Phase 3 Pesticide/PCBs. ( $\mu \mathrm{g} / \mathrm{Kg})$

\begin{tabular}{|c|c|c|c|c|c|c|c|c|c|c|c|}
\hline AMALYTE & cAS* & 800Gs5 & BooGs9 & B00GI7 & B00GV5 & BO0GV6 & Bo0GV7 & Bo0Gv8 & Boogv9 & BO0GWO & 800GN1 \\
\hline & TYPE & Split & Reg & Reg & Reg & Reg & Reg & Reg & Blank & Reg & Reg \\
\hline & POND & $3 A$ & $3 A$ & $3 A$ & $3 A$ & 3B & 38 & 38 & 38 & 3B & 3B \\
\hline & DEPTH & 53 & 66.5 & 97 & 143.5 & 1 & 3.5 & 5.5 & $\cdots$ & 7.5 & 9.5 \\
\hline Toxaphene & $8001-35-2$ & 190 UJ & $260 \mathrm{UJ}$ & $250 \mathrm{UJ}$ & $260 \mathrm{UJ}$ & 250 UJ & 250 UJ & 250 UJ & $1200 \mathrm{UJ}$ & $1200 \mathrm{UJ}$ & $1200 \mathrm{UJ}$ \\
\hline Arochlor 1016 & $12674-11-2$ & 97 UJ & 130 US & 130 UJ & $130 \mathrm{UJ}$ & $130 \mathrm{UJ}$ & $130 \mathrm{UJ}$ & $130 \mathrm{UJ}$ & 120 UJ & $120 \mathrm{UJ}$ & $120 \mathrm{UJ}$ \\
\hline Arochlor 1221 & $11104-28-2$ & $97 \mathrm{UJ}$ & $130 \mathrm{UJ}$ & 130 UJ & 130 UJ & 130 UJ & 130 Us & $130 \mathrm{UJ}$ & $120 \mathrm{UJ}$ & $120 \mathrm{UJ}$ & $120 \mathrm{UJ}$ \\
\hline Arcichlor 1232 & $11141-16-5$ & 97 UJ & $130 \mathrm{UJ}$ & 130 Us & $130 \mathrm{UJ}$ & 130 UJ & 130 UJ & 130 US & $120 \mathrm{UJ}$ & $120 \mathrm{UJ}$ & $120 \mathrm{UJ}$ \\
\hline Arochlor 1242 & $53669-21-9$ & $97 \mathrm{UJ}$ & 130 us & 130 Us & 130 us & $130 \mathrm{UJ}$ & 130 UJ & $130 \mathrm{UJ}$ & $120 \mathrm{UJ}$ & 120 us & $120 \mathrm{UJ}$ \\
\hline Arochlor 1248 & $12672-29-6$ & $97 \mathrm{UJ}$ & $130 \mathrm{UJ}$ & $130 \mathrm{UJ}$ & 130 UJ & 130 UJ & 130 uJ & $130 \mathrm{UJ}$ & 120 UJ & 120 UJ & $120 \mathrm{UJ}$ \\
\hline Arochlor 1254 & $11097-69-1$ & 190 UJ & $260 \mathrm{uJ}$ & 260 US & $260 \mathrm{UJ}$ & $260 \mathrm{UJ}$ & $260 \mathrm{UJ}$ & $260 \mathrm{UJ}$ & $240 \mathrm{UJ}$ & $260 \mathrm{UJ}$ & $240 \mathrm{UJ}$ \\
\hline Arochlor 1260 & $11096-82-5$ & 190 UJ & $260 \mathrm{UJ}$ & $260 \mathrm{UJ}$ & $260 \mathrm{UJ}$ & $260 \mathrm{UJ}$ & $260 \mathrm{UJ}$ & $260 \mathrm{UJ}$ & $240 \mathrm{UJ}$ & $260 \mathrm{UJ}$ & $240 \mathrm{UJ}$ \\
\hline
\end{tabular}


Table A-1. B-Pond Phase 3 Pesticide/PCBs. ( $\mu \mathrm{g} / \mathrm{Kg})$

\begin{tabular}{|c|c|c|c|c|c|c|c|c|c|c|c|}
\hline ANALYTE & CAS* & $800 \mathrm{GW} 3$ & BOOGW4 & BO0GUS & 800GU8 & $800 \mathrm{G} \times 6$ & BoOGz2 & B00G26 & B00G28 & ВоОнОО & В0ОНО1 \\
\hline & IYPE & Reg & Fdup & Split & Reg & Reg & Reg & Reg & Reg & Reg & Reg \\
\hline & POND & 3B & 38 & 38 & $3 B$ & 3B & 38 & 38 & $3 B$ & $3 c$ & $3 c$ \\
\hline & DEPTH & 13 & 13 & 13 & 21 & 61.5 & 90.5 & 118.5 & 123.5 & 1 & 3 \\
\hline alpha BHC & $319-84-6$ & $62 \mathrm{UJ}$ & $62 \mathrm{UJ}$ & $8.0 \mathrm{UJ}$ & $62 \mathrm{UJ}$ & $63 \mathrm{UJ}$ & $63 \mathrm{UJ}$ & $140 \mathrm{UJ}$ & $92 \mathrm{UJ}$ & $120 \mathrm{UJ}$ & $130 \mathrm{UJ}$ \\
\hline beta BHC & $319-85-7$ & $62 \mathrm{UJ}$ & $62 \mathrm{UJ}$ & $8.0 \mathrm{UJ}$ & $62 \mathrm{UJ}$ & $63 \mathrm{UJ}$ & $63 \mathrm{UJ}$ & $140 \mathrm{UJ}$ & $92 \mathrm{UJ}$ & $120 \mathrm{UJ}$ & $130 \mathrm{UJ}$ \\
\hline delta BHC & $319-86-8$ & $62 \mathrm{UJ}$ & $62 \mathrm{UJ}$ & $8.0 \mathrm{UL}$ & $62 \mathrm{uJ}$ & $63 \mathrm{UJ}$ & $63 \mathrm{UJ}$ & $140 \mathrm{UJ}$ & 92 UJ & $120 \mathrm{UJ}$ & $130 \mathrm{UJ}$ \\
\hline gamma BHC (Lindane) & $58-89-9$ & $62 \mathrm{UJ}$ & $62 \mathrm{UJ}$ & $8.0 \mathrm{UJ}$ & $62 \mathrm{UJ}$ & $63 \mathrm{UJ}$ & $63 \mathrm{UJ}$ & $140 \mathrm{UJ}$ & $92 \mathrm{UJ}$ & $120 \mathrm{UJ}$ & 130 U: \\
\hline Heptachlor & $76-44-8$ & $62 \mathrm{UJ}$ & $62 \mathrm{UJ}$ & $8.0 \mathrm{U}$ & $62 \mathrm{UJ}$ & $63 \mathrm{UJ}$ & $63 \mathrm{UJ}$ & $140 \mathrm{uJ}$ & 92 UJ & $120 \mathrm{UJ}$ & $130 \mathrm{UJ}$ \\
\hline Aldrin & $309-00-2$ & $62 \mathrm{UJ}$ & $62 \mathrm{UJ}$ & $8.0 \mathrm{UJ}$ & $62 \mathrm{UJ}$ & $63 \mathrm{UJ}$ & $63 \mathrm{UJ}$ & 140 UJ & 92 Ud & $120 \mathrm{UJ}$ & $130 \mathrm{UJ}$ \\
\hline Heptachlor Epoxide & $1024-57-3$ & $62 \mathrm{UJ}$ & $62 \mathrm{UJ}$ & $8.0 \mathrm{U}$ & $62 \mathrm{UJ}$ & $63 \mathrm{UJ}$ & $63 \mathrm{UJ}$ & $140 \mathrm{UJ}$ & 92 Us & $120 \mathrm{UJ}$ & $130 \mathrm{UJ}$ \\
\hline Endosul fan $I$ & $959-98-8$ & $62 \mathrm{UJ}$ & $62 \mathrm{UJ}$ & $8.0 \mathrm{UJ}$ & $62 \mathrm{UJ}$ & $63 \mathrm{UJ}$ & $63 \mathrm{UJ}$ & $140 \mathrm{UJ}$ & 92 UJ & $120 \mathrm{UJ}$ & 130 UJ \\
\hline Dieldrin & $60-57-1$ & $120 \mathrm{UJ}$ & $120 \mathrm{UJ}$ & $16 U$ & $120 \mathrm{UJ}$ & 130 UJ & $130 \mathrm{US}$ & $290 \mathrm{UJ}$ & $180 \mathrm{UJ}$ & 250 Us & $250 \mathrm{UJ}$ \\
\hline $4,4 \cdot-D D E$ & $72-55-9$ & $120 \mathrm{UJ}$ & $120 \mathrm{UJ}$ & $16 \mathrm{UJ}$ & $120 \mathrm{UJ}$ & 130 UJ & $130 \mathrm{UJ}$ & 290 UJ & 180 US & $250 \mathrm{UJ}$ & 250 UJ \\
\hline Endrin & $72-20-8$ & $120 \mathrm{UJ}$ & $120 \mathrm{UJ}$ & $16 \mathrm{U}$ & $120 \mathrm{UJ}$ & $130 \mathrm{UJ}$ & 130 UJ & 290 UJ & 180 UJ & $250 \mathrm{uJ}$ & $250 \mathrm{UJ}$ \\
\hline Endosulfan II & $33213-65-9$ & $120 \mathrm{UJ}$ & $120 \mathrm{UJ}$ & $16 U$ & $120 \mathrm{UJ}$ & $130 \mathrm{UJ}$ & 130 UJ & $290 \mathrm{UJ}$ & $180 \mathrm{UJ}$ & $250 \mathrm{UJ}$ & $250 \mathrm{UJ}$ \\
\hline $4,4 \cdot-000$ & $72-54-8$ & $120 \mathrm{UJ}$ & $120 \mathrm{UJ}$ & $16 \mathrm{UJ}$ & $120 \mathrm{UJ}$ & 130 UJ & $130 \mathrm{UJ}$ & $290 \mathrm{UJ}$ & $180 \mathrm{UJ}$ & $250 \mathrm{UJ}$ & $250 \mathrm{UJ}$ \\
\hline Endosul fan Sulfate & $1031-07-8$ & $120 \mathrm{UJ}$ & $120 \mathrm{UJ}$ & $16 \mathrm{UJ}$ & $120 \mathrm{UJ}$ & $130 \mathrm{UJ}$ & $130 \mathrm{UJ}$ & 290 UJ & $180 \mathrm{UJ}$ & 250 UJ & 250 UJ \\
\hline $4.4 \cdot-00 T$ & $50-29-3$ & $120 \mathrm{UJ}$ & $120 \mathrm{UJ}$ & $16 \mathrm{UJ}$ & 120 Us & $130 \mathrm{UJ}$ & $130 \mathrm{UJ}$ & 290 UJ & $180 \mathrm{UJ}$ & $250 \mathrm{UJ}$ & $250 \mathrm{UJ}$ \\
\hline Methoxychlor & $72-43-5$ & $620 \mathrm{UJ}$ & $620 \mathrm{UJ}$ & $80 \mathrm{U}$ & $620 \mathrm{UJ}$ & $630 \mathrm{UJ}$ & $630 \mathrm{UJ}$ & 1400 UJ & 920 UJ & $1200 \mathrm{UJ}$ & $1300 \mathrm{UJ}$ \\
\hline Endrin Ketone & $53494-70-5$ & $120 \mathrm{UJ}$ & $120 \mathrm{UJ}$ & $16 U$ & $120 \mathrm{UJ}$ & $130 \mathrm{UJ}$ & $130 \mathrm{UJ}$ & 290 UJ & $180 \mathrm{UJ}$ & $250 \mathrm{UJ}$ & $250 \mathrm{uJ}$ \\
\hline alpha-Chlorodane & $5103-71-9$ & $620 \mathrm{UJ}$ & $620 \mathrm{UJ}$ & $80 \mathrm{UJ}$ & $620 \mathrm{UJ}$ & $630 \mathrm{UJ}$ & $630 \mathrm{UJ}$ & $1400 \mathrm{UJ}$ & 920 UJ & $1200 \mathrm{UJ}$ & $1500 \mathrm{uJ}$ \\
\hline gamma-Chl orodane & $5103-74-2$ & $620 \mathrm{UJ}$ & $620 \mathrm{UJ}$ & $80 \mathrm{UJ}$ & 620 UJ & $630 \mathrm{UJ}$ & $630 \mathrm{us}$ & $1400 \mathrm{UJ}$ & 920 UJ & $1200 \mathrm{UJ}$ & $1300 \mathrm{UJ}$ \\
\hline
\end{tabular}

(Page 5 of 8 ) 
Table A-1. B-Pond Phase 3 Pesticide/PCBs. ( $\mu \mathrm{g} / \mathrm{Kg})$

\begin{tabular}{|c|c|c|c|c|c|c|c|c|c|c|c|}
\hline AMALYTE & CAS\# & B00GW3 & $800 \mathrm{GN4}$ & BOOGWS & BOOGW8 & $800 G \times 6$ & B00GZ2 & B00G26 & B00Gz8 & ВООНОО & ВООНО1 \\
\hline & TYPE & Reg & Fotup & Split & Reg & Reg & Reg & Reg & Reg & Reg & Reg \\
\hline & POND & 38 & 3B & 3B & 38 & 38 & 3B & 38 & 3B & $3 c$ & $3 c$ \\
\hline & DEPTH & 13 & 13 & 13 & 21 & 61.5 & 90.5 & 118.5 & 123.5 & 1 & 3 \\
\hline Toxaphene & $8001-35-2$ & $1200 \mathrm{UJ}$ & $1200 \mathrm{UJ}$ & $160 U$ & $1200 \mathrm{UJ}$ & $1300 \mathrm{UJ}$ & $1300 \mathrm{UJ}$ & 2900 UJ & $1800 \mathrm{UJ}$ & 2500 UJ & $2500 \mathrm{UJ}$ \\
\hline Arochlor 1016 & $12674-11-2$ & $120 \mathrm{UJ}$ & $120 \mathrm{UJ}$ & $80 U$ & $120 \mathrm{UJ}$ & $130 \mathrm{UJ}$ & 130 UJ & $140 \mathrm{UJ}$ & $180 \mathrm{UJ}$ & $130 \mathrm{UJ}$ & $130 \mathrm{us}$ \\
\hline Arochlor 1221 & $11104-28-2$ & 120 UJ & $120 \mathrm{UJ}$ & $80 \mathrm{U}$ & $120 \mathrm{UJ}$ & $130 \mathrm{UJ}$ & $130 \mathrm{UJ}$ & 140 UJ & $180 \mathrm{UJ}$ & $130 \mathrm{UJ}$ & $130 \mathrm{US}$ \\
\hline Arochlor 1232 & $11141-16-5$ & $120 \mathrm{UJ}$ & $120 \mathrm{UJ}$ & $80 \mathrm{U}$ & $120 \mathrm{UJ}$ & $130 \mathrm{UJ}$ & $130 \mathrm{UJ}$ & $140 \mathrm{UJ}$ & $180 \mathrm{UJ}$ & 130 UJ & $130 \mathrm{UJ}$ \\
\hline Arochlor 1242 & $53469-21-9$ & $120 \mathrm{UJ}$ & $120 \mathrm{UJ}$ & $80 \mathrm{U}$ & $120 \mathrm{UJ}$ & $130 \mathrm{UJ}$ & $130 \mathrm{UJ}$ & $140 \mathrm{UJ}$ & $180 \mathrm{UJ}$ & 130 UJ & $130 \mathrm{UJ}$ \\
\hline Arochlor 1248 & $12672-29-6$ & $120 \mathrm{UJ}$ & $120 \mathrm{UJ}$ & $80 \mathrm{U}$ & $120 \mathrm{UJ}$ & 130 UJ & $130 \mathrm{UJ}$ & $140 \mathrm{UJ}$ & 180 UJ & 130 UJ & $130 \mathrm{UJ}$ \\
\hline Arochlor 1254 & $11097-69-1$ & $240 \mathrm{UJ}$ & 240 UJ & $160 U$ & $240 \mathrm{UJ}$ & $260 \mathrm{UJ}$ & $260 \mathrm{UJ}$ & $280 \mathrm{UJ}$ & $360 \mathrm{UJ}$ & $260 \mathrm{UJ}$ & 260 UJ \\
\hline Arochlor 1260 & $11096-82-5$ & $240 \mathrm{UJ}$ & $240 \mathrm{UJ}$ & $160 U$ & $240 \mathrm{UJ}$ & $260 \mathrm{UJ}$ & $260 \mathrm{UJ}$ & $280 \mathrm{UJ}$ & 360 UJ & $260 \mathrm{UJ}$ & $260 \mathrm{UJ}$ \\
\hline
\end{tabular}


Table A-1. B-Pond Phase 3 Pesticide/PCBs. ( $\mu \mathrm{g} / \mathrm{Kg})$

\begin{tabular}{|c|c|c|c|c|c|c|c|c|c|c|c|}
\hline ANALYTE & CAS\# & ВоOH02 & воОно3 & ВоОНО4 & ВоОНО5 & ВоОНО6 & ВоОН07 & $800 \mathrm{H14}$ & воОн10 & ВоОН19 & $800 \mathrm{H} 23$ \\
\hline & TYPE & Reg & Reg & Reg & Fodup & Reg & Split & Reg & Blank & Reg & Reg \\
\hline & POND & $3 c$ & $3 c$ & $3 c$ & $3 c$ & $3 c$ & $3 c$ & $3 c$ & $3 C$ & $3 c$ & $3 c$ \\
\hline & DEPIH & 5 & 7 & 9 & 9 & 11.5 & 11.5 & 30 & $\cdots$ & 60 & 80 \\
\hline alpha BHC & $319-84-6$ & $160 \mathrm{UJ}$ & $63 \mathrm{UJ}$ & $130 \mathrm{UJ}$ & $63 \mathrm{uJ}$ & $130 \mathrm{UJ}$ & $8.3 \mathrm{uJ}$ & $130 \mathrm{UJ}$ & $60 \mathrm{UJ}$ & 130 UJ & 77 UJ \\
\hline beta BHC & $319-85-7$ & $160 \mathrm{UJ}$ & $63 \mathrm{UJ}$ & $130 \mathrm{UJ}$ & $63 \mathrm{UJ}$ & $130 \mathrm{UJ}$ & $8.3 \mathrm{UJ}$ & $130 \mathrm{UJ}$ & $60 \mathrm{UJ}$ & 130 US & 77 Us \\
\hline delta BHC & $319-86-8$ & $160 \mathrm{UJ}$ & $63 \mathrm{UJ}$ & $130 \mathrm{UJ}$ & $63 \mathrm{UJ}$ & $130 \mathrm{UJ}$ & $8.3 \mathrm{UJ}$ & 130 UJ & $60 \mathrm{UJ}$ & 130 uJ & $77 \mathrm{us}$ \\
\hline gamme BHC (Lindane) & $58-89-9$ & $160 \mathrm{UJ}$ & $63 \mathrm{UJ}$ & $130 \mathrm{UJ}$ & $63 \mathrm{UJ}$ & $130 \mathrm{UJ}$ & $8.3 \mathrm{U}$ & ijó UJ & $60 \mathrm{UJ}$ & $130 \mathrm{UJ}$ & $77 \mathrm{us}$ \\
\hline Heptachlor & $76-44-8$ & $160 \mathrm{UJ}$ & $63 \mathrm{UJ}$ & $130 \mathrm{UJ}$ & $63 \mathrm{UJ}$ & $130 \mathrm{UJ}$ & $8.3 \mathrm{U}$ & $130 \mathrm{UJ}$ & $60 \mathrm{UJ}$ & $130 \mathrm{UJ}$ & $\pi$ UJ \\
\hline Aldrin & $309-00-2$ & $160 \mathrm{UJ}$ & $63 \mathrm{UJ}$ & $130 \mathrm{UJ}$ & $63 \mathrm{UJ}$ & $130 \mathrm{UJ}$ & $8.3 \mathrm{UJ}$ & $130 \mathrm{UJ}$ & $60 \mathrm{UJ}$ & $130 \mathrm{UJ}$ & 77 UJ \\
\hline Heptachlor Epoxide & $1024-57-3$ & $160 \mathrm{UJ}$ & $63 \mathrm{UJ}$ & $130 \mathrm{UJ}$ & $63 \mathrm{uJ}$ & 130 UJ & $8.3 \mathrm{U}$ & $130 \mathrm{UJ}$ & $60 \mathrm{UJ}$ & $130 \mathrm{UJ}$ & $77 \mathrm{us}$ \\
\hline Endosul fon I & $959-98-8$ & $160 \mathrm{UJ}$ & $63 \mathrm{UJ}$ & $130 \mathrm{UJ}$ & $63 \mathrm{UJ}$ & $130 \mathrm{US}$ & $8.3 \mathrm{U}$ & $130 \mathrm{UJ}$ & $60 \mathrm{UJ}$ & $130 \mathrm{UJ}$ & $77 \mathrm{UJ}$ \\
\hline Dieldrin & $60-57-1$ & $310 \mathrm{UJ}$ & $130 \mathrm{UJ}$ & $250 \mathrm{UJ}$ & $130 \mathrm{UJ}$ & $250 \mathrm{UJ}$ & $17 U$ & $260 \mathrm{UJ}$ & 120 UJ & $260 \mathrm{UJ}$ & $150 \mathrm{UJ}$ \\
\hline $4,4^{1}-\mathrm{DDE}$ & $72-55-9$ & $310 \mathrm{UJ}$ & $130 \mathrm{UJ}$ & $250 \mathrm{us}$ & $130 \mathrm{UJ}$ & $250 \mathrm{UJ}$ & $17 \mathrm{v}$ & $260 \mathrm{UJ}$ & $120 \mathrm{UJ}$ & $260 \mathrm{UJ}$ & 150 UJ \\
\hline Endrin & $72-20-8$ & $310 \mathrm{UJ}$ & $130 \mathrm{UJ}$ & $250 \mathrm{UJ}$ & $130 \mathrm{UJ}$ & $250 \mathrm{UJ}$ & $17 \mathrm{UJ}$ & $260 \mathrm{UJ}$ & $120 \mathrm{UJ}$ & $260 \mathrm{UJ}$ & $150 \mathrm{uJ}$ \\
\hline Endosul fan II & $33213-65-9$ & $310 \mathrm{UJ}$ & $130 \mathrm{UJ}$ & $250 \mathrm{UJ}$ & $130 \mathrm{UJ}$ & $250 \mathrm{UJ}$ & $17 \mathrm{U}$ & $260 \mathrm{UJ}$ & $120 \mathrm{UJ}$ & $260 \mathrm{UJ}$ & $150 \mathrm{UJ}$ \\
\hline $4,41-D D D$ & $72-54-8$ & $310 \mathrm{UJ}$ & $130 \mathrm{Ud}$ & $250 \mathrm{UJ}$ & $130 \mathrm{UJ}$ & $250 \mathrm{UJ}$ & $17 \mathrm{U}$ & $260 \mathrm{UJ}$ & $120 \mathrm{UJ}$ & $260 \mathrm{UJ}$ & $150 \mathrm{UJ}$ \\
\hline Endosulfan Sulfate & $1031-07-8$ & $310 \mathrm{UJ}$ & 130 UJ & 250 UJ & $130 \mathrm{UJ}$ & $250 \mathrm{UJ}$ & $17 \mathrm{U}$ & $260 \mathrm{UJ}$ & $120 \mathrm{UJ}$ & $260 \mathrm{UJ}$ & $150 \mathrm{UJ}$ \\
\hline $4.41-D D T$ & $50-29-3$ & $310 \mathrm{UJ}$ & $130 \mathrm{UJ}$ & $250 \mathrm{UJ}$ & $130 \mathrm{UJ}$ & $250 \mathrm{UJ}$ & $17 \mathrm{U}$ & $260 \mathrm{uJ}$ & $120 \mathrm{UJ}$ & $260 \mathrm{UJ}$ & $150 \mathrm{UJ}$ \\
\hline Methoxychlor & $72-43-5$ & $1600 \mathrm{UJ}$ & $630 \mathrm{UJ}$ & $1300 \mathrm{UJ}$ & $630 \mathrm{UJ}$ & $1300 \mathrm{UJ}$ & $83 \mathrm{U}$ & $1300 \mathrm{UJ}$ & $600 \mathrm{UJ}$ & $1300 \mathrm{UJ}$ & $770 \mathrm{UJ}$ \\
\hline Endrin Ketone & $53494-70-5$ & $310 \mathrm{UJ}$ & 130 us & $250 \mathrm{UJ}$ & $130 \mathrm{UJ}$ & $250 \mathrm{UJ}$ & $17 U$ & $260 \mathrm{UJ}$ & $120 \mathrm{UJ}$ & $260 \mathrm{UJ}$ & $150 \mathrm{UJ}$ \\
\hline alpha-Chlorodane & $5103-71-9$ & $1600 \mathrm{UJ}$ & $630 \mathrm{UJ}$ & $1300 \mathrm{UJ}$ & $630 \mathrm{UJ}$ & $1300 \mathrm{UJ}$ & 83 us & $1300 \mathrm{UJ}$ & $600 \mathrm{UJ}$ & $1300 \mathrm{UJ}$ & 770 UJ \\
\hline gamma-Chlorodane & $5103-74-2$ & $1600 \mathrm{UJ}$ & $630 \mathrm{UJ}$ & $1300 \mathrm{UJ}$ & $630 \mathrm{UJ}$ & $1300 \mathrm{UJ}$ & $83 \mathrm{UJ}$ & $1300 \mathrm{UJ}$ & $600 \mathrm{UJ}$ & $1300 \mathrm{UJ}$ & $770 \mathrm{us}$ \\
\hline
\end{tabular}


Table A-1. B-Pond Phase 3 Pesticide/PCBs. ( $(\mu \mathrm{g} / \mathrm{Kg})$

\begin{tabular}{|c|c|c|c|c|c|c|c|c|c|c|c|}
\hline AWALYTE & CASE & В0ОНО2 & В0OHO3 & $800 \mathrm{HO}$ & В0OHOS & ВООНО6 & воОНО7 & ВоOH14 & ВоОН10 & воОн19 & ВоOH23 \\
\hline & TYPE & Reg & Reg & Reg & Fdup & Reg & Split & Reg & Blank & Reg & Reg \\
\hline & POND & $3 c$ & $3 c$ & $3 c$ & $3 c$ & $3 c$ & $3 c$ & $3 C$ & $3 c$ & $3 C$ & $3 c$ \\
\hline & DEPIH & 5 & 7 & 9 & 9 & 11.5 & 11.5 & 30 & $\cdots$ & 60 & 80 \\
\hline Toxaphene & $8001-35-2$ & $3100 \mathrm{UJ}$ & 1300 UJ & $2500 \mathrm{UJ}$ & $1300 \mathrm{UJ}$ & 2500 UJ & $170 U$ & $2600 \mathrm{UJ}$ & $1200 \mathrm{UJ}$ & 2600 Us & 1500 UJ \\
\hline Arochlor 1016 & $12674-11-2$ & $160 \mathrm{UJ}$ & $130 \mathrm{UJ}$ & $130 \mathrm{UJ}$ & 130 UJ & $130 \mathrm{UJ}$ & $83 \mathrm{U}$ & $130 \mathrm{UJ}$ & $120 \mathrm{UJ}$ & $130 \mathrm{UJ}$ & $150 \mathrm{UJ}$ \\
\hline Arochlor 1221 & $11104-28-2$ & $160 \mathrm{UJ}$ & $130 \mathrm{UJ}$ & $130 \mathrm{UJ}$ & $130 \mathrm{UJ}$ & $130 \mathrm{UJ}$ & $83 \mathrm{U}$ & $130 \mathrm{UJ}$ & $120 \mathrm{UJ}$ & $130 \mathrm{UJ}$ & $150 \mathrm{IJ}$ \\
\hline Arochlor 1232 & $11141-16-5$ & $160 \mathrm{UJ}$ & $130 \mathrm{UJ}$ & $130 \mathrm{UJ}$ & $130 \mathrm{UJ}$ & $130 \mathrm{UJ}$ & $83 \mathrm{U}$ & 130 UJ & $120 \mathrm{UJ}$ & $130 \mathrm{UJ}$ & $150 \mathrm{UJ}$ \\
\hline Arochlor 1242 & $53469-21-9$ & $160 \mathrm{UJ}$ & $130 \mathrm{UJ}$ & $130 \mathrm{UJ}$ & $130 \mathrm{UJ}$ & $130 \mathrm{UJ}$ & $83 U$ & $130 \mathrm{UJ}$ & $120 \mathrm{uJ}$ & $130 \mathrm{UJ}$ & 150 UJ \\
\hline Arochlor 1248 & $12672-29-6$ & $160 \mathrm{UJ}$ & $130 \mathrm{uJ}$ & $130 \mathrm{UJ}$ & $130 \mathrm{UJ}$ & $130 \mathrm{UJ}$ & $83 u$ & $130 \mathrm{UJ}$ & $120 \mathrm{UJ}$ & 130 UJ & $150 \mathrm{UJ}$ \\
\hline Arochlor 1254 & $11097-69-1$ & $320 \mathrm{UJ}$ & $260 \mathrm{UJ}$ & 260 UJ & $260 \mathrm{UJ}$ & $260 \mathrm{UJ}$ & $170 \mathrm{U}$ & $260 \mathrm{UJ}$ & $240 \mathrm{UJ}$ & 260 UJ & $300 \mathrm{UJ}$ \\
\hline Arochlor 1260 & $11096-82-5$ & $320 \mathrm{UJ}$ & $260 \mathrm{UJ}$ & $260 . \mathrm{UJ}$ & $260 \mathrm{UJ}$ & $260 \mathrm{UJ}$ & $170 \mathrm{U}$ & $260 \mathrm{UJ}$ & $240 \mathrm{UJ}$ & 260 UJ & $300 \mathrm{UJ}$ \\
\hline
\end{tabular}

U The analyte was undetected at the stated limit.

$J$ The associated value is on estimated quantity. 


\author{
WHC-SD-EN-AP-104 Rev. 0 \\ Reasons for Westinghouse Hanford Qualification-- \\ Pesticides/Polychlorinated Biphenyls
}

Reqular. Field Duplicate, and Silica Sand Samples:

HOLDING TIME--All samples were flagged as estimated, "J". All samples extracted outside 7-day criteria established for water. (All samples were analyzed within 40 days of extraction.)

LABORATORY BLANK--Arochlor-1254, beta-BHC, and lindane were detected in laboratory blanks. This resulted in an undetected qualification, "U", of one or more of those anaiytes detected at similar concentrations in the following:

$\begin{array}{llll}\text { BOOFK6 } & \text { BOOGS4 } & \text { BOOGW1 } & \text { BOOHO2 } \\ \text { BOOFK7 } & \text { BOOGS9 } & \text { BOOGW3 } & \text { BOOHO3 } \\ \text { BOOFK8 } & \text { BOOGT7 } & \text { BOOGW4 } & \text { BOOHO4 } \\ \text { BOOFK9 } & \text { BOOGV5 } & \text { BOOGW8 } & \text { BOOHO5 } \\ \text { BOOFLO } & \text { BOOGV6 } & \text { BOOGX6 } & \text { BOOHO6 } \\ \text { BOOFL1 } & \text { BOOGV7 } & \text { BOOGZ2 } & \text { BOOH10 } \\ \text { BOOFL3 } & \text { BOOGV8 } & \text { BOOGZ6 } & \text { BOOH14 } \\ \text { BOOFL4 } & \text { BOOGV9 } & \text { BOOGZ8 } & \text { BOOH19 } \\ \text { BOOGR9 } & \text { BOOGWO } & \text { BOOHO1 } & \text { BOOH23 }\end{array}$

SURROGATE RECOVERY--Recovery was high for sample BOOHO1. All pesticide/ $P C B$ constituents were undetected but qualified as "UJ" for BOOHOI.

\title{
Split Samples:
}

SURROGATE RECOVERY--Recovery was high for sample BOOGS5. All pesticide/ $P C B$ constituents were undetected but qualified as "UJ" for BOOGS5.

MS/MSD--Recovery was high for sample BOOGS5. All pesticide/PCB constituents were undetected but qualified "UJ" per OSM guidelines. 
WHC-SD-EN-AP-104 Rev. 0

Table A-2. B-Pond Phase 3 Herbicide Data. ( $(\mu \mathrm{g} / \mathrm{Kg})$

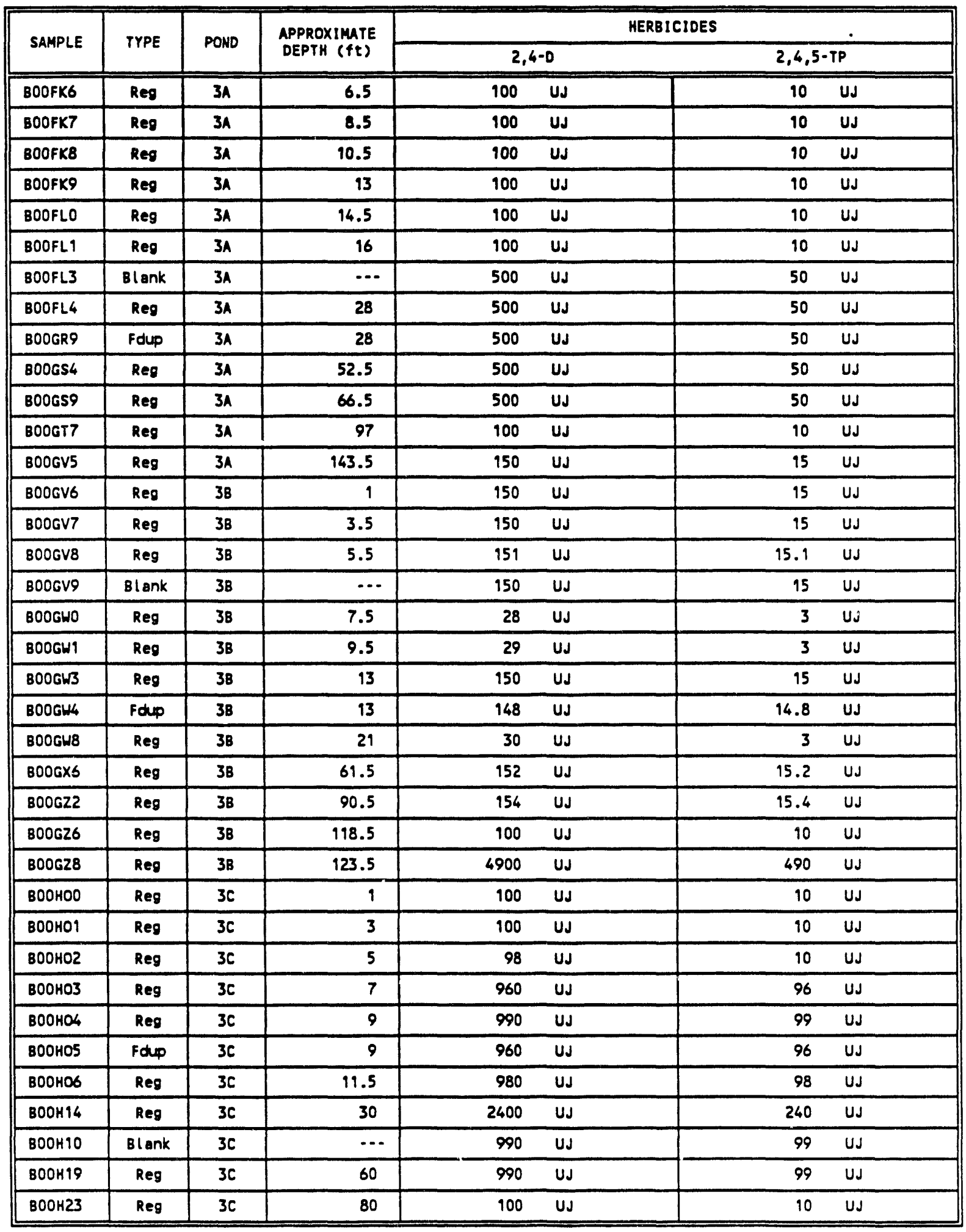

$U$ The analyte was undetected at the stated limit.

$J$ The associated value is an estimated quantity. 
WHC-SD-EN-AP-104 Rev. 0

Reasons for Westinghouse Hanford Company Qualification--Herbicides

Reqular. Field Duplicate, and Silica Sand Samples:

HOLDING TIME--All samples were flagged as estimated, "J". All samples extracted outside 7-day criteria established for water. (A11 samples were analyzed within 40 days of extraction.)

Split Samples:

None. 
Table A-3. B-Pond Phase 3 Organophosphorous Pesticides. (mg/Kg)

\begin{tabular}{|c|c|c|c|c|c|c|c|c|c|c|}
\hline ANALYTE & CAS* & B00FK6 & B00FK7 & BOOFK8 & B00FK9 & BOOFLO & B00fL1 & BOOFL3 & BOOFL4 & BOOGR9 \\
\hline & TYPE & Reg & Reg & Reg & Reg & Reg & Reg & Blank & Reg & Fdup \\
\hline & POND & $3 A$ & $3 n$ & $3 A$ & $3 n$ & $3 n$ & $3 A$ & $3 A$ & 3A & $3 \AA$ \\
\hline & DEPTH & 6.5 & 8.5 & 10.5 & 13 & 14.5 & 16 & $\cdots$ & 28 & 28 \\
\hline Azinphos-methly & $86-50-0$ & NT & NT & NT & NT & NT & NT & MT & MT & NT \\
\hline Chlorpyrifos & $2981-88-2$ & NT & NT & NT & NT & NT & MT & НT & NT & NT \\
\hline Chlorpyrifos methyl & $5598-13-0$ & NT & NI & NT & NT & NT & NT & NT & MT & NT \\
\hline Coumaphos & $56-72-4$ & NT & NT & NT & NT & NT & NT & MT & NT & NT \\
\hline Demeton & $8065-48-3$ & NT & NT & NT & NT & NT & NT & MT & MT & NT \\
\hline Diazanon & $333-41-5$ & MT & NT & NT & MT & NT & NT & NT & TT & NT \\
\hline DDVP (Dichlorvos) & $62-73-7$ & NT & NT & NT & MT & NT & NT & NT & NT & NT \\
\hline Dimethoate & $60-51-5$ & $0.11 \mathrm{Ud}$ & $0.11 \mathrm{UJ}$ & $0.11 \mathrm{UJ}$ & $0.11 \mathrm{UJ}$ & $0.11 \mathrm{uJ}$ & $0.11 \mathrm{UJ}$ & $0.10 \mathrm{UJ}$ & 0.10 UJ & $0.10 \mathrm{UJ}$ \\
\hline Disul foton & $298-04-4$ & $0.06 \mathrm{UJ}$ & $0.06 \mathrm{UJ}$ & $0.05 \mathrm{UJ}$ & $0.05 \mathrm{UJ}$ & 0.05 UJ & $0.06 \mathrm{UJ}$ & 0.05 UJ & $0.05 \mathrm{UJ}$ & $0.05 \mathrm{UJ}$ \\
\hline EPN & $2104-64-5$ & NT & MT & NT & NT & NT & NT & MT & NT & NT \\
\hline Ethion & $563-12-2$ & NT & NT & NT & NT & NT & NT & NT & MT & NT \\
\hline Ethoprop & $13194-78-4$ & NT & NT & NT & NT & NT & NT & MT & NT & MT \\
\hline Famphur & $52-85-7$ & 0.17 UJ & $0.17 \mathrm{UJ}$ & 0.16 UJ & 0.16 UJ & $0.16 \mathrm{UJ}$ & $0.17 \mathrm{UJ}$ & $0.15 \mathrm{UJ}$ & $0.16 \mathrm{UJ}$ & $0.16 \mathrm{UJ}$ \\
\hline Fensul fothion & $115-90-2$ & NT & MT & NT & NT & NT & NT & MT & NT & NT \\
\hline Fenthion & $55-38-9$ & NT & NT & NT & NT & NT & NT & NT & КT & NT \\
\hline Malathion & $121-75-5$ & NT & NT & NT & NT & NT & NT & NT & NT & NT \\
\hline Merphos & $150-50-5$ & NT & NT & NT & NT & NT & NT & NT & NT & NT \\
\hline Mevinphos & $7786-34-7$ & NT & NT & NT & NT & NT & NT & NT & NT & NT \\
\hline Monocrotophos & $6923-22-4$ & NT & NT & NT & NT & NT & NT & NT & NT & NT \\
\hline
\end{tabular}

(Page 1 of 8 ) 
Table A-3. B-Pond Phase 3 Organophosphorous Pesticides. (mg/Kg)

\begin{tabular}{|c|c|c|c|c|c|c|c|c|c|c|}
\hline AMALYTE & CAS\# & B00FK6 & BOOFK7 & BOOFK8 & BOOFK9 & BOOFLO & BOOFLI & BOOFL3 & BOOFL4 & BOOGR9 \\
\hline & IYPE & Reg & Reg & Reg & Reg & Reg & Reg & 8lank & Reg & Fdup \\
\hline & POND & $3 \AA$ & $3 A$ & $3 A$ & $3 A$ & $3 A$ & $3 n$ & $3 \AA$ & $3 A$ & $3 n$ \\
\hline$\cdot$ & DEPTH & 6.5 & 8.5 & 10.5 & 13 & 14.5 & 16 & $\cdots$ & 28 & 28 \\
\hline Naled & $300-76-5$ & MT & NI & NT & NT & NT & WT & NT & MT & NT \\
\hline Parathion ethyl & $156-38-2$ & $0.11 \mathrm{UJ}$ & $0.11 \mathrm{UJ}$ & $0.11 \mathrm{UJ}$ & $0.11 \mathrm{UJ}$ & $0.11 \mathrm{uJ}$ & $0.11 \mathrm{UJ}$ & $0.10 \mathrm{UJ}$ & 0.10 UJ & $0.10 \mathrm{UJ}$ \\
\hline Parathion methyl & $298-00-0$ & $0.11 \mathrm{UJ}$ & $0.11 \mathrm{UJ}$ & $0.11 \mathrm{uJ}$ & $0.11 \mathrm{UJ}$ & $0.11 \mathrm{UJ}$ & $0.11 \mathrm{UJ}$ & $0.10 \mathrm{Ud}$ & $0.10 \mathrm{Ud}$ & $0.10 \mathrm{Ud}$ \\
\hline Phorate & $298-02-2$ & $0.06 \mathrm{UJ}$ & 0.06 UJ & $0.05 \mathrm{UJ}$ & $0.05 \mathrm{UJ}$ & $0.05 \mathrm{UJ}$ & $0.06 \mathrm{UJ}$ & 0.05 UJ & $0.05 \mathrm{Ud}$ & 0.05 UJ \\
\hline Ronnel & $299-84-3$ & NT & NT & NT & NT & NT & NT & NT & MT & NT \\
\hline Sul fot epp & $3689-24-5$ & $0.06 \mathrm{UJ}$ & $0.06 \mathrm{UJ}$ & $0.05 \mathrm{UJ}$ & $0.05 \mathrm{UJ}$ & 0.05 UJ & $0.06 \mathrm{UJ}$ & $0.05 \mathrm{UJ}$ & 0.05 UJ & $0.05 \mathrm{UJ}$ \\
\hline Sulprofos & $35400-43-2$ & NT & NT & NT & ผT & HT & NT & MT & MT & NT \\
\hline IEPP & $21646-99-1$ & NT & NT & NT & NT & NT & NT & MT & MT & HT \\
\hline Tetrachlorvinphos & $22248-79-9$ & NT & NT & NT & NT & NT & MT & MT & MT & MT \\
\hline Thionazin & $297-97-2$ & 0.06 uJ & $0.06 \mathrm{uJ}$ & $0.05 \mathrm{UJ}$ & $0.05 \mathrm{UJ}$ & $0.05 \mathrm{UJ}$ & $0.06 \mathrm{UJ}$ & $0.05 \mathrm{UJ}$ & $0.05 \mathrm{UJ}$ & $0.05 \mathrm{UJ}$ \\
\hline Trichloronate & $327-98-0$ & NI & NT & NT & NT & MT & Мा & MT & NT & NT \\
\hline $0,0,0$-Triethylphos & $126-68-1$ & $0.03 \mathrm{UJ}$ & $0.03 \mathrm{UJ}$ & $0.03 \mathrm{UJ}$ & $0.03 \mathrm{us}$ & $0.03 \mathrm{UJ}$ & $0.03 \mathrm{UJ}$ & $0.025 \mathrm{UJ}$ & $0.03 \mathrm{UJ}$ & $0.03 \mathrm{UJ}$ \\
\hline
\end{tabular}


Table A-3. B-Pond Phase 3 Organophosphorous Pesticides. (mg/Kg)

\begin{tabular}{|c|c|c|c|c|c|c|c|c|c|c|}
\hline ANALYTE & CAS* & B00GS4 & Bo0Gs9 & B00GI7 & B00GV5 & Bo0GV6 & BooGV7 & BOOGVB & 800GV9 & BOOGWO \\
\hline & TYPE & Reg & Reg & Reg & Reg & Reg & Reg & Reg & Blank & Reg \\
\hline & POND & $3 A$ & $3 A$ & $3 A$ & $3 \lambda$ & $3 B$ & 3B & 38 & 38 & 3B \\
\hline & DEPIH & 53 & 66.5 & 97 & 143.5 & 1 & 3.5 & 5.5 & $\cdots$ & 7.5 \\
\hline Azinphos methly & $86-50-0$ & NT & NT & MT & NT & NT & NT & NT & MT & NT \\
\hline Chlorpyrifos & $2981-88-2$ & NT & MT & NT & NT & MT & NT & MT & MT & WT \\
\hline Chlorpyrifos methyl & $5598-13-0$ & NT & MT & NI & NT & NT & NT & MT & MT & NT \\
\hline Coumaphos & $56-72-4$ & NT & NT & NT & NT & NT & MT & NT & MT & MT \\
\hline Demeton & $8065-48-3$ & NT & MT & NT & NT & MT & MT & MT & MT & NT \\
\hline Diazanon & $333-41-5$ & NT & MT & NT & NT & NT & NT & MT & MT & NT \\
\hline DDVP (Dichlorvos) & $62-73-7$ & NT & MT & NI & NT & MT & MT & NT & MT & MT \\
\hline Dimethoate & $60-51-5$ & 0.13 US & $0.11 \mathrm{UJ}$ & $0.10 \mathrm{UJ}$ & $0.11 \mathrm{UJ}$ & $0.10 \mathrm{UJ}$ & $0.10 \mathrm{UJ}$ & $0.10 \mathrm{US}$ & $0.10 \mathrm{UJ}$ & 0.11 Ud \\
\hline Disul foton & $298-04-4$ & 0.06 UJ & $0.05 \mathrm{UJ}$ & 0.05 Ud & 0.06 UJ & $0.05 \mathrm{UJ}$ & 0.05 Us & 0.05 UJ & 0.05 UJ & $0.06 \mathrm{UJ}$ \\
\hline EPM & $2104-64-5$ & NT & MT & NT & NT & MT & MT & MT & $M^{T}$ & MT \\
\hline Ethion & $563-12-2$ & NT & NT & NT & NT & NT & NT & MT & MT & NT \\
\hline Ethoprop & $13194-78-4$ & MT & NT & NT & NT & NT & NT & MT & MT & NT \\
\hline Famphur & $52-85-7$ & 0.19 UJ & $0.16 \mathrm{UJ}$ & $0.16 \mathrm{US}$ & $0.17 \mathrm{UJ}$ & $0.16 \mathrm{UJ}$ & $0.16 \mathrm{Ud}$ & 0.16 US & $0.15 \mathrm{UJ}$ & $0.16 \mathrm{UJ}$ \\
\hline Fensul fothion & $115-90-2$ & NT & NT & NT & NT & NT & NT & NT & MT & NT \\
\hline Fenthion & $55-38-9$ & NT & NT & NT & NT & NT & NT & MT & NT & NT \\
\hline Malathion & $121-75-5$ & NT & NT & NT & NT & NT & NT & NT & NT & NT \\
\hline Merphos & $150-50-5$ & NT & NT & NT & NT & NT & MT & NT & MT & HT \\
\hline Mevinphos & $7786-34-7$ & NT & NT & NT & NT & NT & NT & NT & MT & NT \\
\hline Monocrot ophos & $6923-22-4$ & NT & NT & NT & NT & NT & $N T$ & NT & NT & NT \\
\hline
\end{tabular}

(Page 3 of 8 ) 
Table A-3. B-Pond Phase 3 Organophosphorous Pesticides. (mg/ $\mathrm{Kg}$ )

\begin{tabular}{|c|c|c|c|c|c|c|c|c|c|c|}
\hline ANALYTE & CAS* & B00GS4 & BOOGS9 & 800617 & Bo0GVS & BOOGVG & B00GV7 & 800GV8 & BOOGV9 & BOOGWO \\
\hline & TYPE & Reg & Reg & Reg & Reg & Reg & Reg & Reg & Blank & Reg \\
\hline & POND & $3 A$ & $3 A$ & $3 n$ & $3 A$ & 38 & $3 B$ & 38 & 3B & 3B \\
\hline & DEPTH & 53 & 66.5 & 97 & 143.5 & 1 & 3.5 & 5.5 & $\cdots$ & 7.5 \\
\hline Naled & $300-76-5$ & NT & NT & NT & wT & MT & MT & MT & MT & NT \\
\hline Parathion ethyl & $156-38-2$ & 0.13 UJ & $0.11 \mathrm{uJ}$ & $0.10 \mathrm{UJ}$ & 0.11 u & $0.10 \mathrm{UJ}$ & $0.10 \mathrm{uJ}$ & $0.10 \mathrm{UJ}$ & $0.10 \mathrm{UJ}$ & 0.11 us \\
\hline Parathion methyl & $298-00-0$ & 0.13 UJ & 0.11 UJ & $0.10 \mathrm{UJ}$ & $0.11 \mathrm{UJ}$ & $0.10 \mathrm{UJ}$ & $0.10 \mathrm{UJ}$ & $0.10 \mathrm{UJ}$ & $0.10 \mathrm{UJ}$ & 0.11 uJ \\
\hline Phorate & $298-02-2$ & $0.06 \mathrm{UJ}$ & $0.05 \mathrm{UJ}$ & 0.05 UJ & 0.06 UJ & $0.05 \mathrm{UJ}$ & 0.05 us & 0.05 uJ & 0.05 us & $0.06 \mathrm{UJ}$ \\
\hline Romel & $299-84-3$ & NT & NT & NT & MT & NT & NT & MT & NT & NT \\
\hline Sul fot epp & $3689-24-5$ & $0.06 \mathrm{UJ}$ & 0.05 UJ & 0.05 UJ & $0.06 \mathrm{uJ}$ & $0.05 \mathrm{UJ}$ & 0.05 UJ & $0.05 \mathrm{UJ}$ & 0.05 UJ & $0.06 \mathrm{UJ}$ \\
\hline Sutprofos & $35400-43-2$ & NT & NT & NT & MT & NT & MT & MT & MT & MI \\
\hline TEPP & $21646-99-1$ & NT & NT & NT & NT & MT & NT & MT & MT & MT \\
\hline Tetrachlorvinghos & $22248-79-9$ & NT & MT & NT & MT & NT & NT & MT & NT & NT \\
\hline Thionazin & $297-97-2$ & $0.06 \mathrm{UJ}$ & 0.05 UJ & $0.05 \mathrm{uJ}$ & 0.06 UJ & 0.05 us & 0.05 uJ & $0.05 \mathrm{UJ}$ & $0.05 \mathrm{UJ}$ & $0.06 \mathrm{UJ}$ \\
\hline Trichloronate & $327-98-0$ & NT & NT & NT & NT & NT & NT & MT & NT & NT \\
\hline $0,0,0$-Iriethylphos phorothioate & $126-68-1$ & $0.03 \mathrm{uJ}$ & $0.03 \mathrm{UJ}$ & $0.03 \mathrm{UJ}$ & $0.03 \mathrm{uJ}$ & $0.03 \mathrm{uJ}$ & $0.03 \mathrm{uJ}$ & $0.03 \mathrm{UJ}$ & $0.025 \mathrm{UJ}$ & $0.03 \mathrm{UJ}$ \\
\hline
\end{tabular}


Table A-3. B-Pond Phase 3 Organophosphorous Pesticides. (mg/Kg)

\begin{tabular}{|c|c|c|c|c|c|c|c|c|c|c|}
\hline ANALYTE & CAS* & B00GHI & BOOGW3 & $800 G{ }_{4}$ & 800GU8 & B00GX6 & B0OGZ2 & B00GZ6 & B00Gz8 & ВоОНОО \\
\hline & TYPE & Reg & Reg & Fodup & Reg & Reg & Reg & Reg & Reg & Reg \\
\hline & POND & 3B & 38 & 38 & 38 & 38 & $3 B$ & 38 & 3B & $3 c$ \\
\hline & DEPIH & 9.5 & 13 & 13 & 21 & 61.5 & 90.5 & 118.5 & 123.5 & 1 \\
\hline Azinphos methly & $86-50-0$ & NT & HT & NT & NT & $0.21 \mathrm{uJ}$ & $0.21 \mathrm{UJ}$ & $0.24 \mathrm{UJ}$ & $0.24 \mathrm{UJ}$ & $0.21 \mathrm{UJ}$ \\
\hline Chlorpyrifos & $2981-88-2$ & NT & NT & NT & NT & $0.05 \mathrm{UJ}$ & $0.05 \mathrm{UJ}$ & $0.06 \mathrm{UJ}$ & $0.06 \mathrm{Ud}$ & $0.05 \mathrm{UJ}$ \\
\hline Chlorpyrifos methyl & $5598-13-0$ & NT & NT & NT & NT & $0.05 \mathrm{UJ}$ & $0.05 \mathrm{UJ}$ & $0.06 \mathrm{UJ}$ & 0.06 id & $0.05 \mathrm{UJ}$ \\
\hline Coumaphos & $56-72-4$ & NT & NT & NT & NT & $0.21 \mathrm{uJ}$ & $0.21 \mathrm{uJ}$ & $0.26 \mathrm{UJ}$ & $0.24 \mathrm{UJ}$ & $0.21 \mathrm{UJ}$ \\
\hline Demeton & $8065-48-3$ & NT & NT & NT & NT & 0.1 uJ & 0.1 us & $0.12 \mathrm{UJ}$ & $0.12 \mathrm{UJ}$ & $0.1 \mathrm{UJ}$ \\
\hline Diazanon & $333-41-5$ & NT & NT & NT & NT & 0.05 UJ & $0.05 \mathrm{UJ}$ & 0.06 UJ & $0.06 \mathrm{UJ}$ & 0.05 UJ \\
\hline DDVP (Dichlorvos) & $62-73-7$ & NT & NT & NT & MT & 0.1 UJ & $0.1 \mathrm{uJ}$ & $0.12 \mathrm{UJ}$ & $0.12 \mathrm{UJ}$ & $0.1 \mathrm{uJ}$ \\
\hline Dimethoate & $60-51-5$ & $0.10 \mathrm{UJ}$ & $0.10 \mathrm{uJ}$ & $0.10 \mathrm{UJ}$ & $0.10 \mathrm{uJ}$ & 0.1 UJ & $0.1 \mathrm{uJ}$ & $0.12 \mathrm{UJ}$ & 0.12 uJ & 0.1 uJ \\
\hline Disulfot on & $298-04-4$ & $0.05 \mathrm{UJ}$ & $0.05 \mathrm{UJ}$ & $0.05 \mathrm{uJ}$ & $0.05 \mathrm{UJ}$ & $0.05 \mathrm{UJ}$ & 0.05 UJ & $0.06 \mathrm{us}$ & $0.06 \mathrm{Ud}$ & $0.05 \mathrm{uJ}$ \\
\hline EPN & $2104-64-5$ & NT & MT & NT & NT & $0.05 \mathrm{UJ}$ & $0.05 \mathrm{UJ}$ & $0.06 \mathrm{UJ}$ & $0.06 \mathrm{UJ}$ & $0.05 \mathrm{UJ}$ \\
\hline Ethion & $563-12-2$ & NT & NT & NT & NT & $0.05 \mathrm{UJ}$ & 0.05 UJ & $0.06 \mathrm{UJ}$ & $0.06 \mathrm{UJ}$ & $0.05 \mathrm{uJ}$ \\
\hline Ethoprop & $13194-78-4$ & NT & MT & NT & NT & $0.1 \mathrm{UJ}$ & 0.1 UJ & $0.12 \mathrm{UJ}$ & 0.12 UJ & $0.1 \mathrm{uJ}$ \\
\hline Famphur & $52-85-7$ & $0.16 \mathrm{UJ}$ & $0.16 \mathrm{UJ}$ & $0.16 \mathrm{UJ}$ & $0.16 \mathrm{UJ}$ & MT & NT & NT & MT & NT \\
\hline Fensul fothion & $115-90-2$ & NT & MT & NT & NT & $0.1 \mathrm{uJ}$ & 0.1 UJ & 0.12 Us & 0.12 Us & $0.1 \mathrm{uJ}$ \\
\hline Fenthion & $55-38-9$ & NT & NT & NT & NT & 0.05 UJ & $0.05 \mathrm{UJ}$ & $0.06 \mathrm{UJ}$ & $0.06 \mathrm{UJ}$ & 0.05 UJ \\
\hline Malathion & $121-75-5$ & NT & NT & NI & NT & 0.05 UJ & 0.05 UJ & $0.06 \mathrm{UJ}$ & $0.06 \mathrm{UJ}$ & $0.05 \mathrm{UJ}$ \\
\hline Merphos & $150-50-5$ & NT & NT & NT & NT & $0.1 \mathrm{uJ}$ & 0.1 UJ & $0.12 \mathrm{UJ}$ & $0.12 \mathrm{UJ}$ & $0.1 \mathrm{us}$ \\
\hline Mevinphos & $7786-34-7$ & NT & NT & NT & NT & $0.1 \mathrm{uJ}$ & $0.1 \mathrm{uJ}$ & $0.12 \mathrm{UJ}$ & 0.12 UJ & $0.1 \mathrm{uJ}$ \\
\hline Monocrotophos & $6923-22-4$ & NT & NT & NT & NT & $0.21 \mathrm{UJ}$ & $0.21 \mathrm{UJ}$ & $0.24 \mathrm{UJ}$ & $0.24 \mathrm{UJ}$ & $0.21 \mathrm{UJ}$ \\
\hline
\end{tabular}


Table A-3. B-Pond Phase 3 Organophosphorous Pesticides. (mg/Kg)

\begin{tabular}{|c|c|c|c|c|c|c|c|c|c|c|}
\hline AMALYTE & CAS\# & B0OGW1 & B00GW3 & BOOGW4 & BOOGWB & $800 \mathrm{G} \times 6$ & B00G22 & 800626 & B00G28 & воОноО \\
\hline & TYPE & Reg & Reg & folup & Reg & Reg & Reg & Reg & Reg & Reg \\
\hline & POND & 38 & $3 B$ & 38 & $3 B$ & 3B & 38 & 38 & $3 B$ & $3 c$ \\
\hline & DEPTH & 9.5 & 13 & 13 & 21 & 61.5 & 90.5 & 118.5 & 123.5 & 1 \\
\hline Naled & $300-76-5$ & NT & MT & NT & NT & 0.21 UJ & $0.21 \mathrm{UJ}$ & $0.24 \mathrm{UJ}$ & 0.24 Us & $0.21 \mathrm{UJ}$ \\
\hline Parathion ethyl & $156-38-2$ & $0.10 \mathrm{uJ}$ & $0.10 \mathrm{UJ}$ & $0.10 \mathrm{UJ}$ & 0.10 us & 0.05 UJ & 0.05 us & 0.06 UJ & $0.06 \mathrm{UJ}$ & 0.05 UJ \\
\hline Parathion methyt & $298-00-0$ & 0.10 us & $0.10 \mathrm{UJ}$ & $0.10 \mathrm{UJ}$ & $0.10 \mathrm{UJ}$ & 0.05 UJ & 0.05 uJ & 0.06 UJ & $0.06 \mathrm{UJ}$ & 0.05 uJ \\
\hline Phorate & $298-02-2$ & 0.05 UJ & 0.05 UJ & 0.05 UJ & $0.05 \mathrm{UJ}$ & 0.05 us & 0.05 UJ & $0.06 \mathrm{UJ}$ & 0.06 UJ & $0.05 \mathrm{uJ}$ \\
\hline Ronnel & $299-84-3$ & NT & NT & NT & NT & 0.05 UJ & $0.05 \mathrm{UJ}$ & 0.06 UJ & 0.06 UJ & 0.05 UJ \\
\hline Sul fotepp & $3689-24-5$ & 0.05 UJ & 0.05 UJ & 0.05 UJ & 0.05 UJ & 0.05 uJ & 0.05 UJ & $0.06 \mathrm{UJ}$ & 0.06 UJ & $0.05 \mathrm{UJ}$ \\
\hline Sulprofos & $35400-43-2$ & NT & WT & NT & MT & 0.05 UJ & 0.05 UJ & 0.06 UJ & 0.06 UJ & $0.05 \mathrm{UJ}$ \\
\hline IEPP & 21646-99-1 & NT & MT & NT & MT & 0.21 uJ & 0.21 UJ & 0.24 UJ & $0.24 \mathrm{UJ}$ & 0.21 UJ \\
\hline Tetrachlorvinghos & $22248-79-9$ & NT & MT & NT & NT & $0.26 \mathrm{UJ}$ & $0.26 \mathrm{UJ}$ & $0.30 \mathrm{UJ}$ & 0.31 us & $0.26 \mathrm{UJ}$ \\
\hline Thionazin & $297-97-2$ & 0.05 UJ & 0.05 UJ & 0.05 UJ & 0.05 UJ & NT & NT & MT & MT & NT \\
\hline Irichloronate & $327-98-0$ & NT & NT & NT & MT & $0.05 \mathrm{UJ}$ & 0.05 uJ & $0.06 \mathrm{UJ}$ & $0.06 \mathrm{uJ}$ & $0.05 \mathrm{UJ}$ \\
\hline $0,0,0$-Iriethylphos phorothioate & $126-68-1$ & 0.03 us & $0.03 \mathrm{UJ}$ & 0.03 UJ & 0.03 us & NT & WT & MT & NT & NT \\
\hline
\end{tabular}


Table A-3. B-Pond Phase 3 Organophosphorous Pesticides. (mg/Kg)

\begin{tabular}{|c|c|c|c|c|c|c|c|c|c|c|c|}
\hline AMALYIE & CAS: & воОно1 & ВоОНО2 & воОно3 & 80OHO4 & 800н05 & воОно6 & BOOH14 & воОн10 & ВоОн19 & 800423 \\
\hline & TYPE & Reg & Reg & Reg & Reg & Fdup & Reg & Reg & Blank & Reg & Reg \\
\hline & POND & $3 c$ & $3 c$ & $3 c$ & $3 c$ & $3 c$ & $3 c$ & $3 c$ & $3 c$ & $3 c$ & $3 c$ \\
\hline & DEPIH & 3 & 5 & 7 & 9 & 9 & 11.5 & 30 & $\cdots$ & 60 & 80 \\
\hline Azinphos methly & $86-50-0$ & $0.21 \mathrm{UJ}$ & $0.21 \mathrm{UJ}$ & $0.21 \mathrm{UJ}$ & $0.21 \mathrm{UJ}$ & $0.21 \mathrm{uJ}$ & $0.22 \mathrm{UJ}$ & $0.21 \mathrm{UJ}$ & $0.20 \mathrm{UJ}$ & $0.21 \mathrm{UJ}$ & $0.21 \mathrm{UJ}$ \\
\hline Chlorpyrifos & $2981-88-2$ & $0.05 \mathrm{UJ}$ & 0.05 UJ & 0.05 UJ & $0.05 \mathrm{UJ}$ & 0.05 UJ & $0.05 \mathrm{UJ}$ & 0.05 US & $0.05 \mathrm{UJ}$ & 0.05 UJ & $0.05 \mathrm{UJ}$ \\
\hline Chlorpyrifos methyl & 5598-13-0 & $0.05 \mathrm{UJ}$ & 0.05 us & 0.05 UJ & $0.05 \mathrm{UJ}$ & 0.05 UJ & 0.05 UJ & $0.05 \mathrm{UJ}$ & 0.05 UJ & 0.05 UJ & $0.05 \mathrm{UJ}$ \\
\hline Coumaphos & $56-72-4$ & 0.21 UJ & 0.21 UJ & $0.21 \mathrm{UJ}$ & $0.21 \mathrm{UJ}$ & $0.21 \mathrm{UJ}$ & $0.22 \mathrm{UJ}$ & 0.21 us & $0.20 \mathrm{UJ}$ & $0.21 \mathrm{UJ}$ & $0.21 \mathrm{UJ}$ \\
\hline Demeton & $8065-48-3$ & 0.1 Us & 0.1 UJ & 0.1 us & 0.1 UJ & 0.1 UJ & 0.11 us & 0.11 us & 0.1 UJ & 0.1 us & 0.1 UJ \\
\hline Diazanon & $333-41-5$ & 0.05 UJ & 0.05 UJ & $0.05 \mathrm{UJ}$ & 0.05 UJ & 0.05 UJ & $0.05 \mathrm{UJ}$ & 0.05 UJ & 0.05 UJ & $0.05 \mathrm{UJ}$ & $0.05 \mathrm{UJ}$ \\
\hline DDVP (Dichlorvos) & $62-73-7$ & 0.1 UJ & 0.1 UJ & $0.1 \mathrm{UJ}$ & 0.1 us & 0.1 UJ & $0.11 \mathrm{UJ}$ & 0.11 us & $0.1 \mathrm{UJ}$ & 0.1 uJ & 0.1 us \\
\hline Dimethoate & $60-51-5$ & $0.1 \mathrm{uJ}$ & 0.1 UJ & 0.1 uJ & 0.1 us & 0.1 uJ & 0.11 UJ & 0.11 us & 0.1 UJ & 0.1 us & 0.1 uJ \\
\hline Disulfoton & $298-04-4$ & 0.05 UJ & 0.05 UJ & 0.05 UJ & 0.05 UJ & 0.05 UJ & 0.05 UJ & 0.05 UJ & $0.05 \mathrm{UJ}$ & 0.05 us & $0.05 \mathrm{uJ}$ \\
\hline EPN & $2104-64-5$ & 0.05 UJ & 0.05 UJ & 0.05 UJ & 0.05 UJ & 0.05 UJ & $0.05 \mathrm{UJ}$ & $0.05 \mathrm{UJ}$ & 0.05 UJ & 0.05 Us & 0.05 UJ \\
\hline Ethion & $563-12-2$ & 0.05 UJ & 0.05 UJ & 0.05 UJ & 0.05 Us & 0.05 US & 0.05 UJ & 0.05 us & 0.05 UJ & 0.05 UJ & $0.05 \mathrm{UJ}$ \\
\hline Ethoprop & $13194-78-4$ & 0.1 us & 0.1 us & $0.1 \mathrm{UJ}$ & 0.1 us & $0.1 \mathrm{uJ}$ & $0.11 \mathrm{UJ}$ & 0.11 us & 0.1 UJ & 0.1 us & 0.1 us \\
\hline Famphur & $52-85-7$ & NT & NT & NT & NT & NT & NT & NT & NT & NT & NT \\
\hline Fensul fothion & $115-90-2$ & 0.1 UJ & 0.1 UJ & 0.1 UJ & 0.1 UJ & 0.1 UJ & 0.11 uJ & 0.11 UJ & 0.1 UJ & 0.1 us & 0.1 us \\
\hline Fenthion & $55-38-9$ & 0.05 UJ & 0.05 UJ & 0.05 UJ & $0.05 \mathrm{UJ}$ & $0.05 \mathrm{UJ}$ & 0.05 UJ & $0.05 \mathrm{UJ}$ & 0.05 UJ & 0.05 UJ & 0.05 UJ \\
\hline Malathion & $121-75-5$ & 0.05 UJ & 0.05 UJ & 0.05 UJ & 0.05 UJ & 0.05 Ud & $0.05 \mathrm{UJ}$ & $0.05 \mathrm{UJ}$ & 0.05 US & 0.05 UJ & 0.05 UJ \\
\hline Merphos & $150-50-5$ & 0.1 uJ & 0.1 UJ & 0.1 UJ & $0.1 \mathrm{uJ}$ & 0.1 UJ & 0.11 UJ & $0.11 \mathrm{UJ}$ & $0.1 \mathrm{UJ}$ & 0.1 uJ & 0.1 us \\
\hline Mevinphos & $7786-34-7$ & 0.1 UJ & 0.1 UJ & $0.1 \mathrm{UJ}$ & 0.1 UJ & 0.1 Us & 0.11 us & 0.11 UJ & $0.1 \mathrm{uJ}$ & 0.1 us & 0.1 UJ \\
\hline Monocrotophos & $6923-22-4$ & $0.21 \mathrm{UJ}$ & 0.21 UJ & $0.21 \mathrm{UJ}$ & $0.21 \mathrm{UJ}$ & 0.21 UJ & $0.22 \mathrm{UJ}$ & $0.21 \mathrm{UJ}$ & $0.20 \mathrm{UJ}$ & $0.21 \mathrm{uJ}$ & $0.21 \mathrm{UJ}$ \\
\hline
\end{tabular}

(Page 7 of 8 ) 
Table A-3. B-Pond Phase 3 Organophosphorous Pesticides. (mg/Kg)

\begin{tabular}{|c|c|c|c|c|c|c|c|c|c|c|c|}
\hline ANALYIE & CAS\# & ВООНО1 & ВоОно2 & ВоОНО3 & В0OHO4 & ВоОн05 & ВоОНО6 & 80ОН14 & $800 \mathrm{HO}$ & ВООН19 & $800 \mathrm{H} 23$ \\
\hline & IYPE & Reg & Reg & Reg & Reg & Fodp & Reg & Reg & Blank & Reg & Reg \\
\hline & POND & $3 c$ & $3 c$ & $3 c$ & $3 c$ & 3c & $3 c$ & $3 c$ & $3 c$ & $3 c$ & $3 c$ \\
\hline & DEPTH & 3 & 5 & 7 & 9 & 9 & 11.5 & 30 & $\cdots$ & 60 & 80 \\
\hline Naled & $300-76-5$ & $0.21 \mathrm{uJ}$ & $0.21 \mathrm{UJ}$ & $0.21 \mathrm{uJ}$ & $0.21 \mathrm{uJ}$ & $0.21 \mathrm{uJ}$ & $0.22 \mathrm{uJ}$ & $0.21 \mathrm{uJ}$ & $0.20 \mathrm{UJ}$ & $0.21 \mathrm{uJ}$ & $0.21 \mathrm{UJ}$ \\
\hline Parathion ethyl & $156-38-2$ & $0.05 \mathrm{UJ}$ & 0.05 Us & $0.05 \mathrm{UJ}$ & $0.05 \mathrm{UJ}$ & $0.05 \mathrm{UJ}$ & $0.05 \mathrm{UJ}$ & $0.05 \mathrm{UJ}$ & $0.05 \mathrm{UJ}$ & $0.05 \mathrm{UJ}$ & $0.05 \mathrm{UJ}$ \\
\hline Parathion methyl & $298-00-0$ & $0.05 \mathrm{UJ}$ & $0.05 \mathrm{UJ}$ & $0.05 \mathrm{uJ}$ & $0.05 \mathrm{UJ}$ & $0.05 \mathrm{UJ}$ & $0.05 \mathrm{uJ}$ & $0.05 \mathrm{UJ}$ & $0.05 \mathrm{UJ}$ & $0.05 \mathrm{UJ}$ & $0.05 \mathrm{UJ}$ \\
\hline Phorate & $298-02-2$ & $0.05 \mathrm{UJ}$ & $0.05 \mathrm{UJ}$ & $0.05 \mathrm{UJ}$ & $0.05 \mathrm{UJ}$ & $0.05 \mathrm{UJ}$ & $0.05 \mathrm{UJ}$ & $0.05 \mathrm{UJ}$ & $0.05 \mathrm{UJ}$ & $0.05 \mathrm{us}$ & 0.05 UJ \\
\hline Ronnel & $299-84-3$ & $0.05 \mathrm{uJ}$ & $0.05 \mathrm{UJ}$ & $0.05 \mathrm{UJ}$ & $0.05 \mathrm{uJ}$ & $0.05 \mathrm{us}$ & $0.05 \mathrm{UJ}$ & $0.05 \mathrm{UJ}$ & $0.05 \mathrm{UJ}$ & $0.05 \mathrm{uJ}$ & $0.05 \mathrm{uJ}$ \\
\hline Sul f otepp & $3689-24-5$ & $0.05 \mathrm{UJ}$ & $0.05 \mathrm{UJ}$ & $0.05 \mathrm{UJ}$ & $0.05 \mathrm{UJ}$ & $0.05 \mathrm{uJ}$ & $0.05 \mathrm{UJ}$ & $0.05 \mathrm{uJ}$ & 0.05 UJ & $0.05 \mathrm{UJ}$ & $0.05 \mathrm{UJ}$ \\
\hline Sulprofos & $35400-43-2$ & $0.05 \mathrm{UJ}$ & $0.05 \mathrm{UJ}$ & $0.05 \mathrm{UJ}$ & 0.05 Us & $0.05 \mathrm{uJ}$ & $0.05 \mathrm{uJ}$ & $0.05 \mathrm{UJ}$ & $0.05 \mathrm{UJ}$ & $0.05 \mathrm{UJ}$ & $0.05 \mathrm{UJ}$ \\
\hline IEPP & $21646-99-1$ & 0.21 UJ & $0.21 \mathrm{uJ}$ & $0.21 \mathrm{UJ}$ & $0.21 \mathrm{UJ}$ & $0.21 \mathrm{uJ}$ & $0.22 \mathrm{UJ}$ & 0.21 us & $0.20 \mathrm{us}$ & $0.21 \mathrm{uJ}$ & $0.21 \mathrm{UJ}$ \\
\hline Tetrachlorvinphos & $22248-79-9$ & $0.26 \mathrm{UJ}$ & $0.26 \mathrm{UJ}$ & $0.26 \mathrm{UJ}$ & $0.26 \mathrm{UJ}$ & $0.26 \mathrm{UJ}$ & $0.28 \mathrm{UJ}$ & $0.26 \mathrm{UJ}$ & $0.25 \mathrm{Ud}$ & $0.26 \mathrm{UJ}$ & $0.27 \mathrm{UJ}$ \\
\hline Thionazin & $297-97-2$ & NT & NT & NI & NT & MT & NT & NI & HT & MT & MT \\
\hline Irichloronate & $327-98-0$ & $0.05 \mathrm{UJ}$ & 0.05 Us & $0.05 \mathrm{UJ}$ & $0.05 \mathrm{UJ}$ & 0.05 UJ & 0.05 UJ & $0.05 \mathrm{UJ}$ & $0.05 \mathrm{UJ}$ & $0.05 \mathrm{UJ}$ & 0.05 UJ \\
\hline $\begin{array}{l}\text { 0,0,0-Triethylphos } \\
\text { phorothioate }\end{array}$ & $126-68-1$ & NT & NT & NT & NT & NT & NT & NT & КT & NT & NT \\
\hline
\end{tabular}

NT Not a target analyte for this sample, see text.

$U$ The analyte was undetected at the stated limit.

J The associated value is an estimated quantity. 
WHC-SD-EN-AP-104 ReV. 0

Reasons for Westinghouse Hanford Company Qualification--Organophosphorous Pesticides

Regular. Field Duplicate, and Silica Sand Samples:

HOLDING TIME--A11 samples were flagged as estimated, "J". All samples extracted outside 7-day criteria established for water. (A11 samples were analyzed within 40 days of extraction.)

Split Samples:

None. 
Table A-4. B-Pond Phase 3 Dioxins \& Furans. (ng/g)

\begin{tabular}{|c|c|c|c|c|c|c|c|c|c|}
\hline SAMPLE IO & B00FK 6 & B00FK 7 & BOOFKB & BOOFK9 & BOOFLO & 800FL1 & BOOFL3 & BOOFL4 & BOOGR9 \\
\hline TYPE & Reg & Reg & Reg & Reg & Reg & Reg & Blank & Reg & Fodup \\
\hline POND & $3 A$ & $3 A$ & $3 A$ & $3 A$ & $3 A$ & $3 A$ & $3 A$ & $3 A$ & $3 A$ \\
\hline DEPIH & 6.5 & 8.5 & 10.5 & 13 & 14.5 & 16 & $\cdots$ & 28 & 28 \\
\hline $\begin{array}{l}\text { Total tetrachlorinated dibenzo-p-dioxins } \\
\text { (TCDD) }\end{array}$ & $0.062 \mathrm{UJ}$ & $0.060 \mathrm{uJ}$ & $0.056 \mathrm{UJ}$ & $0.11 \mathrm{UJ}$ & 0.071 UJ & $0.068 \mathrm{uJ}$ & 0.042 ud & 0.056 UJ & $0.051 \mathrm{us}$ \\
\hline $\begin{array}{l}\text { Total pentachlorinated dibenzo-p-dioxins } \\
(P e C D O)\end{array}$ & $0.13 \mathrm{UJ}$ & $0.17 \mathrm{UJ}$ & 0.13 UJ & $0.10 \mathrm{UJ}$ & $0.16 \mathrm{UJ}$ & 0.22 UJ & $0.15 \mathrm{UJ}$ & 0.16 UJ & $0.084 \mathrm{UJ}$ \\
\hline $\begin{array}{l}\text { Total hexachlorinated dibenzo-p-dioxins } \\
\text { (HxCDD) }\end{array}$ & $0.12 \mathrm{UJ}$ & $0.18 \mathrm{UJ}$ & $0.13 \mathrm{uJ}$ & $0.40 \mathrm{UJ}$ & 0.17 us & $0.15 \mathrm{UJ}$ & $0.11 \mathrm{UJ}$ & 0.15 UA & $0.18 \mathrm{uJ}$ \\
\hline $\begin{array}{l}\text { Total heptachlorinated dibenzo-p-dioxins } \\
\text { (HPCDD) }\end{array}$ & 0.15 UJ & 0.21 UJ & $0.19 \mathrm{UJ}$ & $0.19 \mathrm{UJ}$ & $0.16 \mathrm{UJ}$ & 0.23 UJ & $0.17 \mathrm{UJ}$ & 0.15 UJ & 0.27 UJ \\
\hline $\begin{array}{l}\text { Total octachlorinated dibenzo-p-dioxins } \\
\text { (OCDD) }\end{array}$ & 0.13 us & $0.21 \mathrm{UJ}$ & $0.13 \mathrm{uJ}$ & $0.11 \mathrm{UJ}$ & $0.16 \mathrm{UJ}$ & $0.17 \mathrm{UJ}$ & 0.15 Ud & $0.15 \mathrm{UJ}$ & $0.21 \mathrm{uJ}$ \\
\hline $\begin{array}{l}\text { Total tetrachlorinated dibenzo-furans } \\
\text { (TCDF) }\end{array}$ & $0.11 \mathrm{UJ}$ & 0.077 ud & $0.058 \mathrm{uJ}$ & 0.085 UJ & 0.071 UJ & 0.079 UJ & $0.061 \mathrm{UJ}$ & $0.055 \mathrm{UJ}$ & $0.047 \mathrm{UJ}$ \\
\hline $\begin{array}{l}\text { Total pentachlorinated dibenzo-furans } \\
\text { (PeCDF) }\end{array}$ & 0.039 UJ & $0.053 \mathrm{UJ}$ & $0.046 \mathrm{UJ}$ & 0.058 UJ & $0.047 \mathrm{UJ}$ & $0.050 \mathrm{UJ}$ & $0.036 \mathrm{UJ}$ & $0.049 \mathrm{UJ}$ & $0.058 \mathrm{UJ}$ \\
\hline $\begin{array}{l}\text { Jotal hexachlorinated dibenzo-furans } \\
\text { (HXCDF) }\end{array}$ & $0.11 \mathrm{uJ}$ & $0.11 \mathrm{UJ}$ & $0.085 \mathrm{UJ}$ & $0.14 \mathrm{UJ}$ & $0.11 \mathrm{UJ}$ & 0.11 UJ & 0.072 UJ & 0.13 UJ & $0.10 \mathrm{UJ}$ \\
\hline $\begin{array}{l}\text { Total heptachlorinated dibenzo-furans } \\
\text { (HPCDF) }\end{array}$ & 0.13 UJ & 0.17 UJ & $0.11 \mathrm{UJ}$ & $0.13 \mathrm{UJ}$ & $0.13 \mathrm{uJ}$ & $0.19 \mathrm{UJ}$ & 0.13 UJ & $0.23 \mathrm{uJ}$ & 0.14 UJ \\
\hline $\begin{array}{l}\text { Total octachlorinated dibenzo-furans } \\
\text { (OCDF) }\end{array}$ & $0.069 \mathrm{UJ}$ & 0.19 UJ & 0.077 UJ & $0.096 \mathrm{uJ}$ & $0.12 \mathrm{UJ}$ & $0.14 \mathrm{UJ}$ & 0.059 UJ & $0.11 \mathrm{UJ}$ & $0.20 \mathrm{UJ}$ \\
\hline
\end{tabular}


Table A-4. B-Pond Phase 3 Dioxins \& Furans. (ng/g)

\begin{tabular}{|c|c|c|c|c|c|c|c|c|c|}
\hline SAMPLE ID & B00GS4 & BOOGS9 & BOOGI7 & Boogv5 & B00GV6 & BoOGV7 & Boogv8 & Boogv9 & BOOGWO \\
\hline TYPE & Reg & Reg & Reg & Reg & Reg & Reg & Reg & Blank & Reg \\
\hline POND & $3 A$ & $3 A$ & $3 A$ & $3 A$ & 38 & 38 & 38 & 3B & 3B \\
\hline DEPTH & 52.5 & 66.5 & 97 & 143.5 & 1 & 3.5 & 5.5 & $\cdots$ & 7.5 \\
\hline $\begin{array}{l}\text { Total tetrachlorinated dibenzo-p-dioxins } \\
\text { (TCDD) }\end{array}$ & $0.17 \mathrm{UJ}$ & 0.12 uJ & 0.063 UJ & 0.086 UJ & 0.070 Ud & 0.044 UJ & $0.036 \mathrm{UJ}$ & $0.048 \mathrm{UJ}$ & $0.032 \mathrm{UJ}$ \\
\hline $\begin{array}{l}\text { Total pentachlorinated dibenzo-p-dioxins } \\
\text { (PeCDD) }\end{array}$ & $0.30 \mathrm{UJ}$ & $0.35 \mathrm{UJ}$ & $0.21 \mathrm{uJ}$ & $0.20 \mathrm{UJ}$ & $0.16 \mathrm{UJ}$ & 0.12 UJ & 0.087 UJ & $0.11 \mathrm{uJ}$ & 0.057 UJ \\
\hline $\begin{array}{l}\text { Total hexachlorinated dibenzo-p-dioxins } \\
\text { (HXCDD) }\end{array}$ & $0.29 \mathrm{uJ}$ & $0.25 \mathrm{UJ}$ & $0.14 \mathrm{UJ}$ & $0.28 \mathrm{UJ}$ & $0.19 \mathrm{uJ}$ & $0.15 \mathrm{UJ}$ & $0.15 \mathrm{UJ}$ & $0.14 \mathrm{UJ}$ & $0.098 \mathrm{UJ}$ \\
\hline $\begin{array}{l}\text { Total heptachlorinated dibenzo-p-dioxins } \\
\text { (HPCDD) }\end{array}$ & 0.24 UJ & 0.27 UJ & 0.13 UJ & 0.14 UJ & 0.19 uJ & $0.12 \mathrm{UJ}$ & 0.11 UJ & 0.13 UJ & $0.11 \mathrm{UJ}$ \\
\hline $\begin{array}{l}\text { Total octachlorinated dibenzo-p-dioxins } \\
\text { (OCDD) }\end{array}$ & $0.23 \mathrm{UJ}$ & 0.27 us & $0.12 \mathrm{UJ}$ & $0.090 \mathrm{UJ}$ & $0.25 \mathrm{uJ}$ & $0.15 \mathrm{UJ}$ & $0.12 \mathrm{UJ}$ & 0.067 Ud & $0.13 \mathrm{UJ}$ \\
\hline $\begin{array}{l}\text { Total tetrachlorinated dibenzo-furans } \\
\text { (ICDF) }\end{array}$ & $0.14 \mathrm{UJ}$ & $0.16 \mathrm{UJ}$ & $0.058 \mathrm{UJ}$ & 0.084 UJ & 0.051 UJ & $0.038 \mathrm{UJ}$ & 0.033 UJ & $0.038 \mathrm{US}$ & $0.033 \mathrm{Ud}$ \\
\hline $\begin{array}{l}\text { Total pentachlorinated dibenzo-furans } \\
\text { (PeCDF) }\end{array}$ & $0.069 \mathrm{UJ}$ & $0.067 \mathrm{UJ}$ & 0.057 UJ & 0.052 UJ & 0.082 UJ & 0.035 UJ & $0.036 \mathrm{US}$ & $0.051 \mathrm{UJ}$ & 0.046 UJ \\
\hline $\begin{array}{l}\text { Total hexachlorinated dibenzo-furans } \\
\text { (HxCDF) }\end{array}$ & $0.084 \mathrm{UJ}$ & 0.15 UJ & 0.086 UJ & 0.072 UJ & $0.10 \mathrm{UJ}$ & 0.094 UJ & $0.093 \mathrm{UJ}$ & 0.095 UJ & $0.073 \mathrm{UJ}$ \\
\hline $\begin{array}{l}\text { Total heptachlorinated dibenzo-furans } \\
\text { (HpCDF) }\end{array}$ & $0.15 \mathrm{UJ}$ & $0.14 \mathrm{UJ}$ & $0.23 \mathrm{UJ}$ & $0.12 \mathrm{UJ}$ & $0.14 \mathrm{UJ}$ & $0.097 \mathrm{UJ}$ & 0.093 UJ & $0.16 \mathrm{UJ}$ & $0.084 \mathrm{UJ}$ \\
\hline $\begin{array}{l}\text { Jotal octachlorinated dibenzo-furans } \\
\text { (OCDF) }\end{array}$ & 0.030 UJ & $0.19 \mathrm{UJ}$ & 0.12 uJ & $0.13 \mathrm{uJ}$ & $0.21 \mathrm{uJ}$ & $0.10 \mathrm{UJ}$ & $0.13 \mathrm{UJ}$ & $0.13 \mathrm{UJ}$ & $0.066 \mathrm{UJ}$ \\
\hline
\end{tabular}

(Page 2 of 3 ) 
Table A-4. B-Pond Phase 3 Dioxins \& Furans. (ng/g)

\begin{tabular}{|c|c|c|c|c|c|c|c|}
\hline SAMPLE 10 & B00GU1 & 800G43 & Bo0Gu4 & BOOGW & $800 \mathrm{HOO}$ & ВоОНО2 & 800н03 \\
\hline IYPE & Reg & Reg & Fdep & Reg & Reg & Reg & Reg \\
\hline POND & 38 & 38 & 38 & 38 & $3 c$ & $3 c$ & $3 c$ \\
\hline DEPTH & 9.5 & 13 & 13 & 21 & 1 & 5 & 7 \\
\hline $\begin{array}{l}\text { Total tetrachlorinated dibenzo-p-dioxins } \\
\text { (ICDO) }\end{array}$ & 0.0 .51 us & $0.047 \mathrm{uJ}$ & J.031 UJ & $0.044 \mathrm{UJ}$ & $0.10 \mathrm{us}$ & $0.16 \mathrm{UJ}$ & $0.12 \mathrm{UJ}$ \\
\hline $\begin{array}{l}\text { Total pentachlorinated dibenzo-p-dioxins } \\
\text { (PECDO) }\end{array}$ & 0.080 UJ & $0.12 \mathrm{UJ}$ & $0.090 \mathrm{uJ}$ & $0.13 \mathrm{UJ}$ & $0.15 \mathrm{UJ}$ & 0.12 UJ & $0.38 \mathrm{uJ}$ \\
\hline $\begin{array}{l}\text { rotal hexachlorinated dibenzo-p-dioxins } \\
\text { ( } \mathrm{K} \times \mathrm{CDD})\end{array}$ & $0 .: 1$ UJ & 0.12 UJ & $0.087 \mathrm{uJ}$ & $0.16 \mathrm{UJ}$ & $0.20 \mathrm{us}$ & 0.22 UJ & $0.17 \mathrm{UJ}$ \\
\hline $\begin{array}{l}\text { Total heptachlorinateu dibenzo-p-dioxins } \\
\text { (HPCDD) }\end{array}$ & $0.15 \mathrm{UJ}$ & $0.16 \mathrm{UJ}$ & $0.11 \mathrm{UJ}$ & $0.13 \mathrm{UJ}$ & $0.24 \mathrm{UJ}$ & 0.27 UJ & 0.17 U \\
\hline $\begin{array}{l}\text { Total octachlorinated dibenzo-p-dioxins } \\
(O C D D)\end{array}$ & $0.15 \mathrm{uJ}$ & 0.096 uJ & $0.16 \mathrm{UJ}$ & 0.11 us & $0.23 \mathrm{uJ}$ & $0.32 \mathrm{UJ}$ & $0.15 \mathrm{UJ}$ \\
\hline $\begin{array}{l}\text { Total tetrachlorinated dibenzo-furans } \\
\text { (TCDF) }\end{array}$ & $0.035 \mathrm{UJ}$ & $0.039 \mathrm{UJ}$ & $0.050 \mathrm{UJ}$ & $0.052 \mathrm{UJ}$ & 0.062 Us & 0.077 us & $0.067 \mathrm{uJ}$ \\
\hline $\begin{array}{l}\text { Total pentachlorinated dibenzo-furans } \\
\text { (PeCDF) }\end{array}$ & $0.047 \mathrm{UJ}$ & $0.038 \mathrm{~J}$ & $0.045 \mathrm{UJ}$ & $0.035 \mathrm{UJ}$ & 0.19 UJ & 0.10 UJ & $0.11 \mathrm{uJ}$ \\
\hline $\begin{array}{l}\text { Total hexachlorinoted dibenzo-furans } \\
\text { (HXCDF) }\end{array}$ & $0.11 \mathrm{uJ}$ & $0.088 \mathrm{UJ}$ & $0.066 \mathrm{UJ}$ & $0.11 \mathrm{uJ}$ & $0.23 \mathrm{UJ}$ & $0.15 \mathrm{uJ}$ & $0.18 \mathrm{UJ}$ \\
\hline $\begin{array}{l}\text { Total heptachlorinated dibenzo-furans } \\
\text { (HPCDF) }\end{array}$ & $0.10 \mathrm{UJ}$ & $0.10 \mathrm{UJ}$ & 0.079 UJ & $0.082 \mathrm{ld}$ & $0.53 \mathrm{UJ}$ & $0.19 \mathrm{UJ}$ & $0.32 \mathrm{us}$ \\
\hline $\begin{array}{l}\text { Total octachlorinated dibenzo-furans } \\
\text { (OCDF) }\end{array}$ & $0.094 \mathrm{uJ}$ & $0.16 \mathrm{uJ}$ & $0.11 \mathrm{UJ}$ & $0.13 \mathrm{UJ}$ & $0.16 \mathrm{UJ}$ & $0.23 \mathrm{uJ}$ & $0.12 \mathrm{UJ}$ \\
\hline
\end{tabular}

$U$ The onalyte was undetected at the stated limit.

J The associated value is an est imated quantity.

(Page 3 of 3 ) 
WHC-SD-EN-AP-104 Rev. 0

Reasons for Westinghouse Hanford Company Qualification--Dioxins and Furans

Regular. Field Duplicate, and Silica Sand Samples:

HOLDING TIME--All samples were flagged as estimated, "J". All samples extracted outside 7-day criteria established for water. (All samples were analyzed within 40 days of extraction.)

Split Samples:

None. 
Table A-5. Volatile Organic Compounds. $(\mu \mathrm{g} / \mathrm{Kg})$

\begin{tabular}{|c|c|c|c|c|c|c|c|c|c|c|c|}
\hline ANALYTE & CASE & 800FK6 & B00FK7 & BOOFK8 & Boofk9 & BOOFLO & BOOFLI & BOOFL3 & BOOFL6 & BOOGR9 & BooGs4 \\
\hline & IYPE & Reg & Reg & Reg & Reg & Reg & Reg & Blank & Reg & Fdep & Reg \\
\hline & POND & $3 n$ & $3 n$ & $3 n$ & $3 A$ & $3 A$ & $3 n$ & $3 n$ & $3 n$ & $3 n$ & $3 n$ \\
\hline & DEPYH & 6.5 & 8.5 & 10.5 & 13 & 14.5 & 16 & $\cdots$ & 28 & 28 & 52.5 \\
\hline & AMALYSIS DATE & $2 / 20 / 91$ & $2 / 20 / 91$ & $2 / 20 / 91$ & $2 / 22 / 91$ & $2 / 22 / 91$ & $2 / 20 / 91$ & $2 / 22 / 91$ & $2 / 28 / 91$ & 2/22/91 & $2 / 20 / 91$ \\
\hline & MOISTURE $(x)$ & 12 & 10.9 & 5.3 & 6.7 & 6.8 & 11.2 & 0.0 & 4.9 & 5.3 & 23.2 \\
\hline Chloromethane & $74-87-3$ & 110 & 110 & 110 & 110 & 110 & $11 \mathrm{v}$ & $10 \mathrm{U}$ & $11 \mathrm{uJ}$ & $11 \mathrm{u}$ & $13 U$ \\
\hline Bromome thane & $74-83-9$ & $11 \mathrm{u}$ & $11 \mathrm{v}$ & $11 \mathrm{u}$ & 110 & $11 \mathrm{U}$ & $11 \mathrm{U}$ & $10 \mathrm{U}$ & 11 us & $11 \mathrm{U}$ & $13 v$ \\
\hline Vinyl chloride & $75-01-4$ & $11 \mathrm{u}$ & $11 \mathrm{v}$ & $11 \mathrm{u}$ & 110 & $11 \mathrm{u}$ & $11 \mathrm{v}$ & $10 \mathrm{U}$ & $11 \mathrm{uJ}$ & $11 \mathrm{U}$ & $13 v$ \\
\hline Chloroethane & $75-00-3$ & 110 & 110 & $11 \mathrm{u}$ & $11 \mathrm{v}$ & $11 \mathrm{u}$ & $11 \mathrm{U}$ & $10 \mathrm{U}$ & $11 \mathrm{uJ}$ & 110 & $13 v$ \\
\hline Methylene Chloride & $75-09-2$ & $6 \mathrm{U}$ & $4 J$ & $3 \mathrm{~J}$ & 50 & $5 \mathrm{U}$ & $6 U$ & $5 \mathrm{U}$ & 5 Us & $5 \mathrm{U}$ & $7 \mathrm{u}$ \\
\hline Acetone & $67-64-1$ & $11 \mathrm{u}$ & 64 & 55 & $11 \mathrm{u}$ & 13 & $11 \mathrm{u}$ & 17 & 11 us & 27 & $13 \mathrm{U}$ \\
\hline Carbon Disulfide & $75 \cdot 15-0$ & $6 \mathrm{U}$ & $6 v$ & $5 u$ & $5 \mathrm{U}$ & $5 \mathrm{u}$ & $6 u$ & $5 \mathrm{U}$ & $5 \mathrm{UJ}$ & $5 \mathrm{U}$ & $7 \mathrm{U}$ \\
\hline 1,1-Dichloroethene & $75-35-6$ & $6 \mathrm{U}$ & $6 v$ & $5 u$ & $5 \mathrm{U}$ & $5 \mathrm{U}$ & $6 u$ & 50 & 5 UJ & $5 \mathrm{U}$ & 70 \\
\hline 1,1-Dichloroethane & $75-34-3$ & $6 \mathrm{U}$ & $6 \mathrm{u}$ & $5 \mathrm{U}$ & 50 & $5 \mathrm{U}$ & $6 \mathrm{U}$ & $5 \mathrm{u}$ & 5 UJ & $5 \mathrm{U}$ & $7 \mathrm{v}$ \\
\hline 1,2-Dichl oroethene (total) & $540-59-0$ & $6 \mathrm{U}$ & $6 u$ & $5 \mathrm{v}$ & $5 \cup$ & $5 \mathrm{U}$ & $6 \mathrm{U}$ & $5 \mathrm{U}$ & 5 uJ & $5 \mathrm{U}$ & $7 \mathrm{v}$ \\
\hline Chloroform & $67-66-3$ & $6 U$ & $6 u$ & 50 & 50 & 50 & $6 U$ & $5 \mathrm{U}$ & 5 UJ & 50 & $7 v$ \\
\hline 1,2-Dichloroethane & $107-06-2$ & $6 u$ & $6 u$ & 50 & $5 \mathrm{U}$ & $5 u$ & $6 U$ & $5 u$ & $5 \mathrm{UJ}$ & 50 & 70 \\
\hline 2-Butanone & $78-93-3$ & $11 \mathrm{u}$ & 110 & $11 u$ & 110 & $11 \mathrm{u}$ & $11 \mathrm{u}$ & $10 \mathrm{u}$ & $11 \mathrm{uJ}$ & $11 \mathrm{U}$ & $13 U$ \\
\hline 1,1,1-Irichloroethane & 71.55 .6 & $6 U$ & 60 & $5 u$ & 50 & $5 \mathrm{u}$ & $6 \mathrm{U}$ & 50 & 5 UJ & 50 & 70 \\
\hline Carbon Tetrachloride & $56-23-5$ & $6 U$ & $6 \mathrm{u}$ & $5 \mathrm{u}$ & 50 & 50 & $6 U$ & $5 \mathrm{U}$ & 5 U. & $5 \mathrm{U}$ & 70 \\
\hline Vinyl Acetate & $108-05-4$ & $11 \mathrm{u}$ & 110 & $11 \mathrm{U}$ & $11 \mathrm{u}$ & $11 \mathrm{v}$ & $11 \mathrm{U}$ & $10 \mathrm{U}$ & $11 \mathrm{uJ}$ & 110 & $13 \mathrm{U}$ \\
\hline Bromodichloromethane & $75-27-4$ & $6 u$ & $6 v$ & 50 & 50 & $5 U$ & $6 \mathrm{U}$ & $5 U$ & 5 ud & 50 & $7 \mathrm{U}$ \\
\hline
\end{tabular}

(Page 1 of 8 ) 
Table A-5. Volatile Organic Compounds. $(\mu \mathrm{g} / \mathrm{Kg})$

\begin{tabular}{|c|c|c|c|c|c|c|c|c|c|c|c|}
\hline ANAL YIE & CAS* & B00FK6 & BOOFK 7 & B00FK8 & BOOFK9 & BOOFLO & BOOFLI & BOOFL3 & B00FL4 & BOOGR9 & B00GS4 \\
\hline & TYPE & Reg & Reg & Reg & Reg & Reg & Reg & Bl ank & Reg & Fodup & Reg \\
\hline & POND & $3 \wedge$ & $3 n$ & $3 A$ & $3 n$ & $3 n$ & $3 n$ & $3 \wedge$ & $3 n$ & $3 \AA$ & $3 \AA$ \\
\hline & DEPTH & 6.5 & 8.5 & 10.5 & 13 & 14.5 & 16 & $\cdots$ & 28 & 28 & 52.5 \\
\hline & ANALYSIS DATE & $2 / 20 / 91$ & $2 / 20 / 91$ & $2 / 20 / 91$ & $2 / 22 / 91$ & $2 / 22 / 91$ & $2 / 20 / 91$ & $2 / 22 / 91$ & $2 / 28 / 91$ & $2 / 22 / 91$ & $2 / 20 / 91$ \\
\hline & MOISTURE $(x)$ & 12 & 10.9 & 5.3 & 6.7 & 6.8 & 11.2 & 0.0 & 4.9 & 5.3 & 23.2 \\
\hline 1,2-Dichloropropane & $78-87-5$ & $6 U$ & $6 \mathrm{U}$ & $5 u$ & $5 \mathrm{v}$ & $5 \mathrm{u}$ & $6 v$ & 50 & $5 \mathrm{UJ}$ & $5 \mathrm{u}$ & $7 v$ \\
\hline cis-1,3-Dichloropropene & $10061-01-5$ & $6 \mathrm{U}$ & $6 v$ & $5 \mathrm{u}$ & 50 & $5 \mathrm{U}$ & $6 u$ & $5 \mathrm{u}$ & 5 US & $5 u$ & $7 \mathrm{U}$ \\
\hline Irichl oroethene & $79-01-6$ & $6 u$ & $6 u$ & 50 & $5 v$ & $5 \mathrm{U}$ & 60 & $5 u$ & 5 uJ & $5 \cup$ & $7 \mathrm{U}$ \\
\hline Dibromochl oromethane & $124-48-1$ & $6 \mathrm{U}$ & $6 u$ & 50 & $5 \mathrm{v}$ & 50 & $6 U$ & $5 \mathrm{v}$ & 5 us & $5 \mathrm{U}$ & 70 \\
\hline 1,1,2-Trichloroethane & $79-00-5$ & $6 \mathrm{U}$ & $6 u$ & $5 \mathrm{u}$ & $5 \mathrm{u}$ & 50 & $6 U$ & 50 & 5 UJ & 50 & $7 \mathrm{u}$ \\
\hline Benzene & $71-43-2$ & $6 u$ & $6 \mathrm{U}$ & $5 \mathrm{u}$ & 50 & $5 \cup$ & $6 \mathrm{U}$ & $5 \mathrm{U}$ & 5 uJ & 50 & $7 \mathrm{U}$ \\
\hline trans-1,3-Dichloropropene & $10061-02-6$ & $6 v$ & $6 U$ & $5 \cup$ & 50 & $5 \mathrm{u}$ & $6 v$ & 5 u & 5 UJ & $5 \cup$ & $7 \mathrm{u}$ \\
\hline Bromoform & $75-25-2$ & $6 \mathrm{U}$ & 60 & $5 \mathrm{u}$ & $5 \mathrm{u}$ & $5 \mathrm{U}$ & $6 v$ & $5 \mathrm{U}$ & 5 UJ & 50 & 70 \\
\hline 4-Methyl-2-pentanone & $108-10-1$ & $11 \mathrm{u}$ & 110 & 110 & $11 \mathrm{u}$ & $11 \mathrm{u}$ & $11 v$ & $10 \cup$ & $11 \mathrm{Ud}$ & 110 & 130 \\
\hline 2-Hexanone & $591-78-6$ & $11 \mathrm{u}$ & 110 & 110 & $11 \mathrm{u}$ & $11 \mathrm{u}$ & $11 \mathrm{U}$ & $10 v$ & $11 \mathrm{UJ}$ & 110 & $13 \mathrm{v}$ \\
\hline Tetrachloroethene & $127-18-4$ & $6 v$ & $6 u$ & $5 \mathrm{u}$ & $5 \mathrm{U}$ & 50 & $6 \mathrm{U}$ & $5 \mathrm{u}$ & 5 us & 50 & 70 \\
\hline 1,1,2,2-Tetrachloroethane & $79-34-5$ & $6 \mathrm{v}$ & 60 & 50 & $5 \mathrm{u}$ & 50 & $6 \mathrm{U}$ & 50 & 5 UJ & $5 \mathrm{v}$ & 70 \\
\hline Toluene & $108-88-3$ & $6 \mathrm{U}$ & $6 \mathrm{U}$ & $5 \mathrm{u}$ & $5 \mathrm{u}$ & $5 u$ & $6 \mathrm{U}$ & 50 & 5 us & $5 u$ & 70 \\
\hline Chlorobenzene & $108-90-7$ & 60 & $6 u$ & $5 \cup$ & 50 & 50 & $6 \mathrm{U}$ & 50 & $5 \mathrm{UJ}$ & $5 u$ & 70 \\
\hline Ethylbenzene & $100-41-4$ & $6 \mathrm{v}$ & $6 v$ & 50 & $5 U$ & $5 U$ & $6 \mathrm{U}$ & $5 \mathrm{U}$ & 5 UJ & $5 U$ & $7 \mathrm{v}$ \\
\hline Styrene & $100-42-5$ & $6 u$ & $6 U$ & 50 & $5 \mathrm{v}$ & $5 \mathrm{U}$ & $6 \mathrm{v}$ & 50 & 5 UJ & 50 & 70 \\
\hline$x y l$ ene (total) & $1330-20-7$ & $6 u$ & $6 u$ & $5 \mathrm{U}$ & $5 u$ & 50 & $6 \mathrm{U}$ & $5 u$ & 5 UJ & $5 \mathrm{U}$ & 70 \\
\hline
\end{tabular}

(Page 2 of 8 ) 
Table A-5. Volatile Organic Compounds. $(\mu \mathrm{g} / \mathrm{Kg})$

\begin{tabular}{|c|c|c|c|c|c|c|c|c|c|c|c|}
\hline AMALYTE & CAS* & Boogss & Bo0G59 & $800 G 57$ & Boogv5 & Bo0Gv6 & BooGv7 & BO0GV8 & Boogv9 & BOOGWO & BOOGW1 \\
\hline & TYPE & Split & Reg & Reg & Reg & Reg & Reg & Reg & Blank & Reg & Reg \\
\hline & POND & $3 n$ & $3 n$ & $3 n$ & $3 A$ & 38 & 38 & 38 & 38 & 38 & 38 \\
\hline & DEPTH & 52.5 & 66.5 & 97 & 143.5 & 1 & 3.5 & 5.5 & $\cdots$ & 7.5 & 9.5 \\
\hline & AMALYSIS DATE & $2 / 26 / 91$ & $2 / 28 / 91$ & $2 / 28 / 91$ & $3 / 4 / 91$ & $3 / 11 / 91$ & $3 / 11 / 91$ & $3 / 11 / 91$ & $3 / 11 / 91$ & $3 / 11 / 81$ & $3 / 11 / 91$ \\
\hline & MOISTURE $(x)$ & 19 & 7.3 & 4.0 & MA & 5.0 & .0 & 5.0 & 0.0 & 0.0 & 3.1 \\
\hline Chloromethane & $74-87-3$ & $12 v$ & 110 & $10 \mathrm{U}$ & $10 u$ & 110 & $10 u$ & 110 & $10 \mathrm{U}$ & $10 \mathrm{U}$ & $10 \mathrm{U}$ \\
\hline Bromome thane & $74-83-9$ & $12 v$ & 110 & $10 \mathrm{U}$ & $10 u$ & 110 & $10 \mathrm{u}$ & 114 & $10 \mathrm{U}$ & $10 \mathrm{U}$ & $10 \mathrm{U}$ \\
\hline Vinyl chloride & $75-01-4$ & $12 u$ & 110 & $10 \mathrm{U}$ & $10 u$ & 110 & $10 \mathrm{U}$ & 110 & $10 \mathrm{U}$ & $10 \mathrm{U}$ & $10 \mathrm{U}$ \\
\hline Chloroethane & $75-00-3$ & $12 u$ & 110 & $10 \mathrm{u}$ & $10 \mathrm{v}$ & 110 & $10 \mathrm{u}$ & $11 \mathrm{U}$ & $10 U$ & $10 u$ & $10 \mathrm{U}$ \\
\hline Methyleme Chloride & $75-09-2$ & $30 \mathrm{v}$ & 50 & 50 & 54 & 50 & 50 & 50 & $5 \mathrm{U}$ & $5 \mathrm{v}$ & 50 \\
\hline Acetone & $67-64-1$ & $18 u$ & 110 & $10 \mathrm{U}$ & $10 \mathrm{U}$ & 110 & $10 \mathrm{v}$ & 110 & $10 U$ & $10 \mathrm{U}$ & $10 \mathrm{U}$ \\
\hline Carbon Disulfide & $75-15-0$ & $6 \mathrm{U}$ & 50 & 50 & $5 U$ & 50 & 50 & 50 & 50 & 50 & 54 \\
\hline 1,1-Dichloroethere & $75-35-4$ & $6 u$ & 50 & 50 & 50 & 50 & 50 & 50 & 50 & 50 & $5 \mathrm{u}$ \\
\hline 1,1-dichloroethane & $75-34-3$ & 60 & 50 & 50 & 50 & 50 & 50 & 50 & 50 & 5 u & 54 \\
\hline 1,2-Dichloroethene (total) & $540-59-0$ & $6 u$ & 50 & 50 & $5 u$ & 54 & $5 u$ & 50 & 50 & 50 & $5 u$ \\
\hline Chloroform & $67-66-3$ & 60 & 50 & 50 & 50 & 50 & 50 & 50 & 50 & 50 & 50 \\
\hline 1,2-Dichloroethane & $107-06-2$ & $6 \mathrm{u}$ & 50 & 50 & $5 \mathrm{u}$ & 50 & 50 & 50 & 50 & 50 & $5 \mathrm{u}$ \\
\hline 2-Butanone & $78-93-3$ & $12 \mathrm{u}$ & 110 & $10 u$ & $10 \mathrm{U}$ & 110 & $10 \mathrm{u}$ & 110 & $10 \mathrm{U}$ & $10 \mathrm{u}$ & $10 \mathrm{U}$ \\
\hline 1,1,1-irichloroethane & $71-55-6$ & 64 & 50 & 50 & 50 & $5 \mathrm{u}$ & 50 & 50 & 50 & $5 \mathrm{v}$ & 50 \\
\hline Carbon Tetrachloride & $56-23-5$ & $6 u$ & 50 & 50 & $5 u$ & 50 & $5 \cup$ & 50 & 50 & $5 \mathrm{u}$ & $5 \mathrm{U}$ \\
\hline Vinyt Acetate & $108-05-4$ & $12 u$ & 110 & $10 \mathrm{u}$ & $10 \mathrm{u}$ & 110 & $10 \mathrm{U}$ & 110 & $10 \mathrm{U}$ & $10 u$ & $10 u$ \\
\hline Bromodichloromethane & $75-27-4$ & $6 \mathrm{U}$ & $5 U$ & 50 & 50 & 5 u & 50 & $5 U$ & 50 & 50 & $5 \mathrm{U}$ \\
\hline
\end{tabular}

(Page 3 of 8 ) 
Table A-5. Volatile Organic Compounds. $(\mu \mathrm{g} / \mathrm{Kg})$

\begin{tabular}{|c|c|c|c|c|c|c|c|c|c|c|c|}
\hline AHALYTE & CAS\# & BO0GS5 & BOOGS9 & B00GI7 & BooGv5 & BOOGV6 & BooGv7 & BOOGV8 & BooGv9 & BOOGNO & B00GU1 \\
\hline & TYPE & Split & Reg & Reg & Reg & Reg & Reg & Reg & Blank & Reg & Reg \\
\hline & POND & $3 n$ & $3 A$ & $3 n$ & $3 n$ & 3B & $3 B$ & 38 & 38 & 38 & 3B \\
\hline & DEPTH & 52.5 & 66.5 & 97 & 143.5 & 1 & 3.5 & 5.5 & $\cdots$ & 7.5 & 9.5 \\
\hline & AMALYSIS DATE & $2 / 26 / 91$ & $2 / 28 / 91$ & $2 / 28 / 91$ & $3 / 4 / 91$ & $3 / 11 / 91$ & $3 / 11 / 91$ & $3 / 11 / 91$ & $3 / 11 / 91$ & $3 / 11 / 91$ & $3 / 11 / 91$ \\
\hline & MOISTURE $(x)$ & 19 & 7.3 & 4.0 & NA & 5.0 & 4.0 & 5.0 & 0.0 & 0.0 & 3.1 \\
\hline 1,2-Dichloropropane & $78-87-5$ & 60 & 50 & $5 u$ & 50 & 50 & 50 & 50 & $5 \mathrm{u}$ & $5 u$ & $5 \mathrm{U}$ \\
\hline cls-1,3-Dichloropropene & $10061-01-5$ & $6 \mathrm{U}$ & $5 \mathrm{U}$ & 50 & $5 u$ & $5 \mathrm{u}$ & 50 & 50 & $5 \mathrm{U}$ & $5 u$ & 50 \\
\hline Irichloroethere & $79-01-6$ & $6 \mathrm{U}$ & $5 \mathrm{u}$ & $5 \mathrm{U}$ & $5 u$ & 50 & $5 \mathrm{u}$ & $5 \mathrm{U}$ & 50 & 50 & 50 \\
\hline Dibromochl oromethane & $124-48-1$ & $6 \mathrm{U}$ & $5 \mathrm{u}$ & 50 & $5 u$ & $5 u$ & 50 & $5 U$ & $5 \mathrm{U}$ & $5 u$ & $5 U$ \\
\hline 1,1,2-Irichloroethane & $79-00-5$ & 60 & $5 \mathrm{u}$ & 50 & 50 & $5 \mathrm{u}$ & $5 \mathrm{U}$ & 50 & 50 & 50 & 50 \\
\hline Benzene & $71-43-2$ & $6 \mathrm{U}$ & 50 & 50 & $5 u$ & 50 & 50 & 50 & $5 \mathrm{u}$ & 50 & 50 \\
\hline trans-1,3-0 ichloropropene & $10061-02-6$ & $6 \mathrm{U}$ & $5 v$ & $5 \mathrm{u}$ & 50 & 50 & $5 \mathrm{U}$ & $5 \mathrm{u}$ & $5 \mathrm{u}$ & 50 & $5 \mathrm{u}$ \\
\hline Bromoform & $75-25-2$ & $6 U$ & 50 & $5 u$ & $5 \mathrm{U}$ & 50 & 50 & 50 & 50 & 50 & 50 \\
\hline 4-Methyl-2-pentanone & $108-10-1$ & $12 u$ & $11 \mathrm{u}$ & $10 \mathrm{U}$ & $3 \mathrm{~J}$ & $11 \mathrm{u}$ & $10 \mathrm{U}$ & $11 \mathrm{v}$ & $10 \mathrm{U}$ & $10 \mathrm{U}$ & $10 u$ \\
\hline 2-Hexanone & $591-78-6$ & $12 \mathrm{v}$ & 110 & $10 \mathrm{U}$ & $10 \mathrm{U}$ & 110 & $10 \mathrm{v}$ & $11 \mathrm{u}$ & $10 \mathrm{U}$ & $10 \mathrm{U}$ & $10 \mathrm{U}$ \\
\hline Tetrachloroethene & $127-18-4$ & $6 \mathrm{U}$ & $5 \mathrm{U}$ & $5 \mathrm{u}$ & 50 & 50 & $5 U$ & $5 \mathrm{U}$ & $5 \mathrm{u}$ & 50 & 50 \\
\hline 1,1,2,2-Tetrachloroethane & $79-34-5$ & 60 & 50 & 50 & $5 \mathrm{v}$ & $5 \mathrm{U}$ & $5 \mathrm{U}$ & 50 & 50 & 50 & 50 \\
\hline Toluene & $108-88-3$ & $6 \mathrm{~V}$ & $5 \mathrm{U}$ & 50 & 50 & $5 \mathrm{U}$ & 50 & $5 \mathrm{U}$ & $5 \mathrm{U}$ & 50 & $5 \mathrm{U}$ \\
\hline Chlorobenzene & $108-90-7$ & $6 U$ & 50 & $5 \mathrm{U}$ & $5 u$ & 50 & 50 & 50 & 50 & 50 & 50 \\
\hline Ethylbenzene & $100-41-4$ & $6 U$ & $5 \mathrm{u}$ & $5 u$ & $5 \mathrm{U}$ & 50 & $5 \mathrm{u}$ & 50 & 50 & 50 & 50 \\
\hline Styrene & $100-42-5$ & $6 U$ & 50 & 50 & $5 u$ & $5 \mathrm{U}$ & $5 u$ & 50 & $5 \mathrm{U}$ & 50 & $5 \mathrm{U}$ \\
\hline xylene (total) & $1330-20-7$ & $6 \mathrm{U}$ & 50 & 50 & $5 u$ & $5 \mathrm{U}$ & 50 & 50 & $5 \mathrm{U}$ & $5 \mathrm{U}$ & 50 \\
\hline
\end{tabular}

(Page 4 of 8 ) 
Table A-5. Volatile Organic Compounds. ( $(\mu \mathrm{g} / \mathrm{Kg})$

\begin{tabular}{|c|c|c|c|c|c|c|c|c|c|c|c|}
\hline AMALYTE & cAs: & BOOGW3 & B00GW4 & BOOGWS & BOOGWB & $8006 \times 6$ & $800 G 22$ & $800 G 26$ & 800628 & ВООНОО & воОно1 \\
\hline & IYPE & Reg & Folup & Split & Reg & Reg & Reg & Reg & Reg & Reg & Reg \\
\hline & POND & 38 & 3B & 38 & 38 & 38 & 38 & 38 & 38 & $3 c$ & 3c \\
\hline & DEPTH & 13 & 13 & 13 & 21 & 61.5 & 90.5 & 118.5 & 123.5 & 1 & 3 \\
\hline & AMALYSIS DATE & $3 / 11 / 91$ & $3 / 11 / 91$ & $3 / 12 / 91$ & $3 / 11 / 91$ & $3 / 21 / 91$ & $3 / 21 / 91$ & $3 / 21 / 91$ & $3 / 22 / 91$ & $3 / 21 / 91$ & $3 / 21 / 91$ \\
\hline & MOISTURE $(x)$ & 3.0 & 3.0 & 3 & 3.1 & 5.4 & 5.0 & 16.7 & 34.5 & 3.9 & 4.8 \\
\hline Chlorome thane & $74-87-3$ & $10 u$ & $10 v$ & $10 U$ & $10 \mathrm{U}$ & 110 & 110 & 130 & $15 \mathrm{u}$ & $10 \mathrm{U}$ & 110 \\
\hline Bromomethane & $74-83-9$ & $10 \mathrm{U}$ & $10 u$ & $10 u$ & $10 \mathrm{U}$ & 110 & 110 & 130 & $15 \mathrm{U}$ & $10 \mathrm{U}$ & 110 \\
\hline Vinyl chloride & $75-01-4$ & $10 v$ & $10 u$ & $10 u$ & $10 u$ & $11 \mathrm{u}$ & 110 & $13 u$ & 150 & $10 \mathrm{U}$ & 110 \\
\hline Chloroethane & $75-00-3$ & $10 u$ & $10 u$ & $10 \mathrm{U}$ & $10 u$ & 110 & 110 & $13 U$ & 150 & $10 \mathrm{U}$ & 110 \\
\hline Methylene chloride & $75-09-2$ & 50 & 50 & $44 \mathrm{U}$ & 50 & 54 & 50 & 60 & 80 & 50 & 50 \\
\hline Acetone & $67-64-1$ & $10 \mathrm{U}$ & $10 U$ & $19 \mathrm{U}$ & $10 \mathrm{U}$ & 110 & 110 & $13 \mathrm{u}$ & 150 & $10 \mathrm{U}$ & 110 \\
\hline Carbon Disul fide & $75-15-0$ & $5 u$ & 50 & $5 u$ & 50 & 50 & 50 & 60 & 84 & $5 \mathrm{u}$ & 50 \\
\hline 1,1-0ichloroethene & $75-35-4$ & 50 & 50 & 50 & 50 & 50 & 54 & 60 & 80 & 50 & $5 v$ \\
\hline 1,1-Dichloroethone & $75-34-3$ & 50 & 50 & 50 & 50 & 50 & 50 & 60 & 80 & 50 & 50 \\
\hline 1,2-Dichloroethene (total) & $540-59-0$ & 50 & 50 & 50 & 50 & 50 & 50 & 60 & $8 \mathrm{u}$ & 50 & 50 \\
\hline Chloroform & $67-66-3$ & $5 \cup$ & 50 & 50 & 50 & 50 & 50 & 60 & 80 & 50 & 50 \\
\hline 1,2-Dichloroethane & $107-06-2$ & 50 & $5 u$ & 50 & 50 & 50 & 50 & 60 & 84 & $5 \mathrm{U}$ & 50 \\
\hline 2-Butanone & $78-93-3$ & $10 u$ & $10 u$ & $10 u$ & $10 u$ & 110 & 110 & $13 \mathrm{U}$ & $15 \mathrm{U}$ & $10 \mathrm{U}$ & 110 \\
\hline 1,1,1-Trichloroethane & $71.55-6$ & $5 \cup$ & 50 & 50 & 50 & 50 & 50 & $6 \mathrm{U}$ & 84 & 50 & 50 \\
\hline Carbon Tetrachloride & $56-23-5$ & 50 & 50 & 50 & $5 \mathrm{U}$ & 50 & 50 & 64 & 80 & 50 & $5 U$ \\
\hline Vinyl Acetate & $108-05-4$ & $10 \mathrm{is}$ & $10 \mathrm{U}$ & $10 u$ & $10 u$ & 110 & $11 \mathrm{u}$ & $13 \mathrm{v}$ & $15 \mathrm{U}$ & $10 u$ & 110 \\
\hline Bromodichloromethane & $75-27-4$ & su & 50 & 50 & 50 & 50 & 50 & 60 & 84 & 50 & 50 \\
\hline
\end{tabular}

(Page 5 of 8 ) 
Table A-5. Volatile Organic Compounds. ( $(\mu \mathrm{g} / \mathrm{Kg})$

\begin{tabular}{|c|c|c|c|c|c|c|c|c|c|c|c|}
\hline ANALYTE & cas* & $800 \mathrm{GH} 3$ & BOOGH4 & BOOGWS & BOOGW8 & $8006 \times 6$ & BO0GZ2 & B00G26 & B00G28 & ВООНОО & ВООНО1 \\
\hline & TYPE & Reg & Focup & split & Reg & Reg & Reg & Reg & Reg & Reg & Reg \\
\hline & POND & 38 & 38 & 38 & 38 & 38 & 38 & 38 & 38 & $3 c$ & 3c \\
\hline & DEPTH & 13 & 13 & 13 & 29 & 61.5 & 90.5 & 118.5 & 123.5 & 1 & 3 \\
\hline & AMALYSIS DATE & $3 / 11 / 91$ & $3 / 11 / 91$ & $3 / 12 / 91$ & $3 / 11 / 91$ & $3 / 21 / 91$ & $3 / 21 / 91$ & $3 / 21 / 91$ & $3 / 22 / 91$ & $3 / 21 / 91$ & $3 / 21 / 91$ \\
\hline & MOISTURE $(x)$ & 3.0 & 3.0 & 3 & 3.1 & 5.4 & 5.0 & 16.7 & 34.5 & 3.9 & 4.8 \\
\hline cis-1,3-Dichloropropene & $10061-01-5$ & 50 & 50 & 50 & 50 & 50 & 50 & 60 & $8 \mathrm{u}$ & 50 & 50 \\
\hline Irichloroethene & $79-01-6$ & 50 & 50 & 50 & 50 & 50 & 50 & 60 & 80 & 50 & 50 \\
\hline D: Dromochl or rome thane & $124-48-1$ & 50 & 50 & $5 \cup$ & 50 & 50 & 50 & 60 & 80 & 50 & 50 \\
\hline 1,1,2-Irichloroethane & $79-00-5$ & 50 & 50 & 50 & 50 & 50 & 50 & 60 & 80 & $5 \mathrm{u}$ & 50 \\
\hline Benzene & $71-43-2$ & $5 u$ & $5 \cup$ & $5 \cup$ & $5 \cup$ & 50 & 50 & 64 & $8 \mathrm{u}$ & 50 & 50 \\
\hline trans-1,3-0ichloropropene & $10061-02-6$ & 50 & 50 & 50 & 50 & 50 & 50 & 60 & 80 & 5 u & 5 U \\
\hline Bromoform & $73-25-2$ & $5 \cup$ & 50 & 50 & 50 & 50 & $5 \mathrm{u}$ & 60 & 80 & 50 & 50 \\
\hline 4-Methyl-2-pentanone & $108-10-1$ & $10 u$ & $10 u$ & $10 \mathrm{U}$ & $10 \mathrm{U}$ & $3 \mathrm{~J}$ & $3 \mathrm{~J}$ & $13 \mathrm{v}$ & 150 & 100 & 110 \\
\hline 2-Hexanone & $591-78-6$ & $10 \mathrm{U}$ & $10 u$ & $10 \mathrm{u}$ & $10 \mathrm{U}$ & 110 & 110 & $13 \mathrm{u}$ & $15 \mathrm{u}$ & $10 \mathrm{U}$ & 110 \\
\hline Tetrachloroethene & $127-18-4$ & 50 & 50 & $5 u$ & 50 & 50 & $5 \mathrm{U}$ & 60 & $8 \mathrm{u}$ & 50 & 50 \\
\hline 1,1,2,2-tetrachloroethane & $79-34-5$ & 50 & 50 & $5 u$ & $5 \mathrm{u}$ & 50 & 50 & 60 & $8 \mathrm{u}$ & 50 & 50 \\
\hline Toluene & $108-88-3$ & 50 & 50 & 50 & 50 & 50 & 50 & 60 & 80 & 50 & 50 \\
\hline Chlorobenzene & $108-90-7$ & 50 & $5 \mathrm{u}$ & 50 & 50 & 5 u & 50 & 60 & $8 \mathrm{u}$ & 50 & $5 \mathrm{U}$ \\
\hline Ethylbenzene & $100-41-4$ & 50 & 50 & 50 & $5 u$ & 50 & 50 & $6 u$ & $8 \mathrm{u}$ & 50 & 50 \\
\hline styrene & $100-42-5$ & 50 & 50 & 50 & 50 & 50 & 50 & 60 & $B \mathrm{u}$ & 50 & 50 \\
\hline$x y$ lene (total) & $1330-20-7$ & 50 & 50 & 5 u & 50 & 50 & 50 & 60 & $8 \mathrm{u}$ & 50 & 50 \\
\hline
\end{tabular}


Table A-5. Volatile Organic Compounds. ( $\mu \mathrm{g} / \mathrm{Kg})$

\begin{tabular}{|c|c|c|c|c|c|c|c|c|c|c|c|}
\hline AKALYTE & CAS\# & ВООНО2 & ВоОНО3 & ВоОно4 & ВоОНО5 & ВоОно6 & воОно7 & BOOH14 & ВООН10 & ВоОн19 & ВоОН23 \\
\hline & IYPE & Reg & Reg & Reg & folup & Reg & Split & Reg & Blank & Reg & Reg \\
\hline & POHD & 3c & $3 c$ & $3 c$ & $3 c$ & $3 c$ & $3 c$ & $3 c$ & $3 c$ & 3c & 3c \\
\hline & DEPTH & 5 & 7 & 9 & 9 & 11.5 & 11.5 & 30 & $\cdots$ & 60 & 80 \\
\hline & ANALYSIS DATE & $3 / 21 / 91$ & $3 / 28 / 91$ & $3 / 22 / 91$ & $3 / 22 / 91$ & $3 / 22 / 91$ & $3 / 26 / 91$ & $4 / 2 / 91$ & $3 / 28 / 91$ & $4 / 2 / 91$ & $4 / 2 / 91$ \\
\hline & MOISTURE $(x)$ & 4.8 & MA & 5.0 & 4.3 & 5.6 & 6 & 8.7 & $m a$ & 6.1 & 22.3 \\
\hline Chl orome thane & $74-87-3$ & $11 \mathrm{U}$ & $10 U$ & 110 & $10 \mathrm{U}$ & 110 & $11 \mathrm{~J}$ & 110 & $10 \mathrm{U}$ & 110 & $13 \mathrm{U}$ \\
\hline Bromomethane & $74-83-9$ & 110 & $10 u$ & 110 & $10 \mathrm{U}$ & 110 & 110 & 110 & $10 \mathrm{U}$ & 110 & $13 v$ \\
\hline Vinyl Chloride & $75-01-6$ & $11 \mathrm{v}$ & $10 \mathrm{U}$ & 110 & $10 \mathrm{U}$ & 110 & $11 \mathrm{U}$ & 110 & $10 \mathrm{U}$ & $11 \mathrm{u}$ & $13 v$ \\
\hline Chloroethane & $75-00-3$ & $11 \mathrm{u}$ & $10 u$ & $11 \mathrm{v}$ & $10 \mathrm{U}$ & $11 \mathrm{u}$ & $11 \mathrm{v}$ & 110 & $10 \mathrm{U}$ & $11 \mathrm{U}$ & $13 \mathrm{U}$ \\
\hline Methylene Chloride & $75-09-2$ & 50 & 50 & $5 \mathrm{U}$ & $5 \mathrm{U}$ & 50 & 310 & 50 & $5 \mathrm{U}$ & 30 & *U \\
\hline Acetone & $67-64-1$ & $15 \mathrm{U}$ & $10 \mathrm{U}$ & 110 & $10 \mathrm{U}$ & 110 & $20 \mathrm{U}$ & 110 & $10 \mathrm{U}$ & 49 & $13 \mathrm{U}$ \\
\hline Carbon Disulfide & $75-15-0$ & $5 \mathrm{u}$ & $5 \mathrm{U}$ & $5 u$ & 50 & 50 & 60 & $5 U$ & $5 \mathrm{U}$ & 50 & 60 \\
\hline 1,1-Dichloroethene & $75-35-4$ & 50 & 50 & $5 \mathrm{U}$ & $5 u$ & 50 & $6 v$ & $5 u$ & $5 \mathrm{u}$ & 50 & $6 v$ \\
\hline 1,1-Dichloroethane & $75-34-3$ & 50 & 50 & $5 \mathrm{U}$ & 50 & 50 & $6 U$ & 50 & 50 & 50 & $6 U$ \\
\hline 1,2-0ichloroethene (total) & $540-59-0$ & $5 U$ & $5 U$ & 50 & 50 & $5 u$ & $6 U$ & 50 & $5 \mathrm{U}$ & $5 \mathrm{U}$ & $6 u$ \\
\hline Chloroform & $67-66-3$ & $5 \mathrm{U}$ & 50 & $5 u$ & 50 & 50 & $6 U$ & $5 \mathrm{U}$ & $5 \mathrm{u}$ & 50 & 60 \\
\hline 1,2-Dichiloroethane & $107-06-2$ & 50 & 50 & $5 \mathrm{u}$ & $5 \mathrm{v}$ & 50 & $6 U$ & $5 \mathrm{U}$ & $5 \mathrm{U}$ & $5 \mathrm{U}$ & $6 u$ \\
\hline 2-Butanone & $78-93-3$ & 110 & $10 u$ & $11 \mathrm{u}$ & $10 \mathrm{U}$ & $11 \mathrm{u}$ & $11 \mathrm{U}$ & $11 \mathrm{u}$ & $10 \mathrm{u}$ & $11 \mathrm{U}$ & $13 U$ \\
\hline 1,1,1-Irichloroethane & $71-55-6$ & 50 & $5 u$ & $5 u$ & $5 u$ & $5 u$ & $6 U$ & 50 & 50 & 50 & $6 u$ \\
\hline Carbon Tetrachloride & $56-23-5$ & $5 \mathrm{u}$ & $5 u$ & 50 & $5 \mathrm{U}$ & 50 & $6 U$ & $5 \mathrm{U}$ & 50 & 50 & $6 U$ \\
\hline Vinyl Acetate & $108-05-4$ & $11 \mathrm{U}$ & $10 \mathrm{U}$ & $11 \mathrm{u}$ & $10 \mathrm{U}$ & 110 & $11 \mathrm{U}$ & $11 \mathrm{U}$ & $10 \mathrm{U}$ & $11 \mathrm{u}$ & 130 \\
\hline Bromodichlorome thane & $75-27-4$ & 50 & $5 \mathrm{v}$ & 50 & 50 & 50 & 60 & $5 U$ & 50 & $5 u$ & $6 u$ \\
\hline 1,2-Dichloropropane & $78-87-5$ & $5 u$ & $5 u$ & $5 u$ & $5 U$ & 50 & $6 U$ & $5 U$ & 50 & $5 U$ & 64 \\
\hline
\end{tabular}

(Page 7 of 8 ) 
Table A-5. Volatile Organic Compounds. $(\mu \mathrm{g} / \mathrm{Kg})$

\begin{tabular}{|c|c|c|c|c|c|c|c|c|c|c|c|}
\hline ANALYTE & CAS\# & 80ОнО2 & ВОOH03 & воОно4 & воОно5 & ВоОно6 & воОно7 & $800 \mathrm{H16}$ & ВOOH10 & BOOH19 & $800 \mathrm{H} 23$ \\
\hline & IYPE & Reg & Reg & Reg & Fdup & Reg & Split & Reg & Blank & Reg & Reg \\
\hline & POND & $3 c$ & $3 c$ & $3 c$ & $3 c$ & $3 c$ & $3 c$ & $3 c$ & $3 c$ & $3 c$ & $3 c$ \\
\hline & DEPIH & 5 & 7 & 9 & 9 & 11.5 & 11.5 & 30 & $\cdots$ & 60 & 80 \\
\hline & ANALYSIS DATE & $3 / 21 / 91$ & $3 / 28 / 91$ & $3 / 22 / 91$ & $3 / 22 / 91$ & $3 / 22 / 91$ & $3 / 26 / 91$ & $4 / 2 / 91$ & $3 / 28 / 91$ & $4 / 2 / 91$ & 4/2/91 \\
\hline & MOISTURE $(x)$ & 4.8 & MA & 5.0 & 4.3 & 5.6 & 6 & 8.7 & $m$ & 6.1 & 22.3 \\
\hline cis-1,3-Dichloropropene & $10061-01-5$ & $5 \mathrm{u}$ & $5 \mathrm{u}$ & 50 & 50 & 50 & 60 & $5 \mathrm{u}$ & $5 \mathrm{U}$ & $5 \mathrm{u}$ & $6 u$ \\
\hline Irichloroethene & $79-01-6$ & 50 & 50 & $5 u$ & $5 u$ & 50 & $6 \mathrm{U}$ & 50 & 50 & $5 u$ & 60 \\
\hline Dibromochl oromethane & $124-48-1$ & 50 & 50 & $5 \mathrm{u}$ & $5 u$ & $5 \mathrm{v}$ & $6 \mathrm{U}$ & $5 u$ & $5 \mathrm{v}$ & 50 & $6 \mathrm{v}$ \\
\hline 1,1,2-Trichloroethane & $79-00-5$ & $5 \mathrm{u}$ & 50 & 50 & $5 U$ & $5 u$ & $6 u$ & 50 & $5 \mathrm{U}$ & $5 \mathrm{u}$ & $6 v$ \\
\hline Benzene & $71-43-2$ & $5 \mathrm{u}$ & 50 & 50 & $5 \mathrm{v}$ & $5 \mathrm{u}$ & $6 \mathrm{U}$ & $5 \mathrm{u}$ & 50 & $5 \mathrm{u}$ & 60 \\
\hline trans-1,3-Dichloropropene & $10061-02-6$ & $5 \mathrm{u}$ & $5 \mathrm{u}$ & $5 \mathrm{u}$ & $5 \mathrm{U}$ & 50 & $6 u$ & 50 & 50 & $5 \mathrm{u}$ & $6 U$ \\
\hline Bromoform & $75-25-2$ & $5 \mathrm{U}$ & $5 \mathrm{U}$ & 50 & 50 & 50 & 60 & $5 \mathrm{U}$ & 50 & $5 \mathrm{U}$ & 60 \\
\hline 4-Methyl-2-pentanone & $108-10-1$ & 110 & $10 u$ & $11 \mathrm{u}$ & $10 \mathrm{U}$ & 110 & $11 u$ & $11 \mathrm{u}$ & $10 \mathrm{U}$ & 110 & $13 \mathrm{U}$ \\
\hline 2-Hexanone & $591-78-6$ & 110 & $10 \mathrm{U}$ & $11 \mathrm{U}$ & $10 \mathrm{U}$ & 110 & 110 & 110 & $10 \mathrm{U}$ & 110 & $13 \mathrm{U}$ \\
\hline Tetrachloroethene & $127-18-4$ & $5 \mathrm{v}$ & $5 u$ & $5 u$ & 50 & 50 & $6 u$ & $5 \mathrm{v}$ & 50 & $5 \mathrm{u}$ & $6 u$ \\
\hline 1,1,2,2-Tetrachloroethane & $79-34-5$ & $5 \mathrm{v}$ & 50 & 50 & $5 \mathrm{u}$ & $5 \mathrm{U}$ & $6 v$ & 50 & 5 u & $5 \mathrm{U}$ & $6 u$ \\
\hline Toluene & $108-88-3$ & $5 u$ & 50 & 50 & $5 \mathrm{u}$ & $5 \mathrm{U}$ & $6 \mathrm{u}$ & $5 \mathrm{u}$ & 50 & 50 & $6 \mathrm{U}$ \\
\hline Chlorobenzene & $108-90-7$ & $5 \mathrm{U}$ & 50 & $5 u$ & 50 & $5 \mathrm{u}$ & $6 u$ & 50 & 50 & $5 \mathrm{U}$ & 60 \\
\hline Ethylbenzene & $100-41-4$ & $5 u$ & 50 & $5 v$ & 50 & 50 & $6 \mathrm{U}$ & 50 & 50 & $5 \mathrm{U}$ & $6 U$ \\
\hline Styrene & $100-42-5$ & 50 & 50 & 50 & $5 \mathrm{v}$ & $5 \mathrm{U}$ & $6 U$ & $5 \mathrm{U}$ & $5 \mathrm{U}$ & 50 & 60 \\
\hline xylene (total) & $1330-20-7$ & $5 u$ & $5 \mathrm{U}$ & 50 & $5 \mathrm{U}$ & 50 & $6 \mathrm{U}$ & $5 \mathrm{u}$ & 50 & $5 \mathrm{U}$ & $6 v$ \\
\hline
\end{tabular}

$U$ The analyte was undetected at the stated limit.

$\checkmark$ The associated value is an estimated quantity.

(Page 8 of 8 ) 
WHC-SD-EN-AP-104 Rev. 0

Reasons for Westinghouse Hanford Company Qualification--Volatile Organics

Reqular. Field Duplicate, and Silica Sand Samples:

HOLDING TIME--BOOFL4 was qualified as estimated, "J". Fourteen day holding time criteria established for water missed on sample BOOFL4 by 7 days.

LABORATORY BLANK--Acetone was qualified as undetected at $15 \mu \mathrm{g} / \mathrm{Kg}$ in $\mathrm{BOOHO2}$ because acetone was al so reported in the associated laboratory blank (\#910321-027). A summary of VOA Reagent BTanks at Primary Lab:

Nine laboratory blanks total:

6 with no reported contaminants

1 with Acetone at $26 \mu \mathrm{g} / \mathrm{Kg}(3 / 21 / 91)$

1 with 4-methyl-2-pentanone at $3 \mathrm{~J} \mu \mathrm{g} / \mathrm{Kg}(2 / 28 / 91)$

1 with an unknown tentatively identified compound (TIC) at $7 \mathrm{~J} \mathrm{\mu g} / \mathrm{kg}$ $(3 / 22 / 91)$

\section{Solit Samples:}

LABORATORY BLANK--Methylene chloride and acetone were found in laboratory blanks, and were qualified as undetected, " $U$ ", in samples BOOHO7, BOOGW5, and BOOGS5.

CALIBRATION-- Two samples had analytes qualified because of separate exceedances of Westinghouse Hanford-OSM's calibration criteria. All analytes were undetected. Sample BOOHO7 was qualified "UJ" for the following analytes:

$\begin{array}{lll}\text { alpha BHC } & \text { aldrin } & \text { chlordane } \\ \text { beta BHC } & \text { endrin } & \text { gamma chlordane } \\ \text { delta BHC } & \text { alpha } & \end{array}$

Sample BOOGW5 was qualified "UJ" for the following analytes:

$\begin{array}{lll}\text { alpha BHC } & \text { aldrin } & \text { endosulfan sulfate } \\ \text { beta BHC } & \text { endosulfan I } & 4,4^{\prime}-D D T \\ \text { delta BHC } & 4,4^{\prime}-D D E & \text { alpha chlordane } \\ \text { gamma BHC (1indane) } & 4,4^{\prime}-D D D & \text { gamma chlordane }\end{array}$

Additional Note to Volatile Organic Compound Data, Table A-5.

Three "unknown" compounds were reported as VOA TICs: $19 \mathrm{~J}, 22 \mathrm{~J}$, $11 \mathrm{~J} \mu \mathrm{g} / \mathrm{Kg}$ in the regular sample BOOGV5. No similar compounds were found in the associated laboratory blank. 
Table A-6. B-Pond Phase 3 Semivolatiles. $(\mu \mathrm{g} / \mathrm{Kg})$ (Base/Neutral/Acid Compounds)

\begin{tabular}{|c|c|c|c|c|c|c|c|c|c|c|c|}
\hline ANALYTE & CAS: & B00FK6 & BOOFKT & BOOFK8 & BoofKo & BOOFLO & BOOFL1 & BOOFL3 & BOOFL4 & BOOGR9 & BOOGS4 \\
\hline & IYPE & Reg & Reg & Reg & Reg & Reg & Reg & Blank & Reg & Fodp & Reg \\
\hline & POND & $3 n$ & $3 \AA$ & $3 A$ & $3 \AA$ & $3 A$ & $3 a$ & $3 n$ & $3 A$ & $3 A$ & $3 n$ \\
\hline & DEPIH & 6.5 & 8.5 & 10.5 & 13 & 14.5 & 16 & $\cdots$ & 28 & 28 & 52.5 \\
\hline & EXTRACTION DATE & $2 / 24 / 91$ & $2 / 24 / 91$ & $2 / 24 / 91$ & $2 / 24 / 91$ & $2 / 24 / 91$ & $2 / 24 / 91$ & $2 / 24 / 91$ & $2 / 24 / 91$ & $2 / 24 / 91$ & $2 / 24 / 91$ \\
\hline & AMALYSIS DATE & $2 / 28 / 91$ & $2 / 28 / 91$ & $2 / 28 / 91$ & $2 / 28 / 91$ & $2 / 28 / 91$ & $2 / 28 / 91$ & $2 / 28 / 91$ & $2 / 28 / 91$ & $2 / 28 / 91$ & $3 / 1 / 91$ \\
\hline Phenol & $108-95-2$ & $1100 \mathrm{uJ}$ & $1100 \mathrm{UJ}$ & $1000 \mathrm{Ud}$ & $1100 \mathrm{UJ}$ & $1100 \mathrm{us}$ & 1100 us & 990 Ud & $1000 \mathrm{Us}$ & $1000 \mathrm{UJ}$ & $1300 \mathrm{UJ}$ \\
\hline bis(2-chloroethyl)ether & $111-44-4$ & $1100 \mathrm{uJ}$ & $1100 \mathrm{us}$ & $1000 \mathrm{uJ}$ & $1100 \mathrm{us}$ & $1100 \mathrm{UJ}$ & $1100 \mathrm{UJ}$ & 990 UJ & 1000 us & $1000 \mathrm{UJ}$ & 1300 UJ \\
\hline 2-Chlorophenol & $95-57-8$ & $1100 \mathrm{us}$ & $1100 \mathrm{UJ}$ & $1000 \mathrm{UJ}$ & $1100 \mathrm{uJ}$ & $1100 \mathrm{Us}$ & $1100 \mathrm{us}$ & 990 us & $1000 \mathrm{us}$ & $1000 \mathrm{UJ}$ & 1300 UJ \\
\hline 1,3-Dichlorobenzene & $561-73 \cdot 1$ & $1100 \mathrm{uJ}$ & $1100 \mathrm{UJ}$ & $1000 \mathrm{UJ}$ & $1100 \mathrm{UJ}$ & $1100 \mathrm{UJ}$ & $1100 \mathrm{UJ}$ & 990 Us & $1000 \mathrm{UJ}$ & $1000 \mathrm{UJ}$ & $1300 \mathrm{UJ}$ \\
\hline 1,4-Dichlorobenzene & $106-46-7$ & $1100 \mathrm{uJ}$ & $1100 \mathrm{uJ}$ & $1000 \mathrm{UJ}$ & $1100 \mathrm{UJ}$ & $1100 \mathrm{UJ}$ & $1100 \mathrm{uJ}$ & 990 uJ & $1000 \mathrm{UJ}$ & $1000 \mathrm{UJ}$ & $1300 \mathrm{UJ}$ \\
\hline Benzyl Alcohol & $100-51-6$ & $1100 \mathrm{UJ}$ & $1100 \mathrm{UJ}$ & $1000 \mathrm{UJ}$ & $\$ 100 \mathrm{UJ}$ & $1100 \mathrm{Ud}$ & $1100 \mathrm{UJ}$ & 990 UJ & $1000 \mathrm{UJ}$ & $1000 \mathrm{UJ}$ & $1300 \mathrm{UJ}$ \\
\hline 1,2-Dichlorabenzene & $95-50-1$ & $1100 \mathrm{UJ}$ & $1100 \mathrm{UJ}$ & $1000 \mathrm{UJ}$ & $1100 \mathrm{UJ}$ & $1100 \mathrm{Us}$ & $1100 \mathrm{UJ}$ & 990 us & $1000 \mathrm{US}$ & 1000 Us & 1300 us \\
\hline 2-Methylphenol & $95-48-7$ & $1100 \mathrm{UJ}$ & $1100 \mathrm{UJ}$ & $1000 \mathrm{UJ}$ & $1100 \mathrm{uJ}$ & $1100 \mathrm{UJ}$ & $1100 \mathrm{UJ}$ & 990 UJ & $1000 \mathrm{UJ}$ & 1000 UJ & 1300 UJ \\
\hline $\begin{array}{l}\text { bis(2-Chloroi sopropyl) } \\
\text { ether }\end{array}$ & $108-60-1$ & $1100 \mathrm{uJ}$ & $1100 \mathrm{us}$ & $1000 \mathrm{UJ}$ & $1100 \mathrm{uJ}$ & $1100 \mathrm{uJ}$ & $1100 \mathrm{UJ}$ & 990 us & $1000 \mathrm{UJ}$ & $1000 \mathrm{us}$ & $1300 \mathrm{UJ}$ \\
\hline 4-Methylphenol & $106-44-5$ & $1100 \mathrm{UJ}$ & $1100 \mathrm{UJ}$ & $1000 \mathrm{UJ}$ & $1100 \mathrm{UJ}$ & $1100 \mathrm{UJ}$ & $1100 \mathrm{UJ}$ & 990 UJ & $1000 \mathrm{UJ}$ & $1000 \mathrm{Us}$ & $1300 \mathrm{UJ}$ \\
\hline W-Nitrosodipropylamine & $621-64-7$ & $1100 \mathrm{UJ}$ & $1100 \mathrm{uJ}$ & $1000 \mathrm{us}$ & $1100 \mathrm{us}$ & $1100 \mathrm{UJ}$ & $1100 \mathrm{UJ}$ & 990 UJ & $1000 \mathrm{UJ}$ & $1000 \mathrm{UJ}$ & 1300 UJ \\
\hline Hexachloroethane & $67-72-1$ & $1100 \mathrm{UJ}$ & $1100 \mathrm{UJ}$ & $1000 \mathrm{UJ}$ & $1100 \mathrm{UJ}$ & $1100 \mathrm{UJ}$ & $1100 \mathrm{UJ}$ & 990 us & 1000 UJ & $1000 \mathrm{UJ}$ & 1300 UJ \\
\hline Nitrobenzene & $98-95-3$ & $1100 \mathrm{UJ}$ & $1100 \mathrm{us}$ & $1000 \mathrm{UJ}$ & $1100 \mathrm{UJ}$ & $1100 \mathrm{UJ}$ & $1100 \mathrm{UJ}$ & $990 \mathrm{UJ}$ & $1000 \mathrm{UJ}$ & $1000 \mathrm{us}$ & 1300 UJ \\
\hline I sophorone & $78-59-1$ & $1100 \mathrm{UJ}$ & $1100 \mathrm{UJ}$ & $1000 \mathrm{UJ}$ & $1100 \mathrm{UJ}$ & $1100 \mathrm{UJ}$ & $1100 \mathrm{UJ}$ & $990 \mathrm{UJ}$ & 1000 UJ & $1000 \mathrm{UJ}$ & 1300 Ud \\
\hline 2-Nitrophenol & $88 \cdot 75 \cdot 5$ & $1100 \mathrm{UJ}$ & $1100 \mathrm{Ud}$ & $1000 \mathrm{UJ}$ & $1100 \mathrm{us}$ & $1100 \mathrm{UJ}$ & $1100 \mathrm{UJ}$ & 990 us & $1000 \mathrm{uJ}$ & $1000 \mathrm{uJ}$ & $1300 \mathrm{UJ}$ \\
\hline 2,4-0 imethylphenol & $105-67-9$ & $1100 \mathrm{UJ}$ & $1100 \mathrm{UJ}$ & $1000 \mathrm{US}$ & $1100 \mathrm{UJ}$ & $1100 \mathrm{UJ}$ & $1100 \mathrm{UJ}$ & $990 \mathrm{UJ}$ & $1000 \mathrm{UJ}$ & $1000 \mathrm{UJ}$ & $1300 \mathrm{UJ}$ \\
\hline Benzoic acid & $65-85-0$ & $5400 \mathrm{UJ}$ & $590 \mathrm{~J}$ & $520 \mathrm{~d}$ & $5100 \mathrm{uJ}$ & $360 \mathrm{~J}$ & $470 \mathrm{~J}$ & $4800 \mathrm{UJ}$ & $370 \mathrm{~J}$ & $390 \mathrm{~J}$ & $6300 \mathrm{UJ}$ \\
\hline bis(2-chloroethoxy)methane & $111-91-1$ & $1100 \mathrm{UJ}$ & $1100 \mathrm{UJ}$ & $1000 \mathrm{UJ}$ & $1100 \mathrm{UJ}$ & $1100 \mathrm{UJ}$ & $1100 \mathrm{UJ}$ & 990 UJ & $1000 \mathrm{UJ}$ & $1000 \mathrm{UJ}$ & 1300 UJ \\
\hline
\end{tabular}

(Page 1 of 16) 
Table A-6. B-Pond Phase 3 Semivolatiles. ( $\mu \mathrm{g} / \mathrm{Kg})$ (Base/Neutral/Acid Compounds)

\begin{tabular}{|c|c|c|c|c|c|c|c|c|c|c|c|}
\hline AMALYTE & CAS: & B00FK6 & BOOFK 7 & B00FK8 & BOOFK9 & BOOFLO & BOOFL1 & BOOFL3 & BOOFL6 & BOOGR9 & 800GS4 \\
\hline & TYPE & Reg & Reg & Reg & Reg & Reg & Reg & Btank & Reg & Fap & Reg \\
\hline & POND & $3 A$ & $3 n$ & $3 n$ & $3 \AA$ & $3 A$ & $3 A$ & $3 A$ & $3 n$ & $3 A$ & $3 n$ \\
\hline & DEPTH & 6.5 & 8.5 & 10.5 & 13 & 14.5 & 16 & $\cdots$ & 28 & 28 & 52.5 \\
\hline & EXTRACTIOM DATE & $2 / 24 / 91$ & $2 / 24 / 91$ & $2 / 24 / 91$ & $2 / 24 / 91$ & $2 / 24 / 91$ & $2 / 24 / 91$ & $2 / 24 / 91$ & $2 / 24 / 91$ & $2 / 24 / 91$ & $2 / 24 / 91$ \\
\hline & AMALYSIS DATE & $2 / 28 / 91$ & $2 / 28 / 91$ & $2 / 28 / 91$ & $2 / 28 / 91$ & $2 / 28 / 91$ & $2 / 28 / 91$ & $2 / 28 / 91$ & $2 / 28 / 91$ & $2 / 28 / 91$ & $3 / 1 / 91$ \\
\hline 2,4-Dichlorophenol & $120-83-2$ & $1100 \mathrm{UJ}$ & $1100 \mathrm{UJ}$ & $1000 \mathrm{UJ}$ & $1100 \mathrm{UJ}$ & $1100 \mathrm{UJ}$ & $1100 \mathrm{UJ}$ & 990 UJ & $1000 \mathrm{UJ}$ & $1000 \mathrm{UJ}$ & $1300 \mathrm{UJ}$ \\
\hline 1,2,4-Trichlorobenzene & $120-82-1$ & $1100 \mathrm{UJ}$ & $1100 \mathrm{UJ}$ & $1000 \mathrm{UJ}$ & $1100 \mathrm{UJ}$ & $1100 \mathrm{US}$ & $1100 \mathrm{UJ}$ & 990 UJ & $1000 \mathrm{UJ}$ & 1000 Us & 1300 UJ \\
\hline Maphthal ene & $91-20-3$ & $1100 \mathrm{UJ}$ & $1100 \mathrm{UJ}$ & $1000 \mathrm{UJ}$ & $1100 \mathrm{UJ}$ & $1100 \mathrm{UJ}$ & $1100 \mathrm{UJ}$ & $990 \mathrm{UJ}$ & $1000 \mathrm{us}$ & $1000 \mathrm{UJ}$ & $1300 \mathrm{UJ}$ \\
\hline 4-Chloroeniline & $106-47-8$ & $1100 \mathrm{UJ}$ & $1100 \mathrm{UJ}$ & $1000 \mathrm{UJ}$ & $1100 \mathrm{UJ}$ & $1100 \mathrm{UJ}$ & $1100 \mathrm{UJ}$ & 990 uJ & $1000 \mathrm{UJ}$ & $1000 \mathrm{UJ}$ & $1300 \mathrm{UJ}$ \\
\hline Hexachl or obut adi ene & $87-68-3$ & $1100 \mathrm{uJ}$ & $1100 \mathrm{UJ}$ & $1000 \mathrm{uJ}$ & $1100 \mathrm{UJ}$ & $1100 \mathrm{Ud}$ & $1100 \mathrm{UJ}$ & 990 UJ & $1000 \mathrm{uJ}$ & $1000 \mathrm{UJ}$ & 1300 UJ \\
\hline 4-Chloro-3-sethylphenol & $59-50-7$ & $1100 \mathrm{UJ}$ & $1100 \mathrm{UJ}$ & $1000 \mathrm{UJ}$ & $1100 \mathrm{UJ}$ & $1100 \mathrm{UJ}$ & $1100 \mathrm{uJ}$ & 990 us & $1000 \mathrm{UJ}$ & $1000 \mathrm{UJ}$ & 1300 UJ \\
\hline 2-Methylnaphthal ene & $91-57-6$ & $1100 \mathrm{UJ}$ & $1100 \mathrm{UJ}$ & $1000 \mathrm{UJ}$ & $1100 \mathrm{UJ}$ & $1100 \mathrm{UJ}$ & $1100 \mathrm{us}$ & 990 UJ & $1000 \mathrm{Us}$ & $1000 \mathrm{US}$ & $1300 \mathrm{UJ}$ \\
\hline Hexach lorocyclopentediene & $77-47-6$ & $1100 \mathrm{uJ}$ & $1100 \mathrm{UJ}$ & $1000 \mathrm{UJ}$ & $1100 \mathrm{UJ}$ & $1100 \mathrm{UJ}$ & $1100 \mathrm{UJ}$ & 990 uJ & $1000 \mathrm{UJ}$ & $1000 \mathrm{UJ}$ & $1300 \mathrm{UJ}$ \\
\hline 2,4,6-Trichlorophenol & $88-06-2$ & $1100 \mathrm{UJ}$ & $1100 \mathrm{UJ}$ & $1000 \mathrm{UJ}$ & $1100 \mathrm{UJ}$ & $1100 \mathrm{UJ}$ & $1100 \mathrm{uJ}$ & 990 UJ & $1000 \mathrm{UJ}$ & $1000 \mathrm{us}$ & $1300 \mathrm{UJ}$ \\
\hline 2,4,5-Trichlorophenol & $95-95-4$ & $5400 \mathrm{UJ}$ & $5400 \mathrm{UJ}$ & $5100 \mathrm{UJ}$ & $5100 \mathrm{Ud}$ & $5200 \mathrm{UJ}$ & $5400 \mathrm{UJ}$ & $4800 \mathrm{UJ}$ & $5000 \mathrm{uJ}$ & $5100 \mathrm{UJ}$ & $6300 \mathrm{UJ}$ \\
\hline 2-Chlor onaphthal ene & $91-58-7$ & $1100 \mathrm{us}$ & $1100 \mathrm{Ud}$ & $1000 \mathrm{UJ}$ & $1100 \mathrm{UJ}$ & $1100 \mathrm{UJ}$ & $1100 \mathrm{us}$ & 990 uJ & $1000 \mathrm{UJ}$ & $1000 \mathrm{UJ}$ & $1300 \mathrm{UJ}$ \\
\hline 2-Mitroaniline & $88-74-4$ & $5400 \mathrm{UJ}$ & $5400 \mathrm{UJ}$ & $5100 \mathrm{uJ}$ & $5100 \mathrm{uJ}$ & $5200 \mathrm{UJ}$ & $5400 \mathrm{UJ}$ & $4800 \mathrm{UJ}$ & 5000 Ud & $5100 \mathrm{UJ}$ & $6300 \mathrm{UJ}$ \\
\hline Dimethylphthalate & $131-11-3$ & $1100 \mathrm{UJ}$ & $1100 \mathrm{us}$ & $1000 \mathrm{US}$ & $1100 \mathrm{UJ}$ & $1100 \mathrm{UJ}$ & $1100 \mathrm{UJ}$ & 990 uJ & $1000 \mathrm{Us}$ & $1000 \mathrm{UJ}$ & $1300 \mathrm{UJ}$ \\
\hline Acenaphthylene & $208-96-8$ & $1100 \mathrm{UJ}$ & $1100 \mathrm{UJ}$ & $1000 \mathrm{UJ}$ & $1100 \mathrm{UJ}$ & $1100 \mathrm{UJ}$ & $1100 \mathrm{UJ}$ & $990 \mathrm{uJ}$ & $1000 \mathrm{UJ}$ & $1000 \mathrm{UJ}$ & $1300 \mathrm{UJ}$ \\
\hline 3-Nitroaniline & $99-09-2$ & $5400 \mathrm{UJ}$ & $5400 \mathrm{UJ}$ & $5100 \mathrm{UJ}$ & $5100 \mathrm{UJ}$ & $5200 \mathrm{UJ}$ & $5400 \mathrm{UJ}$ & 4800 UJ & 5000 Us & $5100 \mathrm{UJ}$ & $6300 \mathrm{UJ}$ \\
\hline Acenaphthene & $83-32-9$ & $1100 \mathrm{UJ}$ & $1100 \mathrm{UJ}$ & $1000 \mathrm{UJ}$ & $1100 \mathrm{Ud}$ & $1100 \mathrm{UJ}$ & $1100 \mathrm{UJ}$ & $990 \mathrm{UJ}$ & $1000 \mathrm{UJ}$ & $1000 \mathrm{Us}$ & $1300 \mathrm{UJ}$ \\
\hline 2.4-0 initrophenol & $51-28-5$ & $5400 \mathrm{UJ}$ & $5400 \mathrm{UJ}$ & 5100 UJ & $5100 \mathrm{UJ}$ & $5200 \mathrm{UJ}$ & $5400 \mathrm{UJ}$ & $4800 \mathrm{UJ}$ & $5000 \mathrm{UJ}$ & $5100 \mathrm{UJ}$ & $6300 \mathrm{UJ}$ \\
\hline 4-Nitrophenol & $100-02-7$ & $5400 \mathrm{UJ}$ & $5400 \mathrm{UJ}$ & $5100 \mathrm{UJ}$ & $5100 \mathrm{uJ}$ & $5200 \mathrm{uJ}$ & $5400 \mathrm{UJ}$ & $4800 \mathrm{UJ}$ & $5000 \mathrm{UJ}$ & $5100 \mathrm{UJ}$ & $6300 \mathrm{UJ}$ \\
\hline
\end{tabular}

(Page 2 of 16) 
Table A-6. B-Pond Phase 3 Semivolatiles. $(\mu \mathrm{g} / \mathrm{Kg})$ (Base/Neutral/Acid Compounds)



(Page 3 of 16) 
Table A-6. B-Pond Phase 3 Semivolatiles. $(\mu \mathrm{g} / \mathrm{Kg})$ (Base/Neutral/Acid Compounds)

\begin{tabular}{|c|c|c|c|c|c|c|c|c|c|c|}
\hline ANALYTE & BO0FK6 & $800 \mathrm{FK} 7$ & 800Fk8 & 800FKo & BOOFLO & BOOFL1 & $800 \mathrm{FL} 3$ & BOOFL4 & BOOGR9 & B00GS4 \\
\hline IYPE & Reg & Reg & Reg & Reg & Reg & Reg & Btank & Reg & fodp & Reg \\
\hline POND & $3 n$ & $3 n$ & $3 \wedge$ & $3 n$ & $3 A$ & $3 A$ & $3 n$ & $3 n$ & $3 n$ & $3 A$ \\
\hline DEPTH & 6.5 & 8.5 & 10.5 & 13 & 14.5 & 16 & $\cdots$ & 28 & 28 & 52.5 \\
\hline EXIRACIION DATE & $2 / 24 / 91$ & $2 / 26 / 91$ & $2 / 24 / 91$ & $2 / 26 / 91$ & $2 / 24 / 91$ & $2 / 24 / 91$ & $2 / 26 / 91$ & $2 / 26 / 91$ & $2 / 26 / 91$ & $2 / 24 / 91$ \\
\hline AMALYSIS DATE & $2 / 28 / 91$ & $2 / 28 / 91$ & $2 / 28 / 91$ & $2 / 28 / 91$ & $2 / 28 / 91$ & $2 / 28 / 91$ & $2 / 28 / 91$ & $2 / 28 / 91$ & $2 / 28 / 91$ & $3 / 1 / 91$ \\
\hline 3,31-Dichl or obenz ldine & $2200 \mathrm{UJ}$ & $2220 \mathrm{uJ}$ & $2100 \mathrm{UJ}$ & $2100 \mathrm{UJ}$ & $2100 \mathrm{UJ}$ & $2200 \mathrm{UJ}$ & 3000 UJ & 2100 us & $2100 \mathrm{UJ}$ & $1300 \mathrm{UJ}$ \\
\hline Benzo(a)enthracene & $1100 \mathrm{us}$ & $1100 \mathrm{UJ}$ & $1000 \mathrm{uJ}$ & $1100 \mathrm{UJ}$ & $1100 \mathrm{Ud}$ & $1100 \mathrm{UJ}$ & 990 UJ & $1000 \mathrm{UJ}$ & $1000 \mathrm{Us}$ & 1300 UJ \\
\hline bis(2-ethylhexyl)phthalate & $1100 \mathrm{uJ}$ & $1100 \mathrm{uJ}$ & $1100 \mathrm{UJ}$ & $1100 \mathrm{Ud}$ & $1100 \mathrm{UJ}$ & $1100 \mathrm{UJ}$ & 990 us & $1000 \mathrm{US}$ & $1000 \mathrm{UJ}$ & 1400 UJ \\
\hline $218-01-9$ & $1100 \mathrm{us}$ & $1100 \mathrm{UJ}$ & 1000 Us & $1100 \mathrm{uJ}$ & $1100 \mathrm{Us}$ & $1100 \mathrm{UJ}$ & $990 \mathrm{UJ}$ & 1000 Us & $1000 \mathrm{UJ}$ & 1300 Ud \\
\hline Di-n-octylphthalate & $1100 \mathrm{uJ}$ & $1100 \mathrm{uJ}$ & $1000 \mathrm{UJ}$ & 1100 UJ & 1100 UJ & $1100 \mathrm{UJ}$ & $990 \mathrm{UJ}$ & 1000 Us & $1000 \mathrm{UJ}$ & $1300 \mathrm{us}$ \\
\hline Benzo(b)f l woranthene & $1100 \mathrm{uJ}$ & $1100 \mathrm{us}$ & $1000 \mathrm{UJ}$ & $1100 \mathrm{uJ}$ & $1100 \mathrm{UJ}$ & $1100 \mathrm{uJ}$ & $990 \mathrm{UJ}$ & $1000 \mathrm{uJ}$ & $1000 \mathrm{UJ}$ & 1300 UJ \\
\hline Benzo(k)fluoranthene & $1100 \mathrm{UJ}$ & $1100 \mathrm{us}$ & $1000 \mathrm{UJ}$ & $1100 \mathrm{UJ}$ & $1100 \mathrm{UJ}$ & $1100 \mathrm{UJ}$ & 990 us & $1000 \mathrm{us}$ & $1000 \mathrm{UJ}$ & $1300 \mathrm{UJ}$ \\
\hline Benzo(a)pyrene & $1100 \mathrm{UJ}$ & $1100 \mathrm{UJ}$ & $1000 \mathrm{uJ}$ & 1100 us & $1100 \mathrm{UJ}$ & $1100 \mathrm{UJ}$ & 990 Us & $1000 \mathrm{US}$ & $1000 \mathrm{uJ}$ & $1300 \mathrm{UJ}$ \\
\hline Indeno( $1,2,3-\mathrm{cd})$ pyrene & $1100 \mathrm{uJ}$ & 1100 Us & $1000 \mathrm{UJ}$ & $1100 \mathrm{us}$ & $1100 \mathrm{uJ}$ & $1100 \mathrm{UJ}$ & $990 \mathrm{UJ}$ & 1000 Us & $1000 \mathrm{UJ}$ & $1300 \mathrm{UJ}$ \\
\hline Dibenz $(a, h)$ anthracene & 1100 us & $1100 \mathrm{UJ}$ & 1000 us & $1100 \mathrm{UJ}$ & $1100 \mathrm{UJ}$ & $1100 \mathrm{uJ}$ & $990 \mathrm{uJ}$ & $1000 \mathrm{UJ}$ & 1000 Us & $1300 \mathrm{UJ}$ \\
\hline Benzo( $g, h, i)$ perylene & 1100 UJ & $1100 \mathrm{UJ}$ & $1000 \mathrm{us}$ & $1100 \mathrm{UJ}$ & 1100 UJ & 1100 UJ & 990 us & 1000 Us & 1000 UJ & 1300 Ud \\
\hline $\begin{array}{l}\text { OTHER WAC-173-303-9905 DANGEROUS WASTE } \\
\text { CONSTIIUENTS? }\end{array}$ & No & Mo & Mo & No & Mo & $?$ & No & Mo & $?$ & Mo \\
\hline Total IICs & 7 & 7 & 8 & 6 & 8 & 8 & 2 & 7 & 9 & $\mathbf{B}$ \\
\hline IICs without laboratory "B" flegs & 3 & 3 & 4 & 2 & 5 & 5 & 0 & 4 & 6 & 4 \\
\hline
\end{tabular}


Table A-6. B-Pond Phase 3 Semivolatiles. ( $\mu \mathrm{g} / \mathrm{Kg})$ (Base/Neutral/Acid Compounds)

\begin{tabular}{|c|c|c|c|c|c|c|c|c|c|c|c|}
\hline ANAL YIE & CAS: & $800 \mathrm{GS} 5$ & BOOGSO & 8006I7 & Boogvs & Boogv6 & Boogv7 & BooGv8 & Boogvg & BOOGNO & B00GWI \\
\hline & TYPE & Split & Reg & Reg & Reg & Reg & Reg & Reg & Btank & Reg & Reg \\
\hline & POND & $3 \wedge$ & $3 \wedge$ & $3 \AA$ & $3 \wedge$ & 38 & 3B & 38 & 38 & 3B & 38 \\
\hline & DEPIH & 52.5 & 66.5 & 97 & 143.5 & 1 & 3.5 & 5.5 & $\cdots$ & 7.5 & 9.5 \\
\hline & EXIRACTION DATE & $2 / 24 / 91$ & $2 / 24 / 91$ & $2 / 27 / 91$ & $3 / 7 / 91$ & $3 / 7 / 91$ & $3 / 7 / 91$ & $3 / 7 / 91$ & $3 / 12 / 91$ & $3 / 12 / 91$ & $3 / 12 / 91$ \\
\hline & AMALYSIS DATE & $3 / 1 / 91$ & $3 / 1 / 91$ & $3 / 5 / 91$ & $3 / 12 / 91$ & $3 / 12 / 91$ & $3 / 12 / 91$ & $3 / 12 / 91$ & $3 / 14 / 91$ & $3 / 14 / 91$ & $4 / 2 / 91$ \\
\hline Phenol & $108-95-2$ & $450 \mathrm{U}$ & $1100 \mathrm{uJ}$ & $1000 \mathrm{UJ}$ & 990 UJ & $990 \mathrm{U}$ & $990 \mathrm{u}$ & $1000 \mathrm{U}$ & $990 \cup$ & $990 \mathrm{U}$ & $1000 \mathrm{UJ}$ \\
\hline bis(2-chloroethyl)ether & $111-44-4$ & $450 \mathrm{U}$ & $1100 \mathrm{uJ}$ & $1000 \mathrm{us}$ & 990 UJ & $990 \mathrm{U}$ & $990 \mathrm{u}$ & $1000 \cup$ & $990 \mathrm{U}$ & $990 \mathrm{U}$ & $1000 \mathrm{UJ}$ \\
\hline 2-Chlorophenol & $95-57-8$ & $450 \mathrm{U}$ & $1100 \mathrm{UJ}$ & $1000 \mathrm{UJ}$ & 990 UJ & $990 \mathrm{u}$ & $990 \mathrm{U}$ & $1000 \mathrm{U}$ & $990 \mathrm{u}$ & $990 \mathrm{u}$ & $1000 \mathrm{UJ}$ \\
\hline 1,3-0ichl or obenzene & $541-73-1$ & $650 \mathrm{U}$ & $1100 \mathrm{UJ}$ & $1000 \mathrm{UJ}$ & $990 \mathrm{UJ}$ & $990 \mathrm{U}$ & $990 \mathrm{U}$ & $1000 \mathrm{U}$ & $990 \mathrm{U}$ & $990 \mathrm{U}$ & $1000 \mathrm{UJ}$ \\
\hline 1,4-Dichl or obenzene & $106-46-7$ & $450 \mathrm{U}$ & $1100 \mathrm{UJ}$ & $1000 \mathrm{UJ}$ & 990 UJ & $990 \mathrm{U}$ & $990 \mathrm{u}$ & $1000 u$ & $990 \mathrm{u}$ & $990 \mathrm{U}$ & $1000 \mathrm{UJ}$ \\
\hline Benzyl Alcohol & $100-51-6$ & $450 \mathrm{U}$ & $1100 \mathrm{UJ}$ & $1000 \mathrm{UJ}$ & $990 \mathrm{UJ}$ & $990 \mathrm{U}$ & $990 \mathrm{u}$ & $1000 \mathrm{U}$ & $990 \mathrm{U}$ & $990 \mathrm{U}$ & $1000 \mathrm{uJ}$ \\
\hline 1,2-Dichlorobenzene & $95-50-1$ & $450 \mathrm{U}$ & 1100 UJ & 1000 UJ & $990 \mathrm{UJ}$ & $990 \mathrm{u}$ & $990 \mathrm{u}$ & $1000 \mathrm{U}$ & $990 \mathrm{U}$ & $990 \mathrm{u}$ & $1000 \mathrm{UJ}$ \\
\hline 2-Mettoylphenol & $95-48-7$ & $450 u$ & $1100 \mathrm{us}$ & $1000 \mathrm{UJ}$ & $990 \mathrm{UJ}$ & $990 \mathrm{U}$ & $990 \mathrm{U}$ & $1000 \mathrm{U}$ & $990 \mathrm{u}$ & $990 \mathrm{u}$ & $1000 \mathrm{UJ}$ \\
\hline $\begin{array}{l}\text { bis(2-Chloroisopropyl) } \\
\text { ether }\end{array}$ & $108-60-1$ & $450 u$ & $1100 \mathrm{uJ}$ & $1000 \mathrm{UJ}$ & 990 UJ & $990 \mathrm{U}$ & $990 \mathrm{U}$ & $1000 \mathrm{U}$ & $990 \mathrm{U}$ & $990 \cup$ & 1000 UJ \\
\hline 4-Methylphenol & $106-44-5$ & $450 \mathrm{U}$ & $1100 \mathrm{UJ}$ & $1000 \mathrm{UJ}$ & $990 \mathrm{UJ}$ & $990 \mathrm{U}$ & $990 \mathrm{U}$ & $1000 \mathrm{U}$ & $990 \mathrm{u}$ & $990 \mathrm{u}$ & $1000 \mathrm{UJ}$ \\
\hline N-Mitrosodipropylamine & $621-64-7$ & $450 \mathrm{U}$ & $1100 \mathrm{UJ}$ & $1000 \mathrm{UJ}$ & 990 UJ & $990 \mathrm{u}$ & $990 \mathrm{U}$ & $1000 \mathrm{U}$ & $990 \mathrm{u}$ & $990 \mathrm{U}$ & $1000 \mathrm{UJ}$ \\
\hline Hexachloroethane & $67-72-1$ & $450 \mathrm{U}$ & $1100 \mathrm{UJ}$ & $1000 \mathrm{UJ}$ & 990 UJ & $990 \mathrm{U}$ & $990 \mathrm{U}$ & $1000 \mathrm{U}$ & $990 \mathrm{u}$ & $990 \mathrm{v}$ & $1000 \mathrm{UJ}$ \\
\hline Nitrobenzene & $98-95-3$ & $450 \mathrm{U}$ & $1100 \mathrm{uJ}$ & $1000 \mathrm{UJ}$ & 990 UJ & $990 \mathrm{U}$ & $990 \mathrm{U}$ & $1000 \mathrm{U}$ & $990 \mathrm{u}$ & $990 \mathrm{U}$ & $1000 \mathrm{UJ}$ \\
\hline Isophorone & $78-59-1$ & $450 \mathrm{U}$ & $1100 \mathrm{UJ}$ & $1000 \mathrm{UJ}$ & $990 \mathrm{UJ}$ & $990 \mathrm{U}$ & $990 \mathrm{U}$ & $1000 \mathrm{U}$ & $990 \mathrm{U}$ & $990 \mathrm{U}$ & $1000 \mathrm{UJ}$ \\
\hline 2-Nitrophenol & $88 \cdot 75 \cdot 5$ & $450 \mathrm{U}$ & $1100 \mathrm{UJ}$ & $1000 \mathrm{UJ}$ & 990 UJ & $990 \mathrm{U}$ & $990 \mathrm{U}$ & $1000 \mathrm{U}$ & $990 \mathrm{u}$ & $990 \mathrm{U}$ & $1000 \mathrm{UJ}$ \\
\hline 2.4-D ime thylphenol & $105-67-9$ & 4500 & $1100 \mathrm{UJ}$ & $1000 \mathrm{UJ}$ & $990 \mathrm{UJ}$ & $990 \mathrm{U}$ & $990 \mathrm{U}$ & $1000 \cup$ & $990 \mathrm{U}$ & $990 \mathrm{U}$ & $1000 \mathrm{UJ}$ \\
\hline Benzoic acid & $65-85-0$ & $2200 \mathrm{U}$ & $830 \mathrm{~J}$ & $5000 \mathrm{UJ}$ & $4800 \mathrm{UJ}$ & $290 \mathrm{~J}$ & $240 \mathrm{~J}$ & $5100 \mathrm{u}$ & $4800 \mathrm{v}$ & $4800 \mathrm{U}$ & $5000 \mathrm{UJ}$ \\
\hline bis (2-chl or oethoxy) me thane & $111-91-1$ & $450 \mathrm{U}$ & $1100 \mathrm{UJ}$ & $1000 \mathrm{UJ}$ & 990 UJ & $990 \mathrm{U}$ & $990 \mathrm{U}$ & $1000 u$ & $990 \mathrm{U}$ & $990 \mathrm{U}$ & $1000 \mathrm{UJ}$ \\
\hline
\end{tabular}

(Page 5 of 16) 
Table A-6. B-Pond Phase 3 Semivolatiles. $(\mu \mathrm{g} / \mathrm{Kg})$ (Base/Neutral/Acid Compounds)

\begin{tabular}{|c|c|c|c|c|c|c|c|c|c|c|c|}
\hline AMALYTE & cas: & B00GS5 & BooGs9 & BOOGT7 & BoogVs & BooGVs & BooGv7 & $800 G \mathrm{G}$ & BooGv9 & BOOGWO & BOOGWI \\
\hline & TYPE & Split & Reg & Reg & Reg & Reg & Reg & Reg & Blenk & Reg & Reg \\
\hline & POND & $3 n$ & $3 A$ & $3 A$ & $3 A$ & 38 & 38 & 38 & 38 & 3B & $3 B$ \\
\hline & DEPTH & 52.5 & 66.5 & 97 & 143.5 & $\mathbf{t}$ & 3.5 & 5.5 & $\cdots$ & 7.5 & 9.5 \\
\hline & EXTRACTION DATE & $2 / 24 / 91$ & $2 / 24 / 91$ & $2 / 27 / 91$ & $3 / 7 / 91$ & $3 / 7 / 91$ & $3 / 7 / 91$ & $3 / 7 / 91$ & $3 / 12 / 91$ & $3 / 12 / 91$ & $3 / 12 / 91$ \\
\hline & ANALYSIS DATE & $3 / 1 / 91$ & $3 / 1 / 91$ & $3 / 5 / 91$ & $3 / 12 / 91$ & $3 / 12 / 91$ & $3 / 12 / 91$ & $3 / 12 / 91$ & $3 / 14 / 91$ & $3 / 14 / 91$ & $4 / 2 / 91$ \\
\hline 2,4-Dichlorophenol & $120-83-2$ & $450 \mathrm{U}$ & $1100 \mathrm{uJ}$ & $1000 \mathrm{UJ}$ & $990 \mathrm{UJ}$ & $990 \mathrm{U}$ & $990 \mathrm{U}$ & $1000 \mathrm{U}$ & $990 \mathrm{U}$ & $990 \mathrm{U}$ & $1000 \mathrm{UJ}$ \\
\hline 1,2,4-Trichlorobenzene & $120-82-1$ & $450 \mathrm{U}$ & $1100 \mathrm{UJ}$ & $1000 \mathrm{UJ}$ & 990 UJ & $990 \mathrm{U}$ & $990 \mathrm{U}$ & $1000 \mathrm{U}$ & $990 \mathrm{U}$ & $990 \mathrm{U}$ & 1000 UJ \\
\hline Naphthal ene & $91-20-3$ & $450 \mathrm{U}$ & $1100 \mathrm{UJ}$ & $1000 \mathrm{UJ}$ & 990 uJ & $990 \mathrm{U}$ & $990 \mathrm{U}$ & $1000 \mathrm{U}$ & $990 \mathrm{U}$ & $990 \mathrm{U}$ & 1000 UJ \\
\hline 4-Chloroanilline & $106-47-8$ & $450 \mathrm{U}$ & $1100 \mathrm{UJ}$ & $1000 \mathrm{uJ}$ & $990 \mathrm{UJ}$ & $990 \mathrm{U}$ & $990 \mathrm{U}$ & $1000 \mathrm{U}$ & $990 \mathrm{U}$ & $990 \mathrm{U}$ & 1000 UJ \\
\hline Hexachlorobutadiene & $87-68-3$ & $450 \mathrm{U}$ & $1100 \mathrm{UJ}$ & $1000 \mathrm{UJ}$ & 990 UJ & $990 \mathrm{U}$ & $990 \mathrm{U}$ & $1000 \mathrm{U}$ & $990 \mathrm{U}$ & $990 \mathrm{U}$ & $1000 \mathrm{UJ}$ \\
\hline 4-Chloro-3-methylphenol & $59-50-7$ & $450 \mathrm{U}$ & $1100 \mathrm{UJ}$ & $1000 \mathrm{us}$ & 990 UJ & $990 \mathrm{U}$ & $990 \mathrm{U}$ & $1000 \mathrm{U}$ & $990 \mathrm{U}$ & $990 \mathrm{U}$ & $1000 \mathrm{UJ}$ \\
\hline 2-Methyl naphthal ene & $91-57-6$ & $450 \mathrm{U}$ & $1100 \mathrm{UJ}$ & $1000 \mathrm{UJ}$ & $990 \mathrm{UJ}$ & $990 \mathrm{U}$ & $990 \mathrm{U}$ & $1000 \mathrm{U}$ & $990 \mathrm{U}$ & $990 \mathrm{U}$ & $1000 \mathrm{UJ}$ \\
\hline Hexach lorocycl opentadiene & $77-47-4$ & $450 \mathrm{U}$ & $1100 \mathrm{uJ}$ & $1000 \mathrm{UJ}$ & $990 \mathrm{UJ}$ & $990 \mathrm{U}$ & $990 \mathrm{U}$ & $1000 \mathrm{U}$ & $990 \mathrm{U}$ & $990 \mathrm{U}$ & $1000 \mathrm{UJ}$ \\
\hline 2,4,6-Trichlorophenol & $88-06-2$ & $450 u$ & $1100 \mathrm{UJ}$ & $1000 \mathrm{UJ}$ & 990 UJ & $990 \mathrm{U}$ & $990 \mathrm{U}$ & $1000 \mathrm{U}$ & $990 \mathrm{U}$ & $990 \mathrm{U}$ & 1000 UJ \\
\hline 2,4,5-Trichlorophenol & $95-95-4$ & $2200 \mathrm{U}$ & $5200 \mathrm{UJ}$ & $5000 \mathrm{UJ}$ & $4800 \mathrm{UJ}$ & $4800 \mathrm{U}$ & $4800 \mathrm{U}$ & $5100 \mathrm{U}$ & $4800 \mathrm{U}$ & $4800 \mathrm{U}$ & $5000 \mathrm{UJ}$ \\
\hline 2-Chloronaphthal ene & $91-58-7$ & $450 \mathrm{U}$ & $1100 \mathrm{UJ}$ & $1000 \mathrm{us}$ & 990 UJ & $990 \mathrm{U}$ & $990 \mathrm{U}$ & $1000 \mathrm{U}$ & $990 \mathrm{U}$ & $990 \mathrm{U}$ & 1000 UJ \\
\hline 2-Mitroaniline & $88-74-4$ & $2200 \mathrm{U}$ & 5200 UJ & $5000 \mathrm{UJ}$ & $4800 \mathrm{UJ}$ & $4800 \mathrm{U}$ & $4800 \mathrm{U}$ & $5100 \mathrm{U}$ & $4800 \mathrm{U}$ & $4800 \mathrm{U}$ & 5000 UJ \\
\hline Dimethylphthalate & $131-11-3$ & $450 \mathrm{U}$ & 1100 UJ & $1000 \mathrm{uJ}$ & 990 UJ & $990 \mathrm{U}$ & $990 \mathrm{U}$ & $1000 \mathrm{U}$ & $990 \mathrm{U}$ & $990 \mathrm{U}$ & $1000 \mathrm{UJ}$ \\
\hline Acenaphthylene & $208-96-8$ & 4500 & $1100 \mathrm{UJ}$ & $1000 \mathrm{UJ}$ & 990 UJ & $990 \mathrm{U}$ & $990 \mathrm{U}$ & $1000 \mathrm{U}$ & $990 \mathrm{U}$ & $990 \mathrm{U}$ & $1000 \mathrm{UJ}$ \\
\hline 3-Nitroanil ine & $99-09-2$ & $2200 \mathrm{v}$ & $5200 \mathrm{uJ}$ & $5000 \mathrm{UJ}$ & $4800 \mathrm{UJ}$ & $4800 \mathrm{U}$ & $4800 \mathrm{U}$ & $5100 \mathrm{U}$ & $4800 \mathrm{U}$ & $4800 \mathrm{U}$ & $5000 \mathrm{uJ}$ \\
\hline Acenaph thene & $83-32-9$ & $450 \mathrm{U}$ & $1100 \mathrm{UJ}$ & $1000 \mathrm{UJ}$ & $990 \mathrm{UJ}$ & $990 \mathrm{U}$ & $990 \mathrm{U}$ & $1000 u$ & $990 \mathrm{U}$ & $990 \mathrm{U}$ & 1000 UJ \\
\hline 2,4-D initrophenol & $51-28-5$ & $2200 \mathrm{U}$ & $5200 \mathrm{UJ}$ & $5000 \mathrm{UJ}$ & $4800 \mathrm{UJ}$ & $4800 \mathrm{U}$ & $4800 \mathrm{U}$ & $5100 \mathrm{U}$ & $4800 U$ & $4800 \mathrm{U}$ & $5000 \mathrm{UJ}$ \\
\hline 4-Nitrophenol & $100-02-7$ & $2200 \mathrm{U}$ & $5200 \mathrm{UJ}$ & $5000 \mathrm{UJ}$ & $4800 \mathrm{UJ}$ & $4800 \mathrm{U}$ & $4800 \mathrm{U}$ & $5100 \mathrm{U}$ & $4800 \mathrm{U}$ & $4800 \mathrm{U}$ & $5000 \mathrm{UJ}$ \\
\hline
\end{tabular}

(Page 6 of 16) 
Table A-6. B-Pond Phase 3 Semivolatiles. ( $\mu \mathrm{g} / \mathrm{Kg})$ (Base/Neutral/Acid Compounds)

\begin{tabular}{|c|c|c|c|c|c|c|c|c|c|c|c|}
\hline \multicolumn{2}{|c|}{ ANALYTE } & B00GS5 & BooGs9 & 800GI7 & Boogvs & $800 \mathrm{GV} 6$ & $800 \mathrm{GV} 7$ & $800 \mathrm{GV} 8$ & BooGvg & BOOGWO & BOOGU1 \\
\hline \multicolumn{2}{|r|}{ TYPE } & Split & Reg & Reg & Reg & Reg & Reg & Reg & Btank & Reg & Reg \\
\hline \multicolumn{2}{|r|}{ POND } & $3 A$ & $3 \AA$ & $3 n$ & $3 A$ & 3B & 38 & 38 & 38 & 38 & 38 \\
\hline \multicolumn{2}{|r|}{ DEPTH } & 52.5 & 66.5 & 97 & 143.5 & 1 & 3.5 & 5.5 & $\cdots$ & 7.5 & 9.5 \\
\hline \multicolumn{2}{|r|}{ EXTRACIION DATE } & $2 / 24 / 91$ & $2 / 24 / 91$ & $2 / 27 / 91$ & $3 / 7 / 91$ & $3 / 7 / 91$ & $3 / 7 / 91$ & $3 / 7 / 91$ & $3 / 12 / 91$ & $3 / 12 / 91$ & $3 / 12 / 91$ \\
\hline \multicolumn{2}{|r|}{ ANALYSIS DATE } & $3 / 1 / 91$ & $3 / 1 / 91$ & $3 / 5 / 91$ & $3 / 12 / 91$ & $3 / 12 / 91$ & $3 / 12 / 91$ & $3 / 12 / 91$ & $3 / 14 / 91$ & $3 / 14 / 91$ & $4 / 2 / 91$ \\
\hline Dibenzofuran & $132-64-9$ & $450 \mathrm{U}$ & $1100 \mathrm{UJ}$ & $1000 \mathrm{UJ}$ & 990 UJ & $990 \mathrm{U}$ & $990 \mathrm{U}$ & $1000 \mathrm{U}$ & $990 \mathrm{U}$ & $990 \mathrm{U}$ & $1000 \mathrm{UJ}$ \\
\hline 2,4-D init rotoluene & $121-14-2$ & $450 \mathrm{U}$ & $1100 \mathrm{UJ}$ & $1000 \mathrm{UJ}$ & $990 \mathrm{UJ}$ & $990 \mathrm{U}$ & $990 \mathrm{u}$ & $1000 \mathrm{U}$ & $990 \mathrm{U}$ & $990 \mathrm{U}$ & $1000 \mathrm{UJ}$ \\
\hline 2,6-D init rotoluene & $606-20-2$ & MA & $1100 \mathrm{UJ}$ & $1000 \mathrm{UJ}$ & 990 UJ & $990 \mathrm{U}$ & $990 \mathrm{U}$ & $1000 \mathrm{U}$ & $990 \mathrm{U}$ & $990 \mathrm{U}$ & 1000 UJ \\
\hline Diethylphthalate & $84-66-2$ & $95 \mathrm{~J}$ & $1100 \mathrm{UJ}$ & 1000 us & 990 UJ & $990 \mathrm{U}$ & $990 \mathrm{u}$ & $1000 \mathrm{U}$ & $990 \mathrm{U}$ & $990 \mathrm{U}^{*}$ & $10000 \mathrm{~J}^{*}$ \\
\hline 4-Chlorophenyl-phenylether & $7005-72-3$ & $450 \mathrm{U}$ & $1100 \mathrm{UJ}$ & $1000 \mathrm{UJ}$ & 990 UJ & $990 \mathrm{U}$ & $990 \mathrm{U}$ & $1000 \mathrm{U}$ & $990 \mathrm{U}$ & $990 \mathrm{u}$ & 1000 US \\
\hline Fluorene & $86-73-7$ & $450 \mathrm{U}$ & $1100 \mathrm{UJ}$ & $1000 \mathrm{UJ}$ & 990 UJ & $990 \mathrm{U}$ & $990 \mathrm{U}$ & $1000 \mathrm{U}$ & $990 \mathrm{U}$ & $990 \mathrm{U}$ & 1000 UJ \\
\hline 4-Witroaniline & $100-01-6$ & $2200 \mathrm{U}$ & $5200 \mathrm{UJ}$ & 5000 UJ & $4800 \mathrm{UJ}$ & $4800 \mathrm{U}$ & $4800 \mathrm{U}$ & $5100 \mathrm{U}$ & $4800 \mathrm{U}$ & $4800 \mathrm{U}$ & $5000 \mathrm{UJ}$ \\
\hline 4,6-0 initro-2-methylphenol & $534-52-1$ & $2200 \mathrm{U}$ & $5200 \mathrm{UJ}$ & $5000 \mathrm{UJ}$ & $4800 \mathrm{UJ}$ & $4800 \mathrm{U}$ & $4800 \mathrm{U}$ & $5100 \mathrm{U}$ & $4800 \mathrm{U}$ & $4800 \mathrm{U}$ & 5000 UJ \\
\hline N-Nitrosodiphenyl amine & $86-30-6$ & $450 u^{\top}$ & $1100 \mathrm{UJ}$ & 1000 UJ & 990 UJ & $990 \mathrm{U}$ & $990 \mathrm{U}$ & $1000 \mathrm{U}$ & $990 \mathrm{U}$ & $990 \mathrm{u}$ & $1000 \mathrm{UJ}$ \\
\hline 4-Bromophenyl-phenylether & $101-55-3$ & $450 \mathrm{U}$ & $1100 \mathrm{UJ}$ & $1000 \mathrm{UJ}$ & 990 UJ & $990 \mathrm{U}$ & $990 \mathrm{U}$ & $1000 \mathrm{U}$ & $990 \mathrm{U}$ & $990 \mathrm{U}$ & 1000 UJ \\
\hline Hexachlorobenzene & $118-74-1$ & $450 \mathrm{U}$ & $1100 \mathrm{UJ}$ & $1000 \mathrm{UJ}$ & 990 UJ & $990 \mathrm{U}$ & $990 \mathrm{U}$ & $1000 \mathrm{U}$ & $990 \mathrm{U}$ & $990 \mathrm{U}$ & $1000 \mathrm{UJ}$ \\
\hline Pent achl or ophenol & $87-86 \cdot 5$ & $2200 \mathrm{U}$ & $5200 \mathrm{UJ}$ & $5000 \mathrm{UJ}$ & 4800 UJ & $4800 \mathrm{U}$ & $4800 \mathrm{U}$ & $5100 \mathrm{U}$ & $4800 \mathrm{U}$ & $4800 \mathrm{U}$ & 5000 UJ \\
\hline Phenanthrene & $85-01-8$ & $450 \mathrm{U}$ & $1100 \mathrm{UJ}$ & $1000 \mathrm{UJ}$ & $990 \mathrm{uJ}$ & $990 \mathrm{U}$ & $990 \mathrm{U}$ & $1000 \mathrm{U}$ & $990 \mathrm{U}$ & $990 \mathrm{U}$ & $1000 \mathrm{UJ}$ \\
\hline Anthracene & $120-12-7$ & $450 \mathrm{U}$ & $1100 \mathrm{UJ}$ & $1000 \mathrm{UJ}$ & 990 UJ & $990 \mathrm{U}$ & $990 \mathrm{U}$ & $1000 \mathrm{U}$ & $990 \mathrm{u}$ & $990 \mathrm{U}$ & $1000 \mathrm{UJ}$ \\
\hline Di-n-Butylphthalate & $84-74-2$ & $450 u^{*}$ & $1100 \mathrm{UJ}$ & $1000 \mathrm{UJ}$ & 990 UJ & $2500 \mathrm{U}$ & $990 \mathrm{U}$ & $1000 \mathrm{U}$ & $1900 \mathrm{U}$ & $990 \mathrm{U}$ & $1800 \mathrm{UJ}$ \\
\hline Fluoranthene & $206-44-0$ & $450 \mathrm{U}$ & $1100 \mathrm{UJ}$ & $1000 \mathrm{UJ}$ & 990 UJ & $990 \mathrm{U}$ & $990 \mathrm{u}$ & $1000 \mathrm{U}$ & $990 \mathrm{U}$ & $990 \mathrm{U}$ & $1000 \mathrm{UJ}$ \\
\hline Pyrene & $129-00-0$ & $450 \mathrm{U}$ & $1100 \mathrm{UJ}$ & $1000 \mathrm{UJ}$ & 990 UJ & $990 \mathrm{U}$ & $990 \mathrm{U}$ & $1000 \mathrm{U}$ & $990 \mathrm{U}$ & $990 \mathrm{U}$ & $1000 \mathrm{UJ}$ \\
\hline Butylbenzylphthalate & $85-68-7$ & $450 \mathrm{U}$ & $1100 \mathrm{UJ}$ & $1000 \mathrm{US}$ & 990 UJ & $990 \mathrm{u}$ & $990 \mathrm{U}$ & $1000 \mathrm{U}$ & $990 \mathrm{U}$ & $990 \mathrm{U}$ & $1000 \mathrm{UJ}$ \\
\hline
\end{tabular}

(Page 7 of 16) 
Table A-6. B-Pond Phase 3 Semivolatiles. $(\mu \mathrm{g} / \mathrm{Kg})$ (Base/Neutral/Acid Compounds)

\begin{tabular}{|c|c|c|c|c|c|c|c|c|c|c|}
\hline ANALYTE & BooGs5 & BOOGS9 & BOOGT7 & BooGvs & BOOGV6 & BooGv7 & BooGv8 & $800 \mathrm{cv}$ & Bo0GW0 & B00GW1 \\
\hline TYPE & Split & Reg & Reg & Reg & Reg & Reg & Reg & Blank & Reg & Reg \\
\hline POND & $3 A$ & $3 A$ & $3 A$ & $3 A$ & 38 & 38 & 38 & 3B & 38 & 38 \\
\hline DEPTH & 52.5 & 66.5 & 97 & 143.5 & 1 & 3.5 & 5.5 & $\cdots$ & 7.5 & 9.5 \\
\hline EXTRACTION DATE & $2 / 26 / 91$ & $2 / 24 / 91$ & $2 / 27 / 91$ & $3 / 7 / 91$ & $3 / 7 / 91$ & $3 / 7 / 91$ & $3 / 7 / 91$ & $3 / 12 / 91$ & $3 / 12 / 91$ & $3 / 12 / 91$ \\
\hline AMALYSIS DATE & $3 / 1 / 91$ & $3 / 1 / 91$ & $3 / 5 / 91$ & $3 / 12 / 91$ & $3 / 12 / 91$ & $3 / 12 / 91$ & $3 / 12 / 91$ & $3 / 16 / 91$ & $3 / 14 / 91$ & $4 / 2 / 91$ \\
\hline 3,3'-D ichl orobenzidine & $900 \mathrm{u}$ & $2200 \mathrm{UJ}$ & $2100 \mathrm{uJ}$ & $2000 \mathrm{UJ}$ & $2000 \mathrm{U}$ & $2000 \mathrm{U}$ & $2100 \mathrm{U}$ & $2000 \mathrm{U}$ & $2000 \mathrm{U}$ & $2000 \mathrm{UJ}$ \\
\hline Benzo( $\theta$ ) anthracene & $450 \mathrm{U}$ & $1100 \mathrm{UJ}$ & $1000 \mathrm{us}$ & $990 \mathrm{uJ}$ & $990 \mathrm{u}$ & $990 \mathrm{U}$ & $1000 \mathrm{U}$ & $990 \mathrm{U}$ & $990 \mathrm{U}$ & $1000 \mathrm{UJ}$ \\
\hline bis(2-ethylhexyl)phthalate & $450 u^{*}$ & $1100 \mathrm{UJ}$ & $1000 \mathrm{us}$ & 990 us & $990 \mathrm{U}$ & $990 \cup$ & $1000 \mathrm{U}$ & $990 \mathrm{U}$ & $990 \cup$ & $1000 \mathrm{UJ}$ \\
\hline $218-01-9$ & $450 \mathrm{U}$ & $1100 \mathrm{UJ}$ & $1000 \mathrm{UJ}$ & $990 \mathrm{UJ}$ & $990 \mathrm{U}$ & $990 \mathrm{U}$ & $1000 \mathrm{U}$ & $990 \mathrm{U}$ & $990 \mathrm{u}$ & $1000 \mathrm{UJ}$ \\
\hline Di-n-octylphthalate & $450 \mathrm{U}$ & $1100 \mathrm{UJ}$ & $1000 \mathrm{UJ}$ & 990 Us & $990 \mathrm{U}$ & $990 \mathrm{U}$ & $1000 \mathrm{U}$ & 9900 & $990 \mathrm{U}$ & $1000 \mathrm{UJ}$ \\
\hline Benzo(b)fluoranthene & $450 \mathrm{U}$ & $1100 \mathrm{UJ}$ & $1000 \mathrm{UJ}$ & 990 uJ & $990 \mathrm{U}$ & $990 \mathrm{U}$ & $1000 \mathrm{U}$ & $990 \mathrm{U}$ & $990 \mathrm{u}$ & $1000 \mathrm{UJ}$ \\
\hline Benzo( $k$ )f lworanthene & $450 \mathrm{U}$ & $1100 \mathrm{UJ}$ & $1000 \mathrm{UJ}$ & $990 \mathrm{UJ}$ & $990 \mathrm{u}$ & $990 \mathrm{u}$ & $1000 \mathrm{v}$ & $990 \mathrm{v}$ & $990 \mathrm{u}$ & $1000 \mathrm{UJ}$ \\
\hline Benzo(a)pyrene & $450 \mathrm{U}$ & $1100 \mathrm{UJ}$ & $1000 \mathrm{UJ}$ & 990 UJ & $990 \mathrm{U}$ & $990 \mathrm{U}$ & $1000 \mathrm{U}$ & $990 \mathrm{U}$ & $990 \mathrm{U}$ & $1000 \mathrm{UJ}$ \\
\hline Indeno $(1,2,3-c d)$ pyrene & $450 \mathrm{U}$ & $1100 \mathrm{UJ}$ & $1000 \mathrm{UJ}$ & $990 \mathrm{UJ}$ & $990 \mathrm{U}$ & $990 \mathrm{U}$ & $1000 \mathrm{U}$ & $990 \mathrm{U}$ & $990 \mathrm{U}$ & $1000 \mathrm{UJ}$ \\
\hline D ibenz $(\theta, h)$ anthracene & $450 \mathrm{U}$ & $1100 \mathrm{UJ}$ & $1000 \mathrm{Ud}$ & $990 \mathrm{UJ}$ & $990 \mathrm{u}$ & $990 \mathrm{U}$ & $1000 \mathrm{U}$ & $990 \cup$ & $990 \mathrm{U}$ & $1000 \mathrm{UJ}$ \\
\hline Benzo(g,h,i)peryl ene & 4500 & $1100 \mathrm{uJ}$ & $1000 \mathrm{UJ}$ & $990 \mathrm{UJ}$ & $990 \mathrm{U}$ & $990 \mathrm{U}$ & $1000 \mathrm{U}$ & $990 \mathrm{U}$ & $990 \mathrm{U}$ & 1000 UJ \\
\hline $\begin{array}{l}\text { OTHER WAC-173-303-9905 DANGEROUS WASIE } \\
\text { CONSIITUENIS? }\end{array}$ & No & No & No & No & No & No & No & Mo & No & Mo \\
\hline Total TICs & 0 & 8 & 13 & 7 & 17 & 9 & 7 & 16 & 11 & 9 \\
\hline IICs without laboratory "B" flags & 0 & 4 & 11 & 4 & 9 & 2 & 2 & 8 & 4 & 2 \\
\hline
\end{tabular}


Table A-6. B-Pond Phase 3 Semivolatiles. ( $\mu \mathrm{g} / \mathrm{K} \mathrm{g})$

(Base/Neutral/Acid Compounds)

\begin{tabular}{|c|c|c|c|c|c|c|c|c|c|c|c|}
\hline AHALYTE & CAS* & BOOGW3 & BOOGW4 & B00GWS & BOOGWB & $800 \mathrm{G} \times 6$ & $800 G z 2$ & $800 G 26$ & BOOG28 & воОноО & ВоОНО1 \\
\hline & TYPE & Reg & Fodup & Split & Reg & Reg & Reg & Reg & Reg & Reg & Reg \\
\hline & POND & 3в & 38 & 38 & 3B & 38 & 3B & 38 & 38 & $3 c$ & 3c \\
\hline & DEPTH & 13 & 13 & 13 & 21 & 61.5 & 90.5 & 118.5 & 123.5 & 1 & 3 \\
\hline & EXTRACTION DATE & $3 / 12 / 91$ & $3 / 12 / 91$ & $3 / 13 / 91$ & $3 / 12 / 91$ & $3 / 17 / 91$ & $3 / 17 / 91$ & $3 / 21 / 91$ & $4 / 2 / 91$ & $3 / 21 / 91$ & $3 / 21 / 91$ \\
\hline & ANALYSIS DATE & $4 / 2 / 91$ & $3 / 14 / 91$ & $4 / 8 / 91$ & $4 / 2 / 91$ & $4 / 4 / 91$ & 4/4/91 & 4/1/91 & 4/5/91 & 4/1/91 & $4 / 1 / 91$ \\
\hline Phenol & $108-95-2$ & $1000 \mathrm{Ud}$ & $1000 \mathrm{U}$ & $370 \mathrm{U}$ & $1000 \mathrm{UJ}$ & $1000 \mathrm{UJ}$ & $1000 \mathrm{UJ}$ & $1200 \mathrm{UJ}$ & $1500 \mathrm{UJ}$ & 1000 Us & $1000 \mathrm{UJ}$ \\
\hline bis(2-chl oroethyl)ether & $111-44-4$ & 1000 UJ & $1000 \mathrm{U}$ & $370 \mathrm{v}$ & $1000 \mathrm{UJ}$ & $1000 \mathrm{UJ}$ & $1000 \mathrm{UJ}$ & $1200 \mathrm{UJ}$ & $1500 \mathrm{UJ}$ & $1000 \mathrm{UJ}$ & $1000 \mathrm{UJ}$ \\
\hline 2-Chlorophenol & $95-57-8$ & $1000 \mathrm{UJ}$ & $1000 \mathrm{U}$ & $370 \mathrm{u}$ & $1000 \mathrm{uJ}$ & 1000 US & $1000 \mathrm{UJ}$ & $1200 \mathrm{UJ}$ & 1500 UJ & $1000 \mathrm{UJ}$ & $1000 \mathrm{UJ}$ \\
\hline 1,3-0 ichl or obenzene & $541-73-1$ & $1000 \mathrm{UJ}$ & $1000 \mathrm{U}$ & $370 \mathrm{U}$ & 1000 us & $1000 \mathrm{UJ}$ & $1000 \mathrm{UJ}$ & $1200 \mathrm{vJ}$ & 1500 US & $1000 \mathrm{UJ}$ & $1000 \mathrm{UJ}$ \\
\hline 1,4-Dichlor obenzene & $106-46-7$ & $1000 \mathrm{US}$ & $1000 \mathrm{U}$ & $370 \mathrm{U}$ & 1000 UJ & $1000 \mathrm{UJ}$ & $1000 \mathrm{UJ}$ & $1200 \mathrm{UJ}$ & $1500 \mathrm{UJ}$ & $1000 \mathrm{UJ}$ & $1000 \mathrm{UJ}$ \\
\hline Benzyl Al cohol & $100-51-6$ & $1000 \mathrm{uJ}$ & $1000 \mathrm{U}$ & $370 \mathrm{U}$ & $1000 \mathrm{UJ}$ & $1000 \mathrm{UJ}$ & $1000 \mathrm{UJ}$ & $1200 \mathrm{Us}$ & 1500 UJ & $1000 \mathrm{UJ}$ & $1000 \mathrm{UJ}$ \\
\hline 1,2-D ichlor obenzene & $95-50-1$ & $1000 \mathrm{UJ}$ & $1000 \mathrm{U}$ & $370 \mathrm{U}$ & $1000 \mathrm{UJ}$ & $1000 \mathrm{Ud}$ & $1000 \mathrm{UJ}$ & $1200 \mathrm{us}$ & 1500 UJ & 1000 UJ & 1000 UJ \\
\hline 2-Methylphenol & $95-48-7$ & $1000 \mathrm{UJ}$ & $1000 \mathrm{U}$ & $370 \mathrm{v}$ & 1000 UJ & $1000 \mathrm{UJ}$ & $1000 \mathrm{UJ}$ & $1200 \mathrm{UJ}$ & $1500 \mathrm{UJ}$ & $1000 \mathrm{UJ}$ & $1000 \mathrm{UJ}$ \\
\hline $\begin{array}{l}\text { bis(2-Chlorolsopropyl) } \\
\text { ether }\end{array}$ & $108-60-1$ & $1000 \mathrm{UJ}$ & $1000 \mathrm{U}$ & $370 \mathrm{U}$ & $1000 \mathrm{UJ}$ & $1000 \mathrm{UJ}$ & $1000 \mathrm{UJ}$ & $1200 \mathrm{UJ}$ & 1500 Ud & $1000 \mathrm{UJ}$ & 1000 UJ \\
\hline 4-Methylphenol & $106-44-5$ & $1000 \mathrm{UJ}$ & $1000 \mathrm{U}$ & $370 \mathrm{v}$ & $1000 \mathrm{UJ}$ & 1000 US & 1000 US & $1200 \mathrm{UJ}$ & $1500 \mathrm{UJ}$ & 1000 UJ & 1000 UJ \\
\hline W-Wit rosodipropylamine & $621-64-7$ & $1000 \mathrm{UJ}$ & $1000 \mathrm{U}$ & $370 \mathrm{U}$ & $1000 \mathrm{UJ}$ & $1000 \mathrm{UJ}$ & $1000 \mathrm{UJ}$ & $1200 \mathrm{UJ}$ & 1500 Us & $1000 \mathrm{UJ}$ & 1000 UJ \\
\hline Hexachloroethane & $67-72-1$ & $1000 \mathrm{UJ}$ & $1000 \mathrm{U}$ & $370 \mathrm{u}$ & 1000 UJ & 1000 UJ & $1000 \mathrm{UJ}$ & $1200 \mathrm{UJ}$ & $1500 \mathrm{UJ}$ & $1000 \mathrm{UJ}$ & 1000 UJ \\
\hline Nitrobenzene & $98-95-3$ & $1000 \mathrm{UJ}$ & $1000 \mathrm{U}$ & $370 \mathrm{U}$ & $1000 \mathrm{UJ}$ & 1000 US & $1000 \mathrm{UJ}$ & $1200 \mathrm{UJ}$ & $1500 \mathrm{UJ}$ & $1000 \mathrm{UJ}$ & 1000 UJ \\
\hline Isophorone & $78-59-1$ & $1000 \mathrm{vJ}$ & $1000 \mathrm{U}$ & $370 \mathrm{U}$ & $1000 \mathrm{UJ}$ & $1000 \mathrm{UJ}$ & $1000 \mathrm{UJ}$ & $1200 \mathrm{UJ}$ & $1500 \mathrm{UJ}$ & $1000 \mathrm{UJ}$ & $1000 \mathrm{UJ}$ \\
\hline 2-Nitrophenol & $88-75-5$ & $1000 \mathrm{UJ}$ & $1000 \mathrm{U}$ & $370 \mathrm{v}$ & $1000 \mathrm{UJ}$ & $1000 \mathrm{UJ}$ & $1000 \mathrm{UJ}$ & $1200 \mathrm{UJ}$ & $1500 \mathrm{UJ}$ & $1000 \mathrm{UJ}$ & $1000 \mathrm{UJ}$ \\
\hline 2,4-D imethyl phenol & $105-67-9$ & 1000 US & $1000 \mathrm{v}$ & $370 \mathrm{U}$ & $1000 \mathrm{UJ}$ & $1000 \mathrm{UJ}$ & $1000 \mathrm{UJ}$ & $1200 \mathrm{UJ}$ & $1500 \mathrm{UJ}$ & $1000 \mathrm{us}$ & $1000 \mathrm{UJ}$ \\
\hline Benzoic acid & $65-85-0$ & 4900 UJ & $4900 \mathrm{U}$ & $1900 \mathrm{U}$ & 5000 us & $5100 \mathrm{UJ}$ & $5000 \mathrm{UJ}$ & $5800 \mathrm{UJ}$ & $73000 \mathrm{~s} *$ & 5000 UJ & $5000 \mathrm{UJ}$ \\
\hline bis (2-chloroethoxy)methane & $111-91-1$ & 1000 UJ & $1000 \mathrm{U}$ & $370 \mathrm{U}$ & $1000 \mathrm{UJ}$ & $1000 \mathrm{UJ}$ & $1000 \mathrm{UJ}$ & $1200 \mathrm{UJ}$ & $1500 \mathrm{UJ}$ & $1000 \mathrm{UJ}$ & $1000 \mathrm{UJ}$ \\
\hline
\end{tabular}

(Page 9 of 16) 
Table A-6. B-Pond Phase 3 Semivolatiles. $(\mu \mathrm{g} / \mathrm{Kg})$ (Base/Neutral/Acid Compounds)

\begin{tabular}{|c|c|c|c|c|c|c|c|c|c|c|c|}
\hline AHALYTE & CASE & $800 \mathrm{GW} 3$ & BOOGH4 & B00GW5 & B00GW8 & $8006 \times 6$ & B00GZ2 & $800 G 26$ & $800 G 28$ & ВООНОО & в00но1 \\
\hline & TYPE & Reg & Fdup & Split & Reg & Reg & Reg & Reg & Reg & Reg. & Reg \\
\hline & POND & 38 & 38 & 38 & 38 & 38 & 38 & 38 & 3B & 3c & $3 c$ \\
\hline & DEPTH & 13 & 13 & 13 & 21 & 61.5 & 90.5 & 118.5 & 123.5 & 1 & 3 \\
\hline & EXIRACTION DATE & $3 / 12 / 91$ & $3 / 12 / 91$ & $3 / 13 / 91$ & $3 / 12 / 91$ & $3 / 17 / 91$ & $3 / 17 / 91$ & $3 / 21 / 91$ & $4 / 2 / 91$ & $3 / 21 / 91$ & $3 / 21 / 91$ \\
\hline & ANALYSIS DATE & $4 / 2 / 91$ & $3 / 14 / 91$ & $4 / 8 / 91$ & $4 / 2 / 91$ & $4 / 4 / 91$ & 4/4/91 & 4/1/91 & 4/5/91 & 4/1/91 & $4 / 1 / 91$ \\
\hline 2,4-0 ichlorophenol & $120-83-2$ & $1000 \mathrm{UJ}$ & $1000 \mathrm{U}$ & $370 u$ & $1000 \mathrm{UJ}$ & $1000 \mathrm{UJ}$ & $1000 \mathrm{Ud}$ & $1200 \mathrm{UJ}$ & $1500 \mathrm{Ud}$ & $1000 \mathrm{UJ}$ & $1000 \mathrm{UJ}$ \\
\hline 1,2,4-Tríchlorobenzene & $120-82-1$ & $1000 \mathrm{uJ}$ & $1000 \mathrm{U}$ & $370 \mathrm{u}$ & $1000 \mathrm{UJ}$ & 1000 Us & $1000 \mathrm{Ud}$ & $1200 \mathrm{UJ}$ & $1500 \mathrm{UJ}$ & $1000 \mathrm{UJ}$ & $1000 \mathrm{UJ}$ \\
\hline Naphthalene & $91-20-3$ & $1000 \mathrm{UJ}$ & $1000 \mathrm{U}$ & $370 \mathrm{U}$ & $1000 \mathrm{UJ}$ & $1000 \mathrm{UJ}$ & $1000 \mathrm{UJ}$ & $1200 \mathrm{UJ}$ & 1500 US & $1000 \mathrm{uJ}$ & $1000 \mathrm{UJ}$ \\
\hline 4-Chloroaniline & $106-47-8$ & $1000 \mathrm{uJ}$ & $1000 \mathrm{U}$ & $370 \mathrm{u}$ & $1000 \mathrm{uJ}$ & $1000 \mathrm{UJ}$ & $1000 \mathrm{UJ}$ & $1200 \mathrm{UJ}$ & $1500 \mathrm{UJ}$ & $1000 \mathrm{UJ}$ & $1000 \mathrm{UJ}$ \\
\hline Hexachlorabut adiene & $87-68-3$ & $1000 \mathrm{UJ}$ & $1000 u$ & $370 \mathrm{u}$ & $1000 \mathrm{UJ}$ & $1000 \mathrm{UJ}$ & $1000 \mathrm{US}$ & $1200 \mathrm{UJ}$ & $1500 \mathrm{UJ}$ & $1000 \mathrm{UJ}$ & $1000 \mathrm{UJ}$ \\
\hline 4-Chloro-3-methylphenol & $59-50-7$ & $1000 \mathrm{us}$ & $1000 \mathrm{U}$ & $370 \mathrm{v}$ & $1000 \mathrm{uJ}$ & $1000 \mathrm{WJ}$ & $1000 \mathrm{UJ}$ & $1200 \mathrm{uJ}$ & $1500 \mathrm{UJ}$ & $1000 \mathrm{UJ}$ & $1000 \mathrm{UJ}$ \\
\hline 2-Methylnaphthal ene & $91-57-6$ & $1000 \mathrm{UJ}$ & $1000 U$ & $370 \mathrm{u}$ & $1000 \mathrm{uJ}$ & $1000 \mathrm{uJ}$ & $1000 \mathrm{UJ}$ & $1200 \mathrm{UJ}$ & 1500 UJ & $1000 \mathrm{UJ}$ & $1000 \mathrm{UJ}$ \\
\hline Hexachl or ocyclopentadiene & $77-47-4$ & $1000 \mathrm{uJ}$ & $1000 \mathrm{U}$ & $370 \mathrm{v}$ & $1000 \mathrm{UJ}$ & $1000 \mathrm{UJ}$ & $1000 \mathrm{UJ}$ & $1200 \mathrm{UJ}$ & $1500 \mathrm{Ud}$ & $1000 \mathrm{UJ}$ & $1000 \mathrm{UJ}$ \\
\hline 2,4,6-Irichlorophenol & $88-06-2$ & $1000 \mathrm{UJ}$ & $1000 \mathrm{U}$ & 370 u & $1000 \mathrm{UJ}$ & $1000 \mathrm{UJ}$ & $1000 \mathrm{uJ}$ & $1200 \mathrm{us}$ & 1500 UJ & $1000 \mathrm{UJ}$ & $1000 \mathrm{UJ}$ \\
\hline $2,4,5$ - Irichlorophenol & $95-95-4$ & $4900 \mathrm{UJ}$ & $4900 \mathrm{U}$ & $1900 \mathrm{U}$ & $5000 \mathrm{UJ}$ & $5100 \mathrm{UJ}$ & 5000 uJ & $5800 \mathrm{uJ}$ & 7300 Ud & $5000 \mathrm{uJ}$ & 5000 UJ \\
\hline 2-Chloronaph that ene & $91-58-7$ & $1000 \mathrm{UJ}$ & $1000 v$ & $370 \mathrm{u}$ & $1000 \mathrm{uJ}$ & $1000 \mathrm{UJ}$ & $1000 \mathrm{UJ}$ & $1200 \mathrm{UJ}$ & $1500 \mathrm{UJ}$ & $1000 \mathrm{UJ}$ & $1000 \mathrm{UJ}$ \\
\hline 2-Nitroaniline & $88-7 i-4$ & $6900 \mathrm{Ud}$ & $4900 \mathrm{U}$ & $1900 \mathrm{U}$ & $5000 \mathrm{uJ}$ & $5100 \mathrm{UJ}$ & $5000 \mathrm{us}$ & 5800 UJ & $7300 \mathrm{UJ}$ & $5000 \mathrm{UJ}$ & $5000 \mathrm{UJ}$ \\
\hline Dimethylphthalate & $131-11-3$ & $1000 \mathrm{UJ}$ & $1000 \mathrm{U}$ & $370 \mathrm{U}$ & $1000 \mathrm{UJ}$ & $1000 \mathrm{UJ}$ & $1000 \mathrm{UJ}$ & $1200 \mathrm{UJ}$ & $1500 \mathrm{UJ}$ & $1000 \mathrm{UJ}$ & $1000 \mathrm{UJ}$ \\
\hline Acenaphthylene & $208-96-8$ & $1000 \mathrm{UJ}$ & $1000 \mathrm{U}$ & $370 \mathrm{u}$ & 1000 Us & $1000 \mathrm{UJ}$ & $1000 \mathrm{UJ}$ & $1200 \mathrm{UJ}$ & $1500 \mathrm{UJ}$ & 1000 us & $1000 \mathrm{UJ}$ \\
\hline 3-Nitroaniline & $99-09-2$ & $4900 \mathrm{UJ}$ & $4900 \mathrm{U}$ & $1900 \mathrm{u}$ & $5000 \mathrm{UJ}$ & $5100 \mathrm{UJ}$ & $5000 \mathrm{Us}$ & 5800 UJ & 7300 Us & $5000 \mathrm{UJ}$ & $5000 \mathrm{UJ}$ \\
\hline Acenaphthene & $83-32-9$ & $1000 \mathrm{UJ}$ & $1000 \mathrm{U}$ & $370 \mathrm{v}$ & $1000 \mathrm{UJ}$ & $1000 \mathrm{uJ}$ & $1000 \mathrm{us}$ & $1200 \mathrm{UJ}$ & $1500 \mathrm{UJ}$ & $1000 \mathrm{UJ}$ & $1000 \mathrm{UJ}$ \\
\hline 2,4-D init rophenol & $51-28-5$ & $4900 \mathrm{UJ}$ & $4900 \mathrm{U}$ & $1900 \mathrm{U}$ & $5000 \mathrm{UJ}$ & $5100 \mathrm{UJ}$ & $5000 \mathrm{UJ}$ & $5800 \mathrm{UJ}$ & 7300 Us & 5000 UJ & $5000 \mathrm{UJ}$ \\
\hline 4-Nitrophenol & $100-02-7$ & $4900 \mathrm{UJ}$ & $4900 \mathrm{U}$ & $1900 \mathrm{U}$ & $5000 \mathrm{UJ}$ & $5100 \mathrm{UJ}$ & $5000 \mathrm{UJ}$ & $5800 \mathrm{UJ}$ & $7300 \mathrm{UJ}$ & $5000 \mathrm{UJ}$ & $5000 \mathrm{UJ}$ \\
\hline
\end{tabular}

(Page 10 of 16) 
Table A-6. B-Pond Phase 3 Semivolatiles. $(\mu \mathrm{g} / \mathrm{Kg})$

(Base/Neutral/Acid Compounds)

\begin{tabular}{|c|c|c|c|c|c|c|c|c|c|c|c|}
\hline \multicolumn{2}{|c|}{ ANALYTE } & B00GW3 & BOOGW4 & BOOGUS & BOOGW8 & $8006 \times 6$ & 800622 & 800626 & 800628 & ВоОноО & ВоОно1 \\
\hline & TYPE & Reg & folup & Split & Reg & Reg & Reg & Reg & Reg & Reg & Reg \\
\hline & POND & 38 & 38 & 38 & 38 & $3 B$ & 3B & 38 & 38 & $3 c$ & $3 c$ \\
\hline & DEPIH & 13 & 13 & 13 & 21 & 61.5 & 90.5 & 118.5 & 123.5 & 1 & 3 \\
\hline \multicolumn{2}{|r|}{ EXTRACTION DATE } & $3 / 12 / 91$ & $3 / 12 / 91$ & $3 / 13 / 91$ & $3 / 12 / 91$ & $3 / 17 / 91$ & $3 / 17 / 91$ & $3 / 21 / 91$ & 4/2/91 & $3 / 21 / 91$ & $3 / 21 / 91$ \\
\hline \multicolumn{2}{|r|}{ ANALYSIS DATE } & $4 / 2 / 91$ & $3 / 14 / 91$ & 4/8/91 & $4 / 2 / 91$ & 4/4/91 & 4/4/91 & 4/1/91 & 4/5/91 & 4/1/91 & $4 / 1 / 91$ \\
\hline Dibenzofuran & $132-64-9$ & $1000 \mathrm{UJ}$ & $1000 \mathrm{u}$ & $370 \mathrm{v}$ & $1000 \mathrm{UJ}$ & $1000 \mathrm{UJ}$ & $1000 \mathrm{UJ}$ & $1200 \mathrm{UJ}$ & $1500 \mathrm{UJ}$ & 1000 Us & $1000 \mathrm{UJ}$ \\
\hline 2,4-D initrotoluene & $121-14-2$ & $1000 \mathrm{UJ}$ & $1000 \mathrm{U}$ & $370 \mathrm{v}$ & $1000 \mathrm{UJ}$ & 1000 Us & 1000 UJ & $1200 \mathrm{us}$ & $1500 \mathrm{UJ}$ & 1000 UJ & $1000 \mathrm{UJ}$ \\
\hline 2,6-D init rotoluene & $606-20-2$ & $1000 \mathrm{UJ}$ & $1000 \mathrm{U}$ & ma & $1000 \mathrm{UJ}$ & $1000 \mathrm{UJ}$ & 1000 Ud & $1200 \mathrm{UJ}$ & 1500 Ud & $1000 \mathrm{UJ}$ & 1000 us \\
\hline Diethylphthalate & $84-66-2$ & $1000 \mathrm{~J} \star$ & $1000 U^{*}$ & $370 \cup$ & $1000 \mathrm{UJ}$ & 1000 UJ & $370 \mathrm{~J}$ & $1200 \mathrm{UJ}$ & $15000 \mathrm{~J} *$ & $1000 \mathrm{UJ}$ & $1000 \mathrm{UJ}$ \\
\hline 4-Chlorophenyl-phenylether & $7005-72-3$ & $1000 \mathrm{UJ}$ & $1000 u$ & $370 \mathrm{U}$ & $1000 \mathrm{UJ}$ & $1000 \mathrm{uJ}$ & $1000 \mathrm{us}$ & 1200 UJ & $1500 \mathrm{UJ}$ & $1000 \mathrm{Ud}$ & $1000 \mathrm{UJ}$ \\
\hline Fluorene & $86-73-7$ & $1000 \mathrm{uJ}$ & $1000 \mathrm{U}$ & $370 \mathrm{u}$ & $1000 \mathrm{UJ}$ & $1000 \mathrm{UJ}$ & $1000 \mathrm{UJ}$ & $1200 \mathrm{uJ}$ & $1500 \mathrm{UJ}$ & 1000 UJ & $1000 \mathrm{UJ}$ \\
\hline 4-Mitroaniline & $100-01-6$ & $4900 \mathrm{UJ}$ & $4900 \mathrm{U}$ & $1900 \mathrm{U}$ & $5000 \mathrm{UJ}$ & 5100 Ud & $5000 \mathrm{UJ}$ & $5800 \mathrm{UJ}$ & 7300 us & $5000 \mathrm{UJ}$ & 5000 UJ \\
\hline 4,6-D initro-2-methylphenol & $534-52-1$ & 4900 UJ & $4900 \cup$ & $1900 \mathrm{U}$ & $5000 \mathrm{UJ}$ & $5100 \mathrm{Ud}$ & $5000 \mathrm{UJ}$ & 5800 UJ & 7300 us & $5000 \mathrm{UJ}$ & $5000 \mathrm{UJ}$ \\
\hline W-Mitrosodiphenyl smine & $86-30-6$ & 1000 Us & $1000 \mathrm{U}$ & $90 \mathrm{~J}^{1}$ & $1000 \mathrm{UJ}$ & $1000 \mathrm{US}$ & 1000 Us & $1200 \mathrm{UJ}$ & 1500 Ud & $1000 \mathrm{UJ}$ & $1000 \mathrm{UJ}$ \\
\hline 4-Bromophenyl-phenylether & $101-55-3$ & $1000 \mathrm{UJ}$ & $1000 \mathrm{U}$ & $370 \mathrm{u}$ & $1000 \mathrm{UJ}$ & $1000 \mathrm{UJ}$ & $1000 \mathrm{UJ}$ & $1200 \mathrm{UJ}$ & $1500 \mathrm{UJ}$ & $1000 \mathrm{UJ}$ & $1000 \mathrm{UJ}$ \\
\hline Hexachl orobenzene & $118-74-1$ & $1000 \mathrm{UJ}$ & $1000 \mathrm{U}$ & $370 \mathrm{U}$ & $1000 \mathrm{UJ}$ & $1000 \mathrm{UJ}$ & $1000 \mathrm{UJ}$ & $1200 \mathrm{UJ}$ & 1500 UJ & $1000 \mathrm{UJ}$ & $1000 \mathrm{UJ}$ \\
\hline Pentachlorophenol & $87-86-5$ & 4900 UJ & $4900 \mathrm{U}$ & $1900 \mathrm{U}$ & 5000 UJ & $5100 \mathrm{UJ}$ & $5000 \mathrm{UJ}$ & $5800 \mathrm{UJ}$ & 7300 us & 5000 us & $5000 \mathrm{UJ}$ \\
\hline Phenanthrene & $85-01-8$ & 1000 us & $1000 u$ & $370 \mathrm{U}$ & $1000 \mathrm{UJ}$ & $1000 \mathrm{Us}$ & $1000 \mathrm{UJ}$ & $1200 \mathrm{UJ}$ & 1500 us & $1000 \mathrm{UJ}$ & 1000 UJ \\
\hline Anthracene & $120-12-7$ & $1000 \mathrm{UJ}$ & $1000 \mathrm{U}$ & $370 \mathrm{v}$ & $1000 \mathrm{UJ}$ & $1000 \mathrm{UJ}$ & $1000 \mathrm{UJ}$ & $1200 \mathrm{UJ}$ & 1500 UJ & $1000 \mathrm{UJ}$ & $1000 \mathrm{UJ}$ \\
\hline Di-n-Butylphthalate & $84-74-2$ & $1000 \mathrm{UJ}$ & $1000 \mathrm{U}$ & $45 \mathrm{~J}$ & $1500 \mathrm{UJ}$ & $1000 \mathrm{UJ}$ & $1400 \mathrm{UJ}$ & $1200 \mathrm{UJ}$ & 4500 Ud & $1000 \mathrm{UJ}$ & 1000 UJ \\
\hline Fluoranthene & $206-44-0$ & $1000 \mathrm{UJ}$ & $1000 \mathrm{u}$ & $370 \mathrm{U}$ & $1000 \mathrm{UJ}$ & $1000 \mathrm{UJ}$ & 1000 UJ & $1200 \mathrm{UJ}$ & $1500 \mathrm{UJ}$ & $1000 \mathrm{UJ}$ & $1000 \mathrm{UJ}$ \\
\hline Pyrene & $129-00-0$ & 1000 Us & $1000 \mathrm{U}$ & $370 \mathrm{v}$ & $1000 \mathrm{UJ}$ & $1000 \mathrm{UJ}$ & $1000 \mathrm{UJ}$ & $1200 \mathrm{UJ}$ & 1500 UJ & $1000 \mathrm{UJ}$ & $1000 \mathrm{UJ}$ \\
\hline Butylbenzylphthal ate & $85-68-7$ & $1000 \mathrm{us}$ & $1000 u$ & $370 \mathrm{U}$ & $1000 \mathrm{UJ}$ & $1000 \mathrm{uJ}$ & $1000 \mathrm{UJ}$ & $1200 \mathrm{UJ}$ & $1500 \mathrm{UJ}$ & $1000 \mathrm{UJ}$ & $1000 \mathrm{UJ}$ \\
\hline
\end{tabular}

(Page 11 of 16) 
Table A-6. B-Pond Phase 3 Semivolatiles. ( $\mu \mathrm{g} / \mathrm{Kg})$ (Base/Neutral/Acid Compounds)

\begin{tabular}{|c|c|c|c|c|c|c|c|c|c|c|c|}
\hline AMALYTE & CAS* & $800 \mathrm{GW} 3$ & $800 \mathrm{GW}$ & BOOGWS & B00GU8 & $800 \mathrm{G} \times 6$ & B00Gz2 & 800626 & B00G28 & 8оОноО & 80OHO1 \\
\hline \multicolumn{2}{|r|}{ IYPE } & Reg & Fdup & Split & Reg & Reg & Reg & Reg & Reg & Reg & Reg \\
\hline \multicolumn{2}{|r|}{ POND } & 38 & 38 & 38 & 38 & 3B & 3B & 3B & 38 & $3 c$ & $3 c$ \\
\hline \multicolumn{2}{|r|}{ DEPIH } & 13 & 13 & 13 & 21 & 61.5 & 90.5 & 118.5 & 123.5 & 1 & 3 \\
\hline \multicolumn{2}{|r|}{ EXTRACTIOA DATE } & $3 / 12 / 91$ & $3 / 12 / 91$ & $3 / 13 / 91$ & $3 / 12 / 91$ & $3 / 17 / 91$ & $3 / 17 / 91$ & $3 / 21 / 91$ & 4/2/91 & $3 / 21 / 91$ & $3 / 21 / 91$ \\
\hline \multicolumn{2}{|r|}{ ANALYSIS DATE } & $4 / 2 / 91$ & $3 / 14 / 91$ & $4 / 8 / 91$ & $4 / 2 / 91$ & $4 / 4 / 91$ & $4 / 4 / 91$ & 4/1/91 & 4/5/91 & $4 / 1 / 91$ & $4 / 1 / 91$ \\
\hline 3,3'-Dichlorobenzidine & $91-94-1$ & 2000 UJ & $2000 \mathrm{U}$ & $740 \mathrm{U}$ & $2000 \mathrm{UJ}$ & $2100 \mathrm{UJ}$ & $2100 \mathrm{UJ}$ & $2400 \mathrm{UJ}$ & $3000 \mathrm{UJ}$ & $2100 \mathrm{UJ}$ & $2100 \mathrm{UJ}$ \\
\hline Benzo(a) anthracene & $56-55-3$ & $1000 \mathrm{UJ}$ & $1000 \mathrm{U}$ & $370 \mathrm{u}$ & $1000 \mathrm{UJ}$ & $1000 \mathrm{Ud}$ & $1000 \mathrm{UJ}$ & $1200 \mathrm{UJ}$ & $1500 \mathrm{US}$ & $1000 \mathrm{UJ}$ & $1000 \mathrm{UJ}$ \\
\hline bis(2-ethylhexyl)phthalate & $117-81-7$ & $1000 \mathrm{UJ}$ & $1000 \mathrm{u}$ & $54 \mathrm{~d}$ & $1000 \mathrm{UJ}$ & $1000 \mathrm{UJ}$ & $1000 \mathrm{UJ}$ & $1200 \mathrm{Us}$ & 1500 Ud & 1200 Us & $1600 \mathrm{UJ}$ \\
\hline Chrysene & 218-01-9 & $1000 \mathrm{UJ}$ & $1000 \mathrm{u}$ & $370 \mathrm{U}$ & $1000 \mathrm{UJ}$ & $1000 \mathrm{UJ}$ & $1000 \mathrm{Us}$ & 1200 Us & 1500 Ud & $1000 \mathrm{UJ}$ & $1000 \mathrm{UJ}$ \\
\hline Di-n-octylphthalats & $117-84-0$ & 1000 UJ & $1000 \mathrm{U}$ & $370 u$ & $1000 \mathrm{UJ}$ & $1000 \mathrm{UJ}$ & 1000 UJ & $1200 \mathrm{UJ}$ & $1500 \mathrm{UJ}$ & $1000 \mathrm{UJ}$ & $1000 \mathrm{UJ}$ \\
\hline Benzo(b)f lworanthene & $205-99-2$ & $1000 \mathrm{UJ}$ & $1000 \mathrm{U}$ & $370 \mathrm{u}$ & $1000 \mathrm{UJ}$ & $1000 \mathrm{UJ}$ & 1000 Us & $1200 \mathrm{UJ}$ & $1500 \mathrm{UJ}$ & $1000 \mathrm{UJ}$ & $1000 \mathrm{UJ}$ \\
\hline Benzo(k)fluoranthene & $207-08-9$ & $1000 \mathrm{UJ}$ & $1000 \mathrm{U}$ & $370 \mathrm{U}$ & $1000 \mathrm{UJ}$ & $1000 \mathrm{UJ}$ & $1000 \mathrm{UJ}$ & $1200 \mathrm{UJ}$ & $1500 \mathrm{UJ}$ & 1000 UJ & 1000 U J \\
\hline Benzo(B)pyrene & $50-32-8$ & 1000 Ud & $1000 \mathrm{u}$ & $370 \cup$ & $1000 \mathrm{UJ}$ & $1000 \mathrm{UJ}$ & $1000 \mathrm{UJ}$ & $1200 \mathrm{uJ}$ & $1500 \mathrm{UJ}$ & $1000 \mathrm{UJ}$ & $1000 \mathrm{UJ}$ \\
\hline Indeno $(1,2,3$-cd)pyrene & $193-39-5$ & $1000 \mathrm{UJ}$ & $1000 \mathrm{U}$ & $370 \mathrm{u}$ & $1000 \mathrm{UJ}$ & $1000 \mathrm{UJ}$ & $1000 \mathrm{UJ}$ & $1200 \mathrm{UJ}$ & 1500 Us & $1000 \mathrm{UJ}$ & $1000 \mathrm{UJ}$ \\
\hline Dibenz $(\theta, h)$ anthracene & $53-70-3$ & $1000 \mathrm{UJ}$ & $1000 \mathrm{U}$ & $370 \mathrm{U}$ & $1000 \mathrm{uJ}$ & $1000 \mathrm{UJ}$ & $1000 \mathrm{UJ}$ & $1200 \mathrm{UJ}$ & 1500 us & $1000 \mathrm{UJ}$ & $1000 \mathrm{UJ}$ \\
\hline Benzo $(g, h, i)$ perylene & $191-24-2$ & $1000 \mathrm{UJ}$ & $1000 \mathrm{U}$ & $370 \mathrm{U}$ & $1000 \mathrm{UJ}$ & $1000 \mathrm{UJ}$ & $1000 \mathrm{UJ}$ & $1200 \mathrm{uJ}$ & $1500 \mathrm{us}$ & $1000 \mathrm{UJ}$ & $1000 \mathrm{UJ}$ \\
\hline $\begin{array}{l}\text { OTHER HAC-173-303-9905 DAN } \\
\text { CONSTIIUENTS? }\end{array}$ & IGEROUS WASIE & No & No & No & No & Mo & No & No & No & No & No \\
\hline Total TICs & & 6 & 11 & 5 & 13 & 14 & 17 & 11 & 20 & 16 & 17 \\
\hline IICs without laboratory "B & "flags & 0 & 4 & 5 & 7 & 5 & 9 & 1 & 1 & 5 & 0 \\
\hline
\end{tabular}


Table A-6. B-Pond Phase 3 Semivolatiles. $(\mu \mathrm{g} / \mathrm{Kg})$ (Base/Neutral/Acid Compounds)

\begin{tabular}{|c|c|c|c|c|c|c|c|c|c|c|c|}
\hline ANALYTE & CAS\# & ВоОНО2 & ВоОно3 & ВоОНО4 & воОнО5 & ВоОНО6 & воОно7 & 800н14 & ВоОн10 & воон19 & $800 \mathrm{H23}$ \\
\hline & IYPE & Reg & Reg & Reg & Fodup & Reg & split & Reg & Blank & Reg & Reg \\
\hline & POND & $3 c$ & $3 c$ & $3 c$ & $3 c$ & $3 c$ & $3 c$ & $3 c$ & $3 c$ & $3 c$ & $3 C$ \\
\hline & DEPTH & 5 & 7 & 9 & 9 & 11.5 & 11.5 & 30 & $\cdots$ & 60 & 80 \\
\hline & EXTRACTION DATE & $3 / 21 / 91$ & $4 / 2 / 91$ & $4 / 2 / 91$ & $4 / 2 / 91$ & $4 / 2 / 91$ & $3 / 21 / 91$ & 6/2/91 & 4/2/91 & $4 / 2 / 91$ & 4/2/91 \\
\hline & ANALYSIS DATE & $4 / 1 / 91$ & $4 / 5 / 91$ & 4/5/91 & 4/5/91 & 4/5/91 & $4 / 26 / 91$ & 4/5/91 & 4/5/91 & 4/5/91 & $4 / 5 / 91$ \\
\hline Phenol & $108-95-2$ & $1300 \mathrm{UJ}$ & $1000 \mathrm{UJ}$ & $1000 \mathrm{UJ}$ & $1000 \mathrm{Us}$ & $1000 \mathrm{UJ}$ & $340 \mathrm{U}$ & $1100 \mathrm{UJ}$ & 990 UJ & $1100 \mathrm{UJ}$ & $1300 \mathrm{U}$ \\
\hline bis(2-chloroethyl)ether & $111-44-4$ & $1300 \mathrm{UJ}$ & 1000 UJ & $1000 \mathrm{UJ}$ & $1000 \mathrm{UJ}$ & 1000 us & $340 \mathrm{U}$ & $1100 \mathrm{UJ}$ & 990 Us & 1100 Us & $1300 \mathrm{U}$ \\
\hline 2-Chlorophenol & $95-57-8$ & $1300 \mathrm{UJ}$ & $1000 \mathrm{UJ}$ & $1000 \mathrm{Us}$ & $1000 \mathrm{UJ}$ & $\{000$ UJ & $340 \mathrm{U}$ & $1100 \mathrm{UJ}$ & 990 UJ & $1100 \mathrm{UJ}$. & $1300 \mathrm{U}$ \\
\hline 1,3-Dichlorobenzene & $541-73-1$ & $1300 \mathrm{us}$ & $1000 \mathrm{UJ}$ & $1000 \mathrm{UJ}$ & $1000 \mathrm{UJ}$ & $1000 \mathrm{US}$ & $340 \mathrm{U}$ & $1100 \mathrm{UJ}$ & $990 \mathrm{uJ}$ & $1100 \mathrm{UJ}$ & $1300 \mathrm{U}$ \\
\hline 1,4-0 ichlorobenzene & $106-46-7$ & $1300 \mathrm{UJ}$ & 1000 Us & $1000 \mathrm{US}$ & 1000 Us & $1000 \mathrm{UJ}$ & $360 \mathrm{U}$ & $1100 \mathrm{us}$ & $990 \mathrm{UJ}$ & 1100 UJ & $1300 \mathrm{U}$ \\
\hline Benzyl Al cohol & $100-51-6$ & $1300 \mathrm{uJ}$ & $1000 \mathrm{UJ}$ & $1000 \mathrm{UJ}$ & 1000 UJ & $1000 \mathrm{UJ}$ & $340 \mathrm{U}$ & $1100 \mathrm{Us}$ & $990 \mathrm{US}$ & 1100 us & $1300 \mathrm{U}$ \\
\hline 1,2-Dichlorabenzene & $95-50-1$ & $1300 \mathrm{UJ}$ & $1000 \mathrm{UJ}$ & $1000 \mathrm{UJ}$ & 1000 Us & $1000 \mathrm{Us}$ & $340 \mathrm{U}$ & $1100 \mathrm{UJ}$ & $990 \mathrm{UJ}$ & $1100 \mathrm{UJ}$ & $1300 \mathrm{U}$ \\
\hline 2-Methylphenol & $95-48-7$ & $1300 \mathrm{UJ}$ & $1000 \mathrm{UJ}$ & 1000 Us & $1000 \mathrm{UJ}$ & $1000 \mathrm{UJ}$ & $340 \mathrm{U}$ & $1100 \mathrm{UJ}$ & $990 \mathrm{UJ}$ & $1100 \mathrm{us}$ & $1300 \mathrm{U}$ \\
\hline $\begin{array}{l}\text { bis(2-Chloroisopropyl) } \\
\text { ether }\end{array}$ & $108-60-1$ & $1300 \mathrm{UJ}$ & $1000 \mathrm{UJ}$ & $1000 \mathrm{UJ}$ & 1000 Us & $1000 \mathrm{UJ}$ & $340 \mathrm{~V}$ & $1100 \mathrm{Us}$ & 990 us & $1100 \mathrm{Ud}$ & $1300 U$ \\
\hline 4-Methylphenol & $106-44-5$ & 1300 UJ & $1000 \mathrm{UJ}$ & $1000 \mathrm{UJ}$ & $1000 \mathrm{UJ}$ & $1000 \mathrm{UJ}$ & $340 \mathrm{U}$ & $1100 \mathrm{UJ}$ & 990 UJ & $1100 \mathrm{UJ}$ & $1300 \mathrm{U}$ \\
\hline M-Mitrosodipropylamine & $621-64-7$ & $1300 \mathrm{UJ}$ & $1000 \mathrm{UJ}$ & $1000 \mathrm{UJ}$ & $1000 \mathrm{Us}$ & 1000 UJ & $340 \mathrm{U}$ & $1100 \mathrm{us}$ & 990 us & $1100 \mathrm{UJ}$ & $1300 \mathrm{v}$ \\
\hline Hexachl or oethane & $67-72 \cdot 1$ & 1300 UJ & $1000 \mathrm{UJ}$ & $1000 \mathrm{UJ}$ & 1000 UJ & 1000 UJ & $340 \mathrm{U}$ & $1100 \mathrm{UJ}$ & $990 \mathrm{uJ}$ & $1100 \mathrm{UJ}$ & $1300 \mathrm{U}$ \\
\hline Nitrobenzene & $98-95-3$ & $1300 \mathrm{UJ}$ & $1000 \mathrm{UJ}$ & $1000 \mathrm{UJ}$ & $1000 \mathrm{UJ}$ & 1000 UJ & $340 \mathrm{U}$ & $1100 \mathrm{Us}$ & $990 \mathrm{uJ}$ & $1100 \mathrm{US}$ & $1300 \mathrm{U}$ \\
\hline I sophorone & $78-59-1$ & $1300 \mathrm{UJ}$ & $1000 \mathrm{UJ}$ & $1000 \mathrm{UJ}$ & 1000 Us & 1000 Us & $340 \mathrm{U}$ & $1100 \mathrm{UJ}$ & 990 us & $1100 \mathrm{UJ}$ & $1300 \mathrm{U}$ \\
\hline 2-Nitrophenol & $88-75-5$ & $1300 \mathrm{UJ}$ & $1000 \mathrm{Ud}$ & $1000 \mathrm{UJ}$ & $1000 \mathrm{UJ}$ & $1000 \mathrm{UJ}$ & 3400 & $1100 \mathrm{UJ}$ & $990 \mathrm{UJ}$ & $1100 \mathrm{uJ}$ & $1300 u$ \\
\hline 2,4-D imethylphenol & $105-67-9$ & $1300 \mathrm{UJ}$ & 1000 UJ & $1000 \mathrm{uJ}$ & $1000 \mathrm{uJ}$ & $1000 \mathrm{Us}$ & $340 \mathrm{U}$ & $1100 \mathrm{UJ}$ & $990 \mathrm{uJ}$ & $1100 \mathrm{UJ}$ & $1300 \mathrm{U}$ \\
\hline Benzoic ocid & $65-85-0$ & $6300 \mathrm{UJ}$ & $5000 \mathrm{U}$ & $5100 \mathrm{~J} *$ & $5000 \mathrm{~J} *$ & $51000 \mathrm{~J}$ & $1700 \mathrm{U}$ & $53000 \mathrm{u} *$ & $48000 \mathrm{~J}=$ & $51000 \mathrm{~J}^{*}$ & $6200 \mathrm{U}^{*}$ \\
\hline bis(2-chloroethoxy)methane & $111-91-1$ & $1300 \mathrm{UJ}$ & $1000 \mathrm{UJ}$ & $1000 \mathrm{UJ}$ & $1000 \mathrm{UJ}$ & $1000 \mathrm{UJ}$ & $340 \mathrm{U}$ & $1100 \mathrm{UJ}$ & $990 \mathrm{UJ}$ & 1100 us & $1300 \mathrm{U}$ \\
\hline
\end{tabular}

(Page 13 of 16) 
Table A-6. B-Pond Phase 3 Semivolatiles. $(\mu \mathrm{g} / \mathrm{Kg})$ (Base/Neutral/Acid Compounds)

\begin{tabular}{|c|c|c|c|c|c|c|c|c|c|c|c|}
\hline AMALYTE & CAS\# & воОнО2 & ВООН03 & В0OHO4 & ВООНО5 & $800 \mathrm{HOS}$ & ВоОНО7 & ВOOH14 & 800n10 & BOON19 & $800 \mathrm{H} 23$ \\
\hline & IYPE & Reg & Reg & Reg & Fdep & Reg & Split & Reg & Blank & Reg & Reg \\
\hline & POND & $3 c$ & $3 c$ & $3 c$ & $3 c$ & $3 c$ & $3 c$ & $3 c$ & $3 c$ & $3 c$ & $3 c$ \\
\hline & DEPIH & 5 & 7 & 9 & 9 & 11.5 & 11.5 & 30 & $\cdots$ & 60 & 80 \\
\hline & EXTRACTION DATE & $3 / 21 / 91$ & $4 / 2 / 91$ & $4 / 2 / 91$ & $4 / 2 / 91$ & $4 / 2 / 91$ & $3 / 21 / 91$ & $4 / 2 / 91$ & $4 / 2 / 91$ & $6 / 2 / 91$ & $4 / 2 / 91$ \\
\hline & AMALYSIS DATE & $4 / 1 / 91$ & $4 / 5 / 91$ & $4 / 5 / 91$ & $4 / 5 / 91$ & $4 / 5 / 91$ & $4 / 26 / 91$ & $4 / 5 / 91$ & $4 / 2 / 91$ & $6 / 5 / 91$ & $4 / 5 / 91$ \\
\hline 2,4-0 ichlorophenol & $120-83-2$ & $1300 \mathrm{UJ}$ & $1000 \mathrm{UJ}$ & $1000 \mathrm{UJ}$ & $1000 \mathrm{UJ}$ & $1000 \mathrm{UJ}$ & $340 \mathrm{U}$ & $1100 \mathrm{us}$ & $990 \mathrm{UJ}$ & $1100 \mathrm{us}$ & $1300 \mathrm{U}$ \\
\hline 1,2,4-Trichlorobenzene & $120-82-1$ & $1300 \mathrm{UJ}$ & $1000 \mathrm{UJ}$ & $1000 \mathrm{UJ}$ & $1000 \mathrm{UJ}$ & $1000 \mathrm{us}$ & $340 \mathrm{U}$ & $1100 \mathrm{UJ}$ & 990 us & $1100 \mathrm{UJ}$ & $1300 u$ \\
\hline Naphthalene & $91-20-3$ & $1300 \mathrm{UJ}$ & $1000 \mathrm{UJ}$ & $1000 \mathrm{UJ}$ & $1000 \mathrm{UJ}$ & $1000 \mathrm{us}$ & $340 \mathrm{u}$ & $1100 \mathrm{UJ}$ & 990 UJ & $1100 \mathrm{UJ}$ & $1300 U$ \\
\hline 4-Chloroanilline & $106-47-8$ & $1300 \mathrm{UJ}$ & $1000 \mathrm{UJ}$ & $1000 \mathrm{UJ}$ & $1000 \mathrm{UJ}$ & $1000 \mathrm{UJ}$ & $340 \mathrm{U}$ & $1100 \mathrm{uJ}$ & $990 \mathrm{uJ}$ & $1100 \mathrm{UJ}$ & $1300 \mathrm{U}$ \\
\hline Hexachl or obut adiene & $87-68-3$ & $1300 \mathrm{UJ}$ & 1000 UJ & $1000 \mathrm{UJ}$ & $1000 \mathrm{UJ}$ & $1000 \mathrm{UJ}$ & $340 \mathrm{U}$ & $1100 \mathrm{uJ}$ & 990 us & $1100 \mathrm{UJ}$ & $1300 u$ \\
\hline 4-chloro-3-methylphenol & $59-50-7$ & $1300 \mathrm{UJ}$ & $1000 \mathrm{UJ}$ & 1000 us & $1000 \mathrm{UJ}$ & $1000 \mathrm{uJ}$ & $340 \mathrm{~V}$ & נU 1100 & $990 \mathrm{uJ}$ & $1100 \mathrm{uJ}$ & $1300 \mathrm{U}$ \\
\hline 2-Methylnaphthal ene & $91-57-6$ & $1300 \mathrm{UJ}$ & $1000 \mathrm{UJ}$ & $1000 \mathrm{UJ}$ & $1000 \mathrm{UJ}$ & 1000 us & $340 \mathrm{U}$ & $1100 \mathrm{uJ}$ & $990 \mathrm{us}$ & $1100 \mathrm{us}$ & $1300 u$ \\
\hline Hexachlorocyclopent adiene & $\pi 7-47-4$ & $1300 \mathrm{UJ}$ & 1000 UJ & $1000 \mathrm{UJ}$ & $1000 \mathrm{UJ}$ & $1000 \mathrm{uJ}$ & $340 \mathrm{U}$ & $1100 \mathrm{us}$ & $990 \mathrm{us}$ & $1100 \mathrm{us}$ & $1300 u$ \\
\hline 2,4,6-Trichlorophenol & $88-06-2$ & $1300 \mathrm{UJ}$ & $1000 \mathrm{UJ}$ & $1000 \mathrm{UJ}$ & $1000 \mathrm{us}$ & $1000 \mathrm{UJ}$ & $340 \mathrm{U}$ & $1100 \mathrm{UJ}$ & 990 us & $1100 \mathrm{uJ}$ & $1300 \mathrm{U}$ \\
\hline 2,4,5-Irichlorophenol & $95.95-4$ & $6300 \mathrm{UJ}$ & $5000 \mathrm{UJ}$ & $5100 \mathrm{UJ}$ & $5000 \mathrm{Ud}$ & $5100 \mathrm{uJ}$ & $1700 \mathrm{U}$ & $5300 \mathrm{UJ}$ & $4800 \mathrm{UJ}$ & $5100 \mathrm{us}$ & $6200 \mathrm{U}$ \\
\hline 2-Chl oronaph thal ene & $91-58-7$ & $1300 \mathrm{uJ}$ & $1000 \mathrm{UJ}$ & $1000 \mathrm{UJ}$ & $1000 \mathrm{UJ}$ & $1000 \mathrm{UJ}$ & $340 \mathrm{U}$ & 1100 uJ & $990 \mathrm{uJ}$ & $1100 \mathrm{UJ}$ & $1300 \mathrm{U}$ \\
\hline 2-Mitroaniline & $88-74-4$ & $6300 \mathrm{UJ}$ & $5000 \mathrm{UJ}$ & $5100 \mathrm{UJ}$ & 5000 Us & 5100 US & $1700 \mathrm{U}$ & $5300 \mathrm{us}$ & $4800 \mathrm{UJ}$ & 5100 us & $6200 \mathrm{U}$ \\
\hline Dimethylphthalate & $131-11-3$ & $1300 \mathrm{UJ}$ & 1000 UJ & 1000 UJ & $1000 \mathrm{UJ}$ & $1000 \mathrm{UJ}$ & $340 \mathrm{U}$ & 1100 UJ & 990 us & $1100 \mathrm{uJ}$ & $1300 \mathrm{U}$ \\
\hline Acenaphthylene & $208-96-8$ & $1300 \mathrm{UJ}$ & $1000 \mathrm{UJ}$ & 1000 us & $1000 \mathrm{uJ}$ & $1000 \mathrm{UJ}$ & $340 \mathrm{U}$ & $1100 \mathrm{UJ}$ & $990 \mathrm{UJ}$ & $1100 \mathrm{UJ}$ & $1300 \mathrm{U}$ \\
\hline 3-Mitroaniline & $99-09-2$ & $6300 \mathrm{UJ}$ & $5000 \mathrm{UJ}$ & $5100 \mathrm{UJ}$ & $5000 \mathrm{UJ}$ & $5100 \mathrm{UJ}$ & $1700 \mathrm{U}$ & $5300 \mathrm{uJ}$ & $4800 \mathrm{UJ}$ & $5100 \mathrm{us}$ & $6200 \mathrm{U}$ \\
\hline Acenaphthene & $83-32 \cdot 9$ & $1300 \mathrm{UJ}$ & $1000 \mathrm{UJ}$ & $1: i 00 \mathrm{UJ}$ & $1000 \mathrm{UJ}$ & $1000 \mathrm{uds}$ & $340 \mathrm{U}$ & $1100 \mathrm{UJ}$ & $990 \mathrm{us}$ & $1100 \mathrm{Us}$ & $1300 \mathrm{U}$ \\
\hline 2,4-D init rophenol & $51-28-5$ & $6300 \mathrm{UJ}$ & $5000 \mathrm{UJ}$ & $5100 \mathrm{uJ}$ & $5000 \mathrm{UJ}$ & $5100 \mathrm{UJ}$ & $1700 \mathrm{U}$ & $5300 \mathrm{UJ}$ & 4800 US & 5100 us & $6200 \mathrm{U}$ \\
\hline 4-Nitrophenol & $100-02-7$ & $6300 \mathrm{UJ}$ & $5000 \mathrm{UJ}$ & $5100 \mathrm{UJ}$ & $5000 \mathrm{UJ}$ & $5100 \mathrm{UJ}$ & $1700 \mathrm{U}$ & $5300 \mathrm{UJ}$ & $4800 \mathrm{UJ}$ & $5100 \mathrm{UJ}$ & $6200 \mathrm{U}$ \\
\hline
\end{tabular}

(Page 14 of 16) 
Table A-6. B-Pond Phase 3 Semivolatiles. ( $\mu \mathrm{g} / \mathrm{Kg})$ (Base/Neutral/Acid Compounds)

\begin{tabular}{|c|c|c|c|c|c|c|c|c|c|c|c|}
\hline ANALYTE & CASE & ВОOHO2 & воОно3 & Воэно4 & ВООНО5 & ВоОНО6 & ВООНОТ & воOH14 & BOOH10 & во0н19 & 800н23 \\
\hline & TYPE & Reg & Reg & Reg & Fdep & Reg & Split & Reg & Blank & Reg & Reg \\
\hline & POND & $3 c$ & 3c & $3 c$ & $3 c$ & $3 c$ & $3 c$ & $3 c$ & 3c & $3 c$ & $3 c$ \\
\hline & DEPIH & 5 & 7 & 9 & 9 & 11.5 & 11.5 & 30 & $\cdots$ & 60 & 80 \\
\hline & EXTRACTION DATE & $3 / 21 / 91$ & $4 / 2 / 91$ & $4 / 2 / 91$ & $4 / 2 / 91$ & $4 / 2 / 91$ & $3 / 21 / 91$ & $4 / 2 / 91$ & $4 / 2 / 91$ & $4 / 2 / 91$ & $4 / 2 / 91$ \\
\hline & AMALYSIS DATE & $4 / 1 / 91$ & $4 / 5 / 91$ & $4 / 5 / 91$ & $4 / 5 / 91$ & $4 / 5 / 91$ & $4 / 26 / 91$ & $4 / 5 / 91$ & $4 / 5 / 91$ & $4 / 5 / 91$ & $4 / 5 / 91$ \\
\hline Dibenzofuran & $132-64-9$ & $1300 \mathrm{UJ}$ & $1000 \mathrm{UJ}$ & $1000 \mathrm{UJ}$ & $1000 \mathrm{UJ}$ & 1000 UJ & $340 \mathrm{U}$ & $1100 \mathrm{UJ}$ & 990 Ud & $1100 \mathrm{UJ}$ & $1300 \mathrm{U}$ \\
\hline 2,4-Dinitrotoluene & $121-14-2$ & $1300 \mathrm{UJ}$ & $1000 \mathrm{UJ}$ & $1000 \mathrm{UJ}$ & $1000 \mathrm{UJ}$ & 1000 UJ & $340 \mathrm{U}$ & 1100 UJ & $990 \mathrm{uJ}$ & $1100 \mathrm{Us}$ & $1300 \mathrm{U}$ \\
\hline 2,6-D ini trotoluene & $606-20-2$ & $1300 \mathrm{UJ}$ & $1000 \mathrm{UJ}$ & $1000 \mathrm{UJ}$ & $1000 \mathrm{UJ}$ & $1000 \mathrm{UJ}$ & MA & $1100 \mathrm{uJ}$ & 990 Ud & $1100 \mathrm{UJ}$ & $1300 \mathrm{U}$ \\
\hline Jiethylphthalate & $84-66-2$ & $1300 \mathrm{UJ}$ & $1000 \mathrm{UJ}$ & 1000 UJ & 1000 Us & $1000 \mathrm{~J})^{*}$ & $340 \mathrm{U}$ & $1100 \mathrm{~J}=$ & 990 Ud & $1100 \mathrm{us}$ & $1300 \mathrm{v}$ \\
\hline 4-Chl orophenyl-phenylether & $7005-72-3$ & $1300 \mathrm{UJ}$ & $1000 \mathrm{UJ}$ & $1000 \mathrm{UJ}$ & $1000 \mathrm{UJ}$ & $1000 \mathrm{UJ}$ & $340 \mathrm{U}$ & $1100 \mathrm{UJ}$ & $990 \mathrm{UJ}$ & $1100 \mathrm{UJ}$ & $1300 \mathrm{U}$ \\
\hline Fluorene & $86-73-7$ & $1300 \mathrm{UJ}$ & $1000 \mathrm{UJ}$ & $1000 \mathrm{UJ}$ & $1000 \mathrm{UJ}$ & $1000 \mathrm{UJ}$ & $340 \mathrm{U}$ & $1100 \mathrm{UJ}$ & 990 UJ & $1100 \mathrm{UJ}$ & $1300 \mathrm{U}$ \\
\hline 4-Witroaniline & $100-01-6$ & $6300 \mathrm{UJ}$ & $5000 \mathrm{UJ}$ & $5100 \mathrm{UJ}$ & 5000 UJ & $5100 \mathrm{UJ}$ & $1700 \mathrm{U}$ & $5300 \mathrm{UJ}$ & $4800 \mathrm{US}$ & $5100 \mathrm{UJ}$ & $6200 \mathrm{U}$ \\
\hline 4,6-0 initro-2-methylphenol & $534-52-1$ & $6300 \mathrm{UJ}$ & $5000 \mathrm{UJ}$ & $5100 \mathrm{UJ}$ & $5000 \mathrm{UJ}$ & $5100 \mathrm{UJ}$ & $1700 \mathrm{U}$ & $5300 \mathrm{UJ}$ & $4800 \mathrm{UJ}$ & 5100 UJ & $6200 \mathrm{U}$ \\
\hline W-Mit rosodiphenylenine & $86-30-6$ & $1300 \mathrm{UJ}$ & $1000 \mathrm{UJ}$ & $1000 \mathrm{UJ}$ & $1000 \mathrm{UJ}$ & 1000 ud & $340 u^{T}$ & $1100 \mathrm{UJ}$ & $990 \mathrm{UJ}$ & $1100 \mathrm{UJ}$ & $1300 U$ \\
\hline 4-Bromophenyl-phenylether & $101-55-3$ & $1300 \mathrm{UJ}$ & $1000 \mathrm{UJ}$ & $1000 \mathrm{UJ}$ & $1000 \mathrm{UJ}$ & $1000 \mathrm{UJ}$ & $340 \mathrm{U}$ & 1100 us & $990 \mathrm{us}$ & $1100 \mathrm{UJ}$ & $1300 \mathrm{U}$ \\
\hline Hexachlorobenzene & $118-74-1$ & $1300 \mathrm{UJ}$ & $1000 \mathrm{UJ}$ & $1000 \mathrm{UJ}$ & $1000 \mathrm{UJ}$ & 1000 us & $340 \mathrm{U}$ & $1100 \mathrm{UJ}$ & $990 \mathrm{UJ}$ & $1100 \mathrm{UJ}$ & $1300 \mathrm{U}$ \\
\hline Pentachlorophenol & $87-86-5$ & $6300 \mathrm{UJ}$ & $5000 \mathrm{UJ}$ & $5100 \mathrm{UJ}$ & $5000 \mathrm{UJ}$ & $5100 \mathrm{uJ}$ & $1700 u$ & $5300 \mathrm{UJ}$ & $4800 \mathrm{WJ}$ & $5100 \mathrm{WJ}$ & $6200 \mathrm{U}$ \\
\hline Phenanthrene & $85-01-8$ & $1300 \mathrm{UJ}$ & $1000 \mathrm{UJ}$ & $1000 \mathrm{UJ}$ & $1000 \mathrm{UJ}$ & $1000 \mathrm{UJ}$ & $340 \mathrm{U}$ & $1100 \mathrm{Ud}$ & $990 \mathrm{UJ}$ & $1100 \mathrm{UJ}$ & $1300 \mathrm{U}$ \\
\hline Anthracene & $120-12-7$ & $1300 \mathrm{UJ}$ & $1000 \mathrm{UJ}$ & $1000 \mathrm{UJ}$ & $1000 \mathrm{UJ}$ & $1000 \mathrm{UJ}$ & $340 \mathrm{U}$ & $1100 \mathrm{Uj}$ & 990 UJ & $1100 \mathrm{UJ}$ & $1300 U$ \\
\hline Di-n-Butylphthalate & $84-74-2$ & $2000 \mathrm{UJ}$ & $1500 \mathrm{UJ}$ & $2500 \mathrm{UJ}$ & $2100 \mathrm{UJ}$ & $3100 \mathrm{us}$ & $340 \mathrm{U}$ & $2500 \mathrm{UJ}$ & $1100 \mathrm{uJ}$ & $2200 \mathrm{UJ}$ & $3700 \mathrm{U}$ \\
\hline Fluoranthene & $206-44-0$ & $1300 \mathrm{UJ}$ & $1000 \mathrm{UJ}$ & $1000 \mathrm{UJ}$ & $1000 \mathrm{UJ}$ & $1000 \mathrm{UJ}$ & $340 \mathrm{U}$ & $1100 \mathrm{uJ}$ & 990 UJ & $1100 \mathrm{UJ}$ & $1300 \mathrm{U}$ \\
\hline Pyrene & $129-00-0$ & 1300 UJ & $1000 \mathrm{UJ}$ & $1000 \mathrm{UJ}$ & 1000 UJ & $1000 \mathrm{uJ}$ & $340 \mathrm{U}$ & $1100 \mathrm{UJ}$ & $990 \mathrm{uJ}$ & $1100 \mathrm{wJ}$ & $1300 \mathrm{U}$ \\
\hline Butylbenzylphthalate & $85-68-7$ & $1300 \mathrm{UJ}$ & $1000 \mathrm{UJ}$ & $1000 \mathrm{UJ}$ & 1000 Us & $1000 \mathrm{UJ}$ & $340 \mathrm{U}$ & $1100 \mathrm{UJ}$ & $990 \mathrm{UJ}$ & 1100 UJ & $1300 \mathrm{U}$ \\
\hline
\end{tabular}

(Page 15 of 16) 
Table A-6. B-Pond Phase 3 Semivolatiles. $(\mu \mathrm{g} / \mathrm{Kg})$

(Base/Neutral/Acid Compounds)

\begin{tabular}{|c|c|c|c|c|c|c|c|c|c|c|}
\hline ANALYTE & воОнО2 & воОно3 & $800 \mathrm{HO4}$ & $800 \mathrm{HO5}$ & воонов & воОно7 & В0OH14 & B0OH10 & воОн19 & $800 H 23$ \\
\hline TYPE & Reg & Reg & Reg & Fdup & Reg & Split & Reg & Btenk & Reg & Reg \\
\hline POND & $3 c$ & $3 c$ & $3 c$ & $3 c$ & 3c & $3 c$ & $3 c$ & $3 c$ & $3 c$ & $3 C$ \\
\hline DEPIH & 5 & 7 & 9 & 9 & 11.5 & 11.5 & 30 & $\cdots$ & 60 & 80 \\
\hline EXTRACTION DATE & $3 / 21 / 91$ & $4 / 2 / 91$ & $4 / 2 / 91$ & $4 / 2 / 91$ & $4 / 2 / 91$ & $3 / 21 / 91$ & $4 / 2 / 91$ & 4/2/91 & $4 / 2 / 91$ & $4 / 2 / 91$ \\
\hline AMALYSIS DATE & 4/1/91 & $4 / 5 / 91$ & $4 / 5 / 91$ & 4/5/91 & $4 / 5 / 91$ & $4 / 26 / 91$ & 4/5/91 & 4/5/91 & $4 / 5 / 91$ & $4 / 5 / 91$ \\
\hline 3,3'-Dichlorobenzidine & $2600 \mathrm{uJ}$ & $2100 \mathrm{UJ}$ & $2100 \mathrm{uJ}$ & $2100 \mathrm{uJ}$ & $2100 \mathrm{UJ}$ & $690 \mathrm{U}$ & $2200 \mathrm{UJ}$ & 2000 Us & $2100 \mathrm{UJ}$ & $2500 u$ \\
\hline Benzo(a) anthracene & $1300 \mathrm{uJ}$ & $1000 \mathrm{UJ}$ & $1000 \mathrm{UJ}$ & $1000 \mathrm{us}$ & $1000 \mathrm{UJ}$ & $340 \mathrm{U}$ & $1100 \mathrm{UJ}$ & 990 us & $1100 \mathrm{uJ}$ & $1300 \mathrm{U}$ \\
\hline bis(2-ethylhexyl)phthalote & $1400 \mathrm{UJ}$ & $1000 \mathrm{UJ}$ & $1000 \mathrm{UJ}$ & $1000 \mathrm{UJ}$ & $1000 \mathrm{UJ}$ & $340 \mathrm{U}$ & $1100 \mathrm{UJ}$ & 990 us & $1100 \mathrm{UJ}$ & $1300 \mathrm{U}$ \\
\hline $218-01-9$ & $1300 \mathrm{UJ}$ & $1000 \mathrm{UJ}$ & $1000 \mathrm{UJ}$ & 1000 us & $1000 \mathrm{UJ}$ & $340 \mathrm{U}$ & $1100 \mathrm{UJ}$ & 990 us & $1100 \mathrm{uJ}$ & $1300 \mathrm{U}$ \\
\hline Di-n-octylphthalate & $1300 \mathrm{UJ}$ & $1000 \mathrm{Us}$ & $1000 \mathrm{UJ}$ & $1000 \mathrm{uJ}$ & $1000 \mathrm{us}$ & $340 \mathrm{U}$ & $1100 \mathrm{UJ}$ & $990 \mathrm{uJ}$ & $1100 \mathrm{uJ}$ & $1300 \mathrm{U}$ \\
\hline Benzo(b) fluoranthene & $1300 \mathrm{UJ}$ & $1000 \mathrm{UJ}$ & $1000 \mathrm{UJ}$ & $1000 \mathrm{UJ}$ & $1000 \mathrm{UJ}$ & $340 U$ & $1100 \mathrm{us}$ & 990 us & $1100 \mathrm{UJ}$ & $1300 u$ \\
\hline Benzo( $k)$ fluoranthene & $1300 \mathrm{UJ}$ & $1000 \mathrm{UJ}$ & $1000 \mathrm{UJ}$ & $1000 \mathrm{uJ}$ & $1000 \mathrm{us}$ & $340 \mathrm{U}$ & $1100 \mathrm{UJ}$ & 990 us & $1100 \mathrm{UJ}$ & $1300 \mathrm{U}$ \\
\hline Benzo(a)pyrene & 1300 UJ & $1000 \mathrm{UJ}$ & $1000 \mathrm{UJ}$ & $1000 \mathrm{UJ}$ & $1000 \mathrm{UJ}$ & $340 \mathrm{U}$ & $1100 \mathrm{us}$ & 990 us & $1100 \mathrm{UJ}$ & $1300 \mathrm{U}$ \\
\hline Indeno $(1,2,3-\mathrm{cd})$ pyrene & $1300 \mathrm{UJ}$ & $1000 \mathrm{UJ}$ & $1000 \mathrm{UJ}$ & $1000 \mathrm{UJ}$ & $1000 \mathrm{UJ}$ & $340 \mathrm{U}$ & $1100 \mathrm{uJ}$ & 990 us & $1100 \mathrm{UJ}$ & $1300 \mathrm{U}$ \\
\hline Dibenz $(a, h)$ anthracene & $1300 \mathrm{uJ}$ & $1000 \mathrm{UJ}$ & $1000 \mathrm{US}$ & $1000 \mathrm{UJ}$ & $1000 \mathrm{us}$ & $340 \mathrm{U}$ & $1100 \mathrm{UJ}$ & 990 ud & $1100 \mathrm{uJ}$ & $1300 \mathrm{U}$ \\
\hline Benzo( $g, h, i)$ perylene & $1300 \mathrm{UJ}$ & $1000 \mathrm{UJ}$ & $1000 \mathrm{UJ}$ & $1000 \mathrm{Ud}$ & $1000 \mathrm{UJ}$ & $340 \mathrm{U}$ & $1100 \mathrm{UJ}$ & 990 us & $1100 \mathrm{us}$ & $1300 \mathrm{U}$ \\
\hline $\begin{array}{l}\text { OTHER MAC- } 173-303-9905 \text { DAMGEROUS WASIE } \\
\text { CONSTIIUENTS? }\end{array}$ & No & No & Mo & No & Mo & No & Mo & Mo & Mo & No \\
\hline Total IICs & 18 & 21 & 21 & 20 & 21 & 5 & 21 & 21 & 19 & 20 \\
\hline IICs without laboratory "B" flags & 1 & 4 & 3 & 2 & 2 & 5 & 4 & 4 & 2 & 4 \\
\hline
\end{tabular}

$U$ The analyte was undetected at the stated limit.

$J$ The associated value is an estimated quantity.

NOTE: Analyte was qualified as non-detected at the adjusted CROL due to traces in immediate laboratory blank and sample however, other samples

1 analyzed at that laboratory are reported in this table at sub-CRQL concentrations.

Cannot be separated from Diphenylamine.

(Page 16 of 16) 
WHC-SD-EN-AP-104 Rev. 0

\section{Reasons for Westinghouse Hanford Company Qualification-- Semivolatile Organic (Base/Neutral/Acid) Compounds}

\section{Reqular. Field Duplicate, and Silica Sand Samples:}

HOLDING TIME--All samples were flagged as estimated, "J". The following samples were qualified "J" based on extraction outside 7-day criteria established for water. (All samples were analyzed within 40 days of extraction.)

$\begin{array}{llll}\text { BOOFK6 } & \text { BOOGR9 } & \text { BOOGX6 } & \text { BOOHO4 } \\ \text { BOOFK7 } & \text { BOOGS4 } & \text { BOOGZ2 } & \text { BOOHO5 } \\ \text { BOOFK8 } & \text { BOOGS9 } & \text { BOOGZ6 } & \text { BOOHO6 } \\ \text { BOOFK9 } & \text { BOOGT7 } & \text { BOOGZ8 } & \text { BOOH10 } \\ \text { BOOFLO } & \text { BOOGV5 } & \text { BOOHOO } & \text { BOOH14 } \\ \text { BOOFL1 } & \text { BOOGW1 } & \text { BOOHO1 } & \text { BOOH19 } \\ \text { BOOFL3 } & \text { BOOGW3 } & \text { BOOHO2 } & \\ \text { BOOFL4 } & \text { BOOGW8 } & \text { BOOHO3 } & \end{array}$

LABORATORY BLANK--The target compounds diethyl phthalate bis(2-ethylhexyl) phthalate, di-n-butyl phthalate and benzoic acid were detected in laboratory blanks. This resulted in an undetected qual ification, "U", of one or more of those analytes detected at similar concentrations in the following:

$\begin{array}{llll}\text { BOOFK6 } & \text { BOOGS9 } & \text { BOOGW4 } & \text { BOOHO4 } \\ \text { BOOFK7 } & \text { BOOGT7 } & \text { BOOGW8 } & \text { BOOHO5 } \\ \text { BOOFK8 } & \text { BOOGV5 } & \text { BOOGX6 } & \text { BOOHO6 } \\ \text { BOOFK9 } & \text { BOOGV6 } & \text { BOOGZ2 } & \text { BOOH10 } \\ \text { BOOFLO } & \text { BOOGV7 } & \text { BOOGZ6 } & \text { BOOH14 } \\ \text { BOOFL1 } & \text { BOOGV8 } & \text { BOOGZ8 } & \text { BOOH19 } \\ \text { BOOFL3 } & \text { BOOGV9 } & \text { BOOHOO } & \text { BOOH23 } \\ \text { BOOFL4 } & \text { BOOGWO } & \text { BOOHO1 } & \\ \text { BOOGR9 } & \text { BOOGW1 } & \text { BOOHO2 } & \\ \text { BOOGS4 } & \text { BOOGW3 } & \text { BOOH03 } & \end{array}$

Blank qualification criteria were also applied to compounds reported as TICs. The TICs were not reported when present in similar concentrations in the immediately associated laboratory blank.

\section{Split Samples:}

LABORATORY BLANKS--The compounds di-n-butylpthalate, fluoranthene, pyrene, butylbenzylphthalate, and bis(2-ethylhexyl)phthalate were detected at sub-CRQL levels in the laboratory blank associated with BOOGS5. Similar levels in sample BOOGS5 were qualified "U" at the quantitation limit. 
WHC-SD-EN-AP-104 Rev. 0

Additional notes :

The split samples BOOGS5, BOOGW5, and BOOHO7 had a $\mathrm{pH}$ reported in conjunction with the semivolatile analysis. Reported values were 7.1, 7.2, and 6.3 , respectively.

A listing of semivolatile TICs follows in Table A-7. 
Table A-7. B-Pond Phase 3 Semivolatile Tentatively Identified Compounds. Laboratory Reported Compounds Not in the Associated Lab Blank ( 6 sheets)

\begin{tabular}{|c|c|c|c|}
\hline SAMPLE & REPORTED COMPOUND & cas* & CONCENTRATION \\
\hline \multirow[t]{3}{*}{ BOOFKG } & Dioctyl Adipate & $123-79-5$ & $630 \mathrm{~J}$ \\
\hline & Unknown & & $1400 \mathrm{~J}$ \\
\hline & Unknown & & $960 \mathrm{~J}$ \\
\hline \multirow[t]{3}{*}{ BOOFK7 } & Benzal dehyde, 5-hydroxy-3-wetho & $121 \cdot 33 \cdot 5$ & $550 \mathrm{~J}$ \\
\hline & 2-Pyrrolidinone, 1-methyl- & $872 \cdot 50-4$ & $610 \mathrm{~J}$ \\
\hline & Unknown & & $900 \mathrm{~J}$ \\
\hline \multirow[t]{4}{*}{ BOOFKB } & Unknown Hydrocarbons & & $5400 \mathrm{~J}$ \\
\hline & Unknown Hydrocarbons & & $1100 \mathrm{~J}$ \\
\hline & Unknown & & $1500 \mathrm{~J}$ \\
\hline & Unknown & & $500 \mathrm{~J}$ \\
\hline \multirow[t]{2}{*}{ BOOFK9 } & Octenoic Acid & $124-07-2$ & $460 \mathrm{~J}$ \\
\hline & Unknown & & $1600 \mathrm{~J}$ \\
\hline \multirow[t]{5}{*}{ BOOFLO } & Unknown Hydrocarbon & & $2800 \mathrm{~J}$ \\
\hline & Unknown Hydrocarbon & & $810 \mathrm{~J}$ \\
\hline & Unknown & & $520 \mathrm{~J}$ \\
\hline & Unknown & & $1500 \mathrm{~J}$ \\
\hline & Unknown & & $490 \mathrm{~J}$ \\
\hline \multirow[t]{5}{*}{ BOOFLI } & Dimethyl Hydrazine & & $600 \mathrm{JY}$ \\
\hline & Unknown Hydrocarbon & & $530 \mathrm{~J}$ \\
\hline & Unknown & & $1500 \mathrm{~J}$ \\
\hline & Unknown & & $1700 \mathrm{~J}$ \\
\hline & Unknown & & $620 \mathrm{~J}$ \\
\hline BOOFL3 & None & & \\
\hline \multirow[t]{4}{*}{ BOOFL4 } & Benzol dehyde, 5-hydroxy-3-netho & $129-33-5$ & $480 \mathrm{~J}$ \\
\hline & Phosphoric acid, Dioctadecyl e & & $470 \mathrm{~J}$ \\
\hline & Unknown & & $1200 \mathrm{~J}$ \\
\hline & Unknown & & $1600 \mathrm{~J}$ \\
\hline
\end{tabular}


Table A-7. B-Pond Phase 3 Semivolatile Tentatively Identified Compounds. Laboratory Reported Compounds Not in the Associated Lab Blank

( 6 sheets)

\begin{tabular}{|c|c|c|c|}
\hline SAMPLE & REPORTED COMPOUNO & CAS* & CONCENTRATION \\
\hline \multirow[t]{6}{*}{ BOOGR9 } & Benzal detiyde, 5-hydroxy-3-metho & $129 \cdot 33-5$ & $450 \mathrm{~J}$ \\
\hline & Dimethyl Hydrazine & & $460 \mathrm{~J}$ \\
\hline & Unknown & & $630 \mathrm{~J}$ \\
\hline & Unknown & & $440 \mathrm{~J}$ \\
\hline & Unknown & & $790 \mathrm{~J}$ \\
\hline & Unknown & & $640 \mathrm{~J}$ \\
\hline \multirow[t]{4}{*}{ BOOGS4 } & Phosphoric acid, Dioctadecyl e & & $1200 \mathrm{~J}$ \\
\hline & Unknown Hydrocarbon & & $1700 \mathrm{~J}$ \\
\hline & Unknown & & $1300 \mathrm{~J}$ \\
\hline & Unknown & & $650 \mathrm{~J}$ \\
\hline BOOGSS & None & & \\
\hline \multirow[t]{4}{*}{ BOOGS9 } & Butyl Cellosolve & $111-76-2$ & $690 \mathrm{~J}$ \\
\hline & Unknown & & $470 \mathrm{~J}$ \\
\hline & Unknown & & $1400 \mathrm{~J}$ \\
\hline & Unknown & & $490 \mathrm{~J}$ \\
\hline \multirow[t]{11}{*}{ B00GT7 } & Unknown Hydrocarbon & & $3000 \mathrm{~J}$ \\
\hline & Unknown Phthalate ester & & $470 \mathrm{~J}$ \\
\hline & Unknown & & $780 \mathrm{~J}$ \\
\hline & Unknown & & $2000 \mathrm{~J}$ \\
\hline & Unknown & & $820 \mathrm{~J}$ \\
\hline & Unknown & & $2300 \mathrm{~J}$ \\
\hline & Unknown & & $550 \mathrm{~J}$ \\
\hline & Unknown & & $1600 \mathrm{~J}$ \\
\hline & Unknown & & $1400 \mathrm{~J}$ \\
\hline & Unknown & & $1400 \mathrm{~J}$ \\
\hline & Unknown & & $2000 \mathrm{~J}$ \\
\hline \multirow[t]{4}{*}{ BooGv5 } & Unknown & & $780 \mathrm{~J}$ \\
\hline & Unknown & & $1400 \mathrm{~J}$ \\
\hline & Unknown & & $640 \mathrm{~J}$ \\
\hline & Unknown & & $790 \mathrm{~J}$ \\
\hline
\end{tabular}


Table A-7. B-Pond Phase 3 Semivolatile Tentatively Identified Compounds. Laboratory Reported Compounds Not in the Associated Lab Blank

( 6 sheets)

\begin{tabular}{|c|c|c|c|}
\hline SAMPLE & REPORTED COMPQUND & cas" & CONCENTRATION \\
\hline \multirow[t]{9}{*}{ BOOGV6 } & 2-Pyrrolidinone, 1-methyl- & $872-50-4$ & $620 \mathrm{~J}$ \\
\hline & Isohept decanol & & $1800 \mathrm{~J}$ \\
\hline & Sat'd. Hydrosarbon & & $1200 \mathrm{~J}$ \\
\hline & Sat'd. Hydrocartion & & $9100 \mathrm{~J}$ \\
\hline & Sat'd. Hydrocarbon & & $570 \mathrm{~J}$ \\
\hline & Sat'd. Hydrocarbon & & $670 \mathrm{~J}$ \\
\hline & Sat'd. Hydrocarbon & & $1300 \mathrm{~J}$ \\
\hline & Unknown & & $1200 \mathrm{~J}$ \\
\hline & Unknown & & $920 \mathrm{~J}$ \\
\hline \multirow[t]{2}{*}{ BoogV7 } & Hexadecanoic acid & $57-10-3$ & $1500 \mathrm{~J}$ \\
\hline & Tetradecanoic acid, tetradecyl & $3234-85-3$ & $520 \mathrm{~J}$ \\
\hline \multirow[t]{2}{*}{ BOOGV8 } & Pentadecanoic acid & $1002-84-2$ & $820 \mathrm{~J}$ \\
\hline & Unknown & & $640 \mathrm{~J}$ \\
\hline \multirow[t]{8}{*}{ Boogvg } & Unknown Alkoxy Cpd & & $1800 \mathrm{~J}$ \\
\hline & Unknown Alkyl Hydrocarbon & & $1800 \mathrm{~J}$ \\
\hline & Unknown Alkyl Hydrocarbon & & $440 \mathrm{~J}$ \\
\hline & Unknown Phthalate ester & & $890 \mathrm{~J}$ \\
\hline & Unknown & & $400 \mathrm{~J}$ \\
\hline & Unknown & & $4800 \mathrm{~J}$ \\
\hline & Unknown & & $490 \mathrm{~J}$ \\
\hline & Unknown & & $850 \mathrm{~J}$ \\
\hline \multirow[t]{4}{*}{ BOOGHO } & Unknown Alkyl Hydrocarbon & & $470 \mathrm{~J}$ \\
\hline & Unknown Alkyl Hydrocarbon & & $1200 \mathrm{~J}$ \\
\hline & Unknown Alkyl/Alkoxy Cpd & & $990 \mathrm{~J}$ \\
\hline & Unknown Alkyl/Alkoxy Cpd & & $2300 \mathrm{~J}$ \\
\hline \multirow[t]{2}{*}{ BOOGW1 } & Unknown Alkoxy Cpd & & $860 \mathrm{~J}$ \\
\hline & Unknown Alkyl Hydrocarbon & & $1500 \mathrm{~J}$ \\
\hline B00GW3 & None & & \\
\hline
\end{tabular}


Table A-7. B-Pond Phase 3 Semivolatile Tentatively Identified Compounds. Laboratory Reported Compounds Not in the Associated Lab Blank

( 6 sheets)

\begin{tabular}{|c|c|c|c|}
\hline SAMPLE & REPORTED COMPOUND & CAS* & CONCENTRATION \\
\hline \multirow[t]{4}{*}{ 800GW4 } & Unknown Alkyl/Alkoxy Cpd & & $1000 \mathrm{~J}$ \\
\hline & Unknown Alkyl/Alkoxy Cpu & & $2300 \mathrm{~J}$ \\
\hline & Unknown Phthalate ester & & $460 \mathrm{~J}$ \\
\hline & Unknown & & $440 \mathrm{~J}$ \\
\hline \multirow[t]{5}{*}{ BOOGW5 } & Adipate & & $10000 \mathrm{~J}$ \\
\hline & Aldol condensate & & $200 \mathrm{JA}$ \\
\hline & Aldol condensate & & $600 \mathrm{JA}$ \\
\hline & Unknown & & $200 \mathrm{~J}$ \\
\hline & Unknown & & $1000 \mathrm{~J}$ \\
\hline \multirow[t]{7}{*}{ BOOGW8 } & Unknown Alkoxy Cpd & & $670 \mathrm{~J}$ \\
\hline & Unknown Alkyl Hydrocarbon & & $1000 \mathrm{~J}$ \\
\hline & Unknown Alkyl Hydrocarbon & & $450 \mathrm{~J}$ \\
\hline & Unknown Phthalate ester & & $510 \mathrm{~J}$ \\
\hline & Unknown & & $3600 \mathrm{~J}$ \\
\hline & Unknown & & $450 \mathrm{~J}$ \\
\hline & Unknown & & $470 \mathrm{~J}$ \\
\hline \multirow[t]{5}{*}{$800 G \times 6$} & 1-Dotriacontanol & & $3100 \mathrm{~J}$ \\
\hline & Sat'd. Hydrocarbon & & $740 \mathrm{~J}$ \\
\hline & Unknown Alkyl Hydrocarbon & & $3600 \mathrm{~J}$ \\
\hline & Unknown Alkyl Hydrocarbon & & $1300 \mathrm{~J}$ \\
\hline & Unknown & & $830 \mathrm{~J}$ \\
\hline \multirow[t]{9}{*}{800622} & 3-Eicosene, (e)- & & $7900 \mathrm{~J}$ \\
\hline & 7 Hexadecane, (2)- & & $500 \mathrm{~J}$ \\
\hline & 1-Propenol, 2-ethoxy- & & $850 \mathrm{~J}$ \\
\hline & Unknown Alkyl Hydrocarbon & & $3300 \mathrm{~J}$ \\
\hline & Unknown Alkyl Hydrocarbon & & $1400 \mathrm{~J}$ \\
\hline & Unknokn Hydrocarbon & & $500 \mathrm{~J}$ \\
\hline & Unknown Hydrocarbon & & $520 \mathrm{~J}$ \\
\hline & Unknown Hydrocarbon & & $4600 \mathrm{~J}$ \\
\hline & Unknown & & $980 \mathrm{~J}$ \\
\hline
\end{tabular}


Table A-7. B-Pond Phase 3 Semivolatile Tentatively Identified Compounds. Laboratory Reported Compounds Not in the Associated Lab Blank (6 sheets)

\begin{tabular}{|c|c|c|c|}
\hline SAMPLE & REPORTED COMPOUND & CAS* & CONCENTRATION \\
\hline B00G26 & Unknoin & & $1400 \mathrm{~J}$ \\
\hline $800 G 28$ & Unknown Alkyl Hydrocartion & & $2600 \mathrm{~J}$ \\
\hline \multirow[t]{5}{*}{ 80OHOO } & Unknown Hydrocarbon & & $1200 \mathrm{~J}$ \\
\hline & Unknown Hydrocerbon & & $3800 \mathrm{~J}$ \\
\hline & Unknown Hydrocerbon & & $1600 \mathrm{~J}$ \\
\hline & Unknown Hydrocarbon & & $910 \mathrm{~J}$ \\
\hline & Unknown & & $590 \mathrm{~J}$ \\
\hline ВоОНОі & None & & \\
\hline ВOOHO2 & Unknown & & $790 \mathrm{~J}$ \\
\hline \multirow[t]{4}{*}{$\mathrm{BOOHO3}$} & bis (2-Methoxyethyl)ester & $117-82-8$ & $860 \mathrm{~J}$ \\
\hline & Propanoic acid, 2-methyl-, 1-(1 & $74381-40-1$ & $2600 \mathrm{~J}$ \\
\hline & Unknown Alkyl Hydrocarbon & & $900 \mathrm{~J}$ \\
\hline & Unknown Hydrocarbon & & $1200 \mathrm{~J}$ \\
\hline \multirow[t]{3}{*}{$\mathrm{BOOHO4}$} & Propanoic ocid, 2-methyl-, 1-(1 & $74389-40-1$ & $4900 \mathrm{~J}$ \\
\hline & Unknown Hydrocarbon & & $960 \mathrm{~J}$ \\
\hline & Unknown & & $1100 \mathrm{~J}$ \\
\hline \multirow[t]{2}{*}{ BOOHOS } & bis(2-Methoxyethyl)ester & $117-82-8$ & $790 \mathrm{~J}$ \\
\hline & Propanoic acid, 2-methyl-, $1-11$ & $74381-40-1$ & $2300 \mathrm{~J}$ \\
\hline \multirow[t]{2}{*}{ ВOOHOG } & Unknown Alkyl Hydrocarbon & & $1000 \mathrm{~J}$ \\
\hline & Unknown Hydrocarbon & & $940 \mathrm{~J}$ \\
\hline \multirow[t]{5}{*}{ ВOOHO7 } & Adipate & & $6000 \mathrm{~J}$ \\
\hline & Aldol condensate & & $200 \mathrm{JA}$ \\
\hline & Phthalate & & $100 \mathrm{~J}$ \\
\hline & Unknown Hydrocarbon & & $200 \mathrm{~J}$ \\
\hline & Unknown & & $200 \mathrm{~J}$ \\
\hline
\end{tabular}


Table A-7. B-Pond Phase 3 Semivolatile Tentatively Identified Compounds. Laboratory Reported Compounds Not in the Associated Lab Blank (6 sheets)

\begin{tabular}{|c|c|c|c|}
\hline SAMPLE & REPORTED COMPOUND & cas* & CONCENTRATION \\
\hline \multirow[t]{4}{*}{ BOOH14 } & Propanoic acid, 2-methyl-, 2,2-0 & & $1200 \mathrm{~J}$ \\
\hline & Unknown Hydrocarbon & & $780 \mathrm{~J}$ \\
\hline & Unknown & & $800 \mathrm{~J}$ \\
\hline & Unknown & & $890 \mathrm{~J}$ \\
\hline \multirow[t]{4}{*}{$\mathrm{BOOH} 10$} & Propanoic acid, 2-methyl-, 1-(1 & $74381-40-1$ & $1100 \mathrm{~J}$ \\
\hline & Unknown Alkyl Hydrocarbon & & $550 \mathrm{~J}$ \\
\hline & Unknown & & $550 \mathrm{~J}$ \\
\hline & Unknown & & $2100 \mathrm{~J}$ \\
\hline \multirow[t]{2}{*}{ ВоOH19 } & bis(2-Methoxyethyl)ester & $117-82-8$ & $880 \mathrm{~J}$ \\
\hline & Propsnoic acid, 2-methyl-, 1-(1 & $74381-40-1$ & $3300 \mathrm{~J}$ \\
\hline \multirow[t]{4}{*}{$800 \mathrm{H} 23$} & bis(2-Methoxyethyl)ester & $117-82-8$ & $1200 \mathrm{~J}$ \\
\hline & Unknown Hydrocarbon & & $1100 \mathrm{~J}$ \\
\hline & Unknown Hydrocarbon & & $1100 \mathrm{~J}$ \\
\hline & Unknown & & $1100 \mathrm{~J}$ \\
\hline
\end{tabular}

$J$ The associated value is an estimated quantity. 
Table A-8a. Analytes by Inductively Coupled Plasma, Aluminum-Calcium. ( $\mu \mathrm{g} / \mathrm{g})$

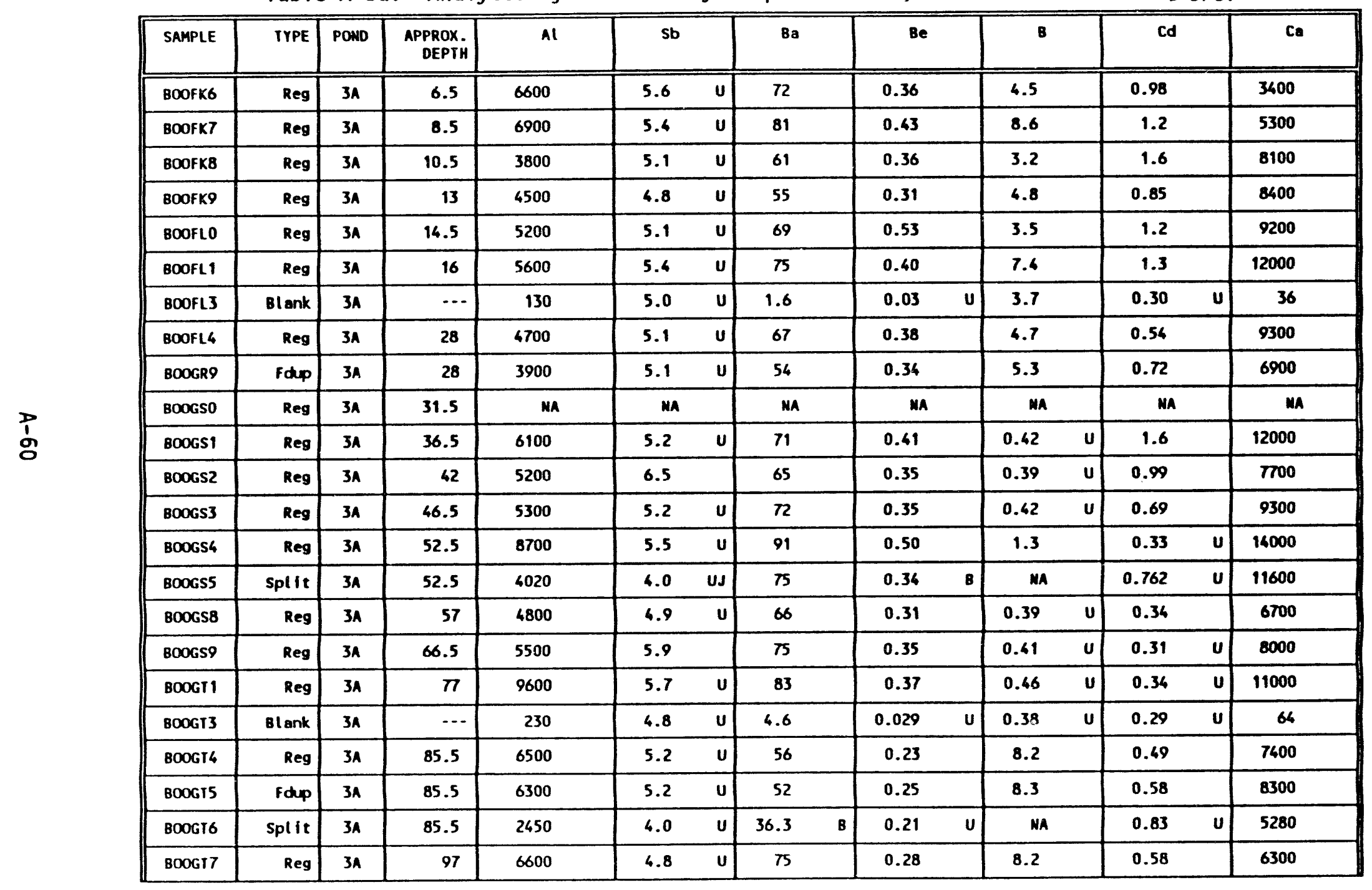

(Page 1 of 4 ) 
Table A-8a. Analytes by Inductively Coupled Plasma, Aluminum-Calcium. ( $\mu \mathrm{g} / \mathrm{g})$

\begin{tabular}{|c|c|c|c|c|c|c|c|c|c|c|}
\hline SAMPLE & IYPE & POND & $\begin{array}{l}\text { APPROX. } \\
\text { DEPIH }\end{array}$ & Al & sb & $8 a$ & Be & B & cd & Ca \\
\hline BOOFK6 & Reg & $3 A$ & 6.5 & 6600 & $5.6 \quad U$ & 72 & 0.36 & 4.5 & 0.98 & 3400 \\
\hline BOOGT8 & Reg & 31 & 102 & 7600 & 14 & 87 & 0.35 & 8.0 & 0.76 & 7800 \\
\hline BOOGVO & Reg & $3 A$ & 122 & 6500 & $4.6 \quad U$ & 71 & 0.29 & 8.8 & $0.28 \quad U$ & 5800 \\
\hline BoOGV1 & Blank & $3 n$ & $\cdots$ & 300 & 4.6 & 6.4 & 0.12 & 5.9 & 0.27 & 60 \\
\hline BOOGV2 & Reg & $3 A$ & 131 & 7400 & 4.6 & 77 & 0.30 & 7.4 & 0.60 & 8000 \\
\hline BOCGV3 & Fdup & $3 A$ & 131 & 7100 & $5.2 U$ & 110 & 0.30 & 9.1 & 0.64 & 7600 \\
\hline BOOGV4 & Split & $3 A$ & 131 & 2590 & $3.76 U$ & 43.7 & $0.28 \quad B$ & MA & 0.79 & 3450 \\
\hline BOOGV5 & Reg & $3 A$ & 143.5 & 6100 & 8.0 & 53 & 0.28 & 9.3 & 0.62 & 6400 \\
\hline BoOGV6 & Reg & 38 & 1 & 4500 & 5.0 & 62 & 0.32 & 8.7 & 0.67 & 6900 \\
\hline BOOGV7 & Reg & 38 & 3.5 & 5200 & 4.9 & 70 & 0.33 & 7.6 & 0.50 & 7700 \\
\hline BOOGV8 & Reg & 38 & 5.5 & 5300 & 5.1 & 87 & 0.35 & 8.9 & 0.31 & 7700 \\
\hline BOOGV9 & Blank & 3B & $\cdots$ & 150 & 5.0 & 2.0 & 0.03 & 7.5 & 0.30 & 37 \\
\hline BOOGNO & Reg & 3B & 7.5 & 7200 & 5.3 & 80 & 0.60 & 6.1 & 0.80 & 13000 \\
\hline BDOGW1 & Reg & $3 B$ & 9.5 & 5000 & 5.1 & 64 & 0.35 & 6.6 & 0.80 & 8700 \\
\hline BOOGW & Reg & $38^{\circ}$ & 13 & 4600 & 5.0 & 80 & 0.35 & 5.8 & 1.7 & 7100 \\
\hline BOOGW4 & Fdup & 38 & 13 & 4900 & $4.8 U$ & 78 & 0.35 & 5.8 & 0.84 & 7600 \\
\hline BOOGWS & Split & 38 & 13 & 2210 & $3.89 \quad U$ & 58.3 & 0.20 & $M A$ & 0.82 & 5220 \\
\hline BOOGW6 & Reg & 38 & 16 & 7000 & $5.3 \quad U$ & 75 & 0.42 & 8.0 & 0.90 & 10000 \\
\hline BOOGW8 & Reg & 38 & 21 & 6000 & 5.1 & 76 & 0.35 & 7.2 & 0.80 & 7600 \\
\hline BOOGW9 & Reg & $3 B$ & 28 & 6500 & 5.2 & 96 & 0.38 & 8.1 & 0.60 & 7300 \\
\hline BDoGX2 & Reg & $3 B$ & 31 & 5500 & 5.1 & 65 & 0.37 & 6.8 & 0.96 & 7200 \\
\hline BOOGX3 & Reg & 38 & 35.5 & 5700 & 5.0 & 63 & 0.33 & 5.2 & 1.6 & 6500 \\
\hline $800 G \times 4$ & Reg & 38 & 40 & 5600 & 5.1 & 75 & 0.37 & 4.7 & 1.7 & 6800 \\
\hline
\end{tabular}

(Page 2 of 4) 
Table A-8a. Analytes by Inductively Coupled Plasma, Aluminum-Calcium. ( $\mu \mathrm{g} / \mathrm{g})$

\begin{tabular}{|c|c|c|c|c|c|c|c|c|c|c|}
\hline SAMPLE & TYPE & POND & $\begin{array}{l}\text { APPROX. } \\
\text { DEPTH }\end{array}$ & Al & sb & $\mathrm{Ba}$ & Be & 8 & cd & $\mathrm{Ca}$ \\
\hline BOOFK6 & Reg & $3 A$ & 6.5 & 6600 & $5.6 \quad U$ & 72 & 0.36 & 4.5 & 0.98 & 3400 \\
\hline $8006 \times 5$ & Reg & 3B & 52 & 6000 & $5.1 \quad v$ & 95 & 0.36 & 7.1 & 1.2 & 6600 \\
\hline $800 \mathrm{G} \times 6$ & Reg & 3B & 61.5 & 5400 & 5.1 & 75 & 0.34 & 4.2 & 1.5 & 7700 \\
\hline $8006 \times 8$ & Reg & 38 & 70.5 & 7400 & 5.2 & 84 & 0.32 & 3.7 & 1.3 & 8000 \\
\hline BOOGYO & Blank & 38 & $\cdots$ & 200 & 4.9 & 3.6 & 0.05 & 6.0 & 0.29 & 49 \\
\hline BOOGY1 & Reg & 3B & 80.5 & 8400 & $5.2 \quad v$ & 80 & 0.29 & 12 & 0.66 & 8700 \\
\hline BOOGY2 & folp & $3 B$ & 80.5 & 7200 & 5.2 & 63 & 0.29 & 8.7 & 0.82 & 8000 \\
\hline "BOOGY9 & Split & 38 & 80.5 & 2930 & 12.5 & 43.7 & 1.0 & MA & 1.0 & 5160 \\
\hline BOOGZ2 & Reg & 3B & 90.5 & 7300 & 5.1 & 84 & 0.31 & 6.9 & 1.0 & 7000 \\
\hline BOOGZ3 & Reg & 38 & 105 & 6900 & 5.1 & 66 & 0.30 & 5.0 & 1.1 & 5800 \\
\hline BOOGZ6 & Reg & $3 B$ & 118.5 & 17000 & 5.8 & 88 & 0.88 & 7.6 & 1.3 & 5000 \\
\hline BOOG28 & Reg & $3 B$ & 123.5 & 13000 & 4.9 & 87 & 0.56 & 9.5 & 1.8 & 3000 \\
\hline $800 \mathrm{HOO}$ & Reg & $3 c$ & 1 & 6000 & $5.2 \quad U$ & 53 & 0.41 & 8.3 & 2.0 & 11000 \\
\hline ВООНО1 & Reg & $3 c$ & 3 & 6200 & 5.0 & 50 & 0.36 & 5.8 & 1.0 & 5900 \\
\hline ВООНО2 & Reg & $3 c$ & 5 & 6500 & 5.2 & 60 & 0.39 & 7.7 & 1.2 & 6900 \\
\hline ВоОНО3 & Reg & $3 c$ & 7 & 5400 & 5.0 & 88 & 0.29 & 11 & 2.5 & 6800 \\
\hline ВОOH04 & Reg & $3 c$ & 9 & 6000 & 5.0 & 92 & 0.21 & 12 & 2.3 & 7300 \\
\hline ВООН05 & Fdup & $3 c$ & 9 & 7100 & 4.9 & 79 & 0.26 & 9.4 & 2.1 & 7600 \\
\hline ВООН06 & Reg & $3 c$ & 11.5 & 4900 & 5.3 & 76 & 0.30 & 12 & 2.3 & 6800 \\
\hline воОнО7 & Splite & $3 c$ & 11.5 & 2300 & 4.0 & 57.1 & 0.36 & MA & $0.8 \quad u J$ & 4820 \\
\hline воОнО9 & Reg & $3 c$ & 16 & 4600 & 5.2 & 170 & 0.23 & 14 & 1.7 & 5300 \\
\hline воОН10 & Blenk & $3 c$ & $\cdots$ & 260 & 4.9 & 3.0 & 0.066 & 3.4 & 0.29 & 75 \\
\hline воОН11 & Reg & $3 c$ & 20.5 & 4700 & 5.2 & 69 & 0.30 & 0.42 & 1.0 & 6200 \\
\hline
\end{tabular}

(Page 3 of 4 ) 
Table A-8a. Analytes by Inductively Coupled Plasma, Aluminum-Calcium. (ug/g)

\begin{tabular}{|c|c|c|c|c|c|c|c|c|c|c|c|}
\hline SAMPLE & TYPE & POND & $\begin{array}{l}\text { APPROX. } \\
\text { DEPTH }\end{array}$ & Al & sb & & $8 a$ & $\mathrm{Be}$ & B & cd & $\mathrm{Ca}$ \\
\hline BOOFK6 & Reg & $3 A$ & 6.5 & 6600 & 5.6 & $u$ & 72 & 0.36 & 4.5 & 0.98 & 3400 \\
\hline BOOH16 & Reg & $3 c$ & 30 & 5600 & 4.8 & $\mathbf{u}$ & 73 & 0.35 & 4.9 & 1.7 & 6800 \\
\hline ВоОН15 & Reg & $3 c$ & 36 & 6000 & 5.2 & $\mathbf{u}$ & 56 & 0.27 & 10 & 1.9 & 6200 \\
\hline воОн16 & Reg & $3 c$ & 40.5 & 5500 & 5.3 & $\mathbf{u}$ & 84 & 0.26 & 12 & 2.3 & 9400 \\
\hline воОн17 & Fodp & $3 c$ & 40.5 & 5500 & 5.1 & $\mathbf{u}$ & 78 & 0.32 & $0.41 \quad u$ & 0.62 & 5800 \\
\hline воОН18 & Reg & $3 c$ & 50 & 5800 & 5.3 & $\mathbf{u}$ & 69 & 0.35 & $0.42 \quad u$ & 1.7 & 7800 \\
\hline воОн19 & Reg & $3 c$ & 60 & 7000 & 5.3 & $\mathbf{u}$ & 97 & 0.29 & 4.5 & 1.2 & 6500 \\
\hline $800 \mathrm{H} 20$ & Reg & $3 c$ & 70.5 & 7300 & 5.2 & $\mathbf{u}$ & 70 & 0.33 & 4.0 & 1.7 & 7400 \\
\hline ВоОН21 & Blank & $3 c$ & $\cdots$ & 150 & 5.0 & $\mathbf{u}$ & 2.4 & 0.04 & 3.9 & $0.30 \quad u$ & 92 \\
\hline ВоОН23 & Reg & $3 c$ & 80 & 8300 & 5.2 & $\mathbf{u}$ & 100 & 0.37 & 3.5 & 1.3 & 7600 \\
\hline ВООН24 & Split & $3 c$ & 80 & $3720 \mathrm{~J}$ & 3.59 & UJ & 46.8 & 0.21 & MA & $0.756 \quad v$ & 4740 \\
\hline
\end{tabular}

$U$ The analyte was undetected at the stated limit.

J The associated value is an estimated quantity.

- The reported value is less than the CLP requited detection

This concentration flag was only reported with split saples. Management. "jw or additional qualification flags may be added.

in Analysís not requested. 
Table A-8b. Analytes by Inductively Coupied Plasma, Chromium-Molybdenum. ( $\mu \mathrm{g} / \mathrm{g})$

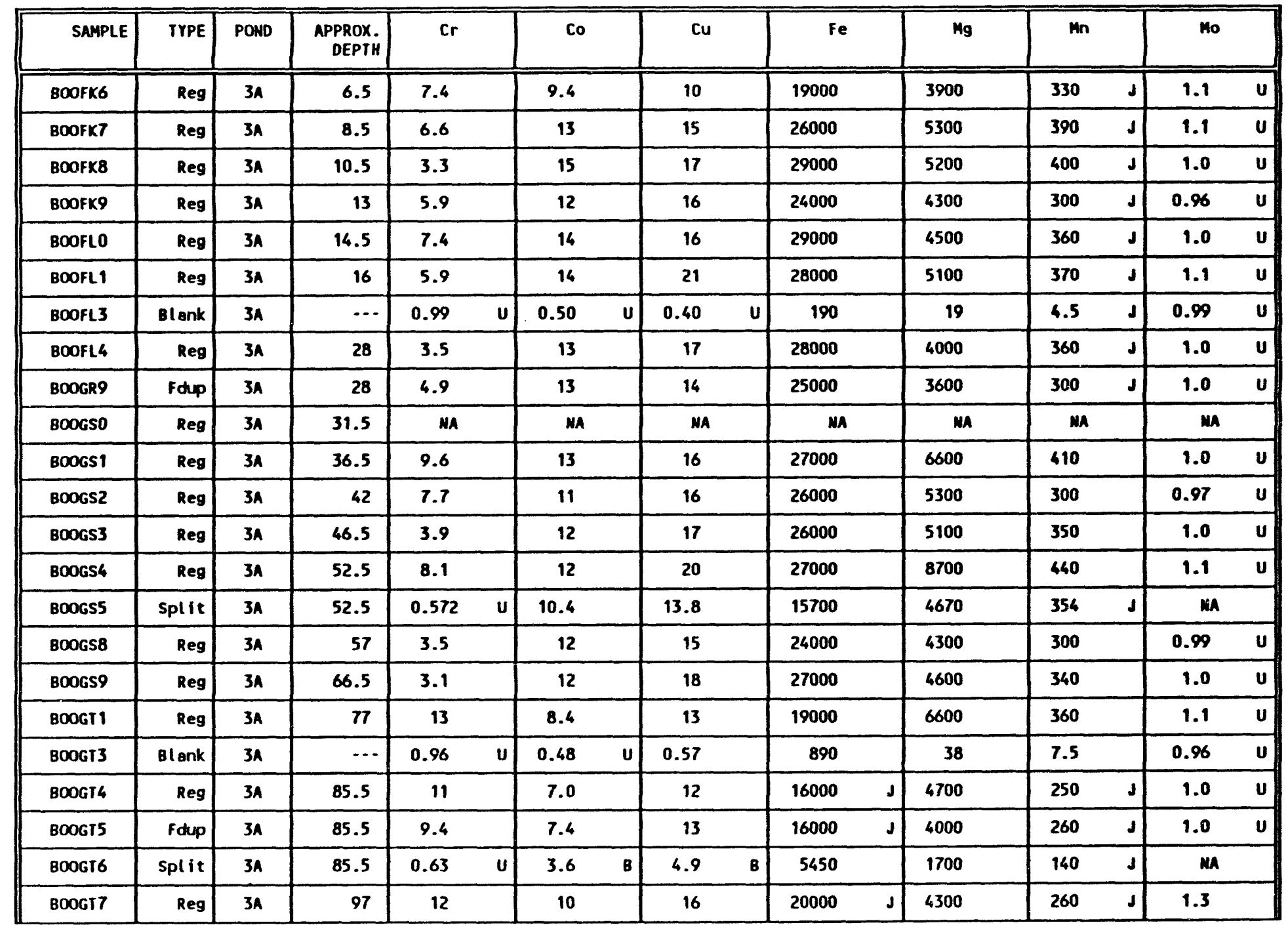

(Page 1 of 4) 
Table A-8b. Analytes by Inductively Coupled Plasma, Chromium-Molybdenum. (ug/g)

\begin{tabular}{|c|c|c|c|c|c|c|c|c|c|c|}
\hline SAMPLE & IYPE & POND & $\begin{array}{l}\text { APPROX. } \\
\text { DEPTH }\end{array}$ & Cr & co & Cu & Fe & $\mathrm{Mg}$ & Mn & Mo \\
\hline B00FK6 & Reg & $3 A$ & 6.5 & 7.4 & 9.4 & 10 & 19000 & 3900 & 330 & 1.1 \\
\hline BOOGTS & Reg & $3 A$ & 102 & 16 & 14 & 27 & 29000 & 5500 & 340 & 1.9 \\
\hline BOOGVO & Reg & $3 A$ & 122 & 9.5 & 12 & 16 & 21000 & 3800 & 250 & 1.1 \\
\hline 80OGVI & Bl ank & $3 A$ & $\cdots$ & 0.91 & 0.72 & 1.4 & 1300 & 42 & 13 & 0.91 \\
\hline BOOGV2 & Reg & $3 A$ & 131 & 10 & 13 & 23 & 24000 & 3800 & 290 & 1.5 \\
\hline BOOGV3 & Folup & $3 A$ & 131 & 14 & 14 & 22 & 24000 & 4300 & 290 & 1.9 \\
\hline $8006 \mathrm{~V} / 4$ & Split & $3 A$ & 131 & 2.9 & 6.3 & 10.1 & 9140 & 2210 & 151 & MA \\
\hline BOOGV5 & Reg & $3 A$ & 143.5 & 16 & 14 & 45 & 25000 & 5100 & 280 & 2.4 \\
\hline BOOGV6 & Reg & 38 & 1 & 8.7 & 12 & 16 & 24000 & 3600 & 280 & 1.2 \\
\hline BOOGV7 & Reg & 38 & 3.5 & 8.6 & 16 & 17 & 25000 & 3800 & 340 & 1.4 \\
\hline BOOGV8 & Reg & 38 & 5.5 & 14 & 13 & 19 & 26000 & 4000 & 350 & 1.5 \\
\hline 800GV9 & Blank & $3 B$ & $\cdots$ & 1.3 & $0.50 \quad u$ & 5.7 & 270 & 22 & 5.4 & 1.00 \\
\hline BOOGWO & Reg & $3 B$ & 7.5 & 9.7 & 11 & 19 & 23000 & 7000 & 410 & 1.3 \\
\hline BOOGWI & Reg & 38 & 9.5 & 5.1 & 14 & 25 & 28000 & 5000 & 360 & 1.4 \\
\hline B00G/3 & Reg & 38 & 13 & 14 & 13 & 19 & 27000 & 4900 & 300 & 1.0 \\
\hline BOOGH4 & Foup & $3 B$ & 13 & 7.2 & 13 & 18 & 25000 & 4200 & 340 & 0.95 \\
\hline BOOGWS & Split & 38 & 13 & 0.61 & $6.1 \quad 8$ & 8.6 & 9620 & 1990 & 152 & $m a$ \\
\hline BOOGH6 & Reg & 3B & 16 & 8.1 & 14 & 17 & 30000 & 5800 & 600 & 1.1 \\
\hline $800 G 48$ & Reg & 38 & 21 & 6.8 & 14 & .18 & 29000 & 4600 & 360 & 1.0 \\
\hline BOOGWP & Reg & 38 & 28 & 9.4 & 15 & 21 & 29000 & 4200 & 340 & 1.0 \\
\hline $800 G \times 2$ & Reg & 38 & 31 & 7.6 & 14 & 17 & 27000 & 3800 & 320 & 1.0 \\
\hline $800 G \times 3$ & Reg & 3B & 35.5 & 9.6 & 13 & 18 & 24000 & 3800 & 270 & 1.0 \\
\hline $800 G \times 4$ & Reg & $3 B$ & 40 & 5.9 & 14 & 19 & 27000 & 4600 & 310 & 1.0 \\
\hline
\end{tabular}

(Page 2 of 4 ) 
Table A-8b. Analytes by Inductively Coupled Plasma, Chromium-Molybdenum. ( $\mu \mathrm{g} / \mathrm{g})$

\begin{tabular}{|c|c|c|c|c|c|c|c|c|c|c|c|}
\hline SAMPLE & TYPE & POND & $\begin{array}{c}\text { APPROX. } \\
\text { DEPTH }\end{array}$ & $\mathrm{Cr}$ & co & Cu & Fe & Mg & Mn & Mo & \\
\hline BOOFK6 & Reg & $3 A$ & 6.5 & 7.4 & 9.4 & 10 & 19000 & 3900 & 330 & 1.1 & $\mathbf{u}$ \\
\hline B0OGX5 & Reg & 38 & 52 & 11 & 13 & 21 & 27000 & 4200 & 300 & 1.5 & \\
\hline $8006 \times 6$ & Reg & $3 B$ & 61.5 & 11 & 12 & 17 & 25000 & 4400 & 310 & 1.2 & \\
\hline B00GX8 & Reg & 3B & 70.5 & 11 & 9.5 & 14 & 21000 & 4800 & 300 & 1.0 & $u$ \\
\hline BOOGYO & Blank & 38 & $\cdots$ & 0.98 & 0.49 & 1.5 & 970 & 32 & 18 & 0.98 & v) \\
\hline BOOGYI & Reg & 38 & 80.5 & 19 & 9.1 & 26 & 30000 & 4300 & 370 & 2.0 & \\
\hline BOOGY2 & Fodup & $3 B$ & 80.5 & 17 & 8.9 & 22 & $29000 \mathrm{~J}$ & 4400 & 350 & 1.4 & \\
\hline *BOOGY9 & Split & 3B & 80.5 & 2.1 & $10.4 U$ & 10.9 & 9600 & 2530 & 183 & ma & \\
\hline $800 G 22$ & Reg & $3 B$ & 90.5 & 18 & 12 & 33 & 26000 & 3900 & 300 & 1.9 & \\
\hline BOOGZ3 & Reg & 38 & 105 & 20 & 11. & 19 & 22000 & 4600 & 280 & 1.4 & \\
\hline 800626 & Reg & 38 & 118.5 & 25 & 9.5 & 19 & 23000 & 8400 & 270 & 1.2 & $u$ \\
\hline BOOGZ8 & Reg & 3B & 123.5 & 18 & 7.3 & 13 & 17000 & 6000 & 270 & 0.99 & u \\
\hline ВООНОО & Reg & $3 c$ & 1 & 6.0 & 13 & 17 & 28000 & 5000 & 370 & 1.0 & u \\
\hline В0ОНО1 & Reg & $3 c$ & 3 & 11 & 11 & 19 & 23000 & 4600 & 290 & 1.0 & u \\
\hline воOHO2 & Reg & $3 c$ & 5 & 13 & 14 & 26 & 29000 & 5000 & 350 & 1.8 & \\
\hline ВООНО3 & Reg & $3 c$ & 7 & 7.6 & 13 & 16 & 25000 & 4500 & 300 & 1.0 & u \\
\hline воOHO4 & Reg & $3 c$ & 9 & 11 & 13 & 18 & 26000 & 4500 & 320 & 2.2 & \\
\hline воOHOS & Fodup & $3 c$ & 9 & 20 & 12 & 16 & 22000 & 5500 & 300 & 1.0 & \\
\hline ВоОнО6 & Reg & $3 c$ & 11.5 & 4.1 & 15 & 17 & 30000 & 5000 & 400 & 1.1 & u \\
\hline ВООНО7 & Split & $3 c$ & 11.5 & 0.634 & 6 & 9.4 & 11400 & 2350 & 172 & MA & \\
\hline ВООНО9 & Reg & $3 c$ & 16 & 4.6 & 10 & 13 & 21000 & 3700 & 250 & 1.0 & u \\
\hline ВоOH10 & Blank & $3 c$ & $\cdots$ & 0.98 & 0.49 & 0.39 & 650 & 44 & 12 & 0.98 & u \\
\hline BOOH11 & Reg & $3 c$ & 20.5 & 5.7 & 13 & 14 & 25000 & 3900 & 300 & 1.0 & v \\
\hline
\end{tabular}

(Page 3 of 4) 
Table A-8b. Analytes by Inductively Coupled Plasma, Chromium-Molybdenum. ( $\mu \mathrm{g} / \mathrm{g})$

\begin{tabular}{|c|c|c|c|c|c|c|c|c|c|c|}
\hline SAMPLE & TYPE & POND & $\begin{array}{c}\text { APPROX. } \\
\text { DEPIH }\end{array}$ & cr & co & $\mathrm{Cu}$ & fe & $\mathrm{Mg}$ & $\mathrm{Mn}_{\mathrm{n}}$ & Mo \\
\hline B00FK6 & Reg & $3 A$ & 6.5 & 7.4 & 9.4 & 10 & 19000 & 3900 & 330 & 1.1 \\
\hline воОн16 & Reg & $3 c$ & 30 & 5.7 & 12 & 17 & 26000 & 4100 & 290 & 0.97 \\
\hline $800 \mathrm{H} 15$ & Reg & $3 c$ & 36 & 7.1 & 12 & 15 & 23000 & $370 \mathrm{C}$ & 280 & 1.0 \\
\hline ВоОн16 & Reg & $3 c$ & 40.5 & 6.3 & 13 & 15 & 26000 & 4300 & 290 & 1.1 \\
\hline В0OH17 & Fodp & $3 c$ & 40.5 & 11 & 14 & 19 & 25000 & 4800 & 310 & 1.0 \\
\hline ВоОн18 & Reg & $3 c$ & 50 & 7.3 & 16 & 17 & 31000 & 4900 & 390 & 1.2 \\
\hline воОн19 & Reg & $3 c$ & 60 & 11 & 8.1 & 15 & 17000 & 4200 & 270 & 1.3 \\
\hline воОн20 & Reg & $3 c$ & 70.5 & 11 & 11 & 19 & 23000 & 4500 & 290 & 1.0 \\
\hline В00Н21 & Blank & $3 c$ & $\cdots$ & 7.2 & 0.50 & $0.40 \quad U$ & 270 & 45 & 6.9 & 0.99 \\
\hline $80 \mathrm{H} 23$ & Reg & $3 c$ & BO & 27 & 12 & 23 & 25000 & 5800 & 310 & 1.0 \\
\hline ВОOH24 & Split & $3 c$ & 80 & 8.5 & 8.1 & 12.7 & 13600 & 3230 & 189 & $M A$ \\
\hline
\end{tabular}

$U$ The analyte was undetected at the stated limit.

1 The associated value is an estimated quantity.

The reported value is less than the CLP required detection limit, but greater than the instrument detection limit.

As reported by laboratory--unvalidated by WHC office of Sample Management. "J" or additional qualification flags may be added.

Ma Analysis not requested. 
Table A-8c. Analytes by Inductively Coupled Plasma, Nickel-Zinc. ( $\mu \mathrm{g} / \mathrm{g})$

\begin{tabular}{|c|c|c|c|c|c|c|c|c|c|c|}
\hline SAMPLE & IYPE & POND & $\begin{array}{l}\text { APPROX } \\
\text { DEPIH }\end{array}$ & $\mathrm{Mi}$ & K & si & Ag & $\mathrm{Na}$ & $v$ & Zn \\
\hline B00FK6 & Reg & $3 A$ & 6.5 & 8.5 & 1400 & 860 & 0.67 & 170 & 45 & 42 \\
\hline BOOFKT & Reg & $3 A$ & 8.5 & 10 & 1200 & 540 & 0.64 & 240 & 67 & 51 \\
\hline BOOFK8 & Reg & $3 n$ & 10.5 & 5.9 & 590 & 550 & 0.61 & 230 & 81 & 51 \\
\hline BOOFK9 & Reg & $3 \AA$ & 13 & 7.7 & 560 & 320 & 0.58 & 230 & 59 & 45 \\
\hline BOOFLO & Reg & $3 A$ & 14.5 & 10 & 600 & 500 & 0.62 & 290 & 86 & 54 \\
\hline BOOFLI & Reg & $3 A$ & 16 & 7.5 & 840 & 510 & 0.64 & 320 & 81 & 55 \\
\hline BOOFL3 & Btank & $3 A$ & $\cdots$ & $0.99 \quad u$ & $59 \quad$ U & 58 & 0.59 & 20. & $0.50 \quad v$ & 2.1 \\
\hline BOOFL4 & Reg & $3 A$ & 28 & 6.4 & 530 & 370 & 0.62 & 220 & 78 & 48 \\
\hline BOOGR9 & Fodup & $3 A$ & 28 & 6.4 & 530 & 370 & 0.61 & 240 & 78 & 47 \\
\hline BOOGSO & Reg & $3 A$ & 31.5 & HA & MA & MA & MA & MA & $M A$ & NA \\
\hline BOOGS1 & Reg & $3 A$ & 36.5 & 15 & 900 & 400 & 1.5 & 280 & 68 & 56 \\
\hline Boogs2 & Reg & $3 n$ & 42 & 13 & 750 & 330 & 1.0 & 270 & 68 & 52 \\
\hline BOOGS3 & Reg & $3 A$ & 46.5 & 12 & 800 & 280 & 1.1 & 280 & 68 & 51 \\
\hline BOOGS4 & Reg & $3 A$ & 52.5 & 12 & 1500 & 480 & 1.1 & 250 & 58 & 60 \\
\hline BOOGS5 & Split & $3 A$ & 52.5 & $6.6 \quad B$ & $1110 \quad U$ & NA & 0.952 & $131 \quad B$ & 18.2 & 32.4 \\
\hline BOOGS8 & Reg & $3 A$ & 57 & 7.1 & 670 & 310 & 0.66 & 330 & 62 & 45 \\
\hline BOOGS9 & Reg & $3 A$ & 66.5 & 7.0 & 710 & 270 & 0.77 & 310 & 74 & 52 \\
\hline BOOGI1 & Reg & $3 A$ & 77 & 16 & 1800 & 450 & 0.83 & 180 & 41 & 62 \\
\hline BOOGI3 & Blank & $3 A$ & $\cdots$ & 0.96 & 57 & 87 & 0.57 & 16 & 0.48 & 0.6 \\
\hline $800 G 14$ & Reg & $3 A$ & 85.5 & 11 & 1000 & 440 & 0.63 & 200 & 38 & 34 \\
\hline BOOGTS & Fdup & $3 A$ & 85.5 & 10 & 830 & 550 & 0.62 & 160 & 40 & 33 \\
\hline BOOGT6 & Split & $3 A$ & 85.5 & 3.6 & 420 & NA & 0.83 & 90.3 & 7.6 & 12.4 \\
\hline BOOGT7 & Reg & $3 A$ & 97 & 10 & 800 & 470 & 0.58 & 540 & 52 & 37 \\
\hline
\end{tabular}

(Page 1 of 4 ) 
Table A-8c. Analytes by Inductively Coupled Plasma, Nickel-Zinc. ( $\mu \mathrm{g} / \mathrm{g})$

\begin{tabular}{|c|c|c|c|c|c|c|c|c|c|c|}
\hline SAMPLE & TYPE & POND & $\begin{array}{c}\text { APPROXX. } \\
\text { DEPTH }\end{array}$ & $\mathbf{M i}$ & $k$ & si & Ag & Ma & $\mathbf{v}$ & $2 n$ \\
\hline B00FK6 & Reg & $3 A$ & 6.5 & 8.5 & 1400 & 860 & $0.67 \quad U$ & 170 & 45 & 42 \\
\hline BOOGT8 & Reg & $3 A$ & 102 & 15 & 1100 & 560 & 0.61 & 740 & 73 & 51 \\
\hline BOOGVO & Reg & $3 A$ & 122 & 11 & 930 & 450 & $0.56 \quad u$ & 490 & 56 & 42 \\
\hline 800GVI & Blank & $3 A$ & $\cdots$ & $0.91 U$ & 83 & 82 & 0.55 & 58 & 3.1 & 7.4 \\
\hline $800 \mathrm{GV} 2$ & Reg & $3 A$ & 131 & 9.8 & 870 & 330 & $0.56 \quad u$ & 810 & 65 & 43 \\
\hline BOOGV3 & focp & $3 A$ & 131 & 16 & 860 & 510 & 0.62 & 770 & 61 & 43 \\
\hline BOOGV4 & Split & $3 n$ & 131 & 6.18 & $390 \quad 8$ & MA & 0.79 & 341 & 15.4 & 15.6 \\
\hline BOOGV5 & Reg & $3 A$ & 143.5 & 24 & 550 & 320 & 0.65 & 600 & 69 & 45 \\
\hline BOOGV6 & Reg & 38 & 1 & 8.2 & 680 & 340 & $0.60 \quad u$ & 320 & 64 & 48 \\
\hline BOOGV7 & Reg & 3B & 3.5 & 8.9 & 660 & 330 & 0.58 & 360 & 72 & 50 \\
\hline BoOGVB & Reg & 38 & 5.5 & 13 & 670 & 360 & 0.62 & 340 & 70 & 52 \\
\hline Boogvg & Blank & 38 & $\cdots$ & 1.4 & $60 \quad U$ & 110 & 0.60 & 34 & 0.50 & 4.1 \\
\hline 800GW0 & Reg & 38 & 7.5 & 11 & 1300 & 260 & 0.64 & 210 & 52 & 48 \\
\hline BOOGH1 & Reg & 38 & 9.5 & 8.2 & 780 & 280 & 0.61 & 230 & 78 & 50 \\
\hline BOOGW3 & Reg & 38 & 13 & 11 & 850 & 300 & $0.60 \quad u$ & 340 & 71 & 46 \\
\hline $800 G 144$ & folup & 38 & 13 & 8.8 & 670 & 220 & 0.57 & 280 & 76 & 45 \\
\hline BOOGWS & Split & 38 & 13 & 4.38 & 491 & MA & 0.82 & 1328 & 11.3 & 17.7 \\
\hline BOOGW6 & Reg & 38 & 16 & 10 & 870 & 300 & 0.63 & 260 & 82 & 51 \\
\hline BOOGWB & Reg & 3B & 21 & 8.3 & 740 & 240 & 0.61 & 450 & 76 & 50 \\
\hline BOOGWO & Reg & 38 & 28 & 11 & 730 & 240 & 0.62 & 560 & 87 & 50 \\
\hline $8006 \times 2$ & Reg & $3 B$ & 31 & 8.9 & 660 & 250 & 0.62 & 390 & 82 & 49 \\
\hline BooGX3 & Reg & 38 & 35.5 & 9.2 & 710 & 290 & 0.60 & 520 & 77 & 44 \\
\hline $8006 \times 4$ & Reg & 3B & 40 & 10 & 780 & 410 & 0.61 & 420 & 76 & 46 \\
\hline
\end{tabular}

(Page 2 of 4 ) 
Table A-8c. Analytes by Inductively Coupled Plasma, Nickel-Zinc. ( $\mu \mathrm{g} / \mathrm{g})$

\begin{tabular}{|c|c|c|c|c|c|c|c|c|c|c|}
\hline SAMPLE & TYPE & POND & $\begin{array}{l}\text { APPROX. } \\
\text { DEPIH }\end{array}$ & $\mathbf{N i}$ & K & si & Ag & $\mathrm{Na}$ & $v$ & $2 n$ \\
\hline BOOFK6 & Reg & $3 A$ & 6.5 & 8.5 & 1400 & 860 & 0.67 & 170 & 45 & 42 \\
\hline BOOGX5 & Reg & 3в & 52 & 9.7 & 910 & 390 & 0.62 & 550 & 72 & 46 \\
\hline $8006 \times 6$ & Reg & 38 & 61.5 & 12 & 770 & 4.50 & 0.61 & 420 & 68 & 43 \\
\hline$B 00 G \times 8$ & Reg & 38 & 70.5 & 12 & 1200 & 400 & 0.62 & 450 & 54 & 40 \\
\hline BOOGYO & Blank & 38 & $\cdots$ & 0.99 & 65 & 100 & 0.59 & 51 & 0.59 & 3.3 \\
\hline BOOGY1 & Reg & 38 & 80.5 & 12 & 970 & 290 & 0.62 & 610 & 45 & 40 \\
\hline BOOGY2 & Folup & 38 & 80.5 & 14 & 1100 & 260 & 0.65 & 410 & 45 & 36 \\
\hline *BOOGY9 & Split & $3 B$ & 80.5 & $\mathbf{u}$ & 1040 U & MA & 2.1 & $1040 \quad U$ & 15.0 & 17.3 \\
\hline BOOGZ2 & Reg & 38 & 90.5 & 13 & 780 & 250 & 0.61 & 710 & 67 & 40 \\
\hline BOOG23 & Reg & $3 B$ & 105 & 15 & 1200 & 430 & 0.61 & 500 & 58 & 39 \\
\hline BOOG26 & Reg & 3B & 118.5 & 21 & 3000 & 430 & 0.70 & 210 & 38 & 56 \\
\hline BOOG28 & Reg & 3B & 123.5 & 14 & 2000 & 290 & 0.59 & 180 & 34 & 43 \\
\hline ВоОНОО & Reg & $3 c$ & 1 & 9.4 & 1100 & 350 & 0.62 & 560 & 77 & 51 \\
\hline воОНО1 & Reg & 36 & 3 & 11 & 830 & 460 & 0.60 & 470 & 62 & 41 \\
\hline ВООНО2 & Reg & $3 c$ & 5 & 13 & 970 & 300 & 0.62 & 620 & 78 & 57 \\
\hline ВООНО3 & Reg & $3 c$ & 7 & 10 & 940 & 410 & 0.60 & 450 & 62 & 49 \\
\hline ВоОНО4 & Reg & $3 c$ & 9 & 11 & 960 & 290 & 0.60 & 510 & 69 & 49 \\
\hline ВООНО5 & Fdup & $3 c$ & 9 & 29 & 790 & 260 & 0.59 & 540 & 58 & 39 \\
\hline ВоОНО6 & Reg & $3 c$ & 11.5 & 7.0 & 670 & 290 & 0.63 & 390 & 85 & 54 \\
\hline воОно7 & Split & $3 c$ & 11.5 & 5.0 & 256 & NA & 0.85 & 263 & 17.3 & 19.3 \\
\hline ВООНО9 & Reg & $3 c$ & 16 & 6.8 & 550 & 290 & 0.62 & 310 & 55 & 38 \\
\hline ВоОн10 & Blank & $3 c$ & $\cdots$ & 0.98 & 59 & 100 & 0.59 & 31 & 0.53 & 5.5 \\
\hline воОН11 & Reg & $3 c$ & 20.5 & 14 & 630 & 270 & 0.62 & 270 & 68 & 47 \\
\hline
\end{tabular}

(Page 3 of 4 ) 
Table A-8c. Analytes by Inductively Coupled Plasma, Nickel-Zinc. ( $\mu \mathrm{g} / \mathrm{g})$

\begin{tabular}{|c|c|c|c|c|c|c|c|c|c|c|}
\hline SAMPLE & TYPE & POND & $\begin{array}{c}\text { APPROX. } \\
\text { DEPTH }\end{array}$ & $\mathrm{Ni}$ & $\mathbf{K}$ & si & $\mathbf{A g}$ & $\mathrm{Na}$ & $\mathbf{v}$ & $2 n$ \\
\hline BOOFK6 & Reg & $3 A$ & 6.5 & 8.5 & 1400 & 860 & $0.67 \quad v$ & 170 & 45 & 42 \\
\hline ВООН16 & Reg & $3 c$ & 30 & 9.6 & 860 & 260 & $0.58 \quad u$ & 440 & 69 & 49 \\
\hline воOH15 & Reg & $3 c$ & 36 & 7.9 & 720 & 250 & 0.62 & 520 & 60 & 42 \\
\hline воОн16 & Reg & $3 c$ & 40.5 & 12 & 750 & 270 & 0.64 & 510 & 72 & 46 \\
\hline воОн17 & Fdup & $3 c$ & 40.5 & 14 & 670 & 300 & 0.61 & 440 & 68 & 45 \\
\hline воон18 & Reg & $3 c$ & 50 & 8.9 & 770 & 370 & 0.64 & 430 & 85 & 54 \\
\hline воОн19 & Reg & $3 c$ & 60 & 11 & 1100 & 430 & 0.63 & 410 & 38 & 34 \\
\hline ВоОН20 & Reg & $3 c$ & 70.5 & 10 & 1100 & 310 & 0.62 & 570 & 63 & 41 \\
\hline ВоОН21 & Blank & $3 c$ & $\cdots$ & 4.1 & $60 \quad U$ & 76 & 0.60 & 56 & $0.50 \quad U$ & 2.2 \\
\hline воОН23 & Reg & $3 c$ & 80 & 18 & 1000 & 350 & 0.63 & 730 & 61 & 42 \\
\hline ВООН24 & Split & $3 c$ & 80 & 9.5 & 694 & MA & 1.1 & 275 & 23 & 23.5 \\
\hline
\end{tabular}

$U$ The analyte was undetected at the stated limit.

The reported value is less then instrument detection limit.

This concentration flag was only reported with split samples.

MA Analysis not requested. 
WHC-SD-EN-AP-104 Rev. 0

Reasons for Westinghouse Hanford Company Qualification-Analytes by Inductively Coupled Plasma (Aluminum-Zinc)

Regular. Field Duplicate, and Silica Sand Samples:

MATRIX SPIKE--The spike recovery for $\mathrm{Mg}$ and Fe was high for several batches. This resulted in an estimated, "J", qualification for samples in those batches. Affected samples are:

$\begin{array}{llll}\text { BOOFK6 } & \text { BOOGT4 } & \text { BOOGV6 } & \text { BOOGYO } \\ \text { BOOFK7 } & \text { BOOGT5 } & \text { BOOGV7 } & \text { BOOGY1 } \\ \text { BOOFK8 } & \text { BOOGT7 } & \text { BOOGV8 } & \text { BOOGY2 } \\ \text { BOOFK9 } & \text { BOOGT8 } & \text { BOOGV9 } & \text { BOOGZ2 } \\ \text { BOOFL0 } & \text { BOOGVO } & \text { BOOGW0 } & \text { BOOGW9 } \\ \text { BOOFL1 } & \text { BOOGV1 } & \text { BOOGW1 } & \text { BOOGX2 } \\ \text { BOOFL3 } & \text { BOOGV2 } & \text { BOOGW4 } & \\ \text { BOOFL4 } & \text { BOOGV3 } & \text { BOOGW6 } & \\ \text { BOOGR9 } & \text { BOOGV5 } & \text { BOOGW8 } & \end{array}$

\section{Split Samples:}

LABORATORY BLANKS--BOOGS5, BOOGT6 and BOOGW5 were qualified as undetected, "U", for $K$ based on traces in the associated blanks. Sample BOOHO7 was likewise qualified for $\mathrm{Na}$ because contamination was present in the associated blank. (Blank concentrations were less than the CLP CRQL.)

INDUCTIVELY COUPLED PLASMA (ICP) INTERFERENCE CHECK SAMPLE--BOOGS5, BOOHO7, BOOH24, BOOGT6 and BOOGW5 Mn results were qualified as estimated, " $J$ ", because of the possibility of false positive results. A "UJ" qualified Sb results for $\mathrm{BOOH} 24$ and $\mathrm{BOOGS5}$ because of the potential for fal se negative results from interference. Sodium results for BOOGV4 were qualified "J", because of the possibility of false positive results.

MATRIX SPIKE--The $C d$ and Mn results for $B 00 H 07$ were qualified "UJ" and "J", respectively because of associated low matrix spike recoveries. The Sb results for BOOH24 and BOOGS5 were qualified "UJ" because of low spike recoveries $(<75 \%)$.

DUPLICATE ANALYSIS--Barium and $\mathrm{Cr}$ results of sample BOOH24 were qualified because of variability among duplicate analyses.

SERIAL DILUTION--Several major soil elements ( $\mathrm{Al}, \mathrm{Fe}, \mathrm{Mn}, \mathrm{Ca}$, and $\mathrm{Mg}$ ) were qualified as estimated, "J", for BOOH24 because of serial dilution results differed from initial sample results by $>10 \%$. 
Table A-9. Analytes by Atomic Absorption Spectroscopy. ( $\mu \mathrm{g} / \mathrm{g})$

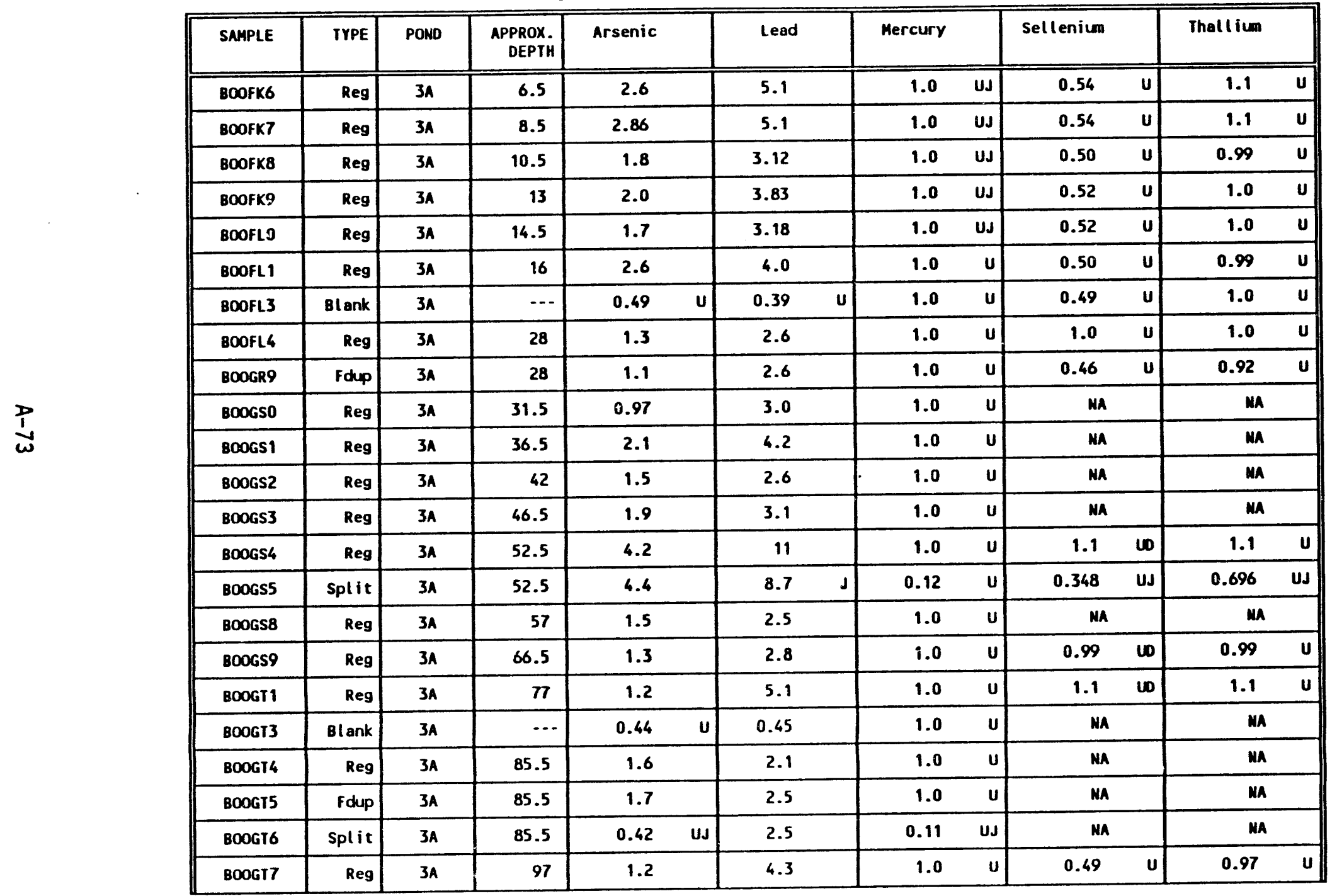


Table A-9. Analytes by Atomic Absorption Spectroscopy. ( $\mu \mathrm{g} / \mathrm{g})$

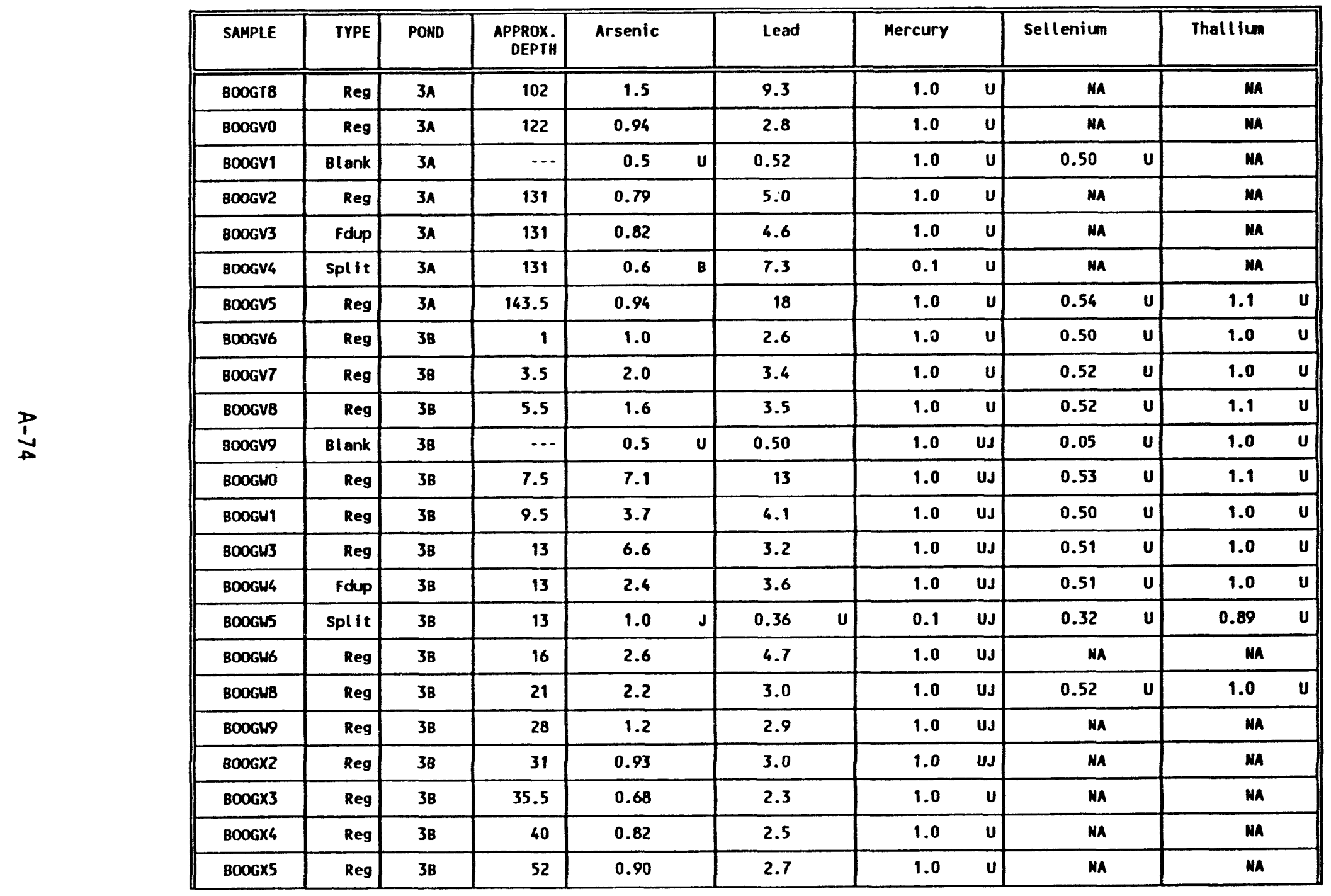

(Page 2 of 4 ) 
T.able A-9. Analytes by Atomic Absorption Spectroscopy. ( $\mu \mathrm{g} / \mathrm{g})$

\begin{tabular}{|c|c|c|c|c|c|c|c|c|c|}
\hline SAMPLE & TYPE & POND & $\begin{array}{l}\text { APPROX. } \\
\text { DEPTH }\end{array}$ & Arsenic & Lead & Mercury & & Seltenium & Thalliun \\
\hline $8006 \times 6$ & Reg & 38 & 61.5 & 0.61 & 2.2 & 1.0 & $u$ & 0.52 & 1.0 \\
\hline$B 00 G \times 8$ & Reg & $3 B$ & 70.5 & 1.5 & 3.1 & 1.0 & $\mathbf{u}$ & MA & $M A$ \\
\hline BOOGYO & Blank & 38 & $\cdots$ & $0.5 \quad u$ & 0.43 & 1.0 & $u$ & MA & MA \\
\hline BOOGY1 & Reg & $3 B$ & 80.5 & 1.6 & 20 & 1.0 & $u$ & MA & MA \\
\hline BOOGYZ & Folup & 38 & 80.5 & 1.9 & 8.8 & 1.0 & $\mathbf{u}$ & wA & MA \\
\hline "BOOGY9 & Spl it & $3 B$ & 80.5 & $1.9 U$ & 7.1 & 0.56 & & MA & MA \\
\hline BoOGZ2 & Reg & 38 & 90.5 & 1.2 & 9.9 & 1.0 & $\mathbf{u}$ & 0.51 & 1.0 \\
\hline 800623 & Reg & $3 B$ & 105 & 0.98 & 2.9 & 1.0 & $\mathbf{u}$ & MA & Ma \\
\hline BOOG26 & Reg & $3 B$ & 118.5 & $0.59 \quad U$ & 8.5 & 1.0 & u & 0.54 & 1.0 \\
\hline B00628 & Reg & $3 B$ & 123.5 & 7.2 & 7.2 & 1.0 & $\mathbf{u}$ & 0.61 & 1.2 \\
\hline ВООНОО & Reg & $3 c$ & 1 & 2.5 & 3.9 & 1.0 & $u$ & 0.51 & 1.0 \\
\hline ВООНО1 & Reg & $3 c$ & 3 & 1.9 & 3.1 & 1.0 & $u$ & 0.51 & 1.0 \\
\hline воОНО2 & Reg & $3 c$ & 5 & 2.3 & 30 & 1.0 & $u$ & 0.52 & 1.0 \\
\hline ВOOHO3 & Reg & $3 c$ & 7 & 2.1 & 2.5 & 1.0 & $u$ & 0.52 & 1.0 \\
\hline воОН04 & Reg & $3 c$ & 9 & 1.8 & 2.6 & 1.0 & $\mathbf{u}$ & 0.52 & 1.0 \\
\hline ВООН05 & Folup & $3 c$ & 9 & 1.3 & 2.6 & 1.0 & u & 0.51 & 1.0 \\
\hline воОН06 & Reg & $3 c$ & 11.5 & 1.7 & 2.5 & 1.0 & u & 0.52 & 1.0 \\
\hline воОНО7 & Split & $3 c$ & 11.5 & 0.9 & 2.2 & 0.1 & $\mathbf{u}$ & 0.16 & 8.0 \\
\hline ВоOH09 & Reg & $3 c$ & 16 & 0.80 & 1.9 & 1.0 & $u$ & MA & MA \\
\hline ВоОн 10 & Blank & $3 c$ & $\cdots$ & 0.5 & 0.51 & 0.1 & UJ & 0.50 & 1.0 \\
\hline $800 \mathrm{H} 11$ & Reg & $3 c$ & 20.5 & 0.82 & 2.5 & 0.1 & us & MA & MA \\
\hline ВОOH14 & Reg & $3 c$ & 30 & 0.92 & 2.4 & 0.1 & Us & 0.52 & 1.0 \\
\hline 80OH15 & Reg & $3 c$ & 36 & 0.65 & 1.8 & 0.1 & US & MA & MA \\
\hline
\end{tabular}

(Page 3 of 4 ) 
Table A-9. Analytes by Atomic Absorption Spectroscopy. ( $\mu \mathrm{g} / \mathrm{g})$

\begin{tabular}{|c|c|c|c|c|c|c|c|c|}
\hline SAMPLE & TYPE & POND & $\begin{array}{l}\text { APPROX. } \\
\text { DEPIH }\end{array}$ & Arsenic & Lead & Mercury & Sellenium & Thallium \\
\hline воОн16 & Reg & $3 c$ & 40.5 & 0.76 & 2.0 & 0.1 us & MA & $m a$ \\
\hline воОн17 & Fodup & $3 c$ & 40.5 & $0.50 \quad u$ & 1.9 & 0.1 & MA & MA \\
\hline 80OH18 & Reg & $3 c$ & 50 & 0.73 & 2.1 & 0.1 UJ & MA & Ma \\
\hline воОн19 & Reg & $3 c$ & 60 & 1.4 & 2.8 & 0.1 & 0.53 & 1.0 \\
\hline ВОOH2O & Reg & $3 c$ & 70.5 & 0.88 & 2.22 & 0.1 & MA & Ma \\
\hline ВоОн21 & Blank & $3 c$ & $\cdots$ & $0.5 \quad U$ & $0.4 \quad v$ & 0.1 us & 0.50 & 1.0 \\
\hline воОн23 & Reg & $3 c$ & 80 & 1.4 & 2.5 & 0.1 & 0.52 & 1.0 \\
\hline ВоОН24 & Split & $3 c$ & 80 & 0.66 & 2.1 & 0.107 UR & MA & $M A$ \\
\hline
\end{tabular}

$U$ The analyte was undetected at the stated limit.

The associated value is an est imated quantity.

MA Analysis not requested.

tey be of fected by dilution.

(he instrument detection lifit.

This concentration flag was only reported with split samples.

- This concentration flag was only reported with splice sef Sample Management. "jw or additional qualification flags may be added.

R Qualified by WHC office of Sample Management as unusable. 


\section{Reasons for Westinghouse Hanford Company Qualification-- Analytes by Atomic Absorption Spectroscopy}

\section{Regular. Field Duplicate, and Silica Sand Samples:}

HOLDING TIME--All holding time criteria were met except for some mercury samples. Those samples were qualified "UJ". All samples were flagged as estimated, "J". The 28 day criteria established for water was exceeded for the following Phase 3 soil samples:

$\begin{array}{llll}\text { BOOFK6 } & \text { BOOGW1 } & \text { BOOGX2 } & \text { BOOH17 } \\ \text { BOOFK7 } & \text { BOOGW3 } & \text { BOOH10 } & \text { BOOH18 } \\ \text { BOOFK8 } & \text { BOOGW4 } & \text { BOOH11 } & \text { BOOH19 } \\ \text { BOOFK9 } & \text { BOOGW6 } & \text { BOOH14 } & \text { BOOH20 } \\ \text { BOOFLO } & \text { BOOGW8 } & \text { BOOH15 } & \text { BOOH21 } \\ \text { BOOGV9 } & \text { BOOGW9 } & \text { BOOH16 } & \text { BOOH23 }\end{array}$

\section{Split Samples:}

LABORATORY BLANKS--Selenium results for BOOGW5 were qual ified as "U" because similar levels were found in the immediately associated laboratory blank.

HOLDING TIME--Mercury sample results for BOOGW5 and BOOGT6 were qualified Because of holding times greater than 28 days. Mercury was not detected in either sample; both were qualified "UJ".

SPIKE RECOVERY--LOW percent recovery of spike led Westinghouse HanfordOSM to qualify As result as estimated, "J" or "UJ" on BOOGW5 and BOOGT6, respectively. The $\mathrm{Pb}$, Se, and $\mathrm{TI}$ results for BOOGS5 were also qualified "J", "UJ", and "UJ", respectively, for spike recoveries outside limits. The $\mathrm{Hg}$ results for $\mathrm{BOOH} 24$ were qualified unusable, "R", because there was no spike recovery. 
Table A-10. Miscellaneous Analytes. ( $\mu \mathrm{g} / \mathrm{g})$

\begin{tabular}{|c|c|c|c|c|c|c|c|c|c|c|}
\hline SAMPLE & TYPE & POND & $\begin{array}{l}\text { APPROX. } \\
\text { DEPTH }\end{array}$ & Amonia & Chloride & Cyanide & Fluoride & Nitrate & Sulfate & Sulfide \\
\hline BOOFK6 & Reg & $3 A$ & 6.5 & 0.001 & 20 & 1.0 & 2 & Us & 20 & 0.1 \\
\hline BOOFK7 & Reg & $3 A$ & 8.5 & 0.001 & 20 & 0.12 & 1.4 & UJ & 20 & 0.1 \\
\hline BOOFK8 & Reg & $3 A$ & 10.5 & 0.001 & 20 & 1.0 & 0.8 & UJ & 20 & 0.1 \\
\hline BOOFK9 & Reg & $3 n$ & 13 & 0.001 & 20 & 1.0 & 0.6 & 20 & 20 & 0.1 \\
\hline BOOFLO & Reg & $3 A$ & 14.5 & 0.001 & 20 & 1.0 & 0.6 & UJ & 24 & 0.1 \\
\hline BOOFLI & Reg & $3 A$ & 16 & 0.001 & 20 & 1.0 & 0.8 & us & 20 & 0.1 \\
\hline BOOFL3 & Blank & $3 A$ & $\cdots$ & 0.001 & 20 & 1.0 & 0.4 & UJ & 20 & 0.1 \\
\hline BOOFL4 & Reg & $3 A$ & 28 & 0.001 & 20 & 1.0 & 0.6 & 20 & 20 & 0.1 \\
\hline BOOGR9 & Fdup & $3 A$ & 28 & 0.001 & 20 & 1.0 & 0.6 & 20 & 20 & 0.1 \\
\hline BoOGSO & Reg & $3 n$ & 30.5 & 0.001 & 20 & NA & 1.2 & 20 & 20 & MA \\
\hline BoOGS1 & Reg & $3 n$ & 36.5 & 0.001 & 20 & NA & 2.2 & Us & 20 & MA \\
\hline Boogs2 & Reg & $3 n$ & 42 & 0.001 & 20 & NA & 1.0 & 20 & 20 & MA \\
\hline BOOGS3 & Reg & $3 A$ & 46.5 & 0.001 & 20 & NA & 1.0 & 20 & 20 & MA \\
\hline BOOGS4 & Reg & $3 A$ & 52.5 & 0.001 & $20 \quad U$ & $1.0 \quad \mathrm{UJ}$ & 2 & 20 & 20 & 0.1 \\
\hline BOOGS5 & Split & $3 A$ & 52.5 & NA & MA & 0.6 UI & MA & MA & ma & MA \\
\hline BOOGSB & Reg & $3 A$ & 57 & 0.001 & 20 & NA & 2 & us & 20 & MA \\
\hline BOOGS9 & Reg & $3 n$ & 66.5 & 0.001 & $u$ & $1.0 \quad U \mathrm{~J}$ & 2 & 20 & 20 & 0.1 \\
\hline BOOGII & Reg & $3 A$ & 77 & 0.001 & 20 & NA & 2 & 20 & 20 & NA \\
\hline BOOGI3 & Blank & $3 A$ & $\cdots$ & 0.001 & 20 & NA & $\mathbf{u}$ & UJ & 20 & MA \\
\hline BOOGT4 & Reg & $3 A$ & 85.5 & 0.001 & 1 & NA & 2 & us & $\mathbf{u}$ & MA \\
\hline BOOGT5 & Fdup & $3 A$ & 85.5 & 0.001 & $\mathbf{u}$ & NA & 2 & UJ & 1 & MA \\
\hline BOOGT6 & Split & $3 A$ & 85.5 & NA & NA & NA & $M A$ & MA & MA & MA \\
\hline BOOGI7 & Reg & $3 A$ & 97 & 0.001 & 1 & 1.0 & $u$ & us & 1 & 0.1 \\
\hline
\end{tabular}

(Page 1 of 4 ) 
Table A-10. Miscellaneous Analytes. $(\mu \mathrm{g} / \mathrm{g})$

\begin{tabular}{|c|c|c|c|c|c|c|c|c|c|c|}
\hline SAMPLE & TYPE & POND & $\begin{array}{c}\text { APPROX. } \\
\text { DEPTH }\end{array}$ & Ammonia & Chloride & Cyanide & Fluoride & Mitrate & Sulfate & sulfide \\
\hline BOOGT8 & Reg & $3 n$ & 102 & $0.001 \quad u$ & 20 & MA & 2 & Us & 21 & Mh \\
\hline BooGvo & Reg & $3 n$ & 122 & 0.001 & 20 & MA & $u$ & 20 & 20 & MA \\
\hline BoOGV1 & Blank & $3 n$ & $\cdots$ & 0.001 & 20 & MA & 2 & 20 & 20 & MA \\
\hline BOOGV2 & Reg & $3 A$ & 131 & 0.001 & 20 & MA & $u$ & 20 & 20 & Ma \\
\hline BOOGV3 & Foup & $3 A$ & 131 & $0.001 \quad U$ & 20 & MA & 2 & 20 & 20 & $m n$ \\
\hline BOOGV4 & Split & $3 A$ & 131 & MA & MA & MA & MA & MA & Ma & MA \\
\hline BOOGVS & Reg & $3 n$ & 143.5 & 0.001 & 20 & Us & 2 & 20 & 20 & 0.1 \\
\hline BoOGV6 & Reg & 38 & 1 & 0.001 & 20 & 1.0 & 2 & 20 & 20 & 0.1 \\
\hline BOOGV7 & Reg & 38 & 3.5 & 0.001 & 20 & 1.0 Us & 2 & 20 & 20 & 0.1 \\
\hline BOOGV8 & Reg & 38 & 5.5 & 0.001 & 20 & $1.0 \mathrm{UJ}$ & $u$ & 20 & 20 & 0.1 \\
\hline Boogv9 & Blank & 38 & $\cdots$ & 0.001 & 20 & us & 2 & 20 & 20 & 0.1 \\
\hline BOOGWO & Reg & 38 & 7.5 & 0.001 & 20 & 1.0 us & $u$ & us & 20 & 0.1 \\
\hline BOOGW1 & Reg & 3B & 9.5 & 0.001 & $20 \quad U$ & 0.1 us & $\mathbf{u}$ & 20 & 20 & 0.1 \\
\hline BOOGW3 & Reg & 38 & 13 & 0.001 & 20 & UJ & $u$ & 20 & 20 & 0.1 \\
\hline BOOGH4 & Foup & 38 & 13 & $0.001 \quad U$ & 20 & $0.1 \quad \mathrm{UJ}$ & 2 & 20 & 20 & $0.1 \quad$ UJ \\
\hline BOOGWS & Split & 38 & 13 & NA & MA & $0.5 \quad u$ & $M A$ & MA & $M A$ & Ma \\
\hline BOOGHS & Reg & 38 & 16 & NA & 20 & MA & $u$ & 20 & 20 & MA \\
\hline BOOGW8 & Reg & $3 B$ & 21 & 0.001 & 20 & $1.0 \mathrm{UJ}$ & $\mathbf{u}$ & us & 20 & 0.1 UJ \\
\hline BOOGW & Reg & 38 & 28 & MA & 20 & MA & 2 & Us & 20 & MA \\
\hline BOOGX2 & Reg & 38 & 31 & MA & 20 & MA & $u$ & Us & 20 & MA \\
\hline $8006 \times 3$ & Reg & 38 & 35.5 & 0.001 & 20 & NA & 2 & 20 & 20 & MA \\
\hline $8006 \times 4$ & Reg & 38 & 40 & 0.001 & 20 & NA & 2.6 & 20 & 20 & MA \\
\hline $800 \mathrm{G} \times 5$ & Reg & 38 & 52 & 0.001 & 20 & NA & 2.4 & 20 & 20 & $M A$ \\
\hline
\end{tabular}

(Page 2 of 4 ) 
Table A-10. Miscellaneous Analytes. $(\mu \mathrm{g} / \mathrm{g})$

\begin{tabular}{|c|c|c|c|c|c|c|c|c|c|c|}
\hline SAMPLE & TYPE & POND & $\begin{array}{c}\text { APPROX. } \\
\text { DEPTH }\end{array}$ & Ammonia & Chloride & Cyanide & Fluoride & Nitrate & Sulfate & sulfide \\
\hline $800 \mathrm{G} \times 6$ & Reg & 38 & 61.5 & 0.001 & 20 & 0.1 & 2.0 & 20 & 20 & 0.1 \\
\hline $8006 \times 8$ & Reg & 3B & 70.5 & 0.001 & 20 & MA & 2 & 20 & 20 & MA \\
\hline BOOGYO & Bl ank & 38 & $\cdots$ & 0.001 & 20 & MA & 2 & 20 & 20 & $M a$ \\
\hline BOOGY & Reg & $3 B$ & 80.5 & 0.001 & 20 & NA & 2 & 20 & 39 & $m A$ \\
\hline $800 \mathrm{Gr} 2$ & fodup & 3B & 80.5 & 0.001 & 20 & MA & 2.0 & 20 & 46 & $M A$ \\
\hline BOOGY9 & Split & 38 & BO. 5 & MA & MA & MA & MA & MA & $m A$ & ma \\
\hline 800GZ2 & Reg & $3 B$ & 90.5 & 0.001 & 20 & 0.1 & 2.2 & 20 & 36 & 0.1 \\
\hline 800623 & Reg & 38 & 105 & 0.001 & 20 & MA & 2.0 & 20 & 25 & MA \\
\hline $800 G 26$ & Reg & 38 & 118.5 & 0.001 & 20 & 1.0 & 3.0 & 20 & 28 & 0.1 \\
\hline BOOG28 & Reg & 38 & 123.5 & 0.001 & $20 \quad U$ & 0.1 & $\mathbf{u}$ & 20 & 26 & 0.1 \\
\hline воОноО & Reg & $3 c$ & 1 & 0.001 & 20 & 1.0 & 2.0 & 20 & 20 & 0.1 \\
\hline 80ОНО1 & Reg & $3 c$ & 3 & 0.001 & 20 & 1.0 & 2.2 & 20 & 20 & 0.1 \\
\hline ВООНО2 & Reg & $3 c$ & 5 & 0.001 & 20 & 1.0 & 2.2 & 20 & 20 & 0.1 \\
\hline ВOOHO3 & Reg & $3 c$ & 7 & 0.001 & 20 & 0.1 & 2 & 20 & 20 & 0.1 \\
\hline 80OHO4 & Reg & $3 c$ & 9 & 0.001 & 20 & 0.1 & $u$ & 20 & 26 & 0.1 \\
\hline воОнО5 & Fodp & $3 c$ & 9 & 0.001 & 20 & 0.1 & $u$ & 20 & 21 & 0.1 \\
\hline ВООНО6 & Reg & $3 c$ & 11.5 & 0.001 & $\mathbf{u}$ & 0.1 & $\mathbf{u}$ & 20 & 20 & 0.1 \\
\hline воон07 & Split & $3 c$ & 11.5 & NA & MA & 0.5 uJ & Ma & MA & MA & $m a$ \\
\hline воОнО9 & Reg & $3 c$ & 16 & 0.001 & 20 & MA & $2 \quad v$ & us & 20 & MA \\
\hline ВоОн10 & Blenk & $3 c$ & $\cdots$ & 0.001 & 20 & 0.1 & 2 & 20 & 20 & 0.1 \\
\hline ВоОН11 & Reg & $3 c$ & 20.5 & 0.001 & 20 & MA & $\mathbf{u}$ & 20 & 20 & $\mathrm{MA}_{\mathrm{A}}$ \\
\hline ВООН14 & Reg & $3 c$ & 30 & 0.001 & 20 & 0.1 & $\mathbf{u}$ & 20 & 20 & 0.1 \\
\hline ВОOH 15 & Reg & $3 c$ & 36 & 0.001 & 20 & NA & 2 & 20 & 20 & $M A$ \\
\hline
\end{tabular}

(Page 3 of 4 ) 
Table A-10. Miscellaneous Analytes. ( $\mu \mathrm{g} / \mathrm{g})$

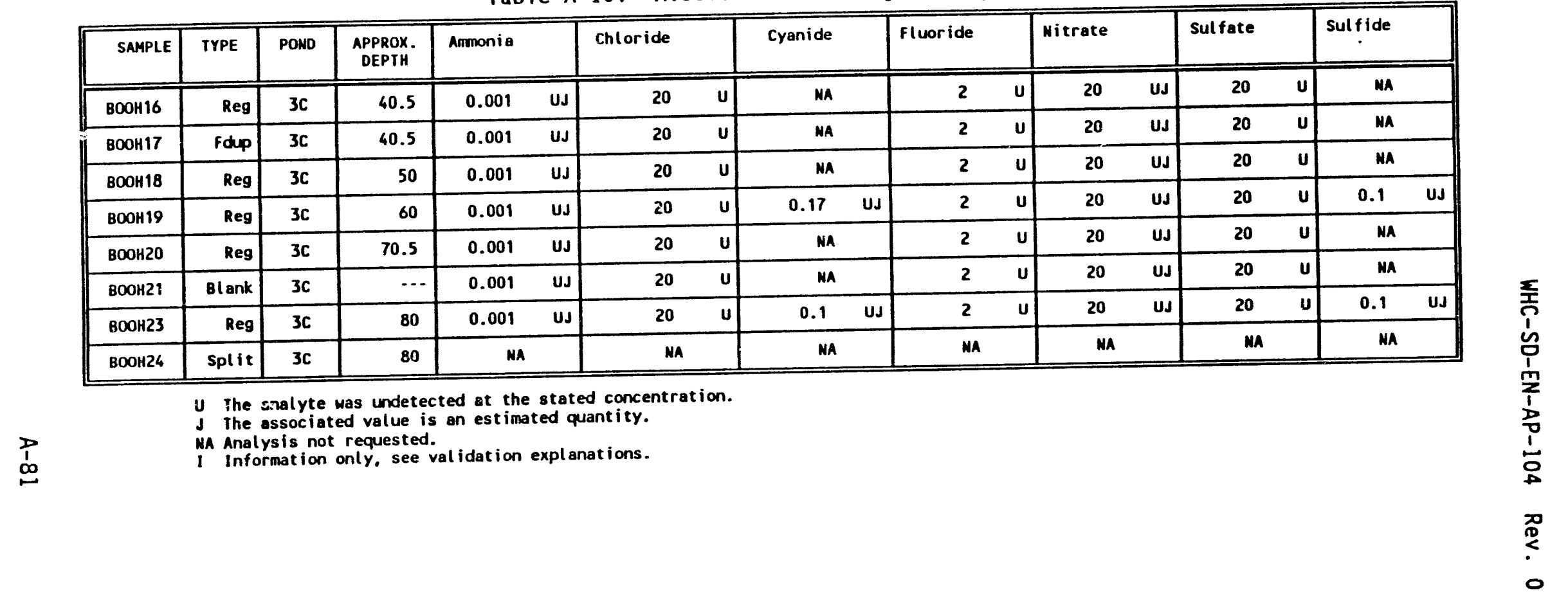




\section{WHC-SD-EN-AP-104 Rev. 0 \\ Reasons for Westinghouse Hanford Company Qualification-- Miscellaneous Analytes}

Regular. Field Duplicate, and Silica Sand Samples:

HOLDING TIME--Nitrate holding time of $48 \mathrm{hrs}$ exceeded for all samples. All samples qualified as estimated, "J", for nitrate. Only BOOGT7, BOOGV7, and BOOGV8 were analyzed within 28 days for sulfide. All other samples were qualified as estimateu, "J", for sulfide. All samples were qualified as estimated, "J", for cyanide because of holding times in excess of 14 days. A 28 day holding time for ammonia analyses was exceeded for the following samples:

$\begin{array}{llll}\text { BOOH10 } & \text { BOOH17 } & \text { BOOH19 } & \text { BOOH21 } \\ \text { BCOH11 } & \text { BOOH18 } & \text { BOOH2O } & \text { BOOH23 } \\ \text { BOOH16 } & & & \end{array}$

\section{Split Samples:}

MATRIX SPIKE/DUPLICATE--No matrix spike or duplicate results were provided for cyanide in sample $\mathrm{BOOGS5}$ or $\mathrm{BOOHO7.} \mathrm{The} \mathrm{undetected} \mathrm{value} \mathrm{for}$ BOOGS5 was qualified as "UI", or information only while a similar undetected result for BOOHO7 was qualified as estimated, "UJ". 
WHC-SD-EN-AP-104 Rev. 0

Table A-11. List of Radioactivity Data $(\rho \mathrm{Ci} / \mathrm{g})$--Unvalidated.

\begin{tabular}{|c|c|c|c|c|c|c|c|c|c|c|}
\hline Sample & Type & Pond & $\begin{array}{l}\text { Approx. } \\
\text { Depth }\end{array}$ & Alpha & $\begin{array}{l}\text { Alphe } \\
\text { Counting } \\
\text { Error }\end{array}$ & Beta & $\begin{array}{l}\text { Beta } \\
\text { Counting } \\
\text { Error }\end{array}$ & ${ }^{90} \mathrm{Sr}$ & $\begin{array}{l}90 \mathrm{Sr} \\
\text { Counting } \\
\text { Error }\end{array}$ & GEA $^{9}$ \\
\hline BOOFK6 & Reg & $3 A$ & -6.5 & 5.34 & 2.9 & -0.221 & 4.8 & 12.7 & 0.84 & NA \\
\hline BOOFK7 & Reg & $3 A$ & -8.5 & 4.5 & 2.9 & 5.0 & 5.0 & 3.47 & 0.51 & NA \\
\hline BoofK8 & Reg & $3 A$ & -10.5 & 3.21 & 2.8 & -0.863 & 4.8 & 3.65 & 0.51 & NA \\
\hline BOOFK9 & Reg & $3 A$ & -13 & 2.4 & 2.7 & -2.61 & 4.8 & 3.86 & 0.52 & NA \\
\hline 80OFLO & Reg & $3 A$ & -14.5 & -2.42 & 2.3 & -9.51 & 4.5 & 1.43 & 4.0 & NA \\
\hline BOOFLI & Reg & $3 A$ & -16 & 2.37 & 2.7 & -1.43 & 4.8 & 0.00 & 0.41 & NA \\
\hline BOOFL3 & Blank & $3 A$ & $\cdots$ & -0.77 & 2.4 & -10.5 & 4.4 & -0.0686 & 0.29 & NA \\
\hline BOOFL 4 & Reg & $3 A$ & -28 & -1.08 & 2.4 & 1.16 & 4.4 & 0.226 & 0.074 & HA \\
\hline BOOGR9 & Foup & $3 A$ & -28 & -2.44 & 2.3 & -12.6 & 4.4 & 3.27 & 0.50 & NA \\
\hline BOOGSO & Reg & $3 A$ & -31.5 & -0.309 & 2.5 & -11.3 & 4.4 & NA & NA & NA \\
\hline Boogs1 & Reg & $3 A$ & -36.5 & -2.39 & 2.3 & -11.2 & 4.4 & NA & NA & NA \\
\hline BooGS2 & Reg & $3 A$ & -42 & -0.337 & 1.9 & 2.33 & 4.7 & NA & NA & NA \\
\hline 800GS3 & Reg & $3 A$ & -46.5 & 1.05 & 2.1 & 6.72 & 4.9 & NA & NA & NA \\
\hline BOOGS 4 & Reg & $3 A$ & .52 .5 & 2.28 & 2.3 & 4.82 & 4.8 & 0.13 & 0.46 & NA \\
\hline BOOGS5 & Split & $3 A$ & -52.5 & 3.4 & 1.3 & 33 & 2 & $<0.04$ & $\cdots$ & Done \\
\hline BOOGS8 & Reg & $3 A$ & -57 & 0.711 & 2 & 3.32 & 4.7 & NA & NA & NA \\
\hline BDOGS9 & Reg & $3 A$ & -66.5 & 1.48 & 0.48 & 2.26 & 0.87 & 379 & 330 & NA \\
\hline BOOGT 1 & Reg & $3 A$ & -77 & 1.67 & 0.51 & 3.35 & 0.93 & NA & NA & NA \\
\hline BOOGT3 & Blank & $3 A$ & $\cdots$ & 0.76 & 0.11 & 0.67 & 0.13 & NA & NA & NA \\
\hline BOOGT4 & Reg & $3 A$ & -85.5 & 2.46 & 2.3 & 8.24 & 5.0 & NA & NA & NA \\
\hline BOOGTS & foup & $3 A$ & -85.5 & 1.84 & 2.2 & 5.49 & 4.8 & NA & NA & NA \\
\hline BOOGT6 & Spl it & $3 A$ & -85.5 & $<3$ & $\cdots$ & 19 & 2 & NA & NA & HA \\
\hline 800GT7 & $R \in g$ & $3 A$ & -97 & 1.81 & 2.2 & 0.815 & 4.6 & jo. 1 & 9.7 & Done \\
\hline BOOGT8 & Reg & $3 A$ & -102 & 42.59 & 5.5 & 4.94 & 5.2 & NA & HA & NA \\
\hline BOOGVO & Reg & $3 A$ & -122 & 1.74 & 1.9 & -2.12 & 4.8 & NA & NA & NA \\
\hline BoOGV1 & Blank & $3 A$ & $\cdots$ & 1.45 & 1.9 & -0.26 & 4.9 & NA & NA & NA \\
\hline BOOGV2 & Reg & $3 A$ & -131 & 1.93 & 1.9 & -0.22 & 4.9 & NA & NA & NA \\
\hline $800 G \sqrt{3}$ & Fonp & $3 A$ & -131 & 2.16 & 2 & 5.84 & 5.2 & NA & NA & NA \\
\hline $800 G V 4$ & Split & $3 A$ & -131 & $<2$ & $\cdots$ & 26 & 3 & NA & NA & NA \\
\hline Boogvs & Reg & $3 A$ & -943.5 & 3.52 & 2.2 & 7.43 & 5.3 & 1.00 & 0.433 & Done \\
\hline BooGV6 & Reg & 38 & -1 & 2.21 & 1.7 & 1.65 & 4.7 & -0.182 & 0.44 & Done \\
\hline BooGV7 & $R \in g$ & $3 B$ & -3.5 & 4.82 & 2.2 & 5.78 & 5.0 & 1.25 & 0.55 & Done \\
\hline BCOGV8 & Reg & $3 B$ & -5.5 & 1.83 & 1.7 & 5.93 & 5.0 & 1.14 & 0.54 & Done \\
\hline Boogv9 & Blank & 38 & $\cdots$ & 2.95 & 1.9 & .0 .72 & 4.6 & -0.016 & 0.45 & Done \\
\hline BOOGUO & Reg & $3 B$ & -7.5 & 3.27 & 1.9 & 8.75 & 5.1 & 36.5 & 1.7 & Done \\
\hline
\end{tabular}


WHC-SD-EN-AP-104 Rev. 0

Table A-11. List of Radioactivity Data $(\rho \mathrm{Ci} / \mathrm{g})$--Unvalidated.

\begin{tabular}{|c|c|c|c|c|c|c|c|c|c|c|}
\hline Semple & Type & Pond & $\begin{array}{l}\text { Approx. } \\
\text { Depth }\end{array}$ & Alphe & $\begin{array}{l}\text { Alpha } \\
\text { Counting } \\
\text { Error }\end{array}$ & Beta & $\begin{array}{l}\text { Beta } \\
\text { Counting } \\
\text { Error }\end{array}$ & ${ }^{90} \mathrm{sr}$ & $\begin{array}{l}90 \mathrm{Sr} \\
\text { Counting } \\
\text { Error }\end{array}$ & GEA $^{9}$ \\
\hline BOOGW1 & Reg & 38 & -9.5 & 2.43 & 1.8 & 3.28 & 4.8 & 0.222 & 0.47 & Done \\
\hline BOOGW3 & Reg & $3 B$ & -13 & 1.22 & 1.6 & 2.91 & 3.8 & 1.55 & 0.40 & Done \\
\hline BOOGW4 & Fodp & 3B & -13 & 4.02 & 2.1 & 3.42 & 4.8 & 1.06 & 0.53 & Done \\
\hline BOOGLS & split & 3B & -13 & $<1$ & $\cdots$ & 19 & 2 & $<0.04$ & $\cdots$ & Done \\
\hline BOOGW6 & Reg & 38 & -16 & 3.89 & 2 & 6.84 & 5.0 & MA & HA & NA \\
\hline BOOGU8 & Reg & $3 B$ & -21 & 1.43 & 1.6 & 0.48 & 4.7 & 1.47 & 0.56 & Done \\
\hline BOOGW & Reg & $3 B$ & -28 & 1.82 & 1.7 & 1.36 & 4.7 & NA & NA & NA \\
\hline $800 G \times 2$ & Reg & $3 B$ & -31 & 4.28 & 2.1 & 3.59 & 4.8 & MA & NA & NA \\
\hline B0OGX3 & Reg & 38 & -35.5 & 3.45 & 2 & 2.06 & 3.8 & NA & NA & NA \\
\hline $8000 \times 4$ & Reg & $3 B$ & -40 & 2.38 & 1.8 & 3.86 & 3.9 & NA & NA & MA \\
\hline $800 \mathrm{G} \times 5$ & Reg & 38 & -52 & 3.01 & 1.9 & 4.57 & 3.9 & NA & NA & NA \\
\hline $8006 \times 6$ & Reg & $3 B$ & -61.5 & 7.29 & 2.4 & 3.74 & 3.9 & 1.22 & 0.38 & Done \\
\hline BDOGX8 & Reg & 38 & -70.5 & 2.54 & 1.8 & 5.88 & 4.0 & NA & NA & NA \\
\hline BOOGYO & Blank & 38 & $\cdots$ & -0.47 & 2.3 & -0.59 & 4.1 & NA & NA & NA \\
\hline BOOGY 1 & Reg & $3 B$ & -80.5 & $=0.94$ & 2.3 & 4.1 & -0.41 & NA & NA & NA \\
\hline $800 \mathrm{GY} 2$ & Fdup & $3 B$ & -80.5 & 1.14 & 2.5 & 4.57 & 4.4 & NA & NA & NA \\
\hline BOOGY9 & Split & 38 & -80.5 & 2.7 & 1.2 & 31 & 2 & NA & NA & NA \\
\hline $800 G 22$ & Reg & 38 & -90.5 & -2.59 & 2 & 3.02 & 4.3 & 0.806 & 0.34 & Done \\
\hline 800023 & Reg & 38 & -105 & -1.77 & 2.2 & 1.37 & 4.2 & NA & NA & NA \\
\hline BOOGZ6 & Reg & $3 B$ & -118.5 & -0.46 & 2.3 & 1.49 & 4.2 & 9.17 & 0.78 & Done \\
\hline BOOGZ8 & Reg & $3 B$ & -123.5 & -2.7 & 2.3 & 4.34 & 4.3 & 2.43 & 0.46 & Done \\
\hline BOOHOO & Reg & $3 c$ & -1 & -1.45 & 2.2 & -0.30 & 4.1 & 1.31 & 0.38 & Done \\
\hline ВоОНО1 & Reg & $3 c$ & -3 & -0.65 & 2.3 & -0.78 & 4.9 & 1.37 & 0.39 & Done \\
\hline ВOOHO2 & Reg & $3 c$ & .5 & -2.25 & 21 & 0.30 & 4.9 & 2.86 & 0.049 & Done \\
\hline ВООНО3 & Reg & $3 c$ & -7 & -1.71 & 2.5 & 2.32 & 4.2 & 2.58 & 0.47 & Done \\
\hline $\mathrm{BOOHOL}$ & Reg & $3 c$ & -9 & -1.87 & 2.4 & -1.37 & 4.0 & 1.86 & 0.42 & Done \\
\hline ВОOHOS & Fodp & $3 c$ & -9 & -3.21 & 2.3 & 0.64 & 4.1 & 1.60 & 0.41 & Done \\
\hline BOOHOG & Reg & $3 c$ & -11.5 & -1.44 & 2.5 & 4.56 & 4.3 & 1.13 & 0.37 & Done \\
\hline BOOHO7 & Split & $3 c$ & -11.5 & 1.9 & 1 & 2 & 25 & $<0.04$ & $\cdots$ & Done \\
\hline BOOHOS & Reg & $3 c$ & -16 & 2.0 & 1.6 & 6.94 & 4.2 & HA & NA & NA \\
\hline BOOH10 & Blank & $3 c$ & $\cdots$ & 0.94 & 1.4 & 2.13 & 4.0 & 0.101 & 0.37 & Done \\
\hline BDOH19 & $R \in g$ & $3 c$ & -20.5 & 3.29 & 1.8 & 3.61 & 4.0 & NA & HA & NA \\
\hline ВоOH 14 & Reg & $3 c$ & -30 & 2.98 & 1.8 & 6.59 & 4.2 & 0.608 & 0.49 & Done \\
\hline BOOH 15 & Reg & $3 c$ & -36 & -1.81 & 1 & -3.12 & 3.6 & NA & NA & NA \\
\hline BOOH 16 & Reg & $3 c$ & -40.5 & 3.02 & 1.8 & 4.11 & 4.1 & NA & NA & NA \\
\hline
\end{tabular}


WHC-SD-EN-AP-104 Rev. 0

Table A-11. List of Radioactivity Data $(\rho \mathrm{C} / \mathrm{g})$--Unvalidated.

\begin{tabular}{|c|c|c|c|c|c|c|c|c|c|c|}
\hline Semple & Type & Pond & $\begin{array}{l}\text { Approx. } \\
\text { Depth }\end{array}$ & Alpha & $\begin{array}{l}\text { Alpha } \\
\text { Count ing } \\
\text { Error }\end{array}$ & Beta & $\begin{array}{l}\text { Beta } \\
\text { Counting } \\
\text { Error }\end{array}$ & ${ }^{90} \mathrm{Sr}$ & $\begin{array}{l}{ }_{\text {Sr }} \\
\text { Counting } \\
\text { Error }\end{array}$ & GEA $^{1}$ \\
\hline ВООН 17 & Fotup & $3 C$ & -40.5 & 3.85 & 1.9 & 3.51 & 4.0 & NA & NA & NA \\
\hline ВоОН18 & Reg & $3 C$ & -50 & 1.86 & 1.6 & 3.51 & 4.0 & NA & NA & NA \\
\hline 800119 & Reg & $3 C$ & .60 & 0.68 & 1.4 & -1.39 & 3.7 & 0.479 & 0.40 & Done \\
\hline воОн20 & Reg & $3 c$ & -70.5 & 2.66 & 2 & 6.38 & 5.1 & NA & NA & NA \\
\hline ВОOH29 & Blank & $3 c$ & $\cdots$ & 2.53 & 2 & -1.47 & 4.7 & NA & NA & NA \\
\hline $800 \mathrm{H} 23$ & Reg & $3 C$ & -80 & 2.46 & 2 & 3.29 & 4.9 & 2.29 & 0.52 & Done \\
\hline $800 \mathrm{H} 24$ & Split & $3 C$ & -80 & $M$ & $M$ & $\mathbf{M}$ & $M$ & NA & NA & NA \\
\hline
\end{tabular}

NA Analysis not requested.

$M$ Missing result, figure not available for this report.

... Result only reported as a "less-than" value--counting error not specified by laboratory.

1. GEA = Gamna Energy Analysis, see Table A-12. 
Radionuclide w/ estimated counting error (Err)

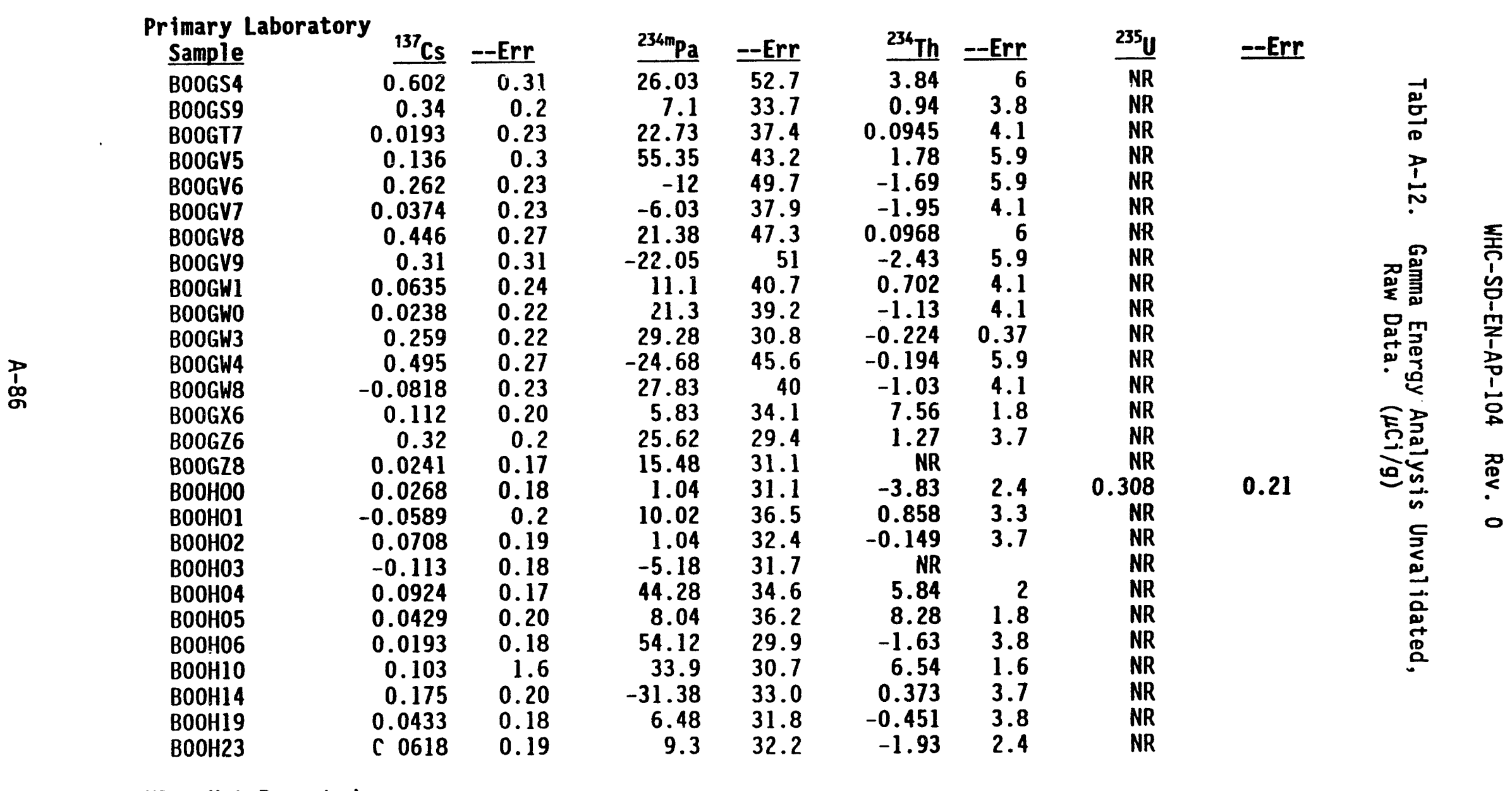

NR Not Reported. 
Radionuclide w/ estimated counting error (Err)

\begin{tabular}{|c|c|c|c|c|c|c|}
\hline $\begin{array}{c}\text { Alternate } \\
\text { Sample }\end{array}$ & $\begin{array}{r}\text { Labgra } \\
{ }_{40}\end{array}$ & $\begin{array}{l}y \\
=-E r r\end{array}$ & ${ }^{226} \mathrm{Ra}$ & - -Err & ${ }^{228} \mathrm{Th}$ & $=-$ Err \\
\hline $\begin{array}{l}\overline{\text { BOOGS5 }} \\
\text { B0OGW5 } \\
\text { B00H07 }\end{array}$ & $\begin{array}{r}14 \\
9.76 \\
10.1\end{array}$ & $\begin{array}{r}1.4 \\
0.98 \\
1\end{array}$ & $\begin{array}{r}1.9 \\
0.853 \\
0.513\end{array}$ & $\begin{array}{l}0.48 \\
0.359 \\
0.297\end{array}$ & $\begin{array}{r}0.864 \\
0.42 \\
0.557\end{array}$ & $\begin{array}{l}0.086 \\
0.042 \\
0.056\end{array}$ \\
\hline
\end{tabular}

Undetected radionuclides reported for the above split samples as "less-than" the following ( $\mathrm{Cl} / \mathrm{g}$-dry):

\begin{tabular}{|c|c|c|c|c|c|c|}
\hline & ${ }^{7} \mathrm{Be}$ & ${ }^{54} \mathrm{mn}$ & ${ }^{58} \mathrm{Co}$ & ${ }^{59} \mathrm{Fe}$ & ${ }^{60} \mathrm{Co}$ & ${ }^{65} \mathrm{Zn}$ \\
\hline \multirow[t]{2}{*}{$\begin{array}{l}\text { B0OGS5 } \\
\text { BOOGW5 } \\
\text { BOOHO7 }\end{array}$} & $\begin{array}{r}<1 \\
<0.8 \\
<0.6\end{array}$ & $\begin{array}{l}<0.04 \\
<0.03 \\
<0.03\end{array}$ & $\begin{array}{l}<0.08 \\
<0.06 \\
<0.05\end{array}$ & $\begin{array}{l}<0.4 \\
<0.3 \\
<0.2\end{array}$ & $\begin{array}{l}<0.03 \\
<0.03 \\
<0.02\end{array}$ & $\begin{array}{l}<0.1 \\
<0.08 \\
<0.08\end{array}$ \\
\hline & ${ }^{95} \mathrm{Zr}$ & ${ }^{103} \mathrm{Ru}$ & ${ }^{106} \mathrm{Ru}$ & ${ }^{131} I$ & ${ }^{134} \mathrm{Cs}$ & ${ }^{137} \mathrm{CS}$ \\
\hline \multirow[t]{2}{*}{$\begin{array}{l}\text { BOOGS5 } \\
\text { BOOGW5 } \\
\text { BOOH07 }\end{array}$} & $\begin{array}{l}<0.1 \\
<0.08 \\
<0.07\end{array}$ & $\begin{array}{l}<0.3 \\
<0.2 \\
<0.1\end{array}$ & $\begin{array}{r}<0.03 \\
<0.2 \\
<0.2\end{array}$ & $\begin{array}{r}<2000 \\
<300 \\
<100\end{array}$ & $\begin{array}{l}<0.04 \\
<0.03 \\
<0.03\end{array}$ & $\begin{array}{l}<0.03 \\
<0.02 \\
<0.02\end{array}$ \\
\hline & ${ }^{140} \mathrm{Ba}$ & ${ }^{141} \mathrm{Ce}$ & ${ }^{144} \mathrm{Ce}$ & & & \\
\hline $\begin{array}{l}\text { BOOGS5 } \\
\text { B0OGW5 } \\
\text { BOOH07 }\end{array}$ & $\begin{array}{l}<30 \\
<10 \\
<5\end{array}$ & $\begin{array}{l}<0.6 \\
<0.4 \\
<0.2\end{array}$ & $\begin{array}{l}<0.3 \\
<0.2 \\
<0.1\end{array}$ & & & \\
\hline
\end{tabular}




\section{WHC-SD-EN-AP-104 Rev. 0}

\section{References}

WHC, 1990, WHC-CM-5-3, Westinghouse Hanford Company, Richland, Washington.

EPA, 1986, Test Methods for Evaluating Solid Waste, Physical/Chemical Methods, SW-846, Third Edition, U.S. Environmental Protection Agency, Washington, D.C. 
WHC-SD-EN-AP-104 Rev. 0

APPENDIX B

ANALYTE VARIABILITY GRAPHS

$B-i$ 
WHC-SD-EN-AP-104 Rev. 0

This page intentionally left blank. 
WHC-SD-EN-AP-104 Rev. 0

\section{LIST OF FIGURES}

Figure B-1. Selected Duplicates: Gross Alpha. . . . . . . . . . . B-2

Figure B-2. Selected Duplicates: Aluminum. . . . . . . . . . B-2

Figure B-3. Selected Duplicates: Arsenic. . . . . . . . . . . B-3

Figure B-4. Selected Duplicates: Barium. . . . . . . . . . . B-3

Figure B-5. Selected Duplicates: Beryllium. . . . . . . . . . . B-4

Figure B-6. Selected Duplicates: Gross Beta. . . . . . . . . . . B-4

Figure B-7. Selected Duplicates: Boron. . . . . . . . . . . . B-5

Figure B-8. Selected Duplicates: Cadmium. . . . . . . . . . . . B-5

Figure B-9. Selected Duplicates: Calcium. . . . . . . . . . . B-6

Figure B-10. Selected Duplicates: Chromium. . . . . . . . . . . B-6

Figure B-11. Selected Duplicates: Cobalt. . . . . . . . . . . . B-7

Figure B-12. Selected Duplicates: Copper. . . . . . . . . . . . . B-7

Figure B-13. Selected Duplicates: Lead. . . . . . . . . . . . . B-8

Figure B-14. Selected Duplicates: Magnesium. . . . . . . . . . . . B-8

Figure B-15. Selected Duplicates: Manganese. . . . . . . . . . . B-9

Figure B-16. Selected Duplicates: Molybdenum. . . . . . . . . . . B-9

Figure B-17. Selected Duplicates: Nickel. . . . . . . . . . . . B-10

Figure B-18. Selected Duplicates: Potassium. . . . . . . . . . . B-10

Figure B-19. Selected Duplicates: Silicon. . . . . . . . . . . B-11

Figure B-20. Selected Duplicates: Sodium. . . . . . . . . . . . B-11

Figure B-21. Selected Duplicates: ${ }^{90} \mathrm{Sr}$. . . . . . . . . . . . B-12

Figure B-22. Selected Duplicates: Sulfate. . . . . . . . . . . B-12

Figure B-23. Selected Duplicates: Vanadium. . . . . . . . . . . B-13

Figure B-24. Selected Duplicates: Zinc. . . . . . . . . . . . B-13 
WHC-SD-EN-AP-104 Rev. 0

This page intentionally left blank. 
Introduction

Appendix $B$ contains graphs of selected validated duplicate data. The graphs show how variability does/does not trend over the observed concentration range of the duplicate pairs. The ONLY points appearing on the graphs are those where each validated member of a data pair were reported at detectable levels. These are based on some of the data appearing in the Appendix A.

Each point on the graphs shows a standard deviation based on only two sample results. The reader is cautioned about making grand inferences from any particular point. Though inferences about a population variability based on only two samples are minimally precise, multiple estimates impart more confidence.

Most graphs display two sets of validated data--field duplicate/regular or split/regular sample pairs. The first is based on the results of field duplicates and their associated regular samples. These were collected concurrently and submitted to the primary laboratory without notification that they were duplicate samples. The first set demonstrates uncertainty in the media and a single laboratory measurement system.

The second set appearing on most graphs is based on the results of split samples and their associated regular samples. Split samples were submitted by Westinghouse Hanford to an alternate laboratory; associated regular samples were submitted to the primary laboratory. This set shows the wider validated data uncertainty associated the media and an independent laboratory estimate of the true average concentration at a particular location. 
WHC-SD-EN-AP-104 ReV. 0

Figure B-1. Selected Duplicates: Gross Alpha.

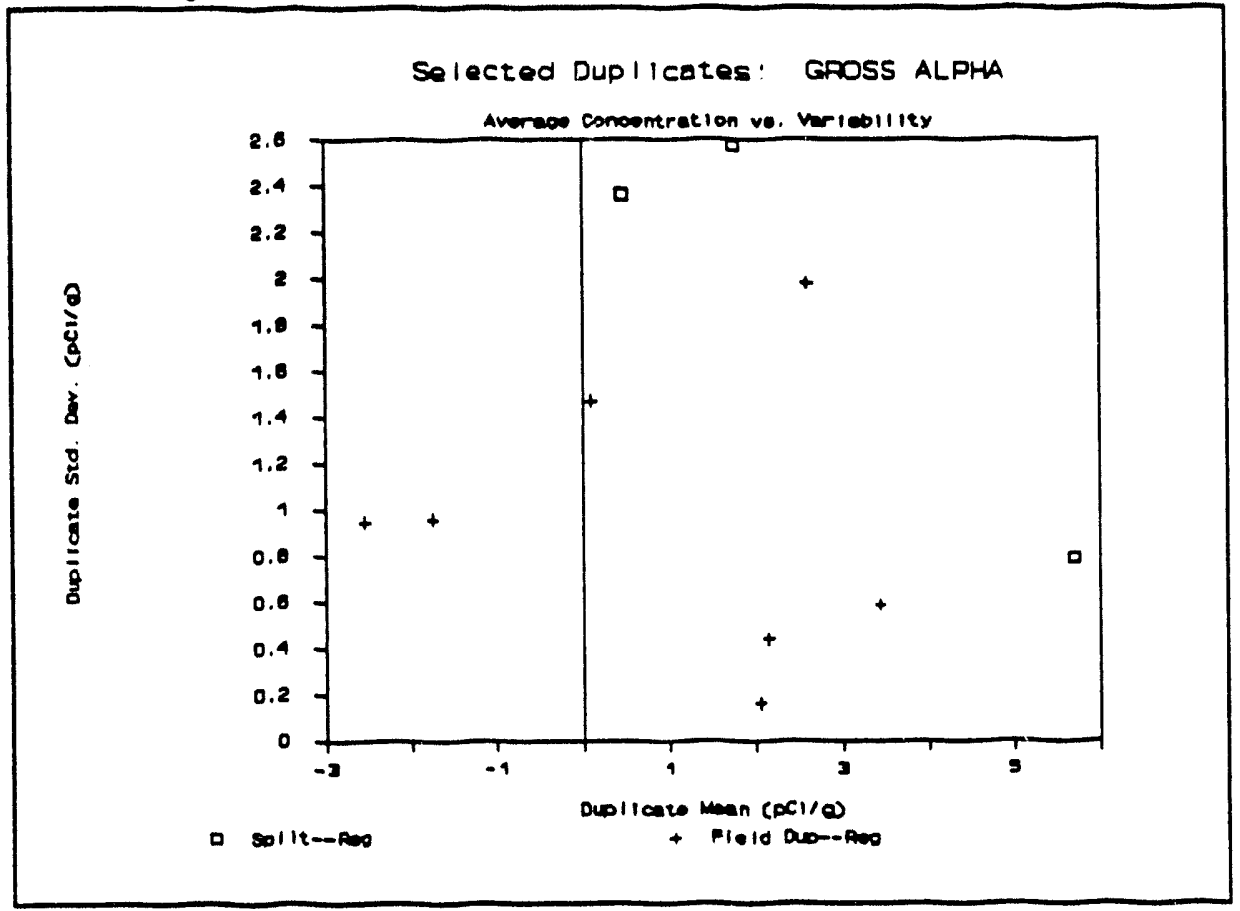

Figure B-2. Selected Duplicates: Aluminum.

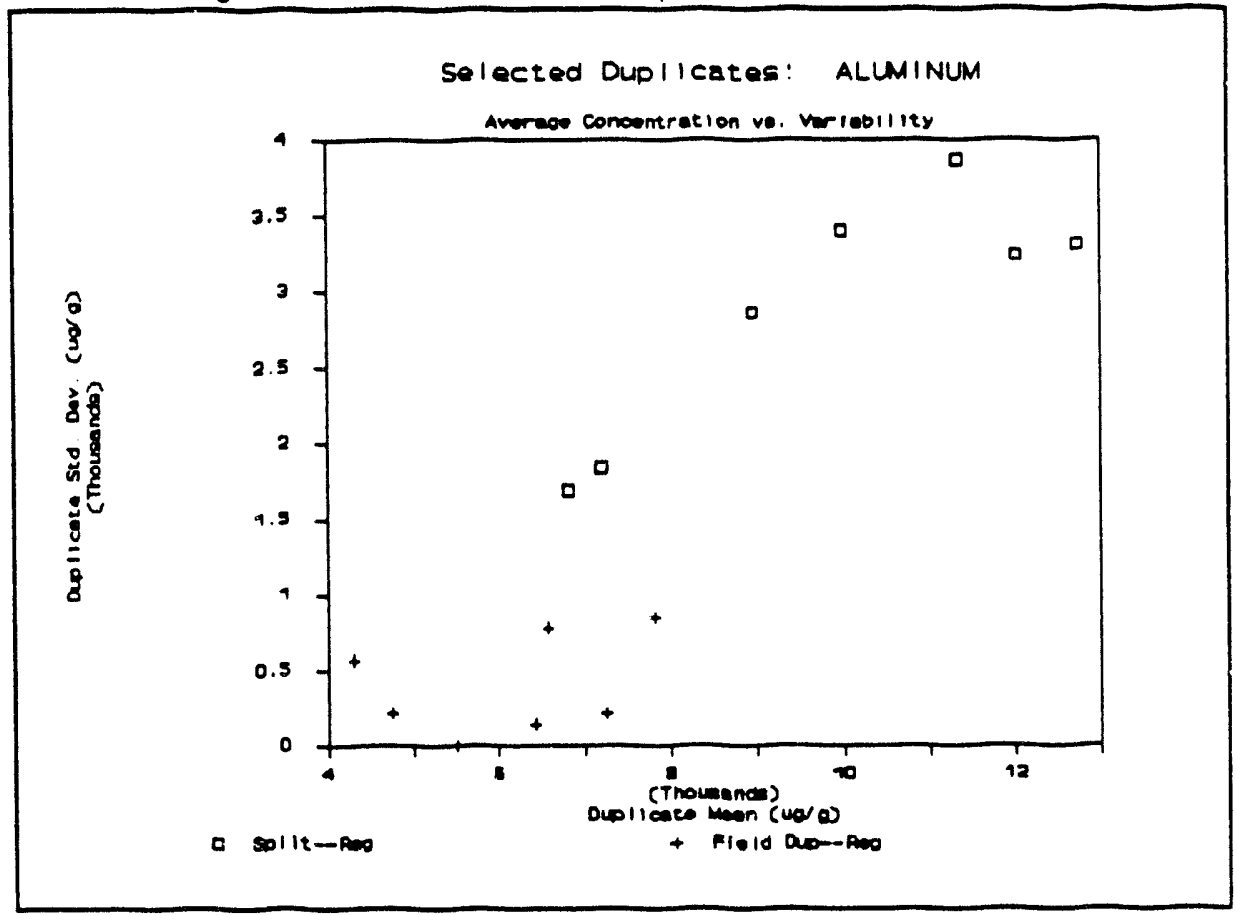




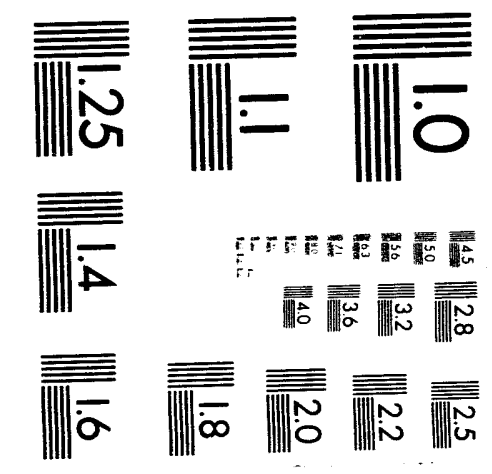



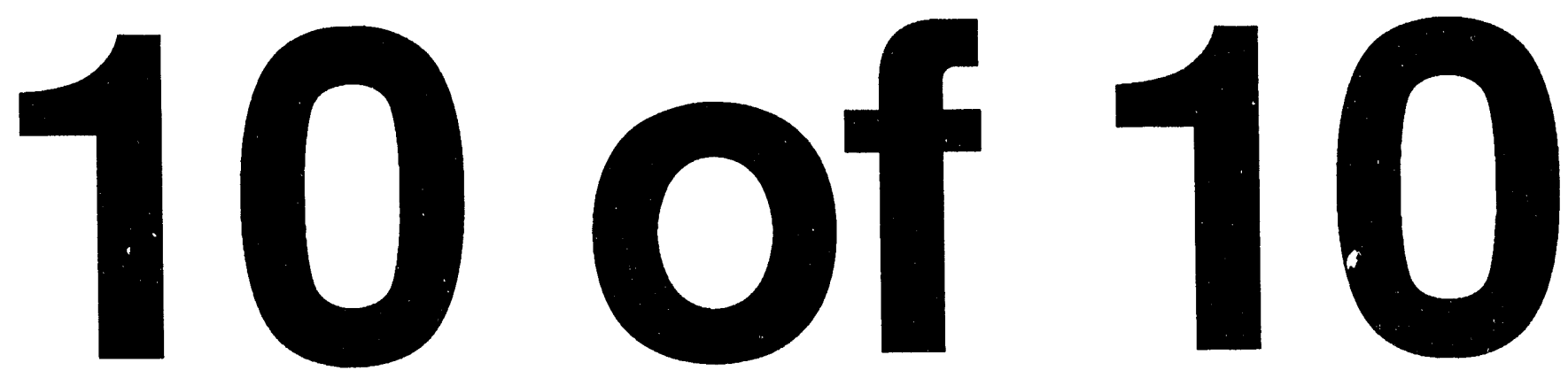
WHC-SD-EN-AP-104 Rev. 0

Figure B-3. Selected Duplicates: Arsenic.

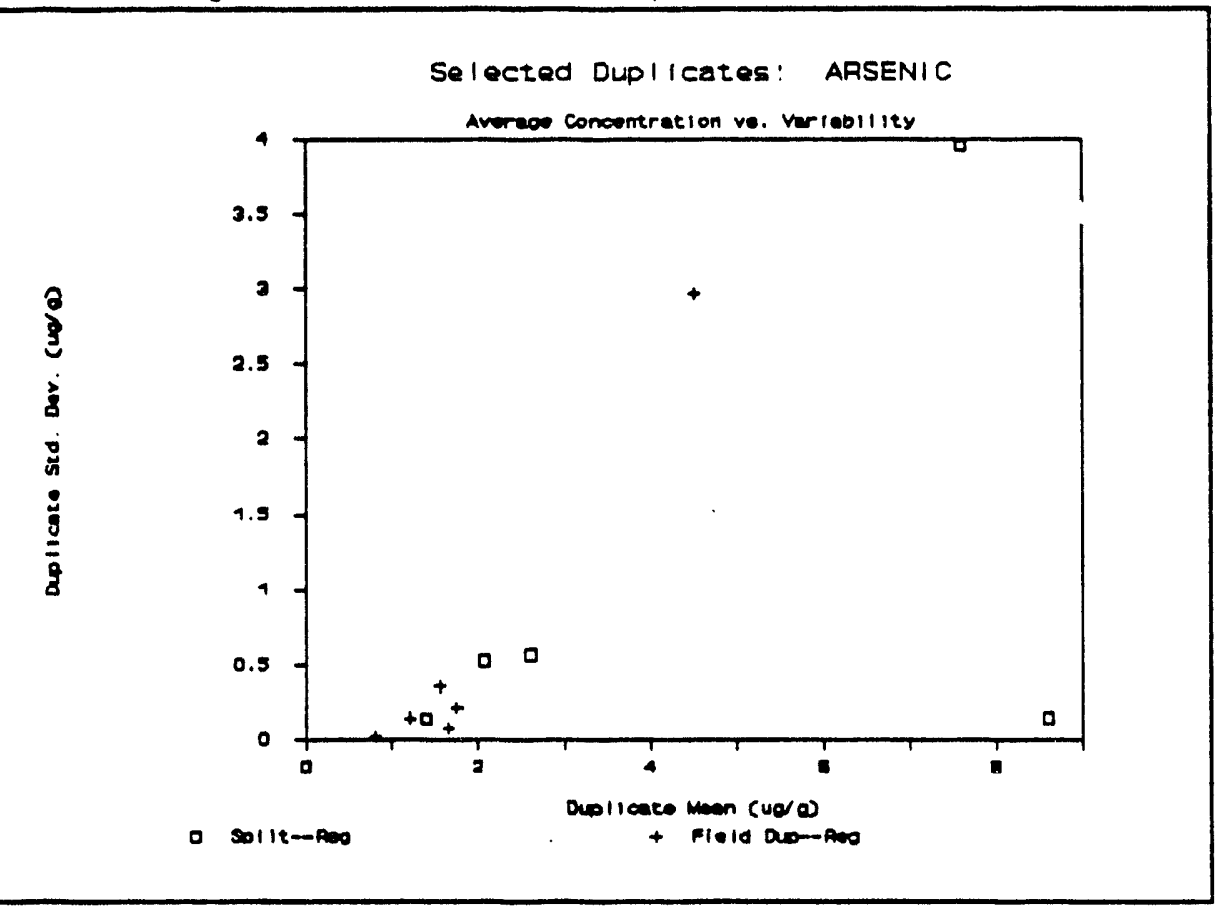

Figure B-4. Selected Duplicates: Barium.

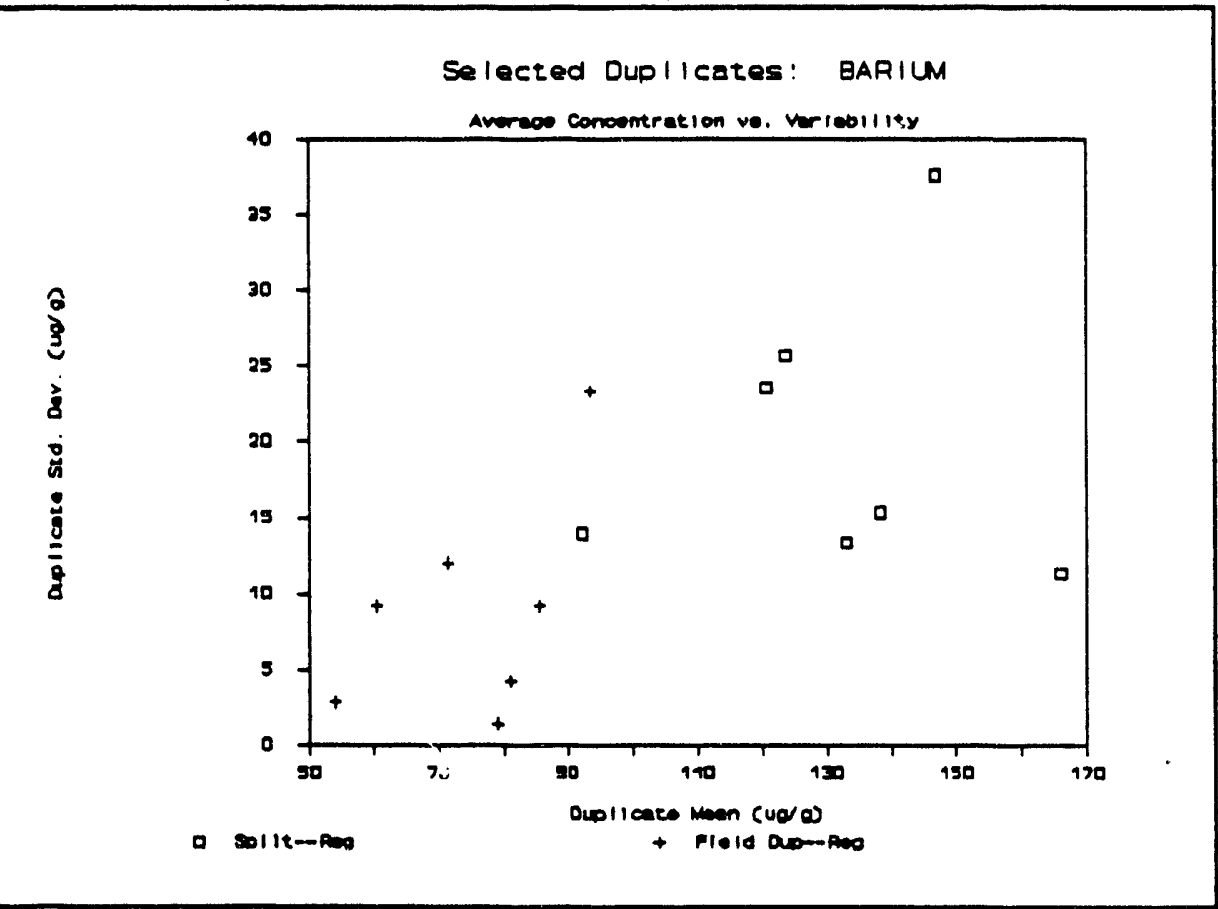


WHC-SD-EN-AP-104 Rev. 0

Figure B-5. Selected Duplicates: Beryllium.

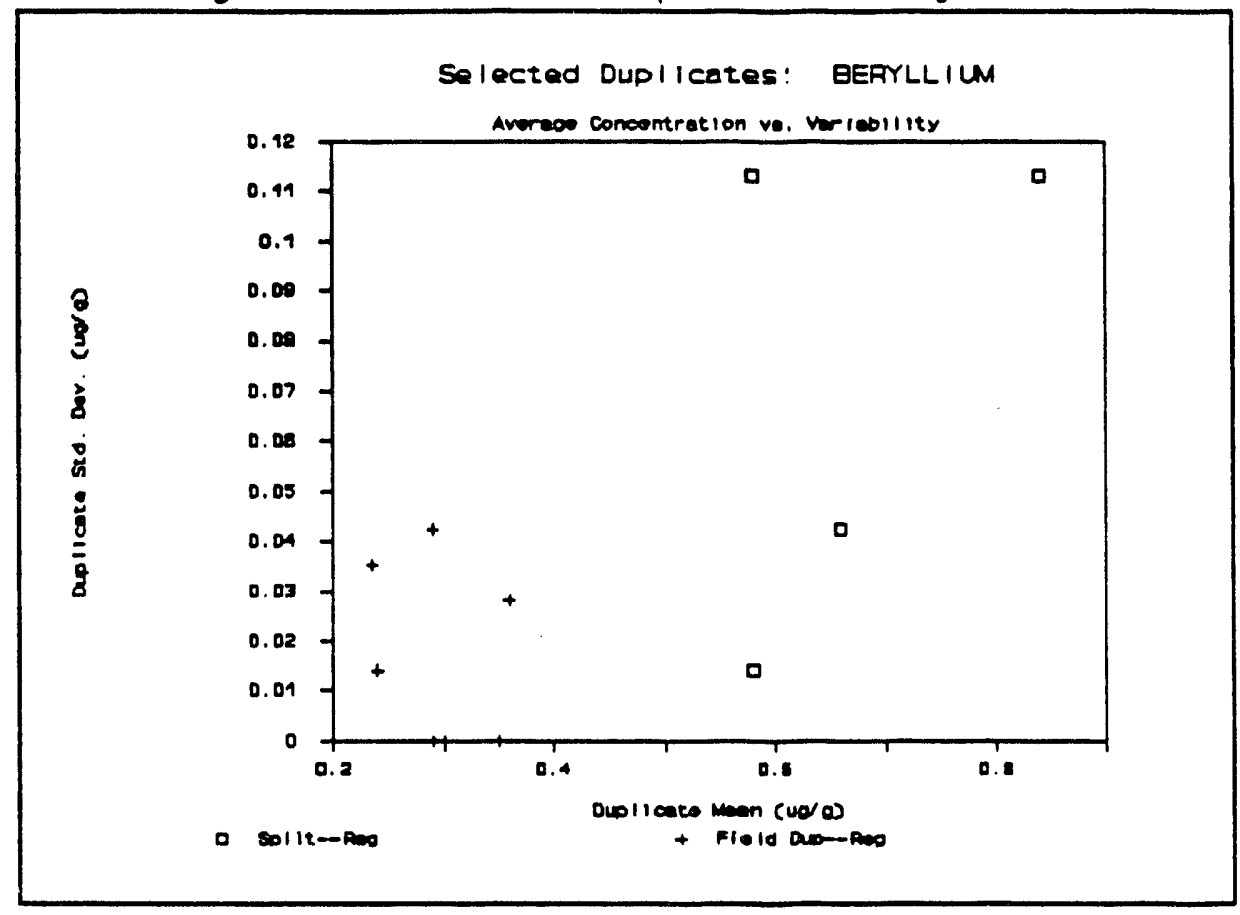

Figure B-6. Selected Duplicates: Gross Beta.

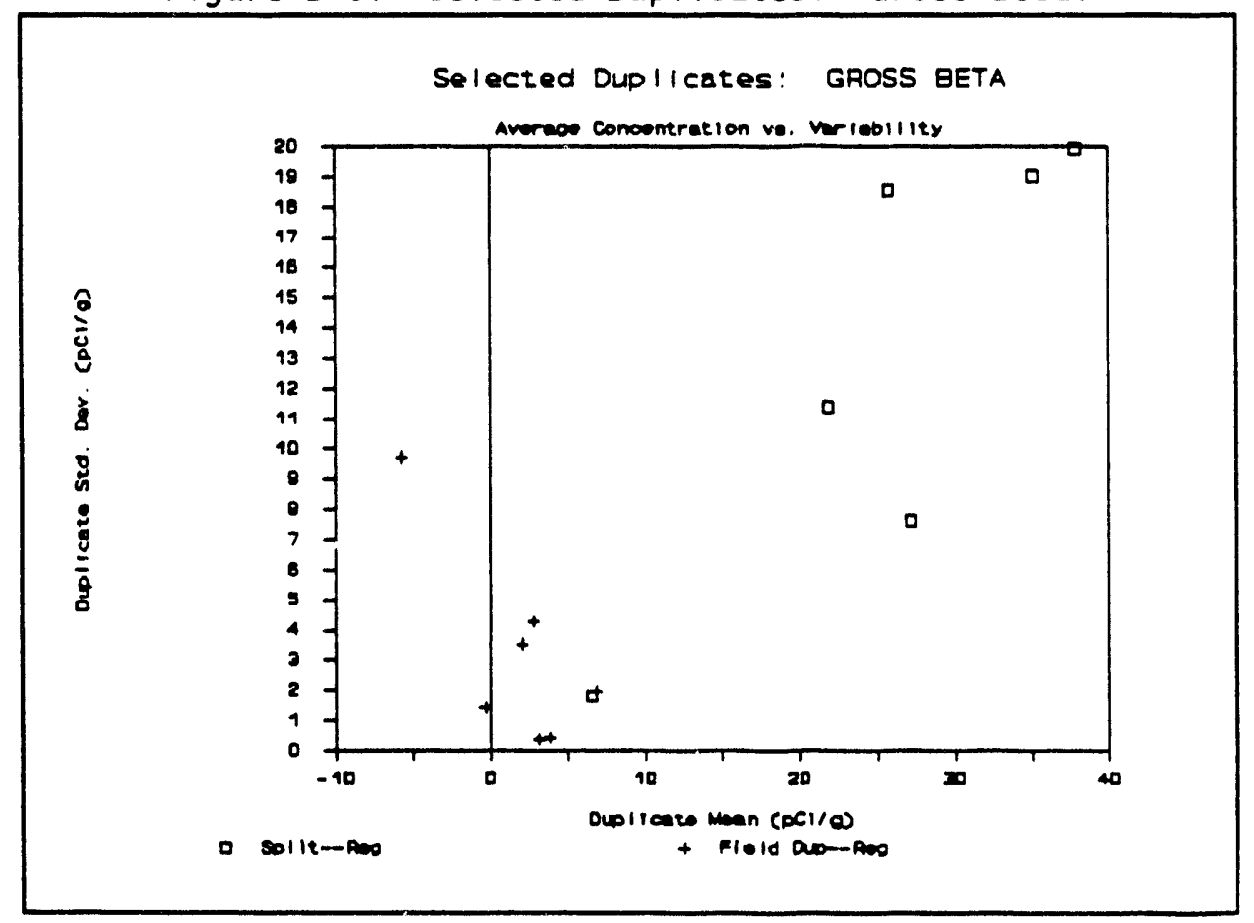



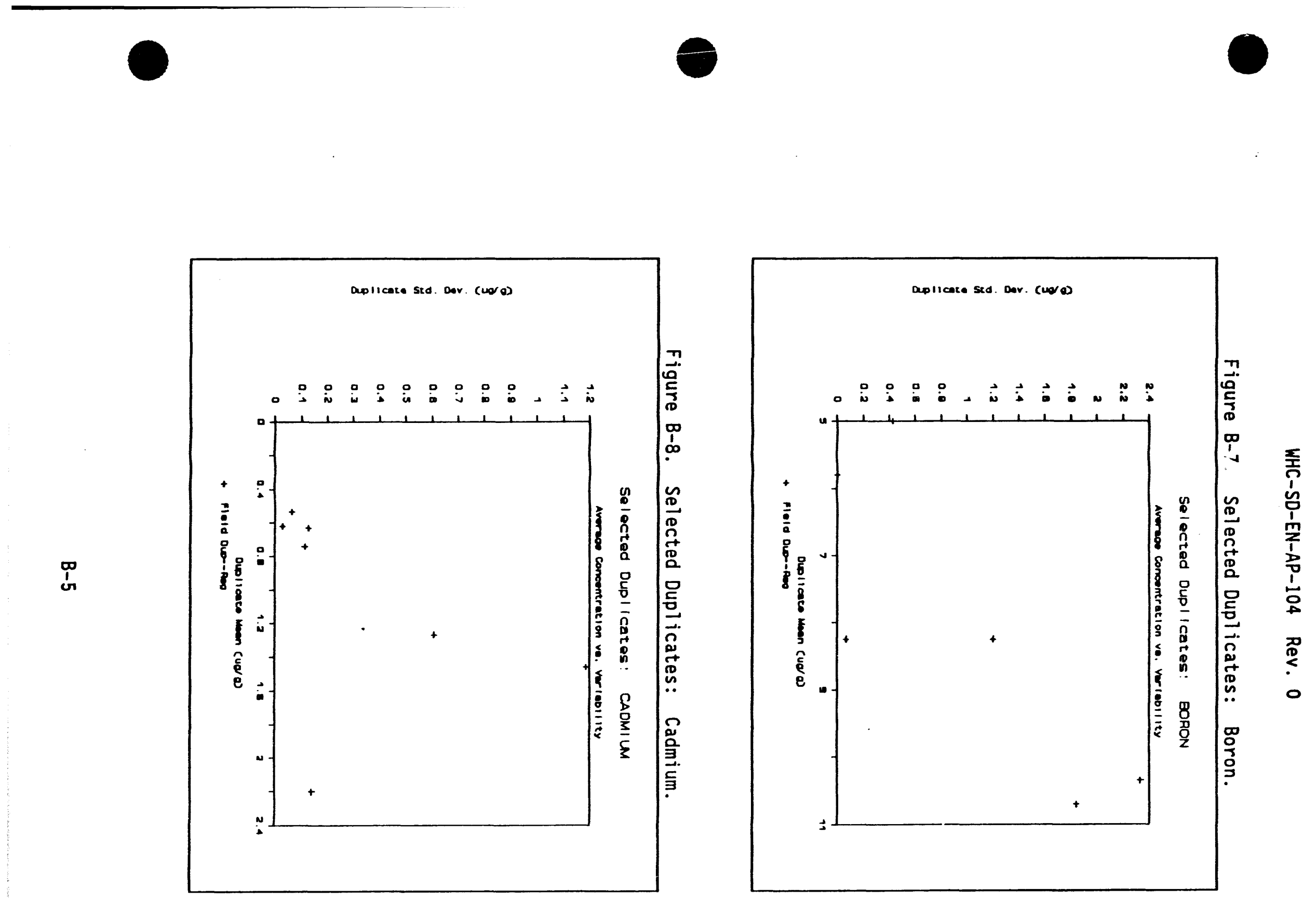


\section{WHC-SD-EN-AP-104 Rev. 0}

Figure B-9. Selected Duplicates: Calcium.

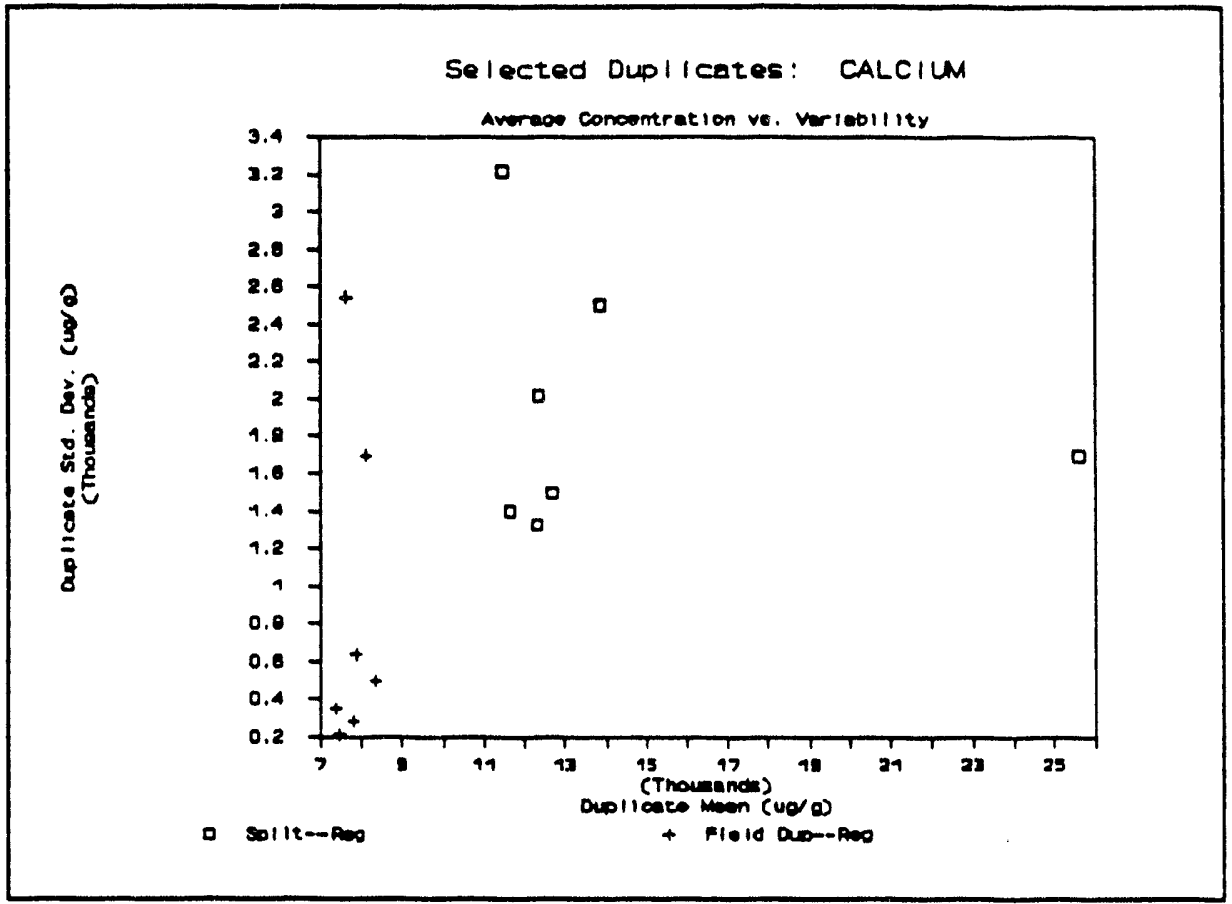

Figure B-10. Selected Duplicates: Chromium.

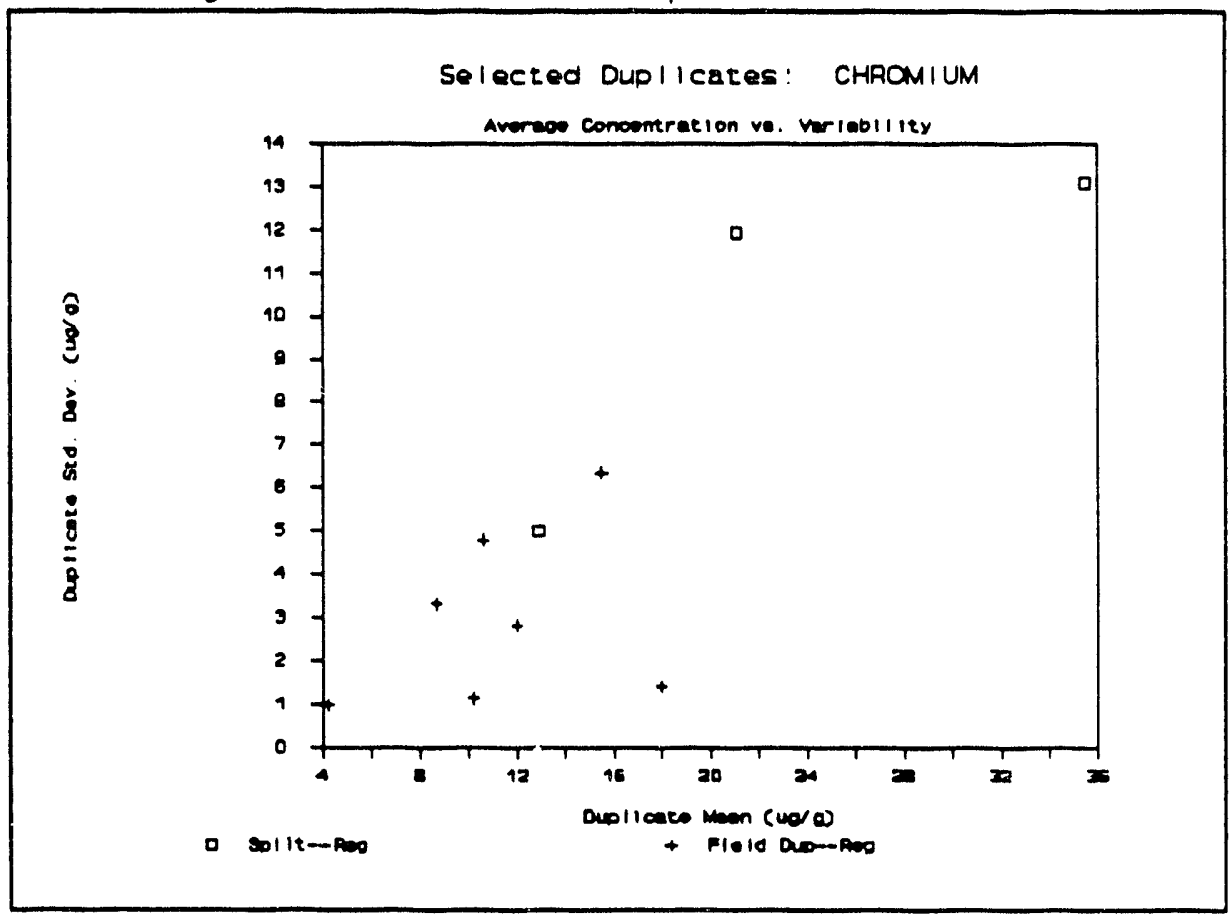


WHC-SD-EN-AP-104 Rev. 0

Figure B-11. Selected Duplicates: Cobalt.

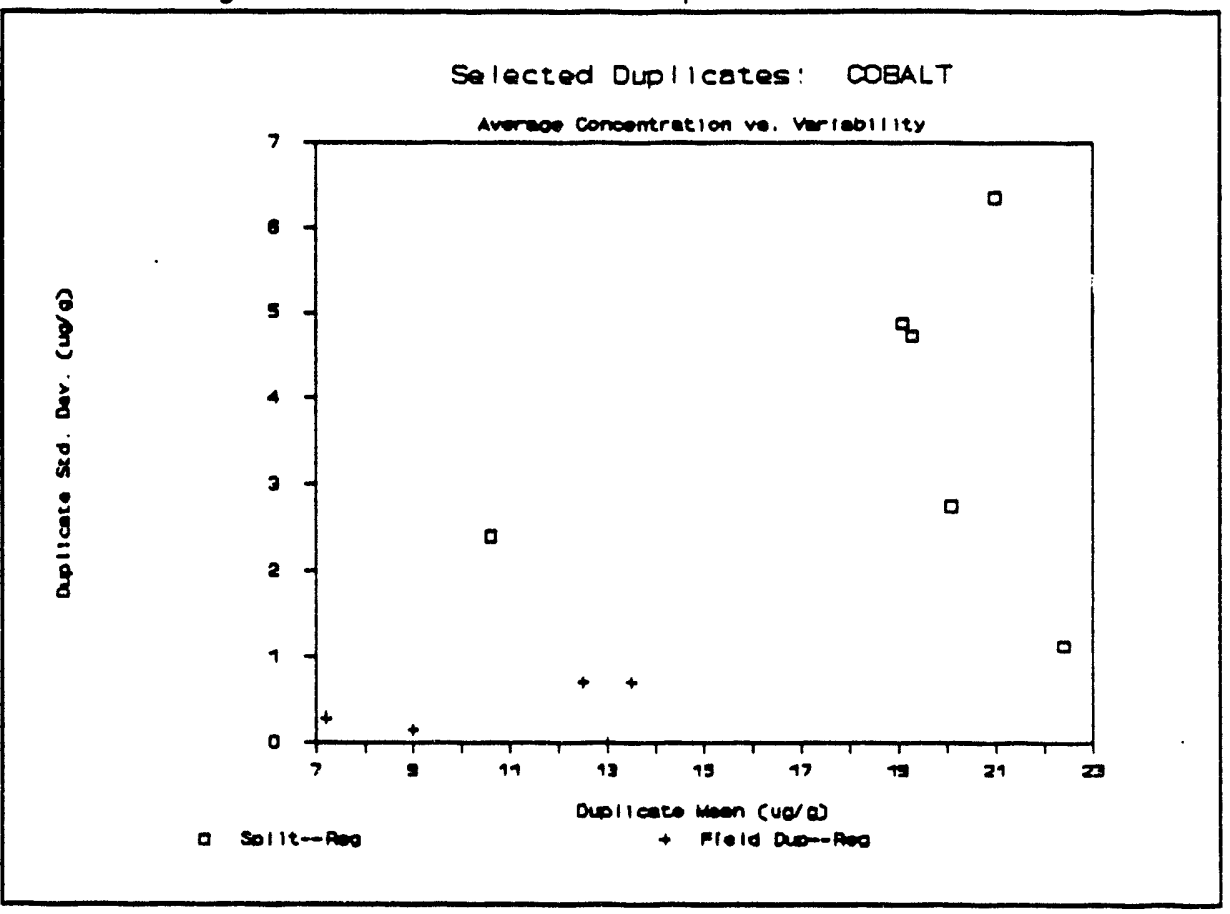

Figure B-12. Selected Duplicates: Copper.

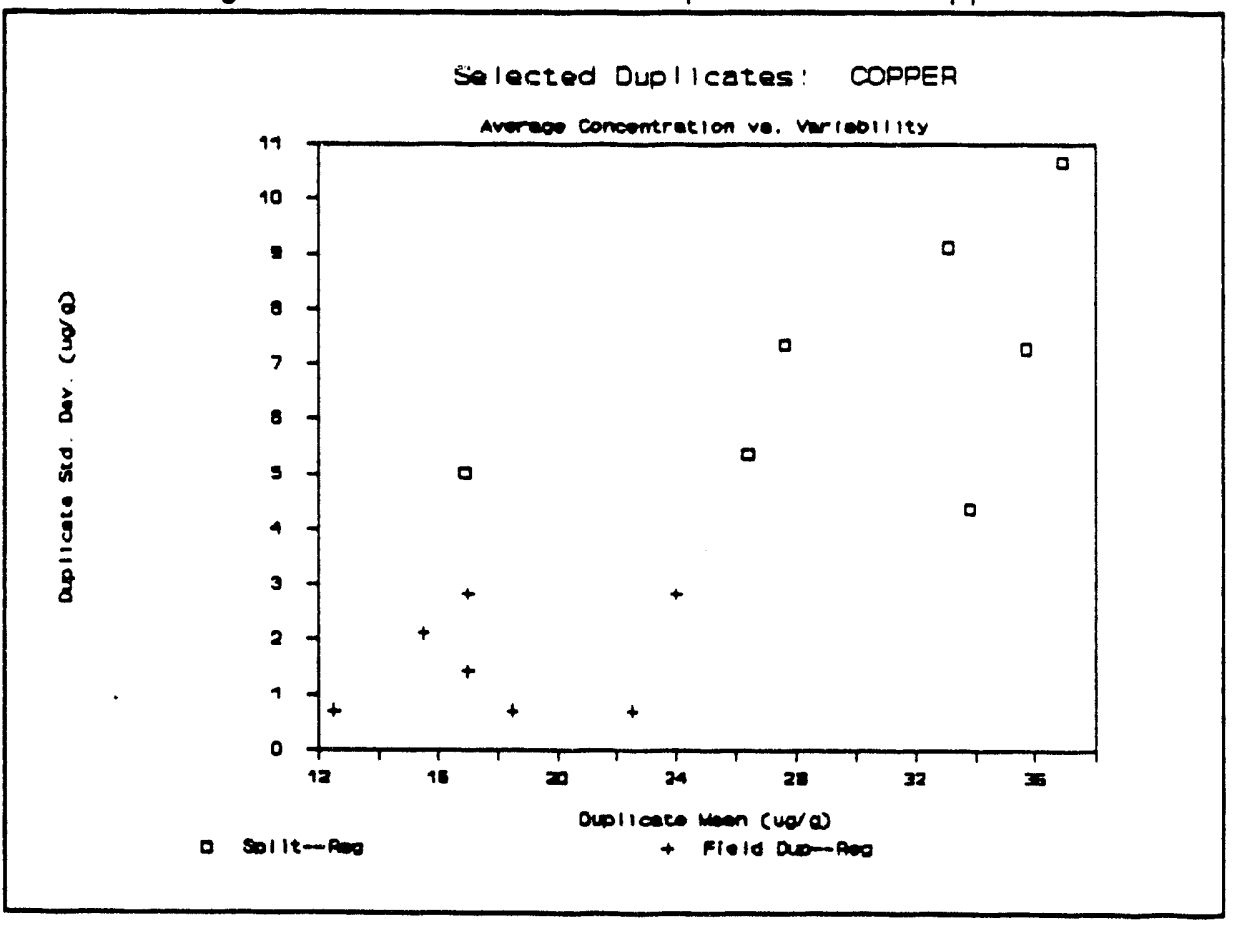


WHC-SD-EN-AP-104 Rev. 0

Figure B-13. Selected Duplicates: Lead.

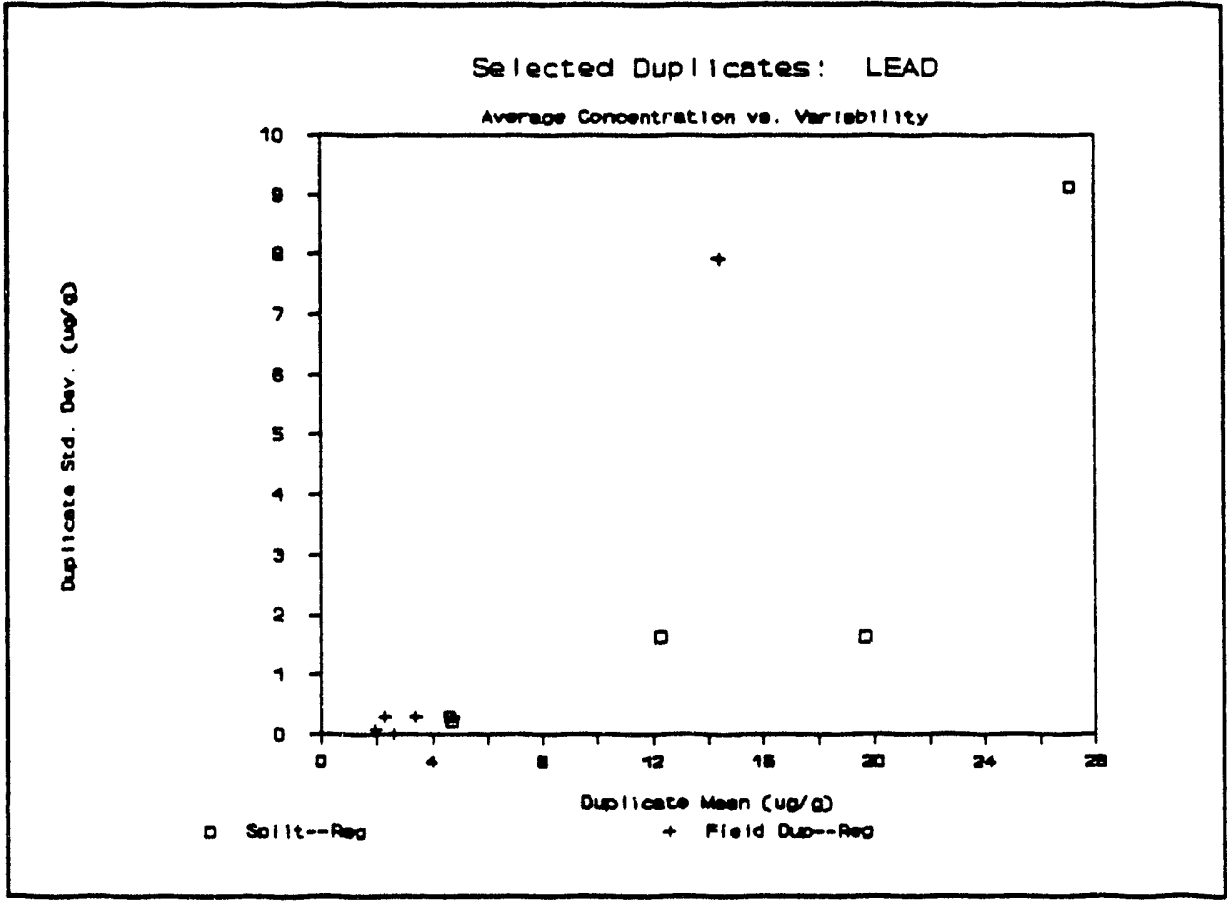

Figure B-14. Selected Duplicates: Magnesium.

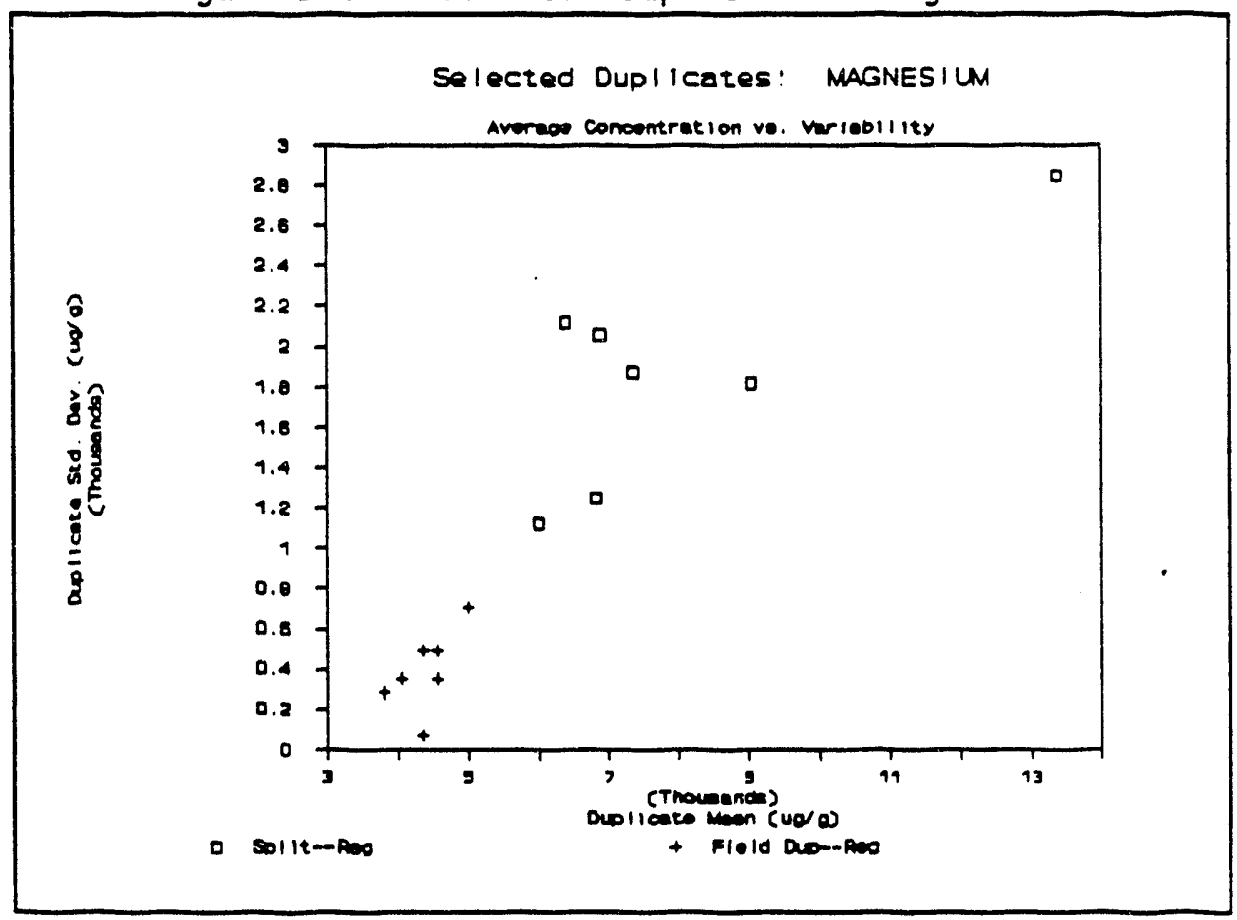


WHC-SD-EN-AP-104 Rev. 0

Figure B-15. Selected Duplicates: Manganese.

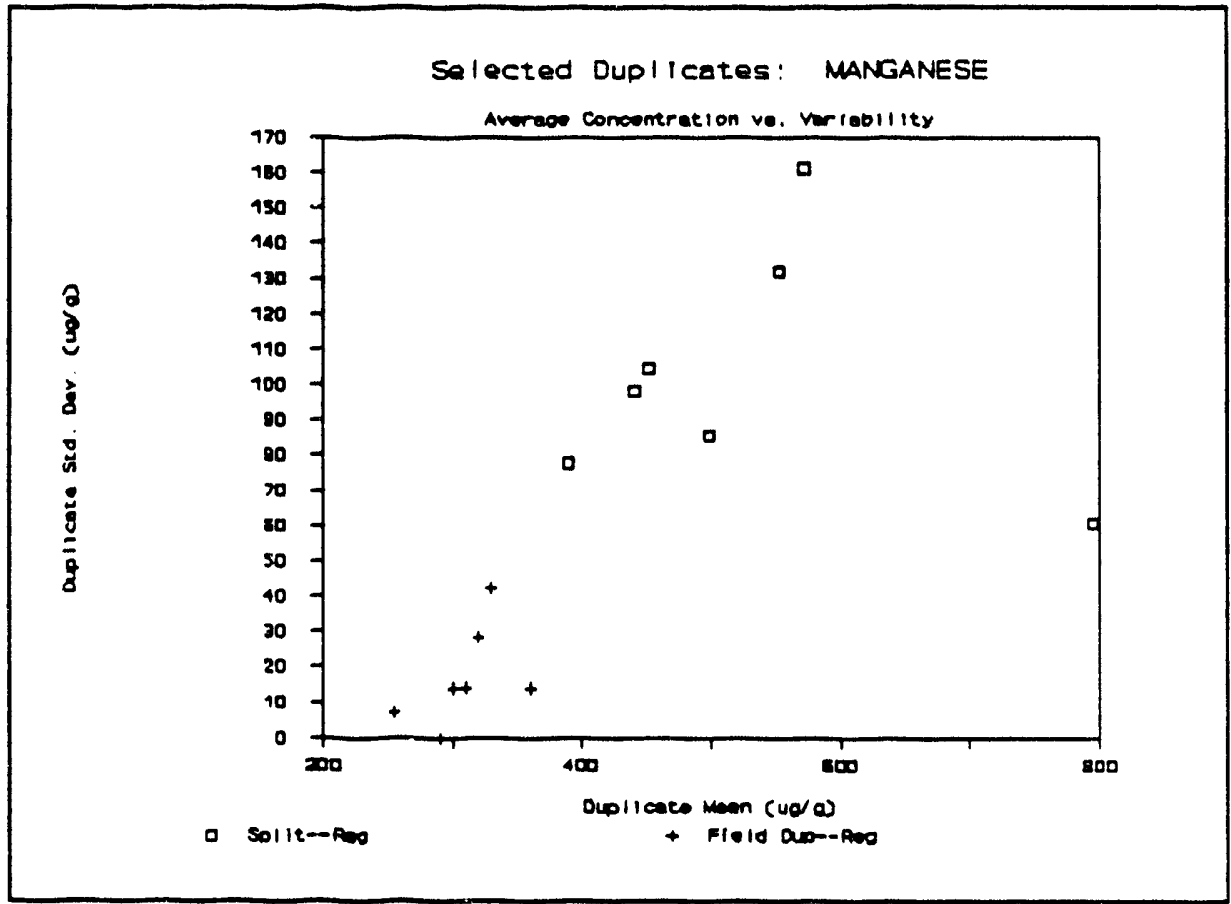

Figure B-16. Selected Duplicates: Molybdenum.

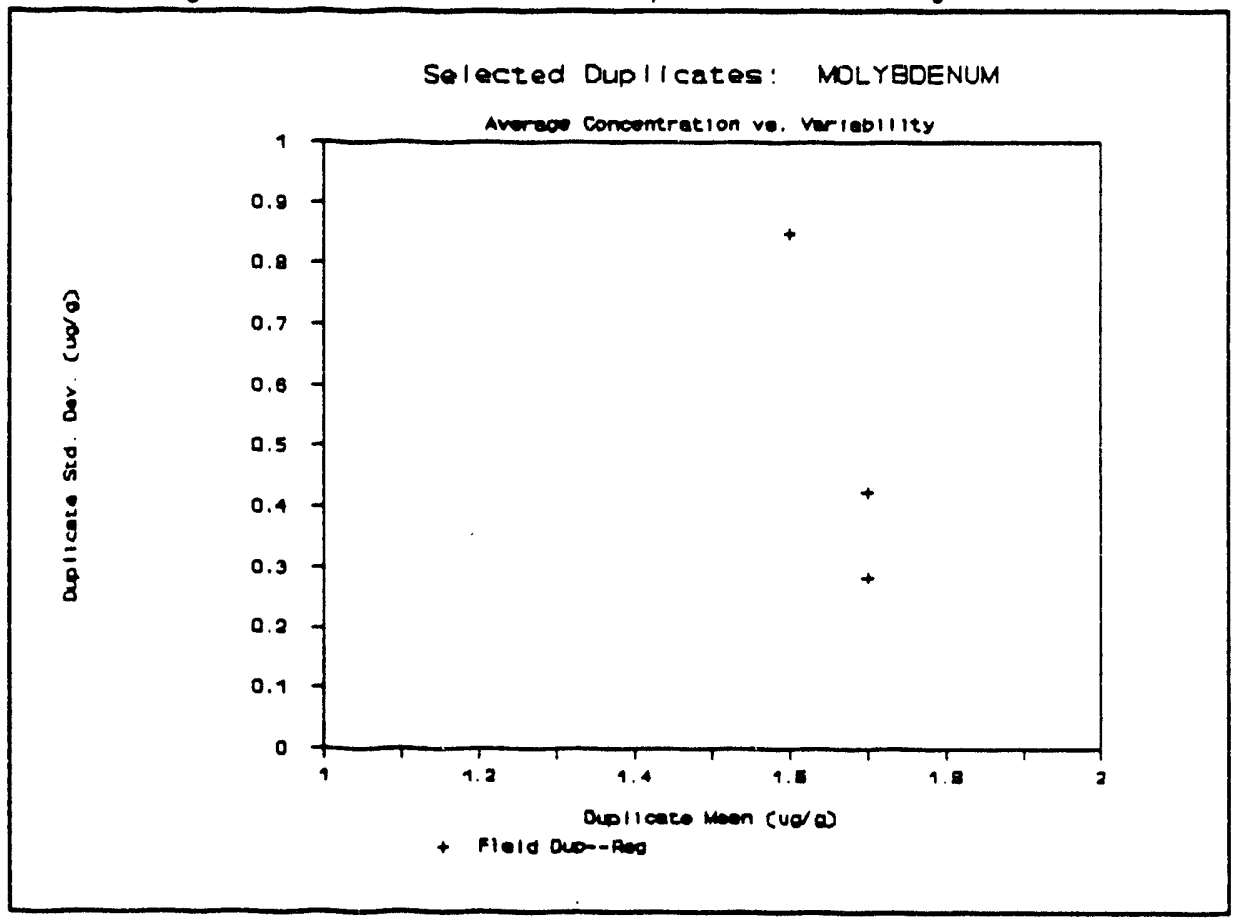


WHC-SD-EN-AP-104 Rev. 0

Figure B-17. Selected Duplicates: Nickel.

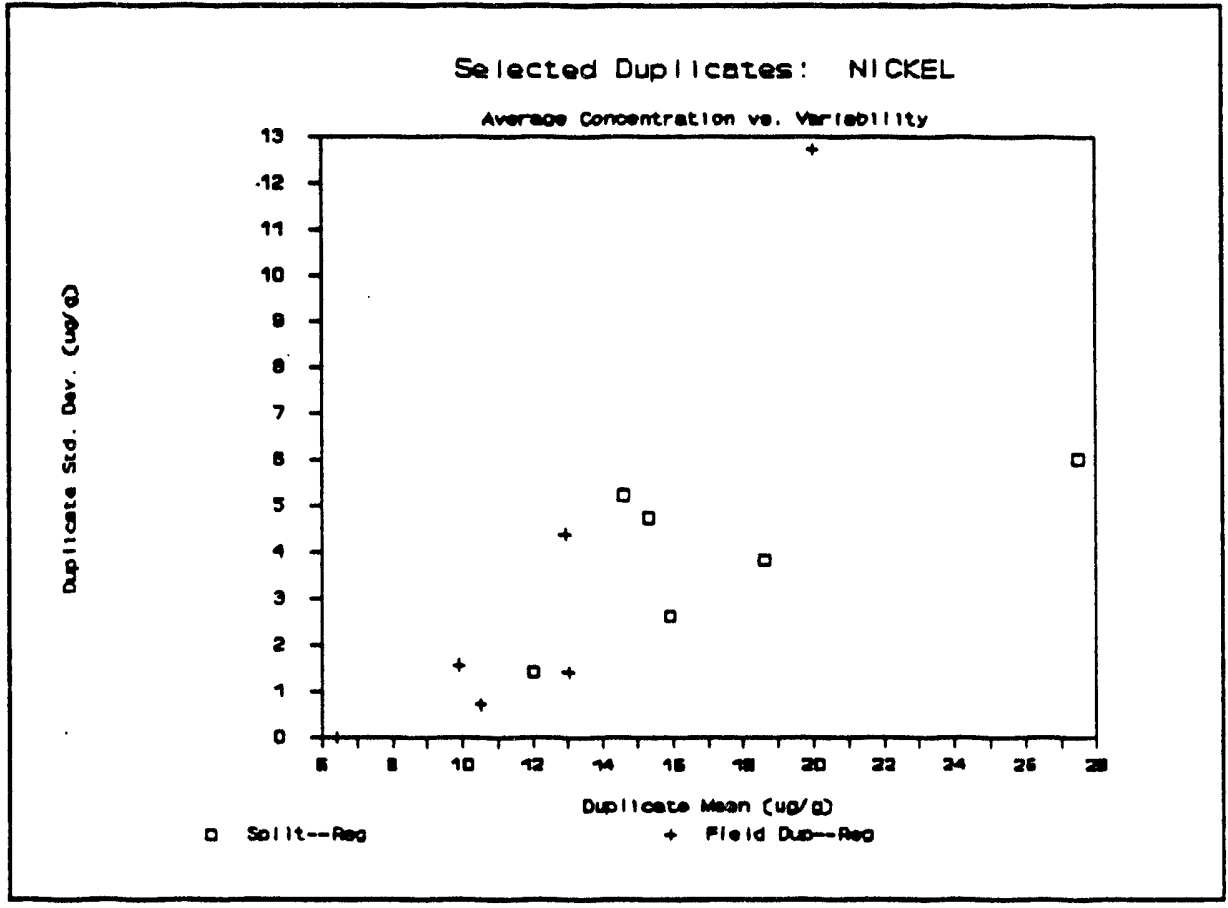

Figure B-18. Selected Duplicates: Potassium.

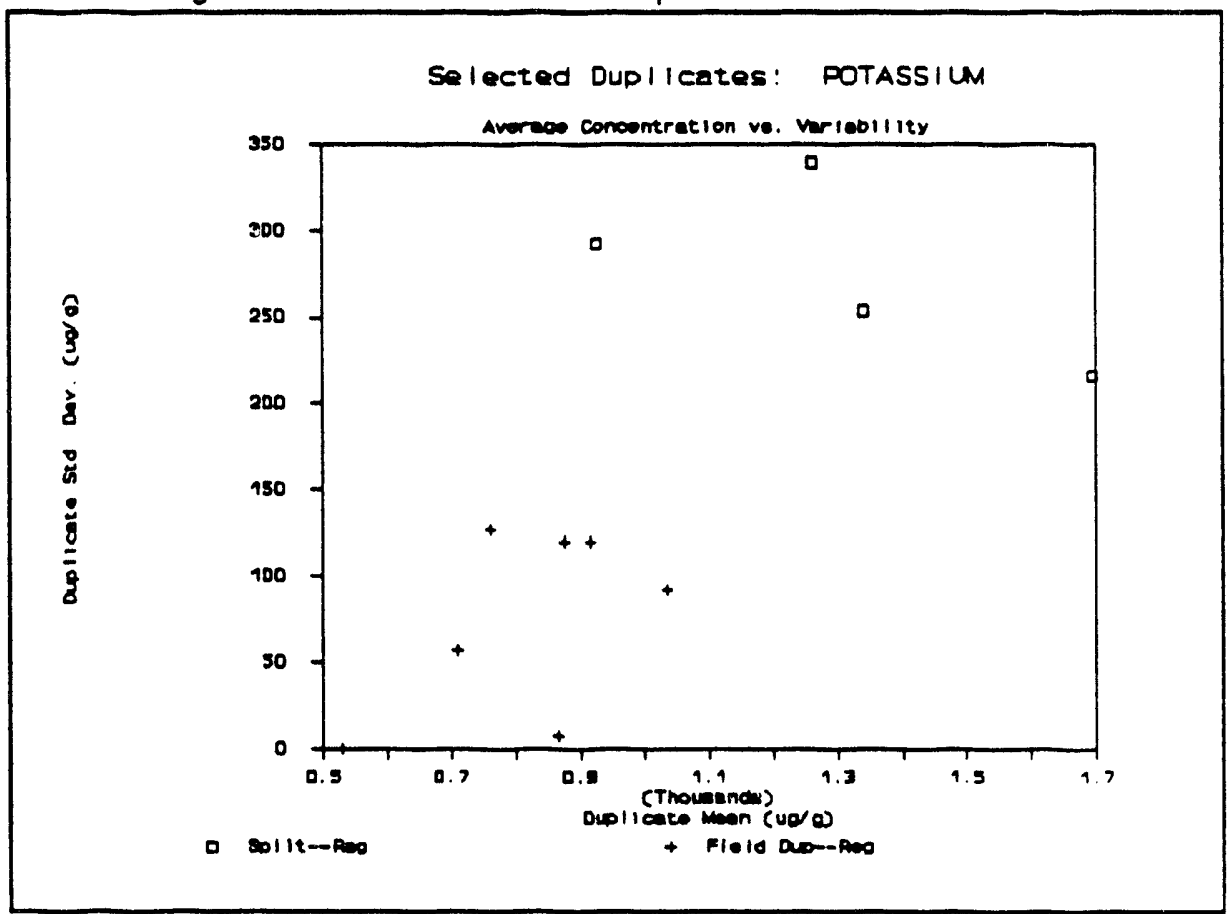


WHC-SD-EN-AP-104 Rev. 0

Figure B-19. Selected Duplicates: Silicon.

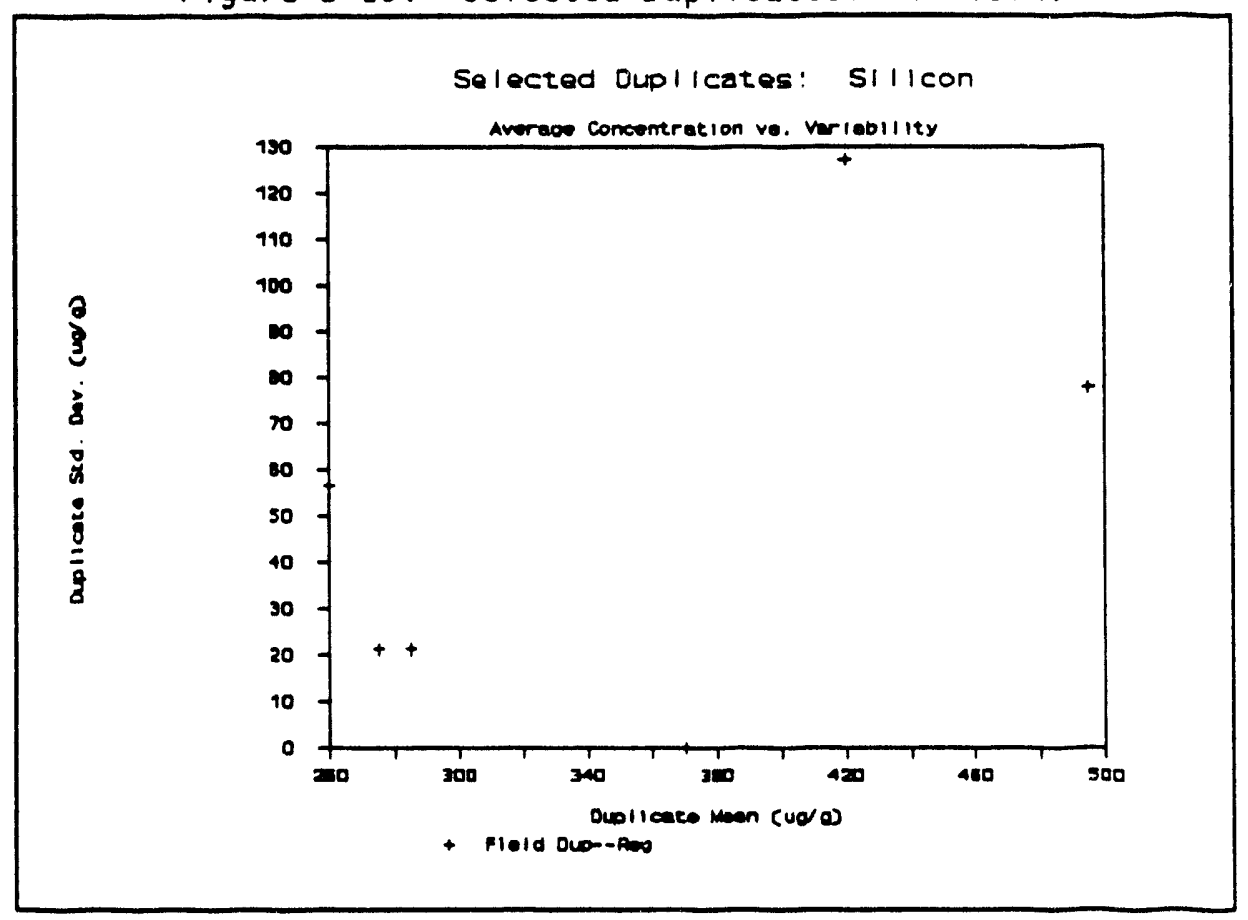

Figure B-20. Selected Duplicates: Sodium.

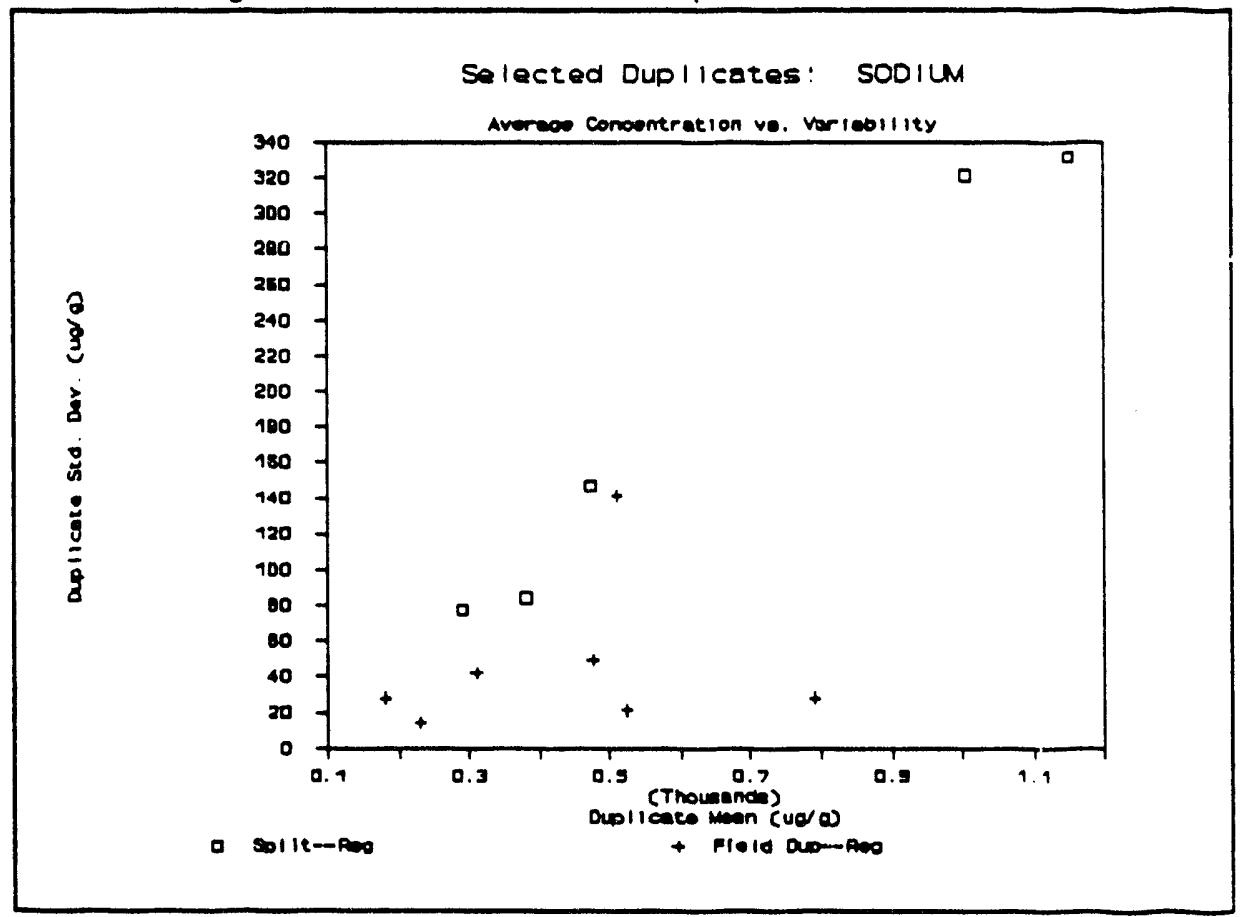


Figure B-21. Selected Duplicates: ${ }^{90} \mathrm{Sr}$.

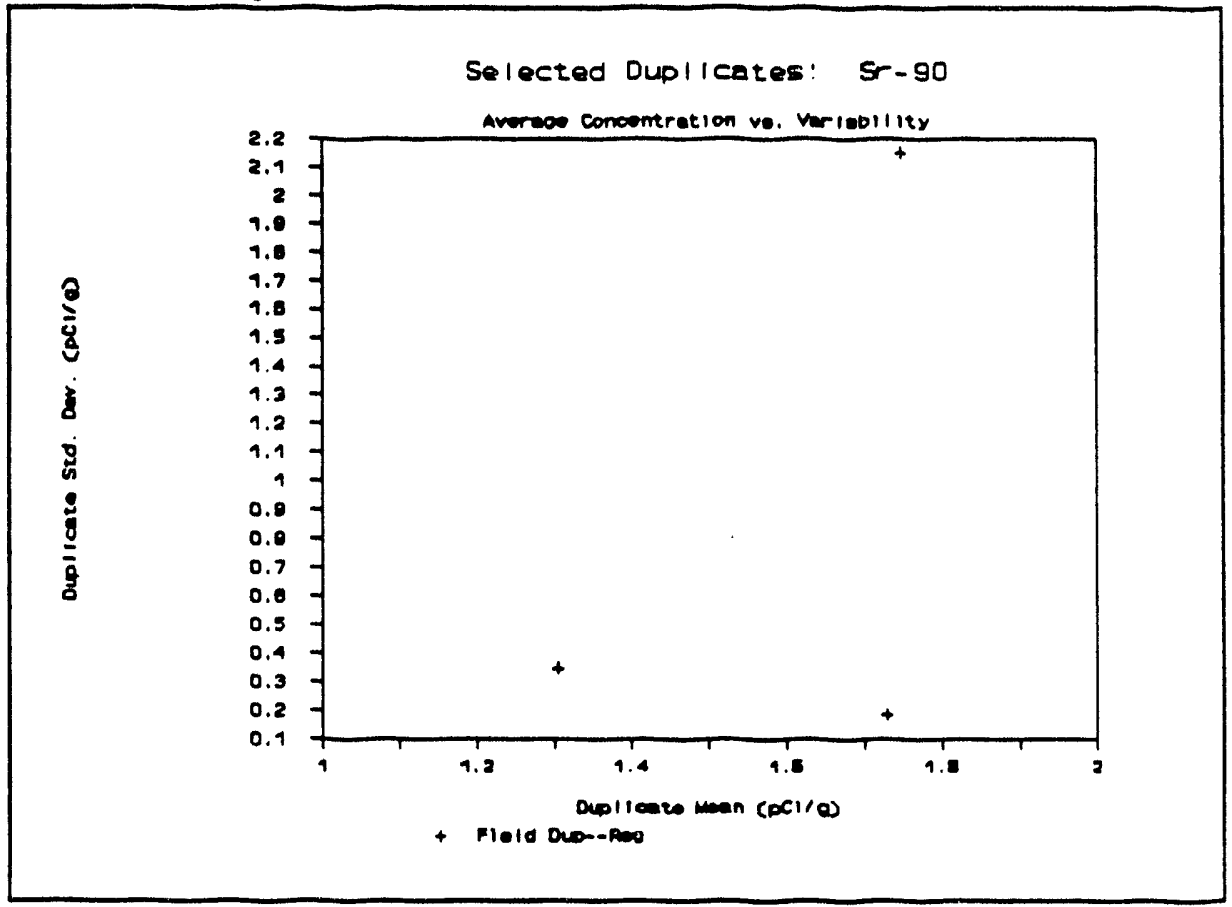

Figure B-22. Selected Duplicates: Sulfate.

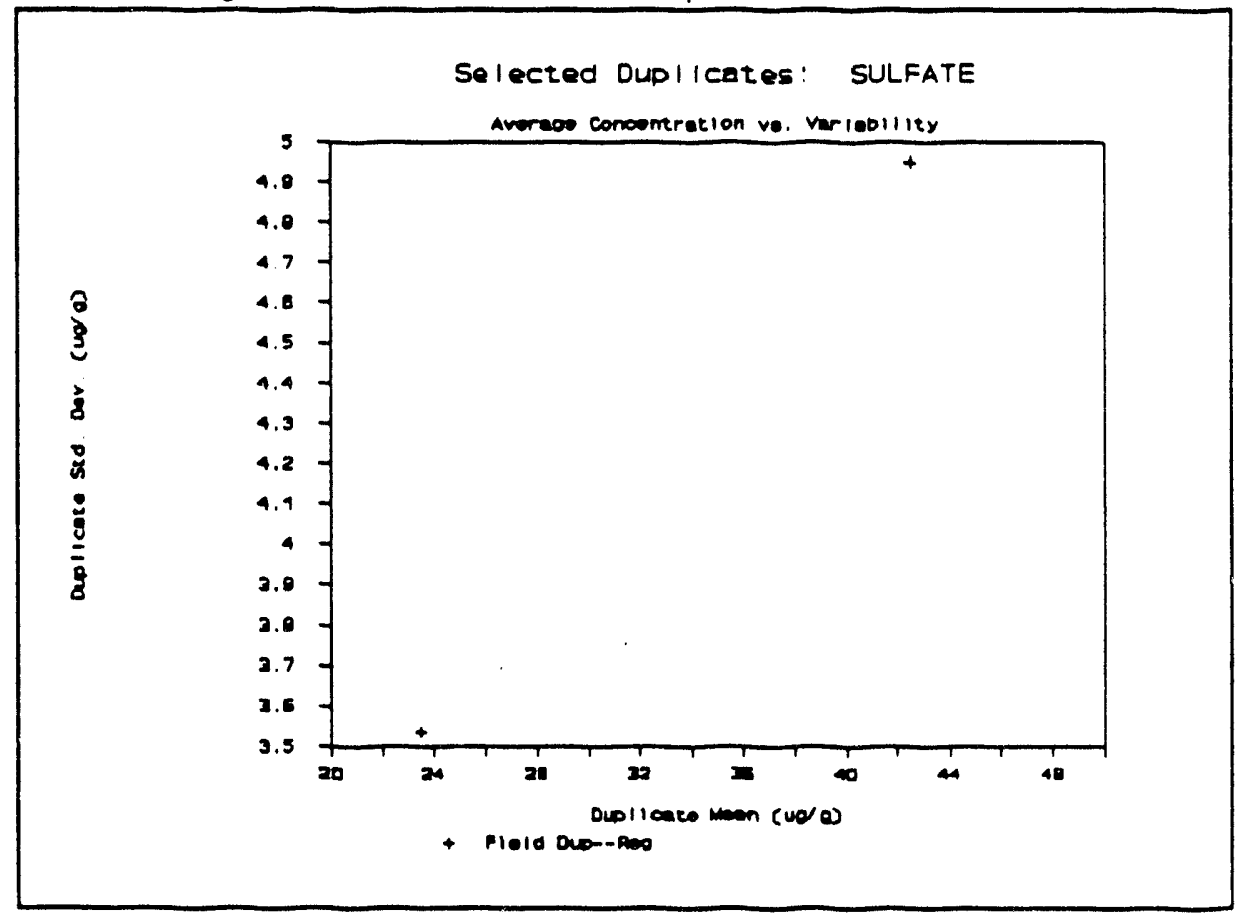


WHC-SD-EN-AP-104 ReV. 0

Figure B-23. Selected Duplicates: Vanadium.

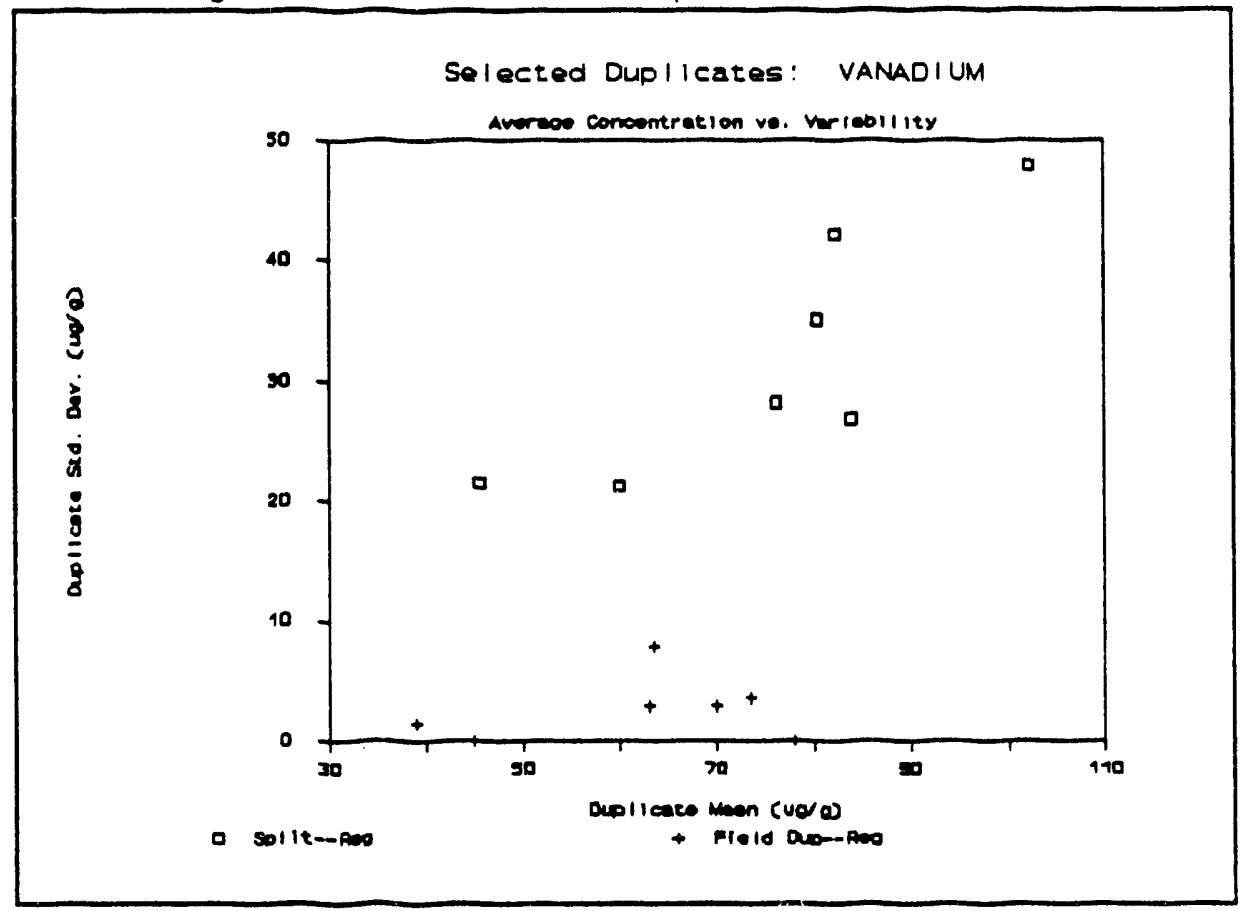

Figure B-24. Selected Duplicates: Zinc.

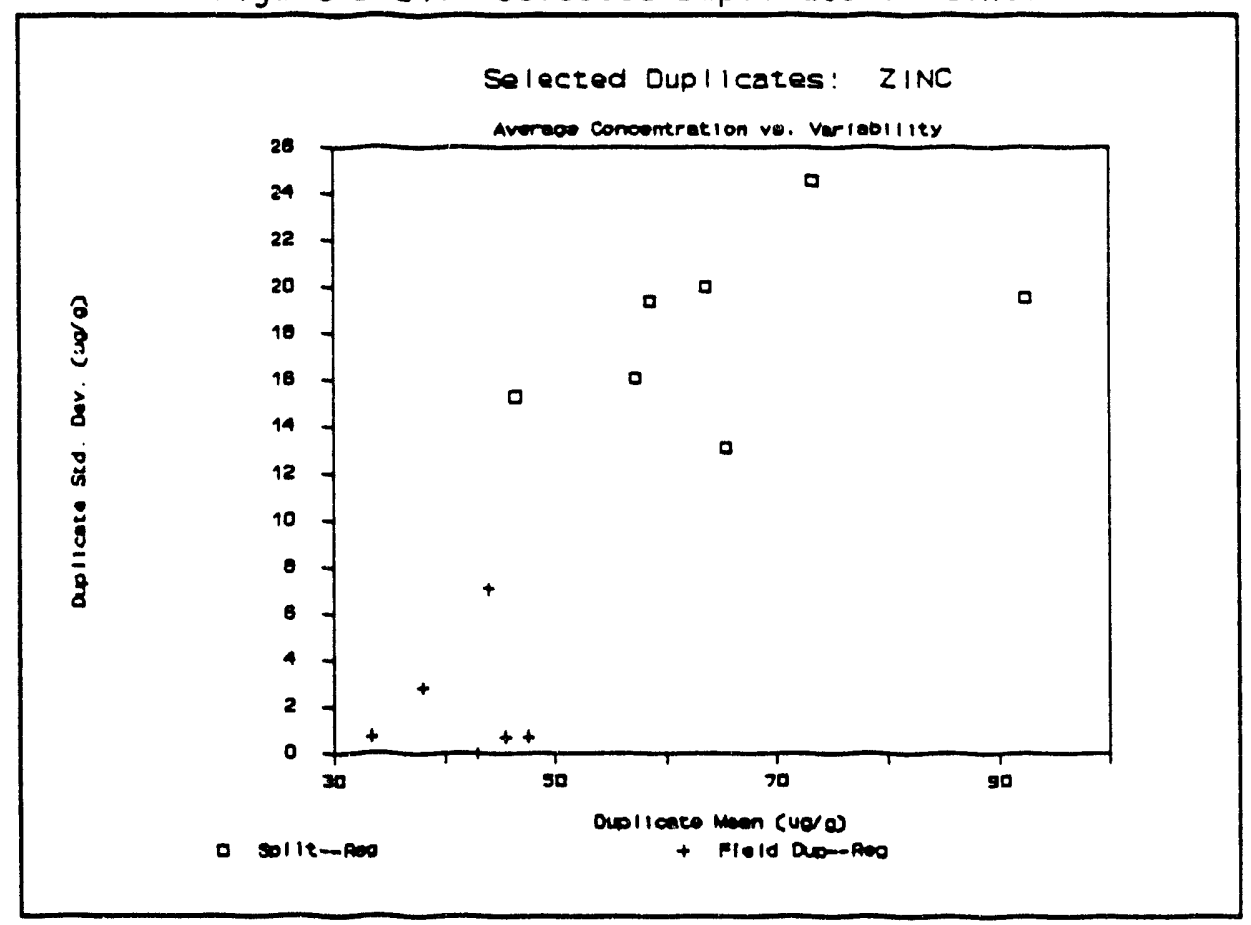


WHC-SD-EN-AP-104 Rev. 0

This page intentionally left blank. 
WHC-SD-EN-AP-104 Rev. 0

APPENDIX C

ENVIRONMENTAL PROTECTION AGENCY OFFICE OF SOLID WASTE AND EMERGENCY RESPONSE MEMORANDUM 
WHC-SD-EN-AP-104 Rev. 0

This page intentionally left blank. 
WHC-SD-EN-AP-104, Rev. 0 .

UNITED STATES ENVIRONMENTAL PROTECTION AGENCY

WASHINGTON. D.C. 20460

INI I 9 15:9

Hr. Thomas C. Jorling

Commissionez

Department of Environmental Conservation

State of How York

Albany, Now York 12233-1010

Dear Kr. Jorling:

I am writing in response to your letter of Hay 5, 1989, is which you ask numerous questions concerning the regulatory status, under the Resource Conservation and Recovery ACt (RCRA), of envirormental media (ground vater, soil, and sediment) contaminated with RCRA-listed hazardous waste.

As you point out in your letter, it is correct that the Agency': "contained-in" interpratation is that contaminated envizonmental godia must be managed as if they were bazardous wastes until they no longer contain the listed waste, or are delisted. This leads to the exitical question of when an environmental medium contaminated by listed hazardous vaste ceases to be a listed hazardous waste. In your letter, you discuss three possible anvwers (based on provious EPA positions and documents) whibh you belleve address this question, and request the Ageney to elarify its Lnterpretation. Each of these is discussed below.

The Ilfst possible anwer you cite vould be that the contaminated media vould be a bazardous vaste unless and until it is delisted, based on the mixture" and derived-erom" oules. As you correctiy state in your letter, a wase that acets a listing description due to the application of elther of these rules remains a listed hazardous vaste until it is delisted. Bowever, these two sules do not partadr to contaninated anvironmental nodia. Onder our ragulatlons, contanisated nadia are not considered coldd wastes in the sense of baling abandoned. recyclad, or Inberantly wasto-like as those terns are defined in the regulations. zherelora, contaninated anvironmental aedia carnot be considered a hazardous vaste via the "nixturen zule (1.e.. to have a hazardous vaste ajxture, a bazardous vaste aust be alxed wth a gelld waste per $40 \mathrm{CRR} 262.3(\mathrm{a})(2)(1 \mathrm{~V}))$. slallarly. ebe "derived-kron" rule does not apply to contaminated adia. Our basis for otuting that contaninated envifonwental acdia must be nanaged as bazardous vastes is that they "contain" 


$$
-2-
$$

listed hazardous wasts. These envirommental medla must be managed as hazardous k'1ste because, and only as long as, they - "contain" a listed hazardous waste, (1.e., until decontaminated).

The second possibility you mention is that environmental media contaminated with a RCRA listed waste no longer have to be managed as a hazardous waste if the hazardous constituents are completely removed by treatment. This is consistent with the Agency' "contained-in" interpretation and represents the Agency's current policy.

The third possibility you discuss comes erom sylvia Lowrance's January 24, 1989 , memorandum that you cited in your letter. This pemorandum indleates that $05 W$ hes not issued any definitive guidance as to when, or at what levels, environmental media contaminated vith Ilsted bazardous waste are no longer considered to contain that hazardous vaste. It also states that until such definitive guldance is issued, the Regions may determine these levels on a case-specifle basis. Where this determination involves an authorized state, such as New York, our policy is that the state may also rake ouch a determination.

Related to such a determination, you ask whether a risk assessment approach that addressed the public health and environwental impacts of hazardous constituents ramaining in treatment residuals would be acceptable. This approach would be acceptable for contaminated nedis provided you assumed a direct exposure scenario, but would not be accoptenble for "derived-erom" wastes under our current rules. Additionaliy, consistent with the statute, you could substitute more stringent standards or criteria for contaminated anvironmental modia than those recomended by the Federal EPA 18 you determined it to be appropriate.

The Agency is currently lnvolvad in a rulameking effort directed at setting de minimin levels for bazardous constituents below which eliglbie listed wastes, treatment residuals from those waster, and environmental sadia contaminated with those listed waster vould no longer bave to be managed as hazardous wastes. The approach being contemplated in the De uinimis progran vould be similar to that used in the proposed RCRA Clean Closure Guldance in terme of the exposure seanario (direct ingestion). the nanagement scenario (not in a waste management unit), and the levelo (prinardiy boaltb-based).

Your Iinal guestion related to wother the "ramove and decontaminate" procedure set lorth in the March 19,1987 Eederal Beairter preamble to the conforming regulations on closing surface impoundmente applies when making complete removal deterinations for soli. These procedures do apply when one 


$$
\text { WHC-SD-EN-AP-104, ReV. } 0 \text {. }
$$

$-3-$

chooses to clean close a hazardous waste surface impoundment by removing the waste. The preamble language states that the Agency interprets the term "remove" and "decontaminate" to mean removal of all wastes, liners, and/or leachate (including ground water) that pose a substantial present or potential threat to human health or the environment (52 DB B706). Further discussion of these requirements is provided in a clarification notice published on March $28,1988,(53 \mathrm{JB} 1144)$ and in OSWER Policy Directive $9476.00-18$ on demonstrating equivalence of part 265 clean closure with part 264 requirements (copy enclosed).

I hope that this response will be helpful to you in establishing and implementing $\mathrm{Ner}$ York's hazardous waste policies on related issues. Should you have additional questions, please contact Bob Dillinger, Chief of the Waste Characterization Branch at (202) 475-8551.

sincerely yours,

Plat they

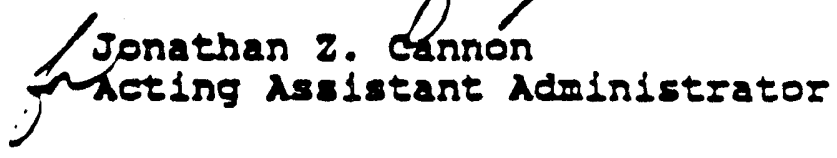

$c-3$ 


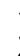

2$$
\begin{aligned}
& 3 \\
& 4
\end{aligned}
$$

5

6

7

8

9

10

11

12

13

14

15

16

17

18

19

\section{DISTRIBUTION}

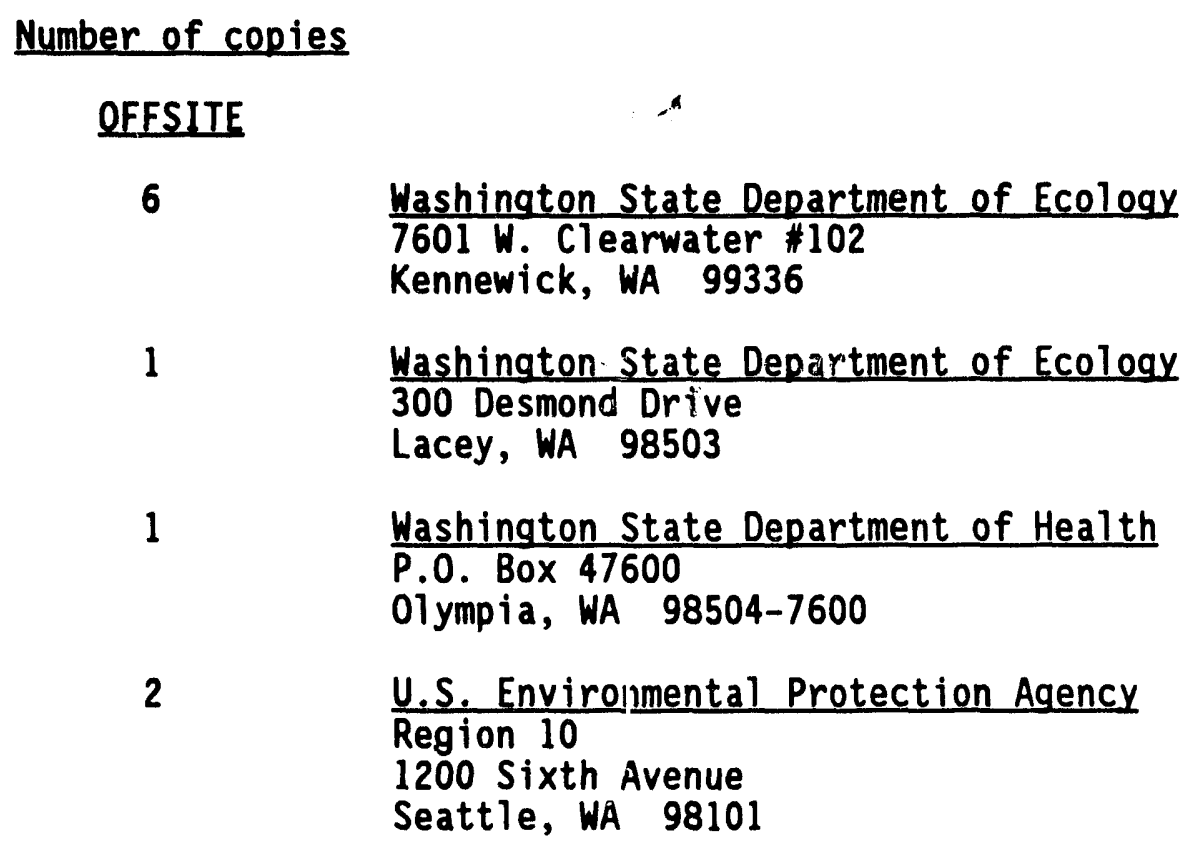

\section{ONSITE}

6

U.S. Department of Energy, Richland Field Office

R. N. Krekel

A5-15

R. G. MCLeod (3)

DOE-RL Public Reading Room

A5-19

GSSC

Al-65

1

Pacific Northwest Laboratory

Pacific Northwest Laboratory

Technical Files

$\mathrm{K} 1-11$

17

Westinghouse Hanford Company

D. A. Guthrie

H6-23

G. H. Landeen/RCRA Files

H6-23

J. R. Laws

A. K. McDowe 11

H6-23

F. A. Ruck III

R1-51

W. A. Skelly

D. L. Smith

R. K. Tranbarger

B. D. Williamson

H6-23

H6- 03

T7-05

H6- 03

Central Files

B3-06

Correspondence Control

L8-04

Document Clearance Administration

Document Processing and Distribution (2)

A3-01

H4-17

EPIC (3) 

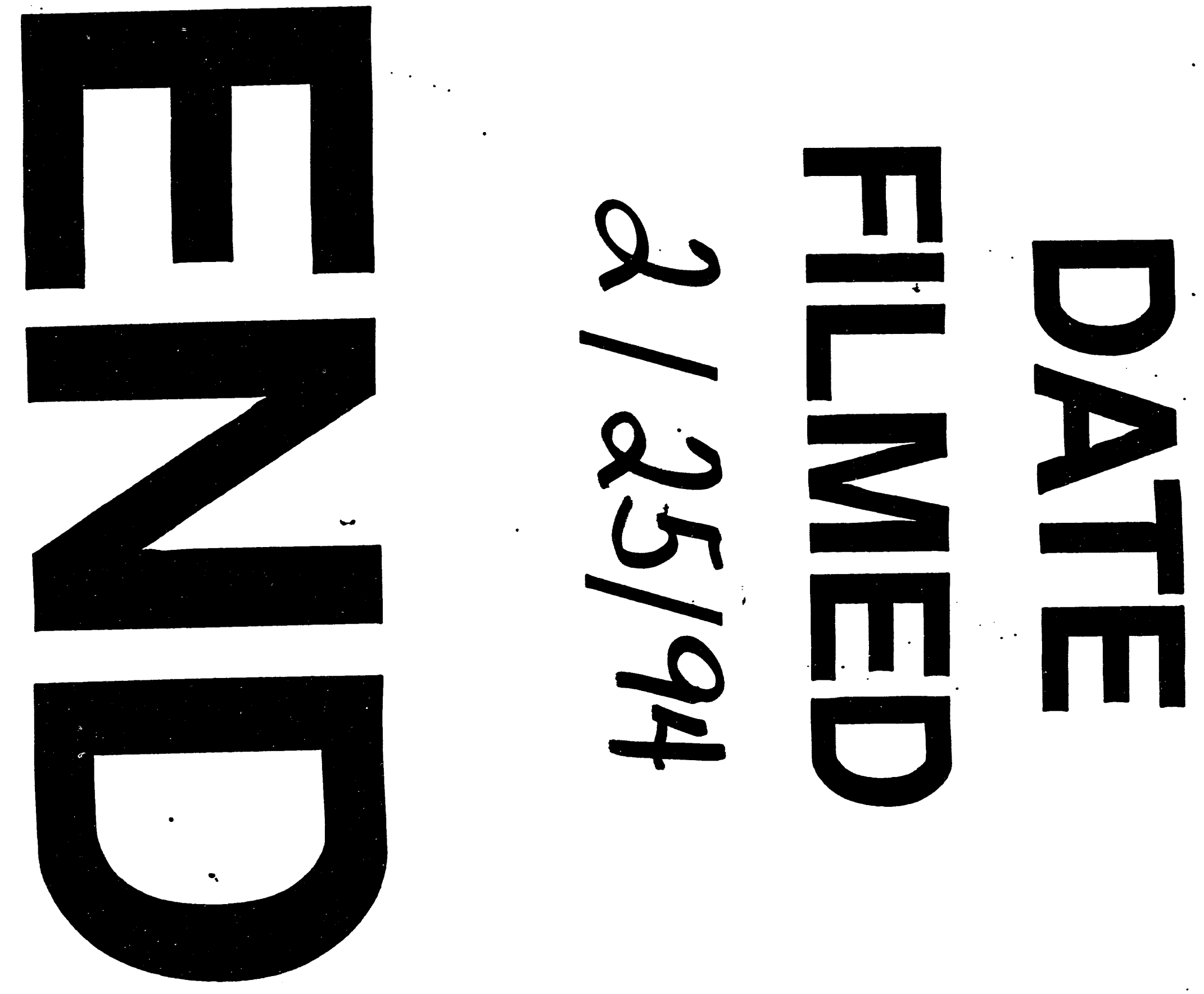


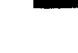

